QP34

T442 Crulumbia Itururrsitty Cpy 1 in tlị Citụ af Ãu Vyark

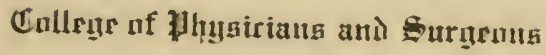

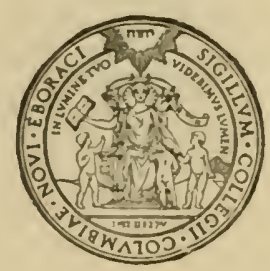

Theterence filmary 




\section{A TEXT-BOOK OF IIUMAN PIIYSIOLOGY}




\section{Digitized by the Internet Archive}

in 2010 with funding from Columbia University Libraries 


\section{A TEXT-BOOK OF}

\section{HUMAN PIIYSIOLOGY}

BY

\section{DR. ROBER'T 'TIGERS'TED'T}

PROFESGOR OF PHYSIOLOGY IN THE UNIVERSITY OF HELAINGFORS, FINLANI

TRANSLATED FROM THE THIRD GERMAN EDITION AND EDITED BY

JOHN R. MURLIN, A.M., PH.D.

AssistaNt professor OF PHYsiology IN THE ENIVERsity ÁND BELLEVUE HOSPITAL MEDICAL CWLEGE, NEW YORK CITY

WITH AN INTRODUCTION TO TIE ENGLISII EIOTION BY

PROFESSOR GRAHAM LUSK, P'H.D., F.R.S. (EDINB.)

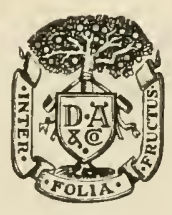

NFit IORK A ND I, ONDON D. A P PI, E'TON A N D ('O) I P A N 
('OPYRIGIT, 1906, m.

D. APPLWTUN AND (OMINYY

$$
\begin{gathered}
12-13693 \\
612 \\
1+79
\end{gathered}
$$

PRINTFI AT TIF: APPIFTUN PRESS SFW Yenk, U. S. A. 


\section{PREFACE TO THE FIRST EDITION}

- To set fixed limits to the subject matter of physiology is a very difficult task, because, properly conceived, large portions of the entire group of medical and biological seiences belong to its province. A text-book designed primarily for medical students ean, however, regard the field as somewhat more restricted; for the prospective physician has abundant opportunity to amplify his knowledge of the bodily functions from his other studies. Hence in this book I have followed the usual eustom and have brought together only so much of our information respecting the human body as can be described as pertaining to its normal functions. The discoreries made in the realms of practical medicine, of experinental pathology and of pharmacology, which in many respects are so full of significance for the processes of the body. are, therefore, for the most part passed by. In like manner the facts of comparative physiology have been alluded to only in exceptional cases, since an exhaustive discussion of them would have increased the size of the book to a not inconsiderable extent.

For the same reason I have been unable to find a place for the short histological discussion customary in text-books. I to not regard this as an error, for a necessarily brief and superficial résumé of the most important histological facts could be of no great service, sinee the student needs a more extensive linowledge of the finer structure of the body and must in any case obtain this from the text-books deroted especially to that subject. I do not therefore at all mistake the great importance of histology for physiology; on the contrary, I would recommend that in the study of a text-book of this science a text-book of histology (and one of anatomy) be always at hand in order to combine the physiological facts with the histological and anatomical facts.

P'hysiological chemistry also has developed so far that more and more it (an claim the right to be regarded as an independent science. On the other hand it is not possible to present the physiological facts without reference to the chemical processes of the londy. While therefore I am compelled to touch upon the facts of physiological chemistry, I have limited the discussion to 
the mon-t important facts of all. leaving matters of detail and comtroverted

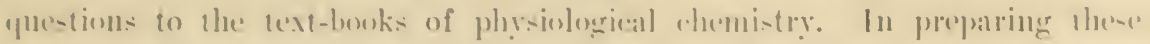

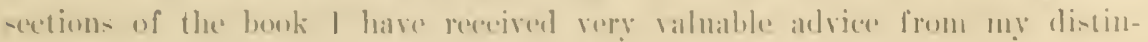

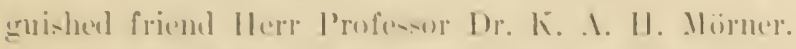

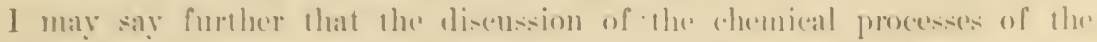
borly is based in the main upon the text-tonks of Ilammarsten and Nemmedster. The experienced reater will find als that I hatre malde fropuent use of the physinlogical monograph- which have appeared within recent rears. Espe-

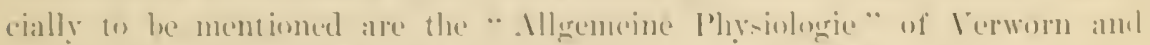

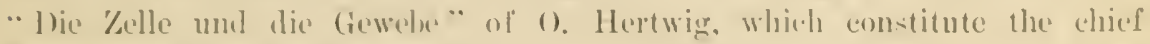
sources of the chapter on the eedl.

With rexard to the physiology of the sense organs I may state that J have tratent them in this hesk chiedly from the point of view of the prateticing physician. For this reason the physical conditions of sensition have beren discuneerl rather fully, while those investigations on semse pererpution falling within the horderland common to physiology and psychology, and of dremselves so extremely important, have been disensed only in roughest outline, an exhanstive discussion being quite beyond the seope of the book.

In the eitation of anthorities I have trienl to hold a midelle enmse hetweris the very numeroms references fomd in mamy text-books and the entire abrence of them found in others. I must acknowledge, however, that I have not in all cases snceceded in finding the proper middle enurse.

'The fow references griven will direct the reader's attention to only the more recent monographice discussions of the applepriate sections. Probahly

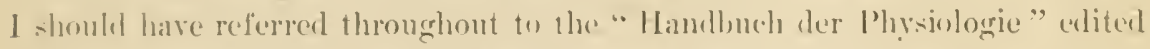
ly Jlermann. I must content myelf, however, with eiting it here once for all.

Amonge the many batutiful illustrations. which 1 owe to the liberality of my publi-her. the majority have heen taken from the original palpers of

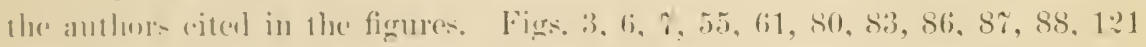

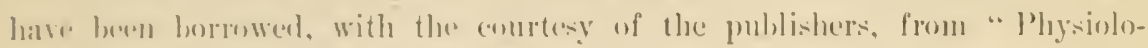
gri-chen ciraphik" of lamerendorti.

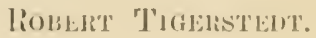

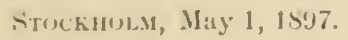




\section{PREFACE TO THE THIRD EDITION}

WHILE adhering to the same principles which I have followed in prerious editions of this book, I have in the present edition thoroughly revised almost all the chapters. In this work of revision the monographic discussions contained in the "Ergebnissen der Ihysiologie" have been of very great service to me, and I would especially direct the reader who may be interested in a deeper study of modern physiology to this collective work.

The more recent literature bearing on the subjects contained in Chapters I to XIV inclusive could for the most part be brought up only to the end of 1903. In the revision of the remaining chapters I have been alsle to make use of the literature of the first half of the present year.

Robert Tigerstedt.

Helsixgfors, October 1, 1904. 



\section{TRANSLATOR'S PREFACE}

Ix preparing this abridged edition of Professor Tigerstedt's well-known "Lehrbuch der Physiologie des Menschens" it has been my endearor to bring the book within the reacl of the second-year medical student in this country: Beliering that those who would make use of the more highly technical parts of the book. as, for example, the mathematical considerations affecting the dynamics of the circulation and the optics of vision, already have access to thesc very valuable discussions in the German, I have, with the author's permission, omitted these parts. All other omissions and condensations have beeu made with the single idea already named. I shall not here enumerate theso changes, because, with the exception of a very few minor ones, which in the interest of clearness it has seemed necessary to make in the proofs, all abridgments have received the author's expressed approval. Professor Tigerstedt has placed me under very great obligations for the readiness he has shown both to adopt my suggestions and to make others of his own motion.

In the actual work of translation I have labored throughout to give the author's thought a clear and accurate expression. While feeling my obligations to the author, therefore, I bave endeavored (not always with success) to leare as little resistance to the thought in the form of German idiom and construction as possible.

Following in reneral the author's usage. I have employed italics for three purposes: for generic and specifie names, for emphasis, and for indicating the key word. phrase, or clause of a paragraph. In this latter use they serve the purpose of subordinate headings.

The few additions to the text which I have rentured to make and for which I assume entire responsibility, have been selected from the most recent literature and will be found, either enclosed in brackets or in the form of foot-notes, bearing the eustomary signature.

After examining a number of the additional illustrations which I proposed he introduced for the benefit of American students. Professor Tigerstedt gave me his entire authorization to make such additions as I might deem suitable. The authors from whose work these illustrations were originally taken are indieated in the several legends which accompany them and 
the immerliate sources from which I have obtaned them are mentioned in the List of Hllustrations.

Finally, I wish to express my sincere thanks to Professor Graham Lusk for many suggestions by which I have profited in my editorial capacity, and to Professor Perey M. Dawson of the Johns Hopkins Medical School for reatling the entire proof.

J. R. II.

New York, 1906. 


\section{INTRODUC'TION TO TIIE AMERICAN EDITION}

"Tigenstedt's Pliysiology" has been the standard text-book of Gemman students ever since its first publication in $189 \%$. The preparation of a third German edition afforded an opportunity of translating the work into English as the new proof was delivered from the foreign presses. Dr. Murlin presents the result of this task in the following careful and accurate reproduction of the original.

The biological introduction is an admirable chapter of the book, aftorling as it does a broad insight into the processes of the humbler forms of living things. In view of the large participation in this department of physiology by workers in our own country, this feature of the book will be especially weleomed.

Tigerstedt early wrote a monograph on the circulation of the blood which to-day stands unrivaled, and in this important section of physiology the present text-book is of commanding anthority. He later established a respiration apparatus for experiments on the metabolism of men. and this he used not only in health but also for determiuations of the life processes in discased conditions. Tigerstedt is the only author of a general text-book of physiology who has had any experimental knowledge in this branch of science. His chapter on metabolism is the most complete general aceount griven in any text-book in any language, and it is certain to have a wide influence among the many in this country who are striving to obtain a kinowledge of those inmer processes of the body which deternine dietary leyuirements in health as well as in discase.

The treatment of the subject of the central nervous system, and the gencralizations regarding its functions, is a masterpicee of its kind. In the other parts of the book a wide range of knowledge is presented with a sustained excellence of arrangement, and with that catholicity of selection which has made the book so snecessful in other lands.

It has been said that good physiology is the best preventive of barl medicine. Tigerstedt's physiology is estentially good physiology. presenting a picture of the modern scientifie structure upon which modern medical 
practice is based. It must be granted that some of the phenomena of life are to be explained only by theoretieal induction. But this is the daily experience of every physician an regards his patient, for he is called upon to interpret disease caused by processes which he cannot see. T'igerstedt's judicions selection of the facts of physiology, and their interpretation along lines of modern eritical research, afford to the student of medieine an opportunity for that kind of intellectual training which best fits him to interpret phenomena both of health and of disease.

The book may be earnestly commended to the medical student and to 1 the practitioner.

GliAHAM LUSK.

University axd Bellevue Hospital Medical College, NEW YORK. 


\section{TABLE OF CONTENTS}

INTRODUCTION

C'hapter I.-General Physiological Method

\$ 1. Physical, Chemical, and Histological Methods . . . . . . 4

\$2. Experiments on Living Animals . . . . . . . . . . 5

§3. Experiments on Surviving Organs . . . . . . . . . . . . $\quad$. 6

$\$ 4$. The Graphic Method . . . . . . . . . . . . . . . 6
A. The Kymograph . . . . . . . . . . . 7
B. Time Recorders . . . . . . . . . . . 10
C. Recording by Air-transmission . . . . . . . . . 11
D. Registration by Photography . . . . . . . . . 13

Ciapter II.-The Cell . . . . . . . . . . . . . . 15

$\$ 1$. General Considerations . . . . . . . . . . 15

A. The Cell as an Elementary Organism _ . . . . . . 15

B. The Reciprocal Relations between the Nucleus and Protoplasm . . 17

C. Physical and Chemical Properties of Protoplasm . . . . . $\quad 19$

D. Morphology of the Cell Contents . . . . . . . 20

$\$ 2$. The Vital Phenomena of Cells . . . . . . . . . . . 22
A. Introductory Survey

B. The Ingestion of Food .

C. Digestion

D. The Oxidative Processes $\quad 39$

E. Elimination of Decomposition Produets . . . . . . . 40

F. Sccretion . . . . . . . . . . . . 41

G. Motility . . . . . . . . . . . . . 42

H. Production of Light . . . . . . . . . . 45

I. Formation of Heat . . . . . . . . . 46

J. Generation of Electricity . . . . . . . . . 46

\$ 3. The Effect of External Influences on Cells . . . . . . . . 50
A. On Stimuli in General . . . . . . . . . . . 50
B. Automatic Excitation . . . . . . . . . . . 52
C. Chemical Stimulation . . . . . . . . . . . 52
D. Mechanical Stimulation . . . . . . . . . . 56
E. Stimulation by Means of Light . . . . . . . . . 56
F. Stimulation by Heans of Heat . . . . . . . . . 58
G. Electrical Stimulation . . . . . . . . . . 59
H. Cosmic Influences . . . . . . . . . . . 61
I. Conductivity . . . . . . . . . . 62
I. The Assimilative Processes Induced by Stimulation . . . $\quad 62$
K. Paralysis and Fatigue . . . . . . . . . . . . . . 65
\$4. Death . . . . . . . . . . . . . . 66 
Chapter III.-The Chemical Constituents of the Body .

$\$ 1$. The Nitrogenous Substances . . . . . . . 68

A. The Simple Proteids . . . . . . . . . . . 68

B. The Compound Proteids . . . . . . . . . 75

C. Substances Resembling Proteids . . . . . . . . 77

D. Other Nitrogenous Substances . . . . . . . . . 78

§ 2. The Nonnit rogenous Substances . . . . . . . . . 79

A. Fats . . . . . . 79

B. Cholesterin . . . . . . . . . 80

C. Carbohydrates . . . . . . . . . . 80

Chapter IV.-Metabolism and Nutrition . . . . . . . . . . . . 83

First Section: Metabolism . . . . . . . . . . . . . . . 83

1. On the Method of Metabolism Experiments . . . . . . . . . \$3

A. The Ingesta . . . . . . . . . . . . . . 833

B. Determination of the Excreta . . . . . . . . . S4

C. Apportionment of the Individual Elements to the Different Excreta . 89

D. Example of a Metabolism Experiment . . . . . . . . 91

\$ 2. Potential Energy of the Foodstuffs . . . . . . . . . . . 92

\$3. Metabolism in Fasting . . . . . . . . . . . . 95

A. The General Condition in Fasting . . . . . . . . . 95

B. Character of the Metabolism in Fasting . . . . . . . . . 96

C. Loss of Substance from the Different Organs . _ . . . . . . 97

\$ 4. Influence of Food on the Metabolism . . . . . . . . 95

A. Influence of the Quantity of Proteid in the Food on Proteid Metabolism 99

B. The Total Metabolism after Ingestion of Proteid . . . . . . 102

C. Metabolism after Ingestion of Fat . . . . . . . . . 104

D. Netabolism after Ingestion of Carbohyclates . . . . . . 105

E. Summary and Discussion . . . . . . . . . . 107

F. Metabolism after Ingestion of Albumoses. Fatty Acids, Gelatin, Alcohol, etc. . . . . . . . 108

\$. Influence of Muscular Work on Metabolism . . . . . . . 110

\$. Influence of the Surrounding Temperature on Metabolism . . . . 114

§. Metabolism in Animals of Different Size. . . . . . . . . . 117

$\$$ 8. Retention of Proteid in the Borly . . . . . . . . . . 120

$\$ 9$. Storage of Carbohydrates in the Body . . . . . . . . . 124

$\$ 10$. Storage of Fat in the Body . . . . . . . . . . . . 129

$\$ 11$. The Inorganic Foodstuffs . . . . . . . . . . . 131

A. General . . . . . . . . . . . 131

B. Phosphorus . . . . . . . . . . 132

C. Calcium and Magnesium . . . . . . . . . . 133

$\$ 12$. Flavors . . . . . . . . . . . . . 133

\$13. On the Theory of Metabolism . . . . . . . . . . 134

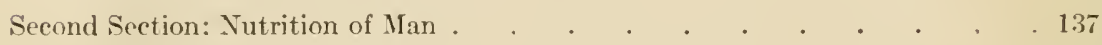

\$1. Utilization of Foodstuffs . . . . . . . . . . . . $13 \mathrm{~S}$

A. Proteid . . . . . . . . . . . . . 137

B. Fat and Carbohydrates . . . . . . . . . . 137

C. Mixed Diet . . . . . . . . . . . 138

§ 2. The Energy Requirements of an Adult . . . . . . . . 140

\$3. Nutrition of the Young . . . . . . . . . . . . 143

$\$ 4$. Construction of the Diet from the Different Articles of Food . . . 145 
Chapter V.-The Blood .

$\S 1$. The Amount of Blood in the Body . . . . . . . . 148

$\S 2$. The Formed Constituents of the Blood . . . . . . . . 148

A. The Red Blood Corpuscles . . . . . . . . . 148

B. The White Corpuscles . . . . . . . . . . . 153

C. The Blood Platelets . . . . . . . . . 153

§3. The Plasma : . . . . . . . . . . . 154

A. Chemical Constitution of the Plasma . . . . . . . 154

B. Coagulation of Blood . . . . . . . . . . 157

Chapter VI.-Circulation of the Blood . . . . . . . . . . 161

First Section: General Survey of the Blood's Movements _ . . . . 161

Second Section: The Movements of the Heart . . . . . . . . . . 162

\$1. The Form Changes of the Heart in Systole . . . . . . . 162

A. Structure of the Ventrieular Wall . . . . . . . . 162

B. The Form Changes of the Heart . . . . . . . . 163

\$2. Regulation of the Blood Flow through the Heart . . . . . . 105

A. The Atrio-ventrieular Valves . . . . . . . . . 165

B. The Semilunar Valves . . . . . . . . . . . 167

\$3. The Heart Sounds . . . . . . . . . . . . 167

\$ 4. Pressure Changes in the Heart During Its Activity . . . . . . I6S

A. Technique . . . . . . . 168

B. Pressure Variations in Different Chambers of the Heart . . . 169

\$5. The Apex Beat . . . . . . . . . . . . . 172

$\$ 6$. Time Relations of the Cardiac Events . . . . . . . . . 176

$\$ 7$. Filling of the Heart in Diastole . . . . . . . . 176

\$ S. Power and Work of the Heart . . . . . . . . . . 177

A. Power . . . . . . . . . . . 177

B. Work . . . . . . . . . . . 178

§9. Properties of Heart Muscle . . . . . . . . . . . 179

A. The Nature of the Cardiac Contraction . . . . . . . 179

B. Nutrition of the Heart . . . . . . . . . . 180

C. The Behavior of Heart Musele under Direct Stimulation . . . 182

$\$ 10$. The Cause of the Rhythmieal Activity of the Heart . . . . . 185

$\S 11$. The Efferent Cardiac Nerves . . . . . . . . . . 188

A. The Inhibitory Nerves . . . . . . . . . . . 188

B. The Accelerator Nerves . . . . . . . . . . 191

$\$ 12$. The Heart Reflexes . . . . . . . . . . . . 193

\$13. The Cardiac Nerve Centers . . . . . . . . . . 195

$\S 14$ Rate of the Heart Beat . . . . . . . . . . . 196

Thirrl Section: The Blood Flow . . . . . . . . . . 198

$\$ 1$. The Flow of a Liquid in Rigid Tubes . . . . . . . . 195

\$ 2. The Flow of a Liquid in Elastic Tubes . . . . . . . . . 199

\$3. The Flow of Blood in the Arteries . . . . . . . . . 200

A. Elastieity of Arterial Wall . . . . . . . . . . 200

3. Methods for the Determination of Blood Pressure . . . . 202

C. Height of the Blood Pressure . . . . . . . . . 204

D. Velocity of the Blood in the Arteries . . . . . . . 209

§4. The Arterial Pulse . . . . . . . . . . . . 212

A. The Movement of Waves in Elastic Tuhes . . . . . . 212

B. The Pulse . . . . . . . . . . . . 214

$\S 5$. Final Survey of the Movements of the Blood $m$ the Arteries . . . 218 
6. The Flow of Blood in the Capillaric

7 . The Flow of Blood in the Veins

A. Pressure and Velocity . . . .

B. Aids to the Blood Flow in the Veins . . . 224

$\S$ S. The Lesser Circulation and the Respiratory Variations of Blood Pressure 227

A. The Pulmonary Circulation . . . . . . . . 227

B. Respiratory Variations of Blood Pressure . . . . . . 229

\$. Vasoconstrictor Nerves . . . . . . . . . . 231

$\$ 10$. Vasodilator Nerves . . . . . . . . . . . . . 234

\$11. Vasomotor Reflexes . . . . . . . . . . . . 235

\$12. The Vasomotor Centers . . . . . . . . . . 237

$\$ 13$. General Considerations on the Distribution of Blood in the Body . . 239

A. Mechanical Influences . . . . . . . . . . . 239

B. The Influence of Vasomotor Nerves . . . . . . 240

Chapter VII.-Digestion . . . . . . . . . . . . . 242

First Section: The Digestive Fluids . . . . . . . . . . 212

$\$ 1$. General Survey . . . . . . . . . . . . . 242

\$2. Saliva . . . . . . . . . . . . . . . 245

§3. Gastric Juice . . . . . . . . . . . . . 246

A. The Acid of the Gastric Juice . . . . . . . . . 247

B. Pepsin . . . . . . . . . 248

C. Rennin . . . . . . . . . . . 250

D. Gastric Steapsin . . . . . . . . . . . . 250

§ 4. Pancreatic Juice . . . . . . . . . . . . . . . 251

A. The Amylolytic Enzymes . . . . . . . . . . 251

B. The Proteolytic Enzyme, Trypsin . . . . . . . . 252

C. Lipolytic Enzyme, Steapsin. . . . . . . . . . . . 253

$\$ 5$. Bile . . . . . . . . . . . 253

$\$ 6$. Intestinal Juice . . . . . . . . . . . . . . 255

Second Section: Secretion of the Digestive Fluids . . . . . . . 256

$\$ 1$. General Surrey . . . . . . . . . . . . . 256

\$2. The Salivary Glands . . . . . . . . . . . . . . 257

A. Secretory Nerves . . . . . . . . . . . . . . 257

B. Morphological Changes During Secretion . . . . . . . 261

\$. The Glands of the Stomach . . . . . . . . . . 263

A. Secretory Nerves . . . . . . . . . . . . 263

B. The Gastric Glands . . . . . . . . . 266

C. Why Does the Stomach not Digest Itself? . . . . . . 269

\$4. Secretion of Pancreatic Juice . . . . . . . . . . . . . 269

A. Secretory Nerves . . . . . . . . . . . . 269

B. Morphological Changes in the Pancreas . . . . . . . 272

$\$ 5$. The Liver and the Secretion of Bile . . . . . . . . 272

A. General Phenomena of Hepatir Secretion . . . . . . 272

B. Dependence of the Secretion of Bile upon the Blood Supply . . 273

C. The Discharge of Bile in Digestion . . . . . . . . 275

$\$ 6$. The Glands of the Intestine . . . . . . . . . . 270

A. Glands of the Small Intestine . . . . . . . . . . 276

B. The Glands of the Large Intestine . . . . . . . . 277

Third Section: Iovements of the Alimentary Canal . . . . . . . . 278

\$. Mastication . . . . . . . . . . . . . . . 278

\$2. Sucking . . . . . . . . . . . . . . . . . . . . 279 
§3. Deglutition

$\$ 4$. Movements of the Stomach
A. Kneading Movements
B. Evacuation of the Stomach
C. Vomiting

Fourth Section: Digestion in the Different Divisions of the Alimentary Canal

§1. Digestion in the Mouth

$\S 2$. Digestion in the Stomach .

\$. Digestion in the Intestine.

$\S 4$. Formation of Fæces and Defeeation . . . . . . . . . . 298

Chapter VIII.-Absorption

$\S 1$. Absorption in General . . . . . . . . . . . . 301

\$2. Absorption of Carbohydrates . . . . . . . . . . . . . . . 303

\$3. Absorption of Fat . . . . . . . . . . . . . . . 304

4. Absorption of Proteid . . . . . . . . . . . . . . 305

$\S 5$. Absorption of Mineral Substances . . . . . . . . . . . 307

Chapter IX.-Respiration . . . . . . . . . . . . . . 310

First Section: Movements of Respiration . . . . . . . . . 310

$\$ 1$. Elasticity of the Lungs and Intrathoraeic Pressure . . . . . 310

\$2. Inspiration . . . . . . . . . . . . . . . 312

A. Registration of Respiratory Movements . . . . . . . $\quad 312$

B. Movements of the Ribs . . . . . . . . . . 314

C. Movements of the Diaphragm . . . . . . . . 316

§3. Expiration . . . . . . . . . . . . . . 317

\$4. The Number of Respiratory Movements. . . . . . . . 318

\$5. Exchange of Air in the Lungs . . . . . . . . . . . . 319

$\S 6$. Coneomitant Respiratory Movements . . . . . . . . . 321

\$. Special Forms of Respiratory Movements . . . . . . . . . 321

8. Pressure Changes in the Respiratory Passages . . . . . . . 321

\$. The Respiratory Sounds . . . . . . . . . . . . . 322

$\S 10$. Means of Proteetion for the Lungs . . . . . . . . . . 323

Second Seetion: Innervation of Respiration. . . . . . . . . . 323

1. The Efferent Nerves . . . . . . . . . . . . . 323

\$2. The Respiratory Center . . . . . . . . . . . . . 325

§3. Respiratory Reflexes . . . . . . . . . . . . . 327

A. Reflexes through the Vagi . . . . . . . . . . 327

B. Fibers from Anterior Parts of the Brain to the Medulla . . . 329

C. Other Respiratory Reflexes . . . . . . . . . 330

\$4. Normal Stimulation of the Respiratory Center . . . . . . . 331

Thirl Seetion: The Blood Gases . . . . . . . . . . . 333

1. Absorption of Gases in Liquids . . . . . . . . . . 334

\$2. The Blood Gases . . . . . . . . . . . . . . . 335
A. Nitrogen and Argon . . . . . . . . . . . . . . 335

B. Oxygen . . . . . . . . . . . . . . 335

C. Carbon Dioxide . . . . . . . . . . . . . . . . . . . . . 33 万

D. The Quantity of Blood Gases . . . . . . . . . . 339

E. The Distribution of Blood Gases between Corpuseles and Plasma . 340

Fourth Section: The Respiratory Exchange of Gases. . . . . . . . 340

1. Mechanism of Exchange between Blood and Alveolar Air . . . . . 340 
\$ 2. Exehange of Gases between Blood and Lymph . . . . . . . 342

$\$ 3$. Changes Produeed in the Respired $\lambda$ ir . . . . . . . . . 342

$\$$ 4. The Absolute Amount of Respiratory Exchange . . . . . . 345

Chapter X.-The Lymph and Its Movements . . . . . . . . . . 347

$\$ 1$. Chemieal P'roperties of the Lymph . . . . . . . . . 347

\$2. Movements of the Lymph . . . . . . . . . . 345

$\$ 3$. The Formation of Lymph . . . . . . . . . 349

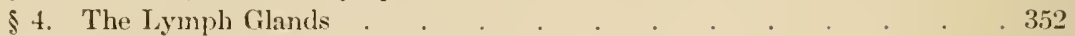

$\$ 5$. Absorption from Serous Cavities . . . . . . . . . . . 353

Chapter XI.-The Influenee of the Organs on One Another . . . . . . . 355

\$1. The Osmotic Phenomena . . . . . . . . . . 355

\$2. Internal Seeretions . . . . . . . . . . 356

A. General . . . . . . . . . . . . . 356

B. The Testes . . . . . . . . . . . . 357

C. The Oraries . . . . . . . . . . . . . 358

D. The Thyroid Gland . . . . . . . . . . 358

E. The Panereas . . . . . . . . . . 362

F. The Adrenal Bodies . . . . . . . . . . . 364

G. The Pituitary Body . . . . . . . . . . . . 367

H. The Kidneys . . . . . . . . . . . . . . . . . 367

I. The Spleen . . . . . . . . . . . . 368

Chapter XII.-The Final Deeomposition of Foodstuffs in the Body . . . . 369

$\S 1$. The Final Destruetion of Proteid . . . . . . . . . . . 369

$\S 2$. The Decomposition of Carbohydrates . . . . . . . . . 374

\$3. The Deeomposition of Fat. . . . . . . . . . . . 376

Chapter XIII.-The Exeretions of the Body . . . . . . . . . . 378

First Seetion: The Urine and Its Exeretion _ . . . . . . . . 379

$\S 1$. The U ine . . . . . . . . . . . . . . 379

A. The General Properties of the Urine . _ . . . . . 379

B. Composition of Urine . . . . . . . . . . . . 381

§ 2. The Exeretion of Urine . . . . . . . . . . . . 384

A. Strueture of the Kidneys . . . . . . . . . . 384

B. Mechanism of the Exeretion of Urine . . . . . . . . 386

§3. Mieturition . . . . . . . . . . . . . . 390

A. The Ureters . . . . . . . . . . . . . . 391

B. The Urinary Bladder . . . . . . . . . . . 391

Seeond Section: Exeretion through the Skin . . . . . . . . . 394

§ 1. The Sebaceous Glands . . . . . . . . . . . 394

§ 2. Exeretion of Sweat . . . . . . . . . . . . 395

A. Composition and Properties. . . . . . . . . . 395

B. The Exeretory Proeess . . . . . . . . . . . 396

§3. The So-ealled Insensible Perspiration . . . . . . . . . 397

Chapter XIV.-Animal Heat and Its Regulation . . . . . . . . . 398

$\S 1$. The Temperature of the Human Body . . . . . . . . . 398

\$2. The Souree of Animal Heat . . . . . . . . . . 402

$\S 3$. Loss of Heat from the Body . . . . . . . . . . . 403

$\S 4$. Protection against Loss of Heat . . . . . . . . . 404

§. Regulation of the Body's Temperature . . . . . . . . 406

A. Regulation of Heat Loss . . . . . . . . . . 407

B. Centers for Heat Regulation . . . . . . . . . 408 
First Seetion: General Physiology of Muscle and Nerve

\$ 1. Fundamental Laws of Nervous Activity.

$\S 2$. The Properties of Resting Muscles .

A. Elasticity

B. Chemistry of Muscle

$\S 3$. Stimulation of Museles and of Nerves

A. The Muscle Curve

B. Rate of Transmission of a Nerve Impulse.

C. Mechanical Stimulation of Nerves

D. Electrical Stimulation of Muscle and Nerve

E. Effect of a Rapid Series of Stimuli

F. Voluntary Contractions

A. Electrical Phenomena . . . . . . . . . . . . 431

B. The Nuscle Tone . . . . . . . . . . . . . 434

C. The Chemical Alterations in Muscle Due to Its Activity . . . 434

D. Mechanical Work . . . . . . . . . . . . 435

E. Heat Formation in Muscle . . . . . . . . . . . 439

§. The Central Innervation of a Skeletal Muscle . . . . . . 440

\$6. Fatigue and Recovery of Muscles and Nerves _ . . . . . . . 441

A. General Phenomena . . . . . . . . . . 441

B. Fatigue of Human Museles and Nerves . . . . . . . 443

$\S 7$. Rigor Mortis . . . . . . . . . . . . . . 447

$\S$ S. Smooth Muscles . . . . . . . . . . . . . 447

Second Section: Reciprocal Relations between the Muscles and Other Organs of the Body

Chapter XVI.-On Sensations in General . . . . . . . . . . 451

First Section: Qualitative Relations between Stimulus and Sensation . . . . 451

Sccond Section: The Quantitative Relations between Stimulus and Sensation . 455

$\S 1$. Weber's LaW . . . . . . . . . . . . . 456

Chapter XVII.-The Sensory Functions of the Skin . . . . . . . 458

$\$$ 1. Sensations of Temperature . . . . . . . . . . . . . . . . . . . .

$\$ 2$. Pressure and Touch . . . . . . . . . . . . . . . 461

§. The Local Sign . . . . . . . . . . . . . . 463

\$4. Pain . . . . . . . . . . . . 465

Chapter XVIII.-Organic Sensations . . . . . . . . . . . . 469

1. Motor Sensations. . . . . . . . . . . . . 469

2. Physiological Significance of Motor Sensations . . . . . . 472

\$3. The Semicircular Canals and the Otolith Sacs of the Inner Ear . . . 473

A. Anatomical . . . . . . . . . 473

B. Experimental Suppression of the Semicircular Canals . . . . . 476

C. Artificial Stimulation of the Semicircular Canals . . . . . . . 479

D. The Otolith Sacs . . . . . . . . . . . 4S1

E. Observations on Men . . . . . . . . . . . . 4S1

Chapter XIX.-Taste and Smell . . . . . . . . . . . . . 483

\$1. Sensations of Taste . . . . . . . . . . . . . . . 483

\$2. Sensations of Smell . . . . . . . . . . . . . . 4\$6 
Chapter XX.-Hearing, Voice, and Speech

First Section: Auditory Sensations

\$1. Stimuli Appropriate for the Organ of Hearing

A. Loudness

B. Pitch

C. Timbre

\$2. Transmission of Sound in the Ear

A. The External Ear .

B. The Middle Ear

\$3. Excitation of the Auditory Nerve

A. The Resonators in the Cochlea

B. Objections to the Resonator Theory .

Second Section: Physiology of Voiee and Speeeh _ . . . . . . . . . 502

$\$ 1$. Aetion of the Laryngeal Museles . . . . . . . . . . 502

$\$ 2$. Voice Production . . . . . . . . . . 504

\$3. Registers of Voice . . . . . . . . . . . . 501

\$ 4. Elements of Speech . . . . . . . . . . . . . . 506

A. Vowels . . . . . . . . . . . . . . 506

B. Consonants . . . . . . . . . . 507

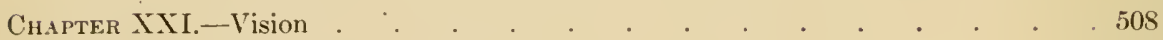

First Seetion: The Eye as an Optical Instrument . . . . . . . . 50S

\$ 1. The Optical Constants of the Eye . . . . . . . . . . 50 s

\$ 2. Images upon the Retina . . . . . . . . . . . . . 513

A. Direct and Indirect Vision . . . . . . . . . . . 514

B. The Light-perceiving Layer of the Retina . . . . . . . 514

C. Visual Angle and the Limits of Vision . . . . . . . 517

§3. Static Refraction in the Eye . . . . . . . . . . 519

$\S$ 4. Optical Defects of the Eye . . . . . . . . . . . . . . . . . . . . . . . .

A. Transparency of the Media of the Eye . . . . . . . 521

B. Form of the Refracting Surfaces . . . . . . . . 522

C. Astigmatism . . . . . . . . . . . . 52?

D. The Angle between the Line of Vision and the Optieal Axis . $\quad .525$

E. Chromatic Aberration in the Eye . . . . . . . . . 526

F. Summary . . . . . . . . . . . . . 527

\$ 5. The Iris. . . . . . . . . . . . . . . . 527

\$6. Accommodation . . . . . . . . . . . . . . . . 529

A. Range of Aecommodation . . . . . . . . . . . . 529

B. Mechanism of Accommodation . . . . . . . . . 530

Seeond Seetion: Excitation of the Retina and Visual Sensations . . . . . 536

\$1. Light Rays . . . . . . . . . . . . . . 536

$\$ 2$. The Phenomena of Excitation . . . . . . . . . . 537

A. Fatigue and Recovery of the Visual Organ . . . . . . 539

\$3. Sensations of Color . . . . . . . . . . . . 541

A. Relations of the Properties of Light to the Different Constituents of the Retina . . . . . . . . . 541

B. Successive Color Induction . . . . . . . . . . 542

C. Color Mixture . . . . . . . . . . . . 542

D. On the Theory of Color . . . . . . . . . . 544

E. Simultaneous Contrast . . . . . . . . . . 547 
Third Section: Movements of the Eyes and Visual Perceptions

$\S 1$. Action of the Eye Muscles.

A. Limits of the Eye Movements

$\S 2$. Significance of the Eye Movements for the Outward Projection of Visual Perceptions

§. Binocular Vision .

A. Correspondence of the Two Retinæ . . . . . . . . . 555

B. Single Vision with Two Eyes . . . . . . . . . 555

C. Perception of Depth . . . . . . . . . . . . 556

Chapter XXII.-The Physiology of the Nerve Cell and of the Spinal Cord

$\$ 1$. General Considerations Concerning the Finer Structure of the Nervous System

\$2. The Structure of the Spinal Cord

$\S 3$. Kinds of Nerves .

A. Classification Aceording to Funetion . . . . . . . . . . 564

B. Special Properties of Different Kinds of Nerve Fibers . . . . 565

C. Magendie's Doctrine . . . . . . . . . . . 565

$\S$ 4. Functions of the Nerve Cell . . . . . . . . . . . . . . 566

A. The Nutritive Funetions of Nerve Cells . . . . . . . . . 567

B. Physiological Stimuli of Nerve Cells . . . . . . . . . 569

C. Mode of Reaction of Nerve Cells to Stimulation . . . . 570

D. Dependence of the Nerve Cell upon the Blood Supply, and the Effects of Poisonous Substances . . . . . . . . . . 572

E. Morphological Changes in the Nerve Cell. Reproduction and Regeneration . . . . . . . . . . . 57t

§5. Reflex Processes . . . . . . . . . . . . . . 575

A. Segmentation in the Central Nervous System . . . . . . 575

B. General Features of Reflexes . . . . . . . . . . 576

C. Inhibition of Reflexes . . . . . . . . . . . . . 577

D. Augmentation of Reflexes . . . . . . . . . . . 579

E. Reflex Responses to Different Stimuli . . . . . . . . 580

\$6. Automatic Excitation . . . . . . . . . . . . 580

\$7. Tonus . . . . . . . . . . . . . . . . 581

$\S$ S. Central Functions of Peripheral Nerve Cells . . . . . . . . . 582

$\$ 9$. Centers in the Spinal Cord . . . . . . . . . . . 585

A. Control of Skeletal Muscles . . . . . . . . . . 586

B. Influence of the Spinal Cord on the Vegetative Functions . . . . 587

$\$ 10$. Conducting Pathways in the Spinal Cord . . . . . . . 58s

A. Electrical Stimulation of the Cord . . . . . . . . 55s

B. Methods of Determining the Conducting Pathways in the Spinal Cord. 589

C. Anatomieal Data Concerning the Conducting Pathways of the Cord . 591

D. Experimental and Clinical Observations on the Conducting Pathways in the Spinal Cord . . . . . . . . . . . 595

Chapter XXili.-Physiology of the Brain-stem . . . . . . . . 599

\$1. General Survey . . . . . . . . . . . . . 599

A. Method . . . . . . . . . . . . . . 599

B. Divisions of the Brain . . . . . . . . . . . 601

\$2. The Medulla Oblongata, or After-brain . . . . . . . . 602

§3. The Cerebellum . . . . . . . . . . . . 605 
$\$$ 4. The Mesencephalon, or Midbrain

A. The Corpora Quadrigemina .

B. The Crura Cerebri.

$\S 5$. The Diencephalon, or "Tweenbrain

$\$ 6$. Functions of the Brain-stem as a Whole

First Section: The Motor and Sensory Areas of the Cortex . . . . . 632

$\$ 1$. The Motor Areas . . . . . . . . . . . 632

A. General Survey . . . . . . . . 632

B. Stimulation of the Motor Cortieal Areas in Different Mammals . . 633

C. Direct and Crossed Effects of Stimulation of the Hotor Cortieal Areas 640

D. The Commissures between the Cortieal Areas of the Two Hemispheres 641

E. Cortical Epilepsy . . . . . . . . . . . . 641

F. Suppression of the Motor Cortical Areas . . . . . . . 643

G. The Course of the Condueting Pathways from the Motor Cortieal Areas to the Nuclei of the IIotor Nerves . . . . . . . . . 647

H. Development of the Motor Areas of the Cortex . . . . . 645

$\S 2$. Influence of the Cerebral Cortex on the Vegetative Proeesses of the Body 649

§3. The Sensory Cortieal Areas . . . . . . . . . . . 650

A. Area of General Sensation and Touch . . . . . . . 651

B. The Cortical Areas of Taste and Smell . . . . . . . . 653

C. The Auditory Area . . . . . . . . . . . 6.54

D. The Visual Area . . . . . . . . . . . . 655

E. Reeapitulation . . . . . . . . . . . 65s

Second Section: Psyeho-physieal Functions of the Cerebrum . . . . . 65s

1. The Significance of the Motor and Sensory Cortieal Areas . . . . 659

\$2. The Language Faeulties . . . . . . . . . . . 661

§3. The Association Centers of Flechsig . . . . . . . . . . 665

A. Anatomical . . . . . . . . . . . . . 666

B. The Anterior Association Center . . . . . . . . 668

C. The Posterior Association Center . . . . . . . . 669

D. Final Survey . . . . . . . . . . . 670

\$ 4. The Time Consumed by Psycho-physieal Proeesses . . . . . . 673

Appendix: Nourishment of the Brain . . . . . . . . . . . 676

Chapter XXV.-Physiology of Special Nerves . . . . . . . . . 680

\$1. Cranial Nerves . . . . . . . . . . . . . 680

§ 2. Spinal lerves . . . . . . . . . . . . . 682

A. Sensory Nerves . . . . . . . . . . . . 682

B. Motor Nerves . . . . . . . . . . . 652

§3. The Sympathetic Nerves . . . . . . . . . . 685

A. Relations of the Sympathetic Nerves to the Central Nervous System. 685

B. Course of the Sympathetic Fibers . . . . . . . . 687

C. Regeneration in the Sympathetic System . . . . . . 6 69

D. Afferent Nerves in the Sympathetic System . . . . . . 689

Chapter XXVI.-Reproduetion and Growth . . . . . . . . . . 691

First Section: Reproduction . . . . . . . . . . . . . 691

\$1. The Iale Sexual Organs . . . . . . . . . . . . 691

A. The Testes . . . . . . . . . . . 692

B. The Accessory Sexual Glands . . . . . . . . . . 692

C. Erection and Ejaculation . . . . . . . . . . . . 693 
\& 2 - The Female Siexuat Ore

A. The Ovaries and Oviduets . . . . . . . . . . . 695

B. The Uterus . . . . . . . . . . . 696

C. Pregnancy and Birth . . . . . . . . . . . . 697

D. Innervation of the Sexual Organs . . . . . . . . 700

\$3. Secretion of Milk . . . . . . . . . . . . . 700

A. The Milk . . . . . . . . . . . . 700

B. Secretion of Milk . . . . . . . . . . . 703

Second Section: Growth of the Human Body . . . . . . . . 705 



\section{LIST OF ILLUSTRATIONS ${ }^{1}$}

FIG.

PAGE

1.- Illustrating the use of the graphic method in recording the contraction of a frog's muscle (drawn for this edition).

2.-Muscle curves recorded on the same drum .

3.-The mercury manometer. . . . . . . . . . . . . . . 8

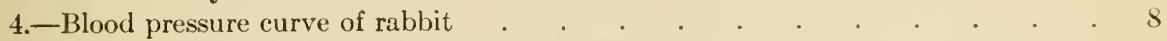

5.-Hembrane manometer (courtesy of Prof. W. T. Porter) . . . . . . . 9

6.-Kymograph with "endless" paper . . . . . . . . . . . . . 9

7.-Electric signal used as time marker . . . . . . . . . . . . 10

8.-Curves of blood pressure in left ventricle and aorta of the dog . . . . 11

9.-Recording tambour of Marey _ . . . . . . . . . . 11

10.-Receiving tambour for pulse record . . . . . . . . . . . . . . $\quad$. 12

11.-Pulse curve from carotid of man . . . . . . . . . . . . . . . 12

12.-Capillary electrometer . . . . . . . . . . . . . . . . 13

13.-Action currents of dog's heart . . . . . . . . . . . . . 13

14.-Polystomella venusta . . . . . . . . . . . . . . . . . . 17

15.-Thalassicola nucleata . . . . . . . . . . . . . . . . 18

16.-Parenchyma cells from root cortex of Frittilaria . . . . . . . . 21

17.-Leaf showing starch formation . . . . . . . . . . . 23

1S. - Root of bean with Bacteria tubercles . . . . . . . . . . . . . 23

19.-Gromia oviformis . . . . . . . . . . . . . . . . . . . . 35

20.-A maba polypodia . . . . . . . . . . . . . . . . . . 35

21.-Phases in the life history of Amreba (from Mill's "Animal Physiology") . . 36

22.-White blood corpusele of frog with bacillus ingested . . . . . . . . 37

23.-I Tampyrella spirogyre . . . . . . . . . . . . . . . . 37

24.-Frontana leucas (courtesy of Prof. Gary N. Calkins) . . . . . . . . 41

25.-Chlorophyll bodies in Lemna triscula . . . . . . . . . . . . . . . 42

26.-Mode of movement of Amrba . . . . . . . . . . . . . . 43

27.-Amœboid movements of white blood corpuscles _ . . . . . . . . 43

28.-Vorticella (from Mill's "Animal Physiology") . . . . . . . . 44

29.-Demarcation current in a muscle . . . . . . . . . . . . . 47

30.-Electric apparatus of cramp fish (from Mill's "Animal Physiology") . . . . 49

31.-Illustrating chemotaxis . . . . . . . . . . . . . . 54

32.-Wotor response in Paramcecium (courtesy of Prof. Gary N. Calkins) . . . 55

33.-Distribution of Bacteria in sunlight . . . . . . . . . . . . . . . 57

34.-Effects of constant current on the shrimp, Palcemonetes . . . . . . . 60

35 - Opalina ranarum . . . . . . . . . . . . . . . 61

36.-Cross section of intestinal musculature of cat . . . . . . . . . . 62

37.-A shoot of Antennularia antennina . . . . . . . . . . . . . 64

35.-Crystals of serum albumin . . . . . . . . . . . . . . . . . . 69

39.-Face mask for respiration experiments. . . . . . . . . . . . . . . 85

1 Unless otherwise stated the illustrations in this edition are the same as in the third German edition. 
FIC.

40. - Schema of Atwater-Benedict respiration calorimeter (courtesy of Prof. Francis (r. Benediet) .

41.-Respiration apparatus of Pettenkoffer and Voit (drawn for this edition) . . 87

42.- Respiration apparatus of Sondén and Tigerstedt

43.- Threc experiments on elimination of urea by fasting dogs _ . . . . . 101

44.- Elimination of $\mathrm{X}$ in urine of man . . . . . . 102

45.-Preparations from the liver (normal and diabetic) of man . . . . . . . 126

46.-Blood errstals . . 150

47.-Absorption spectrum of oxyhemoglobin . . . . . . . . . . . . . 151

45.-Absorption spectrum of hemoglobin . . . . . . . . . . . . . . . 151

49.-Hemin crystals. . . . . . . . . . . . . . 153

50. - ¿chema of the circulation . . . . . . . . . . . . . . . 162

51.-Cross section through a fully contracted human heart . . . . . . . 163

52.-.-"Krehl's cone" of fibers in the left ventricle . . . . . . . . 163

53.-Casts of ventricular cavities of ox heart in rigor mortis . . . . . . 164

54.-Position of atrio-ventricular valves when closed. . . . . . . . . . . . . . . .

5.5.-Cardiographic sound . . . . . . . . . . 168

56. - Intracardial pressure curves of horse . . . . . . . . . . . . . . 169

57.-Pressure curves of right ventricle, left ventricle, and aorta of horse . . 170

5..-Pressure curves from left ventricle and aorta of horse . . . . . . . 171

59. - Schema illustrating Ludwig's theory of the apex beat _ . . . . . 172

60.-Pressure curves in right auricle, right ventricle, and of apex beat (horse) . . 173

61.-Receiving tambour of Marey's cardiograph . . . . . . . . 17t

62.-Curves of apex beat and carotid pulse of man . . . . . . . . . . . 175

63. - Variations of electrical potential in human heart . . . . . . . . 179

64.-Action current of human heart . . . . . . . . . . . 150

65.-Direct stimulation of isolated cat's heart . . . . . . . . . . . 1S3

66.- Influence of temperature on isolated heart of the cat _ . . . . . . 184

67.-Cardiac nerves of $\operatorname{dog}$. . . . . . . . . . . . . . . . . . . . . . 191

65.- Representation of pulse rate . . . . . . . . . . . . . . . . . . 192

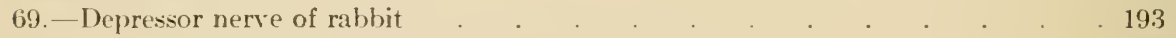

70.--Behavior of blood pressure on stimulation of depressor nerve _ . . . 194

71.--Pulse rate in man at different ages . . . . . . . . . . . . . . . . 197

72 . Flow of liquid through rigicl tube of uniform diameter . . . . . . 198

73.-Flow of liquid through rigid tube of varying diameter . . . . . . . . 199

74.-Artificial schema of mechanics of circulation (courtesy of Prof. W. T. Porter) . 200

75.-Cubic enlargement of anrta of rabbit, increasing internal pressure . . . . 201

7ij.--Erlanger's apparatus for determination of blood pressure in man (eourtesy of Prof. Joseph Erlanger) . . . . . . . . . . 203

77.-Blood pressure curve, feeble stimulation of vagus . . . . . . . . . . 205

7S.-Blood pressure curve, medium stimulation of ragus . . . . . . . . 206

79.-Blood pressure curve, strong stimulation of vagus . . . . . . . . 207

s0.-Current clock . . . . . . . . . . . . . . . . . 209

\$1.-Hæmadomograph with air-transmission . . . . . . . . . . . 209

S2.- Velocity and pressure curves in carotid of horse . . . . . . 210

83.--Plethysmograph . . . . . . . . . . . . . . . 211

84.-Plethysmographic curve . . . . . . . . . . . . . . . 212

85. - Schema illustrating Weber's theory of pulse . . . . . . . . . . 213

86. - Spring of Marey's sphygmograph . . . . . . . . . . . . . 214

S7.-Dlarey's sphygmograph as used . . . . . . . . . . . . . 215

S8.- Radial pulse curve . . . . . . . . . . . . . . 216

89.-Contractile cells embracing wall of capillary . . . . . . . . . . . 220 
FIG.

90.-Capillary constricted by vasomotor influence

91.-Apparatus for determining blood presure in capillaries . . . . . 2. 21

92.-Cubic enlargement of inferior vena cava of cat . . . . . . . 223

93. - Position of human body in which veins are stretched most . . . . 206

94.-Position of human body in which veins are relaxed most . . . 226

95.- Variations of aortic pressure in $\operatorname{dog}$. . . . . . . . . . . . . 2029

96.--Respiratory variations of blood pressure, rabbit . . . . . . . . 230

97. - Reflex rise of blood pressure in rabbit . . . . . . . . . . 236

9S.-Reflex fall of blood pressure in rabbit . . . . . . . . . . . . . 237

99. - Section of hepato-pancreas of an isopod crustacean (courtesy of I)r. Edgar F. Nolan. Philadelphia Academy of Natural ściences) . . . . . 244

100.-Parotid gland of rabbit

101.-Parotid gland of cat

261

102.- - Parts of a tongue gland of the frog

262

103.-Hourly course of secretion of gastric juice in dog's stomach

26.5

104.- Hourly course of the digestive action of gastric juice on proteid . . . 26.5

10.5.- Secretion capillaries surrounding parietal cells of gastric glands . . . . 267

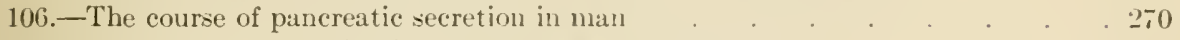

107. - The course of secretion in the pancreas of the $\log$. . . . . . . . . . . . . . . .

105.-Enzymes of pancreatic juice, relative rate of activity of . . . . . 271

109.-Pancreas of rabbit as observed in living animal . . . . . . . . 2-2

110. - Hourly course of discharge of bile into the intestine of the dog . . . . . 275

111.-Glands of large intestine of rabbit . . . . . . . . . . . . . . . . . . .

112. Sagittal optical sections of floor of nouth and neek . . . . . . 241

113. - Motor nerves of throat and palate of monkey . . . . . . . . . . . . . . .

114.- Nerves of stomach musculature . . . . . . . . . . . . . . . . . 4

115. - Schema to illustrate relation of longitudinal muscular filers of intestine . 257

116. - Sichema illustrating rhythmical segmentation of small intestine (courtesy of 1)r.

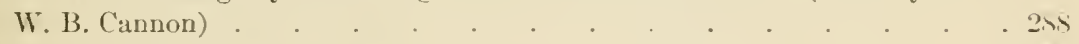

117. - Schema illustrating antiperistalsis (courtesy of Dr. W. B. Cannon) . . . 249

115. - Successive stages in absorption of fat in epithelial cells of froc's intestine . . 304

119. -Duodenum of mouse showing absorption of iron . . . . . . . . . . . . . . . . . . . .

120.-Experiment on expansion of lungs of rabbit (drawn for this edition) . . . 311

121.-Pneumographic curve of mall . . . . . . . . . . . . . . . . . 313

122. - Apparatus for registering volume of the respired air . . . . . . . . 313

123.-Respiratory curve of rabbit . . . . . . . . . . . . . . . . 314

124. - Thorax as seen from the right side . . . . . . . . . . . 315

125.- Schema of movements of the diaphragm, liver, stomach, and spleen in respira-

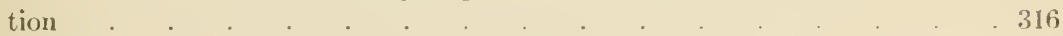

126.-Diaphragmatic and thoracic types of respiration . . . . . . . . 31s

127. - Number of respirations per minute in persons of tifferent ages . . 319

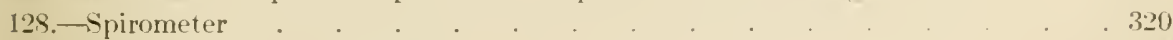

129.-Rexpiratory curve of rabbit . . . . . . . . . . . . . . . . . . . . . . . .

130. - Schema of Ludwig's pump for extraction of blood gases. . . . . . . . . . . . . .

131. - Absorption of oxygen by horse's blood . . . . . . . . . . . . . . . . . . . . . .

132. - Absorption of carbon dioxide in solution of hiemoglobin . . . . . 339

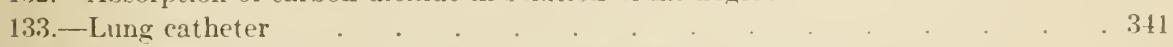

134.- Amount of carbon dioxide expired, measured in two-hour periols . . . 343

135.-Elimination of carbon dioxide on ordinary diet and in fusting . . . . . . . . .

136. - Elimination of earbon dioxide by a boy . . . . . . . . . . . . . . . 345

137.-A myxoedematous woman . . . . . . . . . . . . . . . . . . . . . . . . . . .

135. - A cretinous child (from Holt's "Diseases of Children") . . . . . . . 360 
FIG.

139. - Crystals of urea

140.-Crystals of uric acid

141.-Other forms of uric-acid erystals

142.-Hippuric-acid crystals

143. Schema representing blood vessels of the kidney

144. Schema representing tubules of the kidney

145.- The nerves of the bladder

146.-Portion of the preputial gland of the mouse

147.-The normal diurnal variations of temperature in man

148. - The elimination of carbon dioxide in man determined every two hours

149. - The temperature of the body after death .

150. - Curves of extension and elastic shortening of muscle

151.-Apparatus of Blix and Lovén for recording the elasticity curve of a muscle

152.--Extension and elasticity curves of the frog's gastrocnemius

153.-Fick's apparatus for recording variations in the length and in the tension of a muscle.

154. - Simple contraction curve of the frog's gastrocnemius

155. - Curves illustrating the method of determining the rate of conductivity in the sciatic nerve of a frog (from a student's note-book) .

156. Schema representing the rheocord of Du Bois-Reymond

157.-Nonpolarizable electrodes (courtesy of Prof. W. T. Porter)

158.-Induction coil (courtesy of Prof. W. T. Porter)

159.-Details of the Wagner hammer, or interrupter of the induction coil

160.- Arrangement of apparatus for sending induction shocks through a muscle (drawn for this edition)

161.-Catelectrotonus

162.-Anclectrotonus

163.- Stimulation of a nervè by ascending make and descending break induction shocks.

164.-Distribution of an electric current in a human arm

165.-Entrance into and exit from a nerve of an elcetric current applied to the skin over the nerve

166.-Tetanus curve of the frog's gastrocnemius.

167. - Tetanus curves of the white and red muscles of the rabbit . . . . . 430

168. - Schema representing a rheotome experiment . . . . . . . . . . 431

169.-Rheotome of Bernstein .

170.- Schema representing the spread of an excitation causing an action current . 433

171.-Illustrating the theory of electrotonic eurrents . . . . . . . . . 433

172.- Relation of work to size of stimulus . . . . . . . . . . . . . . . 435

173.-Isotonic and simple projectile contractions . . . . . . . . . . . . 436

174.--Relation of the form of contraction curve to load . . . . . . . . . . . 436

175.-Veratrin curve of frog's gastrocnemius . . . . . . . . . . . . . . 437

176.-Isotonic and isometric contractions . . . . . . . . . . . . . . 438

177.-Fatigue curves . . . . . . . . . . . . . . . . . . . . 441

178.-Fatigue curves (courtesy of Prof. F. S. Lee) . . . . . . . . . . . 412

179.-Ergograph of Mosso . . . . . . . . . . . . . . . . . . . 44t

180.-Fatigue tracings obtained with Mosso's ergograph . . . . . . . . . . 444

181.-Fatigue tracings with different rates of stimulation . . . . . . . . . 445

182.-Arrangement of cold, heat, and pressure spots on the skin of the wrist . . 459

183. - Topographical distribution of cold and heat senses . . . . . . . . . 460

184.- The semicircular eanals of the pigeon, laid bare _ . . . . . . . . $\quad .474$

185.- Relation of the planes of the semicircular canals to each other . . . . 475 
FIG.

1S6.-Distance of the anterior and posterior canals (prolonged) from each other

187.-Pigeon with membranous labyrinths removed

188.- Pigeon five day's after removal of the right membranous labyrinth . . . . 476

159.-Pigeon twenty days after removal of the right membranous labyrinth . . 47

190. - The taste zone of the upper surface of the human tongue . . . . . . 483

191. - Course of the gustatory nerve fibers (from Leube's "Special Medical Diagnosis") ts 4

192.-Olfactometer of Zwaardemaker . . . . . . . . . . . . 457

193.-Seebeck's siren . . . . . . . . . . . . 490

194. Schema representing the relations of overtones to their fundamental . . . 492

195.-Resonator of Helmholtz . . . . . . . . . . . . 493

196.-Transverse section through the left auditory canal and tympanic membrane . 494

197.-Horizontal section through the tympanic cavity . . . . . . . 495

198.-Hammer and anvil . . . . . . . . . . . . . . . . . . . . . . 496

199.-The organ of Corti of the human ear . . . . . . . . . . . . . 500

200.-Action of the posterior crico-arytenoid muscle . . . . . . . . . 503

201.-Action of the lateral crico-arytenoid muscle . . . . . . . . . . 503

202.-Laryngoscopic picture during quiet respiration . . . . . . . . . 504

203.-Appearance of the vocal cords while producing a chest tone . . . . . 505

204.- - Position of the vocal organs in producing the sound of broad A . . . . 505

205.-Position of the vocal organs in producing the sound of long E . . . . 506

206.-Illustrating the refractive index . . . . . . . . . . . 509

207.-Illustrating the refracting surfaces of the eye . . . . . . . . 510

208.-Illustrating a simple refracting system . . . . . . . . . . 511

209.-Illustrating the nodal points in a complex system . . . . . . . 511

210.- Position of the cardinal points in the schematic eve . . . . . . . . 513

211.- Section through the retina of a full-grown dog . . . . . . . . . 515

212.-Illustrating the blind spot in the eye . . . . . . . . . . . . 516

213.-Wiew of the rods and cones from the outer surface of the retina . . . . . . 517

214.-Diagram showing the visual angle . . . . . . . . . . 518

215.-The static refraction of a hypermetropic, an emmetropic, and a myopic eye . 519

216.-Method of demonstrating entoptic phenomena . . . . . . . . . 521

217. Entoptic particle in the vitreous body . . . . . . . . . . . . 522

215.-Illustrating spherical aberration . . . . . . . . . . . . . 523

219.-Refraction of light rays in regular astigmatism (from Fuchs' "Text-book of Ophthalmology") . . . . . . . . . . . 524

220.-Astigmatism chart . . . . . . . . . . . . . . . 525

221.-Diagram illustrating chromatic aberration . . . . . . . . . . . 526

222.-The iris of a cat at rest and on stimulation . . . . . . . . . . . . . . . 5

223. - The iris of a cat with a sector isolated . . . . . . . . . . . . . . . .

224.-Method of demonstrating accommodation in the eye . . . . . . . 530

2:25.--Reflection of images from the eye in accommodation . . . . . . . . 531

226. - The protrusion of the iris in accommodation . . . . . . . . . . . 531

227.-Meridional section through the ciliary body . . . . . . . . . 532

229.-Zonule of Zinn of an adult man . . . . . . . . . . . . . . . . 533

2:29. Schema of the mechanism of accommodation according to Schön . . . 534

230. - Schematic representation of the optic tracts (modified from Fuchs" "Text-book of Ophthalmology," drawn for this edition) . . . . . . . . . 535

231.-Optogram formed in the visual purple . . . . . . . . . . . 537

232. - Morphological changes produced in a frog's eye by light . . . . . . 53s

233.-Disk with white and black sectors . . . . . . . . . . . 539

234 - Illustrating the excitation of the retina successively by white and black sectors 5.39

235. - Excitation of the retina as a function of the time exposed . . . . . 540 
FIG.

236. - Illustrating successive color induction

237. - Excitation of the different components of the visual organ by light rays of different wave lengths

23S. - Excitation of the different components in eyes of König and Dieteriei by different wave lengths. . . . $5 t^{5}$

239. - Illustrating simultaneous eontrast

240. - The extra-ocular muscles and their axes of rotation (from Fox's "Diseases of the Eye") .

241.- Rotation of the eye about the separate axes

242. - The field of vision projected on a distant plane perpendicular to the line of vision

243.-Illustrating Scheiner's experiment

244.--Illustrating optical delusion in judgment of distanees

245.-Illustrating optieal delusion in judgment of distanees

246. - Illustrating optical delusion in judgment of distances

247. - The rivalry of the two retinx

248.- Illustrating the simultaneous formation of images of an oblique line in the two eyes

249. - Showing the positions of these images on the retinx

250.- Stereoseopic vision

251.-Brewster's stereoscope

252 - Ganglion cell of a leech showing intracellular networks

253.-Pericellular network of Golgi, nueleus dentatus of the dog

254. - Semidiagrammatic section of the spinal cord

255.- Schema of connections in the cord

256.--Reflex contractions of the frog's leg, illustrating summation in the nerve cells of the cord

257. - The relative resistance of several different nerve centers to asphyxiation .

259. Sehema of a reflex through several peripheral ganglion eells .

260.- Iltustrating a possible explanation of an axon reflex

261. - Cross section at different levels of the spinal cord .

262. - Secondary descending degeneration in the eord

263. - Illustrating method of stimulating the cord electrically

264. - Seetions through the eervical and lumbar parts of the eord

26.5.-Diagram of the enurse of the sensory condueting pathways (from Strumpell's "A Text-book of Medicine") .

266.-Diagram of the upper and lower motor conducting pathways (from Barker's "Nervous System")

267. - Iedian seetion through the brain, showing divisions

268. - Transverse section of the medulla oblongata

269. - Position of the nuclei of the eranial nerves

270.-Brain of a dog with the cerebellum removed

271.-Diagram showing paths connecting the cerebellum and pons with the cerebrum (from Barker's "Nervous System") 
275.-Brain of a pigeon (from Wiedersheim's "Anatomie der Wirbelticre") . . 6222

279.-Brain of a rabbit (from Wiedersheim's "Anatomie der Wirbeltiere") . . . 623

240.-Lateral view of a dog's brain (from Ellenberger and Baum's "Anatomie des Hundes")

281. - The remainder of the brain of Goltz' dog after removal of the cerebral hemispheres

282.-Dorsal surface of the dog's brain, with excitation points indicated aceording to Fritsch and Hitzig's early experiments .

283.-Latent period of muscular contraction induced by stimulation of the cortex and by stimulation of the underlying white matter

284. - Structure of the cortex of the convolutions bordering on the fissure of Polando 285.- Motor cerebral localization in the monkey, outer surface of left hemisphere (from Barker's "Nervous System")

286.- Hotor cerebral localization in the monkey, inner surface of left hemisphere from Barker's "Nervous System")

287.- - Notor cortical areas in the monkey (from Barker's "Nervous system") . . . 63

288. - The motor cortical areas of the chimpanzee . . . . . . . . 635

289.-Diagram of the external surface of the left cerebral hemisphere of man . . 639

290.-Diagram of the internal surface of the right cerebral hemisphere of man . . 639

291.-The course of an epileptic attack induced by stimulation of the motor cortical zone

292.- - The motor tract at various levels of the internal capsule (from Barker's "Vervous System") . . . . . . . . . . 647

293.- Sensory areas on the outer surface of the right cerebral hemisphere . . . 654

294. - Sensory areas on the inner surface of the left cerebral hemisphere . . . . 654

295. Schematic representation of the optic tracts (modified from Fuchs, drawn for this edition)

296.--Diagram of the speech tract together with various centers of the cerebral cortex concerned in speech (from Leube's "Special Medical Diagnosis") . . . 662

297. - The myelogenetic areas of the human brain, outer surface . . . . . . 666

298.- The myelogenetic areas of the human brain, inner surface . . . . . . . 667

299.-Curve representing the depth of sleep . . . . . . . . . . . . . . . . . .

300.--Distribution of the superficial areas served by the different sensory roots (from Strümpell's "A Text-book of Medicine") . . . . . . . . . 683

301.- Schematic representation of the connections of the sympathetic fibers . . 686

302.-. - Tormal curve of contraction of the uterus . . . . . . . 695

303.- Pressure curve of the last contraction of the uterus in parturition _ . 699

304.-Curves representing the height and weight of boys and girls of different ages . 709

305.- Variations in the height of military recruits in Sweden . . . . . . 710 



\title{
A TEXT-BOOK OF PHISTOLOGT
}

\author{
INTRODUCTION
}

The aim of scientific physiology is, to determine the functions of the animal body and to derive them strictly from the elementary conditions of animal life (LUDWIG).

T're animal boly is composed of a large number of different organs. The first task therefore is to find out what functions are performed by each individual organ. to learn how these functions may be influenced by different conditions. and to determine as exactly as possible the intensity with which each function may be performed under different circmistances.

Of all the rarying conditions. whose influence on the functions of the orcans we shall have to investigate. there is none so important as the action of the organs themsetres upon one another, and the consequent manifold interdependence among them. It is only by giving attention to this interaction of the organs that we can arrive at any real determination of their functions, or make any satisfactory progress toward understanding how the existence and capabilities of the body as a whole result from the collectire activity of the individual organs.

In most of the functions the activity of the elementary constituents of the body. the cells and tissues. is to be reckoned as a fundamental eondition. And the farther modern physiology progresses. the more clearly does it appear that the cell, or as Briicke appropriately ealls it, the elomentary orgunism, represents the real unit of the body, not only in the morphological sense. but in the physiological sense as well. The remarkable properties of the living substance, as exhibited in most of the fundamental processes going on in the living body, are dependent upon much more emplicated enditions than the exact scientific investigations of our time have been able to explain: but in most phrsiological prohlems where research has progressent far enough to warrant theoretical conclusions to any degree well fommled, it has been shown that the fundanental conditions for the functions of the organs and tisues are preciscly those conditions which determine the vital actirity of the cells. It need searcely be emphasized here that in so saying I have meant to give no actual theory, that is to say. no mechanical explanation, of the phenomena in question. If we trace the functions of the organs lack to the rital actirity of the cell. we hare done nothing more than point ont where the solution of the problem is ultimately to be sought. without haring thereby entered more deeply into the problem. 
I wish expressly to state that this enception does not at all imply that in the living boty forees are to he fomel of an essontially ditferent kind from those which rule in the inanimate workl. The fumdamental point of riow of all modern natmal science is this, lhat crery phenomenon is the necessaly consequence of rertain active aluses. which when they coöperate moler the same eiremstances always produce the sime plunomenon. The energy which represents the actire cause of any nitural process is nerer destroyed and is never created anew : it may assume various forms, it may pass from one form to another, hut in its quantitative relations it is never changed.

This principle of the conservation of energy. which was first enunciated by J. R. Mayer, J. P'. Jonle, L. A. Colding, and H. Hehmholtz (18t2-184i). in physioloyy. as in other fiolds, is the foumdation of all scientific thinting. We maintain that in those processes which take place in the living body and which together make up our conception of life, the principle of the conservation of energy holds good: and in so doing we place physiological investigation on the firm basis of exact natural science, eren though we are not vet in position to follow ont this view to the phenomena of life in all their details. or to ennjecture what is the real canse of the activity of living snlustance. This conception of the living woll and of its ruling forces is quite different from the ancient ritalism, now finally abandoned. That doctrine relied upon a canricious phantom of vital force. which, entirely unfettered by natural law, at times was responsible for the most unheard of results, and at others ranished completely from the field.

All animals throughout the whole vast series, from the lowest to the highest. are the proper subject of physiological research. While it is true that the close relation of physiology with medicine has given man and the animals which stand next to him in the sale an exerptionally predominant place in research as well as in elucation, physiology dnes not seck to know the functions of the body and the fundamental enditions of existence in the human species alone. Philosophically all animals possess an equal interest for physiology: and in studying the fundamental conditions of life (cell activity and its dependence upon different variables) we are compolled to widen the province of wur reseurch still more and to draw upon the other large groups of living beings. the unicellular orwanisms and plants. for data looking to the explanation and completion of the results ohtained from higher animals.

Moreorer, it is incumbent upon physiology to study the development of rital phenomena both in the individual and in the animal kingdom as a whole. Thus it is placed side by side with romparative anatom! whose provinee it is to investigate the derelopment of all organic forms from the lowest to the highest. We are not in forget. however, that physiology is an exact natural srience. It is not sutficient to demonstrate how a definite function appears first in its simplest form and then beemes more and more manifold and complicated : physiology must give also a mechanical explanation. Inrestigation of the elementary mechanism of the phenomenon is therefore the chief and all-important thing in physiology, and if we wore to name the ultimate goal of the science. we should say it is to furmish a mechanical explanation of the origin of living heings and of their progressive develomment to higher and higher forms. Within the province of physiology would thus fall the 
mechanical explanation of morphological results, and according to this conception physiology would constitute the rery summit of all biolngical investigation. It is scarcely necessary to remark that in the present state of our knowledge we cannot yet forecast how this far-distant goal shall be reached.

Referexces.-Helmholtz, " ̈̈ber die Weehselwirkung der Naturkräfte und die darauf bezïglichen neuesten Ermittlungen der Physik" (1854). "Über die Erhaltung der Kraft" (1\&62)—in "Vorträge und Reden" by Hermann v. Helmholtz. 1. Braunschweig, 18st. 
CHATTER I

GENERAL PIISEIOLOGICAT, METIIOD

\section{§ 1. PHYSICAL, CHEMICAL, AND HISTOLOGICAL METHODS}

Pirrsiologr makes nse of all the modern aids to researeh in natural seience. We have not infrequently to emplor the finest instruments of precision and the highest mathematical analywis. The physiology of the two highest sense organs, the eve and the ear, has progressed so far that every fact which relates not to our own perceptions and interpretatious, lout to the purely physical condition of their origin, can be treated with a discrimination and exactness of experimentation which place this portion of plysiology on a plane with the most exact of all matural sciences, namely, physies. The same holds, for the most part also, in the general physinlogy of cross-striated muscle and nerve. Here electrical science and several other branches of physics have found wide application.

The study of the cirenlation of the blood presents an extraordinarily conplicated problem in hydraulics; the study of equilibrim and locomotion of the body is to be treated from a purely mechanical point of view; in the discussion of the reppiratory exchange of gaves in the lungs and in the tissues physiology turns to aceount hoth thenretically and experimentally the physical theory of gases; and the doctrine of heat regulation is hased naturally on the physical theory of heat. In short, almost every division of physies has some direct bearing upon our study of the functions of the body.

In the same way chemistry is of far-reaching importance in physological research. The chemical mature of the substances containerl in or formed in the animal borly is one of the first things to be considered. Besides this, chemical physiology has to investigate also the changes which the ingested substances undergo in the vital processes of the body.

Microscopieal investigation furnishes us valuable data with regard to the activity of the rells, and histological methods have therefore rery wide application in physiology.

The phrsiolngy of the sense organs and of the central nervous system stands in very elose relation with psychology and the theory of knowiedge, or to put it more strongly, a thoroughgoing study of this branch of physiology is imposible without a knowledge of these sciences.

Finally, physiology must take into aecount also the discoveries of pathology and of pharmacodynamics. For however the functions of the body are influenced by the different ahnormal changes, or loy poisons. they are not altered in nature; and the study of these changes must evidently throw light on the normal processes. 
As for the rest. physiology must create its own methods according to the nature of the problems to be solved; and in the following presentation of the functions of the body we shall discuss as far as may be necessary for our present purposes the methods in use. There are however some general methods of physiological technique which it will be appropriate to discuss in this place.

\section{§ 2. EXPERIMENTS ON LIVING ANIMALS}

It is true that one can obtain important information concerning the functions of the organs and of the entire body without auy operative interferenre-indeed, all of our direct observations on man have been made under such ciremmstances. But it is often necessary to make the organs accessible to immediate observation. We are therefore often compelled to perform on living animals many kinds of operations, some of which put the skill and inrentive genims of the operator to a serere test. In these operations the animals are as a rule ancpsthetized with ether. chloroform. chloral, morphine or some other narcotic. Only if the purpose of the experiment makes it necessary is the operation performed on un-anesthetized animals. For many physological purposes the animal must be olserred for a long time after the end of the operation, and in such cases it is necesary to nse the antiseptic and aseptic methods of surgery with every possible care. Furthermore, it is many times of adrantage in the experiment to suppress the roluntary morements of the animal, and this is done ly administering the American arrow poison, curare. since this drug paralyzes the respiratory muscles along with others it is necessary to resort to artificial respiration. which is usually accomplished by rhythmically forcing into the lungs with a bellows a quantity of air suitable to the size of the animal. The air is introduced through the trachea by means of a camnula comnected with the bellows. In all operations where the pleural earities must be opened artificial respiration is indispensable (Tesalius, about $15+0)$.

After the animal has been prepared in this way, the particular experiment follows. It would be imposible to describe here even in enndensed form the different prineiples of experimentation which must be observel if perfectly mequirocal results are to be obtained. The following may be giren as an illustration :

There are in general only two ways of discovering the influence of the central nerrous system on a given organ or function: either the nerve supplying that organ may be cut and the effeets on the behavior of the organ noted, or the nerve may be stimulated artificially and the resulting action of the organ be determined. In most cases the latter method gives the clearer results, for mere section of the nerve cannot give us any definite conclusions. unless the nerve at the moment it was cut was actually transmitting impulses from the central system. which of course is by no means always the ease.

It is often of great profit. in dotermining the phrsiological importance of an organ. to extirpate it, and to maintain the animal alive. The resulting absence of certain phenomena frequently permits of rery raluable conclusions. Fspecially is this true in the ease of organs like the throroid gland and the adrenal bodirs, which to direet observation disclose no sign of their func- 
tions. Fxtirpation and transecetion represent important methods of research in stmlying the functions of the eentral nervons system. It cammot be denied

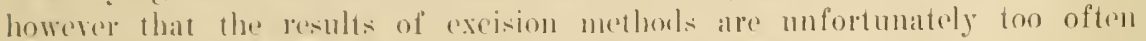
rery ditherelt of explanation, and that their interpretation is not infrequently made still more dillienlt by mintentional lexions.

\section{\$3. EXPERIMENTS ON SURVIVING ORGANS}

In the cold-blooded animals many organs remain ative for a long time after the death of the organisum, eren when they have been cut out of the boly. liy virtue of this popely it has heen posible to collect a great mass of most important facts. (Our knowledge of the general propertics of nerve and muscle rests for the most part on experiments with exsected organs. Organs removed

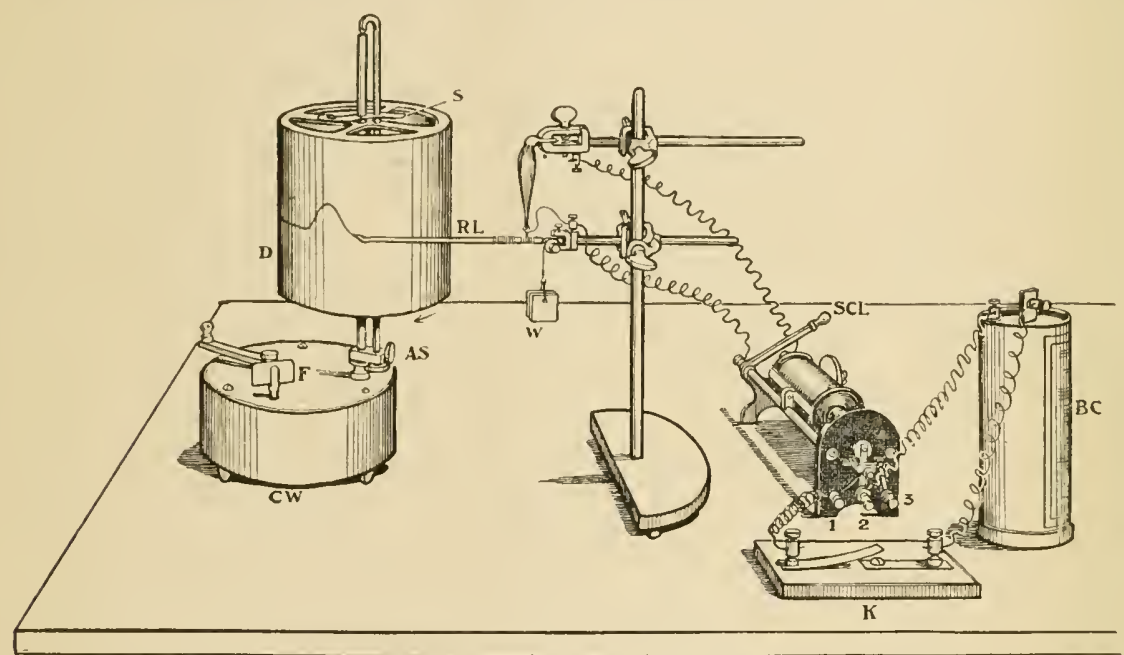

Fic. 1.-Illustrating the use of the graphic method in recorting the simple contraction of a frog's muscle. For description, see text.

from the botly remain still Ionger alive if, as was first done by Ludwig and his school, they le artificially nourished with blood. Under such conditions it is possible also to maintain organs of warm-blooled anmals alive for a ronsidcrable time after death of the boly as a whole. Organs removed from the boly which remain capalsle of activity are called surviving organs.

\section{§4. THE GRAPHIC METHOD}

Functions of organs are not infrequently explesed by ontward movements of some kind, which as a rule are so rapid that their details caunot be followed by the naked eye. 'They can be studied very exactly, however, if one can hit upon a method by which the morements record themselves upon a moving surface (graphic method, Ladwig. 1847).

Sinee this method finds very wide application in most branches of physiol- 
ogy, it is necessary to describe it liere somewhat fully. The apparatus cmployed for reeording movements by the graphie method consists essentially of two parts: (a) the surface upon which the movement is tracel, and (b) the mechanism by which the movement is transferred to the recording surface.

\section{A. THE KYMOGRAPH}

[A very simple illustration of the graphic method is given in Fig. 1, where the simple contraction of a frog's muscle is being recorlect on a moring surface-an application of the method first made by Helmholtz in 15.52. In such an apparatus ${ }^{1}$ the surface consists of a glazed paper covered erenly with the soot from a gas-flame and attached to the surface of the drum (I)) of an instrument called the kymograph. The drum is caused to revolve in the direction of the arrow by a clockwork (CW) inclosed in the base of the kymograph. The clockwork is propelled by a strong spring which is wound by means of the lever at the left. By means of the thumbscrews (AS) and fans (F) of different sizes, the gearing of the clockwork may be so adjusted as to revolve the drum at any desired speed.

The recording lever ( $\mathrm{RL}$ ) terminates in a fine point which bears on the smoked surface, and, as the drum revolves, scratches a tracing in the sont. The muscle, the gastrocnemius of a frog, is so prepared that its tendon of Aclilles is free to be attached to the hook on the lever. The other end of the muscle is still attached to the femur, a stump of which is left to be fastened in the clamp. In order to imitate as nearly as possible the action of the muscle in its normal relations, it is necessary that it be made to lift some weight ( $\mathrm{W}^{\top}$ ) -i. e., to do a certain amount of work. This weight, howerer, has considerable inertia compared with the lever itself, and in order that this may influence the character of the contraction as little as possible, the weight is fastened to the lever quite elose to its axis, the muscle itself being fastened somewhat farther from the axis. Electrical comnections are made so as to send a shock through the muscle.

${ }^{1}$ For the sake of simplicity the recording surface in the figure is shown white, and the tracing black. 


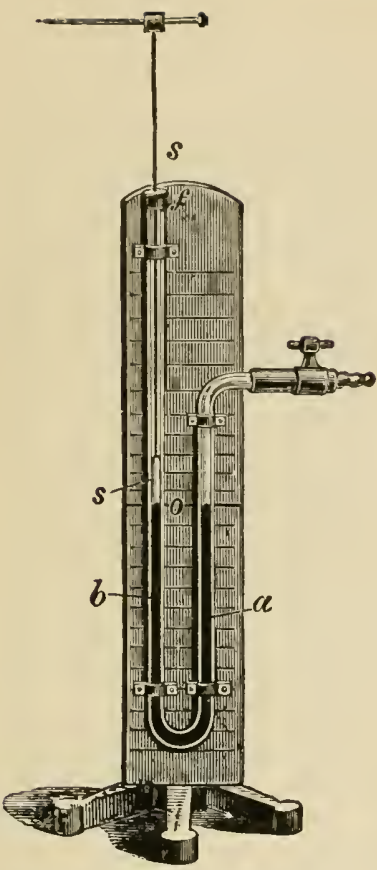

Fig. 3.-The mereury manometer, provisled with a writing point for recording the level of the mercury in the limb (b) of the tube.
When the muscle is thus eased to contract, it lifts the lever and a "muscle curve," or myogram, the proportions of which are determined by the extent of the contraction and the speed of the drum, is recorded.-Ev.]

When it is desired to compare with one another several successive contractions of the same or of different muscles, the eurves may be reeorded one above another by simply lowering the drum on its supporting axis to different levels. Such a scries is shown in Fig. 2 .

Tracings made in this way are preserved for future study by immersing the smoked paper for a moment, after it has been cut loose from the drum, in a solution of shellac in wood alcohol. The alcohol evaporates quickly, leaving a permanently hard varnish over the soot.

The graphic method is arlapted for recording a great many other physiological phenomena. The first we made of it on an extensive scale was that of recording the blool pressure and its variations (Ludwig, 184\%).

The blood pressure in an artery may be determined by tying a cammula into the eentral cut-end of an artery and connecting it with a $\mathrm{T}^{\mathrm{T}}$-shaped tube containing mercury (mercury manometer, Fig. 3). When the connections are properly made and the artery is unclamped, the blood pressure is brought to bear on the mercury columm in the limb $(a)$ of the tube, and the column in the other limb $(b)$ is forced upward. This difference, however, is never

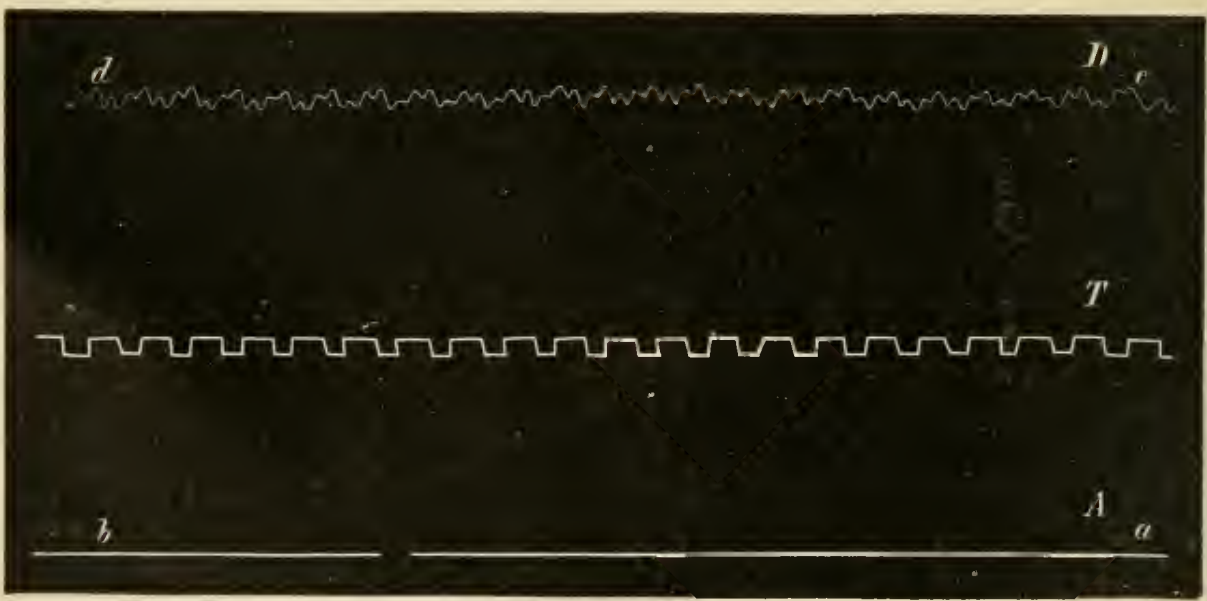

FIG. 4.-Blood pressure curve taken from a rabbit. $A$, the line of no pressure; $T$, the time recorded in seconds; $D$, the pressure tracing. To be read from right to left. 
constant but shows incessant variations corresponding to the heart beats, respiratory movements, etc. These variations produce oscillations in the mereury columm, which are recorded by placing on the free surface of the mereury a float $(s)$ to which is attached a light rod carrying at its upper end a writing point. The writing point is adjusted so as to scratch a tracing on a lightly smoked, revolving

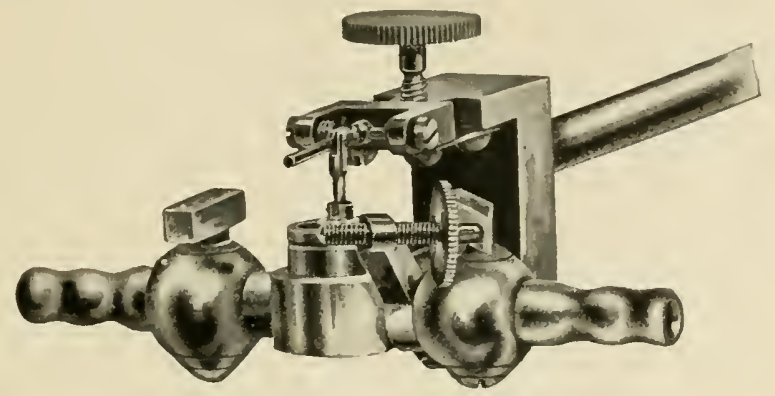

FIG. 5.-A membrane manometer, after Porter.

drum. Fig. 4 represents a traeing $(D)$ of the blood pressure in a rabbit recorded in this way. (Fur further explanation of this experiment, see Chapter V.)

Owing to the inertia of the mereury eolumn, the actual variations of pressure are not exactly reprodueed by this method. They may be more faithfully' portrayed if the blood pressure can be brought to bear on an elastic membrane

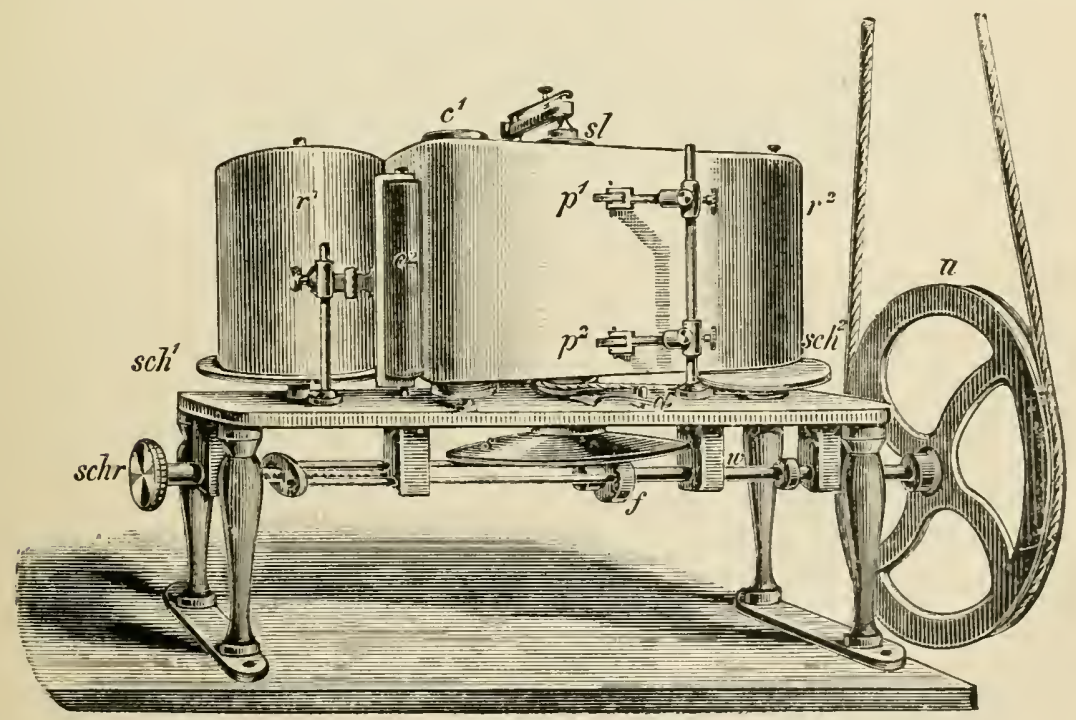

FIG. 6.-A kymograph with "endless" paper, after Ludwig and Bultzar.

or spring (elastic manometer). [Fig. 5 show sueh a manometer. A small chamber about 7 mm. in diameter is rrovided with two stopeocks, one of which is comected with the artery the pressure in which is to be neasured, while the other opens to the atmospheric air. This chamber is closed above by an elastic 
menbrane (not shown) upon which is fasteried by means of cement a small disk supporting a rod which carries a magnifying lever. The height of the writing point, which is fastened to the lever, may be varied by means of the thumbserew at the top. Errors due to inertia of the blood-column itself may be still further diminished by damping its movements with the stopcock between the chamber and the artery. A thumbserew at the right enables one to graduate this resistance as required.-Ev.]

In case it is desired to continue the record of the blood pressure or of other physiological movements uninterruptedly for a long time, a kymograph earring two drums, placed at some distance from each other and so arranged that the smoked paper extends around both, may be employed, and a longer recording surface is thus obtained. A still longer record ean be made in ink on a white surface by means of a kymograph carrying "endless" paper (Fig. 6). By means of a "pen" of suitable construction, a reeord ean be continuer for dars, the paper being unrolled from one spool and rolled onto another at the proper rate of speed, after the ink has had time to dry.

\section{B. TIME RECORDERS}

It is often necessary to know the speed at which the revolving surface passes the writing point. This may be determined roughly by regulating the rerolutions of the drum to a certain uniform speed; but if the exact temporal

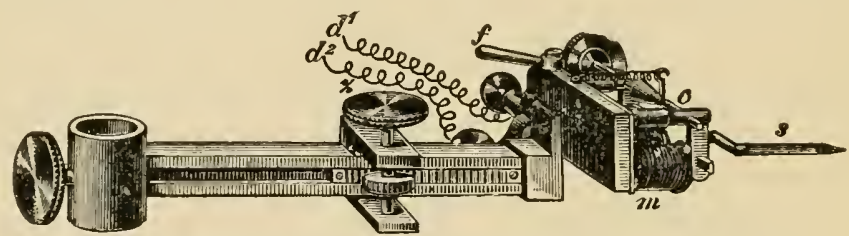

Fig. 7.-An electric signal used as a time marker, after Deprèz.

relations of the events which are being reerded must be known. it is necessary to enploy a time marker. This instrument commonly takes the form of an electric signal.

A convenient form is that represented in Fig. $\%$. An electro-magnet $(\mathrm{m})$ bears on its armature a recording lever $(s)$ which can be arranged so as to write on a smoked surface. The movements of the armature, and hence those of the lever, are determined by making and breaking the current to the magnet at regular intervals of time. If it is desired to mark seconds, as in Fig. 4, a eloek beating seconds may be so arranged as to make and break the current. If small fractions of a second are required as in Fig. 8, a tuning fork vibrating the desired number of times per seeond may be made to dip a platinum wire in and out of mereury with each vibration and so interrupt the current.

The tuning fork itself mar also be employed as the time marker br attaching a very light writing point to one of its prongs and arranging this so that it will make a light tracing on the recording surface while the tuning fork is in ribration.

It will be apparent: (1) that the time interval to be employed must be adapted to the speed of the drum and this in turn to the rapidity of the events 
to be recorded; and (2) that while it is not necessary to have the drum move at a uniform speed, if the time record is made simultaneously with the physio-

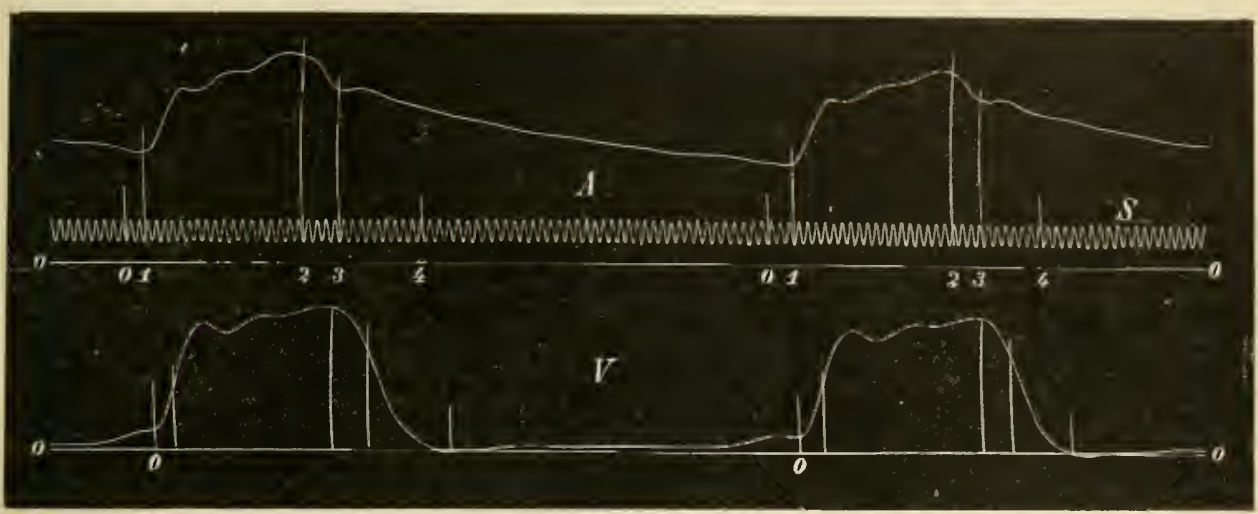

Fig. 8.-Curves of blond pressure in the left ventricle ( $T$ ) and in the aorta (A) of the dog, after Hürthle. $S$, the time-record in tod ths of a second. To be read from left to right.

logical record, much more satisfactory results will be obtained if it does move both uniformly and steadily.

\section{RECORDING BY AIR-TRANSMISSION}

The method of air-transmission for the registration of physiological erents. first introduced into physiology by Buisson (1861) and later brought to perfection by Marey, has also found wide application. The principles of this method may be understood from the following:

When two thin-walled rubber bulbs are comected with each other by means of a rubber tube having fairly rigid walls, and pressure is exerted on the one,

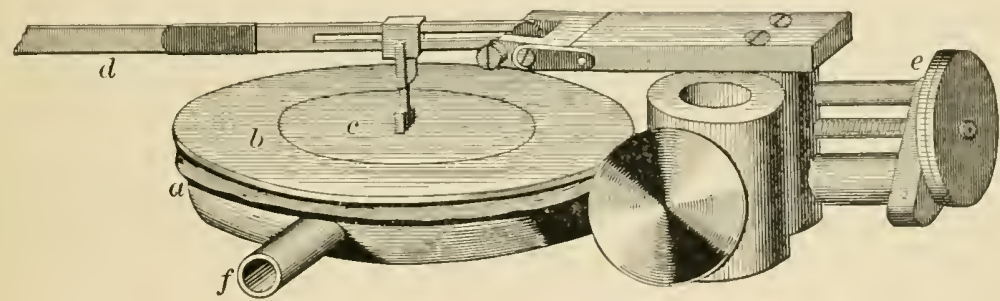

Frg. 9.-Recording tambour of Marey, actual size. $a$, metallic case; $b$, thin India-rubber membrane; $c$, thin disk of aluminium supporting the lever $d$ (a small portion of which only is represented); $e$, serew for placing support of lever vertically over $c$; $f$, metallic tube communicating with cavity of tambour for attaclment to an India-rubber tube.

the other will of course be dilated. Now if a writing lever be eomected with one of the bulbs it can be made to record any such variations in pressure taking place in the other. The apparatus necessary for registration by air-transmission 
consists therefore of two parts: a receiving bulb or tambour, and a recording bulb or tambour.

A rery simple form of recording tambonr is show in Fig. 9. A hollow aluminium tube $(f)$ conveys the air-wares to the elastic membrane $(b)$ fitting orer the chamber. A small metallic disk $(c)$ is cemented to the nembrane and

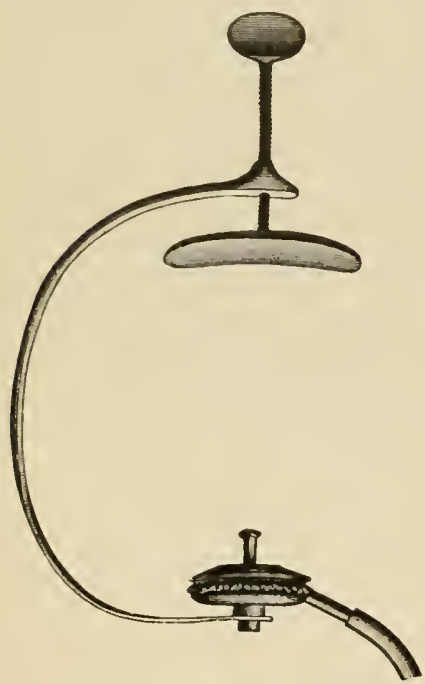

F1G. 10.-Receiving tambour adapted for taking a pulse-record from the carotid artery of man. on the upright bar as a fulerum rests the writing lever $(d)$. The axle of the lever is held in a yoke, the distance of which from the fulcrum can be readily adjusted and the excursions of the writing point be thereby varied as desired.

The second part of the apparatus or receiring tambour is usually in the form of a small rubber balloon or of a small metallic box covered with a rubber nembrane. The form of the recording tambour ean be the same for a great many kinds of physiological movements, but the form of the reeeiving tambour must be adapted to the speeial form of experiment in which it is being used.

The receiver shown in Fig. 10 is arlapted for transmitting movements of the wall of the carotid artery, for the purpose of securing a pulse-traeing. It consists of a small metallic box eontaining three small spiral springs. which serve to give the mombrane eovering it a certain tension. The membrane bears on its outer side a small button or plumger which can be applied to the skin orer the artery. The pulsatory movements of the arterial wall are taken up by the plunger and are conveyed by the tube leading from the chamber of the box to the recorling tambour. The whole apparatus is fastened to the neck by means of the hoop and serew.

With well-constructed apparatus this method of registration has been found to be rery exact. But not all tambours are so eonstructed, and it is necessary before undertaking any exact determinations to prove the apparatus. A very

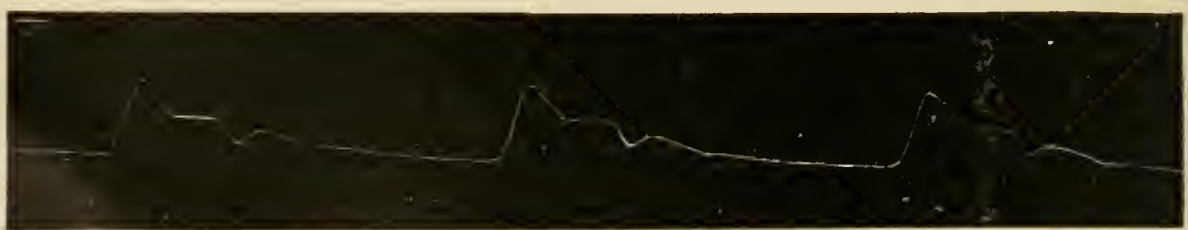

Fig. 11.-Pulse curve from the carotid artery of man, after Edgren. To be read from left to right.

good test for a recording tambour is that of registering a pulse curve, the pulsebeat being received from the earotid artery by an apparatus of given form. With the receiver shown in Fig. 10 the tracing given by the carotid should be essentially like that shown in Fig. 11. 


\section{REGISTRATION BY PHOTOGRAPHY}

Eren the most delicately constructed writing lever has some weight, and hence, hecause of its incrtia, may give an incorrect form to the curve. The ideal recorder would be entircly without mass. We have such a recorcler in

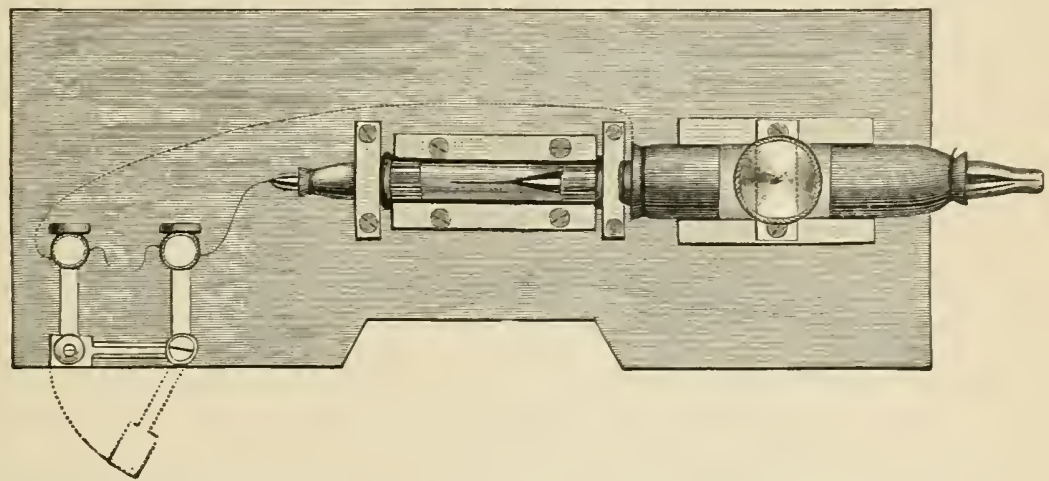

Fic. 12.-Capillary electrometer, after Lovén. The instrument is mounted so that it can be placel on the stage of a compound microscope.

a beam of light, provided the experiment can be so arranged that the novement to be recorded is transmittcd directly to a small mirror which reflect: the beam of light, and the reflected beam can then be made to fall on a moving surface which is sensitive to light.

But the photographic method is of much greater importance for recording movements which cannot be recorded in any other way.

This is the case, for example, with the excursions of the capillary electrometer. This instrument (Fig. 12) consists of a fine capillary tube partially filled with mereury and dipping into a dilute solution of sulphuric acid so that the mereury comes in contact with the acid in the tube. When eleetricity from any source is led into the instrument by connecting one pole with the $\mathrm{Hg}$ and the other with the $\mathrm{H}_{2} \mathrm{SO}_{4}$, the mercury meniseus in the capillary tube will more in the direetion of the current. Such movements can be magnified by a microseope and be recorded on a moving photographic plate. Sinec many forms of activity in the animal body are accompaniced by eleetrical ehanges of potential which camot be demonstrated in any other way than by a very sensitive

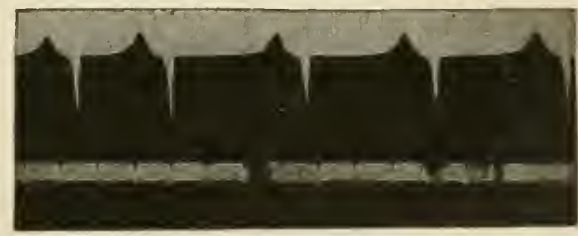

Fig. 13.-Action currents of the dog's heart as recorded by photographing the excursions of the mercury column in the capillary electrometer, after $v$. Kries. Electrical comection was marle with the base and apex of the heart. First phase: base negative to the apex. Fecond phase: apex negative to the base. The upper line represents the time in fifths of a second. To be read from left to right. electrometer, this mode of registration is very valuable for the study of such phenomena. Fiw. 13 represents the photographic curve of the electrical variations (action currents) appearing during the ercle of events in the dog's heart. 
Referencrs.-Cl. Bernard, "Lecons de physiologie opératoire," Paris, 1879.T. G. Brodie. "The Essentials of Experimental Physiologr," New York and London, 1899.-E. Cyon, "Methodik der physiolegisehen Experimenten und Vivisektionen," Giessen, 1876.-W. S. Hall, "A Manual of Experimental Physiology," Philadelphia, 1904.-O. Langendorf", "Physiologische Graphik," Leipzig und Wien, 1891.-W. T. Porter, "An Introduction to Plysiology," Boston, 1906.E. A. Schäfer, "Class-Wrot in Practical Physiology," London and New York. 1901.-F. Schenck, "Physiologisches Practicum." Stuttgart, 1595.-A. D. Waller, "Exereises in Practical Physiology," London and New York, 1896. 


\section{CIIAPTER II}

THE CELL

\section{\& 1. GENERAL CONSIDERATIONS}

\section{A. THE CELL AS AN ELEMENTARY ORGANISM}

TIIf remarkable sulstance whose activity is the basis of all vital phenomena in both animals and plants. and which we call therefore the living subslance, occurs not in a homogencous aggregation but in the form either of discrete masses called cells or of small bodies which represent transformed cells (Schleiden, 1838; Schwann, 1839). Every living being and every separate cell arises from a preëxisting cell (omnis cellula e cellula. Tirchow, 1855). Many animals and plants throughout their lives consist of but one cell. In other's, from the original cell new ones arise; these in their turn multiply. are transformed into a variety of shapes, and thus become adapted for special purposes. In this way the independence which characterizes the single-celled creatures is reduced to a considerable extent, so that cells detached from the parent organism are as a rule mable to maintain themselyes.

The cell is therefore the beginning and the somres of the entire body, and the formed elements of which the lody is constructed are each and all nothing else than cells or cell derivatives. Correpondingly we may say that the powers of the body as a whole represent the sum of the powers resident in the indiridual cells and the cell desendants.

In the study of vital processes we have thus in the first place to consider the actirity of cells. The discoveries, however, which have been made by direct observation upon cells (especially those that are free-living) are not by any means sufficient to serve as the basis for a complete presentation of the general vital phenomena. Besides, there take place in the many-colled organisms, owing to the differentiations oceurring in them, many kinds of phenomena which do not take place in the elementary organism, or which at least with our present means camnot be demonstrated, and at all events can he investigated much more thoroughly in the organs of the many-eellet animals. In any general diseussion of rital phenomena, therefore, one shonld give the results obtained in the different provinces of general physiology each its proper share of attention. Since, however, this text-book has for its special subject the physiology of man, I must linit mrself in the present chapter to the boldest outlines of general phrsiology. Elsewhere the general vital phenomena will be discussed from time to time in connection with the facts of special physiology. 
We know nothing at all about how life first appeared on the earth, and we are unahle to attach any great importanee to the hypotheses which have been put forward conecrning its origin. For a long time it was imagined that many kinds of living creatures arose directly from dead matter by spontaneous generation. But the more deeply studies in this direction were followed, the more improbable this riew hecame, and at last it was held only with reference to the lowest organisms; until finally Pastenr (1861) by his ingenious researches incontestably established the fact that spontaneons generation does not take place at all.

Within the cell the living substance is divided between the nucleus and the surrounding protoplasm. The protoplasm may be manifoldly differentiated into contractile fibers, cilia, ete. Besides, the cell contains in greater or less quantity nonliving substances of the most different kinds, some of which appear elcarly as specialized contents-e.g.. the cell-sap of plant cells and the fat of fat eclls-while some are intimately mixed with the nucleus or protoplasm and are therefore not to he distinguisher from living substance.

Some cells are surrounded by a speeialized cell membrane, while others have none; hence it is not an essential constituent of a cell. Almost all plant cells have even in their early stages a specialized membrane which iucreases in thickness as the cell grows in size. According to present views it represents either a transformation produet of the outer layer of the protoplasm or a seeretion product of the cell. Only a few animal cells have an actual membrane. The zona pellueida of the egg cell, the nembrane of fat cells and probably the sareolemma of muscle fibers are about all that can be named. In other animal cells however the outermust layer of the cytoplasm is often firmer and inore elastic than the imer parts, and is therefore able to protect the cell to a certain extent in the same mamner as a true membrane.

Cells differ greatly in external form. The spherical form which we regard as the type is by no means general: we find on the contrary a great variety of forms, not only in the many-celled organisms, where the shape of the cell is influenced by its position with reference to other cells, but also in free living. isolated cells. Cells likewise vary in size, all the way from that which is perceptible only with the highest magnification of the microscope to that of the giant cells of certain algæ, many meters in length.

The mucleus oceurs usually as a spherieal or oval body in the middle of the cell; but it may take many other forms. As a rule the size of the nnclens bears a direct proportion to the size of the eell. The larger the cell is, the larger is the nuclens. Inowever, there are many exceptions to this rule also. IIost cells contain but a single meleus, although not infrequently two or more may lie present. Inderd, in the giant cells of the bone-marrow, in screral of the lowest organisms, and in some other cells, as many as one hundred nuclei have been observed. 


\section{B. THE RECIPROCAL RELATIONS BETWEEN THE NUCLEUS AND PROTOPLASM}

Most animal and plant cells are nucleated. Only in the Bacteria is the presence of a nucleus doubtful. Some authors claim indeed that these organisms also are to be added to the general cell scheme; but the facts which hare been brought forward in support of this riew are far from sufficient to ennstitute actual proof. Although the red blood corpuscles of the Irammalia contain a nucleus at an early stage of their development. in their mature

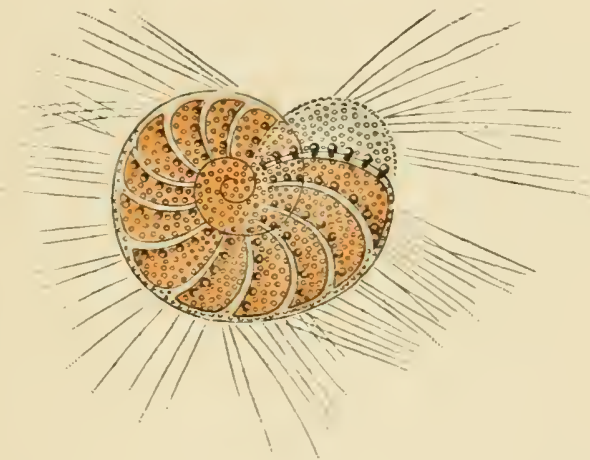

Fig. 14.-Polystumella venusta, a microseopic organism surrounded by a calcareous shell, after Max Scluultze.

state they are. in fir as we know, without nuclei. If so. they are scarcely to be regarded as cells, since haring lost the nuelens they are no longer capalile of reproduction.

IIhereter it occurs the nuclens represents a necessary constituent of the cell. Single-celled forms may be divided by a sharp cut or by other means into a nucleated and a nomncleater part. The former is sonon regenerated to a complete cell eren if it contain but a portion of the nuclens: while the nonnucleated part invariably dies after a short time. for although it may move about quite normally. may ingest foreign bodies (Infusoria). and even kill them, no digestion. or at best only a partial digestion, can take place (Nusibanm).

The moduction of certain substances on the part of the protoplasm is likewise stopper by the removal of the melens. A monnueleaterl portion of Polystomella (Fig. 14) is no longer ahle to elahorate calcium carbonate. while a mucleated piece at once makes gond any defect in its calcareous shell by the depo:it of new carbonate at the injured place (Terworn). In plants it has heen observed that an isolated piece of protoplasm is unable to construct a new celhulose membrane (Klebs). 
By the influence of a low temperature on the eoll of stpirogyra cancht in the ace of division. (iemsimow suceerled in driving all the medear substance inte one danehter cell. leaving the other quite devoid of a moleus. In a series of strels experiments it was seen that in twenty-one days lle growth of the enteleated eells amounted to $0.1-1.5$ per eent of the arerage growth of the nomal cell, while the growth of the cells with a smplus of nuclear material exceded that of the normal cells by as much as seventy-right per

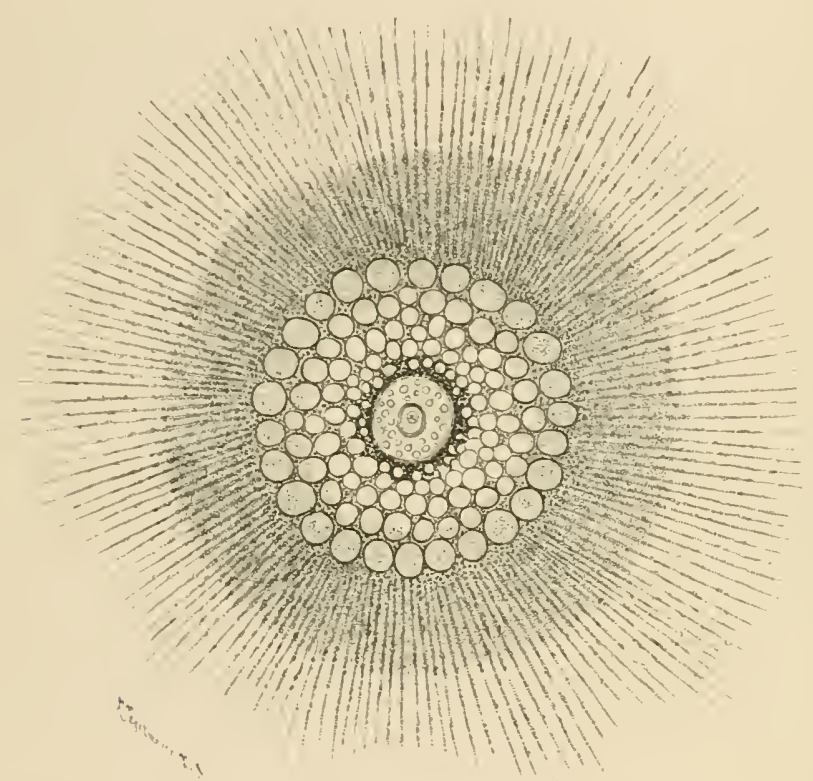

Fig. 15. - A racliolarian, Thalassieola nucleata, after Verworn. Cross section of a normal indiridual. The layers from wilhout inward are: the corona of raclial psendopodia, the gelatinous layer, vascular lityer, pigmented sheath about the cent ral capsule, and the central capsule (in the center).

(ent. It the same time the solution of starch in the enucleated cells either licl not take phace at all or proceeded rery feebly; the onter coll mombrane was less extemsible than usual ; the color of the chlorophyll bands becane constantly paler and their contour lesin clear.

Ihile the muclems is thus of the greatest importance for the mormal activity of the protoplasm, it cannot maintain an independent existenep. When the protophasm is paralyzed with mareotics the nuelens may inded continne its morements (Domoor). showing itself quite as independent of the protoplasm as the protoplasm is of the murleus. Nerertheless, if removerl entirely from the protsplasm. even if it les entime momjured by the manipulation and be protecterl from all external disturlances. as has been done in the case of

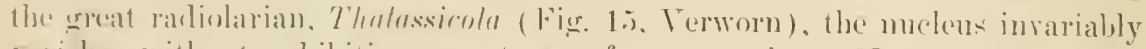
perishes withont exhibiting any trace of regeneration. Nor do muclei ever 
oceur in nature without a protoplasmic sheath; it may be extremely thin in certain cells, but it is never entirely wanting.

Many hypotheses have been advanced to explain the influence of the nucleus and the nature of its reciprocal relations with the protoplasm, but they are yet rather more of a speculative than of an exact seientific nature. The only conclusion which can be drawn with certainty from the discoveries thus far made is that the metabolic processes of the cell go on normally only under the mutual infuence of both nucleus and protoplasm, which after all is only a bare statement of the facts in the ease. ${ }^{1}$

\section{PHYSICAL AND CHEMICAL PROPERTIES OF PROTOPLASM}

Protoplasm appears as a viscous, usually colorless substance which is not miscible with water, and which always contains a varying number of very small, punctiform granules. The distribution of the granules in the cell body is seldom uniform, for one finds as a rule an ontermost layer of greater or less thickness free from them. Since this layer is fimer than the inclosed protoplasm containing granules, it is designated as the hyaloplasm (Leydig) in contradistinction to the granular spongioplasm.

In general it is assumed that resting protoplasm has an alkatine reaction. This appears to be true howerer only with indicators which are not sensitive to $\mathrm{CO}_{2}$ : for with indicators which respond to $\mathrm{C}^{\prime} \mathrm{O}_{2}$, neither animal nor plant cells in the resting state show the alkaline reaction (Friedenthal). But in the case of some lowly organisms-e. g., the fission-fungi and the Amobrthe true reaction of the living substance must still appear doubtful, since these are able to live in strongly alkaline nutrient media-a circumstance which does not, however. constitute conclusive proof of an alkaline reaction for the interior of the cell.

In the gelatinous, colloidal sulstances (e. g.. a solution of gelatin which is drying up through loss of water) with which from a purely physical point of view protoplasm exhibits a close agreenent, all possible gradations are met with from the fluid to the solid state, and for such substances the terms "fluid" and "solid" may have within wide limits a purely relative significance. Hence it is not dithicult to understand that views regarding the state of aggregation of protoplasm are rery divergent, it being regarded by some authors as solid, by others as fluid. IInenver, it is not to be overlooked that in the endless varieties of differentiations met with in different orders of living beings the state of aggregation may present not insignificant ditferences. For the cells which exhibit protoplasmic currents (cf. page 21 ) as well as for the amoboid cells ( $\mathrm{cf}$. page +2 ) and the ega and early embryonic cells. Rhumbler, with strict regard to the laws which apply to fluids, has adduced weighty reasons for the view that the protoplasm posseses in fact a fluid state of aggregation. and has the mechanical peculiarities of a foam the individual alveoli of which are locally of difierent constitution.

${ }^{1}$ Spitzer, Loeb and R. S. Lillie have brought forward considerable evidence that the nueleus is the chief agency in the activation of oxygen within the cell.-ED. 
llater is an integral constitment of living substance and on drying the

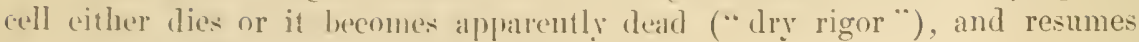
its vital activitices agrain on the aldition of water.

We do not know anyhing drfinite about the manner in which water is combined with the real living substunce. That it is not held in pores of the protoplasm as in a sponge appeals from the fact that water camont be pressed out by mechanieal means. No more ean the water here he regarded as an analogue of the water of crystallization in inorganie salts. It seems more likely that it $\mathrm{j}$ sheld in interstices between the molecules or combinations of molecules which make up the living substance. It is unt impossible also that at the death of the protoplasm a part of the water constitutes a product of disintegration.

'The specific grarity of protoplasm is somewhat greater than that of water. It refracts light more strongly than water, is transparent in thin lavers. opaque in thick layers. Some forms of living matter are doubly refructiue. This property was first observed in eross-striped muscle (Boeck) : lut since that time it has been fomm that practically all contractile substance differeatiated into fibers, such as smonth muscle cells, cilia, etc. is positively (loub) y refractive in such a way that the optical axis enineides with the direction of the fibers (Engelmamin). 'This fart is cridence that the structures in question have a diflerent molecular arrangement from that of other living structures.

Wre know nothing comreming the chemiral ronstitution of living substance. Chemical investigation of dead animal and plant bodies has made us acquainter] with a very large number of different organic and inorganic compounds: lut not wen the delicate micro-chemical reactions have been ahle to furnish any information on the chemical nature of living sulstance. We can only say, therefore, that when the living sulstanee dies we are alle to demonstrate proteid bodies of diflerent kinds as the chief constituents, and that in amimals at least the liring substance can be formed, as it appears, only from proteid bodies (cf. ('hapter III).

\section{MORPHOLOGY OF THE CELL CONTENTS}

Everywhere, in plants as well as in animals. protoplasm has the same appearance, just as it is everywhere essentially the same with respect to its fundamental vital properties. Even with the highest posible magnification we are unable to distinguish the protoplasm of a plant cell form that of an animal cell. This similarity is of course only apparent, for. sinee the life prows in erery particular organism takes place in a way peculiar to itself, and since the protoplasm-outside the nucleus-represents the theater of diflerent vital activities. these nutstanding difforences must be conditioned by a diflerene in the quality of the protoplasin (O. IJertwig).

Leaving ont of acomint the apparent similarity of the protoplasm, different cells may as a whole present a very difierent appearance. This is due partly to the external form of the coll and its onvelope. which must be regarded as something secondary at least. partly to diflerentiations inside the cell (cilia, 
contractile fibers). and partly to different substance- depnsited within the cell. Sometimes the last are present in such quantity that on first sight the cell appears to consist only of substances foreign to protoplasm, as it is here defined.

These cell contents vary a great deal in kind: substances which are taken up from outside by the cell to. be further elaborated in it. substances stored in the cell as reserve material, substances formed in the cell by its own activity to be given out again under appropriate circumstances, ete.

In most plant cells the protoplasm fills but a small pirt of the cell body (Fig. 16). Only those cells which lie close to the growing tip consist entirely of protoplasm. In their growth the wall of the cell inreases in size much more rapidly than the protoplasm, and as a result vacuoles are formed filled with cell-sap. The nucleus then lies cmbedded in a mass of protoplasm, which is connected by means of protoplasmic strands with a layer inside the cell walls. The protoplasm of such cells streams back and forth within the cell wall, carrying with it the granules embedder therein and ofttimes the nucleus as mell.

In the protoplasm of green plant cells are contained specially differentiated chlorophyll bodies (cf. Figs. 25 and 31) to which these cells owe

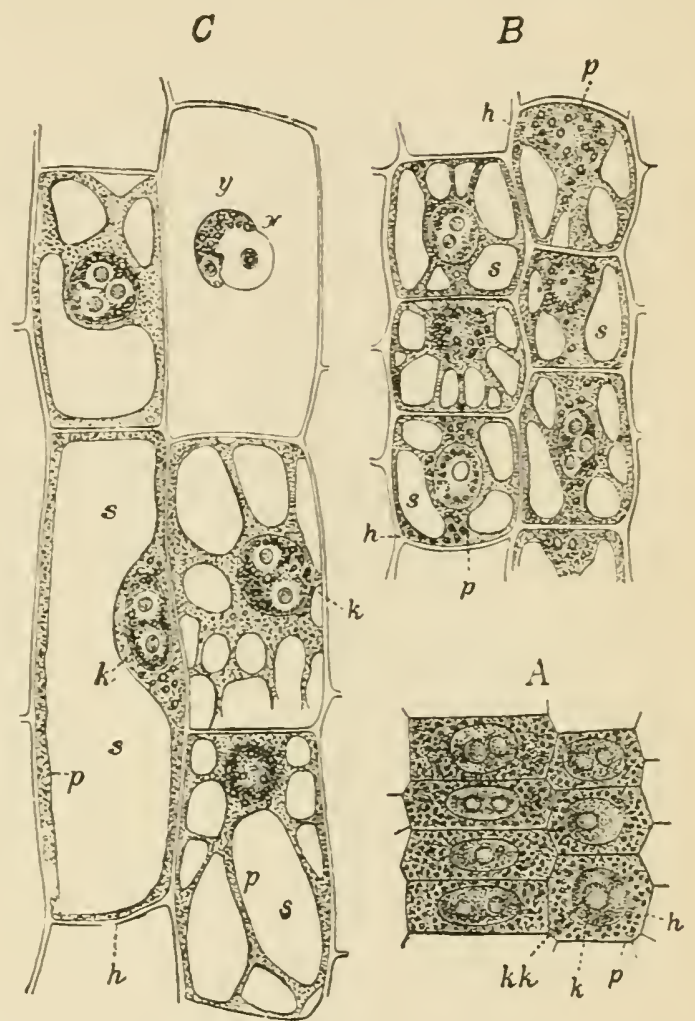

FIG. 16.-Parenchyma cells from the middle layer of the root-cortex of Frittilaria imperialis; longitudinal section, after Sachs. A, portion of the section close to the root-apex, very young cells, without cell-sap; $B$, cells of the same layer about $2 \mathrm{~mm}$. from the rootapex; cell-sap $(s)$ is forming in the protoplasm $(p)$; $C$, cells of the same layer $\bar{t}-S \mathrm{~mm}$. from the apex. The cell at the right above has been ruptured by the razor: its nucleus $(x y)$ is scen much swollen by absorption of water; $k$. nucleus; $k k$, nuclcolus; $h$, cell-membrane.

their green color. and which are of rery great importance in the vital activities of plants (cf. page 2:3). Among the inclosures contained by the plant cell outside the cell-sap, the starch granules are to be especially mentioned, since they represent the first visible product of the assimilative actirity of the plant cell.

Animal cells as a rule consist almost entirrly of protoplasm and contain foreign substances only in relatively small quantitic: they are therefore essentially like young plant cells (Fig. 16). There are some animal cells also in which the protoplasm is almost entirely displaced hy foreign subtances. This is the case for cxample with fat cclls in which the major part of the fat in 
the body is deposited. Eggs likewise contain an abundant smpuly of proteid, lecithin and fat which are to serve as nourishment for the developing embryo.

Other inclosures which oecur in greater or less abundance in animal cells, are: fat droplets in the eells of the mammary glands and of the intestinal mucosa during absorption; pigment granules in the pigment cells of the skin and of the choroid coat in the ere: glyengen granules in the liver cells, ete. In the naked cells which are able to take up solid particles from the surrounding medium we observe often small Algre, Bacteria, Infusoria and the like (Figs. 19, 20, 21 and 22). which serve as nourishment for the cell, and, after digestion is completer, indigestible shells, skeletons, eurelopes, ete. Again small cavities filled with fluid (vacuoles) are present in the protoplasm of eertain animal cells. Among these are to be mentioned especially the so-called contractile racuoles. i. c., drops of fluid which are pressed out of the protoplasm by the contraction of a surrounding sheath, only to be re-collected from the protoplasm in the same place again when the contraction ceases (Figs. 21, 24, 25).

Finally, there are found within the protoplasm of animal eclls certain plant cells, Algx, which do not serve their host as nutritive material, but merely live in company with it (symbiosis). They are of the greatest importance to the life of the animal cell in which they oceur, since through the activity of their chlorophyll bodies, they supply it with the necessary uxyen, thereby rendering it independent of the oxygen eontained in the surrounding medium. We have the most beautiful instance of symbiosis in a lichen, which is nothing more than an aggregate individual consisting of a fungus and an alga.

Reference must be made to works on eytology and histology for a discussion of the ultimate structure of the protoplasm, nucleus and centrosome, as well as for the ehanges in these accompanying eell division.

\section{§ 2. THE VITAL PHENOMENA OF CELLS}

A. INTRODUCTORY SURVEY

The vital activity of all cells, both plant and animal, consists of two opposite processes, assimilation and dissimilation. We include under assimilation all the synthetic processes, of whatever kind, going on in the cell or mnder its influence: under dissimilation all the disintegration processes going on in the cell or under its influence.

A. Assimilation is of two kinds, namely growth of protoplasm, i. e., formation of living substance, and syntheses of new substances not living.

Our knowledge of the growth of protoplasm is still very meager. We can observe how the cell increases in size, and how it multiplies after it has reached a certain size. but the inner meehanism of these processes is still quite olscure. Somewhat more satisfactory is our kuowledge of the syntheses of organic nonliving substanees accomplished by cells. In fact the synthesis which is quite the most important of all. namely. the formation of starch in the green parts of plants. is known with tolerable exactness, and may be descrilied briefly as follows:

'There always oceur in the neighlonrhood of the nucleus of plant cells small, colorless, highly refractive hodies, for the most part oval or elliptical in form, which are called trophoblasts and which arise always, like the nucleus and the 
centrosome, by division of prëixisting trophoblast. 'These structures generate within themselves the dhomphyll.

The property of plants disovered by Ingenhonsz (17:9). Senebier (17821800), and 'Th. de saussure (1804), of reducing creluon dioxide, depends upon this ehloroplyyll. The reduction takes place under the influence of the sun's rays, and starch appears as the first visible product of the resulting synthesis. It is reposited in the chlorophyll bodies in the form of small. highly refractive granules (Julius Sachs, 1862 ). At the same time the plant gives off the oxygen set free by the reduction of carbon dioxide, and if it grows in a closed room the quantity of $\mathrm{C}_{2}$ in the confined air constantly decreases, while the quantity of $\mathrm{O}_{2}$ is corresponding] $y$ increased.

starch serves as the starting point for all further synthetie processes in the plant boly. By its cleavage and hydration different kinds of sugars are produced. and.

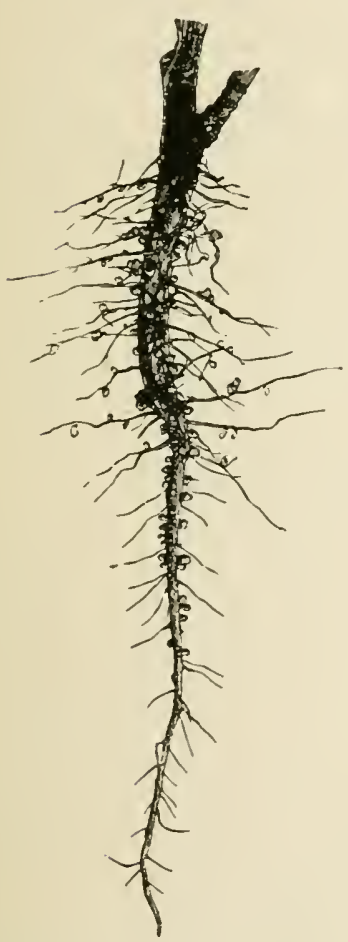

Fig. 18.-The root of the field bean (I icia Faba) thickly beset with bacteria tubercles, after Noll. this being the form in which carbohydrates are transported. they are of great importance in the further sythetic proceses within the plant hody. Tegetahle oils are also formel from starch; and it participates finally in the synthesis of proteids in plants.

Besides the elements found in starch (carbon, lydrogen and oxygen), proteids contain nitrogen and sulphur (some also phosphorus). The plant obtains these elements from the soil prineipally in the form of nitrates. sulphates. phosphates and ammonia compounds. It olstains on the other hand only an insignifieant part of its nitrogen from the ammonia ant nitric acid in the air. The nitrogen. sulphur and phosphorus are liberated from their componds by roceses of reduction and they together with the elements contained in starch are synthetized into protedis. It is very probahle that the amino acids and their amides-e. g.. asparagin (aminosuccinamic acid. $\left.\mathrm{C}_{4} \mathrm{H}_{4} \mathrm{~N}_{2} \mathrm{O}_{3}\right)$-represent intermediate stages in this synthesis: but how such processes take place we do not yet know. Finally from the proteids thus formed, living protoplasm is constructed.

Certain plants are able to absorb free atmospheric nitrogen and to combine it into oreranic compounds. I species of bacterium, C'Tostridium Pasteurianum, which lives in the soil, is an example (Winogradsky). Kriger 


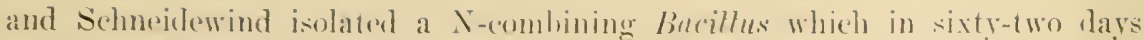

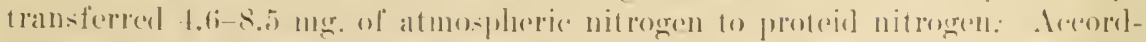
ing to Kulun one hektar of his experiment field in one vear would rexperience

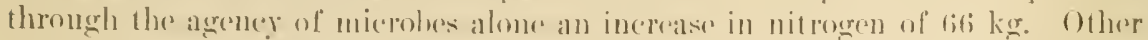
micröreranisms (apahle of tixing nitrogen are the Izolacteria studied by Bererinck. Still others which form on roots of certain species of Jegrmmosat peculiar excresences, called ront tulereles, have the power of transforming free nitrogen into smeh componnds (amiles?) as are ahle to serve not only themselves but also their hosts as the immediate source of nitrogenous food (Hellriegel) ( Fig. 18).

Several other mineral constituents are needed in the development of plants, notably: iron, which is necessary for the formation of chlorophyll; potassium and magnesium, which it is believed play an important rôle in assimilation and the syntheses of the body: caleium, which is very important in the transportation and eombination of the harmful produets of metabolism (oxalic acid), ete. On the other hand, the plant does not require any organic fuodstuffs. If the root of a maize plant which has been germinated in water be placed in a vessel with an artifieial nutrient solution (one per cent potassium nitrate, 0.5 per cent each of sodium chloride, ealcium sulphate, magnesium sulphate, and calcium plosphate, and 0.005 per cent ferrous sulphate) while the foliar part is exposed to the air, the plant grows quite perfectly, develops into a large maize stalk, puts forth leaves and brings forth seed.

(Only the plants contuining chromophyll 1 have the power of feeding exclusively on purely inorganic substances. The parts of the plant devoid of chlorophyll receive their carbohydrates from the parts which contain chlorophyll. Those plants which, like the Fungi, contain no chlorophyll at all must oltain sulsstances already completely organized for their food: and this is likewise the case with the whole animal kingdom.

The beginning of the organic syntheses going on in nature is therefore the formation of starch in the green parts of plants under the influence of sunlight. 'The cnergy stored up by this means is used in all the further proeesses of the plant body. In plants and plant parts lacking chlorophyll as well as in animals all the life processes take place at the expense directly or indirectly of the substances formed in the green parts of plants. The gren plants therefore constitute a necessary condition for the life of all other living beings on the earth. But since carbon dioxide, the nitrates and sulphates required by plants are present on the earth and in the atmosphere entirely independent of the life processes of animals. plants can get along withont the aid of animals.

We are not to suppose, howerer, that synthetic processes do not take place in animals. It is true that animals cannot form complex compounds out of completely oxidized carbon $\left(\mathrm{C}_{2} \mathrm{O}_{2}\right)$ and hydrogen $\left(\mathrm{H}_{2} \mathrm{O}\right)$ and that the animal body can utilize as raw material only compounds of relatively complex consti-

${ }^{1}$ This term, employed by Engelmann, and adopted by the author, includes all the coloring matters in plants capable of exercising an assimilative function. Since, however, by far the most abundant coloring matter is chlorophyll, it will avoid confusion perhaps
to use only the one tern hereafter.-ED. 
tution, chief among then being proteil-. fats and carbohychlates. But from this raw material the animal body has the pouer of forming many new substances, notably lixing protoplasm. by a true synthesis.

Besides the substances just mentioned the animal cell. like the plant cell. requires eertain mineral compounds in order that it may develop fully and accomplish its functions in a normal manner. Thus observation on the IIetazoa has provel that the animal body is continually giving off such substances in its exeretions, and would necessarily become imporerisher in this respect if the supply were not sutticient. Eren in grown animals very profound disturbances ensue as a consequence of such failure of mineral substances. which ultimately end in death. The growing boly has a relatively much greater need of inorganic compounds. for such substances are alsolutely necessary for the construction of its organs.

Among the mineral substances contained in the fluids of the animal body common salt ( $\mathrm{NaCl}$ ) comes first in order of quantity. I solution of common salt alone, of a strength corresponding to its concentration in these fluifls $(0.6-0.9$ per cent), is in fact sufficient to maintain a frog's muscle or a frog's heart in functional condition for a long time after its removal from the hody, whereas an exsected heart will not beat in a solution where TaCl is wanting (Lingle).

In a solution containing only NaC'l. howerer, the contractions of the heart gradually cease, although they may he roused again by the addition of $\mathrm{C}^{\prime} \mathrm{aC} \mathrm{C}_{2}$ in small quantity. The addition of $\mathrm{KC}$ ' is likewise beneficial: hut whereas the Ca salt is farorable to the contraction of the heart, the $K$ salt appears to be important for its relaxation. The heart beats best, therefore, in a nutrient fluid in which are contained $\mathrm{C} a$ and $\mathrm{K}$ as well as $\mathrm{Na}$ (Ringer, Howell and several other authors). ${ }^{1}$

Analogous phenomena appear in other organs. A skeletal muscle of the frog remains alive outsicle the body longer if $\mathrm{CaCl}_{2}$ is added to the $\mathrm{NaCl}$ solution. It is asserted, at least for smooth muscles, that the Ca salt favors the contraction process, and $\mathrm{K}$ ('l the relaxation, just as in the heart. The egg of Fundulus develops in $\mathrm{NaCl}$ solution only when $\mathrm{CaCl}_{2}$ is added (Loeb).

In the present state of our knowledge of this subject it would be premature to conclude that the metals just discussed have the same sweeping importance for all animal cells. As a matter of fact data are at hand which show that such a generalization is not warranted. Thus the vibration of flagella-e.g.. in the spermatozoa-and cilia of both rertebrates and invertebrates, is entirely independent of $\mathrm{NaCl}$ in the surrounding fluid. The same is true of the contractile stalk of Torticella (Fig. 2s) and related Protozoa (Overton). In rery young larres of Arenirola cristata solutions containing $\mathrm{CaCl}_{2}$ favor muscular movements, while solutions containing $\mathrm{MgCl}_{2}$ favor eiliary movements. Pure $\mathrm{NaCl}$ solutions are much more harmful for the latter than for muscular movements; Na-free solutions stop muscular movements, whereas cilia remain active in these, and are quite unaffected by pure $\mathrm{CaCl}_{2}$ or $\mathrm{MgCl}_{2}$ (Lingle). In this connection should be mentioned alsi the facts brought out hy Goldberger that cer-

1 A solution especially well adapted for feeding an excised mammalian heart is the following: eight per cent $\mathrm{NaCl}, 0.075$ per cent $\mathrm{KCl}, 0.1$ per cent $\mathrm{CaCl}_{2}, 01$ per cent $\mathrm{NHCO}_{3}$, and saturated with oxygen. (Compare the composition of the blood ash, Chapter V.) 
tain Ca salts which have so favorable an influence in the higher animals, are poisonous for the l'rotista, while other Ca salts are harmless for them.

Besides the elements just mentioned ( $\mathrm{Ka}, \mathrm{Ca}, \mathrm{K}$ and $\mathrm{Cl}$ ) and those contained in the proteids, fats and earbohydrates (C, H, O, N, S, P), there are still a few others which are just as necessary for the animal body. First among these are: Mer. contained with the Ca in the solid framework of the bones; Fe, which is necessary for the formation of the coloring matter in the red corpuscles; and I, which is a necessary constituent of the secretion of the thyroid gland.

In all processes of assimilation in nature. whatever their kind, energy is stored up. As a measure of the energy contained in a substance we use the amount of heat dereloped by its combustion. Carbon dioxile and water are not combustible substances, but starch produced from them generates a considerable quantity of heat when it is burnerl-possesses therefore a certain quantity of potential energy, amounting in fact to about $t .1$ Cal. ${ }^{1}$ per gram. This potential energy is derived from the sunlight. whose kinetic energy has been transformed under the influence of ehlorophyll to the potential energy of starch.

When a synthesis takes place in a living cell, if the necessary energy is not supplied from without as in starch formation, the synthesis can only he carried out at the expense of potential energy stored in the cell itself. In other words: in all synthetic processes taking place in plant or animal cells without the ageney of sunlight, the potential energy at the disposal of the cell is transformed in one way or another into the potential energy of the newly formed substance.

The assimilative functions of cells are closely bound up with discimilative functions-i.e., if the cell has not the power to develop kinetic energy within itself no new formation of substance appears to take place-and conversely, the more rapid the dissimilative process, the more active is the assimilative process. Neither plants nor the eggs of animals ean develop continuously without oxygen, as was determined suecessively by Spallanzani, Dutrochet. De Saussure and Schwann. In the egg of Ctenolabrus, a marine bony fish, the eleavage cells undergo partial solution and fuse together when oxygen is withdrawn, but are reformed when oxrgen is again supplied (Loeb). Possibly in this connection belong also the facts: that growth is always accompanied ly dissimilation, and that skeletal muscles inerease in size only under the influence of work (involving dissimilation, (ff. page 63 ).

B. The discimilative processes constitute the source of the kinetic energy deroloped in the cells. These processes in plant as well as in animal cells are ererywhere escentially similar. and consist in a destruction of comple.r molscules. Whether this destruction involves the living sulstance of the erll. or only the nonliving cell contents eannot ret he definitely decided. Tnder the general subject of metalonlism we shall find opportunity to discuss this question somewhat more exhaustively. Here we must limit ourselves to the following:

${ }^{1} 1$ Cal. (Calorie) $=$ the amount of heat necessary to raise $1 \mathrm{~kg}$. of water from $0^{\circ}$ to $1^{\circ} \mathrm{C}$. 
1. The above-mentioned destruction in a majority of cases is an oxidation, that is, a combustion of the substances called organic foodstuff:-proteid, fat

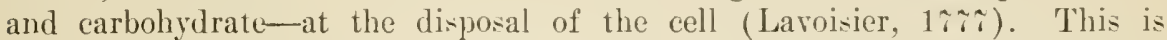
proved by the fact that all animals produce carbon dioxide, and that they succumb in a short time in the absence of oxygen. Since a plant under the influence of sunlight has the power to reduce carbon dioxide and set oxygen free, it follows that under suitable cireumstances plants and animals can live if they be kept together in a closed room; for the carbon dioxide formed by the animals is redueed by the plants with the liberation of oxygen; and thus each receives the gas most useful in its life processes.

And yet we are not to suppose that the plant does not form any carbon dioxide. On the contrary the plant protoplasm in its production of kinetic energy behares exactly like the animal protoplasm and produces carbon dioxide in the same way. The production of carbon dioxide in green plants in the light is masked by the much more abundant reduction of carbon dioxide going on at the same time; in the dark, however, where the reduction processes are checked, it is plainly perceptible.

In the decomposition brought about by the vital activity the combustible substances are not broken down immediately into their end products; but the complex organic molecules are split up gradually into less and less complex ones, oxidation and reduction processes probably taking place in rapid succession (Drechsel). Finally, these intermediate decomposition products are transformed into substances which leave the body as the end products of metabolism.

2. The living cell itself regulates the amount of oxygen consumed. combustion in the body being. within widle limits. entirely independent of the partial pressure of the uncombined oxygen (Pflüger).

In addition protoplasm has the power to store up oxygen in compounds in which it is loosely held, and from which it may be withdrawn again in case of need. This is witnessed by the fact that cells ean develop kinetic energy, though in general only for a relatively short time, without a supply of free oxygen from outside. In eertain cases this happens even at the expense of compounds which contain oxygen firmly bound up ehemically and which cannot be deoxidized with our strongest redueing agents. We have examples of such phenomena in the Myxomyeetes which continue their movements for three hours in an oxygen-free medium; in eiliated eells which ean live still longer without oxygen; in the skeletal muscles which enntract and give off earbon dioxide even in a vacuum. The maworm, Ascaris, ean live five days without a supply of oxygen (Bunge). In this case there occurs in the body of the animal a process of fermentation by which $\mathrm{CO}_{2}$ and a mixture of valerianie acill. caproic acid, etc.. are formed from the glyeogen stored in the animal's tissues (Weinland). Here should be mentioned also the liberation of oxygen by hen's eggs during the first five hours of theil incubation (Hasiselbalch).

A very pretty experiment on the life of higher animals in the absence of oxygen is the following which we owe to Pfliuger. At 2.44 ciclock two frogs were placed in an atmosphere cooled to about $0^{\circ} \mathrm{C}$. from which every trace of oxygen had been earefully removed. At three o'clock they showed the most pronounced dyspncea but no convulsions. They soon became motionless, as if they wished by suppression of their movements to obviate the need for oxygen. 
From time to time they wandered abont the eage, raised their heads and oeeasionally gasped. At eight oiclock they had become still more quiet and were visibly very much exhansted, hut on pricking them with a wire they still showed indubitable signs of phrsiological integrity. On the following morning at nine the frogs lay quite motionless. Even the most rigorous stimulus failed to produce any trace of reaction and there were no signs of respiratory movements. It ten after a duration of seventeen hours the confinement was terminated and oxygen was admitted. When after two hours' exposure to the atmospheric air. and after repeated inflation of the lungs there was no sign of returning life, Pflüger opened the body cariț of me frog and found the heart still beating with great energy and the arteries full of remarkably bright red blood. In spite of this there were no muscular movements for five or six hours. Reflex irritability gradually returned, and spontaneous respiratory movements: bat coördinated movements such as are mediated only by the higher nerve centers did not reappear at all.

3. Finally, certain organisms of the lowest order. especially some of the Bacteria, can maintain life permanently only in the absence of oxygen (anxerobic Bacteria. Pasteur). 'The reast cell furnishes us some information concerning the way in which the energy necessary for the functions of these organisms is liberated. This organism can maintain life for a long time without air and can develop consilerable activity which displays itself notably in the alcoholic fermentation of sugar-i. e.. by splitting grape sugar into $2\left(\mathrm{C}^{1} \mathrm{O}_{2}\right)$ and $\approx\left(\mathrm{C}_{2} \mathrm{H}_{6} \mathrm{O}\right)$. Since now the ealorific energy of the alcohol formed is less than that of the sugar destroved, a certain quantity of energy is developed and is placed at the disposal of the yeast plant (Hermamn. Kühne).

In the dissimilatory processes of the cell the nutrient substances at its disposal are gradually consumed, and if no supply from outside is kept up the cell must of course die of hunger.

The ehanges appearing in the cell body when it is deprived of nourishment have been closely followed by Wallengren on the ciliate infusor Paramecium. During the first days of starvation all the food vacnoles and food masses disappear. Thereupon the small granules present in the protoplasm are consumed, and the endoplasm consequently decreases in quantity. At the end of this period the living substance of the endoplasm is itself probably consumed in part. In spite of the more or less profound changes in the form of the body thereby produced, the eetoplasm, the contractile racmoles and the eilia are still not influeneed in any noticeable way. During this period the activity of the last-named structures is maintained by material supplied by the endoplasm. With further inanition the endoplasm becomes much racuolated, the ectoplasm, as well as a large number of the cilia berome more and more absorbed, and the macronuclens is finally attacked. while the mieronuclens remains comparatively mntoncherl. At last the point is rached where everything which the eoll hody can furnish as nutrient material is enssumed, the living substance remaining is itself exhausted, and the cell, fallen into granular disintegration, perishes.

\section{Temperature.-Since temperature exercjses a very profound influence} on the rarious artivities of cells, it will be appropriate to consider it in this preliminary survey. We may safely assert that for every cell there is a definite temperature which is most farorable to its life processes. The cell perishes if the temperature passes beyond certain limits, although these limits differ 
with different cells and may be gradually elanged more or less for each particular coll by training.

For most animal and plant cels the upper limit of temperotuen compatible with life is from $40^{\circ}$ to $4 \hat{\imath}^{\circ} \mathrm{C}$. They die if they be suljecter even for a short time to a temperature a little higher than this, owing partly at least to the coagulation which takes place at this temperature. And yet there are cells which are able to endure a considerably higher temperature. In the hot springs of Ischia, Alga live at a temperature of $53^{\circ} \mathrm{C}$., and it is said that hetween the filaments of Oscillaria, ciliate Infusoria and Rotatoria survive a temperature of $81^{\circ}$ to $85^{\circ} \mathrm{C}$. (Ehrenherg). Many Bacteria thrive at a temperature of $50^{\circ}-55^{\circ} \mathrm{C}$. or even as high as $72^{\circ} \mathrm{C}$.; and still more resistant against heat are their spores, a dry heat of $140^{\circ} \mathrm{C}$. maintained for at least three hours being necessary to destroy life in then with absolute certainty.

With regard to the lower limit of temperature conpatilsle with life, it los been found that Amobe placed upon ice will cease all movements and remain quiescent until the temperature is raied. If however they loe frozen up in drops of water, warming fails to revive them.

I temperature below $0^{\circ} \mathrm{C}$. is not necessarily fatal for the rell. Pictet observed with certainty that fish which had been cooled in a block of ice to $-15^{\circ} \mathrm{C}$. survived after carefully raising the temperature, although their companions while frozen could be reduced to powder like ice. Fish which were cooled to $-20^{\circ} \mathrm{C}$. conld not be revivel. Frogs survived a temperature of $-28^{\circ} \mathrm{C}$. and myriopods $-51^{\circ} \mathrm{C}$. Seeds of cereals do not lose their power of germination if they be subjected for a long time to a temperature of - $42^{\circ}$ ( . (C'. de candolle). Clolera spirilla and antlurax spores can be kept alive for from twenty hours to seven dars at the temperature of liquid air $\left(-183^{\circ}\right.$ to $-192^{\circ}$ C.). Indeed one species of Bacterium (B. phosphorescens) survived a period of ten liours at $-252^{\circ} \mathrm{C}$. (MeFarlayeu).

One would suppose a priori that at a temperature so low that the protoplasm becomes rigid, life must be temporarily suspenderl. According to the experiment with the fish stated above this does not appear to be correct, for in this case it would be a matter of indifference, so far as external signs go, whether the temperature of a frozen fish were $-15^{\circ}$ or $-20^{\circ} \mathrm{C}$. and yet after cooling to $-20^{\circ}$ it dies. If life were actually suspended at $-15^{\circ}$ it would be difficult to understand why a further lowering of the temperature has any effeet. In any case we may say that at these low temperatures life processes are reduced to the minimum.

If the chemical ennstitution or the temperature of the surromding medim be altered and the cells continue to live, various changes in their properties may be indnced, which, especially in the pathogenic microörganisms, are of great importanee, because the degree of their rivulence may be thereby inereaser or diminished (Pasteur). The protective inoculation introlued by Pasteur is based upon these facts.

After this general discussion we shall now proceed to the different manifestations of life. taking up in order the ingestion of fonl, digestion. the oxidative processes. the elimination of decomposition products, the secretions. and finally the phenomena of motility. production of light. formation of heat and the generation of electricity. 


\section{B. THE INGESTION OF FOOD}

It is self-evident that the metium in which elementary organisms live must contain all the nutrient substances, incluting oxygen and water, neeessary for their subsistence. Besides. different cells have very different requirements with respect to the chemical constitution of the medium, and these peculiarities are conditioned, in part at least, upon the hereditary traits of the species.

Certain unicellular organisms are adapted for life in fresh water, other's for life in salt water. Most of them die if they be placed in distilled water. Likewise if the ehemical composition of the medium in which the cells live be changed suddenly, they die; but if the change take place gradually and slowly, they can adapt themselves to the altered nature of the medium and contimue to live. How great a change may be made before disturbances in the rital activities of the cell appear, depends partly upon the nature of the cell and partly upon the substance added to the medium.

That even in the higher animals and man the properties of the cells are altered by a changed composition of the lymph follows directly from observations on diseases characterized by chronic intoxication (e.g., alcoholism, morphinism).

In multicellular animals the cells are bathed by a fluid, the lymph, which represents the medium in which they live. If the lymph is to be adapted to its purpose. it must contain in the first place all the substances neeessary for the nourishment of the cells, and must possess also the other necessary chemical and physical properties.

Lymph is distinguished from those media in which micellular organisms live, by being inclosed within the body and by being formed essentially through the activity of the cells themselves. The quantity of lymph is not mulimited, for the supply of nutrient materials and oxygen which it contains at any giren tine is soon used up, and their place is taken by decomposition produets which are harmful to the londy. But in order to maintain life in the Metazoa it is necessary in the first place that the lymph shall he always of normal constitution. To this end many organs of the body coüperate, each being adapted for a special purpose.

Experience teaches us that in general a special function cannot be carried out by a single organ, but requires the cö̈peration of several. All those organs which together accomplish a definite purpose are designated as an organ system or apparatus.

In order that the lymph may serve as the medium for the vital activities of the cells, it must contain besides water certain combustible substances and certain mineral constituents (all of which are comprehended under the name foodstuffs) and oxygen. Neither the foodstuffs nor the oxygen come directly into the lymplu; to bring them there not less than three organ systems must coïperate: namely, (1) the circulatory system, (2) the digestive system, and (3) the respiratory system.

The object of the circulatory system is to supply the lymph with nutrient substances and with oxygen. The object of the digestive system is to take up the foodstuffs necessary to the maintenance of the body and to ehange them 
so that they may be transferred to the blood. The respiratory system supplies the blood with the oxygen necessary for combustion in the body.

The decomposition produets arising from combustion must not remain in the lymph, beeause, if they did, they would finally poison the cells. They must therefore be remored by passage first into the blood and thence out of the body through the excretory organs.

In order that these neeessary functions shall be directed to the proper end of maintaining life, they are all subordinated to the influence of the nerrous system whose important object it is to eontrol the organs and to regulate their functions. In addition to this, in the warm-blooded animals a constant body temperature-i.e., a constant temperature of the lymph is maintained through the influence of the nervous system.

1. Cells completely surrounded by membranes can take up only gaseous and dissolved substances. The processes concerned in the ahsorption of gases by the elementary organisms are but little known, and the phenomena accompanying these processes in the higher animals are fully discussed in Chapter IX. Our knowledge has progressed somewhat further concerning the absorption of fluis and compounds in solution, and since the phenomena of osmosis figure prominently in this connection, it seems best to discuss them here somewhat in detail.

Osmosis.-When a laver of pure water is earefully stratified unon a solution-e.g., sugar in water-the layers do not remain separate. The sugar begins at onee to rise in spite of the foree of gravity and to diffuse into the water; and the morement ceases only when the sugar is distributed uniformly throughout the whole volume of water. 'The same thing oceurs if the water and the sugar solution are separated by a partition which is equally permeable for both. The dissolved substance passes from the place of higher concentration to the place of lower coneentration just as if no separating membrane were present.

Quite a different order of things prevails if between the water and the solution a partition is interposed which allows the water but not the dissolved substance to pass through. Such "semipermeable" walls are obtained by soaking a porous clay eell in a solution of eopper sulphate, earefully pouring this out and filling the cell with a solution of potassium ferrocyanide. There is then formed within and upon the clay wall a colierent layer of copper ferrocyanide through which water can be filtered; but if one attempt to filter through it a sugar solution, a much higher pressure is required, and what finally eomes through is not the sugar solution at all but pure water.

If a cell prepared in this way be filled with a sugar solution and be closed by means of a stopper through which connection is made with a manometer, and the cell then be placed in pure water, an inerease in pressure inside the cell is noticed, which finally rises to a definite maximum valne. This value represents the osmotic pressure of the fluid inside the cell, and is equal to the gas pressure which would be exerted by the same quantity of sugar in the form of a vapor inclosed within the same space at the same temperature. For a oneper-cent solution of eane sugar at $13.7^{\circ} \mathrm{C}$. the osmotic pressure amounts to 0.691 atmospheres. A four-per-cent sugar solution raises the pressure to 2.74 atmospheres.

Since there is no membrane which is semipermeable for all substances, it is necessary to resort to indirect methods of determining the osmotic pressure of some solutions. One such methor which has found wide application both in physiology and medicine is based upon the fact that in a watery solution the 
dissolved substance, e.g., salt, exercises a restraining influence on the freezing of the water and consequently lowers the freczing point. The eause of this restraining influence is that the particles of salt by means of the attraction they exercise on the particles of water tend to prevent the latter from cohering with one another, i.e., from passing into the solid state. The greater this attraction. the more difficult is it for the water to be solidified, and the lower must be the temperature before this change of state can be brought about.

The lowering of the freezing point, which is designated with " $\Delta$," is therefore a measure of the osmotic pressure (P) of the salt, caleulated in atmospheres aecording to the formula $\mathrm{P}=12.03 \triangle$. A one-per-cent solution of $\mathrm{NaCl}$ freezes at $-0.606^{\circ} \mathrm{C}$. : the lowering of the freezing point is therefore 0.606 . If one finds for an unknown fluid $\Delta=0.606$, its osmotie pressure corresponds to that of the one-per-eent $\mathrm{NaCl}$ solution, and amounts to $12.03 \times 0.606=7.29$ atmospheres.

When equimolecular quantities of different substances (i. e., quantities proportional to their molecular weights) are brought into solution in the same solvent, and solutions which have the same number of molecules of the dissolved substances in equal volumes are thus obtained, these solutions have at any given temperature the same osmotic pressure.

We have in the electrolytes an apparent execption to this law. The osmotic pressure is higher than it ought to be according to this general statement. This is due to the fact that the substances in question are partially dissoeiated in water into electrically charged atoms or ions-e.g., HCl into $+\mathrm{H}$ and $-\mathrm{Cl}$, $\mathrm{KCl}$ into $+\mathrm{K}$ and $-\mathrm{Cl}$, NaOII into $+\mathrm{Na}$ and - OII, ete. In this way the number of effective molecules in a solution is increased and in consequence the osmotic pressure is raised-in perfeet agreement with the general law.

The degree of dissoeiation depends primarily upon the concentration and upon the nature of the dissolved substance. The more dilute the solution the more complete is the dissociation with one and the same electrolyte-i. e., the greater is the relative (not the absolute) number of free ions. In different electrolytes dissociation presents certain varialions into which we eannot enter at this time. It will suffice here to say that the most important salts in the body, those formed by the alkalies with monobasic acids, are dissociated in dilute solutions of equivalent concentration to a very considerable extent, and are dissociated equally.

The combined osmotic pressure of several substances in the same solution is equal to the sum of the pressures of the separate substances.

When two solutions of different osmotic pressure are separated from each other by a semipermeable membrane, water passes from the one of less pressure to the one of higher pressure until the two are of equal pressure-i. e., are isotonic. With reference to each other these solutions are said to be hypotonic and hypertonic respectively.

Dead animal and plant membranes are as a rule nermeable to water and, though in less degree, to substanees soluble therein. When such a membranc separates water from an aqueous salt solution, the former passes into the solution and the salt passes out until the osmotic pressure on both sides of the membrane is the same. This is the case also when two isotonie solutions of different salts-e. g., $\mathrm{NaCl}$ and $\mathrm{NaNO}_{3}$ are separated by the membrane. The common salt passes from one to the other and vice versa, so that the two solutions remain isotonic. If they are of unequal osmotic pressure-i. e., anisotonicto begin with, an exchange of water and salt molecules takes place until a condition of equilibrium is established. 
From these discoveries on the phenomena of osmosis it follows that every change in the constitution of the medium surrounding the cell or of the fluid contained within it will have power to effect a change in the osmotic pressure prevailing in the cell. This would mean also a change in the quantity of fluid (degree of turgescence) as well as in the chemical constitution of the fluid contained in the cell, or indeed in the constitution of the protoplasm itself, according as the limiting layer of the protoplasm is permeable or not to the substances present.

Plant cells afford us the simplest examples of the influence of osmosis. The cell membrane is permeable to gas, water and solutions. In the living cell the membrane is impregnated with water: hence all substances which are dissolved in the water can penetrate the membrane and thus come into contact with the onter layer of the protoplasm (primordial sheath) just inside the membrane (cf. Fig. 16).

Within the plant cell and surrounded by the primordial sheath we find the cell sap, which is a watery solution of various salts. carbohydrates, etc. The primordial sheath is permeable to water. but prevents entirely the entrance of certain compounds, behaves toward them in other words exactly like a semipermeable membrane.

If therefore the cell is bathed by a solution of a compound whose osmotic pressure is greater than that of the cell sap. water passes out of the cell, the primordial sheath is loosened and shrinks away from the cell membrane (plasmolysis). But if the cell is bathed by pure water, the water can pass through the primordial sheath in the reverse direction and raise the internal pressure above its usual level, whence we have the condition of cell turgor.

The primordial sheath permits the entrance of certain other substances more or less easily, and in the commerce between the cells. where transportation and exchange occur freely, it has the power to change its permeability according to circumstances. From this it follows that neither absorption nor excretion on the part of plant cells is to be described as a simple osmotic process.

In the cells of the animal body, both the cell body and the nucleus permit certain substances dissolved in water to pass through. but exclude others; they behave toward these substances like semipermeable membranes (Hamburger, Hedin). To one and the same substance the permeability of different kinds of cells nay be considerably different, and it appears to vary with the same kind of cells under different physiological conditions (Hamburger).

From the investigations of IIamburger. Hedin, Koeppe and Gryns on the permeability of red blood corpuscles to different substances, one may gather that the K, Na, Ca, Sr, Ba, Mg ions, the different kinds of sugar, arabite and mannite do not penetrate them at all: and that they are hut slightly permeable to amino acids (glycoeoll, asparagin, ete.). In fact they appear to offer a powerful resistance to the amido group in the amino arids, but toward the amido group in the acid amides (acetamide, etc.) the resistance is not so sreat. The red blnod eorpuscles are permeable to $\mathrm{NH}_{4}$ ions, to free acids and alkalies, and to alcohols in inverse proportion to the number of hydroxyl ions in the molecule; also to aldehyles, ketones, ethers, esters, antipyrin, anide, urea, urethan, bile acids and bile salts. The leueoertes of the blood and of the lymph glands. 
so far as this property has ret been studied, are shown to be permeable to elılorine, sulphuric acid, earbon dioxile, iodine, bromine, oxalic acid, phosphoric acid, salieylic acid, benzoie aeid, and arsenic aeid (Hamburger and v. der Schroeff).

Overton has studied the permeability of cross-striated muscle to a large number of organie compounds, and has come to the conclusion that toward the same substances they behave just as do plant eells. All eompounds which are plainly soluble in water and are also soluble in ethyl-ether, in the higher alcohols, in olive oil and similar organie solvents, or which at least are not much more diffieultly soluble in these than in water, penetrate living muscle fibers and other animal and plant cells very easily. But the more the solubility of a compound in water exceeds its solubility in one of the organic solvents, the more slowly does it penetrate these structures. For explanation of this peculiar behavior, Overton has put forward the hypothesis that the limiting layers of the protoplasin are impregnated with a fatty substance, a mixture of leeithin and cholesterin, and that the elective solvent power of this mixture for definite substances governs the pure osmotic nermeability of the cells.

Out of some 75,000 organic compounds known at present more than 60,000 , to accept Overton's rough estimate, can penetrate the cell. Among these however are found neither the carbohydrates nor a number of other substanees participating aetively in the metabolism of plants and animals. Overton remarks that so far as the constitution of these compounds is known, derivatives of them cau always be found which do penetrate the cells very easily. How far his explanation applies to the living body we do not know.

It has been found that different Infusoria are to a great extent independent of the osmotic pressure of the solution, since they ean exist for days at a time in distilled water, without suffering noticeably and without exhibiting any very striking changes in form (Goldberger). The eggs of Fundulus also do not swell if they are suddenly brought from sea water into distilled water; and they do not shrink if the reverse change is made (Loeb). NeCallum found in the case of the medusa, Aurelia, that the salt content of the surromding medium can vary within wide limits without materially affecting the body fluid. The fluid pressed out of the body contains less $\mathrm{SO}_{3}, \mathrm{MgO}$, and $\mathrm{Na}_{2} \mathrm{O}$, and more $\mathrm{Cl}$, $\mathrm{Fe}$, and especially $\mathrm{K}$ than the sea water; the depression of the freezing point also was less for the latter than for the body fluid. While the salt content of the blood of the green crab increases and decreases with that of the sea water, the relation in the crayfish is just the reverse: here the depression of the freezing point of the blood is $0.8^{\circ} \mathrm{C}$., while in the surrounding water it is only $0.02^{\circ}-$ $0.03^{\circ} \mathrm{C}$. (Frederieq). Frogs kept for weeks in distilled water give up only a part of their salt to the water, notwithstanding that between them and the water there is a difference of osmotic pressure amounting to about two atmospheres (Durig).

In the different tissues of any given animal also there are noteworthy differences with respect to osmosis. Membranes consisting of only a single layer of connective tissue coated with a single layer of smooth muscle cells, like the peritoneum and the mesentery, offer very little resistance to the passage of different ions: and their permeability is not noticeably ehanged after the death of the cells by chloroform. But living membranes constructed of specifically differentiated epithelial eells behave differently: their ability to oppose or to facilitate the passage of ions eorresponrls to the physiologieal functions devolving upon them. and disappears with the death of the cell, at which time also the permeability rises signifieantly (Galeotti). 
The fact demonstrated by Schiicking in the case of the snail, A plysin. that long-continued stimulation of the dermal musculature can more than enmpensate the effects of osmotic presure, and the disenveries on absorption from the alimentary eanal (cf. Chapter. TIII), together with the facts smmmarized abore. go to show that the osmotic processes cannot be the only factors at work in the ubsorption of substances by animal cells. The outer limiting membrane of the cell behares in many respects as a semipermeable membrane. but. sn far as we ean grasp the matter at present. it appears to differ in many respects from such a membrane. Just as the cell itself regulates the extent of the oxidation processes taking place within it or inaugurated by it, sn within certain limits, and independently of the quantitive composition and the osmotic pressure of the surrounding medium, it regulates its absorp-

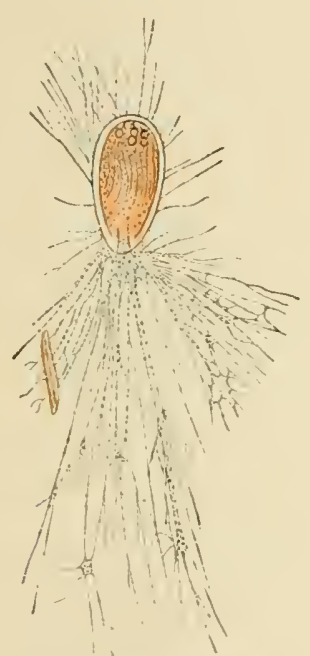

FIG. 19.-Gromin oviformis, after Max Schultze. Some of the pseudopodia have eaught a diatom, which by gradual shortening of the contractile threads will be taken into the interior of the organism. $20 / 1$.

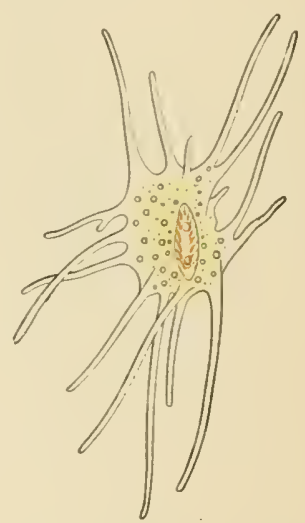

Fig. 20.- 1 mieba polypodia, after Max iehultze. A small organism has been engulfed. 330,1 .

tion and elimination of substance. It is possible that this is due to the speeifie affinities of the living bodies which constitute the protoplasm. Tust as gelatin plates and agar plates take up substances from solution, whether the solution is isotonie. hypotonie, or hypertonie. until their affinity for the substance is satisfied, so the living substance might take up or give nff suhstances aceording to its affinities. independently of the osmotic presinre. Tust what weight this hypothesis, developed by Friedländer and Durig, may lave we cannot say definitely at present.

In connection with the investigations here discussed npportunity has often heen afforded to determine the osmotie tension inside animal cells. It is found to eorrespond to a $\mathrm{XaCl}$ solution of $0 . \tau$ to 0.9 per cent, and amounts to about 5 to 6.5 atmosplieres. In order that the aquenus content of animal cells may be preserved, it is necessary therefore that the surrounding inerlium have a corresponding osmotic pressure. 
Since $\mathrm{taCl}$ plays the most important rôle in maintaining this pressure, one might suppose that this is the only special physiological significance of eommon salt. That is net the ease however, as appears firom the fact that a froges muscle which remains excitable for a long time in a 0.ti-per-eent $\mathrm{NaCl}$ solution very soon loses its excitability in an isotonic solution of eane sugar (Overton).

?. Saked elementary organisms have the power also of ingesting soliel prorticles. In many cases this takes plate in a vory simple manner. The cle-

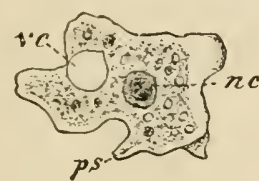

1

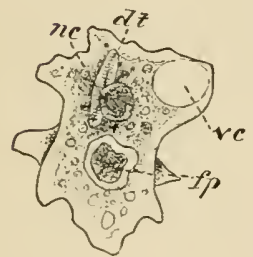

$D$

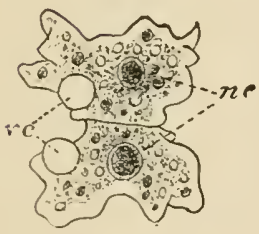

$G$

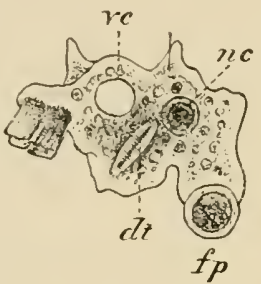

$B$

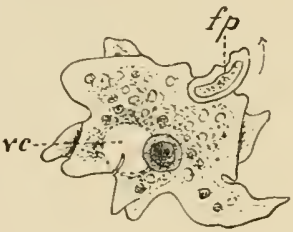

$E$

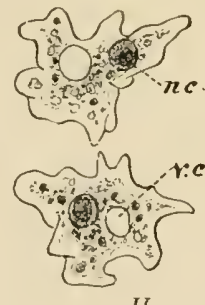

$H$

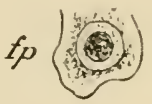

C.

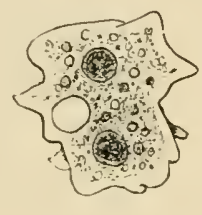

$F$

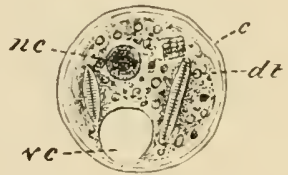

1

FIG. 21.-1-H, Several suceessive phases in the life history of an 1 maba, kept under eonstant observation for three days; $I$, another individual encysted.

A, locomotor plia.e: the setoplasm is seen extending to form a preudoporlium, into which the emloplasm pasies; $b$, a stage in the ingestive phase; $f p$, a regetable organism being ingested; $('$, a portion of the tmaba represented in $b$, after complete ingestion of the formparticle; $I), E$, successive stages in the assimilative and exeretory proeesses; $F, C, H$, suecessive stages in the reproductive proess of the same individual. It will be notieed $(F)$ that the meleus divirles first; $v c$, rontractile vaeuole; nc, nueleus; $p s$, pseudoporlium; $d t$, diatom; fp, fool particle.

mentary organism puts out processes. pseudopodia, which apply themselves to the particles of food, then gradually flow around it until it comes to lie 
within the protoplasm. Examples of this are found in the Amobæ and other Rhizopodal (Figs. 19 to 23 ). and in the leucocytes of all claseses of animals, which very clocely resemble Amothe with respect to their structure.

This ability of the leuencytes is of great importance to the body as a whole, for wherever a destruction of tissues takes place either from normal or patho-
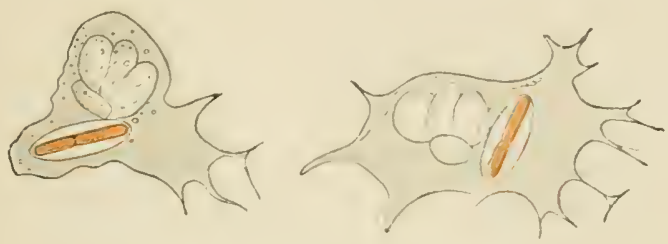

Fig. 22.-A white blood corpusele of the frog, containing an anthrax bacillus. The two figures were drawn from the same ecll at different times, after Metschnikoff.

logical anuses, the débris is taken up ly the lonencytes and is remored. The leueneytes play an important rôle also in clicposing of the pathogenic Bacteria which find their way into the body. since they are ahle to eat and to digest such organisms (Fig. 2.2), and therelyy to atford the body substantial protection against infection ( Mletschuiknfi).

The more highly organized clementary organisms prorided with cilia and a cell mouth, such as the ciliate Infusoria (Figs. : $t$ and 28 ), ingest solid

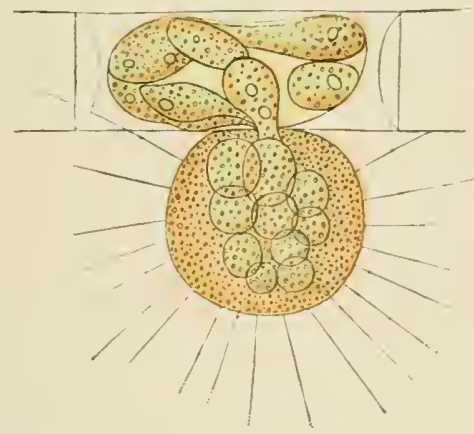

F1G. 23.- Tampyrclla spirnyyra, a rhizopolous: unicellular organism, ingesting the entents of an :lga cell, after ('ienkowski.

particles he creating with their cilia a rortex in directed that the particles are driven into the mouth. In this and other similan waly of taking up solid particles the oreanism cann exereise an actual choice of nourishment; certain lihizopoda for example eat only certain alga cells (cf. Fig. :23). 


\section{DIGESTION}

The solids taken up in this way by the cells must undergen various elatnges: in order that they maly he of use to the cell. Often this is true also with the distolved foods. All such processes hy which the foods are changed so that they may be assimilated or further elaborated by the cell are inchrided under the term digestion.

'The digestion arecomplished by the cell is cither extro-or intracelluthe. In the former case digestion takes place under the influence of special sulsstances, the enzymes, formed by the cell. These substances, like calalytic agents. have the property when present in very small quantity of producing chemical changes in great quantities of complex molecules, therely splitting them into simpler compounds. which in their turn reduce the activity of the enzymes. By the action of enzymes proteid is split into albumoses and perp)tones, starch into sugrar. and fat into glyeerin and free fatty acids (ef. ('hapter VII). It should he noted further that every special enzyme acts only upon a definite compound or group of compounds. The proteid-splitting enzyme therefore does not act upon starch, nor the starch-splitting enzyme on fats. etc.

It is quite possible that the enzymes can produce their effects insirle the cell just as well as in the surrounding medium, and it is rerr doubtful whether an intracellular digestion takes place anywhere without the help of enzymes, though such participation cannot be definitely asserted.

Enzymes which have the property of dissolving proteids just likn the corresponding enzymes in the digestive fluids have been obtained from finely minced organs-spleen. lymph glands, kidneys, liver, heart, ete. It is assumed that they are present in the living cells. thomgh this has not been finally proved. Nothing definite can be said at this time with regard to the importance of such enzymes in the normal processes of the body. It is possible that in starration they may effect the solution of the tissue proteids. also that the antolytic processes which take place after death are initiated and carrier on by such enzrmes.

The cnzymes are moducts of cell activity, but once they are formed they act entirely without the help of the cell and are nonliving substanos. In general it is supposed that they are proteid in nature, and in fact Priselharing has prepared from the stomach of the dog a rery pure enzyme (pepsin) which was free of phosphorus and had the constitution of proteid. Rut it womld be premature to draw any general conclusions from a single observation.

Enzymes oreur in the cells for the most part in the form of precursors. known as zymogens. Often the zymogen is changed into the active enzyme in the act of secretion: or its activation may be brought about under the influence of another enzrme.

Enzyme: are only sightly diflusible. lut they pass through a porcelain filter and can be separated in this way from the cell fragments of an extract or juice. In the disolved state they withstand heating up to $\approx 0^{\circ} \mathrm{C}$ : in the dry state many emzymes are not destroyed ly a temperature of over $100^{\circ} \mathrm{C}$. In general they are most powerfully active at $35^{\circ}$ to $45^{\circ} \mathrm{C}$; at a lower tem- 
perature they act more feelsly, but if warmed again will regain their activity even after having been reduced to a temperature as low as $-192^{\circ} \mathrm{C}$. They are destroyed by mineral acids and alkalies of sufficient strength. With some enzymes also the decomposition products formed by them exert an inhibiting influence on their further activity. On the other hand their activity is but slightly affected by the protoplasmic poisons.

Various facts faror the view that enzymes exereise their specific effects only after uniting with the substance aeted upon. 'Thus pepsin for example unites with the proteid fibrin so firmly that it camnot be removed by washing with water. 'The fact also that when mixed with the appropriate substances enzymes endure a higher temperature than otherwise gives a certain support to this conception.

Recently Croft Hill has shown that the enzyme formed in the reast cell hy which maltose is changed into dextrose, has the power in concentrated solutions of sugar (over four per cent) of changing dextrose back into maltose; that what takes place is therefore a reversible process. Similar phenomena have since been observed with other enzymes. Panereas extract effeets a partial synthesis of ethyl butyrate from ethyl alcohol and butyric acid (Kastle

and loevenhart). By means of a lactose-splitting enzyne E. Fischer and Armstrong prepared isolactose from galactose and glucose in equal quantities, ete.

It is very probable that this reversibility of enzrme action is of very great importance in the transformations taking place in the body, although we are not ret able to foresee its entire range.

\section{THE OXIDATIVE PROCESSES}

Attempts have been made to give an exhanstive theoretical explanation of the oxidative processes going on in the tissuss, and sereral hypotheses have been put forward. Some of these smppose that the influence of the animal tissues on the physiological oxidations consists of an increase in the oxidizing activity of oxygen; some assume that the tissues in mediating oxidations do not influence the oxygen itself, but act on the oxidizable substances making them more accessible to the oxygen.

We canmot here enter into the development of these theories since, as they stand to-day, they are not by any means able to explain the facts. We may say only that from both fresh and dead organs hardened in alcohol, it is possible to extract with water a substance which oxidizes certain substances like benzyl abohol, salicyl aldehrde and glucose (Jacquet). Aceording to spitzer this substance is an iron-containing nucleo-proteid derived from the nucleus. Whether it has any special significance in the physiological processes of the cell cannot he sald definitely as yet. becanse of the posibility that it is set free only by the destruction of tissme elements. That in any ease its physiological importance is only secondary. would appear to be sutliciently shown by the fact that its quantity. or more correctly, its oxidizing function as deternined in the manner above mentioned is considerably greater in the glandular organs (spleen. liver, thyroid, kidneys, ete.) than in the muscles, where combustion takes place nost estensively. 
The following discoreries appear to aflord a wider outlook. In the alcoholic fermentalion effected by the yeast plant, maltose dissolved in water is changed under the influence of an enzyme formed by the reast cells into grape sugar, and this is split into carbon dioxide and alcohol. Intil recently it was supposed that the latter cleavage could only be accomplished by the rital activity of the yeast cells themselves, which appeared in fact to follow from a number of experiments. By trituration of the yeast cells and sulssequent compression with a pressure of $400-500$ atmospheres, however, E. Buchner (1893) suceeded in obtaining a sap, which after being filtered through sterilized "infusorial eartls" and thus being freed entirely of reast cells, was still able to split sugar into alcohol and carbon dioxide." The active substance contained in the sap Buchner named zymaze.

This discorery opens up new prospects for our whole conception of the mode of decomposition in the animal body. It makes possible the assumption that not only the reast cell but all other cells carry out the chemical work characteristic of their vital activities by means of substances analogous to the enzymes and capable of being isolated which are formed within the cells and are given off by them. It would be premature however from the present standpoint of science to make such a generalization even hypothetically. For the substances formed in the processes under consideration are so manifold, and the essence of the processes is still so obscure that immediate dissimilation effected by the rital activity of the cells cannot without further information on the subject be completely excluded. Moreover, the oxidation processes of the body are so well regulated in relation to the amount of work to be done and the time of doing it, that it is difficult to imagine how they could be brought about exclusively by ferment action.

Any dissimilation accomplished by the direct aetion of the cell. in contradistinction to the effect of the enzymes and zymaze, is designated as ferment artion, and the cells participating are known as organized ferments. Substances resulting from such action represent decomposition products formed directly by the vital activity of the cell. Carbon dioxide which is produced in every living being belongs (at least in part) in this category, as do other substances which especially characterize the different organisms, e.g., the peculiar metabolic products of ditlerent Bacteria (toxins).

It is generally true for all cells that the substances produced in their metabolism are harmful to the organisms themselves. and if retained in large quantities they are fatal. Hence neitler yeast cells nor Bacteria can live contimnously in the same solution, even though there is no lack of nourishment, unless prorision is made for the removal of the products of decomposition from the solution.

\section{E. THE ELIMINATION OF DECOMPOSITION PRODUCTS}

The cells of course camnot remore the waste products from the medium in which they live. They can do no more than remove the products from their own bodies. The indigestible residnes of the solid food such as walls of Algax, cases of diatoms, the chitin of rotifers, ctc., are egested from the 
free-living cell body in a manner exactly the reverse of their ingestion. The remmant is brought to the surface of the cell, the protoplasm gives way in this particular place. the borly to be eliminated is extruded, and the cell withdraws from it.

The gaseous exeretions, carbon dioxide and oxygen, are probably eliminaterl according to the laws of diffusion (c.f. ('hapter IX).

We have as yet but little reliable information as to how dissolved substances leave the cell. To reason by analogy with the manner of their absorption we ought to find at work besides the osmotic processes, an active influence on the part of the cell itself. If the products cannot be removed immediately they are sometimes rendered harmless by a combination of some sort. For example. oxalie acid, which is poisonous, is loound up with calcium in the insoluble and therefore harmless compound calcium oxalate. In Chapter XIII we shall discuss a number of analogous processes in the higher animals. A highly specialized mode of removing fluid waste from the body of an Infusorian is shown in Fig. 24.

\section{F. SECRETION}

In unicellular as well as in multicellular organisms, though in the latter probably to a much greater extent, the

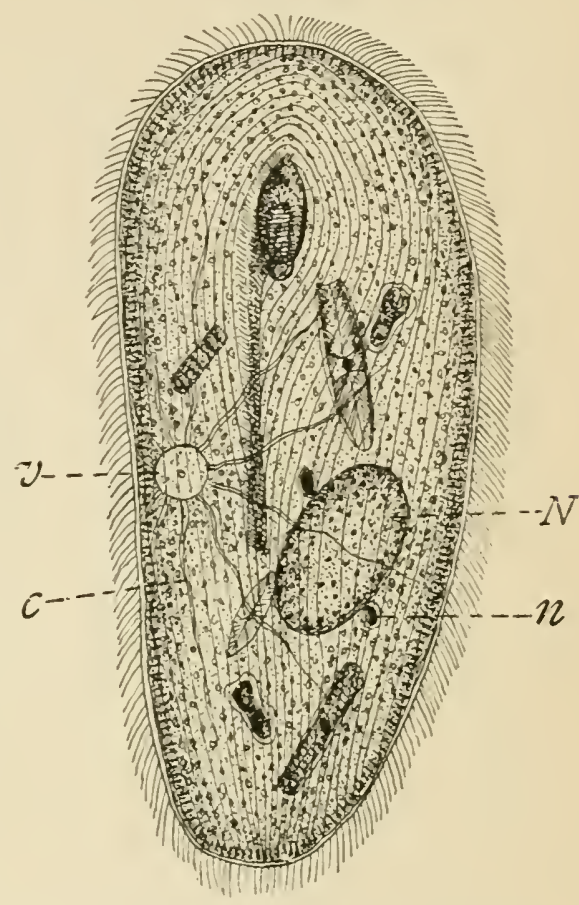

FIG. 24.-Frontana leucas, after Schewiakoff. $N$, macromucleus; $n$, micronucleus; $c$, one of several excretory canals learling into the excretory vacuole; $\imath$, by contraction of which the fluid contents are ejected. Several ingested diatoms are to be seen.

cells by their own activity form rarious substances which either serve the purposes of the cell itself, or. in the multicellular forms. are esential to the purposes of the entire body. We include all such substances under the head of secretions.

To the seeretions belong the enzymes and analogous compounds, such as the products of the so-called intermal secretions ( $\mathrm{ef}$. Chapter XI), also most of the skeletal substances, as the chitinous eases of inseets. the calcareous shells of Foraminifera, the cell membranes, ete.; and, finally, the intereellular substances such as oceur in the fibrillar conneetive tiscue, cartilage and bone. How far these substances arise by transformation of the living protoplasm, or are only produced by its actirity camnot be regarded as settled. But it is probable that the latter alternative holds in the ease of those struetures which are formed of silicic acid or caleium earbonate or phosphate: for it can seareely be supposed that structures of this kind arise directly from protoplasm. 


\section{G. MOTILITY}

It has already lieen necessary to refer hriefly to the movements of the elementary organisms, lut since motility is one of the most important functions of hiving substance, we must study it here in its different manifestations.

1. The protoplasm of a plani cell inclosed within the membrane exhihits different forms of motility. Some of these, as for example the migration of chlorophyll bodies, take place very slowly (Fig. 25). In diffuse daylight the

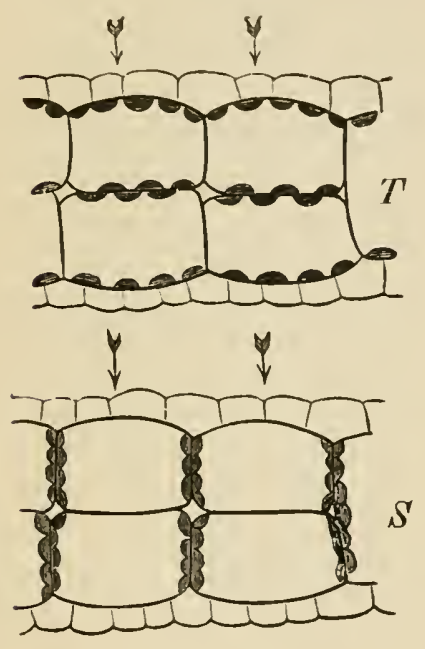
chlorophyll bodies are so placed that they present their greatest surface to the light ( $T$ ) : in direct smomlight they are so placed that their narrow edge is turned toward the incident rays (S); while in windows a third position $\left(N^{\prime}\right)$ may be taken. The purpose of these movements is doubtless to protect the plant in strong illumination from a too intense effect of the light, and in moderate illumination to secure the plant as great an effect as posible.

We observe in plant cells also strenmings of protoplasm which can be followed by the migration of the granules. In these movements the protoplasmic particles either flow in different directions, often in great confusion (circulation), or the protoplasm collectrel along the wall is caught in a rotatory morement all in the same direction, in which the nucleus and often the chlorophyll bodics are dragged along (rotation) (Fig. 16).

2 . The simplest kind of protoplasmie move-

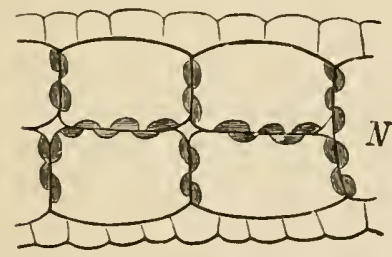

FIG. 25.-Varying positions of the chlorophyll bodies in the cells of Lemna triscula, according to the direction of the incident light rays, after Stahl. ment in the nated rells proceeds in a mammer similar to that just mentioned, as may be observed in the Amoba (Figs. 20, 21, 2(i), and in the lencocytes of multicellular animals (Figs. 2:2, 2i). During rest the Amoba is spherical. When it begins to move one or more processes protrude from the periphery of its body. By a kind of streaming movement the protoplasm of the cell body then flows into this process or processes and the position of the entire mass of the animalcule is thereby changed. The protrusions are not preformed struetures, for the cell has the power to put out such a procesis from any point of its surface and to withdraw it again. It is on account of their transitory character that they are called psendopodia, or false feet.

The appearance of the pseudopodia in different species of elementary organisms is very different. In unicellular animals provided with an external skeleton they are molifien aceording to the character of the openings in the sketeton through which they protrude (ef. e.g., Fig. 14). We meet with short and thick, or long and slender, threadtike or thorn-shaped pseudopodia; or again with those 
which projeet quite independently of each other, or which unite in the most complex sort of a network (Figs. 19, 20, $21,26)$.

Both phases of the morement of pseudopodia in Amoba, namely expansion and contraction, are to be regarded as active processes. and the two are of equal importance in ingesting food or in locomotion. In other kinds of morement the most important phase consists in a retuetion of the surface of the cell-i. e., in entraction. 'To this category belong especially the morements of the smooth and cross-striated muscles. to which we shall derote proper attention in Chapter $\mathrm{X}$.

3. The cell body of certain unicellular organisms presents specially differentiaterl contractile elements. sitentor, for example. has in its outer sheath of protoplasm smooth muscle fibrils ruming almost parallel; Vorticella (Fig. 28) contains only a single smooth muscle fiber composed of several fibrils. This leares the boly as a thick cord. and is surrounded lis an elastic membrane to the inner side of which it artheres along a spiral conlse from one end to the other. It serves as a stalk for the attachment of the organism. If these contractile fibers are roused to activity, they become shorter and thicker

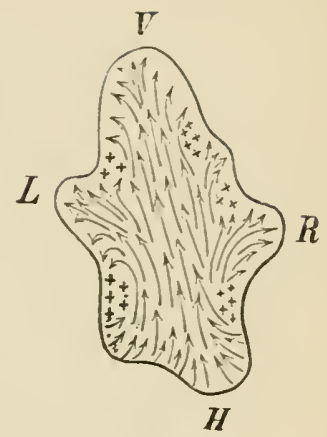

Fig. 26. - Mode of mosement of an Amaba. The arrows indicate the direction and strength of the protoplasmic c u r rents; the crosses, the resting places. For the instant the principal line of movement is from $H$ toward $r$, but at any other moment it may turn toward $L$ or $R$. just like true muscles, and thereby change the form of the cell in a eorresponding way.

4. In numerous unicellular organisms and in numerous cells of multi-

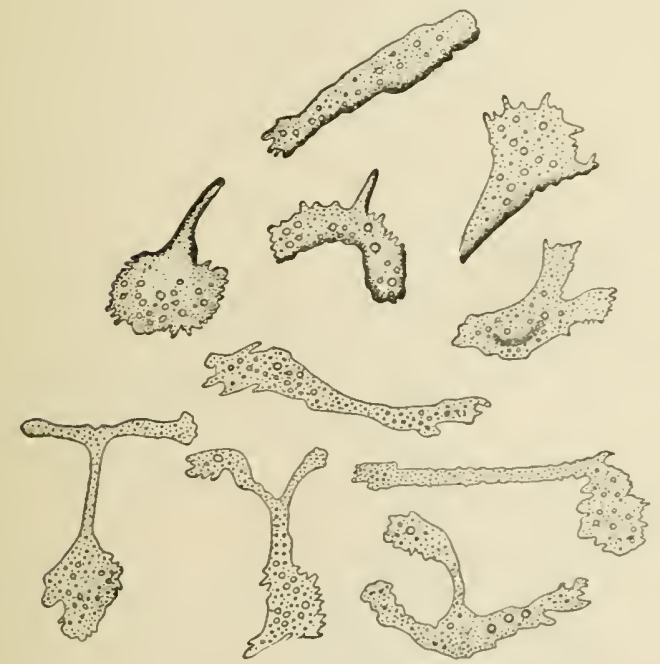

Frg. 27.-White blood corpuscles at $38^{\circ}$ performing amceboid movements, after Max schultze. The different figures are all drawn from the same corpuscle. cellular organisms. we find rilia or flugellie as special dittrerentiations of the cell borly. These are not temporary like poendoporlia. but permanent struetures of greater or less length attached to the onter surface of the cell. Ther are in constant motion and ocenr on every a cell or on al great majority of the cells forming a cilialed surface. If the cell bears only a few (1 to $t)$ such structures. ther are called Hagella: if a larger number. they are calles cilia. In eertain organisms they can be comnterl by the hundreds and thousinds.

Flagella are affixed either to the anterior or the posterior end 
of the cell body. The former arrangement is found in the Flagellata, in the spermatozoids of plants, many Bacteria, and in the swarm spores of many Algre and Fungi. In locomotion the flagella precede and pull the body after them.

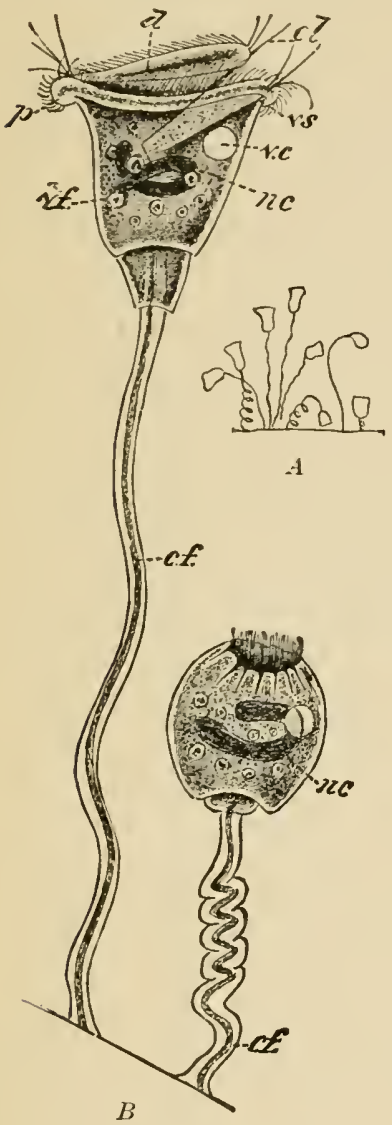

FIG. 2S.-Torticella.

$A$, a group of individuals as seen under the low power; $B$, a single vorticella with stalk extended and beside it another with stalk contracted; $d$, denotes dise; $p$, peristouse ; vc, contractile vacuole; $r s$, vestibule; $c f$, contractile fiber; $n c$, nucleus; $c l$, cilia.

The latter arrangement is found in the spermatozoa of most animals, where the flagellum drives the cell body forward after the manner of a propeller.

If the cilia should beat back and forth in both directions with equal force. only a to-and-fro movement would result, and no locomotion would be posisible. Careful investigation of both flagella and cilia has shown that they always strike more forcibly in one direction than in the other, a fact which at once makes clear the mechanical results of their morements.

In the freely motile cells the object aecomplished by the ciliary movement is locomotion. In addition to this, if the cell is swimming in a fluid specifically lighter than itself, motion of the cilia prevents it from sinking to the botton. Again in certain unicellular animals they participate in the ingestion of food, being arranged in a cirele around the mouth, and when in motion creating a vortex in the water which sucks suspended particles into the mouth (Fig. 28).

The eiliated cells covering the surface of the mucous membranes in Metazoa drive such partieles as may happen to be on the surface in a given direction, and thus play a rôle in many ways very important to the animal.

Cilia are always fastened to a protoplasmic substratum and are never ontgrowth of a firm cell membrane. Very often, however, they are not immediate extensions of the protoplasm. Jut rest directly upon a thin layer of transparent substance which, though rery closely resembling the substance of the cilia, appears not to be contractile but to lie as a kind of eoat on the nakerl surface of the eell protoplasm. The coats of the adjacent cells are so closely connected that in many cases a considerable patch of this layer can be lifted up as one piece.

Certain cilia continue to move even if they be separated entirely from the protoplasm or the loasal part of the cell. Since both cilia and flagella can of themselves perform many complicated moxements we must aswme that they consisl of a contractile substance. If in addition we assume that they contain also a nonentractile supporting substance, we should have a somewhat satisfactory explanation of the difforent forms of movement of these structures (Piitter). 
In most eases ciliary morement is not influenced in any manner by the adjacent or by the distant cells, and in the nucous membranes of the vertebrates it appears to be entirely independent of nerves; for eiliated cells continue to move after they are eut out of the body, and in the human body for as much as three days after death (Valentin). Ilence it is the more remarkable that in a row of cells the cilia always move in complete harmony even if the cilia are not in contact with each other. This and the further fact that a stimulus, applied to a portion of the epithelium where ciliary motion has ceased, can be transmitted to a portion where it is still active, go to show that the basal part of the cell must have something to do with the regulation of ciliary movements. Nevertheless much here remains to be explained.

5. Still other forms of movement than those already discussed oreur in the animate world. The following may be briefly mentioned. Various unicelhular animals (Radiolaria, Rhizopoda) can raise or lower themselres in the water where they live by changes in their specific gravity. Arcella and Diftlugia rise by developing a bubble of earbon dioxide in their cell body. Thrtassicola (Fig. 15) swims at the surface of the sea because its racunles contain a fluid specifically lighter than sea water. Under certain ennlitions it can sink itself by rupturing the sheaths of the racunles which then fuse together. When the vacuoles are reformed the animaleule oner more mounts upward. Finally, in plants a great many movements oceur through suetting of the cell wall, and through changes of turgor, which we eannot disenss in this book.

\section{H. PRODUCTION OF LIGHT}

Certain putrefactive Bacteria which live on decaring flesh of marine fishes and on meat, as well as certain Fungi and a few insects have the power of producing light. In certain places where the sea water glows it is found on filtration that the glowing substance remains on the filter and is not found in the filtrate; the eanse of the light is therefore an insoluble substance. Microsenpieal examination of the residue on the filter reveals millions of phosphorescent organisms belonging to all elasses of the invertebrates.

That the phosphorescence of these animals is not due to previous exposure to the sun's rays follows from the fact that even when they are kept for a long time in complete darkness, they glow just as strongly as their companions which have been in the sunlight. The phosphorescence ceases howerer when the animals are brought into a medium unsuitable for respiration; it therefore represents a true oxidation process.

Closer investigation of this phenomennn proves that it is initiated by the artivity of the living protoplaxm. for the organisms produce light only so long as they are alive. In the case of Pholas (a musicel), the phosplonesent sul,stance ean be thrown out of the body. but it is formed only by the activity of the living protoplasm. The phosphorescence arises thromgly the action of a special enzyme on this substance ( $R$. Dubois). In the "lightning bug," Lampyris, nerve fibers have been demonstrated running to the light-prolucing organ. The animal suppresses its light when there is a noise; the darkening then begins at the proximal end and spreads to the distal end of the 
organ. It is worthy of note also that the light produced by the " lightning bugr " is defieient at bothe ends of the strectrum. We have here in other worls a solure of light which is devoid or almost devoid of the nltra-red and ultraviolet rays (Langley and Very).

\section{FORMATION OF HEAT}

Heat is formed in all disimilative proesses, and sinee processes of this kind oceur everywhere in animate nature, we may say that the generation of heat is unirersal. This cannot always be demonstrated: for in the isolated elementary oramisms the quantity formed is so small that it canmot be measured with our instruments. In plants as a rule heat is formed so slowly that as fast as it is generated, it is radiated to the surrounding medium; conseruently the temperature of the plant cannot be elevated perceptibly above the medium. It should be said also that the abundant transpiration oceurring in plants has much to do with keeping down their temperature. 'The same is true and for the same reason in most of the so-ealled cold-blooded or poikilothermos animals, that is, animals in which the body temperature rises and falls with the temperature of the surrounding medium. In dry air\% on account of eraporation from the surface of the body, the temperature of a cold-blooded animal is usually lower than that of its medium. In a moist or water-saturated atmosphere the hody temperature may rise some tenths of a degree. This is true likewise of colit-hlooded animals which live in water. Only in the so-ealled warm-blooded or, more correctly, homointhermos animals (birds and mammals) - i. e.. animals whose body temperature remains constant in spite of the variations of the surrounding temperature-ean the production of heat be demonstrated directly and without diffieulty. In these animals the temperature of the body is almost always higher than that of the medium in which they live.

Inder certain circumstances it ean be shown very rlearly that in plants as well as in cold-blooded animals heat is actually formed. With poas which have been allowed to germinate in a fummel under a bell jar a rise in the temperature of $1.5^{\circ} \mathrm{C}$. has been observerl. In the spadix of the Aracea (e. ... "skunkcabbage") a temperature of $15^{\circ} \mathrm{C}$. higher than that of its surroundings has often been witnessed. Likewise in the fermentation of sugar solntions by the yeast plant elevations of temprature of about the same extent may oecur.

With regard to the body temperature of the cold-blooded animals, the following data on the excess of the animal's temperature over that of its surroundings have been gathered: various invertebrates in water $0.21^{\circ}-0.60 \quad \mathrm{C}$.; earthworms in a glass ressel $1.4^{\circ} \mathrm{C}$.; bees in a beehive $21^{\circ} \mathrm{C}$.: moving butterflies $14^{\circ}($ ?

The animal heat of warm-blooded animals will be more fully diseussed in Chapter XIV.

\section{J. GENERATION OF ELECTRICITY}

'The enormous number of investigations on animal electricity beginsif we except the electrical fishes-with the pregnant observation of Galvani that a frog's thigh contracts when it is touched in two places with the ends of a metallie are (September 20,1786 ). From this observation Galvani thought 
himself justified in concluding that animals have a peculiar kind of electricity and that it is of very great importance in the functions of the animal body : in fact, physiologists of that time thought their dream of a vital force was at last to be realized.

It was reserved for the discriminating insight of Tolta to show that these contractions are conditioned upon the dissimilarity of the two ents of the metal touching the moist conductor, and upon the production therely of a galvanic are. Further investigation proved. howerer, that electrical differences of potential do oecur in the animal hody. The erents historieally most important from this point of view are: the diseovery of the so-called frog current-i.e., of a current ruming from the feet to the head of the frog (Nobili, 18:5); the demonstration that the joolater musele under definite ejremstances gives a regular eurrent (Matteuci and Du Bois-Reymond. 18+0-1843); the discovery of the electrical variations in muscular activity

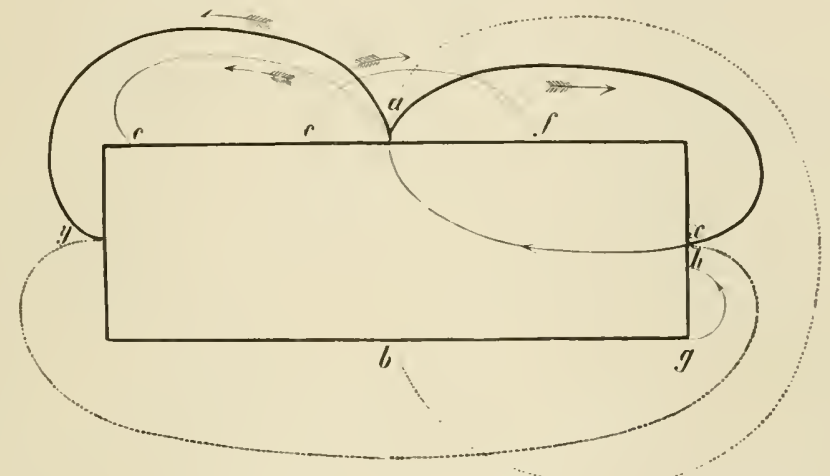

Fig. 29.- Schema representing the current of injury, or demarcation current, in a muscle, after Foster.

(Mattenci and Du Bois-Rermond, 184:) : and the discorery of the nerve current and jts variations (I)n Bois-Reymond. 1843).

The object most nsed in these insestigations is crosis-striated muscle. If two points of an exsected musele be connected with a galvanometer an exeursion of the needle nearly always oceurs: between the two points of the muscle there is, therefore, a difference in tension. More detailed stmly has shown that these tension differences are perferetly regular, and in muscies with parallel fibers they have been found to take the following form (Du Bois-Reymond)

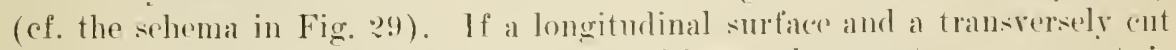
surface of smeh a muscle he commector with a galvanometer. a current is obtained. Which in the muscle is directed from the transverse to the longitudinal surface, and which reaches its greatest intensity (0.06 to 0.08 rolt) if the leading-off electrodes are placed in the middle of the two surfaces. If two asmmotrical points of the longitudinal surface be lexl off weaker eurrents are obtained. which in the muscle arm direxted from the periphery toward the middle. With two asymmetrical points of the cross section a current is obtained which passes from the middle toward the periphery. Finally, if symmetrical points of the cross section or of the longitudinal sur- 
face be connected. no ditlerences of tension are shown (Fig. :?. dotted lines). From these facts it follows that the entire longitudinal surfuce of the muscle possesses a positive tension, erery cross section a negative tension.

It has been shown by Hermam (1867) that in an entirely uninjured, resting muscle there are no such differences of tension. If the skin be removed very carefully from the gastrocuemius of a frog and great pains be taken that it does not come in contact with the seeretion of the skin. no current at all, or only the rery weakest one, is obtained when the muscle is connected with the galvanometer. If on the other hand the muscle be injured in any way in the weighborhool of one clectrode, a strong eurrent appears. The uninjured, resting heárt also gives no current (Engelmann).

These and other diseoreries-among which should be mentioned the faet that the eurrent of injury does not appear in its full strength immediately but develops gradually-indueed Hermann to propound the following theory in explanation of the eurrent of rest, which at this time is the one most acceptable to physiologists. The cause of the difference of electrical tension in the resting muscle lies in the injury which it receives. In a partially injured muscle every point of the injured portion is negative to every point of the uninjured part. The facts may be expressed in the following general proposition: in every injured muscle fiber the demarcation surface between the living and the dead contents of the fiber is the seat of an electromotive force directed towarl the living part. On this aceount Hermann designated the current of rest as the demarcation current.

Exactly the same electrical phenomena as in the resting muscle appear in resting nerve.

Electrical currents appear also when a muscle or a nerve is active, and these currents are intimately connected with the functional condition of the tissue. The general law of these currents (action currents) may be comprehended in the following statement: Erery artive portion of muscle or of nerve maintains a negative relation toward the resting part (Bernstein. 1S6r). We can therefore condense the law for the rest eurrent and the action eurrent into the following simple formulation: In muscle and in nerve every actire or injured part maintnins a negative electricul relation toward every other part which at that time is at rest or is uninjured.

Further stuly of the action eurrent will be postponed to the disenssion of the general physiology of muscles and nerves (Chapter $\mathrm{XT}^{\mathrm{T}}$ ).

We meet with analogons electrieal phenomena in many other tissucs. The eurrents present in glands are of sperial interest. Du Bois-Reymond proved that the skin of the Amphibia is the seat of a current divected from without inward which he ascribel to the secretion of the skin peculiat to these animals. Later investigations have marle us aequainted with similar eurrents in many other objects (nucous membrane of the frog's tongue, of the pharyx and elnaea of the frog, skin of the Amphibia and fishes. and of the leech, ete.). and have show that they are generated by the mucus-forming epithelia composed of single-celled glands, as well as by other epithelia not glandular (Reid). Both the strength and the direction of the eurrent of action may be modified by such agencies as pilocarpine, which stimulates secretion, by excitation of the mueosa or of the glandular nerres, by changes of temperature, of the blood supply and of the water content. 
We find similar skin currents in all Ifammalia including man. If the two hands or the two feet of a man be leel off symmetrically to the galvanometer and one arm or one fort be moved inluntarily the needle makes an exeursion, which is not caused by the museular contraction in itself but by the process of secretion going on at the same time in the sweat glands of the contraeted extremity. This current passes from the outsice to the inside of the skin. A very similar skin current has been observed in the sweating of different mammals.

Biedermann observes that one eannot draw a sharp line of separation between current of rest and eurrent of action in epithelial and glandular cells, for the reason that the differences of tension met with are always the expression of differences in the chemieal relations of the neighboring parts. From this point of view it appears quite arbitrary, on incorrect indeed, to speak of the current of rest in eontradistinction to the current of action of a glandular structure, since in both calses one deals with the effeets of eertain metabolic processes going on in definite parts of the ecll body, which by direet or indirect stimulation are only changed in one direction or another. It is better, therefore, to say that the ordinary skin current is produced by the negativity of that portion of the ceell which is being transformed into mueus, towarl the protoplasmie portion (Hermamn).

As above remarked, this inwardly direeted eurrent may, under certain eircumstances, undergo a complete reversal. To explain this we can make only one assumption, namely, that the same epithelial eell has the power to aet electrieally sometimes in one sense, sometimes in the other. This is borne ont by the fact that each cell is the seat of two different chemical procestres (assimilation and dissimilation), which, going (nn at the same time, give rise to opposite tensions. The deriation oceasionally observed would, arecording to this, always be the resultant of the two antagonistic fores (IIering. Biedermanu).

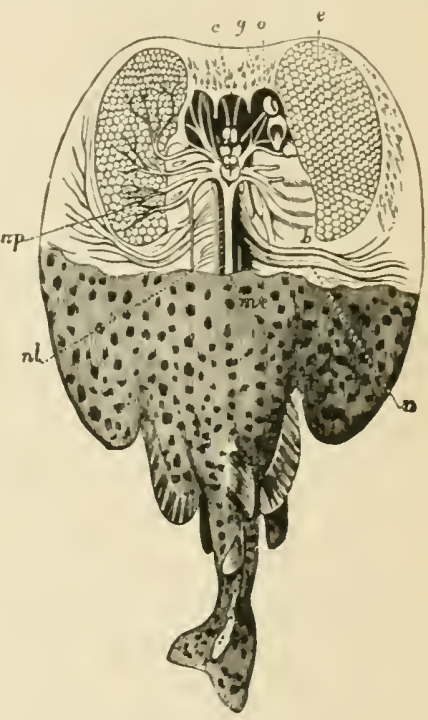

Fig. 30.- The cramp fish, Torpedo, dissecterl to show electrie apparatus, after Huxley; $b$, gills; c, brain; e, electric orgau; $y$, eranimu; me, spinal cord; $n p$, branehes of pneumogastric nerves to electric organs; $0, \mathrm{eyc}$.

It is possible that a relationship similar to this exists between the chemical processes underlying the secretion of water on the one hand and the seeretion of organieally specifie eonstituents on the other (Biodermann). Perhaps from this point of view are to be explained eertain result- obtained with the digestive glands, of whieh more in Chapter V'II.

Electrical currents have been demonstrated even in plants. where, just as in the animal tissues, an injured place is found to be electro-nesative to an uninjured place. Electrical effects appear also under appropriate circumstances in certain parts of plant- which are cutirely uninjured. 'Thus, differenees of tension are obtainerl between cells or cell territories of an organ or of a whole plant which maintain different chemical relations to ach other.

For example, aceording to Waller, the processes taking place in the forma- 
tion of stareh are bound up with eleetromotive phenomena. If a shaded and an exposed part of a green leat (Fig. 1i) be connected with a galvanometer. when the light falls on the exposed part, an electrie current is olserved which rums in the leaf itself from the insolated to the shated part. The deflection begins after some three to ten seconds and lasts as long as the illumination continues. if that time does not amonnt to more than about five minutes. The effeet is least in difluse daylight, greatest in direet sunlight and is abolished by boiling the leaves. All sueh effeets are alsent in flower parts deroin of chlorophyll.

Whether these electrieal variations have any general significance for the cells exhibiting them, or for the incliviluals containing the cells we eammot say definitely. But the matter is clearer in the ease of the well-known electric fishes. of which there are many different speeies. In most of these fishes the electrical organs are metamorphosed muscles, lut in Malapterurus it represents a transformation of the glands of the shin. In rest the organ shows no eurrent: but under the influence of the specific nerves. as well as by direct stimulation it develops very strong electric currents, the foree of which in the cramp fish (Fig. 30) amonnts to thirty-one volts. That such currents must be of great service for these animals in their struggle for existence is at once perfectly obrious.

\section{\& 3. THE EFFECT OF EXTERNAL INFLUENCES ON CELLS}

\section{A. ON STIMULI IN GENERAL}

The fundamental property to which we trace the total activity of the living substance is its irritabitity-i.e., its ability nnder the influence of all kinds of agents to change its metalolism, and therefore to ehange its transformation of energy, in one direction or another. All those agents which have the power to eroke a elange of this kint are ealled stimuti. Among them are to be included different chemical reagents, meehanical agents of all kinds, heat. light and electrieity.

The change in metabolism prodneed by a stimulus is either dissimilative or assimilative (ef. supra page ?2). In the former there is a produetion of linetic energy and the process taking place in the cell is deseribed as an excitation. In the latter we have a storing of potential enerory, and the change is often deseribed as a trophic effeet. The stimulus may however check netabolism for a longer or shorter time. may bring it to a standstill momentarily. or stop it altogether. Te speak then of a paralysis of the cell. l'aralysis represents a negative condition with respeet either to the assimilative or the disimilative responses.

By stimulation of certain nerves the dissimilative action of the innervated organ may be abolished. Of sueh phenomena, described as inhibition, the influence of the ragus on the heart has been most closely studied. When the vagus is stimulaterl artificially the heart beats more slowly, and with a stimulus strong enough it stops in diastole (the brothers Weber, 1846). This inhibition is not a kind of paralysis. for phenomena to be described later (Chapter VI) show that while the heart in ragus standstill is inexeitable, it is not paralyzed. 
The assimilative and disimilative processes often gn on sile by side in the same cell. Since the latter are hest known it will he well to diseuss them first. We shall make five general olservations, which apply to all disimilative processes.

1. The production of energy is many times as great as the energy of the stimulus employed, which will appear for example in the following experiment: A frog's gastrocnemius is fastened in a clamp by the femur and a weight of $48.5 \mathrm{gm}$. is suspended from its lower end. The nerve attached to the muscle is laid upon a solid block. If now a weight of 0.48 .5 gm. be allower to fall upon the nerve from a height of $10.1 \mathrm{~mm}$. the muscle contracts and lifts the weight $3.8 \mathrm{~mm}$. high. The work done by the muscle is $48.5 \times 3.8$ $=184.3 \mathrm{gm} . \mathrm{mm}$. : while the active force of the stimulus is equiralent to ouly $0.485 \times 10.1=4.9 \mathrm{gm}$. mm. of work. The mechanical work of the musele called forth is therefore about thirty-eight times the active force of the stimulus. taking no aceount of the heat deseloped hy the muscle at the same time.

All other cells combluct themselves just like the muscle colls in this experiment. when they develop energy through dissimilative procestes. We meet with numerous analogies also in inanimate nature. For example, a weight of $10 \mathrm{kgr}$. suspended hy a (ond 10 $\mathrm{m}$. above the floor. represents a potential energy of $100 \mathrm{~kg} . \mathrm{m}$. In order to change this potential energy to kinetic we have only to eut the cord. Which of course does not call for an eflort of $100 \mathrm{~kg} . \mathrm{m}$. 'The same is true when powder is exploded by a match, ete.

In all such cases we speak of energy having heen liberutel, a term which conveys to our minds the idea of an impetus by which a transformation from potential to kinetic energy is producel. where in the nature of the case the size of the impetus need be only rery insignificant.

2. Generally speaking. in order to eall forth a remonstrable effect in living substance. the stimulus is effective only from a certain minimum onward. If the stimulus is inereased abore this by uniform increments. the response usually increases. but the incrase becomes less the stronger the total stimulus. until finally the maximmm response is reached, beyond which it cannot rise however much the stimulus is strengthened.

3. Another property characteristic of the beharior of living protoplasm. which is developed to different degrees in different cells. is its power to summate the cffects of stimuli. If a loaded musele be affected by a maximal stimulus, it contracts to a certain extent; lut if it be affected by another stimulus before this contraction ceases. it contracts still further. With a sufficiently rapid succession of stimuli contractions may be olstained which are very much stronger than that obtained by a single stimulus with the same load.

1. All excitation processes are acempanied by the development of heat and electricity. The other forms in which the dissinilative processes manifest themselves differ with different kinds of cells: toward every etfective stimulus, a cell always rearts in " way which is rhameteristic for its hind. 'Thus whaterer the stimulus employed, a muscle cell always responds with a contraction: a salivary gland cell. when stimulated. always secretes saliva, etc. In the following discussion of the different stimuli it rill not be necessary to enter specifically into the rarious forms of activity of the different cells. 
5. Those ngents which reoke a response as a rule also alter the excitabitity of the living sulstance-i.e., under their influence a given simulus produes as strongere or weaker response than if it were acting alone. We must therefore make a distinction between excitulion and the allerations of cxcitability (positive or negative). In excitation may be said to have taken place if a given stimulus can be shown to have started a discimilative process. If, lowerer. the stimulus proluces no cffect of this kind. but a second stimulus under the intluence of the first produces a response stronger or weaker than it otherwise would, then the first stimulus has inereased or diminisher the excitalility of the rells stimulated. If the stimulus beenmes too strong. the functional powers of the living substance may be either reduced or destroyed.

\section{B. AUTOMATIC EXCITATION}

When protoplasm is protected from all posilsle external influenees, it still exhibits the functions which we have learned to regard as essential: absorption of food, motility. digestion, heat formation, etc. There must be therefore inside the cell something which calls forth its activities. and from all that is known to ms on this subject. we may assume with a high degree of probability. that the excitation is caused by the products of metabolism formed in the activity of the coll.

The significance of stimuli arising in the body itself appears from discoveries which have been made enncerning the actirity of the central nervous system in the higher animals. If for example a rabbit be rhoked by rompression of the trachea, within a short time there appear powerful respiratory movements, convulsions of the whole body musculature, contractions of the rascular walls, etc. In this case the decomposition products normally eliminated in the expired air are retained in the body and bring about the powerful stimulation of the central nerrous system in the manner observed (cf. Chapter XXII). Similar phenomena appear when by extirpation of the kidneys the fluid decomposition products otherwise removed from the body by them, are allowed to collect in the body in large quantity.

The direct excitation produced by metabolic products is called antomatic excitation, becausc the exeiting substances are formed by the activity of the protoplasm itsclf. That is to say, in this case the colls develop within themselves the stimuli which rouse them to continued activity.

\section{CHEMICAL STIMULATION}

Automatic excitation, as it is here definer, is a kind of chemical stimulation. and fundamentally is. so far as we can judge. of exactly the same nature as the excitation which we can produce artificially by rarious kinds of chemical sulustances.

Unicellular organisms. Amnelse and other Rhizopoda, are made to contract by contact with a one- to two-per-cent sodium chloride solution, 0.1-percent hrilrochloric acid. one-per-cent potassium hyrdrate or weak solution- of other acids, alkalies and salts: they draw in their pseudoporlia and assume a spherical form. The same substances quicken the morements of the flagel- 
lated and ciliated cells sometimes in a rery high degree. Terves and muscles of the Iletazoa as well as the contractile fibers of the single-celled organisms behave in a similar manner. As regards muscle Hering has shown that various substances which for a long time were supposed to stimnlate chemically, in fact stimulate by closing the demarcation current of the muscle. Here belong the so-called physiological salt solution ( 0.6 per cent), solutions of fixed alkalies up to 1.1 per cent, and different salt solutions. Solutions also, which stimulate chemically, may cause muscular contractions in this way. if they are good conductors. I purely chemical stimulation of the muscle takes place therefore only by means of fluids which do not ennduct electricity or do so rery poorly, or by means of substances applied only to the uninjured longitudinal surface of the muscle.

As Biedermann has shown, the cross-striated muscles of the frog fall into rhythmical contractions, if they are placed in weak solutions of $\mathrm{Na}_{2} \mathrm{HPO}_{3}$, $\mathrm{Na}_{2} \mathrm{CO}_{3} \cdot \mathrm{Na}_{2} \mathrm{SO}_{4}, \mathrm{NaOH}$. Loeb has studied these contractions further in the light of the dissociation theory, and has come to the conclusion that they are produerd only by eertain ions (e.g., Na, Cl. Li, F, T3r, I), but are impeded or rendererl impossible by others (e.g.. Ca, K, M[g, Be. Sr, Co, Mn) - the excitability of the muscle not being changed in either case. Hydroxyl and hydrogen ions hasten the appearance of the contractions without being able directly to call them forth. Solutions which do not contain electrolytes produce no such contractions.

The theoretical significance of these and related facts cannot be discussed here because we cannot yet adequately survey the field recently opened up by these investigations. We may, however, expect from this quarter very valuable results on the chemical relations of the living being in the near future.

Chemical stimuli which have a higher osmotic tension than that of the structures to be stimulated. may exercise an exciting influence or may alter the expitability by the extraction of water, as probably oceurs in many cases with the nerves.

That this is not the only determining factor however, and that the peculiar properties of the chemical substance exercise an essential intluence, appears from the fact that equimolecular solutions in general stimulate more powerfully the higher the molecular weight (Grïtzner). Thus sudium iodide for example stimulates more powerfuly than the bromide and chloride, whereas the osmotic tensions of all these is equal.

Besides these direct responses to stimuli and the alterations of excitability. which we must pass over, eretain substances exercise a very remarkalble influence ${ }^{1}$ on the movements of free-living cells by allweting or repelling them. These phenomena are designated by the term chemotrotix and are described in the one rase as positive, in the other as negative. Different substances exer(cise diflerent inflnences on rarious cells, and the same substance in different encentrations may produce different effects on the same organism.

Some examples of chemotaxis may be eited here. Certain forms of Bacteria are attracted by oxygen, and in a microscopical preparation which contains these Bacteria together with some alga cells one may observe how they gather

${ }^{1}$ First demonstrated by Engelmamn on the Bacteria. 
alrouml the alga drawn by the oxygen which is set free by the chlorophyll (Fig. 31. Engelmanul.

If a capillary tube, fused at one end, be filled with a 0.05-per-cent solution of malic aceid and the open end of it be placed in a drop of water containing the spermatuzoids of a ferm, so that the acid can diffuse gradually into the water,

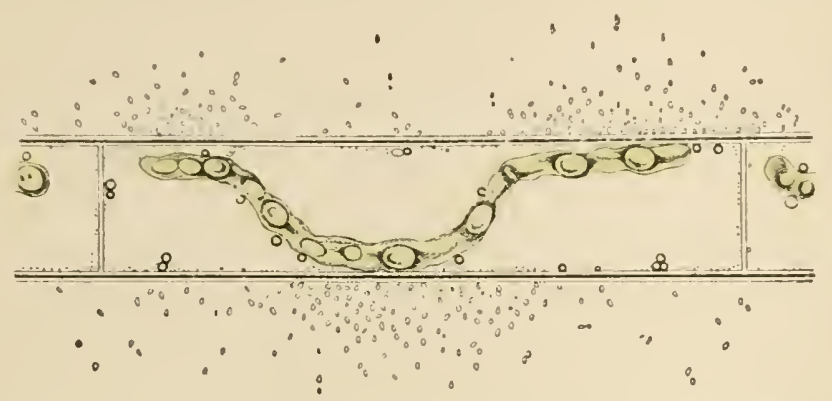

Fig. 31.-Illustrating ehemotaxis. The chlorophyll bodies in the eells of Mcsocarpus scalaris under the influence of light liberate oxygen: the bacteria are most abundant where the elilorophyll budies lie nearest the surface-i. e., where the liberation of oxygen is most active, after Engelmann.

the spermatozoids hegin at once to move toward the opening of the tube and to wander into it. The same phenomenon may be observed indeed with a much weaker solution (0.001 per cent, Pfeffer).

It has been observed that the uterus and Fallopian tubes of rabbits and rats exercise a positive chemotactic influence on the spermatozoa of the corresponding species, but that the ovary itself is entirely indifferent in this respect. Chemotaxis is of the utmost importance in the following connection also. We have seen how the leucocytes have the power to seize and consume Bacteria which find their way into the bolly. They are attracted to the Bacteria by substances given off by those organisms. If a capillary tube, containing a steritized culture of, say Staphylocorcus myogenes albus, be introduced under the skin of a rabbit, after a few hours it is filled with leucocrtes. The same culture fluid by itself exercises no such influence on the leucocytes.

Likewise when the leucocytes assemble in a certain place for the purpose of carrying away the products of normal or pathological tissue destructirn, their migration is eaused by chemotaxis (cf. page 37 ). In short, as far as our present infurmation goes, we may say that the migrations of the leucocytes are controlled, quite independently of the nervous system, essentially by chemotaxis.

From these examples it ought to he apparent that chemotaxis plays a very great rôle in the processes of the living world. since by it the migrations of fres-living cells are often controlled according to their momentary neesls. It is therefore unnecessary to invole any psychical properties in explanation of suclı phenomena.

In the higher animals the sense of smell has been dereloped as a special chemical sense. It is true that many of the movements taking place under its influence are to be regrarded as conscious: but in many other cases they run the course of pure reflexes, and if we may extend the notion of chemotaxis to all morements which either dircetly or indirectly are inangurated and controlled by chemical stimuli without the partieipation of consciousnes.; 
these may be regarded as to a certain extent chemotactic. Thus according to the thorough analysis of Bethe, a whole order of complicated halsits of the ants might be explained as chemotactic reactions, and in the bees several habits are undoubtedly of this origin.

Jennings has shown that there is nothing specifically directive about the chemotactic effects of chemical substances on Infusoria and Bacteria. If, for example, Bacillum volutans be placed in a preparation with a green alga, they are uniformly distributed at first throughout the preparation. When the alga begins to give off oxygen and the bacilli come by chance into this zone rich in $\mathrm{O}_{2}$, they swim through it to the opposite side, turn and swim again to the border. and so on incessantly, but they do not adhere to any definite orientation with respect to the middle point of the oxygen zone.

[The behavior of an Infusorian under chemical stimulation may be illustrated, according to Jennings, as follows: the usual motor response of a Paramocium to any kind of an obstruction is to reverse its cilia and swim backward, then turn toward the side containing the peristome and swim forward again (Fig. 32). When in its wanderings the Paramocium enters a drop of dilute acid, the chemical change of the medium does not eause the reaction, but whenever the organism attempts to leave the drop the chemical change experienced constitutes a stimulus which evokes the usual motor response, and the organism remains entrapped. Coming in contact with an alkali produces the same response and the organism turns so as to avoid the substance. The result is that the organisms collect in dilute acids, including earbon dioxide (positive chemotaxis), and refuse to do so in alkalies (negative chemotaxis). But the acid ean scarcely be
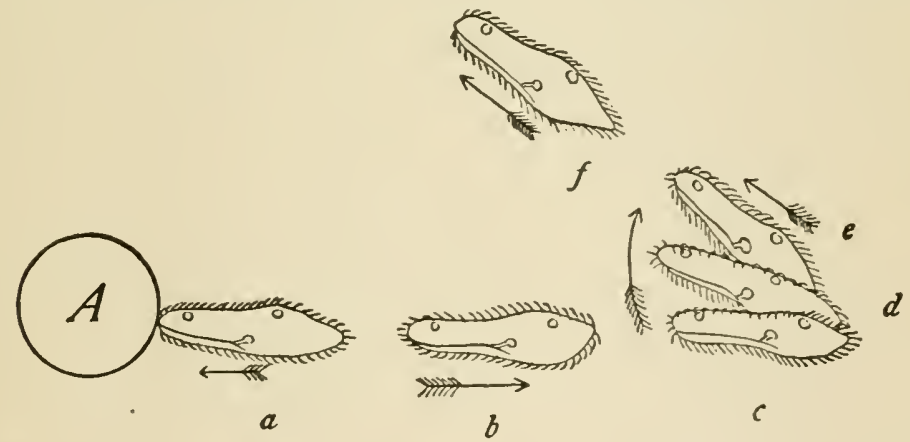

FIG. 32.-Motor response in Paramacium, after Jennings. $a-f$, successive positions after meeting an obstruction, $A$.

said to attract the organisms in any proper sense of the term, nor the alkali to repel them. They remain in the acids loubtlesis becane these substances are favorable ${ }^{1}$ to their life processes and aroid the alkalies because the latter are liarmful.-ED.]

${ }^{1}$ Jennings recognizes this seleetion by random movennents of conditions not interfering with the physiologieal processes as a fixed principle of behavior, not only in the Bacteria and Infusoria but in higher animals as well.-ED. 


\section{MECHANICAL STIMULATION}

In a great many ditlerent kinds of cells the production of energy may be aroused by shocks of a purely mechanical nature. Igencics of this kind may exereise also an important influence mpon the locomotion of many oryanisms.

In so far as they are due to gravitation these ageneies are designated as geotactic.

The collection of Infusoria at the central end of a centrifuge (Jensen); the movement of Paramacium downward in its medinm in condition of hunger and of low temperature, but upward under opposite circumstances; the rertical climbing of Cucumnria, Actinia. Asterina. Peripleneta, ete.; the orientation of fishes: and the behavior of a decerebrated frog are instances of greotaxis. Changes of position, changes of attitude, ete., taking place among the Metazoa are to be regarded as reflexes of a complex order, analogous to those initiated by chemical stimulation (ef. page 54). It is probable that they are brought abont according to the attitude of the animal by the stimulation of the end organs of different nerves (of the skin, joints, etc.) through the pressure of the body or through the pull which is exerted by msupported parts. Finally, we shonld mention the otolith apparatus as a seat of peripheral stimulation (c.f. Chapter XVIII).

A second form of morement produced by mechanical influence is rheotaxis -i. e.. changes of position indneed by Howing water or currents of air.

In mieroscopical preparations it may be shown that spermatozoa move against the enrrent (Roth), and it has long been known that once these elementary organisms enter the oviduct they strive to reach the rery end of the tube, forcing their way against the current produced by the ciliated epithelimm. Wherler has directed attention to the fact that air in motion influences the morements of insects in a similar way.

Another group of phenomena conditioned by mechanical stimulation is the following. Frog's spermatuzoa when mounted on a slide bore into all the little scratehes and crevices of the glass surface. These cells have therefore a decided inclination to be in contact with solid bodies (thigmotaxis). In line with this Junings has found that Paramocium aurelia will attach itself to solid particles in the preparation, and Pütter has demonstrated that thigmotaxis represents probably a quite general phenomenon widely distributed among all classes of the Protista.

Thigmotaxis is exhibited also by many higher animals. There are animals such as the ants, which always seek out the eoncave corners and edges of carities, while other animals as constantly establish themselves on the convex edges and (०)rnw's of bodies.

\section{E. STIMULATION BY MEANS OF LIGHT}

Light, if we include only the so-called illuminating rays, stimulates directly only a few kinds of cells. In higher animals it acts only upon the visual cells. of the retina. on the musculature of the iris, and, if it be concentrated enough, upon the ent organs of the heat nerves. Likewise the skin (of eertain invertebrates at least) is sensitive to liglit rays. In some unicellular oryanisms morements have been observed which are undoubtedly induced by 
light. The red rays are said to exercise the most powerful influence on Amoba (Harrington and Leaming). In frog and triton embryos both in the egg and in the young larval stage. hight calls forth pronomnced morements and in this case the blue and riolet rass are mo-t powerful (Finsen). The Rhizopod Pelomyxa contracts on sudden illumination. A species of Bacterium (photometricum) is stimulated to active morements by light. while in the dark it lies perfeetly still. In the microspectrum (Fig. 33) the majority of these Bacteria wander into the ultra red. while another collection is formed in the orange and pellow (Engelmann).

The effects on the direction of morements produced loy the light are designated by the term photstaxis.

Free-living unicellular organisms, inclosed in a drop of water, collect on the side of the drop turned toward the light (positive phototaxis), if the illumination is moderate. They Hee from this side and collect on the opposite edge (negative phototaxis) if the illumination is strong. Thus we have in different

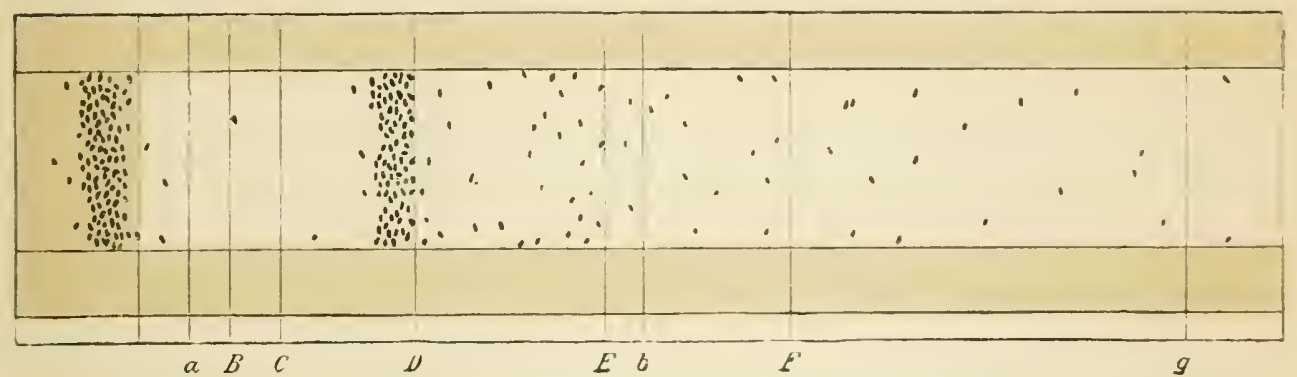

FIG. 33.-The distribution of Bacteria (Bacterium photometricum) in the microspectrum of direct sunlight, after Engehmam.

degrees of illumination the same difference with which we lave become acquainted under chemotaxis. In general the shortwared ras of the spectrum. the blue and violet, are the most important in thi-directive influence.

Loeb, Finsen. Adams, Ierkes, and others have deccribed similar phenomena among the Metazoa. Earthworns exposed to a light varving in strength from 192 to 0.012 candle pow exhibit negation phototaxis. which dimini.shes with the intensity of the light: in $0 .(111$ eandle power they exhibit posiire phototaxis. In diffuse daylight the frog is po-itively phototactic: in direct sunlight it shows at first positive. then nerative plontotaxis.

The morements of the pigment cells of the retina by which their processes become longer and the inner end of the cones shorter may he cited als an ummistakable example of phototaxi- (ef. Chapter XXI). Even the unconscious retlex movements of the eves, of the hearl and of the bouly as a whole. which are produced by stimulation of the risual cells of the retina by licht may be regarded as in a certain measure a kind of phototaxi- (c.t. page $5 \cdot t$ ).

The ultra-violet rays exereise a very marked influenee on cells. On the anterior portion of the eve they produce an axcitation which is characterized by 
catarrhal symptoms of the conjunetiva palpebralis, inflammation and swelling of the conjunctiva oculi, desquamation of the epithelium and clouding of the cornea, as well as contraction of the pupil and discoloration of the iris. Similar effects appear on the skin: it becomes red and swollen; burning sensations and sensitiveness to touch distinguish the affected portions: after, some days the epidermis begins to peel off in the form of large scales, and in abnut fourteen days the skin becomes normal again. There usually remains for a long time, however, a light coloration of the affected part, which is sharply marked off from the surrommling skin (Widmark). With sulficient concentration of the light, the blue-violet rays also are said to exereise a similar influence (Finsen).

The $I$ rays discovered by Röntgen produce in the skin similar but even more powerful effects than those discussed above. Possibly the ultra-violet rays contained in the cathode rays contribute in some degree to this effect. Certain Bacteria (the cholera, anthrax. diphtheria, and tubercle bacilli) are killed by the $\mathrm{X}$ rays, and cells of higher plants suffer a reduction of their activities. Different Protozoa exhibit a very different power of resistance toward the $X$ rays (of fourteen hours' duration): some forms appear not to be affected by them at all, others slightly, some very powerfully. In general it appears that forms which have vacuolated protoplasma react more quickly than those of firmer structure. The presence or absence of membranes and shells may also be significant (Schandinn).

With respect to the Becquerel rays (radinm) Aschkinass and Caspari have found that they weaken markedly the Bacillus prodigiosus in from two to four hours. With a longer exposure to radium (twenty-four and sisteen hours respectively) typhoid and cholera bacilli were killed (Pfeiffer and Friedberger). Schwarz has shown further from researches on the lien's egg that these rays destroy albuminoid bodies by a kind of dry distillation, that they decolorize lutein and act upon the lecithin of the cell substance. In these effects he finds the explanation of the peculiar cell necrobiosis observed by Becquerel himself. Becqnerel once carried in his vest pocket for only two hours a well-wrapped lout highly active radium preparation. Fourteen days later he observed on the abdominal skin opposite the pocket a small burn which became larger and larger and finally developed into a deep wound which did not heal for months.

\section{F. STIMULATION BY MEANS OF HEAT}

Only in relatively few cases does heat appear to exercise a direct stimulating effect on living cells. In the higher animals only the end organs of certain afferent nerve fibers are really roused to activity by heat. Heat, as already remarked above, exercises a more powerful influence on the excitability of the cells. In all cells we find that the life processes increase in intensity with the temperature up to certain limits (ef. supro page 29), and likewise that with a lowering of the temperature they are depressed at least, if not brought to a complete standstill. It is not easy in any given case to separate clearly the actually stimulating effect from the heightening influence 
on the excitability, and the phenomena just mentioned are regarded by some as the expression of actual stimulation.

As an example of the directive ${ }^{1}$ influence of heat on the movements of cells (thermotaxis) the beharior of the ciliate Infusorian, Paramocium. may be mentioned. If the ressel in which they are contained is warmed on one side to about $24^{\circ}-28^{\circ} \mathrm{C}$. the animalcules withdraw to the other side. while with a temperature below this limit they wander to the warmer side-opposite movements therefore according as the same stimulas is strong or weak.

\section{G. ELECTRICAL STIMULATION}

Because they are the most easily manipulated and most easily graduated, electrical stimuli have been studied with rery great exactness. Since their effects are investigated chiefly on nerres and muscles of the rertebrates. we shall deal with them at some length in presenting the phrsiology of nerves and muscles. Suffice it for the present to state that it has been found in nerres and muscles that the electrical current stimulates only at one pole or the other, at the negative pole on closing the current, and at the positive on breaking it (Pflïger). Between the two poles it acts to change the excitability, but not to stimnlate.

In Paramocium, excitation is said to take place with the closing of the current at the anode (Verworn). And there are other exceptions to the law as it applies to nerve and muscle. Carlgren has shown with regard to Paramoecium, that lifeless individuals, immediately after the closing of a sufficiently strong constant current, show at the anode a shrinking up and at the cathode bending movements, both of which are the consequence of the so-called cataphoric effect of the constant current [i.e.. the tendency which this current has to sweep substances in solution along with it-ED.]: and it is not at all improbable that similar phenomena in the living Paramocium are of the same origin.

The following phenomenon might be presented as a secondary effect of the electric current. If a salamander (Amblystoma) be traversed longitudinally by an electric current, the skin glands of the animal begin to produce a copious secretion, which appears only on the side of the anode. The same occurs also with isolated pieces of the animal in which the spinal cord has been destroyed. But this secretion, as Loeb has shown, is not excited by the current itself, but by the electro-positive ions liberated by the eurrent. For if the animal is immersed in a $\mathrm{NaCl}$ solution. the electro-positise ions in their migration toward the cathode are set free on the skin of the animal and are combined with the hydroxyl of water into $\mathrm{NaOH}$. As direct experiments have proved, this alkali exercises a powerful stimulating effeet on the skin glands;

${ }^{1}$ Jennings is of the opinion that these so-called "directive influences" of light and of heat are merely other instances of the selection by random movements of conditions farorable to the life processes. Taking Paramucium as an example we find that when it wanders into a degree of illumination or of temperature which is unfarorable, the organism is stimulated by the change and reacts by making the usual motor response for avoiding an obstacle. The total effect of many such responses is to carry the organism out of the field of unfavorable influences or to keep it in the field of favorable ores.-ED. 
the phenomenon is therefore, only a secondary effect of the current. It shonld be remarked furtlser that neither weak aeids nor electro-negative ions exereise such an influence.

Electrical stimuli like other stimuli exercise a directing influence on Locomotor movements. If a constant current be passed through a vessel in which are frog tadpoles or fish embryos, the animals orient themselves with their long axes in the direction of the eurrent, and with the head direeted toward the cathode. They remain in this position as long as the eurrent is closed; when the eurrent is reversed the animals turn as if by command (Hermann).

Hermann explained this form of galvanotaxis by supposing the central nervous system to be excited by the ascending eurrent, but to be unaffected or even paralyzed by the descending current, so that the larvæ and embryos either instinctively or reflexly take the position in which they are stimulated least. Loeb on the contrary has made it quite probable by experiments on shrimps and

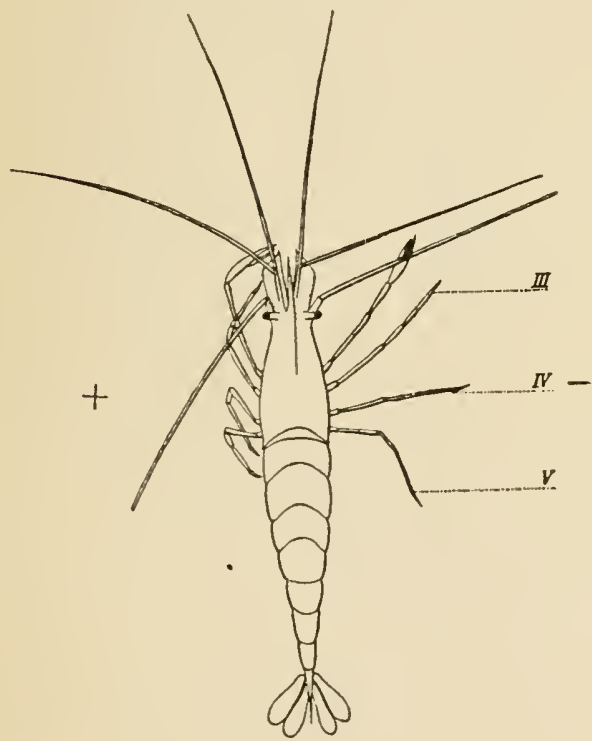

Fig. 34.-Showing the effects of a constant current on the shrimp Polarmonetes, when the current passes transversely through the animal's body, after Loeb and Maxwell. The legs on the side of the anorle are strongly flexed, those on the sicle of the cathode are strongly extended.

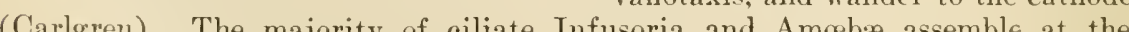
Centhe if an The

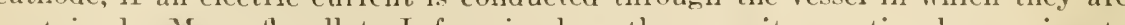
contained. Many Hagellate Infusoria show the opposite reaction by moving to the anode. Finally, it has been observed that the ciliate Infusorian Spirostomum places itself with its long axis at right angles to the current (Verworn). All these differences find an explanation according to Wallengren in the general fact produces parallel changes of tension and energy production in associated groups of muscles, the result of which is that the movement toward one pole is facilitated, but movement toward the opposite pole is impeded. Thus with the shrimps the tension of the flexors predominates on the side of the anode, while the tension of the extensors predominates on the side of the cathode. With a current of medium strength the animals always move toward the anode; if when the current is turned on the head end is already near the anode, the change in position is effected by a forward movement; if the tail end lies nearer the anode, it is effected by a backward movement.

The following examples of galranotaxis may be mentioned. Certain echinoderms in their youngest and oldest stages (free-swimming gastrulæ and the creeping mature animals) exhibit no galvanotaxis, while in the intermediate stages (free-swimming plutei and bipennaria) they exhibit very marked galvanotaxis, and wander to the cathode
usoria and Amoere assemble at the

Amblystoma larve that the current 
that in all ciliate Infusoria the cilia on the side of the cathode beat toward the anterior end, those on the side of the anode, toward the posterior. For example, as long as its anterior end is directed toward the cathode, Opalina ranarum (Fig. 35) always turns toward the right as indicated by the arrow.

Organisms are killed by strong electric currents. Concerning the changes effected by such eurrents on the higher animals, Prevost and Battelli especially have made extensive investigations, of which the following, relating to the dog only, will be mentioned here. With an induction current of lower tension (up to 120 volts) death results from fibrillary contractions of the heart produced by the eurrent, in consequence of which the circulation is ultimately stopped (ef. Cliapter VI). The disturbances in the nerrous system coming on at the same time, indicated by convulsions and the like, have relatively little importance. Respiration is resumed after a temporary pause, and may even continue for two or three minutes after the inception of fibrillary contractions of the heart.

With induction currents of higher tension (more than 1,200 volts) death oceurs as a result of paralysis of respiration, while the ventricles beat rapidly and powerfully and the auricles stop in diastole. Indeed by means of currents of high tension one may even restore a heart seized with fibrillary contractions to its former functional power, when it eannot be restored to its nornal action in any other way.

Strong induction shocks (Rhumkorff, $45 \mathrm{~cm}$.

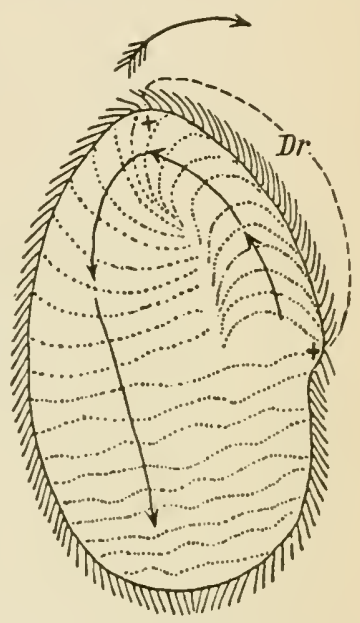

Fig. 35.-Opalina ranarum, a ciliated organism from the intestine of the frog, seen from above, after Wallengren. $D r$, the cilia used by the organism in changing direction to the right. spark, twenty interruptions per second, primary eurrent twenty-five volts) can be conducted from mouth to rectum for one and one-half minutes without danger to the animal. In two and one-half minutes he dies in convulsions produced by failure of respiration; if artificial respiration is maintained the animal can survive such currents acting for ten minutes.

The effect of the electric current is dependent not only upon its tension, but also upon its duration and the place of its application, as well as upon contact between the electrodes and the body. The different animal species also exhibit differences in sensitivity: the dog appears to be the most sensitire, the horse less so, still less the guinea pig, rabbit and mousc.

\section{H. COSMIC INFLUENCES}

It has long been firmly established by general experience that cosmic forces excrcise a marked influence upon organisms; and to convince ourselres of such influence we have only to be reminded of the pains affecting gouty and 
rheunatic individuals with different conditions of weather. We know very little at this time about the real nature of these agents. Recently Arrhenius has sought to bring various physiological processes, notably menstruation, into relation with electrical variations of the atmosphere and the chemical changes thereby effected. But the results thus far obtained on this subject appear to be too limited to justify a fuller presentation in this book.

\section{CONDUCTIVITY}

Besides these artificial stimuli which are able to excite the cells or to increase their excitability, there occurs in the Metazoa a form of stimulus which belongs to the body itself, namely, the stimulation of one cell by another. It is in this connection that the nerves

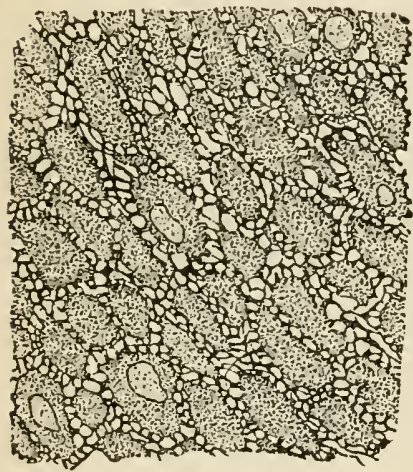

Fig. 36.-Cross section of the intestinal musculature of the cat, after Boheman. The dotted areas represent cross sections of muscle-cells, the black lines between them represent intercellular bridges. are of the very greatest importance; they transfer their excitations to the end organs, the muscle cells, gland cells, etc.; or they are themselves stimulated by other cells, as when the sensory nerve fibers are roused to activity by their peripheral end organs, or when a nerve cell by means of its processes arouses another cell to a state of activity. Here belongs also the case of the stimulation of a smooth muscle cell by its neighbor, which in all probability is accomplished by means of the protoplasmic comnections (intercellular bridges) which have been demonstrated between these as well as between other kinds of cells (cf. Fig. 36). This form of stimulation represents one of the most important mechanisms by which the different parts of the Mletazoan body are made to coöperate harmoniously.

The stimulus is transmitted from one part to the other also in a single cell. The elearest example of this we have again in the nerves, which are nothing else than long processes of nerve cells, and they propagate a stimulus directly transmitted to them by passing it along from one section to the next throughout its entire length. We meet with the same mode of transmission wherever a cell is stimulated at one definite point and the excitation extends throughout the entire cell body.

\section{J. THE ASSIMILATIVE PROCESSES INDUCED BY STIMULATION}

Our knowledge of the assimilative processes induced by different stimuli is still very imperfect.

With respect to the question of most interest to us, namely, the influence of stimuli upon the formation of living substance, we know that the Bacteria and Infusoria multiply rapidly as the result of inereasing the supply of nourishment, and that the sunlight gives the impetus for the formation of the 
green coloring matter of plants; for germinating seeds develop in the dark into a white or whitish seedling which becomes green only when it is exposed to the light. Sinee the ehlorophyll bodies are to be regarded as composed of living substance, we have in the latter instance a ease where an external stimulus actually effeets the formation of living substance. As regards the first example, one might say that the abundant supply of nourishment had given the impetus for a more active formation of living substance; but the matter is not entirely elear. for it might also be that the impulse to multiply in these organisms is just as great with scanty as with abundant nourishment, only with a deficiency of nutrient substances it eannot be manifested.

From observations on the storage of substance in the bodics of young animals it appears that the inherent growth energy is of mueh greater importance than any form of external stimulation. But in mature animals, if any inerease in the living substance takes place under normal cireumstances, we think of it at once as being eaused by some ageney outside the cells themselves; and lence its consideration properly belongs under the present topic. Now results of metabolism experiments show that ordinarily the cells (of the higher animals at least) destroy practically all of their daily supply of proteid nourishment, but that under eertain circumstances (not too great age, and great excess of potential energy in the food, cf. plage 1:0) they store some of the proteid. It appears in fact that in spite of their inner propensity to destroy proteid, an abundant supply of nourishment in some way makes it possible for the cells to change dead proteid into living protoplasm. If this is correct-and the question can scarcely be regarded as finally settled-this storage would be the consequence of a chemical stimulation brought about by the exeess of proteid.

Howerer this may be. the only really effective way known to us of increasing the living substance in the mature higher animals is work; and it is possible to conceive of this also as a special form of ehemical stimulation. A grown man may eat ever so much food, his diet may be adapted perfectly to the purpose. but no significant increase of muscle substance will take place if the muscle does not accomplish sufficient work; whereas a working muscle increases both in power and in rolume-i. e., the work has called forth an inerease of living substance. Since now every museular movement is originated by the motor nerves, and sinee experience shows that a nonworking muscle always decreases in rolume, and a muscle paralyzed by cutting its motor nerves undergoes atrophy and degeneration in a relatively short time, it follows that some kind of a nutrient or trophic influence on the muscle must be exercised by the central nervous system through the motor nerves. What the nature of this influence is, we cannot say definitely. Since, however, the stimuli originating in the body itself are in general of a chemical nature, we may perhap: conclude that the trophie influence mediated by the nerves is a chemical stimulus. Other facts which we shall diseuss somewhat in detail in what follows show that an influence of a similar nature is exerted on other organs by the nerves belonging to them. If the cerebral secretory nerve of the submaxillary gland be cut, the gland atrophies. This nerve is therefore of great importance for the maintenance of this part of the body, 
although it does not follow with certainty from the foregoing that it has contributed also to the formation of living sulstance. ${ }^{1}$

With regard to the original formation of cells and tissues. there are numerous data which go to show that the most willely different stimuli can effect an essential modification of the growth process.

Here belong the effects of gravitation (geotropism), and other mechanical

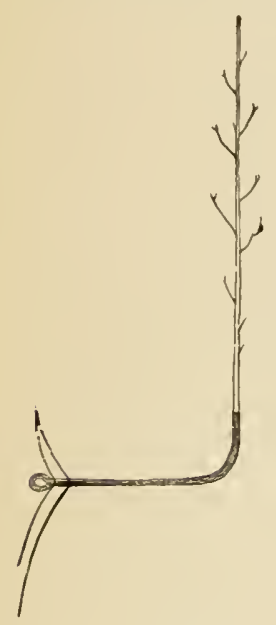

FIG. 37.-A shoot of Antennularia antennina, a small hydroid animal, exhibiting negative geotropism, after Loeb. agencies (rheotropism, thigmotropism), of light (heliotropism), and of galvanism (galvanotropism) upon the orientation of plants and of various sessile animals. 2

The following may be mentioned as examples. The stems of plants grow away from the center of the earth (negative geotropism), the roots toward the center of the earth (positive geotropism). If germinating seeds he placed on a wheel rotating rapidly in a vertical plane so that the influence of gravitation is overcome, the stem grows toward the middle point of the wheel, the roots turn away from it i. e., the stem grows in the direction of least pressure, the root in the direction of the greatest (Kriight).

The hydroid polyp (Antemmlaria antennina) consists of a central stem of $1-2 \mathrm{~mm}$. thickness, and often more than $20 \mathrm{~cm}$. in length, which generally grows perfectly straight up from a tangle of very thin filamentous rootlets. If now an Antemnularia whose stem is in process of growth be brought into a position deviating from the vertieal, the growing tip bends until it finds the vertical direction again, and then grows directly upward. The root on the other hand grows vertically downward but not in so straight a line as the stem (cf. Fig. 3i).

Rheotropism.-Seedlings of maize and other plants germinated in a tub of flowing water grow with roots parallel to the surface of the water and against the eurrent. The hydroid polyp, Eudendrium, also bends in its growth against the current (Loeb).

Thigmotropism.-Numerous plants twine around the vertical stems of other plants and so climb upward.

Heliotropism.--The growing parts of a plant always turn toward the light.

'Perhaps a clearer case of the influence of nervous tissue on the formation of living substance is that of the regeneration of a "head" in a simple worm. C. M. Child has shown that if the anterior end of the flatworm Leptoplana be cut off in such a way as to leave the collection of ganglion cells which serves the animal as a "brain," the animal will regenerate a new "head"; but if the cephalic ganglia be removed with the anterior end no "head" is regenerated, because in this instance the anterior end is no longer capable of functioning as a "head." In other words, the determining factor in the formation of the living substance here, as in the mammalian muscle, is the motor activity dependent upon the nervous system, or, as we have just learned, a special kind of chemical stimulus.-ED.

${ }^{2}$ With Herbst I employ the term geotaxis, galvanotaxis, etc., for the effects on the movements of free-living organisms brought about by external stimuli, and the terms geotropism, galvanotropism, etc., for the changes in growth brought about by external stimuli. The former phenomena are purely dissimilative, the latter are essentially assimilative. These phenomena could only be produced by the constant effect of these stimulating agents acting in a perfectly definite manner. 
Indeed, in many plants one may observe that on a sunny day the whole course of the sun is followed by appropriate movements of the plant. This effect is brought about chiefly by the more strongly refraetive rays of the speetrum.

Galcanotropism.-With long exposure to a constant current root tips turn toward the cathode.

Even in the highest animals we meet with extensive regenerative processes which, in part at least, are caused by a kind of chemical stimulation. Thus if a large part of the liver be cut away, a considerable regeneration of liver tissue follows (Ponfick, Podwyssozki). After extirpation of one kidney, the remaining kidney increases considerably in volume by new formation of kidney tissue. Numerous discoreries of the pathologists on abnormal growths belong here also.

Among the Mammalia, however, the powers of regeneration are relatively small in comparison with those of the lower vertebrates and expecially of certain invertebrates and of plants, for in the former the tendency to regencration is limited to certain tissues, while in the latter whole organs may be formed anew.

The tendency to the syntheses of nomliring substances in the organism appears to be favored to a certain extent by a rich supply of fond. In an atmosphere rich in $\mathrm{CO}_{2}$, under otherwise similar conditions, plants show a greater production of starch; and with an abundant supply of carbohydrates animal cells form fat which is stored up in the fat cells. Animal cells carry on also a multitude of other syntheses the stimulus to which might well be sought for in a chemical exeitation effected by the substances supplied them. Anything more exact than this is quite beyond our knowledge at this time.

\section{K. PARALYSIS AND FATIGUE}

We meet with a true case of paralysis when a dissimilative stimulus is carried beyond a certain strength. This is true of all kinds of stimuli and for all kinds of cells. in so far as they can be roused to a state of activity by the particular stimulus. If the strength of the stimulus be not too great. nor its duration too long, complete restoration may take place after its cessation. But if the stimulus be too strong or if it last too long. it has a fatal eflect on the protoplasm.

Certain chemical substances-e. g., the narcotics, to which helong alcohol, ether, chloroform. morphine. cocaine, paraldehyde etc.-are characterized by their paralyzing effects, oltained even with small doses. After a short period of excitation. the protoplasm exposed to these substances loses to a greater or less extent its vital activity. With small doses and short exposure the paralysis passes oll, but with large doses or long exposure the paralysis becomes more and more profound until death finally ensues.

Fatigue may be considered as a special kind of paralysis. In all living beings (though in different genera and individuals in different degree) there always occurs after a sufficiently intense disimilative activity a reduction of the functional power. as a consequence of which the same strength of stimulus produces a much weaker effect than before. If the stimulation be 
continned long enomgh. the excitability may be entirely destroyed. All these phenomena which are best known in man from his subjective experience of the results of severe museular work are included under the term fatigue.

Now it has been shown that fatigue, for the most part at least, is caused by the products formed in metubolism (.J. hinke). as may be seen from such facts as the following: if the blood of an exhansted dog be injected into a rein of a fresh dog, the latter immediately exhibits very evident sigus of fatigue.

If a fatigued organ be allowed to rest for a long time a remarkable thing oceurs: the organ completely recovers-i. e.. its former functional power has returned. This is not difficult to explain for the free-living unicellular organisms: for they give off the decomposition products to the surrounding medium in a very simple manner. And even in the higher animals the recovery after fatigue presents no great difficulties, for the waste produets are earried away from the organ by the cirenlation of the hlood and lymph. and at the same time the blood places new nutrient material at its disposal. The same phenomenon is observed however in the organs of cold-blooded animals which have been eut out of the body. A frog's musele which by repeated stimulation has been hrought to a condition where it eannot contract at all, reevers and beeomes functional again in spite of the fact that there is no cireulation to carry away waste produets. It follows therefore that recovery is not conditioned solely upon the remoral of waste products, but that other factors also must be taken into aceount, with which we are not yet thoroughly aequainted.

\section{\$ 4. DEATH}

We have seen that the most widely different external ageneies of sufficient intensity and sufficient duration have the power to check life and to bring on death. Changes also which are going on in the cells without any such external influences ean reduce their functional powers. In the eourse of life these alterations come on gradually, in some beings more rapidly than others, but always ineritably. They are known by the term senescence. If they progress far enough, death ensues as the resilt of old age. This form of death is, in man at least, only rarely to be considered; for the body is subjeeted to many external aceidents of all kinds, and only in the most exeeptional cases does it escape all of them. The senescent changes, however, play an important rôle even here, for by their influence the power of resistance of the organism to the aceidents which it must eneounter is more and more rerluced.

After death the body is destroyel as a rule within a short time, partly by autolysis of the organs (c. page is), partly by processes of deeomposition and putrefaction which are earried on by the lowest organisms. The carbon and hydrogen of the body pass off in the atmosphere as carbon dioxide and water vapor; and the nitrogen and sulphur, after a series of transformations taking place under the influence of Baeteria, are combined with metals in the form of nitrates and sulphates which are taken up by the water of the soil. These substances, earbon dioxide, water, nitrates and sulphates are the normal food of green plants, and by the synthetie proeesses going on within them are combined 
again into starch, fat and proteid. Thus they are in condition once more to serve as food for animals and thus the organic elements complete a cireulation between animals and plants, which is interrupted by the eireumstance that the synthesis going on in plants can take place only under the influence of sunlight. The entire living world represents, therefore, a colleetive whole in which every living being fulfills its speeial purpose as a link in the chain.

Referexces.-W. Biedermann, "Electrophssiologie," Jena, 1895.-G. N. Calkims, "Protozoa," New York, 1901.-II. J. Hamburger, "Osmotischer Druck und Ionenlehre in den merlizinischen Wissenschaften," I-II, Wiesbaden, 19021904.-L. Felix IIenneguy, "Leçons sur La Cellule," Paris, 1596._O. Hertwig, "Die Zelle und die Gewebe," I-II, Jena, 1592-98.-H. S. Jennings, "Behavior of Lower Organisms," Carnegie Institution Publications, No. 16, Washington, 1905. -J.Loeb, "Studies in General Physiology," I-II, Chicago, 1905.-C.Oppenheimer, "Die Fermente und ihre Wirkungen: translated by C. Ainsworth Mitchell," London and Philadelphia, 1901.- IT. Pfeffer, "Pflanzenphysiologie: translated by A. J. Ewart," Oxford, 1900.-E. Strasburger, F. Noll, H. S̈chenk, G. Karsten, "Lehrbuch der Botanik," 6th edition, Jena, 1904.- V. Veruorn, "Allgemeine Physiologie: translated by F. S. Lee." New York, 1S99.-E. B. Wilson, "The Cell in Development and Inheritance," 2d edition, New York, 1900. 


\section{CHAPTER III}

THE CHEMICAL CONSTITUENTS OF THE BODY

As already observed at page :0 we know nothing at all concerning the chemieal nature of the living protoplasm. And yet from the dear body we are able to isolate a number of substances derived from the living protoplasm. The most important of these are the simple and the compound proteids. Many substances oceur also as nonliving cell contents and as specialized produets or as assimilative products, part of which are closely related to the proteids, while part have an entirely different constitution. Here belong the gelatin-forming substances, fats. carbohydrates. the enzrmes, the products of internal secretions (cf. Chapter XI), ete. Finally there are found in the body itself as well as in its secretions and its excretions, numerons substanees which owe their origin to the dissimilative processes of the body. These latter substances, as well as the enzymes and the produets of the internal secretions, will be discussed later in connection with the physiological processes involved, but it will be appropriate to treat here the products of the assimilative actirity of the cells, and the final decomposition products of protoplasm so far as they are yet known to us.

\section{$\S 1$. THE NITROGENOUS SUBSTANCES}

\section{A. THE SIMPLE PROTEIDS}

In the purest state obtainable proteids are colloidal, slightly or not at all diffusible, lævo-rotatory bodies of high molecular weight, without emell, without taste, and as a rule amorphous. In the dry condition they are either white or yellowish powders, or are made up of solid rellowish disks transparent in thin layers. Crystallized proteid lras been obtained from plant seeds and from egg albumin (Hofmeister), from whey (Wiehmann), and from serum albumin (Grüber) (Fig. 38).

Proteicts exhibit great differenees with respeet to their solubility: some are soluble in water, others in solutions of neutral salts, others again in weak alkaline or weak acid solutions. and some are not soluble in any of these fluids.

The last mentioned ean be dissolved. in part at least, by means of strong acids or bases, but they at the same time undergo a transformation, and insteard of the original proteid substances we then have what are known as modified proteids. 
Proteids which are dissolved by means of the above-named indifferent solvents can be isolated from the tissues and fluids of the body probably unchanged. and are therefore designated as native proteids.

The solubility of thesc substances is intimately related to their acidic or basic character. Proteids react with both acids and bases forming salts, and themsclves therefore partake of the nature of both bases and acids. The acidic and basic characters, however, are not equally developed in all proteids. Those in which the two are approximately equal have a neutral reaction and are soluble in water and in solutions of neutral salts. Others react as weak acids, are insoluble in nentral fluids, but are soluble in weak alkaline solutions, and are precipitated from the latter by weak acids. Others again react as weak bases, are soluble in weak acids and are precipitated by weak bases.

The proteids are precipitated from their solutions by various reagents. the reactions being for the most part traceable to their double character as acids and bases. As acids they form with the salts of the heary metals precipitates of insoluble proteid-

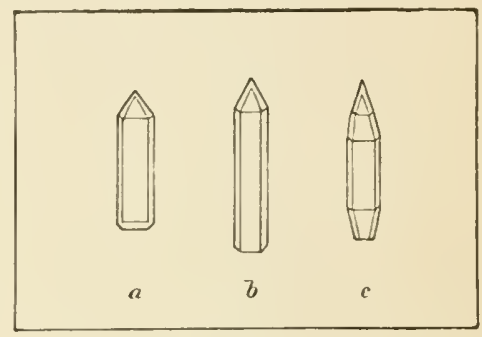

FIG. 38.-Crystals of serum-albumin, after Wichmann.

metal salts. As bases they form insoluble salts with numerous weak acids. such as tannic acid, phospho-tungstic aeid, hydroferrocyanic acid (the socalled alkaloid reagents). P'roteids cannot be recorered unchanged from these precipitates; they have been modified by the reactions.

Proteids are precipitated and at the same time modified by strong mineral acids (e. g.. Heller's test with $\mathrm{HNO}_{3}$ ) and by alcohol. They are modified also by heating their solutions. If a proteid in solution is treated with a concentrated solution of certain nentral salts of the alkalies or metallic earths - particularly ammonium, magnesium or sodiun sulphate-or with these salts in substance, it separates out unmodified-i.e.. is "salted out." The concentration of the neutral salt necessary for salting out varies greatly for different proteids, and we have in this ciremmstance a method of separating different proteids in the same solution from one another.

The chemical elements eharacteristic of simple proteids are C, N, S, H and 0 . A compound in which no $\mathrm{S}$ is found ought not to be described as a true proteid.

The percentage composition of the proteids, which consist of these five elements only, varies within rather narrow limits:

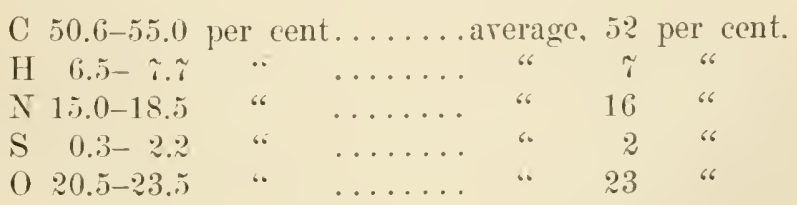

On burning proteid, various mineral constituents remain as the ash. These it appears cannot be completely remored from proteid without changing its 
composition. Tet in none of the analyses of proteid has the ash been taken into account.

Investigators have subjected proteids to various treatments, particularly hrdrolytic eleavage, and have sought to determine the resulting eleavare produets both qualitatively and quantitatively, hoping thus to arrive at the constitution of the proteid molecule. In this way it has been shown that certain groups of atoms are present in all proteid substances, while others oceur only in some and are therefore not characteristic of the proteids as a group. Such compounds as contain the smallest number of atomie groups and at the same time give all of the general proteid reactions would be elassed by this method as simple proteids. The compound proteids would be formed by addition of new groups of atoms to the simple proteid molecule.

The atomic groups thus far known as characterizing the proteids are the following (Iofmeister).

1. The guanidin rest-CNH. $\mathrm{NH}_{2}$.

2. Monobasic a-monamino acids of the series $\mathrm{C}_{\mathrm{n}} \mathrm{H}_{2 \mathrm{n}+1} \mathrm{NO}_{2}$, such as aminoacetic acid (glycocoll, $\mathrm{CH}_{2}\left(\mathrm{NH}_{2}\right)$. COOH), amino-propionic acid (alanin, $\mathrm{CII}_{3}$. $\left.\mathrm{CH}\left(\mathrm{NH}_{2}\right), \mathrm{COOH}\right)$, amino-butyric acid $\left(\mathrm{CH}_{3} \cdot \mathrm{CH}_{2} \cdot \mathrm{CH}\left(\mathrm{NH}_{2}\right) \cdot \mathrm{COOH}\right)$, aminovalerianic acid $\left(\mathrm{CH}_{3} \cdot \mathrm{CH}_{2} \cdot \mathrm{CH}_{2} \cdot \mathrm{CH}\left(\mathrm{NH}_{2}\right)\right.$. $\left.\mathrm{COOH}\right)$, amino-caproic acid, isobutylamino-acetic acid (leucin, $\left.\left(\mathrm{CH}_{3}\right)_{2} \cdot \mathrm{CH} \cdot \mathrm{CH}_{2} \cdot \mathrm{CH}\left(\mathrm{NH}_{2}\right) \cdot \mathrm{COOH}\right)$. Of these compounds leucin, glycocoll and alanin oceur most abundantly, amino-valerianic acid and amino-butyric acid less frequently. Certain of them are wanting in various proteids.

3. Monobasic a- $\omega$-diamino acids of the series $\mathrm{C}_{n} \mathrm{H}_{2 \mathrm{n}+2} \mathrm{~N}_{2} \mathrm{O}_{2}$ : e.g., the $a-\delta$-diamino-valerianic acid $\left(\mathrm{CH}_{2}\left(\mathrm{NH}_{2}\right) . \mathrm{CH}_{2} \cdot \mathrm{CH} \mathrm{CH}_{2} \cdot \mathrm{CH}\left(\mathrm{NII}_{2}\right) . \mathrm{COOH}\right)$ and the a-€-dianino-caproic acid (lysin, $\left.\mathrm{CH}_{2}\left(\mathrm{NH}_{2}\right) . \mathrm{CH}_{2}, \mathrm{CH}_{2}, \mathrm{CH}_{2}, \mathrm{CH}\left(\mathrm{NH}_{2}\right), \mathrm{COOH}\right)$. The former is always associated with the guanidin rest, the compound being described as arginin: $\mathrm{NH}=\stackrel{\mathrm{N} \cdot \mathrm{H}_{2}}{\mathrm{C}}$.

Arginin and lysin oceur in rarying proportions in all proteids (Drechsel, Hedin, Kossel), although as an exception one of them may be entirely absent, as lysin from zeïn. They are particularly abundant in the protamins, first obtained by Miescher from fish sperm, and deseribed by Kiossel as the simplest proteid. This designation, however, is not admissible since protamins do not contain sulphur.

4. A monobasic $\beta$-oxy-a-monamino acid, namely, the $\beta$-oxy- $\alpha$-amino-propionic acid (serin, $\mathrm{CH}_{2}(\mathrm{OH})$. $\mathrm{CII}\left(\mathrm{NH}_{2}\right)$. $\mathrm{COOH}$ ), has been demonstrated so far in serum albumin, globin and edestin, and probably occurs in the other simple proteids, sinee it was found in easein and in fibroin of silk (Fischer).

5. A monobasic $\beta$-thio- $a$-monamino acid: namcly, the $\beta$-thio- $a$-monaminopropionic acid $\left(\mathrm{CH}_{2}(\mathrm{SH}) \cdot \mathrm{CH}\left(\mathrm{NH}_{2}\right) . \mathrm{COOH}\right)$, corresponding to serin, which probably enters into proteids as the disulphide (cystin, COOH.CH $\left(\mathrm{NH}_{2}\right)$. $\mathrm{CH}_{2}-\mathrm{S}-\mathrm{S}-\mathrm{CH}_{2}$. CH $\left(\mathrm{NH}_{2}\right)$. COOH) (K. A. H. Mörner, Embden). Mörner finds that the total sulphur of keratin (cow's horn, human hair), serum albumin, and scrum globulin might oceur as eystin groups. In the shell membrane of the hen's egg as much as three-fourths of the sulphur are present as cystin, in fibrinogen about one-half, and in egg albumin only about one-third. How the remaining sulphur is combined in these and other proteids, we do not know.

6. Dibasic $a$-monamino acids of the series $\mathrm{C}_{\mathrm{n}} \mathrm{H}_{2 \mathrm{n}+1} \mathrm{NO}_{4}$, namely, aminosuccinic acid (aspartic acid, $\mathrm{COOH} . \mathrm{CH}_{2} \cdot \mathrm{CH}\left(\mathrm{NH}_{2}\right) . \mathrm{COOH}$ ) and amino-pyrotartaric acid (glutamic acid, COOH. $\left.\mathrm{CI}_{2} \cdot \mathrm{CH}_{2}, \mathrm{CH}\left(\mathrm{NH}_{2}\right) . \mathrm{COOH}\right)$. The per- 
centage of monamino acids in the proteid molecule is by no means small: 60.2 per cent of the total nitrogen in crystallized serum albumin, 6i.5 per cent in crystallized egg albumin, 55.0 per cent in erystallized edestin, 68.3 per cent in serum globulin (horse).

7. Carbohydrate groups. In many proteids, but not in all, there is a nucleus which on total cleavage appears regularly as glucosamin $\left(\mathrm{CH}_{2}(\mathrm{OH}) \cdot \mathrm{CH}(\mathrm{OH})\right.$. $\mathrm{CH}(\mathrm{OH}) \cdot \mathrm{CH}(\mathrm{OH}) \cdot \mathrm{CHI}\left(\mathrm{NH}_{2}\right) \cdot \mathrm{CH}: \mathrm{O}$ ) (F. Müller). Besides this nucleus, or in its place, nitrogenous or nomitrogenous carbohydrate complexes may also be present.

Among the simple native proteids there appears to be only one thus far known, namely, edestin, which contains no carbohydrate group in its molecule. In the others the number of these groups varies considerably. Crystallized egg albumin contains at least 10.0 to 11.0 per cent of glucosamin, submaxillary mucin 20.8 per cent of reducing substance, pseudomucin from ovarial cysts 30.0 per cent, egg mucoid 34.9 per cent, and the mucin of sputum 36.9 per cent. In crystallized serum albumin the content is very small.

8. A monamino acid of the benzol series, namely. the para-phenyl-aminopropionic acid (phenylalanin,, $\mathrm{CH}_{2} . \mathrm{CH}\left(\mathrm{NH}_{2}\right) \cdot \mathrm{COOH}$ ) and

9. The corresponding para-oxy-compound, $\rho$-oxy-phenyl-amino-propionic acid (tyrosin, $\left.\bigcirc_{-\mathrm{OH}}^{-\mathrm{CH}_{2}} \cdot \mathrm{CH}\left(\mathrm{NH}_{2}\right) \cdot \mathrm{COOH}\right)$

In most proteids tyrosin occurs in far greater quantity than phenylalanin. The maximal vield of tyrosin is 1.5 per cent in erystallized egg albumin, 2.0 per cent in serum albumin, 3.0 per cent in fibrin, 6.3 per cent in thymus histon and 10.1 per cent in zeïn.

10. From numerous observations on the cleavage products formed in putrefaction of proteid, it appears that an indol nucleus is present. It is likely that this nucleus in very small quantities is changed into $\beta$-methy]-indol-amino-acetic acid (tryptophan,

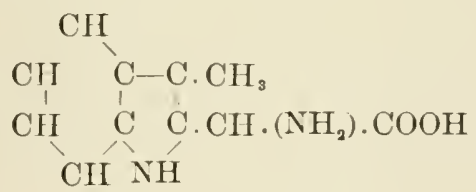

Hopkins and Cole).

11. The heterocyclic pyrrolidin nucleus is represented among the cleavage products of different proteids (edestin, serum albumin, serum globulin, egg albumin, fibrin) by the a-pyrrolidin-carboxylic acid

$$
\begin{aligned}
& \mathrm{CH}_{2}-\mathrm{CH}_{2} \\
& \mathrm{CH}_{2} \mathrm{CH} \cdot \mathrm{COOH} \\
& \mathrm{NH}
\end{aligned}
$$

and

12. By the oxy-a-pyrrolidin-carboxylic acid

$$
\begin{aligned}
& \mathrm{CH}_{2}-\mathrm{CH} \cdot \mathrm{OH} \\
& \underset{1}{\mathrm{NH}_{2}} \mathrm{CH} \cdot \mathrm{COOH}
\end{aligned}
$$

(Fischer). 
13. In many proteids the presence of a hexone base, described as histidin, $\mathrm{C}_{0} \mathrm{H}_{0} \mathrm{~N}_{3} \mathrm{O}_{2}$ has been demonstrated. It appears to be a pyrimidin derivative

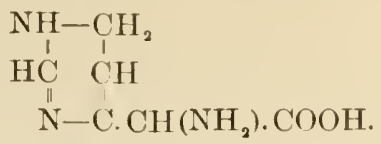

In the following table are brought together after Ehrström the most important nuclei occurring in the proteid molecule, arranged according to the number of carbon atoms which they contain.

$\mathrm{C}_{1} \quad \mathrm{C}: \mathrm{NH}\left(\mathrm{NH}_{2}\right)$

\begin{tabular}{|c|c|c|c|c|c|c|}
\hline $\mathrm{C}_{2}$ & $\begin{array}{l}\mathrm{CH}_{2}\left(\mathrm{NH}_{2}\right) \\
1 \\
\mathrm{COOH} \\
\text { Glycocoll. }\end{array}$ & & $\begin{array}{c}\mathrm{H}_{8} \mathrm{~N} \cdot \mathrm{CH}(\mathrm{NH} \\
\text { I } \\
\text { COOH } \\
\text { Tryptophan. }\end{array}$ & & $\mathrm{C}_{4} \mathrm{H}_{5} \mathrm{~N}_{2} \cdot \mathrm{C}$ & $\begin{array}{l}\mathrm{CH}\left(\mathrm{NH}_{2}\right)(?) \\
\text { l } \\
\text { COOH } \\
\text { din. }\end{array}$ \\
\hline & $\begin{array}{l}\mathrm{CH}_{3} \\
1 \\
\mathrm{CH}\left(\mathrm{NH}_{2}\right) \\
1 \\
\text { COOH } \\
\text { Alanin. }\end{array}$ & $\begin{array}{l}\mathrm{CH}_{2}(\mathrm{OH}) \\
1 \\
\mathrm{CH}\left(\mathrm{NH}_{2}\right) \\
1 \\
\text { COOH } \\
\text { Serin. }\end{array}$ & $\begin{array}{l}\mathrm{CJ}_{2}(\mathrm{SH}) \\
1 \\
\mathrm{CH}\left(\mathrm{NH}_{2}\right) \\
1 \\
\text { COOH } \\
\text { Cystein. }\end{array}$ & $\begin{array}{r}\mathrm{C}_{6} \mathrm{H}_{5} \cdot \mathrm{CI} \\
\mathrm{CI} \\
\mathrm{CI} \\
\mathrm{CC} \\
\text { Phensla }\end{array}$ & $\begin{array}{l}\mathrm{H}_{2} \\
\mathrm{H}\left(\mathrm{NH}_{2}\right) \\
\mathrm{OOH} \\
\text { alanin. }\end{array}$ & 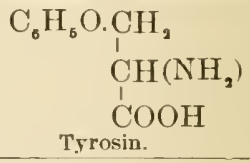 \\
\hline & $\begin{array}{l}\mathrm{CH}_{3} \\
1 \\
\mathrm{CH} \\
1 \\
\mathrm{CH}\left(\mathrm{NH}_{2}\right) \\
1 \\
\mathrm{COOH} \\
\text { ino-butyric acid }\end{array}$ & & $\begin{array}{c}\mathrm{COOH} \\
1 \\
\mathrm{CH}_{2} \\
1 \\
\mathrm{CH}\left(\mathrm{NH}_{2}\right) \\
\text { COOH } \\
\text { Aspartic acid. }\end{array}$ & & & \\
\hline & $\begin{array}{l}\mathrm{CH}_{3} \\
1 \\
\mathrm{CH}_{2} \quad \mathrm{CH}_{2} \\
1 \\
\mathrm{CH}_{2} \\
1 \\
\mathrm{CH}\left(\mathrm{NH}_{2}\right) \\
1 \\
\mathrm{COOH} \\
\text { Amino- } \\
\text { valerianic } \\
\text { acid. }\end{array}$ & $\begin{array}{l}\mathrm{CH}_{3} \\
1 \\
\mathrm{CH} \\
\vdots \\
\mathrm{CH} \\
1 \\
\mathrm{CH}\left(\mathrm{NH}_{2}\right) \\
1 \\
\mathrm{COOH} \\
\text { Leucin. }\end{array}$ & $\begin{array}{l}\mathrm{COOH} \\
1 \\
\mathrm{CH}_{2} \\
\vdots \\
\mathrm{CH} \\
1 \\
\mathrm{CH}\left(\mathrm{NH}_{2}\right) \\
1 \\
\mathrm{COOH} \\
\begin{array}{c}\text { Glutamic } \\
\text { acid. }\end{array}\end{array}$ & $\begin{array}{l}\mathrm{CH}_{2}\left(\mathrm{NH}_{2}\right) \\
1 \\
\mathrm{CH}_{3} \\
1 \\
\mathrm{CH}_{2} \\
1 \\
\mathrm{CH}\left(\mathrm{NH}_{2}\right) \\
1 \\
\mathrm{COOH} \\
\text { Diamino- } \\
\text { valerianic } \\
\text { acirl. } \\
\end{array}$ & 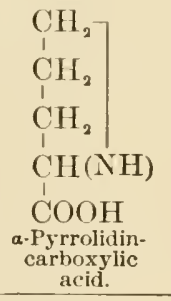 & 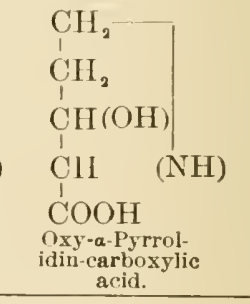 \\
\hline
\end{tabular}

\begin{tabular}{|c|c|}
\hline $\mathrm{CH}_{2}\left(\mathrm{NH}_{2}\right)$ & $\mathrm{CH}_{2}(\mathrm{OH})$ \\
\hline $\mathrm{CH}_{2}$ & $\mathrm{CH}(\mathrm{OH})$ \\
\hline $\mathrm{CH}_{2}$ & $\mathrm{CH}(\mathrm{OH})$ \\
\hline $\mathrm{CH}_{2}$ & $\mathrm{CH}(\mathrm{OH})$ \\
\hline $\mathrm{CH}\left(\mathrm{NH}_{2}\right)$ & $\mathrm{CH}\left(\mathrm{NH}_{2}\right)$ \\
\hline$\underset{\text { Lysin. }}{\mathrm{COOH}}$ & $\begin{array}{c}\mathrm{CH}: \mathrm{O} \\
\text { Glucosamin. }\end{array}$ \\
\hline
\end{tabular}

Certain of these groups can be recognized by characteristic color reactions. (1) The xanthroproteic reaction gives a yellow color with strong nitric acid; after neutralization with ammonia or a caustic alkali, the color passes over to orange or reddish brown. The reaction depends upon the presence of the benzol ring in the proteid molecule (phenylalanin, tyrosin, indol). (2) Millon's reaction gives a red coloration to the precipitate or to the fluid, when a solution of mercuric nitrate containing some nitrous acid is arded to a solid proteid or to a proteid solution. This indicates the presence of the oxyphenyl group 
(tyrosin). (3) The reaction of Adamkiewicz gives a reddish violet color with 1 vol. concentrated $\mathrm{H}_{2} \mathrm{SO}_{*}$ and 9 vol. acetic acid containing some glyoxylic acid, and characterizes the indol group (tryptophan). (4) By means of Molisch's reaction, which is a violet color with concentrated $\mathrm{H}_{2} \mathrm{SO}_{4}$ and $\alpha$-naphthol, the carbohydrate groups are demonstrated, and (5) by boiling with alkali and a lead salt (formation of black lead sulphide) the cystin groups are detected.

The biuret reaction gives a color changing from red through reddish violet to violet blue, on addition of dilute solution of copper sulphate to a proteid solution previously alkalized with caustic potash or soda and then warmed. It is very generally regarded as specifically characteristic for the proteids. This reaction, according to $\mathrm{H}$. Schiff, appears with those substances which contain two $\mathrm{CO} . \mathrm{NH}_{2}, \mathrm{CS} . \mathrm{NH}_{2}{ }^{-}, \mathrm{C}(\mathrm{NH}) . \mathrm{NH}_{2}-$, or, under certain conditions, $-\mathrm{CH}_{2} . \mathrm{NH}_{2}-$ groups, joined together by their own $\mathrm{C}$ atoms, or by a $\mathrm{C}$ atom in a $\mathrm{CH}$-, $\mathrm{CH}(\mathrm{OH})-, \mathrm{CO}$ group, or finally by a $\mathrm{N}$ atom in an $\mathrm{NH}$ group. However, this reaction is not a positive criterion of the proteid nature of a body, for on the one hand substances of so simple a structure as the glycinamid give it, and on the other, it is wanting with the desamido-albumin (obtained by the action of nitrous acid) where all the carbon nuclei of the proteid are present.

As a matter of fact there is at this time no physical or chemical feature by which one can decide positively whether a compound is to be described as a proteid or not; and for this reason certain substances are by some enumerated among the proteids, while by others their proteid nature is positively denied.

After discussing exhaustirely all the facts obtained from the cleavage products of proteids, Hofmeister reaches the conclusion that proteids arise chiefly by condensation of the $a$-amino acids, union taking place regularly and repeatedly by means of the $\mathrm{CO}-\mathrm{NH}-\mathrm{CH}=$ groups. He remarks, however, that this conception of the subject does not explain all forms of linkage in proteid and that, considering our incomplete knowledge of the proteid molecule, other relations are by no means excluded.

A rational classification of the simple proteids can only be carried out when we possess more exact knowledge of their constitution, and are thus able to state what nuclei nceur in each individual proteid and in what quantity. This is far from possible as yet, and witl most proteids we are not even in position to say whether they are actually chemical individuals or are mixtures of different substances. We are compelled therefore to classify the proteids according to their relative solubility and precipitative reactions. This is by no means a scientific principle of classification, but it is justifiable on purely practical grounds.

Accordingly simple proteids have been divided into the following groups:

A. Native proteids. These are obtained from the tissues and fluids of the body by neutral chemical reagents: the albumins, globulins and mucins are the most important.

1. Albumins: soluble in water; not precipitated from aqueous solutions by small quantities of acids or alkalies, but precipitated by larger quantities of certain acids and metallic salts. On boiling, the solutions are coagulated if salts are present. They are precipitated by $\mathrm{NaCl}$ or by $\mathrm{IgSO}_{*}$ only on addition of acetic acid. They are not salted out by half-saturation of their solutions with ammonium sulphate, but are so separaterl with greater concentration of the salt. 
Albumins oceur chiefly in the animal fluids. To this group belong serum albumin, cegr albumin, albumin of milk, etc.

2. Globulins: insoluble in water; soluble in dilute salt solutions, from which they are precipitated by further dilution. Solutions are coagulated by boiling. Soluble in water on addition of very small quantities of acid or alkali, whence they are precipitated by neutralization. Likewise when solution is effected by minimal quantities of alkali, they are precipitated by carbon dioxide and are redissolved by excess of the same. Complete precipitation by saturation with $\mathrm{MgSO}_{4}$, partial, by saturation with $\mathrm{NaCl}$. They are salted out by half-saturation with ammonium sulphate.

This characterization of the globulins howerer is no longer sufficient, for it appears from several recent researches that among the compounds which are precipitated by fractional salting out of the globulins in the blood, there oceur substances which are neither insoluble in water nor precipitated from their solutions with carbon dioxide. The only positive distinction between albumins and globulins therefore consists in their relation to neutralization, and especially to ammonium sulphate: the globulins are precipitated by half-saturation, the albumins are not.

The globulins also occur chiefly in the fluids of the animal body; but they may be obtained from the tissues. To this group belong fibrinogen and serum globulin of the blood, myosin and myogen of the muscles, etc.

3. The true mucins are substances insoluble in water and in solutions of neutral salts, but soluble with very little alkali. The solutions are viscous, and form with acetic acid a precipitate not soluble in an excess of the acid. Chemically the mucins are characterized by their high content of the carbohydrate groups. The true mucins occur in the submaxillary saliva, in the umbilical cord (W'harton's jelly), ete.

The so-called mucoids are distinguished from the true mucins in certain respects which are not yet definitely understood. They are obtained from the ovarial fluids, from the cornea, the vitreous body, the urine, etc.

It is also asserted that the mucins contain fat. If the submaxillary mucin be first extracted with ether and be then digested with pepsin-HCl, one can later extract with ether more than three per cent fat from the substance (Nerking).

B. Simple proteids which can be split off from compound proteids. Here belong globin from hrmoglobin, the proteids from the mucins, etc.

C. The native proteids are changed by the action of alkalies and acids in sufficient concentration into allali and acid albuminates (syntonin). In the formation of alkali albuminates some nitrogen is split off from the proteid, and with stronger action of the alkali some sulplur also is separated.

In spite of their different modes of formation, and in spite of different chemical constitutions, the alkali and acid albuminates are very closely related to each other. In water or dilute $\mathrm{NaCl}$ solution they are almost insoluble, but are soluble on addition of small quantities of acid or alkali. Such a solution (even if neutral) is not coagulated on boiling, without the aldition of sufficient quantity of neutral salts. Solutions of albuminates are precipitated at room temperature by neutralization, by excess of mineral acids, by many metallic salts. An acid solution of albuminate is readily precipitated by $\mathrm{NaCl}$, an alkaline solution only with difficulty.

D. Under the influence of the digestive fluids there are formed by hydrolytic clearage of the proteids a number of new substances, the so-called albu- 
moses and peptones which will be fully treated in our study of digestion (Chapter $\mathrm{Y} 1 \mathrm{l}$ ).

E. Finally, we should mention the compounds arising by coagulation of the soluble proteids, whose properties are less well known than those of other proteid substances. To this group belongs also the fibrin formed in the coagulation of the blood by splitting of fibrinogen (see Chapter $\mathrm{V}$ ).

In order to give a more exact idea of the quantitative eomposition of the simple proteids, we have brought together in the following table the results of analyses by Aberhalden.

\begin{tabular}{|c|c|c|c|c|c|}
\hline PERCENTAGE OF & $\begin{array}{c}\text { In } \\
\text { Casein. }\end{array}$ & $\operatorname{In}_{\text {Gelatin. }}$ & $\begin{array}{l}\text { In } \\
\text { Elastin. }\end{array}$ & $\begin{array}{l}\text { In } \\
\text { Globin from } \\
\text { Ilerna- } \\
\text { globin. }\end{array}$ & $\begin{array}{c}\text { In } \\
\text { Edestin. }\end{array}$ \\
\hline 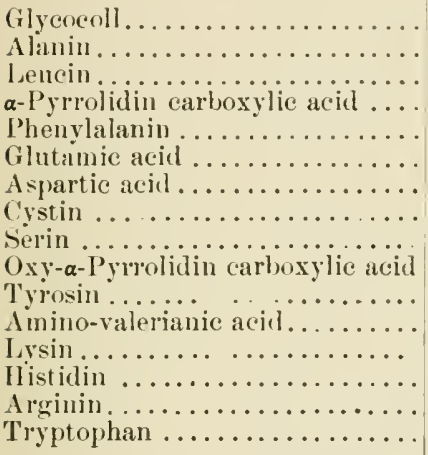 & $\begin{array}{c}0 \\
0.9 \\
10.5 \\
3.1 \\
3.2 \\
10.7 \\
1.2 \\
0.065 \\
0.23 \\
0.25 \\
4.5 \\
1.0 \\
5.80 \\
2.59 \\
4.84 \\
1.5\end{array}$ & $\begin{array}{l}16.5 \\
0.8 \\
2.1 \\
5.1 \\
0.4 \\
0.88 \\
0.56 \\
\ldots \ldots \\
\cdots \\
3.0 \\
\ldots \ldots \\
2.75 \\
7.62 \\
0.40 \\
\ldots\end{array}$ & $\begin{array}{r}25.75 \\
0.58 \\
21.38 \\
1.74 \\
3.89 \\
0.76 \\
\ldots .0 \\
\ldots \ldots \\
\ldots .34 \\
\ldots \\
\ldots \ldots \\
0.3 \\
\ldots \ldots\end{array}$ & $\begin{array}{r}0 \\
4.19 \\
29.04 \\
2.34 \\
4.24 \\
1.73 \\
4.43 \\
0.31 \\
0.56 \\
1.04 \\
1.33 \\
\dddot{3} .28 \\
10.90 \\
5.42 \\
*\end{array}$ & $\begin{array}{l}3.8 \\
3.6 \\
20.9 \\
1.7 \\
2.4 \\
6.3 \\
4.5 \\
0.25 \\
0.33 \\
2.0 \\
2.13 \\
* \\
2.0 \\
11.0 \\
11.7 \\
*\end{array}$ \\
\hline
\end{tabular}

* Present.

\section{B. THE COMPOUND PROTEIDS}

Simple proteids are distinguished largely by the fact that they can unite with each other as well as with other substances to form new compounds. The atomic group conjoined with the proteid in the latter case is described by Kossel as the prosthetic group. Such conjugated proteids can be isolated from the animal fluids and tissues in great numbers. They are classified according to the nature of the conjugant into the following groups:

A. Hamoglobins: These represent compounds of a basic proteid body, globin, with the acid, iron-containing, pigment hæmochromogen, and will be riscused at length in Chapter $\mathrm{V}$.

B. Nurleo-albumins: phosphorus-containing proteids which are characterized by the fact that on digestion with pepsin-HCl a portion remains temporarily insoluble. This portion. like the soluble portion, contains phosphorus, and is described as psendonuelein or paranuclein. It is distinguished from the true nueleins (see below) by not containing any purin bases.

To the nueleo-albumins belong the easein of milk, whose properties will be fully considered later (Chapter XXYI); vitellin found in the yolk of a bird's egg': various proteids of the bile, the kidneys, the mucous membrane of the bladder, etc. 
Little is known yet with regard to the constitution of paranuclein, or the form in which phosphorus is found either in it or in the nucleo-albumins in general. Levene and Alsberg however have isolated an acid (vitellinic acid) from vitellin which possibly represents a compound of proteid with phosphoric acid in the form of an cster. Like the corresponding pseudonuclein this acid contains iron in organic combination, which, as Bunge believes. may serve for the formation of the iron-containing hemoglobin of the young bird. Likewise from casein a paranucleinic acid has been obtained by Salkowski, from which orthophosphoric acid can be split off.

Neither casein nor vitellin contains any carbohydrate group. Twenty-seven and one-tenth per cent of the total nitrogen in cow's-milk casein occurs as diamino-N, and sixty-two per cent as monamino-N. The maximal vield of tyrosin from casein is 4.5 per cent. Only about one-tenth of the sulphur of casein is present in the form of eystin compounds (Alörner).

\section{Nucleins: compounds of proteid with the nucleic acids.}

The nucleic acids are phosphorus-containing substances which yield on decomposition, besides phosphoric or metaphosphoric acid: different characteristic purin bases; the pyrimidin derivatives thymin. uracil, and cytosin; and finally carbohydrates. Moreover they are dextro-rotatory, notwithstanding that nucleins and even the nucleo-proteids (see below) are læro-rotatory.

1. The purin bases (called also alloxuric, xanthin, or nuclein bases) are derivatives of purin, which, according to Fischer, consists of a pyrimidin nucleus and a glyoxalin nucleus joined to the former in the 4,5 position,

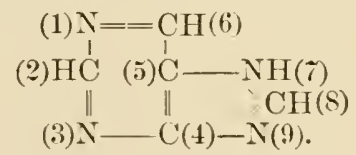

Different lydrogen atoms of this structure mar be replaced by hydroxyl, amid, or alkyl groups. The purin bases are: xanthin (2.6.dioxypurin, $\mathrm{C}_{5} \mathrm{H}_{4} \mathrm{~N}_{4} \mathrm{O}_{2}$ ); guanin (2.amino-6.oxypurin, $\left.\mathrm{C}_{5} \mathrm{H}_{5} \mathrm{~N}_{5} \mathrm{O}\right)$; hypoxanthin (6.oxypurin, $\mathrm{C}_{5} \mathrm{H}_{4} \mathrm{~N}_{4} \mathrm{O}$ ): and adenin (6.amino-purin, $\mathrm{C}_{5} \mathrm{H}_{5} \mathrm{~N}_{5}$ ). In guanylic acid from the pancreas only guanin is found. Several purin bases occur in the other nucleic acids and in the nucleic acid from yeast all of them are found.

2. Thymin, discovered by Kossel in the nucleic acid of the thymus, is 5.methyl-2.6.dioxy-pyrimidin,

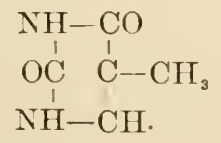

It has been found also in the nucleic acids of the spleen, of fish sperm, of the brain, liver and pancreas.

3. Uracil, 2.6-dioxy-pyrimidin,

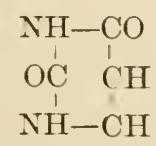

occurs in the nucleic acid of yeast and in those of the pancreas, thymus, herring sperm, etc. (Ascoli). 
4. Cytosin, 6.amino-2.oxy-pyrimidin,<smiles>NCC(Cl)Cl</smiles>

(Kossel) has an equally wide distribution.

5 . In nearly all of the nucleic acids there is a carbohydrate, sometimes a pentose (1-xylose), sometimes a hexose.

Nothing definite is known conccrning the manner in which phosphorus is combined in the nucleic acids.

One can obtain a fair idea of the complexity of nucleic acids from the following structural formula for a-guanrlic acid given by Bang.

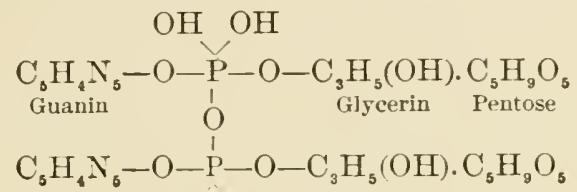

$\mathrm{O} \mathrm{O}$

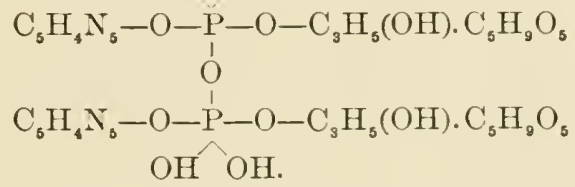

The simplest nucleins are the saltlike compounds of nucleic acids with the protamins and histons. These simple proteids are closely related chemically, and there seems to be a close relationship physiologically as well; for whereas one finds histons in unripe fish sperm, in the ripe sperm protamins are found.

The nucleins finally unite with proteid to form nucleo-proteids, which, it appears, occur in (dead) cell protoplasm and especially in the (dead) cell nucleus, where Miescher first demonstrated them. Their composition is rery complicated, and they represent the first decomposition products of the living substance thus far known. some of them appear to contain iron.

D. Chondro-proteids. Compounds of proteid with chondroïtin-sulphuric acid $\left(\mathrm{C}_{18} \mathrm{H}_{27} \mathrm{NSO}_{1 ;}\right.$ Schmiedeberg) and found in the mucoid of cartilage. amyloid, in tendon mucin, and presumably in other mucous substances.

\section{SUBSTANCES RESEMBLING PROTEIDS}

The following substances are known to be closely related to proteids, from the fact that on decomposition they yield in general the same substances as do proteids. It is possible that some of them should be enumerated among the true proteids.

A. Protamins (see page 70).

B. Keratin, a substance rich in sulphur (2.5-5 per cent); amorphous, insoluble in water, alcohol, ether and the digestive fluids: contained in horn, epidermis, hair, nails, etc. On heating with water in closed tubes it yields albumoses and peptones. It develops the characteristic smell of burnt horn when ignited. 
About the same products (with the exception of carbohydrates) have been obtained by cleavage of the keratin molecule, as from the typical proteids.

C. Albumoid, a substance obtained from the cartilage of the trachea, which stands in certain respeets between the true proteid and keratin. Another albumoid oceurs in the fibers of the cristalline lens.

D. Elastin, a rellowish white, amorphous substance containing only a small quantity of sulphur; insoluble in water, alcohol and ether; and attacked by chemical reagents with great difficulty. It occurs in connective tissue and especially in the ligamentum nuchie.

Among the cleavage products of proteid which have been obtained from elastin, are the guanidin rest, leucin, diamino acids, tyrosin and indol, but neither glutamic acid nor carbohydrates.

E. Collagen, a sulphur-containing substance: insoluble in water, salt solutions, and rery weak acids and bases, but swelling up in less dilute acids; it is the chief constituent of fibrillar comnective tissue and occurs in bone (osseïn) and other tissues.

When collagen is boiled for a long time with water, it passes over into gelatin (glutin).

F. Gelatin, a colorless, amorphous, nondiffusible substance of about the same chemical constitution as collagen. It swells up in cold water and is dissolved in warm water. On cooling the solution sets into a jellylike mass.

Neither carbohydrates, cystin, serin, tyrosin, nor indol occurs in the molecule of gelatin. Sixteen and six-tenths per cent of the total nitrogen is present as arginin, and not less than 8.4 per cent in the form of glycocoll.

Gelatin solutions are not coagulated on boiling, and are not precipitated by mineral acids, acetic acid, alum, lead acetate or metallic salts. They are precipitated by tamic acid in the presence of salt, bs acetic acid and $\mathrm{NaCl}$ in substance, by mercuric chloride in the presence of $\mathrm{HCl}$ and $\mathrm{NaCl}$.

By prolonged cooking gelatin is transformed into a nongelatinizing modification. It is acted upon by the digestive enzymes yielding gelatin albumoses and peptones.

G. Reticulin, a constituent of the connective tissue framework, of the lymph glands, of the spleen, of the intestinal mucosa, the liver, kidneys and alveoli of the lungs.

\section{OTHER NITROGENOUS SUBSTANCES}

Among the remaining nitrogenous substances which may be isolated from animal tissues, lecithin should be especially mentioned. It is found in almost all animal and plant cells, especially in the brain, the nerves, the blood corpuscles and in egg yolk; it occurs also in almost all animal fluids.

Lecithin represents an esterlike compound of a base, cholin, oxyethyl-

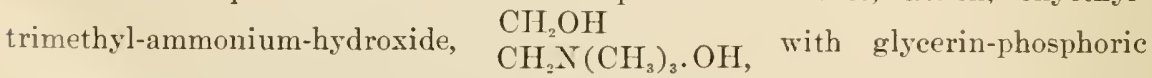
acid which is united with two fatty acid radicles into a glyceride. There are different lecithins therefore according to the kind of the fatty acid radicles. The stearic-palmitic acid lecithin to be obtained from egg yolk, O. $\mathrm{COC}_{18} \mathrm{H}_{35}$

$\mathrm{C}_{3} \mathrm{H}_{5} \mathrm{O} \cdot \mathrm{COC}_{15} \mathrm{H}_{31} \cdot\left(\mathrm{CH}_{3}\right)_{3}$

O.PO $(\mathrm{OH}) \cdot \mathrm{O} \cdot \mathrm{CH}_{2} \mathrm{CH}_{2} \mathrm{~N} \cdot \mathrm{OH}$,

readily soluble in alcohol and ether. With water it swells up forming an opales. cent solution, from which it is precipitated again by means of different salts.

Lecithin is found in several cases in loose combination with proteid or 
other substances. In protagon which occurs in the white substance of the central nervous system, and probably represents a mixture of substances, lecithin is bound up with the cerebrosides, N-containing, phosphorus-free substances, which on boiling with dilute mineral acids yield a reducing sugar. Ovovitillin is a combination of proteid and lecithin, and sinilar compounds are said to be obtained as insoluble residues from peptic digestion of the gastric mucosa, liver, kidneys, etc. These lecithin albumins represent therefore a new group of proteids (ef. under B). Jecorin, which has been demonstrated in the liver and in the blood, is a combination of lecithin and glucose.

\section{$\S 2$. THE NONNITROGENOUS SUBSTANCES}

\section{A. FATS}

The fats are esters of the triatomic alcohols, the glycerins, with monobasic fatty acids, chief of which in the animal fats are: stearic acid, $\mathrm{C}_{18} \mathrm{H}_{3,} \mathrm{O}_{2}$, palmitic acid, $\mathrm{C}_{16} \mathrm{H}_{32} \mathrm{O}_{2}$, and oleic acid, $\mathrm{C}_{18} \mathrm{H}_{34} \mathrm{O}_{2}$. The triglycerides of the first two-slearin, $\mathrm{C}_{3} \mathrm{H}_{5} \cdot\left(\mathrm{C}_{15} \mathrm{H}_{35} \mathrm{O}_{2}\right)_{3}$, and palmitin, $\mathrm{C}_{3} \mathrm{H}_{5} .\left(\mathrm{C}_{15} \mathrm{H}_{31} \mathrm{O}_{2}\right)_{3}-m e l t$ only at a temperature far abore that of the body. The glyceride of oleic acid, olein, $\mathrm{C}_{3} \mathrm{H}_{5} \cdot\left(\mathrm{C}_{18} \mathrm{H}_{33} \mathrm{O}_{2}\right)_{3}$, is on the other hand fluid at ordinary temperatures and solidifies in the form of erystalline needles only at $-5^{\circ} \mathrm{C}$. The melting point of a mixture of the three glycerides must therefore depend upon the relative content of olein-the greater the relative quantity of this fat, the lower is the melting point of the mixture. Horeover the melting point of fat shows considerable variation not only in different species of animals, but also in different parts of the same indiridual, which means that the relative quantity of olein present varies considerably. Traces of fatty acids are also found in animal fat.

The following reactions, among others, serve to distinguish the different fats: (1) the acid equivalent, which is the measure of the content of free acid in a fat, and is obtained by titration of the fat dissolved in alcohol ether with $11 / 10$ alcoholic caustic potash: (2) The saponification equivalent-i. e., the number of $\mathrm{mg}$. of $\mathrm{KOH}$ combined with fatty aeid in saponification of $1 \mathrm{~g}$. of the fat with alcoholic caustic potash; (3) The Reichert-Meissl equivalent, which gives the amount of volatile fatty acid obtained. when, after saponification, the fat is distilled off in the presence of a mineral acid: ( 4 ) The iodine equivalent-i.e., the quantity of iodine taken up by a fat, and serving as the measure of the content of olein.

In the body fat is to be found for the most part inclnsed in the cells of the fatty tissues. These represent in fact a kind of storchouse for fats (cf. Chapter $\mathrm{IV}$ ). It occurs also in very small quantities in the blood and in other fluids of the borly.

Fats are insoluble in water, are dissolsed by boiling-hot alcohol, but are precipitated again on cooling. They are readily soluble in ether, benzol and chloroform. On boiling with caustic alkalies they are decomposed and are split into glycerin and fatty acids, the latter of which mite with the alkali to form soap. The fatty acids are set free from the soap by strong acids. Like the neutral fats they are soluble in ether, but this is not the case with soaps. 


\section{B. CHOLESTERIN}

Cholesterin is a monatomic alcohol, $\mathrm{C}_{23} \mathrm{H}_{43} \mathrm{OH}$, which occurs especially in certain biliary concretions, also in the brain, in nerves and in animal cells generally. From an alcoholic solution it crystallizes in the form of leaflets which have the appearance of mother-of-pearl. With the higher fatty acids cholesterin forms esters, which, unlike the fats, are very resistant toward decomposing reagents and are therefore specially suitable for protection to the skin, being found on both hair and feathers. Lanolin, a compound of this kind prepared from wool fat, has found wide practical use.

\section{CARBOHYDRATES}

The name carbohydrates is applied to substances composed of C. H. and $\mathrm{O}$, in which the $\mathrm{H}$ and $\mathrm{O}$ are present in the proportions to form water. This definition howerer is not sufficient, for there are substances with the same relative quantities of $\mathrm{H}$ and $\mathrm{O}$ which are not carbohydrates; and for other reasons it cannot be regarded as satisfactory from a scientific point of view. A perfectly satisfactory definition of carbohydrates has not yet been given; they are characterized only as aldehyde or ketone derivatives of polyhydric alcohols.

The carbohydrates are divided into three chief groups. namely, monosaccharides, disaccharides and polysaccharides, in each of which are found several familiar substances.

A. The monosaccharides are the direct, isomeric or steren-isomeric aldehydes or ketones of the corresponding alcohols. They occur ready formed in nature, and have also been prepared synthetically.

The monosaccharides most interesting to us in this connection are the hexoses, $\mathrm{C}_{6} \mathrm{H}_{1:} \mathrm{O}_{5}$ : dextrose, mannose, galactose, and levulose, which are the first oxidation products of the stereo-isomeric hexatomic alcohols: sorbite, mannite, and dulcite. The latter have the following constitution: $\mathrm{CH}_{2}$.OH.(CH.OH) . $\mathrm{CH}_{2}$. OH. Dextrose, mannose, and galactose are the respective aldehydes of these alcohols, $\mathrm{CH}_{2}$. OH. (CH.OH) ${ }_{4}$. $\mathrm{CHO}$; levulose is the ketone of mannite, $\mathrm{CH}_{2}$. $\mathrm{OH} .(\mathrm{CH} . \mathrm{OH})_{3} \cdot \mathrm{CO} \cdot \mathrm{CH}_{2} \mathrm{OH}$.

The following reactions are common for all these substances: They are directly fermentable, and under the influence of the reast plant are decomposed into $\mathrm{CO}_{2}$ and alcohol: $\mathrm{C}_{6} \mathrm{H}_{12} \mathrm{O}_{6}=2 \mathrm{C}_{2} \mathrm{H}_{5} \cdot \mathrm{OH}+2 \mathrm{CO}_{2}$. They are easily oxidized and hence reduce the metallic oxides on heating in alkaline fluids. This property is made use of in quantitative determinations of the monosaccharides. They are for the most part crystalline substances of a sweetish taste; readily soluble in water, difticultly soluble in alcohol. The hexoses occurring in nature, in solutions rotate the plane of polarized light either to the right or to the left. This property also is raluable for their quantitative determination.

1. Dextrose (synonyms: grape sugar, glucose) oceurs in sweet fruits (e.g., grapes) and in honey. Under normal circumstances dextrose is found in small quantities in the blood and lymph. In diabetes its quantity in these fluids is greater, and it is found in large quantities in the urine. Dextrose rotates the plane of polarized light to the right.

2. Levulose (ssnonyms: fruit sugar, fructose) occurs together with dextrose in sweet fruits and in honey. It rotates the plane of polarized light to the left. 
Of the other monosaccharides the pentoses, $\mathrm{C}_{5} \mathrm{H}_{10} \mathrm{O}_{5}$, have been demonstrated in animal fluids (urine) and among the cleavage products of animal substances. Arabinose, found in the urine, and $x y l o s e$ in the pancreas are the most important pentoses. They do not ferment under the influence of the yeast plant; but with a certain other fungus, not definitely determined, Salkowsky obtained a large quantity of alcohol from l-arabinose.

B. The disaccharides are anhydric compounds of two molecules of monosaccharides-e. g., $2 \mathrm{C}_{6} \mathrm{H}_{12} \mathrm{O}_{6}=\mathrm{C}_{12} \mathrm{H}_{22} \mathrm{O}_{11}+\mathrm{H}_{2} \mathrm{O}$. On boiling with dilute mineral acids they break up with the absorption of water into monosaccharides. The most important members of this group are saccharose (cane sugar), lactose (milk sugar) and maltose (malt sugar), all haring the formula $\mathrm{C}_{12} \mathrm{H}_{22} \mathrm{O}_{11}$.

The disaccharides are crystalline bodies of a sweetish taste, readily soluble in water. Lactose and maltose reduce an alkaline copper solution, saccharose does not. $\mathrm{By}$ boiling with dilute mineral acids and by the ageney of certain enzymes the disaccharides take up one molecule of water and split into two molecules of monosaccharides thus: saccharose into dextrose and levulose; lactose into dextrose and galactose; maltose into two molecules of dextrose.

Saccharose is dextro-rotatory; on its cleavage into dextrose and levulose it becomes, on account of the stronger rotating power of levulose, lavo-rotatory. For this reason the clearage of saccharose is called inversion.

C. The polysaccharides, $n\left(\mathrm{C}_{6} \mathrm{H}_{10} \mathrm{O}_{5}\right)$. like the disaccharides are regarded as anhydrides of the monosaccharides. but they have their origin in the union of many molecules of the latter and have a high molecular weight, which varies widely.

The polysaccharides have no sweetish taste and for the most part are amorphous. Some are soluble in water, others swell up in water, while still other members of this series are not visibly changed by water. By various means all of them can be transformed by absorption of water into monosaccharides.

The polysaccharides are divided into three chief groups: starches, gums, and cellulose.

1. The starches are not directly fermentable and do not reduee alkaline copper solutions. To these belong:

(a) Vegetable starches (amslum). These are found in many plant eells laid down in the form of microscopie, round or oblong granules which have an organic structure and are insoluble in eold water. On heating with water they swell up at $50^{\circ}$, burst and partially dissolve, forming a slimy solution. known as starch paste, which can be filtered. The soluble part is called starch granulose, the insoluble part starch cellulose. On boiling with dilute acids starch is changed first into dextrin (see below) and later into dextrose. By digestion with saliva or pancreatic juice, or through the influence of malt-diastase it is split into dextrin and maltose (ef. Chapter VII).

(b) Glycogen is an animal stareh which has a very wide distribution in the animal body. It is found in almost all the tissues of the bods, but in largest quantities in the liver and in the muscles: it is a constituent of embryonic tissues especially and all others in which an active cell formation is taking place. Glyeogen is an amorphous, tasteless and odorless white powder: with water it forms an opalescent, dextro-rotatory solution. It is changed by diastatic enzymes into maltose or dextrose aceording to the nature of the enzyme. 
2. Gums are amorphous, transparent, tasteless and odorless substances which with cold water form viscous fluids. They are rery widely distributed in the plant kingdom.

(a) Among the gums the dextrins claim our chief interest here, for they are formed as intermediate products in the transformation of starch in the alimentary canal. They are obtained also by heating starch up to $200^{\circ}-210^{\circ} \mathrm{C}$. In these transformations of starch a series of dextrins is formed which have smaller and smaller molecular weights. The dextrins are white or yellowish white, amorphous, gumlike masses whose aqueous solutions are dextro-rotatory. They are not directly fermentable.

(b) An animal gum is said to be split off from mucin through the influence of superheated steam aud of alkalies. This is not true, however, for all mucins, for several kinds yield gumlike substances which represent nitrogenous bodies derived from the carbohrdrates.

3. Cellulose forms the chief constituent of the cell walls of all plants and exhibits an organic structure. To obtain pure cellulose plant fibers are digested successively with different reagents, such as dilute acids and alkalies, potassium chlorate and nitric acid, alcohol and ether. The cellulose remains as the insoluble residue.

Tuble shouing the percentage composition of the most important substances discussed in this chapter :

\begin{tabular}{|c|c|c|c|c|c|c|}
\hline & $\mathbf{C}$ & H & $\mathrm{y}$ & s & 0 & $\mathbf{P}$ \\
\hline 1. Proteids in general. & $50.6-55$ & $6.5-\tau .7$ & $15.0-18.5$ & $0.3-2.2$ & $20.5-29.5$ & \\
\hline 2. Casein ............. & $52.7-54.0$ & 7.0 & $15.6-15.7$ & $0 . \tau-0.8$ & 22.8 & 0.8 \\
\hline 3. Nuclein ........ & $40.8-42.1$ & $5.4-6.1$ & $14.7-16.0$ & $0.4-0.6$ & $31.1-31.3$ & $5.2-6.2$ \\
\hline 4. Nucleic aciel...... & $34.1-37.3$ & $4.2-5.2$ & $15.3-18.2$ & & $32 . \overline{5}-3 \overline{5} .6$ & โ. $\div-9.9$ \\
\hline 5. Nucleohiston...... & 48.5 & 7.0 & 16.9 & 0.7 & 24.0 & 3.0 \\
\hline 6. Muein........... & $48.3-50.3$ & $6.4-8.2$ & $11.8-13.7$ & $0.8-1.8$ & $2 \pi .4-32.7$ & ...... \\
\hline \%. Chond romucoid ... & 47.3 & 6.4 & 12.6 & 2.4 & 31.3 & ...... \\
\hline 8. Keratin......... & $49.8-58.5$ & $6.4-8.2$ & $11.5-1 \% .5$ & $2.5-5.0$ & $19.6-22.9$ & \\
\hline 9. Elastin .. & $54.0-54.3$ & $7.0-7.3$ & $16.7-16.8$ & 0.4 & $21.8-21.9$ & .... \\
\hline 10. Collagen. & 50.8 & 6.5 & 17.9 & 0.6 & 24.3 & \\
\hline 11. Gelatin ..... & $49.3-51.5$ & $6.5-\tau .1$ & $17.5-18.6$ & 0.3 & $25.2-25.4$ & \\
\hline 12. Reticulin ........ & 52.9 & ค. 0 & 15.6 & 1.9 & 20.0 & 0.3 \\
\hline 13. leeithin.... & (6ĩ. 4 & 11.2 & 1.7 & $\ldots \ldots$ & 17.8 & 3.8 \\
\hline 14. Fats (mean)...... & 76.5 & 12.2 & $\ldots \ldots$ & $\ldots \ldots$ & 11.5 & $\ldots$. \\
\hline 15. Cholesterin. & 83.9 & 11.9 & ...... & & 4.1 & \\
\hline 16. Monosaceharides... & 40.0 & $6 . \tau$ & & & 53.3 & \\
\hline 17. Disaceharides .... & 42.1 & 6.4 & $\ldots \ldots$ & & 51.5 & \\
\hline 18. Polysaccharides.... & 44.4 & 6.1 & $\cdots \cdots$ & $\ldots \ldots$ & 49.4 & $\cdots$ \\
\hline
\end{tabular}

Referexces.-The text-books of phrsiolngical chemistry: of Bunge, second English edition by E. H. Starling, Philadelphia, 1902; of Halliburton, latest edition, London and New York, 1904; of Hammarsten, fourth English edition by John A. Mandel. New York. 190t; of Neumeister. second edition, Jena, 1897. O. Cohnheim, "Chemie der Eiweisskorper," Braunschweig, 1900. F. Hofmeister in "Ergebnisse der Phrsiologie." I, 1. Wiesbarlen, 1902. A. Kossel, "Ber. d. deutschen Ges.," 34, 3, 1902. 


\section{CHAPTER IV}

\section{METABOLISM AND NUTRITION}

THE physiology of metabolism and nutrition ${ }^{1}$ sceks to discover what substances are necessary for the maintenance and growth of the body. to determine the character and extent of the combustion taking place in its tissues and fluids under different circumstances, and to understand the significance of the different substances for these processes.

The substances in question admit of dirision into three groups, namely: (1) organic foodstuffs. substances which supply potential energy and serre therefore to maintain the combustion in the lody: (2) unter and inorganic foodstuff s. which must be taken to make good the constant loss from the body of these constituents, without which profound and eventually fatal disturbances in health may ensue; (3) oxygen necessary for the maintenance of combustion.

\section{FIRST SECTION}

\section{METABOLISM}

\section{§ 1. ON THE METHOD OF METABOLISM EXPERIMENTS}

\section{A. THE INGESTA}

Organic as well as inorganic foodstuffs. mixed together in varying proportions and mixerl with other substances not needed in the body, occur in our common articles of food and in our meals prepared from them. Chemical analysis of the foods has shown that the organic foodstuffs are chicfly of three kinds, namely: (1) proteids and allied substances; (2) fats: (3) carbohydrates. To the inorganic foodstuffs. Which are designated also as ash constituents. belong numerous salts which we shall discuss more in detail hater. $\mathrm{Br}$ chemical analysis of the food we learn its composition, both qualitatively and quantitatively, and determine in this way precisely the intake of the body.

In analysis of the foods and the freces, (1) the nitrogen is determined and the proteid is calculated by multiplying this result by 6.25. Since, loowerer,

${ }^{1}$ It may serve to differentiate the two divisions of the subject somewhat, if we define metabolism as covering all those chemical transformations of the foodstuffs by which energy is supplied to the cells, and mutrition as covering all the processes by which the materials which the cells require are supplied. Obviously the two are inseparable and represent merely different aspeets of the same suhject. We spe:k of the substances as undergoing metalo!ism and of the organism as nourishing itself.- ED. 
nitrogen-containing substances other than proteid occur in both animal and regetable foods, the quantity as calculated by this method is too high. Especially with a low percentage of proteid a considerable error might thus arise. Moreover, the kind of proteid eaten is not a matter of indifference, since one mar well imagine that different proteid bodics behave differently in metabolism. The little we know on this subject will be summarized later. (2) As fat, is reckoned the total extract with ether, although this contains also other substances soluble in ether. (3) The dry substance and (4) the ash constituents are detcrmined by desiccation at $100^{\circ} \mathrm{C}$. and by incineration respectively. (5) The carbohydrates are determined usually by subtracting from the total dry substance the proteid t the fat + the ash.

Finally, under the ingesta is to be reckoned the oxygen, methods for the determination of which will be given under $\mathrm{B}$.

\section{B. DETERMINATION OF THE EXCRETA}

The products of metabolism are eliminated by the lungs, skin, intestine and kidners.

The excreta resulting from the combustion of organic foods. to which we shall confine ourselves for the present, contain the following elements: $N$, $S$, P, C. H, and O. Nitrogen, sulphur and phosphorus are derived from proteics; carbon. hydrogen and oxygen are contained in all the organic foods. In estimating the excreta we hare therefore to determine quantitatively the amount of $\mathrm{N}, \mathrm{S}, \mathrm{P}, \mathrm{C}$. and $\mathrm{H}$ eliminated within a certain time.

The determinations can be simplified considerably, howerer. Ordinarily, in order to find out how much proteid has been metabolized in the body, it is sufficient to determine the amount of nitrogen eliminated. One need not consider the sulphur and phosphorus unless the investigation is especially concerned with the beharior of the phosphorus-containing proteids. The analysis for a complete metabolism experiment therefore can be restricted to N, C, and H. Commonly the excretion of hydrogen also is neglected.

The amount of proteid destroyed in the body is obtained by multiplying the amount of nitrogen eliminated as a product of metabolism by 6.25 .

Analysis for the elements found in the excreta is by no means always sufficient; in many cases it is necessary either for the purpose of gaining a deeper insight into the mode of the metabolic processes, or in order to estimate the percentage of combustible materials in the fxces, to determine the separate compounds quantitatively. In the latter case the aualysis is carried out in precisely the same way as in making similar determinations for the food to be ingested.

If the metabolism experiment is to be of any use whaterer, it is necessary to collect every trace of the excreta for exactly the period covered by the experiment. The urine and the faces offer no particular difficulties in this respect, although some remarks with regard to the latter seem called for.

It is apparent at once that analysis of the fæces can only be of importance for the studs of metabolism, if they can be identified as belonging to a definite 
diet. But in all animals, as in man, the intestine is always more or less filled and one cannot tell without special means whether a given mass of frees comes from the diet which is being studied. To do so it is necessary to separate the frees corresponding to the diet in question from preceding and subsequent fæces. The subject is allowed to fast for some twenty hours, then the particular diet is begun, and with the first meal some substance is given which, like finely powdered charcoal, will impart a characteristic color to the fæces. After the last meal the subject is permitted to fast again for twenty hours, and with the first food eaten after this period charcoal is once more given. With herbivorous animals it is impossible to get a satisfactory separation; but this difficulty may

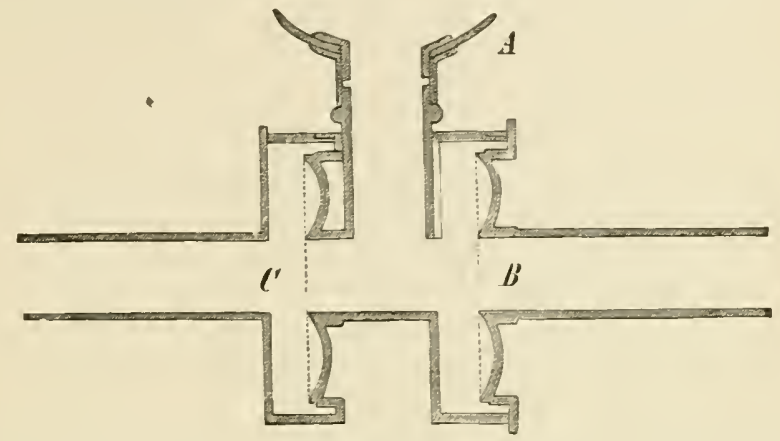

Fig. 39.-Face mask for respiration experiments, after Lovén. Longitudinal section. A, the mouthpiece. $\mathrm{B}$ and $\mathrm{C}$ are thin membranes which act as valves and serve to separate inspired from expired air. Inspiration takes place through B, expiration through C.

be orercome by giving the particular diet under investigation for several days before beginning the experiment.

In order to collect the solid constituents contained in the sweat, the subject is required to wear thoroughly washed woolen clothes which will absorb and retain all such solids.

Rather complicated methods must be emplored to collect and analyze the gaseous products of metabolism (carbon dioxide and water rapor). and to determine the amount of oxygen absorbed. Methods for all these purposes were used by Lavoisier (1750), but they have been dereloped and improved in many ways since his day.

The simplest, if not the most satisfactory method, is to collect the respiratory products by the use of a face mask. The mask is connected by means of tubes with apparatus for the measurement and collection of the inspired and expired air, the two currents of air being separated by means of automatic ralres (Fig. 39). Instead of the face mask a gutta-percha plate, so arranged as to fit between the lips and teeth and provided with a tube through which the air passes, may also be used. A much more nearly air-tight closure of the mouth is possible with this apparatus.

By this method which has recently been improved, especially by Zuntz, the cutaneous respiration is of course not determined, but it is of 110 particular importance (cf. Chapter XIII). A more serious objection is, that with this method it is very difficult, if not impossible, to continue the experiment for more than a quarter of an hour to an hour. Where it is necessary to determine 
the $\mathrm{CO}_{2}$ and water exereted and the oxygen absorbed for a whole day or longer, other methods must be used.

For these purposes several different forms of respiration apparatus have been constructed, among which we shall very brietly describe the following:

1. [The Apparatus of Atwater and Benedict.-In its general features this apparatus, constructed for experiments on human subjects, embodies the prineiples of one originally construeted by Regnault and Rieset (1849) for experiments on smaller animals. The subject is placed in a respiration chamber of suitable size (5.03 cubic meters eapacity) and is supplied with pure air, as indieated in the diagram below (Fig. 40). The air enntaining the respiratory products is drawn out of the chamber by the pump and is made to pass in turn over $\Pi_{2} \mathrm{SO}_{4}$ and soda lime. The gain in weight of the former gives the amount of water

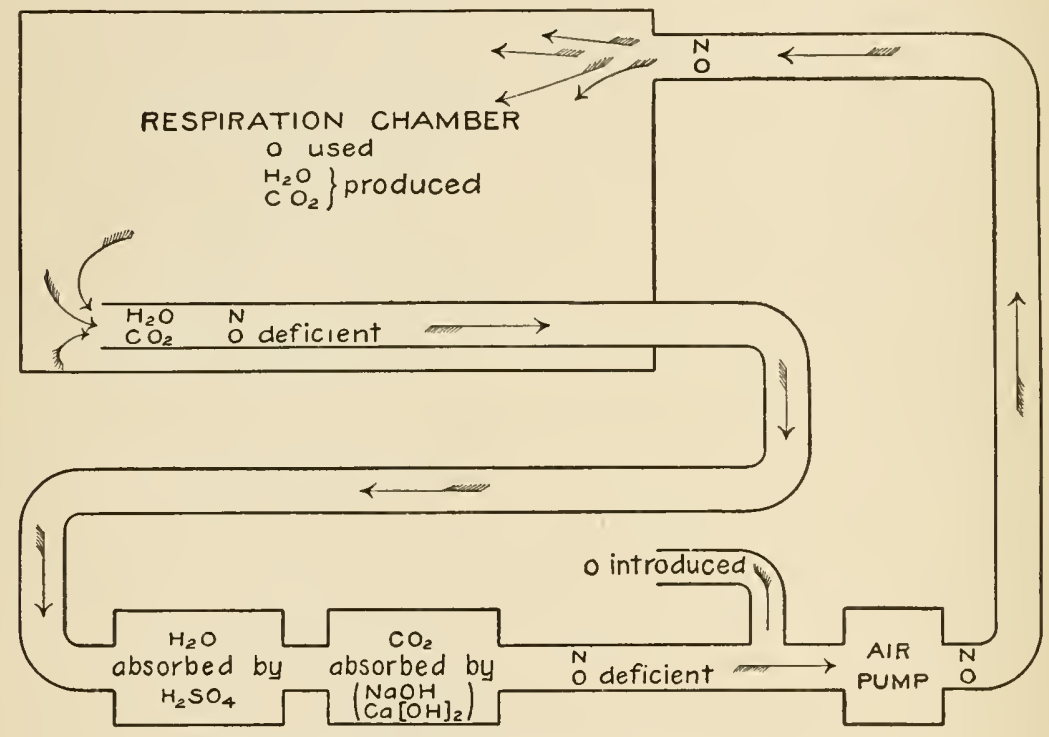

FIG. 40.- Schema of the Atwater-Benedict respiration calorimeter.

eliminated by the respiration and evaporation; the gain in weight of the latter, the amount of carbon dioxide eliminated. Pure oxygen is next admitted to make up what has been taken out by the subject. To determine exactly how much oxygen has been thus absorbed it is necessary to know how much was eontained in the air at the beginning and how much at the end of the experiment. Subtracting the amount present at the end from the total amount supplied-i.e., the amount present at the beginning plus the amount admitted-gives direetly the amount absorbed.

The respiration chamber in this apparatus is provided also with means of measuring the heat lost from the subjeet's body by radiation and conduction, so that the entire apparatus is described as a respiration calorimeter.-En.]

2. The Apparatus of Pettenkoffer.-This consists of a respiration chamber with a capacity of 12.7 cubic meters into which and from which air is pumped in a continuous stream. The air is analyzed both as it goes in and as it comes out of the chamber, a uniform fractional part of the total volume flowing out 


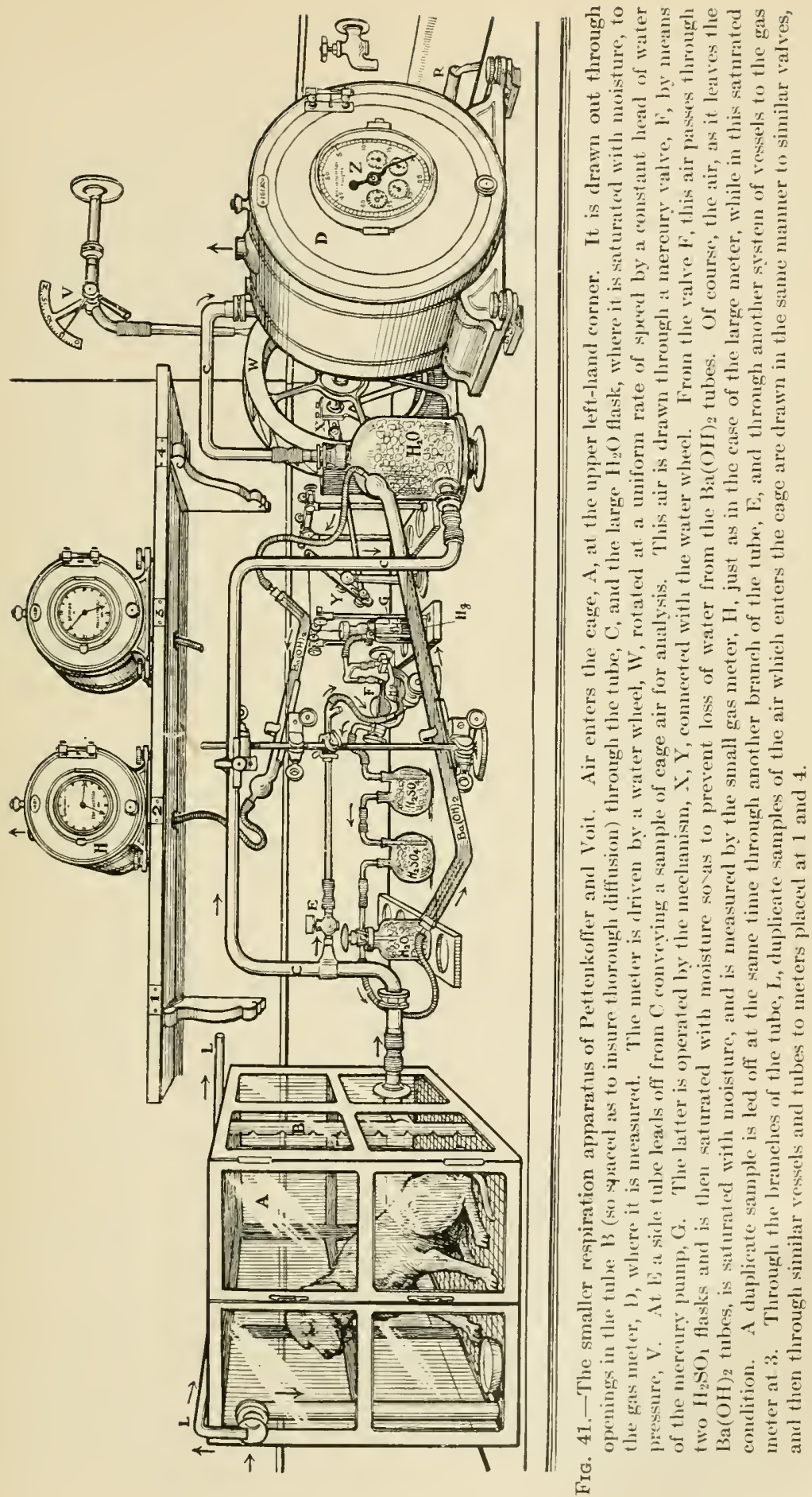


being led off to suitable apparatus for the absorption of earbon dioxide and water.

[A smaller apparatus embodring the same prineiples has been construeted by Voit for experiments on smaller animals (Fig. 41). The cage (A) is rentilated by a current of air kept moring by rotation of the gas meter (D). Throughout the experiment a sample of this air is continually led off br a side tube (E) and is passed orer pumice stone soaked in sulphuric acid and then through $\mathrm{Ba}(\mathrm{OH})_{2}$. The quantits of $\mathrm{H}_{2} \mathrm{O}$ in this air is obtained directly by the difference in the weight of the $\mathrm{H}_{2} \mathrm{SO}_{4}$ flasks, the amount of $\mathrm{CO}_{2}$ by titration of the $\mathrm{Ba}(\mathrm{OH})_{2}$. The large gas meter (D) measures the total rolume of air passing through its works, and the small gas meter $(H)$ measures the rolume of the sample. A duplieate analysis is made by means of a second set of

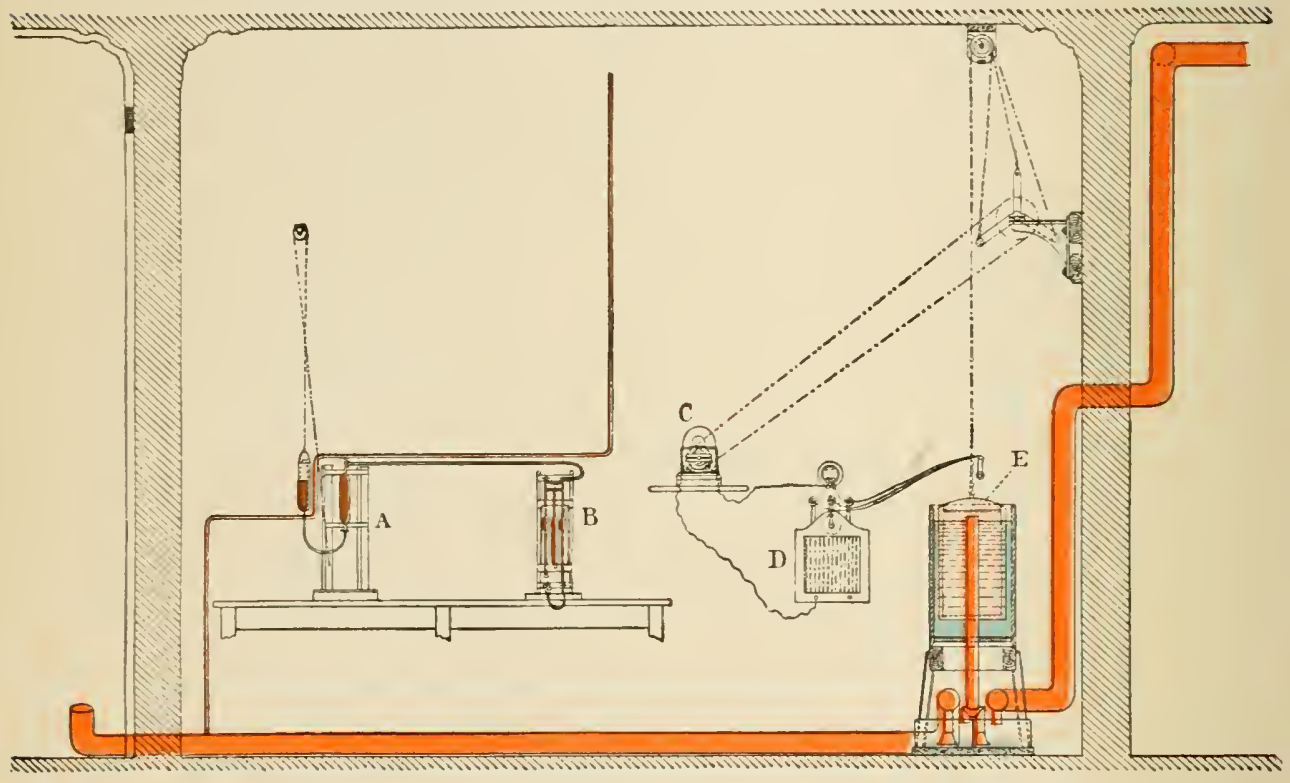

FIG. 42.-The respiration apparatus of Sondén and Tigerstedt. A, container for sample of the room air; $\mathrm{B}$, apparatus for determination of $\mathrm{CO}_{2}$; $\mathrm{C}$, electric motor; $\mathrm{D}$, rheostat; $\mathrm{E}$, hydraulic pump.

ressels, and this sample is measured by a similar gas meter. Duplicate analyses of the air which enters the cage are made in the same manner and the respiratory produets ealeulated by difference.

If the determination of water vapor is satisfactory, the amount of oxygen absorbed by the animal can be obtained by subtracting the combined weight of the animal at the beginning of the experiment and the total ingesta for the period

${ }^{1}$ Voit and Pettenkoffer made very thorough tests of this method, and found that the water is obtained to within 1 or 2 per cent, the slight error being due to condensation on the walls of the tubes. Rubner, employing the same principles of ventilation for his calorimeter, obtained still more exact results. By shortening the distance which the air inust travel on its way from the cage to the $\mathrm{H}_{2} \mathrm{SO}_{4}$ flasks, he was able to prevent entirely the condensation of water on the walls of the tubes. For short experiments he relied upon hair hydrometers placed inside the cage.-ED. 
from the combined weight of the animal at the end and the total excreta for the period.-ED.]

3. The Apparatus of Sonden and Tigerstedt (Fig. 42).-The subject is housed in an ordinary room with a capacity of $100.6 \mathrm{cu.m}$. The walls, ceiling, and floors are covered with sheet zinc and are made air-tight by soldering all the joints. By means of a hydraulic pump (E) air is drawn from this respiration chamber to a gas meter, where it is measured. Fresh air from outdoors replaces the foul air drawn out. A uniform diffusion of the air in the room is insured by a rentilating fan.

To obtain air for analysis, a narrow tube branches off from the main inlet pipe (red), and by means of another hydraulic pump a constant stream is maintained through it, so that the air in the branch always has the same composition as that in the main inlet. At stated intervals samples for analysis are then taken (in the ressel $A$ ) from this branch and the carbon dioxide is estimated by the method of Pettersson (B) for the analysis of gases. The quantity of carbon dioxide is calculated by the rentilation formula of Lenz.

But the body suffers other losses in organic substance than those resulting from combustion. Here belong the losses by sloughing off of the epidermis, cutting the hair and nails, ejection of sperm and menstrual blood. secretion of milk. etc. Such losses. however, are either so slight that they do not affect the results of the investigation, or they come in only occasionally and can generally be neglected, unless the investigation is being directed especially to them.

\section{APPORTIONMENT OF THE INDIVIDUAL ELEMENTS TO THE DIFFERENT EXCRETA}

(1) Expired Air.-It has been known since the beginning of scientific investigation of metabolism and can be demonstrated without the least difficulty that carbon and hydrogen leave the body as $\mathrm{CO}_{2}$ and $\mathrm{H}_{2} \mathrm{O}$ in the expired air. Not so with the nitrogen and nitrogenous compounds. A priori one cannot deny that such substances also might be given off from the body as products of metabolism in the expired air. But from the many researches which have been carried out with reference to this question. it appears certain that this is not the case. So far as metabolism is concerned we need, therefore, to consider among the respiratory products only carbon dioxide and water rapor.

(2) Sueat.-Water is the principal substance given off through the skin. However, the sweat contains also some solid substances. the most important of which is urea. With copious sweating, as under severe labor or in a vapor bath. the quantity of these constituents may rise so much that to neglect them would involve considerable error. Thus, under such circumstances, $0.56 \mathrm{~g}$. I have been found in the sweat; at the same time the nitrogen cxcretion in the urine was $15.9 \mathrm{~g}$. for twenty-four hours. In this casc. therefore, the sweat contained 4.8 per cent of the $\mathrm{N}$ eliminated through the kidneys (Argutinsky).

(3) Urine. - of the chemical elements derired from the organic foodstuffs and found in the urine, nitrogen and carbon are to be specially considered. Both of these occur mainly in the form of urea and uric acid. The daily quantity of nitrogen eliminated in the urine of an adult man amounts 
to about $15-16 \mathrm{~g}$., but exhibits wide variations, depending primarily upon the quantity of nitrogen ingested in the food.

The quantity of carbon in the urine as compared with that in the expired air is very small. Only when very great exactness is desired does it need to be determined directly, for it can generally be calculated without any considerable error from the nitrogen of the urine. The ratio $\mathrm{N}: \mathrm{C}$ in the urine exhibits but very slight rariations; according to Atwater, it has for a mixed diet a mean ralue of about $1: 0.72(0.64-0.79)$.

(4) Faces.-The fæces are composed partly of unabsorbed residues of the food, partly of residues of the digestire fluids, and partly of worn-out epithelial cells and excretory products from the alimentary tract. In a fasting man these residues make up a fæcal mass, which contains from 0.11 to $0.32 \mathrm{~g}$. of nitrogen per twenty-four hours. When a nonnitrogenous diet, or one very poor in nitrogen, is given, from 0.5 to $0.4 \mathrm{~g}$. of $\mathrm{N}$ appear in the fæces per day (Rubner, Rieder). 'This quantity of $\mathrm{N}$ must evidently have its origin in the intestine itself. We can say, therefore, that the intestine has a rery large share in the formation of the fæces. and that in round numbers one gram of the $\mathrm{N}$ eliminated as a product of metabolism is to be found in the intestinal evacuations. The nitrogen contained in the bacteria of the fæces is also included in this figure.

Since experiments from Pawlow's laboratory (Chapter VII) show that the secretion of the digestive juices and their $\mathrm{N}$-content present considerable variations with different diets, one might be tempted to look upon the total quantity of nitrogen in the frees as a pure product of metabolism. But this is not true, for many observations have shown that with certain articles of diet a considerable part of this freal nitrogen actually represents a residue of the food.

In any given case therefore it is quite impossible to decide how much of the frcal nitrogen comes from the one source and how much from the other. For this reason it has become customary to regard the total nitrogen in the frees as a residue of the food. Although it must be admitted that such an assumption is quite incorrect from a purely theoretical point of view, it makes no difference in the calculation of results of metabolism experiments. For if we suppose that the frees are exclusively a product of metabolism, the implication is that all the food was absorbed without loss; and vice versa, if we regard the frces as only a residue of the food, then the quantity utilized must be diminished by the mass of the frees. In both cases we reach exactly the same result with regard to the amount of metabolism actually taking place. In this presentation of the subject of metabolism, therefore, we shall reckon the fæces as a residue of the food.

Respecting the nonnitrogenous substances giren off in the fæces, we may merely mention here the fact that fat occurs in appreciable quantity both on a fat-free diet and in fasting. In the latter case $0.6-1.4 \mathrm{~g}$. per day have been found in the frces, and on a fat-free diet, 3-7 g. per day. If, therefore, on a fat diet the fæces do not contain more than $7 \mathrm{~g}$. of fat per day, we can say that the fat in the food has been almost entirely absorbed in the intestine.

In the frees the ratio of $\mathrm{N}: \mathrm{C}$ for a mixed diet is about $1: 9.2(6.8-13.8)$. Inasmuch as the quantity of nitrogen in the frees ordinarily does not amount to more than $2 \mathrm{~g}$. per day, in most cases it is sufficient to calculate the carbon from the nitrogen. 
We have already seen that under normal eircumstances no nitrogen is eliminated in the expired air as a product of metabolism, and that in the sweat only in exceptional cases is the quantity of any importance. Hence the channels by which nitrogen is exereted are the kidneys and the intestine as will appear plainly from a case of nitrogenous equilibrium.

If an animal be given a diet, which from day to day contains exactly the same quantity of nitrogen and does not vary with regard to the nonnitrogenous foodstuffs, after a few days one finds in the urine and freces exactly as much nitrogen (and sulphur) as had been ingested in the food. This eondition is called nitrogenous equilibrium. As an example the following experiment from Gruber may be given:

\begin{tabular}{|c|c|c|c|c|c|}
\hline DAYS OF EXPERIMENT. & N-intake $g$. & Noutput $g$. & Per cent dif. & S-intake g. & S-output g. \\
\hline I. $\begin{array}{r}1-i) \\
6-1 ; \ldots \ldots \ldots \ldots \ldots\end{array}$ & $\begin{array}{r}90.00 \\
131.60\end{array}$ & $\begin{array}{r}89.81 \\
132.75\end{array}$ & $\begin{array}{l}-0.21 \\
+0.88\end{array}$ & $\begin{array}{l}\cdots \cdots \\
\cdots \cdots\end{array}$ & $\begin{array}{l}\cdots \cdots \\
\cdots \cdots\end{array}$ \\
\hline II. $1-2 \ldots \ldots$ & $\begin{array}{r}35.80 \\
144.50\end{array}$ & $\begin{array}{r}36.16 \\
143.13\end{array}$ & $\begin{array}{l}+1.00 \\
-0.86\end{array}$ & & $\cdots \cdots$ \\
\hline III. $\begin{array}{r}1-\tau \ldots \ldots \ldots \ldots \\
8-1 \tau \ldots \ldots \ldots \ldots\end{array}$ & $\begin{array}{l}154.81 \\
213.72\end{array}$ & $\begin{array}{l}153.02 \\
213.26\end{array}$ & $\begin{array}{l}-0.51 \\
-0.21\end{array}$ & j2. & 12.79 \\
\hline
\end{tabular}

\section{EXAMPLE OF A METABOLISM EXPERIMENT}

The following table after Atwater contains a smmmary of the ingesta and excreta in an experiment with mixed food. The experiment lasted four days, the subject being a man thirty-two rears of age and of aloout $6 \mathrm{it} \mathrm{kg}$. body weight, who remained as quiet as possible throughout the experiment.

Ingesta. mean weight in g. per day

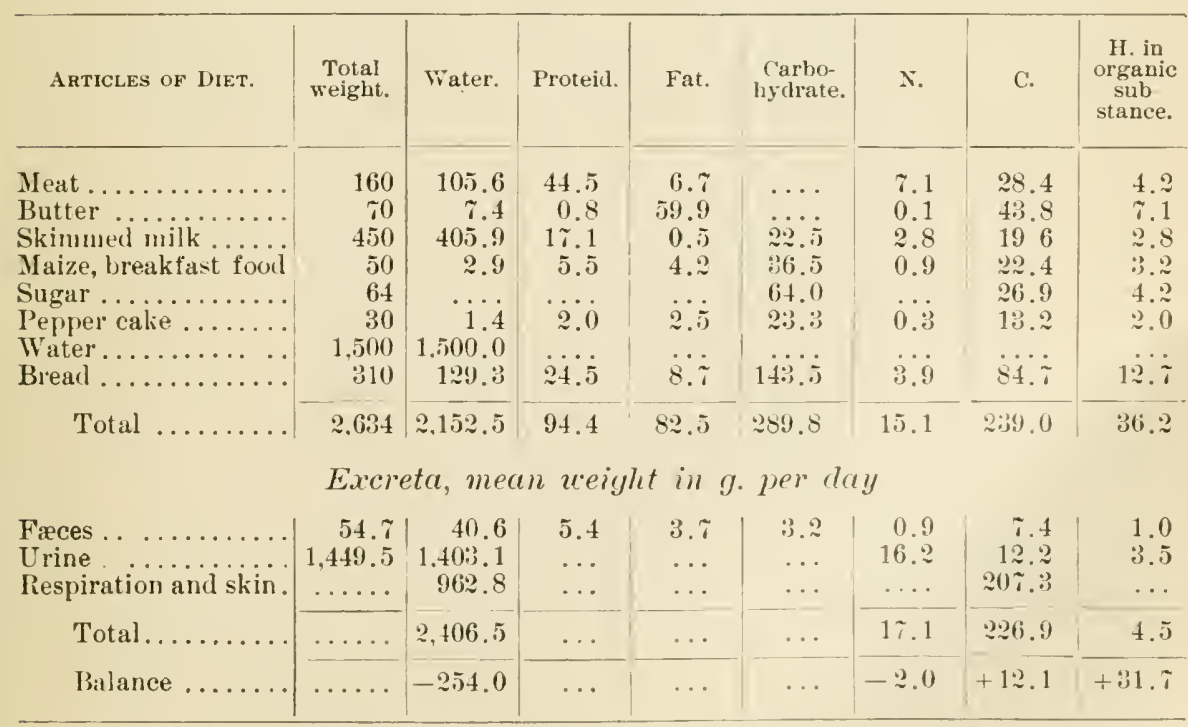


If we consider the faces as pure loss (cf. page 90 ), the body las disposed of $(94.4 \mathrm{~g}$. ingrested $-5.4 \mathrm{~g}$. excreted $=)$ s9.0 g. proteid containing

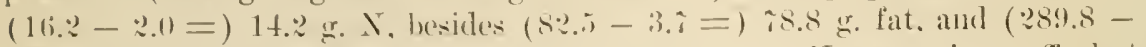
$3.2=): 286.6$ g. carbohydrates. In the urine $16.2 \mathrm{~g}$. N were given off; but 2.0 g. of the $\mathrm{N}$ liave come from the body itself-i. e., $(6.25 \times 2=) 12.5 \mathrm{~g}$. of the body's proteid has heen lost. 'T'he total proteid netabolism, therefore, has been $(89 \mathrm{~g} .+12.5=) 101.5 \mathrm{~g}$. (or $16.2 \times 6.25)$.

The ratio of $\mathrm{X}$ to $\mathrm{C}$ contained in proteid is $1: 3.28$. In the proteid destroyed by this man therefore there were $3.2 \mathrm{~S} \times 16.2=53.1 \mathrm{~g}$. C. The total quantity of ( elminated in the respiration and in the urine was $219.5 \mathrm{~g}$.; there remain $166.4 \mathrm{~g}$. which must have been derived from nonnitrogenous food.

Of carbohydrates 286.6 g. (28!. 9 ingested -3.2 excreted) were absorbed from the intestine, and this by calculation was found to have contained 124.7 g. C. Now we shall see later that carbohydrates burn in the body more easily than fat. We therefore deduct first the $\mathrm{C}$ belonging to carbohydrate. This leaves $41.7 \mathrm{~g}$. C $(166.4-124.7)$ which must have come from fat-i. e., since the fat used contained about seventy-six per cent $\mathrm{C}, 54.6 \mathrm{~g}$. fat were burned in the body.

We conclude that the boly has decomposed a mean quantity of $101.5 \mathrm{~g}$. proteid, $54.6 \mathrm{~g}$. fat and $286.6 \mathrm{~g}$. carbohydrate per day. Comparison with the ingesta, having regard to the C resulting from proteid destroyed, shows that the body las lost $12.5 \mathrm{~g}$. of its proteid but has stored up $24.2 \mathrm{~g}$. fat, containing $12.2+6.5 \mathrm{~g}$. C.

\section{§ 2. POTENTIAL ENERGY OF THE FOODSTUFFS}

The energy stored in a combustible sulstance is measured by the quantity of heat generated in its combustion, and is constant for every individual substance. The heat values of the substances most important for our present purpose, as determined by the calorimeter, are given in the following table. All data are for $1 \mathrm{~g}$. of the substance and the heat values here, as elsewhere in this discussion, are expressed in large Calories (Cal.).

\begin{tabular}{|c|c|c|c|}
\hline SUBSTANCE. & $\begin{array}{l}\text { One g. of dry sub- } \\
\text { stance yields- }\end{array}$ & $\begin{array}{l}\text { One g. of ash-free } \\
\text { substance yields- }\end{array}$ & Author. \\
\hline 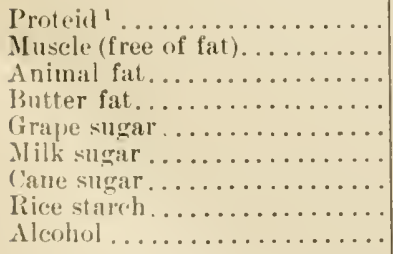 & $\begin{array}{l}5.754 \text { Cal. } \\
5.345 \text { ' } \\
\ldots \ldots \\
\ldots \ldots \\
\ldots \ldots \\
\ldots \ldots \\
\ldots \ldots \\
\ldots \ldots\end{array}$ & 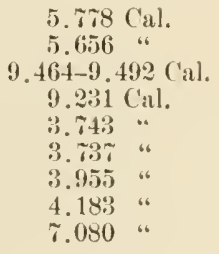 & $\begin{array}{c}\text { Rubner } \\
\text { Stohmann } \\
\text { "، } \\
\text { "، } \\
\text { " } \\
\text { Berthelot }\end{array}$ \\
\hline
\end{tabular}

When fat or carbohydrates are burned in the body, they are completely oxidized inte carbon dioxide and water. If, therefore, the principle of con- 
servation of energy is true for the body, the heat ralue of these substances as determined by the calorimeter must be their heat value in the body.

Quite otherwise is it with proteid. The end products of its metabolism are not all completely oxidized, and hence contain not a little potential energy. To obtain the heat value of proteid for the body we must therefore dednct from its calorimetric heat value the heat value of the waste products resulting from its metabolism. This Rubner has done in the following way.

He fed a small dog with a proteid material whose calorific energy had been previously determined by combustion, and then determined the calorific energy of the corresponding urine and fxees. The former for 1 gram of proteid decomposed was 1.0945 Cal.; the latter, also for $1 \mathrm{~g}$. of proteid, was $0.185+$ Cal. Finally. he deducted 0.05 C'al. for the hydrolytic absorption on the part of the proteid while in the body and for the solution of urea. For $1 \mathrm{~g}$. of dry proteid we would have therefore a physiological heat value of $5.754-(1.0945+0.1854+0.05)=4.424 \mathrm{Cal}$.

In an analogous way the net physiological heat value of muscle deprived of its fat only was found to be 4.001 Cal., and that of the proteid of the bods destroyed in fasting 3.842 Cal. For every gram of $\mathrm{N}$ found in the excreta after feeding the former we should estimate, therefore, $25.95(6.25 \times 4.001)$ Cal. and in fasting $24.94(6.25 \times 3.84) \mathrm{Cal}$.

Human urine vields on the average $8.0 \mathrm{Cal}$. for every gram of nitrogen contained. Human freces, per $1 \mathrm{~g}$. of $\mathrm{N}$, yield all the way from 66 to $159 \mathrm{Cal}$. but per gram of organic substance the fairly eonstant value of $5.2-7.5$ (mean 6.5) Cal. (Rubner, Atwater, Loewy).

In most metabolism experiments one has to deal not with pure lean meat. pure starch, or a definite kind of fat, but with a mixture of rarious fats. carbohydrates, ete. One must be content with the determination by direct analysis of the quantity of total proteid. total fat and total carbohydrate: for absolutely exact analysis of separate kinds of proteid, ete. wonld make all metabolism experiments impracticable. From such determinations as those above mentioned, Rubner calculated the mean dynamic ralue of the chief groups of the organic foodstufts to be as follows:

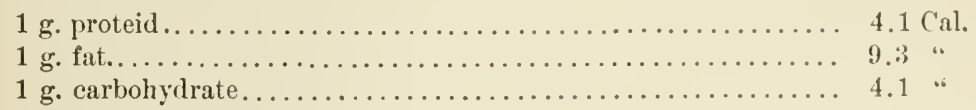

From the standpoint of the conservation of energy, it is to be assumed beforehand that these theoretical calorific values must be correct also for these substances when burned in the living body. In fact we have direct experimental proofs of this; and precisely because these pronfs verify the assumption. they are of the greatest importance for the whole subject of phrsiology.

As long ago as 1883, Rubner showed by a Inng selies of experiments. the details of which we cannot enter into here, that the dilferent organic fondstuffs can replace one another in isodynamie quantities-i. e., in quantities whieh yield equal amounts of ealorifie energy. The foregoing assumption was sufficiently substantiated by these results alone. But Rubner carried his investi- 
gations still further $(1894)$. By the use of the calorimeter he determined on dogs (direct calorimetry) the amount of heat lost, and at the same time estimated from the excreta the total metabolism (see page 92 ); then, from the calorific values of the foodstuffs. he calculated the amount of heat production (indirect calorimetry) in the body represented by this metabolism. The result was that in eight series of experiments covering altogether fortysix days the mean difference between the heat production as calculated from the metabolism and the heat loss determined by the calorimeter was only 0.3 per cent.

In some very careful experiments with men on a mixed diet Atwater has obtained similar results. In these experiments not only were the food and the total excreta analyzed, but the calorific vahes of the food, the urine and the faces were determined directly; and at the same time the heat given off by the subject was measured by the calorimeter in which he was confined.

In the following table are summarized experiments taken at random from Atwater's papers, and in parallel columns are placed figures representing (1) the amount of heat production as calculated by him, and (2) the amount of heat loss determined directly. Besides. in order to test by these observations the heat values of the organic foodstuffs as giren by Rubner, which are generally accepted as standard, we have calculated from Atwater's data the

MeAN PER Day

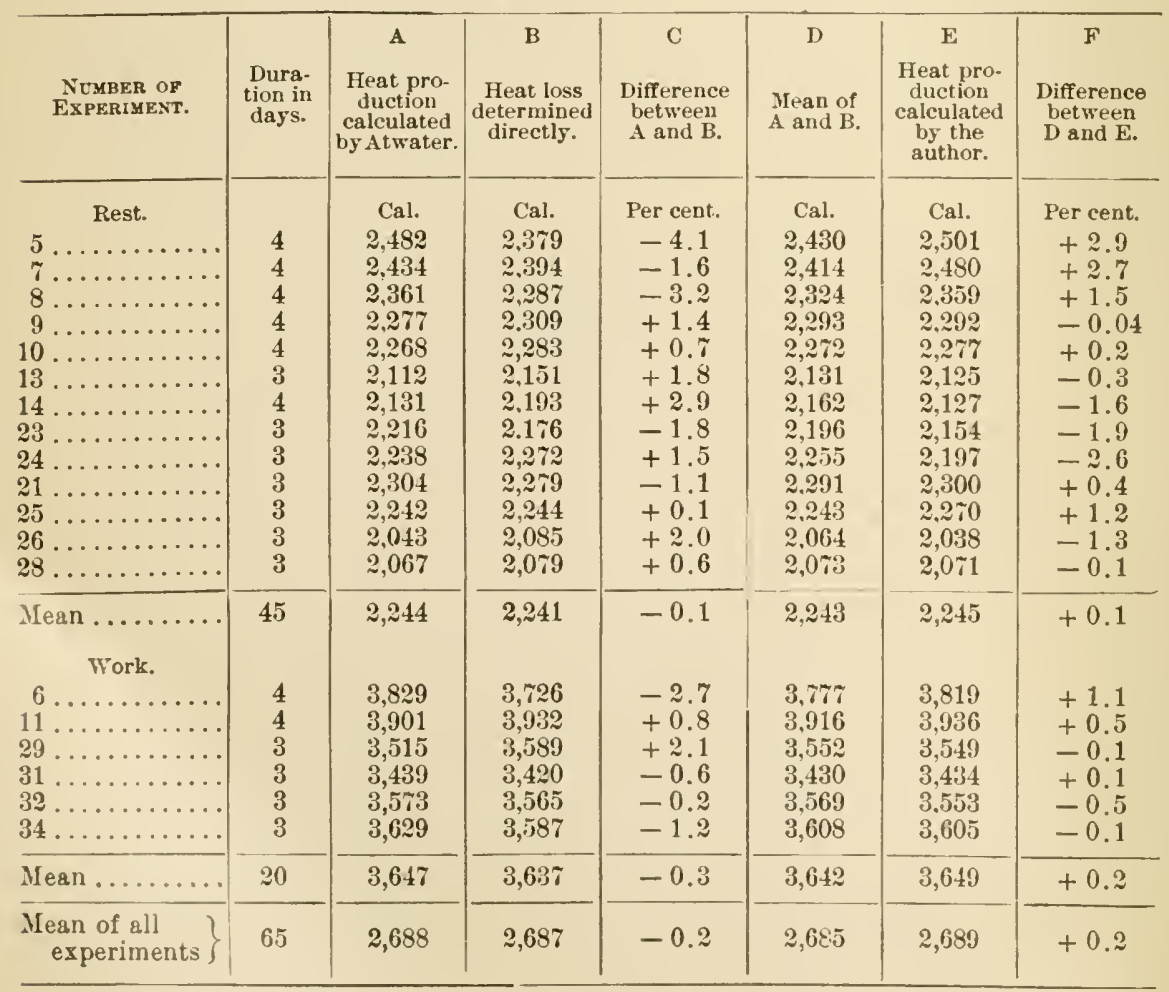


amount of heat proruced in each experiment by the destruction of proteid, fats and carbohydrates. These results are given in other columns. ${ }^{1}$

The greatest difference between A and B is 4.1 per cent, the least difference is 0.1 per cent. In the rest series the mean difference is 0.1 per cent, in the work series 0.3 per cent.

It is, therefore, conclusively demonstrated by Rubner's and by Atwater's experiments that the foodstuffs generate the same quantity of heat when burned within the body as when burned outside the body. From a comparison of column $\mathrm{E}$ with $\mathrm{D}$, in the foregoing table, it follows also that the calorific estimation of metabolism by means of the standard heat values of the organic foodstuffs yields very satisfactory results in the light of the heat production as actually measured.

\section{§ 3. METABOLISM IN FASTING}

Quantitatively considered, metabolism takes the simplest form in the fasting condition, when the body is living exclusively at the expense of its own combustible materials. Hence it will be best to begin the discussion of the processes of metabolism with a presentation of that which takes place in fasting.

\section{A. THE GENERAL CONDITION IN FASTING}

It is commonly supposed that fasting is a rery painful state. But this is not the case. Observations on starving animals as well as fasting experiments recently carried out on men show that no real pain is felt.

During the first day of fasting, especially at the usual meal times, there is a feeling of hunger, but it soon disappears; and it may even happen that when the individual is again permitted to eat, he has no real desire for food. Neither animals nor men have any great need for water during the fasting condition. Fasting dogs often do not drink when water is offered them, and fasting men give out mueh more water than they take in.

What is especially characteristic of the fasting condition is the progressive loss of strength. But even this is not always pronounced, as will be seen from the case of Succi observed by Luciani. Sucei fasted for thirty days, and on the twelfth day he took a horseback ride lasting one hour and forty minutes; the same evening he walked around the room a great deal, ran an endurance race with three young students which lasted for eight minutes, and then went through a fencing exereise. On this day he took 19,900 steps. On the twenty-third day of his fast, he visited the theater in the evening, and there engaged in two bouts with swords, in which he showed endurance, strength and agility. On this day he took 7,000 steps.

The pulse frequency decreases during rest in the fasting state; but with very slight exercise it rises much higher than normal. The body-temperature (rectum) remains normal or falls only $0.1^{\circ}-0.3^{\circ} \mathrm{C}$, until within the last few days (third to ninth) before death by starvation, when it falls rapidly and

1 Since the Calorie as used by Atwater is based upon water at a temperature of $20^{\circ} \mathrm{C}$., and is therefore about 1 per cent lower than that usually employed $\left(0^{\circ} \mathrm{C}\right.$.), we have used the following figures in this calculation: $1 \mathrm{~g}$. proteid $=4.2$ Cal.. $1 \mathrm{~g}$. fat $=9.4,1 \mathrm{~g}$. carbohydrate $=4.15$. 
suddenly. The body weight very gradually declines. The average daily loss in the first five to ten days of long fasting periods endured by men, has been found to be 1.0-1.5 per cent of the original weight.

During fasting a mass consisting of worn-out epithelial eells and residues of the digestive fluids aecumulates in the intestine, which either during the fast or after it is broken is evaeuated as frees (cf. Chapter VII). From observations on fasting men, the daily quantity of fresh faees is estimated at $9.5-22.0 \mathrm{~g}$., of dry frees at $2-3.8 \mathrm{~g}$. They eontain $0.113-0.316 \mathrm{~g}$. of nitrogen, $0.41-1.35 \mathrm{~g}$. of ether extract and $0.25-0.48 \mathrm{~g}$. of ash. Microseopic examination of freces reveals numerous fine, needle-shaped crystals of the fatty acids embedded within a finely granular, amorphous ground substance, but no true formed eonstituents.

\section{B. CHARACTER OF THE METABOLISM IN FASTING}

In fasting the total metabolism falls gradually from the first day onward. Estimated per $\mathrm{kg}$. of body weight, lowever, the daily decline is only relatively small and remains for a long time at about the minimum reached at the beginning of the fasting period. As proof of this statement, we give here the results of a five-day fasting experiment on a man.

\begin{tabular}{|c|c|c|c|c|c|c|c|}
\hline & \multirow{2}{*}{$\begin{array}{c}\text { Body } \\
\text { weight } ; \mathrm{kg} .\end{array}$} & \multicolumn{4}{|c|}{ Decomposed : $\mathrm{g}$. of -} & \multirow{2}{*}{$\begin{array}{c}\text { Total } \\
\text { metab- } \\
\text { olism, } \\
\text { Cal. }\end{array}$} & \multirow{2}{*}{$\begin{array}{l}\text { Cal. } \\
\text { Per kg } \\
\text { of body } \\
\text { weight }\end{array}$} \\
\hline & & N. & Fat. & $\begin{array}{c}\text { Carbo- } \\
\text { hydrate. }\end{array}$ & Alcohol. & & \\
\hline Last food day.. & 67.8 & 23.41 & $8 \pi$ & 267 & 28 & 2,705 & 39.9 \\
\hline First fast day... & 67.0 & 12.17 & 206 & $\ldots$ & . & 2.220 & 33.2 \\
\hline Second fast day. & 65.7 & 12.85 & 192 & & 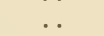 & 2.102 & 32.0 \\
\hline Third fast day. & 64.9 & 13.61 & 181 & .. & . & 2,024 & 31.2 \\
\hline Fourth fast day. & 64.0 & 13.69 & 178 & & 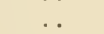 & 1,992 & 31.1 \\
\hline Fifth fast day. & 63.1 & 11.47 & 181 & & & 1,970 & 31.2 \\
\hline First food day .. & 64.0 & 25.44 & 64 & 250 & 22 & 2.437 & 38.1 \\
\hline Second food day. & 65.6 & 18.07 & 72 & 248 & 37 & 2,410 & 36.8 \\
\hline
\end{tabular}

As is customary in fasting experiments, we have assumed that the total quantity of carbon from nonnitrogenous substances comes from fat. But the body contains at the beginning of the fast a certain quantity of glycogen, whose heat value calculated per $\mathrm{g}$. of carbon is less than that of fat. This glycogen disappears for the most part during the first day of starration and a part of the carbon reckoned as fat donbtless has its origin in this glycogen. Our figures for the total metabolism, during the first two fasting days at least, are, for this reason. too large; and hence it is possible that the body reaches its minimum metabolism on the first or second day of fasting.

To enter further into the processes of metabolism in fasting it will be necessary for us to discuss the decomposition of proteid and fat more fully. Nothing further can be said at present concerning the share of carbohydrates stored in the body in these decompositions, and in any case it must be regarded as unimportant in comparison with that of fat.

Experiments show that with well-nourished animals, having a plentiful deposit of fat in their bodies, the destruction of proteid gradually declines day by day until death; whereas with poorly nourished, lean animals after a 
preliminary fall there occurs a rise in the proteid metabolism, sometimes of considerable size.

This great diminution in the proteid metabolism in fasting, although occurring with various fluctuations, has been verified also for men. In the thirtyday fasting experiment on Succi the $\mathrm{N}$-output on the tenth day was forty-nine per cent of the output at the beginning; on the twentieth day it was thirty-two per cent, and on the twenty-ninth day it was thirty per cent. In men also we meet with this peculiar relationship: the $N$-output in the urine increases from the third or fourth day, then falls off again (cf. table, page 94i). The chief reason for this behavior probably is that on the first day the glycogen deposited in the body spares a part of the proteid from being destroyed; but since most of the glycogen is used up on this day, so that on the second day its protecting influence has ceased to exist. more proteid is then attacked. In this way the body must become impoverished in available proteid, consequently its destruction falls again and from now on the combustion in the borly is maintained to a large extent by the fat, provided the body be not too poor in fat (Prausnitz).

From facts concerning metabolism after feeding, which will be summarized under $\$$, we know that of all the foodstuffs ingested proteid is the most easily decomposed. Nevertheless in fasting the share of proteid in the total metabolism (calcnlated in calories) of animals previonsly well nourished is only seven to seventeen per cent. Inasmuch as this proteid comes from the tissues themselves, it follows that they are not by any means so easily decomposed as is the food proteid, or more correctly stated. they give up proteid from their own substance only in relatively small quantities.

The increase in the destruction of proteid which takes place in the later stages of fasting and which continues thence until shortly before death, is a very interesting phenomenon. Voit, who first observed the phenomenon, explained it by supposing that the fat had all been used up, hence the proteid metabolism was increased in order to keep up the energy requirements of the body. This conclusion was fully confirmed by the following experiment by Rubner. The $\mathrm{N}$-output per day he found to be: first to third day, $1.67 \mathrm{~g}$.; fourth to fifth day, $1.46 \mathrm{~g}$.: sixth to eighth day, $3.21 \mathrm{~g}$. The amount of fat burned proved to be: on the second day, $10.3 \mathrm{~g}$.; fourth day, $10.3 \mathrm{~g}$; ; eighth day, $2.4 \mathrm{~g}$.

When at the conclusion of the fast food is again supplicd, the borly shows a pronouneed ability to make good its losses, and now lays on both proteid and fat in large quantities. In the five-day fasting experiment eited above the subject lost during the five dars $399 \mathrm{~g}$. proteid, $938 \mathrm{~g}$. fat. $32 \mathrm{~g}$. ash and $3,8: 9$ g. water. On the succeding diet, which was a rich one. and of which 4,1+1 Cal. were absorbed daily, he destroved a mean quantity for two days of only 2,424 Cal. daily, and thus reenered in these two days twenty per cent of the lost proteid. thirty-six per cent of the lost fat, seventy-one per cent of the lost water, and sixty-nine per cent of the lost ash.

\section{LOSS OF SUBSTANCE FROM THE DIFFERENT ORGANS}

In fasting the body lives at the expense of its ou'n substance. On purely antecedent grounds it would be most natural to suppose that the organs in 
which the greatest amount of work is done would be destroyed to the greatest extent. But this is not true; on the contrary, these very organs seem to suffer the least loss of substance, while the loss is greatest from those organs upon which little or no demand is made in fasting.

If this conception be correct-and it must be admitted that direct observations are still very inadequate-it would follow that in fasting the organs do not do their work at the expense of their own substance. It seems that all the organs contribute to the support of the body; but those organs which are of primary importance for the maintenance of life, utilize the materials thus contributed by all, in the performance of their particular functions; that is to say, they work at the expense of the less vital organs: their own state of nutrition suffers less, and hence they decrease in weight relatively little.

This view receives support from certain experimental facts. The bones, for example, bear a part in the general levy made upon the organs. E. Voit fed pigeons with food which was sufficient in every other respect, but was very poor in calcium. The birds fared very well and were killed after some time. On section it became erident that those bones which were used in the movements of the animal were normal, while others such as the sternum and the skull were brittle and in places were even perforated. Since calcium was being lost from the body all the time, and none was being supplied in the food to replace it, the "resting" bones gave up their calcium to the "active" bones.

Probably a still more interesting example is furnished by Miescher's investigations on the Rhine salmon. This fish leaves the sea in the best condition of nourishment, but it remains in fresh water for six to nine months without eating anything. During this time it naturally becomes exceedingly thin and gaunt, and its muscles greatly diminished in size; but the reproductive organs become the more strongly developed. The substance of muscle has gone to make ova and sperm cells.

Sooner or later, however, there comes a time when the activity of the vital organs and of those most necessary for the generation of heat in the body, falls to the minimum. If animals be wrapped up in bedding they can be kept alive for a brief time longer. But respiration and the heart beat soon cease and the animal dies in a state of the most profound exhaustion.

\section{§ 4. INFLUENCE OF FOOD ON THE METABOLISM}

The most noteworthy thing about metabolism with food is the peculiar position which proteid occupies with reference to the other organic foodstuffs. If a dog be given a sufficient quantity of proteid with no fat or carbohydrate, under proper circumstances the body will remain in an equilibrium of substance, the ingesta and the excreta completely balancing each other. If, however, the dog receive carbohydrate and fat in plentiful quantities but no proteid, equilibrium never occurs. The body continually excretes nitrogenous waste products-which means that proteid is continually being destroyedand after a time, which is somewhat longer than when no food at all is given, the animal finally dies of "proteid starvation."

Since we have no reason to suppose that there is any essential difference between the chemical processcs involved in the final decomposition of the foodstuffs in the $\operatorname{dog}$ and in man, it is theoretically conceivable that a man also 
could be nourished exclusively with proteids. But the capabilities of the digestive organs must be considered. In man they are not able to digest and absorb proteid enough to maintain the body; hence man is always compelled to eat nonnitrogenous foodstuffs in addition to proteid.

\section{A. INFLUENCE OF THE QUANTITY OF PROTEID IN THE FOOD ON PROTEID METABOLISM}

This exceptional position of proteid prompts us to discuss the conditions of its metabolism first. Let us begin by inquiring how the quantity of proteid supplied to the body affects the proteid destruction therein. The following summary of a series of experiments by Bischoff and Voit may serve to give us our bearings. The animal received nothing but meat, which was earefully freed of fat, bones, eartilage, ete. The pereentage of nitrogen in the meat is estimated at 3.4 per cent (corresponding to about twenty-one per cent of proteid).

\begin{tabular}{|c|c|c|c|}
\hline EXPERIMENTS. & $F$ ingested, g. per day. & $N$ excreted, g. per day. & X-balance, g. per day. \\
\hline 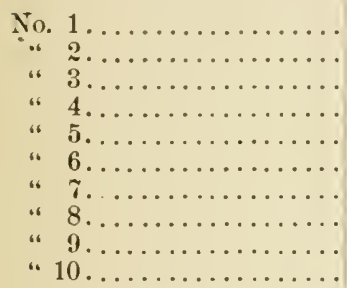 & $\begin{array}{r}61.2 \\
51.0 \\
40.8 \\
30.6 \\
20.4 \\
10.2 \\
6.0 \\
0.0 \\
61.2 \\
85.0\end{array}$ & $\begin{array}{l}57.5 \\
51.4 \\
41.9 \\
37.1 \\
23.1 \\
15.4 \\
12.5 \\
7.7 \\
58.4 \\
81.4\end{array}$ & $\begin{array}{l}+3.7 \\
-0.4 \\
-1.1 \\
-6.5 \\
-2.7 \\
-5.2 \\
-6.5 \\
-7.7 \\
+2.8 \\
+3.6\end{array}$ \\
\hline
\end{tabular}

From this and other similar series of experiments it follows without question: (1) that inereasing the supply of proteid increases its destruction in the body: (?) that the entire supply of proteid. or, when it is large. almost the entire supply. is destroyed; and (3) that proteid is retained in the body (ef. numbers $1,9,10$ ) only when fed in very large quantities.

\begin{tabular}{|c|c|c|c|c|c|}
\hline \multirow{2}{*}{\multicolumn{2}{|c|}{ EXPERIMENTS. }} & \multicolumn{2}{|c|}{ Food per day. } & \multirow{2}{*}{$\begin{array}{l}\text { N excreted, } \\
\text { g. per day. }\end{array}$} & \multirow{2}{*}{$\begin{array}{l}\text { N-balance, } \\
\text { g. per day. }\end{array}$} \\
\hline & & g. s. & g. Fat. & & \\
\hline $\begin{array}{l}\text { No. } \\
\text { ". } \\
\text { "“ } \\
\text { ". } \\
\text { ". }\end{array}$ & 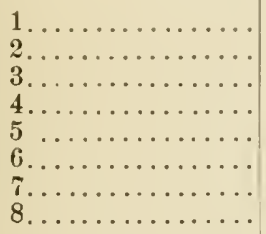 & $\begin{array}{r}5.1 \\
8.5 \\
15.3 \\
17.0 \\
25.5 \\
34.0 \\
42.5 \\
51.0\end{array}$ & $\begin{array}{l}250 \\
250 \\
250 \\
250 \\
250 \\
250 \\
250 \\
250\end{array}$ & $\begin{array}{r}7.9 \\
9.2 \\
11.7 \\
15.1 \\
22.4 \\
29.8 \\
39.2 \\
47.0\end{array}$ & $\begin{array}{l}-2.8 \\
-0.7 \\
+3.6 \\
+1.9 \\
+3.1 \\
+4.2 \\
+3.3 \\
+4.0\end{array}$ \\
\hline $\begin{array}{l}\text { No. } \\
\text { “" } \\
\text { ". }\end{array}$ & 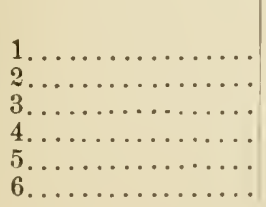 & $\begin{array}{r}23.8 \\
20.4 \\
14.6 \\
8.8 \\
5.1 \\
0.0\end{array}$ & $\begin{array}{r}\text { Starch. } \\
150 \\
150 \\
200 \\
250-350 \\
350-430 \\
450\end{array}$ & $\begin{array}{r}26.3 \\
23.1 \\
18.8 \\
13.4 \\
10.7 \\
5.7\end{array}$ & $\begin{array}{l}-2.5 \\
-2.7 \\
-4.2 \\
-5.6 \\
-5.6 \\
-5.7\end{array}$ \\
\hline
\end{tabular}


The proteid metabolism behaves in essentially the same way when the diet contains a constant quantity of nomnitrogenous organie foodstuffs in addition to proteid. This may be seen from the preceding table.

Just as the body can destroy rery different quantities of proteid. it can also be placed in nitrogenous equilibrium with rery different quantities of this foodstuff (ef. first table on page 91).

The following experiments from Voit will gire some idea of the time required to reach nitrogenous equilibrium:

I

\begin{tabular}{|c|c|c|c|}
\hline DAY. & X-intake, g. per day. & X-output, g. per day. & N-balance. g. per day. \\
\hline 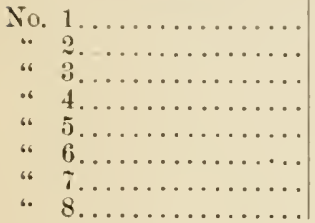 & $\begin{array}{l}1 \% .0 \\
51.0 \\
51.0 \\
51.0 \\
51.0 \\
51.0 \\
51.0 \\
51.0\end{array}$ & $\begin{array}{l}18.6 \\
41.6 \\
44.5 \\
47.3 \\
47.9 \\
49.0 \\
49.3 \\
51.0\end{array}$ & $\begin{array}{r}-1.6 \\
+9.4 \\
+6.5 \\
+3.7 \\
+3.1 \\
+2.0 \\
+1.7 \\
\quad 0.0\end{array}$ \\
\hline
\end{tabular}

II

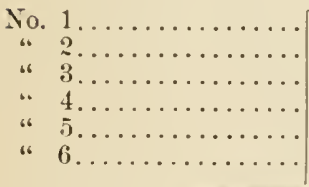

51.0

34.0

34.0

34.0

34.0

34.0

51.0
39.2
36.9
37.0
36.7
34.9

The two experiments were carried out on the same animal. Previous to the first the $\log$ had received $1 \tau \mathrm{g}$. of $\mathrm{N}$ (500 g. meat) daily. Equilibrium had not been established with this quantity, for on the last day of this period he lost $1.6 \mathrm{~g}$. of $\mathrm{N}$ from the body. The supply of $\mathrm{N}$ (in meat) was then increased to 51 g.; immediately the $N$-metabolism rose, but perfect equilibrium was not reached until the seventh dar, and during this time $26.4 \mathrm{~g}$. I were retained in the body.

What beeame of this nitrogen? It might have been retained as dead proteid, as living protoplasm, or in the form of decomposition products. The last possibility has been rendered very improbable by various experiments of Voit. We shall return later to the question of whether the nitrogen is stored as proteid or as protoplasm.

The second experiment is just the reverse of the first. Here the animal had previously received $51 \mathrm{~g}$. $\mathrm{N}(1,500 \mathrm{~g}$. meat) and had been in nitrogenous equilibrium. The $\mathrm{N}$-supply was then eut down to $34 \mathrm{~g}$. The result was that on the very first day the $\mathrm{N}$-exeretion was less than before, and during the following days it sank lower and lower until on the fifth day it reached approximately the level of the amount supplied. During these five days the animal lost $14.8 \mathrm{~g}$. $\mathrm{N}$ from his body.

Nitrogen exeretion runs a similar course during the first few days of starvation. If the same animal be made to fast, in the one ease after feerling a plentiful supply of meat, and in the other after feeding a scant supply, the exeretion of $\mathrm{X}$ in the urine during the first few days behaves very differently: the greater 
the supply of proteid previous to starvation, the greater is the exeretion of $\mathrm{N}$ during the first few days of starvation. It falls rapidly, however, and after about five days the amount of $\mathrm{N}$ eliminated is about the same whatever the composition of the food may have been previous to the experiment (Fig. 43).

Various circumstances favor the idea that this excess of nitrogen exereted from the body does not come from nitrogenous decomposition products left orer from previous days, but that, in the transition from a $\mathrm{N}$-rieh to a $\mathrm{N}$-poor diet or to fasting, a certain quantity of the proteid stored in the body undergoes decomposition until the organism has adapted itself to the diminished supply of proteid.

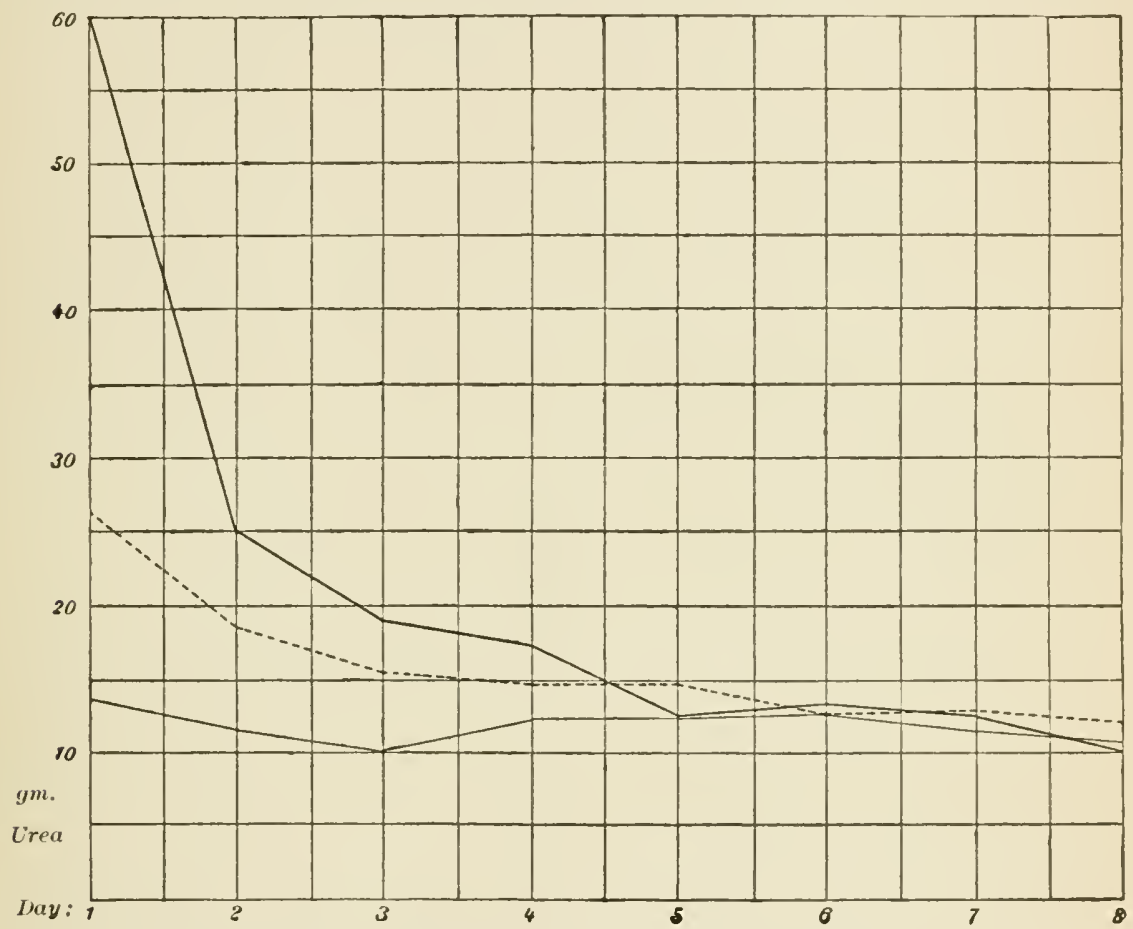

F1G. 43.-Three experiments on the elimination of urea by fasting dogs, after Voit. The food previous to the fasting period in the experiment — consisted of $2,500 \mathrm{~g}$. meat; in ....... $1,500 \mathrm{~g}$. meat; and in only a little proteid.

The body places itself in nitrogenous equilibrium when the food contains both nitrogenous and nomitrogenous substances, in exactly the same way as it does on an exclusively proteid liet.

The fact that proteid decomposition depends primarily upon the amount of proteid supplied is confirmed in a very interesting way by observations on the nitrogen exeretion during the different hours of the twenty-four. The hourly excretion proves to be dependent to a very great extent upon the nitrogen absorption from the intestine. The eurves in Fig. 44 will serve as an illustration. They represent the $\mathrm{N}$-elimination in the urine in two-hour periods, from $8 \mathrm{~A} . \mathrm{s}$. until $12 \mathrm{r}$.s. The dotted line shows the elimination in fasting, the continuous line, on ordinary diet. 


\section{B. THE TOTAL METABOLISM AFTER INGESTION OF PROTEID}

So far we have confined ourselves to the decomposition of proteid without inquiring how the nonnitrogenous organic foodstuffs behare at the same time. But in order to interpret correctly the phenomena just discussed we must consider also the metabolism of the latter-i.e., we must know the total

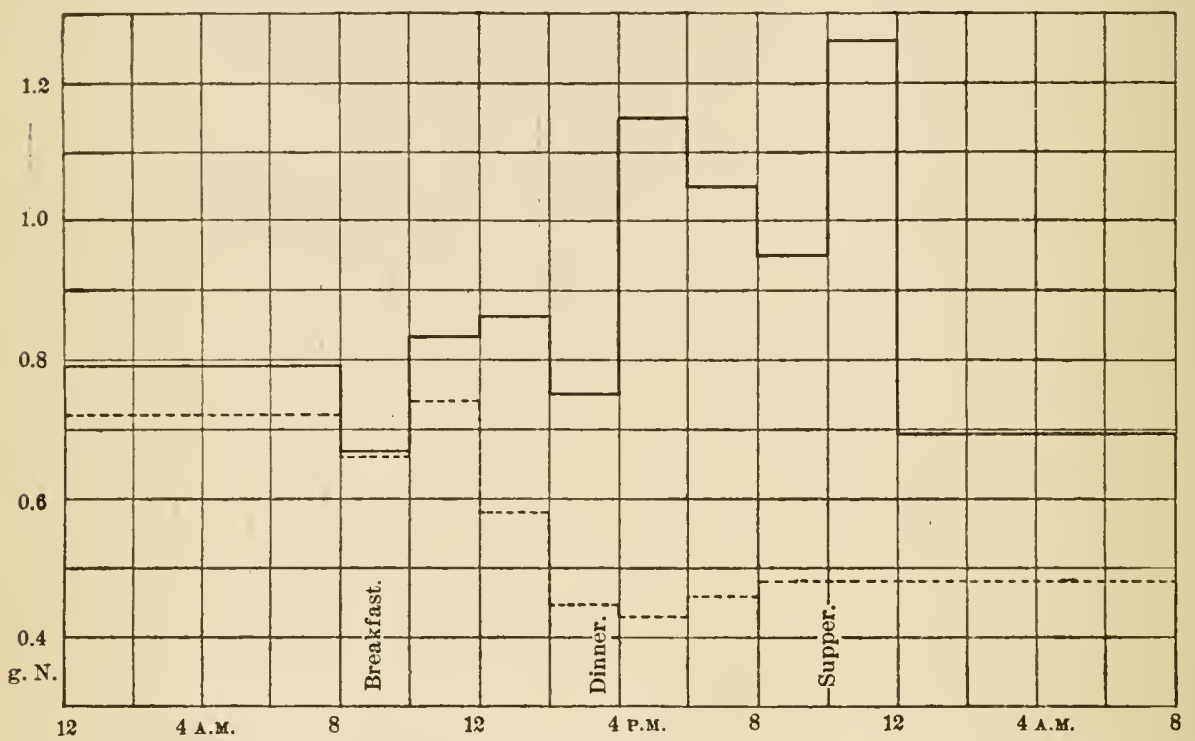

Fig. 44.-The elimination of $\mathrm{N}$ in the urine of man, determined every two hours, after Tengwall.

metabolism. As a basis for this discussion we may start with the famous experiments of Pettenkoffer and Voit on equilibrium, which are given in the following tables:

In the first series of experiments meat only was fed. The nonnitrogenous metabolism is calculated from the carbon excreted (cf. page 90) and is estimated in terms of fat.

\begin{tabular}{|c|c|c|c|c|c|c|}
\hline & EXPERIMENTS. & $\begin{array}{c}\mathrm{N} \text { in food, } \\
\mathrm{g} .\end{array}$ & $\begin{array}{c}\text { N excreted, } \\
\mathrm{g} .\end{array}$ & $\begin{array}{c}\text { N-balance, g. } \\
\text { per day. }\end{array}$ & $\begin{array}{c}\text { Fat-balance, } \\
\text { g. per day. }\end{array}$ & $\begin{array}{l}\text { Total metabo- } \\
\text { lism, Cal. }\end{array}$ \\
\hline $\begin{array}{l}\text { No. } \\
\text { " } \\
. \\
. " \\
\text { " } \\
\text { " }\end{array}$ & 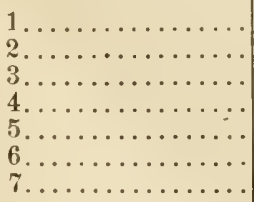 & $\begin{array}{l}17.0 \\
34.0 \\
51.0 \\
61.0 \\
68.0 \\
85.0\end{array}$ & $\begin{array}{r}5.6 \\
20.4 \\
36.7 \\
51.0 \\
59.7 \\
69.5 \\
85.4\end{array}$ & $\begin{array}{l}-5.6 \\
-3.4 \\
-2.7 \\
\cdots \\
+1.3 \\
-1.5 \\
-0.4\end{array}$ & $\begin{array}{l}-98.0 \\
-61.0 \\
-43.0 \\
-24.0 \\
-36.0 \\
+\quad 8.0 \\
+\quad 4.0\end{array}$ & $\begin{array}{l}1,067 \\
1,106 \\
1,360 \\
1,552 \\
1,893 \\
1,741 \\
2,181\end{array}$ \\
\hline
\end{tabular}

In this and the following tables from Pettenkoffer and Voit, the carbon of proteid is calculated by the ratio, $\mathrm{N}: \mathrm{C}=1: 3.28$. [This ratio was first determined by Rubner in Voit's laboratory, but is generally attributed to Pflüger.-Ev.] 
We see that as the amount of proteid fed increases the amount of fat burned decreases, so that, when from 68 to $85 \mathrm{~g}$. of $\mathrm{N}$ are supplied (in meat), a small amount of fat is stored in the body.

Estimation of the total metabolism in Cal. shows that as the amount of proteid in the food is increased, not only is the proteid decomposition increased but also the total decomposition, although the latter to a much less extent than the former. With $85 \mathrm{~g}$. N (2,500 g. meat) in the food the total metabolism is about twice as great as in fasting or with $1 \tau \mathrm{g}$. N (500 g. meat), whereas the proteid decomposition is fifteen times as great as in fasting and about four times what it is with $17 \mathrm{~g} . \mathrm{N}$ in the food.

In his experiments on the metabolism of proteid in the body Voit thought he had found that the smallest quantity of proteid with whieh the body ean place itself in $\mathrm{N}$-equilibrium, even when carbohydrates or fats are administered freely, was higher than the quantity destroyed in starvation after the first few days of abstinence. Further investigations have shown, however, that in ease the body receives enough nonnitrogenous foodstuffs to enable it to maintain a general equilibrium of substance, the quantity of protsid ean be smaller than this.

From experiments by Hirsehfeld. Kunragawa and Kilemperer it appeared that $\mathrm{N}$-equilibrium with small quantities of $\mathrm{N}$ in the food is only obtained when the total amount of food supplied is much in excess of the usual diet. Thus, while an adult man at rest maintains himself in $\mathrm{N}$-equilibrium on about $100 \mathrm{~g}$. proteid a day with a total energy supply of 32-35 Cal. per $\mathrm{kg}$., in their experiments when the supply of proteid was cut down to $43.5 \mathrm{~g} ., \mathrm{N}$-equilibrium only oceurred when the total supply of energy was as much as $47.5 \mathrm{Cal}$. per $\mathrm{kg}$.; and with $33 \mathrm{~g}$. proteid only when the total supply reached 78.5 Cal. per $\mathrm{kg}$.

Sivén has shown however that when the $\mathrm{N}$-supply is not eut off suddenly, but is reduced gradually, no such excess of the total supply of energy is necessary. Under such eireumstances N-equilibrium was obtained, in the ease of a man doing a moderate amount of work, with 41.4 Cal. per kg. per day, although the diet contained only $28.3 \mathrm{~g}$. nitrogenous substance. The quantity of actual proteid here was only $12.4 \mathrm{~g}$. In other words, this man reeeived only $0.08 \mathrm{~g}$. total $\mathrm{N}$ per $\mathrm{kg}$., of which only $0.03 \mathrm{~g}$. was proteid $\mathrm{N}$, and yet he maintained his $\mathrm{N}$-equilibrium.

In the fasting experiment on Sucei (ef. page 95) from the twenty-first to the twenty-fifth day, $0.09 \mathrm{~g}$. $\mathrm{N}$ per $\mathrm{kg}$. were exereted in the urine. In riew of the long abstinence here, it is likely that this nitrogen eame exclusirely from proteid. This being true, it follows that the body ean be brought into $\mathrm{N}$-equilibrium with a supply of proteid which is considerably less than the amount destroyed in the later stages of starration.

In experiments on dogs with food defieient in proteid but otherwise suffieient, I. Munk and Rosenheim obserred from the sixth to the eighth week onward various severe disorders in the health, which finally led to the death of the animals some weeks later. Aceording to this, a diet poor in nitrogen when taken eontinuously would be dangerous even if $\mathrm{N}$-equilibrium were established. The experiments of Jägerroos stand squarely opposed to this view. They show that a dog ean live much longer than eight weeks on such a food without exhibiting any disturbance to the health, provided he receive his proteid in the form of fresh raw meat. It appears, therefore, that in the earlier experiments it was not the deficieney of nitrogen itself, but the unsuitable charaeter of the food which was the eause of sickness and death. 


\section{METABOLISM AFTER INGESTION OF FAT}

If an animal be given as much fat as he uses from his own body in fasting, the latter is entirely replaced by the fat in the food. This will appear from the following observations on the $\log$ ( Toit) :

A

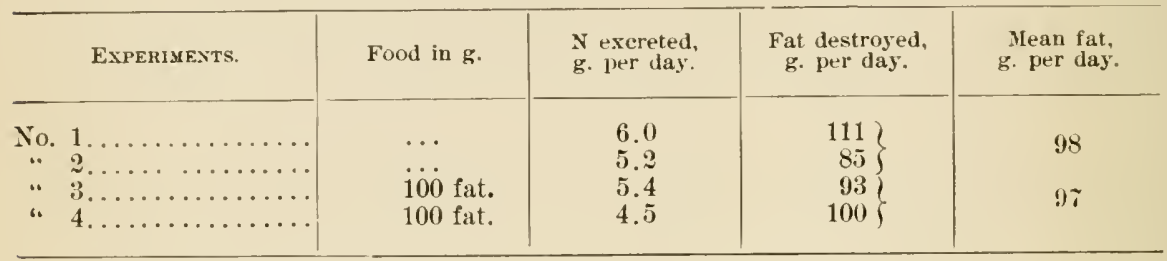

When the supply of fat is considerably greater than the amount of fat destroyed in starvation, its metabolism is inereased.

B

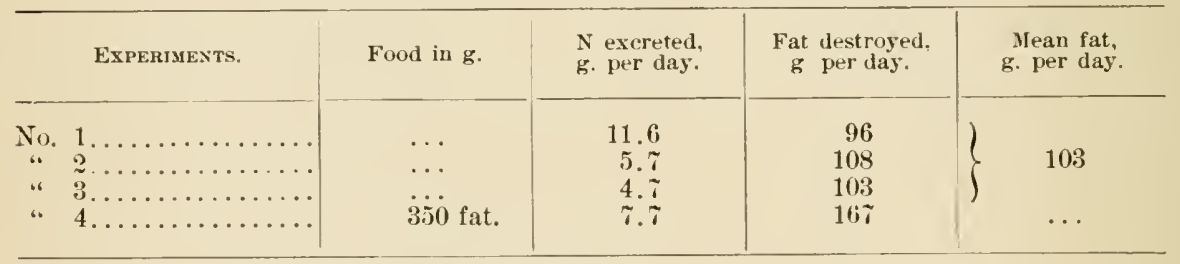

At the same time the total metabolism becomes greater: in No. 1. table B, it amonnts to 1.209 Cal., in No. t. to 1.r80 Cal. The increase is forty per cent. Quite similar results have been obtained in similar experiments by Rubner.

The following table contains a summary of experiments by Pettenkoffer and Voit on the total metabolism after feeding meat and fat:

\begin{tabular}{|c|c|c|c|c|c|}
\hline \multirow{2}{*}{ EXPERINENTS. } & \multicolumn{2}{|c|}{ Food. } & \multirow{2}{*}{$\begin{array}{l}\text { N exereted, } \\
\text { g. }\end{array}$} & \multirow{2}{*}{$\begin{array}{l}\text { Fat destroyed, } \\
\text { g. }\end{array}$} & \multirow{2}{*}{$\begin{array}{l}\text { Total metab } \\
\text { olism, } \\
\text { Cal. }\end{array}$} \\
\hline & N. g. & Fat, $g$. & & & \\
\hline 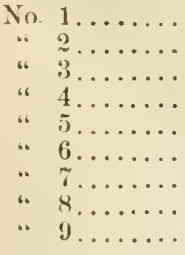 & $\begin{array}{l}17.0 \\
1 \% .0 \\
17.0 \\
51.0 \\
51.0 \\
51.0 \\
51.0 \\
51.0 \\
51.0\end{array}$ & $\begin{array}{r}100 \\
200 \\
30 \\
30 \\
60 \\
100 \\
100 \\
150\end{array}$ & $\begin{array}{l}20.4 \\
16.7 \\
17.6 \\
51.0 \\
49.5 \\
51.0 \\
47.7 \\
49.3 \\
49.5\end{array}$ & $\begin{array}{r}61 \\
75 \\
116 \\
24 \\
2 \pi \\
51 \\
35 \\
18 \\
40\end{array}$ & $\begin{array}{l}1,106 \\
1,144 \\
1,555 \\
1,552 \\
1,542 \\
1.807 \\
1,569 \\
1.451 \\
1,663\end{array}$ \\
\hline
\end{tabular}

We have here two series of experiments on the same animal, the one with $1 \%$, the other with $51 \mathrm{~g}$. $\mathrm{N}$, and with rarying quantities of fat in each ease. 
In the first the destruction of fat increases slightly with the amount of fat fed. In the second we see that the addition of $30-150 \mathrm{~g}$. fat to $1.500 \mathrm{~g}$. meat $(51 \mathrm{~g} . \mathrm{N})$ increases neither the fat destruction nor the total metabolism. Iletabolism, therefore, is not influenced by feeding fat to anything like the same extent that it is by feeding proteid.

\section{METABOLISM AFTER INGESTION OF CARBOHYDRATES}

In order to decide to what extent carbohydrates fed have participated in the total metabolism it is not sufficient to determine merely the $\mathrm{N}$ and $\mathrm{C}$ in the excreta; for we have in these data alone no means of telling how much $\mathrm{C}$ belonging to the nonnitrogenous substances came from carbohydrates and how much from fat. But if the $\mathrm{O}_{2}$ absorbed in the same period be determined also, it is possible to deeide whether the nonnitrogenous metabolism has been mainly from carbohydrates or mainly from fat.

When carbohydrates alone are burned the ratio between the volumes of carbon dioxide excreted and oxygen absorbed-i. e., the respiratory quotient $\left(\frac{\mathrm{CO}_{2}}{\mathrm{O}_{2}}\right)$-is just equal to 1 ; when fat alone is burned. it is only 0.r1. The amount of $\mathrm{C}_{2}$-elimination and $\mathrm{O}_{2}$-absorption corresponding to the proteid destroyed can be calculated without any difficulty from the $\mathrm{N}$-excretion. But a certain quantity of carbon dioxide eliminated and of oxygen absorbed remains to be accounted for by the oxidation of fat or carbohydrate or both. Now if the respiratory quotient is high (near 1 ) we know that carbohydrates hare participated to a great extent, but if it is low (near 0.i5) we know that fat has entered largely into the metabolism.

So far only brief experiments performed by the use of the face mask have been made along this line. From these it may be gathered: that on a carbohydrate diet the respiratory quotient increases orer that found in fasting; that the carbohydrates. therefore, are attacked immediately after their absorption from the intestine: and that in part at least they take the place of body fat in the general metabolism.

From these experimental facts it has been concluded further, that the carbohydrates fed are all destroved before the body fat, and also before the fat in the food: and the results of all experiments in which carbohydrates are ingested by the body are calculated on this basis. This conclusion, however, is not fully warranted by the facts, and in opposition thereto it might be urged, among other things, that even in fasting the body protects its glycogen: and hence this carbohydrate at least is not all destroyed before the body fat.

The matter can only be settled positively by experiments corering a long period of time. in which either the amount of oxygen consumed or the amount of heat lost from the body shall be determined directly. Although unfortunately we have no experiments of this kind, still in the calorimetric studies of Atwater there are some very valuable results which permit us to take perfectly definite ground with regard to this question (cf. page 9t). As mentioned before, the total transformation of energy in these experiments was both calculated indirectly from the heat of combustion of the food and ex- 
creta, and determined directly from calorimetric measurement of the heat given off by the subject of the experiment. In all the experiments carbohydrates were giren in fairly large quantities and in the calculation of the leat values it was presumed, in conformity with the current view, that they were burned first. Now the experiments actually show a very close agreement between the calculated and the observed heat production. From which it follows that the theoretical presumption is a correct one, and that the total quantity of carbohydrates absorbed is burned before the body fat.

Especially instructive are two series of experiments in which both the total calories supplied (2,490 and 2,489 respectively) and the quantity of proteid were the same, but where the proportion of fat to carbohydrates was considerably different in the two. In the one experiment $94.8 \mathrm{~g}$. fat $+247.2 \mathrm{~g}$. carbohydrates were administered, in the other $40.3 \mathrm{~g}$. fat $+375.2 \mathrm{~g}$. carbohydrates. Direct calorimetric determination of the heat production sielded in the first $2,085 \mathrm{Cal}$. , in the second $2,079 \mathrm{Cal}$, showing that the ratio of carbohydrates to fats within these limits at least is a matter of indifference to the organism.

Let us see now in which direction the addition of carbohydrates will influence the total metabolism.

Experiments of Pettenkoffer and Voit along this line gave the following results :

\begin{tabular}{|c|c|c|c|c|c|c|c|}
\hline \multirow{2}{*}{ EXPERIMENTS. } & \multirow{2}{*}{$\mathrm{N}$. } & \multicolumn{2}{|c|}{ Food in $\mathrm{g}$. } & \multirow{2}{*}{$\begin{array}{l}\text { G. of } \mathrm{N} \\
\text { excreted. }\end{array}$} & \multicolumn{2}{|c|}{ Destroyed $\mathrm{g}$. of } & \multirow{2}{*}{$\begin{array}{l}\text { Total metab } \\
\text { olism, }{ }^{2} \\
\text { Cal. }\end{array}$} \\
\hline & & Fat. & Carb. & & Fat.1 & Carb. & \\
\hline 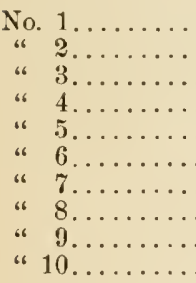 & $\begin{array}{l}17.0 \\
17.0 \\
17.0 \\
17.0 \\
51.0 \\
51.0 \\
61.2 \\
61.2\end{array}$ & $\begin{array}{r}10.2 \\
4.6 \\
10.3 \\
17.5 \\
236.5\end{array}$ & $\begin{array}{l}167 \\
182 \\
167 \\
172\end{array}$ & $\begin{array}{r}7.3 \\
7.2 \\
20.4 \\
19.3 \\
18.3 \\
18.0 \\
51.0 \\
50.2 \\
59.7 \\
50.0\end{array}$ & $\begin{array}{r}103.0 \\
-56.3 \\
61.0 \\
-19.9 \\
-10.9 \\
-14.0 \\
24.0 \\
-38.1 \\
36.0 \\
-112.9\end{array}$ & $\begin{array}{l}379 \\
1 \ddot{6} \dot{7} \\
182 \\
167 \\
1 \ddot{7} \dot{2} \\
\ddot{3} \dot{79}\end{array}$ & $\begin{array}{r}1,164 \\
1,208 \\
1,106 \\
998 \\
1,117 \\
1,020 \\
1,552 \\
1,649 \\
1,893 \\
1,782\end{array}$ \\
\hline
\end{tabular}

From Experiments 1 and 2 jt appears that the total metabolism after ingestion of carbohydrates (and a little fat) is not greater than it is in starvation, that carbohydrates therefore can completely replace the fat destroyed in starvation. From the series with $500 \mathrm{~g}$. meat ( $17 \mathrm{~g}$. N) no influence of the carbohydrates on the total metabolism is indicated. With 1,500 g. of meat addition of $1 \% 2 \mathrm{~g}$. carbohydrates produces only a slight increase (less than ten per cent), with $1,800 \mathrm{~g}$. meat, $379 \mathrm{~g}$. carbohydrates produce no increase at all.

1 A - sign means that fat has been stored in the body.

${ }^{2} 1 \mathrm{~g} . \mathrm{N}=26.0(25.98)$ Cal., $1 \mathrm{~g}$. fat $=9.46 \mathrm{Cal} ., 1 \mathrm{~g}$. carbohydrate $=4.1 \mathrm{Cal}$. 


\section{E. SUMMARY AND DISCUSSION}

It appears from the experimental facts brought together under divisions $B e$ to $D e$, that the ingestion of proteid always raises metabolism to a considerable extent, whereas ingestion of fat and carbohydrates either produces no increase, or at most only a slight one.

The experiments of Pettenkoffer and Voit, from which these conclusions are drawn, were not earried out in a continuous series, and it is possible that the result was due in part to the changed condition of the animal. The following series by Rubner is, therefore, more decisive, because the experiments came one immediately after the other:

\begin{tabular}{|c|c|c|c|c|c|c|}
\hline \multirow{2}{*}{$\mathrm{D}_{\Delta \mathbf{Y}}$} & \multirow{2}{*}{$\mathrm{N}, \mathrm{g}$. } & \multicolumn{3}{|c|}{ Ingesta. } & \multicolumn{2}{|c|}{ Metabolism, Cal. } \\
\hline & & Fat, g. & Carb., g. & Cal. & Total. & Per kg. \\
\hline $\begin{array}{l}2 \ldots \ldots \ldots \\
3 \ldots \ldots \ldots \\
4 \ldots \ldots \\
5 \ldots \ldots \\
7 \ldots \ldots \ldots \\
8 \ldots \ldots\end{array}$ & $\begin{array}{l}56.8 \\
\ldots \\
\ldots \\
\ldots \\
\ldots \\
\ldots\end{array}$ & $\begin{array}{l}\cdots \\
\cdots \\
16 \tau \\
\cdots \\
\cdots \\
\cdots\end{array}$ & $\begin{array}{l}\cdots \\
\cdots \\
\cdots \\
11 i \\
\cdots\end{array}$ & $\begin{array}{r}1,513 \\
1,036 \\
1,046 \\
\ldots \ldots\end{array}$ & $\begin{array}{r}969 \\
1,072 \\
947 \\
963 \\
922 \\
982 \\
977\end{array}$ & $\begin{array}{l}40.2 \\
44.8 \\
39.9 \\
40.9 \\
39.6 \\
42.3 \\
42.1\end{array}$ \\
\hline
\end{tabular}

In fasting (days $2,4,6$ and 8 ) the average metabolism was 40.4 Cal. per $\mathrm{kg}$. of body-weight; on feeding $56.8 \mathrm{~g}$. $\mathrm{N}$ it was $44.8 \mathrm{Cal}$. per $\mathrm{kg}$. . with $167 \mathrm{~g}$. fat, $40.9 \mathrm{Cal}$.; and with $411 \mathrm{~g}$. earbohydrate, $42.3 \mathrm{Cal}$. The percentage inerease orer the fasting metabolism was therefore 11.9 for proteid, 1.2 for fat, and 4.2 for carbohydrate-although, as is evident from the table, the heat value of the food in all eases was almost exactly the same.

In another series on feeding $1,500 \mathrm{~g}$. meat Rubner found an inerease of 24.3 per cent over the fasting metabolism, and on feeding $153 \mathrm{~g}$. lard or $456 \mathrm{~g}$. carbohydrates, an increase of 5.1 per cent.

The results of Pettenkoffer and Voit are abundantly confirmed by these more recent experiments.

In explanation of the fact that increasing the supply of food produces, under certain circumstanees, an increase in the metabolism. we might suppose either that the greater store of combustible material itself induces a more extensive combustion, or that the increase of total metabolism is due to the work of digestion or to muscular movements, etc. The matter can be definitely settled only by experiments on men where the voluntary morements can be controlled.

Both Magnus-Levy and Koraen have made such expcriments and have shown that a clearly marked increase in the metabolism of the resting body makes its appearance only after ingestion of proteid. This increase, howerer, is scarcely to be ascribed to the work of digestion. but is rather the expression of a special property [what Rubner calls "specific dynamic action"-ED.] of proteid to intensify the metaholism independently of muscular morements.

Nevertheless, it should not be asserted that the work of digestion causes 
no increase of combustion, for it is evident that the contractions of the gastric and intestinal walls as well as the secretion of the glands represent dissimilative processes, taking place with the liberation of kinetic energy.

The negative effect of fat or of carluohydrates on the total metaloolism may be explained in one of two ways: either the work of digesting them is too small to produce a distinct rise. or the combustion in other parts of the body than the digestive organs is correspondingly reduced.

But this would apply only in case the bodily movements were suppressed as much as possible. We know from the subjective feeling of improved capacity for muscular work after eating and from an increased tonus of the muscles resulting from the mere ingestion of food, that the amount of metabolism may well be increased by the foods named, if voluntary movements continue. It is evident, however. that such an increase would he wholly independent of the kind of food, and would be only indirectly connected with the act of ingestion.

If the food be of such a quality or quantity as to make umusual demands upon the organs, the work of digestion may cause a considerable increase in the metabolism. Thus in one of Rubner's experiments in which $20-30 \mathrm{~g}$. bones were fed, the metabolism rose ten per cent; and in an experiment of MagnusLevy where 900-1,000 g. of bones were fed the absorption of oxygen increased twenty-four to thirty-three per cent during the first six hours. Likewise after administration of saline purgatives, Mering and Zuntz observed a distinct rise in the metabolism due to increased muscular activity of the intestine.

\section{F. METABOLISM AFTER INGESTION OF ALBUMOSES, FATTY ACIDS, GELATIN, ALCOHOL, ETC.}

Now that we have become acquainted with the metabolism after ingestion of each of the three principal kinds of organic foodstuffs, we shall consider briefly the food value of some substances closely related to them, which either are formed in the course of digestion, or occur more or less commonly in our ordinary articles of diet.

1. The digestion of proteid passes through a number of different stages (Chapter VII). It will be of interest here to inquire whether the substances representing these different stages are themselves all of equal value for the nourislment of the body.

If, with a constant quantity of fat and carbohydrate, an animal be given meat on one day, and on another the so-called protoalbumose formed in proteid digestion so that in both eases he receives the same quantity of nitrogen, the $\mathrm{N}$-excretion and the $\mathrm{N}$-retention exhibit no differences whatever in the two. This albumose, therefore, possesses the same food value as proteid (Blum). Heteroalbumose and peptone behave quite differently. They have the power to replace proteid to a certain extent, but it appears that they cannot maintain the body in $\mathrm{N}$-equilibrium. The reason for this doubtless is that certain carbon nuclei of the proteid molecule which occur in protoalbumose are wanting in heteroalbumose and peptone. Investigations on the constitution of the different products of proteid digestion have shown in fact that the groups which yield tyrosin and indol do not occur in heteroalbumose. Since, apparently, the aromatic groups are not built up in the body, we can readily understand why heteroalbumose alone does not have the full food value of proteid. However, we are not justified in concluding from this that a part of the proteid ingested becomes 
of less value in the process of digestion, for it may well be supposed that all the digestive products taken together are of more service in metabolism than are single ones eaten alone.

2. On few physiological questions have opinions changed so much as on the food value of gelatin. It was once supposed that gelatin is the most important food constituent of meat, because it alone could be dissolved. Then the pendulum swung to the opposite extreme, and it was claimed that gelatin is of no food value whatever. Continued investigation has shown that both views were equally overdrawn.

Since gelatin, like proteid, is not completely oxidized in the body, its physiological heat value is less than that determined directly by the calorimeter. One gram of ash-free gelatin yields to the body $3.58+$ Cal.-i. e., 21.2 Cal. per 1 g. of $\mathrm{N}$.

Voit, Oerum, and others have found that in its combustion in the body gelatin spares proteid to a considerable extent, acting in this way much more powerfully than equal quantities of fat or of carbohydrates (see page 120). Gelatin cannot completely replace proteid, partly at least because it lacks the tyrosin and indol groups. But by feeding gelatin the supply of proteid can be reduced considerably without disturbing $\mathbf{N}$-equilibrium. Thus by feeding a quantity of proteid-free gelatin sufficient to cover one hundred and one per cent of the daily requirements of energy Krummacher found that the proteid destruction was reduced by about thirty-seven per cent of the amount destroyed in starvation.

[Murlin has recently shown that when the full calorific requirements of the body are made up with nomnitrogenous foods (of which a large percentage is carbohydrates), nitrogen equilibrium can be maintained in dogs and man, if two-thirds of the starvation requirements for nitrogen are supplied in the form of gelatin and the other one-third in the form of meat.

Kauffmann also has made a most beautiful experiment on himself. He established nitrogen equilibrium on a diet containing 42 Cal. per kilogram with casein as the source of proteid nitrogen. He then replaced the casein with a mixture of gelatin and certain amino acids, tyrosin, cystin, and tryptophan, which are lacking in the gelatin. The mixture contained exactly the same quantity of nitrogen as the casein and was distributed as follows: Gelatin, ninetythree per cent; tyrosin, four per cent; cystin, two per cent; and tryptophan, one per cent. Perfect equilibrium was maintained for a period of five days.-ED.]

Gelatin spares fat and carbohydrate as well. Thus a $\operatorname{dog}$ fed on $200 \mathrm{~g}$. of gelatin lost only $15 \mathrm{~g}$. proteid and $35 \mathrm{~g}$. fat from his body per day, while on the eighth day of starvation the same dog lost $29 \mathrm{~g}$. proteicl and $102 \mathrm{~g}$. of fat.

Gelatin and glutin-forming substances (which behave just like gelatin. Etzinger and Voit), play but a subordinate part, however, in the normal nutrition. They occur in the ordinary articles of diet in relatively small quantities, and to this extent have exactly the same importance as an equal quantity of proteid. When gelatin is fed in larger quantities to an animal, he soon refuses to eat. It must then be given forcibly by hand and soon causes indigestion. [Kauffmann complains of great languor and general indisposition for work during his gelatin experiment-effects which he ascribes to the lack of the extractive substances necessary to give the diet the proper flavor and to stimulate the nervous system.-ED.]

3. Fat is split up in digestion into fatty acids and glycerin (cf. Chapter VII). The former when fed alone have exactly the same effect on metabolism as a corresponding quantity of fat. I. Munk placed a dog in N-equilibrium with $800 \mathrm{~g}$. meat and $70 \mathrm{~g}$. fat. Then instead of the fat he gave the fatty acids derived from $70 \mathrm{~g}$. of fat: the animal continued in $\mathrm{N}$-cquilibrium. 
It has been shown that glyeerin, which constitutes about nine per cent of fat and has a heat value per gram equal to about half that of fat, can be burned in the body and can spare both fat and proteid.

4. Cellulose, which forms so large a part of the vegetable foods, is acted upon by the digestive fluids of the lower animals (snail, Biedermann; earp, Knauthe); but in herbivorous mammals it is broken up only by the fermentative aetion of Baeteria, the end produets being carbon dioxide, marsh gas, butyric acid, and acetic acid (Tappeiner).

It may be regarded as established that eellulose is dissolved to some extent also in the intestine of man. From twenty-five to sixty-three per cent of the cellulose of earrots, celers, eabbage and lettuce is decomposed in the intestine. Cooking appears to favor its solution. The eellulose in "whole-wheat" bread also is dissolved in considerable quantity (IIultgren and Landergren).

Nitrogen oecurs in plants in a number of nonproteid eompounds, which with the exception of asparagin (amino-suceinie acid) appear to have no real food value. The case of asparagin is not without its practical interest, for this substance is a rather abundant eonstituent of leguminose seeds, oatmeal and potatoes.

5. It is perfeetly eertain that alcohol is burned in the body. Of the total amount absorbed from the stomach only about two per cent is eliminated from the body unchanged; the rest is oxidized to earbon dioxide and water (Atwater and Benediet).

If aleohol were destroyed in the body without protecting other substances from destruetion, the $\mathrm{CO}_{2}$-exeretion ought of eourse to be correspondingly increased. But this is not the case. Experiments by Zuntz and Berdez and by Geppert show that a dose of alcohol, so long as it is not large enough to intoxicate, produces no appreciable inerease in the eonsumption of oxygen, and only an insignificant inerease, if any at all, in the exeretion of earbon dioxide.-By means of experiments in which the total metabolism as well as the heat loss were determined direetly, Atwater and Benedict were able to demonstrate also that alcohol can replace the nomnitrogenous foodstuffs to the full extent of its heat value.-Replaeing a certain quantity of fat by an isodynamic quantity of aleohol produees at first a distinct increase in the destruetion of proteid. If the experiments were interrupted at this time, the result naturally would indieate that alcohol does not save proteid, but rather intensifies its deeomposition. If, however, the experiments be continued, the destruction of proteid falls again and comes back to the original lerel. The body therefore must become aceustomed to alcohol, before the latter can exereise its proteid-sparing power (Neumann, Clopatt).

But aleohol cannot play any considerable part in the normal nutrition of man. The quantity which one unaceustomed to its use ean drink without symptoms of intoxication is very small-only $16-25 \mathrm{~g}$. With a heat value of $7 \mathrm{Cal}$. per g., this would amount to 112-175 Cal.-that is, estimating the requirements of metabolism at 2,500 Cal., 4.5- 7 per cent of the total energy might be supplied in the form of alcohol. Only in very exceptional cases ean aleohol be of any praetical importance as a foodstuff. In diseases aecompanied by redueed powers of digestion, it appears to be of great service as a direet food, quite independently of its effect upon the nervous system.

\section{§ 5. INFLUENCE OF MUSCULAR WORK ON METABOLISM}

It was apparent from Lavoisier's original experiments on the respiratory exchange that combustion is inereased by museular work, and inrestigations carried out since that time have established the fact beyond all doubt. 
When Liebig, with much greater clearness than had been attained up to his time, had made out the chemical composition of foods and of the tissues of the dead body, he set himself the task of determining what foodstuffs are consumed in the work of the body and what significance in general the different groups of organic foodstutfs have for metabolism.

Since organisms are distinguished chemically by the fact that they contain proteid, he assumed that the actirity of the body and especially of the muscles takes place at the expense of the living protoplasm. and that this in turn is built up from the proteid in the food. The nomnitrogenous substances, he said, are used in the formation of heat in the body by direct oxidation, and thm by taking possession of the oxygen they protect proteid from its harmful effects. On this basis the organic foodstuffs were classified as tissue forming or plastic, and heat forming or respiratory.

The second proposition of this hypothesis can be disposed of immediately. Experiment has shown definitely that decomposition of nonnitrogenous foodstuffs is not inaugurated by oxygen but by the activity of the tissues. The dependence of heat production upon the nervous system is evidence of this fact (ef. Chapter XIV).

If this view that bodily work takes place at the expense of the living substance of the muscles, were correct, one wonld expect that work would be accompanied by an increased output of nitrogen. But in the great majority of the experiments made to test this point either no increase or only a very sight one is found on working days.

The following experiments by Voit on the dog will serve as an illustration:

\begin{tabular}{|c|c|c|c|}
\hline & $\mathrm{N}$ ingested. g. per day. & $\mathrm{N}$ excreted, $\mathrm{g}$, per day. & \\
\hline 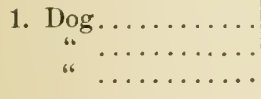 & $\begin{array}{l}\ldots \\
\cdots \\
\cdots\end{array}$ & $\begin{array}{l}5.6 \\
5.7 \\
5.1\end{array}$ & $\begin{array}{l}\text { resting } \\
\text { running } \\
\text { resting }\end{array}$ \\
\hline 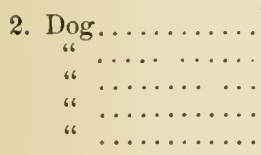 & $\begin{array}{l}51 \\
51 \\
51 \\
51 \\
51\end{array}$ & $\begin{array}{l}51.8 \\
55.3 \\
51.8 \\
53.8 \\
52.2\end{array}$ & $\begin{array}{l}\text { resting } \\
\text { running } \\
\text { resting } \\
\text { running } \\
\text { resting }\end{array}$ \\
\hline
\end{tabular}

The same result was obtained by Pettenkoffer and Voit in their experiments on man. The subject was required to turn a wheel with a crank-a kind of work to which he was aceustomed-the wheel being so loaded as to demand about the same expenditure of energy as his customary work demanded. He worked nine hours of the twenty-four. Fasting and resting, he gare off $12.3-12.5 \mathrm{~g}$. $\mathrm{N}$; fasting and working, $11.7 \mathrm{~g}$. On a moderate diet at rest, he eliminated 16.5 $17.4 \mathrm{~g} . \mathrm{N}$ and at work $17.0-17.4 \mathrm{~g}$. $\mathrm{N}$. Here likewise there is no increase in the daily excretion of nitrogen due to work.

Fick and Wisticenus made a very important experiment on themselves. They ascended the Faulhorn in Switzerland, a momtain which has an altitude of 1,956 meters above the lake at its base. Seventren hours before the ascent they ate their last nitrogenous meal; the aseent itsclf lasted six hours, and seven 
hours later they ate the first nitrogenous food after the experiment. The urine was collected from the beginning of the ascent until seven hours after its conclusion, and was analyzed for nitrogen. Fick's urine contained 5.it g. $\mathrm{N}^{\top}$ and that of $\mathrm{Tr}$ islicenus $5.55 \mathrm{~g}$.. representing a work equivalent, calculated from the heat value of the proteid burned, of 63.378 and 62.250 kilogram-meters respectively. Fick's weight was $66 \mathrm{~kg}$. and Wislicenus's was $76 \mathrm{~kg}$. ; hence the amount of external work actually done in lifting their borlies 1.956 meters was 129,096 and $1+5,656 \mathrm{~kg}$. m. respectivels. The work done at the expense of proteid therefore could not have heen more than one-half that expended merely in lifting their bodies, not taking into aceount the work of the heart, of the respiratory museles and of the other muscles constantly in use in maintaining equilibrium.

But it might be argued that the increased excretion of nitrogen corresponding to the work of a giren day would be eliminated from the body the following day. This idea. first expressed by Liebig. was tested by Argutinsky and Krummacher on themsclves, and was reported by them to be correct. The force of their experiments is considerably diminished, howerer, by the fact that neither of the authors was in nitrogenous equilibrium during the resting days, and that their food was much too poor in absolute quantity of nutrient substances.

Moreover. Krummacher himself has shown clsewhere that when plenty of energy is supplied, the increased output of nitrogen on the day following work is quite insignificant. Thus a man engaged in hard labor received daily $89.3 \mathrm{~g}$. proteid ( $=14.3 \mathrm{~g}$. nitrogen), 175 g. fat, and $903 \mathrm{~g}$. carbohydrate (=5,701 Cal.). During rest while on this diet, he excreted on the average $13.46 \mathrm{~g}$. $N$ in the urine and frees. Then followed a workday on which he did $402,000 \mathrm{~kg} . \mathrm{m}$. of external work, and excreted $14.05 \mathrm{~g}$. $\mathrm{N}$. The output on the two following rest days was 13.70 and $13.47 \mathrm{~g}$. $\mathrm{Y}$ respectively. Only on the first of the two was there any increase over the elimination previous to the workdar, and then it was only 0.24 g. $\mathrm{X}$. This experiment also shows in a particularly beautiful way that muscular work is not done at the expense of proteid when a sufficient supply of nomnitrogenous food is given. The external work of the one day was equivalent to 945 Cal., whereas the total metabolism of proteid on the workday plus the excess on the day following ( $14.05 \mathrm{~g} . \mathrm{N}+0.24 \mathrm{~g}$. $\mathrm{N}=90 \mathrm{~g}$. proteid) was equiralent to only $36+\mathrm{Cal}$.

But we are not to suppose that proteid cannot serve as the source of muscular energy. For in extreme cases when there is no fat and no carbohydrate at the disposal of the body, if muscular work is done. it can only be at the expense of proteid.

Pflüger fed a large dog for a long time on nothing but meat which contained as little fat and carbohydrate as possible. The dog was already very lean before the beginning of the experiment, so that there was no stored fat and glycogen to draw upon. From time to time he was compelled to do severe work varying in amount from $73,072 \mathrm{~kg}$. m. to $109,605 \mathrm{~kg}$. m., and since the fat and carbohydrate in the food were far from sufficient to produce this amount of energy, the work must have been done largely at the expense of the proteid.

It is perfectly casy to show that the nonnitrogenous foodstuffs furnish energy for muscular work. The excretion of carbon dioxide rises almost 
immediately as soon as work begins and has been known to increase from $2 \approx$ to $131 \mathrm{~g}$. per hour. There is no corresponding increase in the excretion of $\mathrm{N}$, as we have seen, hence this excess of $\mathrm{CO}_{2}$ must represent an increased oxidation of nonnitrogenous food.

In the experiments of Pettenkoffer and Toit on men, the daily amount of fat destroyed in fasting rose $1 \% 1 \mathrm{~g}$. as the result of work. and upon an ordinary diet it rose $101 \mathrm{~g}$. The experiments of Atwater have yielded similar results. In one of his subjects the total metabolism during rest amounted to $2,35 \%$ Cal., of which 429 eame from proteid, and 1,928 came from nonnitrogenous food. With serere muscular work the metabolism rose to the mean value of $5.119 \mathrm{Cal}$, of which 462 came from proteid, and $4,65 \%$ from nonnitrogenous food.

By parallel experiments, in which on the one hand chiefly fat, and on the other chiefly carbohydrates were fed, Zuntz has shown very definitely that the muscles can use one kind of nonnitrogenous food as wcll as the other. The same appears also from Atwater's experiments.

We can say, therefore, that the muscles are able to perform their work at the expense of all three classes of organic foodstuffs. that they prefer the nonnitrogenous substances, and, as it appears, they draw upon the earbohydrates first. Thus the one group or the other is utilized according to the kind of food eaten. The specifically carnivorous animals perform their muscular work at the expense of proteid and fat; the herbivorous animals, especially our domesticated farm animals, at the expense of carbohrdrates, and in view of the large quantity of carbohydrates eaten by man the latter is probably true of the human hody also.

It is of special importance for the physiology of general metabolism as well as for the physiology of the muscle itself, to determine how large a part of the increased transformation of energy accompanying muscular activity takes the form of external work.

For this purpose the respiratory exchange has been determined both during rest and while an accurately measured quantity of work was being performed. Subtraction of the earbon dioxide excretion and the oxygen absorption during rest, from the corresponding factors during work, shows an absolute increase which represents the known quantity of extcmal work. In this way one can readily obtain the amount of metabolism which $1 \mathrm{~kg}$. $\mathrm{m}$. of work represents and these figures can be reduced to heat equivalents.

Such determinations have heen made in Zuntz's laboratory in Berlin, and it has been found that the $\operatorname{dog}$ uses $0.00 \%-0.00 \%$ Cal. to do $1 \mathrm{~kg}$. m. of external work and the horse 0.0069 Cal. at the same kind of work (walking uphill). And since theoretically $1 \mathrm{~kg} . \mathrm{m} .=0.0023 .5$ ( $\mathrm{al} .$, or $42 \mathrm{~s} \mathrm{~kg} . \mathrm{m} .=1$ Cal.. we conclude that in these animals about one-third of the actual energy developed in muecular work appears as effeetive external work. In man the heat equivalent of $1 \mathrm{~kg}$. $\mathrm{m}$. of work with the lower extremities (mountain climbing) is about the same. namely $0.00 \%$ ( Cal.: so that one-third of the total energy developed in our own muscles also is utilized as extcrual work.

Even the slightest muscular movements influence the metabolism per- 
ceptibly, and if one wishes wholly to exclucle this effect it is necessary voluntarily to suppress all muscular morements and tensions. Under such circumstances. that is lying as quietly as posible, Johansson found the $\mathrm{CO}_{2}$-exeretion in himself to be about $20 \mathrm{~g}$. per hour. Ordinarily while awake we never observe muscular rest so complete as this, and hence when Johansson merely lay resting in bed without special effort to suppress museular movements. his $\mathrm{CO}_{2}$-exeretion rose to $25 \mathrm{~g}$. per hour. In general we may say that the respiratory exchange in a man not doing any real physical labor, and yet not in absolute rest, is about forty per cent greater than in sleep.

\section{§6. INFLUENCE OF THE SURROUNDING TEMPERATURE ON METABOLISM}

The cold-blooded and warm-blooded animals react very differently toward changes in temperature. Whereas in the latter the respiratory exchange, which may be taken as a relative expression of the total metabolism, rises when the temperature falls. and falls when the temperature rises, in the former the respiratory exchange varies directly with the external temperature. The following experimental results, after H. Schultz, may be given as an example of the reaction of cold-blooded animals:

\begin{tabular}{r|c}
\hline Temperature of the animal (frog). ${ }^{\circ} \mathrm{C}$. & $\mathrm{CO}_{2}$-output per $\mathrm{kg}$. per hour. \\
\hline $1.0-1.6$ & $0.008-0.015$ \\
6.4 & 0.067 \\
$14.5-15.4$ & $0.069-0.085$ \\
$25.0-25.3$ & $0.150-0.171$ \\
$32.5-33.5$ & $0.550-0.670$ \\
34.0 & 0.639 \\
\hline
\end{tabular}

It was first estahlished by experiments from Pflüger's laboratory that when the external temperature declines the metabolism of warm-blooded animals increases over that characteristic of a medium temperature. By increasing the heat production the body protects itself against the heat loss oceasioned by the cooling. Conversely, however, it is to be observed that a rise of the body temperuture also produces an inerease in metabolism: which shows that the energy of the oxidation processes in the warm-blonded also as well as in the cold-blooded animals increases with the temperature of the organs. There is here a fundamental agreement in the basal properties of living tissues in all animals. The inerease of metabolism accompanying a decline in the external temperature is to he considered as a later acquirement on the part of warmblooded animals-as something in fact which has been gradually evolved in the special interest of a constant temperature (Pflïger).

How exact this adjustment of metabolism to external temperature may be has been most beautifully shown by Rubner, as for example, in the following experiment on the $\operatorname{dog}$ : 


\begin{tabular}{|c|c|c|c|c|c|}
\hline \multicolumn{2}{|c|}{ Dog I. } & \multicolumn{4}{|c|}{ Dog II. } \\
\hline $\begin{array}{c}\text { External } \\
\text { temperature. } \\
{ }^{\circ} \mathrm{C} \text {. }\end{array}$ & $\begin{array}{l}\text { Cal. per kg. } \\
\text { per hour. }\end{array}$ & $\begin{array}{c}\text { External } \\
\text { temperature. } \\
{ }^{\circ} \mathrm{C} \text {. }\end{array}$ & $\begin{array}{l}\text { Cal. per kg. } \\
\text { per hour. }\end{array}$ & $\begin{array}{c}\text { External } \\
\text { temperature. } \\
{ }^{\circ} \mathrm{C} \text {. }\end{array}$ & $\begin{array}{l}\text { Cal, per kg. } \\
\text { per hour. }\end{array}$ \\
\hline $\begin{array}{l}13.8 \\
14.9 \\
17.3 \\
18.0\end{array}$ & $\begin{array}{l}78.7 \\
74.7 \\
69.8 \\
67.1\end{array}$ & $\begin{array}{l}11.8 \\
12.9 \\
15.9 \\
17.5\end{array}$ & $\begin{array}{l}40.6 \\
39.1 \\
36.0 \\
35.2\end{array}$ & $\begin{array}{l}13.4 \\
19.5 \\
27.4\end{array}$ & $\begin{array}{l}39.7 \\
35.1 \\
30.8\end{array}$ \\
\hline
\end{tabular}

The following experiment on a grown guinea pig fasting, is giren as an example of the rise in metabolism appearing with a higher body temperature:

\begin{tabular}{|c|c|c|c|c|c|}
\hline $\begin{array}{c}\text { External } \\
\text { temperature. } \\
{ }^{\circ} \mathrm{C} \text {. }\end{array}$ & $\begin{array}{c}\text { Temperature } \\
\text { of animal. } \\
{ }^{\circ} \mathrm{C} .\end{array}$ & $\begin{array}{c}\mathrm{CO}_{2}, \text { g. per } \mathrm{kg} . \\
\text { per hour. }\end{array}$ & $\begin{array}{c}\text { External } \\
\text { temperature. } \\
{ }^{\circ} \mathrm{C} \text {. }\end{array}$ & $\begin{array}{c}\text { Temperature } \\
\text { of animal. } \\
{ }^{\circ} \mathrm{C} \text {. }\end{array}$ & $\begin{array}{c}\mathrm{CO}_{2}, \mathrm{~g} \text {. per } \mathrm{kg} \text {. } \\
\text { per hour. }\end{array}$ \\
\hline $\begin{array}{c}0 . \\
11.1 \\
20.8 \\
25.7\end{array}$ & $\begin{array}{l}37.0 \\
37.2 \\
37.4 \\
37.0\end{array}$ & $\begin{array}{l}2.9 \\
2.2 \\
1.8 \\
1.5\end{array}$ & $\begin{array}{l}30.3 \\
34.9 \\
40.0\end{array}$ & $\begin{array}{l}37.7 \\
38.2 \\
39.5\end{array}$ & $\begin{array}{l}1.3 \\
1.3 \\
1.5\end{array}$ \\
\hline
\end{tabular}

The influence of food on the metabolism at different external temperatures is a matter of great interest. The following experiment of feeding a small dng with different quantities of meat is one of the many published by Rubner on this subject.

\begin{tabular}{|c|c|c|c|c|}
\hline \multirow{2}{*}{$\begin{array}{c}\text { External } \\
\text { temperature. } \\
{ }^{\circ} \mathrm{C} .\end{array}$} & \multicolumn{4}{|c|}{ Calories per kg. and twenty-four hours. } \\
\hline & Fasting. & $\begin{aligned} & 100 \mathrm{~g} . \text { Neat } \\
= & 24 \text { Câ. per } \mathrm{kg} .\end{aligned}$ & $\begin{aligned} & 200 \mathrm{~g} \text {. Meat } \\
= & 18 \text { Cal. per kg. }\end{aligned}$ & $\begin{aligned} & 320 \mathrm{~g} \text {. Yleat } \\
= & 81 \text { Cai. per } \mathrm{kg} .\end{aligned}$ \\
\hline 7.0 & 86.4 & $\cdots$ & $7 \% .7$ & $8 \pi .9$ \\
\hline $\begin{array}{l}15.0 \\
20.0\end{array}$ & 5.5 .0 & 559 & $5 \ddot{5} 9$ & $\begin{array}{l}86.6 \\
76.3\end{array}$ \\
\hline 25.0 & 54.2 & 55.5 & 64.9 & \\
\hline 30.0 & 56.2 & 55.6 & 63.4 & 83.0 \\
\hline
\end{tabular}

From this and other experiments of the same purport we learn that with a sufficiently large supply of meat the metabolism becomes almost independent of the external temperature (experiment with $320 \mathrm{~g}$. meat). while with a supply which is too low to furnish the calorific energy necessary eren at a high temperature. the effect of the external temperature is felt to the full extent. This, in the judgment of the writer, shows that the ingestion of proteid beyond a certain limit inereases the metabolism both at a high and at a low temperature. If the heat production obtained in this way alone is sufficient to enver the requirements of the lody even at a low temperature, a fall in the temperature will have no power of itself to protuee a further rise of motabolism. But if the rise due to proteid is not sufficient, a fall in the temperature will foree the metabolism up, though to a less degree than when no proteid had been fed. 
The alterations of metabolism in the service of heat regulation do not make their appearance. if the influence of the central nerrous system on the muscles be terminated either by curare poisoning or by section of the spinal corrl at a high lerel. This is shown by the following experiment of Velton on a curarized rabbit.

\begin{tabular}{c|c|c}
\hline $\begin{array}{c}\text { Temperature of the animal. } \\
{ }^{\circ} \mathrm{C} .\end{array}$ & $\begin{array}{c}\text { Oxygen absorbed, cc. per kg. per } \\
\text { hour. }\end{array}$ & $\begin{array}{c}\mathrm{CO}_{2} \text { excreted. cc. per kg. per } \\
\text { hour. }\end{array}$ \\
\cline { 1 - 2 } 38.3 & 581 & 571 \\
37.4 & 557 & 541 \\
31.4 & 386 & 383 \\
26.2 & 219 & 202 \\
23.1 & 181 & 178 \\
\hline
\end{tabular}

These facts naturally suggest that under normal circumstances the rise in metabolism here being considered is dne to muscular activity called out by the central nervous system, and this is very generally assumed to be the case. But a question arises as to whether gross, plainly visible muscular morements necessarily occur.

In small animals, such as mice, the bodily movements become very active when the external temperature is greatly lowered. In dogs, on the other hand, Rubner never observed any movements which were directly occasioned by the heat or cold, although he emphasizes the statement that at the upper and lower extremes of temperature marked unrest was at times to be observed.

In the present writer's opinion, it is very difficult or probably impossible to solve the question of the part taken by the muscles in the heat regulation by experiments on animals, for there must always be a certain amount of muscular tension and the like which can scarcely be estimated with any accuracy, although the metabolism may be very considerably increased by them. Thus in experiments by Johansson, the $\mathrm{CO}_{2}$-elimination in an ordinary resting condition, lying in bed, was twenty to thirty-one per cent more than when great care was taken to observe absolute muscular rest. Hence in order to exclude muscular movements altogether, it is obviously necessary to carry out the experiments on persons who are willing and able to enforce the desired state of relaxation of their own bodies.

From the experiments of Loewy it appears that within a period of one and one-quarter to one and one-half hours the respiratory exchange does not always increase. eren though the temperature fall considerably. But whenever an increase did neeur. if the experiment was being performed on an intelligent individual intrusted with the regulation of his own respiration, shivering or increased tone of the muscles was distinctly evident. By maintaining complete rest for one and one-half hours Johansson was unable to secure any evident influence of external temperature upon the excretion of carbon dioxide, althnugh the body was naked and the temperature varied from $14^{\circ}$ to $22^{\circ}$ C. Under Rubner's direction, experiments continued from four to six hours gave, on the whole, similar results.

One is likely to ennclude from these experimental facts that when muscular movements are voluntarily suppressed, the production of heat in man 
is for a time independent of the external temperature. But since, as Voit shoved most clearly, the human body does undoubtedly react against the influence of a falling temperature by a more active production of heat, the conclusion we are to draw from the experiments just mentioned is rather that visible muscular movements constitute the real cause of increased metabolism.

\section{\$ 7. METABOLISM IN ANIMALS OF DIFFERENT SIZE}

It is erident that, other things being equal, the total metabolism must vary with the mass of the body. But if, in animals of different size the metabolism be calculated according to the unit of weight, it proves to be relatively greater in small animals than in large ones.

This proposition may best be tested on fasting animals because the metabolism in them is constant, not being influenced by the kind and quantity of food. The following table, with the exception of experiment number one, is compiled from Rubner:

\begin{tabular}{|c|c|c|c|c|c|c|}
\hline \multirow{2}{*}{ SPECiEs. } & \multirow{2}{*}{ Fast days. } & \multirow{2}{*}{ Weight, kg. } & \multicolumn{2}{|c|}{$\begin{array}{l}\text { Average of fast dass } \\
\text { per kg. of weight. }\end{array}$} & \multicolumn{2}{|c|}{ Calories. } \\
\hline & & & N-excr. & Fat metab. & $\begin{array}{l}\text { Per kg. } \\
\text { weightit. }\end{array}$ & $\begin{array}{l}\text { Per sq. M. } \\
\text { of surface. }\end{array}$ \\
\hline 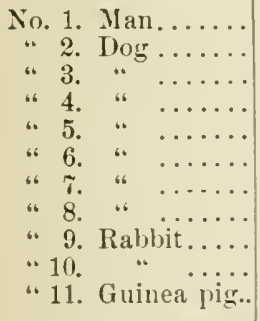 & $\begin{array}{r}3-.5 \\
6.10 \\
1-3 \\
4.8 .9 \\
1.3 \\
2.3 \\
1.2 .5 \\
1.3 .5 \\
4.5 \\
3-8 \\
\ldots\end{array}$ & $\begin{array}{r}64.0 \\
30.4 \\
29.7 \\
19.2 \\
17.7 \\
11.0 \\
6.5 \\
3.1 \\
2.6 \\
2.1 \\
0.55\end{array}$ & $\begin{array}{l}0.20 \\
0.17 \\
0.26 \\
0.17 \\
0.31 \\
0.14 \\
0.35 \\
0.59 \\
0.58 \\
0.51 \\
0.64\end{array}$ & $\begin{array}{l}2.81 \\
3.28 \\
3.51 \\
4.24 \\
3.94 \\
5.74 \\
5.51 \\
7.46 \\
4.00 \\
4.78 \\
19.68\end{array}$ & $\begin{array}{r}31.2 \\
35.3 \\
39.7 \\
44.4 \\
45.0 \\
58.8 \\
60.9 \\
85.3 \\
52.2 \\
57.9 \\
145.8\end{array}$ & $\begin{array}{r}995 \\
997 \\
1,069 \\
1,135 \\
1,040 \\
1,109 \\
1.054 \\
1.091 \\
615^{1} \\
740 \\
1,341\end{array}$ \\
\hline
\end{tabular}

It is fairly erident that some variations between the different species of animals occur, probably because the covering of the body and some other bodily characters are not the same in all species. With this exception, howerer, the table shows a very uniform relationship, the cause of which will be apparent from the following considerations.

The smaller an animal is, the greater is its superficial area in proportion to its volume and weight. Suppose we have two balls. the one, A, 2 cm.. the other, B, $4 \mathrm{~cm}$. in diameter, the surface of $A$ is then $12.56 \mathrm{sq} . \mathrm{cm}$. . that of $\mathrm{B} 50.24 \mathrm{sq} . \mathrm{cm}$.: their rolumes are 4.18 and 39.49 ce. respectively. In the smaller ball the ratio of volume to surface is as $1: 3$, in the larger as $1: 1.5$. Now the animal body loses its heat very largely (about fonr-fifths) through the skin, and the quantity of lieat thus given off is evidently proportional to the skin surface. In order that the temperature may remain constant, the production of heat-i.e.. the metabolism-must also he proportional to the skin surface. If, therefore,

'[It has been shown that when the rabbit's ears are excluded this animal forms no exception.-Ev.] 
a large and a small, warm-blooded animal with fur of the same thickness are to have the same bodily temperature in the same atmospheric temperature, the small animal must produce more heat in proportion to its weight than the large one-i. e., the metabolism per kilogram of weight must be greater in the former than in the latter (C. Bergmann).

In the experimental proof of this relationship which Rubner furnished later (above table numbers 2-8), he measured the superficial area of the body and calculated the metabolism per square meter of the surface. It proved to be the same for all the dogs regardless of size (last column of the table). The same relationship is demonstrable also for animals ou food.

That the growing organism has a greater metabolism per kilogram of weight than has the adult, is erident from the mere difference in size. But experiment shows further that when calculated per square meter of surface, ${ }^{1}$ the metabolism in younger individuals is higher than in older ones; in other words, the metabolism is influenced by something peculiar to the young body, which serves to heep it at a higher pitch.

The following table contains a number of observations by Magnus-Lery and Falk in support of this statement. They were made on indiriduals who had not eaten for some time and who were resting quietly, lying down.

\begin{tabular}{|c|c|c|c|c|c|}
\hline \multicolumn{3}{|c|}{ MaLes. } & \multicolumn{3}{|c|}{ Females. } \\
\hline $\begin{array}{l}\text { AGE. } \\
\text { YEARS. }\end{array}$ & $\begin{array}{c}\text { Weight } \\
\text { kg. }\end{array}$ & $\begin{array}{l}\text { g. } \mathrm{CO}_{2} \text {-exc. } \\
\text { per sq. II. } \\
\text { surface } \\
\text { per hour. }\end{array}$ & $\begin{array}{c}\text { AGE. } \\
\text { YEARS. }\end{array}$ & $\begin{array}{c}\text { Weight } \\
\text { kg. }\end{array}$ & $\begin{array}{l}\text { g. } \mathrm{CO}_{2} \text {-exc. } \\
\text { per sq. MI. } \\
\text { surface } \\
\text { per hour. }\end{array}$ \\
\hline 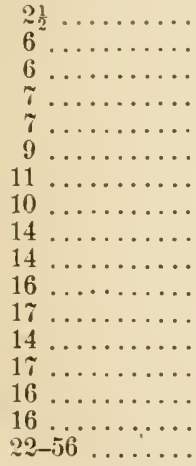 & $\begin{array}{r}11.5 \\
14.5 \\
18.4 \\
19.2 \\
20.8 \\
21.8 \\
26.5 \\
30.6 \\
36.1 \\
36.8 \\
39.3 \\
40.0 \\
43.0 \\
44.3 \\
56.5 \\
57.5 \\
43.288 .0\end{array}$ & $\begin{array}{l}17.7 \\
17.4 \\
15.5 \\
17.5 \\
17.4 \\
15.3 \\
14.4 \\
15.7 \\
13.8 \\
13.5 \\
13.3 \\
14.1 \\
14.0 \\
15.3 \\
12.4 \\
12.9 \\
11.2\end{array}$ & $\begin{array}{r}7 \ldots \ldots \\
6 \frac{1}{2} \ldots \ldots \\
12 \ldots \ldots \\
13 \ldots \ldots \\
11 \ldots \ldots \\
14 \ldots \ldots \\
12 \ldots \ldots \\
11 \ldots \ldots \\
17-40 \ldots\end{array}$ & $\begin{array}{r}15.3 \\
18.2 \\
24.0 \\
25.2 \\
31.0 \\
35.0 \\
35.5 \\
40.2 \\
42.7 \\
31.0-68.2\end{array}$ & $\begin{array}{l}15.7 \\
15.2 \\
14.3 \\
12.4 \\
14.9 \\
14.0 \\
13.7 \\
12.6 \\
13.5 \\
11.8\end{array}$ \\
\hline
\end{tabular}

The few direct observations which we have on the total metabolism of growing children give the same result, as will be seen from the following summary :

${ }^{1}$ The following formula devised by Meeh is used in calculating the superficial area of the body from its weight: $\mathrm{A}=c \sqrt[3]{/ \mathrm{W}^{2}}$, where $\mathrm{W}$ is the weight in grams and $c$ is a constant empirically determined for each animal species. This constant varies somewhat with age, and for man it has a mean value of 12.3 , for the dog, 11.2, for the rabbit, 12.9, for the rat, 9.1 , and for the guinea pig, 8.9 . 


\begin{tabular}{|c|c|c|c|c|}
\hline $\begin{array}{l}\text { AGE. } \\
\text { YEARS. }\end{array}$ & $\begin{array}{c}\text { Weight } \\
\text { kg. }\end{array}$ & $\begin{array}{c}\text { Total } \\
\text { metabolism } \\
\text { per kg. }\end{array}$ & $\begin{array}{l}\text { Calories } \\
\text { per sq. YI. } \\
\text { surface } \\
\text { in } 24 \text { hours. }\end{array}$ & Al'THOR. \\
\hline $\begin{array}{r}9 \frac{1}{2} \ldots \ldots \\
9 \frac{1}{2} \ldots \ldots \\
11 \ldots \ldots \\
11 \ldots \ldots \\
12 \ldots \ldots \\
12 \ldots \ldots \cdots \\
11 \ldots \ldots \ldots \\
\text { Adiit } \ldots \ldots\end{array}$ & $\begin{array}{l}23.2 \\
24.0 \\
26.0 \\
32.1 \\
38.0 \\
38.3 \\
41.0 \\
70.0\end{array}$ & $\begin{array}{l}63.0 \\
\ddot{52.0} \\
56.0 \\
\dddot{4} .0 \\
44.0 \\
32.0\end{array}$ & $\begin{array}{l}1,499 \\
1,37 \% \\
1,290 \\
1,391 \\
1.300 \\
1,254 \\
1,321 \\
1,071\end{array}$ & $\begin{array}{l}\text { Hellström. } \\
\text { Rubner. } \\
\text { Rubner (not in N-equilibrium). } \\
\text { Sondén and Tigerstedt. } \\
\text { Rubner. } \\
\text { Sondén and Tigerstedt. } \\
\text { Rubner. }\end{array}$ \\
\hline
\end{tabular}

The results of Camerer and others on the amount of food taken by children of different ages give exactly the same result. We give here only the figures obtained by Camerer.

\begin{tabular}{|c|c|c|c|c|c|c|c|}
\hline \multicolumn{4}{|c|}{ MLLES. } & \multicolumn{4}{|c|}{ FeMaLes. } \\
\hline $\begin{array}{c}\text { AGR. } \\
\text { YEARS. }\end{array}$ & $\begin{array}{l}\text { Weight } \\
\text { kg. }\end{array}$ & $\begin{array}{l}\text { Calories } \\
\text { per } \mathrm{kg} \text {. }\end{array}$ & $\begin{array}{l}\text { Calories } \\
\text { per sq. M. } \\
\text { of surface. }\end{array}$ & $\begin{array}{l}\text { AGE. } \\
\text { YEARS. }\end{array}$ & $\begin{array}{l}\text { Weight } \\
\text { kg. }\end{array}$ & $\begin{array}{l}\text { Calories } \\
\text { per } \mathrm{kg} \text {. }\end{array}$ & $\begin{array}{l}\text { Calories } \\
\text { per s.. If } \\
\text { of surface }\end{array}$ \\
\hline $\begin{array}{r}5-6 \\
\tau-10 \\
11-14 \\
11-14 \\
15-16 \\
1 \tau-18 \\
\text { Adult } \ldots \\
\end{array}$ & $\begin{array}{l}18.0 \\
24.0 \\
34.0 \\
53.0 \\
59.0 \\
70.0\end{array}$ & $\begin{array}{l}7 \% .0 \\
62.0 \\
47.0 \\
40.0 \\
38.0 \\
32.0\end{array}$ & $\begin{array}{l}1.680 \\
1.440 \\
1.250 \\
1.220 \\
1.200 \\
1,071\end{array}$ & $\begin{array}{r}2-4 \\
5-i \\
8-10\end{array}$ & $\begin{array}{l}13.0 \\
17.0 \\
22.0 \\
32.0 \\
41.0 \\
45.0 \\
56.0\end{array}$ & $\begin{array}{l}75.0 \\
69.0 \\
59.0 \\
52.0 \\
33.0 \\
40.0 \\
32.0\end{array}$ & $\begin{array}{r}1,4 i 0 \\
1.460 \\
1,390 \\
1,330 \\
930 \\
1,150 \\
999\end{array}$ \\
\hline
\end{tabular}

In infancy, as was to be expected. the metabolism per kilogram of weight proves to be much higher than in adult life; but calculated per unit of surface of the body it is decidedly less than in children somewhat older (cf. the following table). This is probably connected with the fact that the new-born child sleeps most of the time and the tonus of its museles is but slightly developed.

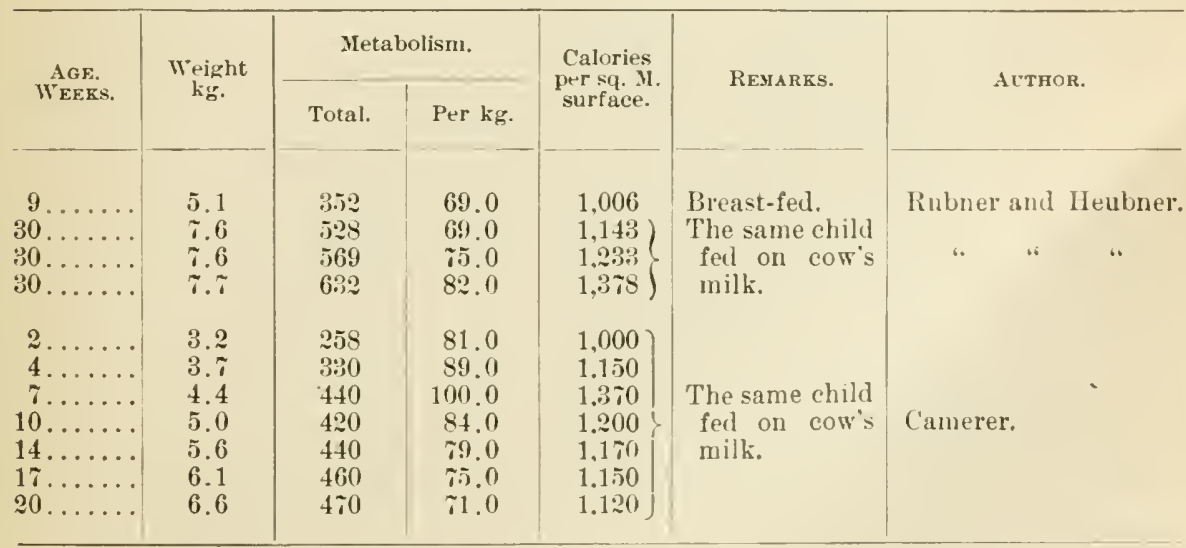


In old age the metabolism estimated by the syuare meter of surface is appreciably less than in middle life. While the $\mathrm{CO}_{2}$-excretion in men between the ages of twenty-two and fifty-six was found to be $11.16 \mathrm{~g}$. per square meter per hour, between the ages of serenty and serenty-seven years it was ouly $9.18 \mathrm{~g}$.; for women between the ages of seventeen and forty it was found to be $11.5 \mathrm{~g}$.. between the ages of serenty-one and eighty-six, $9.79 \mathrm{~g}$. (MagnusLery and Falk). The results of Ekholm on metabolism in the aged agree perfectly with these. This author found the mean of ten experiments on individuals between sixty-eight and eighty-one years of age to be 902 Cal. per square meter of body surface per day, while in resting men of middle age it amounts to $1.0 \% 1 \mathrm{Cal}$.

We can say, therefore, that the age of the individual is one of the factors determining the intensity of metabolism, it being greater per square meter of body surface during the period of growth (with the exception of infancy) than in middle life, and greater in middle life than in old age.

\section{§ 8. RETENTION OF PROTEID IN THE BODY}

In our study of the decomposition of proteil in the body, supplied with meat alone, we found that but a few days elapse hefore the body places itself in $\mathrm{N}$-equilibrinm. The retention of proteid with such a diet continnes therefore for only a short time and cannot reach any considerable amount. The greatest quantity of " flesh " which Toit was able to lay-on in dogs kept on a pure meat diet was $1,365 \mathrm{~g}$. $(=46.5 \mathrm{~g} . \mathrm{N})$. On the average he was unable to bring alont a deposit of more than $500 \mathrm{~g} .(=17 \mathrm{~g}$. N $)$. With meat alone one may keep an animal in a uniform endition of proteid nutrition which has been attained previously in some other way, but once it is lost he cannot restore this condition with an exclusively proteid diet. nor bring about a "deposit of flesh."

From his experiments on an exclusive meat diet Voit drew the further conclusion that under circumstances otherwise the same, proteid is stored to a greater extent and for a longer time before $N$-equilibrium sets in, if the animal be already fat than if he be lean. In other words, the fat already deposited in the body saves the proteid fed from being destroyed and thereby permits a greater retention.

We have already seen that the $\mathrm{N}$-ontput equals the $\mathrm{N}$-intake even with a mixed diet composed of proteid and nomnitrogenoms sulsstances. But the destruction of proteid is reduced to a certain extent by the presence of these $\mathrm{N}$-free substances; hence we might expect that a more extensive storage of proteid continuing for a longer time conld be brought abont loy feeding nonnitrogenous substances with proteid.

Voit's many experiments with such eombinations show this to be true. It is evident from these same experiments, however, that the saving of "flesh" is not much greater with a rich supply of meat than with a small supply. With $2,000 \mathrm{~g}$. of meat and $250 \mathrm{~g}$. of fat the daily sparing was $186 \mathrm{~g}$.; with $1,000 \mathrm{~g}$. meat and $300 \mathrm{~g}$. fat it was $16 \mathrm{f}$ g., while with $1,800 \mathrm{~g}$. meat and $250 \mathrm{~g}$. fat it was $140 \mathrm{~g}$., and with $1,500 \mathrm{~g}$. meat and $150 \mathrm{~g}$. fat, only $70 \mathrm{~g}$. It is impossible to 
formulate any definite law from these experiments, but they appear to indicate that a large daily sparing of proteid depends not only upon the absolute quantity of meat, but is best attained when the supply of fat in proportion to the supply of meat is relatively large.

But we are concerned not so much with the conditions for a large daily deposit of proteid, as with those which insure a large aggregate deposit. It may well be that with a certain combination of meat and fat the daily deposit of proteid would be high, but would continue for only a few days; while with another combination the deposit per day would be less but would hold out longer, so that the total deposit would be greater in this case than in the first before $\mathrm{N}$-equilibriun sets in.

It appears in fact from Voit's obscrvations that it is not the greatest supply of proteid which brings about the greatest total deposit. With $1,800 \mathrm{~g}$. of meat and $250 \mathrm{~g}$. of fat $\mathrm{N}$-equilibrium appeared in one case after seven days, and in this time there was a total retention of $55 \mathrm{~g}$. of "flesh"; with the same animal on $500 \mathrm{~g}$. meat and $250 \mathrm{~g}$. fat, $\mathrm{N}$-equilibrium did not appear within thirty-two days, but during this time not less than $1,794 \mathrm{~g}$. "flesh" was laid on. With this combination the storage of proteid was very evenly distributed orer the entire period: in the first twelve dars the mean daily deposit was $71 \mathrm{~g}$., in the following ten days $42 \mathrm{~g}$., and in the last ten days $52 \mathrm{~g}$.

In order to obtain the greatest total deposit of proteid in the body, just as for the largest daily deposit. it appears to be best, therefore, to give a relatively large quantity of fat in proportion to the quantity of meat. It is evident, of course, that the supply of proteid must not fall below a certain limit.

The carbohydrates bear the same relation to the retention of proteid as does fat, with the exception only that their proteid-sparing power is much greater than isodynamic quantities of fat.

This superiority of carbohydrates is shomn in a very suggestive way by the experiments of Landergren. He gave an adult man an almost $\mathrm{N}$-free diet, consisting (after deduction of the loss by ficces) of $1.6 \mathrm{~g}$. proteid, $73 \mathrm{~s} \mathrm{~g}$. carbohydrate, and $17 \mathrm{~g}$. aleohol, yielding altogether 45.2 Cal. per kilogram of body weight. On this diet the nitrogen exeretion in the urine fell from $12.5 \mathrm{~g}$. on the day before the experiment to $3.5 \mathrm{~g}$. on the fourth day of the experiment. From the fifth day on the earbohydrates were almost entirely excluded, and instead an isodynamic quantity of fat was given (a net supply of $304 \mathrm{~g}$. fat, $2.1 \mathrm{~g}$. carbohydrate, and $30.4 \mathrm{~g}$. alcohol, yielding altogether $43.7 \mathrm{Cal}$. per kilogram). On this diet the nitrogen excretion in the urine from the fifth to the seventh day rose as follows: $4.3,8.9,9.6 \mathrm{~g}$.

In explanation of these facts it has been supposed that carbohydrates are in a less stable state of equilibrium, owing to their aldehyde or ketone groups, than fat is, and for this reason they are more readily decomposed and thus protect proteid to a greater extent. But this can scarcely be true. for as Landergren has shown, the carbohydrates exhibit their characteristic proteidsparing effect even when they are fed with a considerable quantity of fat. Thus in an experiment with a net supply (i.e., deducting the loss by the faces) of $6.5 \mathrm{~g}$. proteid, $143 \mathrm{~g}$. fat, and $308 \mathrm{~g}$. carbohydrate, yielding alto- 
gether 45 Cal. per kilogram, the $N$-excretion in the urine on the fourth day was reduced to $3 \mathrm{~g}$. The same thing appears from an experiment by Tallqrist, in which $\mathrm{N}$-equilibrium was recorered just as casily with forty-four per cent of the nomitrogenous energy supplied by carbohydrates as with eighty-three per cent. Therefore, in the presence of a certain minimum of carbohydrate, fat exercises just as great a $\mathrm{N}$-protection as an isodynamic quantity of carbohydrate. whether $\mathrm{N}$ is being supplied in the food or not. The cause of this we shall discuss later.

We have no detailed experiments to show what conditions favor the greatest total deposit of proteid under the protecting influence of carbohydrates. But considering that the netabolism of proteid runs the same with carbohydrate feeding as with fat feeding, it is probable that there is an agreement in other respects also and that the storage of proteid is greatest when the proportion of carbohydrates to proteids in the food is high.

These results are of great practical importance, for they show that it is not best to feed a convalescent or a man in a poorly nourished general condition with proteid to the exclusion of other foods. Proteid cannot be deposited, and this means that the organs camnot be built up, on a diet composed only of proteid. Plenty of fats and carbohydrates are necessary as well as proteid.

It is generally supposed to be rather difficult for the adult body to lay on proteid, and this is borne out by the fact that N-equilibrium is very quickly established even with a very rich supply of proteid in the food. This behavior is really what one would expect. An excess of proteid would of necessity either raise its percentage in the fluids of the body (blood or lymph), or would be organized into the liring protoplasm. The upper limit for the quantity of proteid in the former state is of course sonn reached. and if still more proteid is to be retained. it can only be deposited as protoplasm. But, as $v$. Hoesslin has pointed out, the body seeks to maintain its normal mass of living substance within the narrowest limits possible; becanse a disproportionately large consumption is associated with the growth of cells, and with this large consumption there goes an increased functional capacity, just as a diminished capacity accompanies a falling off of living substance. The body maintains an arerage, even level of efficiency by keeping the mass of its functional parts approximately constant. The opposite of this namely, an intimate dependence of the organism and of its functional state on the amount of protoplasm, or a rapid fluctuation in the mass of the body proteid would not be to the purpose- $i$. e. would be less advantageous than the existing arrangement. For this reason the body destroys most of the excess of proteid which it gets from the food.

\begin{tabular}{|c|c|c|c|c|c|c|}
\hline $\begin{array}{l}\text { DLRA- } \\
\text { TION OF } \\
\text { EXPERI- } \\
\text { MEXT IN } \\
\text { DAYS. }\end{array}$ & $\begin{array}{l}\text { Calories } \\
\text { per kg. } \\
\text { body weight } \\
\text { per day. }\end{array}$ & $\begin{array}{c}\text { N-supply, } \\
\text { mean } \\
\text { per day, g. }\end{array}$ & $\begin{array}{l}\text { N stored, } \\
\text { mean } \\
\text { per day. } \\
\text { g. }\end{array}$ & $\begin{array}{l}\text { N stored } \\
\text { in per cent } \\
\text { of N- } \\
\text { supply. }\end{array}$ & $\begin{array}{l}\text { SLBJECT OF } \\
\text { EXPERIMENT. }\end{array}$ & ACTHOR. \\
\hline $\begin{array}{l}15 \ldots \\
27 \ldots \\
18 \ldots \\
11 \ldots\end{array}$ & $\begin{array}{r}72.0 \\
32.5-38.0 \\
70.0-90.0 \\
67.0-96.0\end{array}$ & $\begin{array}{r}15.5 \\
20.2-24.6 \\
17.2-24.2 \\
15.0-17.3\end{array}$ & $\begin{array}{l}3.3 \\
2.8 \\
3.8 \\
5.7\end{array}$ & $\left.\begin{array}{r}21 \\
10-16 \\
15-26 \\
34\end{array}\right\}$ & $\begin{array}{l}\text { Self. } \\
\text { Female patient. }\end{array}$ & $\begin{array}{l}\text { Krug. } \\
\text { Dapper. } \\
\text { Kaufmann and Mohr. }\end{array}$ \\
\hline
\end{tabular}


But, as appears in the table on the preceding page, with a sufficient excess of ealorific energy a considerable storage of proteid can be accomplished even by the adult human body.

From this we see that while an excess of nourishment is of first importance for the retention of proteid, still other conditions are necessary. In adults. especially, muscular activity exerts a very great influence which cannot be explained solely by the greater supply of food which the working body denuands. This is evident from the following experiment by Caspari.

A dog received a constant ration, containing 2,058-2,099 Cal. and $25.1 \mathrm{~g}$. $\mathrm{N}$ per day. During rest the $\mathrm{N}$-balance for three days was $-0.5,+1.3$, and $+1.2 \mathrm{~g}$; ; then followed a working period of four days with a daily $\mathrm{N}$-balance of $-1.4,0.0,+0.1,+1.5 \mathrm{~g}$. A period of rest inserted showed a N-balance of $+1.3 \mathrm{~g}$.; whereupon the following five days at work gave $+2.5,+3.7,+2.9$, $+3.5,+3.5 \mathrm{~g}$. $\Lambda \mathrm{t}$ the same time the animal fell off in weight during the first working period from 33.0 to $32.6 \mathrm{~kg}$., and in the seennd from 32.9 to $32.1 \mathrm{~kg}$. In this case there was no excess of nourishment, and yet a considerable quantity of nitrogen was retained.

To study more elosely the conditions for the storage of proteid in the growing body, and at the same time to exclude the influence of mere size. it is necessary to compare the metabolism of two individuals of the same size. one of which is grown and the other still growing. For this purpose Soxhlet has brought together the results obtained by him on a suckling calf $50 \mathrm{~kg}$. in weight with those obtained by Henneberg on a grown sheep weighing $45.5 \mathrm{~kg}$.

\begin{tabular}{|c|c|c|c|c|}
\hline & \multicolumn{2}{|c|}{ In food per $\mathrm{kg}$. } & \multirow{2}{*}{$\begin{array}{l}\text { Grams } \\
\text { x exereted } \\
\text { per kg. }\end{array}$} & \multirow{2}{*}{$\begin{array}{c}\text { Grams } \\
\mathrm{x} \text { retained in } \\
\text { body } \\
\text { per kg. }\end{array}$} \\
\hline & $N, g$. & C, $g$. & & \\
\hline $\begin{array}{l}\text { Suckling calf.......... } \\
\text { Sheep.............. }\end{array}$ & $\begin{array}{l}0.784 \\
0.212\end{array}$ & $\begin{array}{l}9.8 \\
5.6\end{array}$ & $\begin{array}{l}0.204 \\
0.167\end{array}$ & $\begin{array}{l}0.580 \\
0.045\end{array}$ \\
\hline
\end{tabular}

From facts censidered further back, we know that in the adult body the rule is for the quantity of nitrogen excreted to agree very elosely with the quantity in the food. But, as the table shows, this is not true in the suckling calf. Hence, it follows that the conditions for the combustion of proteid in the growing body are much less favorable than in the adult body. And since this difference cannot all be due to the greater absolute quantity of food for the calf, we cannot choose but suppose that the cells of the growing organism possess a speeial ability to appropriate proteid from the fluids of the body, and to convert it into protoplasm. More than this we do not know at present.

From facts obtained on the dog. eoncerning $\mathrm{N}$-metabolism with a low supply of $\mathrm{N}$ in the food, the riew has often been expressed that in order to protect a store of proteid once obtained. as much proteid must be ingested as was necessary to aequire it, or at least that the supply of calories must he as great. But the experiments by Caspari mentioned above are opposed to this 
conchsion. and other observations tend in the same direction. It is evident from fasting experiments that the body offers great resistance to the dissoIntion of proteid once it has been organized into living protoplasm (ef. page $92)$ : and the following experiment by siven shows that the body can maintain its status of proteid on a very small amount of proteid in the daily ration.

The subject was a man, thirty years of age, whose ordinary diet eontained about $16 \mathrm{~g} . \mathrm{N}$ daily (=100 g. proteid). By giving a correspondingly larger quantity of nonnitrogenous food, his proteid was gradually reduced to $6.3 \mathrm{~g}$. N per day. The results are summarized briefly in the following table:

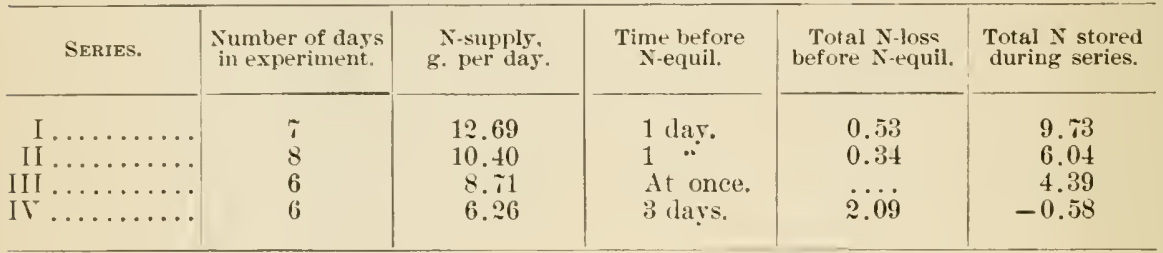

During this experiment the body not only did not lose proteid, but during the first three series it actually gained $20.16 \mathrm{~g}$. $\mathrm{X}$. aud even in the fourth series lost but $0.58 \mathrm{~g}$. That is to say, by proper adjustment of the diet the supply of proteid can be reduced to a very low level, ${ }^{1}$ without entailing any loss of the body's own proteid.

Recently several authors, notably Loewi, have published observations according to which the final end products of proteolytie digestion not only ean replace proteid ${ }^{2}$ in the metabolism, but are able to bring about a $\mathrm{N}$-retention in the body. If these observations should be confirmed in their entirety, the fact would be of the greatest significance for our eoneeption of the metabolie processes. For the present we would not renture to express any definite opinion on the subject.

\section{§ 9. STORAGE OF CARBOHYDRATES IN THE BODY}

In $1848 \mathrm{Cl}$. Bernard and Barreswill reported that the liver differs from all the other organs in that it contains a large amomut of sugar, whatever the character of the fond. Some years later Bermard demonstrated that this sugar is produced by the liver from a substance diffienltly soluble in water, and in 185: he isolated this mother-substance as glycogen.

Glycogen is very widely distributed in organie nature and probably occurs in all animals. In the rertebrates it has been found in almost all organs where it has been sought. which must mean that glyeogen is of great physiological importance in the bodr.

The amount of glyeogen in the different organs varies considerably. It oecurs most abundantly in the liver and the muscles. but in the latter it is to be ohserved that different muscles in the same animal may have a very different percentage of glyeogen. Likewise. corresponding muscles on the two

${ }^{1}$ For discussion of the optimum amount of proteid in the diet see page 142.

${ }^{2}$ Cf. also page 109. 
sides of the body do not have exactly the same percentage: : hence it is not sufficient to analyze single muscles in order to obtain the amount of glyengen in the animal body.

In the following table are brought together some data on the pereentage of glycogen in the new-born child, in a dog after a twenty-eight dars fast, and in the frog:

\begin{tabular}{|c|c|c|c|}
\hline ORGAN. & $\begin{array}{l}\text { New-born child. } \\
\text { (Cramer.) }\end{array}$ & $\begin{array}{c}\text { Fasting dog. } \\
\text { (Calculated as sugar) } \\
\text { (Pflüger.) }\end{array}$ & Frog. (Athanasiu.) \\
\hline 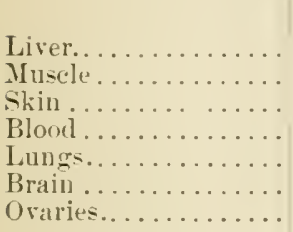 & $\begin{array}{l}\text { Per cent. } \\
1.00-2.15 \\
0.0-1.85 \\
0.0 .5-0.0 \% \\
\ldots .10-11.19 \\
0.01-0.0 \% \\
\ldots \ldots \quad \ldots\end{array}$ & $\begin{array}{c}\text { Per cent. } \\
4.79 \\
0.16 \\
0.09 \\
0.01 \\
\ldots . \\
\ldots \\
\ldots\end{array}$ & 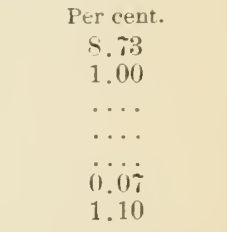 \\
\hline
\end{tabular}

The total quantity of glveogen calculated as sugar in Pflüger'= fa-ting dog was 5.2.j g.-i. e., 1.5 g. per kilogram of body weight.

The amount of glycogen in the body is raised considerably by rich feeding. In a fattened goose, as much as :2:? g. per kilogram of borly weight has been observed.

From many analyses of the organs of hens and rabbits. Otto has found that the absolute quantity of glycogen in the liver is about half the total quantity in the body. The same appears from Pfluger's experiment on the fasting dog. When therefore Pary found in the dog's liver alone a quantity of glycogen amounting to $7.82 \mathrm{~g}$. per kilogram, it is to be supposed that the total quantity in the animal's body was about $15 \mathrm{~g}$. per kilogram. Pflüger takes $11 \mathrm{~g}$. as the average amount of glyeogen per kilogram in the dog.

In man the glyeogen in the liver is estimated at $150 \mathrm{~g}$. and the total amount in the body at $300 \mathrm{~g}$., which is only about $4 \mathrm{~g}$. per kilogram. Possibly this estimate is too low.

Glycogen is laid down in the cells of the liver in large flakes (Fig. 45). It is deposited in the muscles partly between the fibrilla and partly in them.

It is evident that glycogen must be formed in the liver because not only does it oceur there in largest quantities. but when animals previously deprived of most of their ylycogen by a fasting period are fou with carbohridrates. the liver is the first of all the organs to show a storage of glyeogen. An indepentent formation of glycogen in other organs. and especially in muscles, is not thereby excluded. howerer. and in fact there are certain indications that glycogen is thus formed. For example: gryeogen las been demonstrated in chick embrvos hefore the rudiment of the liver appears, whereas the ege, hefore levelopment. is said to contain no glyogen: the glycogen of the muscles of fowls presents certain difference from the liver glyengen : icain paralyzed museles are loaded with glycogen, etc. But this question probably ought not to he regarded a definitely settled. 
In view of the great variations in the percentage of glyeogen in the body, if one is to determine directly the influence of different foodstuffs on its storage, it is necessary first to deprive the animal, as far as possible, of all its glyeogen. As appears from Pfliger's experiment on the dog eited above, a considerable quantity of glyeogen may remain in the body eren after prolonged fasting. Glycogen is far more completely removed from the body by severe muscular work; in fact under such cireumstances it sometimes disappears almost completely, both from the liver and from muscles, in the course of a few hours. Naturally, the effect of muscular work is assisted by a previous fasting period.

There are a great number of different substances which have been claimed to bring about an increase in the percentage of glycogen in the liver. Among
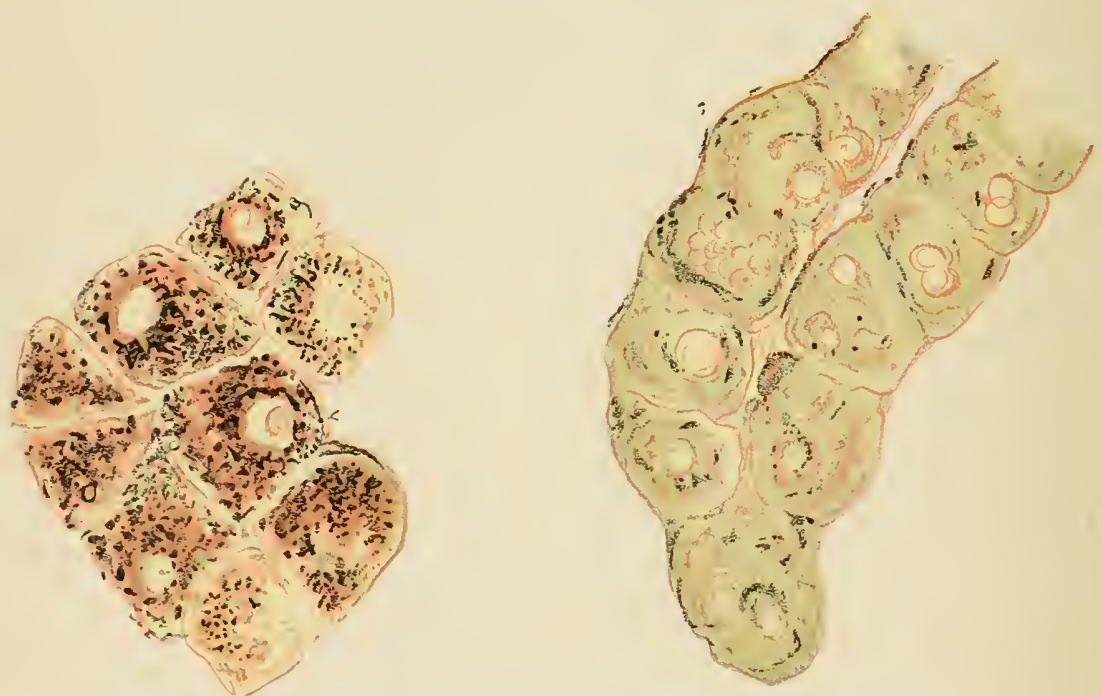

Fig. 45.-Preparations from the liver of a man, after Frerichs. A, section through the normal liver containing glycogen; B, section through the liver of a diabetic, almost free of glycogen. Both preparations treated with iodine.

them are several which, at most, act only indirectly, either by stimulating the liver cells to produce glyeogen or by diminishing its consumption. We shall pass over these substances and consider here only the true glycogen formers.

There is no longer any doubt that certain carbohydrates constitute an important source of glycogen; proofs of this are present on every hand. For example. after feeding with cane-sugar, grape-sugar or starch. 14. 1 per cent of glyeogen has been found in the liver of hens, 10.5 per cent in that of the goose, and 16.9 per cent in the rabbit's liver.

It might be supposed that the earbohydrates had not contributed directly to this storage of glyeogen, but that they only proteet glyeogen split off from proteid from heing further oxidized. Otto has shown, however, that eren if we assume that the greatest possible amount of glyeogen has been formed from proteid, there always remains a considerable exeess which could only have come from carbohydrates. Similarly Popielski found that in dogs in which an Eek 
fistula had been made between the portal vein and inferior vena cava, but which were otherwise healthy, from twelve to twenty-four per cent of the sugar eaten was excreted in the urine. At least this quantity therefore is retained by the liver of normal animals (and is converted into glyeogen).

The following carbohydrates at least can serve as a source of glycogen: dextrose, levulose, galaetose, milk-sugar, cane-sugar, maltose, the last three after being inverted. In this connection it is noteworthy that the glycogen coming from levulose is also dextrorotatory. Levulose, therefore, is either changed first into dextrose, or it passes directly into a dextrorotatory glycogen; in either case the ketone group of levulose is transformed into an aldehyde group.

Many authors have found a second source of glycogen in proteids. In fact it has been observed that the quantity of glycogen in the liver inereases after feeding meat extracted with boiling water, fibrin or chemically pure proteid substances. Pflüger on the other hand comes forward with the claim that the quantity of glycogen demonstrated in such experiments is not greater than the maximum which has been observed in fasting animals of the same speeies. Schöndorff found no increase of the glycogen in frogs after feeding them with casein.

The problern has been attacked also from another side. Under normal circumstances sugar appears in the urine only in mere traces; the total quantity of carbohydrate absorbed from the intestine is therefore either burned in the body, or is stored up after having been transformed into glyeogen or into fat. It is only when the percentage of sugar in the blood, due to a rich supply of sugar in the food, exceeds a certain low limit $(0.2-0.3$ per cent), that a part of the sugar is eliminated through the kidneys (alimentary glycosuria). In this respect starch forms an exception to the rule for the carbohydrates, which is probably due to its relatively slow rate of digestion, a sudden flooding of the blood with sugar being thereby prevented. But in diabetes mellitus as well as after complete extirpation of the pancreas, or after poisoning with phloridzin, the body loses to a greater or less extent either its power to burn carbohydrates or its power to store them, and the urine under these circumstances always contains more or less sugar.

These facts have been made use of in attempting to determine whether or not sugar is formed from proteid. Thus, sugar appears in the urine in these diseased conditions after feeding proteid, and if it ean be shown that this sugar actually comes from proteid, we should have proof that under some circumstances at least glycogen can be formed from proteid. For the sugar formed from proteid. as well as any other sugar, could, from what we have seen, be changed into glycogen.

It is a matter of great moment in these experiments to decide whether more sugar appears in the urine than can be accounted for by the glycogen already deposited in the body at the beginning of the experiment. Pfliger, who recently has subjected the observations on this subject to a searching criticism, takes the view that no proof has thus far been given for the formation of sugar from proteids. It appears, however, that this is going somewhat too far; for in many of the experiments, to explain the quantity of sugar appearing in the urine as derived from the body glyengen, it would be neeessary to suppose that the animal at the beginning of the experiment had had 
its maximum percentage of glycogen; but this can scarcely have been the case in all the experiments.

[For example, Lusk and his co-workers have shown that producing phloridzin diabetes in fasting dogs may cause the proteid metabolisu to rise 333 to 560 per cent. They have also shown that in these diabetic dogs, whether fasting, or fed on meat alone or on fat alone, no more fat is burned than in the same dog when he is normal and fasting. Thus, in one experiment a dog weighing $11 \mathrm{~kg}$. burned on the second fasting day $20.19 \mathrm{~g}$. proteid and $55.87 \mathrm{~g}$. fat with a total of 606.81 Cal. Made diabetic, he lost on the fifth day $39.4 \mathrm{~g}$. of dextrose in the urine. He burned on this day $67.38 \mathrm{~g}$. proteid and $51.15 \mathrm{~g}$. fat, a total of $605.77 \mathrm{Cal}$. The calories lost in the urinary sugar, therefore, are very exactly compensated for in the increased proteid metabolism. Since this dog had receired only $115 \mathrm{~g}$. of fat as food in the seven days, it is of course impossible that the great amount of sugar in the urine should have come from glveogen stored in the body (cf. also page 125). It must have come largely from proteid.-ED.]

Recently the question of a final conversion of fat into glycogen has been actirely discussed. As proof of this cases of diabetes occurring naturally or produced artificially have been cited, in which on a carbohydrate-free diet the quantity of sugar in the urine was too large to be accounted for by the proteid destroyed.

The first question to be asked in this connection is, how much sugar can proteid yield? In a number of experiments on dogs with pancreatic diabetes, Minkowski found the ratio of $N$ to dextrose in the urine to be $1: 2.8$; in phloridzin diabetes, as $\mathrm{v}$. Mering has shown, the ratio may be $1: 5 .{ }^{1}$ Remembering that for every $1 \mathrm{~g}$. $\mathrm{N}$ in the human urine, on the average $0.72 \mathrm{~g}$. $\mathrm{C}$ are eliminated by the same channel, and that proteid contains $3.28 \mathrm{~g}$. C for every gram of $\mathrm{N}$, the carbon remaining in the body which might go to form sugar would amount to $2.56 \mathrm{~g}$. (3.28-0.i2) for each gram of $\mathrm{X}$ ingested. Since dextrose is forty per cent carbon, $2.56 \mathrm{~g}$. C would correspond to $6.49 \mathrm{~g}$. dextrose and hence the utmost yield from proteid alone would be $6.4 \mathrm{~g}$. dextrose for each gram of $\mathrm{N}$.

In order to prove a formation of glycogen from fat it is necessary therefore that the proportion of dextrose to $\mathrm{X}$ in the urine should be greater than $6 . t$ to 1. [Now Lusk has shown that in phloridzin diabetes in dogs and in the most acute form of diabetes mellitus the ratio is fairly constant at 3.65 to 1 ; and nobody has ever positively observed a ratio so high as 6.4 to 1 .--ED.] For the present then we must say that fat is not to be reckoned among the sources of glycogen or sugar in the body. On the other hand it is fairly certain that glycerin is a mother-substance of glycogen.

Proceeding on the assumption that fat is not a producer of glycogen, Landergren has endeavored to explain the ability of carbohydrates, mentioned at page 121, to spare proteid to a greater extent than does fat. In his opinion the body has a specific need for carbohydrates. If they are not supplied in the food, they

${ }^{1}$ [In the experiments of Lusk and others a ratio as high as this is only obtained immediately after the injection of phloridzin, when there is a preliminary sweeping out of sugar.-ED.] 
must be formed from proteid; hence the inerease of proteid destruction when carbohydrates are excluded from the diet. Since in such experiments on man the $\mathrm{N}$-exeretion rose some $5 \mathrm{~g}$. per das, the daily requirement of carbohydrates would amount to about $32 \mathrm{~g}$. $(5 \times 6.25=31.25$; proteid Cal. $=$ carbohydrate Cal.).

\section{§ 10. STORAGE OF FAT IN THE BODY}

Yoit laid special stress upon proteid as the most important source of the fat which is stored in the body. Using the ratio of $\mathrm{N}: \mathrm{C}$ in proteid as found by Voit and Pettenkoffer, their experiments on the state of equilibrium actually show that a eonsiderable portion of the $\mathrm{C}$ ingested in the form of proteid was retained. Since the formation of glycogen was never very large, Voit and Pettenkoffer were fully justified in concluding that some of the $\mathrm{C}$ was retained as fat.

But the percentage of $\mathrm{C}$ in proteid is not so high as Voit and Pettenkoffer supposed. Caleulating their results on the basis of $1: 3.25$, the ratio of $\mathrm{N}: \mathrm{C}$ now generally accepted, a very different conclusion is reached. Pflüger has shown that instead of 57.5-58.5 g. of fat, which Toit and Pettenkoffer estimated as the amount stored in the dog as the result of feeding $2,000 \mathrm{~g}$. of meat per day, the newer ratio allows only $11.8-13.6 \mathrm{~g}$., and that with $1.500 \mathrm{~g}$. of meat practically no fat could have been stored. We are compelled, therefore, to conclude that these experiments contain no proof of a transformation of proteid into fat.

Later, however, Cremer obtained in the cat a retention of $\mathrm{C}$ from excessive meat feeding which he regarded as a safe indication of the production of fat from proteid. The cat excreted $11.2 \mathrm{~g}$. of $\mathrm{N}$ per day and $81.2 \mathrm{~g}$. $\mathrm{C}$ per day. But ealculating the $\mathrm{C}$ from the $\mathrm{N}$ on the basis of the ratio of $1: 3.2$ would give $35.7 \mathrm{~g}$. $\mathrm{C}$ as the amount ingested. Since only $31.2 \mathrm{~g}$. of this was eliminated in the excreta, $4.5 \mathrm{~g}$. of $\mathrm{C}$ per day must have been retained, and in seven days this would amount to $31.5 \mathrm{~g}$. According to Cremer's subsequent analysis the animal's body contained not more than $40 \mathrm{~g}$. of glycogen with $18 \mathrm{~g}$. C. The remainder of the $31.5 \mathrm{~g}$. of C, namely $13.5 \mathrm{~g}$., must therefore have been laid on as fat. Unfortunately this experiment is quite too short and stands too much alone to be accepted as a positive demonstration of the point. (Gruber accomplished a retention of $81.9 \mathrm{~g}$. C in a similar experiment on a dog, but the amount of glycogen was not determined.)

The other ground on which Voit based his idea that proteid is an important source of fat, was the degeneration of proteid under some circumstances into fat, and the great production of fat in the larræ of blowflies living exclusively on meat. As regards the former, we now know that, at least in the case of the phosphorus poisoning of the frog (Athanasiu), the supposed fatty degeneration is in fact an infiltration of fat transported from the fatty deposits of the body and deposited in the cells, instead of a formation in situ by the destruction of proteid. Whether all forms of fatty degeneration are to be explained in the same way, has not ret been settled. Lindemann has found that the fat of the degenerated eardiac tissue is different in some essential respeets from the fat deposited elsewhere in the body, as about the kidneys and under the skin. This faet, however, does not constitute strict proof against an eventual transportation of fat, for it is easily conceivable that the fat might undergo some change in the process of its liberation from the depository whence it came.

Pfliger explains the occurrence of fat in the larve of blowflies which lived on blood, as observed by Hofmann, by supposing that the fat was formed from the blood under the influence of Bacteria, and was merely absorbed as such by 
the larva. Moreover, as O. Franck has shown, the method of determining the fat, which was employed by Hofmann, does not permit of any positive conclusion from his experiment.

When we examine these observations critically, we must conclude with Pfliger that no single experiment has yet been given which proves beyond question that fat is formed from proteid. Since, howerer, most of the proteids contain a carbohydrate group and the body in all probability can form glycogen at the expense of proteid, and since carbohydrates are unquestionably a source of fat, the possibility of a final production of fat from proteid cannot be exchuded entirely: although to judge from results thus far obtained, such a roundabout production is not large and never takes place except with a very rich supply of proteid. In man a transformation of proteid into fat is scarcely to be admitted at all, for he has the power to digest and absorb only a relatively small quantity of proteid.

On the other hand. we have any number of experiments which show that fat can be formed in the body from nonnitrogenous substances.

That fat given in the food can be directly stored in the body, follows from the experiments of Pettenkoffer and Voit cited on page 104, and is shown with particular clearness by the following experiment of I. Munk.

Munk let a dog starve for thirty-three days, during which time most of the fat was of course lost from his body. He then gave the dog $300 \mathrm{~g}$. meat and $160 \mathrm{~g}$. rape-seed oil daily for seventeen days, and killed him at the end of that time. On dissection a very large deposit of fat was found, which could not possibly have been derived from the meat fed. This in itself showed that the fat of the oil had been stored; but in addition to this erucic acid, which is a constituent of rape-seed oil but does not occur in dog fat, could be demonstrated in the fat laid down from the food.

Moreorer, soaps and free fatty acids of the food can, after synthesis into neutral fat. be directly stored in the body. This Radziejewski and Tunk have shown in the same way as in the experiment just mentioned, by feeding a soap of rape-seed oil and the fatty acids set free from mutton fat, respectively.

Whether or not fat can be formed from carbohydrates in the body, is a question which has been discussed for a long time. Since the latter spare fat from being metabolized, great importance has always attached to them in the laying on of fat, and weighty reasons were found for such a transformation in the case of herbivorous animals and especially of swine and cattle, which are fattened for the market very largely on carbohydrates. Thereupon, the discussion turned to carnivorous animals and man; and it has now been completely demonstrated by I. Munk and Rubner in experiments which we cannot go into here, that the transformation takes place in these also.

We see, therefore, that fattening always occurs if the supply of nonnitrogenous substances is greater than the needs of the body. Under such circumstances the body can store almost any quantity of fat. Underneath the skin, around the internal organs, in short everywhere in the body, fat can be accumulated. 


\section{$\S 11$. THE INORGANIC FOODSTUFFS}

\section{A. GENERAL}

If an animal be fed proteid, fat and carbohydrates sufficient in quantity, but deprived as far as possible of mineral constituents, very evident disorders in the health of the animal soon make their appearance. Such food, poor in salts, will not be eaten voluntarily, and even though the animal may receive plenty of organic foodstuffs, and though he may absorb them for a long time in perfeetly normal fashion, he becomes continually weaker and gaunter. Within two weeks symptoms of general weakness come on, the gait is sluggish and staggering, the muscles tremble, and the animal becomes exceedingly irritable in disposition. If the experiment be carried still further, convulsions ensue and finally death.

If, late in the course of events, the animal's ordinary diet be restored, at first he shows no desire to eat. The appetite however increases gradually, and finally becomes ravenous. The symptoms of weakness, trembling of the muscles, etc., pass away but slowly, and traces of them are to be observed for a month or more after the salts are restored to the diet.

It is perfectly certain therefore that the mineral constituents of the food are just as important as are the organic foodstuffs. In fact, it appears from researches by Forster, that the body can endure absolute abstinence better than it can endure deprivation of salts.

In order to understand the reason for this great importance of the mineral substanees, it is necessary to know the effect of deprivation on the secretions and exeretions of the body. We saw above that digestion goes on normally for a relatively long time; later, however (after three and one-half to four and one-half weeks), digestive disorders are exhibited. The animal vomits his food; or it may remain in the stomach for hours without being digested. In any case the vomited contents always contain a fairly large quantity of chlorine.

Forster has shown that the excretion of $\mathrm{P}_{2} \mathrm{O}_{5}$ never ceases entirely, it only becomes less than with the usual food; and, moreover, it decreases in proportion to the quantity of ash-free food ingested. The same is true of $\mathrm{NaCl}$ : during the first days of deprivation a relatively large quantity is exereted; later it falls off considerably so that finally in $200 \mathrm{cc}$. of urine only indeterminably small traces could be demonstrated. During the last days, when the animal was drawing heavily upon his own body for organic substances, larger quantities of $\mathrm{NaCl}$ were given off in the urine.

Forster considers himself justified by these experimental results in generalizing as follows: although the mineral constituents of the body are eliminated in smaller quantities when salts are no longer supplied, their excretion never ceases entirely. The quantity eliminated is least when organic foodstuffs are fed in abundance.

This is because mineral constituents for the most part form loose compounds with the combustible substances of the body, especially the proteids. When organic foodstuffs are not supplied in sufficient quantity so that the 
body must draw on its own store of these. the mineral constituents are set free. find their way into the fluids of the body, and are eliminated through the killners.

If an animal receive more salts in his food than he needs the excess is likewise eliminated in the excretions.

The importance of the individual elements has already been discussed on general lines at page ?5. It remains for us to mention briefly the helavior of some of them in metabolism. It will be neeessary to limit the diseussion to phosphorus, calcium and magnesium. With regard to iron ef. Chapter X.

\section{B. PHOSPHORUS}

Phosphorus, like several other inorganic foodstuffs, is eliminated mainly in the frecs. In following the metabolism of proteids containing phosphorus we have therefore to consider both the urine and the freces, whereas the metabolic products of proteids containing no phosphorus are almost all given off in the urine.

For a long time it was assumed that only the inorganic phosphorus compounds are absorbed from the intestine. This was based partly on results indicating that the excretion of phosphorus in the urine plainly rose after the addition of phosphates, and partly on the supposition that the phosphorus component of different proteids was indigestible. It has been shown, however: that pancreatic juice, acting for one to two hours, dissolves from one-half to one-third of the phosphorus in the nuclein of thymus (Popoff); that in the digestion of casein by gastrie juice the greater part of the phosphorus passes into the soluble digestive products (Salkowski); and that under the action of panereatic juice almost all of the phosphorus of casein is brought into solution (Sebelien).

It is not a difficult matter to show that the phosphorus from these substanees is actually absorbed from the intestine. In some experiments on dogs Marcuse found that at least eighty-one to eightr-four per cent of the phosphorus of easein was absorbed; and in experiments on man Loewi observed an absorption of about seventy-nine per cent of phosphorus derived from nuclein.

But we cannot decide positively from these experiments whether the phosphorus is actually absorbed in organic combinution or not. We know, indeed, that phosphorus is ver: easily split off from such substances by all sorts of agencies. In any ease if it eould be shown that phosphorus is stored in the body only after feeding with a proteid eontaining phosphorus in its molecule, we should then know that the body must depend upon such compounds as a source for this element. The experiments of Zadig seem in fact to prove that this is the case; but in a more recent series of experiments Leipziger was ablc to demonstrate a storage of phosphorus after feeding a P-free edestin and a phosphate. Hence there is as ret no proof that phosphorus may not be supplied as well in inorganic as in organic form. Experiments by Loewi have shown however that the ratio of $\mathrm{N}$ retained to $\mathrm{P}$ retained after excessive feeding with the nucleins agrees fairly well with the ratio of their percentages in the food, and indicates therefore that nucleins may be absorbed from the intestine, partly at least, in unchanged form.

In order to determine the absolute requirement of the human body in phosphorus it is necessary to measure directly the income and the output.

In human freces the quantity of $\mathrm{P}$ varies, according to the eharacter of the food and the $\mathrm{P}$ contained in it, from $0.25 \mathrm{~g}$. to $3 \mathrm{~g}$. and more per day. In the urine the limits for an adult are $0.4 \mathrm{~g}$. and $2.8 \mathrm{~g}$. When the phosphorus is 
drawn from the body itself, the quantity in the urine is less-only $0.4-0.7 \mathrm{~g}$. per day. If after a period of deprivation plenty of phosphorus is supplied, the elimination in the urine is only about $0.9 \mathrm{~g}$. The absolute need of the adult human body, therefore, would be $0.9 \mathrm{~g}$. plus the amount in the frees. But under ordinary circumstances in P-equilibrium, the quantity eliminated in the urine appears to be somewhat larger, and may be estimated at $1.5 \mathrm{~g}$. Adding to this the average daily quantity in the frees $(0.75-1 \mathrm{~g}$.$) , the total requirement of the$ adult body for P-equilibrium would be something more than $2 \mathrm{~g}$.

\section{CALCIUM AND MAGNESIUM}

Both these elements are absorbed from the intestine in inorganic compounds. This we know from their appearance in the urine after the administration of calcium and magnesium salts.

An unlimited absorption of $\mathrm{Ca}$ and $\mathrm{Mg}$ is impossible because of the alkaline reaction of the blood, although it appears to be easier for Mg than for Ca. It is also very probable that $\mathrm{Ca}$ occurs in the blood only in the form of a proteid compound which is not precipitable by an alkaline reaction merely (Kühne). If, therefore, these elements occur in the diet in large quantities, the greater part is passed out unabsorbed in the freces. Besides, Ca and $\mathrm{Ig}$, like $\mathrm{P}$, are exereted through the intestinal mucosa, proof of which is afforded by their oceurrence even in starration freces. (In the ease of Cetti $0.07 \mathrm{~g}$. Ca and $0.006 \mathrm{~g}$. Mg per day; in the ease of Breithaupt 0.03 and $0.01 \mathrm{~g}$. respectively per day.) With a diet extremely poor in mineral constituents generally, Renwall observed in the faces an average of $0.16 \mathrm{~g}$. Ca and $0.06 \mathrm{~g}$. $\mathrm{Mg}$ per dar.

When we compare the herbirora with the carnirorous animals we find considerable difference in the proportion of the calcium and magnesium excreted in the urine and the freces. In the former, only about four to five per eent of the $\mathrm{Ca}$ and twenty-four to thirty-two per cent of the $\mathrm{Mg}$ appear in the urine, while in the latter, the urine contains as much as twenty-seren per cent of the total Ca exeretion and sixty-fire per cent of the total $M$ g exeretion.

From the few observations thus far reported, we may judge that the excretion of $\mathrm{Ca}$ in the human freces would amount to thirty-six to fifty-eight per cent of the total $\mathrm{Ca}$ exeretion, and that of $\mathrm{Mg}$ sixty to seventy per cent of its total, the exact amount in each case depending on the power of the urine to dissolve the metal.

Very few attempts hare been made to place the human body in an equilibrium of $\mathrm{Ca}$ and $\mathrm{Mg}$, and for this reason it is scareely possible to give definite figures as to the actual need for them. From the few facts at hand we may conjecture that an adult man would reach an equilibrium on a daily supply of $0.3-0.7 \mathrm{~g}$. Ca, and of something more than $0.4 \mathrm{~g}$. Mg.

\section{\$12. FLAVORS}

A dict consisting of pure proteid. pure fat, pure carbohydrates. ash and water, each in sufficient quantity, would not be agrecable and would not be eaten except in case of extreme necessity. And yet we have in such a diet everything that one needs with a single exception-namely. something to give the fond an agreeable taste and odor: in short. a froror to make it palatable. We must not suppose that this aversion to the pure fondstuffs is due to the love of pleasurable sensations which characterizes man in the civilized state. for an animal will not voluntarily eat a perfectly tasteless food, eren if it contains everything that he needs. 
We may reckon among flavors not only the substances commonly understood by the word in its strictest sense, such as that which gives the characteristic taste to roast beef, or that developed in the baking of bread, the spices, extracts, etc., but also coffee, tea, alcoholic drinks, tobacco, etc.-in short, anything which adds to a meal an element of pleasure. In this sense we might include also the various extraneous means of making a meal enjoyable, like neat service, lively conversation, etc.

Some of the foodstuffs themselves serve at the same time as flavors-e.g., sugar and salt. The body requires $\mathrm{NaCl}$; but in the quantities in which we ordinarily eat salt, it is really a flavor.

The physiological importance of flavors consists in the stimulus they afford for the secretion of the digestive fluids. Sight or smell or even the thought of an appetizing dish makes the mouth water-i. e., makes the salirary glands secrete profusely. As we shall see later under digestion, the same can be demonstrated for the gastric glands. If a meal or its accompaniments are not pleasant, these reflex effects are not fortheoming (ef. Chapter VII).

If one eats too much or too frequently of a dish once palatable, it becomes distasteful or even "turns against" him; and the more pronounced the taste of the dish, the more quickly will it become distasteful. On this account there are only a few articles of diet, such as bread, which we can eat every day or in large quantities. Herein lies the importance of variation in diet, even different modes of preparing the same articles being advantageous. For example, the people who live mainly on flour or meal of cereals do not eat these substances exclusirely in the form of bread, but use them also in the preparation of dumplings, noodles, pancakes, etc.

\section{§ 13. ON THE THEORY OF METABOLISM}

In order to comprehend fully the processes of metabolism it is needful that we inquire to what extent, if any, the organized substance of the body is broken down in combustion.

When we consider how very much the destruction of proteid depends upon the amount ingested (page 99), how the $\mathrm{N}$-excretion after meals is very closely connected with the absorption of proteid into the blood (page 101), and when we remember that the nonnitrogenous foodstuffs do not essentially alter the destruction of proteid (page 105), and that physical work with plenty of $\mathrm{N}$-free foodstuffs supplied does not increase the proteid combustion (page 111). we are almost compelled to suppose with Voit that it is the proteid of the food and not the living protoplasm which first breaks down in metabolism.

Since the living protoplasm is derived from proteid, and upon its degradation after death again forms proteid, it is quite common in the physiology of nutrition to apply to it the name of tissue proteid, and to the dead proteid coming from food and found in the fluids of the body, the name "circulating proteid." In order to avoid misunderstanding we shall use here the terms: living substance, in whatever tissues it may occur, and food proteid-i.e., the proteid absorbed from food but not transformed into living substance. 
The food proteid is distinguished in the first place by the ease with which it is destroyed by the organs of the body. No other organic foodstuff ean compare with it in this respect. It is true that fat and carbohydrates, if supplied in sufficient quantity, can reduce the destruction of proteid to a certain extent, but in a general way this destruction bears about the same relation to the proteid ingestion whether the $N$-free foodstuffs be eaten or not.

The digested proteid passes into the blood as food proteid. If the quantity absorbed is not too small, and if at the same time plenty of $\mathrm{N}$-free foodstuffs are present, a part of it may remain in the body undestroyed, but, as a rule, the greater part of it is destroyed within twenty-four hours.

In sharp contrast with this is the fact that the mass of living substance has but a very slight influence on the amount of proteid destroyed. We have seen (page 11 $\tilde{i}$ ) that there is no direct proportion between the weight of the body and the amount of proteid metabolism, and (page 12t) that beyond a certain lower limit the body can maintain its proteid status on widely different quantities of proteid, provided only that the nonnitrogenous foodstuffs be present in sufficient quantity.

It follows. therefore, that the living substance is not destroyed either in the metabolism of proteid or in that of the nonnitrogenous foodstuffs, but on the whole is relatively stable.

The doctrine of Voit, given preference here, that the food proteid is destroyed first and the living substance only when the food proteid is not sufficient for the needs of the body, is still disputed by many authors of high rank, who advoeate the view, first put forward by Liebig, but modified later by Pflüger and others. According to this view the living molecules of which the cells are composed are continually being destroyed and built up again in the life process; the cells as such do not break down, but their molecules are incessantly changing; the living moleeule disintegrates much more easily than that of dead proteid, and the latter is destroyed only after it has been transformed into living molecules; of itself it is much more stable than the living substance.

It is indeed a matter of everyday experience that when an organ is taken out of the living body, it dies within a relatively short time, and on the other hand, that dead proteid in a dry condition can be preserved for any length of time unchanged. But we are not to conelude from such observations that in the living body, dead proteid is less destructible than living protoplasm. For an extirpated organ, by the very act of its removal from the body, is placed in altogether abnormal eireumstances. In the living body the medium in which the cells and the tissues carry on their activities is the lymph. Wherever this fluid is wanting, or has not the proper temperature and the normal constitution, is not renewed oftcn enough or is not provided with sufficient oxygen, protoplasm there represents a very destructible substance. But we are not justified by this alone in maintaining that the living substance behaves in the same way, when the lymph is perfectly normal. What we know is, that when the lymph is normal, the living substance carries on its functions; and there is no ground for the assumption that it is then less stable than the dead substances found in the fluid by which it is bathed.

If the living substance were always breaking down when it is active, what a tremendous work of synthesis would be required in order to keep it restored from the dead food proteid! And if this were true, how should we explain the extraordinary difficulty with which the adult body lays on protcid? If the food 
proteid had first to be organized in order to be used by the cells, the same would of necessity be true of the nomnitrogenous foodstuffs, of alcohol, etc.; before they could be destroyed they would have to become integral constituents of the living substance. We cannot get away from this consequence; but what direct proof have we for it?

How much simpler is the other view that the organized tissues do not themselves break down-their molecules not being destroyed-during activity, but are relatively stable substances which perform their duties at the expense of the combustible stuffs present in the lymph; that the tissues draw upon the lymph for whaterer they require; that in all probability they take up these stuffs (proteid, fat, carbohydrate, etc.), into their own mass, not, however, organizing them into their own substance, but destroying them sooner or later, according to the intensity of their vital activities, as so much fuel.

In so regarding the living substance as relatively stable, we do not mean to say that, longer periods of time considered, it may not be destroyed and be restored again. Indeed, it will be found expressly stated under the appropriate sections, that certain organized structures, like the blood corpuscles, epidermal cells of the skin and its appendages, epithelia of the intestine, etc., are all the time breaking down and being lost, and it is more than probable that the other tissues exhibit the same phenomena.

There is another question, the satisfactory solution of which is of the greatest importance for this conception of metabolism, namely. IThy is it that with sufficient nonnitrogenous foodstuffs to cover the calorific requirements of the body, it cannot entirely dispense with proteid in the food?

Of course this is partly due to the fact that the living substance is being destroyed to a certain extent, and needs proteid for its restitution. More than this, proteid is used up in the formation of the digestive fluids, in the secretion of milk, etc. Just how great is the quantity necessary to cover these absolute requirements of the body, cannot be stated at this time; but it is considerably less than the quantity which appears to be necessary to maintain the body in a satisfactory state of nutrition.

Voit answered the question before us by simply saying that the tissues have need of a certain amount of proteid for their own maintenance. But this answer is only another way of stating the facts to be explained. The following appears to throw some light on the question.

The lymph is the medium in which the cells and the tissues live. It contains proteid as one of its necessary constituents. But when proteid is present, it is destroyed by the tissues with the greatest avidity. In starration the proteid of the lymph, therefore, is gradually used up, so that the latter would become unsuitable as a medium for the tissues, if they did not themselves give up some of their proteid to the lymph. This proteid is in its turn destroyed. and a new moiety from the tissues takes its place. Thus it goes on continually; and our question, why proteid is destroyed in the body not only in starvation but even when the supply of nonnitrogenous food is as great as possible, is to be answered through this continual need of a lymph with the same peculiar constituents all the time, and through the peculiar preference of the cells for proteid before all the other organic foodstuffs. Such an explanation does not require us to suppose that the tissues or the organized molecules themselves must break down with every manifestation of life. From the same point of view we can explain also the phenomena attending deprivation of salt (cf. page 131). 
[On the basis of some very thorough studies of the composition of normal human urines following different diets, Folin has worked out a theory of proteid metabolism which has received such extensive notice as to deserve mention in this connection. Folin finds that in order to explain the changes in the composition of the urine with reference to nitrogen and sulphur, it is necessary to assume that the proteid metabolism is of two kinds. "One kind is extremely variable in quantity, the other tends to remain constant. The one yields chiefly urea and inorganic sulphates, no creatinin and probably no neutral sulphur. The other, the constant metabolism, is largely represented by creatinin and neutral sulphur and to a less extent by uric acid and ethercal sulphates."

The variablc metabolism is conceived as consisting of a series of hydrolytic splittings of food proteid (cf. Chap. VII), begun in the intestinal wall and completed in the liver, which result in the elimination of the proteid nitrogen as urea. This is called exogenous metabolism. The constant metabolism represented by creatinin (and uric acid) is regarded as a true index of that destruction of living substance necessary to the continuation of life, and is therefore called endogenous metabolism. In Folin's view, only that amount of proteid necessary for the endogenous metabolism is really needed by the body. The greater part of the proteid in ordinary diets, i. e.. that amount representing the exogenous metabolism, is not needed, or at least its nitrogen is not needed.

This theory agrees with Voit's theory as stated above in regarding the living substance as relatively stable, but differs from it in regarding the more ready dissolution of ingested food-proteid not as a matter of preference on the part of the cells, but as a specially developed means for removing the unnecessary nitrogen of the proteid ingested. The earbonaceous part of the proteid molecule, which alone is conceived as undergoing true oxidations similar to those whieh fats and earbohydrates undergo, is thereby rendered available.

The theory seems to explain the facts of proteid metabolism as stated by the author in this chapter quite as well as Voit's theory, and in addition seems to place a new physiological significance on the portal circulation.-ED.]

\section{SECOND SECTION}

\section{NUTRITION OF MAN}

If the diet contains in sufficient quantities and in the proper proportion all those substances which the borly needs, it constitutes what Toit calls a "food." As applied to a healthy adult man. this ration is that quantity of foodstuffs which is necessary to keep the body in an equilibrium of substance. For growing children as well as for adults in a poor state of nutrition, the ration must be more plentiful so that a part of it can be retained in the body.

In this section we have to study the mutritive requirements of man and some of the circumstances affecting them. Naturally we cannot go into details here: important as they are, they belong to hygiene and dietetics, rather than to the physiology of nutrition.

The nutritive requirements of a man are represented by those quantities of the different foodstuffs which must be added to the body from the intestine every day. But inasmuch as we do not commonly eat pure foodstuffs, but meals prepared from various articles of food. the question may be raised. 
whether the foodstuffs contained in the different articles of food are utilized in the intestine to an equal extent. Experiment has shown that as a matter of fact the ntilization of the foodstuffs in different articles of food and "dishes" is very different (Rubner). For the method of these investigations and the share which the intestine las in the formation of the faces, see pages 85 and 96 , also Chapter VII.

\section{\&1. UTILIZATION OF THE FOODSTUFFS}

\section{A. PROTEID}

We have already seen that the quantity of $\mathrm{N}$ in the frces which comes from the body itself, and therefore represents a product of metabolism, amounts to $0.5-1.4 \mathrm{~g}$. per day. If then we find only this quantity of nitrogen in the faces after a certain diet, we may say that the ingested nitrogen has all been ntilized.

This is generally the case with animal foods. In experiments with meat, fish, eggs, milk and cheese, the daily elimination of $\mathrm{N}$ in the freces varies from 0.14 to $1.9 \mathrm{~g}$.; only in one case-with $4,100 \mathrm{~g}$. of milk-do we find in the literature of this subject a greater quantity $(3.1 \mathrm{~g}$.$) of \mathrm{N}$ in the fieces. If the total $\mathrm{N}$ in the freces be calculated as lost from the $\mathrm{N}$ ingested, it amounts to only $2.0-\% .7$ per cent.

Kermauner has taken the pains to estimate quantitatively the residue of meat recognizable as such in the faces of three individuals, and has found that after an ingestion of $266 \mathrm{~g}$. meat per day the highest amount in the faeces was $4.7 \mathrm{~g}$. and the lowest $0.3 \mathrm{~g}$. $(=0.16$ and $0.01 \mathrm{~g}$. N respectively).

With vegetable foods the quantity of $\mathrm{N}$ in the frees is considerably greater, and in certain experiments has been known to reach the high value of $9.09 \mathrm{~g}$. per day; the loss in this case amounts to as much as forty-eight per cent and as a rule is more than fifteen per cent.

This is due primarily to the fact that vegetable foods contain nitrogenous compounds in their husks, coats, ete., which are not proteid and are not digested in the intestine. The more husk, ete., a vegetable food contains, the less favorably does the utilization of its nitrogen prove to be. For this reason we find in the frecs from rye bread made from whole meal $2-4 \mathrm{~g}$. nitrogen, representing a loss of thirty to forty per cent. If, on the other hand, most of the bran be removed, the utilization appears more favorable with a loss, namely, of only $2 \mathrm{~g} . \mathrm{N}$ or ten to twenty per cent. Other factors tending to make the utilization of coarse vegetable foods less favorable are their relative bulkiness, the acid fermentation of the carbohydrates, and the percentage of indigestible substanees. All these conditions tend to stimulate the museulature of the intestine and thus to produce a more rapid evacuation of the intestinal contents.

\section{B. UTILIZATION OF FAT AND CARBOHYDRATES}

The daily frees from a diet which contains no fat will lose $3-7 \mathrm{~g}$. by extraction with ether. If, therefore, the faces after ingestion of a rertain fat contain no more fat than this, we can say that that particular fat has 
all been absorbed from the intestine. This is true of eggs, milk, butter, margarine, lard-in fact, of fats generally which are fluid at the temperature of the body and are not surrounded by membranes. However, even with other fats, like bacon fat, which is inclosed in membranes, the utilization is commonly very complete. Thus, with $350 \mathrm{~g}$. per day, most of which was bacon fat (unrendered lard), only $45 \mathrm{~g}$. appeared in the fæces.

Carbohydrates also are well absorbed in the intestine, inasmuch as the loss by the frces from the ordinary articles of diet rises only to about ten or eleven per cent at the highest, being as a rule smaller than this. It is true of carbohydrates also that with finely prepared foods the utilization is much better (0.8-3.2 per cent loss) than with coarse foods (6.9-11 per cent loss). The digestibility of cellulose has already been discussed at page 110 .

By microscopic examination of the freces J. Moeller has shown that healthy men digest the starch of cereals and potatoes almost completely, even if the starchy food is but imperfectly ground up. If, however, the starch is present in the form of leguminous seeds or is eaten in green regetables, it is passed out undigested. The hard-walled cells of the ripe leguminous seeds appear not to be digested at all, so that only that part of the starch which is liberated from the cells by mechanical destruction of their walls is of any benefit in nutrition. The starch of green leguminous plants, on the other hand, is just as completely digested as that of cereals. The gluten layer of the latter behaves like the leguminous seeds: their membranes, consisting of pure cellulose, are not digested, and their contents, consisting of proteid and fat, are digested only so far as they are set free by rupture of the cell membranes.

The absorption of mineral eonstituents of the diet. calculated in percentages of the amount supplied, is generally rather poor. But we must remember that the ash of the fæces comes mainly from the body itself, seeing that many mineral substances are excreted through the intestinal wall.

\section{UTILIZATION OF A MIXED DIET}

The experiments which we have discussed so far relate chiefly to the absorption of individual articles of food. We might suppose, howerer, that a mixed diet, such as is ordinarily eaten by man, would be utilized more adrantageously than these experiments indicate; and in fact it has been shown that certain mixtures are absorbed better than their separate components. But all the experiments on the utilization of a mixed diet which we have as yet, go to show that animal nitrogen is absorbed better than regetable nitrogen.

A few words remain to be added on the utilization of the total potential energy of the diet. We assume here as before, that the total fæces represent a residue of the ingested food. For a mixed diet Rubner, on the basis of one experiment on the heat value of the frces. estimates the loss at 8.11 per cent of the gross calorifie value of the food. In those experiments with a mixed dict in which the utilization of all the foodstuffe has been investigated, the results show a loss in potential energy of 4.8 to 13.9 per cent. By direct determinations of the heat value of the food. and of the frees, Atwater has found in 117 experiments with a mixed diet of easily digestible substances, 
that the loss of potential energy was from 2.6 per cent to 11.7 per cent. In this important series the loss in proteid was 3.8 to $11 . i$ per cent, in fat $1 . \gamma$ to 12.7 per cent, in carbohydrates 0.9 to 5.2 per cent.

An arerage figure to express the utilization of energy in the food ought not be placed too low. Suppose we assume that ten per cent of the potential energy is lost, then to supply a man with $3,000 \mathrm{Cal}$. his diet should have an indicated value of $3,333 \mathrm{Cal}$. Because of the many analyses necessary, a complete experiment on the utilization of foods in the intestine is attended by considerable difficulties. But for all practical purposes it is sufficient to determine the dry residue of the diet and of the corresponding frees; for the percentage loss in dry substance, so far as our experience yet goes, varies but slightly from the percentage loss in energy.

\section{§ 2. THE ENERGY REQUIREMENTS OF AN ADULT}

It is already clear that the requirements of an adult must be determined essentially by the phrsical work to be done, for work is inseparable from a consumption of substance. Hence we have first to investigate how great the total supply must be for different amounts of work. The problem is simplified materially by excluding the inorganic foodstuffs, for it has been shown that if the diet is sufficient and has the proper constitution in other respects, it will contain also plenty of inorganic substances.

To determine the minimal requirement, observations must be made on the metabolism in complete muscular rest. Such observations have given the following results :

A woman, twenty-five years of age, weighing 49.5 kilograms, who was in an hysterical sleep and ate nothing, excreted in twenty-four hours $6.21 \mathrm{~g}$. $\mathrm{N}$ and $107 \mathrm{~g} . \mathrm{C}=38.8 \mathrm{~g}$. proteid and $113.2 \mathrm{~g}$. fat, corresponding to $1,228 \mathrm{Cal}$., or 1.03 Cal. per kilo per hour.

In his calorimetric experiments Atwater obtained as a mean of sixteen determinations of the heat loss in sleep (from $1 \mathrm{~A}$. M. to $7 \mathrm{A.M}$.), the value of $1.03 \mathrm{Cal}$. per kilo per hour.

The minimal requirement of the adult man may be placed, therefore, at 1 Cal. per kilo per hour-i. e., for a man of $70 \mathrm{~kg} .1,680 \mathrm{Cal}$.

But for patients in a weak bodily condition muscular rest so complete as this never occurs. The skeletal muscles are alwars moved to a greater or less extent; hence metabolism must be somewhat greater than in sleep.

The experiments of Pettenkoffer and Voit on individuals at rest give an arerage (for twenty-four hours) of 2,303 Cal. in fasting and 2,675 Cal. on a moderate diet-i.e., 32.9 and 38.2 Cal. respectively per kilo per day. In experiments by Sondén and the author on eight resting men between the ages of nineteen and forty-four years, the metabolism varied from 1,853 to $2,292 \mathrm{Cal}$, or from 26.3 Cal. to 36.0 Cal. per kilo per day. Eckholm's results on ten students and thirteen soldiers between nineteen and twenty-five years gave a mean result of 35.6 and 37.0 Cal. respectively. From Atwater's calorimetric experiments carried out on three different subjects and covering forty-fire days, we get a total metabolism for the resting man of 2,241 Cal.-i. e., 32.9, 33.3, and 33.4 Cal. per kilogram. 
The metabolism of a grown man, who neither rests absolutely, nor does any real physical work (providing he receive not too limited a supply of food), may be estimated, therefore, at 30-36 Cal. per kilogram per twentyfour hours-i. e., for a body weight of $70 \mathrm{~kg}$., 2,100 to 2,520 Cal. Consequently a ration which does not supply at least 2.000 Cal. net (i.e., allowing ten per cent waste; ef. page 140) must be declared insufficient for a physical laborer.

Laborers' rations may be divided, according to the amount of energy required, into several different groups. The following is arranged especially for men:

\begin{tabular}{|c|c|c|c|}
\hline Grote. & Calories (net). & Sufficient for a & Climate. \\
\hline 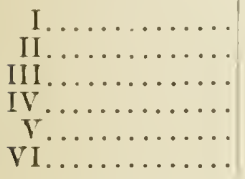 & $\begin{array}{l}2,001-2,400 \\
2,401-2,700 \\
2,701-3,200 \\
3,201-4,100 \\
4,101-5,000 \\
\text { Over } 5,000\end{array}$ & $\begin{array}{l}\text { Shoemaker. } \\
\text { Weaver. } \\
\text { Soldier. } \\
\text { Farın laborer. } \\
\text { Excavator. } \\
\text { Lumberman. }\end{array}$ & $\begin{array}{l}\text { Fngland. } \\
\text { Saxony. } \\
\text { Germany. } \\
\text { Scotland. } \\
\text { France. } \\
\text { Bavaria. }\end{array}$ \\
\hline
\end{tabular}

The following may be given as examples of rations which would yield an average supply of energy sufficient for each of these classes:

\begin{tabular}{|c|c|c|c|c|c|c|}
\hline Grour. & $\begin{array}{c}\text { Proteid, } \\
\text { gross } \\
\text { g. }\end{array}$ & $\begin{array}{c}\text { Fat, } \\
\text { g. }\end{array}$ & $\begin{array}{l}\text { Carbo- } \\
\text { hydrate, } \\
\text { g. }\end{array}$ & $\begin{array}{c}\text { Calories, } \\
\text { gross. }\end{array}$ & $\begin{array}{l}\text { Calories, } \\
\text { net. }\end{array}$ & $\begin{array}{l}\text { Calories per kg. } \\
\text { body weight } \\
\text { (mean = io kg.). }\end{array}$ \\
\hline 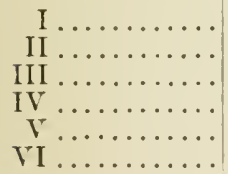 & $\begin{array}{r}84 \\
88 \\
130 \\
141 \\
167 \\
152\end{array}$ & $\begin{array}{r}56 \\
39 \\
64 \\
71 \\
89 \\
139\end{array}$ & $\begin{array}{r}399 \\
512 \\
520 \\
677 \\
774 \\
1,062\end{array}$ & $\begin{array}{l}2,483 \\
2,825 \\
3,257 \\
4,020 \\
4,685 \\
6,269\end{array}$ & $\begin{array}{l}2,235 \\
2,538 \\
2,932 \\
3,618 \\
4,218 \\
5,642\end{array}$ & $\begin{array}{l}32 \\
36 \\
42 \\
52 \\
60 \\
81\end{array}$ \\
\hline
\end{tabular}

Within the last few years a large number of observations on the nutrition of men who had free choice of their own food. have been made under Atwater's direction in the United States. The results are recorded in the following table:

\begin{tabular}{|c|c|c|c|c|c|c|c|c|}
\hline Grour. & Cal., net. & $\begin{array}{l}\text { Number } \\
\text { of obser- } \\
\text { vations. }\end{array}$ & $\begin{array}{l}\text { Proteid, } \\
\text { gross; g. }\end{array}$ & Fat, $g$. & $\begin{array}{l}\text { Carbo- } \\
\text { hyd., g. }\end{array}$ & $\begin{array}{c}\text { Cal., } \\
\text { gross. }\end{array}$ & Cal., net. & $\begin{array}{c}\text { Cal. } \\
\text { per kgg.: } \\
\text { b. w. (70). }\end{array}$ \\
\hline I. & $2,001-2,400$ & 23 & 87 & 90 & 303 & 2,434 & 2,191 & 30 \\
\hline II. & $2,401-2,700$ & 15 & 89 & 112 & 362 & 2.891 & 2.602 & 37 \\
\hline III. & 2.701-3,200 & 37 & 103 & 125 & 409 & 3,262 & 2,936 & 41 \\
\hline IV. & $3,201-4,100$ & 35 & 124 & 147 & 510 & 3,966 & 3.569 & 51 \\
\hline V. & $4,100-5,000$ & 14 & 145 & 215 & 612 & 5,102 & 4.592 & 66 \\
\hline
\end{tabular}

Yoit based his practical conclusions for the nutrition of an adult man on the requirements of a moderate worker. He describes as a " moderate worker," 
a man strong enough to do nine to ten hours work every day heavier than that of a tailor and lighter than that of a blacksmith-the work for example of a mason, a carpenter, or a joiner. Moderate work so defined corresponds fairly well to the amount done by most manual laborers, and comes nearest to Group III in our classification.

Voit's ration for the moderate worker is: $118 \mathrm{~g}$. proteid, $56 \mathrm{~g}$. fat, and $500 \mathrm{~g}$. carbohydrate $=3,055$ Cal. gross or $2, i 49$ Cal. net.

While it has been generally admitted that the absolute supply of energy in this ration corresponds well with the actual requirements and is estimated rather too low than too high, it has been remarked by many that the amount of proteid is too high and that a moderate worker can get along perfectly with less proteid. Munk for example proposes $110 \mathrm{~g}$. proteid instead of $118 \mathrm{~g}$. Now it is not a matter of great moment whether the diet contain 110 or $118 \mathrm{~g}$. proteid. The rations which we have brought together for our Group III contain on the a verage $130 \mathrm{~g}$. with 113 and $151 \mathrm{~g}$. as the extremes. From Atwater's results we have for the same group $103 \mathrm{~g}$. with 52 and $152 \mathrm{~g}$. as the extremes. This is not the place to discuss the grounds which have been taken for a reduction of proteid in the ration. In the opinion of the author these grounds are by no means sufficient for the purpose intended, hence the best thing to do is to choose for a normal ration on containing not less than $118 \mathrm{~g}$. proteid, even is many observations do show that a "moderate worker" can get along with less.

[Chittenden's recent experiments on several groups of men of different degrees of muscular and mental activity (university professors, college athletes, and United States soldiers) indicate strongly that Voit's proteid ration is excessive. He found that without exception these persons (numbering twenty-six in all) were able to maintain their physical and mental vigor for periods of from five to nine months on an average of 56 grams of proteid per day. These results accord with Folin's theory of metabolism (cf. page 137), which looks upon a large part of the proteid ingested in the average diet as so much waste material to be removed at once from the circulation by the liver.-ED.]

Voit's motive in dividing the nonnitrogenous foodstuffs for a moderate worker between fat and carbohydrates as he did, was to make the diet as inexpensive as possible. He takes, therefore, as much carbohydrate as in his opinion the intestine can digest easily-i. e., $500 \mathrm{~g}$. The remainder of the energy required he takes from fat.

Of course it would not be correct to regard $500 \mathrm{~g}$. as a real maximum of carbohydrates-and Voit does not. The intestine can manage greater quantities; but this alone is no reason for increasing the carbohydrate at the expense of fat. Experience has shown with perfect clearness that the human body has a very pronounced, if not always a perfectly intelligible, need for fat; so that the quantity in Voit's ration ( $56 \mathrm{~g}$.) ought probably to be regarded as the minimum for the diet of a moderate worker (cf. tables on page 141).

When the amount of work to be done is greater than that of a moderate worker, experience teaches us that both proteid and $\mathrm{N}$-free substances are eaten in greater quantities, but the supply of proteid is not increased as much as that of the $\mathrm{N}$-free substances. According to Voit, soldiers in field maneu- 
vers (hard labor) require $135 \mathrm{~g}$. proteid, $80 \mathrm{~g}$. fat, and $500 \mathrm{~g}$. carboliydrates $=3,348$ C'al. gross and 3,013 C'al. net, and in war (serere labor) $145 \mathrm{~g}$. proteid, $100 \mathrm{~g}$. fat and $500 \mathrm{~g}$. carbohydrate $=3,575$ Cal. gross and 3,218 C'al. net.

Our Group IV contains on the average 3,618 Cal. net which can be supplied in $141 \mathrm{~g}$. proteid, $71 \mathrm{~g}$. fat, and $677 \mathrm{~g}$. carbohydrates. We see that this ration agrees on the whole very well with that demanded by Voit. For a similar class (3,569 Cal.) Atwater (IV) finds $124 \mathrm{~g}$. proteid, $147 \mathrm{~g}$. fat, and $510 \mathrm{~g}$. carbohydrates to be the requirement.

The following data by Atwater may be given as further examples of diets suited to severe labor: Participants in a rowing contest (American students): $155 \mathrm{~g}$. proteid. $177 \mathrm{~g}$. fat, $440 \mathrm{~g}$. earbohydrates $=4,085$ Cal. gross. Football players: (1) $181 \mathrm{~g}$. protcid, $292 \mathrm{~g}$. fat, $557 \mathrm{~g}$. carbohydrates $=5,740 \mathrm{Cal}$ ( gross); (2) $270 \mathrm{~g}$. proteid, $416 \mathrm{~g}$. fat, and $710 \mathrm{~g}$. carbohydrates $=7,585 \mathrm{Cal}$. (gross).

Direct information on the diet of uomen is still extremely meager. Having a smaller body than man, and doing as a rule less physical work, a woman naturally requires a smaller supply of energy than a man. Assuming that the weight of the woman's hody is four-fifth that of the man's and that her metabolism bears the same relation to his. we obtain Voit s ration for female workers: $94 \mathrm{~g}$. proteid, $15 \mathrm{~g}$. fat and $400 \mathrm{~g}$. carbohydrates $=2.444 \mathrm{Cal}$. (gross) and 2,200 Cal. (net).

\section{\$3. NUTRITION OF THE YOUNG}

It is evident that the growing body needs relatively more food than the adult, both because it is smaller and hecause its organs must increase in size. Moreover. experiment has shown that the young body has a more active metabolism per unit of body surface regardless of its maller size (page 118).

In order to make possible a fuller presentation of the metabolism in the growing body, we have brought together in the following table a number of observations on the mean $\mathrm{CO}_{2}$-output taken a short time after a meal while the individuals were sitting quiet. Still other data will he found on page 119:

\begin{tabular}{|c|c|c|c|c|c|}
\hline \multicolumn{3}{|c|}{ MALES. } & \multicolumn{3}{|c|}{ Females. } \\
\hline Age. years. & $\begin{array}{c}\text { Mean } \\
\text { Bodyweight, kg. }\end{array}$ & $\mathrm{CO}_{2}$. g. per hour. & Age. & $\begin{array}{c}\text { Mlean } \\
\text { Bodyweight, } \mathrm{kg} \text {. }\end{array}$ & $\mathrm{CO}_{2}$.g. per hour. \\
\hline $9_{2}^{2} \ldots \ldots \ldots$ & 28 & 33 & $8 \ldots \ldots$ & 22 & 25 \\
\hline $10 \frac{1}{2} \ldots \ldots \ldots$ & 50 & 33 & $10 \ldots \ldots \ldots$ & 27 & 23 \\
\hline $11 \frac{1}{2} \ldots \ldots \ldots$ & 32 & 34 & $11 \ldots \ldots \ldots$ & 31 & 26 \\
\hline $12 \frac{1}{2} \ldots \ldots \ldots$ & 34 & 34 & $12 \ldots \ldots$ & 36 & 27 \\
\hline $14 \ldots \ldots \ldots$ & 45 & 4.5 & $13 \ldots \ldots \ldots$ & 40 & 28 \\
\hline $14 \frac{1}{4} \ldots \ldots$ & 45 & 44 & $14 \ldots \ldots \ldots$ & 44 & 29 \\
\hline $15 \frac{1}{2} \ldots \ldots .$. & 51 & $4 \div$ & $15 \ldots \ldots \ldots$ & 49 & 27 \\
\hline $17 \ldots \ldots \ldots$ & 56 & 45 & $16 \ldots \ldots \ldots$ & 50 & 32 \\
\hline $19 \frac{1}{2} \ldots \ldots \ldots$ & 60 & 43 & $17 \frac{2}{8} \ldots \ldots$ & 54 & 27 \\
\hline $23 \ldots \ldots \ldots$ & 65 & 38 & $30 \ldots \ldots \ldots$ & 54 & 29 \\
\hline $25 \ldots \ldots \ldots \ldots$ & 68 & 38 & $45 \ldots$ & 67 & $3 \pi$ \\
\hline $35 \ldots \ldots \ldots$ & 68 & 35 & $65_{4}^{3} \ldots \ldots \ldots$ & 67 & 26 \\
\hline $45 \ldots \ldots \ldots$ & 77 & 37 & & & \\
\hline $58 \ldots \ldots \ldots$ & 85 & 34 & & & \\
\hline
\end{tabular}


With males we see that the exeretion of earbon dioxide is greater between the ages of fourteen and nineteen than in older or younger individuals of the same sex. This agrees very well with Key"s observation on the growth of boys, namely that beginning with the fourteenth year the increase of the body in length and weight takes place much more rapidly than during the years immediately preceding (nine to thirteen). This period of rapid growth continues for four years (cf. Chapter XXVI, second section).

To judge by the elimination of $\mathrm{CO}_{2}$, a boy from nine to thirteen, therefore, would need almost as much food as a man resting. and boys between fourtecn and nineteen still more. We must not orerlook the faet. howerer, that the ealorifie value of the $\mathrm{CO}_{2}$ is very different according as it has its origin in the metabolism of fat, carbohydrates or proteid. Since in the above table the individuals on whom the experinnents were made belonged to the same class of society, and so far as the diet, etc., were concerned lived on the whole on the same plane, it may be assmmed with great probability that the average composition of their diet, and consequently the share of the different foodstuffs in the formation of $\mathrm{CO}_{2}$. was about the same.

With females the $\mathrm{CO}_{2}$-elimination does not show the significant rise which appears in boys between fourteen and nineteen. From the eleventh year on but slight differences due to age make their appearance: in an eleven-year-old girl the $\mathrm{CO}_{2}$-exeretion was $26 \mathrm{~g}$, in a woman of thirty, $29 \mathrm{~g}$. We might say, therefore, that the requirements of a girl of eleven are just as great as those of an adult woman at rest.

Comparison of the $\mathrm{CO}_{2}$-output of males and females of the same weight and age shows that during the years of growth it is considerably greater with the former than with the latter, and that the ratio of female metabolism to male metabolism estimated per kilogram of body weight is about 100:140. In men and women who have already passed the period of growth this difference gradually diminishes, and as old age comes on disappears altogether.

The figures of this table differ considerably from those given by MagnusLevy and Falk in the table on page 118. The reason is that the subjects of their experiments had not eaten recently and were in absolute muscular rest, while the results brought together in the table now under consideration were obtained upon individuals in a sitting posture shortly after a meal. On this account Magnus-Levy and Falk found no difference in the $\mathrm{CO}_{\ddot{z}}$-exeretion by males and females. The difference which we have noted above is, in all probability, traceable to a greater tonus in boys' muscles than in girls'.

By way of comparison with the direct data on the metabolism of the growing body we may add also the standard figures which Atwater uses in apportioning the diet of a family to its different members. Taking the food requirements of the father as 1 , the requirements of the others would be:

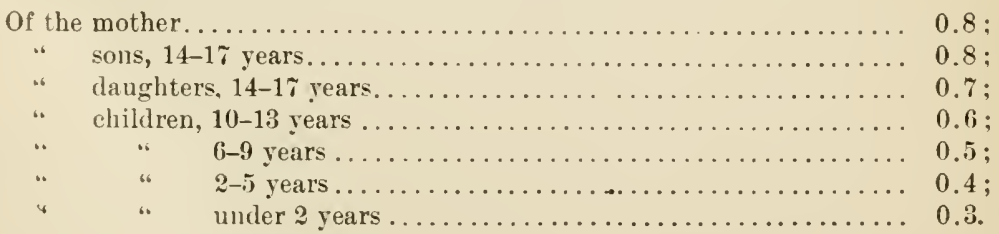




\section{§4. CONSTRUCTION OF THE DIET FROM THE DIFFERENT ARTICLES OF FOOD}

In satisfying the requirements of his body, man has a great variety of foods, both animal and regetable in origin. from which to choose. Recently the question has been much discussed in certain quarters whether the natural food of man should be mixed or should be purely regetable.

That a purely animal diet is not suited to the requirements of the human body after the period of infancy is passed need not he proved at length. On the one hand. if we except milk and liver, the carbohydrates are practically absent entirely from such a diet; and on the other hand. the relatively long human intestine is not sufficiently stimulated by an exelusirely animal diet to prevent the residues of the food and the digestive fluids from remaining orerlnng in the intestine.

All the requirements of the body can be met, howerer, by foods of regetable origin alone: for they contain fats and carbohydrates as well as proteid.

Vegetarians assume that a purely plant diet is the only natural food of man. But a number of objections can be raised against this conception. For example. fat occurs in plants in large quantities only in the form of regetable oils, and the only place the latter figure to any extent in the preparation of rictuals is in southern countries. Hence. in many regions it is not easy on a purely regetable diet to supply the body with a sufficient quantity of fat. To obtain fat the body must appropriate animal foods. Again. most regetable fonds in proportion to their percentage of proteid are much more bulky than animal foods, and their rolume is still more increased by the absorption of water in their preparation, whereas animal foods lose water in preparation and hence become less hulky. Besides, the nitrogenous constituents of most regetable foods are but poorly absorbed in the intestine. In order to supply the body with plenty of proteid from purely regetable sources one is compelled, therefore. to eat a rather roluminous diet. In so doing he runs the risk of exacting too much work of the digestive organs, whence various untoward effects might result. To prerent these. it is needful that a part of the daily ration be drawn from animal sources.

This is admitted by the regetarian who eats no meat, but allows himself the pleasure of milk, eggs and dairs products. In his case the diet is no longer purely regetable, for it contains both fat and proteid derived from animal sourecs. Cheese is an article very rich in proteid. and in butter and milk the bods can get all the fat it requires. So far as the question is debatable at all, it narrows itself to whether or not meats shall be included in the diet.

From a purely phrsiologieal point of riew, we can find no reason why a healthy man should forego the use of so excellent an article of food. ennsidered with respeet to its eontent of proteid and fat or its eminent adaptability, as we know meat to be. But in so stating. I do not wish to be understond as saying that one should eat any quantity of meat he pleases, or should cover too much of his requirements with meat. In too large quantities the extractive substances found in meat may possibly produce disorlers of one kind or another in the body (cf. Chapter XII, §1). The metabolism might also take an abuormal or unfarorable form, if the fluids of the borly were flooded with too much pro- 
teid. Finally, it is possible that in certain diseased conditions, meat would be harmful, and that some persons have a positive aversion to it.

If, therefore, the individual get a sufficient supply of proteid and fat in other articles of diet, like checse and butter, so that great bulkiness can be aroided, meats are not absolutely necessary. But from the standpoint of the phrsiology of mutrition, there is no reason for avoiding them.

Against the claim that the regetable foods constitute the natural-i.e.. the original diet of man-this additional objection can be raised: the most important of the regetable foods, namely the cereals, are subject to the action of the digestive fluids only after thorough preparation; whereas man had lived a long time on the earth before he had progressed so far as to mnderstand how to cultivate the soil, cook his fond. grind his grain and bake bread. Meat, however. requires no further preparation for eating than to be divided into small pieces. We bave reason, therefore, for claiming rather that man was originally carnirorous.

There are those who would have us believe that the really natural diet of man consists of fruits. But it is not a very easy matter at best to get proteid and fat enongh from fruits, and besides. in many inhabited lands it is quite impossible to raise any fruits or any kind of regetable foods in large enough quantities to provision the population.

Our conclusion is that the diet most generally suitable for man is a mixed diet, composed of both animal and regetable foods. It is only by reason of his ability to utilize all sorts of foods that it has been possible for man to people the entire earth from the equator to the poles.

Referexces.-Armsby, "Principles of Animal Nutrition," New York, 1903. -Atunter and others, L. S. Dept. of Agr., Office of Experiment Station, Bulletins Nos. 44, 63, 69, 109, 136.-Atwater and Benedict, "A Respiration Calorimeter. with Appliances for the Direct Determination of Oxygen," Publications of the Carnegie Institution of Washington. No. 42, 1905.-R. H. Chittenden, "Physiological Economy in Nutrition," New York, 1905.-Otto Folin, "A Theory of Protein Metabolism," in A merican Journal of Physiology, XIII, 1905. -Pobert Hutchinson, "Food and Dietetics," 叉l edition, New Iork and London. 1906.-Ludolf Krehl, "Pathologische Phrsiologie," Leipzic, 1904._Graham Lusk, "Elements of the Science of Nutrition," Philadelphia, 1906.-I. Munk and C. A. Ewald, "Die Ernährung des gesunden und kranken Menschen," 3ri edition, Wien and Leipzic, 189f._-Pfïger, "Glycogen," ๖d edition. Bonn. 1905.Rubner, "Energieverbrauch." Leipzic and Wien, 1902.-C. Toit. "Physiologie des allgemeinen Stoffwechsets und der Ernährung" (Hermann's Handbuch d. Physiologie, VI, 1), Leipzic, 1581. 


\section{CIIAPTER $\mathrm{V}$}

THE BLOOD

The blood is the common nutritive fluid of the body. Driven by the heart through the rascular system in an uninterrupted stream, it supplies all parts of the body with all the substances necessary for their growth and maintenance, as well as for the combustion going on in them. Besides, the blood remores from ail parts of the body the greater part of the decomposition prolucts formed in the life processes. and is in its turn relieved of these products during its passage through the excretory organs.

The blood is a red, opaque fluid, somewhat hearier than water (sp). gr. in man 1.05i-1.066, in woman 1.053-1.061). It has a salty taste. a neutral reaction, and a peculiar, stale odor. Its specific heat amounts to 0.8693 (at about $38^{\circ}$ C.).

The blood holds its neutral reaction with the greatest tenacity. In order to obtain a red coloration witl phenolphthalein by addition of caustic soda to the serum of ox blood. one must arld serenty times as much of the alkali as would be necessary if it were being added to pure water in order to obtain the same reaction. The same serum mixed with methrl-orange requires three hundred and twenty-seren times as much $\mathrm{n} / 10 \mathrm{HCl}$ as does pure water in order to bring out the red coloration. The explanation of this behavior lies in the variable acid and basic character of the serum proteids (Friedenthal).

On microsopic examination the blood is found to consist of a fluid. the plasma, in which float great numbers of formed elements. These latter constitucnts which cause the opacity of the blood are: (1) the red blood corpuscles to which the blond owes its red color: (:) the white corpuscles: (3) the platelets.

1 few minutes (in man three to twelve) after the blood is drawn from an open blond ressel it sets into a jellylike mass. which, as will be more fully disclised later. is due to the fact that a proteid hody present in the plasma is separaterl out (coagulated) in the form of a solid. the so-calted fibrin.

The coagulated fibrin is a fibrous structure. which, although it amounts to only $0.2-1.0$ per cent of the blood. permeates and incloses in its meshes the entire mass of the clot. Ciratually the fibrin shrinks, in consequenee of which a pale gellowi-h fluid is pressed out. The quantity of this fluid, the scrum, inerease progressively and finally there rentains of the coagulmu a smaller residual mass. which consist of the fihrin. the blond corpuseles incloserl in it. and the serum still present in its interstices. The hlood plasma therefore consists of fibrin and serum. 
Fibrin may be separated out also by whipping shed blood with a stiek. After this operation the blood remains fluid, the fibrin having been collected in the form of a white, stringy mass on the stick.

\section{§ 1. THE AMOUNT OF BLOOD IN THE BODY}

The method of determining the amount of blond in the body is in brief as follows: a normal sample of blood $(b)$ is first drawn; then the animal is bled and the vascular system is washed out with water until the water flows out perfectly clear. The water and blood are added together and the total quantity designated $w$. The normal sample of blood is now brought by addition of water $v$ to the same color as a sample of $w$. Then if we designate by $y$ the amount of blood washed ont, it is evident that $b: b+v:: y: w$. From which $y=\frac{b \times w}{b+v}$ The total quantity in the body is therefore $b+y=b+$ $\frac{b \times w}{b+\imath}$ (Weleker). This method is not, however, quite exact. for after the washing there still remains in the organs from eight to sixteen per cent of the total hamoglobin.

The amount of blood determined in this way amounts to seren to nine per cent of the body weight in the dog. five to nine per cent in the rabbit (in the latter after removal of the intestinal contents). Bisehoff found in the dead bodies of two exeeuted eriminals the quantities $\% .1$ and $\% .7$ per cent of the body weight.

\section{§ 2. THE FORMED CONSTITUENTS OF THE BLOOD}

\section{A. THE RED BLOOD CORPUSCLES}

In most mammals the red blood corpuseles are thin, flat, slightly hiconeave, circular disks, composed of a soft, extensible and very elastic substance. By transmitted light the color in thin layers is yellowish green; in thick layers, red. In birds, reptiles, amphibia and most fishes, as well as in the eamel family, they are oval instead of circular. In the cold-blooded animals and in birds they have a nucleus: in the mammals no nucleus is present in the mature form of the corpuscle (cf. page $1 \%$ ).

The diameter of the red blood corpusele in man is $0.00 \%-0.008 \mathrm{~mm}$., its thickness about $0.0016 \mathrm{~mm}$. The volume of a single corpuscle, according to Welcker, amounts to $0.0000000 \% \mathrm{cu}$. mm., and its surface to $0.000128 \mathrm{sq}$. min. One eu. mm. of human blood contains about 5.000,000 red eorpuseles for man and about 4,500.000 for woman. The total surface of the red corpuscles in $1 \mathrm{cu}$. mm. of blond therefore amounts to $640 \mathrm{sq} . \mathrm{mm}$. in man and $5 \% 6 \mathrm{sr} . \mathrm{mm}$. in woman. Since the total mass of the blood in man is about seven per cent of the body weight, i. e., in a body weighing $70 \mathrm{~kg}$., about $5 \mathrm{~kg}$. in round numbers, the total number of red hlood corpuseles in a man is $25,000,000,000,000$, and their total surface $3,200 \mathrm{sq} . \mathrm{m}$. (=0.8 aere nearly). 
(The body surface of a grown man is only about $2 \mathrm{sq} . \mathrm{m}$.) This enormous extent of surface of the red blood corpuscles is of great significance in connection with their function in respiration (Chapter IX).

Moreover the number of red blood corpuscles in $1 \mathrm{cu}$. $\mathrm{mm}$. of blood varies not a little under perfectly normal circumstances. Some authors have observed an increase, others a decrease in the number after meals. There is substantial agreement, however, that complete or partial abstinence from food does not reduce the number. Rarefaction of the air. as on mountain tops, increases the number of red corpuseles per cubic millimeter of blood rery considerably, and the effect is not due to an excessive elimination of water from the bndy, for the same thing has been noted on animals where an increased transpiration of water was impossible. The increase has been regarded as an attempt on the part of the organism to offset incomplete saturation of the blood with oxygen, resulting from lower air pressure. But this explanation does not suffice, for the increase takes place just the same before the reduction of pressure is sufficient to affect the absorption of oxygen.

It should be remarked in connection with these and other normal variations in the number of red blood corpuseles, that blood-counts give us only the relative number, and do not throw any light on the total number of corpuscles. For it must not be forgotten that under some circumstances the relative number of corpuscles in different parts of the body varies greatly (Zuntz), nor that an exudation of plasma from the ressels may produce an apparent increase (Bunge)-in short, it is not an easy matter properly and exactly to estimate the total number of blood corpuscles.

The specific gravity of the red corpuscles (1.008-1.105) is greater than that of the plasma or of the serum (the sp. gr. of the latter in man amounts to about $1.01 \%$ ). Hence they sink to the bottom of a ressel in which the blood is caught, provided we are dealing with whipped blood. or blood whose coagnlation is artificially stopped or retardert. Since the separation of the blood corpuscles from the plasma or sermm ean be accomplished much more rapidly with the centrifnge than by mere settling, this instrument is often used in blood work.

On the addition of rery small quantities of most acids or acid salts of Fe, Al, Zn, C'u, IIg, Sn. Ag. Au, Ur. IIb, the red blood corpuscles become agglutinated, and thereby precipitated. The same takes place even with hrmnglobin-free stromata as well as with the lencocytes, and is probably caused by an effect on the contained globulin (Peskind).

The weight of the red blood corpuscles in 100 parts of blood is estimaterl, aceording to Alex. Schmidt, in the following mamner: (1) The percentage of dry residue (' $\mathrm{T}$ ) in the whole blond is determined: (2) the percentage of dry residue $(t)$ in the scrum belonging to this quantity of blood; (3) the dry residue $(r)$ of the red hlood corpuseles obtained from $100 \mathrm{~g}$. of blood. The dry residue of the sermm obtained from $100 \mathrm{~g}$. of blood is then $\mathrm{T}-\mathrm{r}$, and the corresponding quantity of serum is $\frac{100 \times(\mathrm{T}-r)}{t}$, so that the weight of the red blood corpuscles in 100 parts of blood is $100-\frac{100 \times(\mathrm{T}-r)}{t}$. 
By this method it has been found that the weight of the corpuscles in $100 \mathrm{~g}$. of defibrinated blood is $48 \mathrm{~g}$. (mean of nine observations) for the mun and $35 \mathrm{~g}$. (mean of eleven observations) for the woman.

The red blood corpuscles are contimully going to pieces in the body in great numbers. especially, as it appears, in the liver. Naturally there is, under normal conditions. a corresponding production of new ones. In embryonic life the liver and spleen play a prominent part in their formation. In the adult, aceording to most authors, red blood corpuscles are formed only in the red marrow of the bones. (For the importance of Fe in the formation of hamoglobin, see ('hapter VIII.)

The blood corpuscles owe their red color to the pigment substance hamoglobin, whose chemical properties were first closely investigated by Hoppe-

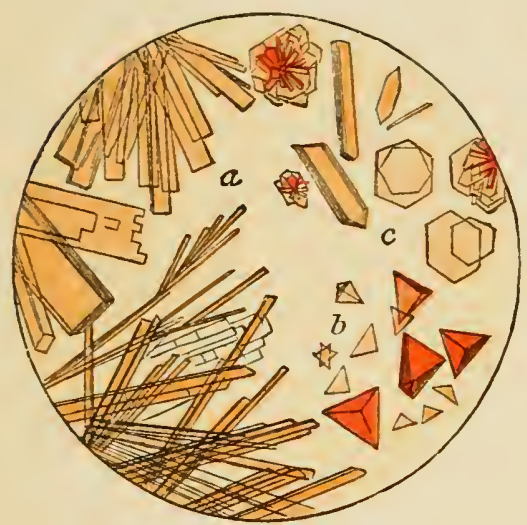

Fig. 46.-Blood crystals, after Funke. $a$, from the human blood; $b$, from the blood of the guinea pig; $c$, from the blood of a squirrel. Seyler. It unites with oxyen into a compound called oxyhamoglobin, the amount of which depends (to some extent) upon the partial pressure of the arailable oxygen. The hæmoglobin in the arterial blood oecurs chiefly in this form; in renous blood hemoglobin as well as oxyhemoglobin is found: but in aspleyriated blood only hamoglobin.

By thinning with water. by repeated freezing and thawing. by addition of ether, chloroform or bile, or of acids or bases. the coloring matter may he washed out of the corpuseles and brought into solution. The blood is then said to be of a laky color, or is laked. In many cases the passage of the hamoglobin out of the corpuscle does not run parallel to the outward diffusion of the electrolytes. Under certain eireumstances the hæmoglobin passes out while the electrolytes remain behind. Under others the opposite takes place: the electrolytes leave the corpusele and the hæmoglobin remains. This shows that the mode of combination of the hamoglobin and of the electrolytes is somewhat different (Stewart).

According to Hoppe-Seyler neither the hæmoglobin nor the oxyhamoglobin is present as such in the red corpuscle, but as a tolerably firm eombination with another substance, probably lecithin. The combination which contains oxyhrmoglobin is called arterin, while that of which hæmoglobin is a constituent is known as phlebin.

After the coloring matter is dissolved out of the red blood corpuseles there remains a colorless mass called the stroma. This consists of lecithin. cholesterin. proteids, urea, and mineral substances. chiefly potassium, phosphoric acid and chlorine, and in the red blood corpuseles of man. sodium.

By far the greatest part (eighty-seren to ninety-five per cent) of the dry substance of the red blood corpuscle consists of himoglobin: the stromin of the blood corpuscles amounts therefore to only five to thirteen per cent. In 
the blood of a man there is found 13.8 per cent hæmoglobin, and in that of a woman $1 \% .(;$ per cent.

The quantity of hæmoglobin in the hlood shows great variations under different cireumstances, and as a rule. though not always, it raries directly as the number of corpuscles. The quantity of hamoglobin in proportion to the body weight is greatest in the newborn and sinks rapidly during the first few days after birth-e. g.. in the rabbit in twenty-two dars, it sinks from about $13 \mathrm{~g}$. to 4 g. per $\mathrm{kg}$. of body weight. During this time the absolute quantity of hamoglobin increases and the iron -tored up in the body in other forms decrealses (Abderhalden).

Oxyhamoglobin crytallizes out of its solution more or less readily. The crystals (Fig. $4(i)$ are blond red, are transparent, anil belong. whatever their form. to the rhombic system (Lang). From fresh human blood one may obtain three forms of crystals, namely: (1) large. scalariform plates, $(2)$ sharply defined, dark red, doubly refractive, four-angled prisms, and (3) sharply defined rods much split up at the ends (Frieboes). Only the oxyhemoglobin of the squirrel (Fig. 46 c) crystallizes in six-sided tablets of the hexagonal srstem.

Hæmoglobin is distinguished from oxyhæmoglobin chiefly by being more easily soluble. and more difficult of crystallization, although the two are as a rule isomorphic. The crytals and the water solution of hæmoglobin are darker, more violet. or purple colored than the crystals and the solution of oxyhæmoglobin. In thin layers hamoglobin is greenish, in thicker layers red. Oxyhæmoglobin solutions are always red whatever the thickness. Finally, the two show noteworthy differences in their absorption spectra, as will be evident from Figs. $4 \%$ and $\frac{1}{2}$. If the solution is not too concentrated the absorption spectrum of oxyhrmoglobin shows two bands $a$ and $\beta$ hetween the $\mathrm{D}$ and $\mathrm{E}$ lines. With weaker solutions the $\beta$ band disappears first. The more concentrated the solution is, howerer, the broader the bands beeme until finally they fuse together, whereby the blue and

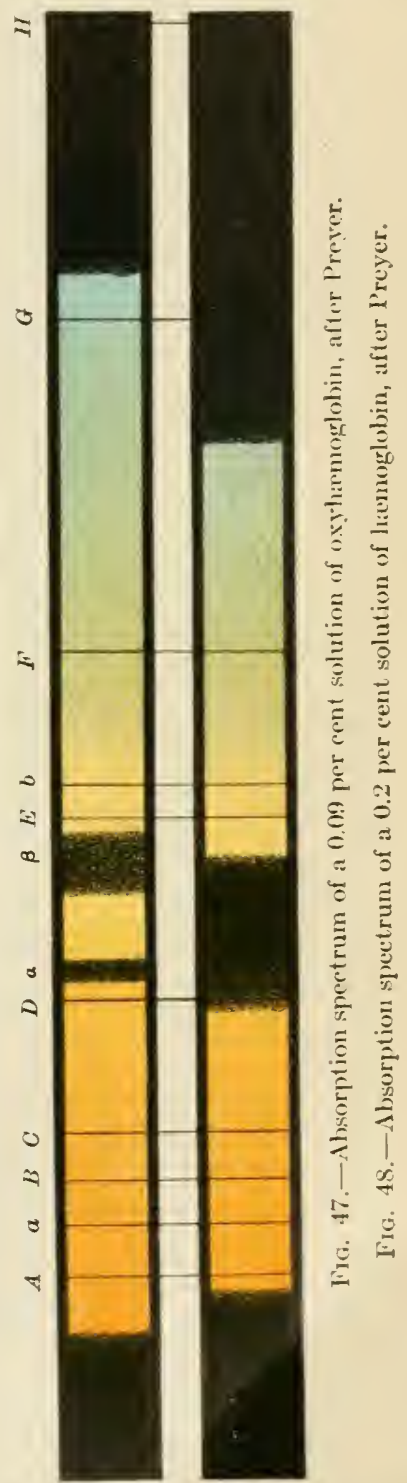
the violet parts of the spectrum are at the same time more and more obscured. The alisoption spectrum of hamoglobin on the contrary shows a single broad band hetween the $\mathrm{D}$ and $\mathrm{E}$ lines. but nearer the $\mathrm{D}$.

In methamoglobin oxygen oceurs in the same quantity as in oxyhamo- 
globin. but is more firmly united. There is also a compound of hamoglobin which contains less oxygen than the oxyhamoglobin. but is not completely redneed like the hamoglobin. It is called psendohomoglobin and has the same absorution spectrum as hamoglobin (siegfried).

Hamoglobin unites with still other substances, as carbon monoxide (carbon-monoxide homoglobin) a compound corresponding to oxyhemoglobin but more stable. with carbon dioxide (carbon-dioxide hamoglobin, cf. Chapter IX) and nitric oxide (nitric-oxide hamoglobin).

From analytical data Hïfner has calculater the following formula for the hæmoglobin of the dog's blood: $\mathrm{C}_{636} \mathrm{H}_{1025} \mathrm{~N}_{164} \mathrm{FeS}_{3} \mathrm{O}_{1 \mathrm{~s} 1}$ (molecular weight = $14.1 ? 9)$.

In different animals hamoglobin has a somewhat different constitution: for the hamnglobin of the dog. horse, swine, guinea pig. and squirrel various authors have found the following constitution: C $51.2-54.9$ per cent, H $6.8-7.4$ per cent, N 16.1-17.9 per cent, S 0.39-0.s6 per cent. Fe 0.34-0.59 per cent, O 19.5-23.t per cent.

For every molectle of hæmoglobin contained in oxyhæmoglobin there is one molecule of oxygen-i. e., for 1 atom of iron, 2 atoms of oxygen. From this it can be shown that $1 \mathrm{~g}$. of hamoglobin ean absorb 1.34 c.c. of oxygen. The dependence of the oxygen absorption by hamoglobin upon partial pressure will be discussed more fully in Chapter IX.

Hamoglobin is a conjugated proteid (cf. page 75 ) in which a simple proteid is compled with an iron-containing pigment. homochromogen (HoppeSeyler). In 100 parts of hemoglobin there are $9+$ parts proteid and $t$ parts coloring matter. The former consists for the most part of a histon-like basic body, glohin (Schulz), which like other simple proteids is lavorotatory, while hamoglohin itself is dextrorotatory (Gamgee and Croft-Hill).

On clearage of hamoglobin, hrmochromogen is formed, and by $a b-$ sorption of oxygen it passes over into hematin: $\mathrm{C}_{34} \mathrm{H}_{34} \mathrm{O}_{5} \mathrm{~N}_{4} \mathrm{Fe}$ (Kiister). $\mathrm{C}_{34} \mathrm{H}_{35} \mathrm{O}_{5} \mathrm{~N}_{5} \mathrm{Fe}$ (Zernek). $\mathrm{Br}$ treatment of the blood pigment with $\mathrm{HCl}$. hamin is obtained (Fig. 49): $\mathrm{C}_{32} \mathrm{H}_{32} \mathrm{O}_{3} \mathrm{~N}_{4} \mathrm{FeCl}$ (Nencki).

Acids change hematin by loss of iron into the pigments mesoporphyrin. $\mathrm{C}_{16} \mathrm{H}_{1}, \mathrm{O}_{2} \mathrm{~T}_{2}$ (Nencki) and hematoporphyrin. $\mathrm{C}_{16} \mathrm{H}_{18} \mathrm{O}_{3} \mathrm{~N}_{2}$ (Nenchi). Energetic reduction of the latter vields an oily, oxygen-free substance, hromopyrrol. $\mathrm{C}_{8} \mathrm{H}_{13} \mathrm{~N}$ ( Nencki). Which according to Nencki and Zaleski is either an isobutyl prirol or a methyl-propyl pyrrol.

Hamatoporphyrin is only slightly different from a chlorophyll derivative, phylloporphyrin $\mathrm{C}_{10} \mathrm{H}_{18} \mathrm{ON}_{2}$, prepared by Schunk and Marchlewski. This fact which inclicates a close agreement between the structure of the most important coloring matter of plants, and that of the most important coloring matter of animals suggested to Nencki and Marchlewski the possibility of obtaining identical prorlucts from the two. Ther succeded in producing hamopyrrol from chlorophyll. In view of the importance of pyrrol in the molecule of both hremoglobin and chloropliyll, we may conclude that the two are in fact rery closely related. 


\section{B. THE WHITE CORPUSCLES}

These are colorless, nucleated cells. Some varieties of them, at least, lave, like the free-living amaba, the power to more independently from one place to another by the protrusion of pseudopodia. On account of this rery remarkable property they probably play a very important rôle in many processes of the body, although this rôle is not yet sufficiently well known. Their activity is entirely independent of the nerrous swtem and is controlled. in great part at least, l,y chemotactic influences (cf. prage 54 ). Their general function, so far as investigation has yet been able to determine. is to provide for the transportation of rarious substances inside the body and to destroy or to remore foreign substances from the body.

The number of uhite corpuscles shows considerable rariation under normal circumstances, a fact dependent in part at least on their entrance into or withelrawal from the hlood stream in greater or less

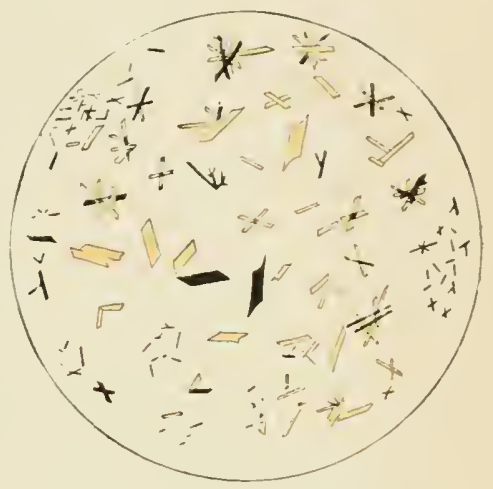

FIG. 49.-Hæmin crystals, after Preyer. numbers. (Concerning the multiplication of white blood corpuscles appearing in digestion of. Chapter TIII.) In the adult the arerage number is 8.000 to 9.000 per $\mathrm{cu}$. mm.-i. e., one white to every 500 to 600 red corpuscles. In the newhorn the lencocytes are much more numerous and reach on the arerage 18.000 per $\mathrm{cu}$. mm.

The white corpuscles are formed in extrauterine life chiefly in the spleen and lymphatic glands: from these issue mononuclear cells (lymphocytes) which. according to some authors, are transformed into polynuclear cells in the blood stream. Noreover they exhibit a variety of forms and are divided according to their appearance and staining reactions into several groups (see text-books of histology).

\section{THE BLOOD PLATELETS}

Discovered by Hayem (183i) and demonstrated in the circulating hlood by Bizzozero and Laker, the blood platelets are spherical or ellipsoital hodies which send out in all directions processes of rariable number and length. composed of the same shiny material as the hody. According to the investigations of Deetjen. Dekhuyzen and others, they have the full value of cells, consist of nucleus and protoplasm, and are capable of amoloid morement. Their size varies between 0.005 and $0.005 .5 \mathrm{~mm}$. Their number, according to Brodie and Russel, amounts to ahout 635.000 in $1 \mathrm{cu}$. mm. of blood. With respect to their chemical comstitution it is especially emphasized that they contain a nuclein body coupled with proteid: and with respect to their physinlogical purpose it is assumed by several authors that they play an csential part in the coagulation of the blood. Their origin is as yet conjectural. 


\section{ร 3. THE PLASMA}

Is already mentioned on page $14 \%$, the blood coagulates a few minutes after it has left the body, and before a separation of the plasma from the blood corpuscles can take place. Coagulation may be postponed by chilling the blool to $0^{\circ} \mathrm{C}$. Then on account of their greater weight the corpuscles sink to the bottom and (especially with horse's blood) a plasma entirely free of corpuscles may be obtained for study. Most inrestigations on the fluids of the lilood relate however to the serum, which is distinguished from the plasma chiefly by the fact that it contains no fibrinogen and less ash, because the fibrin when it separates out carries down with it either mechanically or in chemical combination, some of the ash constituents.

\section{A. CHEMICAL CONSTITUTION OF THE PLASMA}

Both plasma and serum are clear, faintly yellow fluids with a specific grarity of about $1.0 \% 8$. The specific heat of serum is 0.9401 , greater therefore than that of the whole blood.

Besides water. plasma contains ehiefly proteid substances of different kinds, and mincral constituents. The osmotic tension of plasma is about equal to that of a 0.9 per cent $\mathrm{NaCl}$ solution and is dependent mainly on its mineral constituents. The proteid bodies also appear to influence this property. though only to a relatively slight extent.

The mineral constituents in the serum are dissociated into their ions to the extent of about serenty-five per cent (Bugarsky and Tangl); while in the whole blood, electrolytic dissociation amounts to only about forty per cent (Oker-Bloom).

The electrical conductivity of the whole blood is less than that of the -erum, because this property is diminished by the presence of the corpuscles, as in general the eonductivity of a solution is diminished by nonconducting particles in su-pension (Bugarsky and Tangl. Oker-Blom, et al.).

The mineral substances in the serum differ essentially from those in the corpuscles, in that sodium salts predominate in the former, potassium salts in the latter. Among the sodium compounds, common salt occurs in greatest quantity (about 0.6 per cent). Besides this, various other inorganic sulstances have been found in the serum. On the whole the mineral substances in the serum of human blood amount to about 0.85 per cent.

The organic substanees in the serum amount to about ten times as much, namely, $\% .7-9.0$ per cent. Among these the proteids are the most important and make up by far the greatest part of the organic matter (about ninetenths). The chief proteid of the blood plasma are fibrinogen, serum ghohulin and serum albumin. The latter two howerer are not to be regarded as indivisible substances: for numerous investigations in recent years have shown. if one may judge by their hehavior in salting out. that at least two, probalby sereral, glohulins (euglobulin. psendoglolulin) are present in the blood (cf. page it) : and, according to results of fractional heat coagulation, that serum albumin also is a mixture of different proteid substances. 
Besides the proteids we find in the blood: fats (and the cholesterin ester of fatty acich. but as a rule no free cholesterin. Hinthle); glycerin and carbohydrates (sugar, probably for the most part in combination with lecithin as jecorin : Jacobsen, Henriques, Bing) ; also substances which are formed in the activity of the tissues and either represent decomposition products to be given off from the body (like urea, uric acid, creatin, carbamic acid. paralactic acid, hippmic acid. etc.) or are formed for the prrpose of influencing the functions of different nrgans (internal secretions. ef. ('hapter XI) -in short. everything which the tissnes have need of for their activity. and most of the products arising from this activity.

With the exception alwars of the proteids, these substances nceur in rery small quantities in the blood. In the intervals of digestion one finds from one to seven per cent of fat in the serum, while during digestion it mounts much higher. Even in starvation (one hundred and twenty hours after food has been taken) the fat content of the blood is higher than in the inanitiate condition (twelve hours after the last meal) - a fact comected with the morement of the body's fat for the purpose of covering the food requirements (Selullz). In the healthy condition the sugar content of the serum amounts to about $1-1.5$ per cent, but after very abundant feeding of carbohydrates may increase to three per cent and higher. The maximum urea content is about one per cent, etc. These quantities appear at first sight to be astonishingly small, but ther become intelligible when we reflect that the blood is in continual motion and its contributions of fat and carbohydrates to all the tissues are continually being replaced from the great storehouses of the body. In the same way it takes up the decomposition products from the tissues, and continually elimirates them by way of the excretory organ so that under normal conditions it contains at any given time a rery small quantity of these substances also.

Various enzymes have been demonstrated in the blood. Thus according to Michaëlis and Cohnstein. there is an enzyme which in the presence of red blood corpuscles and oxygen destroys fat (lipolytic enzyme). Arthus has found an enzyme which splits monobutyrin into glycerin and butrric acid; but an enzyme which would split neutral fat has not been certainly demonstrated. Further, a diastatic enzyme which changes starch into maltose. one changing the latter into dextrose, and an enzyme by which sugar is destroyed (glycolytic enzyme), are said to he present. Hedin mentions a feeble enzyme which digests proteid in an alkaline medium.

Likewise there are found in the blood substances which act against the enzymes peculiar to the body, represent therefore antienzymes, and derelop antipeptic. antitrytic, and antichymotic effects.

Serum contains moreover certain substances which have the pouer to hill Bacteria and foreign cells generally. The serum of one animal species destroys the blood corpuscles of another species, if the species are not rery closely related-a fact which explains, in part at least. the harmful effects of a transfusion of forcign blood. This globulicilal action, as it is called, as well as bactericidal action of the blood is very different in diflerent senera of animals. Thus the sermm of horse's blond is only slightly poisonous to man and is tolerated in pretty large doses. The serm of human blood exercises a powerful elfect on the typlioid and cholera bacteria. while on the pus- 
forming staphrincocei a weaker effect, and on the streptococei, the diphtheria and anthrax hacilli. no effect at all. On the other hand the sermm of the rabhit kills the bacteria of anthrax and of typhoid ferer, but is harmless for the pus-forming staphylocoeci, ete.

It has long been known that many disenses confer on the individual who survives them. as an after effect, an immunity or unsusceptibility toward those particular diseases. Now it has been shown (Behring and Kitasato, 189(1) that the blood or the serum of an individual who has become immune in this way against an infectious disease. has the properts. when it is injected in sufficient quantity, of conveying the immunity to another individual previonsly susceptible to the disease. A blood or serum of an individual who has snccessfully withstood the disease receives therefore as an after effect properties which it dicl not possess before.

These discoreries represent the point of departure of numerous inrestigations on the rarious changes which appear in the blood after injection of different substances. In general, one may say that if a foreign substance of a certain kind (such as the toxins formed by the Bacteria. foreign blood, rarious proteid substances, finels minced organs, etc.) is brought into the animal by subcutaneous, intraperitoneal or intravenous injection, the blood of the animal acquires the ability to change the foreign substance in some way, and thus to neutralize its effect on the organism. Since in such cases there are found in the blood specific antibodies, we infer that the changes appearing in the blood are of different kinds according to the nature of the substance injected.

If a bacterial toxin is injected into the blood, there arises in the latter an antitoxin specific for just this toxin. which has the prower to abolish the effect of the former, probably by a kind of neutralization. Different toxins possess an elective power for different cells of the body: and precisely those cells which are attacked by a definite toxin appear to be most active in the formation of the antitoxin. $\mathrm{Br}$ a kind of internal secretion the antitoxin is given off to the blood and in such abundance that it may be used (for example, diphtheria serum) as a remedr in other animals.

The power of the blood to destroy blood corpuscles. Bacteria and foreign cells generally. like its antitoxic properties, can be increased by the addition of appropriate substances. Here also we have to suppose that under the influence of the foreign cells, the cells of the body (certain leucocytes especially) are the seat of production of the antibodies. As with the antitoxin serum, the cytolytic serum can also exercise its specific effects outsicle of the body-from which it follows that these are not bound up in the formed constituents of the blood, and in general not in the living substance.

If the serum of an animal immunized against-say typhoid fever-is mixed with a fluid culture of Bacillus typhosus, the latter become stuck together, agglutinated. There has been formed in the blood of the animal therefore a substance which produces this effect. The same influence may be obserred also on the blood corpuscles. When an animal has been treated with a foreign blood, its own serum added to the blood in question brings about an entirely similar agglutination of the corpuscles of the foreign blood.

After intraperitoneal injection of cow's milk the serum of the animal employed acquires the ability to throw down a precipitate in the cows milk-i. e.. a precipitin has been formed in the blood. Br injection of different kinds of blood or proteid solutions, one may obtain different precipitins which on the whole are specific since they produce precipitates especially well in solutions of 
the substances injected. This specific eharacter is not however by any means absolute.

If we add to what has been said-above, that after the injection of an agglutinating serum into an animal an antiagglutinating effect may be obtained, after injection of a precipitating serum an antiprecipitating effeet, after a cytolytic serum an antilytic effect, it ought to be apparent without further discussion that under the influence of rarious chemical agents, extraordinarily important and complex changes can be induced in the blood.

These changes are produced in part by a special activity of different cells of the body, developed by the attack, in part by certain leueocytes.

There can be no doubt that all these changes are protective adaptations of the body against harmful influences. Especially is this true of the antitoxins, the bacterialysins, and agglutinins.

The matter is not so elear with regard to the other lysins and the precipitins; but it is to be presumed that they also have some definite purpose. It appears that they are specialized substances, which, like the antienzymes, come down in the globulin precipitates: but whether they are true proteid bodies or are only attached to such, cannot be said definitely as yet.

We must forego a presentation of the theoretical views which are held in explanation of these phenomena, since a discussion of them would require too much space. We would not, however, omit to mention the side-chain theory of Ehrlich, since this has had a very stimulating efteet on research in this field, and has very suceessfully gathered together under one general point of view the complicated phenomena which eonfront us in this province.

Since the chemical processes in different organs are in many respects very diflerent. the blood returning by the vein must have a more or less variable constitution according to the organ from which it flows. Analysis of these different kinds of blood would be well calculated to give at some future time very valuable conclusions as to the chemical transformations taking place in the corresponding organs. At present however our information is quite too inadequate for any disenssion of the subject.

The blood flowing from the different parts of the body is collected finally in the two renæe cave and is emptied by them into the right heart. where the different kinds of blood, not ret thoroughly mixed in the reins. are mixed together; so that blood driven from the left ventricle to all parts of the body is entirely homogeneous.

\section{B. COAGULATION OF BLOOD}

If blood be drawn directly from an open artery into a saturated solution of magnesium sulphate, it can be kept for days without coagulating. The blood corpuscles can be remored from such blood by filtering. by centrifugalizing. or simply by letting it stand, and in this way a fluid is obtained known as the sall plasma (Alex. Sehmidt). By preeipitation with an equal rolume of saturated $\mathrm{NaCl}$ solution, there is thrown down a proteid body, the fibrinogen. which ean be further purified by varions means. Fibrinogen is soluble in weak $\mathrm{YaCl}$ solution and its solution will keep at room temperature until putrefaction sets in without showing a trace of coasulation. If however some blood or blood serum be added to such a solution. fibrin formation takes place 
at once. The same effect is produced also by blood clot washed free of all color with water. Such a clot contains fibrin and the remains of white corpuscles, so that one is inclined for many reasons to assume that the substance which must be added to a solution of fibrimogen to make it clot, and which has been designated the fibrin ferment or thrombin (A. Schmidt) comes directly from the white blood corpuseles. It appears from several observations that the white corpuscles themselves do not of necessity break down under such circumstances, and Arthus has expressed the view that they give off the fibrin ferment by a process of secretion.

Coagulation cannot take place, as Arthus was the first to demonstrate, without the presence of a soluble calcium salt. This is probably due to the fact that fibrin ferment does not exist in the blood as such but in the form of a mother substance, or zymogen, and is activated only in the presence of $\mathrm{Ca}$ salts (Hammarsten. Pekelharing). The calcium does not appear to be necessary for the formation of fibrin, however, for a solution of fibrinogen coagulates in the presence of thrombin even when the calcium salts are removed by an oxalate.

Coagulation is considerably accelerated by addition of extracts of all possible kinds of organs, and even by mere contact of the blood with the wound. On this account it has been assumed that the contained nuclon-proteids might represent precursors of the thrombin. On the contrary Arthus, Morawitz and others believe that they only hasten the formation of the enzyme and that the mother substance of the latter occurs exclusively in the blood.

According to Morawitz the organ extracts effect the formation of the proenzyme from a zymngen stage, thrombogen. wherempon thrombin arises from the proenzrme under the influence of the calcium ions.

The formation of thrombin is stopped immeliately by sodimm fluoride and by addition of this salt in small quantities it is possible therefore to follow the course of thrombin formation more closely. In this way it has been shown that at the moment it flows from the ressel the ilood contains no thrombin at all, that the quantity of the enzyme increases quite slowly at first. and that shortly before coagulation it undergoes a rapid increase. Thrombin is formed for a time also after coagulation has taken place (Arthus).

When blood serum stands exposed to the air its enzyme gradually decreases in quantity and disappears entirely after about six days. No more enzyme is obtained after this time by addition of calcium salts. But by means of acids, alkalies, alcohol, etc., one can demonstrate an effective fibrin ferment; there is present therefore in the serum a body from which active fibrin ferment may be formed. This body is absent from normal plasma and seems to make its appearance for the first during coagulation. According to Fuld and Norawitz, it is probable that this substance is thrombin itself, which had merely passed over to an inactive state.

The transformations brought about by enzymes in general appear to proceed in such a way that the substance acted on absorbs water and is subsequently split into two new substances. This is probably the case in fibrin formation; the fibrinogen is split into insoluble fibrin which constitutes the 
chief bulk, and fibrino-globulin which remains in solution and is formed only in small quantity (Hammarsten).

The difficulties with which the subject of coagulation "s beset, and which we have been able to discuss here only in a cursory manner, are still more multiplied when we ask why the blood does not clot in the vessels. That the constant morement of the blood is not the reason is proved by the fact that blood coagulates outside the body more rapidly when it is stirred. Cooling of the blood cannot account for coagulation. for it is possible to postpnne the process for a long time by this very means. Neither can contact with the air be considered. for coagulation goes on in the usual manner if blood is collected (over mercury) by exclusion of air.

Coagulaticn does not occur if the blood is draun by means of an oiled cannula, or if it is caught in an oiled ressel: in fact it can now be stirred with an oiled rod without producing coagulation. But if it is stirred with an ordinary rod. or if small solid particle: be introluced, coagulation take: place immediately (Freund). The reason why coagulation does not take place under the abore-mentioned circumstances doubtless lies in the fact that the blood is prevented by the oil from coming in contact with the wall of the ressel. Attempts have been made to explain the absence of coagulation in the blood ressels in a similar manner. by assmming that in health the necessary adhesion of the blood to the walls is wanting. When the endothelial lining of the ressels becomes abnormally changed in any way so that internal adhesion occur., intraraseular clotting enstes. Agrainst this conception however it may be objected that the blood always thoroughly wets the internal wall of the blood ressels (B. Lemr).

Beautiful examples of the inhibiting properts of the rascular walls are found in the facts that blood remains tluid for a long time in a section of a rein ligated off at both ends (Hewson): and that a turtles heart filled with blood beats for days without any clotting if the temperature of the contained blood be low (Brücke).

Opinions differ considerably as to the real nature of the changes produced by adhesion of the blood to rough surfaces. so that at this time we are unable to form any definite conception of the matter. But since substances have been found in the blood which exercise an inhibiting influence on cnagulation. it is at least conceirable that during life and with uninjured rascular walls, the inducing and inhibiting bodies neutralize each other. while in shed blond the former preponderate and thus bring about coagulation.

In the living body the coagulability of the blond can be abolished by intrarascular injection of albumoses (Schmidt-Mühlheim. Fano) or of leech extracts (Haycraft). If the blood is diverted from the liver and the intestine so that it circulates only through the extremities. the head and the lungs: it likewise loses its ability to coagulate.

Coagulation of the blood is of extremely great importance as a means of protection for the body, since bleerling from injured ressels. muless they be too large, is thereby stopped. If the hlood did not coagulate every slight injury would involve great loss of blood. When the larger ressels are ruptured coagulation does not suffice: for the blood flow out in such quantity and with such 
speed that the first blood does not have time to coagulate before new blood replaces it. And if coagulation should take place in the wound. the clot would not be sufficiently firm to withstand the great force of the escaping blood.

Referexces. - L. Aschoff. "Ehrlich's Seitenkettentheorie und ihre Anwendung auf künstlichen Immunisierungsprozesse." Jena, 1902.-Hermann Sahli, "Diagnostic Methods," Chapter on "Examination of the Blood"; English edition edited by Kinnicutt and Potter. Philadelphia, 1905.-Alex. Schmidt, "Zur Blutlehre," Leipzic, 1592._- Weitere Beiträge zur Blutlehre," Wiesbaden, 1895. - The Textbooks of Physiological Chemistry mentioned on page s:. 


\section{CHAPTER VI}

\section{CIRCULATION OF TILE BLOOD}

IF the blood were to stand still in any particular rascular region, it would become impoverished in nutrient substanees, especially oxygen, would become overladen with products of tissue activity, and so would be rendered unfit to fulfill its phrsiological purposes. But by the fact that the blood is continually in motion, this is prevented, for as it mores it both replenishes its store of nutrient substances taken from different parts of the body and gets rid of the products which are useless or harmful to the body.

This continual movement is maintained by the activity of the heart. The heart represents the motive power which drives the blood through the ressels. The latter howerer are not mere passive tubes, but in various ways they actively participate in the distribution of the blood throughout the body.

\section{FIRST SECTION}

\section{GENERAL SURVEY OF THE BLOOD'S MOVEMENTS}

The heart of warm-blooded animals is divided by means of a septum running from above downward, into tu'o completely separated halves, a right and a left (Tesalius, 1542). Each half consists of two communicating chambers, an upper, the auricle, and a lower, the ventricle. The opening between auricle and rentricle can be elosed in both halves of the heart by means of valves.

Blood ressels connect with both aurieles and ventricles. In those leading from the ventricles blood flows from the heart, and they are called arteries. In the ressels communieating with the auricles blond is conveyed to the heart, and they are called reins.

The arteries communicate with the veins by means of the capillaries, so that the heart and the ressels form a connected system of tubes entirely shut off from the outside.

In this srstem, as was first established by Harrey (16?8), the blood more: in the following manner (Fig. 50). It is poured by the two vena cavæ into the right auricle, and is driven by the latter into the right ventricle. By the contraction of the rentricle it is pressed out into the pulmonary arteries pioceeding therefrom, and flows through the vessels of the lungs and the pulmonary veins into the left auricle. This part of the circulation is called the lesser circulation, and was first described by Servet (1553) and Colombn (1559). From the left auricle the blood is driven into the left ventricle and 
from there again into the aorta. Thence it flows through all branches of the aorta to the capillaries, from there to the systemic reins and through the vence cave back to the right auricle. That portion of the circulation from

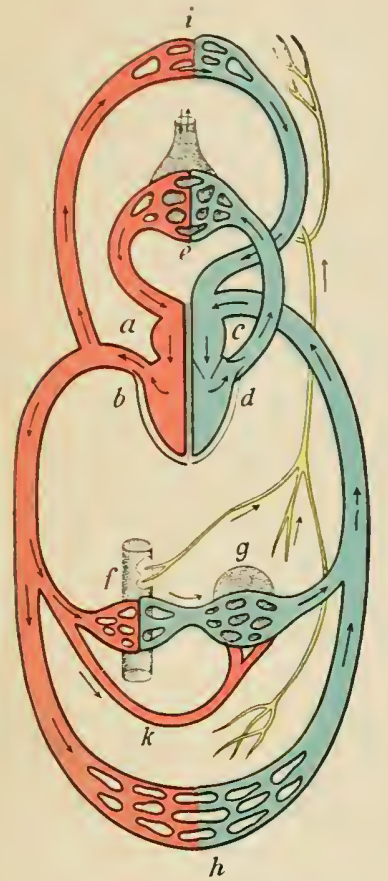

FIG. 50.-Schema of the circulation, seen from the dorsal side. $a$, left auricle; $b$, left ventricle; $c$, right auricle; $d$, right ventricle; $c$, pulmonary circulation; $f$, capillaries of the intestine; $g$, capillaries of the liver; $h$, capillaries of the lower extremity; $i$, eapillaries of the head and upper extremities; $k$, hepatic artery. Arterial blood, red; venous bloor, blue; lymph vessels shown only in outline. the left rentricle to the right auricle is called the greuter circulation.

In warm-blooded animals the entire quantity of the blood must flow through the lungs in order to pass from the right half of the heart to the left. During a complete circuit therefore the blood flows through two systems of capillaries: namely. (1) that of the greater circulation, and (?) the pulmonary system. For the blood which passes through the capillaries of the stomach, intestine, pancreas and spleen still another capillary sysem is interpolated. This blood flows to the liver in the portal vein which there breaks up into a new system of capillaries. whence arise the hepatic reins, conducting the blood away to the leart. The same is true of the kidney blool, for in the kidneys themselves the blood flows first through the capillaries which form the glomeruli of the Malpighian corpuscles, and secondly through the capillary plexus by which the kidney tubules are surrounded.

The contraction of the heart is designated the systoie and its relaxation. the diastole.

\section{SECOND SECTION}

\section{THE MOVEMENTS OF THE HEART}

\section{s 1. THE FORM CHANGES OF THE HEART IN SYSTOLE}

After opening the pericardium of a beating heart it can be seen that the contraction begins at the outlet of the great reins. which are here surromided he circular muscle fibers. and proceeds thence onto the auricles.

The two auricles contract simultaneously, and immediately after the auricular systole the rentricles contract, likeuise simultancously. Neither auricles nor ventricles completely empty themselves by their contractions.

\section{A. STRUCTURE OF THE VENTRICULAR WALL}

The arrangement of the muscular mass which forms the walls of the ventricles is very complicated. Our description here must be very brief.

Of the two rentricles the left possesses a much stronger musculature than 
the right, a condition which conforms with the much heavier work to be done by the former. In fact the outer wall of the right rentricle is formed for the most part of fibers which come from the left. To a certain extent therefore the right rentricle may be looked upon as a cleft in the wall of the left, as shown in Fig. 31.

With regard to the structure of the ventricles the following is worthy of mention: From the fibro-tendinous rings at the base of the left rentricle, and from the muscular sides of the aorta superficial fibers pass obliquely downward to the apex of the heart, enter for the most part the vertex of the left ventricle and double round into its interior, to be inserted either into the papillary mus(') and chordae tendine:e, or into the atrio-ventricular ring.

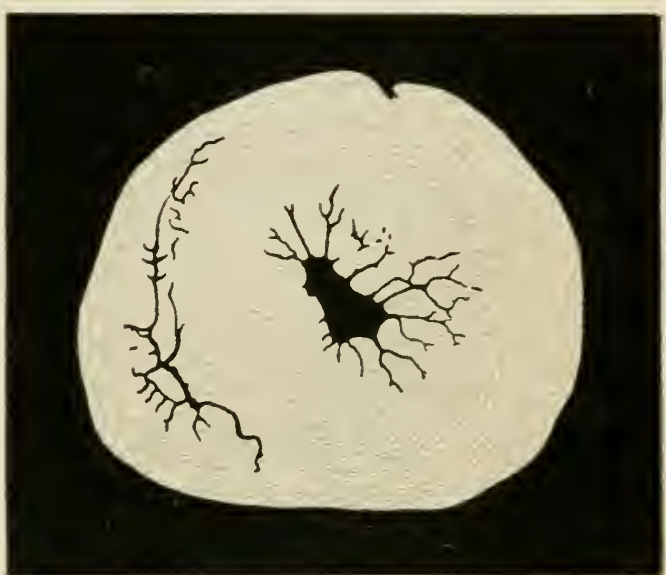

FIG. 51.-Cross-section through a fully contracted human heart at the junction of the upper and midllle thirds, after Krehl.

The two layers thus formed

are separated by a median layer, which, when isolated by a special method of preparation, has the form of a muscular cone. It is connected also by many fibers with the outer and inner layers. The fibers of this median part describe loops, which, not having any tendinous connections, return to their starting point (Fig. 52). It is obvious that this strongly dereloped median layer must play a

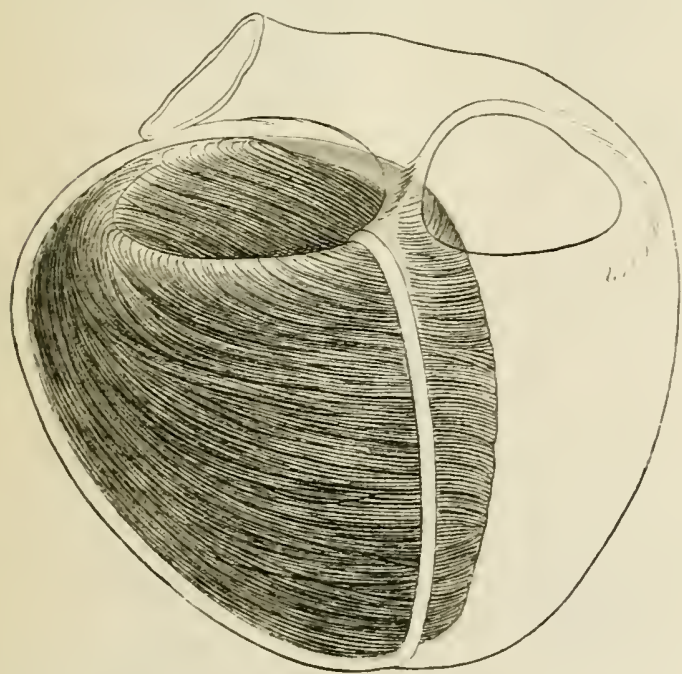

FIg. 52.-Laver of fibers in the left ventricle of the human heart which have no tendinous insertions. The more external and more internal lavers have been removel. The outline of the entire heart is shown. After Krehl. prominent part in the contraction of the left rentricle.

'The srnchronism of contraction of the two rentricles naturally depends on the fact that the museular fibers are in part common to both rentricles. Nevertheless various olservations indicate that this synchronism is not an absolute one. but that each ientricle possesses a certuin physiological independence (Knoll).

\section{B. THE FORM CHANGES OF THE HEART}

In diastole the form of the ventricles of an empty heart outside the body depends in the main upon the way in which they are supported. whereas 
under normal eireumstances their form depends in the main upon the degree to which they are filled. In systole when, as Harrey put it, " the heart makes tense all of its fibers," the rentrieles whether empty or filled have a perfectly definite form, which is entirely independent of the diastolie form. Hence if the heart is lengthened in any one of its diameters during diastole, it is shortened in this diameter during systole.

In the living body and in the unopened chest the heart lies in the pericartium and is covered for the most part by the lungs. It is suspended upon
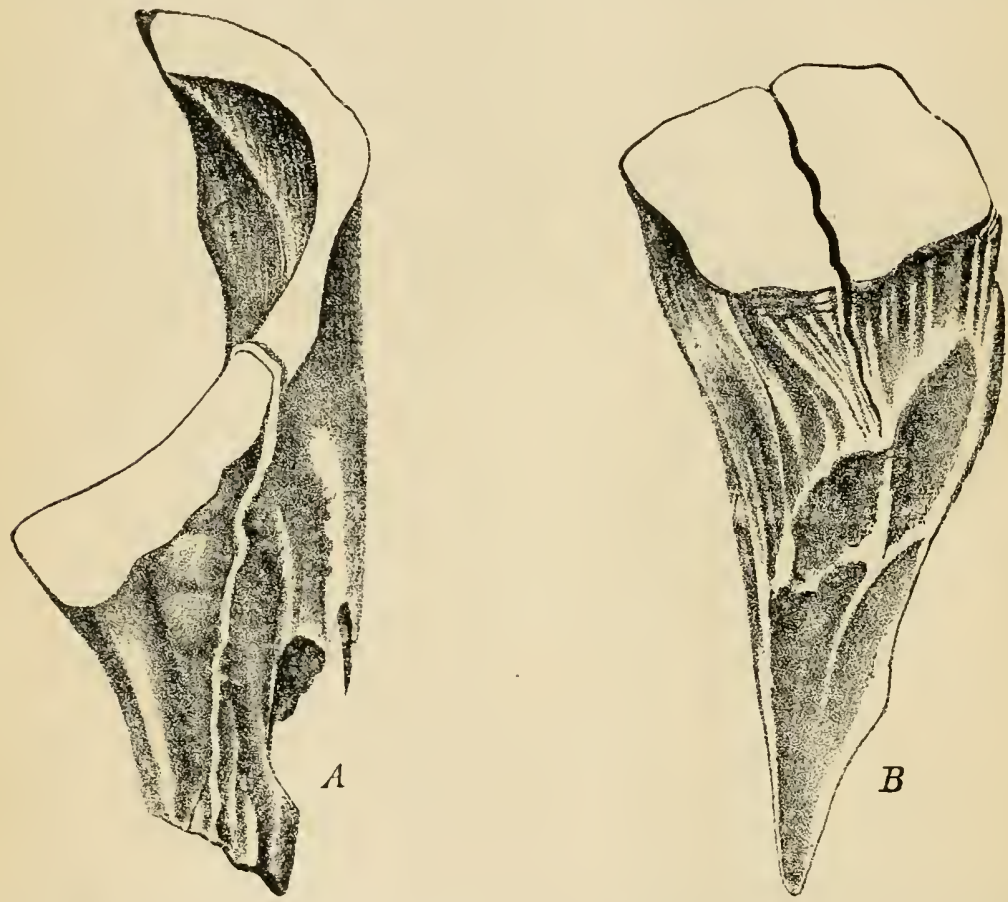

FIG. 53 - Casts of the ventricular cavities of the ox heart in rigor mortis, after Worm-.Müler and Sandborg. $A$, cavity of the right ventricle; $B$, of the left. Two-thirds natural size.

the great arteries and so far as the pericardium will permit, is movable in different directions.

If one observes the heart of a mammal in the usual supine position of the animal in experimentation, the diastolic heart is flattened somewhat in the anterior-posterior dircetion, while its transverse diameter is increased. Under such circumstances one finds that the long axis and the transverse diameter shorten in systole, while the sagittal axis beeomes longer.

In the natural position of the body the heart is supported for the most part by the lungs; these are to be looked upon as air cushions which influence the form of the diastolic heart only to a slight extent. In the natural position of the animal therefore the base of the heart must be more circular than in the supine position with the chest open. By means of needles stuck throngh the chest wall into different parts of the heart, so that their ends gave by their 
movements the directions of shortening, Haycraft found that the heart in its natural position contracts in all its dimensions.

According to Braun, in the shortening of the long axis of the heart during systole its conical end becomes blunter and the long axis of the left ventricle comes to form with that of the right a more acute angle than during diastole; at the same time the apex of the heart moves slightly to the right.

Since the apex of the leart is its freest part, one would suppose that on contraction of the long axis in ventricular systole the apex would approach the base. But this is not the case: the base on the contrary appmaches the apex, and the heart as a whole makes no change in position. This phenomenon appears to he explained partly at least by the recoil of the blond when it rushes out throngh the arterial openings. That is to say, when the rentricles drive the blood into the great arteries the apex is prevented by this recoil from moving toward the hase: and instead, presents a relatively fixed point toward which the base is drawn (Chanvean and Fairre).

The changes in form of the heart cavities have been studied only in heat or in death rigor. where the contraction of the heart muscle has proceeded much farther than it ever does in life. From such observations it appears that even in these extremely contracted conditions the cavities of the heart are never entirely obliterated. In the left ventricle an evident cavity remains above the summits of the papillary muscles; while the right rentricle is transformed into a narrow slit, so that the two walls in the upper portion underneath the atrio-ventricular opening are still separated from each other by a certain distance (Hesse, Worm-Müller and sandborg: ef. Fig. 53).

\section{§ 2. THE REGULATION OF THE BLOOD FLOW THROUGH THE HEART}

The normal course of the blond through the heart is determinal rhiefly by its valves. but partly also by other means. which prevent the blood from flowing in the wrong direction.

\section{A. THE ATRIO-VENTRICULAR VALVES}

Between the auricle and rentricle we have in the right heart the tricuspid value, in the left the mitral ralve.

The tricupsid is composed of a tubular membrane fastened around the entire circumference to the atrio-ventricular ring. It is divided by deep incisions into three large and one or two small flaps. These are attached by musus of the chorde tendine to the papillary muscles or to the ventricular wall. The chordie tendina run partly to the free edge of the valvular flaps, partly to their ventricular surface where they are attached broadly to the connective-tissue framework of the Haps.

The mitral valve is similar in all essential respects to the tricuspirl. only it is more firmly constructed in all its parts and consists of but two flaps.

When the rentricles contract the blond is prevented by closure of the ralves from flowing back into the auricles, and is forced to take the right path into 
the arteries. Without the valves not a drop of blood wonld reach the arteries, for the resistance in the arteries is considerably greater than that in the auricles and in the great reins emptying into them.

During the rentricular diastole the atrio-ventricular flaps are more or less closely approximated by simply floating into position on the blood as it fills the rentricle. When the ventricular systole sets in and the pressure in the rentricles rises suddenly, the ralvular flaps naturally strike together and so cut off connection of the ventricle with the auricle.

Because the pressure in the auricle at the systole of the rentricle is infinitesimally small as compared with that in the rentricle itself. the ralves must close so quickly that at most only a rery insignificant quantity of blood can get back into the auricles before the clesure is complete. It appears even that the valves work so promptly that absolutely no regurgitation of the blond

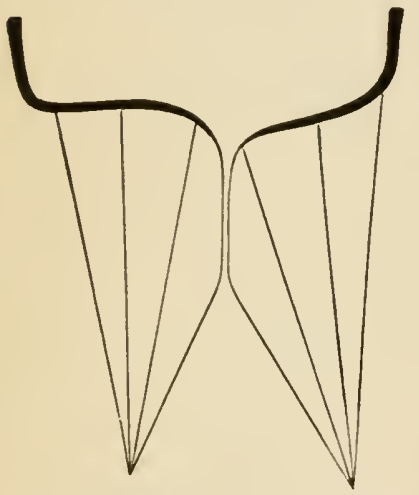

FIG. 54.-Position of the atrioventricular valves when closed. schematic drawing, after Krehl. in to the auricle takes place. When the auricle contracts, the ventricle is somewhat distended owing to the flexibility of its resting wall and its contents are subjected to a certain tension. At the moment the contraction of the auricle abates somewhat or ceases altogether the pressure in the ventricle becomes greater than that in the auricle, and by this means the valvular flaps are brought together even before the rentrieular systole begins (Baumgarten).

The great pressure which is brought to bear on the valves during the rentricular systole would cause them to turn up into the auricles, and thereby cause serious disturbance to the circulation, were it not for the chordx tendinx. Since the chorda are attached not only at the free edges but also on the flat surface of the valves, the latter are prevented not only from turning up into the auricle, but even from bulging toward it.

Because of the chordie tendinæ the closed valve takes a perfectly definite position, the central parts of the flaps being pushed up to the level of their attachment, and their turned-down edges being applied to each other as in Fig. 54. By this means closure is established orer a greater surface and is secured also by the fact that the bent portions of the edges doretail into each other by toothlike folds, so that the valres are able to sustain the great pressure. The circumference of the base of the heart, and at the same time that of the atriorentricular opening, becomes very much smaller in ventricular systole: the muscles surrounding the opening therefore must be credited with a share in the closure of the passage.

The rôle of the papillary muscles in the closing of the atrio-ventricular valves has been conceived in rery different wars. The most probable view is, that they prevent swinging of the valves into the auricles, the approach of the heart base toward the apex being compensated by their contraction and consequent pull on the chordæ tendinæ.

When the auricles contract, regurgitation of blood into the great reins is prevented by contraction of the circular musculature passing around the latter, 
their openings being in this way either narrowed considerably or actually closed.

\section{B. THE SEMILUNAR VALVES}

Since the blood cannot flow back into the auricle during the rentricular systole, it must pass into the great arteries. The mouths of the latter are closed by means of valves, cach consisting of three pouchlitie flaps.

These flaps are semicircular membranes, fastened by their curred edges to the wall of the ressel, so that ther stand out with their straight edges from the wall and present concave surfaces toward the arteries. In this war pouches are formed in which the blood is caught and dammed back. while at the same time the wall of the pocket turned toward the lumen of the ressel is put on the stretch.

In both the aorta and the pulmonary artery the wall bulges outward directly above the attached edges of the valve, forming in each three enlargements. the sinuses of Talsalva. In the aorta one sinus is directed baekwarl, two forward, right and left. From the latter two the right and left coronary arteries take their origin.

When the pressure in the rentricle is lower than in the corresponding artery, the semilunar valves are closed with their edges applied tightly together. When the pressure in rentricular systole increases enough to exceed that in the aorta or pulmonary artery, the valves open and the blood flows out. When the ventricle again passes into diastole the ralve is closed once more.

What position the ralves take in systole is not yet definitely determined, although various observations make it probable that their free edges stand out some distance from the sinuses. thus narrowing the arterial mouths. It should be added that there are certain muscular folds springing from almost all sides of the artery, which serre as supports for the valres (Krehl).

In consequence of this arrangement the blood is pressed through a narrow muscular cleft into a wider space alove the ralves. This must cause rortices and celdies to be formed, which tend constantly to press the flaps of the ralve together, and they are unable so to do only because the blood is being forced through at high pressure. When the outflow ceases, the ralves are pressed together suddenly, and without any regurgitation. The closure is rigidly maintained by the difference between aortic and rentricular presire- a difference which is morc than sufficient once the muscles of the rentricle relax and the above-mentioned muscular supports of the ralres give war.

\section{§3. THE HEART SOUNDS}

If the ear he placed over the breast wall, with every heart beat one hears a dull, long-drau'n-out sound, and after this a shorter. clear sound. Then follows a pause, then again the dull souml. and so on. The Inng sound is called the first heart sound, the following one, the seeond. The first is heard thronglunut the entire rentricular srstole, and nnly then. The secom follows immediately after the first. i. c.. immediately after the end of the rentricular systole, and after it comes the parise. 
The cause of the first heart sound is to be sought chiefly in the so-called muscle tone: that is to say, in the tone or noise which is to be heard whenerer a milscle contracts (cf. Chapter $\mathrm{XV}$ ). The first sound is clearly audible in the case of a heart which is almost entirely empty of blood and air, and in which accordingly the ralres cannot be stretched and cannot therefore he set in vibration (Luilwig and Dogiel).

Other factors coöperate in the production of the first sound, notably the closure of the atrio-ventricular valves at the beginning of systole, and the vibra-

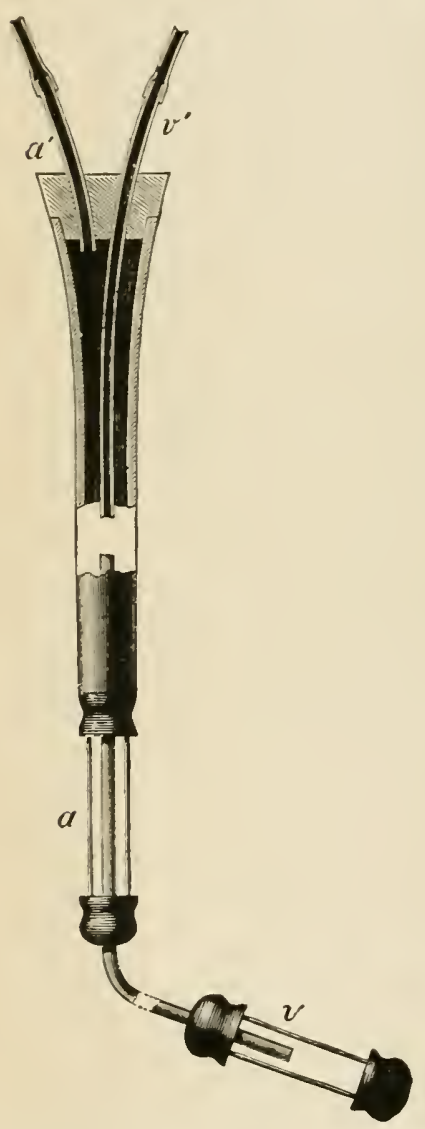

Fig. 55.-Heart sound, after Chauveau and Marey. veau and Marey). Sounds can be passed likewise by the jugular vein into the right auricle and right rentricle. In the opened thorax sounds can be thrust either directly through the walls into the different heart cavities, or they can be passed into the ventricles first through the walls of the auricles, then through the atrio-rentricular openings.

Various instruments have been constructed for the study of the pressure tions set up in them and in the blood by their
closure. It is not impossible that ribrations which are caused by the opening of the semilunar valves play a certain part also in the production of this sound. Howerer the most prominent factor of all is a muscle sound with which these other sounds are associated.

The second heart sound is produced by the sudden tension of the semitunar valves, and by other simultaneous vibrations in the blood consequent upon their closure. Sudden stretching of these ralres in an excised aorta prodaces a sound which agrees exactly in character with the second heart sound (Carswell and Roumet).

It will be apparent at once that we have in reality four sounds, two first and two second. Practical experience teaches however that the first two occur simultaneously and the second two simultaneously: and this is also evidence of the fact that both rentricles begin their contractions simultaneously and that the semilunar valres of the two sides are closed at the same instant.

\section{\$ 4. PRESSURE CHANGES IN THE HEART DURING ITS ACTIVITY}

\section{A. TECHNIQUE}

In order to measure the pressure and its rariations in different chambers of the heart, it is necessary that these should be connected with a manometer. This can be done in the closed thorax by passing a cannula or sound from the carotid through the aorta into the left ventricle, 
variations. The requirements for such an instrument are rery serere: indeed there occur in the ventricles variations of $130 \mathrm{~mm}$. of $\mathrm{Hg}$. in 0.06 of a second -i. e., 2,170 mm. Hg. in a second. The instrument to be used must be capable therefore of righting itself very quickly, and nust be at the same time to a high degree aperiodic so that it has no oscillations of its own. The first instrument used for this purpose was the writing tambour of Marey. This was connected with a sound of peculiar construction (cardiographic sound) passed into the heart chambers. Such a sound (Fig. 55) consists of a tube, the end of which, to be placed in the heart chamber, carries a rubber bulb. The latter is supported by a steel frame $(a, v)$ so that it is not completely compressible. The

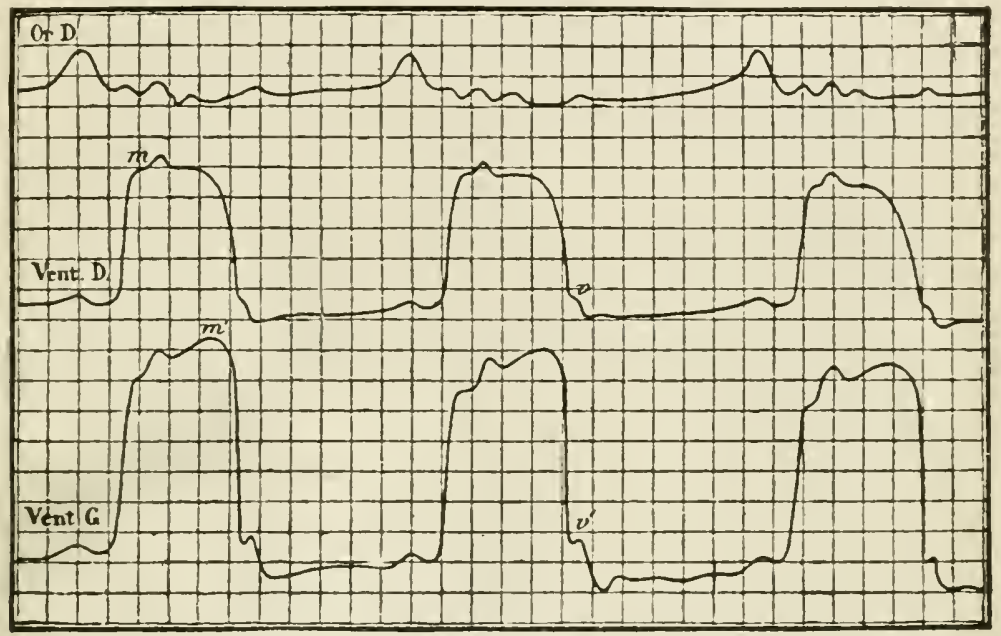

FlG. 56.-Intracardial pressure curves of the horse, after Chauveau and Marey. Or. D., right auricle; Vent. D., right ventricle; Vent. G., left ventricle.

free end of the sound is connected with the writing tambour. With the pressure changes in the heart cavity the air pressure in the bulb changes and the writing tambour records these variations graphically. By suitable means the curres thus obtained can be estimated in absolute terms (millimeters of $\mathrm{Hg}$.).

\section{B. PRESSURE VARIATIONS IN DIFFERENT CHAMBERS OF THE HEART}

As already observed the auricles contract first. The duration of their systole up to the point of maximum pressure is. in the horse. 0.1 second: that of the ventricles up to the point where the fall in pressure begins is considerably longer. namely. 0.t second (also in the horse). The maximum presure in the right auricle of the dog is giren as $20-2 \cdot 2 \mathrm{~mm}$. $\mathrm{Hg}$. (Goltz and (iaule).

The form of the pressure variations in the lheart chambers is variously figured, according to the instruments used in their graphic registration. The difference is dire to the fact that not all the different instruments give the rapid variations in pressure with sufficient exactness.

The most correct form of the intracardial pressure curve appears to correspond to the type represented in Fig. 56. If we neglect details which are relatively unimportant, the intracardial pressure runs somewhat as follows: 
(1) a small clevation. (?) a very stecp ascent, (3) a subsequent much slower ascent, or a plateau almost parallel to the abscissa, (4) a rapid fall from the maximum, (5) a very gradual ascent (Fig. 56).

The maximum pressure of the ventricular systole has been determined also by the Ho-manometer, by interpolating between the heart and the $\mathrm{Hg}$ a maximum valve which opens with every increase in the ventricular pressure, but prevents the return of mereury with the fall of pressure.

The maximum pressure in the left rentricle may amount to $200 \mathrm{~mm}$. $\mathrm{Hg}$. (in the dog). The pressure in the right rentricle is considerably lower; in the dog the pressure in the pulmonary arteries varies between 10 and $33 \mathrm{~mm}$.

$\mathrm{Hg}$., in the rabbit between 6 and 35 , and

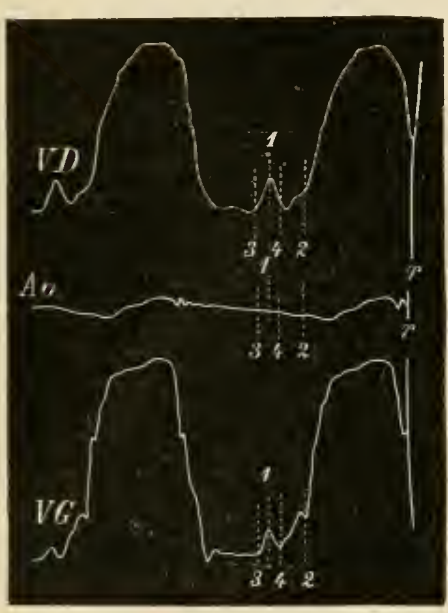

F1G. 57.-Pressure curves of the right ventricle $\left(I^{r} D\right)$, of the left ventricle $(V G)$, and of the aorta $(A o)$ of the horse, after Chauveau. 3-4 auricular contraction; 4-2 intersystole. To be read from left to right. in the cat between 8 and $25 \mathrm{~mm}$. $\mathrm{Hg}$. A definite ratio between the pressures in the lesser and the greater circulations does not obtain, lecause even with very great variations in pressure in the greater circulation, only relatively slight variations generally occur in the lesser (cf. Section III, $\$$ ).

On the pressure curves given above, various single points are found which are sometimes more, sometimes less clearly marked. Some of these-e. g., various peaks which oceur in many tracings at the height of the platean-are donbtless artifacts produced by extreme vibrations, while others are definite expressions of exents in the heart. The latter we must discuss. therefore, somewhat more in detail.

At the beginning of the pressure curve, before the ascent which corresponds to the strong rise in the ventricular systolic pressure, a slight elevation is sometimes very beantifully shown. This eleration, as we learn from Fig. 56, is caused by the auricular contraction and the ensequent rise in pressure in the rentricle.

In the intracardial pressure curve of the horse, Chanvean has demonstrated between the peaks corresponding to the auricular systole and the beginning of the true veutrieular systole a more or less clearly marked intersystole (Fig. 5i). A similar elevation appears now and then also in the cardiagram of man, and represents doubtless a hrief rise in the pressure inside the ventricle. This has been referred with great probability to the elastie rebound of the vestricular wall after the completed anricular systole. Obviously it can appear clearly only in case a measurable time intervenes between the maximum of the auricular contraction and the heginning of the ventricular systole.

After the ventricular systole has begun, it requires a certain time before the power of contraction becomes sufficient to overeome the pressure exerted by the blood in the vessels upon the semilunar valves (period of rising ten- 
sion). It is evident that the scmitumar valves must open the moment the pressure in the aorte is exceeded by that in the rentricle. So smoothly is this point passed that it is not marked on the pressure curve by any special fluctuation.

The period of rising tension can be determined on an animal by recording the pressure in the aorta and in the left rentricle at the same time. It is

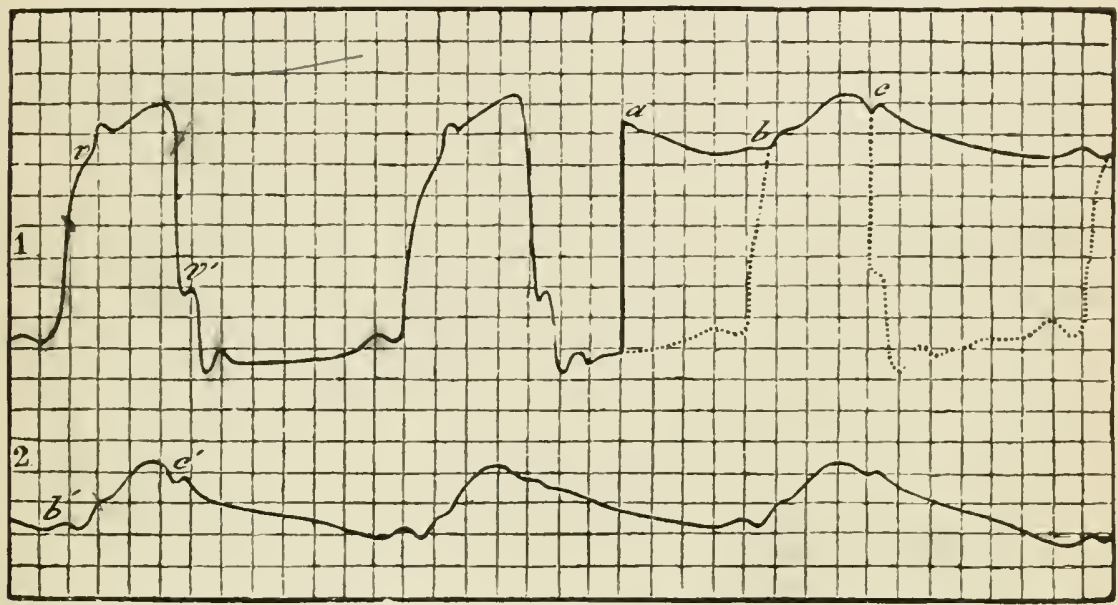

Fig. 58.-Pressure curves from the left ventricle (1) and the aorta (2), of the horse, after Chauveau and Marey.

found (cf. Fig. 58) that the pressure eurve of the rentricle rises from the abseissa in the horse about 0.1 second, in the $\operatorname{dog} 0.03$ second earlier than does the pressure curve of the aorta. The period shows but slight rariation with varving blood preswre or with different rates of heart beat, which means that the heart possesses in a very high degree the ability to meet almost without los: of time very different demands upon its powers.

In man the period of rising tension has been obtained by eomparison of the simultaneous apex and pulse curves, and is given by diflerent authors at from 0.0 .5 to 0.1 second.

Closure of the semilunar valves must take place whenever the pressure in the aorta exceeds hy ever so little that in the left ventricle. Br simultancous registration of presisure in the aorta and in the left ventricle it has been found that the moment of equal pressure follows shortly after the beginning of the steep deseent in the rentriele, but this instant is not shown in any speeial manner on the trucing.

So long as the pressure in the rentriele is higher than that in the aorta or pulmonary arteries, the blood is beine driven ont of the heart. The duration of the period of ejection depends on the aortic pressure at the beginning of systole, or upon the pulse frepuener only to a very slight extent : it amounts to about 1$) .18-0.20$ second in the $\log$.

At the elose of systole the heart chambers gradually fill with blood and as a consequence the intracardial pressure gradually rises slightly. 


\section{\$ 5. THE APEX BEAT}

We hare in the apex beat a means of studying the different questions which hare to do with the pressure relations and the form changes of the heart in the normal animal and in man. By placing the hand on the chest wall, where the heart is not covered by the lungs-i. e., in the fourth or fifth intercostal space-an impulse can be felt with

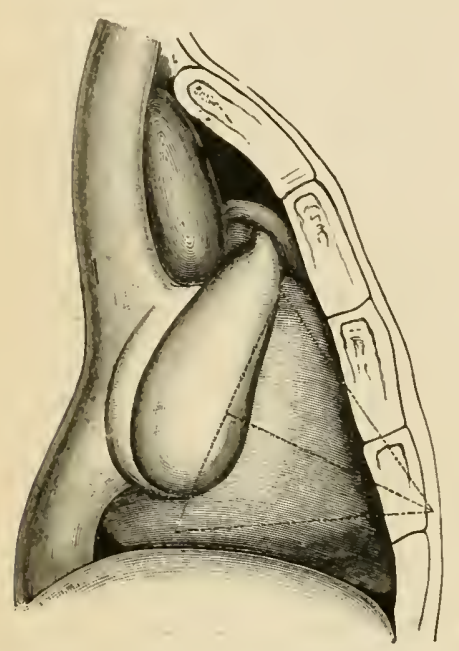

FIg. 59.-Schema illustrating Ludwig's theory of the apex beat. The dotted line represents the position of the heart in systole. every ventricular systole, which is called the apex beat. In lean indiriduals an clevation of the intercostal wall can be observed with the eye. This fact is of itself sufficient to show that the heart actually strikes against the chest wall, but does not on the other hand prove that the rentricle withdraws from it in diastole. In diastole the heart is flabby and weak. If one presses with the finger on the exposed henrt at this time. only a little resistance is felt, even though the finger does not make a permanent impression.

As soon however as the rentricular systole begins, the heart suddenly becomes hard and exerts a rery strong pressure on the finger. Everywhere it feels as if the finger were being pressed against. This sudden hardening is the essential cause of the apex beat (Harrey, Kiwisch, Marey). In addition to this however there is an effort on the part of the rentricle to assume such a form that the apex will stand rertical to the base (Carlile, Ludwig). Consequently the heart in its systole takes the position with reference to the chest wall described by the dotted line in Fig. 59. The apex, therefore, strikes against the thoracic wall and pushes it forward to a slight extent.

In opposition to this, Shreiber remarks that the heart chambers must assume the same form (a right cone) after the auricular contraction and before the beginning of the systole. But this follows of necessity only in case the rentricles become turgid with blood-a thing which rarely results from auricular contraction. With an ordinary filling of the ventricles their diastolic form may be very different, just as an india-rubber balloon may vary in shape until it is highly inflated, when it becomes spherical.

Other factors also have been brought forward for theoretical explanation of the apex beat. It has been assumed, for example, that the heart beat against the thoracie wall is due chiefly to the rebound consequent upon the ejection of blood from the ventricle, or in other words, has its origin in the stretching and elongation of the great arteries by means of which the heart is thrown forward. It is possible that these factors do in fact contribute to a certain extent in producing the beat. But that they are not the only factors, and do not even represent the most important mechanism concerned, appears from such facts as these: first, the forward movement can be observed on an exeised heart empty of blood 
as well as on one with ligated arteries; and secondly, the movement appears immediately at the begimning of the ventricular systole, while the npening of the semilunar valves and the ejection of blood into the great arteries follows appreciably later (ef. page 171).

The apex beat offers the only possibility of studying the heart morements on a living man. and for this reason much attention has been deroted to its graphic record, called the cardiogram.

On animals the intracardial curve and the cardiogram ean of eourse be recorded simultaneously, the latter by pushing in between the chest wall and the heart a small balloon which communieates with the writing tambour. In the two curves, as shown in Fig. 60, we observe varions similarities and dif-

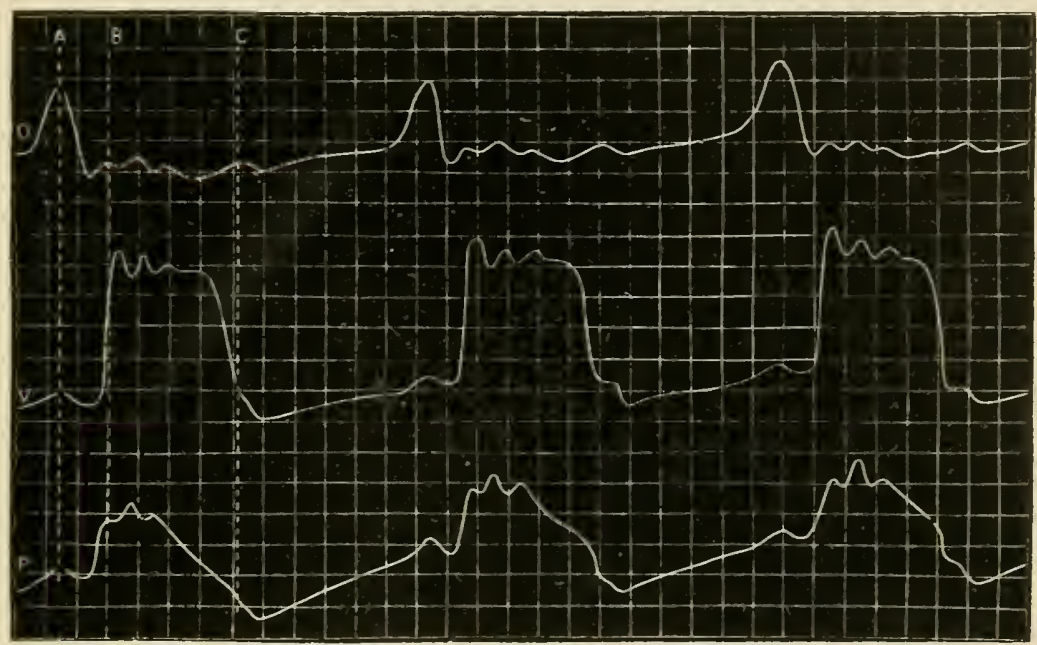

Fig. 60.-Curves of pressure in the right auricle $O$, in the right ventricle $V$, and of the apex beat $P$ (horse), after Chauveau and Marey.

ferences. In both we have at $A$ the elevation eaused by the auricular contraction; likewise the steep rise at the begimning of the systole. On the cardiogram this reaches its maximum earlier than does the ascending limb of the pressure curve (B). After the maximum is once reached the pressure curve runs almost parallel with the abscissa, or it rises gradually, then sinks suddenly at the end of the ventricular systole. The eardiogram begins to fall much earlier, but does so more gradually although finally it shows also a steep fall.

At the line $C$ we find almost at the base of the descending limb of both curves a small eleration, which we shall presently discuss further. After the end of systole the ventricle is filled with blood, and the pressure rises slowly up to the suceeeding systole. At the same time the cardiogram rises slowly above the abscissa. If the contraetion of an empty heart be recorrled it has quite another form from that of the cardingram. From which it is evident that the latter is not a simple contraction eurve, but must be regarded as in fact a combined pressure and rolume curre of the heart chambers. It is a pressure curve, for the reason that the button plaeed over the breast wall exerts a pressure against which the heart does work. It is however at the same time a volume curve, in so far as it is influenced by the volume changes of the heart. 
While the heart is filling during diastole, the curve rises gradually above the abseissa; but while the rentricles are being emptied, i.e., while the semilunar valves are opened, the presine against the breast wall is somewhat less and the recording tambour cammot therefore follow the mogressive increase of blood pressure.

For the graphic registration of the apex beat in man the method of air transmission is generally used, as for example with the apparatus represented

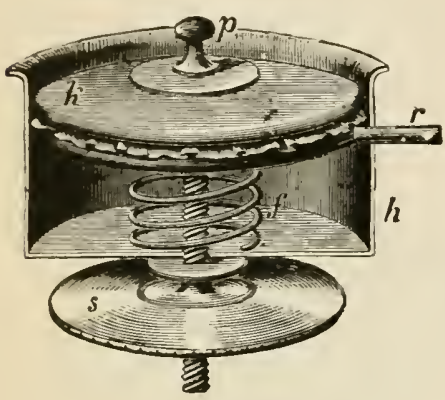

FIG. 61.-Receiving tambour of Marey's cardiograph. in Fig. 61 (cardiograph of Marey). A metallic box bears the plunger, $p$, fastened into two small metallie disks, between which the rubber membrane of the tambour is placed. A spiral spring between the inner of these disks and the bottom of the box gives a suitable tension to the membrane. The eardiograph is placed over the thoracie wall in such a manner that the plunger presses on the area of the apex beat. The sile tube, $r$, leading out of the box places it in connection with the recording tambour.

It is evident that an apparatus placed orer the chest wall in this manner must give a eurve which agrees essentially with the one obtained by means of a ballonn inserted between the heart and chest wall; for the movements of the chest wall. which is now between the tambour and the heart, are determined by the movements of the heart.

The human cardiograms published in the literature show considerable differences in form, depending primarily upon the nature of the recording apparatus employed. From what we know of the possibilities of this apparatus (Hiirthle) we may say that the form of the normal cardiogram of man is about that represented in Fig. 6\%. We have here, as in the animals, an ascending limb, a plateau. which inclines toward the abscissa or runs parallel to it. and a descending limb. Besides there are some small elerations, which in part at least are artifacts.

Often, if not alwars, the cardingram begins with a small elevation which is caused by the contraction of the auricle. After this follows the steep rise caused by the contraction of the ventricle. In this case the beginning of the rentricular contraction can be clearly recognized. It may happen howerer that the auricular contraction is not specially marked. but passes uninterruptedly into the ascent produced by the rentricular contraction, in which case it would be erroneons to reckon the latter from the foot of the ascending limb. This form of the curve results often from too little tension of the cardiograph.

On the cardiogram one sometimes finds at the end of the auricular systole the above-mentioned (page 170) elevation, called by Chauvean the intersystole, which indicates the moment of closure of the atrio-ventricular valves. As a rule, however, the elevation does not occur on the human cardiogram. On the other hand, the moment of opening of the semilunar valves in some cases comes out clearly at the first turning point of the cardiogram, where the ascending limb passes over into the plateau (Fig. 62, b). The time interval between the base and the first turning point of the cardiogram, therefore, represents the period 
of rising tension (period of elosure) of the rentriele. This period is not by any means always clearly delimited, and eould have but small praetical ralue.

In order to determine the moment of closure of the scmilumar valves on the human cardiogram, the heart sounds have been auseultated and marked on the eurve by means of an electric signal. The exactness of this method is not great however, and from observations of this kind one can say with certainty only that the second heart sound falls somewhere in the course of the descending limb of the cardiogram. Attempts have been made therefore to determine this moment by other methods.

In man Hürthle and Einthoven have registered the heart sounds automatically in various ways and have found that the second sound comes about 0.02 second after the beginning of the steep descent.

Finally, Edgren has attempted to solve the problem by simultaneous registration of the apex beat and the pulse. Sinee the pulse ware requires a eertain time to propagate itself from the root of the aorta to the place where the pulse is taken, this time must be subtracted. It is then found that the elevation on our eardiogram designated $f$ eorresponds to a similar mound on the intracardial pressure curve (Fig. is, $\left.v^{\prime}\right)$, and corresponds exactly with the well-known dicrotie elevation of the pulse eurve. This, as we shall see later, is intimately conneeted

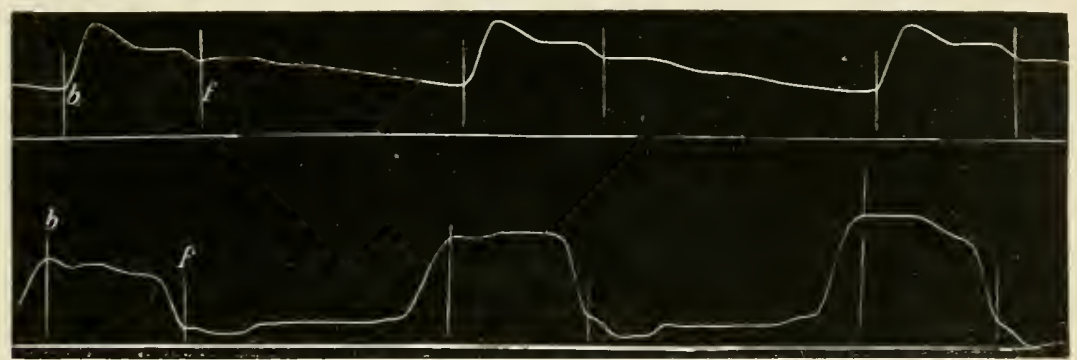

Fig. 62.-Curves of the apex beat (lower line) and of the carotid pulse (upper line) of man, simultaneously recorded, after Edgren. $b, b$, and $f, f$, are corresponding points.

with the elosure of the semilumar valves. On this ground it appears justifiable to assert that the mound is produeed by the stretching of the semilunar valve.

In so doing we do not wish to assert that the valves are closed then for the first: for that this event transpires much earlier is proved by a comparison of the pressure curves of the ventricle and of the aorta (Fig. 58). It is not improbable that a short time after the noiseless closure of the values, they are sucklenly put on the stretch by the antic blook acting under ereat pressure. and that they produce in this way the second somel of the heart. This much is eertain, that the second sound camnot legin hefore the chosure of the semiInnar valves (shortly after the begimning of the descending limb of the eardiogram) and not later than the mound $f$.

On a typical cardiogram we can make, therefore, a definite determination of the following points: auricular svstole, beginning of the ventricular srstole: $b$, opening of the semilunar valves, beginning of relaxation; $f$, stretehing of semilunar ralres. 


\section{\$ 6. TIME RELATIONS OF THE CARDIAC EVENTS}

The duration of the auricular systole is very short. In man, as in the horse and dog, it may amount to 0.1 second.

The duration of the rentricular systole shows but slight variations, notwithstanding considerable differences in the pulse frequency. Thus in variations between 32 and 124 beats per minute the time oceupied by the systole varies only between 0.38 ? and 0.190 second (man). In animals also where the pulse frequeney is made to vary between wide limits by stimulation of the inhibitory and accelerator nerves (cf. \$11) the srstolic time varies only a little, whereas the diastolic time presents considerable variations. We may say therefore that the variations of pulse frequency in the same individual as well as in different individuals of the same genus are due in the main to variations in the length of diastole. On the average the length of ventricular diastole in man may be estimated at abont 0.4 second.

\section{FILLING OF THE HEART IN DIASTOLE}

The most important factor in the filling of the heart during diastole is the impetus which the heart has given the blood in systole. But since the blood meets with great resistance in its passage through the ressels, the residual driving power is relatirely small, and the accessory mechanisms play an important part.

One important mechanism is the suction of the thoracic cavity (cf. Chapter IX). Almost the entire air pressure takes effect on the great reins outside the thorax. A small part of it of course is borne by the skin, etc. : but it may be assumed as certain that the air pressure on the extrathoracic reins is greater than the pressure which is exerted on the organs inside the thorax by the lungs. Consequently in the static position of the thorax the intrathoracic reins and the heart are to a certain extent expanded.

In expiration the negative pressure inside the thorax decreases and both the intrathoracic veins and the auricles become less distended: hence the return flow of the blood into the thorax becomes more difficult. Quite otherwise is it with inspiration. The intrathoracic pressure decreases in direct proportion to the depth of inspiration and to the degree of expansion of the lungs: and sinee this decrease of pressure is continuous throughout the entire act of inspiration, a continuous expansion of the intrathoracic veins and of the auricles must result, and therefore a direct suction of the blood from the reins to the heart must take place. Under certain circumstances this suction is felt eren by the farthest reins.

The return flow of the blood is farored likewise by a static inspiratory position of the chest wall; but in this instance direct suction cannot result. because this would gresuppose that the auricles are being continually expanded by extrancons forces, which is not the case unless the chest wall is actually moving.

If the air pressure inside the chest be raised sufficiently the return flow of the blood to the heart is hindered; the circulation stops, and death may result, if the al,normal increase in pressure in the thorax is too long continued. 
Furthermore, the heart in its own systole exereises a farnrahle influence on the return flow of the blood. During systole the rolume of the ventricles is diminished by exactly the solume of the blood driven out. This hlood is partly taken up by the intrathoracic arteries and the pulmonary vessels, but part of it leares the thorax. The consequence is that the content of the thorax is smaller. This in its turn produces a suction in the thoracic cavity which acts either to draw air into the lungs throngh the open glottis (cardiopneumatic mocement), or to produce a sinking of the chest wall, or finally to expand the intrathoracic veins wherehy blood is drawn into them.

Finally, it has been demonstrated that the heart exercises a suction on the blood in passing into diastole. By means of a minimum valve Goltz and Gaule and others have olserved in the open thorax of a dng a negative pressure of $100-320 \mathrm{~mm}$. of water in the left ventricle, 10-25 $\mathrm{mm}$. of water in the right rentricle. Under the same circumstances (open thorax) a negative pressure can be demonstrated in the auricles (De Jager et al.).

One sueceeds howcer in demonstrating such a suetion only with a vigorously active heart. If the heart movement is weak and if the heart does not empty itself well when it contracts, the suetion effeet is considerably diminished. What the forces are which bring about this suetion is not fully explained.

Excessire filling of the left rentricle is prevented by its thick wall. In the right ventricle the wall is ton thin to present sufficient resistance against a very powerful flow of blood. but the danger of overdistention is prevented in part at least by the fact that muscular cords are stretched across the cavity of the right ventricle at different levels.

Moreover the pcrieardium plays an important rôle, as appears from the following among other observations: a cat's heart held $12 \mathrm{ce}$. when the pericardium was uninjured, when the pericardium was punctured 11 ce. more eould still be driven into the heart (ehiefly the right auricle and right ventricle) with the same pressure. Even when beating normally the heart during diastole protrudes through a slit made in the pericardium. Finally it should be remarked that a relative insufficiency in the right atrio-ventricular valve appears after opening of the pericardium. The elosure of this valve is insured by the support which the perieardium affords to the heart (Barnard).

\section{§ 8. POWER AND WORK OF THE HEART}

\section{A. POWER}

We have already seen that the left rentricle in its systole may exert a pressure of $200 \mathrm{~mm}$. IIg. and more on the blond. A weight of this size might then be said to press upon the inner wall of the rentricle. Nerertheless it is able to contract, and its power must be everywhere sufficient to halance such a maximal pressure. In other words, the power of every square centimeter of the internal surface of the left ventricle is equal to the weight of a columm of $\mathrm{Hg} .1 \mathrm{sq} . \mathrm{cm}$. in section and as high as the maximal pressure expressed in terms of $\mathrm{Hg}$. If we assume that the maximal pressure amounts to 200 $\mathrm{mm}$. Hg., the power of the left ventricle for every square centimeter of its 
inner surface is $200 \mathrm{~mm} . \times 100 \mathrm{sq} . \mathrm{mm} . \times 13.6^{1}=2 \mathrm{i}^{2} \mathrm{~g}$. It is searcely wortls while to grive a value for the total power of the left ventricle, since it is not possible to determine with any acemracy the area of its internal surface during systole. In progressive contraction the residual power of a muscle becomes smaller and smaller. But in the heart this is compensated by the fact that at the same time the internal surface of the rentricle is constantly becoming smaller.

Since the maximal pressure of the right rentricle amounts to about 30 $\mathrm{mm}$. Hg., its power per square centimeter of internal surface would be sufficient to balance $40.8 \mathrm{~g}$.

\section{B. WORK}

The work of any chamber of the heart at each systole is expressed hy the formula $\mathbb{H}=p \mathrm{R}+\frac{m x^{2}}{\partial g}$, where $p$ is the weight of the output, $\mathrm{R}$ is the resistance or mean arterial blood pressure maintained by it, $v$ the velocity per second imparted to the blood, and $g$ the acceleration of gravity.

In order to estimate the work done by the left ventricle. for example, we must determine the pressure and the velocity of the blood in the aorta, as well as the mass of blood driven ont at each svitole. In the following section we shall go into the subject of blood pressure and velocity in the aorta more fully: here in order to carry ont the calculation, we shall say in advance only that the mean pressure may be estimated at about $150 \mathrm{~mm}$. Hg. and the velocity at alout $0.5 \mathrm{~m}$. per second.

We cannot say as yet with any definiteness how great is the quantity of blood expelled from the human heart at each systole. It is very probable that the pulse rolume is somewhere between 50 and $100 \mathrm{~g}$. per beat. If we adopt these values and substitute them in the above formula, we ohtain as the limits of the work necessary to force the blood against the aortic pressure: $50 \times$ $0.150 \times 13.6^{1}=10^{\circ}$ gram-meters : $100 \times 0.150 \times 13.6=204 \mathrm{~g}-\mathrm{m}$.

The work which it requires to impart a velocity of 0.5 meters to the pulse volume is aceordingly $\frac{50 \times 05^{2}}{2 \times 9.8}=0.64$, or $\frac{100 \times 0.5^{2}}{2 \times 9.8}=1.28 \mathrm{~g}-\mathrm{m}$. The total work of the left ventricle in its systole would be therefore $102.6 t$ to $20 \% .28$ g-m. We see that by far the greater part of the work of the ventricle is nsed in overcoming the resistance in the rascular system and that only a very small part is necessary to give the blood its mean velocity. This result is perfectly positive in spite of the very arbitrary values used in our calculation, for the pulse volume exercises no influence on the reciprocal relation of the two factors, and even if we estimate the speed in the aorta much higher, and the blood pressure there much lower, the factor $p R$ would still be many times greater than the factor $\frac{p v^{2}}{2 g}$.

We have no direct information as to the quantity of blond expelled from the right ventricle in its systole. But we may assume that its pulse volume is the same as that of the left ventricle; for the left ventricle drives the blood through the greater circulation to the right auricle, and the right drives

1 The specific gravity of mercury. 
it through the lesser circulation to the left auricle. Should the two rentricles not expel exactly the same quantity of blood at a systole or in a unit timewe except accidental disturbances-the blood would collect somewhere in the rascular system. Under the assumption that the mean pressure in the pulmonary arteries of man is equal to that of the dog. we obtain for the work of the right rentricle 14.24 to $28.48 \mathrm{~g}-\mathrm{m}$.

In connection with the subject of the blood movements in the arteries we shall diseuss more fully how the work of the heart depends upon changes in the vessels and upon their degree of fullness.

\section{§ 9. PROPERTIES OF HEART MUSCLE}

\section{A. THE NATURE OF THE CARDIAC CONTRACTION}

If the contraction curve of an empty heart be recorded graphically, one chserves an unmistakable resemblance to an ordinary muscular twitch produced by a single stimulus. We have in the action current of the heart (cf. page 48 ) a means of testing this inference. This test can be applied to the human subject also. if symmetrical points of the body's surface be connected with a galvanometer, for the electrical currents generated by the heart's activity diffuse according to the usual laws throughout the entire body (ef. Fig. 63). Fig. 64 represents the action current of the human heart as recorded by the exeursions of the capillary electrometer. An upward stroke signifies that the base of the heart is negative to the apcx. The rentricular systole begins with the point $R$; there follows a negative stroke $S$ (the apex negative to the base), and finally, after an interval, a positive stroke $\mathrm{T}$ (base negative to apex). From this curve of electrical variations we may infer that the contraction begins at the

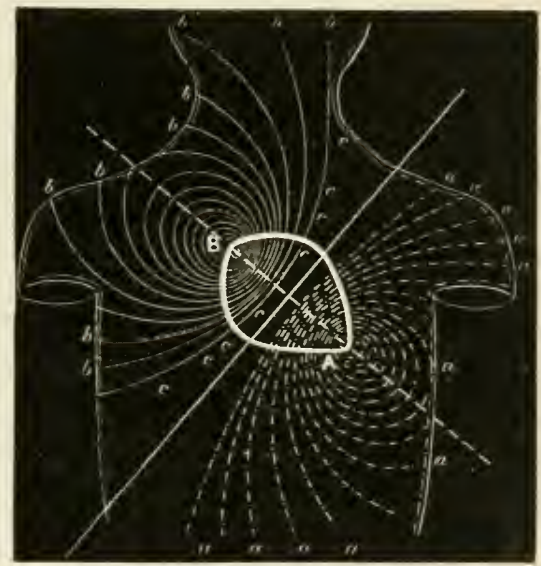

FIG. 63.-Schematic representation of variations of electrical potential associated with the beat of the human heart, and their distribution in the body, after Waller. base and proceeds from there to the apex;

for a certain time (a portion of the stretch from $\mathrm{S}$ to $\mathrm{T}$ ) the ventricle is contracted in all its parts, so that the base and the apex cxhibit no difference of potential. The contraction ceases sooner at the apex than at the base-which in all probability is due to the return course of the muscular fibers (page 16:3)-and the base becomes once more negative to the apex. The interval of time betreen the beginning $R$ and the end $T$ is about 0.32 scend, which corresponds fairly well to the duration of a rentrieular systole.

From all this it appears that the rentricular systole is comparable with a simple museular contraction and cannot be regarded as a summated contraction (cf. Cliapter $\mathrm{XV}$ ). 
Before the electrical variations corresponding to the ventricular systole a small diaphasic action current is to be ohserved (Fig. 6t, $P($ ) ). which is probably caused by the auricular contraction. 'This lasts only about 0.13 second (Einthoven).

\section{B. NUTRITION OF THE HEART}

The heart gets its blood supply through its coronary arteries, for distribution of which the text-books of anatomy should be consulted. Here it should be reealled only that they do not anastomose with each other, and are therefore terminal arteries. Besides, the heart wall obtains blood from the heart carities through the reins of Thebesius, which are in comnection with the coronary vessels (arteries and veins) by means of capillaries, and with the reins by means of somewhat larger vessels. The capillary network of the heart is very elose, and besides this, the smallest ressels proceed direetly from relatively large stems. In those places where sereral muscle fibers unite, spiral ressels are found which

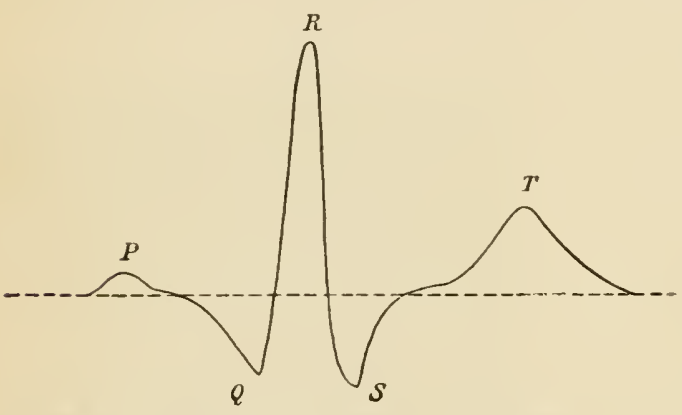

FIG. 64.-Schematic representation of the action current of the human heart, after Einthoven. seem adapted to maintain the blood supply when the fibers shift their position and change their form (Heynemanu).

The following is to be observed with regard to the behavior of the blond flow through the coronary iessels in different phases of the heart's activity. In diastole of the rentricle the ressels of the heart wall are open, and offer no hindrance to

the blood stream. When the rentricles contract they must sooner or later exert such a pressure on the capillaries of the heart wall that the blood flow in them is intermpted for a time, and is only resumed at the beginning of relaxation. By this eompression of the coronary ressels. blond is driven ont into the right amricle. It is found in fact that the quantity of blood flowing in the coronary veins increases during systole. The evacuation of the coronary veins thus brought about has the effect of diminishing the resistance to the blood. so that at the next relaxation they are filled more easily.

This variation in the caliber of its ressels produced by the movements of the heart-to which is to be added possibly a dilatation of the arteries taking place at the beginning of systole-causes a greater quantity of blood to flow through the coronary ressels of a beating heart than of a quiescent one, the quantity being in direct proportion to the force and frequeney of the heart beat (Porter. Langendorff). On the other hand the rolume of bloor flow in a heart suffering from loss of coördination of its muscle fibers may be eren greater than in a normally beating heart. which is probably due to the fact that no eompression of the coronary ressels now takes place. while the waring morements of the cardiac muscle fibers facilitates the passage of the blood by a sort of light massage (Langendorff). The quantity of blood 
flowing through the heart is diminished by a greater internal pressure and a consequent distention of the heart, even when it is beating (Hyde).

The flow of blood from the coronary veins is temporarily hindered by the contraction of the right auricle, since at this time the mouth of the common sinu: is narrowed-an effect which is aided also by the valve of Thebesins. But the same temporary stoppage tends to faror dilatation of the heart wall, thereby making the auricular systole that much easier. When the auricles relax the coronary reins empty themselves again. and the elasticity of the rentricular wall. which is inportant for the prompt closure of the atriorentricular valves, can the more readily assert itself ( $r$. Vintschgau. cf. page 166 ).

Since the cornnary arteries do not anastomose with one another, ligation of one of its branches deprives the corresponding part of the heart wall of its blood supply. and a coagulation necrosis then makes its appearance. In such a region the power of contraction is retained however for at least eleven hours; and in animals which survived well the operation of tying off a large arterial branch, the frequency and rhythm of the heart heats and the heart sound: were normal throughout for thirty-six to fifty-four hours afterwards (Baumgarten). Small restricted anæmias were in general well borne.

It is evident that the heart muscle must erentually die. if one of the larger branches of the coronary arteries becomes impassable. What is difficult to explain howerer is the circunstance that the coördination of the cardiac muscle fibers, upon ligation of a large arterial branch. ceases almost immediately (within one hundred to one hundred and twenty seconds) and the heart falls into fibrillury contractions. The same thing happens even if the ligature is loosed before the inception of these disturbances (Cohnheim and $r$. Schulthes-Rechberg). Since, however, one often meets with cases where such sudden disturbance of the heart's activity does not follow stoppage of its blood supply. it has been assumed by many that this is traceable to some injury to the rentricular wall. Porter on the contrary has shown that fibrillary contractions appear if the blood flow in an artery is stopped in such a way that no posible injury to the rentricular wall can occur. and takes the view therefore that such contractions are caused by scanty nourishment to the heart muscle. That they do not appear in the heart at death from all manner of causes. he explains lyy saying that the heart is seized with fibrillary contractions only in case it is working against great resistance when the disturbaner to its nourishment occurs. When the resistance is not great (and is diminishing gradually) the contractility of the heart muscho decreases steadily, but gradually, and when finally the heart comes to a standstill the residual contractility remaining in it is no longer sufficient to produce well-llefined fibrillary entractions. Whether this explanation is correct in all points cannot be definitely decided at this time.

The heart muscle can get its nourishment not only through the coronary arteries but also through the veins of Thebesius. From observations on extirpated hearts, it is seen that the food which ean be supplied by these ressels is suffeient to maintain rhythmical contractions for a considerable time. The same is true of artificial perfusion through the cormary veins (Pratt). 
It has long been known that hy artificially supplying blood to the extirpated heart of eold-blowled animals, activity ean he maintained for a considerable time (Iudwig). Later Newell irartin and Langendorff aecomplished the same thing with the heart of warm-blooded animals. For this purpose blood is led into the aorta by means of a cannula tied in it and directed toward the heart. Beeause the semilunar valves are elosed by the pressure from the cannula, the blood flows through the eoronary ressels to the right auricle. whence it is allowed to eseape. Numerous observations have hern made on such preparations as to the way a heart works under different conditions when separated from the central nervous system and from the blond ressels: and as to the effect which rarious agents exereise on the performance of the heart.

However it is not necessary to use blond as the nutrient fluid in order to keep the lowart heating. for several hours at least: for both in cold-blooded (linger) and in warm-blooded animals (Locke) a solution of certain inorganic salts has been found sutficient ( 0.1 per cent $\mathrm{NaHCO}, 0.1$ per cent $\mathrm{CaCl}_{2}$, 0.03 per cent $\mathrm{K}(\mathrm{l}$, eight per cent $\mathrm{Na}(\mathrm{l})$. For the warm-blooded heart the Huid must be saturated with oxygen. By addition of a small quantity of dextrose also this artificial serum is still more effective.

The significance of these substances has been discussed already at page 25. Here it may be added only that the farorable action of the $\mathrm{NaHCO}_{3}$ might be due to the $\mathrm{C}_{2}$. for with a sufficient supply of oxygen, earbon dioxide actually increases the energy of the isolated frog's heart (Göthlin).

The great tenucity of life exhibited by the exsected heart is truly remarkable. By artificial perfusion with the above-mentioned solution (and dextrose). Kuliabko olstained well-marked contractions of the entire heart of the rabbit five days after the death of the animal. He also succeeder in completely reviring the heart of a four-year-old boy who had died of pnenmonia duplex and eatarrhus intestinalis. twenty hours after death.

Moreover the tenacity of life in the different portions of the heart is very different. When the heart is dying, the left ventricle stops first, then the right, but the auricles continue to beat for a considerably longer time. Finally the pulsations of the left auricle cease and last of all those of the right. Even then the contractions of the great veins alwars go on for a time, and only when these have ceased is the heart entirely dead.

When the oxygen supply to the heart is ent off the heart beats become less and less frequent as asphyxiation eomes on, and other changes make their appearance which cannot be disenssed here. However it should be observed that the heart, especially of cold-blooded animals, has great power of resistance against oxygen hunger (cf. page 28 ).

\section{THE BEHAVIOR OF HEART MUSCLE UNDER DIRECT STIMULATION}

If the heart muscle be stimulated with induction currents of different strength, either it dnes not eontract at all, or it contraets to its utmost extent (Bowditeh). The response of the heart muscle therefore is always maximal. while the eontraction of skeletal musele is great or small aceording to the 
strength of the stimulus. This fact is often referred th as the "all or none" law of cardiac contraction. The crustaeean heart (lobster) torms an exception to this rule, since it behaves to stimuli of different strength exactly like skeletal muscle.

Another peeuliarity of heart muscle is that in both cold-blooded animals and in Mammalia it is inexeitable during its contraction up to the maximum of shortening-i. e.. all stimuli which fall upon it during this ("refractory") period are entirely without effect (Marey). Only after the maximum shortening has been reached does the heart muscle become excitable again. A stimulus applied then calls forth an extra contraction. which is greater the later in diastole it falls. Ifter this extra eontraction a longer (" compensatory") pause usually oceurs, and the first contraction following the pause is

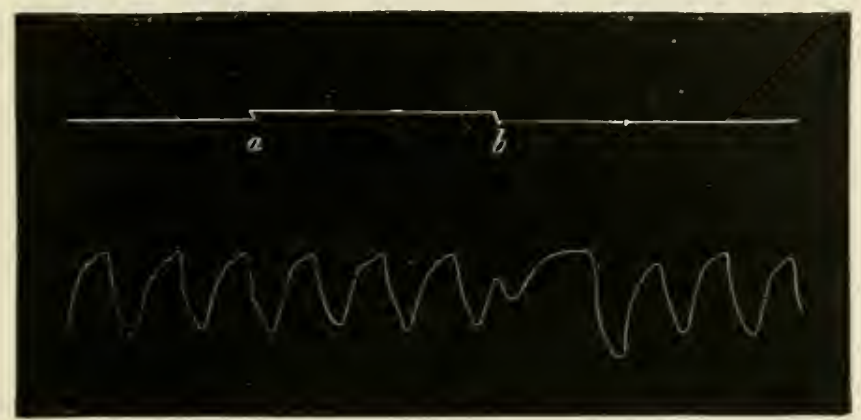

FIG. 65.-I Direct stimulation of the isolated heart of the cat while beating, after Langendorff (to be read from left to right; systole represented by the downward stroke). Stimulation at the beginning of systole (a) produces no effect. Stimulation at any time during diastole (b) gives an extra contraction. Following this are seen the compensatory pause and considerable augmentation in the strength of the next systole.

considerably augmented. The smaller the extra contraetion, the longer is the subsequent pause and vice iorsa. After such an interference in the regular rhythm of the beats, there is therefore a eompensation by which both the frequeney and the amount of work done by the heart are conserved (c.f. Fig. 65).

The compensatory pause appears only in those portions of the heart which beat in consequence of a stimulus communicated to them from other portions: it is not seen therefore in a tracing from the renous sinus of the frog. In explanation of this difference it is supposed that the excitation of the renous sinus is continuous, but that it seuds a discontinuous stimulus to the other chambers of the heart. When an extra contraction has been induced in the ventricle, one of these regular disentinuous stimuli from the venous sinus would fall at a time when the rentricle is refractory, henee would produce no effect. The rentricle must therefore wait until the next regular stimulus, and thus we get the compensatory pause. It is quite different with the sinus: as soon as the extra contraction has reached its maximum, the constant stimulus again becomes effective and produces the next systole without an intervening pause.

The inability of the heart nuscle to receive stimuli which fall on it during systole, is the reason why with rapidly repeated shocks it cannot be thrown 
into an actual tetanus, like skcletal muscles. Since all the stimuli which fall during systole are entirely ineflective, there can be no superposition and summation of effects.

This rule is not strictly without exception, however. By simultaneous stimulation of the ragus and the renous sinus O. Frank was able to demonstrate a condition of tetanus in the frog's heart; Walther obserred the same thing on stimulation of a frog's heart poisoned with muscarine. In the latter case the refractory period of the heart is shortened as a result of the poison, and the barrier to the production of tetanus is thereby removed.

Iany other discoveries have been made on the exsected heart concerning

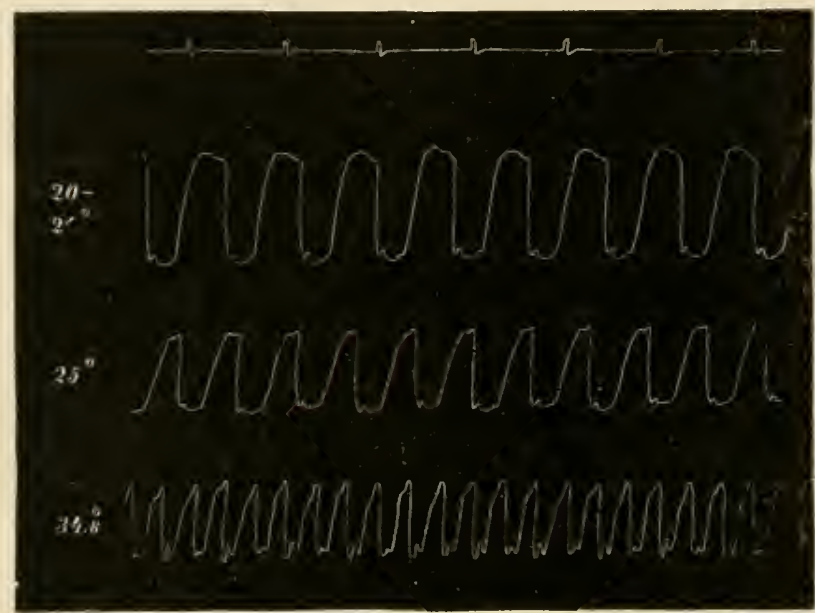

Firs. 66--Influence of temperature on the isolated heart of the cat, after Langendorff. The heart was supplied with blood kept at the different temperatures indicated.

the properties of heart muscle, but they cannot be discussed here. We wish to call attention only to the following peculiarities:

(1) The frequency of the heart beat raries directly with the temperature -i.e., the higher the temperature the greater the frequency, the lower the temperature the less the frequency. Thus at $40^{\circ} \mathrm{C}$. it is four times as great as at $15^{\circ} \mathrm{C}$. With a fall in the frequency, the extent of contraction increases up to a certain limit, and at the same time the shortening becomes slower and more drawn out (Fig. 66).

(2) The quantity of blood which the left ventricle discharges at each systole depends upon the quantity of flow from the great reins: the greater the inflow the greater the amount discharged, but the latter increases more slowly than the former.

(3) The quantity of blood flowing through the coronary ressels exercises but little influcnce upon the frequency, although it is of great importance for the force of the heart beat.

(4) If the heart has no work to do it has need of only a very small quantity of blood. 


\section{$\S$ 10. THE CAUSE OF THE RHYTHMICAL ACTIVITY OF THE HEART}

In warm-blooded animals direct nerve fibers to the auricles as well as to the right and left coronary plexuses, come from the two divisions of the cardiac plexus, which in turn is formed by branches from the ragus and sympathetic. The threads of this network are provided with numerous ganglia, and the fibers radiating to the auricle and ventricle from the network are also interspersed with small ganglia.

In the heart itself ganglion cells have been found in the following places: in the auricles around the opening of the great veins, along the periphery of the septum, and, though in smaller number, in the outer wall; in the atrioventricular groove, especially in the region of the aorta and pulmonary artery at the level of the semilunar valves; and in the uppermost part of the ventricle.

Fine nervous nets supply an abundance of nerve fibers to all parts of the heart.

As appears from what has been said concerning exsected hearts, this organ possesses the property of acting quite independently of the central nervous system. In order to determine the cause of this peculiarity we have to investigate first the behavior of the separate divisions when they are isolated from the whole heart. In this we shall consider chiefly the phenomena appearing in the Mammalian heart, because a detailed discussion of those observed in the hearts of cold-blnoded animals would call for entirely too much space.

By introducing into the auricle a small instrument provided with curved plates on two sides, it is possible to sever all the nerrous and muscular connections between the auricles and rentricles without producing hemorrhage. After this operation the ventricles entinue to pulsate without interruption.

In this experiment the line of separation can be brought close to the auricular boundary. Since now all the nerves which run to the heart along the great arteries are afferent in function (Wooldridge), and since the results are the same in ease the great arteries are pinched off directly above the upper edge of the semilunar valves. it follows that the isolated portion of the heart, i. e., the rentricles and a very small part of the auricles, have within themselves all the conditions necessary for rhythmical activity.

One can go still further. Porter has succeeded by means of artificial circulation through the coronary arteries in maintaining regular rhythınical contractions in isolated pieces of the rentricular wall, connected with the rest of the heart only by the arterial branch. We can extend the proposition stated above therefore, and say that every portion of the ventricular wall possesses all the conditions necessary for rhythmiral articity.

In these experiments one meets with cases where the rhythm of the separated portion is materially less than that of the whole heart or that of the divisions remaining after isolation of the ventricles. But under normal circumstances the rate of the rentricular systole is determined by the rhythm of those parts of the heart which inaugurate the systole (the venous ostia of the auricles; cf. page 162 ). 
It is most probable that we have to do here with a chemical stimulus of some kind, which is to be sought among the products of decomposition formed in the activity of these parts. If this is so, it follows that the inorganic constituents which, as mentioned above, must be present in an artifieial fluid in order to maintain the heart's activity, and which occur in the blood, are not to be considered as the real excitant of the heart beat, but merely as a condition.

Since the structure of cardiae muscle agrees essentially with that of skeletal muscle, and the latter is set in action normally only under the influence of a stimulu communicated to it from the central nerrous srstem, it was for a long time supposed that the rhythmical contractions of the heart were not caused by any specific property of the muscle fibers, but were discharged by intracardial ganglion cells. This view found weighty support in the fact that these cells were demonstrated in just those parts of the heart where the systole begins. In more recent times various anthors, notably Caskell and Engelmann, have alrocated the view that the spontaneous contractions of the heart are of muscular origin, and are due to a special property of cardiac muscle.

The following facts among others have been adduced as arguments for this conception. The renous sinus in the frog contains a large collection of ganglion cells. known as Remak's ganglion. which on the ganglion hypothesis has often been referred to as the originator of the heart beat. Now it has been found that normal pulsations can be started from every other place in the sinus region; the sinus ganglion is not, therefore, absolutely necessary. In the frog in the normal course of events, t'le contraction waves probably proceed not from the sinus but from the great veins. These pulsate spontaneonsly if they are isolated entirely from the rest of the heart, even if the isolated portion contains no ganglion cells. The same is true of the bulbus arteriosus of the frog:s heart, in which no ganglion cells are present. Noreorer in the heart of the higher invertebrates, and in the spontaneously contractile reins of the bat's wing. notwithstanding diligent search, no ganglion cells have been found. Again the embryonic heart of mammals beats in a perfectly characteristic manner at a time when no nerve or muscle cells have yet been differentiated.

All these and still other circumstances go to show that a rhrthmical, automatic activity of contractile tis.ue can be brought about without the participation of ganglion cells: and it is, therefore. possible that the automatiom of the fully leveloped vertebrate heart is of muscular origin. The great tenacity of life of the heart speaks strongly for this view also; for from all that wo know of ganglion cells elsewhere, they perish in much shorter time than is required for the exsected heart to lose its power of rhythmical contraction.

The fact that this power is developed to different degrees in different parts of the heart, and that individual parts, like the clamped-off apex of the frog's rentricle, will never pulsate spontaneonsly under the influence of the normal stimulus, is explainer! according to the muscular theory by supposing that automatism. originally common to all the cardiac muscle cells, has disappeared in the course of derelopment from some places, notably the apex, but remained in others, notably the region of the renous sinus. 
The number of authors who have taken the side of this hypothesis has constantly increased-a fact not difficult to understand in view of the great logical precision with which it has been developed. Nevertheless it appears that there are still certain diffieulties to be overcome. For example, the questions: how it transpires that the vence cave and the pulmonary veins, although separated by a considerable distance, are roused to aetion simultaneously; and how the normal coürdination of the heart muscle, as well as the disturbances of the same by electrical stimulation, by anxmia and by mechanical abuse (ef. page 153), are brought about have not yet been satisfactorily answered.

Any explanation of the origin of the contraction must take account also of the question as to how the excitation is propagated through the heart, whether through the musculature itself or through a set of nerves; beeause, if the muscular theory of the heart beat is correct, it follows almost of necessity that the propagation of the stimulus is muscular, and vice versa.

If the rentricle be artificially fel by the eoronary arteries, and he divided up into different parts connected together by the arterial branehes, and joined by thin mmscular bridges, all the portions beat smehronously, no matter in what direction the euts are made. After section of the muscular bridge. the synchronism stops and each part beats after its own rhythm, but does not show any signs of fluttering (Porter).

Neither these phenomena nor the eorresponding observations made on the frog's heart are, however, to be regarded as conclusive proof of the muscular theory of propagation, inasmuch as the cardiae musele fibers themselves are surrounded by nerves which could only be exeluded by complete division of the last museular bridges, and might therefore eause the synehronism.

The passage of the excitation from the auricles to the rentricles once constituted a serious diffieulty in the way of a muscular theory. It was supposed that the musculature of these two divisions were completely separated. It has been shown, however, that direet museular connections are indexd present between the two (Kent, His, J'.), and the excitation might therefore pass from the auricle to the rentricle without any participation of nerves.

As mentioned above, a certain time intervenes between the auricular and the rentricular systoles. From the standpoint of the ganglion hypothesis this delay would not be diffieult to explain, since we know from many other observations that ganglia in general do delay the propagation of impulses. But the muscular theory also has been able to offer an explanation by supposing that the transmission of the motor stimulus takes place rery quickly within each separate division of the heart, while over the cells which form the conneetions between the separate parts, the transmission is very slow, just as it would be orer smooth or embryonic museles.

What appears to disprove conclusively the hypothesis of nerrous propagation, and is therefore a very weighty support for the muscular hypothesis, is the following. If the auriele of a frog's heart be injured by a light pinch, the rhythmie excitation travels just as before over the entire heart. But if the vagus be now stimulated, as long as the inhibitory aetion lasts, the ordinary excitation passes only up to the injured spot and stops there. If the propagation were through a nerrous mechanism, we should have to suppose that the conductivity is tem- 
porarily abolished exactly at the injured place (F. B. Hofmann), which howerer could only be explained by an action of inhibitory fibers on motor fibers. Such effects are entirely unknown elsewhere and are therefore extremely improbable here. The phenomenon presents no special difficulty on the other hand, if we suppose that the transmission is purely musenlar, and has been rendered impossible by the action of the inhibitory nerves on the injured musele.

The sxnehronism of the two rentricles is not effeeted by simultaneous impulses from the aurieles, but by their muscular or nersous connection with each other. For if the two be separated from one another, but be left in conmection with their respective aurieles, the synchronism is broken and each beats in its own rliytlim (Porter).

\section{\$ 11. THE EFFERENT CARDIAC NERVES}

The activity of the heart is controlled by impulses from the central nerrous system brought to it orej the ragns and sympathetic fibers. Afferent nerves also pass to the brain from the heart, and these influence both the heart itself and the blood vessels of the general system reflexly. 'The rich supply of nerve fibers to the ultimate musele fibers of the heart are the terminal branches of these same nerres.

The importance of these regulatory influences ean scarcely be overestimated. This is well shown by the following observations of Friedenthal on a dog, whose extracardiae nerves were all cut, the afferent fibers from the lungs, and the fibers to the stomach and the resophagus being preserved on one side. The animal, which had survived the last operation for more than eight months and had then succumbed to aeute strophanthus poisoning, showed in the meantine on superfieial examination searcely any abnomality. The number of heart beats, for example, was not noticeably changed. When, however, the animal was required to run, the abnormality became very apparent. Although he had recorered his original weight within two months of the operation, he was unable afterwards to run half a mile. The ability to do even a moderate amount of work had therefore been lost, because the mechanism for inereasing the heart action was wanting.

\section{A. THE INHIBITORY NERVES}

If the ragus be eut in the neck and its peripheral end he stimulater with tetanizing induction shocks, slowing of the heart boat or complete diastolic standstill, according to the strength of stimulation, results. The vagus therefore inhibits the heart morements. We owe this important discorery to the brothers, E. H. and E. F. Weber $(18+j)$.

If both ragi of an animal be cut. the heart immediately beats faster. Tnder normal ciremstances therefore a constant restraint is being exercised by the central nerous system upon the heart, in consequence of which it beats more slowly than it otherwise woult.

The ragus influences not only the frequeney of the heart beats. but also the force. In fact it mar happen under certain circumstances that when the ragus is stimulated the pulse frequency remains entirely unchanged, while the size of the contraction becomes constantly smaller (Heidenhain. Gaskell). According to Muskens, this takes place in the frog and turtle only in the exciced heart or after loss of blond. The leart relaxes in diastole more during 
ragus stimulation than otherwise. but this might be caused by the Jonger pause, affording nıre time for relaxation (O. Frank, F. B. Hofmann).

The following observations have been made with regard to the way in which the ragus acts upon the different divisions of the mammalian heart. The inhibiting influence extends not only to the heart itself, but also to the central reins, so that their eontractions may completely cease on vagus stimulation (Knoll). With reference to the auricles it is unanimously asserted that it is the foree of contraction which is primarily diminished, and that it may even happen, in spite of a considerable decrease in the extent of the contractinu, that the rhythm remains entirely unaltered. On the other hand, it invariably happens that a fall in frequency is accompanied by a reduction in the size of the contraction.

Results differ somewhat as to the behavior of the ventricles. It seems, however, to be pretty certain that with weak stimulation where the heart beats are not retarled very much, the erntractions of the ventricles are somewhat stronger than otherwise; and that with stronger stimulation and ernsiderable retardation the contractions become weaker. The augmentation in the first instance need not be a direct effect of the vagus, for it may be due to the fact that with a slower cadence a greater volume of blood is at the disposal of the heart at each systole; besicles, it must not be forgotten that with the longer diastole the blond pressure in the arteries must fall, so that the heart has less resistance to overcome.

The cause of the reduction in frequency. or the complete standstill of the rentricle cifected ly the ragus is to be sought in a direct effect on the ventricles themselves. (Ine would think that when the auricles are stopped they would no longer discharge impulses to the rentricles. While this is possible it does not sem rery probable, at least for the mammalian heart. for under certain circumstances the ventricles may beat at the rhythm of the great reins while the auricles are perfectly quiescent (Knoll). Besides. the power of the ventrieles to beat rhythmically when isolater from the auricles is so great that mere stoppage of the auricles may not necessarily affect the rentricles. Tagus retardation may, however. le brought about in such a way that the impulse cannot be propagated from auricles to ventricles. Thus there are cases where the auricles beat at a more rapid rhythm than the rentricles, although the excitability of the latter is not diminished in the least. Finally, it has been shown that when the heart is brought to a complete standstill by strong ragus excitation, the cardiac muscle is less excitable to direct stimulation and cannot be roused to contractions so extensive as is normally the case. All of which bears out the statement that the ragus acts directly on the rentricular muscle.

Engelmann describes these effects of ragus exeitation as negatively chronotropic (rotarding), negatively inotropic (weakening), negatively dromotropic (diminishing the enductivity), and negatively bathmotropic (reducing the irritability): and is inclined to the assumption that they are bronglat about by four speeial sets of nerve fibers. This coneeption, based on the frug's heart, receives some support from Pawlow's observations on the stimulation of separate fibers in the carliac plexus of the deng, aceording to which either the force or the frequency of the heart beat could be influenced either in a positive or negative direction, alecorling to the fibers stimulated. Other authors take the view that the inhibitory nerves consist of only one set of tibers, and that the different 
effects depend upon their condition at the time of stimulation. A definite decision of the matter is not possible at this time.

The view has often been expressed that the vagus influence on the heart is of a nutritive or troplic nature. The following facts might be construed in faror of such a view : the strength and working power of the heart, as well as the ability of the heart muscle to propagate a stimulus, increases after vagus stimulation; the heart's activity, if it is weak, is materially raised by vagus stimulation: and in the asphyxiated animal the heart beats longer if the ragi are left intact, than if they be eut, ete. But these phenomena might be explained also by the longer resting period after each systole.

Conclusive proof of the correctness of this view would be afforded, if degenerative changes conld be demonstrated on a heart whose vagi had been cut. Such have in fact often been mentioned, and it has even been asserted that they are confined to different parts of the ventricles, accoriling as the right or left ragus is eut. But we have the researehes of Pawlow and Friedenthal to the contrary. They find that the heart of dogs which had survived bilateral vagotomy for several months presented no anatomical changes whatsoever. The long time during which the animals remained alive in these researches, as well as in those of Nikolaïdes and Ocaña, itself goes to show at least that the vagus cannot be exclusively a trophic nerve for the heart.

That the inhibitory process is, nevertheless, acempanied by demonstrable molecular changes, and that the stoppage is not therefore a lind of paralysis, appears from the electrical variations in the heart muscle which accompany vagus stimulation. In the turtle's heart it is possible to separate the auricles from the venous sinus withont injuring the nervous fibers of the former. The auricles stop for a time. If now the apex be killed by immersion in hot water, and both base and apex be then led off to a galvanometer, the usual demareation current is observed with the injured spot, i. e., the apex, negative toward the base. If the vagus is stimulated the auricles remain at rest; but the galvanometer shows a positive variation (Gaskell). This variation of the animal current is evidently opposite in sign to that which takes place in the work of the heart muscle (ef. page 1\%9). Fano obtained quite similar results when he stimulated the vagus of an active turtle heart so feebly that it was not stopped but only retarded. The positive phase of the variation was increased, but the negative was diminished or abolished altogether.

Since now the negative variation is quite certainly the expression of a dissimilatory process, one wonld be forced by the appearance of a positive variation on stimulation of the ragus to the conclusion that this nerve calls ont processes of a synthetic nature. If, however, this is true, it follows from the above observationis on vagotomy that these synthetic processes are not of critical importance for the maintenance of the normal structure of the heart.

In discussing the intracardial innervation of the heart (page 186), the significance of the ganglia was left an open question. It will be appropriate to revert to the subject here, because some observations on the vagus should be able to give the desired answer. Langley has shown that niontine puts an end to the transmission of an impulse throngh the sympathetic ganglion cells with which the nerve fibers (preganglionic) coming from the central nervous 
system are connected. whereas the fibers (postganglionic) arising from these cells retain their excitability (cf. (hapter XXY). This method has been employed also for the study of the ganglionic connections of the ragus fibers. In a frog poisoned with nicotine, stimulation of the ragus trunk produces no inhibition of the heart; but stimulation of the nerves running in the auricular septum under certain circumstances gives very marked weakening of the heart beat. The ganglion cells of the renons sinus must thereforc be regarded as a relay station for the eardiac inhibitory fibers (F. B. Hiofmann).

\section{B. THE ACCELERATOR NERVES OF THE HEART}

These arise from the simpathetic (Fig. 67). They pass out of the spinal cord in the upper four or tive (most of them in the second and third) thoracie spinal roots, and run in the smmpathetic chain to the first thoracic ganglion ( $n$ ). The latter sends out two comnecting branches to the inferior cervical ganglion ( $l$ ), or to the ragus $(a)$, which rum on either side of the subelavian artery forming the annulus of Yiensens. Either from the inferior eervical ganglion itself, or from the annulus, or from the trunk of the vagus just below the inferior cervical, the accelerator nerves $(g)$ are given off to join the cardiac plexus. Besides, accelerator fibers are found in the cervical portion of the vangus, since with the inhibitory fibers thrown out of function by atropine poisoning vagus stimulation produces an acceleration of the heart beat. The accelerator fibers running in the sympathetic are described by physiolegists as the accelerator nerres.

Stimulation of the accelerator increases the pulse frequency more or less (v. Bezold, the brothers Cron) aceording as the frequeney was previnusly low or high. The absolute maximum of frequeney attainable by stimulation of the accelerator mechanism is entirely independent of the previous rate

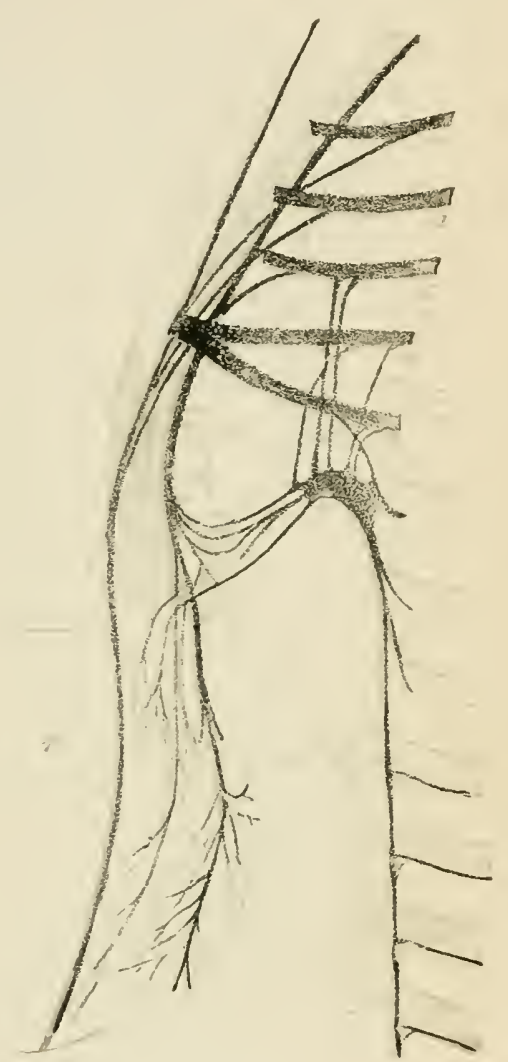

Fig. 67.-The cardiac nerves of the dog, after Ellenberger and Baum. $a$, united ragus and sympathetic; $b$, vagus; $c$, connecting fibers between the vagus and the inferior cervical ganglion of the sympathetic; $d$, cardiac nerves springing from the vagus; $e$, cardiac plexus; $f$, recurrent laryngeal; $y, y^{\prime}$, pulmonary plexus; $l$, inferior cervical ganglion; $m$, annulus of Vieussens; $n$, first thoracic ganglion (stellate ganglion); $o$, rami communicantes from this ganglion to the lost cervical nerves; $p$, rami communicantes to the first and second thoracic nerves; $y$, cardiac branch from the stellate ganglion; $r$, trunk of the sympathetic in the thorax; $\varepsilon$, rami communicantes to the spinal nerves; $s^{\prime}$, intercostal nerves; $v$, phrenic nerve; 16 , heart; 17 , innominate artery; 18 , left subelarian vein; 19 , aorta. 
(Baxt). The increase is accomplished mainly by shortening the diastole. When stimulation has ceased an after-effect remains which in favorable eases lasts for as much as two minutes.

Just as with the inhibitory nerres, the accelerators appear to exerrise a tonic infuence on the heart. Eridence for this we have in the fact that

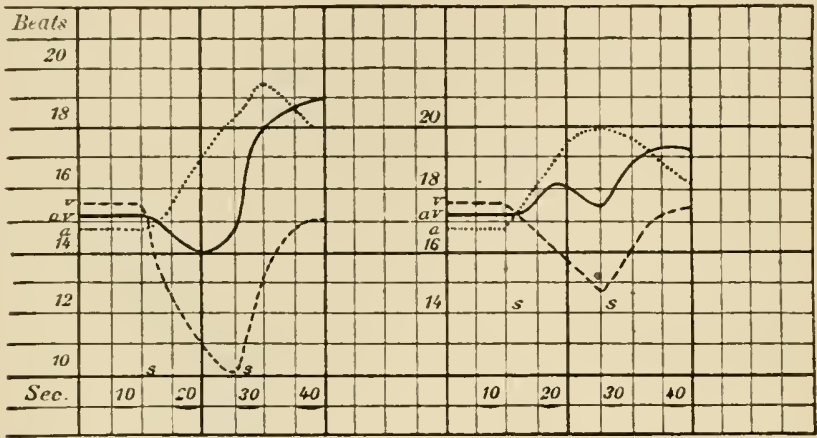

FIG. 6S.-Graphic representation of the pulse rate: $\imath$, on stimulating the vagus; $a$, on stimulating the accelerator nerves; $a$, , on stimulating both simultaneously, after Hunt. Stimulation lasted fifteen seconds in each case, $s-s$.

bilateral extirpation of the lowermost cervical and uppermost thoracic ganglia, after seetion of both ragi, diminishes the pulse frequency. The normal rate of the heart beat therefore is determined by the accelerator nerves as well as ly the inhibitory. and it appears from Friedenthal's results, giren on page 188, that the former are just as necessary for the heart's activity as the inhibitory nerves.

The size of the auricular and the rentricular contraction in most cases increases upon stimulation of the accelerator. But it may happen also that the extent of the contraction increases. While the heart frequency is not influenced at all, and, vice rersa, acceleration may take place without any increase in extent. In any case these nerves improve the execution of the heart and heighten the dissimilatory processes going on within it; hence the proposed lesignation of them by Hofmann as the promoting nerves in contradistinction to the inhibitory nerves, very aptly characterizes their properties.

By way of analogy with his conception of the inhibitory nerres of the heart, Engelmann supposes that the accelerator nerres also have several kinds of fibers: positively chronotropic (increasing the rate); positively inotropic (increasing the force); positively dromotropic (increasing the conductivity); and positively bathmotropic (increasing the excitability). The same comment would apply to this conception as to that concerning the inhibitory fibers (page 189).

It has been found. mainly by the use of the nicotine method, that the "promoting fibers" also mite with intracardial ganglion cells.

With regard to the antagonistic relations of the ragus and accelerator. experiments show that the one nerve or the other predominates aceording to the relative strength of its stimulation. and that with a stimulus of suitable strength for each. the two effects may be made to balance each other so that 
botll the rate of the heart beat and the duration of its different phases may remain almost entirely unchanged (Bayliss and Starling, O. Frank, Hunt. et al.).

And yet we are not to suppose that the resultant effect is the algebraic sum of the two when acting separately. For upon stimulation of the two together, if the ragus effect predominates during stimulation, a characteristic after-effect of the accelerator comes on when stimulation has ceased (Fig. 68). The two nerves are not therefore to be regarded as true antagonists; for if they were, stimulation of the two onght to give the same result as stimulation of neither; that is, the peculiar after-effect of the accelerator ought not to appear (Baxt). In riew of these facts. it seems probable that the inhibitory and "promoting fibers" have different modes of connection with the cardiac muscle fibers.

\section{\& 12. THE HEART REFLEXES}

The efferent cardiac nerves are roused to action reflexly both by the afferent nerres of the heart itself, and by other nerves. and the heart is variously influenced.

On the anterior as well as on the pnsterior wall of the rentricle run numerous nerves. which, on stimulation of their central eut ends, reflexly raise or lower the blood pressure. and accelerate or retard the rate of the heart beat (Wooldridge). The heart itsolf therefore through its own afferent nerves can set in action mechanisms by which the cireulatory apparatus can be changed in one sense or the other. according to the inomentary requirements.

The depressor nerve disonvered by Ludwig and Cron. which runs as a separate nerve in the rabbit, is the most important of the nerve trunk convering fibers from the eardiac plexus. It rises as a rule by two roots, one from the cervical portion of the ragus. the other from the superior laryngeal. and runs parallel with the ragis to the eardiac plexus (Fig. 69). According to Koster and Tschermak. the depressor dnes not come from the heart but from the aorta. Becanse of its great importance for the action of the heart. we shall disenss it in this connection.

Stimulation of its neripheral end has no effect whatever. Stimulation of the central end produces a fall in blond pressure and retardation of the heart beat (Fig. 80 ). If the ragi are cut the latter effect is wanting. but the fall in presure oceurs inst as hefore. The retardation is therefore due to reflex 
excitation of the vagus, the fall in pressure to a reflex dilatation of the blood ressels.

The ratural assmption with regard to the normal action of the depressor, is that it is stimulated hy dilatation of the arta, when for example the pressure there beemes rery high :o that it is dificult for the heart to empty itself. The blood ressels are dilated at the result of the depresor impulses, and the leant. working now again-t less reistance. (mpties itself more usily. Since the heart heats more slowly al:o as the result of the ragus reflex, it has a hetter opportmity to renver after the previous overexertion. These conclusions have been confirmed by recent observations; e. g., when high presure

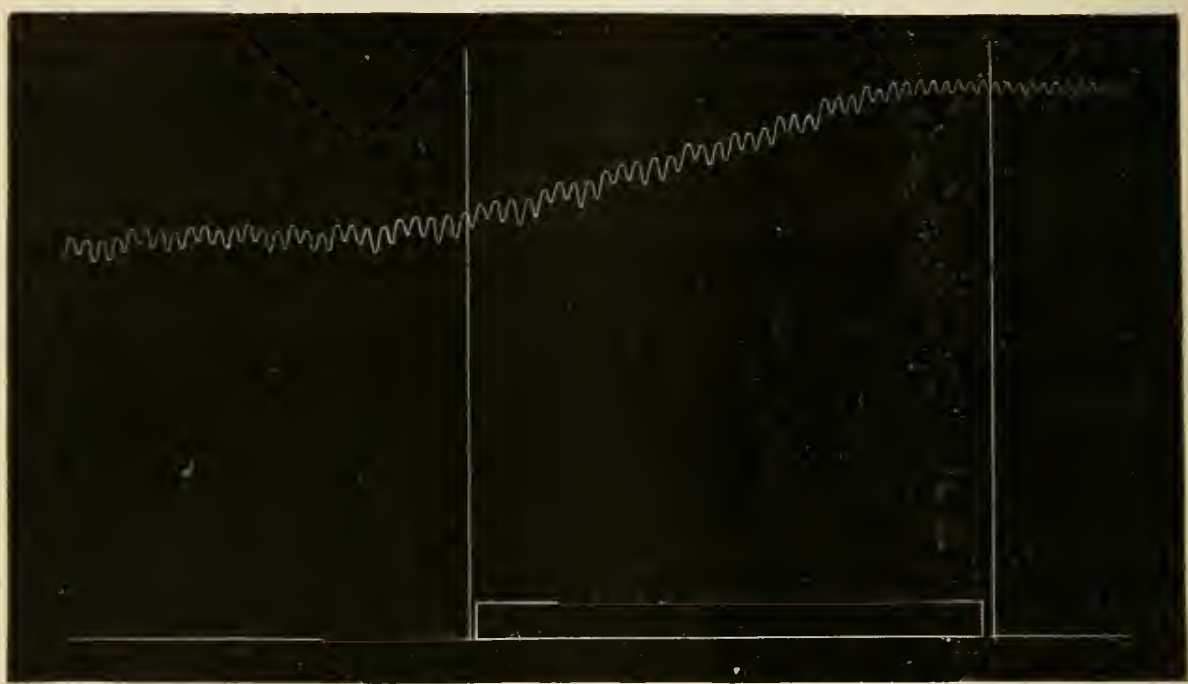

FIG. 70.-Behavior of the blood pressure on stimulation of the depressor nerve. To be rearl from right to left. The two vertical lines indicate the time of stimulation. $\overline{7}=$ ten seconds.

is produced artificially in the arch of the corta, an action current appears in the trunk of the depresor (Tiehermak), and if both depresors are elit when the presure is high, the presure rises still further (Pawlow).

Acording to cyon, the depresor has a third root. central stimulation of which produces an acceleration of the heart; this ront $i$ connected with the superior cervical ganglion.

The heart does not appear to hare nerres which mediate tactile sensation:; on the other hand reflexes may be -tarted from its afferent nerres which take effect in the skeletal muscles.

The heart may he influeneed reflexly by a great many other nerves. If one rasus be cut. and the other be left intact. central stimulation of the cut nerve produces a slowing of the pulse. which disappears when the other is cut. Among the different afferent fibers of the ragus. those enming from the lungs are most effective. those from the heart much less sn, and those springing from points below the lung fibers are still less effectire (Brodie and Russell). The inhibitory nerves of the heart are excited also by stimulation of the 
central end of the superior laryngeal, of the splanshnic and of the trigeminal.

Acceleration is olstained by inflation of the lungs: and in man it has been found that any increase of intrabronchial air pressure, as in speaking, singing, rapid and forced respiration, etc., accelerates the heart beat.

The effect on the heart of central stimulation of sensory nerves in the strict sense, as well as nerves of the special senses, is twofold: either an acceleration or a slowing. Only the trigeminal gives an invariable retardation; stimulation of the nasal mucous membrane stops the heart immediately. It is possible that the result of stimulation depends upon its strength, inhibition following strong, acceleration following the weak current. We may also suppose that such nerves consist of two kinds of fibers, one of which brings about inhibition of the heart beat, the other acceleration; but this is improbable. The afferent nerves from the muscles appear to exercise but a slight influence on the heart.

Although the heart reflexes have not been studied at all sufficiently, we may aftirm with a moderate degree of certainty that acceleration as well as inhibition of the heart beat can be brought about reflexly by a great many afferent nerves.

Inhibition is certainly to be regarded as a reflex carried over to the ragus, as appears unequivocally from the fact that when both vagi are cut the heart beats faster. It is generally supposed also that acceleration is mediated by reflex cxcitation of the accelerator nerves. Ilowever, Hunt has made some researches from which he concludes that reflex acceleration is caused by a reduction in the tonus of the inhibitory center, and he has endeavored with great skill to prove that in most cases of augmented heart action the cause inheres in this rather than in excitation of the accelerator, although he admits that angmentation is stronger with uninjured accelerators, than when these are destroyed, because with diminshed tonus of the vagus they can act on the heart more powerfully.

\section{\$13. THE CARDIAC NERVE CENTERS}

We designate as the center of a nerve, that place in the central nerrous system from which its activity is influenced either antomatically or reflexly.

Nothing definite is known about the location of the augmentor center for the heart. But since a stimulus applied to the upper part of the merlulla produces acceleration of the heart beat, it is natural to locate this, with the other regetative centers of the body, in the medulla.

It is perfectly certain that the inhibitory center is in the medulla. A needle puncture halfway up the medulla and pretty well to one side, canses slowing and stoppage of the lieart.

The cardiae nerves are influenced also by portions of the brain anterior to the medulla, including even the cerebral cortex. This is confirmed by our daily experience that the psychic states-joy. fear, hope. etc-increase or diminish the frequeney of the heart beat. Irost persons. however. find it imposillle to influence these centers by direct effort of the will.

The frequency of the heart leat can be ehanged in one direction or another he the so-called motor areas of the eerebral motex and by different lower parts of the brain. But it is not eorreet to regard these mortions as the seat of the active centers of the cardiac nerres. It seems preferable to recard the cere- 
l)rum. etc., as peripheral orans by which the cardiac centers are excited reHexly, just as they are roused to activity ly afferent fibers enming from otler parts of the borly (Franck). Iccording to this conception the actual center of the inhibitory nerves would lie only in the medulla. It ean be acted upon hy a great many aflerent nerves-from the skin, from the heart itself, from the abkominal viscera, the lungs, the sense organs, and from the different parts of the brain.

The blood pressure also exercises an influence on the rate of the heart beat. It is true that in an exsected heart, one observes no influence upon the pulsefrequency by variations of the arterial pressure within the vital limits, and the variations of the pulse produced by great variations of the renous pressure are not especially large. But under normal conditions of the circulation, very evident changes in frequency often occur as the result of variations in pressure. and this even if every possible connection of the heart with the central nervous system is broken. Thus it is found that if an increase in blool pressure due to a local rasoconstriction occurs, there often goes with it an acceleration of the heart beat, the chief cause of which is probably to be sought in the suddenly increased blood supply to the heart. By this means those portions of the heart where the contraction starts are roused to more frequent action.

In a heart completely isolated from the central nervous system an increase of pressure may produce also a retardation. The inhibitory mechanism therefore as well as the motor mechanism can be excited by a rise of blood pressure. The result will depend upon the relative irritability of the two mechanisms.

When all the cardiac nerves are intact, the heart frequency decreases with a rise in blood pressure and increases with a fall, whatever the order in which the variations succed each other. Since slowing of the heart is not the usual result of increased arterial presure when the vagi are cut, it is clear that the above-mentioned phenomenon is an effect of the vagus center.

This excitation of the vagus center is called out in part by the depressor; but is probably also connected with a change in the circulation of the brain, excitation of the center following an increase of intracranial pressure.

Nothing ecrtain is known as to how the accelerator center acts with a rise of pressure. The increase of pulse frequency observed in an anxmic condition of the brain might possibly be referred to an excitation of this center, but it can be explained also by a fall in the tonic influence of the vagus center.

From the facts just discussed, it cannot be looked upon as fully established that effects on the efferent cardiac nerves, which can be obtainel by stimulation of afferent nerves, are caused exclusively by a reflex from the cardiac centers, for it is not impossible that a change in the blood supply to the brain. brought about by a reflex effect on the vascular system, has participated to some extent.

\section{\$14. THE RATE OF HEART BEAT}

Now that we have studied the influence of nerres mpon the rate of the heart beat, it remains for us to inquire what are the normal variations in man.

If all disturbing influences be removed as far as possible-i.e., if the individual be resting quietly in bed and abstain from food-only very slight rariations in the pulse frequency appear in the course of the day. But the pulse rate is quickly affected by all sorts of influences. 
Heary bed clothing sufficient to produce a growing sensation of warmth quickens the pulse frequency con-iderably. Exposure of the naked body to air at a low temperature reduces the rate; but if the temperature of the air is high the rate rises. Hot and cold drinks have the same effect as external temperature: drinking hot water accelerates, drinking cold water retarts the pulse. A burning sensation or sellation of presure, etc.. in the stomach or inte-tine puickens the pulse.

Ender such circumstances it isevident that a meul may exercise an important influence on the pulse frerpency. and this is confirmed by experience. The pulse rate as a rule is higher at meal times. owing mainly to the addition of heat to the body.

bodily morements exercise the most profound influence on the pulse rate, and we cam almost say that the rate increases in direct proportion to the effort required and the extent and vigor of the morement. Detailed experiments are at hand showing that the increase is due in small part to a direct effect of products formerl in

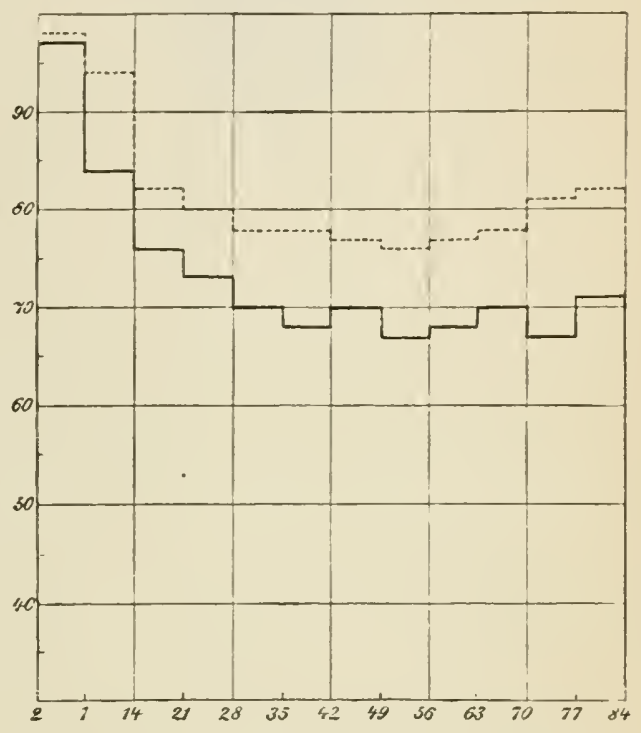

Fig. 71.- The pulse rate in man at different ages, after (iuy. ___ males; ............, females. the muscular activity on the heart itself. but in ly far the greater part to the fact that along with the voluntary impulses from the higher brain centers to the muscles there go also involuntary impulses to the carliac centers. wherely the tonns of the inhibitory center is diminished or the accelerator center is excited (Johanson; (f. page 19:5).

ligure il shows how the pulse rate raries with age. In the first rear it is highest: it then falls to a minimum of about seventy per minute near the twentieth rear (for male-). where it remains until the approach of old age. when it again rises somewhat.

The higher pulse rate in children is due in part to the smaller size of the body. just as we find in grown animals of different species that the large onehave a slow pulee. the small ones a rapid pulse (e. g.. horse and ox 36 to 50 . rabhit ?on per minute). 'This difference is without doubt connected with the relatively more active metabolism of small and young indiriduals (cf.

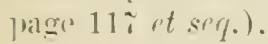

Figure it also furnishes information with regard to the influence of sex. The pulse frequency for all ages above two years is lugher in the female than in the male. The smaller size of the female hody is the most important factor in this ditterence. One finds on comparison of the pulse rate in men and women of the same height that it is somewhat higher in the latter. lut the 
difference is much less than when male and female individuals of the same age. without regard to size, are compared.

Again we meet with considerable variation of pulse rate in different indiriduals. a very low ( $26-20$ per minute) and a very high rate (120 per minutc) liaving been observed in men of perfectly sound health.

\section{THIRD SECTION}

\section{THE BLOOD FLOW}

\section{\$ 1. THE FLOW OF A LIQUID IN RIGID TUBES}

If a reservoir be so arranged as to deliver a liquid through a tube of uniform diameter as represented in Fig. 72 . the mean velocity of the flow will be the same in every cross section of the tube. This follows from the fact that fluids are not compressible. Moreover, the internal friction of the fluid creates a resistance which causes it to flow more slowly than it would if it were pouring directly from an opening in the reservoir; and in eonsequence of this friction the liquid in the tube is subjected to a tension, which, howerer, is smaller than it would be if the flow from the end of the tube were hindered in some way. This tension manifests itself as a lateral pressure which can be measured by means of rertical tubes leading off at intervals along the delivery tube. If the highest points of the columns of liquid be comnected with each other, a straight line is obtained-i. e., the lateral pressure decreases miformly in the direction of the current, to the end, whore it is nil. The lateral pressure at any given point along the delirery tube is equal to that part of the whole pressure which

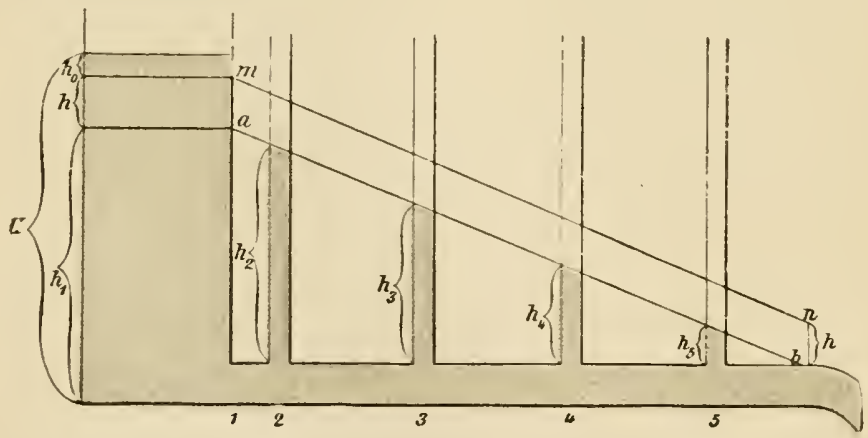

FIG. 72.- The flow of a liquid through a rigid tube of uniform diameter.

is necessary to overeome the resistance of the current from that point onward.

If the system through which the liquid flows consist of a number of tubes of different diameter fastened together, as in Fig. 73, the same fundamental laws hold good. Because the liquid is not compressible the same quantity must flow through every cross section of the tube, whatever its size, in unit time. Consequently the relocity in the different sections of the tube stands in inverse relation to their cross section. The lateral pressure within the different sections falls at different rates-most rapidly in the narrowest, most slowly in the widest. In sections of the same diameter, whether they are separated by narrow or wide 
portions, the fall in pressure is the same, for the relocity and hence the internal friction also, are the same in these.

When a main-delivery tube is divided up into a number of small branches, whose total cross section area is greater than that of the stem tube, and these branches then reunite into a single tube of smaller cross section than the branches, so as to imitate roughly the relationships of arteries, capillaries and

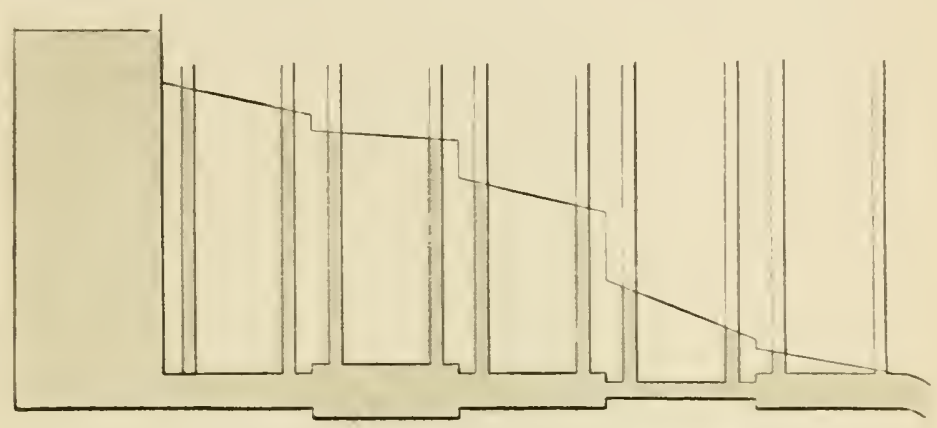

FIG. 73. - The flow of a liquid through a rigid tube of varying diameter.

veins, the same quantity of liquid will flow through every total cross section of the system in unit time, and the relocity again will be inversely proportional to the total cross section area. In such an enlargement of the total cross section by branching the superficial contact between the liquid and the walls of the tubes becomes greater as the diameter of the branches becomes smaller, and the resistance therefore also becomes greater. Now increased resistance acts against the farrorable influence which the mere widening of a current bel produces. Consequently the effect on the How of the current produced by any particular branching of the bed will be the resultant of these two opposing factors.

\section{\& 2. THE FLOW OF A LIQUID IN ELASTIC TUBES}

The laws which apply to a constant current in rigid tubes holds also for tubes with elastic walls. But an important difference exists between rigil and elastic tubes, when the fluid is driven into them intermittently. We leare out of account here for the present wavelike movements in elastic tubes.

If a fluid be pumped rhythmically into one end of a rigid tube, it will fiow out of the other end in jets of the same rhythm. But if we use an elastic tube for such an experiment, and if the resistance in the tube is sufficient and the rate of inflow rapisl enough, the outflow may become continuous. This conversion of an intermittent to a constant flow is explained by the fact that the elastic wall of the tube is put on the stretch br the injecting force so that a part of the energy is stored in the wall. Then when the inflow ceases for a moment, the stretched wall exerts pressure on the contained fluid in consequence of which the latter flows during the pause between jets.

These conditions are realized in the vascular system. The bland is driven by the heart into the arteries in spurts: the arterial walls are elastic; the smaller arteries and capillaries present a high resistance. Consequently the arterial wall is stretched by the blood at every systole of the heart, and dur- 
ine diastole the elastic recoil of the wall drives the blood forward into the capillaries where its flow becones constant.

The elasticity of the arteries spares the heart a considerable quantity of work. If they were rigid tubes. it would be necessary for the heart to drive the entire quantity of blood contained in them forward at once. But since they are elastie. the volume of blood discharged at each systole is accommolated by the temporary enlargement of the larger arteries and is then

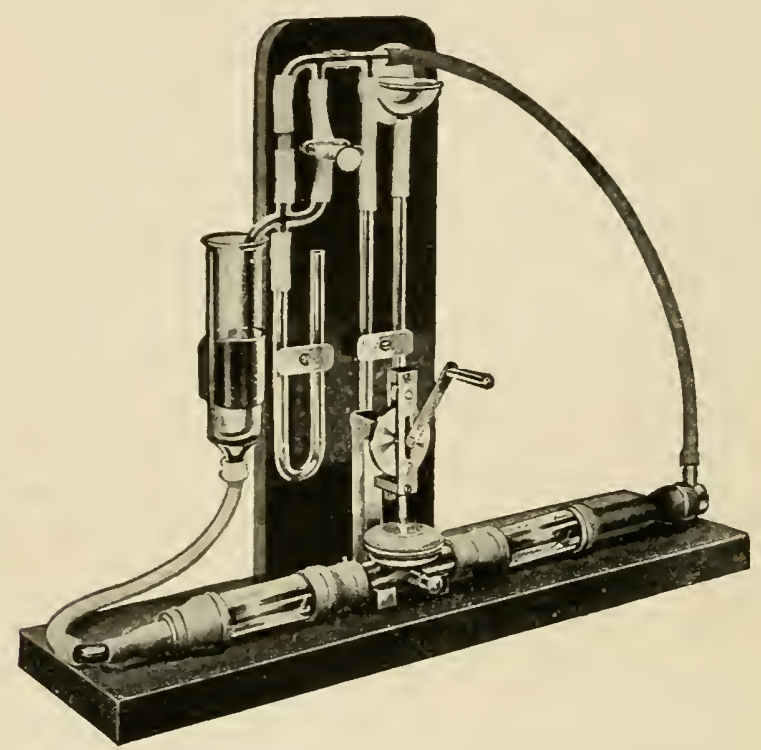

FIG. 74.-An artificial schema for illustration of some points in the mechanics of the circulation, after Porter. The schema consists of an "auricle" in the shape of a small cylindrical reservoir, shown at the left; a "ventricle" in the shape of a small rubber pump, the pressure within which is raried by means of a piston operated through an eccentric wheel which is rotated by a crank: a valve between the auricle and ventricle representing the atrio-ventricular valves; another beyond the ventricle representing the semilunar valves; tubes representing blood ressels; a set of "capillaries" in the shape of a section of porous cane where the "peripheral resistance" is high, and a side tube provided with a clamp by which the peripheral resistance can be lowered; and mercury manometers which exhibit the relative arterial and venous pressures.

driven forward by the force stored in their walls, so that only a part of the column must be mored at the time of systole (E. H. Weber).

The rhythmical feeding of the ressels has still another adrantage. The blond corpuscles are given a kind of to-and-fro motion. which, as experiment has shown. materially facilitates the flow through the eapillaries (Hamel).

\section{THE FLOW OF BLOOD IN THE ARTERIES}

\section{A. ELASTICITY OF THE ARTERIAL WALL}

If a strip) cut from an artery be stretched by adding to its load equal increments of weight, the amount of lengthening produced by each successive 
weight becomes steadily less the greater the total loal. The coefficient of elasticity of the arterial wall therefore increases as the stretehing force increases. so that the curve of elongation resembles an hyperbola (Wertheim).

As to the rate of cubic distention of the arteries caused by increasing internal pressures, which is a matter of much greater importance for understanding the circulation, the results of investigators differ widely. While Marey and others have found that the cubic enlargement runs the same course as the elongation of the strip cut from the wall. Roy asserts that this is the case only in arteries taken from animals and men who have suffered from some wasting disease, and finds that with perfectly sound arteries the increase in volume with equal inerements of internal pressure rises at first up to a certain limit (variously given for the dog from 32.2 to $120 \mathrm{~mm}$. $1 \mathrm{Igr}$.). but with still higher internal pressure the distensibility falls (Fig. i5).

At any rate, it is certain that the cubie enlargement of the arteries beyond that given by a certain internal pressure. which as a rule is not higher than a medimm, normal l, lood pressure, beeomes less and less with equal inerements of pressure. From which it follows that when the arterial blood pressure

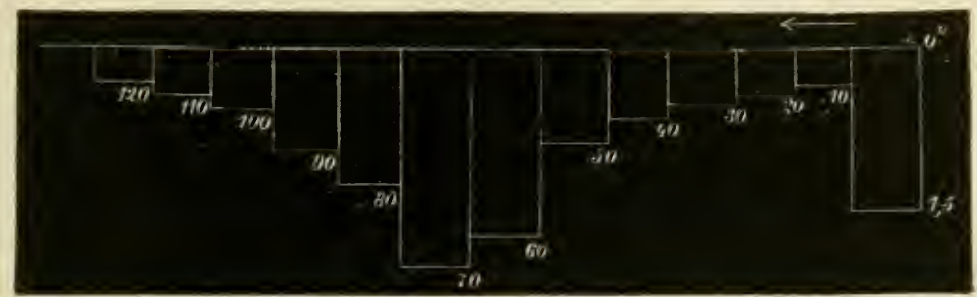

Fif: 75.-The cubic cnlargement of the aorta of a rabbit, under a uniformly increasing internal pressure, after Roy.

is already high. any stealy increase in the quantity of blond discharge from the heart will canse a more than proportionate rise in the blood pressure and will correspondingly increase the work of the heart.

Fron results thus far at hand it appears that with any given increase in pressure the arteries are distended relatively more the farther they are situated from the heart.

In the body arteries as well as veins are always on the streteh longitudinally, whatever the internal pressure; for the moment they are eut out of the body they at once retract, becoming shorter and thicker. It is always possible to find a stretehing foree which will give an exsected ressel the dimensions it would have if it were completety fixed in situ. when empty. This stretehing force explrensed as pressure in millimeters of $\mathrm{Ig}$ is looked upon by R. Fuehs as the measure of the longitudinal tension when there is no internal pressure; it amounts to from 50 to $90 \mathrm{~mm}$. Hg. in the thoraeie aorta of the dog, and is therefore below the mean blood pressure.

The elastirity of the arteries is perfect-i. e., if they be subjected to a high internal pressure, and the execssive pressure be then removed, they immediately return to the original volume.

Furthermore, the resistones of the arteries to high pressure is exeeedingly great. The internal pressure necessary to rupture the earotid of the dog is four 
to eleven atmospheres, the earotid of man seven to eiglit atmospheres (mean). Sinee the maximum normal blood pressure in the earotid may be estimated at one-quarter atmosphere, we see that arteries ean be ruptured only by a pressure twenty-eight to thirty-two times the normal. The resistance of the smaller arteries is still greater. This means that arteries ean never be ruptured by excessive blood pressure, unless they have first been abnormally weakened (Hales, Gréhant and Quinquaud).

\section{B. METHODS FOR THE DETERMINATION OF BLOOD PRESSURE}

The mercury manometer is eommonly used in letermining arterial blood pressure, because it gives directly the absolute value of the pressure without any calculation. The elastic manometer also (page 9) finds wide applieation where it is desired to follow exactly the variations of pressure aceompanying individual heart beats.

The $\mathrm{Hg}$-manometer is not adapted for following rapid variations of pressure because of the inertia of the $\mathrm{Hg}$ column, which causes the maxima and minima corresponding to systole and diastole to be incorrectly reproduced. With a slow rhythm the maxima are too high, the minima too low; while with a quicker rhythm the maxima are too low, the minima too high.

But a tolerably satisfactory value of the mean pressure for a giren time can be obtained by means of the Hg-manometer in the following way (r. Kries): In the figure given on page 8 the smaller oscillations on the eurve represent individual heart beats, the larger represent pressure variations eaused by the respiratory movements; the line $a b$ is the line of no pressure, and the line $\mathrm{T}$ gives the time in seconds. When the mercury mores up the free limb of the manometer, it naturally falls just as much in the other limb (Fig. 3). If we negleet the error due to inertia of the $\mathrm{Hg}$. column, the blood pressure at any instant is therefore twice the distance of the curve from the line of no pressure. Hence, in order to determine the mean blood pressure-e.g., during the period $a$ to $b$, vertical lines are drawn from $a$ and $b$ to the eurve, then the surface $a b d c$, is measured in square millimeters and is divided by the line $a b$. The quotient is the height of a rectangle of the same surface as $a b d c$, and with a base $a b$. This height doubled is the mean pressure in millimeters of mercury.

If the pressure curve presents no very great variations but runs along with perfectly regular oseillations as in Fig. 8 the mean pressure ean be determined by simply measuring the highest and lowest points during the period, and doubling the mean of these two.

The mode of connection of the cannula with the artery must be borne in mind in interpreting the pressure obtained. If a T-eamnula be used, and the unpaired limb be connected with a manometer, so that the current in the artery is not interrupted, the manometer records the lateral pressure of the blood in this particular artery at the place where the cannula is inserted. But as a rule it is more convenient to make the eannula terminal to the central end of the artery, so that the manometer records the lateral pressure of the larger artery of which the one used is a branch. Thus a cannula in the central end of the earotid gives the lateral pressure of the blood in the aorta.

Several methods, which proceed upon the prineiple of finding the pressure necessary to stop the blood flow in the artery investigated. have been devised for determining the blood pressure in man.

The sphygmomanometer of $\mathrm{v}$. Basch consists of a button or plunger, bound to a metal manometer by means of a rubber tube. The button is placed orer some superficial artery (preferably one that is supported on a solid substratum- 
e. g., the radial), and pressure is applied until no pulse ean be felt by the finger placed peripherally to the instrument. The pressure which the manometer now shows is the desired value. This instrument appears to be ineapable of giving an absolute value of sufficient accuracy, although it has proved admirably fitted

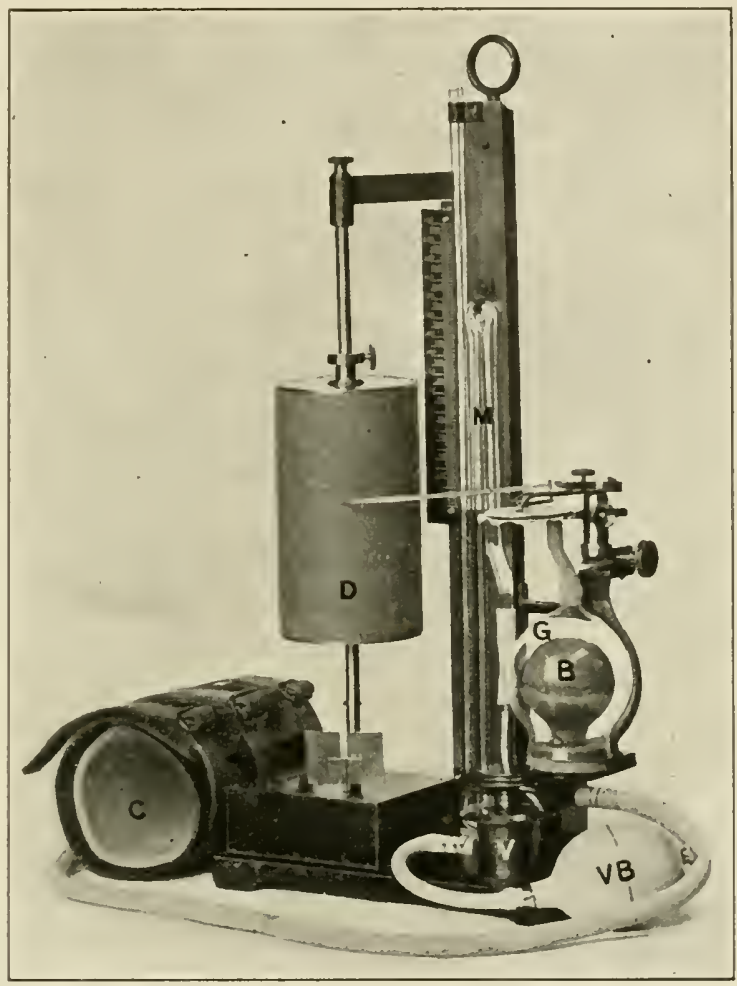

FIg. 76.-Frlanger's apparatus for cletermination of the blood pressure in man. The apparatus is providel with a pneumatic cuff, $C$, whieh eonsists of an inside rubber bag and an outside leather band. The whole euff ean be buckled around the arm above the elbow. The air cavity within the rubber log of the euff communicates through a thick-walled rubber tube and a four-way connection, ${ }^{2}=$ with the three other essential parts of the apparatus, namcly: (1) dounuard, with the valved bulb, $V B$, by means of which air ean be forcel into the cuff and ean thus be macle to eompress the arm; (2) to the lcft, with the mercury manometer, $H$, from which the amount of pressure applied to the arm ean be read directly in $\mathrm{mm}$ of $H y$ : and (3) upuard, with the clistensible bag, $B$, insirle the glass chamber, $r$. This hag, last mentionel, responds to fluetuations of pressure insirle the rubber bag of the arm, which are due to vibrations of the arterial wall, and the tambour at the top records sueh vibrations on the drum, $D$.

for the determination of rariations in pressure in the same person, provided neitler too little nor too much time is eorered by such valiations.

Other authors compress a section of a whole limb by means of a suitably constructed pneumatic cuff, and measure the pressure inside the euff at which the pulse in some distal artery disappear's or reappears. As II, v, Reeklinghausen has shown, one must choose for this purpose a cuff of considerable breadth, for otherwise a portion of the pressure is eonsumed by the neighboring soft parts and one obtains too high a value. The broader the cuff, the more is this disad- 
vantage obviated. With a breadth of about $15 \mathrm{~cm}$. v. Reeklinghausen observed in eight trials a variation of only $3 \mathrm{~mm}$. $\mathrm{Hg}$. in the blood pressure determined in the brachial and the femoral arteries at the same time. (In animal experiments the pressure in these two is in general found to be the same.) Such a method therefore gives very satisfactory results, as it is also much more easily manipulated than other methods thus far devised for this purpose.

[With Erlanger's apparatus ( Fig. 76) it is possible also to determine the maximum systolic and minimum diastolie pressures. To determine the former the arm is compressed until no pulse can be felt in the radial artery. Even at this time the tambour of the instrument shows vibrations due to pulsations in the central stump of the artery; but if the air pressure on the arm be now lowered gradually by means of an escape valve ( $\mathrm{V}$ in the Figure) these vibrations will suddenly become larger. The pressure which the manometer shows when this takes place is the pressure which the pulse wave can just overeome and is, therefore, the maximum systolic pressure. If the pressure be lowered still further the vibrations shown by the lever of the tambour will become still larger until a point is reached at which they begin to decrease. The pressure at which the arterial wall makes the widest fluctuations. and the lever therefore its largest ribrations, is the minimum diastotic pressure.-Ev.]

\section{HEIGHT OF THE BLOOD PRESSURE}

Since the normal blood pressure in the antre of different mammals shows but relatively slight differences, we ean form an approximate picture of the blood pressure in man from the numerous determinations made dirertly upon difierent speeies of animals. The normal pressure in the dog is $130-180$ $\mathrm{mm}$. Hg., in the rabbit $80-120$, in the horse $150-200$. We may say, therefore, that the mean normal blood pressure in man varies between 100 and 200 mm. Hg., and if we wish to use a single figure we may assume that 150 $\mathrm{mm}$. is the most probable value.

We are not, however, to regard the blond pressure as constant; on the contrary very considerable variations make their appearance on slight provocation. We have, therefore, to study the factors upon which the blood pressure depends.

These are essentially three: the energy of the heart, the resistanee in the arteries, and the total volume of the blood.

1. The Energy of the IIeart.-The quantity of blood which the heart expels in a given time may be taken as a measure of its energy. If, other things being equal, the quantity expelled in a given time decreases. the blood pressure falls as is the ease for example upon stimulation of the ragus (Figs. 7 -79. If, on the other hand, the decrease in pulse rate is only slight, and is compensated by a larger pulse volume (cf. page 189), the mean blood pressure falls only a little or not at all (Fig. $\%$ ).

The quantity of blood expelled from the heart may decrease also without a fall in the frequency of heart beats (ef. page 188), in which ease of course the blood pressure falls.

On the nther hand the energy of the heart may increase without any change in frequency of the pulse (cf. page 192), and a rise in pressure results.

When the heart is accelerated by division of both vagi, or by stimulation of the accelerator nerves, it may or may not expel more blood in a given 
time. If it does, the blood pressure inereases (supposing that the caliber of the vessels has not changed); if not, the pressure remains the same. For a quicker rate does not necessarily imply greater energy of the heart beat, and so does not of neeessity produce a greater output. Now it is evident that unless the total output in a unit time is inereased, the quantity of blood coming back to the heart between two systoles is less with a rapid pulse than with a slow one. or, in other words, the pulse rolume is less. Hence, the blood pressure following acceleration will depend upon the reeiprocal relation between the increase of pulse rate and the decrease of pulse rolume.

Dircet investigations of this subject have resulted in showing that no general law ean be formulated. If a large quantity of blood is found in the

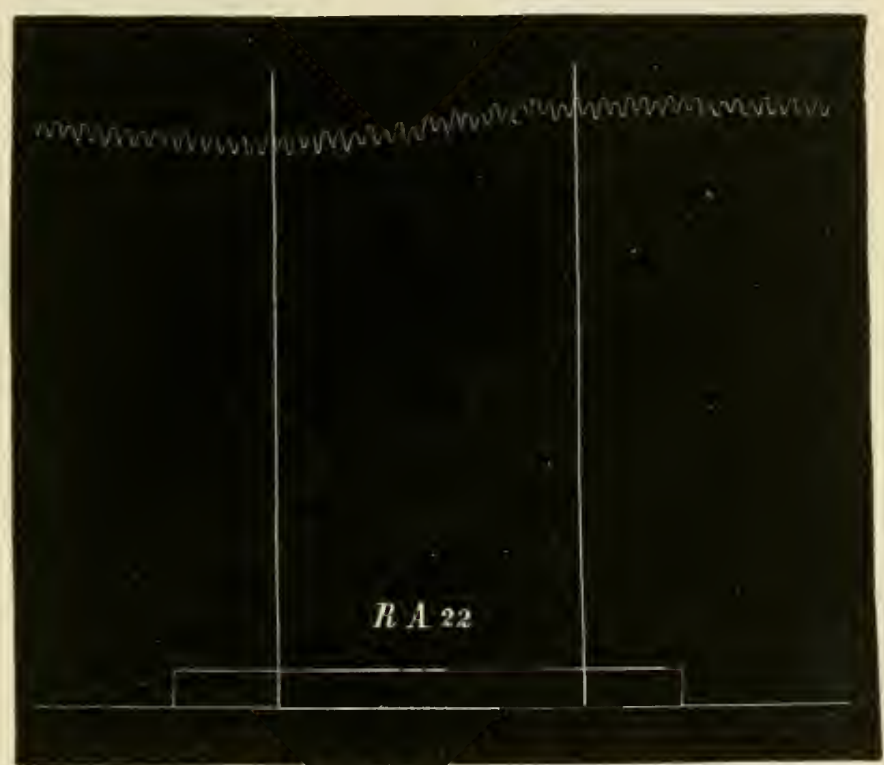

Fig. 77.-Blood pressure curve, showing a slight fall under feeble stimulation of the vagus. To be read from right to left. The time of stimulation is indicated by the two vertical lines. $\rceil=$ ten seconds.

great veins, and is only waiting an opportunity to get into the heart, and if the resistanee in the arterial srstem is suffieiently high, acceleration may produce a considerable inerease in blood pressure. If these conditions are not fulfilled, the increased frequeney will oceasion no rise in pressure worth mentioning.

2. Resistance in the Arteries.-It is evident that with a given heart energy, if the resistance in the vesscls decreases. the pressure also must deerease. If the resistance increases the pressure also must increase.

A fall in pressure in consequence of diminished resistance occurs, if the ressels in a large vascular region lose their tomus. Not only the arteries, but the reins as well are to be eonsidered as taking a part in this; for the latter possess a certain tonus with the disappearance of whieh they are considerably dilated and so can contain more blood than usual. Hence the blood 
stagnates in the veins, and its flow to the heart is lessened considerably. The fall in blood pressure, therefore, is oceasioned not only by the diminished resistance but also by the deficient flow to the heart.

The resistance in the ressels is increased either by constriction in a large vascular area, or by compresion of a large arterial stem. for example the

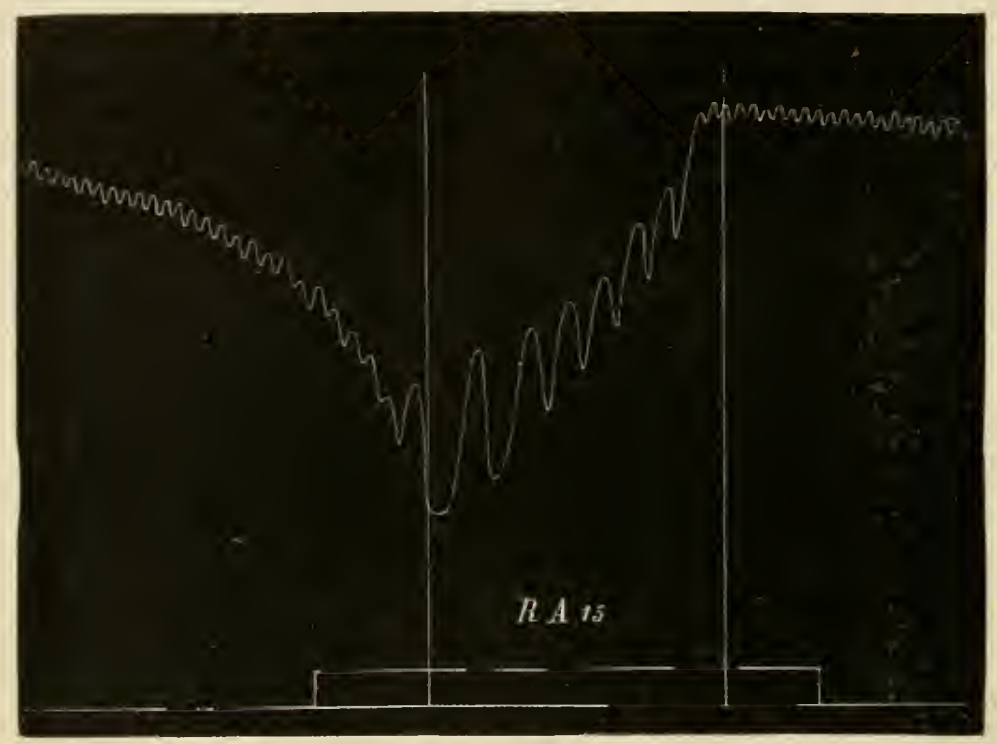

FIg. 78.-Blood pressure curve, showing a pronounced fall due to slowing of the heart, as the result of ragus stimulation of medium intensity. To be read from right to left. The time of stimulation is indicated by the two vertical lines. $\square-\square=$ ten seconds.

abdominal aorta. In the first case the blood flow to the heart is at the same time angmented, since the blood contained in the ressels is driven forward by their contraction. It is possible therefore that a larger quantity of blood will be expelled by the heart under these circumstances.

It might be supposed that by compression of the vessels the pressure conld be forced up indefinitely. But this is not the case. The reflex mediated by the depresior nerve comes into play, so that either the vessels are dilated or the heart beats are retarded. But eren if this reflex fails. there is an upper limit to the blood pressure beyond which it cannot p.ss. The artivity of the heart is not unlimited, and we have good reason, based on many observations. for asserting that with a high resistance in the ressels the quantity of blood cxpelled in a given time aetually diminishes.

3. Quantity of Blood.-Investigations on the influence of the blood rolume go to show that when the ressels are overfilled the blood pressure does not exceed the normal phrsiological limits, and that when the ressels contain less than the normal quantity mechanisms are at hand for the purpose of maintaining the blood pressure at its normal height.

In what follows we shall consider first the results of adding to the normal quantity of fluid in the ressels. Let us suppose that blood or some other harm- 
less fluid is transfused into the veins of an animal. The transfused fluid does not all go to the heart at once; a considerable part of it remains in the central veins, which thus become overfilled; and in the liver, which after the transfusion of a large quantity may become almost as hard as a board.

Furthermore, the entire quantity of transfused fluid does not remain in the vascular system, for the vessels relieve themselves by transudation. The nature of the Huid has much to do with the amount transuded. By means of blood counts it has been found, for example, that after transfusion of blood, about half the quantity transfused remains in the ressels at the end of the first day; while if distilled water is used in transfusion the blood quickly recovers its normal eonstitution (Worm-Miiller, Regéezy).

Along with transudation the secretory activity of the glands increases and this coöperates to diminish the quantity of fluid in the ressels. Particularly is this true of the mueous membrane of the intestine and of the kidners. If a $\mathrm{NaCl}$ solution be transfused not too rapidly into a vein, after some time transfusion and secretion of urine exactly balance each other (Dastre and Loye).

Thus by transudation and secretion the quantity of fluid is gradually brought back to the normal. But this takes place as a rule rather slowly, and other factors meantime must step in to regulate the blood pressure. One such factor is rasodilation, by means of which the resistance in the vessels is lowered (WormMiiller). Another is the activity of the heart. If transfusion be performed

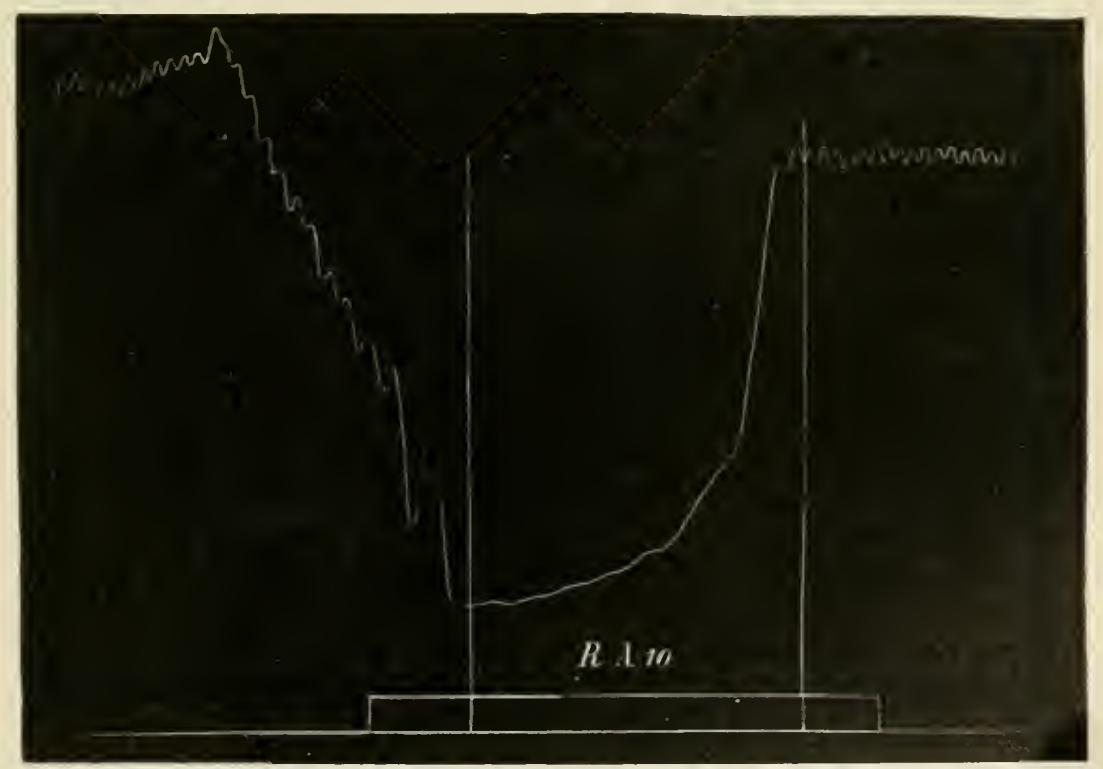

Fig. 79.- Blood prissure curve, showing a sudden fall due to stoppage of the heart, as the result of strong stimulation of the vagus. The time of stimulation indicated by the two vertical lines. I $\longrightarrow$ - ten seconds.

slowly enomgh, the heart is ahle to throw a enrespondingly larger quantity of blood into the vessels and so to preserve the cardiac pressure within safe limits. But if the transfusion take place more rapidly, or if the total quantity transfused be very large, the heart may drive more blood into the ressels than before the transfusion but not enough to prevent stasis of blood in the heart. Finally, 
the quantity transfused becomes so great that sooner or later the demands upon the heart are excessive, and the artrial blood pressure falls in spite of the abnomally large quantity of fluid in the ressels. One sometimes meets with cases where the lieart works powerfully cnough during the transfusion to overcome the increased quantity of blood, but later in the course of the experiment, after transfusion has ceased, symptoms of acute fatigue suddenly appear. In such eases the heart may be relieved and death averted by withdrawing a sufficient quantity of blood from the ressels.

We have in the circumstances mentioned above the explanation of heart weakncss whieh sometimes follows ingestion of very large quantities of fluid by way of the stomach.

The reverse processes take place in bloodletting. The heart empties itself as completely as possible and drives the greatest possible quantity of blood into the ressels; the ressels contract and thereby present a high resistance to the blood stream; the kidneys, salivary glands and probably all the other glands diminish their secretions, and there oceurs an increased passage of fluid from the lymph to the blood ressels.

$\mathrm{By}$ the coopperation of these factors the blood pressure under normal circumstances raries in general wilhin rether norrom limits, notwithstanding the many influences which tend to change it in hoth directions. And ret, in order to produce significant rariations in the pressure artificially it is often necessary to use only rery weak stimulation. In fact, the stimulus may be so slight that at times one is wholly at a loss to make ont the cause of the sudden increase or decrease in pressure which results. More on this subject will be found under the discussion of rasomotor nerves.

By means of an instrument constructed on the prineiple of the Basch Sphygmomanometer and applied to the radial artery of man, the blood pressure in the sitting or reclining position was found by Hill and Barnard to be 100$108 \mathrm{~mm}$. Hg. It rose to 120,130 or $140 \mathrm{~mm}$. under various influences such as bodily movements, but sank again very rapidly toward the valuc for rest when the movements ceased. The blood pressure is raised also by a cold bath, but is depressed by a warm one (Edgeeombe and Bain).

Blood pressure in the large arteries is not much higher than in those of smaller caliber. and decreases only slightly therefore with the distance from the heart. Especially is this true of diastolic pressure, whereas differences of systolic ${ }^{1}$ pressure are greater. The canse of this slow fall in pressure in the arterial system is purely hydrodynamic in nature. The resistance against which the blond pushes in the larger arteries is small in comparison with that to which it is subjected in the smallest. The consequence is that the

$\left[{ }^{1}\right.$ From numerous comparative observations made on dogs, I)awson concludes that " in coinsidering variations in the systolic pressure, it is absolutely essential to distinguish between end pressures obtained from the branches of the main arterial trunk and those obtained from the main trunk itself. In the former case the systolic pressure shows a steady and considerable falling off which becomes apparent in end pressures taken, for example, in the thyroid arteries, in branches arising from the axillary and in branches from the lower part of the aortico-femoral trunk. When, however, the systolic end pressure is taken in the main arterial trunk, it is found that this pressure either remains high (axillary and brachial) or may even greatly exceed the corresponding lateral pressures in the aorta (iliac and femoral)."-ED.] 
driving power is not consumed rapidly until the smallest arteries are reached, and hence the fall in pressure in the large and medium sized arteries is only relatively small (ef. page 2:2:).

\section{VELOCITY OF THE BLOOD IN THE ARTERIES}

There are two ways of determining the velocity of the blood in the arteries, according as one wishes to obtain the mean velocity in unit time, or the variations in speed which take place during a single heart beat.

The velocity can only be determined by plaeing the neeessary apparatus directly in the path of the blond without interrupting its flow. Several forms

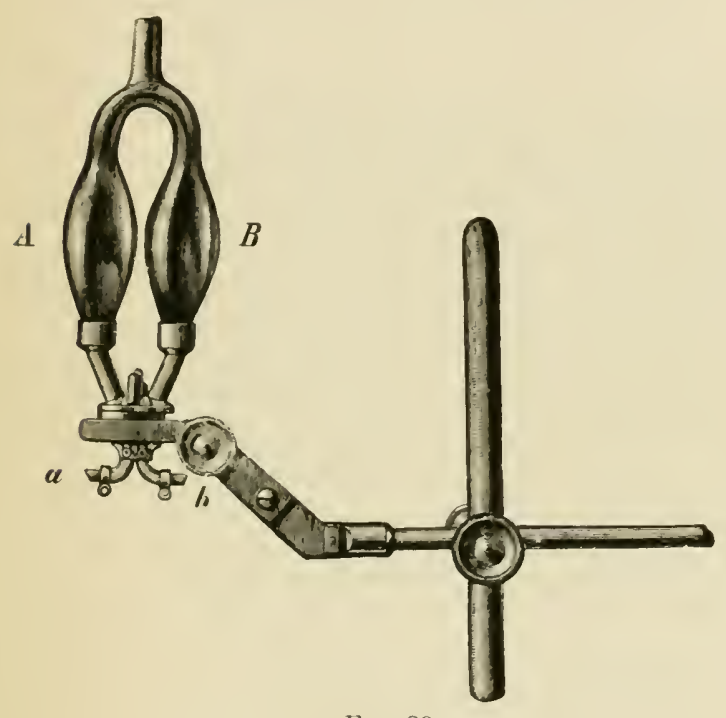

FIG. 80.

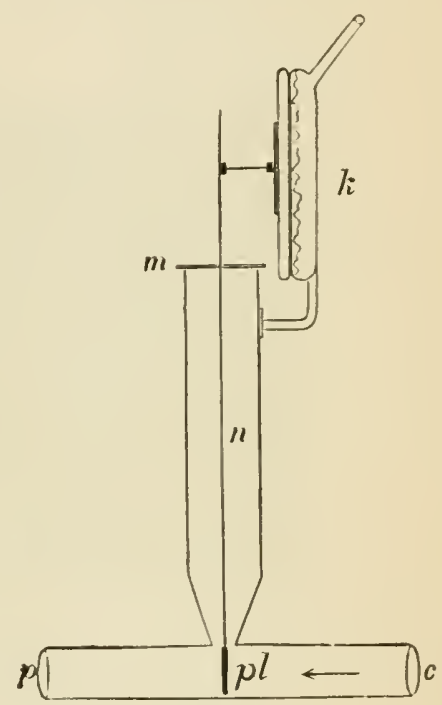

FIG. 81 .

Fig. S0.-Ludwig's Stromuhr or "current clock."

Fig. 81.-Chauvenu's hamadromograph with air transmission. $n$, the needle; pl, small plate on the pendulum; $k$, a tambour influenced by the strokes of the pendulum. The blood flows in the direction of the arrow. $m$, a hard-rubber membrane which serves as a lid for the vertical tube and as a fulcrum for the pendulum.

of apparatus have been constructed for this purpose, the best known of which is Ludwig's Stromulh or "current clock" (Fig. S0). It consists of two glass lualbs of equal size $(A, B)$ which communicate directly with each other by means of the U-shaped tube above. By means of the opening at the top oil is placed in one bulb, $A$, and salt solution in the other, $B$, and the opening is then closed. The two fluids are in enntact with each other above. The tube $A$ is now eonnerted with the central end and the tube $B$ with the peripheral end of an artery. When the arteries are unclamped the blood flows into $A$ and drives the contained oil over into $B$, the salt solution meantime being foreed into the peripheral end of the artery. When the blood has completely filled the bulb $A$, the two bulbs are reversed, so that the blond flows now into $B$. displaeing the oil onee more and driving the blond from $A$ into the peripheral end of the artery. The capacity of the bulbs being known, by counting the number of reversals necessary one 
ean ealeulate the volume of blood which Hows through the artery in a certain time. Registering eurrent clocks have been devised by Ludwig and II iirthle.

In order to determine the variations of speed accompanying a single heart beat. Vierordt employed a hydrometrie pendulum. If a pendulum be hung in a eurrent of fluid, the length of its swing will depend on the linear velocity of the eurrent, and on a small seale it will reproduce correctly all the variations of speed. Chaureau conneeted this pendulum with a writing tambour and by this mons registered direetly the variations in speed, and after graduating the instrument, determined their absolute values (Fig. 81).

The following results may be mentioned. The amount of blood expelled per second by the left heart of a rabbit (of $1.59 \mathrm{~kg}$. body weight) into the aorta $\mathrm{is}$ on the average 1.35 c.c. The extremes in al series of fourteen experiments were 0.91 and 3.26 c.e., the mean was 2.10 c.c. 'The mean linear relocity,

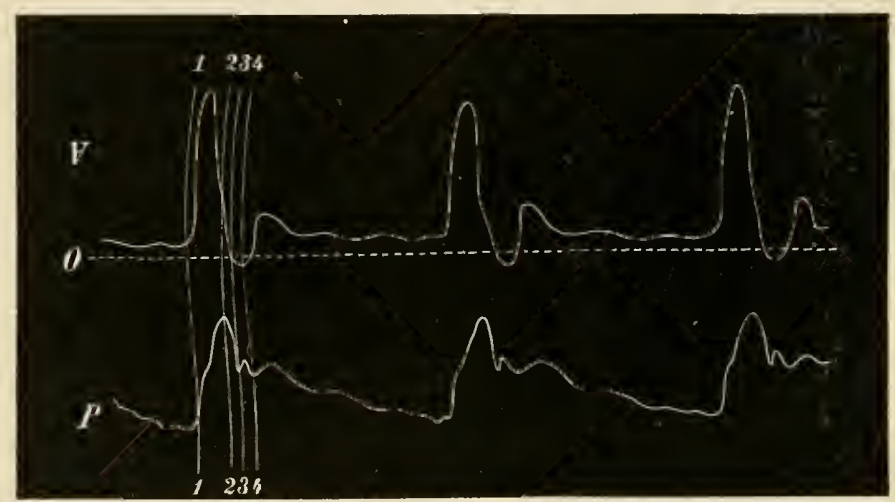

Fig. 82.-Velocity curve $V$ and pressure curve $P$, carotid of the horse, after Lortet. The lines $1,2,3,4$ give the corresponding points on the two curves. At 1 the blood is forced into the aorta; between 3 and 4 the semilunar valves are closed.

calculated from the diameter of the cannula tied into the aorta was $128 \mathrm{~mm}$. per second (extremes $9: 2$ and $340 \mathrm{~mm}$.).

During systole it is evident that the velocity is greater than during diastole (cf. Fig. 82). In the carotid of the horse Lortet found $520 \mathrm{~mm}$. per second in systole and $150 \mathrm{~mm}$. per second in diastole. At the end of diastole the velocity in the peripheral arteries is greater than in the central: while at the begiuning of systole it increases considerably in the central and only slightly in the peripheral.

In dogs with a mean body weight of about $14 \mathrm{~kg}$. Tschuewsky found for the velocity in the carotid and crural arteries the values summarized in the following table:

\begin{tabular}{|c|c|c|c|c|c|c|}
\hline Body wt. & Artery. & $\begin{array}{l}\text { Yol. per } \\
\text { second. }\end{array}$ & $\begin{array}{l}\text { Lin. Veloc. } \\
\text { per second. }\end{array}$ & $\begin{array}{l}\text { Diam. of } \\
\text { artery. }\end{array}$ & $\begin{array}{l}\text { Blood } \\
\text { pressure. }\end{array}$ & Remarks. \\
\hline $\begin{array}{l}13.7 \mathrm{~kg} . \\
14.6 \text { " } \\
14.1 \%\end{array}$ & $\begin{array}{l}\text { Crural. } \\
\text { Crural. } \\
\text { Carotil. }\end{array}$ & $\begin{array}{l}0.63 \text { с } е \\
1.69 \quad \cdots \\
1.95 \quad \cdots\end{array}$ & $\begin{array}{l}128 \mathrm{~mm} . \\
275 \quad \cdots \\
241 \quad \cdots\end{array}$ & $\begin{array}{l}2.5 \mathrm{~mm} . \\
2.8 \quad . \\
3.3 \quad .\end{array}$ & 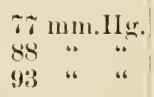 & $\begin{array}{l}\text { Nerves uninj. } \\
\text { Nerves cut. } \\
\text { Nerves uninj. }\end{array}$ \\
\hline
\end{tabular}


Thus the velocity is seen to increase considerably after section of the nerres controlling the arteries, and to be considerably greater in the carotid than in the crural. One cannot therefore draw conclusions as to the relocity in one artery from determinations made for another.

IThen one carotid is ligated the relocity in the other increases materially, as for example in two dogs of $13.2 \mathrm{~kg}$. mean body weight, on the arcrage from 2.63 c.c. and $266 \mathrm{~mm}$. per second to 3.4 i c.c. and $350 \mathrm{~mm}$. per second.

Likewise the relocity increases considerably after a temporary compression of the artery, as for example in the crural (dng 13.2 kg.) from 0.is3 c.c. and

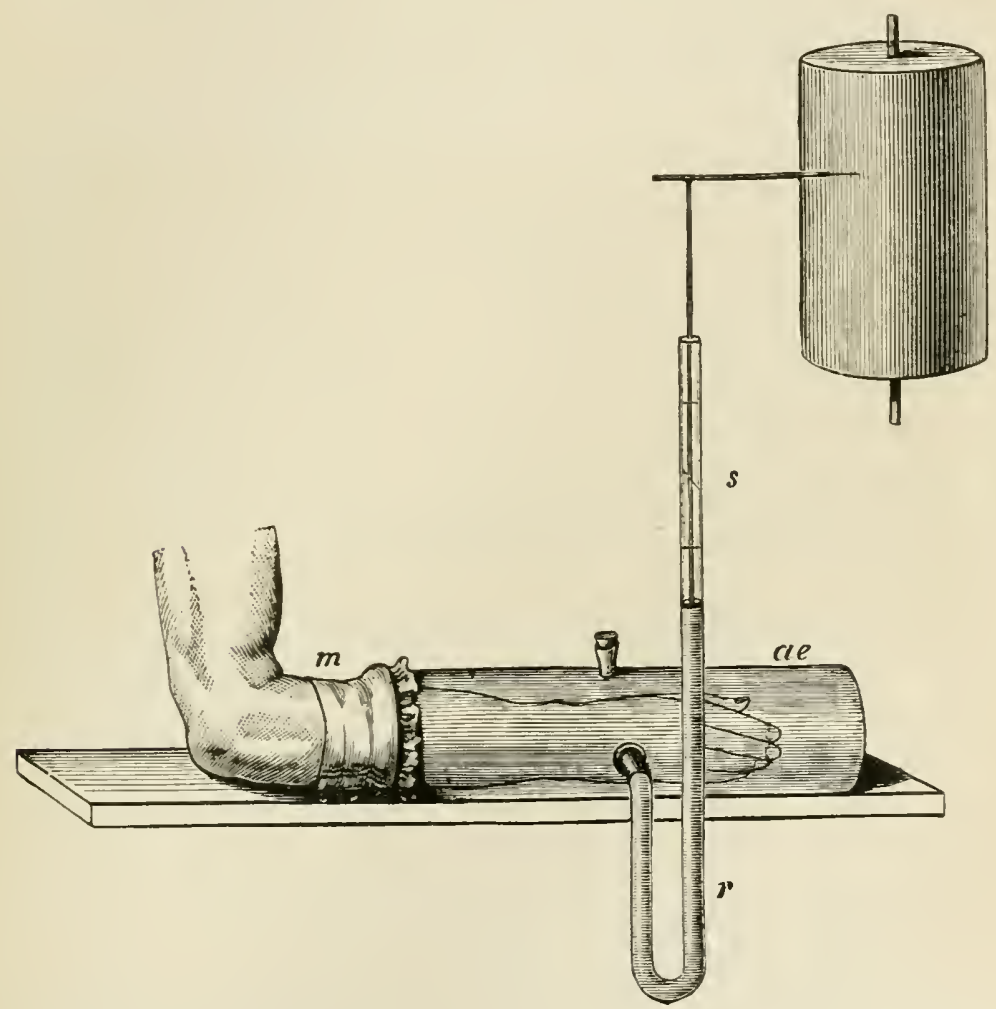

F1G. 83.-Plethysmograph, after Fick. $a$ e, the cylinder; $m$, rubber cuff by which the cylinder is made to fit air-tight over the arm; $r$, recording monometer.

$149 \mathrm{~mm}$. per second before compresion to 1.252 c.e. and $95.5 \mathrm{~mm}$, after. The presiure in lonth cases was $8 ? \mathrm{~mm}$. Hg.

On account of the dilatation taking place in the arterioles of an organ during its actirity, the velocity is increased ennsiderably in the arteries supplying it. Thus Chanvean observed that the relocity in the carotid during mastication rose to five or six times its usual hejght.

Finally. when the resects are dilated as a rewlt of section of the spinal corl. the velocity increases during systole, but is extremely small during diastole. 
In man the variations of velocity in the peripheral arteries can be cstimated. but no absolute ralue can be obtained.

To understand the principle of the method emploved, we must bear firmly in mind that the blood in the peripheral reins flows continuously, exhibiting as a rule no variation due to the heart beats or to the respiratory movements.

If a part of the body-for example, an arm-be placed in an air-tight crlinder the cavity of which is connected with a suitable recording device, a Marey tambour or manometer (plethysmograph, Fig. 83), a curve is traced in which the separate heart beats appear clearly marked. The variations thus recorded are caused by the variations in the volume of the arm, and the so-called plethysmographic curve (Fig. S4) is therefore a volumetric curve.

Since the return flow in the veins is constant, the variations are produced by fluctuations in the arterial flow. When the curve rises the arterial inflow is

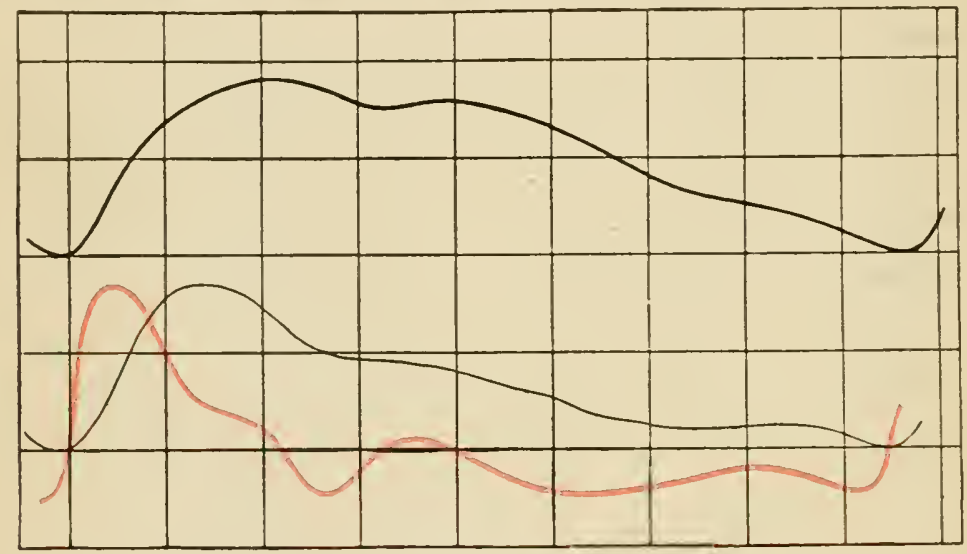

FIG. 84.-Plethysmographic curve (the upper black line). Pulse curve (the lower black line), and velocity curve (red) in man, after Fick. To be read from left to right.

greater than the renous outflow; when it sinks, the inflow is less than the outflow, and when the curve runs horizontally inflow and outflow balance each other.

It is clear however that the volume changes of the arm will follow more quickly the more rapid is the flow of blood to the arm. Thus if we estimate the steepness of the changes in different sections of the curre, we can construct a velocity curve from the volume curve (Fick). In Fig. $8 t$ the red line represents the velocity curve derived from the volume curve (the upper line). Its similarity to the curve recorded by means of the hydrometric pendulum. and pictured in Fig. 82, is unmistakable. In both we have, after a sharp rise, a fall, upon which follows an increase in velocity again. The latter coincides in time with the so-caller dicrotic wave of the pulse curve (cf. below).

\section{§4. THE ARTERIAL PULSE}

\section{A. THE MOVEMENT OF WAVES IN ELASTIC TUBES}

Imagine an elastic tube, filled and distended with water, to be divided by fixed lines into the segments $a, b, c, d, e, f, g, h, i$ (Fig. 85). The piston, we 
will suppose, has driven the water from the rigid tube $(k)$ into the distensible tube (ai), with a veloeity at first inereasing and then diminishing, and has thus dilated the tube, while the water contained in the different segments has been given a veloeity indieated by the number of dotterl arrows in each. If then the ring-shaped seetions of the wall inclosing the segments exert a pressure upon the eontained liquid, the amount of which is represented by the solid-line arrows, it is evident that the partieles of water contained in the segments $e, f, g, h$, will be accelerated in the direetion $i$ (since they were already moving in this direction). On the other hand the particles contained in the segments $d, c, b, a$ will be retarded in their movement, since the pressure indieated by the solid arrows is exerted in the direetion of $k$.

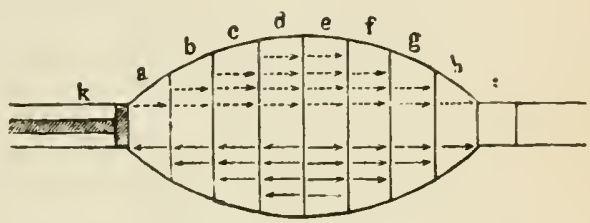

FIG. S5.-Schema illustrating F. H. Weber's theory of the pulse. For this reason the liquid in a comes to rest within the next few moments, and the distended wall of this segment returns to its original diameter. During the same time, the water in segment $i$, which until now had not been moved, is pushed forward and its wall is distended. Thus the wave is propagated from one segment to another in the direetion of the dotted arrows (E. H. Weber). The water presses upon the wall of the tube, the wall in turn presses upon the water, and the ware spreads with a velocity $(V)$, which is inversely proportional to the square root of the specifie gravity $(\Delta)$ of the liquil, and of the internal diameter of the tube $(d)$; direetly proportional to the square root of the wall's thickness $(a)$ and of its elastic eoefficient $(e)$ (Moens). The law is expressed by the following formula $V=k \sqrt{\frac{g e a}{\Delta l}}$ in which $k$ is a constant and $g$ is the acceleration of gravitation.

The wave is ehanged in form nore or less in its propagation through the tube by the resistance due to friction. Its height is less and its length greater than if there were no friction.

The moment an elastic tube, already filled with an incompressible liquid, receives an extra quantity, a uave of increased pressure is started, and is propagated along the tube. If the flow be maintained for a time, the pressure keeps a eertain level for each point along the tube, the value of which is determined by the sance laws that apply to the flow of a liquid in rigid tubes (ef. page 198).

If one end of an elastic tube filled and distended with water be surdenly relaxed by removal of a quantity of water, a fall in pressure is propagated in the form of a negative wave to the other end of the tube. Likewise if a regular current flowing through an open elastic tube be suddenly cheeked. a negative ware is set up which travels in the direction of the eurrent.

Besides, if the tube be not so long that waves thus set up entirely disappear, as the result of friction, new ones will arise by reflection from the end of the tube, which will materially affect the wave movements. If the end of the tube where the refleetion oceurs be closed. the wave will be reflected with the same sign, a positive wave as a new positive wave, a negatice wave as a new negative nne. If the end of the tube be open, the wave will be reflected with its sign reversed, a negative as a positive and a positive as a negative. The same wave may by repeated reflection rum the length of the tube several times. If the end of the tube be only partially elosed, every prinary positive wave will be transformed into a reflected one which is partly positive and partly negatire. 
Since both these reflected waves travel through the tube with the same relncity and naturally interfere with each other, it depends on the degree of constriction whether the algebraic sum of the two will be a positive or a negative wave, or will be nil (Grashey).

If from a simple tube $A$, a side branch $B$ be given off, every wave which runs through $A$ will traverse also the branch $B$; and, it matters not whether the wave arises in the wide or in the narrow tube, it will traverse both. This statement holds also for a complex system of tubes, and we may say in general that when a wave starts from any point of a branching system of vessels, it is propagated to all the branches.

Reflection takes place in such a system at every dividing place. But if the velocity witl which the waves are propagated changes at any point in the same proportion as the cross section changes, no reflection occurs (v. Kries).

All the conditions for the origin of primary and reflected waves and of interference are found in the arterial system. The difficulty consists only in isolating from among the theoretically possible movements, those which cause the peculiarities of the arterial pulse.

\section{B. THE PULSE}

The ancient phrsicians distinguished in the pulse a number of different qualities, which can be reduced to four: frequency, size, velocily and hardness.

With respect to frequencr, the rapidly repeated pulse (pulsus frequens) is to be distinguished from the less frequent (rarus). With respect to size we have the large (magmus) in which the expansion of the artery under the finger is large, and the small pulse (parrus) in which the expansion is small. With respect to relocity the quick pulse (celer) in which the artery presses against

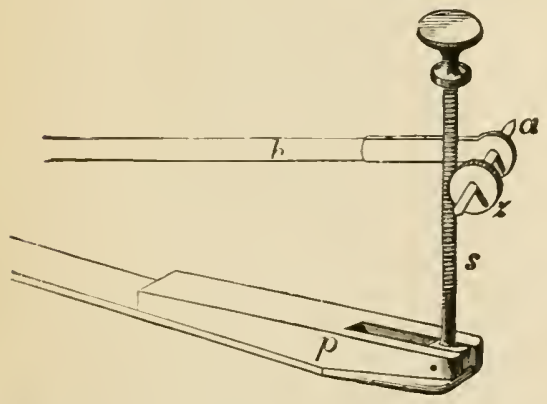

FIG. 86.-The spring of Marey's sphygmograph. the finger suddenly and disappears suddenly, can be distinguisher from the shggish pulse (tardus) in which the impact is more prolonged. And with respect to hardness, the pulse (durus) which ean be compressed with difficulty, can be distinguished from the one (mollis) which can be easily obliterated by pressure. On the basis of these four fundamental qualities a series of other qualities can be named, but we shali not diseuss them further.

Knowledge of the pulse has made rapid progress since E. H. Weber gave it a mechanieal explanation (18.50) and Tierordt showed that it eould be graphieally reenrded (18.5.5). The first pulse recorder (*phy!gmograph) to give correct pulse curves was constructed somewhat later ( 1860$)$ by Marev.

The most important part of the sphygmograph (Fig. 86 ) is the steel spring (p) with a contact surface to be placed over the artery. This spring responds to the morements of the artery and transmits the movements to the writing lever, which magnifies and records them on a writing surface driven by a small clockwork. The morements of the spring are transmitted to the lever by means of the screw $s$, jointerl to the contact surface, and the tension of the spring can 
be regulated by means of another serew. The whole apparatus is fastener by means of a band to the lower end of the forearm (Fig. S:). Mauy modifications of this instrument are in use.

The method of air transmission is often used also, especially when it is desired to register the pulse eurres of two or more arteries, or the pulse curve and cardiogram, at the same time. A receiving tambour of about the same con-

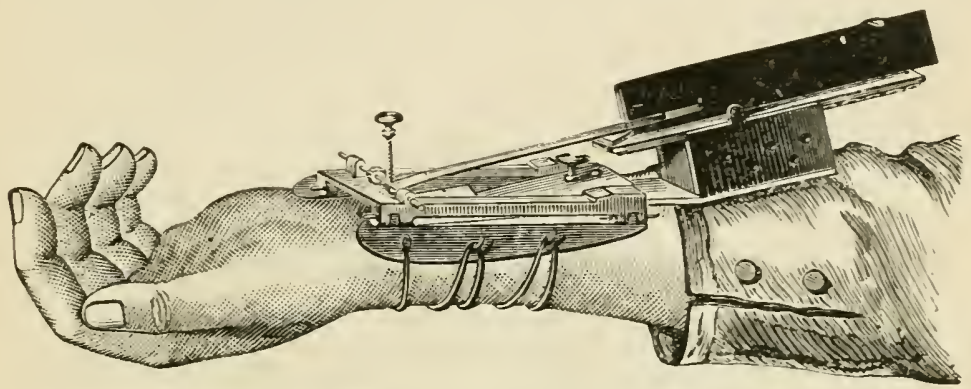

FiG. 87.-Marey's sphygmograph as used.

struction as that described for the apex beat is fastened orer the artery and is connected in the usual way with the recording tambour ( $\circ \mathrm{f}$. Fig. 10, page 12).

The sphygmograph has often been tested and it has been foum to give the pulse movements with surprising accuracy. It has been shown, for example, that it reproduces rery exactly the waves, already known, by other means, to oceur in an elastic tube (Mach); that the pulse eurve has exactly the same appearance when the pulsations are recorded without magnification and where the inertia of the lever is thus reduced to a minimum (Marey): and that pulse curves having exactly the same form as those recorded by the sphrgmograph, are obtained if a rery small nirror is fastened to the skin over an arter, so that the light may he reflected on a wall.

But we must not suppose that every sphygmograph records pulse waves so perfectly. It often happens on the contrary that the instrument distorts the eurve considerably. It is, therefore, necessary in every exact study of the pulse by the graphic method to assure oneself of the effieiency of the instrument and of the maximal speed permissible for the lever.

The velocity of the pulse wave is measured hy taking at the same time pulse tracings from two arteries separated by sone distance from rach other. The relocity of propagation found in this way varies with rifferent individnals. and with the same individual under different circumstances. In a healthy man it amounts to $:-10 \mathrm{~m}$. per second. The velocity is greater. the greater the coefficient of elasticity. It increases therefore with a rise of blont presisure, for, as we have seen at page ?01, the cofficient of elasticity of the arterial wall increases, at least within certain limits. as the internal presine increases.

The length of the pulse ware $\lambda$ is obtained from the formula $n \lambda=h$; or $\lambda=\frac{h}{n}$, where $h$ is the velncity of transmission and $n$ the rhythm. Since with each rentricular systole the bloot is driven into the aorta for 11.2 of a second, the rhythm number is 5 . With a relncity of $8 \mathrm{~m}$. the length would be $\lambda=\frac{8}{5}=1.6 \mathrm{~m}$. In a grown man the distance from the heart to the 
farthest arteries is just about equal to this ware lengrth. Only the rery longest arterial paths in the body, therefore, are long enough to include the entire length of a pulse wave: for the end of a wave enters the aorta only after the beginning of it has already reached the periphery.

Since the morements of the contact surface of the instrument are caused by fluctuations of pressure inside the artery, the pulse curve gives expression to the rise and fall of this pressure. But it does not represent the variations of arterial pressure exactly. for the arterial pressure is exerted not only against the contact surface but also against the arterial wall and the neighboring soft parts.

The sphymograph is affected also by other movements than those of the blood in the arteries-e. g. by changes of turgor of that part of the body where it is applied. If the return flow of the blood from the veins is hindered, the

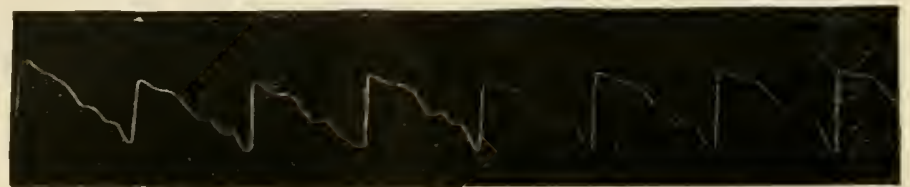

FIG. S8.-Radial pulse curve recorderl with Marey's sphygmograph, after Langendorff. To be read from left to right.

entire series of curres in the sphygmogram rises because the swelling skin increases the tension of the spring. One dare not infer a rise of blood pressure, therefore, from such a rise in the series of curres.

When suitable apparatus is employed the pulse eurve presents a number of peculiarities, some of which constantly recur more or less well marked. whatever the artery from which the curve is taken.

The pulse curve (Fig. 88, cf. also Fig. 11) begins with a rather steep ascent which corresponds to the positive wave caused by the inflow of blood into the aorta. This line usually reaches its highest point without interruption, whence hegins immediately the descending limb of the curve. The latter shows several irregularities, one of which at least. the second mound. oceurs in all pulse curves (Fig. 88). This mound is designated as the dicrotic elevation. That it is not an artifact has been shown by the abore-mentioned tests to which the sphygmograph has been subjected.

The dicrotic elevation is without doubt a positive wave running in the centrifugal direction; but opinions differ as to the uny in which it arises. Of the two hypotheses which at present are worthy of discussion, one accounts for the eleration by supposing that the primary pulse wave is reflected as a positive wave from the periphery of the arterial system. This reflected wave comes into the aorta. strikes against the closed semilunar ralres, and is once more reflected withnut change of sign. The second reflection (that from the semilunar valves) is the cause of the dicrotic eleration (r. Kries. r. Frev).

According to the other hypothesis the dierotic eleration arises in the following manner. When the cardiac contraction ceases. and the semilunar valves are no longer supported by the blood in the heart, or by their own 
muscular folds (c.f. page 16i), a negative wave starts from the root of the aorta rumning towarl the periphery, and a portion of the aortic blood flow: back toward the heart. When this returning blood strikes against the semilunar valves, which have just been closed, a positive centrifugal ware starts at the roet of the aorta, producing the dicrotic eleration (Marey, Grashey et al.).

We cannot discuss here the principles underlying these two explanations. Both hare eminent adrocates and an agreement is not ret in sight.

However we conceive the dicrotic character to be produced, it is certain that waves reflected from the periphery of the arterial sistem have a very material influence on the form of the pulse curce. The reflected waves interfere with the direct ones; they spread to neighboring arteries where again they are propagated as direct waves, which in turn interfere with both the direct and reflected waves proper to these arteries, and so on. Thus a great rariety of pulse tracings with a varying number of secondary and tertiary elevations on the pulse curve may be obtained.

Attempts liave frequently been made to draw conchusions as to the activity of the heart, the condition of the blood ressels, and the blood pressure from the character of the pulse curve. This is posible to a certain extent. lunt must be done with great caution.

The pulse curve may give some approximate information as to the temporal course of events in the heart. The heginning of the pulse eurve corresponds to the entrance of the blood wave into the arteries and the beginning of the dicrotic eleration is synchronous with the beginning of a corresponding deration on the cardiogram. Since this point appears at a slight interral after the closure of the semilunar valres (c.f. page $1 \% 5$ ), the time elapsing between the beginning of the pulse curve and the dicrotic elevation is slightly greater than the time during which the left rentricle and the arteries are in open communication with each other.

It might be supposed also that a pulse curve of large amplitude would indicate a large pulse volume; but this is true only in a rery limited sense, for the pulse curve of a given artery depends to so great a degree upon the tonus of this artery and upon the resistance in its peripheral branches that no definite relation between rolume and size can be laik down.

Moreover, a large amplitude of the pulse curve is br no means significant of a high hood pressure. but at best signifies only that the fluctuation of pressure is great. But since we know that the rariation of systolic pressure is within certain limits less with a high than with a low pressure, we might posibly say that under circumstances otherwise the same the greater amplitude means a lower blood presure. Put eren this is not invariable. The degree of ennstriction of the artery under investigation has nuch to do with it.

Again the height of the dicrotic elevation has often been regarded as an index of the pressure. a greater eleration being proluced with a low than with a high pressure. In many cases this is true. But there are exceptions. since the degree of dilatation of a particular arterial region may influence the production of any particular dicrotic pulse.

All of this show how careful one must he in drawing conclusions from the pulse curve regarding the endition of the vascular system. 
The pulse. as a rule, can be detected only in the arteries. This is explained by the fact that in any elastic tulse a wave tends to be obliterated by friction. In an umbranched tube the length necessary for this obliteration would he very great. but in one composed of many branches like the vascular system, the obliteration is favored by every bifurcation, since therehy the total wall becomes greater and the active force of the wave is consumed the more rapidly. The wave is reflected also at every point where the vascular wall changes direction, and on this account it is consumed sooner than otherwise.

\section{§5. FINAL SURVEY OF THE MOVEMENTS OF THE BLOOD IN THE ARTERIES}

Now that we have learned the details of the blood flow in the arteries, it remains for us to reconstruct these details into a connected whole. We shall follow for this purpose the description of E. H. Weber.

Let us suppose that the heart consists of only one ventricle, also that to begin with the blood in all divisions of the vascular system is under the same pressure. When the ventricle contracts the atrio-ventricular valves close and prevent the blood from flowing backward. All the blood must therefore take the same direction into the arteries. If these were rigid tubes no blood conld be pressed into then without at the same time setting in motion the entire column of blood in all its parts. In this case no ware would be produced. but only a stream of blood which would last as long as the contraction of the ventricle continued. But since the arteries are elastic tubes, propulsion of the different segments of the blood column takes place successively. The mass of blood discharged from the ventricle can find a place for itself only loy distending a portion of the arterial system, and thus producing a positive wave of high pressure which spreads through the vessels.

If there were no semilunar ralves, and if the rentricular contractions stopped immediately after the discharge of the blood, the distended arteries wonld at once drive a part of the blood back into the ventricle. But since this is prevented by the semilmmar valves, the successive parts of the blood column are moved a little farther forward in the vascular system by each rentricular systole.

As soon as the heart relaxes at the end of systole and the atrio-ventricular valves are open, the blond flows from the veins into the heart and protnces a negative wave which is propagated along the veins. The valves connected with the heart are so arranged that with the systole and diastole of the heart periodically alternating, positive waves pass out only along the arteries, negative waves only along the veins.

If the vascular system were composed of a single continuous tube of uniform diameter every wave would run through the entire system with great velocity, and would produce a state of equilibrium in the entire circuit before the next rentricular systole could follow. But becanse of the resistance in the smallest arteries, veins and capillaries, matters are quite otherwise. On account of the friction in the smaller vessels the blood cannot pass through as rapilly as would be necessary for the propagation of a positive wave all 
the way back to the heart. The wavelike movement is reflected. therefore, at the capillaries, etc., and under normal circumstances the pulse eannot be perceived in the veins.

Supposing now, as we have done, that the pressure is everywhere the same to begin with, then if the regular contractions of the heart were repeated rapidly enough, there would be an accumulation of blond in the arteries. for at each systole more blood would be thrown into the arteries than conld be pressed through into the veins in the same time. At every diastole of the heart the total quantity of blood in the reins would be still further reducerl, because more blood would pass from them into the heart than could come into them through the capillaries from the arteries. Thus the quantity of hoorl in the arterics would go on increasing, and the quantity in the reins would go on decreasing until the difference in pressure between the two would leceme on great that from one systole to another just as much blood was pressed throngh the capillaries as was heing discharged by the heart into the arteries. Once this degree of difference in pressure between the two dirisions of the rascular system had heen reached, if the heart activity continued the same, the difference would become constant-i. e., the pressure in the arteries would be permanently greater than in the veins.

It is because of this constant difference in pressure between arteries and weins that the movement of the blood from the former to the latter takes place in a steady stream. For this reason also the blond continues to flow from arteries to reins for some time after the heart stops beating. Any sort of influence which changes either the resistance in the vessels or the energy of the heart. disturbs this stationary condition and a new equilibrium is established at a different level of arterial pressure. Every variation in pressure is in turn followed by a change of one kind or another in the character of the blood flow.

\section{§. THE FLOW OF BLOOD IN THE CAPILLARIES}

The capillaries are unquestionably the most important part of the vascular system. The purpose of the circulation, which consists in supplying combustible materials and oxygen to the organs, and in relieving them of decomposition products, is accomplished in the capillaries. In them the blood is separated from the lymph by only a thin wall, consisting of a single layer of cells, through which the exchange of diffusible substances is readily earried on. 'T'he arteries and reins are only tubes conveying the blond to and from the eapillaries: the latter constitute the real clearing-house of the vascular system.

Since oxygen is consumed in large quantities in the tissues, it is evidently of great importance that the blood should unt flow too slowly through the capillaries. The high pressure which prevails in the arteries is necessary in order to keep the blood flowing through the capillaries with sufficient speed.

Whenerer the pressure in the anrta falls, the pressure in the capillaries also falls. If an artery becomes constricted, the lateral pressure in this artery central to the place of constriction increases. but at the same time the pressure and relocity peripheral to that place, that is, in the capillaries, decreases. 
Whenever, other things heing equal, an artery is dilated. the lateral pressure in this artery may fall, but a larger amount of blood flows into the eapillaries and as a result the pressure in them increases.

1ll the complicated mechanisms which help to regulate the blood pressure have for their immediate purpose the maintenance of a normal pressure in

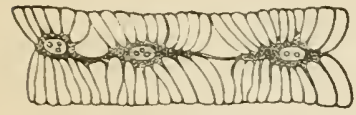

Fig. 89.-Branched contractile eells embracing wall of a capillary ressel in the hyaloid membrane of the frog's eye, after Rouget. the aorta, in order that the blood may flow under normal pressure through the capillaries.

The total quantity of blood in the body is by no means sufticient to supply all the capillaries at once with as much blood as the organs require at their maximum activity. Fortunately all the organs are never at their maximum at the same time, so that their requirements vary. In fact the quantity of hlood flowing through the eapillaries varies incessantly. In organ upon which devolves an extra quantity of work receives for the time a greater supply of blond than if it were relatively inactive. The arteries belonging to the organ dilate, while the arteries which convey blood to the other organs at the same time constrict. By this means a fall in the aortic pressure is prevented and the blood flows more copiously to the capillary system whose arteries have been enlarged. Pressure and velocity in this region increase together.

The length of the capillaries is given as $0.4-0.7 \mathrm{~mm}$. (in the liver as much as 1.1 ) ; their diameter is about $0.009 \mathrm{~mm}$.

The capillary wall is composed of flattened eells which fit together by their edges. That they are capable of constricting in many places was first demonstrated by Stricker. Rouget and S. Mayer then showed that this constriction is

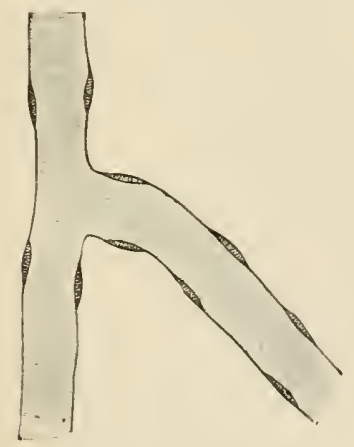

$A$

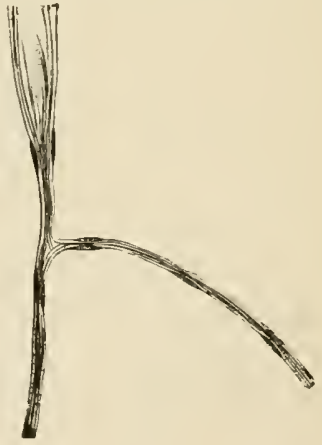

$B$

F1G. 90.-A, capillary when not stimulated; $B$, the same eapillary stimulated. The lumen is entirely obliterated, after Steinach.

brought about by contractile elements situated outside the basement membrane and entirely distinct from it. The nuclei of these cells are arranged parallel to the long axis of the vessel and their cell substance is often divided into little strands which run out at right angles to the nucleus and embrace the capillary vessel like the hoops of a barrel (Fig. 39). The contraction of these elements may entirely obliterate the Jumen of the vessel; at the same time fine Iongi- 
tudinal folds or wrinkles appear in the cell membrane, which increase in number, clearness and extent as the capillary wall draws together, and entirely disappear when the ressel dilates again (Fig. 90). However, certain individual capillaries or capillary tracts are quite exempt from this contraction (Steinach).

The most favorable object for the demonstration of these phenomena is the nictitating membrane of the frog. Quite similar results have been obtained also in other eapillary systems of the frog and even of II ammals.

Capillaries are abundantly supplied with nerves, and Steinach has succeeded in producing a contraction of the capillaries in the frog's nictitating membrane by stimulation of the sympathetic.

Since the diameter of the eapillaries may vary independently of the blood pressure, it follows with great probability that in virtue of their contractility the capillaries themselves participate to a considerable extent in the regulation of the blood supply to the different organs.

The blood in the capillaries flow's in the following manner. If the capillary ressel is not so small that the blood corpuscles entirely fill it, the red corpuseles move along with their long diameters in the direction of the current, and keep to the center of the vessel, so that between them and the vascular wall a clear space is left filled with plasma. In this space are found numerous white blood corpuseles which sometimes come to rest there, sometimes roll along very slowly making frequent pauses. As a rule, the current in the capillaries is continuous. But there are exceptions to this rule. With suffieient dilatation of the small arteries in a given vascular region the blood stream in the capillaries may exhibit rhythmical vibrations synchronous with the heart beats. A continuous flow presupposes therefore that the blood in the small arteries meets with suffieient resistance to obliterate these pulsations.

In the field of the microsope the relority of blocer flow in the capillaries can be determined hy simply observing the time consumed by a particular corpusele in traversing a measured distance on the evepiece mierometer. The velocity determined in this way is given as

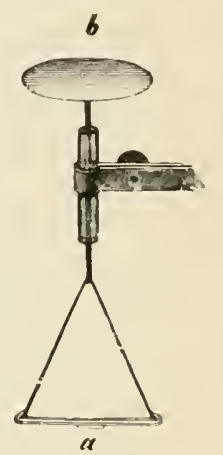

Fig. 91.-Apparatus for determining the blood pressure in the capillaries, after Ludwig. The small glass plate $a$ is placed on the skin, and the pan $b$ is loaded with weights until the skin unclerneath $a$ is blanched. $0.5-0.8 \mathrm{~mm}$. per seend. These values howerer are maximal, for they relate to the current in the central part of the vessel. The mean relocity is somewhat less.

Attempts have been made to returmine the blood messure in the capillaries by neasuring the pressure upon the outer surface of the skin or upon the giums of the teeth (Fig. 91), at which a distinet change in color appears. This is said to indieate that the most superficial capillaries are completely compressed. The limits of error of this methol are rather wide, and the values obtained can only be regarded as hare approximations to the truth. This appears more clearly when we hear in mind that the pressure thus determined is not the total eapillary pressure. for the lymph exerts an opposite pressure on the outer side of the capillary wall. and this depends upon the tersion and the turgor of the skin.

The eapillary pressure which one obtains when the effect of the hydrostatic 
pressure of the blood column is exchuled-i.e., when the eapillary region inrestigated lies at the same lerel as the heart, amounts to about $33 \mathrm{~mm}$. of mercury (N. v. Kries. gnms of the rabbit). Since the aortic pressure in the rahbit amounts to about $100-120 \mathrm{~mm}$. Hg.. the capillary pressure would be one-thind to two-serenthe of the aortic presine.

Poisseuille has given the following formula for the flow of a fluid through a horizontal capillary whose wall is wet by the fluid: $Q=\pi \frac{p_{1}-p_{2}}{s \eta} r^{4} t$ where () represents the volume of fluid flowing through the capillary in the time $t$, $n_{1}$ the lydraulic pressure at the beginning of the capillary, $p_{2}$ that at the enr, $l$ the length, and $r$ the radius. $\eta$ is the constant of internal friction If ail the dimensions are given in millimeters and milligrams, $\eta$ in milligrams is the retarding force of the friction taking effect upon one square millimeter of surface, when the difference in relocity hetween two adjacent layers of the fluid one millimeter apart is $1 \mathrm{~mm}$. per second, the change in relocity being mniform. The greater the ralue of $\eta$ (i. c., the more visenus is the fluid), the less becomes the volume of fluid which will flow through the tube in unit time.

It has been shown by B. Lewy that this law is true also for the blood. At a temperature of $36^{\circ}-40^{\circ} \mathrm{C}$. he found the mean value of $\eta$ to be 0.00025 (swine. sheep), whereas the corresponding value for distilled water is $0.0000 \%$. The internal friction of defibrinated blood is thus on the average 3.5 times as great as distilled water. The internal friction of normal blood is somewhat greater. According to the researches of Hiirthle, at $3 \%^{\circ} \mathrm{C}$. it amounts to 4.7 for the dog, 4.3 for the cat, 3.3 for the rabit, that of distilled water being taken as 1 . Moreorer the internal friction of blond raries considerably under different circumstances. It decreases after bloodletting; it is smaller in starvation than after feeding: and in the dog it reaches its highest ralue after feeding meat (Burton-Opitz). Relying upon data concerning the internal friction of defibrinated blond, and under certain assumptions as to the length. breadth, etc., in different parts of the rascular system, B. Lewy has calculated the fall in pressure in the capillaries and has found it equal to 20-60 $\mathrm{mm}$., or by using the highest value of $\eta$ (0.00068) olserved hy him, equal to $150 \mathrm{~mm}$. of blood. ${ }^{1}$ At the most, therefore, about one-fourteenth part of the entire blond pressure is consumed in the capillaries themselves. From which it follows that it is not the capillaries which constitute the chicf resistance to the blood stream, but rather the smaller arterinles central to them.

Camphell also has reachel the same vicw from altogether different consirlerations. Among other things he emphasizes the point that if the resistance in the capillaries were very great, so that the pressure at the beginning of a capillary were much higher than at its ent, the very thin caprillaries would be funnel shaper with the wide opening directed toward the arteries, which. as we know, is not the case.

With the help of Poisweuille's formula, and on the basis of data alreary at hand for the internal friction of the blood, for the quantity of blool flowing through the aorta, and for the pressure therein, Itürthle has calculated the absolute resistance in the aortic path (rabbit). As is evident from the formula,

${ }^{1}$ Approximately $11 \mathrm{~mm}$. Hg. 
this is expressed as the length of a tulse through which just as much blood would flow in unit time as flows through the animal body. Aecording to this calculation the resistance is equal to that of a cylindrical tube with the diameter of the aorta and with a length of $296 \mathrm{~m}$. It need searcely be remarked that this value relates only to a special case, and that it is adduced here only for the purpose of giving an approximate idea of the amount of resistance in the rascular system.

\section{\$. 7. THE FLOW OF BLOOD IN THE VEINS}

\section{A. PRESSURE AND VELOCTTY}

The cubic distention of a rein to internal pressures increasing hy equal increnents is exactly like its longitudinal distention to loads increasing by equal increments-i. (a.. it becomes less the higher the total preswure becomes (Fig. 9:). The veins, therefore, behave differently in this respect from the

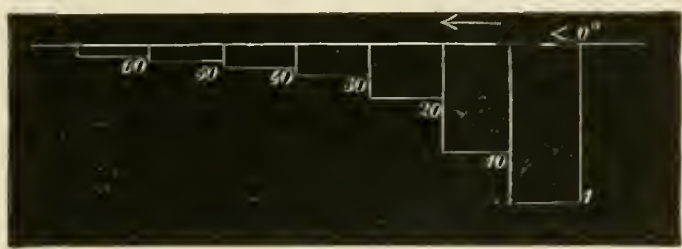

FIG. 92.-The cubir enlargement of the inferior vena cara of the cat, under uniformly increasing internal pressure, after Roy.

arteries (c.f. page 201$)$. The resistance of the veins to rupture by internal pressure. is. under normal conditions, very great, just as it is in the arteries.

The escential phrsiological purpose of the reins is to return the blood to the heart. 'The force which drives the l, lood forward in the veins is the force of the heart itself. But the friction in the small arteries and in the capillaries, has by this time consumed the major part of the heart's driving power, consequently the total energy with which the blond flows in the reins is but a fractional part of the energy which it posseswerl as it left the heart. The greater part of that energy has been transformed into heat during the passage of the blond through the arteries and capillaries.

The lateral pressure in the veins is, therefore, much smaller than in the arteries. In the central veins of the thorax the blond pressure is negative lecause of the aspirating aetion of the thorax. In more peripheral reins it is positive and is higher the farther the rein from the lueart. e. g.. in the right jugular of the sheep. $0.2 \mathrm{~mm}$. Hg.. in the external facial 3.0, internal facial 5.2. brachial 4.1 , in a branch of the latter 9.0 . in the erural $11.4 \mathrm{~mm}$. Hg. (Jacobson); in the superior vena cava of the dog close to its entrance into the right auricle $-3.0 \mathrm{~mm}$. Hg., in the distal portion of the same vein -1.4 , in the right external jugular -0.1 , left external jugular 0.5. in the right brachial 3.9. in the left facial 5.1 . left femoral 5.4 . left saphena $5.4 \mathrm{~mm}$. IIg. (Burton-Opitz). Ohservations on the sheep and on the dog. as will be seen, agree on the whole very closely.

After opening the thorax and thereby obliterating the negative intra- 
thoracic pressure, the pressure in all the veins rises ennsiderably. so that a negative pressure can no longer be demonstrated.

In order to determine the pressure in a vein it is necessary to avoid stoppage of the blood; a $\mathrm{T}$-cannula is used and on account of the low pressure a soda solution is substituted for mercury in the manometer.

Just as in the arterial system, the pressure in the veins is conditioned upon the quantity of blood flowing from the heart in unit time, and upon the resistance. If the veins meet with great resistance in emptying their blood to the heart, the pressure in them inereases. This happens for example when the heart is checked or brought to a standstill by stimulation of the vagus. In this case the heart is unable to drive forward all the blood which collects in the reins, and the consequent accumulation raises the renous pressure. If in spite of the inhibition, the right heart still expels in unit time just as much blood as it did before, the renous pressure suffers no ehange. The pressure in the veins is increased likewise if the lungs are highly inflated, for by this means the flow of blood into the intrathoracic veins is hindered, and it becomes more difficult for the right heart to empty itself.

On the other hand, the venous pressure falls as a result of all conditions favoring the return of the blood to the right heart or its discharge therefrom -e. g.. acceleration after section of the ragus-provided the heart discharges in unit time a larger quantity of blood than before.

These influences take effect primarily on the central veins. In the periphery the pressure depends mainly upon the variations of blood volume and of resistance in the arteries. If an artery be completely clamped off, the pressure in the corresponding vein sinks to the level of the minimal pressure in the larger vein to which it is tributary. If a vein be elamped off. the pressure increases peripherally to the ligature because in this case the rein represents only a blind end of the artery.

The variations in pressure in the venæ caræ give rise to pulsations in the larger veins of the trunk and the extremities, which are transmitted centrifugally with a velocity of one to three meters per second. The velocity of transmission through the jugular vein is greater than that through the vena cava to the crural vein (Morrow).

In order that the blood may flow uniformly, it is necessary that the same quantity be delivered by the veins to the heart in unit time as is expelled by the heart into the arteries, and this has been proved by the direet observations of Cyon and Steinmann, and of Burton-Opitz, to be the case. The rolume of flow is, therefore, about the same in corresponding arteries and veins; but on account of the greater cross section of the veins, the linear velocity in them is less than in the arteries-e. g., in the external jugular of the dog $147 \mathrm{~mm}$., in the femoral $62 \mathrm{~mm}$. per second. After section of the vagi, the volume of the current in the jugular rein increases 2.8 times, but decreases about fifty-seven per cent on compression of both earotids (Burton-Opitz).

\section{B. AIDS TO THE BLOOD FLOW IN THE VEINS}

The blood flow in the veins can be very easily disturbed by all kinds of external influences; but to offset this we have several special mechanisms 
which faror the flow. One such is the suction of the thorax already discussed at page 1:6, as well as that of the heart itself. Besides these. several other conditions in connection with the valves of the veins, operate to prevent stasis of blood in the veins.

The valves of the reins discorered by Fabricius ab Aquapendente in 15it. are semilunar folds of the lining membrane, so arranged that they open torard the heart but prevent the flow of blood in the opposite direction. Two such ralves as a rule stand opposite each other.

Then external pressure of any kind is exerted upon a rein. the backuard flow of blood is checked by the nearest valve, and it is compelled therefore to more in the direction of the heart. As a result we find that with every muscular contraction there is an increase in the quantity of blood flowing from the corresponding vein. If the muscle be thrown into tetanus. there follows at first an acceleration, then a retardation of the blood flow, which lasts until the tetanus abates, and the pressure on the rein eaused by it ceases.

Thus Burton-Opitz found the volume of flow in the femoral vein in one experiment with a resting muscle to be 1.1 c.c. per second: with a tetanizing stimulus of the sciatic nerve, lasting 8.1 seconds, the volume mas 4.0 c.c. during the contraction, 0.4 c.c. during complete tetanus, and after relaxation of the muscle 1.3 c.c.

Under ordinary circumstances clonic. cramplike contractions of the muscles never occur, but with every movement of the body contraction and relaxation alternate. Because of the intermittent pressure upon the reins which such an alternation produces, the usual muscular contractions must materially favor the movement of the blood in them.

Changing the attitudes of the body also is an important aid to the flow of renous blood.

The femoral vein under Poupart's ligament and in the fossa oralis, becomes empty of blood and collapses when the thigh is turned outward and at the same time mored backward so as to stretch it as much as possible. It fills full again as soon as the leg is brought back to its former position or is brought still further forward or flexed as much as possible. These changes of position take place with every step which ne make (Braune).

Finally, we have in the stretching movements of the body a means of accelerating the blond in the reins. When a rein is elongated without at the same time being compressed its cubic eapacity is increased, and it then exerts a suction on the blood column. For the renous system of the mpper extremities such a suction is obtained when with fists clinehed and wrists bent, the arms are stretched horizontally and moved backward in a certain plane of rotation. I general state of relaxation and consequent stagnation are obtained when with fingers stretehed and the hand flexed dorsally the arms are bent at the elbows and bronght close to the thorax. The reins of the lower extremities are stretcher when the thighs are spread apart and turned ontward at the hip joint as far as possible, the knees and feet being at the same time extended. Flexion, adduction and turning of the thighs inward. bending of the knees and dorsal flexion of the feet bring about a 


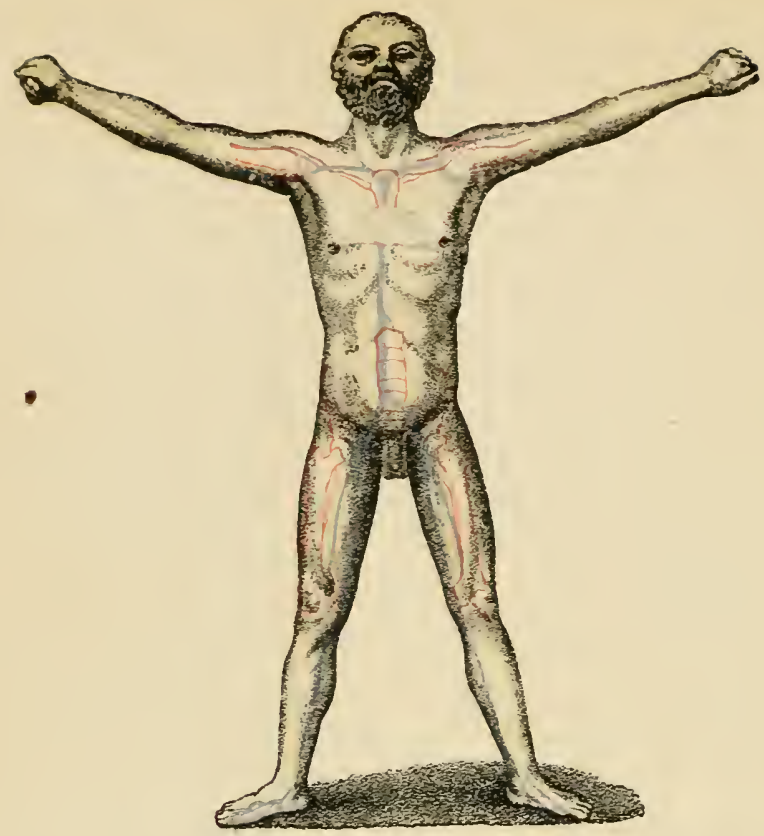

FIG. 93.-Position of the body in which the veins are stretched as much as possible, after Braune.

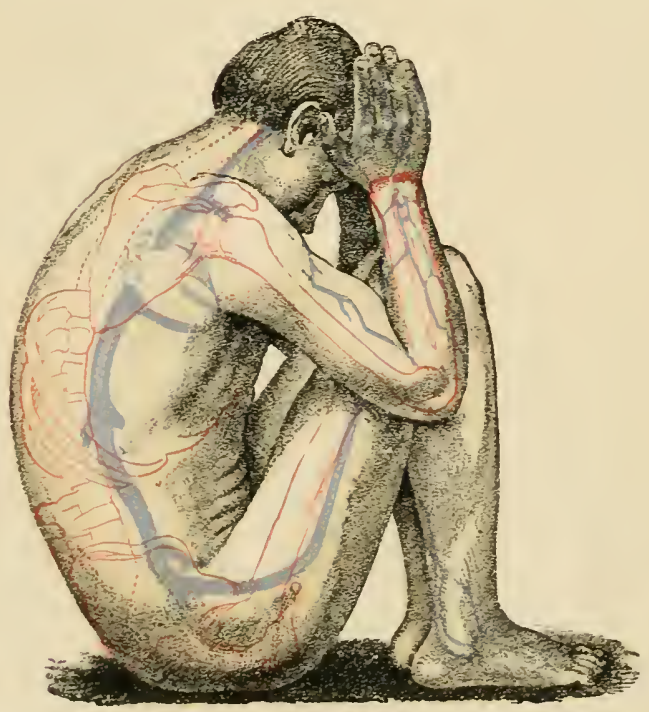

FIG. 94.-Position of the body in which the venous system is relaxed as much as possible, after Braune. 
general relaxation of the same chief trunks. The position in which the venous ststem is in general stretched most strongly corresponds well with the attitude which one takes involuntarily when, after working at a desk for a long time. he stands up and stretches himself (Fig. 93). It is, therefore, to be assumed that such a stretching of the trunk and of the extremities acts farorably upon the renous circulation. which has been disturbed by sitting ton long (Fig. 94), and this quite independently of the direct effect of muscles and fascia (Braune).

It may happen at times that a greater quantity of blood flows to the right heart than can be disposed of. This is possible, for example. when a powerful vasoconstriction occurs throughout a large vaseular region. A large quantity of blood is then forced from the arteries into the reins, and from these to the right heart. while at the same tine the diseharge of llood from the left rentricle hecomes more difficult on account of the high resistance in the contracted arteries.

We do not know how often or to what extent this may happen. We only know that after extirpation of the liver. the portal vein having been previously connected with the inferior vena cava, the heart is found dilated to its utmost, and the great reins are filled swelling full of blood (Stolnikow). The liver takes up al considerable quantity of blood like a sponge. and protects the right heart from an oversupply, just as it aids in the relief of the heart when orerdistention oceurs as a result of transfusion (cf. page 202 ).

\section{\$ 8. THE LESSER CIRCULATION AND THE RESPIRATORY VARIATIONS OF BLOOD PRESSURE}

\section{A. THE PULMONARY CIRCULATION}

In general the same laws which we have learned in our study of the blood movements in the greater circulation hold good for the lesser circulation. The presure is dependent upon the quantity of blood discharged from the right heart and upon the resistance in the pulmonary ressels. The quantity of blood which the right ventricle forces into the pulmonary arteries depends upon the quantity of blood which flows from the greater circulation through the venæ cara into the right heart. This quantity is determined partly by events in the antic system, and partly by the pressure changes in the thoracic cavity which accompany the different phases of respiration.

Thus every hindrance of any moment to the flow of blood into the venæ caræ reduces the pressure in the pulmonary arteries. An increased supply of blood to the right heart, such for example as is brought about by powerful contraction of the abdominal vessels, increases the pulmonary pressure.

We have already emphasized the fact that with each act of inspiration the thoracic cavity exerts suction on the blond ressels which enter it. The right ventricle, therefore, receives more blood during inspiration than during expiration: nevertheless the pressure in the rentricle itself (Talma) and in the puhmonary arteries (Knoll) declines only to rise again at the next expiration.

These variations of blond pressure are caused partly by the effect of variations in the intrathoracic pressure on the thin-walled right ventricle, and partly 
by their effect on the diameter of the ressels in the lumgs. The diameter of these ressels, as d'Arsonval, De Jager, Heger and others have shown, increases with the expansion of the lungs during inspiration, and decreases with the collapse of the lungs during expiration. Since the two factors operate in the same direetion, there remains for us to determine to which of them the greater significanee is to be ascribed. We must first inquire to what extent the resistance in the pulmonary ressels is elianged by the different phases of respiration.

This question does not admit of a direct answer; but we have certain wellestablished facts which show very elearly that the resistance in the pulmonary channels is in general so small that only a considerable change in the diameter of the ressels could exereise upon it any very marked influence.

We should mention first the results which Lichtheim obtained by occluding a large part of the pulmonary ressels. It was shown with dogs which received artificial respiration by rhythmieal inflation of the lungs, that about threefourths of the territory supplied by the pulmonary arteries could be shut out without diminishing in the least the flow of blood to the left ventricle. Again, the left pleural eavity of a rabbit breathing naturally has been opened without interfering with the respiration on the other side, and the entire left lung tied off at the hilus: yet as a rule no fall of blood pressure was observed in the greater eireulation.

We may say, then, that one-half (in eurarized animals still less) of the pulmonary blood channel is enough to supply the necessary quantity of blood to the left heart. The explanation might be sought in an increased blood pressure in the lesser eirenlation and a eonsequent greater dilatation of the ressels which remain open. But the increase in pressure is so insignificant (it nerer amounts to more than a few millimeters of $\mathrm{Hg}$.) that it is very doubthul whether it eould produce such an effeet. Again we might imagine a vasomotor influence upon the pulmonary ressels; but the faets which we have at present on this subject seareely point to any considerable direct eontrol of these ressels by the eentral nervous system. Finally, it is possible that under normal eircumstances the lungs are never uniformly filled with blood, but that eertain regions remain relatively empty, being made accessible to the blood only by unusual opportunities like that just mentioned.

Be this as it may, it certainly follows from the facts before us that the resistance in the pulmonary vessels is very small. This eonclusion is confirmed also by facts which we possess coneerning the veloeity of the blood flow in the lungs. Sterart has shown, for example, that a foreign fluid injected into the jugular rein passes the lesser circulation in three to four seeonds. When the lungs are inflated by a positive internal pressure suffieient to stop the flow of blood in the pulmonary ressels, and the lungs are then released, the pressure in the greater circulation returus to its normal height in three to four seconds.

In view of this low pressure in the pulmonary vessels, one hesitates to suppose that the changes in their diameter which take place in spontaneous respiration as the direct result of alterations in the lung tissue can play the more important part in determining the variations of blood pressure in the lesser eirculation. The changes in intrathoracic pressure are much rather to be assigned the place of first importance. The pressure in the right rentricle falls in inspiration not ehiefly beeause the ressels in the lungs dilate a little, but because the inspiratory suction distends the heart, and vice versa.

The blood pressure in the pulmonary arteries is very low on account of the low resistance in the smaller pulmonary ressels. On the average it amounts 
in the $\operatorname{dog}$ to abont $20 \mathrm{~mm}$. Hg., in the eat to about 18 and in the rabbit to about 15 (cf. page 170 ).

As mentioned abore (page 208 ). the pressure in the greater circulation in the same individual may exhibit great rariations from one moment to another. The pulmonary eireulation is entirely different in this respect, the pressure variations there being on the whole very small-scarcely ever more than 10-15 mm. under normal cireumstances.

It follows that the work of the left rentricle must vary in amount much more than that of the right, and this is borne out also by the fact that the left ventricle becomes more or less fatigued, when the right is still entirely capable.

The lesser eirculation is dependent upon the greater not only because it draws its supply from the vena cave, but also because it must deliver its blood to the left ventricle and so is affected by the conditions of the blood flow from that chamber. If, for example, the left ventricle is unable, because of high resistance, to discharge all the blood coming to it, so that a certain quantity accumulates within this chamber, a state of affairs will finally be reacherl where the flow from the right heart is hindered, which in fact has been experimentally demonstrated (Waller).

In general, however, this reverse effect of the left heart on the right is only slight, a fact associated with the great capacity of the pulmonary ressels. The lungs serve the same purpose with respect to the flow of blood into the left heart as does the liver with respect to the flow of blood to the right (ef. page 227).

Moreover, the great capacity of the pulmonary vessels has this advantage, that in great respiratory distress where the ressels of the greater eireulation are powerfully contracted, the greatest possible quantity of blood is exposed to the alveolar air and the greatest possible quantity of oxygen is therefore absorbed. By this means the blood is relieved of the products of combustion, and the influence which these exert through their stimulation of the vasomotor centers is diminished to some extent.

\section{B. RESPIRATORY VARIATIONS OF BLOOD PRESSURE}

Just as the leser circulation is influenced in several respects by the greater, it in turn exerts no less an influence upon the greater. Consequently there

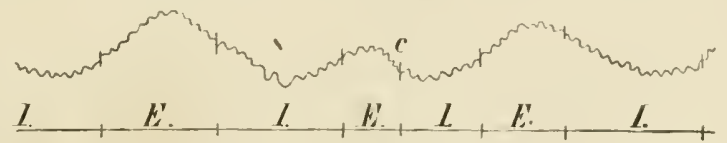

FIG. 95.-Variations of the aortic blood pressure in the dog, due to normal respiratory movements, after De Jager. $I$, inspiration; $E$, expiration. To be read from right to left.

appear in the aorta variations of blood pressure which are synchronous with the respiratory movements and are doubtless dependent upon these and upon the variations in the pulmonary circulation. The mechanism ly which these influences are brought to bear are rather complicated, and we have to take into account the following conditions.

The following circumstances tend during inspiration to increase the blood pressure in the aorta:

(1) The aspiration of the blood to the right heart increases; 
(2) The diastole of the heart is favored;

(3) The flow of the blood in the pulmonary vessels is facilitated because of their dilatation;

(4) The pressure in the abdominal cavity increases because of the descent of the diaphragm; and the blood is foreed in greater quantity to the right heart.

The following circumstances tend to lower the aortic pressure:

(1) The heart systole is rendered more diffieult because of the increased suction in the thorax;

(2) At the beginning of inspiration, while the pulmonary vessels are still dilating, a part of the blood expelled from the right ventricle must remain in

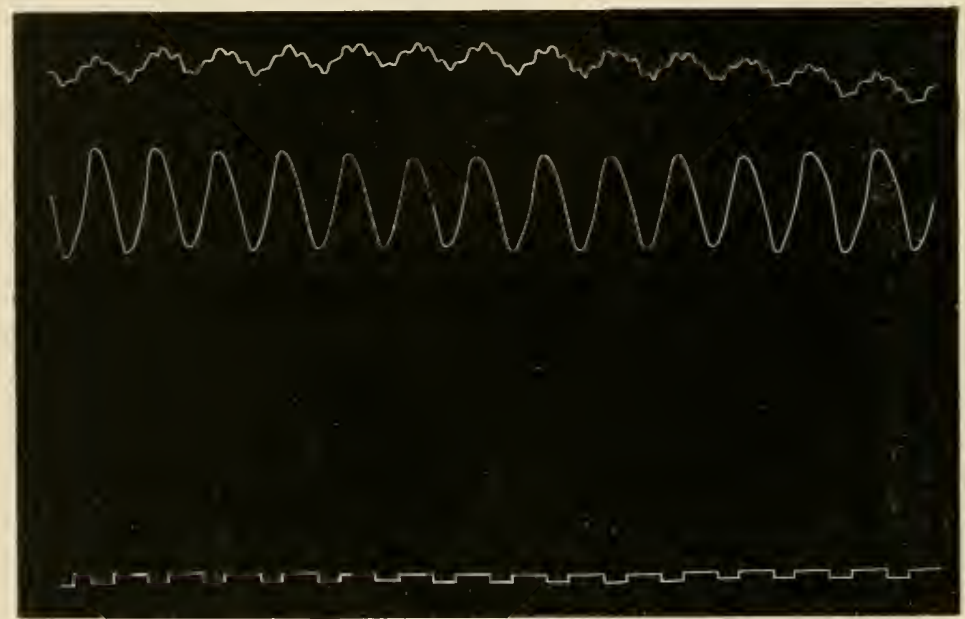

FIg. 96.-Respiratory variations of blood pressure in the rabbit. To be read from right to left. The upper line represents the blood pressure, the middle line the respiratory movements (downward stroke, inspiration), the lower line the time record in seconds.

them, and by this means the mass of blood flowing from the left heart deereases until the pulmonary ressels have been filled, after which the flow is increased.

In expiration naturally these mechanisms work in the reverse direction.

Among these factors the alterations of blood flow to the right heart is of the first importance. The respiratory variations of the aortic pressure witnessed in a dog breathing quietly (Fig. 95) could be explained therefore in the following manner. In expiration the right heart has less blood at its disposal, the left heart receives less blood, and the aortic pressure falls. When inspiration sets in, and the flow to the right heart beeomes greater, it ean drive a greater quantity to the left heart, and the aortie pressure rises. But a short time must always elapse before this increased supply to the right heart can be felt in the left heart and in the aorta ; henee at the beginning of inspiration the pressure is still falling. Likewise at the very beginning of the following expiration the right heart still has at its disposal a portion of the inereased supply; the rise in pressure in the aorta continues therefore for a moment until the diminished supply to the right heart ean be felt on the left, when the aortic pressure begins to fall. 
When the rate of respiration is somewhat more frequent (of. Fig. 96), the influence of expiration is felt for the first during the following inspiration and vice versa; the aortic pressure rises therefore during expiration and falls during inspiration.

In still more frequent and shallow breathing the variations of the flow to the right heart are so slight that 110 respiratory variations of blood pressure appear in the greater eirculation.

Besides these, eertain nervous events exercise an unmistakable influence on the respiratory variations of blood pressure in the aorta. During expiration the pulse rate deereases in consequence of an automatic stimulation of the ragus (depressor effect), and the vascular tonus increases as the result of an automatic stimulation of the vasomotor nerves (pressor effect). These factors make themselves felt only with a rhythm which is not too rapid, and even theu they may not be able to alter the course of variations in the aortic pressure produced by the mechanical factors alleady diseussed.

Still other more or less regular variations of pressure (Traube-Ifering waves) occur in the aortic system, which may run parallel with eertain periodic variations in the frepueney and depth of respiration extending over several respiratory eycles (Cheyne-Stokes breathing, Chapter IX) or may be entirely independent of them. But further discussion of their nature would lead us too far at this time.

Artificial respiration gives in all respects just the reverse effects of natural respiration. Thus with inflation of the lungs the blood flow to the right heart is rendered more diffieult on aceount of the positive intrapulmonary pressure, and the resulting eompression of pulmonary vessels. The consequence is that the aortic pressure rises at the beginning of inflation, and falls again in the further reourse of the same phase.

The cause of these artificial pressure variations must be mainly the alterations in diameter of the pulmonary vessels. At the beginning of inflation the blood pressure rises because of the eompression produeed and the consequent emptying of the blood toward the heart. The subsequent fall is the result of the increased resistance in the pulmonary vessels. At the beginning of the artifieial collapse a certain quantity of blood remains behind in the dilated ressels and the pressure sinks still farther until the influence of diminished resistance in the pulmonary vessels makes itself felt and the left heart is more abundantly supplied.

\section{VASOCONSTRICTOR NERVES}

The musenlar coat of the blood vessels is under the influence of two kinds of nerve fibers. namely, those through whose excitation the muscle fibers are caused to contract (vasoronstrictor nerves), and those through whose excitation the muscle fibers are caused to relax (resorlitulor neress). 'The former

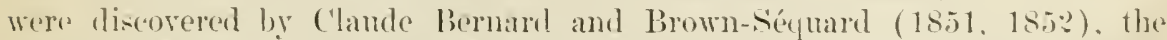
latter by seluiff (185.5) aud C'laude Bernard (18.5). The importance of the rasomotor nerves for the cireulation was first clearly established by Lndwig $(186 t)$.

If the cervical sympathetic be cut, one observes among of her things that the ressels of the ear dilate so that small arteries and reins which were formerly invisible now stand out clearly. If the elge of the ear be snipped off. blood flows more freely from the wound than before section of the nerre. The temperature of the ear is higher than that of the other side. Blood flows 
more rapidly through the organ and does not have time to undergo the changes which it otherwise would in the eapillaries; the color of the venous blood is therefore lighter, and its properties are similar to those of arterial blood.

If now the end of the cervical sympathetic toward the head be stimulated, the arteries are constricted-with powerful stimulation, so much so that their lumen disappears; the venous blood flows slowly and has a dark color: the blood flows but feebly from a fresh cut, and the temperature of the ear falls.

Sinee section of the cervieal sympathetic causes a vasodilation of the ear, and its stimulation constricts the blood ressels in the same ear, it follows that this nerve must contain fibers which preside over contraction of the muscular coat in these vessels-i. e., which are vasoconstrictor fibers for the ear. It follows moreover that these nerves must be under tonic-i.e., continuous-stimulation from the central nervous system.

Now we have nerves running to all, or at least to most, of the arterial regions of the body, which have the same properties as those just deseribed. The vascular tonus maintained by their eonstant stimulation is of the ntmost importance. For should all the ressels for any reason be completely relaxed, there would collect in them, especially in the veins, so great a quantity of blood that the rolume flowing back to the heart would not be sufficient to maintain the necessary supply; the blood pressure would fall to a low level and, although the heart might continue to act for a time, it would be unable to accomplish anything. All of which means that the total quantity of blood in the body is sufficient to fill the blood ressels to the proper extent, only when they are partially constricted.

The vasoconstrietors are given off from the central nervous system in the anterior nerve roots, and are distributed to the sympathetic paths throughout the whole body. The following results have been obtained so far with regard to their course:

Most of the rasoconstrictor nerves pass out from the thoracic portion of the spinal cord. The nerves running to the head arise from the first to the fifth thoracic nerves, pass over into the cervical sympathetic and are distributed to the different parts of the head. This is attested by the fact that stimulation of the cervical sympathetic causes vasoconstriction in all the organs of the head. With regard to the brain, however, results are less positive. While some authors assert that they have found vasoconstrictor nerves for the brain in the cerrieal sympathetic, others have come to the conclusion that although nerve fibers have been demonstrated anatomically for the blood vessels of the brain, in general the blood supply to this organ is not regulated by means of vasomotor nerves, but by alterations in the supply to other organs of the body.

With respect to the further course of these nerves to the head, our information is very incomplete. According to some they pass over into the sympathetic plexuses surrounding the blood vessels, according to others they unite with the cranial nerves. The latter has been demonstrated for the tongue at least, since its vasoconstrictor nerves run for the most part in the hypoglossal.

The vasoconstrictor nerves of the anterior extremities pass out from the spinal cord in the third to the tenth thoracic nerves, those of the posterior extremities in the eleventh thoracic to the third lumbar nerves. It is stated also that the vasoconstrictor nerves of the toes are contained in the sixth lumbar to the first sacral nerves. 
The tail gets its vacoconstrictor nerves from the third to the fourth lumbar nerves; and the dorsal side of the trunk from the posterior branches of the spinal nerves corresponding to the different segments of the back.

The nerves pass from their origin through the trunk of the sympathetic and from there for the most part to the different organs of the body by way of the ehief nerve trunks.

The vasoconstrictor nerves of the abdominal viscera leave the spinal cord by the third thoracic to the first or third lumbar nerves, run for the most part in the splanchnics, and are distributed by them to the different organs of the abdominal cavity. The nerves of the large intestine pass out of the spinal cord in the seventh thoracic to the second lumbar nerves; those of the liver in the sixth thoracic to the second lumbar; those of the pancreas in the fifth thoracic to the first lumbar nerve.

The vasoconstrictor nerves of the organs of generation pass out in the last lumbar and in the first sacral nerves, and proceed to their end arborizations through the hypogastric plexus.

The lungs also possess vasoconstrictor nerves; according to the majority of authors, they leave the spinal cord in the second to the fifth thoracic nerves, and proceed by way of the sympathetic paths to the lungs. Recently the presence of vasomotor nerves in the lungs has been absolutely denied.

Vasoconstrictor nerves apnear to traverse other paths also. Thus we find in the second and third nerves of the cervical plexus vasoconstrictor fibers for the tip and lateral parts of the ear, which reach their destination by way of the auricularis cervicalis nerve. It is further asserted that the vagus convers rasoconstrintor nerves to the heart, to the stomach, to the intestine (not confirmed by all authors) and to the lidncys, and also that in it are contained vasoconstrictor fibers for the lungs. It is indeed not impossible that these fibers might arise from the sympathetic (since it is definitely asserted that the vasoconstrictor nerves in the auricularis cervicalis arise in the thoracic sympathetic and run through the stellate ganglion), and it is also conceivable that they actually belong to the branches of the vagus.

liecaun of the great vaseular territory committed to their control the splanchnirs play the most important part of all rasomotor nerves. For this reason the libod pressure falls after bilateral section of these nerres, and show a very great rise on stimulation of them.

Constricting nerve fibers have been demonstrated also for the veins. If the aorta be tied off immediately below the origin of the left subelavian, and the blond supply to the hinder part of the body be thereby cut off, stimulation of the splanchnics drives through the inferior vena cava into the right heart a quantity of blood which runs up to twenty-seven per cent of the total quantity in the animal. According to Mall, this is caused by contraction of the portal system.

Constrictor effects of nerve stimulation in other reins are mentioned by different authors; but R. F. Fuchs has published experiments in which he obtained no active constriction of the reins either by direct stimulation of the reins themselves or by electrical stimulation of nerves, wherefore he denies entirely the presence of vasomotor nerves for the veins.

Finally, the musculature of the vessels contracts under high internal pres- 
sure and relaxes in ennsequence of a fall in pressure. Aceording to Bayliss these ehanges are entirely independent of the central nervous system and ean be demonstrated under natural conditions as well as in exsected arteries.

\section{\& 10. VASODILATOR NERVES}

If the lingual nerve be stimulated. and attention be direeted to the submaxillary gland. the ressels of the gland may be seen to dilate. The veins of the gland swell up, the blood flowing in them takes on a brighter eolor, and sometimes actual pulsations appear in them. From this it follows that this nerve contains fibers, the stimulation of which cause the vessels of the gland to dilate. Such nerves are described as resodilutor nerres.

Where these nerves oceur unmixed with rasoeonstrictor nerves, one meets with no diffieulty in demonstrating them. Where they are mixed with such nerves for the same organ, it is necessary to adopt a special order of experimentation, hecause the rasoconstrictor effect of stimulation often. if not always. predominates. $A$ strong vasodilation appears as an after-effect of the simultaneous stimulation of both kinds of nerres. The two are, therefore, not strictly antagnnistic, but must affect the ressels at different points, just as the two kinds of cardiac nerves have different points of application in the heart (V. Frey; ff. page 193).

On the other hand, weak stimulation of the constrictor nerves is overeome by stronger stimulation of the dilators. This appears, for, example, in the ease of the submaxillary gland with the cervieal sympathetic intact. Although the ressels of the submaxillary gland are under the influence of the constrietor fibers eontained in this nerve, stimulation of the lingual produces vasodilation.

If a nerve trunk be ent in two transversely, and the animal be allower to live. degeneration of the peripheral stump appears in a short time. If the degenerating nerre be stimulated some four days after the section. vasodilation is obtained (Goltz). whereas stimulation of the fresh nerre causes rasoconstriction. This means that the dilator nerves retain their irritability somewhat longer than the constrictor nerves after connection with the central nerrous system has been destroyed.

By appropriate variation of the stimulus the presence of dilator fibers can be demonstrated also in freshly ent nerves. Thus it has been shown that the latter are more irritable than the enstrictor nerves if the stimulus is weak or is applied rhythmically at a slow rate (Ostroumoff. Bowditch).

Finally, it has been found that eren if the two kinds of nerve fibers run in the same peripheral nerve trunk, they make their exit by way of different roots of the spinat rord. and can be separated one from the other by this means (Dastre and Morat).

Other eharaeteristies of the dilator nerves are the following: (1) the latent period for their stimulation appears to be somewhat longer than that of the constrictor nerves; (2) whereas the maximum effect of the constrictors is quickly reached, that of the dilators takes more time: (:) the after-effect is longer.

The Course of the Tasodilator Nerves. - We have already become aequainted with the vasodilator nerves which traverse the lingual nerve to the submaxillary 
gland. They come from the facial and pass by way of the chorda tympani to the lingual. In the same path are found also the dilator nerves for the anterior two-thirds or three-fourths of the tongue. The dilator fibers for the posterior part of the tongue, for the anterior pillars of the fauces, and the tonsits run in the trunk of the ytossopharyngeat.

The rasodilator fibers of the mucous membrane of the lips, the cheeks, the hard palute and the externat nares. as well as of the corresponding parts of the skin of the face comes from the second to the fifth thoracie nerves, traverse the cervical sympathetic and unite for the most part with the trigeminal, which itself also contains fibers of this kind for the face and for the eye (Dastre and Morat).

The ear gets its dilator fibers from the eighth cervical and first thoracic nerves.

The dilator nerves of the anterior extremities leave the spinal cord from the fifth to the eighth thoracic: those of the posterior extremities probably in the second to the fourth lumbar nerves. Here we meet with the remarkable eireumstance that the latter nerves pass out exelusively in the posterior roots of the lumbar nerves (Strieker. Bayliss; ef. Chapter XXII). The presence of vasodilator nerves in the posterior roots of the brachial plexus has been asserted also. We have the following faets with regard to the dilator nerves of the abdominal organs: Vasodilator fibers in abundance are found in the seeond to twelfth thoracic as well as in the first and second lumbar nerves of the dog: the twelfth and thirteenth thoracie contain a number of these in their dorsal roots; the splanchnies and the upper thoracic nerves contain the rasodilator fibers for the organs of the abdomen.

The ragus is said to convey vasulilator nerves for the coronary arteries of the heart. Most of the dilator nerves for the coronary vessels however traverse the sympathetic pathways. They probably pass out of the spinal cord, and reach the heart by way of the stellate ganglion (ef. Fig. 67, page 191).

According to some authors the lungs receive dilator fibers from the cervical sympathetic as well as from the ragus.

The ressels of the mucous membrane of the $\operatorname{laryn} x$ are provided with dilator nerves from the superior laryngeal.

Vasodilator nerves which play an essential rôle in the ereetion of the penis pass to that organ by way of the anterior roots of the first to the third saeral nerres, and the hypogastric plexus.

\section{\$11. VASOMOTOR REFLEXES}

Like the cardiac nerves. the vasomolor nerres are stimulated reflexly, and the blood supply to the various organs as well as the arterial blood pressure is rariously influenced.

We lave different observations tending to show that vasomotor reflexes can be discharged by the ressels themselves, so that the ressels may be said to participate in the reflex regulation of their own functions. Whe know also that these reflexes are set up by all other possible kinds of afferent nerres.

The reflex takes effect primarily in the same vascular region whenee came the afferent impulse. Possibly the congestion which has long been known to take place on rubbing or warming the skin belongs to this class of reflexes. also the congestion which is seen in the intestine when the abdominal carity is opened. 
Generally speaking the result of these localized reflexes is a vasodilation, but under certain circumstances vasoconstriction may be the result. The reflex may spread to the corresponding part of the body on the opposite side, and not infrequently parts far removed from the region innervated by the atferent nerve show a reflex constrietion or dilation of their vessels. Thus the vast region innervated by the splanchnics is very easily constricted by stimulation of all possible kinds of sensory nerves. It may also be dilated as the result of a sensory excitation. The vessels of the skeletal muscles as a rule appear to be dilated by sensory impulses. The dilation appears first in the muscles which stand in close functional relationship with the nerves stimulated: but it may be called out also by excitation of distant afferent nerves.

If these reflex effects are not confined within too small a rascular field, they influence the general blood pressure.

Since in almost every afferent stimulation, vessels somewhere are constricted and others dilated, it is evident that ehanges of pressure may take place in both the po.itive and the negative direction.

As a rule, afferent excitation prodnees a reflex rise of pressure (Fig. 9\%). Under certain circumstances a fall is obtained instead, for example: when

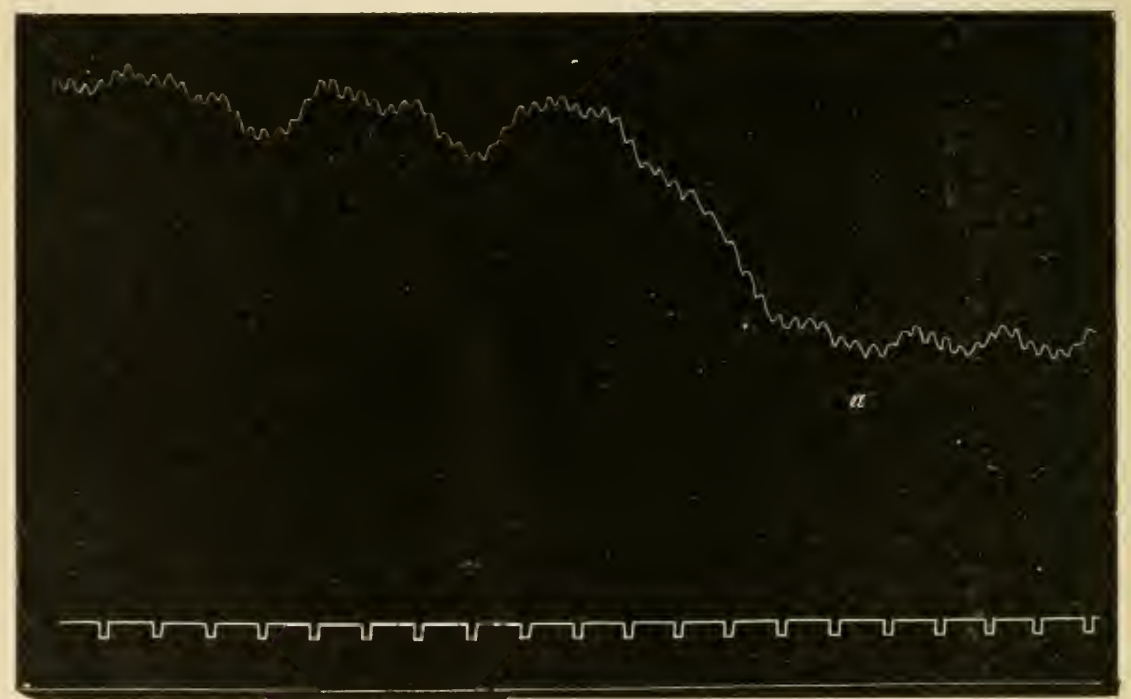

FIG. 97.-Reflex rise of blood pressure in the rabbit (to be read from right to left). At $a$ the skin was stimulated.

the afferent nerve stimulated is subjeeted to the cold; when after having been sectioned it is allower to regenerate to a certain stage; if the stimulus is weak.

At present it is impossible to decide whether these different reflexes are caused by two kinds of efferent nerves or by the difference in behavior of the vasomotor center to stimuli of different strength. There are nerves however which. so far as our present information goes, mediate only a fall of pressure, whatever the strength of stimulus. Such a nerve is the depressor, already 
mentioned at page 193. The afferent nerves from the muscles have the same influence on the blood pressure (Fig. 98).

The reflex fall of pressure on stimulation of the depressor appears with both vagi cut; hence, it is independent of changes in the heart frequency and is caused essentially by a vasodilaticn. This involves primarily the region of the abdominal cavity innervated by the splanchnies, although other parts of the body may take part in it.

The reflex rise of pressure is produced primarily by a contraction of the vaseular region innervated by the splanchnies, even though other regions also

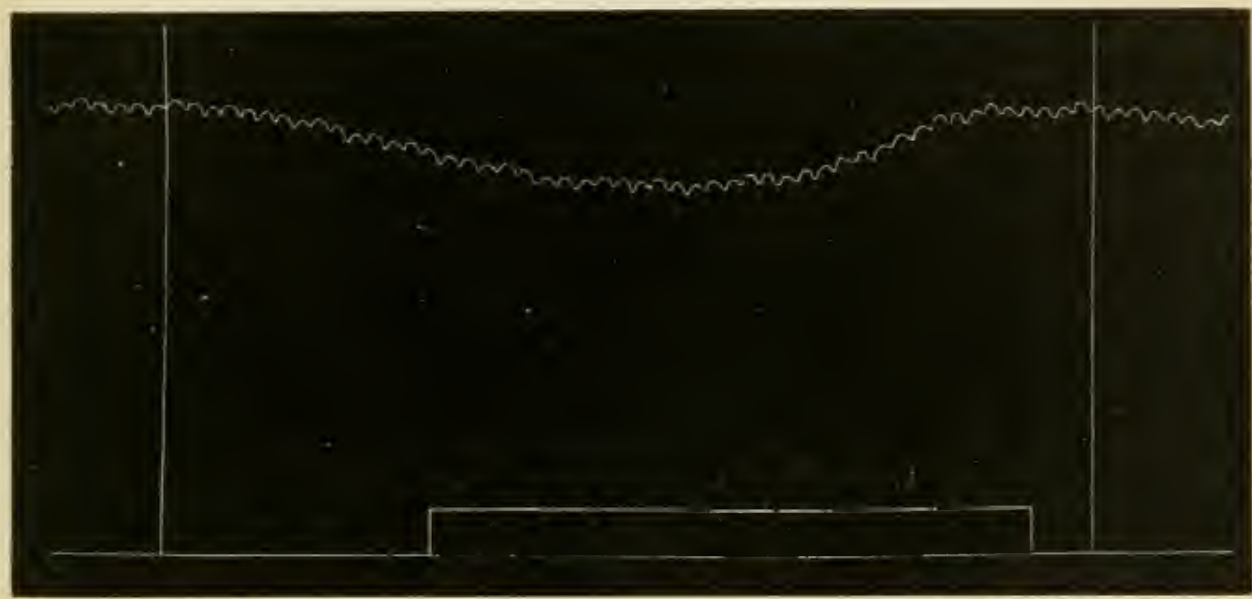

FIg. 9.5.-Reflex fall of blood pressure in the rabbit produced by stimulation of an afferent muscular nerve (to be read from right to left). The period of stimulation is indicated by the vertical lines. $\longrightarrow=$ ten seconds.

may be concerned. Not all the vascular regions of the body are constricted, at least not to the same extent, when the pressure rises; for vasodilatation has often been observed in different organs, especially in the muscles.

It is difficult to decide in many cases whether a given dilator effect is active or passive. It may be that with an increase of pressure produced by an extensive contraction of the splanchnic region, various other regions dilate only beciuse of the high pressure. Or it may be that dilatation is actively produced, either by a decline in the tonus of the constrictor nerves or by stimulation of the dilator nerves.

A fall in pressure obtained reflexly is caused by a reduction of tonus in some of the great vaseular regions. But as in the case of a rise of pressure, the reduction may be due either to stimulation of dilator nerves, or to diminished activity of the constricters. After excluding all the vasoconstrictor nerves of the hind limb, Bayliss suceceded in demonstrating vasodilatation in the same region by stimulation of the vagus. In this case, therefore, the dilatation took place through the activity of the vasodilator nerves.

\section{\$ 12. THE VASOMOTOR CENTERS}

We have no positive data as yet for the location of centers for the rasodilator nerves. 'These nerves have been followed far into the eentral nervous 
sytem. and it is very probable that their chief renter. like the centers of the other regetative functions, lies in the medulla oblongata.

The chief center for the rasoconstrictor neres is positively known to lie in the medulla. In the rabbit it nceupies on each side a small prismatie space: in man in a cross section taken at the level at which the facial nerve passes off. it appears as one or more aggregations of gray matter on the median side of the facial tract. From this center the rasoconstrietor nerves deseend chiefly. but not exclusively, in direct paths along the enrd and pass out in the nerre roots already mentioned (page ?3:). As we have scen, the center is under tonic stimulation. If by transecting the rord, its influence be cut off. the vaseular tonus falls and as a consequence the blond pressure becomes considerably less.

But the rascular tonus is not entirely obliterated by this operation. On the entrary. it has been shown that throughout the entire length of the spinal cord, with the exception only of the cervical region. and the lowest part of the lnmbar, there are centers for the vasoconstrictor nerres which can he stimulated both reflexly and by asphyxiation. These eenters appear to be less excitable than the rasomotor center in the medulla (although this is denied). They do not reast sn promptly as that center: but their aetivity lasts longer: and in virtue of their greater endurance they appear to be of no less importance for the maintenance of vascular tonus.

Experiment has shown also that after destruction of a large part of the spinal cord, the tonus of the ressel may be gradually restored. The ressels which reeeive their constrictor nerves from the destroyed part of the spinal cord are at first entirely paralyzed, and they are dilated to their maximal extent. But gradually their tonus returns; they react to local application of cold and heat much the same as in the normal condition. but are not influenced by distant parts of the body (Goltz and Ewald). Either the rascular wall itself must have the property of contracting in a tonic manner. when it is entirely isolated from the central nerrous system, or this tonic eontraction is caused by ganglion cells strewn along the peripheral course of the vasomotor nerves, which then serve as vasomotor centers of a third order. A definite decision letween these two alternatives is not possible, and the inherent probability of the one or the other naturally shapes itself according to one's inclination to ascribe greater or less importance to the peripheral ganglia.

The fact remains however that ressels entirely isolated from the central nerrous system ean recover their tonus. And the action of the vasodilator nerves favors the idea that vascular tonus is, at least in part, of peripheral origin. We know of no muscles whose coutraction could eause the vessels to dilate. Dilatation must be caused therefore by diminishing the actirity of the circular muscle fibers-i.e., vasodilator nerves must be a kind of inhibitory nerves. Ther can (ven exercise their characteristic influence upon the ressels when all the vasoconstrictor nerves to the same part of the body have been ent. In other words. a certain tonus of the ressels remains after section of the constrictor nerves, which however is entirely obliterated by stimulation of the vasodilator nerves.

We can form the following conception, therefore, of the innervation of the blood ressels. The musculature of the vessels is under the influence of the central nerious system and of peripheral structures. In the former is found 
the vasomotor center located in the medulla, which constitutes the chicf center of the vasoconstrictor nerves. The centers distributed in the spinal cord represent centers of the second order. and the peripheral ganglia or the musculature of the ressels. as the case may be, represent centers of the third order. The last named can cxert a powerful influence even when they are isolated from the others. As a rule. the musculature of the ressels is in a state of tonic contraction because of impulses passing out over this chainlike series of centers. The contraction is more or less weakened by stimulation of the rasodilator nerves, since they exert an inhibitory influence on the peripheral mechanism.

The parts of the brain above the medulla, especially the motor zone of the cerebrum, influence the blood ressels. With regard to this influence, I believe with Fr. Franck that it is to be conceived in the same way as that produced by the same parts upon the cardiae nerves-i. e., that the vasomotor center of the medulla is set in action by these parts of the brain in exactly the same way as it is stimulated by the other parts of the body through their afferent nerves. And just as we have seen that in muscular activity the acceleration of the heart is conditioned by this influence of the cerebrum upon the medulla, we may infer from the facts which we already have that the ehange in rascular tonus taking place in muscular work are produced by a similar influence.

\section{\$ 13. GENERAL CONSIDERATIONS ON THE DISTRIBUTION OF BLOOD IN THE BODY}

The distribution of blond in the body depends partly upon mechanical conditions, but chiefly upon the rasomotor nerres.

\section{A. MECHANICAL IMFLUENCES}

To these belong first the caliber of the afferent arteries; the greater the ealiber, the greater, other things being equal, must be the supply of blood to the part. Moreover the attitude of the body plays a prominent part especially in the flow of blood in the veins. In the upright position, for example, the veins of the lower extremities are dilated because of the hydrostatie pressure of the blood column, and they contain a large quantity of blood. In changing to the horizontal position the rich supply of blood to the lower extremities deereases. The quantity which is shifted in this way amounts in a grown man to about 100 g. (Mosso).

The influence of the respiratory movements on the circulation has already been discussed. With a positive pressure in the thoracic cavity, for example, in severe museular effort, when the lungs are inflated and the glottis is closed, the return flow of blood to the heart is hindered and the quantity in the extremities increases.

If with the body in a vertical position, the head being upward, the splanehnies be eut so as to paralyze the great vascular region of the abdominal viseera, and the respiration be then interrupted, the circulation stops at once. The dilated vessels of the abdomen eontain so much blood that the heart no longer receives a suffieient supply. In sueh cases, lowever, the eireulation can be restored to some extent by respiratory movements. the blood heing drawn by the aspiration of the thorax from the vena cave to the heart (Hill and Barnard). 
An increase or decrease of turgor in a certain part incident to different positions of the body must evidently produce in other parts changes of an opposite character. The volume of one arm is greater when the other is held passively above the head; the volume of the hand increases when both fcmoral arteries are compressed, etc. Reflex activity of the rasomotor nerves often comes in here to influence the result.

\section{B. THE INFLUENCE OF VASOMOTOR NERVES}

In general one may say that under normal circumstances every part of the body receives exactly as much blood as it has need of, and that by dilatation of ressels a particular part receives more blood the more active it is. At the same time blood vessels in other parts of the body are constricted, and in this way the normal blood pressure necessary for life is maintained by an incessant reciprocity between the different vascular regions.

In the state of bodily rest the organs of the thorax and abdomen contain a relatively large part, as a rule more than half. of the total quantity of blond in the body. The content of blood in these oroans amounts to about twenty per cent of their weight, while the blood content of the skin, skeleton, muscles and the nervous substances amounts to only two to three per cent of their weight (Ranke et al.). The blood stored up in the internal organs is always at the disposal of any organ which has need of a larger supply.

Thus in muscular work the vessels of the muscles and skin are dilated, while at the same time the vessels innervated by the splanchnic nerve are constricted to a greater extent. Consequently the blood pressure as a rule, if not alirays, increases.

By the use of apparatus constructed for the purpose of determining the relocity of the blood, the quantity flowing through some of the organs in a given time has been measured directly (cf. also page 211). In the dog Tschuewsky found the quantity per minute and per $100 \mathrm{~g}$. of organ to be 3.4 c.c. for the hind limbs with the nerves intact, and 9.9 c.c. after section of the nerves. The head received 16.6 c.c., muscles with uncut nerves 13 c.c., the thyroid gland 590.9 c.c. (!), all per minute and per $100 \mathrm{~g}$. of organ.

In the researches of Chauvean and Kaufmann the quantity of blood flowing through the levator superiorus proprius muscle of the horse was: in rest, or the average, 17.5 c.c. per $100 \mathrm{~g}$. ; in activity, it rose to 85 c.c. According to Bohr and Henriques, the dog's heart receives on the average 30 c.e. per minute per $100 \mathrm{~g}$.

In view of its function of removing from the body the nitrogenous products of metabolism, the kidney receives a relatively large quantity of blood, especially if great demands are made upon it by transfusion of a diuretic agent (cf. Chapter XIII). There then flows through the kidney (dog) per minute a quantity of blood which amounts to one humdred and forty per cent of its own weight (average ninety-six per cent). In the same animal the quantity of blood expelled from the left heart per minute may be estimated at abont ten per cent of the body weight. Hence, in strong diuresis the blood supply to the kidney would be relatively fourteen times as great as to all the organs taken together.

Furthermore the distribution of blood to the different parts of the body exhibits incessant fluctuations produced by the vasomotor nerves, which are connected either with the activity of the organs, or with the heat regulation of the body; for the heat regulation is controlled in the main by vasomotor nerves (cf. Chapter XIV). 
The blood flow to the brain calls for a special discussion. In the child while the skull is not yet completcly ossified, the great fontanel exhibits pulsations which are undoubtedly eaused by the heart beats and by the respiratory movements, and which show moreover that the blood supply to the brain may vary under different circumstances.

How far this is true in the mature, uninjured skull has been much debated. Were the skull cavity rigidly elosed on all sides, and were the brain substance nearly incompressible, the same quantity of blood should be present in the brain at all times. But this would not be true, if water or other material were secreted from the blood vessels or otherwise extravasated; for then the quantity of blood equivalent to the volume of material poured out of the vessels would be displaced. Otherwise blood flowing away by the veins would always make room for the blood flowing in by the arteries.

But it has been shown that this conclusion is not strictly correct, and that the quantity of blood in the brain can in fact increase and decrease. The skull cavity is not surrounded on all sides by solid bony walls. It communicates with the spinal canal, between the inner surface of which and the outer surface of the dural sac are numerous venous plexuses connected with the veins of the general system. The foramina intervertebralia are filled with a vacuolated tissue, which can be pressed outward. The subdural space communicates with the deep lymph ressels and glands of the neck, as well as with the lymph tracts of the peripheral nerves.

The subarachnoid spaces are likewise in connection with the lymph tracts of the peripheral nerves. The cerebrospinal canal therefore must be regarded as a rigiel-walled cavity with an elastic door.

Now it has been found both by experiments on animals, and by physical (Grashey) and mathematical (Lewy) calculations, that the regulation of the blood flow to the brain takes place in exactly the same way as in the other organs-i.e., dilatation of the arteries produces an increase in the flow, constriction a diminution. Any stasis of venous blood canses an arterial anxmia, just as does a serere compression, as for example by a foreign body forced into the skull eavity. So long, therefore, as it is a question only of the alterations in arterial volume, which correspond to the physiological needs, the cireumstance that the brain is inclosed by a solid, unyielding capsule is of no essential importance.

Jensen has fomnd that the quantity of blood flowing to the brain of a rablit is on the average 136 c.e. per $100 \mathrm{~g}$. per minute (extremes $60-278$ c.c.). In the dog he found as a mean of two researches $138 \mathrm{ec}$. The brain receives relatively more blood than any of the other organs thus far studied except the thyroid gland.

References.-R. Tiegerstedt, "Lehrbuch der Physiologie des Kreislanfes," Leipzic, 1893. 


\section{CHAPTER VII}

\section{DIGESTION}

THe purpose of digestion is to so change the foodstuffs that they can pass into the blond and be utilized in metabolism. To this end the food is subjected to mechanical division and chemical transformation in the digestive organs.

Of all the combustible constituents of our diet, only sugar is soluble in water. Starch and coagulated proteid are insoluble in water : but by digestion they are so changed that they can be taken into solution. Fat also, which is insoluble in water. is transformed so that it can be absorbed from the alimentary tract into the blood.

The organic foodstuffs, which are already soluble, undergo transformations in the alimatary eanal which adapt them to the requirements of metabolism. The noneombustible eonstituents of the diet. water and the salts, do not require to be digested in order to be taken into the blood.

In man the work of the digestive system is materially aided by the preparation of " dishes" of food. since the foodstuff's are thereby rendered more easily accessible to the digestive fluids.

The heat necessary to boil or roast meat swells the comneetive tissue, which holds the muscle fibers together, and changes it partly into gelatin. The meat at the same time becomes less compact, and so is the more readily reduced to fine bits by our teeth. In the eooking of regetable foods, the cell membranes are ruptured by the heat and the starch granules are transformed into a soluble modification. In bread baking the dough is rendered spongy by the earbon dioxide formed in "raising," and this is earried still further by the heat of the oven, by which also the starch granules are transformed in the same way as in ordinary cooking.

\section{FIRST SECTION}

\section{THE DIGESTIVE FLUIDS}

\section{\$1. GENERAL SURVEY}

The fluids secreted by the digestice glands serve either to change the chemical nature of the foodstuffs so that they shall be fit for absorption. or they aid the processes going on in the alimentary eanal in some other way. rertain products also which are given off with the digestive fluids are des- 
tined merely to be eliminated from the body. In this section we shall consider in the main only the constituents important in digestion.

In order to study the chemical properties and the action of the different digestive fluids, one may use either extraets of the appropriate glands or the natural secretion collected from their ducts. In the latter case the duet is shifted from its normal connections and is made to open as a fistula on the outer surface of the body. so that it conveys the secretion to the exterior.

The first fistula of a digestive gland to be the subject of a thoroughly seientific investigation was one resulting. from a gunshot wound in the stomach of a Canadian hunter. As a consequence of his accident, the hunter had all the lest of his life a stomach fistula opening at the upper part of the abdomen, through which the interior of the stomach could be observed and gastric juice could he obtained. From observations on this man extending over a number of years (1525-1833) Beaumont collected a large number of important facts enncerning the digestive process in the stomach, and concerning the movements of that organ. Later Bassow and Plondlot (1St2) showed how a stomach fistula may be made on an animal. Sinee that time such fistulx have been made for therapeutie purposes on man himself, and they have been used to good advantage for the study of gastric digestion.

The pancreatic juice is obtained by means of a cannula fastened in the duet of Wirsung, or from the open duet sutured to the abdominal wall, or finally by isolating that portion of the intestine into which the duet opens and bringing it forward to the abdominal wall.

In order to study the secretion of bile. fistula are made in the gall bladder. The ductus eholedochus can be tied off and the bile can thus be entirely shut out of the intestine. or the duet ean be left open. so that the bile flows as usual to the intestine exeept when the fistula is open (amphibolous biliary fistula). The intestinal loop erntaining the mouth of the duet ean also be reseeted and brought forward to the abdominal wall. Br the last method espeeially it is possible to observe how the bile flow is affeeted by different kinds of food.

To obtain pure intestinal juice a loop of the intestine is isolated, one end of it is sutured to the skin and the other is closed (Thiry's fistula): or both ends may he sutured to the skin (Vella's fistula), in which ease the intestine is of course more aceessible.

The most important constituents of the digestive fluids are certain enzymes which may be classified in three groups: proteid disonlving (proteolytic). sugar forming (diustatic or amylolytic) and fat splitting (lipolytic). All of the digestive enzrmotic processes agree in this. that the organic fondstufls acted upon absorb the constituents of water and are split into simpler compounds (hydrolytic eleavage).

The enzynes are formed in the different glands of the alimentary canal; namely, the proteolytic in the glands of the stomach and in the pancreas: amylolytic in the salivary glands. in the panceas and in the glands of Lieberkiihn of the small intestine, lipolytic in the mucous membrane of the stomach and in the pancreas.

Two enzymes which aet on the same foodstuffs are not necessarily identieal. For example, pepsin from the gastrie glands aets on proteid in an acid medium, while trypsin from the pancreas acts on proteid in neutral and alkaline media. 
The enzymes are. so far as we know, formed in the glands themselves. During the intervals between meals they are deposited in the glands, to be poured out when required for digestion. But we do not find the finished product in the glands: insteal, precursors of the enzymes, the so-ealled zymogens, are claborated in them and are transformed into the enzynes either during the act of secretion or in the secretory product after it is given off (Fig. 99).

Artificial digestion is often employed in sturlying the action of the digestive fluids on the foodstuffs-i, e., a given food is mixed either with the fluid secreted by a gland or with an extract of the gland, and the mixture is kept for a time

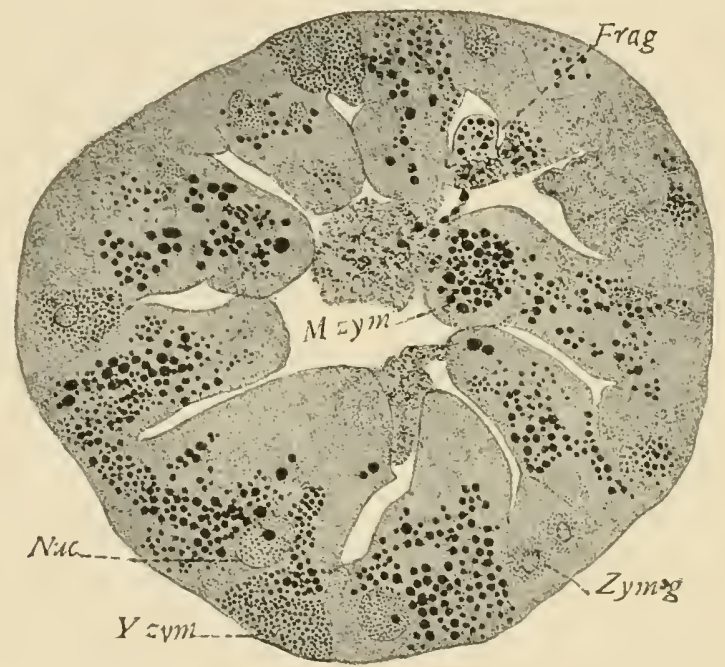

Fig. 99.-Transverse section of the hepato-pancreas of an isopod crustacean, fixed in osmic acid, showing the gradual transformation of zymogen granules into secretion droplets, after Murlin. The zymogen granules appear first immediately about the nucleus $\left(Z y m^{\prime} y\right.$.). As the cell grows in size the granules increase in number so as to almost fill the cell ( $Y$. zym.). Still later they absorb fluid from the protoplasm and swell up, being finally discharged from the free border of the cell as secretion droplets $(1, z y m$.). Fray., fragment of a cell broken off and lying in the lumen of the gland; $N u c$. , nucleus of a mature eell.

at body temperature. A great mass of important facts has been obtained in this way; but we cannot apply the results of artificial digestion to the natural process in the body withont some reservation. For, even neglecting the mechanical work of the alimentary canal, there are several important differences between the two. (1) In natural digestion the fluid is always adapted in quantity and quality to the quantity and character of the food acted upon, while in artificial digestion both the quantity and the character are fixed for a given experiment. (2) In the natural process the products of digestion are removed by absorption as soon as they are formed; in artificial digestion they remain in the mixture. This is of no small consequence; for in the one case the course of digestion is affected by the presence of these products (cf. page 38 ), while in the other this is prevented by their prompt removal from the sphere of action. (3) Finally, in the normal course of digestion the different secretions may influence each other so that the final result may be essentially modified. 
Mett employs the following method of determining the strength of a proteolytie enzyme in a digestive Huid. Fresh white of egg is sucked into a narrow glass tube, the tube is dipped into water at $95^{\circ}$ and is then allowed to cool slowly. The tube is now broken into small pieces and one of them is placed in the fluid to be tested. The number of millimeters of the coagulated albumin dissolved in a unit of time affords a measure of the enzymotic action. Amslolytic action ean be determined in a similar way by means of tubes eontaining colored starch paste, and lipolytic action by finding the amount of fatty acids set free in a given time from a known quantity of neutral fat.

\section{§. SALIVA}

Saliva is secreted by the three pairs of large salivary glands located in the neighborhood of the buecal cavity and opening into it by their several ducts, and also by small glands embedred in the mucous membrane of the inouth.

'The product has a varying constitution according to the gland by which it is formed, and on the basis of the characteristic properties of their secretions the salivary glands may be divided into two chief groups. One group, called albuminous glands, produce a thin, watery secretion, which contains only proteids, salts, and in certain cases a diastatic enzyme. Here belong the parotid gland of all mammals, the submaxillary of the rabbit, some of the glands in the nose and tongue, and the lachrymal glands. The other group-the mucous glands-secrete a more or less viscid fluid, which contains mucin as its characteristic ingredient, besides salts and small quantities of proteid. This group includes the submaxillary glands (with few exceptions), the sublingual, part of the buccal glands, those in the mucous membrane of the pharynx, the larynx, trachea and oesophagus. There are also mixed glands-e. g.. the submaxillary of man-in which a part of the gland conforms to one of these types, and a part to the other.

The mixed saliva of man is a colorless or light-blnish. turbid, odorless, slippery and riseid fluid, which upon standing for a time separates into an upper, transparent and a lower, turbid layer, the latter consisting of mucous flakes, salivary corpuscles, epithelial scales from the month, ete. The reaction as a usual thing is weakly alkaline although it may be neutral, or eren weakly acid. It is asserted that the reaction early in the morning is weakly acid, neutral or amphoteric, that after every meal it hecomes alkaline and then gradually returns to the neutral or weakly acid reaction. The specifie gravity is $1.002-1.009$.

The chief constituents of mixed saliva are: proteid, mucin, a diastatic enzyme (ptyaliu), and potassium sulphocyanide (KCNS). ${ }^{1}$ Besides, we find inorganic salts, gases and traces of ammonia, nitrons acid, urea, ete. Certain drugs also are remored from the blood in the salivary secretion.

lecording to recent analyses, the human saliva contains $98.8-99.5$ per cent water, and $0.5-0.2$ per cent solids of which $0.1-0.4$ per eent is organic: the

${ }^{1}$ We can only say with regard to this substane that its $\mathrm{N}$ and s probably come from proteid. It has been assumed to confer an antiseptic action on the saliva, but this is not confirmed. 
salt content is 0.1-0.2 per eent and the KCSS, $0.003-0.01$ per cent. The quantity of mixed human saliva secreted in twenty-four hours is about 1.500 (.e.

The Diastatic Enzyme.-In 1831 Leuchs found that saliva gradually dissolves starch and converts it into the soluble carbohydrates, dextrin and sugar. This action is to be ascribed to an enzrme, called ptyatin.

Dry starch is not soluble. but it swells up in warm water, forming stareh paste. On heating stareh with glycerin up to $190^{\circ}$, or by acid fermentation of the paste. it is rendered soluble. Soluble stareh is also the first product of digestion under the action of ptralin. In the further course of this action soluble starch is split by absorption of water into dextrin. isomaltose, and maltose. There is present in saliva a trace of an inverting enzrme. maltase. ${ }^{1}$ which converts a small quantity of maltose into dextrose (Röhmann).

More in detail, this transformation of stareh into sugar proceeds about as follows: First the solulsle starch is split into erythroulertrin (red color with iodine) and maltose. Then from the ervthrodextrin is formod an arhroodextrin (no color with iodine) and more nualtose, and achroölextrin in its turn vields another achroödextrin and more sngar, ete.

In artificial digestion starch can nerer be completely changed into sugar. But if the experiment be so arranged that the sngar can be removed by dialrsis as it is formed. the transformation may be carried much farther than is possible otherwise (Lea). Since provision for removal of the sugar is made in the digestire system, it is probable that all the starch is transformed, provided only that the ptyalin has the opportunity of acting long enongh.

Human saliva acts very rapidly. Then equal volumes of saliva and starch paste are mixed. at londy temperature the stareh disappears in abont two and a half hours. Cooked starch is digested more rapidly than raw, and pulverized starch more rapidly than nompulrerized.

Ptyalin appears to act more powerfully in a neutrat or ueakly acid medium: hence best results are obtained when the alkaline saliva is carefully neutralized by addition of a rery small quantity of acid (not more than $0.000 \%-0.001:$ per (cent $\mathrm{HCl}$; Cole).

\section{§. GASTRIC JUICE}

Gastric juice cannot be obtained pure from an ordinary gastric fistula, for eren if the particles of food could be excluder. it would be mixed with some saliva which had been swallowed. In the dog, howerer, these difficulties can be orercome, by making both a stomach fistula and an resophageal fistula (Pawlow). The stomach ean also be cut off from both csophagus and duodenum, the latter two sutured together, and the juice collected from the isolated stomach (Fremont).

Gastric juice obtained in this way, when it is freed from the stomach mucus, is perfectly elear in color, acid in reaction and is dernid of foreign taste. Its specific grarity is $1.003-1.0039$. In a laver $20 \mathrm{~cm}$. long it rotates the plane of polarized light $0.20^{\circ}-0.2 .3^{\circ}$ to the left. Its dry residne amomts

'In general the enzymes are named by adding the suffix ase to the name of the substance on which it acts. Exceptions to this rule are older names still in use. 
to $0.29-0.60$ per cent, the ash to $0.10-0.17$ per cent. It contains neither peptone, nor leucin, nor tyrosin, but always contains proteid, and at times traces of fatty acids. At a low temperature it becomes turbid, and separates into three layers: an upper clear layer, a median turbid layer, and a lower one consisting of a sediment of small, homogeneous, strongly refractive granules.

The analysis by Schumow-Simanowsky of the pure gastric juice of the dog is as follows:

\begin{tabular}{|c|c|c|}
\hline Acill & \multicolumn{2}{|c|}{$0.46-0.58$ per cent. } \\
\hline Chlorine..... & $0.49-0.62$ & \\
\hline Dry residue $\ldots \ldots \ldots \ldots \ldots \ldots \ldots$ & $0.43-0.60$ & .• \\
\hline Asi $\ldots \ldots \ldots \ldots \ldots \ldots \ldots \ldots \ldots \ldots \ldots \ldots \ldots \ldots$ & $0.09-0.16$ & " \\
\hline 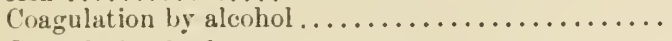 & $0.14-0.19$ & “ \\
\hline Coagulation by heat...$\ldots \ldots \ldots \ldots \ldots \ldots$ & $0.13-0.18$ & “ \\
\hline Precipitation at $0^{\circ} \mathrm{C} . \ldots \ldots \ldots$ & $0.011-0.003$ & “ \\
\hline Phosphoric acid $\ldots \ldots \ldots \ldots \ldots \ldots \ldots \ldots$ & 0.004 & ." \\
\hline
\end{tabular}

Gastric juice inverts cane sugar, digests proteid, gelatin and gelatinforming substanees, coagulates milk and splits emulsified fats into fatty acid and glycerin.

The inversion of cane sugar is accomplished by the acid, the digestion of proteid, etc., by pepsin, the coagulation of milk by rennin, the cleavage of emulsified fats probably by a third enzyme, the gastric steapsin. We have now to study more closely the acid and these enzymes of the gastric juice.

\section{A. THE ACID OF THE GASTRIC JUICE}

Proof was given by Prout as early as $184 t$ that the acid reaction of the gastric juice is due to free $\mathrm{HCl}^{1}$; but it was not ineontestably established until ('. Schmidt (1852) by his convincing analyses showed that more chlorine is secreted by the mucous membrane of the stomach than can unite with all the inorganic bases, including ammonia, present in the gastric juice.

The percentage of $\mathrm{HCl}$ in the gastric juice is very different in different animals. In the dog it amounts to $0.46-0.58$ per cent; and in the case of a boy with a complete cosophageal stricture and a stomach fistula, it was found to be $0.39-0.5$ per cent. In other fistulous patients $0.05-0.3$ per cent has been observed.

When proteids are taken into the stomach. the $\mathrm{HCl}$ unites with them, and later with the products of their digestion (Sjöquist). On this account and because the $\mathrm{HCl}$ reacts with the phosphates of the food with liberation of phosphoric acid, great difficulty is experienced in determining the quantity of $\mathrm{HCl}$ in the stomach contents, and in following its quantitative rariations. Nevertheless. the mucous membrane secretes more acid than is necessary to eombine with the proteid, ensequently free acid ean alwars be demonstrated, at least in certain stages of digestion.

The $\mathrm{HCl}$ combined with proteids seems to insure their digestion; the conception that only free acid could be of importance is therefore not sound.

${ }^{1}$ Lactic acid found in the stomach is probably formed by bacterial decomposition of carbohydrates. 


\section{B. PEPSIN}

After Spallanzani (about 1is0) laad shown that the gastric juice can produce chemical changes outside the boly. Eberle (1834) was the first to demonstrate the same effects with extracts of the gastric muensa, and schwann (1836) pointed out that a substanee formed in the mucosa, which he named pepsin, is involved in this aetion.

Under this name is described the enzyme which acts in acid medium upon proteid, gelatin and connective tissues. cansing them to absorb water and to split into simpler compounds. Pepsin has no effect in neutral solution, and is destroyed in soda solution.

From pure gastrie juice of the dog, Neneki and Sieber, also Pekelharing. hare prepared by dialysis a rery pure pepsin. This is a proteid body. containing 51-52 per cent C, 6. -7.1 per cent H. 1t.t per cent $T, 1.5-1.6$ per cent $\mathrm{S}$, and 0.5 per cent $\mathrm{Cl}$. and some Fe. On clearage it yields a pentose, purin hases, and an acid (pepsinie aeid, 50.8 per cent C, 7.0 per eent H. 14.4 per cent $\mathrm{X}, 1.1$ per cent $\mathrm{S}$ ). Since in a strongly actire preparation no trace of phosphorus could be demonstrated. pepsin cannot be numbered among the nucleoproteids. On the other hand. it is possible that it unites with lecithin to form a compound analogous to jecorin (page 79 ).

Pepsin oeeurs in the mueous membrane only in the preliminary form of its zymogen, pepsinogen. We have seen that pepsin is destroyed by soda. If however the mucous membrane be extracted with a weak soda solution and the extract be then acidified with $\mathrm{HCl}$, a pepsin-containing fluid of good digestive properties is obtained (Langley). Therefore there must be in the mucosa a substance which is not destroyed by soda, and which is transformed into pepsin by treatment with acids.

In artificial digestion the quantitative results depend upon the following factors: temperature; the amount of pepsin; the amount and the kind of acid; the kind and the amount of proteid; the presence of the products of digestion; and the presence of certain inorganic salts.

The quantity of enzyme necessary to produce a very powerful digestive action is very small. Thus in a certain artificial gastric juice of very exeellent digestive power, there was found for example only 0.067 per cent of nonrolatile organic matter.

If, howerer, the quantity of $\mathrm{IICl}$ and of proteid remaining the same, the quantity of pepsin be increased, the rate of digestion is increased, so that up to a certain limit the action is proportional to the square root of the eonecntration of the enzyme (Sehütz). The same law holds also for the enzymes contained in the pancreatic secretion (W'aither).

The acidity of the digest is a matter of particular importance. We find: (1) that the optimum acidity is very different for different proteids; (2) that too much or too little acid stops all digestive action. The most powerful action on fibrin, for example, is said to be obtained with an acidity of 0.09 per cent IICl; at 0.13 per cent and 0.02 per cent the action is very feeble. But on coagulated white of egg the best effeet is obtained with $0.16-0.25$ per cent $\mathrm{HCl}$.

In the transformation of proteid under the influence of pepsin a number of different substances arise hy clearage. the composition of which becomes simpler and simpler the farther the clearage progresses. 
These substances may be separated one from another by fractional precipitation with ammonium sulphate. Those preeipitated by a degree of saturation of twenty-four to forty-two per cent are called primary allumoses (heteroalbumose, protoalbumose). Those precipitated by stronger concentration of the sulphate are designated deuteroalbumoses. Those easily diffusible products not precipitated by the salt, but still giving the biuret reaction, are known as peptones. After acidification of the solution the peptones, in an impure condition, can be separated from other end products by precipitation with pieric acid.

We have then from peptic clearage of proteid (besides acid albuminate) first, two primary albumoses (hetern- and protoalbumose), and then deuteroalbumose (Pick, Zunz). Primary albumoses show a higher pereentage of $\mathrm{C}$ and $\mathrm{N}$ and a lower pereentage of $\mathrm{O}$ than the original proteid (e.g., in fibrin, there are 52.5 per cent $(.16 .9$ per cent X. 1.1 per eent $S$, and 2.2 .5 per cent 0 , while in the primary albumoses derived from it we find 55.4 per cent C. 1\%.S per cent X. 1.2 per cent $S$, and 19.1-18.r per cent 0 ). Heteroalbumose from fibrin contains thirty-nine per cent of the total nitrogen in hasie form and fifty-seven per cent as monoamino acids. While the corresponding numbers for protealbumose are twenty-five and sixty-eight per cent respectively. Ifeteroalbumose contains only a small quantity of the aromatic groups which yield tyrosin and indol, but it is rich in those groups which yield leucin and glyeocoll. Protoalbumose, on the other hand, yields abundance of tyrosin. indol and skatol. but only a little lenein and no glyeocoll.

The third direct product of digestion is a deuteroalbumose (synalbumose) which is characterized chiefly by the fact that it contains a carbohydrate group, whenever such a group oecurs in the parent proteid molecule. Its quantitative eomposition differs materially from that of the primary albumoses: thus

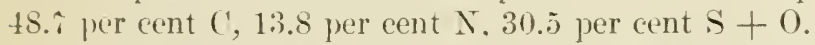

On further clearage with pepsin, primary albumoses yield secondary albumoses which appear to be very numerous. Among them thioalbumose shonld be expecially mentioned nn account of its high content of $\mathrm{s}$ (three per cent).

Ieuternalbumoses are transformed into peptones. the molecular weight of which is relatively small -only about 500 by the depression of the freezing point, whereas the molecular weight of deuteroalbumose is about 3.200 .

Aceorling to Kïhne, peptie cleavage of proteid could proceed only as far as the formation of neptones. Later it was found that from the beginning of the cleavage, substances separate off which no longer give the biuret reaction. Among these are certain intermediary substanees, the peptoids, comparable in their structure to the peptones, from which after long-continued digestion the end proluets finally appear. Probably all of the hydrolytic cleavage products (ef. page i2) belong here, for already the following have been demonstrated in sueh digestive mixtures: leuein, asparatic aeid, cadaverin, putresein, glutamie acid, tyrosin, amino-valerianie acid, dihexosamin, lysin, nenta-methyl-endiamin, phenỵlalanin, exstin, a-pyrrolidin-earboxylic aeid, tryptophan (Pfaundler, Lawrow, Jangstein, Salaskin, Fiseher, and Abderhalden).

The relative proportion of primary digestive prolucts obtained from different kinds of proteids is very different. The kind of albumoses formed is 
likewise very different, though they are all included under the common name proteoses. 'The glutin-forming substances are changed by gastric juice into gelatin, and this into gelatin peptones.

The same decompositions which proteids suffer in digestion they exhibit also when treated with acids or alkalies or superheated steam, and when they fall under the influence of putrefactive Bacteria. In fact, weak salt solutions have a digestive action on proteids (Dastre). The action of the enzymes is not to be regarded, therefore, as particularly exceptional.

Loss of the power of eoagulation on the part of the blood and other harmful effects which have long been known to follow intrarenous injection of albumoses have lately been attributed to other substances-e.g., peptozymes-mixed with them (Pick and Spiro). Peptozymes, acting mainly in the liver, cause the production of a substance which prevents eoagulation (Contejean, Gley).

\section{RENNIN}

It has long been known that milk coagulates by precipitation of its cascin when it comes in contact with the mucous membrane itself, or is mixed with an extract of the membrane. Since acids produce the same effect it was supposed that this precipitation was due to the acid reaction of the mucosa. But the investigations of Selmi and Heinz, and especially those of Hammarsten (18:2) and of Alex. Schmidt showed that coagulation takes place in a neutral or alkaline reaction. that the acid is, therefore, quite superfluous, and finally that coagulation of milk is effected by a special enzyme called rennin or chymosin.

Rennin occurs in the mucous membrane as a precursor, rennin-zymogen, which like pepsinogen is more resistant to alkalies than its enzyme, can be extracted from the mucosa with water. and is transformed into the active enzyme by addition of acids. In its action rennin resembles the other digestive enzymes. One part of the impure enzyme can coagulate $\$ 00.000$ to $\$ 00,000$ parts of casein.

In the coagulation of milk produced by rennin, casein first suffers cleavage into paracasein, and whey proteid, a substance rcsembling albumose; the former, which is the chief product, then precipitates out in solid form, provided $\mathrm{Ca}$ salts are present in the solution. If $\mathrm{Ca}$ salts are absent, clearage occurs under the influence of rennin, but no coagulation.

\section{GASTRIC STEAPSIN}

After Marcet. Cash and Ogata had demonstrated the decomposition of nentral fat in the stomach, Volhard made further inrestigations on the subject and established this property of gastric juice beyond doubt- with the limitation, however, that it acts only on emulsified fats, but on these very powerfully.

The rule holds for stomach steapsin, as for other enzymes, that its action is proportional to the square root of concentration. It is quickly destroyed in a strongly acid gastric juice. The pure pepsin of Pekelharing has no fatsplitting action, a fact which speaks decisively for the independence of the gastric steapsin. 


\section{\& 4. PANCREATIC JUICE}

Pancreatic juice presents different properties according as it is obtained from a long-established fistula or a recent one (page 243 ). In the latter case it is riscid or almost ropy. and at a low temperature passes over into a transparent jelly from which a thin fluid separates out. At $0^{\circ} \mathrm{C}$. there is formed a gelatinous, flocculent precipitate, readily soluble in dilute acids. Under some circminstances the secretion is so rich in proteid that the whole fluid coagulates when heated. The secretion from a permanent fistula is thinner and contains a smaller quantity of solids.

According to Pawlow the latter is to be regarded as the normal secretion. In his cxperience the thick, sirupy secretion is due to the effects of the operation on this uncommonly sensitive gland.

The quantity of pancreatic juice secreted daily is no more to be estimated with exactness than is the quantity of gastric juice. In cases of pancreatic fistula in man a daily secretion of from 293 to 840 c.c., with an arerage of something more than t(00 c.e., has been observed.

Pancreatic juice is always alkaline in reaction and often contains an abundance of proteid as the following analyses show:

\begin{tabular}{|c|c|c|}
\hline & Dog (Zawadsky). & Man (Glaessner). \\
\hline 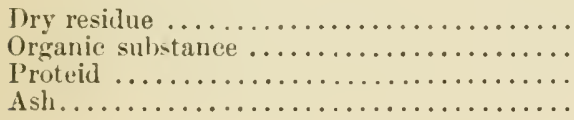 & $\begin{array}{l}13.59 \text { per cent. } \\
13.25 \text { " } \\
9.21 \text { " } \\
0.34 \text { " }\end{array}$ & $\begin{array}{l}1.25-1.27 \text { per cent. } \\
0.50-0.54 \quad " . \\
0.13-0.17 \quad " \\
0.57-0.70 \quad \text { " }\end{array}$ \\
\hline
\end{tabular}

Kudrewetsky has found that the alkalinity as determined by the quantity of IICl in g. necessary to neutralize 100 c.c. of dog's pancreatic juice is $0.05-0.89$.

Its most important constituents are the enzymes: two or three amylolytic. one protenlytic and one lipolytic. Probably all of these occur in the gland as zymogens. That they are actually different enzymes probably follows from the fact that the amylolytic, proteolytic and lipolytic effects either of the secretion or of the pancreatic extract do not keep pace one with another.

\section{A. THE AMYLOLYTIC ENZYMES}

Talentin (184t). alsn Bonchardat and Sandras (1846) found that pancreatic secretion transforms starch into sngar. The very same clearages appear in this as in the action of ptralin on starch. Besides. pancreatic juice contains an enzyme (mallase) which changes maltose to dextrose (Röhmann) and according to Weinland, another (lactase) which splits milk sugar into dextrose and galactose.

Glacssner was unable to demonstrate any action of human pancreatic juice on cane sugar, maltose or milk sugar.

The action of the amylolytic enzyme is favored by small quantities of hydrochloric acid and of bile (Rachford). 


\section{B. THE PROTEOLYTIC ENZYME, TRYPSIN,}

is distinguished from pepsin mainly by the fact that it digests proteds in an alkaline medium. Purkinje and Pappenheim as early as 1836, and $\mathrm{Cl}$. Bernard later alluded to the proteolytic action of the panereatic juice, but Corvisart (155i) must be looked upon as its real discoverer. Later Kühne, especially, did large service for our knowledge of this enzrme.

Trypsin as such does not occur in the panereas, but instead a zymogen, which, like those of the other enzymes, is nore resistant toward all kinds of injurious agents than the enzyme itself. But even the seereted jnice does not contain any trypsin and is entirely without effect on proteid. if it is not first activated by an enzrme, called enterolinase (Pawlow), found in the intestinal juice. The formation of trypsin from its zymogen presupposes therefore the presence of this special enzyme, and according to Delezenne. Popielski, Bayliss and Starling, there is no other means of bringing about this change. (The mnactirated secretion, nevertheless, will digest boiled fibrin and easein, though very slowly.)

Opposed to these observations however are others according to which a powerfully active extract is obtained, if, for example, the gland be allowed to lie twenty-four hours before extraction. Hekma is of the opinion that this is a case of bacterial action, since with antiseptic fluids no formation of trypsin could be observed.

According to Schiff and Herzen, the spleen may have much to do with the formation of trypsin, since addition of splenic infusion or of splenic venous blood activates the pancreatic extract. This in Herzen's opinion is due to an . internal secretion of the spleen.

The elearage of proteids by trypsin goes on in the same way as that produeed by pepsin, saving only that the end products are formed in less time in tryptic than in peptic digestion. However, hydrolytic clearage of proteid may be earried further, if peptic digestion preceles the tryptic digestion (Güiber). Siegfried finds two peptones $\left(\mathrm{C}_{10} \mathrm{H}_{15} \mathrm{~N}_{3} \mathrm{O}_{5}, \mathrm{C}_{11} \mathrm{H}_{19} \mathrm{~N}_{3} \mathrm{O}_{5}\right.$, molecular weights, 259 and 273 respectively), and Fischer and Abderhalden find a more complex residue containing all the monamino acids, which stubbornly resist further cleavage with trypsin.

Trypsin also dissolves gelatin, elastic substance and structureless membranes; likewise the gelatin-forming tissues, if they first be treated with acids or warmed to $90^{\circ} \mathrm{C}$. Bokai states that trypsin does not act upon the uucleins; but after autodigestion of the pancreas, Kutseher found xanthin, hypoxanthin, and guanin - just the cleavage products of nucleic acids. Blood serum and serum globulin are not attacked by trypsin, although both are digested without difficulty by gastric juice.

The pancreatic juice of mans mammals (human pancreatic juice uncertain) also coagulates milk, and according to Vernon the action is due to a special enzyme. Instead of paraeasein, however, the elot contains a substance known as metacasein, which may represent a product of tryptic digestion of casein (Roberts). 


\section{LIPOLYTIC ENZYME, STEAPSIN}

In $1846 \mathrm{Cl}$. Bernard observed that in the dog fat suffered digestive changes immediately after its entrance into the duodenum. whereas in the rabbit it took place somewhat farther from the pylorus. 'The cause of this difference he found to be the fact that in the dog the chief pancreatic duct opens into the intestine in common with the ductus choledochus quite close to the prlorus, while in the rabbit it opens some $30-35 \mathrm{em}$. farther down. It follows that the pancreatic secretion must have a determining influence upon the digestion of fat. Further researches have shown that this effect consists in a cleavage of the fat into glycerin and free fatty acid. We shall discuss the importance of this cleavage more fully in our study of digestion in the intestine.

\section{$\S 5$. BILE}

Human bile as it flows from the liver is a beatiful reddish-yellow or yellowish-brown, or green, alkaline fluid, which on standing for some time in enntact with the air assumes a green or greenish-yellow color. It contains a not insignificant amomnt of mucin, and the quantity of solids amounts to 1.5-t per cent or more. of which $0.8-0.8$ per cent is mineral.

The daily output of bile, taken from men with biliary fistulas, has been found to valy from 500 to 1.100 e.c.

During the intervals of digestion the bile does not flow into the intestine, but eollects in the gall bladder, where by absorption of its water and mixture with bladder mucus, it becomes more concentrated, so that its content in solids may rise sixteen or seventeen per cent higher. The specific gravity of bile is 1.01-1.04.

The most important constituents are mucin, the bile acids, and bile pigments. The bile acids never necur free, but always as salts of the alkalies. They are compounds of glycocoll and taurin (amino-ethyl-sulphonic acid: $\left.\mathrm{N}_{2 .} \cdot \mathrm{C}_{2} \mathrm{H}_{4} . \mathrm{SO}_{2} \mathrm{OH}\right)$ with cholie acid. Glyeocholie acid $\left(\mathrm{C}_{26} \mathrm{H}_{43} \mathrm{NO}_{6}\right)$ and tanrocholic acid $\left(\mathrm{C}_{26} \mathrm{H}_{45} \mathrm{NSO}_{7}\right)$ oceur in different biles in relatively different quantities. In man the former is always present in greater quantity. Besides the usual cholic acid, whose formula is $\mathrm{C}_{20} \mathrm{H}_{31}\left\{\begin{array}{l}\mathrm{CHOH} \\ (\mathrm{CH} O H)_{2} \\ (\mathrm{CHOH}\end{array}\right.$, two other acids, choleie acid $\left(\mathrm{C}_{24} \mathrm{H}_{40} \mathrm{O}_{4}\right)$, and fellic acid $\left(\mathrm{C}_{23} \mathrm{H}_{40} \mathrm{O}_{4}\right)$ have been demonstrated in human bile. Numerous derivatives can be obtained from the bile acids.

'The bile pigments are very numerous and they ean be changed by various means into still others. Under physiological conditions we have. properly speaking, only two such pigments-the reddish-yellow, bilirubin, and the green. bitiverdin. 'The former, which is easily erystallized in rhombic tablets, is to be regarded as the mother-substance of biliverdin and all other bile pigruents.

Bilirubin has the formula $\mathrm{C}_{16} \mathrm{H}_{15} \mathrm{~N}_{2} \mathrm{O}_{3}$ (Maly). Tt is transformed by oxidation into biliverdin $\mathrm{C}_{11} \mathrm{H}_{18} \mathrm{~N}_{2} \mathrm{O}_{4}$, nnd vice reese the latter can pass by reduction into bilirubin again. Biliprasin, according to Dastre and Floresco, is to be regarded as an intermediate stage between the two. Bilirubin, acted upon by 
naseent hydrogen, is reduced to hydrobilirubin $\mathrm{C}_{32} \mathrm{H}_{40} \mathrm{~N}_{4} \mathrm{O}_{7}$ whieh also oecurs at times in the human bile. Since bilirubin and biliverdin are commonly present together in the bile, the color of the fluid is somewhere between red and green, and varies toward one or the other aceording as one pigment or the other predominates.

The bile contains also mucin, cholesterin, jecorin, lecithin, neutral fats and soaps, ethereal sulphuric acids, paired glyeuronie acids, cholin, glyeerin-phosphoric acid (both the latter, decomposition produets of lecithin), and various mineral constituents, namely: the alkalies in eombination with the bile acids, sodium chloride, potassium chloride, calcium and magnesium phosphate and iron. Sulphates occur, if at all, in very small quantities. A diastatic and a fibrin-splitting ferment have been demonstrated in the bile of certain animals; but it is not quite eertain that they are formed in the liver, for they might represent enzymes only reabsorbed into the bile.

The following summary of analytical results with regard to the quantitative composition of bile may be given:

\begin{tabular}{|c|c|c|c|c|}
\hline & Bladder bile. & \multicolumn{3}{|c|}{ Liver bile. } \\
\hline 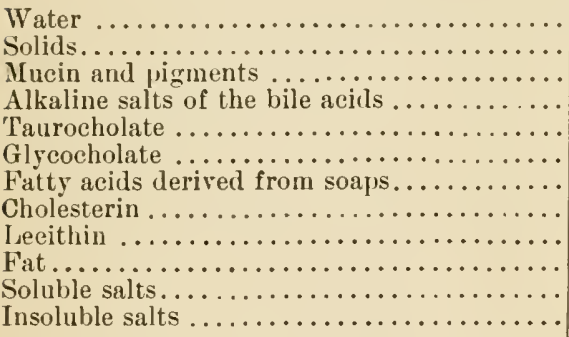 & 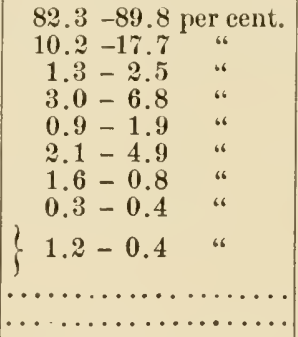 & $\begin{array}{l}96.5 \\
1.2 \\
0.1 \\
0.2 \\
0.05 \\
0.2 \\
0.02 \\
0.05 \\
0.005 \\
0.01 \\
0.7 \\
0.02\end{array}$ & $\begin{array}{l}-98.8 \\
-3.5 \\
-0.5 \\
-1.8 \\
-0.3 \\
-1.6 \\
-0.14 \\
-0.16 \\
-0.13 \\
-0.10 \\
-0.9 \\
-0.05\end{array}$ & $\begin{array}{l}\text { per cent. } \\
\text { "6 } \\
\text { ". } \\
\text { "6 } \\
\text { "6 } \\
\text { "6 } \\
\text { "6 } \\
\text { " }\end{array}$ \\
\hline
\end{tabular}

The chief importance of bile in digestion appears to be that, in virtue of its bile salts it has the power to dissolve the free fatty acids and to inerease the solubility of soaps; but more on this under the subject of absorption from the intestine.

Proof that the bile pigments are formed for the most part in the liver is found in the fact that when this organ is extirpated from birds, or when all the blood vessels of the liver and the bile ducts are ligated, not a trace of bile pigments can be demonstrated anywhere in the animal.

The bile pigments are universally regarded as derivatives of hromoglobin. The following faets among others speak for this view. A pigment called homotoidin found in old blood stains is closely related to bilirubin and probably is identical with it. Hamatinic aeid, $\mathrm{C}_{5} \mathrm{H}_{0} \mathrm{NO}_{4}$, which is the first oxidation product of hæmatin when oxidation takes place at the lowest possible temperature, appears to be identical with biliverdinic acid, an oxidation product of bilirubin (Kiister).-When dissolved hamoglobin is injected into the blood, or when substances which liberate hrmoglobin from the corpuscles are taken into the body, the quantity of pigments excreted in the bile increases materially.

Since it has been shown in these and other researches that the secretion of bile pigments never runs parallel to that of the bile acids, it follows that these two chief eonstituents are not derivatives of the same substance. 


\section{$\S 6$. INTESTINAL JUICE}

The intestinal juice of man is a thin, clear, alkaline fluid containing epithelial cells, Bacteria and fat crystals, which effervesces on addition of acids. Freed of solid bodies by means of the centrifuge. it contains from 0.2 to 0.5 per cent $\mathrm{Na}_{2} \mathrm{CO}_{3}, 0.2-0.6$ per cent $\mathrm{Cl}$, and about 1.1 per cent dry residue. Its specific gravity is in the neighborhood of 1.007 (Hamburger and Hekma).

Intestinal juice acts but feebly on starch. It inverts cane sugar. splits maltose, and, in young animals at least, also milk sugar. According to Röhmann and Nagano, the action of secreted intestinal juice on cane sugar and malt sugar is much less than that of the intestinal mucosa: it might be therefore that the clearage of these sugars takes place in the mucosa itself, or that mere contact with the surface of the mucous membrane is sufficient for this purpose.

Emulsified fats appear to be attacked to some extent by the intestinal juice.

The native proteids, with the exception of casein and fibrin, are not digested by the intestinal juice. On the other hand, an extract of the intestinal mucosa in weakly alkaline or neutral reaction splits albumoses and peptones into simpler compounds: $\mathrm{NH}_{3}$, leucin, tyrosin, lysin, arginin, histidin, etc. (Cohnheim). This action is heightened by warming the solution, and it is regarded therefore as the effect of a special enzyme called erepsin. The normal secretion (man, $\operatorname{dog}$ ) has the same effect, only to a less extent, from which we may perhaps conclude that this clearage of the primary products of digestion really takes place in the mucous membrane.

The nucleic acids are not decomposed by trypsin; but when they are exposed to the action of erepsin they are split into phosphoric acid and the purin bases. This fact speaks very strongly for the specific nature of erepsin (Nakayama).

Pawlow has discovered a new enzyme in the intestinal juice which he calls enterokinase, and which, as mentioned on page 252. transforms the raw mothersubstance of trypsin in the pancreatic juice into the active enzyme. We know that this is not identical with erepsin from the fact that (in the human intestinal juice) the latter is destroyed by a temperature of $59^{\circ} \mathrm{C}$, whereas the enterokinase is not destroyed below $66^{\circ} \mathrm{C}$.

Gachet and Pachon, as well as Glaessner, assert that the glands of Brunner, which have an entirely different strueture from that of the glands of Lieberkühn, secrete a proteolytic enzyme.

The grlands of the large intestine produce no enzymes, but secrete a mueus which is of importance as a lubricant for the fecal miss. 


\section{SECOND SECTION}

\section{SECRETION OF THE DIGESTIVE FLUIDS}

\section{§ 1. GENERAL SURVEY}

The sceretory process presents many points of similarity in all digestive glands. For this reason. it is desirable to consider the process in broad outline before taking up in detail the peculiarities of the individual glands.

In the year 1851 Ludwig showed that section of the cerebral nerre supply to the salivary glands was followed by complete cessation of the flow of saliva (submaxillary, parotid). For hours there was not the least trace of fluid in the cannula which had been inserted into the duet. As soon howerer as the cerebral nerve was stimulated. saliva gushed out of the duet. In a thoroughgoing inrestigation, which is to be reported more fully under s?. Ludwig demonstrated that this secretion is not a filtrate from the blood, but is prodneed by the specific activity of the gland cells under the influence of the nerres.

These diseoreries stond quite alone for several decades. It is true that some observations were collecting, from which it appeared with a certain degree of probability that the secretion of the gastric glands and of the parcreas were influenced considerably by secretory nerves (IHeidenhain, Richet et al.). But the existence of such nerves was conclusively proved by Pawlow only a few years ago. We do not know definitely even yet whether the other digestive glands, those of Lieberkithn, of Brumner, and the liver, are under the influence of secretory nerres in the same way as those already mentioned.

It would be a matter of the greatest interest to know exactly the anatomical connection between the sceretory nerves and the gland cells. The many efforts of histologists in this direction have not been entirely successful as yet, although it has been stated recently that the nerves penetrate the membrana propria of the acini and terminate in end organs lying in direct contact with the secreting cells. The end organs are said to have either the form of mulberrylike clumps or of small twigs beset with nodules.

Under normal circumstances the seeretion of those glands which are plainly under the control of the central nerrous system is evoked by reflex action, set up in many cases by perfectly definite chemical substances (Pawlow) (cf. page 264 ). These reflexes as a rule stand in a very close relationship with the ingestion of food, and in general it may he said that in the intervals of digestion when there is no desire for fond, the digestive fluids are seereted only in rery small quantities.

Bile forms an exception to this rule, since even in the fasting condition it is produced and is given off by the liver. Possibly this is due to the fact that bile is not only a digestive fluid, but contains also various substances which, so far as our knowledge at present goes, have no significance whateser in digestion, and must be looked upon as real waste products. As such they would naturally be produced continuously, just as in the ease of urea and the decom- 
position products found in the expired air. However, the bile passes into the digestive eanal only after the ingestion of food; in the meantime it is being stored in the gall bladder.

In 1868 Heidenhain published the important observation that after longcontinuel activity the submaxillary gland exhibits morpholngical changes. and some years later he ascertained that the same is trme of the parotid and of the fundus glands of the stomach. Investigation in this direction was extended by several other authors, and it has been proved by their work that while the gland is resting-i.e., is not pouring out secretions-a substance is being laid down within it in the form of small gramules. which to a greater or less extent disappears during the activity of the gland. This sulstance must be regarded as the source of the specific constituents of the glantular secretions.

Heat is grenerated by the glands in the act of secretion. Cl. Rernard (18.56) fomd the temperature of the hepatic blood anstantly higher than that of the portal blook. At the time of active secretion of bile the difference rose to $0.7^{\circ}-0.9^{\circ} \mathrm{C}$. The following rear Ludwig and spiess observed that the temperature of the sulmaxillary saliva may be more than $1^{\circ} \mathrm{C}$. higher than that of the lilood in the earotil of the same side. The increase in oxven consumption and of earbon-dioxide production indicate a highly active metaholism going on in a working gland; loth are three to four times as great in a strongly active condition of the submaxillary as in a resting condition (Bareroft).

Attention has already been directed to the electric phenomena of glands (page 48). Bayliss and Bradford report that on stimulation of the cerebral secretory nerves of the dog, a strong electric variation is produced both in the submaxillary and in the parotid, since the surface of the gland becomes negative to the hilus. Stimulation of the sympathetie proulueed an opposite variationthe surface becoming positive to the hilus. Moreorer, they showed that these electrieal variations are not due either to alterations of the blood flow or to the flow of the secretion through the duet. On the basis of these and other observations, the authors conclude that the negativity of the surface towarl the hilus is the result of a passage of fluid through the wall of the acini or is the result of changes in the gland cells set up by stimulation. which preeerle the passage of the fluirl. The positivity of the surface would be the expression of those changus in the gland cells by which the organie constituents of the secretion are formed.

\section{§. THE SALIVARY GLANDS}

\section{A. SECRETORY NERVES}

The salivary glands receive their nerves by two different pathways, namely the eerebral and the sympathetie. The former were demonstrated hy Ludwin as mentioned on page 25t: while the discovery that the sympathetic can caluse secretion of saliva we owe to Eckhard.

In the dog the cerebral nerves to the submaxillary and sublingual glands proced from the facial nerve through the chorda tympani to the lingual branch of the trigeminal, and from this along the duets to the gland. Thre corebral supply to the parotil of the dog springs from the glossopharygeal and reaches the 
auriculo-temporal branch of the fifth nerve through the nerve of Jacobson, the small superficial petrosal, and the otic ganglion.

The sympathetic fibers run in the eervical sympathetic trunk to the superior cervical ganglion, and from there follow the blood resscls to the hilus of the appropriate gland.

Ganglion cells are interpolated in the course of these nerves-those of the sympathetic fibers for the sublingual and submaxillary being located in the superior cerrical ganglion. The ganglion cells of the cerebral secretory fibers for the sublingual gland are distributed as small ganglia over the entire gland (to these belong also the sublingual ganglion); those for the submaxillary lie for the most part in the hilus of the gland itself (Langley).

On stimulation the different secretory nerves give different results, which vary with the species of animal experimented upon. TVe shall consider here only the results obtained in the dog.

Stimulation of the cerebral fibers to any of the glands causes almost immediately a copious secretion of a fluid poor in solids, which may continue for hours, if the stimulation be maintained at the proper strength. The seeretion produced from the submaxillary by excitation of the sympathetic appears later. At first a few drops of a fluid rich in solids come from the duet, then the secretion ceases, but reappears on continued stimulation. The parotid as a rule gives no secretion on stimulation of the sympathetic, probably because the thick fluid stops up the duet.

Since stimulation of the cerebral fibers causes a considerable dilatation of the blood ressels of the gland and a consequent increase of blood flow (as much as six times the original) (cf. page 234), whereas stimulation of the sympathetic causes rasocontraction and a considerable decrease of blood flow, it wight be thought that the difference in the secretion in the two cases is due to the difference in the amount of blood supplicd. But this is not true. For if the arteries of the gland be entirely closed off and the cerebral fibers be then stimulated, the quantity of secretion obtained is smaller, but it has all the properties of the normal cerebral saliva and its percentage content of solids is not greater than when the circulation is unhindered.

Heidenhain, with some reservation it is true, has sought to explain these phenomena as follows. He supposes that every gland is provided with two kinds of nerve fibers: (1) those which preside over the transudation of water and of the salts, the "secretory fibers," and (2) those which control the formation of the soluble eonstituents and the growth of the protoplasm, the "trophic fibers." These fibers occur in the different nerres of the glands in different numbers. Thus the cerebral fibers in the $\operatorname{dog}$ would be relatively poor in trophic but relatively rich in secretory fibers, while the sympathetic would contain only a few secretory but many trophic fibers.

It is not to be denied-that Heidenhain has brought many facts to the support of this view. For example, simultaneous stimulation of the sympathetic and the glossopharyngeal in the $\log$ increases considerably the percentage composition of solids in the parotid saliva. But it is not possible to explain all the known facts concerning the influence of nerves on the salivary secretion from this point of view. Thus if the glands be poisoned, not too sererely, with atropine, stimulation of the chorda is entirely without effect at a time when stimulation of the sympathetic is still effective. Now it is very probable that atropine acts so as to paralyze the end organs of the cerebral fibers, and from the fact just 
given we know that this poison acts upos the end organs of the two nerves in an entirely different was. Hence we can scarcely say that the sympathetic and the chorda are composed of the same kinds of fibers in relatively different numbers (Langler).

The discovery of Gerhardt with regard to morphological changes in the submaxillary after section of the srmpathetic and of the chorda, speaks to the same effect. In the former case the protoplasm remains unchanged, whereas the nucleus shrinks. although not in all cells: after section of the chorda the nucleus remains normal, but the protoplasm in mans cells undergoes significant changes becoming turbid, finely granular and opaque.

A further difficulty for Heidenhain's theors is the so-called paralytic secretion discovered by $\mathrm{Cl}$. Bernard. Some twenty-four hours after section of the cerebral nerves, the submaxillary gland begins to secrete, slowls at first, then faster and faster until within a week a drop issues from the duct erers twent minutes. It makes no difference whether the sympathetic is injurer or not; section of this nerve produces no paralytic secretion. In the course of time after section of either nerre the size of the gland gradually diminishes, and the gland acquires a waxlike appearance.

A priori it might be supposed that secretion is only a process of fitration from the blood through the capillary walls. But we have great difficulty on such an hypothesis to account for the chemical properties of the secretion; for sereral substances found in the secretion and in the glands are not found at all in the blood, and must. therefore. be formed in the gland cells. This is attested also by facts to be discussed later with regarl to morphological changes appearing in the glands. But more convincing is the following. If the duct of the submaxillary gland be connected with a Hg-manometer and the cereloral nerre be then stimulated. the mercury in a very short time. even within twentyfive seconds. rises $100 \mathrm{~mm}$. higher than the mercury in a manometer connected with the carotid. That is. the secretion pressure becomes higher than the blood pressure. Finally, the remotest possibility of regarding the secretion as a process of filtration is exchded by the fact that stimulation of a secretory nerve causes a flow of saliva in animals which have been bled to death.

When a nerve is stimulated. the constituents already deposited in the gland cells during rest are not only given off. but there is at the same time an increased production of them. This is plainly indicated by the fact that the quantity of nitrogen in both the secreting gland and its secreted saliva is greater than that of the resting gland on the other side (Pawlow). When the nerves are excited with stimuli of increasing strength. not only does the alsolute quantity of the secretion and of its solid constituents increase, but the pereentage content of the latter rises higher the more rapid the rate of secretion bromes. This increase almavs affects the inorganic constituents. but not the oranic. unless care be taken not to fatigue the gland lyy orerwork. If the sland be fatigued, the percentage content of organic substancemay "won rectine in the face of an increased rate of secretion.

The may summarize the effects produced in the glands by stimulation of their nerves as follows: (1) I change takes place in the gland cells dereloping certain forces which are expresed by the act of secretion: ( 2 ) at the same time an increased formation of the specific constituents of the secretion appears: and (3) if the stimulation continue for a long time, the gland gradu- 
ally heenmes fatigued. so that the delivery of secretory products exceeds the new formation of specific constituents.

Under normal eircumstances the secretion of saliva is eaused by a refiex act induced chiefly from the mouth, and Pawlow has shown that thr quantity as well as the quality of saliva in the dng is adapted with extraordinary nicety to the properties of the substances introduced into the mouth.

Mechanical stimulation of the buccal mucous membrane does not alwars produce a flow of saliva. If, for example, a handful of pebbles be thrown into

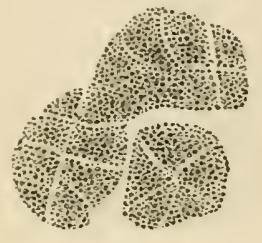

A

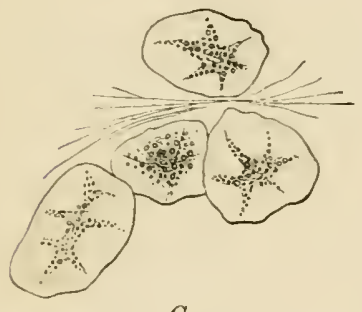

C

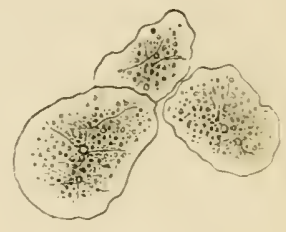

$B$

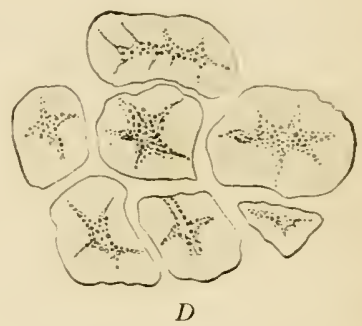

Fig. 100.-Parotid gland of the rabbit as seen in a fresh, unstained preparation, after Langley. $A$, resting state. $B$, after injeetion of a slight quantity of pilocarpine. $C$, after stimulation of the cervical sympathetic. $D$, the same, only a stronger effect.

a dog's mouth, the dog moves them to and fro in his efforts to get rid of them, but no saliva, or at most only a drop or two, is poured out. If on the other hand sand be used instead of pebbles, a copious flow of saliva is set up. because the sand cannot be remored from the mouth without a stream of fluid. Nor is there any discharge of saliva from application of water or snow, but with acid, salty, bitter or caustic substances which require to be diluted or washed out of the mouth, a discharge at once occurs.

In all these cases the saliva is thin, watery and contains onl r a trace of mucin. But with all kinds of edible substances a viscid, mucous saliva is secreted such as is necessary to facilitate swallowing the bolus. Besides, the quantity of saliva depends upon the dryness of the food: the drier it is, the more saliva.

It is unnecessary actually to place the stimulant into the mouth in order to produce a flow of saliva. Sight or smell of it is sufficient. or indeed, as our own experiences prove, imagination even of savory substances will produce the effect. With regard to the quality and quantity of saliva, the same differences are observed as when the stimulus is applied to the mouth carity: from which we may conclude that a psychical influence of no small value is involved, although this cannot be exercised by direct effort of the will. 
The salivary nerve centers are located in the medulla; for reflex secretion is obtained after transsection of the brain in the pons. A puncture in the medulla is followed likewise by secretion. Unilateral injury to the floor of the fourth ventricle a little behind the origin of the trigeminal nerve causes secretion in both submaxillary glands and in the parotid of the same side. Both cerebral and sympathetic nerves are roused to activity in this case. It is posible that the glands on each side of the body have their own eenters, and that these are connected togrether by commissures (Beck).

The salivary glands can be set in action also by artificial stimulation of that part of the cerebral cortex which corresponds roughly to the motor zone. It is rery probable that the above-mentioned psychical influence on the salivary glands depends upon this cortical field.

\section{B. MORPHOLOGICAL CHANGES DURING SECRETION}

The more recent investigations of this subject have been made upon practically fresh material instead of, as formerly, upon preserved material. We shall follow the deseriptions given by Langley and by Biedermann.

In the albuminous glands (Fig. 100) Langley found that in the resting state, the cells are filled with a collection of granules so abundant as to obscure the cell boundaries. When the gland has secreted for some time, the cells increase in size, the granules gradually disappear especially from the outer zone, or the side toward the membrana propria, while the inmer zone or the side toward the lumen of the gland still contains granules. These changes are constant whether the gland be caused to secrete by the natural stimulus, by injection of pilocarpine, or ly stimulation of its nerves.

According to E. Müller, there occurs here a conversion of strongly refractive granules into feebly refractive ones, which pass into the sceretion as small spherieal drops-the so-called secretion racuoles (Fig. 101; cf. also Fig. 99). In rery active secretion the first-named granules pass directly orer into the

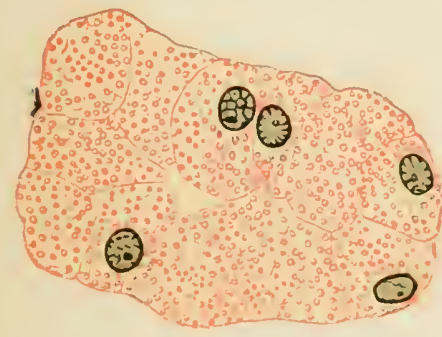

$A$

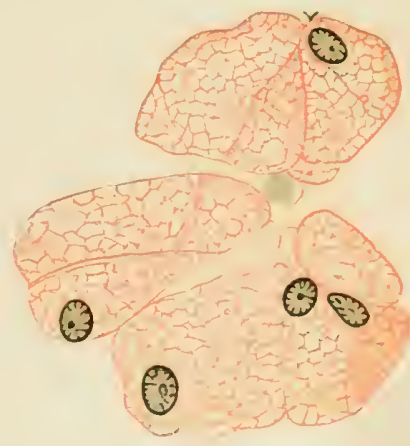

$B$

Fig. 101.-Parotid gland of the cat, after E. Miller. Sublimate fixation. A, after twenty-four hours' fast. $B$, during active discharge of the seeretion.

secretion vacuoles. When they leave the gland cells they pass first into the secretory capillaries running between the cells where they are dissolred and whence the secretion flows into the ducts of the gland. 
We meet with similar phenomena in fresh preparations of the mucous glands. I gland from the tongue of Rana esculenta teased in a 0.6-per-cent salt solution (Biedermann) almost always shows cells, which in the ends turned toward the lumen are thickly set with dark, strongly refractive granules. When the same object is observed in active secretion the dark granules have disappeared for the most part, or form only a narrow border along the inner edge of the cells. The latter contain also clear, vacuolar drops (Fig. 10:).

From these observations it appears that in the albuminous as well as in the mucous glands, a substance is formed during the resting state, which in the fresh gland has the form of small granules. This substance is liberated from the cells in the act of secretion and as a consequence the cells decrease in size, especially after a copious discharge; the main part of the cell is now clear.

Are the specific constituents of the secretion derivatives of the living protoplasm, or are they to be regarded as products of its activity? This question cannot be answered definitely at present. Heidenhain conceived that in the mucous glands at least the cells as a whole are converted into the secretion, and that the so-called demilume cells of Gianuzzi are young cells destined to replace

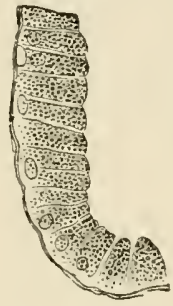

A

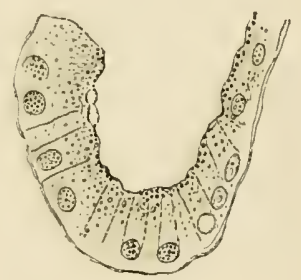

$B$

FIG. 102,-Parts of a tongue gland of the frog (Rana esculenta), fresh condition, after Biedermann. $A$, resting state. $B$, after stimulating the glossopharyngeal nerve for three hours.

the mucous cells after their disintegration. This assumption however is not in accord with the fact that cell divisions are very rarely net with in secreting glands. That cells do occasionally perish in very active secretion and can be replaced by division, has nothing whatever to do with the process of secretion as such. And as for the demilumes, they appear from recent researches (Stöhr, Noll) to be simply empty mueous cells.

Other investigators, with Altmann at their head, regard the granules as morphological derivatives of formed constituent elements, and claim that the manner of their origin, their growth and their transformation indieate that they are vital units.

From all that we know, however, the granules found in the resting gland might just as well represent products of the metabolic aetirity of the protoplasm: hence no destruction of living substance would be involved in their formation. The material at hand is by no means suffieient to decide a question fundamentally so important. 


\section{§3. THE GLANDS OF THE STOMACH}

\section{A. SECRETORY NERVES}

Early observations on the secretion of gastric juice for the most part tended to show that this process scarcely came within the control of the central nervous system. Some few observations there were, it is true, which indicated such an influence, but they were rather scattered and were outnumbered by other observations which made it more likely that the extrinsic nerves to the stomach had no influence of a direct kind upon its secretory activity. In the year 1889, however, Pawlow and Schumow-Simanowsky demonstrated that the ragus contains secretory fibers for the gastric glands.

Richet had found in the case of a man with an mophageal stricture and upon whom a stomach fistula had been made, that chewing strongly sapid foods produced immediately a flow of gastric juice from the fistula. It was natural to regard this secretion as a reflex.

The above-named authors undertook to establish this conclusion experimentally, and for the purpose made on dogs an osophageal fistula besides the usual stomach fistula. When the animal received something to eat and swallowed a bolus, it of course came out through the opening in the neck without ever reaching the stomach ("fictitious feeding"). Nerertheless, after a latent period of five to six minutes a copious secretion of gastric juice made its appearance. In this way it was proved that the secretion can in fact be called out reflexly.

The efferent nerves concerned in this reflex are the vagi. If the ragi be cut, the reflex fails. If they be stimulated a clear fluid begins to trickle from the fistula, which in comparison with the normal gastric juice shows a lower acidity, but digests proteids. In addition to these the vagus appears to contain also fibers. which inhibit the glands of the stomach.

But the secretion of gastric juice is not dependent alone upon the vagus. There are perfectly trustworthy statements in the literature which show that the secretion does not cease after section of the vagi, although the reflex from the mouth be excluded: but that animals thus operated upon digest their food in the stomach. Besides, analysis of the urine reveals no products of abnormal putrefaction in the alimentary canal of such animals, and we may conclude that a real gastric juice is secreted which contains just as much hydrochloric acid, but ennsiderably less pepsin, than the normal juice.

Thus there are two modes of gastric secretion. nanely, one under the influence of the secretory nerve fibers which traverse the vagus, and the other independent of those fibers.

(1) The Secretion under the Influence of the Tagus.-Neither excitation of the nerves of taste, nor the act of chewing, nor the movements of deglutition have of themselves any power to cause a reflex secretion of gastric juice. Only when the animal exhibits some desire for food does secretion result. The imagination of savory substances would seem therefore to be of special importance, and this is confirmed by the fact that gastric sceretion occurs when one merely offers a dog a piece of meat without giving it to him. This "psychical" secretion is at times very abundant; but if not, the amount of secretion is considerably increased by fictitious feeding. From these and similar facts it appears that although excitation of the afferent nerves from the month and the osopha- 
gus does not of itself produce any gastric secretion, yet when the animal has some desire for food this excitation intensifics considerably the psychical secretion which would otherwise take place, and raises both the acidity and the digestive power of the secretion.

In the case of a fire-rear-old boy with a complete rsophageal stricture and a gastric fistula, Hormborg found that cliewing palatable foods induced, after an average latent period of seven minutes, a secretion which lasted for forty minutes or more, whereas chewing disagrecable foods, or chemically active (lemons) or indifferent substances (rubber) was without any influcnce on the gastric glands. It is worthy of note that the secretion failed when the boy was not permitted to eat immediately food particularly palatable to him, and began to cry; also that every time he was fed through the stomach fistula he wished for something edible to chew. Mere sight of food was not effective in provoking the secretion.

(2) The Secretion Independent of the Tagus.-Mechanical stimulation of the stomach mucosa, even when it is very energetic, causes no secretion of gastric juice whaterer; only an alkaline mucus flows from the fistula (Pawlow). The sccretion not mediated by the vagus must be the result, therefore, of chemical stimulation. In order to study this question more closely and to prevent mixture with foreign substances. Heidenhain separated the fundus portion from the rest of the stomach by a surgical operation, and thus prepared an isolated "fundus fistula." In this operation the branches of the vagus which mediate the secretory reflex were cut. Nevertheless, when the animal received something to eat secretion appeared in the blind sac. It began fifteen to thirty minutes after eating and continued for a longer or shorter time according to the quality and quantity of the food-after a moderately full meal, thirtecn to fourteen hours; after a very full one, sixteen to twenty hours. When the dog was giren very slightly digestible food, such as coarsely chopped ligamentum nuchæ, no sceretion appeared, but began when he was subsequently allowed to drink. Even then the secretion continued for only a short time, one and one-half to four hours at most.

Pawlow and Chigin carried out even more detailed experiments on dogs in which the blind sac was prepared without section of the vagus branches. The substances whose effects on the mucous membrane were to be tested were introduced (without the dog's knowledge) through a fistula directly into the main part of the stomach. Water, 0.1-0.5-per-cent $\mathrm{HCl}$ solutions, etc., in quantities of 100-150 c.c. exerted only a very slight influence on the process of secretion in the isolated sac. In quantities of 500 c.c. pure water, ten-per-cent solutions of cane sugar or starch, or egg albumin provoked a somewhat stronger secretion. This began in a majority of cases after thirteen to twenty-nine minutes. Since distilled water evoked just as much secretion as the solutions, it is assumed that the effects here are only those of the solvent. Weak soda solutions reduced the effect of water. Fats also exerted an inhibitory influence.

When meat gravy, meat juice and meat extract or milk, or a solution of gelatin in water were introduced into the stomach in the same way, results were very different. An abuudant secretion began after an average latent period of thirteen minutes, which continued for about three hours. Neither egg albumin nor albumose nor bread had any such effect. It appears therefore that certain extractives contained in meat, to which however creatin and creatinin do not belong, certain constituents of milk, etc., are specific stimuli for the stomach. Furthermore, there are experiments which show that once the secretion is started by these substances, it is considerably augmented when, for example, egg albumin, of itself but slightly active, is introduced. In the same way starch introduced with meat can intensify the secretory process considerably. 
From these observations we can form provisionally the following conception of the conditions for secretion in the stomach. Secretion of gastric juice is started by a complicated reflex process, which is set in operation by the sight of food as well as by its passage through the mouth and cesophagus, and

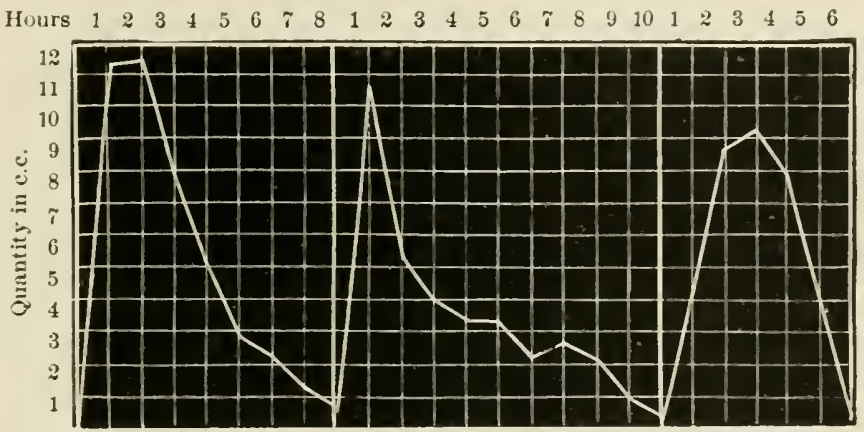

Meat.

Bread.

Milk.

Fig. 103.-Hourly course of seeretion of gastric juice in the dog's stomaeh, after Pawlow. Exclusive diets of meat, bread, and milk were given.

is mediated by the vagus. This secretion itself lasts for a fairly long time; but it is angmented by the stimulating influence on the mucous membrane of ingested water and. above all, of certain extractives. etc., contained in the food.

Chigin's experiments on the course of the secretion in the blind sae with the vagi preserved show very instructively how the aetivity of the mucous membrane under the influenee of the vagus reflexes and the excitation of the food, is adapted to the momentary requirements upon it. With all the articles of food thus far tested the secretion began at about the same time. It reached its maximum during the first or the second hour (with milk during the third hour). After the maximum was reached the secretion fell immediately and became gradually less and less until it finally ceased. The absolute quantity of gastric juice with the same article of food was greater, the greater the mass of food

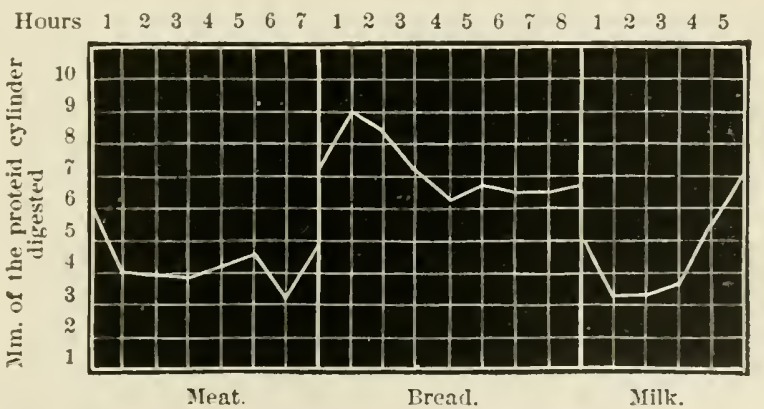

Frg. 104. - Hourly enurse of the digestive aetion of gastric juice on proteid, after feeding exclusively meat, breed, and milk (l'awlow).

introfluced. The quantity secreted, for example, was greater with $200 \mathrm{~g}$. of meat than with $200 \mathrm{~g}$. of bread or $600 \mathrm{~g}$. of milk (Fig. 103). The digestive power of the fluid secreted with the articles of food just mentioned. when tested from hour to hour, shows characteristic variations (Fig. 104). Feeding meat, 
milk and bread with the same $\mathrm{N}$-content (about $3.4 \mathrm{~g}$.), there appearer in the isclated sac 27,34 and 42 c.c. respectively of gastric juice having a digestive power of $4.0,3.1$ and $6.16 \mathrm{~mm}$. of egg albumin (cf. page 245 ). Since the digestive power is proportional to the square ront of the quantities of pepsin, the quantities in this series would be to each other as 430,340 , and 1,600 .

The center of these reflexes mediated by the vagus probably coincides with the vagus nucleus. The psychic influence on the secretion is exercised naturally through the cerebrum. In the dog Bechterew obtained a secretion of gastric juice and of gastric mucus on stimulating a region lateral to the anterior portion of the gyrus sigmoides just at the forward end of the third convolution. Stimulating for four to five minutes the secretion continued for thirty to fifty minutes and exhibited an unmistakable similarity with that obtained by fictitions feeding. After extirpation of this cortical field no secretion appeared on offering food.

The mechanism of the secretion which is independent of the vagus is much more difficult to explain. It might be caused either by some reflex process or by the direct exciting effects of absorbed substances upon the glands themselves. There are difficulties in the way of both hypotheses and the matter cannot be regarded as settled.

\section{B. THE GASTRIC GLANDS}

The mucous membrane of the stomach presents considerable differences between the fundic and pyloric portions. The pyloric portion is pale and whitish in color and is beset by a few high folds, here and there united together. The rest of the mucous membrane has a reddish-yellow or reddish-gray color, and possesses numerous folds bound together into an iriegular network, and in addition to these, fine secondary folds likewise arranged as a net. Into the depressions formed by the folds open the gastric glands, whose epithelial cells are continuous with the epithelium which clothes the free surface of the membrane.

This superficial epithelium secretes the gastric mucus and behares probably like similar cells of the salivary glands.

The glands of the mucous membrane are tubular and belong to two different types, one constructed of one kind of cells, the other of two kinds. The spatial distribution of the two kinds presents certain differences in different mammals. In the dog and man the glands formed of one kind of cells occur only in the pylorus: those with two kinds oceur only in the fundus. For this reason they are named pyloric and fundie glands respectively. The boundary between the two divisions of the mucous membrane is not howerer very sharp.

The secreting elements of the pyloric glands are cylindrical cells arranged in a single layer upon the basement membrane of the glands. The fundic glands contain similar cylindrical cells similarly arranged. These cells were discovered by Rollet and Heidenhain, and are called the chief or adelomorphous cells. 
In addition to the chief cells and situated outside of them are other socalled parietal or delomorphous cells. These lie between the chief cells and the membrana propria, but do not form a continuous layer. Just as in the salivary glands, there are fine secretory capillaries between the gland cells. Those belonging to the parietal cells surround them in a basketlike fashion and are connected by cross ducts with the lumen of the gland (Fig. 105).

It has been known for a long time that the pepsin is formed in the chief cells (Wassman, 1839).

If small pieces of the fundus mucosa be digested in a warm place with dilute hydrochloric acid, they dissolve leaving only small flakes behind. Boiled white of egg digested at $35^{\circ}-40^{\circ} \mathrm{C}$. in acidulated water, to which a small piece of the fundic mucosa has been added, dissolves in one to one and one-half hours.

Since it had been observed further that the prlorus mucosa withstood digestion much longer on similar treatment, and since the chief cells had not yet been discovered, it was supposed that the fundic glands were the only seat of pepsin production, and that the pyloric glands produced only mucus like the superficial epithelium. It has since been proved that the pyloric glands also produce pepsin.

Simply to make an extract of pylorus mucosa and demonstrate pepsin therein, would not be a fair test, for it might be that the pepsin came from the gastric juice and had only been absorbed by the pyloric mucosa. The matter takes quite another aspect however when we discover that the pyloric mucosa is not completely freed of its pepsin by washing for forty-eight hours in ruming water. Several other observations show the same thing, and conclusive evidence is furnished by the following: By an operation the pyloric portion can be isolated from the rest of the stomach in the same way as has already been described for the fundic portion, and a pyloric fistula be thus established (Klemensiewicz, Heidenhain, Akerman). The animals recover and exhibit no sort of disturbance in their general health. From this pyloric sac a fluid is obtained which always contains pepsin even if collected weeks or months after the operation. There can be no question here of absorption from the gastric juice.

We have still to decide, however. whether the pepsin is formed in the chief or the parictal cells of the fundic glands. Several facts indicate the former.

(1) If freshly isolated fundic glands be warmed in a drop of dilute hydrochloric acid under the microscope, the chief cells may be seen to disintegrate rapidly, whereas the parictal cells only swell up and become transparent. (2) In shcep embryos it has been observel that the parictal cells appear first in the course of development and the chief cells much later. Pepsin produc- 
fion can be demonstrated in the mucous membrane only after the latter appear. (3) If different parts of the stomach mucosa be extracted. it is found that the quantity of pepsin shows no dependence upon the number of parietal cells in the different parts, but varies in direct proportion to the number of chief cells.

How far the parietal cells participate in the formation of pepsin must be regarded as still an open question. In various lower vertebrates whose gastric glands possess cells of only one kind, it has been observed that both pepsin and hydrochloric acid are produced. But we cannot draw any positive conclusion with respect to the more differentiated gland of the higher vertebrates from this discovery.

Weight for weight the pyloric mucosa produces much less pepsin than does that of the fundus-which is quite intelligible when we consider that the fundic glands are much more thickly set than the pyloric glands, and also that the length of the former is considerably greater than that of the latter.

The amount of rennin of the gastric juice during the different stages of digestion always runs parallel to the amount of pepsin. From this and other facts it appears permissible to conclude that although rennin is not identical with pepsin (page ?50), it is formed in the prloric glands as well as in the chief cells of the fundus glands. Whether it originates in the parietal cells also cannot yet be decided.

Views are widely divergent as to the seat of hydrochloric acid production. While some assume that it is produced in all the gland cells of the stomach. others suppose that it originates only in the parietal cells of the fundic glands.

As a matter of fact it appears to be shown with a fair degree of certainty that the pyloric glands do not produce hydrochloric acid. for in the secretion of the isolated pyloric sac one finds in exceptional cases an alkaline reaction and, what is important also, the mucous membrane of the blind sac exhibits at such times perfectly normal properties throughout. Moreover, it is stated that the free surface of the mucosa gives an acid reaction only in places where glands with two kinds of cells are found; at other places it reacts alkaline.

After considering all the facts obtainable bearing on this subject. Heidenhain came to the conclusion that hydrochloric acid is formed in the parietal cells of the fundic glands. It must be stated. however, that he reached this conclusion by the process of exclusion and not by direct evidence.

The cells of the gastric glands in the process of secretion undergo morphological changes which have been followed by Langley on fresh preparations. In the fasting condition the chief cells are strongly granular, but during digestion are clear-i.e., the outer zone (about one-third to one-half of the entire cell) shows no granules: they occur only along the luminal border of the cell. Extracts from different parts of the mucosa yield pepsin in greater abundance, the richer the glands in granules.

We find therefore the same state of affairs in the cells of the gastric glands as in the salivary glands. During the fasting period a substance is laid down in the chief cells. which in fresh preparations appears in the form of granules. During the act of secretion this substance is gradually used up; at the same 
time a new formation of the substance is going on, as we know from the fact that the percentage of pepsin of the mucosa increases again after the ninth hour of digestion.

\section{WHY DOES THE STOMACH NOT DIGEST ITSELF?}

Sereral hypotheses have been put forward to account for the fact that the stomach does not digest itself. The mucus of the stomach might act as a kind of varnish to protect the mucosa itself from the action of the gastric juice, or the epithelium of the mucosa might preserve the underlying parts in some way, or the gastric juice might be neutralized by the alkalinity of the blood, or the mucosa might be absolved from the destructive action of the gastric juice by its absorption. However, many objections can be urged against all of these hypotheses as well as the experimental facts uuderlying them, and the question was left to a certain extent undecided by simply assuming that the proteolytic enzymes cannot act upon the living cells of the same bods.

A nearer approach to an explanation seems to have been attained in Weinland's discovery of an antipeptic and antitryptic action of the stomach and intestinal mucosa. This action is probably due to antienzymes which are found throughout the whole animal scale, and occur not only in the intestinal tract but also in cells of other organs. As mentioned at page 155, such antienzymes are present also in the blood.

\section{§ 4. SECRETION OF PANCREATIC JUICE}

\section{A. SECRETORY NERVES}

That the secretion of pancreatic juice is to a certain extent under the control of the central nervous system was rendered very probable by the fact, ascertained by Heidenhain, that it can be started up or accelerated by electrical stimulation of the medulla oblongata. Later Pawlow succeeded in completing the evidence of secretory nerves to the pancreas.

These nerve fibers traverse the vagus. If, with the observance of certain precantions which are necessary to shut out the restraining influence of various sensory stimuli, the ragus be stimulated, a more or less active secretion of pancreatic juice is plainly demonstrable. The vagus also conveys fibers which inhibit the pancreatic secretion.

The splanchnic likewise contains secretory fibers for the pancreas, but its action is much less powerful than that of the ragus (Kudrewetsky).

Secretion of the pancreatic juice in the herbivorous animals is continuous -a condition doubtless connected with the continuous character of digestion in these animals. In the carnivora it is intermittent. and (in the dog) the first drops flow from the duct one and one-half to three and one-half minutes after eating. In man also a rise oceurs after eating and reaches its maximum in the fourth hour, from which time on it gradually falls (Glaessner; Fig. 106).

To what extent the secretion of pancreatic juice is caused like that of the gastric juice by stimuli from the mouth, or what rôle the psychic factor plays in the process must remain for the present undecided. Howerer, still another influence is of far-reaching importance here. If an acid (no matter what 


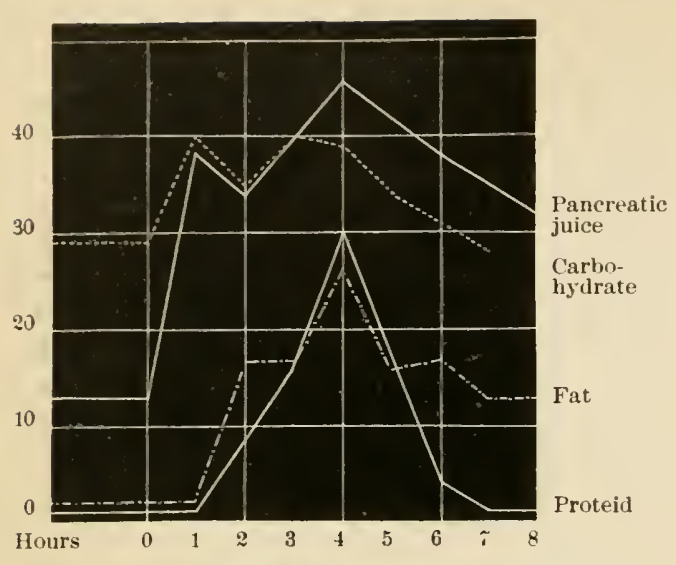

FIG. 106. - The course of pancreatic secretion in man, after a meal consisting of soup, meat, and rolls, after Glaessner. one) be introduced into the duodenum, after a short latent period, a copious seeretion of pancreatic juice is ponred out. The acid gastric juice flowing through the pylorus obviously must have exactly the same effect (Gottlieb. Pawlow). As soon as the pyloric sphincter opens and gastric juice pours out into the small intestine, the conditions are present for an abundant flow of pancreatic juice.

This influence of acids is beautifully confirmed by the fact that a flow of pancreatic juice caused by the gastric secretion is reduced considerably when the stomach contents are neutralized by administration of alkaline fluids.

Since the ragus causes the flow of gastric juice also, it might be thought that the secretion of the pancreas under the influence of this nerve begins only under the stimulating aetion of the acil gastric juice. But this is not true, for on artificial stimulation of the vagus the pancreas begins to secrete sooner than the stomach, and besides, the pancreatic secretion makes its appearance even if the pylorus be firmly ligated so as to prevent any passage of gastric juice (Popielski).

Water and neutral fats in the intestine are mentioned by Pawlow as special excitants of the pancreatic secretion (in man administration of fat was without effect); other authors have succeeded in indueing a secretion by means of mustard, pepper, chloral hydrate, ether, etc.

Formerly it was supposed that this secretion is in the nature of a reflex and is mediated by the afferent

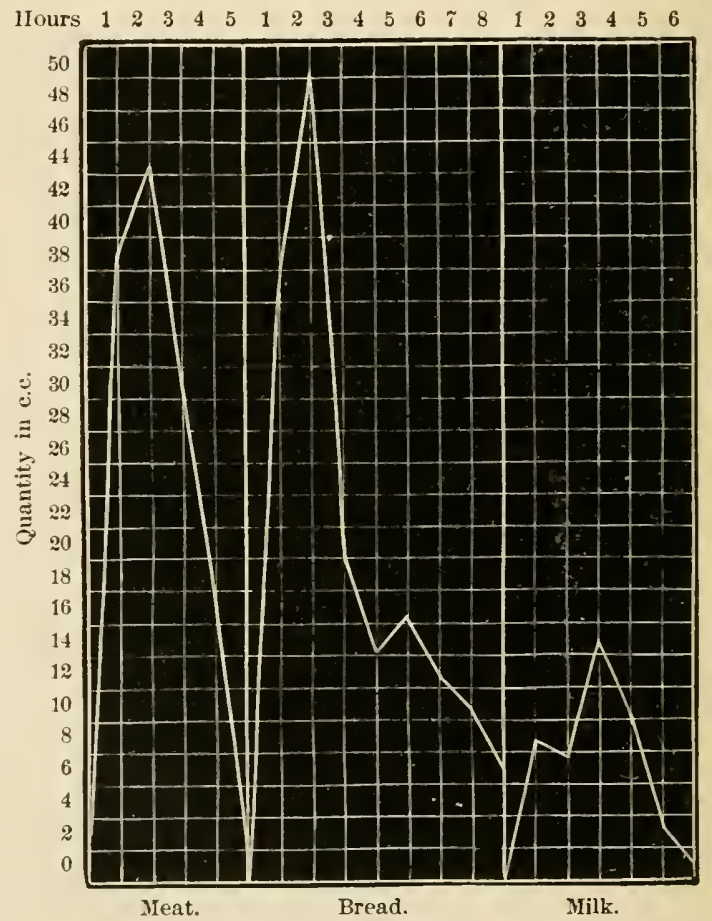

Fig. 107.-The course of secretion in the pancreas of the dog, after feeding exclusively with meat, with bread and with milk, after Walther. 
nerves of the small intestine. It could be pointed out in support of this riew that injection of acids into the rectum or directly into the blood evaked no secretion, and that therefore the glands could not be stimulated from the blood. Bayliss and Starling, however, observed that an extract of the intestinal mucous membrane with $\mathrm{HCl}$, injected into a vein, called forth the pancreatic secretion at once. The acid dissolves out of the mucous membrane a substance, not destroyed by boiling and called by the authors secretin, which in their opinion acts specifically upon the pancreas and constitutes the only natural cause of its secretory activity.

Beyond all doubt secretin is a powerful excitant of the pancreatic secretion; but its specific nature is denied by several authors. Since, however, $\mathrm{CO}_{2}$ from the small intestine also produces a flow of pancreatic juice, and there is of course no secretin extract of the mucosa in this; since, further, the acid introduced into an intestinal loop has an excitiug action on the pancreas, even when the renous blood of this loop is direrted and the thoracic duct is tied off, one is justified in the assumption that on introduction of acid into the intestine the secretion is produced partly by a reflex set up by the acid, and partly through the secretin in the blood.

Nothing definite can be said concerming the nerve centers of pancreatic secretion. The observations which pur-

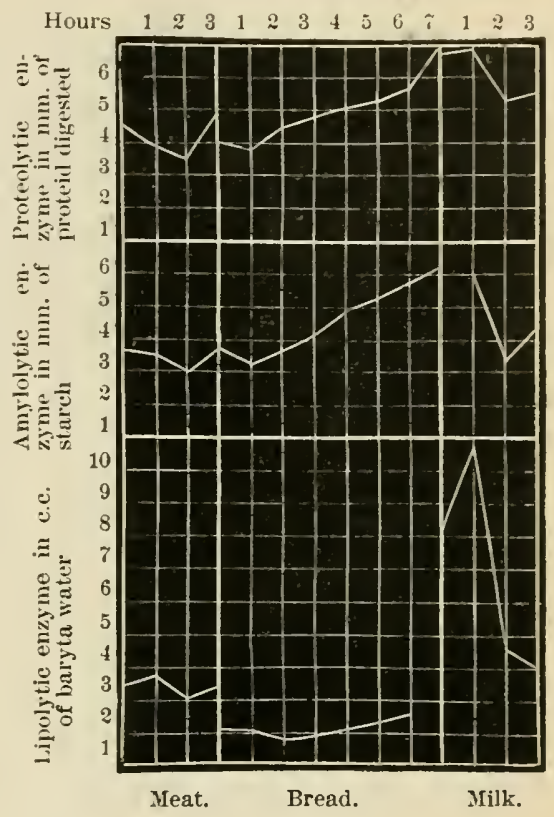

Fig. 108.-The enzymes of panceratic juice, after feeding exclusively with meat, with bread and with milk, after Walther. ported to demonstrate reflex centers in the gland itself are no longer convincing since the discovery of secretin.

The hourly course of the secretion, which appears to be connected with variations in the discharge of the stomach contents into the intestine, as well as the amount of the different enzymes present in the secretion, shapes itself according to the food ingested, as may best be seen from the diagrams in Figs. $10 . \%$ and $108 .^{1}$

From these diagrams it is evident that the absolute rate of secretion following milk is different from that following the ingestion of meat and bread: that the content of amylolytic enzyme is considerably greater for bread than for meat and milk, and that the content of steapsin is much greater for milk than for meat and bread.

The total quantity of nitrogen which is giren off in the pancreatic juice during a period of digestion varies much with different foods. In fact with the

${ }^{1}$ With regard to Fig. 108 it should be said that the observations there represented were made before the discovery of enterokinase, and give therefore only the manifest trypsin content of the juice. 
same amount of $\mathrm{N}$ in the food, it is about twice as great for bread as for milk or meat, and in the former case rises to about one-fifth the amount of $\mathrm{N}$ ingested. In a carnirorous animal like the dog, the digestion of bread seems to call for a much greater effort on the part of the pancreas than the digestion of meat or of milk (Walther).

\section{B. MORPHOLOGICAL CHANGES IN THE PANCREAS}

Kithe and Lea observed directly on the living rabbit the changes which take place in the cells of the pancreas during secretion (Fig. 109). When secretion hegins a change of form comes orer the cells, which is expressed in a striking change of configuration of the tubule. While in the inactive state the latter appears perfectly smooth on the onter edge, during activity convex swellings which correspond to the separate cells become visible. The resting cells form an optically continuous picture within the tubule, but the actire

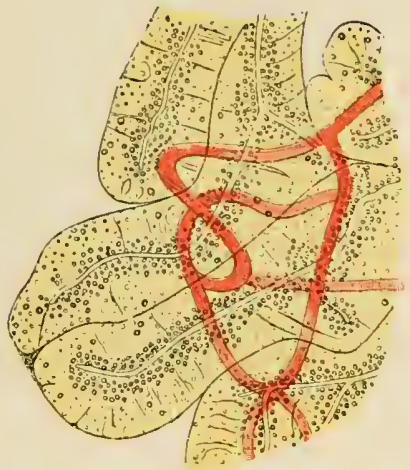

A

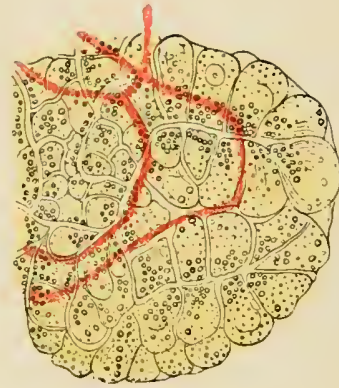

$B$

FIG. 109.-The pancreas of the rabbit, as observed in the living animal, after Fühne and Lea. $A$, resting state; $B$, secretion.

cells are marked off from one another by sharp and, for the most part, double boundary lines. Likewise during the active condition the striations in the outer zone, running from the base toward the inner border, stand out more clearly. The granules of the inner zone withdraw gradually from the region of the nucleus toward the lumen, become smaller and softer, and finally disappear altogether.

\section{\$. THE LIVER AND THE SECRETION OF BILE}

\section{A. GENERAL PHENOMENA OF HEPATIC SECRETION}

The secretion of bile differs from the other secretory processes thus far studied, primarily by being continuous. but also by the fact that, notwithstanding many researches, secretory neres hare not yet been found for the liver.

In this respeet there is complete agreement between the bile and the urine, and one might suppose that these two seeretory processes do not require the coneration of secretnry nerves, since in order to discharge their function of removing exeretory products from the body they must go on continuously. As 
far as the kidneys are concerned, we know indeed that certain diuretic substances in the blood intensify the secretion of urine quite independently of the nerrous system. It is possible that the same thing is true of the liver and that here, as probably in the kidneys, the regulation of secretion is the result of a vasomotor influence. However, this conclusion does not exclude the possibility of some controlling influence by secretory nerves, for experience with the seeretory nerves of the stomach and pancreas teaches that the results of stimulation may be entirely masked by various different circumstances.

Although the secretion of bile goes on continuously, it shows certain variations which are not ret satisfactorily explained. Indeed the statements of facts themselves exhilsit a difference in many points, which is but little gratifying. 'This much appears, however, from the observations at hand, that the food exprts an important influence. 'The quantity of bile secreted is least in fasting and declines steadily as the period is prolonged. The increase effected by the food depends in the first place upon the kind: meat causing a considerable increase. carbohydrates causing little or none at all.

Even in fasting the secretion of bile varies from hour to hour. After feeding meat the rise mentioned above does not appear at once, but, as a rule, only after the lapse of twenty to thirty minutes. The latent period is still longer after feeding fat. Statements disagree as to when the maximum oceurs.

This long latent period is of great importance for our theoretical conception of the causes of the secretion, and seems to speak decisirely for the view that the increase results from an exciting influence of substances absorbed from the alimentary canal, and that these substances act. therefore, directly on the liver. Whether this view actually represents the truth of the matter, or whether the increase in the secretion of bile which is to be observed after feeding is due to a reflex effect upon vasomotor or secretory nerves, must for the present be regarled as another open question.

The dirert stimulation of the liver by bile-producing (cholagogic) substances is illustrated further by the following facts to which Schiff first directed attention. If both a biliary and an intestinal fistula have been established in a dog. and the bile obtained from the former be injected into the latter, or if ox bile be used for the same purpose, a considerable increase in the amount of bile flowing from the biliary fistula is obtained. Schiff explained these facts by saying that the injected bile was absorbed from the intestine, came to the liver and was again seereted.

We have direct proof of the correctness of this view in the fact that sheep's bile, when injected into a mesenterial rein of a dog whose hepatic arteries have been tied off, is secreted in the bile of the dog and can be demonstrated by the speetroseopie test for cholohematin. which oceurs normally only in the bile of the sheep. At the same time the absolute quantity of bile rises. Bile or bile salts given by the mouth have the same effect. The percentage content of solids rises at the same time (Spiro and Voit).

\section{B. DEPENDENCE OF THE SECRETION OF BILE UPON THE BLOOD SUPPLY}

The supply of blood to the liver manifustly influenees the secretion of bile to a considerable extent. If the general blogl presure be reduced mark- 
edly by bleeding. the quantity of bile secreted is diminished; at the same time, howerer, the percentage of solids increases. Cutting down the supply of blood by tying off several branches of the portal vein likewise diminishes the secretion. And when the vena cara inferior is compressed-so that the rolume of blood passing through the liver in a unit of time is materially reduced - the same result is obtained.

The secretion of the bile declines on stimulation of the spinal cord, because of excitation of the vasoconstrictor nerves to the abdominal viscera, and a consequent fall in the blood supply to the liver. Section of the cervical cord produces a general fall of pressure throughout the vascular system and is accompanied by a deeline in the output of bile. The output, on the other hand, increases after section of the splanchnic, because, in spite of the fall in general blood pressure, the blood supply to the liver increases on account of the dilatation of the portal vessels.

These and other kindred facts can be fully explained by variations of blood supply and contain no proof whatever that the secretion of bile is directly affected by secretory nerves. It is possible also that the rise of the secretion mentioned by some authors as beginning shortly after the ingestion of food, is produced by the dilatation of stomach and intestinal vessels during digestion.

We may summarize the facts thus far discussed as follows: The liver secretes bile continnously. This secretion is intensified by abundant supply of blood, also by certain bile-producing substances. especially the digestive products of proteids. There is yet at hand no single observation which would permit us to speak of any influence of secretory nerves on the liver. Like the other digestive fluids. bile represents an elaborated product of the secreting cells of the gland, for its specific constituents do not occur in the blood. The secretion pressure of the bile also is higher than the blood pressure in the portal vein.

Since the liver receives blood from several sources (hepatic arteries, portal vein and by return flow from the inferior vena cava), it is of interest to inquire whether any one of these vessels is indispensable to the production of bile, or whether all three can maintain the secretion independently. On closing off the hepatic arteries, secretion still takes place in abundance. Likewise after ligation of the portal feeding one of the lobes of the liver, the arterial branch supplying the same lobe alone mediates the secretion. Eck has shown that by an operation (Eck fistula) the portal blood can be conducted directly to the inferior vena eava, thus evading the liver altogether; and Stohikow has found that secretion of bile continues after such an operation. This secretion occurs at least in part at the expense of blood flowing backward in the hepatic reins. For if the hepatic artery is tied off after the new route for the blood is established, the secretion still continues. It ceases however when the hepatic vein in addition is tied. Either kind of blood therefore seems to be sufficient to produce bile.

The hepatic artery supplies the gall bladder, the bile ducts and the interlobular branches of the portal vein with blood through its vasa nutritia. When these are ligated and the arterial blood supply thus completely stopped, multiple necrotic foci make their appearance in the liver. From the larger foci cysts develop; the smaller ones become transformed into connective tissue, and are followed finally by an hepatic cirrhosis.

When the discharge of bile into the intestine is prevented, the bile is reab- 
sorbed. It does not pass direetly from the biliary ducts into the blood, but is taken up, in part at least, by the lymphatic ressels. If the thoracie duet as well as the bile duct be tied off, it may happen that no constituents of the bile will pass into the blood (Harley); but there are statements to the effect that even under these circumstances they may find their way into the general circulation (Wertheimer and Lepage).

\section{THE DISCHARGE OF BILE IN DIGESTION}

When digestion is not going on the secreted bile collects in the gall bladder; there it loses water and becomes thicker. Neither borlily movements, nor movements of the alimentary canal, fasting, nor appetite have any effect

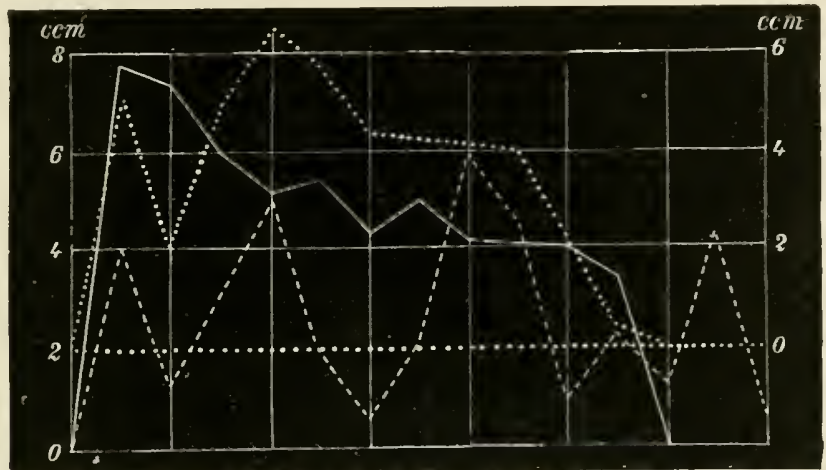

FIG. 110.-The hourly course of the discharge of bile into the intestine of the dog, following ingestion of different foods, after Bruno. - meat;-.-- -bread; ........ milk.

in causing the gall bladder to empty its contents: the bile begins to flow from the bladder into the intestine only at the beginning of digestion.

The outflow of bile into the intestine is adapted to the immediate requirements by the following mechanisms. The discharge of bile from the ductus choledochus is controlled by a special sphincter. The gall bladder and the bile duct possess muscles which are under the influence of the splanchnic nerve. It is said that the duodenal sphincter of the ductus choledoehus is innervated by the vagus. Phenomena witnessed on stimulation of the splanelnic show further that the gall bladder, as well as the ductus choledochus and the sphineter, may be reflexly dilated. Again by central stimulation of the vagus, reflex contraction of the gall bladder and relaxation of the sphincter may be produced.

The evacuation of the gall bladder and the discharge of bile in digestion, according to Bruno, are elicited by the passage of the stomach contents into the intestinc. The substances active in this are the digestive produets of proteids, extractives of meat and fats. The earbohydrates evoke no discharge of bile. Since the passage of the stomach contents into the intestine is gorerned by the kind of food, the discharge of hile is naturally different for different foods, as appears also from the diagram in Fig. 110.

With respect to the properties of the bile. it should be mentioned that the portions first discharged are thicker than that which enmes later, hecanse the former comes from the gall bladder, while the latter is freshly seereted. 


\section{\$6. THE GLANDS OF THE INTESTINE}

\section{A. GLANDS OF THE SMALL INTESTINE}

In fasting animals scarcely any secretion of intestinal juice takes place. But if the intestinal mucosa be stimulated directly, either by mechanieal, plectrical or chemical means, or if food be ingested, it makes its appearance. Whether an isolated loop of the intestine into which no food can pass begins to secrete without direct stimulation, nust, in view of recent discoveries, be regarded as very doubtful.

If the nerve fibers rumning in the mesentery beside the blood ressels to an intestinal loop be cut, either immediately or after some time, an extremely abundant secretion appears in the loop, whereas the adjacent parts of the intestine outside of the tract deprived of its nerves show nothing of the kind. This secretion, which may reach the enormous value of one-eleventh of the body weight, contimes for some hours, becomes somewhat seanty after four or five hours, but does not cease within twenty-four hours. At first the secretion is quite clear, containing no solid flakes, or at least only a few; but as time goes on the quantity increases so that finally a veritable "pap" is produced. At times the secretion is milky, like a thin gruel, and contains an abundance of intestinal epithelia (Moreau). Somewhat similar phenomena, more or less degenerative in character, make their appearance after extirpation of the ecoliac plexus.

It is not casy to explain this secretion. We might regard it as primarily a transudation of fluid caused by the rasodilatation, and not as a true process of secretion at all if our knowledge of transudation in general did not speak decisively against such an explanation. If it were an actual secretion of the glands of Lieberkïhn-a view which is confirmed by the properties of the fluidit were easy to assume that the nerves whose seetion produced the hypersecretion exert a tonic influence which inhibits the glands. When the glands eseape from this inhibitory influence they fall into the comdition reseribed. This hypothesis assumes that in the intestine itself conditions are present which would set the glands in excessive action, if they were not restrained by the nerves. But we know nothing more about it. Meantime let it be remembered as was remarked conceming the other digestive glanrls-the paralytic secretion of the salivary glands, etc.- that certain phenomena have been observed which point to such an inhibitory influence.

Other than this we have no knowledge of an ultimate influence of the nervous system upon the secretion of the intestinal juice. Tagus stimulation thus far has given only negative results.

So far as the few scattered observations on this subject go, the secretion of the lower part of the small intestine seems to be more abundant than that of the upper. It is stated also that the quantity of sliny flakes in the upper parts is greater. These flakes consist essentially of swollen cellular elements (epithelial cells and leuencytes) and of desquamated cells undergoing fatty degeneration.

If the two ends of an isolated loop of the intestine be sewed together and the intestinal ring thus formed be lowered into the abdominal earity, one finds, when the animal is killed some montlss later, that the intestinal ring is filled full of a semisolid mass (IIermann). This mass, like the above-mentioned flakes in the intestinal juice, consists of clead eellular elements. It appears therefore 
as if cells of the mueous membrane perish in great numbers, even if, as in this case, no food or anything of the kind comes into the intestine. Nevertheless. this conclusion is not quite definitely established, for it eannot be maintained that the isolated loop is in a perfectly normal eondition. And, in fact, Klecki has observed that if he washed the intestinal ring tolerably free of Bacteria with boracic acid and artificial gastric juice before sewing it up, and if in the further course of the experiment no pathological changes of any kind made their appearance, he found after the lapse of more than two months onlr a scanty leposit of rellowish, sticky, waxlike substance adherent to the surface of the membrane. This, like the contents mentioned above, consisted mainly of desquamated intestinal epithelial cells, but was by no means so abundant.

Histological studies of the glands of Licherkibn have shown that their fundic cells love the same morphological character as the cells of the other digestive glands. Likewise in these the preliminary stages of the secretion appear in the form of grannles which gradually inerease in size and finally passover into the secretion. These colls are very sharply distinguisher by their properties from the mucous cells (goblet cells) of the intestinal epithelimm (II. Mäller).

\section{B. THE GLANDS OF THE LARGE INTESTINE}

The gland: of Lielserkithn in the larye intestine do not secrete a digestive fluid. 'The properties of their secretion have heen studied by making an opening into the large intestine and introducing various suhstances incloserl in small sacs of

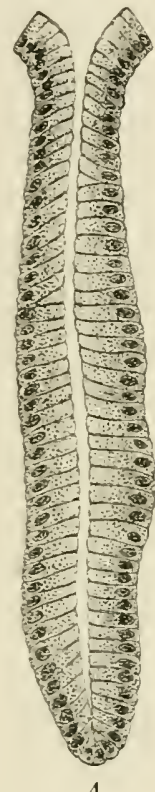

A

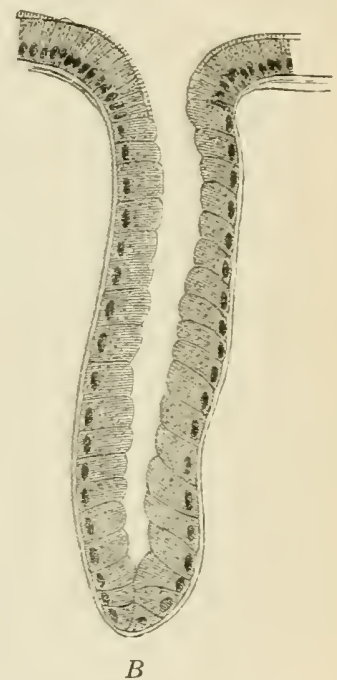

Fig. 111.-Glands of the large intestine of the rabbit, after Heidenhain. $A$, after very active secretion: $B$, after a long period of rest. network. It ha- been found in this way that neither fibrin nor starch is digested. The secretion, which is but scanty. is a water-elear, odorless. thickly gelatinow and sticky mass of neutral reaction. containing turbid flakes of varinus sizes (Kilug and Koreck).

The secretion of the large intestine, therefore, plays no part in digestion. The mucus entained in it probably serves to facilitate the pariage of the intestinal contents which have leeome thicker by the absorption of water.

If the mucous memlirane of the large intestine be studied under the mieroscope, after injection of pilocarpine into the animal. the glamls are seem to be composed of cells which are strikingly like those of the grands in the suall intestine. In atcoholic preparations the cells of both are small. Iongitudinally striated, and contain romel or oval nuclei (Fig. 111. 1). After prolonged rest the glands of the large intestine present quite another picture. The 
grcat majority of the tubes are clothed from base to mouth with cells which have gone through a process of mucous degeneration, and have taken the form of goblet cells-i. c.. swollen structures with the nuclei in the basal end (Fig. 111, B). The contents of these cells behave exactly like those of the typical mueous cells (Heidenhain).

Likewise in the glands of the small intestine are found goblet cells between the true epithelial cells; but they are often wanting. Frequently they occur separately in the region of the upper end of the tube, rarely also at the lower end.

From these facts it follows that the cells during rest undergo mucous degeneration: in activity the mucus is discharged and the cell itself often perishes in the process. Just to what extent the latter takes place has not been finally determined. At the base of the epithelium are found here and there small round cells which are looked upon as substitutes for the cells which disintegrate.

\section{THIRD SECTION}

\section{MOVEMENTS OF THE ALIMENTARY CANAL}

\section{\$1. MASTICATION}

The movements of mastication are for the purpose of dividing the food mechanically and of saturating it with saliva, so that a bolus may be prepared suitable for swallowing. Mastication is accomplished by movements of the lower jaw against the upper, the morsel of food being placed by appropriate movements of the tongue and cheeks, between the two rows of teeth, and being ground up by the latter acting against each other under the force of the powerful jaw muscles.

The teeth and the mode of chewing are unmistakably adapted to the kind of food eaten, so long as regard is had to the animals whose natural food is exclusively animal or exclusively vegetable. In man the teeth and movements of the jaw present no pronounced characteristics, doubtless because, with the assistance of the art of cooking, he has learned how to subsist upon so many different articles of diet. Raw meat cannot be properly reduced by the teeth of man; but if properly boiled or roasted so that the connective tissue binding the muscle fibers together is loosened, it is easily masticated. Likewise the seeds of cereals, which are otherwise incapable of being attacked by the human digestive apparatus, are rendered fit for food by boiling or by baking. Among all the articles of diet which are generally accessible to the higher animals, strictly speaking only grass and hay are incapable of serving man as food.

The actual grinding of the food is attended to primarily by the molar teeth, those in the front of the mouth serving only for biting off morsels of suitable size. The lower jaw is drawn upward by the masseter and temporal muscles, forward and upward by the internal pterygoids, forward by the external pterygoids. It is drawn downward by the digastric, the mrtohyoid and the geniohyoid, and backward by the posterior belly of the digastric. 
By contraction of the external pteryoid musele of one side the jaw is moved toward the opposite side. In the depression of the lower jaw, the articular tubercle is moved forward in a line which is concave upward, at first slowly, then rapidly and at last slowly again.

The lips. eheeks, and tongue coöperate to bring the new or incompletely masticated portions of the morsel between the teeth. to facilitate saturation of it with the saliva and finally to form the mass into a bolus to be swallowed.

\section{\$ 2. SUCKING}

The buceal eavity is capable of being closed air-tiglst. It can also be enlarged withont admission of air, and in this way suction ean be produced by which fluids may be drawn into the mouth.

When the buceal earity is closed so as to be air-tight, the tip of the tongue lies against the teeth and the alveolar process of the upper jaw; the base of the tongue is raised on both sides against the back teeth and the neighboring parts of the upper jaw; the lower surface of the tongue rests on the edge of the lower jaw, and the soft palate hangs down loosely orer the root of the tongue. Holding the jaws perfectly still with the parts in this position, a negative pressure of from 2 to $4 \mathrm{~mm}$. of $\mathrm{H}$. prevails in the mouth (Mezger, Donders). One can easily convince himself that the cavity is really air-tight, for if he depress the lower jaw without opening the mouth, the cheeks are drawn between the rows of teeth.

By drawing the tongue back or by lowering the jaw, the buceal carity is enlarged and a suction is thus produced, which becomes still stronger if the tongue be drawn downward.

The space inclosed by the mouth parts in the act of sucking is about $i$ c.e., three-eighths of which is due to the depression of the jaw. and fire-eighths to the lowering and flattening of the tongue.

The power of suction in the human mouth is rery great. It is possible by repeated efforts to develop a negative pressure of $900 \mathrm{~mm}$. of $\mathrm{Hg}$.

A child in nursing grasps the nipple of the breast with the lips in such a way that the mouth is elosed air-tight. In the absence of teeth this is facilitated by special. membranous. and very vascular prominences on the erlge of the gums of loth jaws. These structures are found in the position of the four canines and. especially in the lower jaw, are united by a membranous seam projecting $1-3 \mathrm{~mm}$. high.

\section{\$3. DEGLUTITION}

We include under deglutition all those processes hy which the bolus of food is propelled from the mouth into the stomach. it is a very complicated reflex process in which many museles eö̈perate.

After the bolus is formed and is placed on the lack of the tongue, the swallowing reflex is elicited by stimulation of the sensory nerves in the back of the mouth. In the ape the holus. Hhrown into the pharyx. exeites the reflex act in gliding over the tonsils (Kahn). In man no definite part of 
the month cavity from which the reflex ean invariably be started has yet been made out. We ean only say that it is indueed when the bohus is foreed back of the soft palate into the region of the tonsils. Thus far the process is under control of the will and the swallowing reflex therefore is inangurated voluntarily, but thereafter it is independent of the will.

The first muscles to contract are the mylohyoids, and the pressure in the mouth eavity is raised by their eontraction alone to about 20 e.c. of water. Almost at the same instant the hyoglossi contract causing the free surface of the base of the tongue. which in rest is directed backward and npward, to execute a movement backward and downward. By this contraction, according to Kronecker and Meltzer, fluid foods are spirted through the whole length of the esophagus to its lower end before the contractions of the pharyngeal and asophageal muscles can be brought to bear on them. Against this view, howerer, it may be observer that at the moment of the mylohyoid contraction the essophagus is still elosed by an elastic pressure exerted by the larynx. This closure is broken only when the larynx is drawn upward and forward, which takes place some 0.2 (Schreiber) to 0.3 of a second (Eykman) after the inception of the aet-i.e., at a time when the effect of the mylohyoid is already past. If this be true, the movements of the ahove-named minseles of the tongue can only force the food mass into the pharynx (cf. Fig. 112, in which a sagittal section of the floor of the mouth and of the neek in both the normal position (A) and the open position (B) of the passageway is represented after $\mathrm{I}$ ray photographs: from $\mathrm{B}$ it is plain that the tongue in swallowing lies against the posterior wall of the throat).

When the food reaches the pharynx there follows in order the contractions of the pharyngeal and the esophageal museles. In the osophagus the movement is executed at two different rates of speed. The muscle fibers in the cerrical part of the esophagus are cross-striated and the movement consequently is rapid; in the thoracic portion the cross-striated musele layers are replaced more and more by smonth muscles and the movement of the food is eonsequently slower. The total time from the beginning of the act of deglutition until immediately before the opening of the cardia is about seven to eight seconds.

If the esophagus be eut in the neck or even if a long piece of it be extirpated, and the superior laryngeal nerve, which very easily discharges the swallowing reflex, be stimulated, a perfectly regular act of swallowing results in which the contraction not only extends over the upper part, but appears just as usual in the part lying below the section (Mosso). The peristaltic wave of contraction therefore runs from above downward, under the direct control of the central nervous system. In deeply anesthetized dogs this experiment does not succeed (Wild); but if in such animals the anatomical continuity be preserved, the contraction wave travels over the entire msophagus. From this it follows that the contraction can be propagated through the esophagus without the coöneration of the central nervous system, a circumstance which Meltzer supnoses to be due to the action of peripheral reflex centers.

We have, therefore, to conceive the act of deglutition as taking place in such a way that once the reflex is indnced, the different divisions of the passageway (floor of the mouth and tongue, pharynx, the rarious divisions 
of the ossophagus) are excited in a perfectly definite order by impulses coming from the central nerrous sytem.

The nerves for the upper part of the cesphagus are found in the recurrent laryngeals, for the lower part in the pulmonary and cesophageal plexuses.

since the pharynx is in open communication not only with the cesophagus but with the nose and the larynx. the presure dereloped in swallowing might easily force the food into the wrong opening. But because of the different protective mechanisms brought into play this does not happen. The return of the bolus into the mouth carity is prevented by contraction of the palatoglossal muscls. which approximates the tongue to the palate and narrows the i-thmus of the fauces. This is assisted also by the styloglossal muscles, which raise the tongue and press it forward against the soft palate. The nasal cavity is shut off from the mouth and pharynx by elevation of the soft palate.

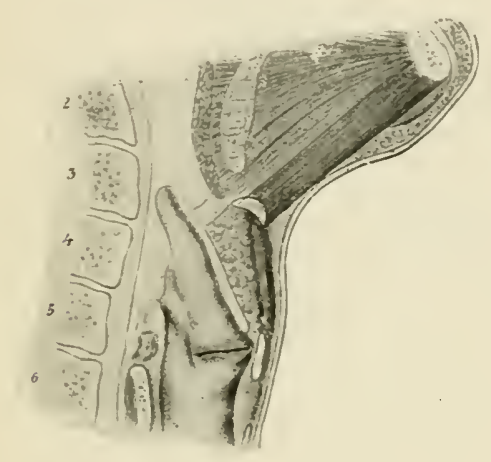

$A$

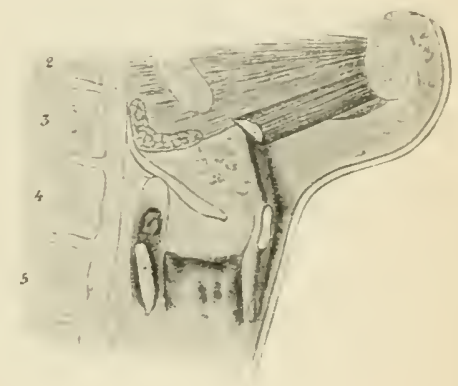

$B$

Fic. 112.- Sagittal, optical sections of the floor of the mouth and of the neck, reconstructed from I ray photographs, after P. H. Eykman. A, position of quiet inspiration; B, position in swallowing; the passageway for food into the crsophagus is open. The observer is supposed to be looking into the left half of the laryux. In At the epiglottis is shomn in the erect position. In $B$ it is depressed, by the backward motion of the tongue, against the posterior wall of the pharynx (only the edge of the epiglottis is seen). In $B$ the cricoit cartilage is raisect to the upper border of the fourth cervical vertebra.

When the palate muscles are paralyzed, water sometimes passes out the wrong way through the nose.

The larmx is raised in swallowing both for the purpose of releasing the pressure on the msophagus so that it may be freely open, and for the purpose of presenting the passage of food into the larynx itself. This morement may be described as follows:

The geniohyoid, mrlohyoid and anterior belly of the digastrie muscle draw the lipoid bone and the larmx. the lower jaw being fixed. forward and upward. The hyothrroid museles serte to keep the laryux close up to the hyoid bone. At the same time the base of the tongue mores downward and backward, a morement alreary deseribed as the effect of the hyoglossal and geninglossal muscles. By this means the cushion of fat which is found immediately orer the epiglnttis is pressed together from above downward. so that with the epiglottis it is pushed in as far as the bottom of the supraepiglottidean space. and the aryepiglettidean 
folds are applied to the posterior side of the epiglottis (Fig. 112, B). The epiglottis itself cannot play any great part in the closure of the pharynx; for it can be extirpated without interfering with the act of swallowing. Nor do the muscles of the epiglottis appear to be of any importance.

This extremely complicated process of swallowing is in all probability presided over and controlled by the medulla. Accolding to Marchwald the center lies lateral to and above the summit of the alæ cineræ.

When the bolus has reached the lower end of the esophagns it is forced into the stomach. The eardia is normally elosed by tonic entraction of its sphincter muscle. as is evident from the fact that no regurgitation of food takes place even when the pressure in the abdominal cavity is very greatly

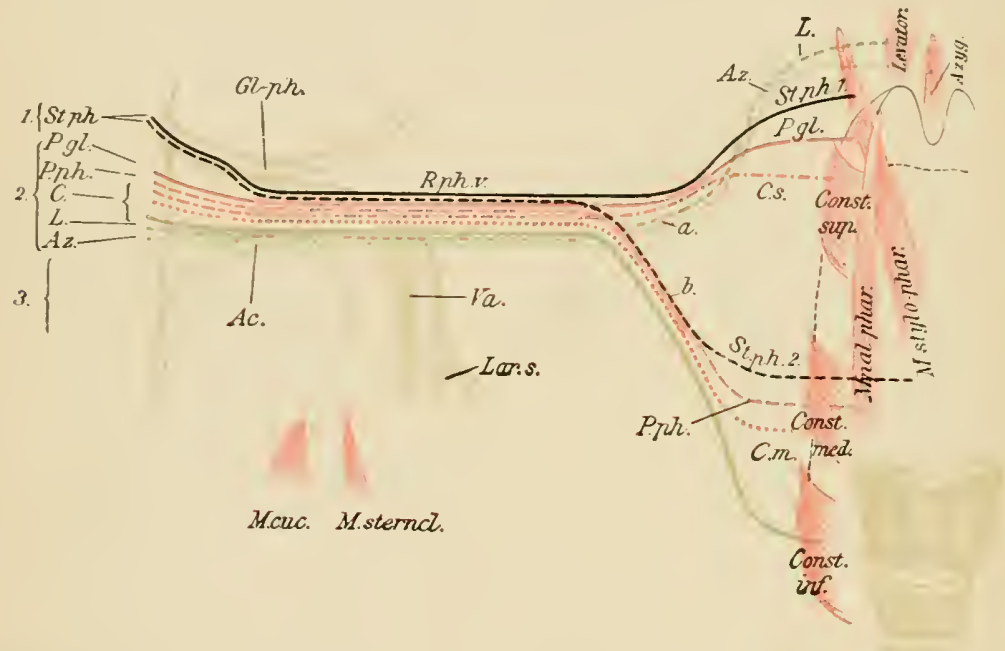

Fig. 113.- The motor nerves of the throat and palate of the monkey, after Réthi. 1, upper; 2, middle; 3, lower bundle of roots. Gl-ph., glossopharyngeal nerve; I'a, vagus; Lar.s, superior laryngeal; $A c$. accessory nerve; $R$. ph., $v$. pharyngeal root of the vagus; $S t$. $p h$., the motor nerves of the stylopharyngeal muscle; $P . g l$. motor nerves of the palatoglossal muscle; $P$ ph., the motor nerves of the palatopharyngeal muscle; $C$., motor nerves of the constrictor muscles of the pharynx; $L$., motor nerves of the levator veli palatini; $A z$., those of the azygos. urulse.

increased. The cardia is opened ly the action of its dilator nerves (cf. $\$ t)$, and the bolus of food is pushed into the stomach by contraction of the lowermost section of the cesophagus. When the cesophagus is paralyzed by section of its nerres. food remains in it, and may be sucked into the lungs. producing inflammations which result fatally.

By auscultation of the region over the cardia in man two sounds mav be heard after deglutition, the one almost immediately after the ineeption of the act, the other some six to seven seconds later. The first sound is seldom heard and appears to be caused by an abnormal gaping of the cardia. In this case the food is probably spirted by contraction of the muscles in the upper passages. directly into the stomach. The second sound corresponds in its occurrence to. the time when the food is being forced into the stomach, and it is probably caused by this procedure. 


\section{\& 4. MOVEMENTS OF THE STOMACH}

\section{A. KNEADING MOVEMENTS}

The purpose accomplished by the morements of the stomach is to mix the food with the gastric juice and to reduce it mechanically by kneading and grinding. By this means the chemical changes to be wrought by the gastric juice are aided materially. The digestion of proteid in an artificial gastric juice requires much less time if the proteid is kept moving than if it is allowed to remain quiet. The proteid is more accessible to the gastric juice by reason of the morement, and the kneading, such as takes place in natural digestion, easily reduces to small pieces the masses already rendered brittle by the preliminary effect of the gastric juice.

With reference to the musculature of the stomach, we have to distinguish the two openings, the cardia and pylorus, as well as the main budy or fundus, and the antrum pylori. The openings are surrounded by strong muscular fiber: and are as a rule closed. The fundus, or body of the stomach, has a relatively weak musculature, the antrum a very strong one.

Observations on the movements of the stomach after the ingestion of food all agree in finding the contractions of the pyloric portion much more powerful than those of the body of the stomach. The former is marked off from the fundus by a ring muscle called the splincter of the antrum. Relatively weak peristaltic waves sweep over the fundus from the eardiac end, and are continued by the rery powerful contractions of the antrum. beginning at the sphincter of the antrum and spreading toward the pylorus.

Meltzer found that the fundic portion does not respond, even to very strong stimulation with easily recognizable contractions, whereas the pyloric portion with the same stimulus contracts more energetically the closer the stimulus is applied to the pylorus itself.

In a patient with a stomach fistula, a pressure of 14 to $35 \mathrm{~mm}$. Hg. has been observed in the body of the stomach, and $130 \mathrm{~mm}$. in the antrum. The antrum. it seems, may be closed off completely by contraetion of its sphincter or by local contractions of separate sections, from the parts of the stomach lying to the left.

Since the pressure exerted by the fundic wall is commonly not very strong and the antrum is filled therefore during the dilatation which follows its own contractions under a very weak vis a tergo, the coarser portions of the food are probahly not pressed into the antrum. but only the easily mobile. more fluid and more gruelly portions. If this is true, it follows further that the changes which the food undergoes in the body of the stomach are principally of a chemical nature. while the antrum represents the truly motnr part of the stomach. where the bits of food already more or less comminuted are intimately mixed with the gastric juice and still more thornughly ground up by powerful contractions.

Experiment shows that the stomach. deprived entirely of nerres. or eren cut out of the hody, undergoes spontaneons contrartions: that like the heart. the stomach has. therefore. within itsolf all the necessary ennditions of it: movements-which is probably due to the ganglion cells found in the stomach 
wall (ef. page 2ss). But these morements are presided over and regulated in many way by the eentral nervous system. The very complieated relations of the nerves concelned in this control will be evident from the scheme devised by Openchowski (Fig. 11t).

The stomach receives its motor neres in part from the vagus, in part from

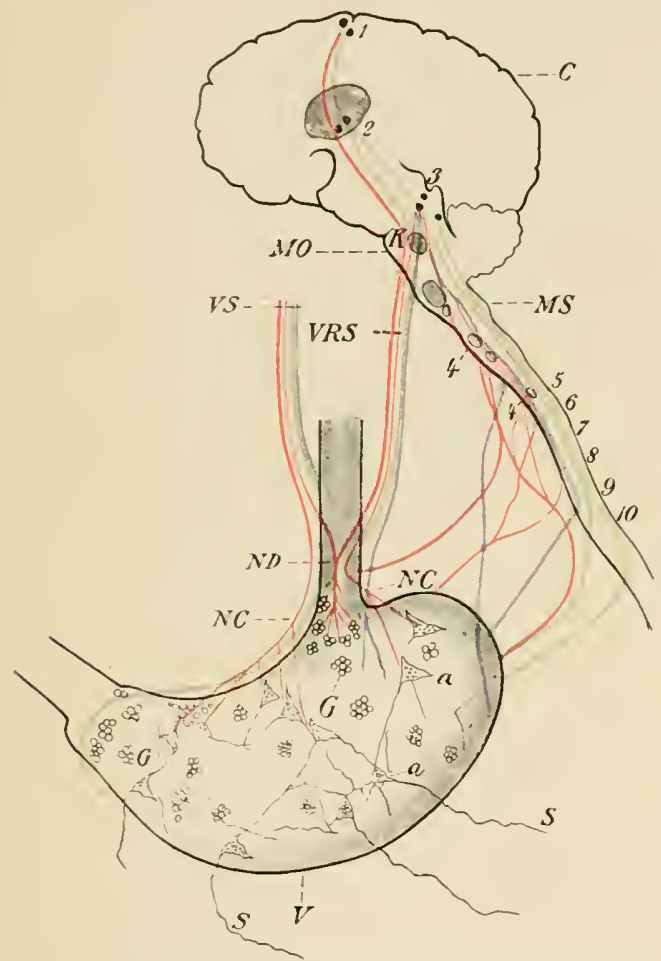

Fig. 114.-The nerves of the stomach musculature, blue, the paths to the body of the stomach; green, the paths to the pylorus. $C$, the cerebrum; $I$, stomach; MO, medulla; $M S$, spinal cord; 5-10, thoracic roots; VRS, right vagus; VS, left vagus; $\triangle D$, dilators of the cardia; $\mathrm{NC}$, constrictors of the cardia; $a$, Auerbarh's plexus; $S, S$, fibers from the sympathetic plexus. 1, sulcus cruciatus; 2, corpus striatum; 3 , corpus quadrigemina; 4 , centers in the spinal cord. after Openchowski. Red, the paths to the cardia; the sympathetic nerves. 'These nerve paths have been followed up to the cerebrum as follow: :

a. The Cardia: (1) From the region of the posterior eorpora quadrigemina constrietor fibers run for the most part through the vagi; some run in the sympathetic paths, reaching their destination oy way of the spinal cord and the fifth to eighth thoracic roots, thence through the two splanchnies. In the thoracic sympathetic the fibers are only sparingly represented. (2) The eardia is dilated by fibers which emerge from that region of the brain where the anterior lower end of the nucleus caudatus is united with the nueleus lentiformis, and join the vagus. In the spinal cord also as far as the fifth thoracic root, there are eenters for the opening of the eardia which send their fibers by sympathetic pathways.

b. The Body of the Stomach between the cardia and the pylorus: (1) The brain centers for the contraction of this part. lie in the eorpora quadrigemina, and the paths traverse both the ragi (chiefly) and the spinal eord, thenee hy way of the lower thoracic eord through the symurathetic trunks. (2) Inhibitory centers lie in the upper part of the eord and the paths traverse the sympathetic and splanchnicu (aceording to Langley also the vagus). ${ }^{1}$

c. The Pylorus and Pyloric Antrum: (1) Contraction centers are found in the corpora quadrigemina for both the prorus and its antrum. The elief path is the ragus, but the eonstrictor fibers rm also through the spinal eord. (2) The dilator center for the cardia gives inhibition of the prlorie morements. but no

${ }^{\prime}$ Cannon has shown that distress inhibits gastric movements not only in the normal animal, but after the two ragi are cut, and after the four splanchnics are cut...... 
opening. The path lies through the eord as far as the tenth thoracie root, then through the splanehnies. Inhibitory centers for the antrum are present in the corpora quadrigemina; and opening of the pylorus ean be indueed from the olivary body over a pathway whieh runs through the eord. The dilator nerve of the eardia under all circumstances proves to be a closing nerve for the pylorus. Opening of the eardia and contraction of the pylorus occur simultaneously. Langley finds inhibitory fibers for the pylorus also in the vagus.

\section{B. EVACUATION OF THE STOMACH}

When the stomach contents have been changed by the united action of the gastric juice and the movements of the stomach into a gruelly mass known as chyme, the object of gastric digestion is fulfilled; the pylorus is opened and the chyme is forced into the intestine.

The length of time the food is retained in the stomach depends to a great extent upon the kind of food eaten. In dogs having a duodenal fistula, Moritz has shown that pmre fluids (water and uncoagulated milk) leare the stomach very quickly. With coagulated milk the evacuation is considerably slower. It is longest of all with the solid foods (meat. sausage). The consistency of the stomach contents therefore determines primarily when the food will be eracuated. But its chemical properties also are of considerable importance in this respect. 'The experiments of Moritz upon himself tended to show that water, weak salt solutions, and houllon leave the stomach rery quickly, but water containing $\mathrm{C}_{2}$. weak acid solutions, milk and beer remain considerably longer. If meat or bread be caten the expulsion of water ingested at the same time is delayed considerably.

[Cammon fed fat, carbohydrate and proteid foods, uniform in amount (25 c.c.) and consistency and mixed with a small quantity of subnitrate of bismuth, to eats, and with the aid of the fluoroseope observed the rate of their discharge from the stomach. He found that fats remain longest in the stomach, proteids next, and carbohydrates a rery short time. When earbohydrates and proteids were mixed in equal parts, the mixed food did not leave the stomach so slowly as proteids alone or so rapidly as carbohydrates alone. Fat mixed in equal amounts with proteids and with carbohydrates eaused both these to be discharged more slowly than when each was fed alone.-ED.]

Even with a dict of firm consistency, small portions having the consistency of gruel are foreed into the duodenum as they are formed. and thus the evacuation of the stomach goes on gradually. It has been shown further that the pylorus closes and the expulsive movements of the stomach cease temporarily when a certain portion of the contents has been emptied (Hirsch, v. Mering). Not only the degree of fullness, but the reaction of the intestinal contents is of importance in this connection. A slight stream of $\mathrm{HCl}$ or pure gastric juice poured steadily through a fistula into the duodenum, will cause a soda solution previously introduced into the duodenum to be kept there for an indefinite time. A sola solution poured into the duodenum in the same way has no smch effect. From this it follows that each ontflow of stomach contents into the intestine stops further evacuation until the $\mathrm{HCl}$ of the gastric juice is neutralized by the alkaline fluids of the intestine ( 'awlow). 


\section{VOMITING}

Tomiting is an abnormal process by which the stomach contents are emptied though the cardia instead of through the pylorus. Several museles are concerned in romiting. but chiefly those of the diaphragm and abdomen. These contract all at once, producing a high intrabdominal pressure which naturally takes effect on the stomach wall. When the cardia is elosed romiting does not result. We know that this must be true beeause when simultaneous contractions of the diaphragm and abdominal muscles take place under other circumstances. for example in defecation. the stomach is not emptied through the cardia. The stomach wall it-elf plays little part in the process, for the entire stomach may be replaced by a swine's bladder and romiting therefrom may be produced (Magendie). Ind yet it must be observed that the pyloric portion of the stomach contracts powerfully in romiting and expels its contents into the fundus.

In romiting the larvix and nasal passages are protected in the same way as in swallowing. and the mass of stomach contents ejeeted from the stomach under high pressure must therefore take its way through the mouth. The tongue is not raised as in swallowing, but is pressed down and held out in the form of a groove.

Tomiting is induced cither by certain drugs or by reflexes set up from the base of the tongue, the throat, the stomach or the uterus. It may be caused also even by the imagination or sight of something nauseating, or by exeessive disturbances of the brain.

As appears from the foregoing, a large number of muscles coöperate in the act of romiting in a perfectly definite manner, and our eurrent views of the action of the central nervous system make it very probable that this coördination is obtained by a special center (the vomiting eenter). In faet it is stated that in the dog the destruetion of an area lying in the midline of the medulla in the region of the ealamus seriptorius prevents vomiting-i.e., that this place is the romiting center. This center is bilateral and lies in the deep layers of the medulla (Tumas). Whatever the facts as to the actual presence of such a center, this much appears certain, that the romiting center and respiratory eenter are not identical, as has often been assumed. For while eertain respiratory muccles take part in vomiting, many other movements supervene which have nothing to do with respiration. Besides, simultaneous inspiratory contraction of the diaphragm and expiratory contraction of the abdominal muscles never takes place in respiration.

\section{\$. 5. MOVEMENTS OF THE INTESTINE}

The murpose of the intestinal movements is to mix thoronghly the contents of this division of the alimentary canal with the digestive fluids poured into its cavity, and to move the contents gradually along in the direction of the anus.

Acending to Griitzner, antiperistaltic eontractions neeur normally in the intestine, by which the intestinal contents may be driven upward for some distance.

In the fasting state the intestine appears as a rule to be quiet. But about one-quarter hour after eating it begins to move. These movements are indueed 
also by swallowing, by brief inhalations of ether, by psychic influences, application of cold to the abdomen and by direct stimulation (cf. infra).

Attempts have been made by investigation of intestinal fistule to determine the rate of propagation of the intestinal contractions, and different rates have been observed-which really was to be expected a priori, if one but considers how much the degree of fullness and the nature of the contents must affect the results. This consideration is confined by the observation made unon an exsected intestine, that a contraction locally produced is propagated along the intestine only when it is induced by the moving contents.

By observations on Vella fistule a value of $1 \mathrm{~cm}$. in two to ten minutes, and $1 \mathrm{~cm}$. in thirty to forty seconds, have been found for the rate of propagation of intestinal contractions, the latter value after ingestion of food. According to other observations the peristaltic wave would travel the entire length of the intestine of a dog in about ninety minutes. Again, the relocity of the intestinal movement has been estimated by passing a little balloon fastened to a string through a stomach fistula into the duodenum and measuring on the string the rate at which the balloon was forced along. In the uppermost perts the rate was greater than in the lower parts, and in the former reached the high value of $10-18 \mathrm{~cm}$, in a minute. In view of the long time the food sojourns in the intestine this appears abnormally high.

The intestine is of course constricted by the contraction of its circular muscles; it is shortened and at the same time dilated by eontraction of its longitudinal muscles. Suppose, e. g., that in Fig. 115 the small eircles lying side by side represent cross sections of the longitudinal muscle fibers. When they contraet, they become thicker; each fiber therefore claims more space, and the fibers lying side by side becoming thicker

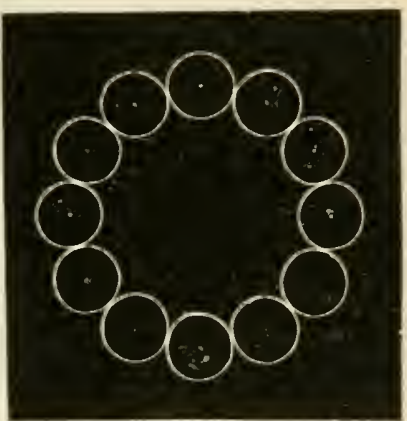

Fic. 115.-Schema to illustrate the relation of the longitudinal muscular fibers of the intestine to each other.

all at once must have the effect of making the circumference larger-i. e.. of dilating the lumen. This conclusion has been eonfirmed also experimentally (Exner).

With regard to the movements actually taking place in the intestine within the body, Cannon observed with the help of the liontgen rays, after feeling a food mixed with bismuth subnitrate, that the food in an intestinal lonp is divided all at oner into small segments. From these segments new ones are contimully being formed by rhythmical contractions [what Cammon calls "rhythmical segmentation" $\mid$. at the rate of about thirty por minute. liy this means the food is very intimately mixed with the intestinal fluids and is brought into close contact with the intestinal wall. The contents are then pusherl along and the process is repeated over and over (Fig. 116).

The intestinal movements are to a certain extent independent of the centrul nerroms system. for an exsected intestine may contract spontaneously. In animals whose nerves to the intestine have all been cut, two kinds of contraetions may he olserved.

(1) The intestinal Inops excente pendulum movements-i.e.. morements to and fro, in which the longitudinal, and, to a less extent, the circular 
muscles are active. By virtue of the latter, small wares arise in the intestinal wall, which are propagated rather rapidly (:-5 cur. per seeond), usually from above downward.

(2) In separate parts of the intestine powerful contractions oceur which proceed much more slowly than the above-mentioned small waves, but like them from above downard. 'These are the true peristaltic movements. In the propagation of these contractions the intestine is always dilated just

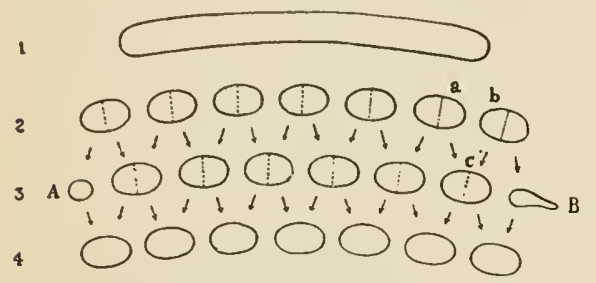

Fig. 116.-Schema to illustrate the rhythmical segmentation of the small intestine, after Cannon. 1, the contents of the intestine unsegmented; 2, the contents constrieted into separate masses; 3 , the next phase, the original segments are split in half by new constrictions and become fused into new nasses, as $a$ and $b$ into $c ; 4$, the first segmentation restored. below the place which at that moment is contracted.

The peristaltic movements may be produced on an e-nervated intestine by a weak mechanical stimulus of the outer surface, or better still by the introduction of a balloon into the intestine. Every such stimulns excites the seetion lying above the point at which it is applied and relaxes that lying immediately below (Bayliss and Starling).

Peristalsis in the intestine is therefore a tolerably eomplicated phenomenon which calls for a definite, regular eoördination of different portions of the intestine, and in all probability requires for its excitation the participation of a nervous mechanism. Since this can be observed in all its regularity both in an exsected intestine and in the intestine deprived of extrinsic nerves, the mechanism concerned must lie within the intestiral wall itself, and we have probably to regard the plexus myentericus as that mechanism.

Magnus is autbority for the statement that the spontaneous morements continue unchanged in their character in surviving portions of the intestine, or in those preserved in Ringer's solution, after removal of the submucosa and of Meissner's plexus. But separation of the circular layers from Aucrbuch's plexus stops their movements, whereas the longitudinal muscles left in connection with this plexus continue as before to eontract. From these results it would appear that all the automatic movements of the intestine lepend upon the action of Auerbuch's plexus.

The intestinal movements are regulated in many ways by the central nervous system; and we can say further that the small intestine receives its efferent nerves partly through the vagus and partly throngh the splanchnic. But with regard to the action of these nerves, until very recently there was absolutely no unanimity of opinion. Indeed one may say without exaggeration that every conceivalle possibility has been represented by the different authors.

However, most anthors now agree that the splanchnics contain inhibiting fibers for the intestine (Pflïger, 185\%). If the abdomen of a fasting dog, having the splanehnics still intact, be opened, the above-mentioned contractions are not observed-the intestine is perfeetly quieseent. A loeal stimulus is either entirely without effect or it produces only a cireumseribed contrae- 
tion. If now the splanchnics be cut, after some fifteen to twenty minutes the intestine begins to move as above described (page 2ss). 'These resnlts show that the splanchnic under normal cirenmstances exercises a tonic restraining influence on the intestinal musculatme. This inhibition appears still more clearly if the splanchnic be stimulated while the intestinal movements are in progress: the contractions immediately cease, and the tonus of the wall decreases.

Since the splanchnic conveys vasoconstrictor fibers for the intestinal vessels, it might be supposed that the cause of the intestinal calm following stimulation is to be found not in a specific inhibition, but in the resulting anamia. But it is to be observed against this hypothesis that the necessary parallelism is wanting between the two phenomena. 'The increase in blool pressure is sometimes very considerable while the inhibition at the same time is only slight. The inhibitory effect is not evident at the first stimulation of the splanchnic and decreases with each snceeding stimulation, while the blood pressure goes on increasing. And finally, inhibition of the intestinal movements ean be demonstrated even after the eireulation is completely stopped by extirpation of the heart.

Many anthors agree also that the vagus is a motor nerve for the intestine, while others have obtained no effect at all on the intestine by ragns stimulation. It is possible that this failure is due to the inhibiting influence of the splanchnies, wherefore it is recommended to sever the splanchnics first in such experiments (Jacobi). In order to prevent disturbanees to the circulation resulting from stoppage of the heart by stimulation of the vagns, either the stimulation must be applied below the cardiac branches, or the latter must be paralyzed by atropine. Under such circumstances Bayliss and Starling and also Bunch have observed as the trpical result of vagus stimulation, first a brief imbibition and then a contraction which beenmes stronger and stronger. It would thus seem that the vagus contains looth inhilitory and motor fibers, the former with a short and the latter with a long latent period. In the opinion of some authors these effects cxtend to both musele layers; in the opinion of others the vagus inhibits the longitudinal fibers and excites the circular fibers (Ehrman. IVinkler).

As soon as the intestinal contents pass into the large intestine a powerful contraction of the ceem and colon can be seen with the Röntgen rays (Cannon) to take place, and the contents are noved

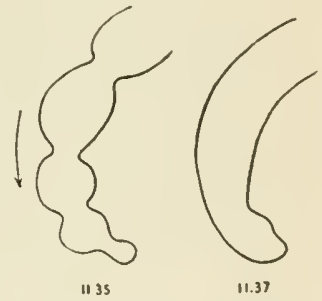

Fig. 117.-Schema illustrating antiperistalsis in the ascending colon, after Cannon. towarl the rectum. A moment later peristalsis is sneceeded lyy antiperistalsis. and the latter in rhythmical order now represents the nsnal form of movement of the ascending and transverse colon. Finally, howerer; it ceases. the eontents eollect in the transwerse colon and are driven into the descending colon.

As for the innervation of the large intestine and reetum, Bayliss and Starling have shown that the former deprived of its uerves acts just as does the small intestine under the same cireumstances. The vagus is said to contain motor 
fibers for the first part of the large intestine. The other parts and the reetum are supplied by the lumbar and the sacral nerves. The former arise from the second to the fourth lumbar roots, pass through the sympathetic to the inferior mesenteric ganglion and so to the intestine. The saeral nerves arising from the II-IV sacral roots traverse the so-called nervi errigentes (Langley, ef. page 233).

[According to Elliott the large intestine also receives inhibitory fibers from the simpathetic.-ED.]

\section{FOURTH SECTION}

\section{DIGESTION IN THE DIFFERENT DIVISIONS OF THE ALIMENTARY CANAL}

Now that we have become acquainted with the properties of the different digestive fluids. and the processes by which they are formed, as well as with the morements of the alimentary canal, there remains yet for us to consider the digestive process itself in the different divisions of the canal, and to study the relative importance of each division.

$\mathrm{By}$ way of general remark it must be emphasized here onee more that appetite is of great and deep-seated importance for the entire aetivity of the digestive apparatus. Only under its influence does a plentiful secretion of gastric juice take place immediately after the ingestion of food. The acid of the gastric juice in turn rouses the seeretion of the pancreas which then without delay pours its seeretion into the intestine; when, after a longer or shorter time, the stomach is emptied, the intestine is immediately prepared to continue the work of digestion and to earry it forward to the end.

Our knowledge of the conditions which control the movements of the alimentary eanal are still too meager to permit us to say anything as to the importance of appetite and of eating for them. Certain observations of Pawlow show that desire for food does exert an actual influence on the movements of the stomach. Thus spontaneous movements of this organ are suppressed when the animal is greatly excited by the sight of food: the stomach is preparing itself for the reception of food (cf. also note, page 284).

\section{\& 1. DIGESTION IN THE MOUTH}

The most important function of the mouth with reference to digestion is the mechanical reduction of the food, and the admixture of saliva with it. Substanees soluble in water are dissolved by the saliva and, what is more important, the morsel of food is rendered slippery by the mucin therein contained, and thus is the more easily passed through the gullet to the stomach.

The latter function is confirmed by the following observation of $\mathrm{Cl}$. Bernard. An osophageal fistula was made in the neek of a horse and the animal was given mouthfuls of wet oats. In one minute there came through the opening of the fistula $55 \mathrm{~g}$. of the oats. After the duets of the two parotid glands were cut off so as to shut out the saliva from the mouth, only $14.4 \mathrm{~g}$. eame through in .one minute.-The mucus secreted by the glands of the pharynx and osophagus also aids the passage of the bolus. 
In sereral species of animals a diastatic enzyme is wanting in the saliva, and in these the physiological importance of saliva is restricted to the abovementioned purely mechanical action. In general it has heen supposed that even where the ptyalin is present the formation of sugar induced by it plays only a subordinate part in digestion. either becanse of the short time the food remains in the mouth, or because the swallowed saliva would quickly lose its diastatic power on account of the acid of the gastric juice. The latter conclusion presumes either that the acid content of the gastric juice is sufficiently high to neutralize the alkaline reaction of the saliva at once or that the stomach contents are very quickly permeated by the gastric juice. But neither presumption is warranted by the facts. Hensay has shown that as much as eighty per cent of the carbohydrates raised from the human stomach at the end of half an hour is maltose or the closely related dextrin. According to Cannon and Day, an acid reaction in the interior of the stomach contents of the cat can only be observed after one to one and one-half honr's from the time of feeding, and during this time the ptyalin has every opportunity to act on the starch. This was confirmed also by direct experiments in which human saliva was given.

\section{§ 2. DIGESTION IN THE STOMACH}

The first division of the alimentary canal in which the food is chemically changed to any considerable extent, is the stomach. Here the carbohydrates are split up partly by the ptyalin of the swallowed saliva, partly by the acid and the Bacteria of the stomach contents. Starch paste is changed by the acid of the stomach to soluble starch, and from this with the help of acid fermentation under the influence of Bacteria, dextrin, sugar and lactic acil are formed.

Emulsified fat is split to a considerable extent by the stomach steapsin (cf. page $\cdot 50$ ). C'asein is coagulated under the influence of the remin, and the curd thus formed is dissolved again by the gastric juice. Noreover, what is of particular importance for the nourishment of children, almost the entire quantity of phosphorus from the eurd passes, aceording to experiments in vitro, into solution in organic combination. The passage of the cascin, which is the most important constituent of milk, into the intestine is delayed by its coagulation in the stomach.

The pepsin-hydrochloric acid dissolves all kinds of true proteids, the gelatin-forming substanees and elastic tissues: but keratin is not acted npon. 'The influence of gastric juice on the gelatin-forming substances appears to he especially significant for the whole process of digestion: it is eren said that they are dissolved more easily and more empletely by the gastric juice than are proteids (Bikfalvi).

This is quite in line with all that we know abont the function of the stomach. This function in brief is to transform the ingested food into a souly mass, the chyme- to prepare it, in other words, for entrance into the intestine. The ability of the gastric juice to dissolve gelatin-forming substances aids in this direction; for the tissue elements which bind together the cells of the animal foods are composed of just such substance, and as soon as they are dissolved the cells are set free and the chyme is formed. 
It is naturally a matter of great interest to determine how the transformation of proteid actually goes on in the stomach; for one can never form any definite conclusion about the clearages actually taking place in life from experiments in vitro (page 24t). Imong the more recent contributions to our knowledge of this subject are the researches of Zunz on the digestion of meat in the stomach of the dog. At whatever time between one-half hour and six hours after feeling, the stomach contents were obtained, they consisted in by far the greatest part (eighty-six to ninety-cight per cent of the total nitrogen) of albumoses. Acid albumin was present only in small quantities and the total quantity of peptones, peptoids and end products only exceptionally reached more than ten per cent of the total nitrogen. Among the latter was found only a very sparing quantity of erystalline products, leucin, tyrosin, etc., and these might have been formed previously in the meat fed.

These results are to be explained in one of two ways: either the cleavage of proteid in the stomach proceeds only so far that about ten per eent of the proteid-N is transformed into end produets, or the end products as they are formed are absorbed more rapidly through the stomach wall than the albumoses. It is not easily conceivable that the end products already in solution should pass into the duodenum more rapidly than the albumoses present in the same solution.

Looking to a decision between these two possibilitics, Reach made experiments on surviving stomachs. The animals were killed at the end of the second hour of digestion; the stomach, tied off at both ends and cut out of the body, was maintained for four hours longer in a moist chamber at blood temperature. Since no absorption could take place, this experiment was well calculated to show how far the cleavage of proteid had actually gone. The result was that thirty-two to fifty-six per cent of the total $\mathrm{N}$ in solution (average forty-four per cent) was present in the form of albumoses, and fifty-six per cent in the form of peptones and end products, the latter alone containing some thirty-two per cent of the total nitrogen. It appears therefore that the reason for the ninety per cent and more of albumose nitrogen found in the intravital digestion is not that the enzyme action stops at the albumose stage, but that absorption going on at the same time removes the simpler products very rapidly.

Parlly because of its hydrochloric acid, and partly quite independently thereof (London), the gastric juice plays no small rôle as an antiseptic. This property of the gastric juice is by no means sufficient to destroy all the Bacteria which find their way into the stomach; for very many are found throughout the alimentary eanal, and in certain species of animals they play a very important part - of which more under the discussion of intestinal digestion.

Since the food always remains for a tolerably long time in the stomach, this organ most of all must suffer the harmful effects of an ill-adapted dict. We speak also of a digestible or indigestible article of food according as it is digested with greater or less ease in the stomach. It would be very important, therefore, if general rules conld be established as to what is digestible and what is not. Unfortunately, however, this ean be done only to a very limited extent, for the stomach is very capricious, and what is well suiter to one stomach is unsuited for another. 
Attempts have been made to determine the digestibility of different articles of diet and dishes by subjecting the stomach contents obtained from fistulous patients or from healthy individuals by means of the stomach tube, to investigation at certain intervals after eating. But it has been shown that in the same person the same food on different occasions requires a very different time for its formation into chyme. A presentation of these results would call for a discussion of a mass of details which would be out of place here. Besides, the fact just stated has lost much of its strangeness in view of the recent contributions on the conditions of secretion in the stomach (page 263).

Nevertheless, the following general prineiples as to the digestibility of a diet in the stomach may be laid dow'

(1) A too voluminous meal is harmful to the stomach; for in order that it may be properly saturated with gastric juice, a very copious secretion-i.e., a great effort on the part of the gastric glands-is required, and in order to knead and mix it thoroughly, an unusual demand is made upon the stomach musculature.

(2) Poorly masticated or very compact food will likewise call for too great an effort on the part of the stomach; for the larger and more compact the piees swallowed, the longer will be the time required to saturate them with gastric juice and dissolve them.

(3) Animal foods which are tough-e.g., meat from old, poorly nourished animals-are difficult to chew, and offer great resistance to the action of the stomach. The looser and more porous the food, the more easily is it digested in the stomach; a sick or weakly stomach, therefore, receives best a soft or gruelly food.

(4) Fat in the food has a great influence, ${ }^{1}$ partly through its inhibitory action on the glands of the stomach. But not only so; if it permeates the food thoroughly, it forms a kind of protective film, which prevents the entrance of the gastric juice to the proteid or gelatin constituents. This is especially true if the fat eaten be not fluid at the body temperature.

(5) Strong spices, alcohol, etc., act unfarorably on digestion in the stomach, partly because, as with alcohol in great concentration at least, they reduce the action of the gastric juice on the food in some way or other.

(6) Digestion in the stomach is influenced also by other circumstances than the character of the food. Thus the digestive power of the gastric juice is reduced for a time by intense sweating, since both the $\mathrm{HCl}$ and the absolute quantity of the secretion are thereby diminished. Again exhaustion from intense muscular work causes a decrease in the quantity of gastric juice, which becomes thick, ropy and strongly mucous. It has even been observed that stomach digestion ceases entirely under heavy muscular work.

Since the function of the stomach is to change the food into a semifluid or gruelly mass, one might suppose a priori that the stomach could be dispensed with entirely, if the food taken were already of this gruellike nature. And this is in fact the ease. The stomach has been suecessfully remored from dogs (Czerny"), cats, and even from men suffering from carcinoma of the stomach, without endangering life or preventing digestion. It is only necessary to administer food in small portions and in a very finely divided state in order to maintain life as usual.

Our knowledge of gastric digestion and related phenomena show therefore that the essential function of the stomach, aside from the antiseptic 
action of the gastric juice, is that of transforming the food into a gruelly. mass; but that its work can be replaced by careful comminution of the food before eating. And yet this rôle of the stomach is of rery great importance; for it is owing to the gastrie digestion that we ean utilize all possible kinds of food for our nourishment, and ean limit our eating to a few meals per day. If the food were to be introdnced immediately into the intestine, we would be compelled to eat only fluid or semifluid foods. and it would be necessary to eat much more frequently than we do. Nore than that. the stomach protects the intestine from excesses of temperature whether high or low and from all kinds of harmful substances. It brings all the food to the temperature of the body and dilutes harmful substanees with the gastric juice hefore allowing them to pass into the intestine. In short, the stomach is a protecting organ for the intestine, and permits us to derive our sustenance from a very great variety of foods.

\section{\$ 3. DIGESTION IN THE INTESTINE}

Comparative anatomy teaches us that the length and diameter of the intestine are intimately related to the character of the food of the animal speeies. In earnisorous animals the intestine is considerably shorter than in herbicorous animals; while in man its length is intermediate between these two extremes.

The most important part of the work of digestion is earried out in the intestine. and, as it appears, chiefly under the influence of the panereatic secretion.

When the ehyme enters the intestine from the stomach it is subjected to the action of this secretion, of the bile and of the intestinal juice.

The pancreatic secretion continues the transformation of proteids begun in the stomach. As we have already seen, the proteolytic enzyme of the pancreas is essentially different from that of the stomach. We may add to what was said before that the pancreatic juice acts rather feebly on the gelatinforming sulstances (ef. page 291), whereas it acts very powerfully on the true proteids. This fact is in perfeet agreement with the condition already emphasized, that the food must be of a gruelly nature in order to be adapted for digestion in the intestine. The proteolytic, the amylolytic and especially the lipolytic action of the panereatic juice are assisted in some way not fully monderstood ly the bile (Rachford and Southgate, Bruno. Ussow).

The action of pepsin-IICl on proteid is soon stopped in the intestine. In the first place the bile hinders the swelling of proteid neeessary for pepsin digestion; moreorer it has the property of precipitating proteids in aeid solution, whenee the pepsin is removed from the fluid with the precipitate. This precipitation of proteids by the bile can be very prettily demonstrated in vitro; but in natural digestion it appears to transpire only to a slight extent; for the bileacid precipitate is easily redissolved by the bile salts, and by other salts like sodium chloride, lactate or acetate. It is stated also that one never finds any such precipitate in the intestine of an animal killed during digestion.

Hydrochlorie acid in small quantities has no harmful effect on tryptic digestion and is even said to favor it in the presence of bile. 
With regard to the extent of digestion of proteids in the intestine. Zunz has found that in the uppermost $50 \mathrm{~cm}$. of its length the relative quantities of albumose and end products varies in favor of the latter. the longer digestion continues. After four hours, the nitrogen in the form of albumose amounts to seventy-six to ninety-five per cent of the total nitrogen; after six hours, seventy-one to eighty-three per cent; after eight hours, forty-four to forty-six per cent; and after ten hours, thirty-two to forty-four per cent. The end products increase therefore with the duration of digestion. We cannot draw from this any positive conclusion as to the form in which the digested proteid is chiefly absorbed, for it might very well be that the albumoses are more quickly absorhed from the intestine than are the end products. We shall discuss this question more fully in our study of absorption.

Proteid and its digestive products are attacked also by the Bacteria present in the intestine. To judge from observations on men with intestinal fistula, this action is only rery slight; and this is probably the reason why the eontents of the small intestine have no fecal odor. In the large intestine the Bacteria act much more extensively on the proteid. and as a result we find there besides carbon dioxide and marsh gas, sulphureted hydrogen, methyl mereaptan, skatol. phenol, ete., which give the fieces their charaeteristic odor. The bile pigments are destroved in the large intestine by Bacteria, and bilirubin is changed into sterkobilin, which is probably identical with urobilin.

The putrefactive products arising in the intestine, which in so far as they are basic in eharacter (like cholin and the different uric acid and ereatin derivatives), are called leucomaines, are taken up by the blood and are there changed by chemical reactions into relatively harmless substances, and are finally eliminated in the urine. Formed in too large quantities and absorbed, however, they may remain in the body and cause a kind of poisoning, autointoxication, which produces more or less profound disturbances of the system.

Moreover, the body strives in many ways to overcome all hinds of poisonous substances which may be taken up with the food. Some are not absorbed from the intestine, some, as in the case of the different Bacterial decomposition products, are destroyed by the digestive fluids, some are retained and rendered innocuous by the liver and the mesenteric glands. It is plain that these processes, which cannot be discussed more fully here, are of the very greatest importance for the body, although the protection provided by them is not in all cases sufficicut to sare the body from poisoning.

Until recently it was rather generally assumed that fat is partly loroken down by the pancreatic juice into the fatty acids and glycerin, that the former unite with the alkalies of the intestine to form soaps. and that the soaps bring about an emulsification of the fat. On account of its alkalies bile was said to play a prominent part. Unlike the other nutritive substances fat would then pass from the intestinal cavity into the mucous membrane, not in solution but in the form of an emulsion. The following two facts support this view: rancicl fat is emulsified easily by alkalies, and the absorption of fats from the intestine is very considerably reduced by exclusion of the bile.

But by more exact investigation of the phenomena acempanying absorption of fat several facts have come to light which speak strongly against this 
conception. Free fatty acids are very well absorbed from the intestine even when their melting point is higher than $50^{\circ} \mathrm{C}$. and when they cannot therefore become fluid in the body (I. Munk). The fine emulsion, known by the name of chyle, is in many cases entirely wanting from the intestine of the dog: and even when chyle is introduced into the intestine, the fine emulsion entirely disappears after three hours, and there is found now only larger fat drops surrounded by a turbid granular mass. Lanolin which is a mixture melting at $40^{\circ}-42^{\circ} \mathrm{C}$., made up of compounds of fatty acids with cholesterin, isocholesterin, etc., very difficult to split into their constituents, is not absorbed at all from the intestine of the $\mathrm{dog}$ (Cohnstein). Finally the histologieal findings in preparations of the intestinal muessa made during absorption of fat are of such a character that they ean scarcely be explained from the standpoint of the emulsion hypothesis (cf. page 304 ).

Against the emulsion hypothesis it has been observed also that in the dog the reaction throughout the greater part of the small intestine is acid in spite of very active absorption of fat; and in man the reaction of the small intestine is said to be acid. This reaction, however, is caused by an exeess of organic acids and of earbon dioxide, and eamnot be adduced as proof against an eventual formation of soaps (Moore and Rockwood).

In the light of these facts the emulsion theory eannot he looked upon as sufficiently well founded, and in fact another possibility is at hand to explain the absorption of fats. This is. that the fats are completely decomposed in the intestine and that the fatty acids formed are absorbed either as soaps or in a solution brought about by the bile.

This view, adrocated especially by Altmann, Pflüger, Moore and Ratchford. and supported by many histological facts. is not contradicted by anything known concerning the extent of the decomposition of fats in the intestine, for that decomposition is in fact very great. To find, after feeding neutral fat. that some of it is not decomposed, of course proves nothing against the assumption, for the free fatty acids are absorbed as they are formed, and if the absorption goes on properly they might never be present in large quantity in the intestine.

It has been known since Strecker's time (1848) that bile and bile salts dissolve fatty acids quite easily. One hundred c.c. of dog's bile ean dissolve $6 \mathrm{~g}$. of mixed fatty acids from swine's fat, $5.5 \mathrm{~g}$. from ox fat and $2 \mathrm{~g}$. from sheep's fat. The solubility of the fatty aeids in the bile depends therefore essentially on the presence of oleic aeid. which has been shown also by direet experiment. The bile salts of themselves have a much smaller solvent power than the bile, among whose constituents leeithin must be the most important for this action. The solubility of soaps is inereased also by the bile.

After exclusion of bile from the intestine, the absorption of fats deelines considerably-a fact very easily understood in the light of the coneeption now under diseussion. Put eren under these circumstances a certain quantity is absorbed, probably in the form of soaps. In the intestinal eontents there is always found under normal eireumstances more alkali than is necessary for the neutralization of the inorganie acids present, and there oceurs as a consequence a certain amount of saponification. The soaps as they are taken up by the 
intestinal mucosa are again decomposed into fatty acids and alkalies, and the alkalies would then be at the disposal of the intestinal contents once more.

Likewise when the panereas is extirpated, the utilization of fats is usually much diminished if not entirely stopped; fatty acids are then found in abundance in the freces. The pancreas may be caused to waste awar slowly, if its duct be ligated and 0.2 per cent sulphurie acid be injeeted into the gland. In this ease the absorption of fat declines, but not to any considerable extent until a longer time has elapsed than in the case of extirpation. The eleavage of fat under such eircumstances might be brought about either by the enzyme (formed in eells which are still functional) being absorbed and reaching the intestine by some roundabout way, or, as after extirpation, through the ageney of Bacteria (Rosenberg). But the question is not yet finally settled.

If the conception here presented is in the main correct, then the principle upon which the transformation of foodstuffs in the alimentary canal proceeds would be the same for all. namely: they are changed by hydrolytic cleavages into substances which ean be brought into solution by the fluids present in the alimentary canal, or by fluids poures into it from the glands.

The carbohydrates are changerl into soluble carbohydrates principally in the intestine. The pancreatic juice plays the chief part in this. although it is assisted by the bile and the intestinal juice. Besides, the Bacteria present aet upon the carbohydrates to a considerable extent. In this way, partieularly in the small intestine, alcohol. lactic acid, acetic aeid and succinic acid among other things (Nencki and his pupils) are formed. The acid reaction of the intestinal contents depends in part on these products.

The intestinal Bacteria have a very special part to play in the herbirorous animals; for by their ageney cellulose is deeomposed and the foodstuffs locked up by it are made accessible to the digestive fluids (Tappeiner).

The participation of Bacteria does not appear to be necessary in the digestion of animal foods, for various polar animals have no Bacteria at all in the intestinal contents (E. Lewin). Thierfelder and Nuttal have demonstrated the same thing for guinea pigs fed on milk and finely prepared regetable food, such as cakes. Schottelius sueeeded also in maintaining chicks for a time on perfeetly sterile food. But from twelve dars on the animals decreased in weight and died of hunger at about the seventeenth day. From this it seems that a coarse regetable diet camot be properly and eontinuously disposed of by the higher animals without Bacteria. And yet it must be added that the facts are by no means sufficient to warrant definite eonelusions, for Lewin finds the intestine perfeetly sterile in herbivorous polar animals.

In the lower animals enzymes (eytases) have been demonstrated which themselves destroy cellulose. The seeretion of the snail's liver is an instance (Biedermanu and Moritz; ef. page 110).

The putrefactive processes in the intestine are generally restricted within very moderate limits. The reason liss partly in the action of the hydrochlorie acid of the gastric juice which reduces the number of Bacteria entering the intestine, and partly in the fact that the foodstuffs as soon as they are sufficiently digested, are removed hy absorption from the sphere of influence of the Bacteria. 
A rery intense putrefactive process has often been observed in animals with a biliary fistula, and on this ground it has been assumed that the bile is a powerful antiseptic. But this conclusion is not correct; for in the first plaee it has been shown by direct experiments that bile is not a good antiseptie reagent, although it does exert an adverse influence on the development of certain Baeteria for a short time; and in the second place, animals with a biliary fistula which receive little or no fat but plenty of other food, do not, in spite of the diversion of the bile, experience any more putrefaction in the intestine than do normal animals. The loss of bile is therefore not of itself the cause of the putrefaction, when the diet is not exactly regulated. It is rather to be explained by the scanty absorption of fat: for when fat remains in the intestine as a foreign body, it affords a good culture medium for all kinds of Bacteria, which multiply prodigiously and produee an intense putrefaetion, and through this a severe intestinal eatarrh.

The same thing happens with new born children when they are fed with starches. The starch is ineompletely digested in the intestine, it remains there as a foreign body and an offensive diarrhea develops, notwithstanding the presenee of bile.

A large part of the small intestine can be removed from man as well as from animals. and digestion will not be interfered with to any considerable extent. After the removal of $3.1 \mathrm{~m}$. of the intestine of a man, however, the intestinal evacuations were more abundant and the ntilization of proteid was less than normal (Riva-Rocei). In the dog only slight permanent changes made their appearance, when as much as serenty per cent of the intestine was extirpated; althongh the diet had to be carefully regulated and an excess of fat especially avoided (Erlanger and Hewlett).

\section{§4. FORMATION OF FECES AND DEFECATION}

Digestion is continued in the large intestine by enzymes carried in with the intestinal contents. In the dog, digestion in this part of the alimentary canal appears to be of little importance, since eomplete removal of the large intestine reduces the absorption of foodstuffs but slightly. The proteids only are less perfectly ntilized than normally (Harley).

In herbivorous animals the large intestine must play a more important part, for in the horse, for example, the cxenm is two to three times as large as the stomach. And yet rabbits from which the excum is removed live for months withont showing any permanent disorder in the digestion or in the general health (Hultgren and Bergman).

The chicf function of the large intestine is to provide for the absorption of foodstufls capable of being absorbed which have not already been cared for by the small intestine, and by withdrawal of water to reduce the residue to a firmer consisteney. The intestinal contents thus transformed are then finally voided from the body as the frees.

The faces contain some undigested constitnents of the food, some unabsorbed products of digestion. putrefaction and fermentation in the intestine, dead intestinal epithelium and residues of the digestive fluids, and finally substances which are given off by the wall of the alimentary canal as excre- 
tory produets (cf. pages 133, 308). The quantity of frees evacuated daily varies somewhat according to the nature and quantity of the food eaten. With an ordinary diet it is estimated for the adult man at $120-150 \mathrm{~g}$. with $30-37 \mathrm{~g}$. dry substance.

The hardened masses to be remored collect in the large intestine and in the rectum, and are from time to time discharged from the body. The herbivorous animals (whose food is itself rery roluminous, and in which the work of digestion goes on continuously) have frequent eraeuations, notwithstanding the great diameter of the intestine. With carnivorous animals, whose food is very concentrated, the frees are voided less frequently. Man ordinarily has one stool per day.

The intestinal contents are retained in the rectum by the tonic contraction of the two sphincters, the sphincter ani externus and internus. The sigmoid flexure of the descending colon has the effect of lessening the load to be borne by the sphineters. The action of the outer sphincter is strengthened by the levator ani, this muscle being thrown round the rectum like a loop.

The center for the external sphincter in the rabbit lies within the spinal cord in the region of the sixth to the seventh lumbar vertebra, in the dog at about the lower end of the fifth lumbar vertebra. Since this sphineter can be strengthened voluntarily, this center is also under the influence of the higher nerve centers. Contractions of the sphincters are obtained by stimulation of the motor zone of the cerebral cortex $(\mathrm{dog})$. On the other hand, the tonus of the sphineters may be abolished by strong psychic excitation (involuntary defecation), and by stimulation of the motor zone of the cortex with the nervi errigentes cut (FranklIlochwart and Fröhlich).

From the spinal cord the nerves to the sphincters run partly in the hypogastric nerves and partly in the nervi errigentes, and in the dog the former are said to be inhibitory, the latter motor. Besides, the latter mediate contractions of the rectococcygealis and of the other longitudinal muscles of the rectum.

The tomus of the anal sphincters is not obliterated even by destruction of the spinal cord (Goltz and Ewald), a fact explicable in part at least by the presence of a center for the sphincter nerves in the inferior mesenteric ganglion (Frankl-Hochwart and Fröhlich).

Defecation is mediated by a reflex process not yet thoroughly investigated, which is induced from the rectum, and which is modified by infuences of the will upon the muscles concerned. The sphineters relax and the hardened masses are discharged by contraction of the rectal musculature with the assistance of the abdominal pressure. The levator ani muscle may eontribute to the general effect. By its contraction it presents a point of insertion for the longitudinal museles of the rectum, and the compression of the rectum produeed by it, enineident with the relaxation of the sphincters and the powerful effect of the abdominal pressure, assists in discharging the contents (Henle).

By abdominal pressure we mean the pressure upon the abdominal riscera produced by simultaneous contration of the diaphragm and of the abdominal museles. The part it plays in defecation depends upon the consistency of the contents of the rectum. If this is soft, defecation ean take place without 
any assistance from the abdominal presure; hut with rery solid exerement, the power of the intestinal musculature itself is not sufficient and the abdominal pressure is called upon.

RfFerexces.-W. Connstein, "Über fermentative Fettspaltung." in Die Ergehnisse der Physiologie, III, 1, 190t_-D. Gerhardt, "Über Darmfäulnis," in Die Ergebnisse der Physiologie, III, 1, 1904.-J. P. Pawlow, "Die Arbeit der Verdaunngsdrüsen," Wiesbaden, 1898,-C. Oppenheimer, "Die Fermente und ihre Wirkungen," 2d edition, Leipzie, 1903. 


\title{
CIIAPTER TIII
}

\author{
ABSOLIPTION
}

By absorption we understand all those proceses by which the digested foodstuffs are taken up from the carity of the alimentary canal into its mucous membrane and are forwarded thence to the general circulating fluids.

\section{§ 1. ABSORPTION IN GENERAL}

After Dutrochet had discovered the osmotic phenomena, it was thought that absorption in the intestine could be easily explained by nsmosis. Digestion was for the purpose of changing the foodstuffs contained in the food into easily diffusible substances, if they were not already diffusible. Hence absorption took place according to the well-known physicochenical laws of osmosis.

More searching investigation, however. of matters as they are, have made us acruainted with facts which prechde so simple a process, and have led us for the present to the riew that the activity of the living mucous membrane plays an essential part in absorption. It is perfeetly evident that purely physicochemical processes. like filtration, osmosis, imbibition, ete., are involved, and this requires no further argument.

Among the more important observations for the theoretical explanation of absorption, those upon the behavior of weak salt solutions and of blood serum should be mentioned first (Voit, Heidenhain and others). If normal or slightly diluted blood serum be placed in an intestinal loop of a dog, notwithstanding that the conditions of the experiment exclude the coöperation of osmotie pressure, water and salts are absorbed in almost the same proportion as that in which they exist in the serum introduced, whereas the organic substances take part in absorption in far less proportion. If a solution of common salt whose osmotic tension is higher than that of the blood be introduced, aceording to the laws of osmosis no water should be absorbed; but it is absorbed. And, vice versa, common salt is absorbed from a solution in which the osmotie tension is less than that of the blood. The absorption of water from a weak dextrose solution is not changed, if the osmotic pressure of the blood be raised by intravenous injection of common salt (Reid). From equimolecular and therefore isosmotic solutions of different kinds of sugar which are sterenisomeric, the quantities of sugar absorbed in unit time are not equal (Rïhmann and Negano).

Noreover it has heen shown that the movement of salt in the normal intestine takes place in the direction from lumen to tissues, much more easily than in the opposite direction (O. Cohnheim): that an intestine eut out of an animal in full digestion, if bathed beth within and without with a salt solution of the 
same strength, transports fluid only from the mucous membrane outward and not in the reverse direction (Reid); that if the cells of the intestinal epithelium be injured functionally, but not, so far as can be seen, anatomically by poisoning with sodium fluoride, absorption is actually altered so that osmosis now brings about only an exportation of fluid from the intestine.

Finally, attention should be ealled to the discoveries mentioned at page 34 with regard to the permeability of animal cells for different substances. According to those results, the entrance of a substance into a cell would depend upon its solubility in the lipoid limiting layer of the cell, carbohydrates not being soluble therein. To surmount the difficulty which carbohydrates present, Hoeber supposes that the absorption of these and other compounds which do not penetrate such a membrane oceurs only between the cells. Something of the kind might be true of substances which are taken up in very small quantities; but carbohydrates are absorbed by the mucosa so abundantly that this explanation appears to have little probability in its favor.

The power of absorption is very different in different divisions of the alimentary canal. In the stomach pure water is not absorbed at all. Sugar or peptone or salts (if concentrated) are absorbed from their water solutions in the stomach the more plentifully, the stronger is the solution. T'he water is absorbed also under these circumstances, and, as it seems, most actively from solutions of peptone. Absorption of water from peptone solutions increases with the concentration, while from solutions of sugar it decreases with the concentration (v. Mering).

In the upper part of the small intestine (jejunum), sugar and fat are absorbed more rapidly than in the lower part (ileum). On the other hand the water of sugar solutions is said to be taken up by the mueous membrane more slowly in the jejunum than in the ileum (Röhmann and Negano).

Correspondingly, under a pressure of $10 \mathrm{~cm}$. of water for $1 \mathrm{~cm}$. of length, about 0.7 c.c. of a six-per-cent salt solution was absorbed in one hour by the upper part of the small intestine of the dog, and 1.3 c.c. by the lower part, while in the large intestine under the same circumstanees the amount was 2.1 c.c.

The large intestine appears therefore to be especially well adapted for the absorption of water. Organic foodstuffs also in easily absorbable form are taken up from the large intestine, as has been shown by experiments with nutrient enemas, in which a supply of as much as 1,200 Cal. per day has been maintained. It is to be observed, though, that the ileocæcal valve is not an absolute barrier to the passage of the contents back into the small intestine, and that a part of the nourishment might be absorbed there instead of in the large intestine. According to observations on men and dogs with fistulæ into the large intestine, carbohydrates are absorbed there best of all the foodstuffs; fats and proteids only to a slight extent. The salt content of the enema also appears to have a certain importance in promoting absorption.

All kinds of locally stimulating substances (e. g., spices) cxert a remarkable influence on the absorption in the stomach and intestine. In the former alcohol is absorbed even to the last trace in two hours, and besides, it accelerates the absorption of other substances. Common salt, oil of mustard, peppermint, pepper, etc., have the same effect. The condiments therefore not 
only faror the secretion of the digestive fluids, they further the absorption of the digested foodstuffs. Whether this action is due to a stimulating influence of these substances on the absorbing elements of the mucous membrane, or to rasodilatation caused by them. must for the present be regarded as undecided, although in the opinion of the author the former supposition is the more probable.

Comparison of absorption in the stomach with that in the intestine brings to light this fact. which is important for our understanding of the gastrie functions: that the stomach tolerates much more highly concentrated solutions of the foodstuffs than does the intestine. The stomach acts as a reservoir for the ingested food, in order that the gruelly contents, properly diluted, may be discharged into the intestine gradually. But the latter plays the chief part in absorption.

In this connection we may mention also the experiments of Ogata in which the absorption of proteid was investigated after meat feeding, once when the meat was fed by the mouth, and another time when it was brought directly into the duodenum through a stomach fistula. The nitrogen output in the urine was taken as an expression of the absorption. It was shown that after direct introduction of meat into the duodenum the $\mathrm{N}$-output rose much more rapidly and exhibited greater rariations than when the meat had first to undergo digestion in the stomach. The absorption of proteid therefore takes place much more rapidly when it is placed directly in the intestine, than when it must pass through the stomach. We have then to add to what we have already learned about the importance of the stomach, that in rirtue of its function as a storehouse. the absorption of ingested proteid is distributed more uniformly than it would be otherwise.

\section{\$ 2. ABSORPTION OF CARBOHYDRATES}

We have no exact information as to how the carbohydrates are remored from the intertinal cavity (cf. page 30?).

That they are carried off chiefly by the blood ressels, and not by the lymphatics, appears to be shown by a number of observations. For example. after a meal rich in carbohydrates. the amount of sugar in the chyle is no greater than after one poor in carbohydrates, while the portal blood shows a considerab]e increase in the former case. On the basis of these resulti and of the location of the blood ressels in the rilli. Heidenhain has made the general statement that all substances soluhle in water pass for the most part into the roots of the portal rein. Only when the quantity of fluid is very great does any sugar enter the lacteals.

This conclusion is confirmed in its entirety by obserrations on a roung girl who had a fistula in the receptaculum chyli, from which all the chyle flowed out of the body. In this patient it was found that not more than five-tenths per cent of the absorbed sugur was taken up by the lymphatics (I. Munk and Rosenstein). 


\section{\&3. ABSORPTION OF FAT}

Because of the ease with which fat can be demonstrated by micro-chemical reactions. much attention has been given to its absorption.

It hals already been stated (page $29(6)$ that fat is probably not absorbed as an emulsion. but in the form of a solution of fatty acids effected by the bile acids. or in the form of soaps.

Since the chyle, even after feeding with free fatty acids, contains neutral fat almost altogether, and free fatty acids only in much smaller amount, and after feeding ethylesters of the ligher fatty acids contains only triglycerides and not a trace of the esters fed (Frank). we may deem it fully established that the free fatty acids absorber from the intestinal canal are synthesized again to neutral fats in the intestinal wall. This is confirmed by the observa-

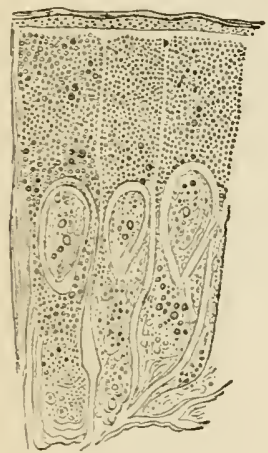

$A$

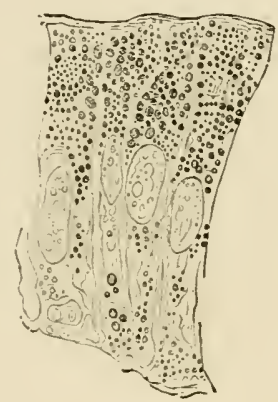

$B$

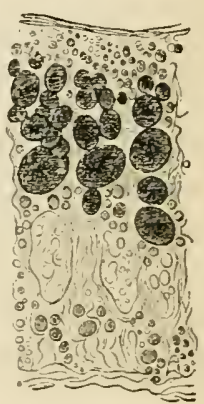

C

FIG. 118.-Successive stages in the absorption of fat in the epithelial cells of the frog's intestine, after Krehl.

tion that the intestinal mucosa at the height of digestion contains far more neutral fat than free fatty acids. and that on digestion of the finely divided mucous membrane with a mixture of soaps and glycerin neutral fat is formed.

This synthesis, like the absorption of fats from the intestinal cavity. is probably carried out by the cellular elements of the mucosa-possibly by the numerous leucocytes occurring therein. but more probably by the epithelium of the villi.

If the intestinal epithelium of the frog in different stages of fat absorption be studied in osmic acid preparations, all transitions are seen from small dustlike gray points to large, black fat droplets (Fig. 118. A to $\mathrm{C}$ ). In the Mammalia the fat in certain early stages of absorption does not enter in the form of blackened granules. but of small black circles with a clear center. These circles increase in size and depth of color in the further course of absorption-just the behavion we should expect if the fat were taken up as a solution of fatty acids and synthesized in the intestinal wall to neutral fat again.

With regard to the further fate of the absorbed fat, it is supposed that it is free to more inside the parenchyma of the villus only in the pericellular, fluid- 
filled spaces incompletely separated from one another by the connective-tissue trabeculæ of the stroma.

It has long been known that fat. for the most part, passes into the lacteals and is conveyed thence to the thoracic duct. Recent experiments have shown, however, that no small part of it passes also into the blood ressels of the intestine. In the case of the above-mentioned patient with a fistula in the receptaculum chyli, only about sixty per cent of the absorbed fat, and still less when free fatty acids were fed. was found in the chyle. Some forty per cent, therefore, had taken the pathway through the portal vein.

Besides the fatty substances absorbed from the food, other fats pass into the chyle, which have their origin in the intestine and its fluids. In this way, possibly, we may explain the fact that after feeding a fat of high melting point the mixture of fat in the ehyle melts at the temperature of the body-i.e., that in the transition from intestine to chyle a lowering of the melting point has taken place.

When soaps are injected directly into the blood, they produce symptoms of weakened heart activity, the respiratory exchange of gases declines, the coagulability of the blood is abolished, and, with a dose of only $0.1 \mathrm{~g}$. oleie aeid per kilogram of body weight, rabbits are killed (I. Munk). The eause of these phenomena, aceording to Friedlander, lies in the fact that the calcium of the blood is precipitated by the fatty acids.

\section{§4. ABSORPTION OF PROTEID}

If the digestive enzymes continue to act long enough, the proteids are finally decomposed into simple crystallizable end products. To what extent this clearage takes place in normal digestion, i. e.. whether the proteid substances are taken up chiefly as albumoses or as crystalline end products, we eannot say definitely at present. It is possible, as some authors assume, mainly on the ground of the action of erepsin, that the cleavage of proteid, either in the intestine or in the mucous membrane, extends all the way to the final end products; but it is conceivable also that the albumoses, as soon as they are formed, are taken up from the intestinal eavity, and are not further decomposed in the mucous membrane.

The experiments of Voit and Bauer have shown that even native proteids in solution can be absorbed from the intestine without previous digestion. As mueh as fifty-eight per cent of egg albumin placed in a loop, isolated from the rest of the intestine, disappeared within five and one-half hours; twenty-eight per cent of blood serum in the course of one hour; ete. This however constitutes no proof that the first products would be absorbed in the course of normal digestion.

If blood be passed through the ressels of a surviving intestine, in whose cavity a peptone solution is contained, the peptone is absorbed lut none of it can be demonstrated in the blood. From this, and from the fact that after a meal rich in proteid, the blood of the portal vein contained no more albumose than the blood of the carotid, it was concluded that the absorbed products of proteid digestion were changed in the mucosa to proteids of the same kind as those occurring in the blood. 
But these experiments are not conclusive. If peptones are not to be found under the circumstances named. it might be due to further decomposition, and the discovery of erepsin makes such a view not improbable. The rapid rise of the $\mathrm{N}$-output in the urine after feeding proteid shows that it is destroyed rery soon after absorption. It would be a waste of energy if the body were to construct native proteids out of albumoses and peptones, only to destroy them immediately. The difficulty of obtaining a storage of proteid in the adult body also can be easily harmonized with its ultimate clearage in digestion.

Direct observations thus far at hand are not by any means sufficient to establish a definite view of the matter. On the one hand, Cohnhein has found that one-third of a cat's intestine surviving was able to split $0.6 \mathrm{~g}$. of peptone into its end products in two hours; on the other hand, Glaessner finds that albumoses are changed by the surviving nucous membrane into coagulable compounds; whereas Emden and Linoop reach the conclusion that in the surviving intestine taken while absorption of proteid was going on, there is neither a reconstruction of coagulable proteid out of albumoses and peptones, nor a cleavage of them into final products. They as well as Langstein state that from all appearances albumoses occur plentifully in the blood.

So far as the question can be judged at present, we might say that a part of the proteid eaten is absorbed as end products of digestion, another part as albumoses and peptones. How and where the latter are transformed into native proteids, and whether a synthesis of proteid from the end products can take place under any circumstances, cannot yet be decided.

Our knowledge is still unsatisfactory also with regard to the manner of the absorption of proteids. Hofmeister has supposed that the levcocytes of the mucous membrane are especially actire in this, and the following facts among others appear to faror such an hypothesis. After meat feeding the lrmph srstem in the small intestine of rats exhibits a larger number of cellular elements than after feeding lard or starch, but with the latter, more than in fasting (Asher). An lour after a meal rich in proteid. the number of leucocrtes in the portal blood of the dog is considerably increased, and reaches a maximun probably during the third hour of digestion. This increase does not occur if the animal receires water. meat extract. salt. starch or fat, but no proteid. In proteid absorption, finally, the number of lencocytes in the renous blood of the intestine is greater than in the arterial blood (Polil).

Some have sought to demonstrate an increase in the number of lencocytes in the skin capillaries of man after a meal rich in proteids; but this digestive leucocytosis is often wanting and is entirely denied by some authors. The possibility remains, howerer. that the lencoctes may take part in the absorption of proteids; for it is easily conceivable that the transportation of proteids from the intestine might be assisted by them, without their entering the general cireulation in larger numbers.

The pathway which the proteids take in leaving the intestine is almost exclusively that of the portal ressels. In the fistulous patient above-mentioned (page 303) it was inpossible after a meal rich in proteid to demonstrate any increase in the percentage of proteid in the chyle. 


\section{ABSORPTION OF MINERAL SUBSTANCES}

Since the eatily diffusible salts, like sodium chloride, are absorbed by rirtue of the activity of the epithelial cells this must the more be true of the heary salts which diffuse slowly.

With regard to the behavior of different salts. Hower has shown that solutions of different salts isotonie with one another are aborbed at different rates. Since in these experiments solutions so dilute that the salts were almost wholly dissociated were used, their different beharior is to be ascribed to the properties of individual ions. Of the cations $\mathrm{K}, \mathrm{Na}$ and $\mathrm{Li}$ are absorbed with approximately the same rapidity, $\mathrm{NII}_{4}$ and urea more rapidly, ('a more slowly and $\mathrm{Mg}$ slowest of all. Of the anions $\mathrm{Cl}$ is absorbed most rapidly, then follow in order $\mathrm{Br}, \mathrm{I}, \mathrm{NO}_{3}$ and $\mathrm{SO}_{4}$. Now we know that the rate of diffusion of a salt in any

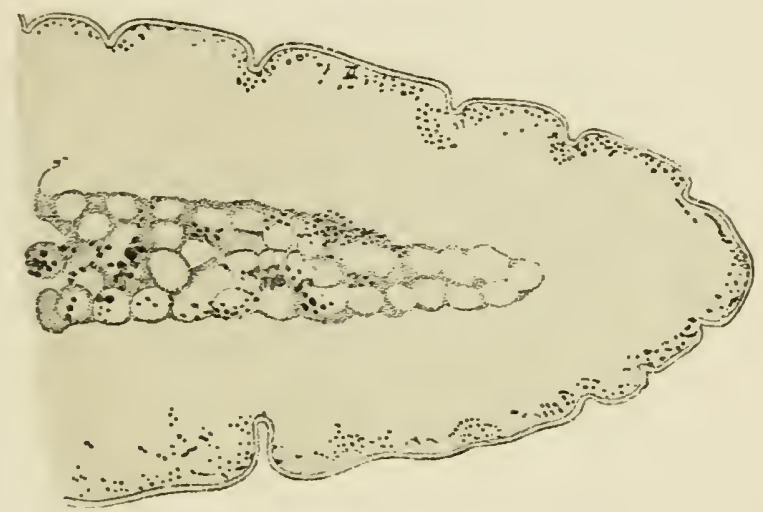

FIG. 119.-Duodenum of the mouse, after Hochhaus and Quincke. The section has been treated with ammonium sulphide. The black granules represent absorbel iron. The animal had caten eheese impregnated with " carniferrin" containing three per cent Fe. (Carniferrin is a derivative of carnic acid obtained from meat extract, and eontains both phosphorie acid and iron.)

given solution depends, first upon the degree of dissociation of its molecules, and secunlly upon the velocity of migration of the ions. This law applies also in absorption; for the rates of absorption of salts are proportional to their rates of diffusion. However, parallelism between diffusion and absorption is subject to some limitations, which make other auxiliary hypothe-es necessary and show once more that the physical facturs are not sutticient to explain the behavior of the salts in the intestine.

In order to follow the absorption of water and of substances soluble in water more closely, a solution of methylene blue has been introlueed into an intestinal loop and the nucous membrane studied microsopically. The pigment was found partly in the epithelial cells and partly between them, which means that absorption takes place here both between the cells and through them (Heidenhain).

The soluble salts, like the earbohylrates, are earried away from the intestine by the portal ressels; only in ease the quantity of absorbed fluid is great does a part of it pass out by way of the limph ressels.

The absorption of iron deserves special consideration. After it hal been 
observed that rery good results are obtained in the treatment of chlorosis by administration of different preparations of inorganic iron, and observers were pretty well conrinced that these preparations were actually absorbed in the intestine, Bunge set up the doctrine that all the iron which is added to the blood and is the source of the iron contained in the hrmoglobin, arises exclusively from complicated proteidlike compounds, the hamatogens, which are formed in the life processes of plants. Such compounds, resembling nucleo-albumins, occur also in egg 5olk, etc. That iron preparations are certainly of great use in chlorosis, Bunge would not deny, but he explained the facts on the hypothesis that inorganic iron compounds in some way protect the organic compounds from decomposition in the intestine, and thus prerent the iron in them from being split off. Other authors have adranced other hrpotheses, and attempts hare eren been made to explain the therapeutic effects of iron as the result of hypnotic suggestion.

Howerer, it appears with greater definiteness from recent researches that the so-called inorganic iron compounds are absorbed in the intestine (Kunkel, MacCallum, Hall, Hochhaus, and Quincke et al.). A research carried out a short time ago br Abderhalden in Bunge's own laboratory shows the same thing, namels, that iron furnished in inorganic compounds, in hæmoglobin and hæmatin is absorbed even in small doses, and without destroying the complicated iron compounds. The absorption takes place through the activity of the epithelial cells (cf. Fig. 119). These cells then deliver the absorbed iron either to the leucocytes or directly to the blood stream.

Some of the absorbed iron passes into the thoracic duct (Gaule). According to MacCallum and Hall, if the amount of iron given be small, it is absorbed only in the uppermost part of the duodenum: with larger doses its absorption appears to take place in the lower parts of the small intestine, especially in Peyer's patches, and, according to Tartakowsks, almost throughout the entire extent of the gastrointestinal tract.

We have the following data with regard to the further fate of iron in the body. The iron contained in the body can be split off in part from its compounds br certain micro-chemical reactions (treatment with ammonium sulphide and ammonia, or with potassium ferrocranide and hydrochloric acid); another part remains, howerer, in rery stable compounds (e.g., hæmoglobin) in which it can be demonstrated only by their decomposition. The iron contained in these compounds represents the real iron stock of the body, other iron being in a state of transition and belonging either to the intake or the output of the body (Hall).

A part of the absorbed iron is used to renew or increase the supply of iron in the stable compounds, which may have been attacked in metabolism (hæmoglobin), a part is stored in the spleen, the liver and the bone marrow. In the spleen iron occurs as an inclosure within the pulp cells (Hall). According to Tesse, the iron compounds of the spleen represent products which have arisen by transformation of red blood corpuscles. The iron-containing substances of the liver are either nucleins (hepatin. Zoleski) or albuminates (ferratin, Schneideberg), or saltlike compounds (Woltering).

We have ret much to learn as to the way in which the artificial suppls of iron affects the formation of hrmoglobin. It is conceivable that the iron is itself used in this formation, but it is also possible that the iron salts circulating in the blood stimulate powerfully the blood-forming cells of the bone marrow.

Even with food entirely free of iron, a regular elimination of this element from the body goes on, chiefly through the bile and through the mucous mem- 
brane of the stomach, creum, colon and rectum-although the separate portions of the intestine appear to participate to a different degree in different species. Elimination into the intestine appears to be accomplished by emigration of leucocytes and desquamation of epithelial cells. In certain animals the kidneys also take part in the process (Hall, Hochhaus and Quincke).

It is asserted by Raudnitz that the absorption of calcium and strontium takes place chiefly in the duodenum. 


\section{CHAP'TER IX}

\section{RESPIRATION}

THE fulletion of respiration is to provide for an exchange of gases between the tissues and the external air. The blood in its eireulation through the lungs takes up oxygen from the alveolar air and gives off to it gaseous products of decomposition, especially carbon dioxide. In order to renew the supply of oxygen and to free the alreolar air of decomposition products, a constant rentilation of the lungs is kept up by the respiratory morements. We have therefore to study first the movements of respiration and then the exchange of gases in the lungs.

\section{FIRST SECTION}

\section{MOVEMENTS OF RESPIRATION}

\section{§ 1. ELASTICITY OF THE LUNGS AND INTRATHORACIC PRESSURE}

The lungs are inclosed in an air-tight cavity-i.e., between them and the thoracic wall or the other organs contained in the thorax there is no air. Since the lungs are hollow saes with elastic and easily distensible walls, it is obrious that they must dilate every time the thorax is expanded and must become smaller every time it is contracted. Since, further. the lungs are in open communication with the external air by the respiratory passages, it follows that in the former event air must be sucked into the lungs, and in the latter it must be driven out. The former phase of respiration is called inspiration, the latter expiration.

In the static position of the thorax, the entire atmospherie pressure takes effect through the air passages upon the inner surface of the alveoli. Indirectly through the alveoli the air pressure acts upon the inner wall of the thorax and upon the organs-heart, œsophagus, etc.-lying between it and the lungs. Since now the lungs are elastic, a part of the air pressure is expended in unfolding them, and the pressure taking effect upon the inner wall of the thorax must be less than the atmospheric pressure, hy just so much as is necessary to expand the lungs. The intrathoracic pressure is therefore negative. Igain, the more the thorax is dilated, the greater is the amount of the air pressure consumed in expanding the lungs, consequently the greater this negative pressure becomes. 
The following methods have been used for determining intrathoracic pressure. A manometer may be eouneeted terminally with the trachea of a corpse, and the thoracic eavity opened without injuring the lungs. Since the pressure within and without the lungs is thereby equalized, the lungs contract in virtue of their elasticity, the force of the eontraction being measured by the pressure which the air column exerts on the mercury of the manometer. This is evi-

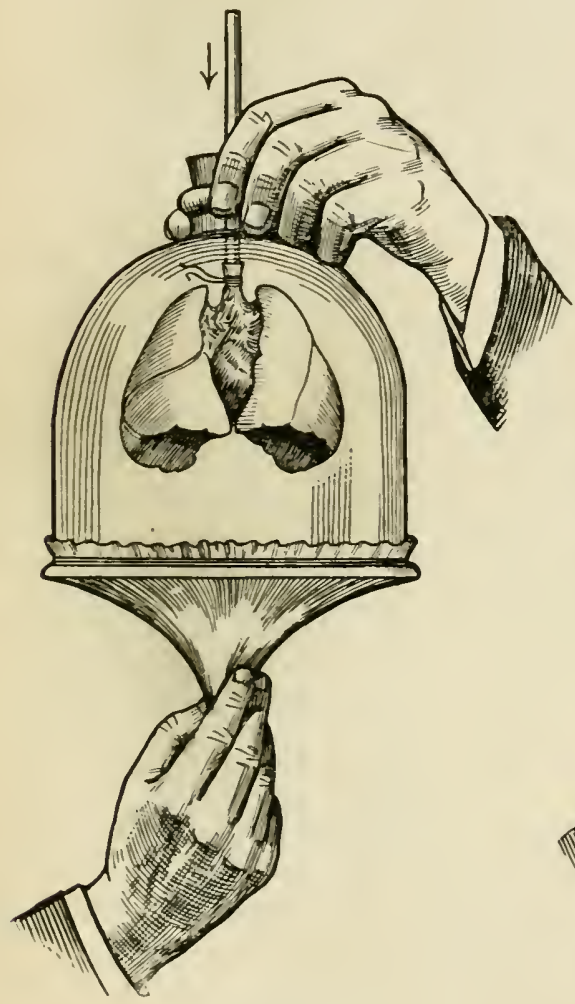

$A$

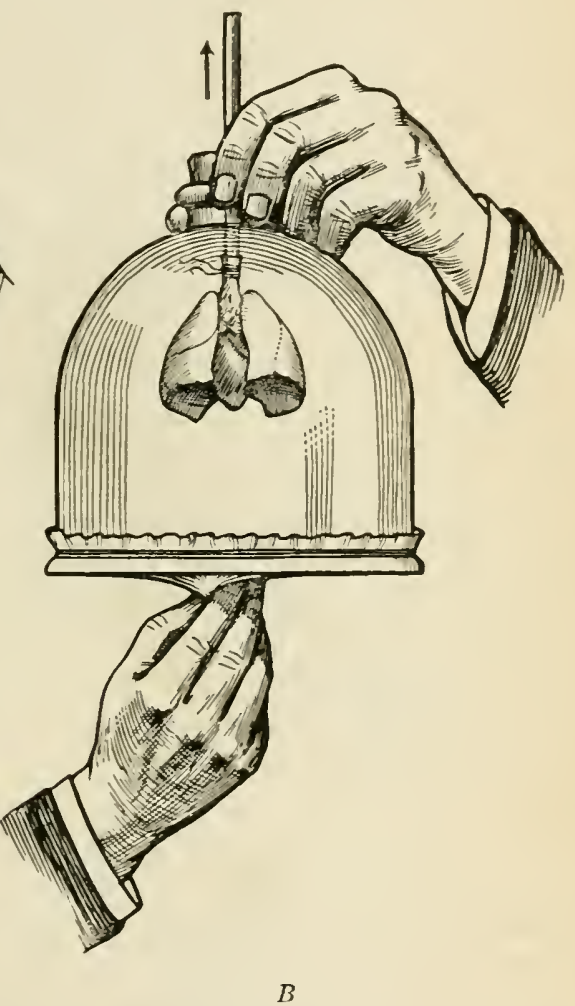

$B$

Fia. 120.-A simple experiment with the lungs of a rabbit to illustrate the normal expansion and collapse of the lungs in response to variations of the intrathoracic pressure. When the rubber membrane representing the diaphragm is drawn down (A) a negative pressure is produced inside the bell jar and the air enters the lungs through the glass tube tied into the trachea. When the nembrane is released $(B)$ the pressure inside the bell jar becomes less negative and the lungs collapse in virtue of their own elasticity, foreing the air out. The elastic recoil of the membrane, which tends to increase the pressure inside the jar, may be taken to represent the elastic recoil of the abdominal wall (ef. p. 317). A monometer can be eonnected through a second opening in the rubber stopper and the actual variations of intrathoracic pressure demonstrated at the same time.

dently equal to the pressure which was previously neeessary to expand the lungs to their original volume. If the thorax were dilated more or less before being opened, the value of the pressure obtained on eontraction would vary aceordingly (Donders).

The intrathoracic pressure ean be determined on a living animal also, by introdueing a flattened cannula through a slitlike opening into the pleural eavity, eare being taken to prevent the entrance of air (Frederieq). 
By the former method the intrathoracic pressure in man has been found to be: for the normal expiratory position. -5 to $-6 \mathrm{~mm}$. $\mathrm{Hg}$.; for ordinary inspiration, in the neighborhood of -8 to $-9 \mathrm{~mm}$. Hg.; for deepest inspiration, $-30 \mathrm{~mm}$. Hg. Since the intrathoracic pressure rises immediately after death, thesesfigures may be somewhat too low (van der Brugh).

With the glottis open the pressure in the pleural space is never positive. But when the glottis is closed and expiratory efforts are made so that the air in the lungs is compressed, the intrathoracie pressure may beeome positive. But in this case also the pressure within the lungs is greater than in the pleural spaces, for even now a part of the air pressure is consumed in unfolding the lungs.

The effect of suction in the thorax on the circulation has already been mentioned (pages $1 ; 6$ and 22\%). It plays an impertant part also in respiration. For the work to be done by the inspiratory museles is considerably increased by this negative pressure. whereas expiration is favored by it. Thus since the air pressure acting upon the inner wall of the thorax is lower than the atmospheric pressure exerted upon the outer wall, every dilatation of the thorax is counteracted by a force corresponding to the difference between the outer and the inner pressure. If the pressure necessary to expand the lungs be taken as $8 \mathrm{~mm}$. Hg., with an atmospheric pressure of $760 \mathrm{~mm}$. the internal pressure would be only $752 \mathrm{~mm}$. Hg. That is, the inspiratory effort at every movable point of the thoracic wall would be opposed by a pressure of $8 \mathrm{~mm}$., and this resistance increases more and more as the expansion increases. It is obvious without further discussion that the expiratory contraction of the thoracic wall is favored by the same circumstances.

\section{$\S 2$. INSPIRATION}

The expansion of the thorax is accomplished in two ways: by elevation of the ribs and by contraction of the diaphragm.

\section{A. REGISTRATION OF RESPIRATORY MOVEMENTS}

Some of the methods in use are for the purpose of recording movements of the thoracic wall or of the diaphragm. The former can be registered either for man or animal by fastening a reeeiving tambour to the chest wall by means of a girth of suitable form, and transmitting the pressure variations aecompanying the respiratory movements to a recording tambour. Fig. 121 represents a pneumographic eurve obtained in this way.

Through a small hole in the upper part of the anterior wall of the abdomen a spoon-shaped instrument may be introduced between the diaphragm and the liver, and the movements of the diaphragm recorded by the movements whieh the instrument makes (phrenograph of Rosenthal).

By still other methods the volumes of inspired and expired air may be recorded. To this end tracheotomy is performed on the animal, and the trachea is connected with a receiver of suitable size (Fig. 122, B), which in its turn communicates with a recording tambour of Marey, or, better still, with a small spirometer (Fig. 122, A), or a similarly devised box known as an aero- 


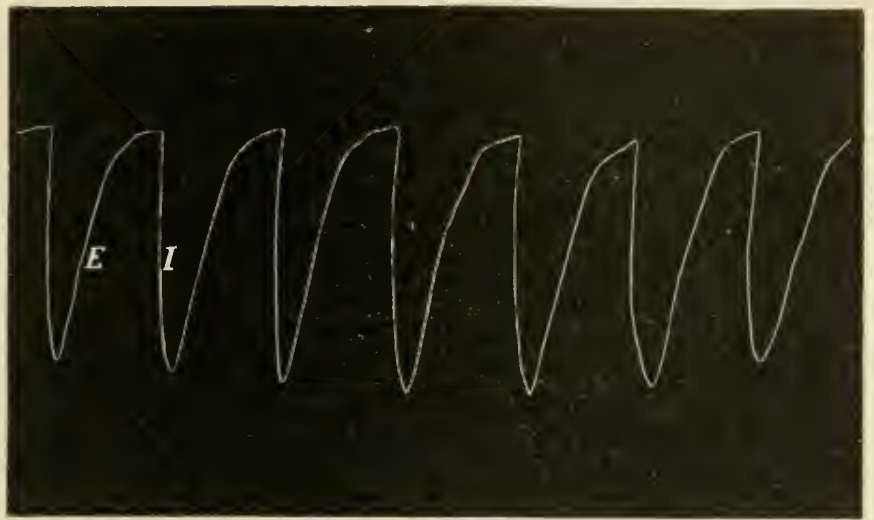

Fig. 121.-Pneumographic curve of a man, after Langendorff. To be read from left to right. $E$, expiration, $I$, inspiration.

plethysmograph (Gad). In Fig. 123 is reproduced a respiratory curve made with the apparatus pictured in Fig. 122.

The variations of intrathoracic pressure also are used for registration of the respiratory movements.

Finally, the respiratory morements can be recorded with the plethysmograph by placing the entire animal in a closed, air-tight box and allowing

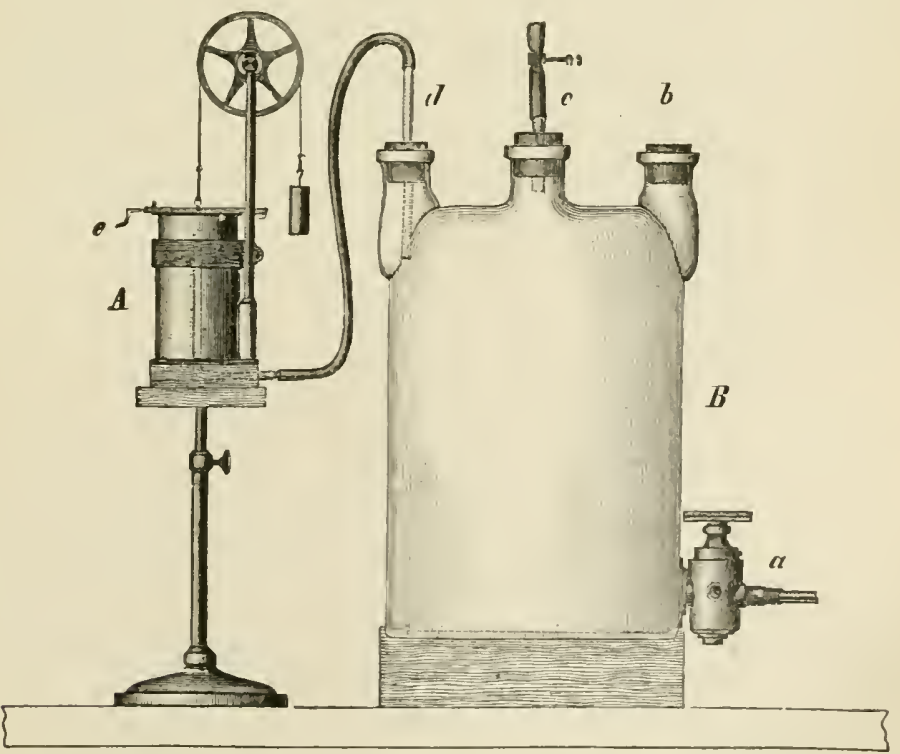

FIG. 122.-Apparatus for registering the volume of the respired air. $B$, receiver; $A$, spirometer; $e$, writing point. The trachea of the animal is conuected with $a$. The openings at $b$ and $c$ serve to ventilate the receiver. 
him to breatle through a tube opening to the exterior. The respiratory movenents are represented by the rariations in the rolume of the inclosed air (Hering).

\section{B. MOVEMENTS OF THE RIBS}

The twelve ribs (Fig. 124) are thin, partly bony, partly eartilaginous hoops projecting from each side of the thoracic vertebra, and bending outward, forward and downward, so as to inclose a space ealled the thoracie eavity. The

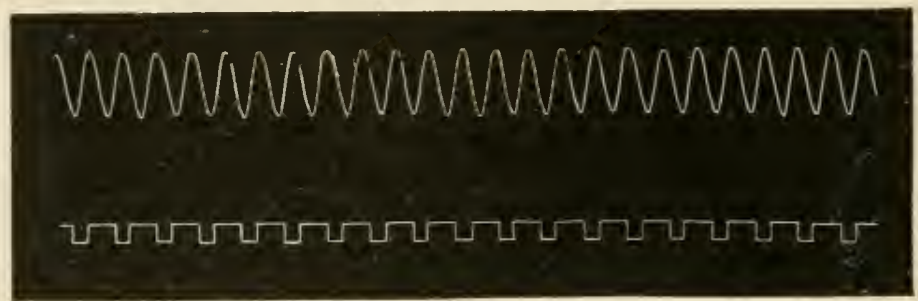

FIG. 123.-Respiratory curve of a rabbit. To be read from right to left. The downstroke represents inspiration. The lower tracing is a time record in seconds.

upper seren pairs are fastened in front direetly to the sternum along the midline of the body, while of the lower five pairs, two or three unite with the sternum indirectly and the others end freely.

Each rib is joined to its rertebra by two articulations, one with the centrum, the other with the transverse process. Hence the axes around which the ribs rotate in their movements are determined by the relative position of the two articular surfaces. Aceording to Landerer, the axes of the ribs from the first to the tenth lie in horizontal planes, but are not parallel, the angles which the axes make with the median plane being of unequal size. This angle for the first rib is about $80^{\circ}$, and decreases nearly uniformly from the first to the tenth where it is $44^{\circ}$. From this follows a fact very important for the study of the movements of the ribs, and which has been confirmed also by direct observation, namely, that the individual ribs by no means deseribe identieal ares. The axes of rotation of the last two ribs are inclined at angles of $10^{\circ}$ and $20^{\circ}$ respectively from the horizontal, while their interseeting angles with the median plane are $50^{\circ}$ and $55^{\circ}$ respectively.

When the ribs are raised on their axes, in the first place the distance of their anterior ends from the backbone is increased, and in the second place the lateral parts of the ribs are carried outward. The thoracic cavity is enlarged therefore in both the dorso-rentral and the transverse diameters. The extent to which this enlargement takes place at the level of the individual pairs of ribs depeuds upon the inclination of each and mpon the intersecting angle it makes with the median plane. The greater the inclination. the greater, for ribs of equal length. becomes the dorso-ventral enlargement, and the smaller the intersecting angle of the axis with the median plane, the greater is the transverse enlargement.

In this clevation and projection of ribs the sternum is of course advanced, and this can only be accomplished by its rotation alont a horizontal axis passing through the upper end of the manubrium. Since, moreover, the dis- 
tances of the sternal ends of the different pairs of ribs from the spinal column are unequal, the separate segments of the sternum must be mored unequally and must be bent on each other; and. what is more important. the costal cartilages are thrown into a twist. Naturally this occasions some resistance to the elevation of the ribs, which, in ardition to the resistance of their weight and of the negative pressure in the thoracic carity, must be oreronme by the muscles of inspiration.

If the ribs be moved out of their natural position by any force and this force then cease to act, they uill return of themselves to the position of rest by reason of the abore-mentioned anatomical circmstances.

since. therefore. the elevation of the ribs causes an expansion of the chest. we shall designate as inspiratory all those muscles by the contraction of which the ribs are raised. 'This is not equiralent to saying that these muscles always act in inspiration. some of the rib-lifting muscles, be it expressly observed, are active only in rery exceptional cases, while in natural, yuiet breathing only certain of the muscles participate.

The most widely different views have been expressed from time to time as to what muscles actually lift the ribs. This is especially true of the intercostal muscles. In the opinion of some, both the external and the intemal intereostals are inspiratory muscles, in the opinion of others both are muscles of expiration; others again believe that the extermal tend to raise, the internal to depress the ribs: and finally, the view has been maintained that these museles are present only for the purpose of regulating the tension in the intereostal spaces and of rotating the thorax in its long axis. By obsertations on living animals in which all the museles of respiration were excluded except the intercostals,

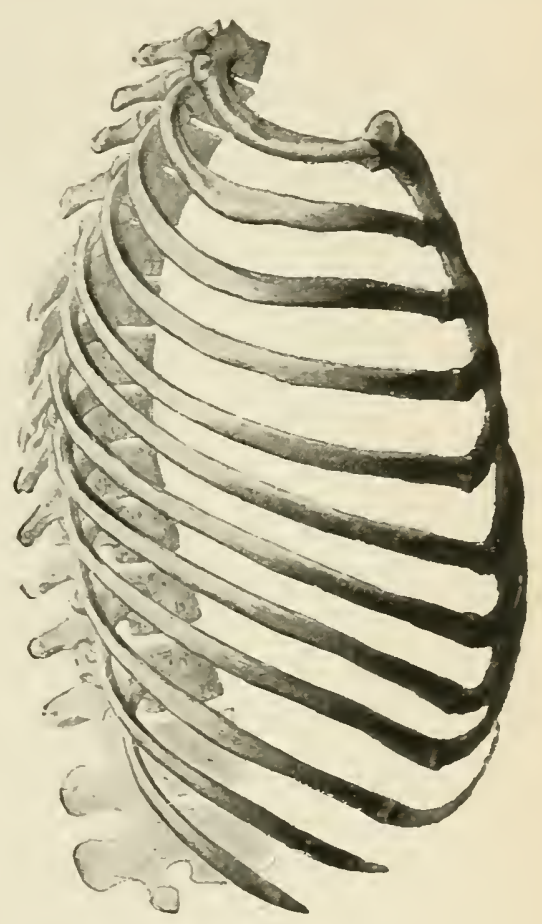

FIG. 124.-The thorax seen from the right side, after Spalteholtz. it has now been made clear that the outer layer, as well as that part of the inner included between the costal cartilages, serves to elevate the ribs. while the remainder of the inner laver draws the ribs down (Bergendal and Bergman, R. Du Bois-Reymond and Masoin, R. Fick).

In the rabbit at least the interenstal muscles are the most important so far as the thoracic breathing is coneerned. When greater demand is made upon the muscles of inspiration, the leratores costarum and the scaleni are added first. The levatores alone are able to look after the respiratory movements for a certain time, and their action in the cat is very important (Kioraen and B. Möller). Since these muscles are inserted quite elose down to the hinder ends of the ribs, 
they can, with rery slight contraction, produce rery marked movements of the anterior ends.

In the rabbit with more vigorous respiration the serrati postici superiores, the sternohyoidei and the sternothyroidei come into play. In man, finally, Duchenue has found that in the greatest respiratory distress the following muscles are active: the sternocleido mastoids which lift the sternum when the head is fixed; the pectorales minores which lift the third to the fifth ribs with the scapula fixed; the serrati antici magni, the pectorales majores and the subclavii.

\section{MOVEMENTS OF THE DIAPHRAGM}

The diaphragm springs from the entire inner surface of the lower edge of the thoracic skeleton; its fibers converge toward the axis of the body, and attach themselves to the flat tendon situated in the center of the muscle. It presents

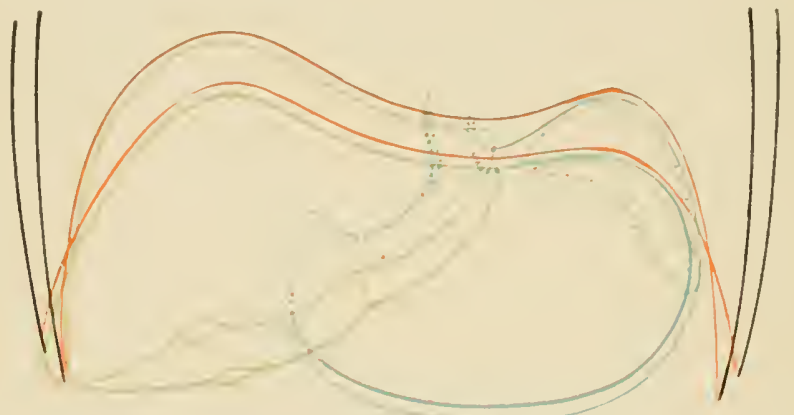

FIG. 125.-Schema, after Hasse, showing the movements of the diaphragm, liver, stomach, and spleen in respiration.

a convex curvature toward the thoracic cavity, being. so to speak, arched orer the convex upper surface of the liver.

Then the muscle fibers of the diaphragm contract. its dome-shaped upper part is flattened and mores downward. The central tendon takes part in the morement and becomes flattened because of the pull of the muscle fibers on all sides of its periphery. Howerer, in deep respiration the dome itself always descends further than does the center (Hasse. Fig. 125). According to observations made with $\mathrm{I}$ ravs ( $\mathrm{Cowl}$ ), during deep respiration the sweep of the diaphragm corresponds to the distance from the middle of the tenth to the upper edge of the twelfth thoracic rertebra. The maximal excursion of the central tendon is about $t \mathrm{~cm}$. (Grönroos).

At the same time by eleration of the ribs and of the sternum. the lower end of the thorax is increased in diameter (Duchenne). This is possible because the abdominal riscera. although depressed as an entire mass by the contraction of the diaphragm. present their upper surface as a fulcrum on which the circumference of the diaphragm is lifted. If the abdominal viscera be remored. when the diaphragm contracts the lower ribs approach each other and the lower end of the thorax is narrowed.

$\mathrm{Br}$ reason of these changes the thoracic activity is enlarged from above downirard and, at the extreme lower end. is enlarged also from side to side. 
With regard to the relative importance of the diaphragm and the rib-lifting muscles in inspiration, we find among cirilized people that in the man the diaphragm plays a more significant part than it does in the woman. Attempts have been made to relate this difference to the state of pregnancy and the attendant growth of the uterus. But this appears to he true only to a limited extent, for Sewall and Pollak have found that the respiration of Indian women is plainly of the abdominal type. The respiration of growing (European) girls is characterized by Gregor as a combination of the abdominal and the thoracic types. with the diaphragmatic part predominant, and with weak action of the shoulder girdle; that of boy- as predominantly thoracic with strong action of the shoulder muscles. In forced respiration of boys the chief auxiliary mechanism caller into play is the shoulder muscles, in girls it is the diaphragm. All this means that the actual cause of the feminine type of respiration, often considered as normal, is to be sought in the compression of the abdomen by elothes. especially the corset; and this has been confirmed directly by the observations of Fitz. Is a consequence of this compression a woman gradually acquires the costal type of respiration. until finally it becomes normal for her.

We have at present but a single measurement of the absolute ralue of the diaphragmatic as compared with the costal enlargement of the thorax; namely, out of 490 c.c. of inspired air (in a mans) about 320 c.c. devol:ed upon the elevation of the ribs and only 170 c.c. on the descent of the diaphragm (Hultkrantz).

\section{\$3. EXPIRATION}

In ordinary quiet respiration the thorax appears to pass into the expiratory position principally by mere cessation of the inspiratory phase. When the diaphragm contracts it pushes the abdominal viscera downward and produces an inereased tension of the abdominal wall. When it relaxes, it is brought back to its position of rest by the elastic recoil due to this tension. The ribs are brought back from the inspiratory position to their position of rest by the force of gravity and by the elasticity of the eartilaginous connections between the ribs and the sternmm. Both in the abdominal and the thoracic types of respiration, the return to the expiratory position is aided by the elastie pull of the lungs (cf. page 311).

Ordinary expiration appears. therefore, not to require any muscular effort. The fact that expiration does not begin suddenly. lut gradually: can be explained by saving that the contraction of the inspiratory muscles does not cease all at once, but rather slowly. According to some authors, however, the internal intercostal muscles. which, as we have scen, tend to lower the ribs, are active in ordinary expiration.

Under some circumstances expiration takes place br reason of muscular activity, and the volume of the thoracic cavity is diminisher considerably more than is ordinarily the case. This kind of expiration is described as active to distinguish it from the ordinary or passive expiration. It is executed chiefly by the abdominal muscles.

By the contraction of these muscles (primarily the recti and external oblique, secondarily the internal oblique, and least of all the transversi) the 
ribs are drawn downward and the abdominal carity is compressed so that the relaxed diaphragm is foreed deeper into the thoracic cavity. In this way the thorax is narrowed as much as possible in all directions.

In Fig. 126 are represented according to Hasse two extreme types of respiration: in A a purely diaphragmatic type, and in B a purely thoracic type. In $A$ no morement of the thoracic wall can be recognized, and the

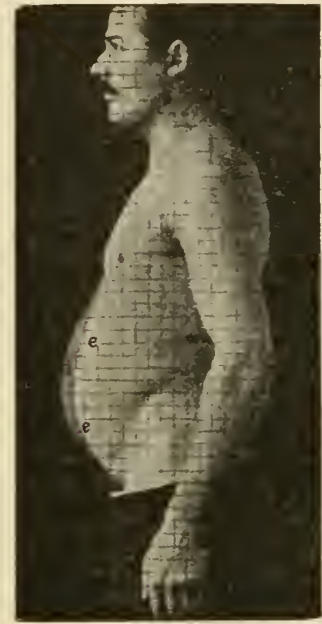

A

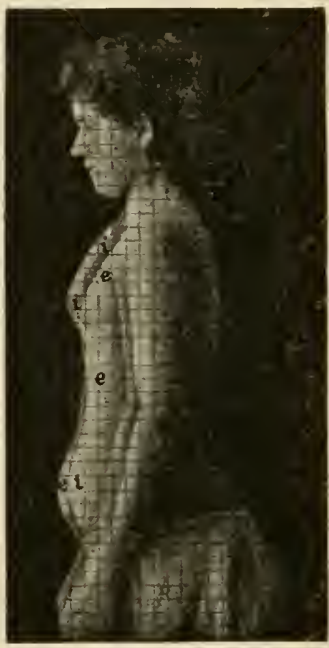

$B$

FIG. 126. - A, a purely diaphragmatic type of respiration. $B$, a purely thoracic type, after Hasse. $i, i$, the profile of the body in inspiration; $e, e$, the same in expiration.

anterior contour of the abdominal wall only is projected in inspiration (i). In $B$ the strong inspiratory morement of the thoracic wall forward and upward is erident. Because of the passive eleration of the diaphragm the anterior wall of the abdomen is at the same time drawn in; when the ribs fall in expiration the anterior abdominal wall curves forward again. The contour $i, i$, is the position of inspiration, the contour $e, e$, that of expiration.

\section{§4. THE NUMBER OF RESPIRATORY MOVEMENTS}

In quiet breathing the number of respiratory morements in the adult man is, on the arerage. 16 to 19 per minute; the extremes are about 11 and 24 (Quetelet). With younger persons the respiratory frequency is greater. being, for example. during the first year on the average $4+$ (maximum 60 , minimum 23) per minute, and during the fifth year on the average 26 per minute (cf. Fig. 12r).

Various circumstances, however, serve to alter the respiratory frequency. It is increased, for example, by muscular work (see below). by higher external temperature, or by an elevated body temperature, and may reach a very high value. 


\section{ร. 5. EXCHANGE OF AIR IN THE LUNGS}

The rolume of air taken in with an ordinary inspiratory effort is estimated for the ardult man at about 500 c.c. With a frequency of 16 per minute this would give a ventilation rolume (breath volume, Rosenthal) of 8.000 c.c. $=$ s liter: per minute.

Aceording to Gregor, the average breath volume of children in the first month amounts to 1,300 e.e. per minute, in the twelfth month 3,000. and between the second and thirteenth rears it raries between 4,000 and 5,000 e.c.

After an inhalation of the arerage wolume. a eonsiderable quantity of air can still be taken into the lungs. and after an ordinary expiration a considerable quantity ean still be expelled from the lungs. But if we make the most extreme expiratory effort with the assistance of all the expiratory muscles. there remains in the lungs a certain quantity of air which, so long as the thorax is uninjured. ean never be expelled.

This air left over is called the residual air. Ittempts have been made, by various methods which eannot be described here, to determine it - amount,

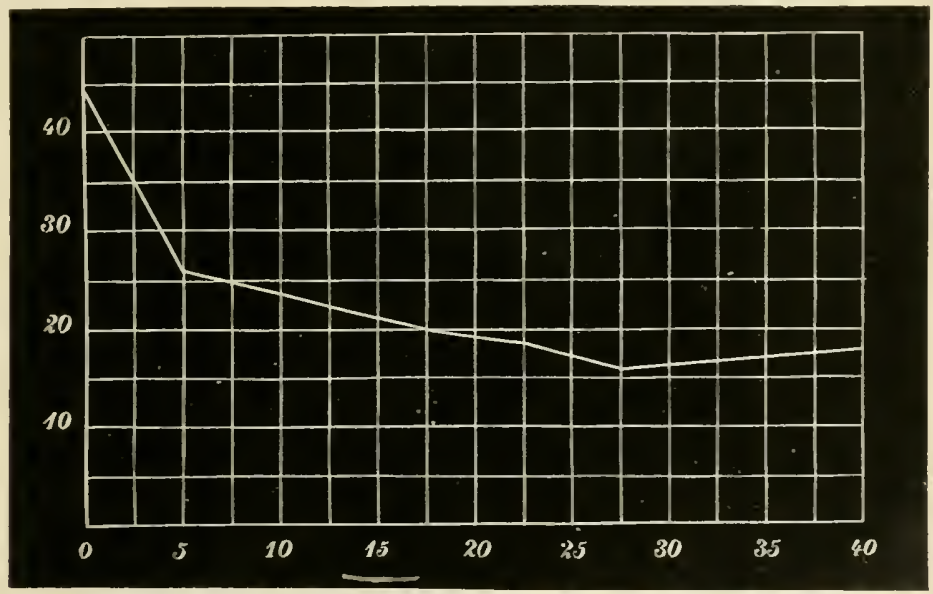

Fig. 127.-The number of respirations per minute in persons of different ages, after Guetelet.

and, if we neglect the values which are obviously ineorrect, it has been found to vary from 500 to 1,600 c.e. We shall probably make no great mistake if we estimate it for the healthy adult man at 1.000 c.c. in round numbers.

The reason why the residual air cannot be expelled from the lungs is simply that when entirely collapsed the hungs inelose a much smaller space than does the thorax eontracted to its smallest capaeity. Since the lungs are pressed against the thoracic wall by the air inclosed within them, their rolume cannot of eourse be diminished beyond the rolume of the chest itself. When, however. the thoracie wall is opened, and the air pressure inside and outside the lungs is thereby equalized, they collapse in virtue of their own elasticity and drive out the contained air. 
Even the collapsed lungs are not wholly empty of air: incleed, a lung which has onee respired can never he entirely freed of its air by mechanical means. The reason of this is that in their collapsed state the walls of the smallest bronchioles press together and thus prevent further exit of air from the alveoli. This last quantity of air is spoken of as the minimal air (Hermann). That rolume of air which can be expelled after an ordinary expira-

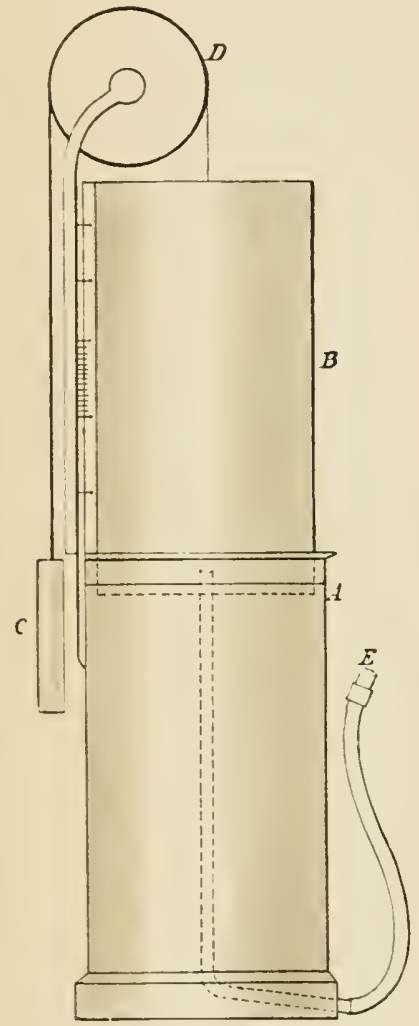

Fig. 12S.-Spirometer, after Hutchinson. The expired air is blown into the tank $B$ through the tube $E$. The weight $C$ serves to offset the weight of the tank. tion amounts to about 1.600 e.e. and is called the reserve air. If after the usual tidal volume of 500 c.e. has been inbaled. inspiration be continued further, one ean with the greatest possible effort of the inspiratory muscles take in some 1,600 e.e. more. 'This is called the complemental air. The sum of the complemental, the tidal and the reserve air $(1,600+500+$ $1.600=3.200$ (.c.) represents the maximal extent of the exchange of air possible with a single complete respiration, and is called the rital capacity of the lungs.

The vital capacity is measured by first taking as deep an inspiration as possible, and then exhaling with the help of all the expiratory muscles into a spirometer (Fig. 12s).

From the facts thus far discussed we reach this important conclusion, that we always have the power of increasing considerably the quantity of inspired or expired air without exhausting the capabilities of the respiratory apparatus.

To be able to judge the effective result of pulmonary rentilation, it is of great importance to know whether the inspired air aetually reaches the alreoli. The respiratory exchange of gases takes place in the alveoli; but the air which remains in the air passages. including the smallest bronchioles, can only contribute to this exchange by diffusion with the alveolar air, and, in view of the small diameter of the smallest bronchioles and of the frequeney witl which air in the passages is changerl, this diffusion must be relatively insignificant. The only way to determine whether air goes directly to the alveoli is to estimate the total capacity of the respiratory passages from the nasal openings to the smallest bronchinles. Knowing already the volume of tidal air, we should then know whether the air passages alone were sufticient to aecommodate the tidal volume. Only two such direct determinations have yet been made, but according to these the "noxions air space," as it has been called. amounts to about 140 c.c. (Zuntz). By an indirect method, the principles of which cannot be presented here, the lower limit of this capacity is said to be about 100 c.e. and the upper 150 c.e. (Loewy). Of the rolime 
taken in at each inspiration the greatest part therefore reaches the alreoli. It is evident that this noxions space must exercise a greater influcuce, the more superficial the respiration.

\section{\&6. CONCOMITANT RESPIRATORY MOVEMENTS}

Besides the muscles already considered as influencing the capacity of the chest, still others are active at the same time, which are of some importance for normal respiration.

Among these are the muscles which move the rocal cords. In quiet respiration the glottis is rather widely open and makes but shight movements (Czermak). But in more active respiration it is widened by contraction of the posterior cricoarytenoid muscles at each inspiration. When the muscles of the vocal cords are paralyzed, the cords take an oblique position with their upper surfaces directed outward. Their inner edges are thus separated but slightly from one another and, being relaxed, are dram toward each other by the current of air. In young animals complete closure of the glottis may be produced in this way and suffocation be the result (Le Gallois).

\section{§ 7. SPECIAL FORMS OF RESPIRATORY MOVEMENTS}

The following are to be mentioned as special forms of respiratory morements: (1) Coughing, a powerful expiration produced reflexly and begun with a closed glottis, which is then opened by an explosive blast of air under high pressure, whence the accompanying sound; (2) Sneezing, a powerful reflex expiration, with open glottis and the mouth eavity closed off from the pharynx: it is often introduced by a deep inspiration; (3) Laughing, a series of short and weak expiratory blasts with lightly closed glottis; (4) Yawning, a deep inspiration with the glottis widely open, and as a rule with the mouth open; (5) Sighing, a deep inspiration followed by a prolonged expiration with partially closed glottis; (6) Sobbing is distinguished from sighing only by the relocity of the inspiratory act; it is usually accompanied by a spasmodic ascent of the laryx. All these forms of respiratory movements are produced reflexly, or are the accompaniments of psychical states and are even then to a certain extent reflex.

\section{§ 8. PRESSURE CHANGES IN THE RESPIRATORY PASSAGES}

On account of the slight force necessary to expand the hungs. when the thorax is enlarged they begin to expand immediately at the beginning of inspiration, and the alveolar air naturally is at first somewhat rarefiel. Irith the glottis open new air flows in from outside; but in riew of the relative narrowness of the respiratory passage and the constrictions necurring at different places along it. the inflow cannot take place instantly, and as a consequence one always finds a negative pressure in the air passages during the inspiratory phase. Tire rersa, when cxpiration takes place, the air to be exhaled cannot escape immediately: hence we always find a positive pressure in the passages during the expiratory phase.

With an open glottis and a static condition of the thorax, the tension of 
the pulmonary air very quickly strikes a balanee with that of the onter air, so that we meet the pressure rariations just described only when the eapaeity of the lungs is being changed by inspiratory or expiratory morements.

In order to determine the absolute value of these pressure variations, a T-shaped eanmula is introdueed into the trachea of a dog, the animal breathes as usual througl the uninjured glottis, and the variations of pressure are measured by a manometer connected with the unpaired limb of the cannula (Kramer). This method has been used also on patients with a tracheal fistula. With normal persons either the manometer tube is placed in one nostril and the subject breathes through the other (Donders), or he is allowed to breathe from a wide bottle eonnected on one side with a manometer and on the other by a wide tubulure with the outside air (Ewald).

It is evident that the values obtained in these experiments must be smaller, the nearer the manometer is brought to the outer openings of the respiratory passages. By the last-named method Ewald found a pressure of $-0.1 \mathrm{~mm}$. $\mathrm{Hg}$. for inspiration and $+0.13 \mathrm{~mm}$. for expiration. When Donders placed the manometer tube in one nostril, he obtained for inspiration about -0.7 and for expiration $+0.5 \mathrm{~mm}$. Hg. In experiments on men with a tracheal fistula, Aron obtained below the glottis the value of $-1.9 \mathrm{~mm}$. for inspiration and +0.7 for expiration.

In order to measure the force of the different phases of respiration. a $\mathrm{Hg}$. manometer is placel in air-tight connection with the month and nose by means of a closely fitting mask, and the subject breathes into the apparatus (Talentin, Hutchinson). Of course no air ean pass into or out of the lungs. but instead the air ahready in them is rarefied or compressed according as the effort is made to inhale or exhale. The pressure rearlings given by the manometer may then serve as relative expressions of the power employed in the two phases. By such a method Hutchinson found in ordinary breathing a pressure of $-50 \mathrm{~mm}$. Hg. for inspiration and $+\gamma 6 \mathrm{~mm}$. for expiration. With the deepest possible inspiration the pressure is giren at something like -140 to $-150 \mathrm{~mm}$. Hg.: for the most intense cxpiratory effort possible the figures vary between $+10 \mathrm{~S}$ and $+256 \mathrm{~mm}$. $\mathrm{Hg}$.

On three different individuals Mosso determined the inspiratory pressure for pure costal and pure diaphragmatic breathing and found the value in the former to be from -32 to $-40 \mathrm{~mm}$., in the latter from -10 to $-20 \mathrm{~mm}$. $\mathrm{Hg}$. (c.f. page 317 ).

\section{\$ 9. THE RESPIRATORY SOUNDS}

By auscultation of the lungs and of the air passages, tro different sounds can be heard; namely, (1) the vesicular. and (2) the bronchial sound.

To imitate the character of the resicular sound one has only to suck in air through the mouth with the lips pursed: a sipping sound is produced which is almost exactly like the vesicular sound. It is said to be produced at the moment when the air current enters the alveoli.

During expiration there is to be heard in the normal condition of the thorax a weak and soft. indefinite aspirating sound which shows no trace of the sipping, vesieular sound of inspiration.

Over the larynx one can hear during both inspiration and expiration a very 
loud, sharp, aspirating sound in which $h$ or ch is the prédominating component. This laryngeal sound is propagated along the trachea and the two main bronchi, with gradually diminishing intensity (the bronchial sound).

\section{\$ 10. MEANS OF PROTECTION FOR THE LUNGS}

The air passages leading to the lungs (nasal cavities, throat, trachea and hronchi) serve to protect the pulmonary alveoli from varions kinds of injurie-

The narrowness of the nasal passages and the bend which the air passage makes in the plarynx serve the useful purpose of freeing the inspired air very largely of its dust particles since the latter athere to the mucus-covered walls of nne cavity or the other. This protection is largely wanting in breathing by the mouth. The dust particles are also driven ontward by the cilia of the epithelium lining the air passages. This movement, especially in the parts below the larrnx. is of great serrice in keeping the alvenli free of dust.

Of greater importance still is the fact that the parts of the respiratory passages below the glottis under ordinary circumstances do not permit the development of Bacteria: they are either entirely sterile or they contain an insignificantly small number of Bacteria (Jundell). since the tracheal secretion possesses no antiseptic properties, this sterility must be accounted for in some other way as yet quite unknown.

Only in very exceptional eases does the inspired air have the temperature of the body; but the expired air comes out warmed to the temperature of the body and saturated with moisture. These changes occur chiefly in the wider passageways so that the bronchi and especially the delieate alvooli are protected from the harmful effeets of loss of heat and loss of water. In fact, it has been fouml that when, by means of an aspirator, air at $10^{\circ}-12^{\circ} \mathrm{C}$. is taken in at one nostril and passed out at the other, entrance to the pharyx being closed, it comes out warmed to $31^{\circ} \mathrm{C}$. and saturated with moisture. If the outside temperature be $0^{\circ}-4^{\circ} \mathrm{C}$., it is warmed to $27.5^{\circ} \mathrm{C}$. In similar experiments with mouth breathing, the air reaching the pharynx was some $0.5^{\circ} \mathrm{C}$. colder than with nose breathing (Aschenbrandt, Kayser). From these observations we are entirely justified in eoneluding that the air in the middle-sized bronchi at least has acquired the temperature of the body, and is immediately saturated with moisture at that temperature.

The rlosure of the laryus which takes place in swallowing (pace os 1 ) as well as diflerent expiratory reflexes which are to be discused in the following section are essentially for the protection of the lungs.

\section{SECOND SECTION}

\section{INNERVATION OF RESPIRATION}

\section{\$ 1. THE EFFERENT NERVES}

Those muscles hy the eontraction of which the thoracic cavity is onlarged or diminished in size (if we neglect the purely acessory muscles) receive their nerves from the spinal cord: the nerves to the scaleni pass by way of the 
second to the serenth cerrical roots; those to the levatores costarum and the abdominal muscles by the thoracic nerves; those to the diaphragm chicfly by the third and fourth cerrical roots and the phrenic nerve. According to Luschkia and Caralié, the edge of the diaphragm receives some fibers also from the lowermost intercostal nerres.

If the spinal cord be sectioned below the exit of the last intercostal nerves, the operation eridently has no direct influence on the respiratory movements. But if the section be made in the thoracic cord, those muscles whose nerves emerge from the spinal cord below the section are paralyzed. After section abore the first intercostal nerves, for example, the movements of the ribs, with the exception of those prorided for by the sealeni muscles, cease entirely and the animal now breathes only with the diaphragm and the scaleni.

With still higher section of the spinal cord all the muscles above named are paralyzed and there remain only the movements of the glottis, the mouth and the nose (Galen, Le Gallois, Flourens).

When the diaphragm is paralyzed by bilateral section of the phrenics, various disorders in respiration appear, especially in animals which breathe mainly by the help of the diaphragm. These may be accounted for partly by the fact that the rib-lifting museles now have all the work to do, and partly by the fact that since the diaphragm is now relaxed, the abdominal viscera are sucked into the thorax with each inspiration. However, no real danger to life is occasioned, if one is dealing with grown animals, which have a rigid chest wall and strong muscles. Young animals die after bilateral section of the phrenics, because the yielding chest wall and the immature muscles make it impossible to dilate the chest, once it has become narrowed by paralysis of the diaphragm.

Observations on men have shown that when all the muscles except the diaphragm are paralyzed, as well as when the diaphragm alone is paralyzed, life may be still maintained. $I_{n}$ the latter case the respiratory frequency becomes greater than normal and breathing goes on, without any participation of the accessory muscles, under the coöperation of the levatores, the intercostals and the scaleni. Great bodily exertion, however, results in severe respiratory distress.

The motor nerves for the muscles of the larynx and bronchi run in the trunk of the vagus. Among the laryngeal muscles the cricothyroid is innerrated from the superior laryngeal, the others from the inferior laryngeal.

It was asserted by Longet (1842) that the bronchial muscles also are under the influence of the ragus. This statement was often disputed by later authors, but it has been established by the newer, much improved technique that the ragi do in fact produce contraction of the bronchial muscles, and, especially in the cat, contain inhibitory fibers also for these muscles.

The bronchial muscles of the dog are under weak tonic stimulation, those of the horse under a strong tonus; they are influenced, feebly as a rule. by various afferent nerves, both contraction and relaxation appearing as the results of stimulation. The most important broncho-constrictor reflexes appear to be started from the mucous membrane of the respiratory passages (nose, larmx), and may possibly be regarded as protective reflexes, for the narrower the bronchi become the more likely is the dust of the air to adhere to their walls. 
The chief service of the bronchial muscles is that when the intrabronchial pressure rises, they give by their contraction a greater degree of firmness to the bronchial walls.

The mucous glands of the larynx and of the trachea receive their nerve fibers through the laryngei nerres. In these also are afferent fibers which produce a reflex secretion of mucus in the larynx and trachea (Kokin).

\section{§ 2. THE RESPIRATORY CENTER}

Since in the morements of respiration a large number of muscles contract in a definite sequence, it is to be assumed in conformity with our present views of innervation, that somewhere in the central nervous system is a center controlling these movements.

From the fact that these movements do not cease when the brain is cut through as high up as the pons, it follows that the respiratory center must be situated below that point-i. e., not higher than the medulla. When such a section is made, the diaphragm stops for a moment. but begins of itself to contract, and continues quite regularly unless some unintentional lesion has occurred.

When, on the other hand, the medulla is separated from the spinal cord, respiration ceases. Galen knew that in the upper part of the spinal cord there is a place the destruction of which at once stopped respiration, and Le Gallois (1812) showed that this spot is in the medulla. For a long time it was generally agreed that the respiratory center was to be sought only in the medulla. Recently, however, it has been claimed with great positiveness that, although there is a regulatory apparatus in the medulla, the true centers for the respiratory movements are to be sought in the spinal cord, and the advocates of this doctrine go so far as to say that the nuclei of the respiratory nerres are stimulated simultaneously by the blood, thus giving the impulse for a coördinated respiratory activity (Brown-Séquard. Langendorff. Wertheimer). The stoppage of respiration after section of the cervical cord would, in their opinion. be due not to separation of the respiratory nerves from their center, but to the shocklike, inhibitory effect of the section.

There are numerous experiments which show that direct stimulation of the spinal cord with electricity or by mechanical means may stop respiration, and the view just mentioned is well supported by such facts. But it is at present impossible to deeide how long such an effect of shock may last. If an animal whose cord has been sectioned in the neek be maintained by artificial respiration, it ean be kept alive for hours. But if the animal still does not breathe spontaneously one cannot refute the claim that shock still persists.

In cases where artificial respiration is first maintained for a long time, rhythmical respiration has been observed on animals with the cord severed in the neck. Some of the first observations of this kind were made on newly born animals and some on animals whose reflex irritability had been artificially increased with stryehnia (Rokitansky, Langendorff). Later Wertheimer succeeded in obtaining spinal respiration in grown animals which had not been poisoned. But when spinal respiration does appear it is never of the same extent as that controlled from the medulla, and it continues, so far as is yet known, at most 
for only three-quarters of an hour. Often it eamnot be induced at all. The animal reacts unusually well to all kinds of sensory stimuli causing reflex muscular contractions, and the spinal vasomotor centers react powerfully to the stimulus of asphyxiation. The effect of shock therefore is past; and yet as a rule one observes no genuine respiration. To maintain the doctrine of the preponderance of spinal respiratory centers under such eircumstances, one must assume that these centers react toward shock in quite another way from the other spinal centers.

The fact that hemisection of the spinal cord rery often does not result in cessation of the respiratory movements of the same side (Brown-Sequard et al.) speaks against the hypothesis of shock. Moreover, when cessation does occur, it is immediately nullified if the phrenic of the opposite side be cut (Porter). If the mechanical injury of sectioning were to produce so strong a shock, as the advocates of the spinal centers assume, hemisection of the spinal cord should stop the respiratory morements on the side of the section for a time at least.

We reach the conclusion therefore that the medulla is not only of great importance in the regulation of respiratory movements. but that it controls also the coördinated artirity of the respiratory muscles. Only in rare cases is such an effect carried out by the nuclei of the spinal cord, and, although we can speak in general terms of spinal respiratory centers, it appears that in comparison witl those of the medulla they have but little to do with producing the normal stimuli.

The exact location of the respiratory center in the medulla is not yet definitely known. This much appears certain, howerer, that it is not a small, circmscribed spot, but is a region of relatively large extent. This is what we should expect in riew of the very large number of nerrous connections which it has.

After median section of the medulla, the respiratory movements of the two halves of the diaphragm (Langendorff) and those of the rocal cords and the nose (Kreidl) continue synchronously-which shows that the influences originating the respiratory movements proceed simultaneously on the two sides of the center. But this synchronism is abolished by section of both ragi, and each half of the body then breathes independently of the other.

That section of the vagus on one side does not always stop the synchronism just mentioned, goes to show that the two centers are connected by commissural fibers. The presence of a crossed connection between the respiratory center and the nuclei of the respiratory muscles follows also from the above-mentioned facts, that respiration can proceed undisturbed on one side after hemisection of the cord on that side and section of the phrenic on the opposite side.

The respiratory movements can be influencer also by stimulation of parts of the brain anterior to the medulla. Martin and Bonker obtained inspiratory effects by stimulating the surface of a section between the anterior and posterior corpora quadrigemina: Christiani obtained the same on stimulation of the floor of the third ventricle. and expiratory effects on stimulation of the entrance of the aqueduct of Sylvius. Finally, the cerebral cortex evidently exercises control orer the respiratory movements, as is seen, for example. in the extremely fine gradations of these movements which ean be executed 
by a good singer. Respiratory movements can be accelerated or retarded by electrical stimulation of the motor cortex of the $\log$ and cat. 'The result, according to F. Franck. does not depend upon the place of stimulus, but upon its strength: strong stimulus giving a retardation, weak stimulus an acceleration. The depth of respiration also is changed in one direction or the other.

These parts of the brain act only through the mediation of the respiratory center in the medulla; the fibers rumning from them to the eenter are therefore to be regarded as afferent pathways. The warrant for this view lies in the fact already mentioned, that the respiratory movements continue after section above the medulla. Moreover. it is not to be denied that some of the results just discussed can be obtained by stimulation of the conducting pathways. The so-called brain centers for respiration seem therefore to represent only pathways to the center in the medulla. We shall see immediately that these paths and certain parts of the brain are, under certain circmistances, of great service.

\section{§ 3. RESPIRATORY REFLEXES}

Like all the other more complicated processes of the body the respiratory morements are influenced by all possible kinds of atferent nerres. But there are two of these paths more important than the rest, namely (1) the vagus, and $(\because)$ the fibers which connect the higher parts of the brain with the respiratory center. These accordingly we must consider first.

\section{A. REFLEXES THROUGH THE VAGI}

Notwithstanding the roluminous literature that has accumulated on the influence of the alferent vagus fibers, our knowledge of their action on respiration is still very meager. The statements of authors as to the facts bearing on even the most inportant points differ considerably, and we can therefore present the action of the vagus on respiration only in the broadest outline.

Generally speaking, in the investigation of the influence of any nerre on the processes of the body one obtains the best results by direct stimulation of the nerve. Tnfortmately this is not the ease with the pulmonary vagus, for section of the nerve is followed by much more profound effects than its stimulation.

A nerve cannot be cut with a pair of scissors without at the same time stimulating it. Besides, an clectric current (demarcation current, see page 48) is set up in a cut nerre, and this may possibly exercise a stimulating influence. Gad has shown, however, that the pulmonary ragi can be thrown out of action without stimulation by cooling them sufficiently. For this purpose the ragi are laid upon silver tubes which are filled with a cold mixture (c.g., a solution of ammonium nitrate in water).

Even under such circumstances different authors have not ohtained perfectly harmonious results, although all are agreed that after bilateral blocking of the vagus (1) the respiratory frequency falls. (2) that the inspirations become deeper and (3) that the summit of inspiration shows a pause of greater or less length (Fig. 129). But with respect to expiration after double 
ragotomy, riews are very divergent: Gad asserts that it no longer reaches its former level. whereas Lindhagen has found that the relaxation of the inspiratory muscles is diminished little or none at all, and Boruttan remarks that sooner or later expiration reaches the same height as before freezing the ragi. According to Gad and Lindhagen, the expiratory pause is nearly always shortened, according to Boruttau it is the same as before or even a little longer. These statements all apply to the rabbit. In the dog, after freezing of the vagi, the expiratory muscles fall into a state of almost regular activity (Boruttau). The breath volume also, according to Gad, becomes smaller after freezing the ragi; according to Lindhagen, it remains on the whole unchanged.

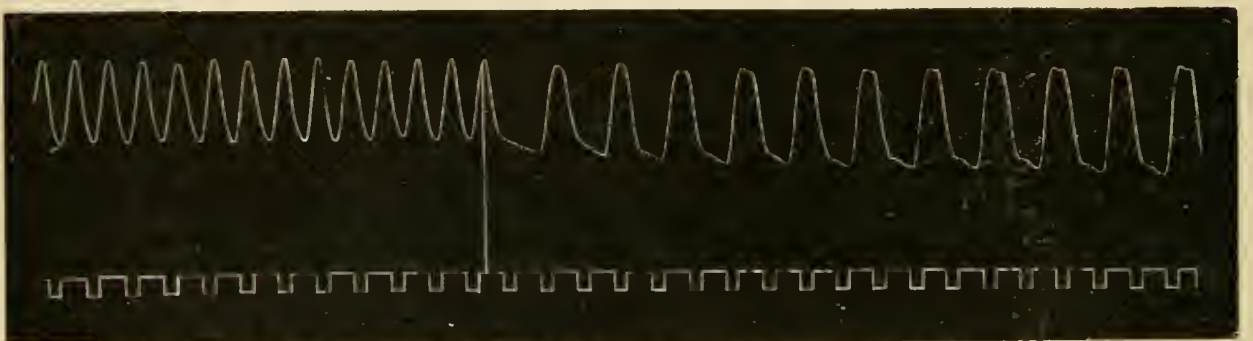

Fig. 129. - The respiratory curve of a rabbit recorled with the apparatus shown in Fig. 122, after Lindhagen. To be read from left to right. The downstroke representing inspiration. The lower tracing is a time record in seconds. At the vertical line the two vagi were "blocked" by freezing.

These discrepancies depend in part at least upon the species of animal used in the experiment, in part upon the depth of narcosis and upon other circumstances not ret fully understood. We shall soon see, howerer, that ther can be explained without great difticulty (cf. page 330 ).

This much, at all erents, is well established by the experiment of disconnecting the ragi by rendering them nonirritable, that the control exereised by those nerves is such as to induce respiratory acts of greater frequency and of less depth than otherwise. and that the inspiratory pause is thereby prevented. Since this inspiratory pause is not of the least service in the rentilation of the lungs, and the contraction of the muscles of inspiration maintaining it is therefore of no use whaterer, it is evident that even when the breath volume before and after disconnection of the ragi is the same, respiration afterwards is carried on with greater effort than normally. The result achieved by the vagus reflex, therefore, is that respiration takes place with less expenditure of energy.

The investigations of Hering and Breuer have yielded some rery valuable results as to the way in which that regulation is accomplished. Artificial inflation of the Iungs inhibits the inspiratory museles and induees an act of expiration; collapse of the lungs calls ont an act of inspiration. Self-regulation of the respiratory morements wonld thus seem to be afforded by the ragi -i.e., when the lungs have expanded to a certain extent inspiration is reflexly interrupted, and when they are afterwards emptied to a certain extent, expiration is interrupted and an act of inspiration is reflexly induced. Both phases of the regulation are lost when the vagi are sectioned. 
We may conceive, therefore, that the peripheral endings of the afferent pulmonary fibers of the vagi are excited by the variations in the volume of the lungs, and this is confirmed by the fact that if the ragus be eut on the one side and the lung on the other side be eaused to eollapse by puncture of the pleural carity, we get the same result as after section of both vagi (Loewy).

Any more preeise explanation of these facts is very difficult to give. It has been supposed that there are two kinds of fibers in the vagus, one of whieh serves to mediate an inspiratory effort, the other an expiratory effort. But it is also possible to suppose that there is but a single kind of fibers and that the effect produced depends upon the momentary eondition of the respiratory center. Thus, if the center already roused to inspiratory action were affected by a stimulus arriving over the vagus, it might be inhibited, and the result of stopping the inspiratory morements might be to inaugurate the relatively passive movements of expiration. Then after expiration proceeds to a certain stage, the collapsing lungs might send up a stimulus by the vagus and the inspiratory phase would be started because the respiratory center at that particular instant was in a condition to discharge suel an impulse. We have as a matter of fact some data which can be harmonized very well with this coneeption of the way in which the respiratory center works (ef. Chapter XXII). But there is still another explanation possible, namely, that the respiratory eenter eonstantly tends to discharge inspiratory impulses, but this tendency is inhibited by an impulse resulting from the inflation of the lungs; that after the lungs have collapsed to a certain extent, the inhibition is then removed and the tendency to inspiration once more asserts itself. This explanation is strongly supported by the observation made by Lewandowsky, that inflation of the lungs is accompanied by an action current in the vagus, but that eollapse is not.

Artificial stimulation of the central cut end of the vagus ought, one would think, to give a definite answer to this question as to the mode of action of the nerve. But it does not. For in the many experiments of this kind which have been made, both inspiratory and expiratory effects of stimulation have been observed, and the statements of authors differ so much that it is impossible as yet to draw any definite conelusion from them. Still less is it possible to decide from these experiments whether one or two kinds of nerve fibers are coneerned.

\section{B. FIBERS FROM ANTERIOR PARTS OF THE BRAIN TO THE MEDULLA}

We have already seen that the brain can be sectioned above the medulla without affecting respiration to any considerable extent. If, however. the vagi be sectioned in such an animal, or if the brain be sectioned above the medulla in an animal whose ragi have already been cut, noteworthy alterations of the respiratory movements ensue. Respiration is greatly diminished in frequency, since the inspiratory pauses are now rery much prolonged. Inspiration becones spasmodic, expiration begins rery suddenly and not infrequently is aided by contraction of the abdominal muscles. The expiratory pause is of short duration. being soon interrupted by a new, long-drawn inspiration. The breath volume is very much diminished and the animal dies for want of suffieient respiratory exchange in the lungs: (Marckwaldl). These phenomena may appear in varying degree, and it is even stated that the inspiratory spasms may be at times entirely wanting after this operation.

The respiratory center isolated from the higher parts of the brain mar therefore maintain respiration in an essentially normal fashion even after section 
of both ragi, although it is rery often unable to do so. At any rate, it appears from these facts that the paths coming from the brain are, under certain circumstances, of very great importance for respiration, and, what is more, that they act in the same way as the ragi nerves-i.e., to inhibit inspiration. Explanation of thesc phenomena is rendered more difficult because we cannot tell yet to what extent they depend upon the stimulus given at the time the section is made, and to what extent upon the mere disconnection of the pathways.

In view of the profound infuence of these brain pathways over the movements of respiration, it is not difficuit to understand why the severance of the vagi is not always accompanied by the same results; for the effect must depend largely upon the state of excitability of these brain paths at the time. For example, it is possible that the shortening of expiration and the tonic contraction of the inspiratory muscles mentioned by Gad (but not observed by others), was due to a stronger narcosis, on account of which the influence of the pathways in the brain was somewhat weaker than in the investigations of the other authors.

\section{OTHER RESPIRATORY REFLEXES}

The respiratory movements are influenced in one way or another by other afferent nerves. Among these the nerves of the respiratory passages are of the greatest interest, because through them certain reflexes are discharged which are of great service as a means of protection to the lungs.

The nasal openings and the mucous membrane of the nasal passages receive their sensory fibers from the trigeminal nere. Stimulation of this nerve retards respiration. When the mucous memlorane of the nose is stimulated at the external openings or on the anterior or posterior end of the middle and lower turlomated bones. or on the corresponding parts of the septum, retardation or expiratory standstill, or even sneezing, results, according to the strength and the kind of stimulus employed. Sneezing mar also be abortive -i.e. only the first phase of it, the deep inspiration, may occur. Expiratory standstill may also be induced by stimulation of the skin of the face under certain circumstances, as when an animal's head is submerged in water (J ratschmer).

Inasmuch as these reflexes prevent the entrance of foreign bodies or of noxious vapors into the wider respiratory passages, the afferent nerves of the larynx, particularly the superior laryngeal. serve to protect the deeper respiratory passages from foreign bodies. With feeble stimulation of the superior laryngeal slowing of respiration and prolongation of the expiratory pause are obtained: on this account the individual respirations become deeper and longer. With stronger stimulation one may obtain expiratory standstill or active expiratory morements. Inspiratory spasms can be stopped by stimulation of the superior laryngeal.

The coughing reflex is discharged principally by the same nerve. The statements of authors do not agree entirely as to the places in the larynx and trachea from which the reflex is produced.

The have the following statements concerning the effect of other afferent nerres. Stimulation of the olfactory by an actual odor either slows or quickens respiration or gives an expiratory pause. Stimulation of the optic by electricity or by light has an accelerating effect on inspiration. The auditory nerve has 
the same effect. After destruction of the semicircular canals respiration becomes slower and deeper. According to Marckwald, the glossopharyngeal produces respiratory staudstill in whicherer phase the respiratory center happens to be overtaken by the stimulus, but according to others it behaves just like the other cutaneous nerves. The last named have an inspiratory effect with weak stimulation, and an expiratory effect with strong stimulation. The phrenic also contains afferent fibers which appear to act like the cutaneous nerves, and other afferent muscular nerves behare on the whole like these. With regard to the sympathetic nerres it is stated that the splanehnic causes only an expiratory eontraction and that the cervical svmpathetic influences both phases of respiration. Finally, by stimulation of the heart and of the aorta, reflex respiratory movements and contractions in the air passages have been obtained.

\section{§4. NORMAL STIMULATION OF THE RESPIRATORY CENTER}

Seeing then that the respiratory center is reflexly influenced ly the most widely different afferent nerves. it would be natural to suppose that it is roused to action only in the reflex manner. But this conclusion is not warranted. The have already seen indeed that the respiratory center isolated from the brain patluas on a vagotomized animal is still rery powerfully active. This might be due partly to the stimulating effect of the section and partly to the afferent impulses still reaching the center. But respiratory morements continue when the cerebrum is extirpated, the ragi cut and the spinal cord sectioned below the exit of the respiratory nerres (Rosenthal). It can scarcely be assumed that the respiratory morements are called out by the few afferent impulses remaining after all these operations. Besides there are still other facts which tend to prove that the excitation of the respiratory center is attributable mainly to the properties of the blood.

The fœetus in the uterus does not breathe: respiration begins only after birth. What is the cause of the rery first act of respiration? The blood of the fotus is arterialized, so long as the placental circulation is maintained, at the expense of the mother's blood. The temperature of the amniotic fluid in which the fotus is submerged is exactly the same as that of the fotus itself, so that it is not subjected to any temperature stimuli nor to any other cutaneous stimuli. At birth the circumstances of life change suddenly : the placental circulation ceases and the skin is subjected to different sensory stimuli. The cause of the first act of respiration is to be sought therefore either in the cessation of the placental circulation or in the sensory stimulation of the skin.

Both these possibilities have their advocates. But from the present information it would seem that the discontinuance of the placental circulation is the real determining factor. It is true that one can produce various motor reflexes, and respiratory movements among them, by means of cutaneous stimuli applied while the placental cireulation is still continuous. But such responses are both infrequent and temporary in character. Besides, eutaneous stimulation may be kept up for a long time without erer a sign of a respiratory morement. Contrast with this the result of destroying the placental circulation. However the experiment be performed, whether by clamping or bleeding the umbilical cord, or, the nterus being undisturbed, by poisoning the mother with earbon dioxide or, finally, by bleeding the mother, respiratory movements of the fotus are always obtained. 
If then the first act of respiration be induced by some property of the blood, it follows with a high degree of probability that the respiratory center is roused to activity in the same way throughout life. This is confirmed also by a large number of experimental facts. Thus it has been shown that everything that tends to heighten the combustion in the body or to render more difficult the elimination of the gaseous products of decomposition or the absorption of oxygen, produces an augmented respiration. This condition of things is described as dyspnœa, if it involves the coöperation of the accessory muscles of respiration.

One might conceive that the products of combustion present in the blood in inereased quantity stimulate the end arborizations of the afferent nerves, and that the augmented respiration now under consideration is therefore reflex in nature. Even if this were true, experiment has shown in the clearest possible manner that, in muscular work, for example, the increased respiration is not due to this cause alone; for it appears when the hinder parts of the body, cut off from every possible nervous communication with the fore parts, are stimulated to active contractions, but is entirely wanting if the return flow of blood from the hinder parts is prevented. The blood returning from the posterior active parts has therefore a direct stimulating effect upon the respiratory center (Zuntz and Geppert).

Finally it has been shown that the respiratory movements react very delicately to any change in the carbon-dioxide content of the blood, since, the respiratory frequency remaining almost unchanged, the breath rolume of the individual respirations increases with an increasing quantity of $\mathrm{CO}_{2}$ in the inspired air (Miescher). On the other hand, considerable changes in the oxygen content of the surrounding air (12.5 to 60 volumes per cent) influence the respiration relatively little.

We conclude, therefore, that the respiratory center is excited by the direct effect of the blood or the lymph, but that its action is regulated by all kinds of afferent nerves, especially by the ragi and the brain pathways.

The condition of apnœa, or respiratory standstill, which is induced by excessive inflation of the lungs, or in man by one or more very deep inhalations, has often been regarded as a very important fact in support of the conception here presented. Apnoe might have its justification in the unusual opportunity which the blood has, in consequence of unusually ample ventilation, of becoming saturated with oxygen and of freeing itself of earbon dioxide, so that the next respiration would be less necessary. But the matter is not so simple. It has been made clear, for example, that in the rabbit apnca is much more difficult to obtain if the vagi are eut. These nerves must have something to do, therefore, with bringing about this condition. Mloreover, apncea appears as the result of inflation with hydrogen and can be induced by foreing the same air into the lungs over and over (Gad). Finally, it ceases only after the other organs have shown signs of asphyxiation. We may say, therefore, that apnœa depends at least in part upon an inhibitory action of the vagus upon the respiratory center. But the condition of the blood is not without its importance also, as the following experiment shows. Two dogs were operated upon in such a way that the carotid blood of the first was led into the head of the second. A condition of apncea was then induced in the second dog by artificial respiration applied to the first (Fredericq). We might distinguish this form of apnœa 
which is evoked mainly by a diminished quantity of $\mathrm{CO}_{2}$ in the blood as true apnœa, and that mediated by the vagus as false apnœa (Miescher).

In asphyxiation and severe hemorrhage we meet with inhibitory effects upon the respiratory mechanism which are of central origin. Both conditions agree in that the supply of oxygen to the organs of the central nerrous system and the $\mathrm{CO}_{3}$ removed from them are diminished. The consequence is, first a wellmarked dyspnœa, upon which follows, after a time, a period of apnœa of greater or less duration. This in its turn is interrupted by a series of new respiratory morements (gaspings). Closer analysis of the apnoea seen here shows that it probably owes its origin to the action of some inhibitory mechanism upon the respiratory center (Landergren).

In certain diseases, in chloral narcosis and certain other forms of poisoning, and with pressure upon the medulla, etc., a special form of respiration is observed, known after two English physicians as the Cheyne-Stokes respiration. It consists of a regular rise and fall in the depth of the respiratory acts. No positive explanation of the phenomena has yet been given.

We have spoken so far of the respiratory eenter as a whole. Closer inrestigation, however, reveals that here, just as in the meehanism of deghtition, we have to do with several functional centers bound together, the anatomical relations of which are at present unknown to us, but the indiriduality of which can be demonstrated by physiological experiments (Mosso).

It is a fact by this time familiar to us that expansion of the thorax ean be accomplished either by the diaphragm or by the rib-lifting museles. But experiment has shown that in the same indiridual these two groups of muscles do not always contribute toward the expansion of the thorax in the same ratio. This appears most plainly in sleep, when respiration in man is essentially of a costal type, whereas the diaphragm exhibits a certain paresis, in some persons behaving like an inert membrane. In deep distress just the opposite occurs: the diaphragm moves after the rib movements have ceased. These and other observations to the same effect bear witness that the centers for the rib-lifting muscles and for the diaphragm are to a certain extent independent. Again, the eenters which preside over the expiratory museles are independent; and finally, it has been shown that the respiratory movements of the mouth and nose, as a rule, begin before those of the thorax, which is evidence of the relative independence of the centers for those parts.

\section{THIRD SECTION}

\section{THE BLOOD GASES}

As long ago as the middle of the serenteenth century, Robert Boyle pumped a gas from the blood, and Mayow (16rt) claimed that this gas contained a substance ealled by him spiritus nitrocreus (oxygen). Likewise Priestley demonstrated the presence of oxygen in the blood, and H. Davy found carbon dioxide in it. These statements, howerer, were disputed by others and only after Magnus (1838) had demonstrated beyond a doubt the presence of oxygen. carbon dioxide and nitrogen in the blood, were the facts generally accepted. 
A very important advance in our knowledge of the blood gases was made by the introduction of the Torricelli vacuum for the purpose of extracting

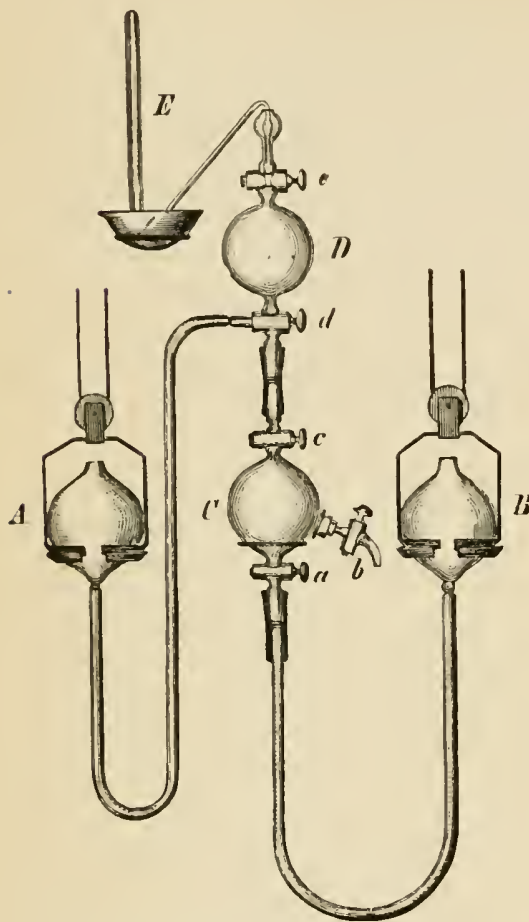

FIg. 130.-Schema of Ludwig's pump for extraction of the blood gases. The pump consists of two bulbs $C$ and $D$ connected by rubber tubing with the mercury bulbs $A$ and $B$. When the stopcocks $a, b, c, d$ are opened and the bulb $B$ is raised, the bulbs $C$ and $D$ are filled with mercury. Then if the stopcock $c$ is closed and the bulb $B$ lowered until the difference in level between $B$ and $C$ is greater than barometric pressure, a Torricelli vacuum is created in $C$. When $C$ is empty of mercury $a$ is closed. Then if a ressel containing blood, which has not been exposed to the air, but has been drawn directly from an artery or vein, is connected with $b$, the contained gases will bubble off into $C$. $B y$ suitable manipulations, which may be readily understood from the figure, the gases are transferred to $D$ and finally to the graduated burette $E$, where they are measured. mixture. For example: Water is in contact with air under a pressure of $760 \mathrm{~mm}$. Hg. Air consists of 21 vols. per cent of oxygen, and 79 vols. per cent Ludwig (1859), after Collard, de Martigny, and Hoppe-Seyler had tried it for other purposes. Sinee that time it has been improved in many ways by many different authors (Fig. 130).

\section{§ 1. ABSORPTION OF GASES IN LIQUIDS}

When a liquid stands in contact with a space filled with gas, the gas passes from the space into the liquid until the latter has taken up as much gas as the conditions will permit. We must distinguish elearly between two of these conditions.

A. The liquid exercises no chemical attraction upon the gas. In this case the amount of gas absorbed depends upon three factors: (1) the nature of the liquid and the gas, (2) the temperature, and (3) the pressure to which the gas is subjected. We may formulate the facts in the following law: The volume of a gas absorbed under different pressures by a given liquid, when reduced to the same pressure and temperature, is proportional to the pressures (Law of Henry).

The coefficient of absorption is the volume of the gas (reduced to $0^{\circ}$ and 760 $\mathrm{mm}$. $\mathrm{Hg}$.) which is absorbed by a unit volume of the liquid under a pressure of $760 \mathrm{~mm}$.

When several gases within the same space are brought in contact with a liquid, the absorption of each is quite independent of the others, and depends only upon that pressure which the gas itself exerts (Law of Dalton).

This partial pressure of each gas ean be calculated, if the total pressure exerted by the mixture and the composition of the mixture are known. It is always that percentage of the total pressure, represented by its volume percentage of the them. This method was first used by 
of nitrogen. The partial pressure of the oxygen therefore is $.21 \times 760=159.6$ $\mathrm{mm}$. $\mathrm{Hg}$., and that of nitrogen is $.79 \times 760=600.4 \mathrm{~mm}$. Hg. The absorption of oxygen into water takes place then under a pressure of 159.6 and that of nitrogen under a pressure of $600.4 \mathrm{~mm}$. $\mathrm{Hg}$.

$\mathrm{B}$. When the liquid exercises a chemical attraction for the gas, it is not only absorbed physically, but is combined chemically. We have, however, to distinguish two cases, according as the chemical combination does or does not depend upon the partial pressure of the gas. If it does not, the whole quantity of gas will be absorbed whatever the pressure. If it does, that is, if the combination between the liquid and the gas is a function of the gas pressure, the combination will gradually become less and less as the partial pressure diminishes, and with a partial pressure of zero will cease entirely on account of dissociation. In the latter case, therefore, just as when the absorption is purely physical, the quantity of gas entering a liquid is a function of the pressure, but with the important difference that there is here no direct proportion between the volume absorbed and the pressure.

When a liquid has stood for a long time in contact with a certain volume of mixed gases until it has become saturated with the different gases in the mixture, the tension of each gas in the liquid is equal to its partial pressure in the surrounding space. If the partial pressure of any one gas becomes less, the liquid gives off just enough of this gas to establish equilibrium once more, and vice versa.

In order to determine the tension of gases in a liquid, the liquid is placed under a definite pressure in contact with a mixture of gases previously analyzed, and, after a certain time, the mixture is again analyzed. The tension of any gas in the liquid is equal to the partial pressure of this gas in the surrounding space, if at the end of the experiment its partial pressure is the same as it was before. In order to hasten the equalization of tensions, the liquid can be shaken up with the mixture of gases, or may be allowed to flow through them in a fine stream.

\section{§ 2. THE BLOOD GASES}

\section{A. NITROGEN AND ARGON}

These gases are only absorbed physically in the blood. The coefficient of absorption for nitrogen at the temperature of the body is about 0.013-0.02 and the content of nitrogen and argon together is in the neighborhood of 2 vols. per cent; aceording to Regnard and Schloessing the blood contains some 0.04 vols. per cent of argon.

When the air pressure is very much increased, as in diving and in eaisson work, the quantity of nitrogen taken up by the blood must be considerable. If the pressure is removed rapidly, the nitrogen (the other gases of the blood in part also) passes suddenly over into the form of a gas and air emboli are formed in the vaseular system, which may cause more or less serious disorders or even death (Hoppe-Seyler, Bert). The gas collected from the heart in such cases consists of about eighty per cent nitrogen.

\section{B. OXYGEN}

After Inthar Meyer had demonstrated that the oxygen content of the blood presents but slight variations with diterent partial pressures, whence 
it is known to be chemically combined, Hoppe-Seyler showed that oxygen is found exclusively in the red blood corpuscles combined with the hrmoglobin.

Many investigations, some of them with hrmoglobin solutions, some with blood, were then made looking to a closer determination of the dependence of oxygen absorption upon its partial presiure. It was not to be expected a priori that the hæmoglobin solutions would conduct themselves in exactly the same way as the blood, for hæmoglobin does not occur in the blood corpuscles as such, but in combination probably with lecithin. It appears from these experiments that equal quantities of blood and hæmoglobin combine the same maximum quantities of oxygen, but at lower partial pressures the two behave very differently.

It is impossible to discuss here the facts bearing on the absorption of oxygen by hæmoglobin solutions of different concentrations and the theoretical conclusions appertaining thereto. I shall limit myself therefore to the summarized results obtained by Bohr with dog's blood, by Krogh with horse's blood (Fig. 131 ), and by Loewy with human blood, all at a temperature of $38^{\circ}$.

\section{Oxygen Absorption in Percentage of Saturation}

\begin{tabular}{c|c|c|c}
\hline $\begin{array}{c}\text { Partial Pressure of } \\
\text { Oxygen; mm. Hg. }\end{array}$ & $\begin{array}{c}\text { Dog's Blood } \\
\text { (Bohr). }\end{array}$ & $\begin{array}{c}\text { Horse's Blood } \\
\text { (Krogh). }\end{array}$ & $\begin{array}{c}\text { Human Blood } \\
\text { (Loewy). }\end{array}$ \\
\cline { 1 - 2 } 10 & 33 & 24 & 36 \\
20 & 67 & 68 & 53 \\
30 & 81 & 82 & 67 \\
40 & 9 & 91 & 75 \\
50 & 93 & 95 & 81 \\
80 & 97 & 98 & $\cdots$ \\
\hline
\end{tabular}

Oxygen in small quantities is present also in the plasma. If all the oxygen were to be removed from the plasma at once, dissociation of the oxyhæmoglobin would of course take place immediately, and continue until equilibrium was once more established between the oxygen tension in the plasma and in the blood corpuscles. The coefficient of absorption of oxygen in the blood at body temperature is approximately 0.025 .

Since the partial pressure of oxygen in the atmospheric air may be estimated at about $160 \mathrm{~mm}$. Hg. and in the alreoli. as we shall see later. at 120-130 mm. Hg., it follows that under normal circumstances the blood can be saturated with oxygen up to ninety-eight per cent at least (Fig. 131). At a partial pressure of $50 \mathrm{~mm}$. Hg. the absorption of oxygen in man falls to nineteen per cent of saturation, and in the dog to seven per cent. On the other hand, the absorption is not noticeably greater in an atmosphere of pure oxygen.

These conclusions are confirmed by observations on respiration under different oxygen pressures. So far as absorption of oxygen is concerned, respiration runs a perfectly even course when the partial pressure of oxygen is raised from twenty-one to sixty, serenty-five, and ninety per cent. There is an increase in the absorption only during the first three minutes of respiration in air rich in oxygen, and this is due to the physical effect of a higher 
partial pressure in the alveoli. A storage of oxygen in the tissues does not take piace under such circumstances (Falloise. Durig).

Neither does the absorption of oxygen suffer any change in consequence of a fall in the partial pressure to $86 \mathrm{~mm}$. or lower. Only when the atmospheric pressure sinks to $380 \mathrm{~mm}$. (partial pressure of oxygen. $80 \mathrm{~mm}$.) does a decline in the oxygen content of the blood become evident; at a partial pressure of $55 \mathrm{~mm}$. the decline is marked (Loewy).

The absorption of oxygen becomes less as the carbon-dioxide tension in the blood increases. At an oxygen tension of $50 \mathrm{~mm}$. Hg. and a carbon-dioxide tension of $5 \mathrm{~mm}$., the absorption of oxygen was ninety-three per cent; with the

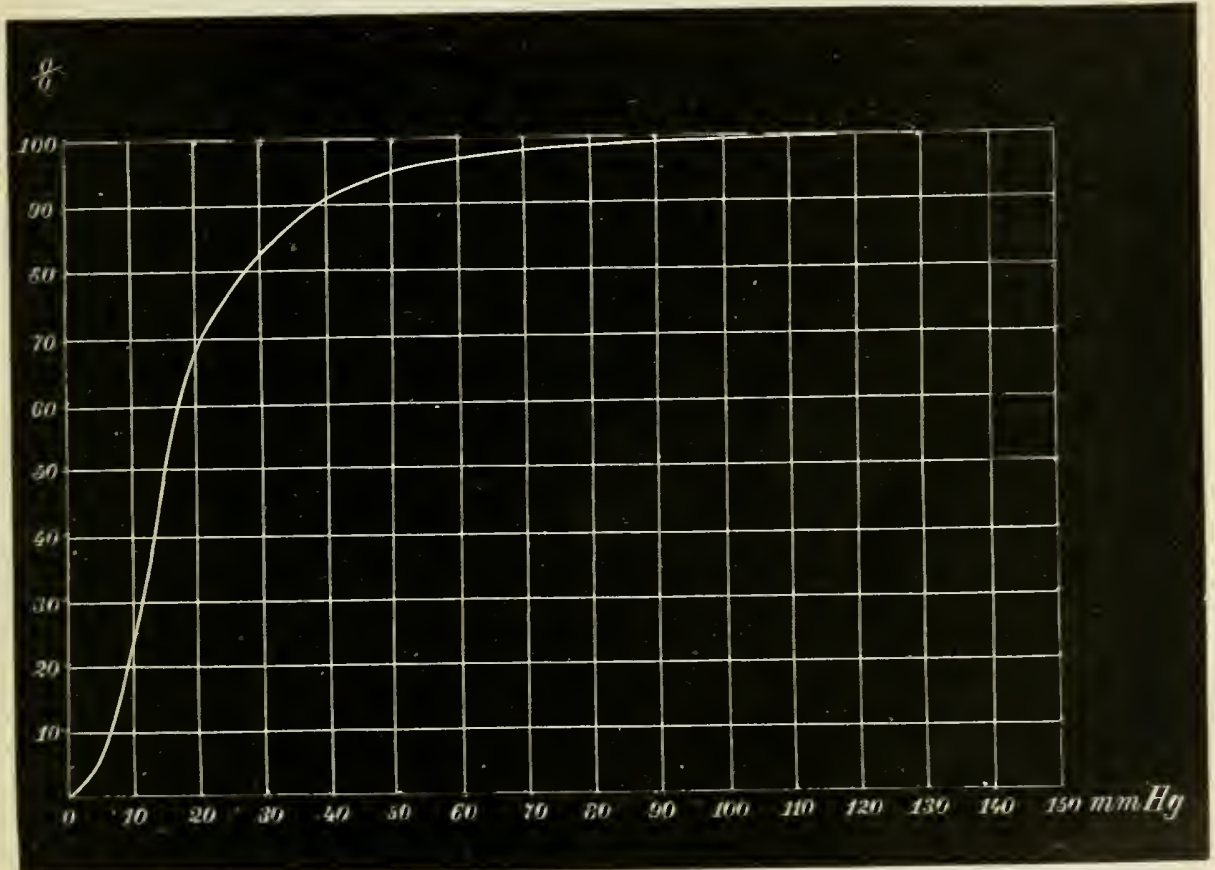

Fig. 131. - The absorption of oxygen by horse's blood, after Krogh. The abscissæ represent the partial pressures of oxygen and the ordinates percentages of saturation.

same oxygen tension and a carbon-dioxide tension of $40 \mathrm{~mm}$. it was seventycight per cent. As the blood flows through the capillaries the oxygen is gradually used up and at the same time the carbon-dioxide tension increases; the latter has the effect of conferring a greater tension on the oxygen present, as a consequence of which a larger quantity of oxygen can be placed at the disposal of the tissues. The influence of this factor is especially great in asphyxiation (Bohr, Hasselbach and Krogh).

\section{CARBON DIOXIDE}

Where carbon dioxide occurs in the blood and how it is combined are much more complicated questions than in the case of oxyen, and notwithstanding many investigations directed to this end, the matter is not to be 
considered as by any means settled. The difficulty lies just here, that whereas oxygen is evidently present only in hemoglobin, carbon dioxide is unitcd with several different substances.

The researehes of Paul Bert, Zuntz, Setchenow, and others have made it perfeetly evident that carbon dioxide is present for the most part in dissociable compounds, the existence of which depends upon the prevailing partial pressure of $\mathrm{CO}_{2}$. In accorlance with what was said regarding the combination of oxygen with hæmoglobin, it is evident also that a certain quantity of free $\mathrm{CO}_{2}$ in the blond must be present in physieal eombination (cf. page 336). The eoefficient of absorption of carbon dioxide in water at $37^{\circ}$ is 0.569 . The dissociable compounds are found both in the plasma and in the corpuscles.

Of the substances in the blood with which carbon dioxide can be combined, sodium biearlonate $\mathrm{NaHCO}_{3}$ is likely to be thought of first. The phenomena of dissociation in solutions of this salt show however that it cannot play any great part in this connection; for aceording to Bohr a 0.15 -per-eent solution of sodium bicarbonate under a pressure of $0.6 \mathrm{~mm}$. Hg. takes up eighty per cent of the total quantity of carbon dioxide which can be taken up under a pressure of $120 \mathrm{~mm}$., and at a pressure of only $10 \mathrm{~mm}$. it is almost completely saturated.

Again great importance has been ascribed to the phosphates in the combination of $\mathrm{CO}_{2}$, since it was supposed from analyses of the blood that the plasma contained large quantities of these salts. But it has been shown that the phosphorus found in the ash is primarily a constituent of lecithin and nucleoalbumin, and occurs only in traces as $\mathrm{Na}_{2} \mathrm{IPOO}_{4}$.

The globulin-alkali compounds, on the other hand, appear to be of far greater importance for the combination of $\mathrm{CO}_{2}$ in the blood. The globulins play the part of weak acids and enter into saltlike combinations with the alkalies of the blood. They can be replaced from these compounds by carbon dioxide and can themselves in turn replace the carbon dioxide.

The significance of this fact will be more apparent from the following:

If two acids of different avidity represented respectively by $a$ and $b$ be present in a solution of a basic substanee, they divide the basic substanee between them in the ratio of $a / b$. Under the influence of equal mass equivalents of the two acids and of the base, $\frac{a}{a+b}$ equivalents of the one aeid, and $\frac{b}{a+b}$ of the other will unite with the base. But if the substances are not present in equal mass, the distribution of the base between the two acids will depend upon the relative masses of the two, so that the acid present in the greater quantity relatively, even if its avidity is weaker, will get the greater quantity of the base.

Applied to the problem before us, this would mean that, if the mass of carbon dioxide, or more properly its tension in the plasma, is high, the globulin will be forced out of its alkali compound. If, however, the blond comes into such relations that the carbon dioxide tension falls, the globulins again succced to their rights and the earbon dioxide leaves the alkali ('Torup).

As already observed, carlon dioxide occurs also in the blood corpuscles in the form of dissociable compounds. It is very probable that the globulinalkali compounds of the blood corpuscles act in the same way as those of the 
serum. It should be added, however, that the curve of $\mathrm{CO}_{2}$ absorption for the corpuscles exhibits a much greater dependence upon the partial pressure of $\mathrm{CO}_{2}$ than that for the serum (Bohr). The constituent most actively concerned here again is the hæmoglobin (Fig. 132).

Hamoglobin therefore can combine carbon dioxide as well as oxygen. We are not yet elear just how this takes place. Bohr has shown that the absorption of carbon dioxide by hæmoglohin free of alkalies is influenced little

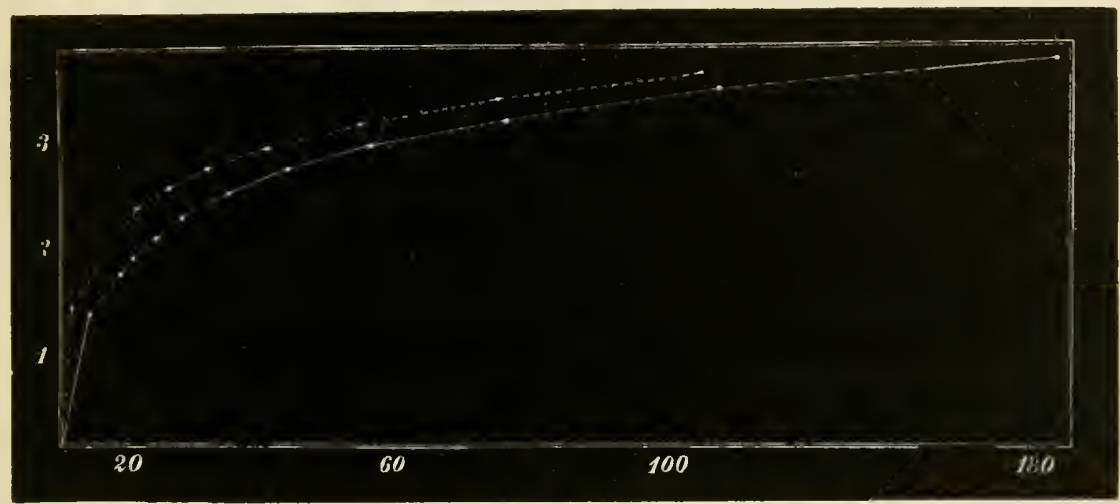

FIG. 132. - The absorption of carbon dioxide in a solution of hæmoglobin, after Bohr, - ..... 1.76 per cent solution; _- 3.8 per cent solution. The abscissa represent the pressure to which the gas was subjected, the ordinates the amount of carbon dioxide in c.c. absorbed by $1 \mathrm{~g}$. of hremoglobin.

or not at all by oxygen. For this reason he assumes that the two gases are combined with different parts of the hæmoglobin molecule- the oxygen with the pigment nucleus, and the earbon dioxide with the proteid eomponent.

\section{THE QUANTITY OF BLOOD GASES}

The content of gases is very different in arterial and renous blond. Analyses of the gases in dog's blood, carried out under the direction of Ludwig and P'flïger, give us, according to the summary of Kuntz, the following average pereentages: arterial blood, 18.3 vols. per eent oxygen and 38.3 vols. per cent carton dioxide. By very rapid extraction of the gases Pflitger obtained for arterial blood $2 \% .6$ vols. per cent oxygen and 34.3 vols. per cent carbon dioxide. Merely by standing, therefore, the blood uses up oxygen and forms carbon dioxide. From arterial human blood Setehenow obtained 21.6 vols. per cent oxygen and 40.3 rols. per cent carbon dioxide. The pereentage of oxygen and earbon dioxide in arterial blood moreover exhibits considerable variations.

The entent of gases in venous blood depends naturally upon the velocity of blood flow and upon the activity of metabolism. That the blood gases exhibit great variations in the different vascular regions, according as the organs are more or less active, is quite beyoud question. But at present we have analyses of only the mixed hlood from the right heart and from the central veins. These give $n s$, according to the summary of Zuntz, as compared with 
arterial blood, a mean inerease of 9.2 rols. per cent carbon dinxide, and a deficit of 8.15 rols. per cent oxygen, or, after correcting for the venous stasis caused by the eatlieter, $+8.2 \mathrm{CO}_{2}$ and -7.15 vols. per cent $\mathrm{O}_{2}$ respectively.

\section{E. THE DISTRIBUTION OF THE BLOOD GASES BETWEEN CORPUSCLES AND PLASMA}

The distribution of the blood gases between corpuseles and plasma has been studied by Frederieq on the renous blood of the horse, and in this case only the carbon dioxide was determined; $\gamma 1.4$ rols. per cent were found in the plasma, 49.6 rols. per cent in the corpuseles.

All other determinations along this line relate to defibrinated blood. The following noteworthy facts have been reeorded. Only traces of oxygen $(0.1-0.2$ vols. per cent) occur in the sermm; almost the entire quantity belongs to the blood corpuscles. We have already remarked that these traces ean never be entirely absent from the serum so long as the blood corpuscles crintain oxygen at all.

The serum, on the other hand, contains most of the carbon dioxide. According to the investigations of Fredericq, Zuntz, and A. Schmidt, the carbon dioxide of the serum amounts to about eighty-six per cent of the total quantity in the blood. Howerer, it is not impossible that by changes taking place in the process of defibrination carbon dioxide might wander from the scrmm to the blood corpuseles or from these to the serum. The observations of Hamburger indicate that in changing the quantity of gases in the blood. substances pass from the serum to the corpuscles and vice versa, and it is possible that such migrations might occur in coagulation, as the result of which the earbon dioxide carriers of the blood would probably become differently distributed between the corpuseles and the serum.

When the whole blood is exposed to a vacuum, the entire quantity of carbon dioxide escapes. Not so with the serum: it loses in a vacumm only a part of its carbon dioxide, while a part can be driven out only by the addition of acids. According to Pflïger, the carbon dioxide firmly combined in the serum amounts to fire to nine rols. per cent. Since this portion firmly combined is expelled in the presence of the blood corpuscles without the addition of acids, there must be present in the corpuscles eertain constituents which act as an acid.

\section{FOURTH SECTION}

\section{THE RESPIRATORY EXCHANGE OF GASES}

\section{§ 1. MECHANISM OF EXCHANGE BETWEEN BLOOD AND ALVEOLAR AIR}

Knowing that the carbon dioxide exists in the blood in the form of a dissociable compound independent of the partial pressure, it is reasonable to suppose that the transfer of carbon dioxide from the blond to the alveoli of the lungs takes place by the equalization of the existing difference in tension. 
It is likewise to be assumed that the absorption of oxygen into the blood is the result of a difference in oxygen tension between alveolar air and venons blood.

The method of determining the tension of a gas in a liquid has been given above (page 335). For the measurement of gas tension in the blood, Pflüger let the blood flow in a fine jet directly from the open vessel through a tube charged with a mixture of gases of known composition, and afterwards analyzed the gas. By this method the blood is but a short time in exchange with the mixture of gases, and on this account a complete equalization of tension differences is not insured.

For the purpose of obtaining pure alveolar air for analysis, Pflüger constructed a special instrument, the lung catheter (Fig. 133). This consists of two tubes, one inclosed within the other. The outer tube, made of hard rubber, communicates with a soft rubber bulb (a), the thin-walled end of which can be inflated by means of the air pump (b) after it is introduced into the bronchus, so as to close hermetically the bronchial opening. The inner tube $(d)$, an ordinary elastic catheter, places the confined lung space in comection with a suitable

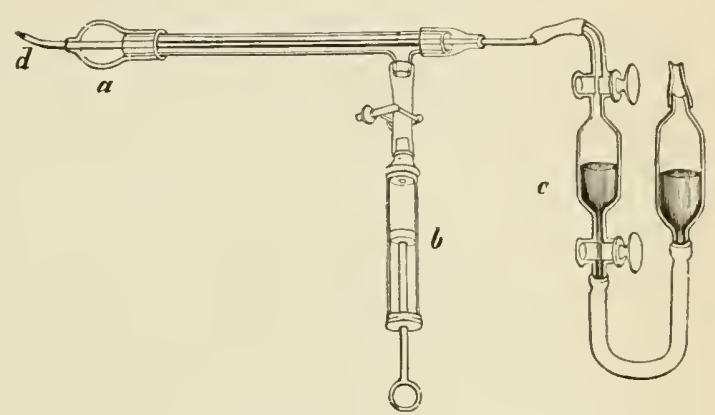

FIG. 133.-The lung catheter, Ludwig's construction. tube $(c)$ filled with mercury. After the air has been confined for the desired length of time, it can be drawn into this tube $c$ by allowing the merenry to run out.

From determinations carried out by this method, chiefly in Pfliiger's laboratory, the tension of earbon dioxide in the arterial blood has been found to be 2.8 atmospheres. and in the renous blood 3.8 to 5.4 atmospheres; that of oxygen in the arterial blood at most fifteen per cent of one atmosphere. Since the partial pressure of carlon dioxide in the alveolar air proved to be less, and that of oxygen greater, than the tensions of these gases in the arterial blood, evidence was found for the conception that the respiratory exchange takes place by a simple equalization of tensions.

Bolir has entered the lists decidedly opposed to this view. By a special method he determined the tension of the gases in flowing blood, and analyzed the expired air at the same time. He found that the tension of carbon dioxide in the arterial blood may be lower than the partial pressure of earbon dioxide in the air which passes the bifureation of the trachea; also that the tension of oxygen in the arterial blood may be greater than the partial pressure of oxygen in the same air. Other factors than the tension differences therefore must lie coneerned in the respiratory exchange. Bohr lays special stress upon the activity of the alveolar wall, which is said to secrete carbon dioxide and actively absorb oxrgen.

In general it may be assumed that the total amount of earbon dioxide given off in the lungs comes to the lesser circulation from the veins of the greater circulation. However, the opinion was long ago expressed by Lavoisier in his 
studies on the respiration, that carbon dioxide is formed in the lungs; and recently Bohr and Henrique have published experiments which purport to show that a considerable part (two to sixty-six per cent) of the earbon dioxide given off is formed there. If these results should be confirmed, it would be neeessary to suppose that in the combustions going on in the body in addition to carbon dioxide, a number of intermediary products of decomposition are formed, given off to the blood. and there further oxidized (ef. page 339); also, possibly, that some final oxidation takes place in the lungs.

\section{§ 2. EXCHANGE OF GASES BETWEEN BLOOD AND LYMPH}

During its passage through the capillaries the blood gives off oxygen to the tissues and receives earbon dioxide from them. We know very little at present about the manner of this exchange in the tissues. But. since the tension of oxygen in the tissues is extremely small, while according to Strasburg the tension of carbon dioxide there exceeds that of the venous blood $\left(\mathrm{CO}_{2}\right.$ tension in venous blood $42 \mathrm{~mm}$. IIg.. in the intestine 59 , in the bile 51 , in acid urine $6 \%$ ), the exchange might be looked upon as a simple matter of equalizing the tension. In view of the facts with which we have just become aequainted under respiratory exchange in the lungs, and since the consumption of oxygen (ef. page $2 i$ ) does not depend upon the oxygen tension but upon the activity of the tissues, it is possible that the vital activity of the vascular wall should exercise some influence-but we have no positive information on this at present.

\section{§3. CHANGES PRODUCED IN THE RESPIRED AIR}

The excretory products eliminated in the breath are carbon dioxide, water vapor and possibly some other gaseous substances as yet imperfectly known.

Inspired air contains in round numbers twenty-one vols. per cent oxygen and seventy-nine vols. per cent nitrogen, if we disregard argon, ete. To these are to be added some carbon dioxide, which amounts to only 0.03 per cent in atmospheric air, but sometimes to considerably more in room air, and water rapor, the quantity of which varies within wide limits.

The expired air is saturated with water vapor, which for the most part has its source in the respiratory passages (ef. page 323). To what extent this water vapor represents a product of metabolism eannot yet be decided.

In different animals and in different individuals, as well as in the same individual under different circumstances, the amount of carbon dioxide in the expired air exhibits wide variations according to the depth and frequency of the respiratory movements, etc. The figure generally given for the normal pereentage of $\mathrm{CO}_{2}$ in the expired air of man is 4.1 vols. per cent (Vierordt). With quicker and deeper respirations the lungs are better ventilated and the amount of $\mathrm{CO}_{2}$ sinks to about 2.5-2.78 vols. per cent. Along with this the quantity of $\mathrm{CO}_{2}$ given off per minute becomes greater, which in itself however serves only as an expression of the improved ventilation and signifies nothing concerning the way in which the formation and elimination of $\mathrm{CO}_{2}$ 
are influenced by the altered frequency and extent of the respiratory morements. As far as this latter question is concerned, numerous observations teach us that augmented respiration increases the absolute output of $\mathrm{CO}_{2}-$ not in consequence of the greater exchange of air, but on account of the increased work of the respiratory museles.

The percentage of oxygen in the expired air is of course less than that of the inspired air, and in fact it decreases more as a rule than the pereentage of $\mathrm{CO}_{2}$ increases. When carbon burns in oxygen, the volume of the gas does not ehange. Sinee in respiration, however, the amount of oxygen which has disappeared is greater than that of the carbon dioxide formed, it follows that the oxygen is used in the body for other oxidations than that of earbon. The ratio between carbon dioxide formed and oxygen used $\frac{\mathrm{CO}_{2}}{\mathrm{O}_{2}}$ is called the respiratory quotient.

The value of the respiratory quotient is very different under different cireumstances, and depends upon the kind of foodstuffs which at the time are

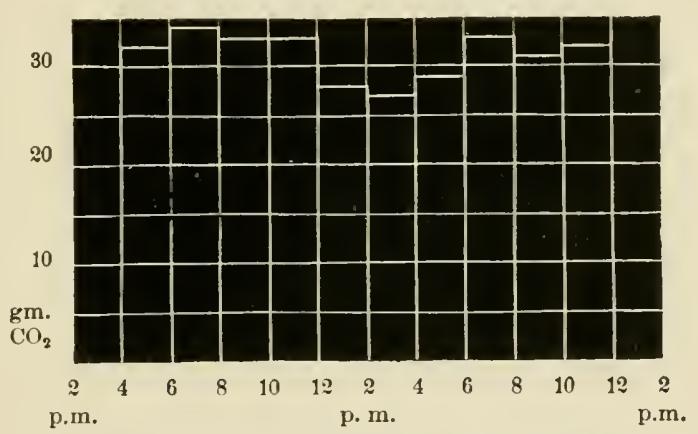

FIG. 134.-The amount of carbon dioxide measured in two-hour periods, expired by a woman who slept during the entire time, and who for five days previously had eaten scarcely anything.

being burned in the body. The carbohydrates contain in their molecule just as much oxygen as is necessary to completely utilize their hydrogen. The total quantity of the inspired oxygen therefore ean be used for the oxidation of their carbon. Hence, if carbohydrates exclusively are being burned, the value of the respiratory quotient will be 1 .

Fat and proteid require more oxygen than carbohydrates for their complete oxidation because the oxygen contained in their molecule is not sufficient for the complete saturation of their hydrogen. Consequently when these substances are being burned the respiratory quotient will be less than 1 -for fats 0.71 and for proteid 0.78 . (Fat contains on the average 76.5 per cent $\mathrm{C}$, 12 per cent H, 11.5 per cent 0 ; proteid (dry muscle) 50.5 per cent $\mathrm{C}$, .6 per cent $\mathrm{H}, 15.4$ per cent $\mathrm{N}$ and 20.97 per cent $\mathrm{O}$, of which 11.3 per cent $\mathrm{C}$, 2.8 per eent $H, 15.4$ per cent $\mathrm{N}$, and 11.44 per cent $\mathrm{O}$ are eliminated in the urine and freces, leaving 39.2 per cent $C, 4.8$ per cent $H$, and 9.53 per cent $O$ to be eliminated in the breath.) Since it only rarely happens that carbohydrates alone are burned in the body, the respiratory quotient as a rule is 
less than 1, and with ordinary food may be estimated at about 0.8 . When fat is being formed from carbohydrates and being stored the respiratory quotient may exceed 1.

Reduced to dryness and to $0^{\circ}$ the expired air, therefore, has a smaller

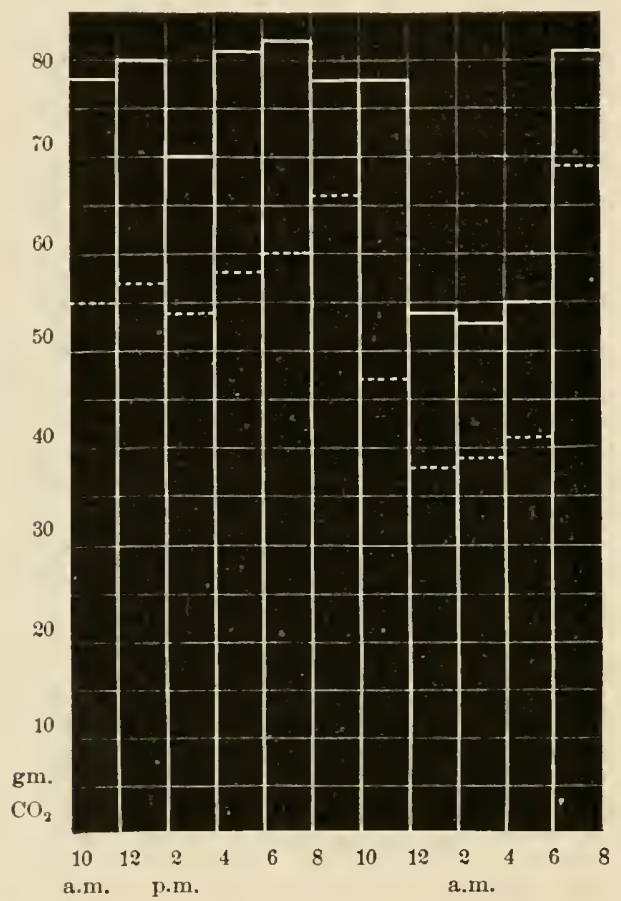

FIg. 135.-The elimination of carbon dioxide: ___ on ordinary diet (mean for three days); and ......... while fasting (mean for five days). All the determinations were made on the same individual, a man twenty-five years old. On the food days he slept between 12 o'clock midnight and 6 A.m. On the fasting days he slept between 10 P.M. and 6 A.M.

volume than the inspired air. Measured direetly its rolume is greater because of its water rapor and higher temperature.

For example, let us sappose that the inspired air (500 e.e.) has a temperature of $20^{\circ} \mathrm{C}$., and that it is saturated with water vapor at this temperature (tension $17.4 \mathrm{~mm}$. Hg.). Expired air, we will suppose, has a temperature of $37.5^{\circ} \mathrm{C}$., is saturated with water vapor (tension at this temperature $47 \mathrm{~mm}$. $\mathrm{IIg}$.) has lost 4.783 per cent oxygen and has gained 4.380 per cent carbon dioxide. Measured directly then the expired air would have a rolume of 554.89 c.e.-i. e., approximately one-ninth greater than inspired air. The difference would evidently be greater the eolder the inspired air (J. R. Ewald).

During recent years the question whether the expired air contains poisonous gaseous constituents has been very actively discussed. Brown-Séquard 
and D'Arsonval on the basis of numerous experiments had answered the question in the affirmative. Their statements were put to the test by several other authors, but by most of them without results. Formánek, however, proved by exact methods that the poisonous effects observed by the abovenamed authors on confined animals came in fact only from ammonia set free from the solid and fluid excretions of the animal employed.

Since the carbon dioxide in the air may rise to four or five per cent and higher without cxercising any harmful effects, we may conclude that the indisposition which results from long confinement in badly ventilated or overcrowded rooms is due, not to the influence of any poisonous constituents of the expired air, but to other circumstances-e. g.. higher temperature, higher humidity, gaseous substances coming from the intestine or from an unclean skin, etc. It is assumed of course that the ventilation is not so bad that carbon dioxide accumulates in too large quantities.

\section{§ 4. THE ABSOLUTE AMOUNT OF RESPIRATORY EXCHANGE}

In the section on the nutrition of man (page 13\%) will be found fuller information bearing on this subject. Here we must limit the discussion to

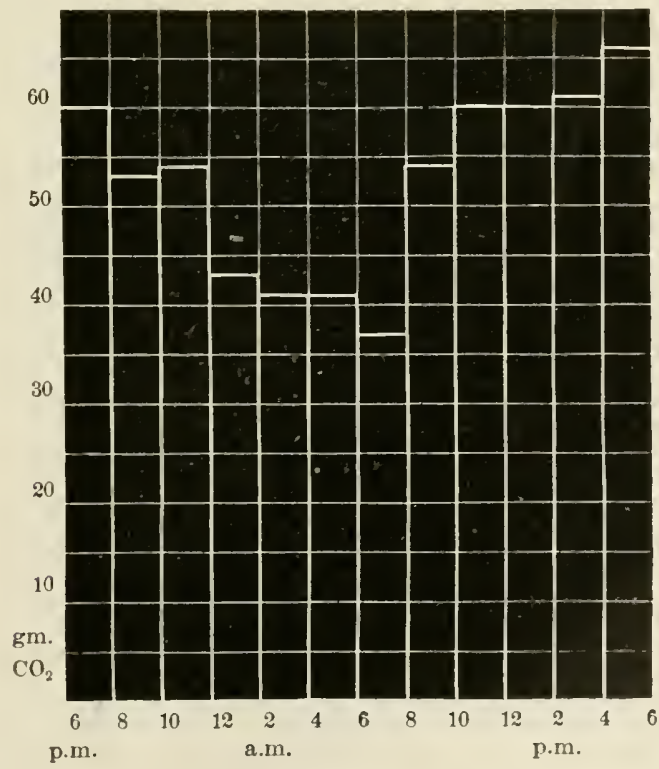

FIG. 136. - The elimination of carbon dioxide, in two-hour periods, by an eleven-year-old boy. He slept between 10:30 P.M. and 8 A.M.

some facts concerning the variations in the normal output of carbon dioxide (Figs. 134, 135, and 136) estimated for two-hour periods.

In view of the many circumstances which affect the amount of metabolism and therefore the output of $\mathrm{CO}_{2}$. it is impossible to specify in a few figures 
the quantities exereted daily. In a man not at work it can be estimated on the basis of direct observations for twenty-four-hour periods at $0.5 \mathrm{~g}$. per hour per kilogram of body weight, which for a person of the average weight of $70 \mathrm{~kg}$. would amount to $35 \mathrm{~g}$. per hour and $840 \mathrm{~g}$., or $427 \mathrm{l}$. per twenty-four hours. At heavy physical labor the hourly output of $\mathrm{CO}_{2}$ may rise to $169 \mathrm{~g}$. and higher; in complete bodily rest it falls to about $20 \mathrm{~g}$. per hour (Fig. 134).

The intake of oxygen, like the output of carbon dioxide depends upon the food, work, temperature, age, ete. With a respiratory quotient of 0.80 the oxygen consumption corresponding to a carbon dioxide output of $42 \% \mathrm{l}$. per day would be 534 l., or $764 \mathrm{~g}$. Aceording to the indireet determinations of Pettenkofer and Voit, in the grown man fasting and at rest it amounts to \%40-780 g., fasting and at work $1.070 \mathrm{~g}$., on a moderate diet and at rest 700-900 g., on a moderate diet and at work 1,000 g., ete. By direet determinations with the respiration apparatus of Hoppe-Seyler the oxygen absorption in a grown man on a mixed diet and not at work amounted to $559-586 \mathrm{~g}$. per twenty-four hours (Laves). In experiments of shorter duration MagnusLevy found the oxygen absorption in a fasting individual at eomplete rest to be $1 \% .5-19 \mathrm{~g}$. per hour, which corresponds to a daily absorption of 428 to $456 \mathrm{~g}$. 


\section{CIIPTER X}

THE LYMPH AND ITS MOVEMENTS

The lymph or "tissue fluid" is the medium in which the cells of the body live. In part it is imbibed into the living substance itself, and in part is collected in otherwise empty spaces about and between the cells. The entire body is permeated throughout with such spaces which are of the greatest variety of forms: clefts, minute canals, sheaths, sacs, etc.. and exhibit the greatest possible difference in size. Some, such as the so-called serous sacs, like the peritoneum, the pleura, the pericardium, the serous sacs surrounding the organs of the central nervous system, etc., are enormously large, while others can only be detected with high magnification. All these fluid-filled spaces, of whatever kind, communicate ${ }^{1}$ with the lymph ressels, and through them with the blood system.

The lymph comes from the blood and is conveyed again by the lymph ressels to the blood. Besides, certain constituents of the lymph are taken up directly into the blood vessels throngh the permeable walls of the capillaries.

From the blood the lymph receives all the substances neecssary for the life of the cells; from the cells it receires the products formed in their own life processes, both those which arise as a result of the dissimilatory activities and those which are formed by synthetic processes in one organ or another for use in still other organs. It follows that the lymph in the different nrgans must be of different composition, since on the one hand the requirements of the different organs are different both qualitatively and quantitatirely, and on the other the products of assimilation and dissimilation are different.

However, we have at present no complete analyses of the lymph in the different organs, nor of the lymph flowing from the different organs; our knowledge is limited almost entirely to the composition of the mixed lymph to be obtained from the thoracic duct.

\section{§ 1. THE CHEMICAL PROPERTIES OF THE LYMPH}

The lymph, as one of the discoverers of the lymph system (Olaus Rudheck, 1673) remarked, is a water-clear liquid of salty taste, which coagulates spontaneously. Our knowledge is at this time but little more extensive.

The lymph contains seattered leucocytes. Its chemical composition agrees qualitatively with that of the blood plasma but quantitatively differs from it

${ }^{1}$ According to the recent researches of McCallum and Sabin, the lymph vessels are closed tubes like the capillaries. If so, we must think of the tissue-spaces and serous cavities as separated by thin walls from the real lymph channels.-Ev. 
chiefly in that the lymph is poorer in proteid. In comparison with the total proteid of the plasma, the lymph is said to contain less globulin.

In the dog's lymph Hammersten found almost no oxygen, but found thirty-seren to fifty-three vols. per cent of carbon dioxide. It is stated that the carbon dioxide tension in the lymph is greater than in the arterial blood. but less than in the renous blood.

According to analyses at present available. the lymph of man contains: 93.5-95.9 per cent water. $4.2-6.4$ per cent solids, $0.01-0.05$ per cent fibrin, $3.5-4.3$ per cent proteid, $0.7-0.8$ per cent ash, $0.1-0.9$ per cent fat, cholesterin and lecithin.

There are found in lymph also substances which have a marked influence on certain parts of the central nervous system. If lymph from the cervical lymph trunks of the dog be injected into the internal earotid of the same animal, changes in the eirculation are noted. Certain nervous mechanisms are stimulated, others are paralyzed, and the form of the blood-pressure curve is altered. Similar injections of blood have no such effect (Asher and Barbèra). The chemical nature of these substances is not ret perfectly known, but in all probability they are products of combustion in the organs.

The quantity of lymph, inclusive of the chyle, which flows through the thoracic duct into the blood stream in twenty-four honrs may be estimated for man at one to two liters. In riew of the passage of certain constituents into the blood by way of the capillaries. an exact determination of the quantity of fluid flowing through the thoracic duct possesses no great interest.

\section{§ 2. MOVEMENTS OF THE LYMPH}

To determine the flow of lymph quantitatively, a fistula is made in the thoracic duct or in one of the larger lymphatics. The quantity which flows from the thoracic duct immediately after the operation is fairly large owing to the stoppage incident to tying-in the cannula. but it declines rapidly. In the further course of an experiment of this kind the quantity may either remain constant for a time. or may continue to fall; the latter appears to be the rule.

No lymph at all is to be obtained from the main lymph ressel of an extremity, unless its flow is aided by actire or passire morements of the part. From this we may conclude that by far the greater part of the lymph flowing from the thoracic duct, when the animal is perfectly quiet, comes from the riscera.

The lymph ressels are always full; the pressure of lymph in the cerrical trunk of the dog and horse is from 10 to $20 \mathrm{~mm}$. soda solution. The velocity of lymph flow is much less than the relocity of blood flow in ressels of similar size.

Among the forces which maintain the flow of lymph, the tension which is exerted by the elasticity of the tissues should be ranked first; every increase of tissue fluid must naturally heighten this tension and thus accelerate the flow of lymph. 'The morements of the individual parts of the body whether they be passire or actire, occasion elerations of pressure on the lymph spaces 
and lymph ressels, which act in the same way as the tension of the tissues to faror the flow. Besides, throughout such passive tissues as tendons and fascia stresses occur, in some cases regularly and rhythmically as the result of voluntary movements, but more often quite accidentally, which favor the movements of the lymph.

In certain animals (rats and guinea pigs), the walls of the lymph ressels execute rhythmical contractions, and in the Amphibia the flow of lymph is aided materially by the so-called lymph hearts-small contractile structures situated on both sides of the coccyx and beneath the scapula. The lymph is forced by their contractions into the iliac and jugular veins respectirels.

The liquid flowing from the villi of the intestine through the lacteals is forced along by contraction of the smooth muscle fibers of the villi. Finally, the suction of the thorax must be taken into account, inasmuch as it affects the flow of the lymph just as it does the flow of blood in the central reins. It is criclent at once that the ralves of the lymph vessels are of great importance for all of the above-named factors.

The smooth muscles of the receptaculum chyli and of the thoracic duct at least are under the influence of the central nerrous system. The left splanchnic contains dilating fibers, and, though in smaller numbers, constrictors also, for the receptaculum. The motor nerves for the thoracic duct are in the thoracic sympathetic. Here also the dilator fibers are superior to the constrictors in their control over the wall of the duct. The dilating nerves can be excited reflexly by various afferent nerves (Gley and Camus).

\section{§3. THE FORMATION OF LYMPH}

Since the blood pressure in the capillaries is higher than the tension of lymph in the surrounding tissues, it was for a long time supposed that the lymph is pressed out of the capillaries by this difference in pressure (filtration), and that the osmotic processes betreen the blood and lymph exercise a more ol less considerable influence on both the quantity and composition of the latter.

The most important experimental support of this riew was the easily confirmed fact that the lymph streams become swollen considerably after tying off a vein, as a consequence of which the pressure in the capillaries is increased (renous hyperæmia). On the other hand it was shown that an increase in capillary pressure produced by dilatation of an artery (arterial hyperæula) often does not increase the formation of lymph in the least.

If the cerrical and brachial nerres of an animal be cut so that the ressels of the arm are removed from the influence of the nervous srstem, and the cervical spinal cord be tlien stimulated, the blood ressels all orer the bods, with the exception only of the arm, contract, wherefore the blood flow to the arm, and consequently the blood pressure in its capillaries are greatly increased. Notwithstanding this, the quantity of lymph flowing from the lymph ressels of the arm by the aid of passire movements is not increased in the lcast, but continues to fall gradually as before (Ludwig and Paschutin). The same is true of the submaxillary gland, when after section of the cervical sympathetic of an animal 
poisoned with atropine, the spinal cord and the chorda tympani are stimulated: the greatly augmented supply of blood to the gland produces not a trace of adema (Heidenhain).

The difference in pressure between the blood and lymph, therefore, is at least not the only cause of the formation of lymph.

After the insufficiency of the filtration hypothesis had been established, there still remained a possibility of explaining the formation of lymph by reference to osmotic processes. In the numerous investigations which have been carried on in the last few years many facts have been observed which present no special diffienlty for this hypothesis. But there are other phenomena which cannot be explained so simply, and which have led therefore to the hypothesis that not only the difference in pressure and the osmotic processes, but some specific secretory process in the capillary wall also is concerned in the formation of lymph (Heidenhain).

Of the facts which led Heidenhain to adopt this riew. some have lost much of their force, in view of more recent work; others, however, are not yet satisfactorily explained from the physical point of view. We shall discuss briefly and in order the most important of these phenomena.

1. If a hypertonic solution of common salt or of sugar be injected into the blood vessels, within a short time a large quantity of water passes from the lymph into the blood, while simultaneously the salt or sugar rapidly disappears from the blood, and the lymph stream beeomes greatly augmented for a long time.

This phenomenon might be explained by saying that the vascular wall is less permeable for sugar (or salt) than for water; eonsequently water passes into the blood ressels by osmosis until the sugar can pass out. Once out of the vessels the sugar in its turn draws water from the tissues and thus occasions the increase of lymph. Among the difficulties which such an explanation encounters is this, that, according to Heidenhain, the content of sugar in the lymph surpasses that found at the same time in the whole blood or in the serum: the escape of sugar from the blood, therefore, cannot be explained by any process of osmosis, but may be due to the activity of the capillary wall.

Cohnstein, in opposition to this view, remarks that it is not fair, because of the slow morement of lymph, to compare the composition of blood and lymph drawn at the same time, but in order to obtain hamonious results one must compare only the maximum concentrations of the two. If this rule be observed, the maximum concentration of serum is generally higher than that of the lymph. But sometimes the opposite relationship obtains, and this Cohnstein thinks may be because the blood test is not made immediately after injection of the fluid. But, again, it might be said that the injected fluid had not had time to mix thoroughly with the blood. Be that as it may, the phenomena now under discussion can undoubtedly be explained on a purely physico-ehemical basis, and constitute therefore no conclusive proof for the secretion hypothesis.

2. Likewise, the fact emphasized by Hamburger that the osmotic tension of the lymph flowing from the lymphaties of the extremities under perfectly normal circumstances is greater than that of the blood from the corresponding arteries, is not a conclusive proof, for it is conceivable that the lymph owes its high tension to the contained products of decomposition from the tissues (Koranyi).

3. The following facts appear to be of greater weight. There is a large number of noncrystalloid substances, which when injeeted into the blood produce a considerable increase in the formation of lymph (Heidenhain). To these belong 
curare, extracts of crab's muscle, lecch extract, dilute solutions of egg albumin and peptone, nuelein and metabolic products of Baeteria, water extract of strawberries, etc. The seat of this increased formation is almost exclusirely in the liver and the pressure in the liver capillaries shows only a temporary rise. The cause in this case cannot be sought in any sort of filtration, and the osmotic processes cannot play any part, since the quantity of injected substance was always very small. It is most natural therefore to conecive of the process as secretory in nature, unless one supposes with Starling that the liver capillaries are injured by the substances used and thus permit a freer passage of fluidwhich however is not yet proved.

The flow of lymph from the glandular organs at least always increases when the glands are active. Stimulation of the salivary glands through their secretory nerves for example raises the quantity of lymph in the ressels of the neck. Injection of sodium taurocholate produces a copious secretion of bile and the lympl stream in the lymphatics of the liver swells in size. The same is true when the formation of urea in the liver is intensified by the injection of ammonium tartrate; and we should probably include here also the increase in the luantity of lympl flowing through the thoracic duct during digestion of proteid.

Accorling to Asher and Barbèra, the activity of the gland cells is the primary phenomenon in these processes and the increased production of lymph is only secondary. It is clear of course that a secreting gland must receive more water, the more active is its production. It ean be easily understood also that a certain part of this water should be carried away by the lymphatics; the only question is, What are the forees which cause the increased output of lymph?

Here, again, one may conceive of an active participation of the capillary endothelium, and ret the possibility of a change in the osmotic tension of the lymph by the process of secretion of such a nature that new quantities of lymph would pass out of the capillaries by pure osmosis is not excluded. A definite decision between these two explanations is not possible at present, because exact quantitative determinations of the osmotic pressure of the lymph and of its changes during secretion are wanting.

4. Not only water, however, but salts and organic foodstuffs also pass from the blood into the lymph. Here again theoretical explanation of the phenomena meets with certain difficulties. The metabolism of the different organs of the body differs greatly with respect both to quantity and kind; they require different substances in very different quantities. A milking cow, for example, secretes daily from the milk glands 25 l. of milk containing $42.5 \mathrm{~g}$. of calcium; which means that from the capillaries of the milk glands there passes a much larger quantity of calcium than from all the other capillary regions of the body put together.

This holds true with regard to combinations of iodine by the thyroid gland. The thyroid takes up the iodine occurring only in excessively small quantities throughout the body (the blood of the dog contains according to Gley and Bourcet $0.01-0.11 \mathrm{mg}$. of iodine per liter) and stores it up in a compound very rich in iodine (Baumann).

The different organs, therefore, must possess a specific power of selection, in virtue of which each levies upon the blood for the constituents necessary to its activity. Since however the gland cells are not attached to the capillary cells, but are separated from them by lymph spaces, they cannot themselves exercise this power of choice but must delegate it to the capillary cells.

Cohnstein rejoins with the supposition that after the parenchyma cells of the glands, etc., have removed a certain constituent from the lymph, the latter receives its replenishment from the blood by a process of diffusion, so that no 
delegation of the selective power is necessary. But to make this supposition valid. it must first be shown that the distribution of the individual substances in the lymph of the different organs is the same, that, for example, iodine oecurs in the lymph of all the organs as plentifully as it does in that of the thyroid gland. Only when such proof has been furnished can we regard the assumption of an active participation of the capillary wall in the delivery of these substances as finally refuted.

5. We can say nothing definite at present concerning the entrance of proteid and fat into the lymph. What we know of filtration elsewhere, in the opinion of the author, speaks very decisively against the assumption often made, that we are here dealing with a simple phrsical process of this kind.

To sum up the foregoing discussion we may say, that purely physical forces such as difference of pressure and of osmotic tension are not of themselves sufficicnt to explain all the phenomena incident to the formation of lymph. At present we are forced to suppose that the living capillary wall participates in the formation by some sort of a secretory process. This does not exclude the purcly physical factors, although we cannot as yet distinguish what part should be ascribed to them, and what to the vital activity of the capillary wall.

If this view be correct, it follows that the capillary wall ${ }^{2}$ can be thrown into action by the most different substances, including such as are present in the normal composition of the blood; also that the capillaries in the different organs are different in certain respects. In general they offer a certain resistance to the passage of water and other substances, but after death or under certain abnormal conditions-e.g., renous stasis, poisoning with chloroform, chloral, and ether (Magnus) - this resistance is more or less rednced. Hamburger seems even to assume that the increased outflow of liquid in renous stasis is caused by the stimulating action of lymphagogic substances collected in larger quantity. The following phenomenon observed by Hamburger may be mentioned in this connection. If a horse with his head perfectly quiet moves his legs, the flow of lymph in the cervical lymphatic trunk increases. We probably have to do here with an excitation of the rascular wall induced by some product formed in the working muscles and given off to the blood.

Against the general view which is given most prominence here it might be objected that the capillary wall is so thin that it is bound to permit a plentiful filtration, and that this physical process must therefore play a much greater part than has here been assumed. It appears, howeser, that other living animal membranes, if they are uninjured, do not permit any filtration. This is the case, for example, with the lung of the frog, and with the membrane of Descemet (Leber) in the eye. When they have been killed they filter very well; but in the living state they do not let a single drop of an indifferent liquid pass through. The thinness of the capillary cells signifies nothing against the assumption that they can develop a powerful secretory actirity. They are thin because they live immediately in the blood and hence need not maintain a reserve store of material within their own borders.

\section{§ 4. THE LYMPH GLANDS}

Our information as to the functions of the lymph glands is at present very meager. From what we know of the leucocytes on other grounds it is 
conceivable that the glands change the substances in the liquid flowing through them in some way. From the fact that they swell up under various pathological conditions we may also conclude that they retain injurious substances to some extent and thus prevent their entrance into the blood stream.

If the afferent and efferent ressels of a lymph gland be tied, but the blood ressels be left open, the leucocytes in the gland disappear (Koeppe). From this it would scem to follow that the lymph eonstitutes a stimulus for the lymph gland, to which the latter responds by the formation of leucocytes (Asher and Barbèra).

\section{\$ 5. ABSORPTION FROM SEROUS CAVITIES}

Dissolved substances as well as water ean pass from the lymph into the blood ressels. This we know because solutions injected subcutaneously or injected without injury into the blood ressels of a limb which is ennnected with the rest of the body only by means of the blood ressels, are completely absorbed (Magendie).

Substances ean also be absorbed from the serous earities of the body, sueh as the peritoncal space, the pericardial carity, pleural earity, ete. A fluid, whether serous in character or not, and whatever its origin, when injected into such a cavity is always first rendered isotonic with the blood plasma. If it be hypertonic - as e. g. a two-per-cent solution of $\mathrm{NaCl}$-to begin with, it is diluted by the addition of water until it has exactly the osmotic pressure of the blood plasma; if it be hypotonic-e. g., a 0.5-per-cent solution of $\mathrm{NaCl}-i$ loses water until it has the osmotic tension of a 0.92 -per-cent $\mathrm{NaCl}$ solution, and then in either case remains at this concentration until absorption is complete.

These alterations of the osmotic pressure are unquestionably to be referred to osmotic processes going on between the injected fluid and the blood plasma.

It might be very naturally supposed that absorption from these eavities takes place through the lympls spaces which open into them, and in the case of the pleural carities and the peritoneal space this seems to be quite readily demonstrable. But absorption from the abdomen and the thorax can take place also through the blood ressels, and in fact the latter scem to play the chief rôle here.

Now, since the blood ressels can. as may be assumed without definite proof, absorb fluids isutonic with their contents, one would be inclined at once to aseribe the action to some specific vital activity of the endothelial cells. But the surprising thing is that absorption from these carities ean take place to about the same degrec in dead animals as in live ones. Active cells therefore are not essential to the process.

There remains to be mentioned, besides the processes of diffusion and the attractive power of proteid for water (ef. page 15t), the process of imbibition. All tissues, living as well as dead, have the power of taking up fluids either by molecular imbibition-i. c., of absorbing fluids througl homogeneous substance -or by capillary imbibition-i. c., through diserete pores. Hamburger supposes that by imbilition of the first kind fluids are absorbed by the homogeneous cement substance between the endothelial cells lining the peritoneum, and that by the same process the fluid is passed on into the subepithelial connective tissue. Also, that the cement substance between the endothelial cells of the eapillaries acts in the same way, and by means of the minute lumina of the capillaries an imbibition $h_{y}$ eapillarity assists in draining the abdominal cavity.

This power of imbibition, however, is limited and would soon come to a stop, since a given volume of tissue could only take up a certain quantity of fluid. 
After a time a plethoric state would be reached which would cause stagnation unless the fluid entering the capillaries were rapidly drained off in the blood stream. In fact it is found that perfusion of fresh serum through the blood ressels of a dead animal accelerates the process of absorption very materially.

Besides we are not to suppose that the mechanisms here spoken of are everywhere the means of absorption of fluids by membranes, for it is fairly certain that in the absorption of substances by the frog's skin the epidermal cells take up the substance from the outside and pass it over into the inside. A surviving frog's skin placed between solutions of $\mathrm{NaCl}$ of equal strength will take up salt from the outside surface and pass it through to the inside surface-a thing which does not occur in the dead skin. Similar phenomena have also been mentioned in comnection with the absorption from the intestine of mammals (page 301).

Solid particles also like milk droplets, carmine granules, etc., can be absorbed from the serous cavities probably by way of the lymph spaces. They can also be ingested and carried away by leucocytes.

Our conclusion must be that, aside from the passage of fluids into the open channels [if such there be; ef. note page $34 \%$ ] communicating with the serous cavities, the purely physicochemical processes of diffusion, chemical attraction, molecular and capillary imbibition go far toward explaining the absorption of liquids from those cavities.

Referexces.-Alexander Ellinger, "Die Bildung der Lymph" in "Die Ergebnisse der Phrsiologie," I, 1, 1902. 


\section{CHAPTER XI}

THE INFLUENCE OF THE ORGANS ON ONE ANOTHER

Altirovgir the individual organs, and indeed the individual cells of the Iletazoa, earry on their life to a certain extent independently, they are in many ways dependent on one another. In truth it is only by this mutual relationship that the activity of the numberless minute parts can result in the life of the whole body.

This interdependence of the indiridual parts of the body is made effective primarily through the nervous system. There occur, howerer, between the separate organs many reciproeal influences more or less independent of the nervous system, which are of very great importance for the functions of the body and which participate largely in the regulation of its mechanisms. Here belong osmotic processes brought about by alterations in the cells or in the lymph, and the influence which different organs exereise on one another by means of products formed in them and delirered to the liquids of the body.

\section{\& 1. THE OSMOTIC PHENOMENA}

All the cells of the body are permeable to water, although some of them are permeable only in one direction. If salts were neither added to nor lost from the body, in time, by the absorption and elimination of water, the same osmotic pressure would come to prevail not only in all the cells, but throughout all free liquids of the body. After the exchange between water and the ultimate particles of salts had ended, an equilibrium would everywhere be established between the contents of the eells and the liquid bathing the cell.

This condition of absolute equilibrium of osmotic pressure within the whole organism would cease lowever, and in fact would cease all at once for the entire system, the instant the osmotic pressure at any one place were changed by the solution or by the deposition of new molecules. If the osmotic pressure in a eell be raised by an increase in the number of molecules dissolved in it, the following phenomena may ensue: (1) if the cell walls are perfectly permeable to salt molecules, the latter in their endeavor to diffuse uniformly will wander out of the cell-i.c., will betake themselves from a place of higher concentration to a place of lower until equilibrium again prevails everywhere; (2) if the cell wall is impermeable to these molecules, then in their cndeavor to diffuse they will exert a pressure upon the wall, and water will pass from the surrounding medium into the eell. In this way the liquid in the immediate neighborhood of the eell becomes more eoneentrated and now aets in turn to draw water toward the periphery of the eell. The movement of water thus set up continues until the difference of pressure becomes too small to be effective. $\Lambda$ third ease still is eonceivable, namely that the cell wall is not absolutely permeable to the salt 
moleeules, but only imperfeetly so. Then an emigration of salt moleeules and immigration of water molecules will take plaee simultaneously.

Aceording to the foregoing, the least change in the osmotic pressure of a single cell will result in a movement of substance of some kind. For a eomplex of cells the eurrents of the individual cells will be added together if they proceed in the same direetion; they will weaken or entirely neutralize each other if they proceed in opposite directions. We must think of the entire organism therefore as permeated by numberless currents and eounter currents. Never during life ean there be a moment of complete equilibrium, and yet there is a constant endeavor to reach this condition. Thus we might expect a priori what is abundantly eonfirmed by experience, that the osmotic pressures of the different fluids of the body are approximately the same though never exactly so. In the same way the osmotic pressure of the same fluid will not always be uniform, but will vary within narrow limits (Koeppe).

\section{§. INTERNAL SECRETIONS}

\section{A. GENERAL}

The organs affect one another in many ways by means of their metabolic produets. Carriel by the blood to all parts of the body, these produets act either to heighten or to reduce the aetivities of the other organs.

The so-ealled automatic excitation (ef. page 52) by the aetion of decomposition products of the organs on different parts of the central nervous system is of vast importance in the regulation of the physiological activities of the body, and is to be mentioned first in this comeetion (cf. also Chapter XXII). For example, when by the activity of the digestive apparatus proteid in increased quantity is thrown into the blood, and the proteid destruetion in the body rises as a consequence, the effect in all probability is due to the direet influence of the proteid and its digestive products on the organs-i.e., the aetivity of the digestive apparatus has brought about an increase in the decompositions of the body without the eoöperation of the nervous system (cf. page 99).

Varions products of the deeomposition of proteid formed in the different parts of the body are carried by the blood to the liver and there are transformed into urea (cf. Chapter XII). With more active destruction of proteid urea is formed in larger amount and this according to our present information stimulates the kidneys to inereased activity (ef. Chapter XIII).

The organs act upon one another not only by their katabolic products, but also by substances formed synthetically in some organs, which, entering the blood, profoundly influence the general bodily fuuctions. Such substances, the chemical nature of which is for the most part entirely $110 \mathrm{known}$ to $11 \mathrm{~s}$, are formed by the testes, ovaries, thyroid gland, pancreas. and adrenal bodies, probably also by the pituitary body and the kidneys. It is very likely that such internal secretions (Brown-Séquard) are formed by other and perhaps by all organs.

Strictly speaking, the enzymes formed in the different organs belong here. Since their importance for the general processes of the body has not been established, we shall not consider them here, but shall merely refer to the facts already cited at page 38 .

In the investigation of these internal secretions, workers have often been content to test the action of organ extracts upon the body. This method of 
experiment of itself, however, does not preclude the possibility that the active constituents of the extract are products of post-mortem changes and have therefore no real significance normally. In order to establish the presence of an internal secretion, one must demonstrate that the venous blood flowing from the organ exercises a specific influence upon the bodily functions. also that the extirpation of the organ produces disturbances which are not due to accidental lesions, and which eventually disappear on transplantation of the organ or upon administration of its extract.

\section{B. THE TESTES}

It has long been known that castration produces a series of profound changes in both men and animals. A steer which has been castrated loses the vehement strength of the bull and becomes a relatively tractable and quiet animal. If a boy be castrated, his roice does not change as it otherwise would at puberty, but retains more of the high register of the ehildish roice. The power and endurance of the eunuch's muscles are not those of a fully grown man. but are as a rule soft and flabby. His body frequently has a b. loated appearance and becomes rery corpulent. The amount of oxygen absorbed also declines after castration. Aside from their sexual functions, which call forth profound physical and psychical phenomena at the time of sexual heat, the testes, therefore, exercise a very marked influence orer the entire body.

It might be supposed that this influence is mediated in some way by the afferent nerves of the testes. But even if this were true-and we do not know that it is-still other cireumstances would have to be considered. If both testes be removel from a rery young cock, and pieces of then be grafted into the abdominal cavity, the secondary sexual characters which are otherwise wanting after castration make their appearance much as usual. Since the testes were in this case entirely separated from their nerrous (onnections, their influence ean only be explained from the viewpoint of an internal secretion (Foges).

The compounds given off to the body are probably the same as the active constituents of a glycerin extract of the testis, the subcutaneous injection of which, according to Brown-Séquard, raises the tomus and power of the neuromuscular mechanisms and aets favorably upon the bodily conditions in general.

On the basis of Brown-Séquard's recommendation, testicular extract has found a very extensive use in the treatment of various forms of weakness. It was often assumed that the unquestionably favorable effects were psychical, for it is well known that very often a medicine, of itself absolutely without effect, produces a very marked improvement or even cures all sorts of nervous disorders if only the patient is eonvinced beforehand that he will be eured. It has been shown, however, by means of experiments, which appear to be entirely trustworthy, that the extract really favors the action of muscular exereise either by raising the power of the neuromuseular apparatus, by diminishing its exhaustibility or by improving its ability to recover. This effect lasts for a long time after the conclusion of exereise and after the injections have ceased. and disappears very gradually (Pregl and Zoth). Even nn the isolated heart perfused with blood testicular extract exerts a distinet and powerful effeet (Hedbom).

The active substance of the extract has not ret been isolated and is known only in solution. The seat of its action in faroring muscular exereise is not definitely known, but is probably central. 


\section{THE OVARIES}

Just as removal of the testes produces deep-seated changes in the male organism, the failure of the ovarial function, whether by reaching the climacteric or by artificial removal of the ovaries, is signalized by a series of disturbances-cardiac palpitations, sweatings, vertigo, and the like-which cannot be due to the cessation of the sexual activity alone. Since an ovary completely isolated from its nervous connections, and engrafted into some other part of the body, prevents the atrophy of the other sexual organs, including the mammary glands, and prevents the failure of menstruation (Halban), it is evident that the influence here spoken of cannot be due exclusively to the nervous relationships of the organ, but that we have to do again with an internal secretion, the removal of which causes the disturbances alluded to.

It is often stated by gyneeologists that eastration of the woman, exactly as in man, is in many eases followed by pronounced eorpuleney, which indieates that metabolism declines after the operation. This eonclusion is eonfirmed by a series of experiments on fasting dogs by Loewy and Richter. After removal of the ovary the consumption of oxygen fell on the average twelve per cent, whereas feeding the eastrated females with ovarial substance raised the metabolism again, in some eases above the original level. The ovarial substanee has no influence on the metabolism of normal, noncastrated male or female animals; but on castrated male animals its action is intense.

How this substance raises metabolism, whether because of an increased muscular tonus, or muscular activity, or in some other way, nothing can be said at present. We only know that the destruction of proteid appears to suffer no change under its influence.

\section{THE THYROID GLAND}

Exact knowledge of the physiological purpose of the thyroid gland dates properly from 1882, when J. L. Reverdin drew attention to the profound disturbances which follow total extirpation of the gland for goiter. Shortly afterwarls Kocher and Reverdin pointed out the great similarity of these changes with the eomplex of symptoms which was first described by Gull (1873) and named by Ord myxadema.

The contribution of lieverdin induced Schiff to take up again certain experiments on the extirpation of the thyroid in dogs which he had carried out as far back as 1856 . but which had remained unnoticed. Ont of 60 dogs operated on by Schiff, 59 died within four weeks. From this time on spirited efforts were made to throw light on the function of the thyroid gland, and all observers reached the same result: that its removal from the dog led to a fatal end within a few days or weeks; that in man its removal caused very considerable disturbances in the nutrition of the body; also that younger individuals suceumbed to the operation more quickly than older ones.

It has sometimes been assumed that the resulting symptoms, which will be discussed more fully presently, are caused by the incidental effects of the operation. But this is certainly not correct. The whole operation can be carried on in the roughest possible manner, and the animal will show none 
of the characteristic symptoms if one fails to remove the glands (Fano). If only a part of the gland is left the symptoms do not appear, but hypertrophy of the part remaining takes place. The disease of myxcedema in man also speaks against such a riew. And. finally, it is controverted absolutely by the fact that intraperitoneal grafting protects the patient from the consequences of thyroidectomy so long as the transplanted gland continues to be functional (v. Eiselberg) : if it atrophies. the usual symptoms appear.

Likewise by subcutaneous injection of thyroid extract, as well as by administration of thyroid preparations by the stomach (Howitz), the same favor-

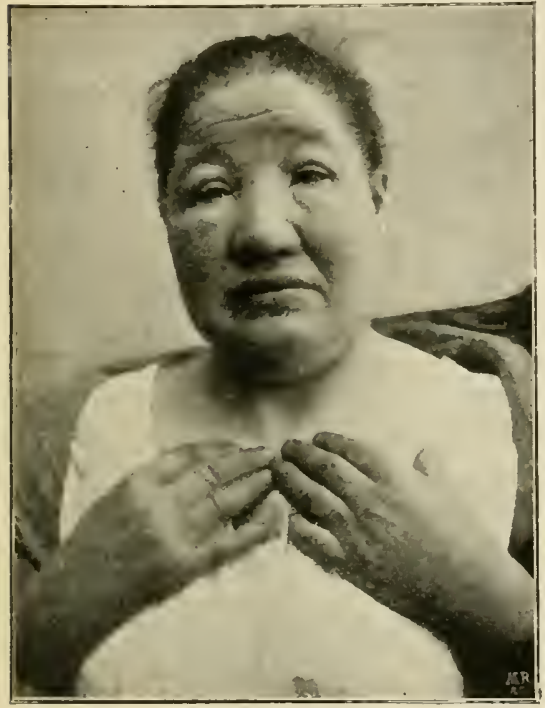

$A$

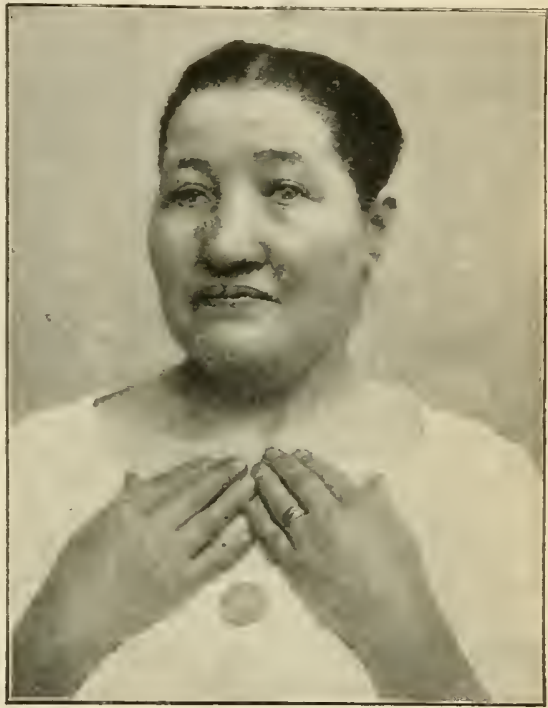

$B$

Fig. 137.-A myxcedematous woman, after J. A. Andersson. A, before treatment. B, after seven months' treatment with thyroid extract.

able effect is obtained-i. e.. the harmful effects of the removal of the throid can be prevented by artificially introducing thyroid substance into the body.

It happens exceptionally that a dog, after extirpation of the thyroid, is not attacked by the usual symptoms. In this case there are probably accessory thyroids which have taken up the function of the main gland.

The disturbances appearing after extirpation of the thyroid affect the most widely different organ systems of the body. We shall now summarize them briefly with special reference to their appearance in man.

The skin, espccially of the head and face, becomes greatly swollen (Fig. $137, \Lambda$ ) because of an accumulation of mucin in the subcutaneous connective tissue. In later stages of the disease the muein decreases, and atrophic changes of the connective-tissue fibers appear along with general emaciation. The skin becomes hard, rough and dry; its secretion ceases: the hairs change and fall out: the visible mueous membranes become swollen; and the voice becomes harsh and monotonous. The internal organs exhibit marked pathological changes; 
the kidneys and the liver undergo fatty and colloidal degeneration, and the arterial walls a hyaline degeneration.

Metabolism is abnormally low; in one of the patients investigated by J. A. Andersson it amounted on the average to only about 1,200 Cal. per day-i.e., 18.8 Cal. per kilogram of body weight. The appetite is poor and the utilization of foodstuffs is below the normal. On the other hand no notewortliy change is observed in the rate of the pulse.

The disturbances of the nervous and muscular systems are very marked. In the monkey the individual contractions of the museles succeed each other after the usual manner of clonic convulsions; then comes a summation of con-

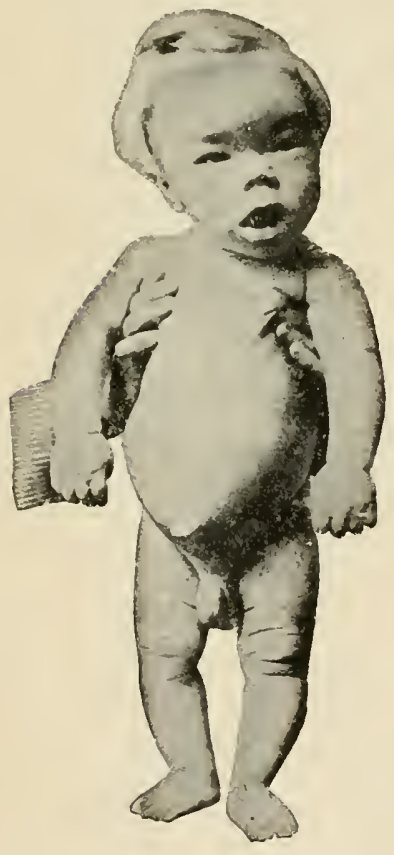

$A$

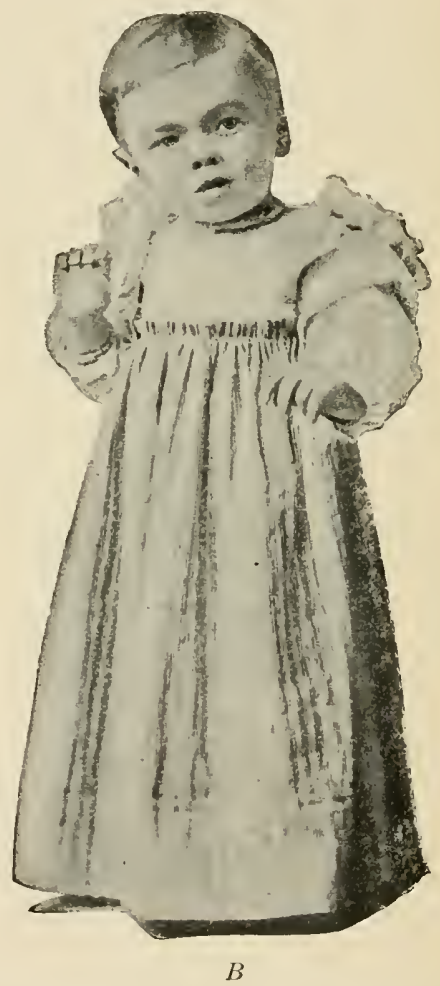

Fig. 138.-A cretinous child, after Holt. A, twenty-three months old, previous to treatment. $B$, after six months' treatment with thyroid extract.

tractions and after this tetanuslike spasms, ending finally in complete rigidity and contracture. Besides these, indications of reduced nerrous activity oceur in the form of paralysis and ancesthesia. Thyroidectomy not inf requently brings on functional neuroses, such as epilepsy, ete. These disorders are not of peripheral origin, for they are wanting after seetion of the notor nerves; on the other hand they are not abolished by seraping off the motor zone of the cerebral cortex. The point of discharge of impulses for the muscular convulsions appears therefore to lie in the lower parts of the central nervons system, although the higher nerve centers are not in a perfeetly normal condition, as judged by histological appearances after extirpation of the thyroid. This appears 
also from the fact that the motor cortical fields soon become fatigued by electrical stimulation, until in the later stages of the disease, when the voluntary movements become extremely slow and imperfect, stimulation produces no visible effect at all. The same is true also with stimulation of the eorona radiata and of the spinal cord. At the height of the eonvulsions, on the contrary, the excitability of the entire nervous syestem is plainly inereased.

Again, all those parts of the brain which are active in the psychical functions become functionally reduced by extirpation of the thyroid. In mrxœdematous patients we meet with weak memory, extreme irritability, stupidity, etc., which in turn find expression in a decline of muscular tone and in the vigor of the bodily movements generally.

Finally, disturbances in the temperature and the heat regulation of the body are seen. A considerable rise in temperature has very often been observed during the height of the muscular convulsion: but when this stage has passed a decided fall ensues-in the monkey to $33^{\circ}$. In man also the subnormal temperature is one of the most constant symptoms, and the patient feels cold.

In the growing organism after suppression of the thyroid, the bones fall considerably behind in their development and the ossification of the epiphysial cartilages and symehondroses is delayed materially. The psychical disturbanees are probably more pronounced also than in grown persons (Fig. 138).

Host of these disorders gradually disappear after treatment with preparations of thyroid. The skin acquires again a normal appearance (Fig. 137, B); metabolism increases-in the above-mentioned case, reported by Andersson, after nine months' treatment it had returned to the normal value of $2,099 \mathrm{Cal}=32.3$ Cal. per kilogram of body weight; the utilization of foodstuffs is more complete; the muscular and nervous disorders are redueed, and in young individuals nne ean often obserre with this treatment absolutely brilliant results (Fig. 138, B).

From all this it follows that the thyroid gland must be regarded as an organ which, by internal secretion of certain substances, performs a vitally important function. These substances represent either important constituents of the liquids of the body, or are used for the neutralization of poisons which may be present. We cannot say definitely whether the thyroid has still other functions or not.

From histological investigations of the process of secretion in the thyroid, we appear to be justified in the assumption that the follicular contents are elaborated by the epithelium surrounding the follicle; and that it passes through openings in the wall of the folliele-formed by simple atrophy (colloidal fusion) of the epithelial cells-from the cavity of the follicle into the lymph spaces of the gland. In the lymph spaces the contents are gradually diluted with lymph; the secretion soon loses its characteristic consistency and ability to take stains, and is added to the general circulation through the lymph ressels (Hiirthle).

Our knowledge of the innervation of the thyroid is still very imperfect. Aceording to Exner, Jr., after section of the thyroid nerves of the cat on one side, when the opposite half of the gland has been removed, various disturbances (hyperæsthesia, apathy, convulsive twitchings, etc.) appear during the first few days, but disappear completely witlin a few weeks. How far these disturbanees are the direct result of the loss of nervous control, or whether they are duc to other circumstances, can scarcely be decided at present. Hiirthle and Tiatzenstcin were unable to produce any histological changes by stimulation of the thrroid nerves. The latter suceeded, however, in demonstrating distinet signs of degeneration in the thyroid of the dog after seetion of its nerves. 
Recently attempts have been made in many ways to isolate the active substance of the thyroid, and the iodothyrin produced by Baumann has been the special object of numerous investigations.

Iodothyrin is a brown-colored, amorphons substance which on heating swells up enormously and is decomposed, yielding an odor suggestive of the ryridin bases. It is almost insoluble in water, and is soluble with difficulty in alcohol. It dissolves readily in dilute alkalies and is precipitated again on addition of acids. Concentrated caustic soda with heat decomposes it slowly. The gland can be boiled for days in a ten-per-cent sulphuric acid without destroying its iodothyrin.

This substance gives none of the proteid reactions. but always contains phosphorus in organic combination $(0.56$ per cent $P)$ and, what is most important, at least 9.3 per cent iodine. Notwithstanding that it oecurs in the thy roid gland to the extent of only 0.3 per cent, iodothyrin has a marked effect on the symptoms following the suppression of the thyroid, even when administered in very minute quantities.

According to Baumann, iodothyrin occurs in the gland in combination with proteid; and Ostrald has reached the conclusion that the so-ealled colloid of the thyroid gland consists of two proteid bodies, only one of which, the thyreoglobulin, contains iodine; the other is a meleoproteid containing a carbohydrate group. By boiling the former with ten per cent $\mathrm{H}_{2} \mathrm{SO}_{4}$, Ostwald isolated a product containing 14.3 per cent $\mathrm{I}$, which he regards as an extremely pure iodothrrin.

The entire rield of this substance calculated on the basis of iodine is, however, only about one-tenth of the iodine in the gland, and it is therefore doubtful, as Blum and Tambach have remarked, whether ioclothyrin oceurs as a conjugant with proteid in the gland, or whether it is not first split off by destruction of the proteid molecule.

A fuller presentation of the views expressed by different authors concerning the nature and the mode of action of the thrroid substance is impossible here. We may mention only the fact that S. Frankel, as well as Drechsel and Kocher, Jr., have isolated two other substances of a basic nature which exert a wellmarked, though not very strong, favorable action on animals whose thyroid has been removed.

If a healthy animal be fed with a great quantity of thyroid, various symptoms of poisoning make their appearance, such as tachycardia, polydipsia, polyphagia, polyuria; the quantity of urea increases, sugar appears after some time in the urine, and the animal falls off in weight. Likewise in men when thyroid is administered as a medicine, in too large doses, excitement, abnormal sensation of heat, increased destruction of proteid, jaundice, albuminuria, cardiac palpitation and eardiac weakness make their appearance.

\section{E. THE PANCREAS}

When the pancreas of a mammal (dog, cat, pig) is totally removed without any accidental lesions, a severe diabetes (according to some authors invariably, according to others generally) ensues (v. Mering, Minkowski, de Dominicis, 1889).

The appearance of sugnr in the urine does not alway show immediately after the operation. It appears somctines sonner, sometimes later, but inrariably increases in intensity within the next twenty-four lours, and as a rule 
also on succeeding days. In most cases on the first day there are found only traces, up to one per cent; on the following day from four to six per cent: and only on the third day does the sugar elimination reach its maximum of eight to ten per cent and over. If now food be not given, the quantity of sugar in the urine begins gradually to fall off; but it does not disappear altogether after seven days of fasting. With a plentiful supply of food the sugar in the urine may amount to ten or twelve per cent. and the daily quantity of sugar eliminated by a dog of 15 kilos on a pure meat diet may reach $102 \mathrm{~g}$., and on addition of carbohydrates may reach a still higher value.

From these observations it is clear that the pancreas is extremely important for the normal decomposition of the carbohydrates of the body. But it is conceivable that the effects described are dne to some accidental lesion attending the operation. This is opposed by the following experimental facts. If a relatively small piece of the gland be left in the abdominal cavity, diahetes does not oceur, notwithstanding that the operative procedure is the same. Further. if in the operation a piece of the gland be grafted under the abilominal skin in such a way that it remains in rascular connection with the abdominal eavity, and after it has become healed in, the rest of the gland left in the normal position be removed, the animal does not become diabetie, nor does diabetes result from section of the rascular stalk to the subcutaneous graft. But sugar appears in the urine immediately and in large quantities, and the sugar content in the blood rises considerably, as soon as the subcutaneous graft is removed, although the operation for its removal is quite an insignificant one. We must conclude that neither the operative lesions nor the alsence of the pancreatic secretion from the intestine can be the cause of the sugar elimination. The panereas therefore exercises a specific influence on the transformation of sugar in the body.

The pancreas may be made to waste away by gradual injection of fat or of acids into the duct of Wirsung. When this is done in the dog, in many cases no sugar appears in the urine (Hédon, Rosenberg). To explain these remarkable facts, we are almost compelled to assume that some other organ has taken over the function of the pancreas in the metabolism of sugar, and that this can only happen in case the function of the pancreas is abolished very gradually. The most natural explanation, namely that portions of the pancreas remain intact, is exclucted by the express statements to the contrary of the authors themselves who report these experiments.

How are the phenomena which follow extirpation of the panereas to be explained: Even under normal circumstanees with a very large amount of sngar in the foorl, a part of it passes out in the urine (alimentary glycosuria). Diflerent kincls of sugar behave differently in this respeet. Lerulose is almost all burned, while cane sugar, grape sugar and espeeially milk sugar pass over in relatively large quantitie into the urine. Ifter extirpation of the pancreas, much larger quantities of sugar than usual are foumd circulating in the blood; it is evident, therefore, that sugar mnst also appear in the urine.

The different carbohydrates fed to an animal whose pancreas has been removed behave very differently. On feeding grape sugar the entire quantity fed appears in the urine. Maltose is transformed into dextrose and as such is 
eliminated. On the other hand the lievorotatory earbohydrates (lerulose, inosit) are used by the body, although they are in part transformed into grape sugar and are excreted as such. After feeding with eane sugar, neither eane sugar itself nor levulose are to be found in the urine; instead there always appears a considerable increase of the dextrose output. Presumably therefore the cane sugar is inverted, and besides the usual dextrose arising from it, a part of the levulose also leaves the body as dextrose. Milk sugar also appears to be transformed into grape sugar and to be eliminated as such.

The glycogen disappears from the liver of animals made diabetic in this way, down to the last traces. But in animals in which parts of the pancreas have been left in the abdominal cavity. fairly large quantities of glycogen are still found. Finally, after feeding levulose, there ocenrs under certain circumstances a consilerable deposit of glycogen in the liver, and, what is especially noteworthy, this glyeogen is dextrorotatory as usual.

After suppression of the pancreas, therefore, the power of the body to form glycogen or fat from dextrose is destroyed. Such animals show an increased destruction of tissue proteid. which is most clearly attested hy the fact that in spite of an excessive supply of food, they very rapidly become emaciated, losing in two weeks as much as one-third or more of the body weight. That is, they live prineipally at the expense of their own bodies. since, in spite of this. sugar is eliminated in large quantities in the urine, the organism must have lost the ability to burn sugar to the usual extent.

The consequences of removing the pancreas make it evident, therefore, that this organ plays an essential part for the storage of carbohydrates in the body, for their transformation into fats, and for the combustion of sugar.

In explanation of these effects of the pancreas on the transformation of sugar, one might conceive either that a substance is formed in the gland which is necessary for the normal metabolism of sugar, or that the gland destroys some substance formed elsewhere, the retention of which in the organism would produce the effects deseribed. The former of these suppositions appears the more probable, although there is searcely yet to be found any binding proof of it, and nobody has so far succeded in obtaining the active substance from the pancreas. It appears from some facts not presented here that the discharge of this substance into the blood is under partial eontrol of the eentral nervous system.

\section{F. THE ADRENAL BODIES}

In 1855 Brown-Séquard announced that bilateral extirpation of the adrenal bodies resulted fatally within a short time after the operation. Later experiments have on the whole confirmed this statement. Death follows within a few hours or days at most. If the organs are removed in several operations, portion at a time. the animals (cats) die somewhat later. If some time be allowed to elapse between the operations for the two sides, the animal (rabbit) may exlibit no abnormal symptoms within a month.

After extirpation of one adrenal body and a part of the other, animals may continue to lire, though in a reduced state of health, for some time after the operation. They are more sluggish than usual, they quickly hecome fatigued by muscular efforts, and the body rapidly falls away in weight. 
These conditions gradually pass away and the animals recorer. When only a part of one adrenal borly is left in position. regeneration of its substance takes place, just as, after unilateral extirpation, a compensatory hypertrophy of the one remaining appears. In both man and animals accessory adrenals are found which are sufficient to maintain life after total extirpation of the main hodies.

Hultgren and 0 . Andersson describe the abnormal phenomena appearing after the remoxal of the adrenals as follows: The animal recovers from the operation within a few hours. and aside from a poor appetite or none at all, shows no unfarorable symptoms within the next few days. During the last twenty-four hours before death, or still earlier when the symptoms run a slower course, the animal becomes dull and stupid, most of the time sits perfectly quiet and, what is particularly striking, in eats, exhibits weakness and uncertainty in the movements of its hinder extremities. At the same time the temperature begins to fall, and as this continues the general listlessness and weakness of the animal increases. Cats lie most of the time with the nose on the floor, and with eyes half-closed follow what is going on about them, but not with the usual interest. They react to stimuli more feebly and more slowly than before. They walk unsteadily and with a peculiar stiffness of the hinder legs. In leaping down from a chair they are likely to fall in a heap. They become fatigued with very slight morements, and lie for a long time deeply exhausted. This loss of strength continues more and more and finally dyspnœa sets in; respiration becomes deep and slower: the heart becomes less frequent and irregular, and death ensues. Conrulsions rarely oceur in eats and dogs, but in rabbits they are fairly common.

Among other eonditions observed on such animals the following may be mentioned. Neither digestion, nor the combustion of proteid, nor the eontent of hremoglobin in the blood, nor the number of red blood cells is influenced by the operation. No paralyses are to be observed and the electrieal exeitability of the nerves remains unchanged to the time of death.

The blood pressure falls immediately after the operation and in the last few hours reaches a very low level.

The blood of the operated animals is said to have a pronounced toxie action. Thus if blood from one operated animal be injected into another whose adrenals have also been removed, the symptoms which would otherwise not appear for several hours come on within a short time.

The profound effects of the remoral of the adrenals cannot be caused by the operation alone nor by aceidental lesions. This we know from the observation that portions of the adrenals which have been left unintentionally suftice to keep the animal alive; also from the fact that no disturbance occurs if the adrenals be separated from all their connections except those with the vascular system.

The evil effects of the extirpation of the adrenals are therefore due to the loss of some function which is important for the whole lody. This funetion may be one of two kinds: either they destroy some product or products formed in metaholism whieh, when present in larger quantity than the normal, poison the organism. or they form sulstances which are necessary for the normal activities of the body. The results of extirpation, and especially the influence 
set up by the injection of the blood of one animal deprived of its adrenals into another animal operated on in the same way, appear to speak rather definitely for the former supposition. Even if this were correet. howerer, the physiological purpose of the adrenals would not be wholly explained therehy. for injection of adrenal extract or of blood from the adrenal vein ( $\mathrm{Cy}$ Julski) into animals which have lost their adrenal bodies produces a marked improvement in the symptoms for some time, and has an unmistakable effect on perfectly normal animals. The conclusion which seems to be inevitable is that the adrenals give off to the blood one or more specifically active substances.

These substances are dialyzable: soluble in water, dilute alcohol and in glycerin, but insoluble in absolute alcohol and ether; withstand drying at $110^{\circ} \mathrm{C}$. and boiling, if not too prolonged. They are destroyed by alkalies, but not by acids. Numerous attempts have been made to isolate and identify this substance. According to v. Fürth, it is related to the pyridin series and contains a ring nucleus with two hydroxyl groups in the ortho position (adrenalin). It has an alkaline reaction and forms salts with the acids. Its empirical formula, aecording to Takamine, is $\mathrm{C}_{10} \mathrm{H}_{15} \mathrm{NO}_{3}$, according to Abel $\mathrm{C}_{10} \mathrm{H}_{13} \mathrm{NO}_{3}$. $+\frac{1}{2} \mathrm{H}_{2} \mathrm{O}$. The pereentage of this substance in the adrenals is said to be about $0.1-0.17$ per cent.

If the extract be injected directly into a vein, it acts powerfully in very small quantities. Thus Takamine obtained a distinct rise of pressure by injecting $0.0000013 \mathrm{~g}$. of adrenalin. The chief effect of such an injection of this extract is a sudden rise of blood pressure. This is due in part to an augmented heart action which can be demonstrated also on an exeised heart or heart muscle, and in part to a powerful contraction of the smaller arteries eaused by a direct action of the extract on the musculature of the ressels. According to Cyon, the vasomotor center in the medulla and the cardiac inhibitory center are excited. The slowing of the heart beats observed by many authors, which do not appear after section of the vagi (according to most authors), is said to be a direct effect of the injection and the result of a sudden increase of intracranial pressure.

Most of the effects of injection of adrenalin last only a few minutes, and then gradually disappear. This temporary character might be due either to a transformation of the adrenalin taking place in the blood stream, or to its removal from the vessels. Adrenalin is eliminated in the urine only in very small quantities.

When injeetion is made subeutaneously in animals from which the adrenals have becn removed, it produces a rise during the premortal fall of temperature, and improves the general bodily condition of the animals. They become more active, the weakuess and uneertainty of their movements are diminished and they leap with much more vigor than before. After repeated injections, however, the effect fails, and it is possible to prolong the life of the animal in this way for only about twenty-four hours (Hultgren and O. Andersson). On administration of very large quantities of adrenalin to normal animals, especially after intravenous injection, profound toxic effects ensue which result fatally.

Writh regard to the influence of the nervous system on the formation and secretion of the active substance of the adrenals. Biedel and Dreyer state that stimulation of the splanchnic below the diaphragm produces, quite independently of the alterations in the blood flow, a copious seeretion of it into the blood. 


\section{G. THE PITUITARY BODY}

On the basis of anatomical and embryological facts most authors assume a close physiological relationship between the hypophysis cerebri-i.e., anterior part of the pituitary body-and the thyroid gland. This supposition is supported by the facts, to this extent at least, that hrpertrophy of this structure has been observed in animals after extirpation of the thyroid, and in men suffering from myxnedema. A satisfactory explanation of this relationship has not yet been found.

Recently many experiments have been made on the effect of injeeting extract of the hypophysis into the circulation, and a distinct action upon the heart and blood ressels has becn obtained. According to Schäfer and Vincent, we have to $\mathrm{d} \rho$ here with two different substances, which are distinguished chemically by their solubility in alcohol and ether, one being soluble, the other not.

The former brings about a very temporary fall in the arterial blood pressure. The other increases the blood pressure, slows and strengthens the heart beat and produces a marked diuresis. The effeet is tolerably permanent, although it becomes less and less with successive injections. From experiments on the isolated heart or heart muscle it appears that this influence extends to the peripheral end apparatus of the cardiae nerves. Other observations indicate that the extracardial center also is stimulated (Cyon). The rasomotor nerves behare in the same way: on the one hand the ressels contract after destruction of the medulla (Oliver and Schäfer); on the other, the rasoconstriction occurs if the extract is injected into the brain ressels only (Cyon). In Cyon's opinion the effects of an extract on the heart and on the ressels depends upon two different substanees.

Curiously enough the substances which produce this effect upon the cireulation, according to Howell, Schäfer, and Vincent, are, for the most part at least, not contained in the anterior glandular part of the pituitary body, but in the posterior infundibular part. However, this section of the pituitary body also contains glandular epithelial cells, which surround eavities filled with a colloidal substance (Berklệ).

From results thus far before us no positive conclusion can be drawn as to the normal working of the hypophysis." It is conceivable that the substances obtained by different methods from the gland are normally formed there and are given off to the blood. But it is also possible that they represent products of decomposition which are formed post mortem only, in the methods of extraction.

A definite choice between these two possibilities is not yet possible, since from the many conflicting statements as to the results of extirpation, we cannot tell certainly whether any disturbances follow loss of the hypophysis alone.

\section{H. THE KIDNEYS}

Certain observed faets indicate that the kidners not only remore different products of decomposition from the body, but give off to the blood one or more substances which are of service in the body. When the kidners are remored from an animal, or are rendered functionless in man, within a few dars symptoms of severe uremic poisoning make their appearance. The most natural assumption is that the symptoms are caused by the retention of the produets

${ }^{1}$ Fischera has reported quite recently that castration of cocks, guinea pigs and rabbits produces a marked hyperplasia of the hypophysis. The change in the capon is very sudden and can readily be recognized in microscopical sections of the part. Injection of testicular extract just as quickly abolishes the hyperplasia or prevents it altogether.-ED. 
otherwise eliminated. But it has been observed that patients who suffer with anuria for weeks may not show any signs of uræmia. Brown-Séquard explains this failure of abmormal results by supposing that only the excretion of urine, but not the production of the "internal secretion" of the kidneys, has ceased. In support of this riew he carried out experiments, in which animals whose kidneys were removed and which showed the uramic symptoms were very much benefited by injection of an aqueous extract of kidney. Moreover E. Meyer has shown that nephrectomized animals which exhibited the periodic respiration resulting from uræmia, again began to breathe normally after intraperitoneal injection of a kidney extract or intravenous injection of blood of a normal animal. Other authors have reached entirely negative results with similar experiments. The view of Brown-Séquard therefore camnot be regarded as by any means pstablished in fact.

\section{THE SPLEEN}

Extirpation of the spleen produces no serious effects; it is therefore not a vitally important organ. According to Schiff and Herzen, the spleen is in some way concerned in the formation of trypsin from the zymogen formed in the pancreas, and this has recently been confirmed by Gachet and Pachon (ef. page 252). The quantity of bile pigments formed in the liver is also said to fall considerably after extirpation of the spleen (Pugliese). This is in line with the view arrived at by many authors, and latterly by Jawein, that the spleen removes from the blood and transforms the worn-out red blood corpuseles.

An intravenous injection of splenic extract at first lowers the blood pressure and later raises it slightly; it also appears to be able to regulate the rhythm of the excised heart. Again, it is said to hare the same effect as an infusion of red bone marrow in raising the number of red blood corpuscles and the eontent of hiemoglobin in the bloor (Danilewsky).

Since we have no data as to the effect of the venous blood from the spleen, these results furnish no definite point of rantage for the explanation of the physiological purpose of this still very enigmatical organ. 


\section{CHAP'TER III}

\section{THE FINAL DECOAPOSITION OF FOODSTLFFS IN THE BODY}

As already mentioned at page $2 \%$, the foodstuffs in their combustion do not pass over immediately into their end products, but are gradually split up into simpler and simpler sulsstances, oxidation and reduction processes probably succeeding each other in rapid succession. In order to secure more light on these processes, investigators have studied the transformations which organic substances, more or less closely related to the foodstuffs, undergo in the body. Important as these investigations are, and signifieant as are the results which we expect from this field in the future. we must limit onrselves here, for want of space, to the transformations of the true foodstuffs. ['nfortunately our knowledge of these subjects is still very imperfect and the views of authors are considerably at variance with one another on many of the most important points.

\section{\$ 1. THE FINAL DESTRUCTION OF PROTEID}

In its digestion in the alimentary canal, proteid is for the most part split up into relatively simple products. To what extent it is absorbed in the form of albmmoses and peptones we eannot say definitely. Yor is anything known concerning the extent to which synthesis of proteid from the end produets just named erentually takes place in the body. If the proteid is not stored. loth the primary and the final digestive products are still further decomposed until the elements of proteid are ready to be eliminated as carbon dinxile, water and urea.

Formerly it was supposed that proteid in its decomposition is split up into a nitrogenous and a nonnitrogenous portion. This view however is no longer tenalile, for from the fact that numerous nitrogenous compounds appear sncessively in the hydrolytic cleavage of proteid, it follows that the final separation of the carbon from the nitrogen takes place at a rery late stage of the process.

In the body proteid and its digestive products do not undergo a continnons. progressive cleavage by oxidation. There undoubtedly oceur a number of synthetic processes by which the groups contained in the proteid molecule undergo many changes of position of one kind and another. Hence, the problem of the decomposition of proteid in the body is extremely complicated and cannot be regarded as by any means solved.

In the destruction of proteid by chemical reagents outside the body a certain quantity of urea is formed, which comes from arginin, not by oxida- 
tion. but by clearage of the arginin with absorption of water into urea and diamino-ralerianic acid (Drechsel).

Drechsel estimated that 100 parts of protcid undergoing cleavage in the body would be able to vield in this way 3.5 parts of urea without suffering any oxidation. Since, further, 100 parts of proteid vield altogether 34.3 parts urea. it follows that about one-ninth of the total urea eliminated may issue from the proteid by a simple process of cleavage. In fact we always find in all animals, eren in those in which the greatest part of the nitrogen of the urine appears as uric acid, a certain quantity of urea (ef. pages 70 and 75 for the arginin content of the different proteids).

But by far the greatest part of the urea eliminated arises from proteid by processes of oxidation. When amino acids (glycoeoll, lencin, aspartic acid) are digested with finely ground, fresh organs, ammonia is split off from them (Lang). In the mammals these compounds as well as ammonia are transformed into urea and as such are giren off through the kidneys (Nencki, Salkowski et a7.). It is ennceirable, therefore. that ammonia represents an intermediate stage in the formation of urea. Since. howerer, both ammonia and the abore-mentioned amino aeids contain only one atom of $\mathrm{Y}$ in the molecule. and urea contains two. the latter can only be formed from the former by a process of synthesis. This might take place by the combination of ammonia with carlon dioxide into earbamic acid or ammonium earbamate, and the formation of urea from these by the loss of water. In fact, Drechsel succeeded in preparing urea by subjecting an aquenus solution of ammonium carbamate to electrolysis with an automatic commutator in the circuit, so that the salt was alternately exposed in rapid succession to oxidation by nascent nxygen and reduction by nascent hydrogen. The processes taking place are illustrated by the following scheme:

$$
\begin{aligned}
& \text { I. } \mathrm{NH}_{2} \cdot \mathrm{CO} . \mathrm{O} . \mathrm{NH}_{4}+\mathrm{O}=\mathrm{NH}_{2} \cdot \mathrm{CO} . \mathrm{O} . \mathrm{NH}_{2}+\mathrm{H}_{2} \mathrm{O} \\
& \text { ammonium carbamate } \\
& \text { II. } \mathrm{NH}_{2} \cdot \mathrm{CO} . \mathrm{O} . \mathrm{NH}_{2}+\mathrm{H}_{2}=\mathrm{NH}_{2} \cdot \mathrm{CO} . \mathrm{NH}_{2}+\mathrm{H}_{2} \mathrm{O}
\end{aligned}
$$

The fact that earbamic acid can be demonstrated in the blood and in the urine constitutes a strong arcument for this riew.

The formation of urea might also take place by the union of an amido residue, $\mathrm{CONH}_{2}$, at the instant of its formation, with the amidogen, $\mathrm{NH}_{2}$, arising by oxidation of ammonia (Hofmeister).

A definite decision between these two possible explanations is not to be had at present; besides, it is not at all certain that the formation of urea takes place by one method only.

Concerning the seat of urea formation. we can think of two possibilities: either it is formed in all parts of the body whererer proteid is broken down, or certain organs have the function of transforming the intermediary products of metabolism into urea. After remoral of the kidness urea collects in the body in considerable quantities: these organs cannot therefore play an all-important part in its production. Meissner found in the liser of the dog larger quantities of urea than in the blood. and so designated this organ as the one in which the major part of the urea of mammals originates. 
This riew received substantial support in the experiments of $\mathrm{r}$. Schroeder, in which by artificial perfusion of an excised dog's liver with ammonium carbonate or formate, the production of urea from these salts was demonstrated directly. Experiments earried out in the same way on the kidneys and inuscles gare only negative results. Likewise by digestion of glycocoll with crushed liver tissue or liver extract, urea, or, to be more exact, a closely related compound is formed (Richet, Loewi et al.).

Indirectly the importance of the liver in this connection is shown by the experiments of Nencki and Pawlow on dogs with an Eck fistula between the portal vein and the inferior vena cava (ef. page 2it) in which the liver therefore received its blood by the hepatic artery only. In these animals the elimination of ammonia in the urine increased and the power of the organism to form urea from earbamic acid introduced into the stomach was lost. After a time characteristic abnormal symptoms made their appearance (namely, somnolence, ataxia, excitation, loss of vision, epilepsy, anæsthesia, tetanus) and these could be produced at will by an abundant supply of nitrogenous food, ammonium salts, or glycocoll.

In birds and reptiles the nitrogen of the decomposed proteid leares the body chiefly as uric acid. Any information we can get as to the seat of uric acid production in birds ought therefore to be strongly suggestive of the seat of urea production in mammals. Birds are especially well arlapted to experimental inrestigation of this subject becanse extirpation of the liver is relatively easy on account of the peculiar relations of the circulation. The animals live for as much as twenty hours after the operation. Their urine, however, is very poor in uric acid, since only about three to four per cent of the total nitrogen is now eliminated in this form. whereas the percentage of ammonium salts (lactate) is considerably increased. Amino acids, which normally are transformed into uric acid in birds, when fed to geese deprived of the liver, are eliminated as ammonium lactate. Urea passes out unchanged (Minkowski). The quantity of uric acid eliminated also has been increased by electrical stimulation of the liver (Milroy). Ilence the liver must be regarded as the seat of uric acid production in birds.

We may conchde also that urea is formed from ammonia to a rery large extent in the liver, and that the other organs probably have at most only a small share in this function. The digestive tract is indicated as the chief source of the ammonia; for, according to the investigations of Nencki, salaskin and others. the pereentage of ammonia in the intestinal and gastric mucosa is considerably greater than that of the other organs; the portal blond also is considerably richer in ammonia than the blond of the hejatic arteries and reins. The ammonia split off in the liver from the amino acids must be taken into account also.

There is in all this however no pronf that all of the urea, exclusive of that split off directly from the proteid (ef. page 369). comes from anmonia and is formed in the liver. Ohservation shows rather that in the dog large quantities of urea are eliminated even after complete extirpation of the liver. Similarly it has been found that in diseases of the human liver where the entire organ. to judge from examination of sections. harl hecome completely inefficient. more than sixty per cent of the total nitrogen in the urine has 
been exereted as urea. Now if it be true that only the liver ean transform ammonia into nuea, it follow that only a part of the nitrogen enntained in proteid passes orer into ammonia, while another part rums through other stages until finally it also is given off from the body as urea.

Under normal circumstances ammonia in eertain quantities is always present in the urine. This ammonia is necessary in order to help saturate the acids excreted in the urine, for the fixed bases are not sufficient for this purpose. If the acid production in the body is large, or if free acids are taken into the body, the quantity of ammonia is larger and the quantity of urea correspondingly deereases. With increased supply of fixed alkalies the quantity of ammonia falls, and the quantity of urea rises. The formation of urea from ammonia varies therefore according as a greater or less amount of ammonia finds employment as such. It appears to follow from what has already been said that the regulation of this function is committed to the liver.

The uric acid which is eliminated from mammals in general does not represent a product of proteid decomposition. but appears to come mainly from the nucleins (Horbaczewski). The nucleins are split up in the body into proteid, phosphorie acid and purin bases (ef. page ic). The latter pass by oxidation over into uric acid: however, some purin bases besides uric acid oceur in the urine, though the quantity of these is rather small.

Recent observations (Burian and Schur. Sivén) have proved that uric acid is derived in part from purin bases which are introdueed into the body with the food (exogenous), and in part from those present in the body itself (endogenous).

The amount of the latter is constant for the same individual-for an adult man in health amounting to $0.3-0.6 \mathrm{~g}$. (=0.1-0.2 g. $\mathrm{N})$ per day. It ean be determined direetly if a diet containing no mueleins (purin bases)-consisting for example of milk, cheese, eggs, potatoes, rice, white bread, etc--be given. The amount of purin bases and of uric acid in the urine is then relatively eonstant, notwithstanding that very great rariations in the quantity of proteid may be supplied in such foods. We have no positive information yet as to the processes upon which the so-called endogenous acid depends.

If, however, the diet consist of foods which contain purin bases (meat, liver, thymus, ete.) the quantity of uric acid eliminated inereases in proportion to the amount of purin eaten. The amount of any purin base that will appear in the urine as such, or as the closely related uric acid, depends upon its chemical nature. Thus with hypoxanthin (meat, liver, spleen) one-half, and with adenin (thrmus) one-fourth of the purin nitrogen fed appears again in essentially the same form in the urine (Burian and Sehur).

According to the investigations of Wieners, uric acid is formed at least in the liver, the thrmus and spleen, and it is not unlikely that all the organs participate in its production aceording to the quantity of nucleins contained in them.

At any rate, the purin derivatives given off in the urine of mammals is only a fractional part of that taken up in the food, or of that formed in the body itself. A considerable part of both must be further oxidized and be transformed into urea. Probably the best proof of this is the fact that after extirpation of the kidneys, uric acid does not accumulate in the blood. Henee the normal elimination of uric acid might be due to the circumstance that the transformation of urea is not quite complete, but the blood takes the opportunity presented 
during its passage through the kidneys of partially ridding itself of waste in the form of uric acid.

Allantoin appears in the urine of the dog after ingestion of uric acid (Salkowski). It has been demonstrated also in the urine of man-e.g., in hepatic cirrhosis. This compound might, therefore, represent an intermediary step in the destruction of uric acid. The genetic relationship between the substances considered here will be evident from the following formula:
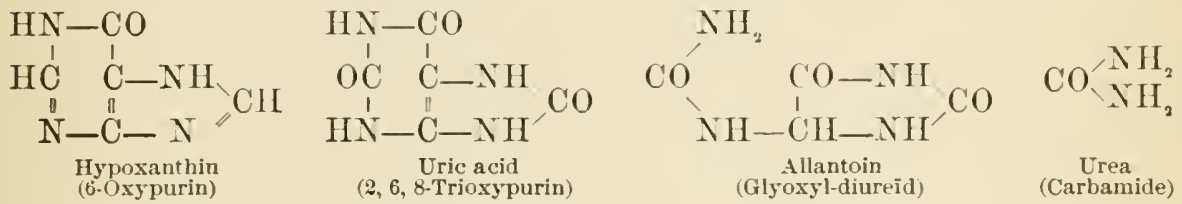

It appears from several observations that the liver is the seat of the destruction of uric acid. By artificial perfusion of this organ with blond, or by digestion of uric acid with ground liver substance, urie acid disappears. Moreover. aceording to Burian and Schur, it immediately appears in the blood of neplirectomized dog's when the liver also is thrown out of the cireulation. And yet there are other observations which go to show that other organs also are capable of decomposing uric acid.

Uric acid therefore represents an intermediary product of metabolism in Mammalia. In birds it is the chief nitrogenous end product of proteid, and is formed for the most part by a synthetic process carried to completion in the liver. A residue of urea and sarcolactic acid are probably to be regarded as the basal material of this synthesis.

The sulphur contained in proteid is eliminated in the urine mainly as sulphates and ethereal sulphates ("acid sulphur"), but in part also as "neutral sulphur" (sulpho-cyanic acid, derivatives of taurin, cystein, oxyproteï acid, and other organic compounds). A part of the sulphur moreover is given off as taurocholic acid in the bile (cf. page 253). It is likely that this sulphur comes mainly from the cystein group.

As mentioned at page $12 \%$ it is very probable that under certain circumstances at least, earbohydrates are formed in the body from proteid. and. indeed. that this may take place without the participation of the carbohydrate group contained in most proteids. From all that we know of the manner of clearage of proteids, this formation of carbohydrates must be regarded as a synthetic process, in which sugar is constructed by splitting off of the amido groups, and by synthesis and partial oxidation of the $\mathrm{N}$-free fraction remaining ( $F$. Ifüller).

Aceording to a summary of Langstein, the following possibilities are to be considered. Lactic acid can be obtained very easily from alanin by the action of nitrous acid. This is an isomer of glreerin aldehyde which easily condenses to dextrose.

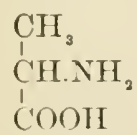

Alanin

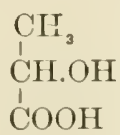

Lactic acid

$$
\begin{aligned}
& \mathrm{CH}_{2} . \mathrm{OH} \\
& 1 \\
& \mathrm{CH} . \mathrm{OH} \\
& \text { ' } \mathrm{CHO}
\end{aligned}
$$

Glycerin aldehyde

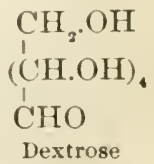


In fact after feeding with alanin lactic acid is observed in the urine, sometimes also an inerease of the liver glveogen. Whether we have here a direct or an indirect formation of glyeogen (cf. page 126) eannot be deeided.

Moreover sugar might be formed from leucin by passing through the stage of tetra-oxyamino-caproic acid (actually demonstrated in the body) to dextrose.

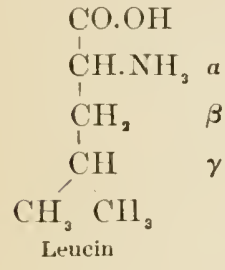

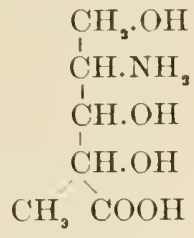

Tetra-oxyaminocaproic acid

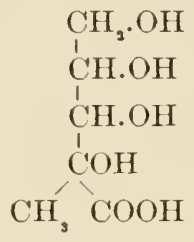

Saccharinic acid

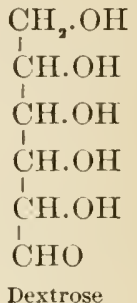

Dextrose

It would be possible also for leucin, by breaking down the carbon chain between the $\beta$ and $\gamma$ atoms, to pass into sugar by way of alanin and lactic acid." Observations on diabetic patients likewise favor this idea of a production of sugar from lenein: for by feeding leuein, a distinet inerease of the sugar elimination is obtained.

Finally, a production of sugar from diamino acids by way of oxyamino acids is possible.

\section{\$ 2. THE DECOMPOSITION OF CARBOHYDRATES}

The carbohydrates absorbed from the intestine reach the blood for the most part as dextrose. If the percentage of sugar in the blood by reason of an extra large quantity in the food, exeeeds a certain low limit (from 0.2 to 0.3 per cent), a part of the sugar is eliminated through the kidneys in the urine (alimentary glycosuria, ef. page 12\%) ; otherwise the urine contains only traces of sugar. The kind of sugar appearing in the urine under these conditions is always the same as that fed in excess. Starch does not produce alimentary glycosuria, probably because a sudden flooding of the blood with sugar is prevented by its relatively slow rate of digestion.

Sugar which is not immediately oxidized is stored in the body either as fat or as glycogen, and is then drawn upon as required. The greatest part of the glyeogen is deposited in the liver. but it is not burned there. It passes in some way into the general cireulation and is oxidized in the tissues of the body, especially in the muscles. It is possible that this transportation is accomplished in part by the help of the leueocytes. Another and in all

${ }^{1}$ This possibility is strengthened by the observation of Embden, Salomon and Schmidt that acetone is obtained by perfusion of leucin through a glycogen-free liver. Quite recently also Lusk and A. R. Mandel have shown that in phloridzin diabetes sarcolactic acid, injected subcutaneously, can be synthesized into dextrose; and Almagia and Embden have obtained a production of lactic acid by perfusing blood containing glycogen or dextrose through a liver containing no glycogen, as well as by perfusing a blood poor in sugar through a liver rich in glycogen. Lusk has suggested, therefore, that the history in the body of carbohydrates derived from proteid may include the following events: (1) lactic acid, (2) dextrose, (3) glycogen, (4) dextrose, (5) lactic acid.--ED. 
probability a much more important part takes place by the transformation of glycogen into dextrose, which is then carried in solution by the blood plasma.

The physiological produetion of sugar in the liver which was diseorered by Cl. Bermard (1553), has since that time often been denied on the assumption that the increase of sugar easily demonstrated in an excised liver, is due to post-mortem processes. This explanation, however, is not borne out by wellauthenticated faets obtained from many experiments; hence the formation of sugar in the liver must be regarded as a physiological proeess.

For example, if a puneture in the middle of the floor of the third ventricle between the points of origin of the auditory nerve and the vagus, be made with a blunt needle, sugar immediately appears in the urine (puncture diabetes of Cl. Bernard), and the liver glyeogen rapidly disappears. If, however, the puneture experiment be performed on a fasting animal whose liver glyeogen is alrearly used n1, no sugar appears in the urine.

After a time the liver recovers its ability to store up earbohydrates as glyeogen. On this ground the formation of sugar might be regarded as the result of a stimulus, and not as the result of decomposition. The stimulus is conreyed to the liver by the splanchnics, for after seetion of these nerres the puneture is ineffective.

Sugar in the urine can be caused also by stimulation of numerous afferent nerves, as well as by various traumatic and operative effects widely different in character (e.g., concussion or hemorrhage of the brain, inflammation of the brain membranes, neuralgia, ete.). Reflexes are involved here, which, with the eoöperation of the medulla, lead to an inereased formation of sugar in the liver. By means of these reflexes the working organs, especially the muscles, remove from the liver the carbohydrate fuel required in the performanee of their funetions. They constitute, therefore, as Pflüger has pointed out, an important regulatory meehanism for the consumption of the available material in the body.

The transformation of glyeogen to sugar is regarded by some authors as an expression of the vital activity of the liver cells; others explain it as the effect of a special enzyme which is formed in the cells.

After extirpation of the pancreas ( $\mathrm{cf}$. page 362 ). after poisoning with the glucoside phloridzin, in diabetes mellitus, and under certain other circumstances, the metabolism of the carbohydrates undergoes a chronic change, so that sugar in abnormally large quantities is given off in the urine. In phloridzin poisoning this is caused primarily by an increased permeability of the kidneys to sugar, whereas the other forms of morbid glycosuria arise because the body has lost to a greater or less extent the power either to burn sugar or to store it up as glycogen or fat.

In the so-called light form of diabetes, sugar is given off through the kidueys only in case the food contains earbohydrates; if carbohydrates are prohibited, the loss of sugar ceases. In the serere form of the disease to which pancreatic diabetes belongs, sugar appears in the urine even if no carbohydrates be given in the food. The body then oxidizes little or no sugar. although its power to oxidize is not at all reduced. Since, as was above remarked. at page 1:8. sugar is probahly not formed from fat in the body, the sugar in this case must come from the proteid. 
In diabetes there appear in the urine besides sugar the so-ealled acetone bodies: $\beta$-oxybutyric acid, aceto-acetic aeid and acetone, the relations of which to each other are evident from the following formula:

$\begin{array}{lll}\mathrm{CH}_{3} & \mathrm{CH}_{3} & \mathrm{CH}_{3} \\ \mathrm{CH} . \mathrm{OH} & 1 & 1 \\ 1 & \mathrm{CO} & 1 \\ \mathrm{CH} & 1 & \mathrm{CH} \\ 1 & \mathrm{CH} & \begin{array}{c}\text { Acetone } \\ \text { COOH }\end{array} \\ \text { s-oxybutyric acid } & \mathrm{COOH} & \text { (di-methyl-ketone) }\end{array}$

With the exception of acetone, which is eliminated in small quantities under physiological conditions also, these compounds never, so far as known, appear in the normal urine; from which it follows that diabetes must be intimately comected with deep-seated changes in the general metabolism.

Most of the carbohydrates pass througin the stage of hexoses before they are further decomposed in the body. Lilie the other foodstuffs they are not immediately oxidized to their end products, but pass through more or less complex groups before being eliminated as carhon dioxide and water. To these intermediary products belong: glycuronic acid CrO.(CrOH) ${ }_{4} \mathrm{COOH}$, which in its turn can be transformed into oxalic acid in the body : sarcolactic acid (:) ; and ethyl alcolol. It camnot be decided yet from the olservations thus far reported whether sugar always breaks up in the same way, or whether under different circumstances and in different organs it runs through different cleavage products.

\section{§3. THE DECOMPOSITION OF FAT}

Fat eaten in excess is directly deposited as such in the fat cells. How it is transported and how deposited is not vet entircly clear. Netzner in his investigations of this question was mnable to find anywhere a depository where fat was entering cells in corpuscular form; he never found in the immediate neighborhood of cells any fatty granules similar to those found inside of the cells. Noreorer, in the very early stages of deposition, fat is not laid down in the form of granules, but in the form of minnte vacuoles which expand and enlarge from day to day (cf. page 304 ). These facts are interpreted by Metzner and Altmann to mean that fat is added to the cells only in the form of soluble cleavage products (fatty acids), which are synthesized again into nentral fats in the cell. It is not unlikely that fat is again split up when it leaves the fat cells and is carried to the different organs in soluble form.

For the purpose of obtaining some light on the oxidation of fats in the animal organism, Pohl has studied the behavior in the body of those intermediary cleavage products which theoretically may be expected to appear in the normal course of fat destruction. Thus, if the series of substances which can be formed in the oxidation of highly complex fatty bodies-i.e., fatty acids and carbohydrates-be arranged in order, it is seen that relatively simple intermediary compounds precede the formation of $\mathrm{CO}_{2}$, alike for the most widely different bodies. If now it can be shown by experiments on animals that some 
of the theoretically possible predecessors of carbon dioxide, when injected directly into the animal body, are destructible but others are not, some idea can be formed whether or not such intermediary compounds appear in the physiological oxidation of complex fat bodies. Pohl's investigation has shown, for example, that oxalic acid is indestructible in the animal body; that the acids presumably occurring in the oxidation of the ethane derivatives, glycolic acid, $\mathrm{CH}_{2} . \mathrm{OH}$. $\mathrm{COOH}$, and glyoxylic acid, $\mathrm{CH}(\mathrm{HO})_{2} . \mathrm{COOH}$, can be destroyed in relatively large quantities without forming any oxalic acid, as occurs when they are oxidizer outside the bodx. Therefore, the most highly oxidized acid of the series, which is combustible in the body, namely glyoxylic acid, may be considered as the stage immediately preceding the earbon dioxide excreted. Glycol, $\mathrm{CH}_{2} \mathrm{OH}$. $\mathrm{CH}_{2} \mathrm{OH}$, is only partly combustible in the body without forming oxalic acid. Malonic acid, $\mathrm{CH}_{2}(\mathrm{COOH})_{2}$, tartronic acid, $\mathrm{CH} . \mathrm{OH}(\mathrm{COOH})_{2}$, mesoxalic acid, $(\mathrm{HO})_{2} \cdot \mathrm{C} .(\mathrm{COOH})_{2}$, glyceric acid, $\mathrm{CH}_{2} \cdot(\mathrm{OH}) . \mathrm{CH}(\mathrm{OH}) . \mathrm{COOH}$, are combustible and thus their production as intermediary stages in animal combustion is rendered possible. On the other hand, the body has the power to burn tartaric acid. $\mathrm{C}_{4} \mathrm{H}_{6} \mathrm{O}_{6}$, only to a slight extent. 


\section{CHAPTER XIII}

\section{THE EXCRETHONS OF THE BODY}

SEveril organs, the skin, the intestine and liver. the lungs and the kidneys, in addition to their other functions have the function of eliminating varions substances which are useless or harmful to the body. We place first among these substances the products formed in the decomposition of the foodstuffs. Substances also which enter the body in one way or another, and themselves exert a harmful influence are thrown out either unchanged or more or less transformed by the activity of some organ. These transformations in many cases are for the purpose of changing harmful substances, which cannot be eliminated at once, into relatively harmless ones. We have already become acquainted with an example of this in the formation of urea ont of aumonium salts (c.f. page 370 ). Here belong also the following phenomena :

In the putrefaction of proteid in the intestine there arise among other products indol, skatol, paracresol, phenol, phenyl-propionic acid, phenyl-acetic acid, paroxy-phenyl-acetic acid, paroxy-phenyl-propionie aeid, ete., all belonging to the aromatie scries-which in part pass into the eirculation. Of these the last two named (the so-ealled aromatic oxyacids), paroxy-phenyl-propionic acid, $\mathrm{C}_{6} \mathrm{H}_{4}(\mathrm{OII}) \cdot \mathrm{C}_{2} \mathrm{H}_{4}$. COOH, derived from tyrosin by the splitting off of ammonia, and the oxidation product of this acid, paroxy-phenyl-aeetie acid, $\mathrm{C}_{6} \mathrm{H}_{4}(\mathrm{OH})$. $\mathrm{CH}_{2}$. $\mathrm{COOH}$-these two pass out in the urine mostly unchanged. The others are not burned in the body, but before they come out in the urine, they undergo a synthetic transformation by which they are rendered innocuous.

The earliest known example of such transformations is the demonstration by Wöhler (1824) that benzoic acid, when ingested into the animal body, passes over into an aeid rich in carbon, but poor in nitrogen, namely hippurie aeid, and is excreted as such through the kidneys. Hippuric acid, $\mathrm{C}_{6} \mathrm{H}_{5}$. $\mathrm{CO}$

HN.CH ${ }_{2} \cdot \mathrm{COOH}$, is a compound of glyeocoll (amino-aeetic acid, $\mathrm{NH}_{2}, \mathrm{CH}_{2} \cdot \mathrm{COOH}$ ) with benzoic acid, which is an oxidation product of phenyl-propionic acid $\left(\mathrm{C}_{6} \mathrm{H}_{5} \cdot \mathrm{CH}_{2} \cdot \mathrm{CH}_{2}\right.$. COOHI) formed in intestinal putrefaction.

The synthesis of hippurie acid takes place in the dog exclusively in the kidneys (Sehmiedeberg and Bunge), but in the rabbit in other organs also such as the liver and museles. If salicylic acid, oxybenzoic acid, paroxy-benzoic acid, ete., instead of benzoic acid, be fed to mammals they all undergo transformations analogous to that of benzoic acid into hippurie acid, since like it they unite to a greater or less extent with glyeocoll. The acids thus formed have been designated as salicyluric, oxybenzurie, paroxybenzuric, etc. 
The following syntheses appear to take place in different organs of the body, especially in the liver:

Indol, $\mathrm{C}_{6} \mathrm{II}_{\text {Nú CH }}^{\mathrm{CH}}$ passes after absorption into indoxyl, $\mathrm{C}_{6} \mathrm{H}_{\mathrm{NH}}^{\mathrm{C}}$ and this body then unites with sulphuric acid into indoxyl-sulphuric acid, urine indican, $\mathrm{C}_{6} \mathrm{H}_{4}^{\mathrm{C}} \mathrm{CH}$

In an exactly similar way there arise from skatol or methyl-indol, C. $\mathrm{CH}_{3}$ $\mathrm{C}_{6} \mathrm{H}_{4} \mathrm{CH}$, first skatoxyl, $\mathrm{C}_{6} \mathrm{H}_{4}$ C.OI, and then, skatoxyl-sulphurie NH C. $\mathrm{CH}_{3}$ NH

aciel, $\mathrm{C}_{6} \mathrm{HI}_{4}^{\prime}$ C. $\mathrm{O} . \mathrm{SO}_{2}(\mathrm{OH})$; from phenol, $\mathrm{C}_{6} \mathrm{H}_{5} . \mathrm{OH}$, phenol-sulphuric acid, $\mathrm{NH}$

$\mathrm{C}_{6} \mathrm{H}_{6} \cdot \mathrm{O} . \mathrm{SO}_{2}(\mathrm{OH})$; from paracresol, $\mathrm{C}_{6} \mathrm{H}_{6}^{\prime} \stackrel{\mathrm{OH}}{\mathrm{CH}}$, paracresol-sulphuric aciel, $\mathrm{C}_{6} \mathrm{H}_{4} \backslash \mathrm{CH}_{3}-\mathrm{O}_{2}(\mathrm{OH})$

If the sulphuric acid available is not sufficient for the combination of the phenols, they are paired with glveuronie acid (page 376). This acid is an intermediary product of metabolism and is further decomposed except when it is protected from combustion by pairing with other substances.

We have already studied the processes of excretion in the intestine, in the liver and in the lungs. There remains for us to discuss excretion through the kidueys and the skin.

\section{FIRST SECTION}

\section{THE URINE AND ITS EXCRETION}

\section{§. THE URINE}

The urine is formed hy the action of the kidneys. It contains the most of the nitrogenous and sulphur-containing products of metalolism as well as a large number of other substances to be eliminated from the body.

\section{A. THE GENERAL PROPERTIES OF THE URINE}

The reaction of a sample of urine differs accorling to the indieator used. With phenolphthaleïn it is acid, with litmus acid, neutral or alkaline, with methyl orange, alkaline. This difference is referable to the properties of the different indicators, which, according to the theory worked out by Ostwald, represent weak acids or bases whose radieals as free ions possess other colors than those which the electrically neutral molecules pussess. Thus phenolphthalein in 
the nondissociable condition is colorless; as soon however as the solution is rendered alkaline a salt of high dissociability is formed, and the intensely red color of its negative ion comes to the fore. But in order that the reaction may appear with a very slight exeess of hydroxyl or hydrogen ions the acid or base used as the indicator must be very weak in comparison to the acid or base to be tested. The acidity of weak acids obriously can only be determined by the help of an indicator which itself is still weaker than the weakest of the acids to be tested; in the presence of weak bases the alkalinity can only be ascertained with the help of a somewhat stronger acid as indicator-e. g., methyl orange.

Now the urine contains weak acids such as $\mathrm{CO}_{2}$ and $\mathrm{H}_{3} \mathrm{PO}_{4}$ in considerable quantities and a rather weak base, ammonium in very small quantities. In order to obtain the true reaction of urine, one must, therefore, use a rery weak acid as indicator. Neither methyl orange nor litmus is weak enough to be liberated by carbon dioxide or to detect phosphoric acid as a dibasic, much less as a tribasic acid. Phemolphthalein, however, is sensitive to both, although the third hydrogen atom of phosphoric acid escapes it.

Writh phenolphthaleïn the reaction of the urine is always neutral or weakly acid. A plainly alkaline reaction is never met with except in urine which has suffered bacterial decomposition (Auerbach and Friedenthal).

By titration one may ascertain the true chemical acidity of the urine measured as the quantity of alkali which must be added to displace all the acid hydrogen with a metal. From the physico-chemical standpoint, however, acidity means the concentration of hydrogen ions present in the liquid. According to $\mathrm{r}$. Rhorer and Hoeber, 1 l. of urine contains on the average about 0.003-0.005 (minimum 0.0004, maximum 0.01) mg. of ionized hydrogen as compared with $0.0001 \mathrm{mg}$. in distilled water. This acidity corresponds to an acid which in $\frac{n}{30}$ solution is dissociated to $\frac{1}{100}$ per cent, and is some ten thonsand times less than that determined by titration.

In view of the rery complicated phrsico-ehemical relations of the urine, it is searcely possible to determine the share of the different constituents in its total aeidity.

Fresh urine as a rule is perfectly clear; but on standing it sometimes becomes turbid owing to the separation of urates. There also appears in it a weak. flocenlent precipitate (nubecula), which, according to K. A. H. Mörner. contains a special mucous substance (urine mucoid), probably formed in the mucous membrane of the urinary passages and mixed with the urine as a weak gelatinous solution.

The color of the urine depends to a certain extent upon its concentration, and raries with increasing concentration from straw yellow to dark reddish yellow and reddish brown. Its taste is salty. its odor peculiarly aromatic.

The quantity of urine depends upon many circumstances, and therefore varies considerably. The average quantity for an adult man may be estimated at about 1.500 c.c. per day.

The specific gravity of the urine also raries in man from $1.01 \%$ to 1.020 ; but it may fall as low as 1.002 and rise as high as $1.04 \%$.

The molecular concentration $(\Delta)$ of the urine, measured by the lowering of the freezing point, stands in a certain relation to the specifie gravity $(s)$, and 
can be estimated approximately by the formula: $\Delta=75(s-1)$. The relation between the moleeular concentration of organic $(\mathrm{Co})$ and inorganie $(\mathrm{Ci})$ molecules, $\frac{\mathrm{Co}}{(\mathrm{i}}$, is eommonly 0.75 (Burgarsky).

Trine injected intravenously into an animal produces an acute poisoning which results fatally. The toxieity of different urines appears to be somewhat different. and Bouchard designates as the toxic unit (urotoxy). the quantity (cubic centimeters per kilogram) of urine suffieient to kill a rabbit: this quantity varies from 30-60 c.e. According to Beck, the toxicity of normal urine depends upon the presence of potassium salts; however. there are alkaloidal substances in the urine which are present only in small quantities normally, but under abnormal conditions are probably eliminated in larger quantities. and these might therefore increase its toxicity.

\section{B. COMPOSITION OF URINE}

1. Erea. or carbamide (ef. page 320 ; also Fig. 139), is the most important and most abundant constituent of urine. The daily excretion depends upon the supply of proteid in the food. On Toit's normal ration for a moderate worker, the quantity is about $30 \mathrm{~g}$. per day. Usually two to three per cent of the urine is urea. Abont ninety per cent of the total quantity of nitrogen in the urine of man appears in the form of urea.

Trea was first separated from urine by Rouelle (17:3). In 182s Wöhler sueceeded in preparing it synthetically by heating a solution of ammonium isocranate:

$$
\mathrm{C}=\underset{\substack{\text { Ammonium } \\ \text { isocsanate }}}{\mathrm{N} \cdot \mathrm{NH}_{4}}=\mathrm{CO} \underset{\substack{\mathrm{NH}_{2} \\ \text { Urea }}}{\mathrm{NH}_{2}}
$$

This synthesis was the first instance of the production by artificial means of a substance oceurring in the animal body, and led the way for all the organie syntheses possible to modern seience. For this reason Berżelius proposed that the radical of urea be named proin (signifying "dawn").

The origin of urea in the animal body has already been considered in Chapter SII. Here we mav add the following data from Schöndorff with regard to the percentage of urea in the different organs. These relate to a dog of $32 \mathrm{~kg}$. weight after abundant meat feeding. The organs investigated amounted altogether to fifty-three per cent of the entire body.

\begin{tabular}{|c|c|c|}
\hline Orgas: & Per cent of urea. & Absolute quantity in $\mathrm{gms}$. \\
\hline 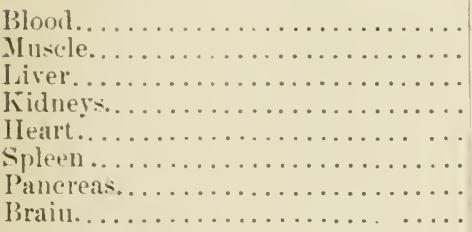 & 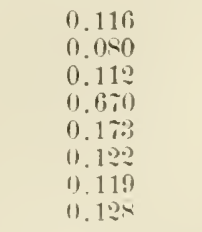 & $\begin{array}{r}1.36 \\
12.1 .5 \\
0.94 \\
1.04 \\
0.29 \\
0.12 \\
0.06 \\
0.92\end{array}$ \\
\hline Total. ................ & & 16.88 \\
\hline
\end{tabular}


The percentage of urea in the individual organs, with the exeeption of the muscles. the heart and the kidners, is thus about the same as that of the blood-i.e., on the arerage 0.12 per cent. The high percentage in the kidneys is to be explained by the presence there of urea formed in other organs, and which is necessarily included in making the analysis.

:. Oxyproteï acid was di-corered by Bondzynski and Gottlieh (189i). Its barimm salt, according to the analyses of rarious authors, has the follow-

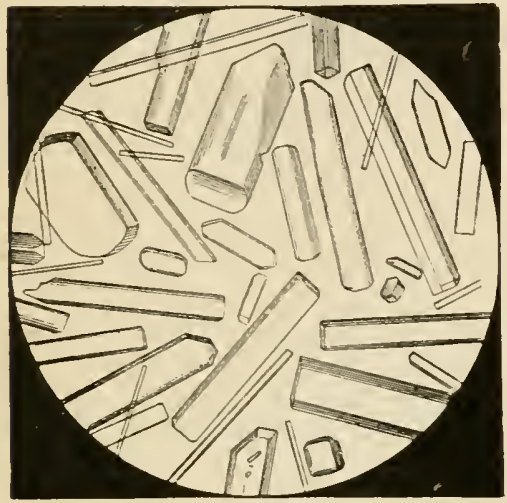

FIG. 139 .

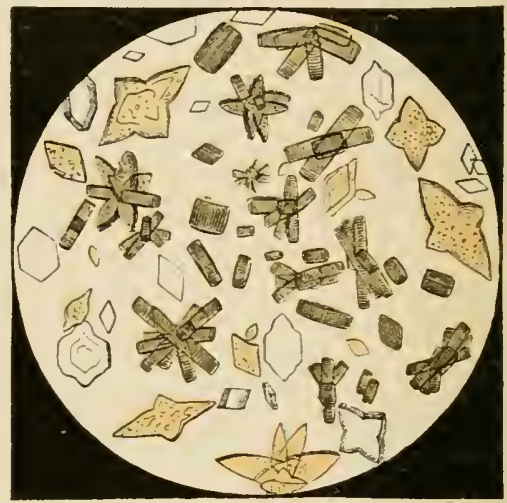

FIg. 140 .

Fig. 139.-Crystals of urea, obtained from human urine after long-continued evaporation, after Funke.

Fig. 140.-Crystals of uric acid, after Funke. Some of the forms represented were obtained by solution and recrystallization of chemically pure uric acid; some by treatment of urinary sediments containing urates with mineral acids; some by spontaneous crystallization from urine. Most of the crystals are tinged with urea.

ing composition : C 2r.5-30.0. H 3.9-4.1. N r.0-10.6, S 1.6-1.8. Ba 28. $026.5-31.6$. The quantity of this acid (calculated as the Ba salt) excreted in twenty-four hours amounts to not less than $3-4 \mathrm{~g}$.

3. Creatinin, Methyl-glyco-cyanamid, $\mathrm{NH}: \mathrm{C}^{\mathrm{NH}}-\mathrm{CH}\left(\mathrm{CH}_{3}\right)$. CH extent of about 0.25 per cent in the urine. The daily output in the urine amounts to $0.6-2.1 \mathrm{~g}$. and may be estimated at $1 \mathrm{~g}$. as a mean value.

4. Ammonia, $\mathrm{NH}_{3}$. The daily quantity amounts to $0.5-0.9 \mathrm{~g} .=$ two to four per cent of the nitrogen in the urine. The ratio of ammonia to urea is approximately $1: 40$ (cf. page $3: 1$ ).

5. Uric acid (Figs. 140 and 141) 2, 6, 8-tri-oxypurin (page 3:3) occurs in the urine of man and the mammals only in small quantities (about $0.7 \mathrm{~g}$. per day). This is a dibasic acid. Of the alkaline urates, the neutral potassium and lithium salts are the most soluble, the acid ammonium salt least so; the urates of the alkaline earths are also very difficultly soluble. In the urine, uric acid probally occurs as monosodium urate which is held in solution mainly by disodium phosphate.

6. Urie acid is derived from the purin bases and is in its turn oxidized to allantoin (cf. page 3r3). These substances also occur in the urine: the purin bases to the extent of $0.08-0.13 \mathrm{~g}$. (mean). 
Of the total organic substance in the urine, urea, creatinin, ammonia, uric acid and purin bases together constitute serenty-five per cent, but they contain ninety-three per cent of the total nitrogen of the urine (Donzé and Lamblirg $)$.

7. Oxalic acid occurs in very slight traces.

8. Mippuric acid (Fig. 142), benzoyl-glycocoll (page 3\%8) occurs in considerable quantity in the urine of herbirorous animals and in smaller quantity in the urine of man. In the latter on ordinary diet it amounts to only about $0.7 \mathrm{~g}$. per day; after a plentiful quantity of regetable foods it may reach $2 \mathrm{~g}$. or more per day.

9. The ethercal sulphates and the aromatic oxyacids already mentioned at page 379. The quantity of the former per day in the urine of man is only about $0.09-0.62 \mathrm{~g}$.; the oxyacids amount to about 0.03 per day.

10. Among the pigments of the urine the iron-free, nitrogenous urochrome, carefully studied by Garrod, is the most important. Besides, there are present in normal urine: the red pigment uroprythrin, hamatoporphyrin (in very small quantities), and urobilin, first described by Jaffé. 'The latter has a red or reddish-yellow color, and in the opinion of many authors is identical with hydrobilirubin $\left(\mathrm{C}_{32} \mathrm{H}_{40} \mathrm{~N}_{4} \mathrm{O}_{7}\right)$ : but this is contested by others on the ground that hydrobilirubin contains twice as much nitrogen as urobilin.

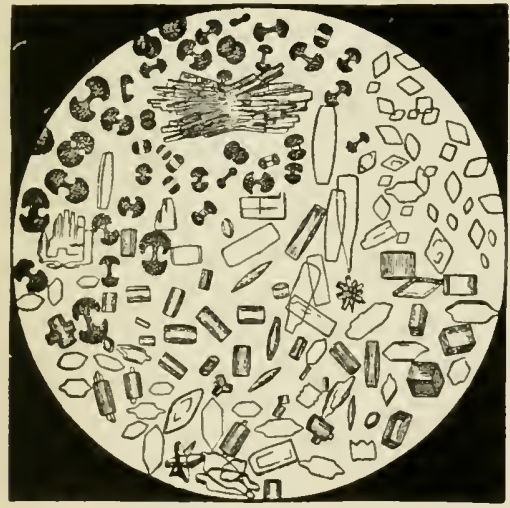

FIG. 141.

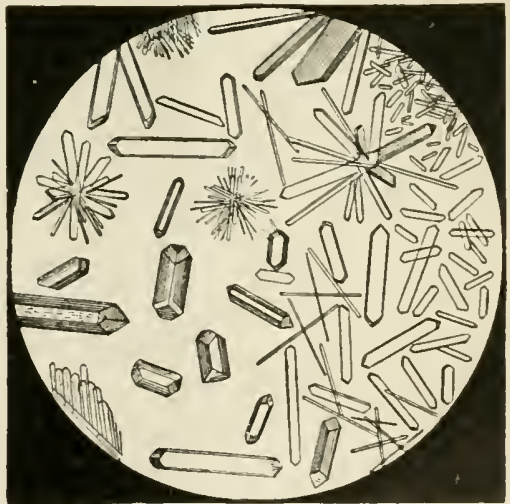

Fig, 142 .

Fig. 141.-Still other forms of uric-acid crystals, after Funke. The "wheat stone" and "shcaf" crystals especially are shown. Some of them were found ready formed in urinary sediments; others were obtained by treatment of ordinary sediments containing sodium urate with acicls.

Fig. 142.-Hippuric-acid crystals, obtained from human urine by recrystallization from a water solution, after Funke.

Sterkobilin (cf. page 295 ), on the other hand, has exactly the same composition as mohilin. At all events urobilin, as well as other piginents, probably stands in a close relationship both to the bile pigments and to the blood pigments.

11. The urine contains also under perfectly normal circumstances reducing substances and proteids, though in very small quantities.

Besides uric acid and creatinin, the reducing substances are dextrose, isomaltose (?), animal gum, and conjugated compounds of glycuronic acid (page 
376. The redueing power of normal urine corresponds to a $0.15-0.6$-per-eent solution of dextrose.

Heller's test (cf. page 69) is commonly used to demonstrate proteid in the urine. A urine which does not give this reaetion is generally regarded as free of proteid. And yet there is proteid, chiefly serum albumin, even in such urine.

12. The inorganic constituents of the urine on a normal diet amount to about $25 \mathrm{~g}$. per day. For the most part they come from the ingested food, and consequently decrease in fasting. Naturally their percentages vary greatly; hence the following table is only for the purpose of giving a general idea of the arerage quantities:

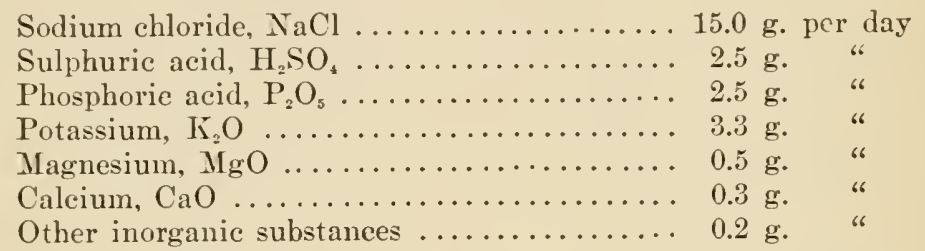

Besides these the urine contains $4-5$ vols. per cent of $\mathrm{CO}_{2}$ which for the most part is physically absorbed, but occurs also in the form of acid carbonates.

13. Accidental constituents. The urine may contain either in solution or suspension a large number of different bodies coming from substances ingested for one reason or another, or originating from abnormal processes in the body. I shall merely enumerate the most important of these:

(a) Blood, blood pigments and their derivatives; blood corpuscles, hæmoglobin, methæmoglobin, hæmatin, melanin, etc.

(b) Bile acids, bile pigments, and their transformed products.

(c) Leucin, tyrosin, and dioxy-phenyl-acetic aeid, $\mathrm{C}_{6} \mathrm{H}_{3}(\mathrm{OH})_{2} \cdot \mathrm{CH}_{2} \cdot \mathrm{COOH}$.

(d) Proteid.

(e) Sugar.

(f) Acetic acid, $\beta$-oxybutyric acid and acetone.

(g) Drugs, either as sueh or as transformed produets.

\section{\$2. THE EXCRETION OF URINE}

In no other secreting organ are the peculiarities of structure so significant for a conception of its function as in the kidney. It is therefore necessary to discuss the microscopic structure of the kidney here somewhat in detail.

\section{A. STRUCTURE OF THE KIDNEYS}

The larger branehes of the renal artery (Fig. 143) run along the outer surface of the pyramids to their base and there form an anastomosing network. From this network branches pass toward the surface of the kidney (radial arteries), and others pass off in tufts toward the pelvis of the kidney. The individual branches of the latter run between bundles of urinary tubules in the pyramids.

The radial arteries send out small branehes, vasa afferentia, which soon break up in the so-called glomeruli of the Malpighian corpuseles presently to be 
deseribed. From these, a new vessel, the ras efferens, arises and this in its turn breaks up into a capillary network which embraces the kidney tubules. Those vasa efferentia which belong to the deeper layers of the cortex push down into the outer layer of the medulla, and from here run between the renal tubules and break up into tufts

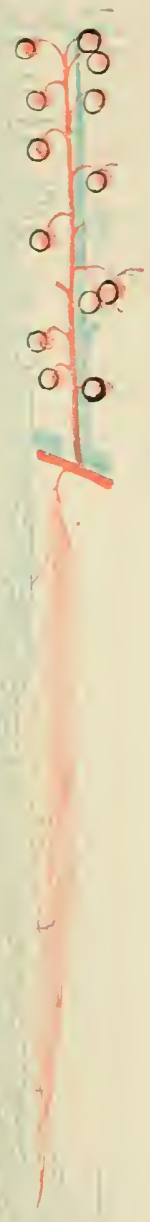

Fig. 143.- Schema representing the distribution of the blood ressels of the kidney, after Ludwig. Arteries red, veins blue. of vessels, whence again proceed capillaries to the tubules.

From the capillaries of the renal cortex the blood collects in venous trunks which run parallel with the radial arteries to the outer layer of the medulla, and like them form an anastomosing network at the base of the pyramids. Into this

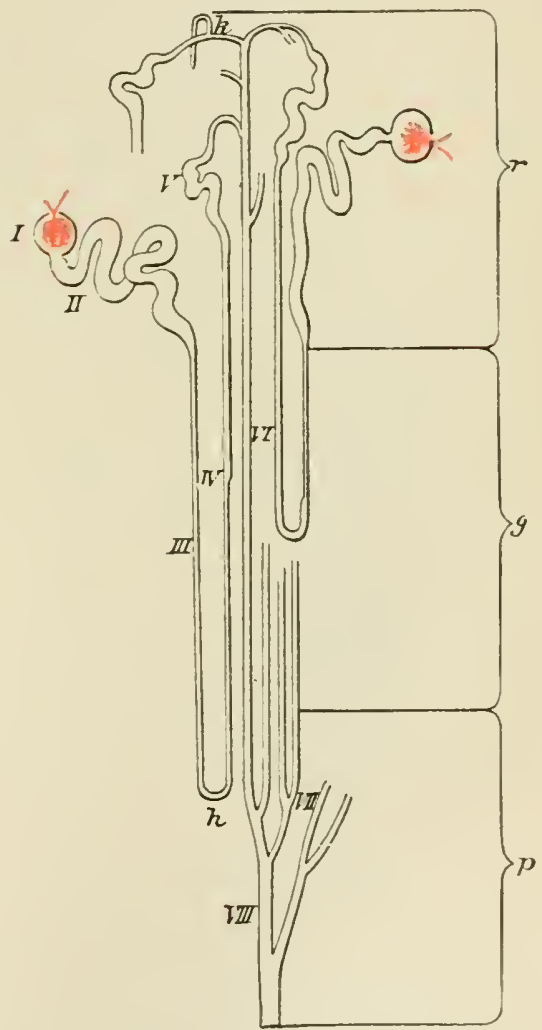

Fig. 144.-Schematic representations of the secreting and eonducting elements of the kidney, after Iudwig. $I$, Bowman's rapsule; $I I$, first convoluted tubule; $I I I, I T$, Henle's loop; I. second convoluted tubule: $V I$, collecting tubule; $r$, cortex; $q$, medulla; $p$, papilla.

network empty the reins from the medullary substance, which, like the arteries, run in the interstices between the reual tubules and converge forming tufted groups.

The glomerulus interpolated between the vas afferens and the vas efferens has the following structure. The afferent arteriole breaks up into several 
branches, each of which by repeated division forms a lobule composed of sereral collateral vessels. These vessels do not anastomose, but unite finally to form a simple ras efferens, the begiming of which lies in the middle of the glomerulus. They have a simple wall and hence are to be regarded as capillaries. In the kidney therefore the blood passes through two sets of capillaries, one in the glomeruli and the other between the secreting elements.

The secreting and conducting elements of the kidney are numerous, muchconroluted tubules, which begin at the glomeruli and end on the free surface of the papillae. The glomerulns is surrounded by a thin capsule (the capsule of Bowman), the whole constituting a Malpighian corpuscle (Fig. 14t, I). The capsule is a resicle composed of thin epithelial cells of 0.13 to $0.22 \mathrm{~mm}$. diameter, and, like the serous sacs, consists of two lavers, a visceral and a parietal. The former layer is closely applied to the surface of the glomerulus and is reflected at the place where the ressels enter the glomerulus to form the latter layer. From the point opposite the entrance of the ressels the capsule is continued into the renal tubule. In the transition to this there comes first a short, narrow neck; then follows a much conroluted portion (II) $0.045 \mathrm{~mm}$. in diameter which reaches down to and enters the outer layer of the medullary substance. Here the tubule suddenly diminishes in size very considerably (the diameter is only $0.01+\mathrm{mm}$.) and passes into the medullary substance, then turns back, forming a loop (loop of Henle, III and IV) and runs toward the cortex. Sooner or later it becomes enlarged $(0.026 \mathrm{~mm}$.) and soon thereafter becomes convoluted again $(\mathrm{V})$. Then it unites by means of a narrow connecting portion with a collecting tubule (VI).

Up to this point each tubule is independent of every other. forming no anastomoses. The collecting tubes, however, in their course through the medullary substance, unite repeatedly with others, so that finally the number of tubes opening on the surface of a papilla is only about fourteen to twenty, whereas there are from 4,000 to 6,000 collecting tubules tributary to them.

The epithelium of the urinary tubule and of the collecting tubule is different in different divisions. In the human fotus Bowman's capsule is composed of cubical cells; in the newborn child the cells are flatter, and later they become rery thin. The convoluted tubules, the thicker portion of Henle's loop, and the collecting tubule are lined with fairly tall epithelial cells, which present minor differences in the different divisions named. In the narrower portion of Henle's loop the epithelium consists of clear, flat, spindle-shaped cells.

\section{B. MECHANISM OF THE EXCRETION OF URINE}

Any attempt to explain theoretically the process of secretion in the kidneys must take into account the remarkable arrangement of its blood ressels and the renal tubules.

In the glomeruli the blood flowing in is suddenly dirided into a considerable number of tiny streams, which of course mist faror the passage of constituents into the capsule. Moreorer, the vas efferens has a smaller diameter than the vas afferens, and it is divided up within a short space into another true capillary network. The resistance distal to the glomeruli must therefore be inuch greater than the resistance proximal to them. which means that the blood must flow through the glomeruli under a relatively high pressure. If now the further fact that the renal tubules begin with the Bowman's capsule surrounding the glomeruli be considered, it cannot readily be denied that. seen merely from the anatomical point of view, the glonerulus and the 
eapsule must play an extremely important part in the secretion of urine. A theoretical account of the kidney function must assign some purpose also for the tortuous course of the tubules up to the point where they enter the collecting tubules.

This has been done in the view advanced by Ludwig and supported by many experiments, namely that a process of filtration takes place from the glomerulus into the capsule, and that the filtrate represents a very dilute urine, which during its passage throngh the tubules becomes gradually concentrated by transfusion of water into the lymph bathing their outer surface.

To test this view we have first of all to form some conception of the physicochemical processes necessary for the filtration of liquid through the capsular epithelium. As Tammann was the first to show, the latter cannot be regarded as a semipermeable membrane, for, if it were, a blood pressure sufficient to overcome the osmotic pressure of the plasma-sereral atmospheres-would be required to force the filtrate through. On this account Tammann considers the epithelium completely permeable to all the crystalloids dissolved in the urine, and impermeable only to the colloids. In order to separate a proteid-free filtrate of the composition of the crystalloids found in the plasma, the blood pressure need only be high enough to overcome the osmotic pressure of the colloids occurring there. The latter according to Starling amounts to about $25-30 \mathrm{~mm}$. Hg.

However, the osmotic pressure of the sugar in the blood (more than 100 $\mathrm{mm}$. IIg.) is not taken into account in this calculation; whereas it may be considered that the eapsular epithelium is permeable to sugar just as to the other crystalloids. It is possible too that the sugar is not free, but occurs in the blood in chemical composition with other substances such as lecithin or proteid. If this were true the osmotic pressure occasioned by the sugar would of course be considerably lower than if it were dissolved as such in the plasma.

The lowest pressure in the glomeruli at which a production of urine could take place would thus be about $25-30 \mathrm{~mm}$. Hg. And yet Gottlieb and Magnus have shown that under the influence of diuretic substances, separation of urine can take place with a carotid pressure of only 6-9 $\mathrm{mm}$. $\mathrm{Hg}$.

- Besides this difficulty we have another just as little to be explained from the standpoint of the filtration hypothesis, and that is this: if the supply of the blood to the kidney be completely interrupted by clamping the renal artery for a short time, say one and one-half minutes, the formation of urine stops and is resumed again only after a considerable time (as much as forty-five minutes). The properties of a perfectly inert filter could scarcely be changed to such an extent by anæmia of so short a duration.

The second part of Ludwig's theory likewise meets with several difficulties. If the glomerular filtrate as above assumed has the same composition and therefore the same osmotic pressure as the blood plasma (with the exception of the colloids) then only the osmotic pressure occasioned by the colloids can have anything to do with the concentration of the filtrate. Whether or not this force is sufficient to produce the necessary transfusion of water back into the lymph has not yet been decided. Moreover, the proportion of crystalloids in the urine is quite different from that in the blood. It requires more than the mere absorption of water to get a fluid with the properties of the urine ont of such a filtrate as we are able to suppose this to be; we must assume an unequal absorption of different constituents. Finally, it would be impossible for this fluid to be absorbed back into the lymph by purely osmotic processes, for the osmotic pressure of the urine as a rule is higher than that of the blood plasma. 
For these and other reasons those authors who regard the process in the glomeruli as a pure filtration are themselves inclined to explain the reabsorption from the urinary tubules postulated by this theory, as an active process carried on in virtue of the vital properties of the parenchyma cells. By so doing. howerer, the fundamental position of Ludwig's theory is surrendered. for that theory set out to give a purely physico-chemical explanation of the secretion of urine, without reference to vital processes.

But can it be regarded as proved that a reabsorption of fluid passed through the capsule actually takes place in the urinary tubules? Is it not possible that we have here not an absorptive but a secretory process?

In order to answer this question Heidenhain carried out some experiments on the elimination of sodium indigosulphate, which is easily recognized in microscopical preparations, and reached the conclusion that this salt is thrown out by the epithelium of the urinary tubules. From analngy he concluded that the same is true of urea and other specific constituents of the urine, and that therefore the tubules have the function of enriching the fluid coming from the capsule with solid constituents.

Direct observations on the elimination of urea are not feasible because there are no micro-chemical reactions by which urea can be recognized. But in birds and reptiles it is not a difficult matter to demonstrate uric acid mieroscopically. And ret investigators of the subject have not succeeded in satisfactorily demonstrating uric acid within the epithelial cells. Hence, the mode of separation of sodium indigosulphate cannot be regarded as determinative for the elimination of the normal constituents of the urine. IIoreover. the microscopical findings after injection of dyes are not harmonious, for the pictures obtained have been regarded by other authors. like $r$. Sobieranski. as the indication of an absorptive process going on in the urinary tubules.

The following experimental fact speaks strongly for secretion by the epithelium of the urinary tubules. The frog's kidney receires its blood ressels partly from the renal artery, partly from the renal-portal vein. The former provides the glomerulus, the latter the tubules. As was remarked by Nussbaum, and later verified by Beddard, the glomeruli or the urinary tubules can be thrown out by tying off the one or the other of these vessels. After tying the renal artery the flow of urine ceases entirely. If the fluid coming through the capsule of Bowman during its passage along the tubule were to become thicker by absorption of water, then tying the renal portal ought to produce an increased flow of urine. But according to Gurewitsch this is not true; instead, the quantity of urine is reduced by the operation.

If this observation proves to be absolutely correct, it constitutes a conclusive argument against the doctrine of absorption in the renal tubules. Accordingly, the epithelium would hare the function of taking up the specific constituents of the urine from the blood and of delivering them to the urinary tubules.

We come therefore for the present to the following view. first expressed by Bowman and further elaborated by Heidenhain, concerning the activity of the kidneys. The cells covering the glomerulus give out water and salts by a true process of secretion, those of the convoluted tubules and of 
the wide part of Henle's loop secrete the specifie constituents of the urine and water.

As an indirect support of this theory, the following consequence of the filtration hypothesis, emphasized by Heidenhain, is to be considered. If the outflow of fluid from the glomeruli takes place by filtration, the filtrate cannot be richer in urea than the blood; it would contain therefore about 0.05 per cent urea. Since however the urine as voided contains two per cent of urea, the filtrate must be concentrated forty times. With a daily excretion of $1,500 \mathrm{~g}$. urine containing $30 \mathrm{~g}$. urea the total quantity of filtrate would thus amount to $60,000 \mathrm{~g}$. of which $58,500 \mathrm{~g}$. would have to be absorbed again into the urinary tubules.

Various other circumstances favor the idea of a secretory process in the kidneys. (1) The excretion of urine occasions a measurable rise of temperature (the temperature of the urine may be $0.4^{\circ} \mathrm{C}$. higher than that of the blood) (Grijns). (2) Atropin which is poisonous for all glands reduces the excretion of urine to a considerable extent (Thompson), although pilocarpine which is stimulating for glands in general has no effect on the activity of the kidneys (Loewi). (3) When by feeding benzoic acid and glycocoll the kidneys are called upon to synthesize hippuric acid (ef. page 378 ), the output of $\mathrm{NaCl}$ in the urine is considerably increased, notwithstanding that the flow of blood and the pereentage composition of $\mathrm{NaCl}$ in it remain constant (Asher).

The amount of work done by the kidneys depends essentially on two factors, namely, the volume of the blood flowing through them. and the percentage of diuretic substances in the blood.

The influence of the blood flow was first established by Ludwig and his pupils on the basis of a great many experimental observations. Everything which inereases the blood flow, such as great but not excessive distention of the vaseular system, extensive vasoconstriction with the renal nerves eut, ete., intensifies the seeretion of urine. Conversely it falls pari passu with the llood flow, whether that fall be oceasioned by diminution of the general blood pressure due to stimulation of the ragus, to bleeding, to seetion of the spinal cord, or be eaused by a local eonstriction or empression of the renal ressels.

Sinee every ehange of the arterial blood supply alters the pressure in the eapillaries in the same direction, the above-mentioned facts were adduced as the most important support for the filtration hypothesis; for it is evident that filtration through the glomeruli should be more abundant, the higher the pressure brought to bear on them. Likewise if the exeretion of urine be the result of a secretory process, the rariations of the blood flow are of rast importance, for by this means the activity of the kidney eells ean be influenced in one way or the other.

The action of diuretic substances is shown most clearly by experiments on the secretion of urine with the renal veins compressed. It is well known also that the kidney is surrounded by a tolerably firm capsule, and that its mass is incompressible. Here, as in the brain (cf. page ?+1), venous stasis must, therefore, cause an arterial anæmia. Consequently when the renal vein or inferior rena cara is eonstricted. the secretion of urine deelines or stops altogether. If, however, a solution of sodium nitrate, for example. be then injeeted into the blood, the urine gushes out in a strong stream, even if the 
general blood pressure be low (l'aneth). It is erident that the same effect ean be produced with the renal circulation unobstrueted.

To the diuretic substances belong: urea, common salt, sodium nitrate, eaffein, grape sugar, peptone, albumoses, etc. Their effect undoubtedly depends in part upon the accompanying dilatation of the renal vessels; but it is connected also with a rise in the osmotic pressure of the blood occasioned by these substances, and the consequent abstraction of water from the tissue spaces into the blood ressels. In this way the blood is diluted, and the ressels are more tensely filled, the result being a more copious flow of blood through the kidneys. Here we have almost the same process as when water is slowly transfused into a vein after a certain quantity has been injected; the excretion of urine increases up to a certain point, beyond which the transfusion and excretion keep pace with each other.

The effects of diuretic substances cannot, however, be explained from this point of view alone. For there are various experimental facts which indicate that the irigested substance stimulates the kidneys to increased activity, quite independently of changes in the diameter of the blood ressels, etc., and that, therefore, these substances are specific stimuli for the kidney cells.

Finally, the general condition of the body plays a part in the secretion of the urine which is not to be neglected. When certain diureties are given to a body poor in sodium ehloride, there is no increase in the excretion of $\mathrm{NaCl}$. Notwithstanding the diuresis, the body holds on to its $\mathrm{NaCl}$ very energetically, giving it up only in the smallest possible quantities. But in eases where the body has plenty of $\mathrm{NaCl}$. whenever there is a strong seeretion of urine, there is also an abundant output of this salt.

It has long beeu known that one kidney is sufficient for all purposes of metabolism. One can even remove as much as two-thirds of the kidney substance and still leave an efficient excretory apparatus. Here moreover we meet the remarkable fact that the renal secretion increases considerably and permanently. At the same time the elimination of urea is increased and animals die within two to six weeks in spite of a fairly good appetite (Bradford). IIow this phenomenon is to be explained or what theoretical weight it has, we are not able to say at present.

Nothing is known which would indieate the presence of secretory nerves to the kidneys. It is true that by various operations on the central nervous system or on peripheral nerves, changes in the seeretion of urine may be obtained; but all these admit of an explanation as vasomotor effects. The secretion continues also, though somewhat diminished, after division of the nerres running along the renal vessels. So far, then. as we are able to judge at present, the secretion of urine is accomplished by the influence of the urineproducing substance in the blood. and is regulated by variations in the quantity and the quality of these substances, as well as by alterations in the blood supply to the kidney.

\section{§3. MICTURITION}

From the pelvis of the kidney the urine flows through the ureters into the bladder, remains there for a time, and is finally expelled at varying intervals. 


\section{A. THE URETERS}

Contractions of the ureters begin always at the upper end and pass progressively downward to the bladder, but do not involve the musculature of the latter. They appear to be started by the entrance of the urine into the ureters themselves. After one contraction the lumen gradually fills again at its upper end, until the next one follows.

In the ureters of man subjected to direct observation it has been found that as a rule the bladder ends of the two do not contract at the same time, that in the same ureter the contractions do not succed each other at regular intervals, and that the total quantity of urine eonveyed in a unit of time varies greatly. The maximum quantity delirered to the bladder by a single contraction is placed at 4 e.e. On the contrary, Bardier and Frankel have found that the How of urine from the ureters of dogs is generally pretty uniform whether one or both be considered.

Fagge states that stimulation of the hypogastric nerre produces a series of contractions of the ureter. Furthermore, the ureter when entirely eut out of the body contraets rhythmically. Whether these contractions are due to ganglion cells present in the wall of the ureter, concerning whose occurrence authors still differ, or whether they are due essentially to the automatic activity of the musculature of the wall (Engelmam), is not ret decided.

\section{B. THE URINARY BLADDER}

The ureters pierce the bladder wall obliquely. The greater the pressure inside the bladder becomes, the more securely are the mouths of the ureters elosed; the consequence of which is that the return of urine from the bladder to the ureters is prevented. However, this elosure is not absolutely seeure; for although no return flow is possible so long as the bladder wall is passively stretched, it may happen when the wall contracts, as it will, for the purpose of preventing excessive distention. Entrance to the ureter is possible even then onls at the end of a contraction of the ureter itself. when its mouth is open. In the dng, each mouth is guarded by a strong muscular band. If this band be cut, regurgitation is comparaticely easy. From the ureter the urine may pass on into the pelvis of the kidnes and be presed into the lymphaties and the renal tubules, thence in some way or other into the renal ressels. Even solid matters from the minary blarlder can in some such way reach the general eirculation (L. Lewin).

The closure of the external opening of the bladder appears to be accomplished mainly by its anatomical position. for after death when the voluntary sphineters are relaxed. the urine does not escape. However, the bladder will stand a stronger intermal pressure, without being emptied, during life than it will after deatl. The difference is due to the external sphincter and the so-called internal sphincter-i.e.. the strong band of muscle fibers beginning on the neck of the blatiler and reaching to the prostate (Rehfisch).

'The desire to urinate is in all likelihool roused primarily by the sense of fulluess of the bladder. This is preceded by a greater iegree of tension of the bladder wall. Cold and warm fluids in the bladder also canse the sensation named and the consequent desire to urinate, but indifferent fluids at the temperature of the bonly. especially urine. are not felt at all. Stimulation of the prostatic part of the urethria is felt. but does not pro- 
duce the desire to empty the bladder: hence the doctrine that this desire is due to the eseape of the urine into the urethra is not correct (Guyon). The flow of urine can be suppressed by roluntary contraction of the outer sphincter (probably also of the imner).

Jicturition results from a roluntary relaxation of the external sphincter. whereupon the reflex contraction of the whole musculature of the bladder,

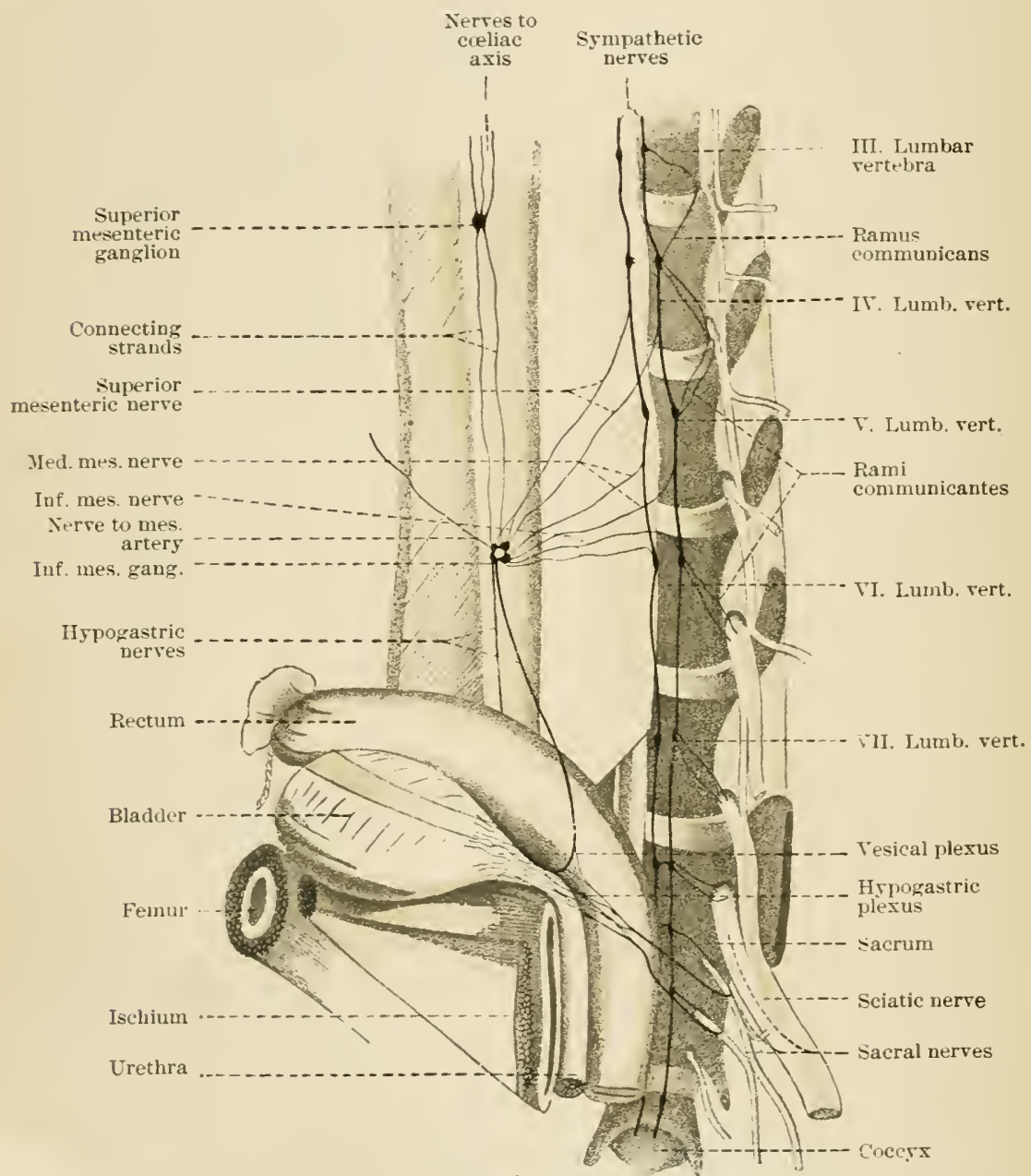

Fig. 145.-The nerves of the bladder, after Nawrocki and Skabitschewsky.

including that of the internal sphincter. follows. A large part of the longitudinal fibers pass over without interruption into the fibers of the sphineteran arrangement which insures the dilatation of the opening. (Rehfisch adrocates the riew that the internal sphincter also relaxes when the passage is opened.) Ificturition is aided by the bulbo-carernosus muscle. in that it compreses the bulbous urethre. thin expelling the contents of the latter. Ab- 
dominal pressure plays no essential part in micturition, and unaided is not sufficient to empty the bladder.

The bladder receires its motor nerves in part from the lumbar. in part from the sacral nerves (Fig. 14.5). The former in the dog emerge in the second to fourth lumbar roots and run through the lumbar part of the srmpathetic, the mesenteric nerves. the inferior mesenteric ganglion, the hypogastric nerves and the hypogastric plexus to the resical plexus. The sacral nerres arise from the second to fourth sacral roots, and pass in the neri errigentes. through the hypogastric plexus to the plexus of the bladder.

Both the circular and the longitudinal muscle fibers are supplied through these nerres: action extends in part also to the opposite side. so that the function of the bladder is not impaired if the nerves of one side only are uninjured.

According to v. Zeissl. Rehfisch, and others, the sphineter of the bladder is relaxed by stimulation of the nerrus errigens: C. Stewart has observed also a relaxation of the contraeted bladder under the influence of these nerves. Such an inhibiting effect, however, is positively denied by other authors.

A bilateral center for the control of the bladder is located in the lumbar cord (Goltz). Each half of this center has control of the entire bladder. Besiles. the higher parts of the central nerrous system exert an influence on the bladder. Contractions (in the cat) are obtained by stimulation of the anterior portion of the sigmoid grrus of the cerebrum. The conducting pathway is said to pass through the thalamus, the crura cerebri, the pons and the medulla to the spinal cord. In the cord the paths traverse the posterior section of the lateral columns. and are direct as far as the lumbar cord (and the inferior mesenteric ganglion) where they undergo a partial crosing ( $\mathrm{C}$. stewart).

These centers are roused by rarious reflex influences. contractions of the bladder haring been observed as the result of stimulation of all kinds of afferent nerves except the ragus. Of still greater interest are the true afferent rerves from the bladter which reach the cord mainly by the second and third posterior sacral roots. The reflex center lies between the third and fifth Iumbar roots, and the sacral nerres to the bladder only contain the efferent fiber.- Contractions are reflexly produced also by stimulation of the central end of the hypogastric nerres, the inferior mesenteric ganglion in this case astuming the rôle of a reflex center (Nawrocki and skabitschewste cf., howerer. "axon reflex" in ('hapter XXII).

The bladder is not absolutely dependent on the coopperation of the central nerrous system in carrying out its morements. Dogs, whose spinal cord was extirpated below the thoracie portion, showed at first a greater or lesis disturbance of the hadder function. but the condition gradually improved. the urine was expelled spontaneously and in larger quantities at a time. and after some months micturition was performed in a manner perfectly adequate for the continuance of health (Goltz and Ewald).

Tnder normal cireumstances the urine in the blathler does not undergo any visible changes, either by diffusion or absorption. Even with forced retention of the urine diffusion is ton slight to be held responsible for any of the symptoms acemplanying that condition. 


\section{SECOND SECTION}

\section{EXCRETION THROUGH THE SKIN}

Tarious substances are eliminated by the skin through the sebaceous and sweat glands. as well as through the so-called insensible perspiration. And ret secretion through the skin has an essentially different purpose from the excretion of urine and faces. for its object is partly to protect the skin from varions sorts of injuries, partly to play a leading part in the regulation of the body temperature.

\section{§. THE SEBACEOUS GLANDS}

With the exception of the palm of the hand and the sole of the foot, the skin everywhere contains sebaceous glands. which secrete the so-called sebum. Freshly secreted, this is an oily, semifluid mass, which hardens into a shining

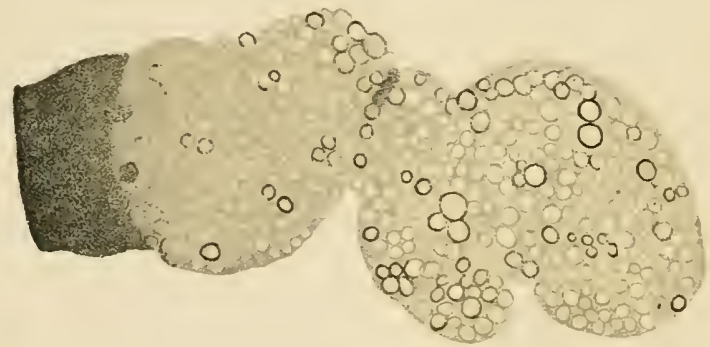

FIG. 146.-Portion of the preputial gland of the mouse, after treatment with osmic acid, after Altmann.

greasy coat on the surface of the skin, and consists of proteid substances, fat and cholesterin. By means of this secretion the skin is oiled and is thereby rendered soft. pliant and almost impervious to water. Eren after a warm bath, only those parts of the skin which contain no sebaceous glands exhibit distinct traces of the effect of water. The skin in a bath at $32.5^{\circ} \mathrm{C}$. takes up alont $0.0006 \mathrm{~g}$. of water per square centimeter of surface, and in a bath at $39.5^{\circ}$ (. $.0 .0048 \mathrm{~g}$. For the entire skin (? sq. m.) this would amount to 12 and $96 \mathrm{~g}$. respectively (Spitta). The hair also owes its pliancy to the sebum.

Fig. 146, which represents a portion of the preputial gland of a mouse. will give some idea of the formation of the sebum. The resicular end of the fundus is filled with spherical granules, the periphery of which is formed br a fatty membrane of greater or less thickness. Nuclei and cell boundaries are not visible, being obscured by the granular structures. In the middle portion of the fundus we see the ring-shaped gramules more and more fused together, until in the mouth a compact black mass is formed. We find the same black-colored secretion throughout the ducts of the gland (Altmann).

Certain experimental facts appear to indicate that the secretion of sebum is under the influence of the simpathetic nerves (Arloing). 


\section{§ 2. EXCRETION OF SWEAT}

\section{A. COMPOSITION AND PROPERTIES}

Sweat is the thinnest of all the body fluids, and, when filtered, is clear and colorless, and has a specific gravity of $1.003-1.008$. Its reaction to litmus may be acid, neutral or alkaline; its taste is salty; its odor is unpleasant and differs for the different portions of the body. The odor is destroyed by heating it up to $110^{\circ} \mathrm{C}$.

In the following table two analyses of sweat are given. The one by Harnack is taken from the sweat of a rheumatic patient, secreted in one to two hours in a vapor bath; the other by Camerer, Jr., was taken from sweat seereted in an electric-light bath in the course of seventy-fire to ninety minutes.

\begin{tabular}{|c|c|c|}
\hline & Harnack. & Camerer, Jr. \\
\hline 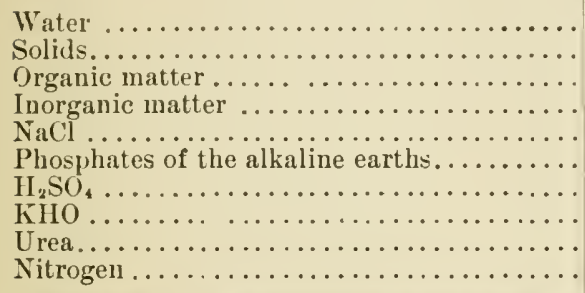 & $\begin{array}{r}99.09-99.16 \text { per cent. } \\
0.91-0.85 \\
0.24-0.20 \\
0.6 \%-0.65 \\
0.52 \\
0.03 \\
0.05-0.06 \\
0.05-0.04 \\
0.12 \quad \text { “" } \\
\ldots \ldots\end{array}$ & 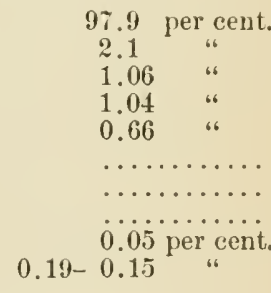 \\
\hline
\end{tabular}

Human sweat is said to contain also about 0.045 per cent proteid matter and two enzymes, one diastatic and the other proteolytic, as well as ethereal sulphates, aromatic oxyacids, skatol ard creatinin in small quantities.

According to Arloing, the sweat of a healthy man possesses toxic properties; by intravenous injection of a dose of 10-15 c.c. per kg. of body weight, it kills a $d o g$ in fifteen to eighty-four hours. The sweat produced in work is more poisonous than that given off during a vapor bath. Vomiting and congestion of the alimentary canal are mentioned as the most prominent symptoms. Participation of Bacteria in these phenomena appears to be excluded, because sweat is said to lose only a little of its toxicity by sterilization in the autoclave.

It has long been known that animals, in which the cutaneous secretions are stopped by means of rarnishes, die within a short time: and attempts were made to explain this effect by the retention of products normally given off in the sweat. Then came the conviction that the sweat does not remove any toxic substances from the body. and the influence of the varnish was soinght in the great radiation of heat caused by it. It is altogether possible that the increased loss of heat has a certain, probably even a great. signifieance. But if the above-mentioned experimental facts with reference to the toxicity of sweat are confirmed, we must again ascribe the most important rôle to the retention of decomposition products. This view is supported moreover by the fact that rarnished animals take only a little food. notwithstanding great loss of heat and the increased heat production thereby demanded- 
which has induced Loulanie to describe the death of these animals as death by inanition.

The quantity of sureat exereted daily is variable. It depends chiefly upon the requirements of heat regulation. The greater the quantity of sweat secreted, the greater is the absolute quantity of solid constituents, among which urea is of special importance. Ordinarily the output of urea in the sweat is negligibly small, and yet as already observed (page 89), under certain circumstances it may become considerable.

\section{B. THE EXCRETORY PROCESS}

In view of the importance of sweat in regulating the temperature of the body, it is but natural to assume that the action of the sweat glands is under the control of the central nerrous system. This is confirmed by experiment.

Stimulation of the cut sciatic nerve or of the brachial plexus in a cat produces in a short time large drops of sweat on the balls of the foot (Goltz). This production of sweat is an actual secretion and not a filtration from the blood, for: (1) a powerful secretion can be evoked by stimulation as much as twenty minutes after amputation of a leg (Kendall and Luchsinger); (2) secretion occurs when the pressure of the surrounding air is higher than that of the aortic blood (Levy-Dorn); (3) it does not occur without stimulation when a paw is subjected to a low air pressure; and (4) it is prevented by very small doses of atropine, despite the strongest nerve stimulus.

The sweat fibers for the fore paw of the cat have been found in the median and ulnar nerves, for the hind paw in the sciatic. It appears however that most of them do not come directly from the spinal roots of these nerves, but that they first traverse the sympathetic paths (thoracic or abdominal trunk) hefore they join the nerres to the extremities. 'The sources of the sweat fibers in the abdominal sympathetic are the three lower thoracic and the four upper lumbar roots; those of the fore paw spring from the fourth thoracic root.

Sueat centers are present in the spinal cord; for if the cord of a young cat be cut at the level of the fourth thoracic root, secretion can be obtained on the hind paws by the influence either of heat or of dyspnos. Considering the importance of sweat in heat regulation, it is very probable that a general sweat center is present in the medulla, although we know nothing definite about it at this time.

Secretion of sueat is induced by psychical stimuli (fear, ete.), by heat, asphyxiation, and reflex effects, as well as by various poisons. Among the latter, pilocarpine is especially worthy of mention, for it has the power to produce sweat even when the secretory nerves are cut.

The effectiveness of a stimulus applied to the secretory nerres depends mainly upon the temperature of the glands. When very cold, no effect at all is produced, although at a body temperature of $22^{\circ}-28^{\circ} \mathrm{C}$. the glands of a cat's foot can be made to secrete by psychic excitation, by reflex action or by asphyxiation. On the other hand heat produces secretion of sweat even in case the spinal cord is severed at the ninth thoracic root and all the posterior roots of the severed cord are cut-i.e., heat, like asphyxiation, has a direct stimulating effect upon the sweat centers. 
Various experimental facts favor the view that sweat glands are under the influence of inhibitory nerves, which, like the secretory fibers, traverse sympathetic paths.

Many animals do not sweat at all; others, like the cat. sweat only in certain places, as the balls of the feet. In man the ability to sweat is very highly developed: in rarying degrees it is a function of the entire skin-principal places being the brow, palms of the hands and the soles of the feet.

\section{§3. THE SO-CALLED INSENSIBLE PERSPIRATION}

We include under this head the excretion of carbon dioxide through the skin, and the exhalation of water independently of the sweat glands.

The elimination of carbon dioxide through the skin is very small in comparison with the elimination through the lungs. Both this and the exhalation of water vapor have repeatedly been studied on limited areas of the skin; but such investigations, although they may rield valuable results as to the influence of different factors, give no certain criteria for the estimation of the total output of $\mathrm{CO}_{2}$ and water vapor for the whole surface of the hody. In order to make such a determination, an individual is inclosed, all but his head, in a cabinet suitably ventilated, so that the elimination may go on continuously.

According to Schierbeck and v. Willebrand, the output of $\mathrm{CO}_{2}$ at a temperature of $20^{\circ}-33^{\circ} \mathrm{C}$. is fairly constant, and amounts to $0.35 \mathrm{~g}$. per houri. e., 7.2-8.t g. per day. If the surrounding temperature be raised above $33^{\circ} \mathrm{C}$. the output of $\mathrm{CO}_{2}$ suddenly increases, so that at $33.5^{\circ}-34^{\circ} \mathrm{C}$. it reaches the relatively high value of $0.8 \%-1.35$ g. per hour (=20.9-32.4 g. per day).

This sudden rise is coincident with the appearance of "sensible perspiration "; it is possible, therefore, that it may be due to the increased work of the sweat glands.

Excretion of water vapor goes on also below this eritical temperature. Other conditions being equal, it is greater the higher is the surrounding temperature, and from $12^{\circ}-31^{\circ} \mathrm{C}$. the output from the naked body. according to v. Willebrand, is proportional to the atmospheric temperature (e. g.. at $12^{\circ}$. $10.5 \mathrm{~g}$. per hour; at $18.2^{\circ}, 18.4 \mathrm{~g}$.; at $24^{\circ}, 22.7 \mathrm{~g}$. ; and at $28^{\circ}, 27.3 \mathrm{~g}$.), hut with the appearance of visible sweat it rises suddenly.

We can think of two possibilities as to the source of the water given off from the skin before the appearance of sweat: either it is a product of the sweat glands, or it is derived by a purely physical process of diffusion from the gland cells and the epidermis. Considering the proportional increase parallel with the temperature up to the point where water is poured out as visible sweat, the latter possibility seems the more likely. 


\section{CHAPTER XIV}

ANIMAL HEAT AND ITS REGULATION

\section{§ 1. THE TEMPERATURE OF THE HUMAN BODY}

BrRDs and Mammals differ from all other living creatures in that their body temperature remains constant in spite of all rariations in the temperaiure of the surrounding medium. For this reason they are called homoiothermous, or, since the temperature of the medium in which they live is generally lower than their body temperature, warm-blooded animals.

Among different species of warm-blooded animals the body temperature cxhibits considerable differences. In general it is higher in birds $\left(39.4^{\circ}-43.9^{\circ}\right.$ C.) than in mammals $\left(35.5^{\circ}-10.5^{\circ}\right.$ C.), and among the latter many genera have a higher temperature than that of man, $37.5^{\circ} \mathrm{C}$. With a temperature as high as the normal in birds, or even as high as the normal in some other mammals, a man would be rery ill.

The temperature of an animal is usually taken in the rectum, that of man either in the rectum or in the mouth or in the axilla. It is evident that the thermometer must always remain in place for a certain length of time if it is to register the temperature exactly; also that the temperature cannot be the same in these different places owing to loss of heat from the superficial parts of the body; and further that of the places named the temperature is highest in the rectum, lowest in the axilla. If the person is doing physical work the temperature in the mouth may fall. whereas the temperature in the rectum rises. This circumstance, which shows that the registration of temperature in the mouth does not always give trustworthy results, is probably due to the cooling of the skin of the face through the agency of sweat, to the augmented respiration by which the lining of the mouth is cooled, etc. (Pembrey and Nicol).

In taking the rectal temperature it is necessary that the thermometer be inserted to a sufficient depth to register the actual temperature of the interior of the body. In the mouth the thermometer bulb is placed under the tongue and the mouth is closed. The posterior opening of the mouth eavity (see page 279) normally is always closed. The axilla never forms a completely closed cavity, but for the purpose of taking the temperature, can be approximately closed by pressing the arm firmly against the chest wall. It requires, however. some time for the temperature in such a cavity to reach its maximum, and hence the thermometer must remain longer in the axilla than in the mouth or in the rectum.

The temperature of the surface, especially of the parts habitually exposed, varies greatly, but for the clothed parts can be estimated in general at 
$33^{\circ}-35^{\circ} \mathrm{C}$.; the naked skin in a bath of $5^{\circ} \mathrm{C}$. still has a temperature of $17^{\circ}$, and in a bath of $18^{\circ}$ and $25^{\circ}$ has a temperature of $22^{\circ}$ and $26.5^{\circ}$ respectively. The temperature $2 \mathrm{~mm}$. below the surface-i.e., in the subeutaneous tissues-under the same circumstances is $24^{\circ}, 24.8^{\circ}$, and $27^{\circ} 5^{\circ}$ respectirely, and in the muscles $12 \mathrm{~mm}$. below the surface is $36.3^{\circ}, 35.9^{\circ}$, and $36.9^{\circ} \mathrm{C}$. (Leferre). The organs in the upper part of the abdominal carity are still warmer than the muscles and the rectum. According to Quincke, the temperature in the interior of the stomach (man) is $0.12^{\circ} \mathrm{C}$. higher than the rectal temperature, and according to Ito, that of the duodenum (rabbit) is $0.7^{\circ} \mathrm{C}$. higher. These higher temperatures may be due. in part

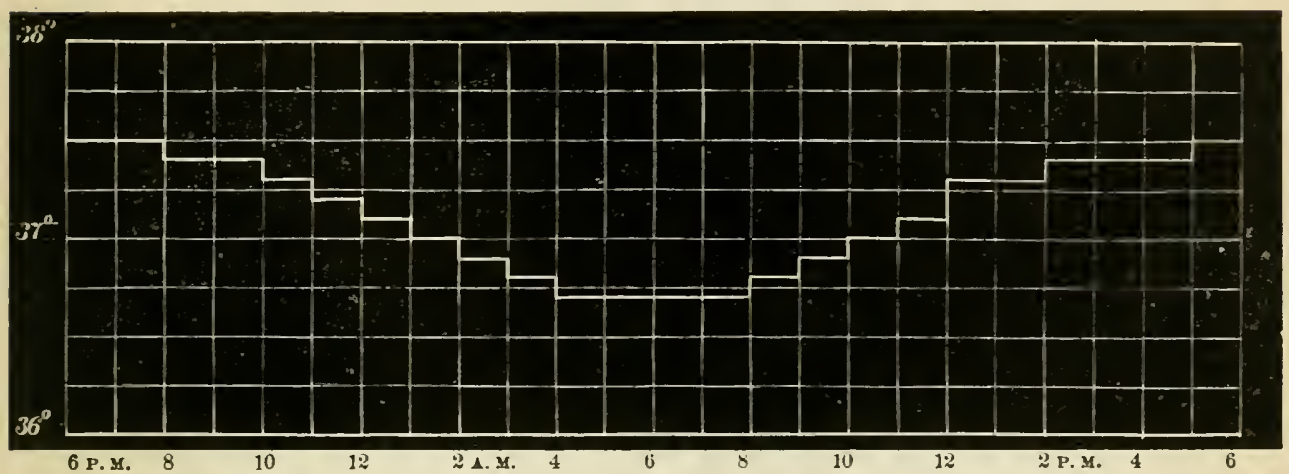

FIG. 147.-The normal diurnal variation of temperature in man, after Jürgensen.

at least, to the proximity of the liver, for, according to Leferre, the temperature of the liver (of the $\mathrm{dog}$ ) may be more than $1^{\circ} \mathrm{C}$. higher than the rectal temperature.

Numerous determinations of the normal body temperature of man hare shown that it presents individual variations of some tenths of a degree. As a mean value $3 \% .5^{\circ} \mathrm{C}$. is giren as the temperature in the rectum. $37.2^{\circ} \mathrm{C}$. in the mouth, and $37^{\circ} \mathrm{C}$. in the axilla. Moreover it is not entirely correct to say that man has a constant temperature. Even if we neglect the variations due to diseases or the diminutions due to excessive cooling of the body. it has been shown that the temperature of man in the course of a day undergoes certain normal variations. The difference between minimum and maximum in a thoroughly healthy individual may amount to $1^{\circ}-1.5^{\circ}$ or more. These variations run a very regular course which, according to Jürgensen, shows a minimum early in the morning from three to six oclock, increases gradually from that time, and after some fluctuations, reaches a maximum about six to seren o'clock in the evening (Fig. 147).

The cause of these variations is primarily the variations in the intensity of metabolism. If the $\mathrm{CO}_{2}$ elimination. which to a certain extent may be looked upon as an expression of the relative amount of metabolism, be determined at different times of the day, a surprising agreement is found between its conrse and that of the body temperature (cf. Fig. 148). It should be noticed that the temperature curve in the figure was not taken from the same 
subject as the $\mathrm{CO}_{2}$ curve. The discrepancies between the two are no more than can be satisfactorily explained by this circumstance alone.

If the $\mathrm{CO}_{2}$ output at different hours of the day be obtained on the fasting body in purposely enforced physical rest, it shows, as Magnus-Levy and especially Johansson have pointed ont, but very slight variations; and in the course of any given period, the body temperature decreases because of the relatively small metabolism. From which it follows that the above-mentioned variations in the intensity of metabolism are called forth primarily by the variations in the movements and tension of the muscles oceurring for one reason or

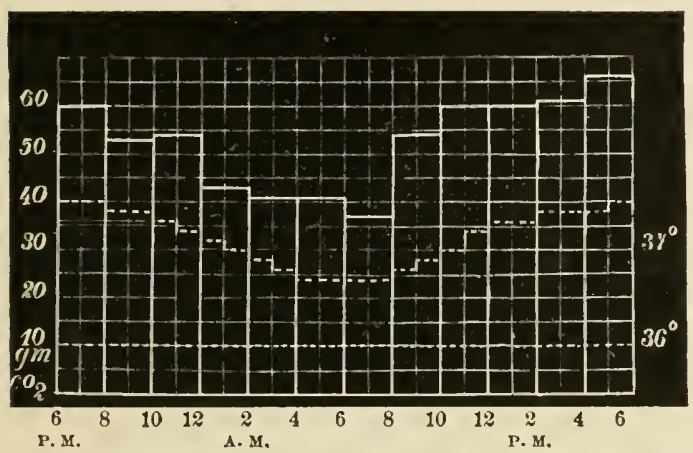

Fig. 148.-The elimination of carbon dioxide in man, determined every two hours. $-\mathrm{CO}_{2}$, in grams. ....... diurnal variation of temperature from the curve by Jürgensen in Fig. 147. another in the course of the day. A coöperating factor, though not of itself by any means so potent as the muscular work, is the increase of metabolism due to taking food.

One infcrence from this view is that with a reversal of the daily habits, the temperature variations ought to be reversed. According to some authors this actually takes place. But Benedict and Snell were unable to observe any perceptible tendency to a reversal of the temperature curve in the case of a man who, for ten successive days, worked at night and slept by day, although the eurve did vary decidedly from the normal.

In my opinion one cannot conclude from these observations that other factors than those mentioned above are concerned in production of the daily variations of temperature. In this researeh the subject slept, as the authors remark, a much shorter time than he was aceustomed to, and it is in fact a fairly common experience that a man eannot accustom himself to a reversed mode of life to the extent of completely converting day into night and night into day. On this account the muscular activity cannot be exactly adjusted to the changed order of life. Moreover, we possess observations on monkeys which show that the reversed order does produce a complete reversal of the temperature variations. When these animals were kept for days either in complete darkness or constantly in the light, the normal variations ceased and were replaced by quite irregular ones (Galbraith and Simpson).

Temporary changes of the body temperature in one direction or the other may be produced by various voluntary acts which tend to inerease either the heat production or the heat loss. Thus the temperature falls as the result of sitting perfectly still, of drinking cold water, etc.; it rises as the result of muscular work, ete.

However, all these changes in the body temperature are as a rule very insignificant, and this very remarkable fact has been established-that the 
mean value of the body temperature obtained from a large number of determinations extending over periods of twenty-four to forty-eight hours, remains the same in spite of all such disturbances. This maintenance of the mean body temperature unquestionably is closely related to the fact that, with a free choice of food, and within periods of some days, the body automatically measures out its supply of energy with unerring regularity.

Variations of the temperature between persons of different age are but slight. Since the foetus has a certain small metabolism of its own, its body temperature must be somewhat higher than that of its mother, which direct observations tend to prove. The difference amounts however to only $0.3^{\circ} \mathrm{C}$. After birth the temperature of the child sinks from $0.5^{\circ}$ to $0.8^{\circ} \mathrm{C}$., a fact dependent in part only on the first bath; it returns during the first week, as it appears, with some fluctuations, and then is maintained at the value given above until old age, when the temperature is said to become some tenths of a degree higher.

When the body is subjected to excessive loss of heat, it is no longer able to maintain its temperature at a constant level. The lower the temperature of the body falls, the greater are the disturbances thereby produced. The highest nerve centers are the first to suffer from t?lis cooling, but the centers of the medulla which are important for the maintenance of life, are not paralyzed until the reduction has been carried much further. Theoretically it may be assumed that in man restoration is possible from a very considerable reduction of the body temperature, so long as the centers of the medulla have not lost their ritality. Cases have been observed in fact where patients recovered from a fall of the body temperature to $24^{\circ} \mathrm{C}$. due to great exposure. Indeed, a case has been reported of a man who retained consciousness with a temperature of only $26.7^{\circ} \mathrm{C}$.

In like manner, an increase

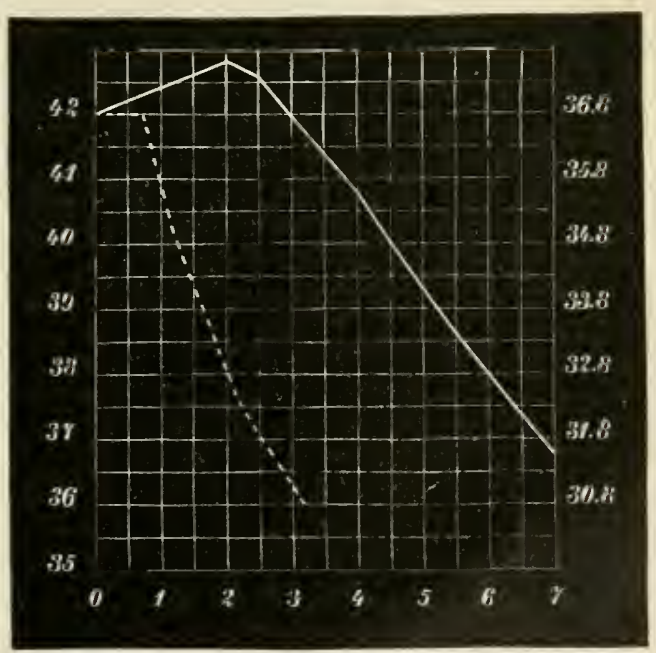

FIG. 149.-The temperature of the body after death (Niederkorn). - typhoid fever (the temperature in degrees centigrade is given at the left). - . ......, pulmonary consumption (temperature at the right). The abscissæ represent hours after death.

of the temperature, if it passes a certain limit, which is different for different individuals, involves first disturbances to the general health, and later loss of consciousness, while the centers of the medulla remain functional. In general it may be said that the body stands a fall better than a rise in its temperature. A rise of only $2^{\circ}$ or $3^{\circ}$ C. causes very serere disorders, and experience has shown that a temperature of $41^{\circ}-42^{\circ} \mathrm{C}$. constitutes a very dangerous symptom. And yet a man can endure still higher 
temperatures provided they do not last too long. The highest authenticated temperatures of patients who afterwards recovered are: $43.6^{\circ} \mathrm{C}$., sunstroke; $44^{\circ} \mathrm{C}$., scarlatina, malaria ; $46^{\circ} \mathrm{C}$., malaria (?).

After death the body of eourse cools down, but not always immediately. Thus it has been shown that the temperature of a body which has died from infectious fevers or injuries to the brain or medulla rises for a time. This is an indication that the metabolism and eonsequent heat production do not cease everywhere in the body the moment the patient draws his last breath. Also after death from chronic, long-continued diseases, where no such post-mortal rise of temperature is observed, the manner in which the fall of temperature oceurs is evidence that combustion in some organs does not cease the moment of death. We find in sueh cases that the temperature remains unchanged for a time, or falls very slightly, and then declines rapidly. The first stage can only be explained by supposing that heat production is still going on after death (Fig. 149).

\section{§ 2. THE SOURCE OF ANIMAL HEAT}

The source of animal heat is the combustion going on in the body (ef. page 46). Inasmuch as combustion takes place in all parts of the bodv, all the different organs participate in the production of heat. And yet the share of the different organs in this process is very different, since in certain organs metabolism is more active than in others.

The eross-striated muscles are the most important in this connection. They constitute about forty per eent of the total weight of the body, and, if we neglect the skeleton, where the absolute quantity of heat produced is not very significant, they constitute fully fifty per cent of the weight.

Even the perfectly quiescent muscles generate heat. Meade-Smith determined simultaneously the temperature of the blood in the aorta and in the leg muscles, diverting the blood meantime from the muscles. He was able to show that the temperature of the muscle at the beginning of five-minute periods without blood was as a rule higher, and at the ends of these periods invariably higher than the temperature of the blood in the aorta; also that the temperature of the muscle always rose during the period. The inerease might amount to $0.1^{\circ} \mathrm{C}$. and the difference between muscle and blood might at the end of the period be $0.6^{\circ} \mathrm{C}$. Then with every muscular contraction, as work is performed, additional heat is generated. Indeed the energy consumed as work is never more than a fractional part of that which appears as heat (cf. page 113).

Next to the muscles, the glands, especially the liver, stomach and intestines, are great producers of heat; but no great importance is to be aseribed to the bones (except the red marrow), the skin or the lungs. Tery active metabolism takes place in the gray matter of the central nervous system. But since the metabolism in the white matter is very slight (ef. Chapter XV), and since the entire nervous system amounts to only about 1.9 per cent of the body weight, it is not to be supposed that this system produces any considerable fraction of the total quantity of heat formed. It is not yet possible to determine more accurately the share of the different organs in this important function. 


\section{§ 3. LOSS OF HEAT FROM THE BODY}

The heat formed in the body is partly utilized in warming the food, including water ingested and the air inspired, is partly given off by conduction and radiation through the skin, and partly disappears in the evaporation of water from the air passages and from the skin, and in the liberation of earbon dioxide from the lungs. The following estimate, agreeing essentially with those of Helmholtz and Rosenthal, indicates approximately the proportion of losses in an adult man by these different avenues.

\section{A. Warming the Food aNd Air}

(1) Water drunk at $15^{\circ} \mathrm{C}$, and warmed to $37.5^{\circ}$-raised therefore $22.5^{\circ} \ldots \ldots=33.15 \mathrm{Cal}$.

(2) $1,500 \mathrm{~g}$. food eaten at $25^{\circ} \mathrm{C}$. (mean) and warmed to $37.5^{\circ}$-raised therefore

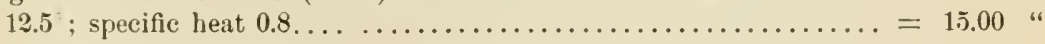

(3) $15,000 \mathrm{~g} .\left(=11,500 \mathrm{l}\right.$.) air respired at $15^{\circ} \mathrm{C}$. and warmed to $37.5^{\circ}$-raised therefore $22.5^{\circ}$; specific heat $0.237 \ldots \ldots \ldots \ldots \ldots \ldots \ldots \ldots \ldots \ldots+\frac{79.15}{128.70}$ "

\section{B. Loss of Water aNd $\mathrm{CO}_{2}$ in the Breath}

(4) It is assumed that the inspired air is half saturated with water vapor at $15^{\circ} \mathrm{C}$., and that the expired air is fully saturated at $37.5^{\circ} \mathrm{C}$. Approximately $450 \mathrm{~g}$. of water would be given off, therefore, in the form of vapor from the respiratory passages; the latent heat of the water vapor is 0.537 Cal. ..................................... 241.70 "

(5) The absorption of heat in the liberation of $\mathrm{CO}_{2}$ from the lungs $(800 \mathrm{~g}$.$) :$ 0.134 Cal. per g. ....................................... 348.90 “

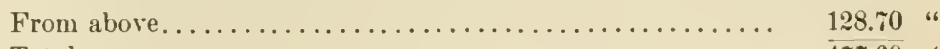

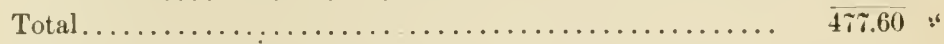

The sum of heat losses specified under these five headings amounts to $47 \% .60$ Cal. Estimating the total heat loss of an adult man at 2.400 Cal., this sum represents only about twenty per cent of the total. The remaining cighty per cent (in round numbers) takes place throngh the skin.

The direct calorimetric measurements by Atwater give approximately the same result. In a series of experiments lasting forty days the mean heat loss, in the case of a resting man, by conduction and radiation was $1,669 \mathrm{Cal}$, through the urine and fieces $31 \mathrm{Cal}$, by evaporation of water $550 \mathrm{Cal}$ - - i. e., in percentages $74.2,1.4$, and 24.4 respectively. In the case of a man at work, the mean for twenty days by conduction and radiation was 2,2 $\%$ Cal., through urine and fieces 19 , by evaporation of water 1,126 ; or in percentages, $66.5,0.6$, and 32.9 respectively. The proportion of evaporation from the skin and from the lungs was not determined.

The skin gives off heat to the surrounding air. or to other cold substances coming in contact with the body, by conduction, radiation and evaporation. The relative importance of these factors varies greatly under different circumstances. The quantity of water vapor given off from the skin depends to a great extent both upon the temperature and humidity of the surrounding air, and also upon the heat production going on in the body, which in turn varies with the kind and the quantity of food eaten and the amount of work done. 
It is therefore impossible to give definite figures for the amount of water given off throngh the skin: for all of the twenty-four-hour determinations thus far published have reference only to the total output of water vapor, and not to the apportionment between lungs and skin.

Using the abore-mentioned figures (table, page 403 ) for the output of water vapor in respiration, we can form some approximate idea of the amount of water vapor eliminated by the skin. Some examples are adduced here in which the necessary reductions have already been made. A fasting individual gave off through the skin on the fifth day of his fast approximately $350 \mathrm{~g}$. of water; loss of heat $188 \mathrm{Cal}$. The same individual on a plentiful diet gave oft through the skin $710 \mathrm{~g}$. water, loss of heat $381 \mathrm{Cal}$., twice as much therefore as in the first case. Another subject at rest and on a moderate diet excreted through the skin $480 \mathrm{~g}$. of water (=258 Cal.); on the same diet at severe work, 1,280 g. water (= 686 Cal.) (ef. also page 397 ).

According to Zuntz, soldiers on the march in cold weather eliminate about one-fifth of the total output of water through the respiration, in warm weather only about one-sixth. In extreme cases the loss of heat by eraporation may reach the enormous value of ninety-five per cent of the total heat loss.

The loss of heat by radiation and conduction also exhibits great variations, which depend on the temperature of the surrounding air and the heat production going on in the body, as well as upon the clothing. Both radiation and conduction are considerably greater on exposed parts of the skin than on clothed parts. From experiments on covered portions, the total heat loss by radiation has been calculated for a grown man at about $700-800$ Cal., while from observations on the naked skin, it is estimated at 1,700-1.800 Cal. Similar differences have been observed with regard to loss of heat by conduction.

\section{§ 4. PROTECTION AGAINST LOSS OF HEAT}

Notwithstanding considerable variations in the temperature of the surrounding air, homoiothermous animals maintain an even balance between heat production and heat loss. That this is possible with so small a quantity of heat production in the body is due to the fact that provisions are made in warm-blooded animals for restraining the loss of heat through the skin. These provisions are. (1) the subcutaneous adipose tissue, and (:2) the natural hairy or feathery covering of the body.

We have already seen that the muscles come first in the order of heat production. The heat formed in them, however, cannot be readily conducted to the superjacent skin because the intervening adipose tissue is a very poor conductor of heat. A piece of skin $2 \mathrm{~mm}$. in thickness will allow 0.00248 cal. (small) to pass through in one minute, when the difference in temperature is $18.2^{\circ} \mathrm{C}$. The same piece of skin plus a $2 \mathrm{~mm}$. layer of fat under the same circumstances will allow only 0.00123 cal. to pass. With less difference in temperature on the two sides the protecting influence of the fat is still greater, so that for example with a difference of $9^{\circ} \mathrm{C}$. a layer of fat $2 \mathrm{~mm}$. in thickness retains 0.8 of the total quantity of heat which would otherwise be allowed by the skin to pass through (K'lug). In considering the properties of fat deposited at different places in the bridy, Henriques and Hansen have directed attention to the lower melting point of fat which lies nearer to the outer surface of the body. This is doubt- 
less eonnected with the fall in temperature met with in passing from the interior toward the surface: for-the lower the temperature the lower must be the melting point of the fat in order that it may remain in a fluid state.

The great importance of the subcutaneous fat is most beautifully seen in the case of the great warm-blooded marine animals of the aretics. They live habitually among the ice blocks in a medium which conducts heat at least twenty times better than air. and yet they are able to maintain a body temperature of $35^{\circ}-40^{\circ} \mathrm{C}$. The skin is subjected to conditions which would abstract an enormous amount of heat, but the extraordinarily thick layer of subeutaneous fat isolates the muscles and the organs-in short, the real body -from the skin.

For warm-blooded animals which live in the air, the loss of heat is greatly reduced by the hair and feathers; and elothing serves the same purpose for our own bodies.

Air is itself a very poor conductor of heat, but when in motion it may carry away great quantities of heat. Let us imagine a naked man in an atmosphere colder than his skin. The layer of air immediately adjacent to his skin is first warmed by his body and as a consequence it becomes lighter. It rises and is replaced by fresh, cold air, which in its turn is warmed. replaced, and so on incessantly. The body produces therefore by virtue of its own heat an uninterrupted current of air, which abstracts great quantities of heat from it.

This active exchange of air is considerably restricted by the clothing, whatever the material of which it is made, inasmuch as it prevents free aceess of the air to the skin. The air inclosed by the clothing is relatively stationary and thus, because of its poor conducting qualities, it constitutes a thermally insulating laver around the body. Moreover, not only the air between the elothing and the skin, as well as between the different garments, but the air in the meshes of the clothing material itself is to be taken into consideration. For clothing materials, like hair and feathers, are of themselves nuch better conductors than air. The amount of air held in the meshes of the clothing of a man as ordinarily dressed (excluding wraps) is estimated at 20-301. (Rubner).

Important as this layer of surrounding air is, it must not stand absolutely still, but must be kept in continual motion, even if it be very slow motion; for otherwise the air very quickly becomes saturated with water vapor given off by the skin, and then no further loss of water vapor can take place. The result is great disconfort and, under some eireumstances, great disturbances in the regulation of heat.

The loss of heat by radiation is likewise redueed considerably by the elothing. Since the clothing materials consist of substances which do not permit the passage of radiant heat, they absorb the heat radiating from the skin and are themselves warmed by it. Consequently this heat remains longer in the neighborhood of the body and thus helps to warm the air immediately surrounding it. When one feels that he is losing heat from the immediate righborlood of the body too rapidly, he eovers the garment from which the heat is escaping with still another, which catches the heat radiating from the first and delays it still longer. A shirt, rest, eoat, ete., aet in this way.

The radiation of heat from the skin is still further diminished by water vapor, because it reduces the diathermic capacity of the air. 
As a result of these protectire measures, the temperature of the air immediately surrounding the body is generally somewhat above $30^{\circ} \mathrm{C}$. The skin itself in places where it is clothed has a temperature of $33^{\circ}-35^{\circ} \mathrm{C}$, on naked places its temperature is lowel (cf. page $39 y$ ).

That warm-blooded animals can maintain a constant body temperature, when exposed to a very low external temperature. is due to their natural or artificial clothing. This is perfeetly evident from the fact that the temperature of an animal declines more or less when it is shorn. as well as by the experience that a naked man at rest can only maintain his temperature at the normal level when the surrounding temperature is at $2 \Upsilon^{\circ} \mathrm{C}$. or higher (Senator).

By experiments with the calorimeter Rubner has determined the saving of heat to the body accomplished by clothing in some special cases. A guinea pig lost normally by radiation and conduction on the average 3.37 Cal. per hour: after being shorn the hourly loss was 4.19 Cal.-i. e., 33.3 per cent nore. In the human subject the loss from the naked arm by radiation and conduction at ordinary room temperature was about thirty per cent more than that from the elothed arm.

And yet the saring actually accomplished by the clothes is somewhat less than this would indicate: for the output of water vapor from the elothed body is greater than from the naked because of the higher temperature of the air immerliately adjacent to the skin. From experiments on the naked forearm and on the hand it has been found that in a dry atmosphere at a temperature of $15^{\circ}-20^{\circ} \mathrm{C}$. about twenty per cent of the total heat loss takes place by evaporation. From the naked arm the elimination of water amounted to $3.59 \mathrm{~g}$. , and from the elothed arm $4.39 \mathrm{~g}$.- - a difference of twenty-two per cent. Using this value the saving of heat due to clothes mas be calculated as follows:

The total loss of heat through the skin ................. 100

By radiation and conduction $\ldots \ldots \ldots \ldots \ldots \ldots \ldots \ldots . . . \ldots$

By evaporation............................ 20

The loss by radiation and conduction is diminished by the clothes twenty per cent, learing therefore................ 56

While the loss by evaporation is increased twent $r$-two per

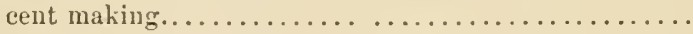

Total......................... 80

The saring according to this amounts to about twenty per cent at ordinary room temperature, and of course at lower temperature is much greater.

Just as man seeks to reduce as much as possible the loss of heat during the winter by wearing heavier clothing. sn the animals offset the influence of the lower temperature by a thicker coat of hair or feathers. What this thick coat actually does for its owner may be seen in polar animals living in the air, which maintain a normal hody temperature even at an external temperature of $-40^{\circ}$ C. (Parry).

\section{§. REGULATION OF THE BODY'S TEMPERATURE}

The facts thus far discussed relate only to the necessary conditions for the maintenance of the body temperature. but by no means suffice to explain this phenomenon theoretically. For, while both animals and men are all the 
time being exposed to greater or less variations in the temperature of the surrounding medium, neither the thickness of the clothing nor that of the adipose tissue is being changed to correspond with these rariations; and ret the body maintains its ten perature unchanged. The sum total of all those processes by which this constaney is maintained is comprehended under the term heat regulation of the body. These processes can be divided into tro groups according as they relate to heat production or to heat loss.

The way in which the production of heat varies under the influence of the surrounding temperature has been already presented in Chapter IT (page 114). But heat production is influenced also by the amount of food, and in controlling the latter we have a means of adapting the transformation of substance in the body to the requirements of heat regulation.

A noteworthy illustration is given by Kr: E. Ranke, who studied his diet both in Germany and during a scientific expedition to Brazil. Allowing himself free choice of food, the amount being controlled only by his appetite, his total intake between the temperatures of $15^{\circ}$ and $22^{\circ} \mathrm{C}$. was on the average $3,300-3,500 \mathrm{Cal}$. In a dry elimate at a temperature of $25^{\circ} \mathrm{C}$., it fell to 2,800 Cal., and at an atmospheric temperature of $25^{\circ}-28^{\circ}$ with a humidity of about eightythree per cent, it reached the low level of 1,970 Cal. $(=26.9$ Cal. per $\mathrm{kg}$. body weight). His body weight decreased howerer on this low ration. In order to recover his original weight he was obliged to adopt a richer diet, but various disturbances in his general health appeared while he was experimenting in this direction.

\section{A. REGULATION OF HEAT LOSS}

As we have seen above the temperature of the skin depends primarily upon the blood supply; the greater the amount of blood flowing through it, the warmer it becomes. But the warmer the skin becomes, other conditions being the same. the greater is the fos of heat from the skin by radiation and conduction. The heat loss ly radiation and conduction therefore depends upon the amount of blond supplied to the slin.

The blood ressels of the skin, like the other ressels of the body, are under the influence of the rasomotor mechanisms, and are constricted or dilated according to the momentary requirements of the heat regulation. Thus in cold weather and when the production of heat in the body is not greatly increased by muscular work, they are constricted; and in hot weather they are dilated.

These changes in the blond supply of the skin serve in another. and perhaps still more important manner, to regulate the loss of heat. During its flow through the cutaneous ressels, the blood naturally gives off heat, and returns to the interior somewhat conled. When the ressels are dilated, more blood flows through them. and more heat is thus lost than when they are constricted and the quantity of blood flowing through them is small. While the cutaneous ressels are constricted. the ressels of the abdominal viscera and, as it appears from the investigations of Wertheimer. those also of the muscles -i. e.. of the most important heat-producing organs-are dilated: while during dilatation of the cutaneous vessels, those of the abdominal viscera are constricted. 
Experience proves that a man can maintain his body temperature without increase in an atmosphere whose temperature is much higher than that of his body. This appears the nore remarkable when we consider that the metabolism and heat produetion of the body never eease, howerer high the surrounding temperature may be. The fact, as was first observed by Benjamin Franklin, is to be explained by the seeretion of sweat. At a higher atmospherie temperature the sweat glands are stimulated, and evaporation of the sweat thus poured out upon the skin absorbs a large quantity of heat from the body. In this way the body is eooled and maintains its temperature unchanged, whether the outside temperature exceeds or only approaches that of the body.

But the amount of sweat secreted depends not only upon the temperature of the air, but also upon the amount of heat being produced in the body at the time. If the heat production of the body be eonsiderably inereased as the result of severe museular work, the body will sweat even at an atmospheric temperature of $0^{\circ} \mathrm{C}$. After a full meal, owing to the inereased heat production a greater quantity of sweat is secreted than when the metabolism is reduced for laek of food.

\section{B. CENTERS FOR HEAT REGULATION}

Among the many so-called "heat centers," located in different parts of the eentral nervous swstem. which have been mentioned by different authors, only a single one seems to be fairly entitled to the name. If a fine needle be thrust into the brain from above downward in such a direetion as to strike the medial elge of the corpus striatum, a rise in temperature appears in the skin, in the muscles and in the reetum; likewise an inerease of metabolism and of heat loss as determined by the ealorimeter (Aronsohn and Sachs, Richet). The increase of temperature amounts to more than $2^{\circ} \mathrm{C}$., the increase of metabolism and of heat loss to about 20 per cent. The maximum effeet appears within twenty-four to seventy-three hours after the puncture, unless the needle be pressed through to the base of the cranium, in which case it appears within two to seven hours. The results of electrical stimulation by means of electrodes insulated to the ends show that the effect of puneture is due to stimulation and not to destruetion of the parts eneountered.

Te cannot form any definite opinion at present, as to the signifieance which this and other "heat centers" have in the regulation of this important function.

How the centers for heat regulation (wherever they may be located) are stimulated, is another question which cannot be conclusively answered as yet. It is indeed fairly certain that the cold and heat nerves of the skin play a great part, since heat production and heat loss are reflexly influenced in one direction or the other according to conditions reported by these nerves. Changes in the temperature of the blood also might play a part; that is, cold might by direct action on the heat centers bring about an increase of metabolism and a constriction of the cutaneous vessels, or warmed blood might rouse the sweat centers to increased activity. This mechanism does actually participate in some such way in the regulation of heat, for in muscular work the sweat breaks out only when the body temperature has inereased $0.3^{\circ}-0.5^{\circ} \mathrm{C}$. (Frederieq). Likewise 
the augmented respiration appearing with a high external temperature (page 318 ) is eaused by a direct exciting effect of the blood, for it can be reproduced in all its essential features by loeally warming the blood in the earotids on the way to the brain; but it will not appear, notwithstanding a very strong heat stimulus, when the head is cooled.

The ability to maintain a constant temperature in certain species of animals, including man, is not fully deseloped immediately after birth. In such warm-blooded animals as have a well-developed nerrous sistem at birthc. g., guinea pig and chick-the heat-regulating meehanism also is completely functional at this time. But those which, like rats and pigeons, are born lilind and helpless. only acquire the power of regulating their own temperature in the course of the second week (Pembrey). The newborn child also has not yet come into full possession of its power to regulate its heat (Raudnitz). It is probalole that this post-embrynie development of the regulatory mechanism is intimately connected with the development of the neuromuscular apparatus going on at the same time. 


\section{CHAPTER XT}

\section{THE FUNCTIONS OF CROSS-STRIATED MUSCLES}

THE purpose of the cross-striated muscles is twofold: first to provide for the bodily movements, and secondly to participate in the production and regulation of heat in the body. In this chapter we shall first inquire into the general properties of the muscles and shall then briefly discuss their relations to other organs.

\section{FIRST SECTION}

\section{GENERAL PHYSIOLOGY OF MUSCLE AND NERVE}

Inasmuch as the general properties of muscles and of nerve fibers agree in many respects. and the information gained from nerves very often throws light on the corresponding phenomena of muscles, it seems best to discuss them here together.

Physiologists have for a long time given preference to the study of the general properties of museles and nerves because at first it promised to yield very important results bearing on the fundamental properties of the living substance in general. A great number of facts have been collected by the work done in this field, but mnfortmately they do not as yet afford us a basis for any consistent theory of nervous and muscular activity. Significant as these facts are, we must be eontent to mention only the most important of them, a more exhaustive presentation being quite beyond the possibilities of a text-book of this size.

When not otherwise expressly stated, the facts given may be understond as applying to the surviving nerves or muscles of the frog, exsected from the body (ef. page 6). I motor nerve is generally employed in investigation of the general properties of nerves, and in most cases the muscle connected with it serves as the indicator of the state of the nerve. The changes in the form of the muscle are usually registered by the graphic method (cf. page 6).

\section{\$ 1. FUNDAMENTAL LAWS OF NERVOUS ACTIVITY ${ }^{1}$}

A nerve is irritable to ordinary artificial stimnli at all points of its course, and it transmits the stimulns in both directions from the point of stimulation. This is best shown by means of the action current (page 48). If a nerve be stimnlated at its middle. each of the two ends being at the same

${ }^{1}$ The properties of different kinds of nerve fibers will be discussed more fully in Chapter XXII. 
time conneeted with a galvanometer, the action eurrent appears in both. This is true not only of mixed nerve trunks composed of both afferent and efferent fibers, but can be demonstrated on the anterior roots of the spinal nerres which contain only efferent fibers (D) Bois-Reymond).

If a living nerve be severed, it of course no longer has the power to transmit the stimulus. But the same is true if the nerve be simply tied off. To be capable of conducting, a nerve must, therefore, be intact, not only in the physical, but also in the physiological sense.

The conductivity of a nerve may be diminished or abolished for a time by various agents: external pressure-e.g., when, as we say, the limbs "go to sleep"; chloroform; alcohol, etc. All such agents have this in common, that they reduce or even abolish the physiological continuity of the nerve, without destroying its physical integrity. And yet the local excitability of the nerve in the same place may persist. Under certain circumstances it may happen also that a segment of the nerve, which for some reason is not excitable, still has the power to transmit the stimulus received at some other point on the nerve. This is witnessed, for example, in certain stages of regeneration of a nerve that has been eut. Moreover, the excitability of the nerve docs not always heep even pace with its conductivity, possibly because the nerve responds in a different manner to its natural stimulus propagated from one segment to another, from what it does to the artificial stimuli.

A stimulus once received by a nerve fiber is transmitted only within the same fiber and its branches. never passing to the fibers running beside it in the same trunk (law of isolated conduction).

This law holds also for the conducting pathways in the central nervous system. One can convince himself of its validity in a very simple way. If, for example, he touch the tip of his tongue, at each of two places about $1 \mathrm{~mm}$. apart, with a sharp point, he can distinguish the two points very accurately, which of course would not be possible if the two stimulated the same nerve fiber.

In very elose relation with this law belongs the discovery of the specific churacter of the response to excitation-i. e., that stimulation of a definite nerve produces an effect in its own answering organ and in that organ only. By the ansuering organ we mean that particular organ connected with the nerve and specially influenced by it. The answering organ of an ordinary motor nerve is the muscle which it innervates, the answering organ of a secretory nerve is the gland which it controls, ete. The answering organs of the alferent nerves are nerve cells situated in the eentral nervous system. From these new nerve paths originate, and end in other nerve cells, and thus stimulation of a single afferent nerve may rouse a whole series of different nerve cells united together. Finally, a nerve cell connected with an efferent nerve may be set in aetion by an afferent nerve, and a peripheral organ may thus be stimulated withont the participation of the will or even of ensciousness. Such a phenomenon we call a reflex (Chapter XXII). Because of the manifold way in whieh the nerve fibers are combined with one another in the central nervous system. very emmplex effects may result from a single afferent stimulus, without in any way invalidating the law of specific response. 


\section{\$ 2. THE PROPERTIES OF RESTING MUSCLE}

\section{A. ELASTICITY}

If a metallic wire rertically suspended be loaded with a certain weight, almost immediately it assumes the maximum length for that load and, practically speaking. is not extended further howerer long the weight remains. A musele or other organic tissue behares rery differently. If we load a fresh

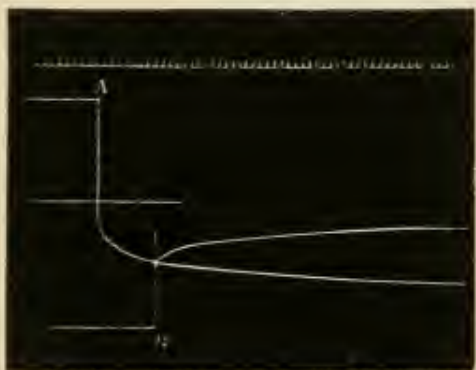

Fic. 150.-Curves representing the extension, $A$, and elastic shortening, $B$, of two adduetor muscles, after Blix. A was suddenly loaded with $100 \mathrm{~g}$. of weight and $B$ was suddenly relieved of its weight. muscle with a weight, for a moment it takes a certain length aceording to the size of the load, but thereafter as long as the weight remains it continues to streteh, at first rapidly and then more and more slowly. This secondary stretching is spoken of as the after extension. When a muscle already stretehed by a certain weight is unloaded, it shortens rapidly at first. then more and more slowly. In this ease it is said to exhibit secondary elasticity, or after shortening (Fig. 150).

These secondary phenomena render the investigation of the elasticity in muscles and the influence of load rather difficult. In order to reduce the effect of after extension as much as possible. Marey and Blix have hit upon a device by which the load can be increased or diminished continuously and rery rapidly, and the rariations in length of the muscle can be recorded at the same time (Fig. 151).

The support (i) bears the muscle lever $(c)$ on which the musele is fastened at $m$. The lever is loaded by means of the weight $h$, and is counterbalanced by the weight $k$. The plate $(f)$ with the recording surface $(l)$ attached to it can be moved back and forth between the two ledges screwed fast to the base. At the same time the weight $h$ controlled by the bar $b$ is moved along the lever,

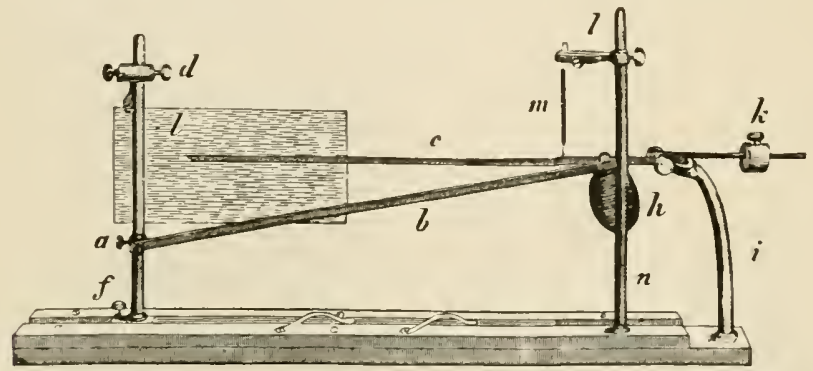

FIG. 151.-Apparatus of Blix and Lovén for recording the clasticity curve of a muscle.

and in this way the load acting on the muscle is changed in proportion to the excursion of the writing surface. Curves obtained with the apparatus represent the extensibility and elasticity of the muscle with a uniformly inereasing and uniformly diminishing load. 
Such a curve is given in Fig. 152. We see that the inerease in length of the muscle with a load increasing at a uniform rate is less, the greater the absolute load-i. e., the coeflicient of elasticity becomes greatcr as the tension of the muscle increases. Moreover, it appears from the figure that the elasticity eurre runs below the extension curre, a circumstance not dne to after extension. The elasticity, it will be observed, is very complete, since the muscle when it is released resumes its original length. Permanent lengthening appears to a noticeable extent only when the muscle substance is torn by too great an extension.

\section{B. CHEMISTRY OF MUSCLE}

The reaction of fresh, resting muscle was for a long time regarded as acis. But Du Bois-Reymond pointed out that the reaction of the flest of different mammals is more or less alkaline. Further investigation has shown that there is no one reaction for resting musele, but rather two: alkaline to laemoid and neutral or faintly alkaline to cureuma. The aqueous extract of erossstriated muscle reacts in the same way. According to Röhmann, the acid reaction of the water extract to eureuma is essentially due to sodium monophosphate, and the alkaline reaction to lacmoid to the acid earbonate of sodium, to the diphosphate of sodium and to alkaline compounds of the proteids.

Among the proteids which make up the insoluble stroma

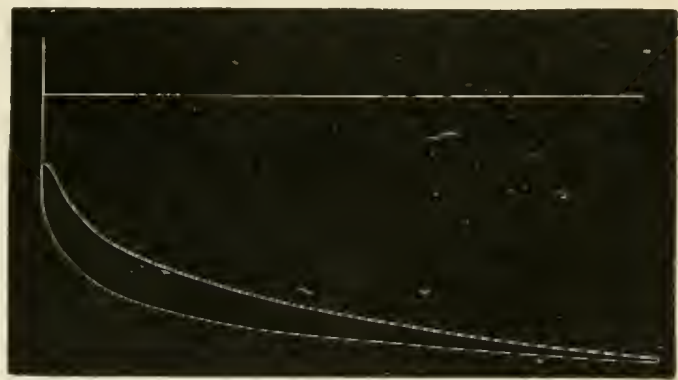

FIG. 152.-Extension and elasticity curves of the frog's gastrocnemius, after Nerander. This tracing was obtained with the apparatus shown in Fig. 151. The upper line represents the curve of extension and the lower line the curve of elastic shortening. of muscle, there are two bodies, one a globulin (myosin. v. Fiirth: paramyosinogen. G. N. Stewart) and the other a globulin-like substance (myoyen, r. Fïrth; myosinogen) which can be extracted from fresh, blood-free rabbit's muscle with normal salt solution. In dear muscle both pass over spontaneously into insoluble molifications (myosin fibrin and myogen fibrin) but they are distinguished $h y$ their preeipitation reactions and the temperature at which they coagulate. Mrosin coagulates at $44^{\circ}-50^{\circ} \mathrm{C}$. myogen at $5.5^{\circ}-(i 5)^{\circ}$ C. Of the total quantity of proteid which goes into solution with normal salt. myosin constitutes about twenty per cent and myogen about eighty per cent (r. Fürth).

Other nitrogenous eonstituents of musele represent the decomposition products of proteid: ereatin (0.1-0.4 per cent in fresh muscle), hypoxanthin, xanthin, and guanin $(0.23,0.05$ and 0.02 per cent of dry substance respectively). Here belong also the phosphocarnic acid (0.1-0.2 per cent); inosinic acid $\left(\mathrm{C}_{10} \mathrm{H}_{13} \mathrm{~N}_{4} \mathrm{PO}_{8}\right)$ from which hypoxanthin can be split off; carnosin $\left(\mathrm{C}_{0} \mathrm{H}_{14} \mathrm{~N}_{4} \mathrm{O}_{3}\right)$ closely related to arginin: and carnin $\left(\mathrm{C}_{6} \mathrm{H}_{4} \mathrm{~N}_{4} \mathrm{O}_{3}\right)$.

The nonnitrogenous organic enstituents are: inosit (hexa-hydroxy-benzol, $\mathrm{C}_{6} \mathrm{H}_{6}\left(\mathrm{OH}_{6}+\mathrm{H}_{2} \mathrm{O}\right)$, glycogen, sugar, fat, ete. 
Muscles owe their color to a peculiar red pigment (myochrome) which is closely related to hamoglobin but does not agree with it spectroscopically (K. A. H. Mörner).

\section{§3. STIMULATION OF MUSCLES AND OF NERVES}

\section{A. THE MUSCLE CURVE}

1. Method.-A muscular contraction can be recorded in several ways which differ in principle but which finally reduce to two groups, according as the shortcning induced by the stimulus is allowed to take place or not. In the latter case

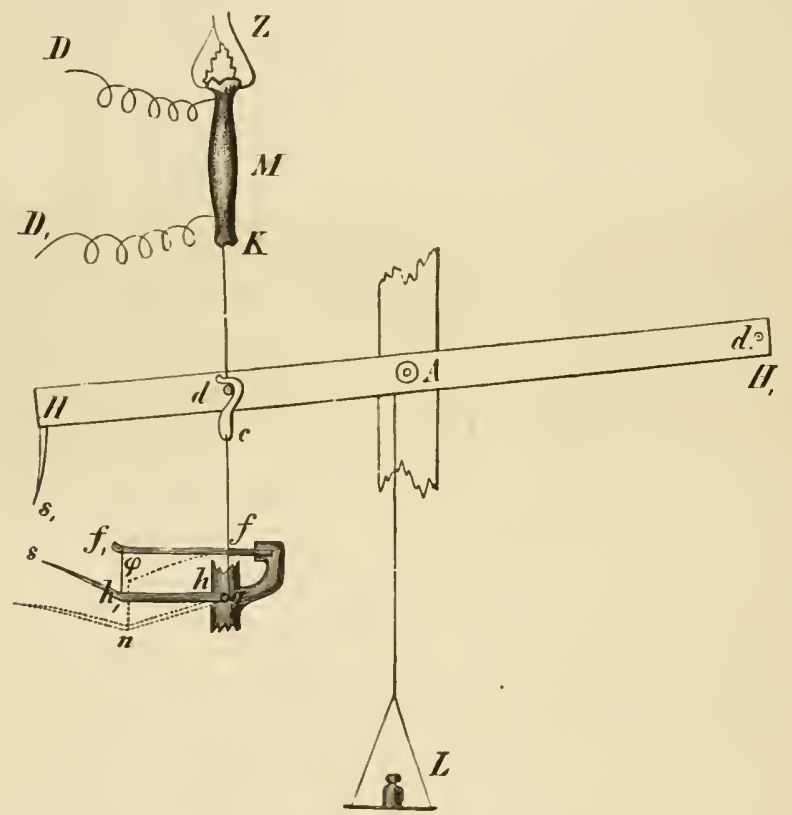

Fig. 153.-Apparatus of Fick for recording variations in the length and in the tension of a muscle artificially stimulated. By unhooking the tension recorder the lever, $H H$, is allowed to move freely up and down like an ordinary muscle lever. For further explanation, see text.

the tension of the muscle increases as a result of the excitation, but its length remains constant. For this reason such contractions are called isometric contractions, and the rariations of tension are recorded after Fick's method as follows (Fig. 158). The muscle (M) is attached to a strong steel spring ( $f$ ) which bears a long writing point $(h)$ for magnifying and recording its movements. When the muscle is stimulated, it attempts to bend the spring, but since the latter yields but slightly, the muscle cannot shorten to any appreciable extent; consequently the whole effect of the muscular activity is to increase the tension.

In the other method a lever loaded with a weight is commonly used, and the weight is so chosen that the effort of the muscle to shorten when stimulated is effective. The lever is lifted, therefore, and the resulting curve is a record of rariations in the length of the muscle during the contraction. 
A loaded lever lifted in this way suffers a certain acceleration in its movement upward, which is often so great that from a certain moment onward the lever moves of its own inertia, and not at the instance of the muscle. It is evident that a musele curve recorded under such circumstances can be trusted only for information as to the very begiuning of the contraction. In order to prevent this "throw" due to inertia a rery light lever is employed, and the load is applied as near to the axis as possible (Fig. 160), while the muscle is attached at a greater distance therefrom. Since it is assumed that the tension of the muscle remains the same throughout, this sort of a contraction is ealled isotonic. An actual condition of isotony, however, is scarcely ever to be had (cf. page 435).

To be able to analyze the temporal course of the muscular contraction exactly, one must record it on a writing surface moving with sufficient speed (300$600 \mathrm{~mm}$. per second).

2. The simple contraction. The muscular contractions caused by the various stimuli are either simple or summated. By simple contraction, or merely contraction, we mean that act of the muscle which is discharged by a single

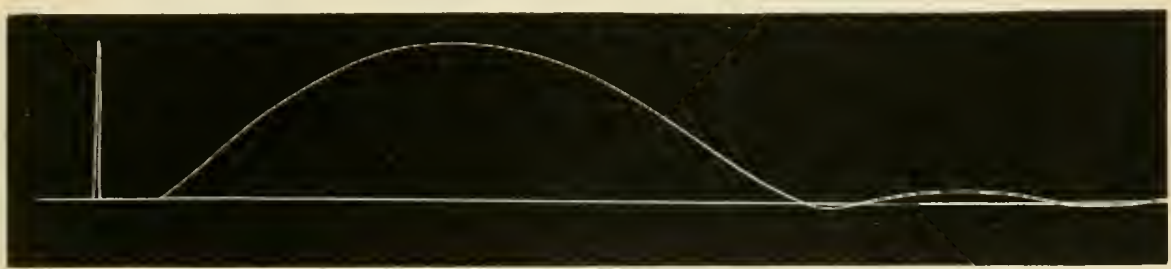

FIG. 154.- Simple contraction curve of the frog's gastrocnemius. The vertical line at the left marks the movement of stimulation. The interval between this line and the point at which the contraction curve leaves the base line is the latent period.

stimulus. $\mathrm{By}$ summated contractions we understand the contractions discharged by a series of stimuli following each other in rapid succession (cf. page 51).

When a muscle receires a stimulus, a measurable time always elapses between the instant of stimulation and the appearance of a visible effect, and this time is designated as the latent period (IIelmholtz. 1850).

The general procedure in making exact determinations of this as well as of other physiological periods may be explained by the following method: On the lower edge of the drum of a kymograph a metallic peg is securely fastened, so that when the drum is revolving this peg can break an electric contact. The contact forms a part of the primary eurrent to an induction coil. If now the secondary current be convered to the musele, and the drum be set going so that the muscle lever makes a tracing, it is clear that the instant the peg opens (or closes) the primary current the muscle will receive a shock. But it is equally clear that, owing to the latent period, the instant the resulting contraction begins will not be the instant of stimulation. To find on the tracing the instant when the muscle receives the shock, let the drum be moved rers slowly until the peg once more breaks the primary eurrent. Since the drum is now as gond as standing still the resulting contraction will trace a vertical line (Fig. 154) which marks the instant of stimulation. The interval between this vertical line and the rise of the muscle curve above the base line is the latent period. The period can of course be measured in fractions of a second if the vibrations of a tuning 
fork be recorded while the drum is going at the same rate of speed. Sometimes it is difficult to say just when the musele eurve rises from the base line. The exact moment ean be determined if the experiment be so devised that the muscular contraction, the instant it begins, opens the current to an electrie signal.

The length of the latent period, which has generally been determined on the frog: mnsele, depends upon various ciremstanees. With a maximal break induction shock and at ordinary room temperature $\left(17^{\circ}-19^{\circ} \mathrm{C}\right.$.), the mean length is about 0.004 second; at a higher temperature it is shorter, at a lower temperature longer. The latent period increases also as the height of the contraction decreases. On the other hand, under circumstances otherwise the same, it is influenced very little by the load or by the tension of the muscle (i. e., up to a certain limit).

If a muscle prepared for stimulation be placed in a horizontal position and a lever be attached to each of its two ends in such a way that any increase in the thickness of the muscle at either end will be reenrded, and if the musele be now stimulated at one end, it is found that the response spreads from the point of stimulation throughout the muscle at a measurable rate of speed (Abey). This rate of propagation, which according to Engelmann is independent of the strength of the stimulus, amomints in the frog muscle to $3-4 \mathrm{~m}$. per second (Bernstein. Hermann), or $5-6 \mathrm{~m}$. (Engelmann), and in human muscles to $10-13 \mathrm{~m}$. per second (Hermann).

If in an experiment like the one cited above for the determination of the latent period, the two electrodes be placed on opposite ends of the muscle, the excitation will start from the negative eleetrode (ef. page 59), and will spread from there throughout the muscle. But before the lever ean be raised, the exeitation must have reached the entire musele; whence it is evident that the mechanical latent period of the part first exeited must be shorter than that indieated for the whole musele.

After the latent period the muscle curve rises to its maximum height and then falls. Accordingly in every muscular eontraction we have to distinguish: (1) latent period, (:) period of shortening. (3) the summit, and (4) the preriod of relaxation. In the frog's gastrocnemins the period of shortening lasts $0.05-0.0 \%$ second, the period of relaxation somewhat longer.

The course of the simple contraction may be very different in different muscles, and in point of time we meet with all possible gradations from the extremely short twiteh of certain insects' muscles, lasting only 0.0033 second, to the contraction of smooth muscles continning for several seconds.

Ranvier first directed attention to the fact that the skeletal muscles of the same animal which differ in color, differ also in their physiological propertie: Thus in such animals as the rabbit, we can easily distinguish red and white muscles. With the red the latent period is longer, the height of the contraction is less-the deseending limb of the eurve especially being very much drawn out; hut the foree and endurance are greater than in the white muscles. The former are therefore more eapalle of severe work. Griitzner showed later that individual museles generally are emposed of red and white sections, and that the mixture of the two kinds of fibers is often very intimate. 


\section{B. RATE OF TRANSMISSION OF A NERVE IMPULSE}

It is necessary for the sake of a more complete study of the excitation of rerves that we discuss here the rate of transmission of the stimulus within them. 'The first researches bearing on this subject we owe again to Helmholtz. The principle of his method is very simple. The latent period is determined as above described, but instead of stimulating the muscle directly the stimulus is applied to its nerve: (1) as near as posibible to the muscle and $(?)$ as far as possible from it. We find that the latent perior is greater in the second case than in the first. If the two contractions are the same size (Fig. 155), this difference can only be due to the greater length of nerve

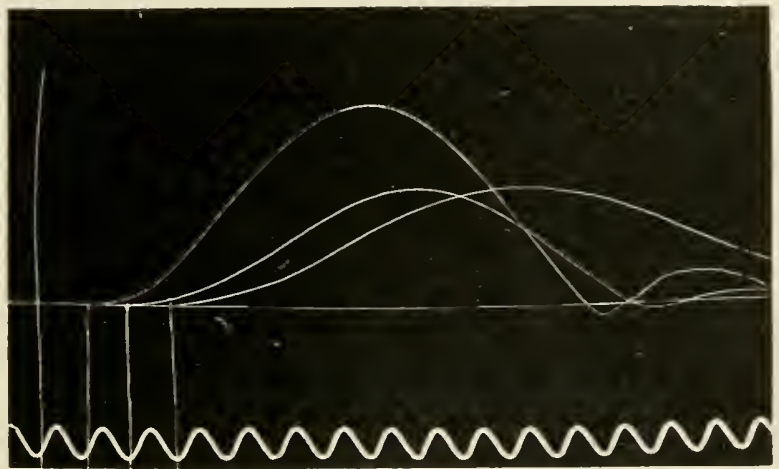

$A \quad B \quad C \quad D$

FIg. 155.-Curves illustrating the method of determining the rate of conductivity in the seiatic nerve of a frog. A, marks the point of stimulation. The first curve which leaves the base line at $B$ (really a little farther to the right than indicated) was obtained by direct stimulation; the sceond curve $(C)$ was obtained by stimulating the nerve as elose as possible to the muscle; the third curve $(D)$ by stimulating the nerve as far away from the muscle as possible. The lag of the third curve behind the second should give the time necessary for the stimulus to travel from the second point of stimulation on the nerve to the first point-in this case about $55 \mathrm{~mm}$. Since one complete vibration of the tuning fork (below) represents $2_{2}^{1}$ th of a second and this is (almost exactly) the time from $C$ to $D$, the rate of transmission in this particular case is only about 11 meters per second $(200 \times .055)$.

traversed by the stimulus in the second case. Knowing the difference of length in millimeters and the difference of time in hundredths of a second, we can easily calculate the rate of transmission in meters per second. In the motor nerves of the frog at room temperature this rate is $?(1)-20 \mathrm{~m}$. per second. It lower temperatures it is less; besides, there is a certain dependence upon the strength of the stimulus, a stronger stimulus increasing the rate sometimes very considerably.

In the incertebrates the rate is very much lower and appears to be less the slower the normal movements of the animal. In a mussel (Anodonta) it is only $1 \mathrm{~cm}$. per second, in an oetopus $3-5 \mathrm{~m}$. per seeond. The nonmedullated fibers of the olfactory nerve of a fish (pike) transmit a stimulus at $20^{\circ} \mathrm{C}$. at the rate of 14-24 m. per seeond (Nicolai).

By recording the contractions of the muscles in the ball of the thmmb on stimulation of the median nerve at different points the rate of transmission in 
human motor nerves has been estimated at $33 \mathrm{~m}$. per second. Lately mueh higher figures, up to $66 \mathrm{~m}$. per second. have been given.

The stimulus passes from the motor nerve to its muscles through the motor end plates. Here a delay is experienced which with a maximal stimulus amounts to about $0.002-0.003$ of a second (Bernstein).

\section{MECHANICAL STIMULATION OF NERVES}

All kinds of mechanical disturbances, provided they take place with sufficient abruptness, have a stimulating effect on a nerve.

A light hammer let fall from different heights upon the nerve, resting upon a solid support, is commonly used for demonstrating the mechanical stimulation. If the nerve be subjected to a slowly increasing pressure or tension, its excitability at first increases, then as the pressure or tension becomes still greater it falls. Berond a certain limit pressure applied to a nerve entirely abolishes its power of conclueting impulses (see page 411). According to Kühne and Üxkull, stimulation may occur on releasing a nerve from pressure.

\section{ELECTRICAL STIMULATION OF MUSCLE AND NERVE}

1. Method.-The kinds of electrical stimuli the effects of which have been most fully studied are the constant and induction currents.

In applying the electric current to a muscle or nerve, or in leading off electrical currents generated by animal tissues to a galvanometer, nonpolarizable electrodes are used wherever it is practicable. Metal electrodes-e.g., of platinum-are not well adlapted to such a purpose, partly because it is diffieult to find two pieces of metal between which there would be no rlifferences of poten-

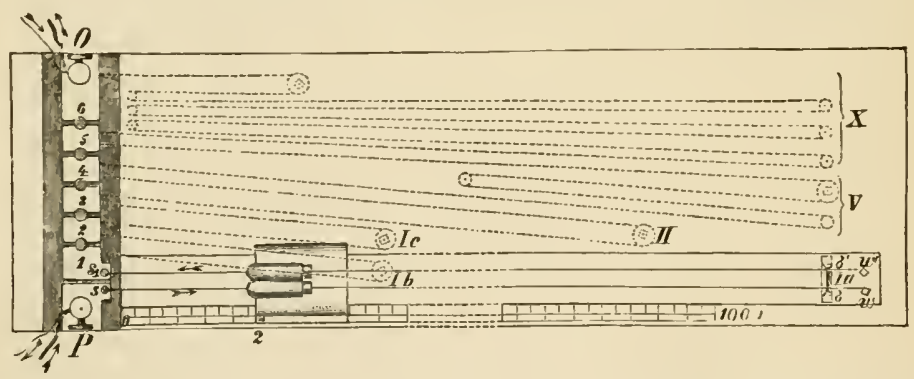

F1G. 156.- Schema of the rheocord of Du Bois-Reymond. The battery wires and the electrodes are connected with the rheocord by means of the binding posts $O$ and $P$. The current coming to the binding post $P$ splits into two lesser currents, one going through the rheocord, the other through the electrode. The strength of current which will pass through the electrodes will depend on the amount of resistance in the rheocord. This resistance is increased by moving the slide 2 , from left to right, also by throwing into the circuit other coils of wire by means of the metal connections $1,2,3,4$, etc.

tial, and partly because the contact of such electrodes with moist animal tissues may very easily set up a difference of potential. In either case the nerve would be subjected to an extraneous current generated by the eleetrodes themselves, which often perhaps would make no essential difference in the results of the experiment, since such a current would necessarily be very weak; but in many investigations, especially when exact determinations of potential differences aris- 
ing in the nerve, muscle, etc., are desired, the polarization, which after a time would be produced by the extraneous current, would greatly vitiate results.

The discovery by Jules Reguauld that zinc in a concentrated solution of zinc sulphate gives no polarization was of very great service in the development of the methods of general nerve-muscle physiology. The fluid, however, must

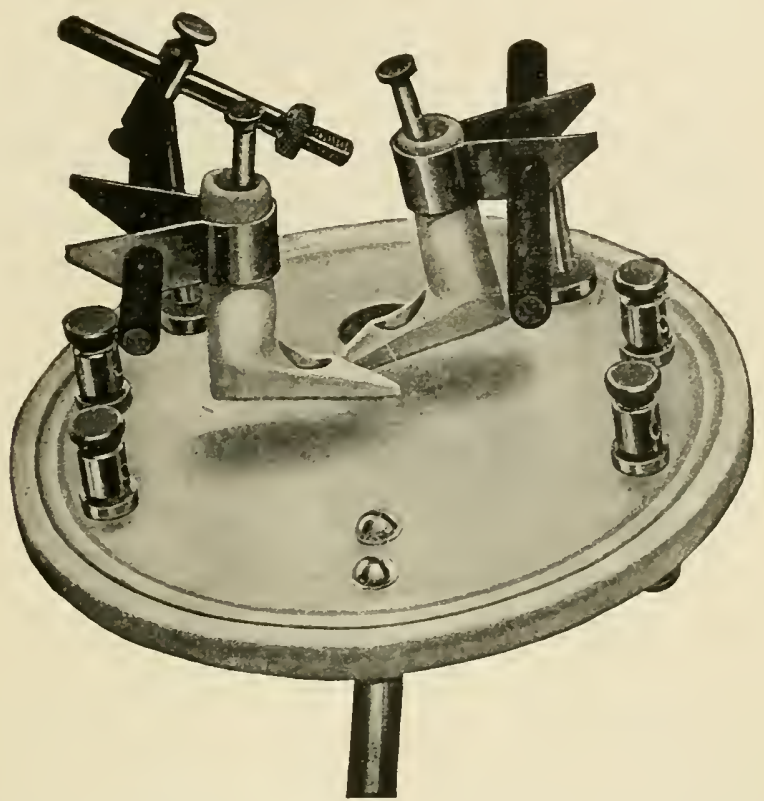

FIG. 157.-Nonpolarizable electrodes, after Porter. Each electrode consists of a porous clay "boot," which may be filled with saturated solution of $\mathrm{Zn} \mathrm{SO}$. Connection with the battery is made to the zinc bars placed inside the boot. A hollow place on the surface of the "toe" is filled with normal saline and the nerve is laid across those two reservoirs in such a way as to keep it continually moistened with the saline. The entire nerve-muscle preparation can be kejt moist by covering boots and all with a glass top which fits in the groove around the edge of the porcelain base.

not come in contact with the animal tissues, for they are completely destroyed by so concentrated a solution. The current therefore is applied to the tissues through porous-clay points molded into a suitable shape, and soaked with 0.6 -percent solution sodium chloride (Fig. 15i). Such a mass is but slightly polarizable. Often the clay tip is sealed into the end of a glass tube filled with zincsulphate solution into which amalgamated zinc bars connected with the source of electricity are dipped. The boot-shaped electrodes represented in Fig. 157 themselves serve at once as the clay tip and the containers for the zinc sulphate. When it is desired to localize the stimulus, or the connection with the galranometers very sharply, the tissue is connected with the porous-clay tips of the nonpolarizable electrodes by means of woolen theads wet with 0.6 per cent $\mathrm{NaCl}$.

It is presumed that the student is already acquainted with the principles of the induction coil. If not, a text-book of phrsies should he consulted.

Since the strength of the induction current depends on the abruptness with which the primary current is changed, it is very important that closing and opening the circuit should take place with equal precision. Many different kinds of keys have been devised to supply this requirement: one is shown in Fig. 160. 
Often it is necessary to have the stimuli follow one another very rapidly. The deviee most commonly employed for this purpose is that known as the Viguer hammer (Fig. 159). The eurrent, starting from the hattery $h$, passes through the post $g$, the spring $h$ provided with an armature, and the serew $f$ to the primary coil $c$, and from there through the electro-magnet $b$ back to the battery. If the current is closed at the serew $f, b$ is magnetized and draws the armature of the spring $h$ down; in this way the current is broken at $f$, the mag-

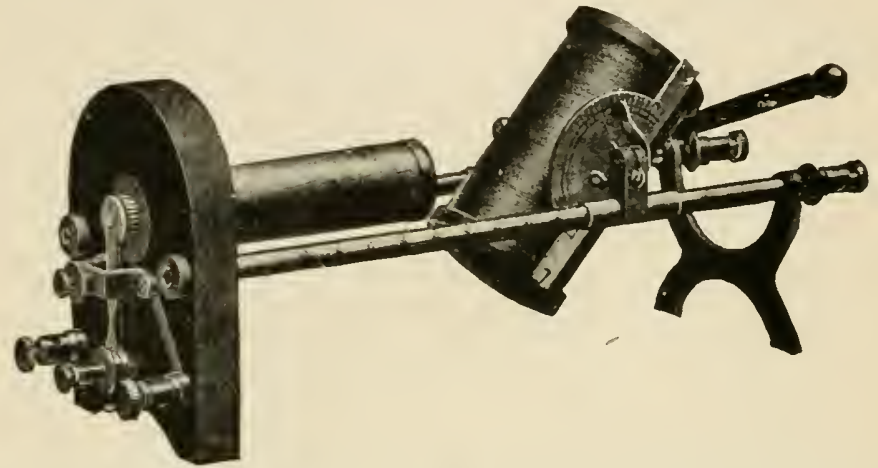

Fig. 15S.-Induction coil of Du Bois-Reymond, after Porter. The strength of the induced currents is raried by sliding the secondary coil on the horizontal bars and also by revolving it about its axis.

net consequently is demagnetized, the spring $h$ is released until it again touches $f$, when the current is once more closed, and so on. The number of interruptions per second can be varied by the position of the serew $f$. The make and break shocks from such an interrupter are not, howerer, of equal strength. In order to equalize them a side wire is inserted between $g$ and $f$ and the screw at $f$ is raised until the hammer can no longer touch it. The screw $f^{\prime}$ on the other hand, is raised so that the spring in its downward motion comes in contact with it. Now when the hammer vibrates the primary eurrent is never entirely broken, but varies between two extreme ralues. Consequently the make and break shocks are weaker but (for reasons which we camnot go into here) they are also more nearly equal in strength.

2. The General Lau of Electrical Stimulation.- All the effects of an eleetric current upon the medium through which it flows depend upon the strength and the density of the current. With the same conductor the density of course is direetly proportional to the strength.

In 1843 1)n Bois-Reymond, on the basis of his discoveries concerning the electrical stimulation of motor nerves, laid down the following general law: The electric current does not stimulate by means of its absolute density, but by means of the alterations which it undergoes from one moment to another: lience the impetus toward a movement which results from these alterations is greater the more rapidly they occur, or the more extensive the alteration in a unit of time. The contraction of a muscle produced by an increasing density of the current was called the "closing contraction," that produced by decreasing density, the "opening contraction."

This law was supported by such facts as the following: a current passing through a nerve may, if increased very gradually, reach a high density without 
producing any contraction; whereas a much weaker current closed suddenty produces a maximal effect. And conversely, a stronger current if resluced very gradually, may be brought down to nil withont causing an excitation: whereas the sudden opening of a much weaker current is accompanied by a strong contraction.

But under eertain circumstances a constant current flowing through a motor nerve may stimulate not only at the moment of closing, but during the entire period of closure. This happens for example with frog's nerves when the latter are taken from frogs which have been kept for a long time at a temperature below $10^{\circ} \mathrm{C}$. (v. Frey); also with the nerves of warm-blooded animals when the current is not too weak. Again, if a constant current has been flowing through a nerve for a sufficient time, on opening the current there often appears a prolonged contraction instead of a simple short contraction. This continued state of eontraction is often spoken of as "Pitter's tetamus." Often also aftor the summit of the closing contraction has been passed, a cross-striated muscle does not recover its natural length immediately, but remains more or less shortened ("Wundt's tetanus"), and only returns to its resting condition when the enrrent is broken-i. e., in case no opening contraction ocenrs. If the stimulus is very weak, the constant excitation is only a loeal one, spreading orer a limited

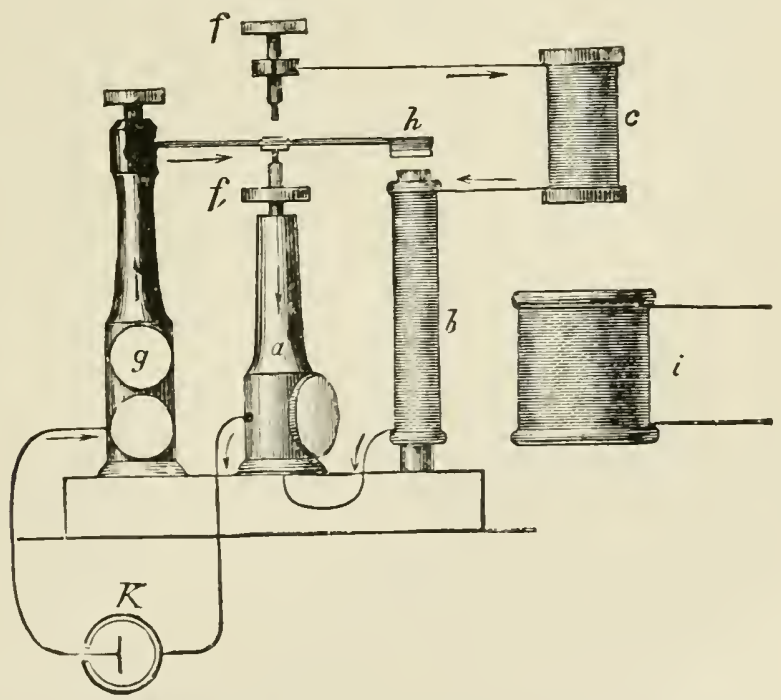

Fis. 159.-Details of the Wagner hammer or interrupter of the induction coil. c, primary coil ; $i$, secondary eoil. The primary current is generated in the battery $K$ and the scondary or induced currents are led off by electrodes attached to the ends of the secondary coil.

portion of the musele. Finally, when a constant current is applied to an afferent nerve, a distinet sensation is felt during the entire periol of elosure, even when the peripheral end organs are exehded (Grïtzner, Langendorff, Biedermamm).

We find therefore so many exceptions to Du Bois-Reymondls law, that in its original form it can no longer be regarderl as of general application, although, so far as muscle alone is ennerned. the excitation of large masses appears to depend upon sudden eluanges at the place of direct stimulation. Noreover. the law must take into acenunt the nature of the irritable tissue: 
the more irritable it is, the more do the risible phenomena of continuous excitation remain in the backgromo. whereas the eflects of variation in the current become the more apparent (Biedermann).

For all irritable tissues there is a minimum duration of the electric current necessary to give a stimulus. Other things being equal, the more this time is shortened, the less beeomes the stimulating effeet until finally it fails altogether. The length of time necessary to produce the maximal effect depends primarily on the strength of the current. The greater the strength the shorter the time may be. A constant current of medium strength requires 0.016 second to produce its maximal effeet on motor nerves (J. König);

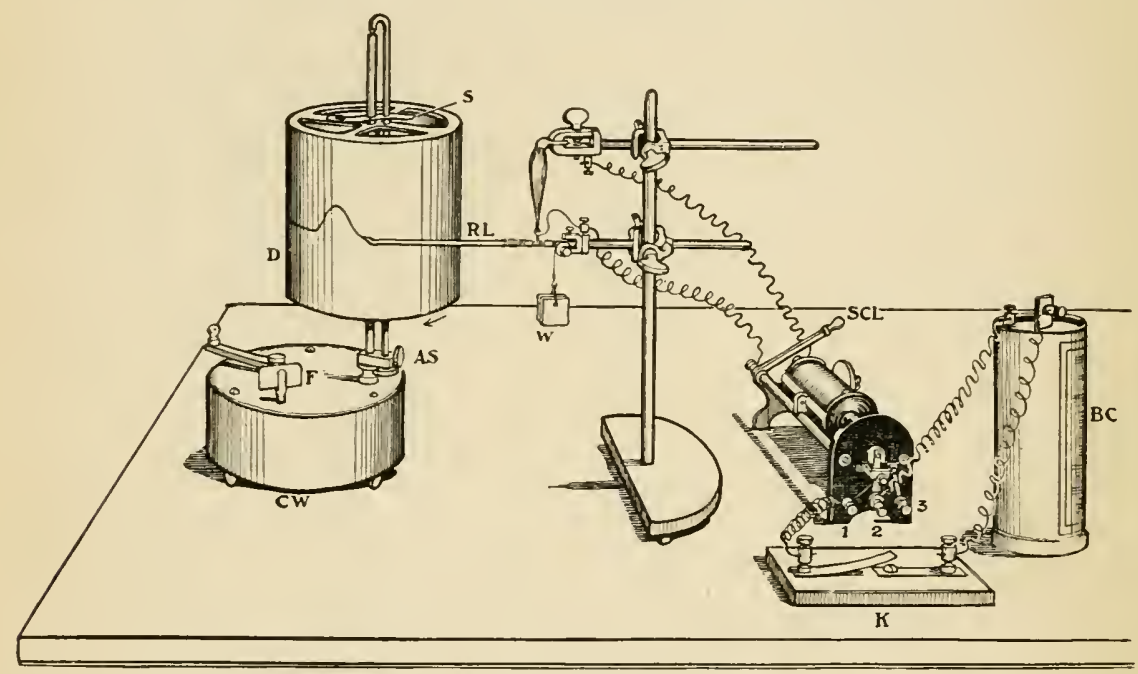

FIG. 160.-A convenient arrangement of the apparatus for sending induction shocks through a muscle is shown in this Figure. $B C$, the battery cell; $K$, key for closing and opening the primary current. When the wires are connected with binding posts 1 and 2 of the induction coil, single make and break shocks are obtained from the sccondary coil and are conveyed by the wires connected therewith to the muscle. When the wires are connected with binding posts 1 and 3 of the induction coil the automatic interrupter is brought into play and a series of rapidly repeated (tetanic) shocks is obtained. By means of hand electredes connected with the secondary end of the induction coil, stimuli may be applied in various other ways.

no contractions are obtained if the time be reduced below 0.002 second. Induction shocks are still shorter than this; nevertheless, beeanse of their high tension they are the most effective stimuli for the nerves.

So far we have considered only the effeets of currents suddenly turned on in their full strength. It is possible also by means of special apparatus to arrange the experiment so that starting from nil the current will increase gradually and only reach its maximum after a certain measured time. When this measured time does not exceed зово th of a second the effect is the same as that of a current of equal intensity suddenly opened in full force. When it is more than $\frac{1}{000}$ th of a second the effect varies with the intensity of the current, being for a weak current less effective than the sudden opening, and with a strong current more effective (Gildemeister). But the most characteristic thing about these 
"time stimuli," as they are called, is that the contractions which they induce continue for a noticeably longer time, and the nerves and muscles can therefore be thrown by them into a state of excitation which lasts longer, than is the case with the sudden stimuli. This peculiarity, as we shall see later, is of great importance for the theoretical explanation of voluntary muscular contraction.

The nature of the irritable tisste again has much to do with the length of time required to stimulate it: the more slowly it reacts, the longer must the stimulus act to produce a visible effect.

A single induction shock, which is so effective for the nerve, is but slightly effective for smooth muscles. In certain stages of degeneration the skeletal muscles exhibit a very much reduced or even absolute lack of sensitivity toward induction currents, whereas their excitability to constant currents remains unimpaired or may even be increased (Erb). With the rapidly contracting frog's muscles, stimulation of the nerve by the break-induction shock is much stronger than by the make-induction shock, because the former is a more sudden stimulus. Nerve-muscle preparations of the turtle, which are much more sluggish in their action, behave in exactly the reverse manner.

3. Law of Contraction.-The stimulating effect of the constant current depends not only upon the strength but also upon the direction of the current in the nerve. If the current is weak it generally produces a contraction only when it is closed. no difference in which direction it is flowing. If the current is increased in strength (medium current), contractions occur also when it is opened, whether the current is flowing toward the muscle (descending) or away from it (ascending), although opening contractions do not always appear with the same strength of current in the two cases. Increasing the strength still more (strong current) we find that with the ascending current the closing contraction gradually becomes smaller until it finally isappears, while the opening contraction continues at its maximum. With the descending current we find the reverse condition: the closing contraction remains at its maximum however strong the current be made, but the opening contraction becomes smaller and smaller as the strength increases, and not infrequently it disappears. Howerer, the strength at which the closing contraction disappears, when the current is ascending. is not always the same. And sometimes when the current is descending the opening contraction does not disappear at all but persists at a certain minimal size.

These generalizations may be summarized in the following formula, known as Pflüger's law of contraction:

Strength of Current.

Weak.. $\left\{\begin{array}{l}\text { Closing } \\ \text { Opening }\end{array}\right.$

Medium $\left\{\begin{array}{l}\text { Closing } \\ \text { Opening }\end{array}\right.$

Strong $\left\{\begin{array}{l}\text { Closing } \\ \text { Opening }\end{array}\right.$
Ascending current.

C

o

C

C

O

C
Descending current.

C

0

C

C

C

O or weak $\mathrm{C}$

$\mathrm{C}=$ contraction $; \quad \mathrm{O}=$ no contraction. 
It will be understood that the terms ueak, medium, and strong as applied to the current in this diseussion do not designate any absolute values of the curlent, since wlat is mediun current for one nerve-muscle preparation may be strong for another. 'The terms are purely relative to any given preparation.

This peculiar behavior of a nerve-muscle preparation to currents of different strength. Which finds expression in the law of contraction. depends upon another law enunciated by Pfliger, namely, that a constant eurrent has

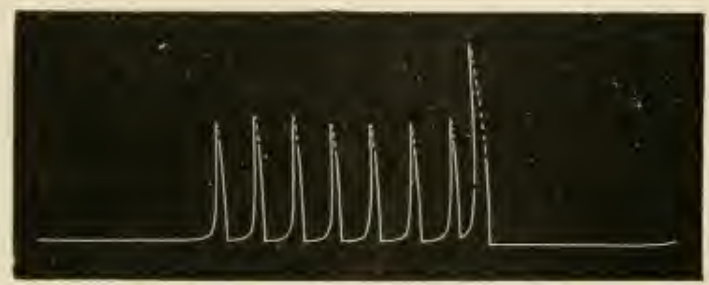

Fig. 16il.-Catclectrotonus. The traeing is to be read from right to left. The nerve was first stimulated in the neighborhood of the cathode of the polarizing eurrent with stimuli too wrak to prochee any effect while the polarizing eurrent was not running. The polarizing eurrent was then turned on, and, without changing the st rength of the stimuli, they became effective. When the polarizing current was again turned off, the stimuli were again subminimal.

no stimulating action on the nerve hetween the poles. but acts only at the poles. On closing the current the stimulus starts from the cathode, on opening from the anode.

This polar lax of excitation may be illustraterl by the following experimental facts. If in stimulating with the constant current the electrodes be applied to the nerve as far apart as possible, and the latent period of the closing contractions be determined both for the ascending and descending currents, we find this period to be longer for the former than for the latter (v. Bezold). With the descending current the eathole is nearer the musele than with the ascending current; hence the stimulus has a shorter distance to travel to reach the muscle with the former than with the latter. In a similar way it ean be shown that the stimulus starts from the anode when the eurrent is broken.

The law of contraction may be illustrated hy carrying the experiment farther. Thus if from the leterminations of the latent period just mentioned the rate of transmission of the stimulus be ealeulated, it will be found considerably lower than when it is determined on the same nerve, by the method (described on page 41\%) of stimulating at two points with the induction current. The reason is that with the ascending current the stimulus on its way to the muscle has experienced some resistance at the anode. This resistance raries considerably in amount aceording to the strength of the stimulating current. When the current is weak or of medium strength the stimulus at the cathode on elosing the eurrent is strong enough to overeome the resistance at the anode. But when the eurrent is strong the resistance at the anode is ton great to be overeome by the stimulus at the eathode, and it constitutes therefore a complete block. It can be shown also that when the cathode intervenes between the anole and the muscle, it ereates a resistance to the anodic stimulus.

The polar law of excitation was deduced by Pflïger mainly on the ground of the alterations in excitability produced in the nerve by a constant current. 
While the current is flowing the excitability is increased on both sides of the cathode; on both sides of the anode it is derreased. 'These alterations appear' immediately (within 0.0000 s second at most) after closing the current. In the intrapolar region there is found an indiflerent point where the excitability of the nerve is not ehanged: and as the constant current increases in strength this point moves toward the cathode. At the same time the estrapolar alterations of excitalsility spread over greater lengths of the nerve.

Likewise during the first few moments after the current is opened alterations in the excitability appear, but they are just the reverse of those which oceur while the current is closed-i. e., reduced at the cathode and increased at the anode.

These alterations may be studied in the following manner. A nerve is stimulated rhythmically, say once a second, with a current of constant strength, and the resulting contractions are recorded in the usual manner. If now while the stimulation is going on at the regular rhythm, a constant enrrent be led into the nerve, and the stimuli fall in the neighborhood of the eathode of this enrrent, the contractions at once become stronger; if they fall in the neighborhood of the anode, the contractions decrease in sizc and lisappear altogether (see Figs. 161 and 162). When the current being led through the nerve is broken, contractions from stimuli applied at the eathole become smaller, those from stimuli at the anode beeome larger.

The increase of excitability at the eathode while the current is elosed soon fails and passes orer into a depressed condition. which, as Biedermann observes, is probably the expression of a loeal fatigue of the nerve.

The phenomena comprehended under the law of contraction may then be explained through the law of polar exeitation as follows: Weak currents give a closing contraction beeause when the eurrent is closet, the sudden rise in irritability of the nerve at the cathode is great enough to constitute a stimulus of itself. The stimulus is effective whether the current be aseending or descruding, for in the one case the cathode is townd the musele, and in the other the

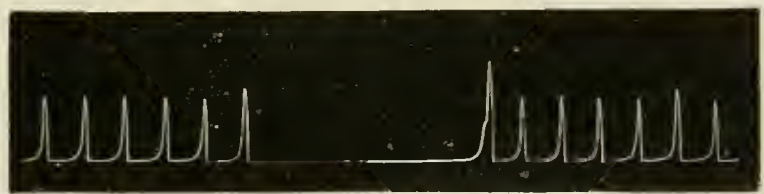

Fin. 162.-Aneleetrotonus. The traeing to be read from right to left. A series of stimuli just strong enough to produce slight contractions were applied in the neighborhood of the anorle for the polarizing current. When the polarizing current was turned on the stimuli became ineffective. When it was again turned off the stimuli again became effeetive.

resistanee at the anode. due to the deerease in irritahility, is not great enough to block the stimulus. The sudden inerease in excitability produced in the nerve at the anode when the enrent is broken is not ret sufticient to constitute a stimulus.- With the medium current the inclease in exeitability at the cathode on closing and at the anote on opening are both sufficient to produee a stimulus, and in weither case is the opposite pole strong enough to block it. The strong current is distinguished from the medium by the rireumstanee that while the current is rensed the resistance at the annle is stronger than the exeitation at the eathule and rice persa when the eurrent is opened. Consecpuently with the ascending current the excitation started at the cathorle cannot break through 
the anode, and the elosing contraction is wanting. With the descending current the excitation started at the anode meets with a resistance at the cathode which may or may not completely block it; hence the opening contraction either fails altogether or is greatly diminished.

Exactly the same laws hold for the induction currents as for the constant current. 'They also stimulate at the cathode as they appear and at the same time produce a resistance at the anode. When they are strong enough, they have a stimulating effect also as they disappear and then the stimulus starts from the anode.

The fact that the induction eurrents produce a resistance at their anode is demonstrated by the following experiment: a nerve is stimulated with ascending induction currents which, beginning with very weak shocks, are gradually

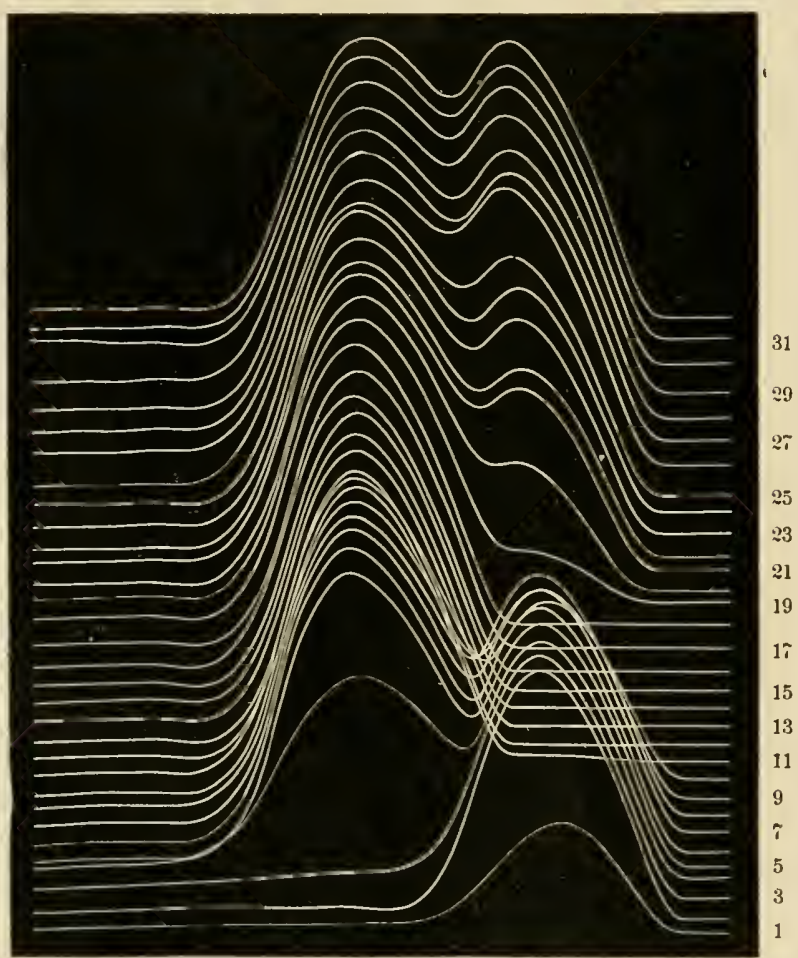

FIG. 163.--Stimulation of a nerve by a series of ascending make- and descending break-induction shocks of increasing strengtlı. To be read from right to left. The first contraction of each pair was obtained by the ascending closing and the second by the descending opening shock. There are no "gaps" in the latter series.

increased in strength (Fig. 163). The height of the contractions at first increases, but after a time deereases, and with a certain strength the musele remains at rest (Fig. 163; Nos. 11-18). If the strength of the shocks be raisel still further, contractions appear again, which at first are weak (Nos. 19, 20), but gradually become stronger until they finally may become supramaximal. With a 
series of shocks of increasing strength we have therefore a gap in the resulting contractions (Fick). This is only observed with the ascending eurrents, and is the result of a block at the anode. The absence of the contractions is therefore entirely analogous to the corresponding phenomena for the strong ascending constant eurrent. The contractions coming after the gap and gradually increasing in size are produced really by the excitation taking place at the disappear-

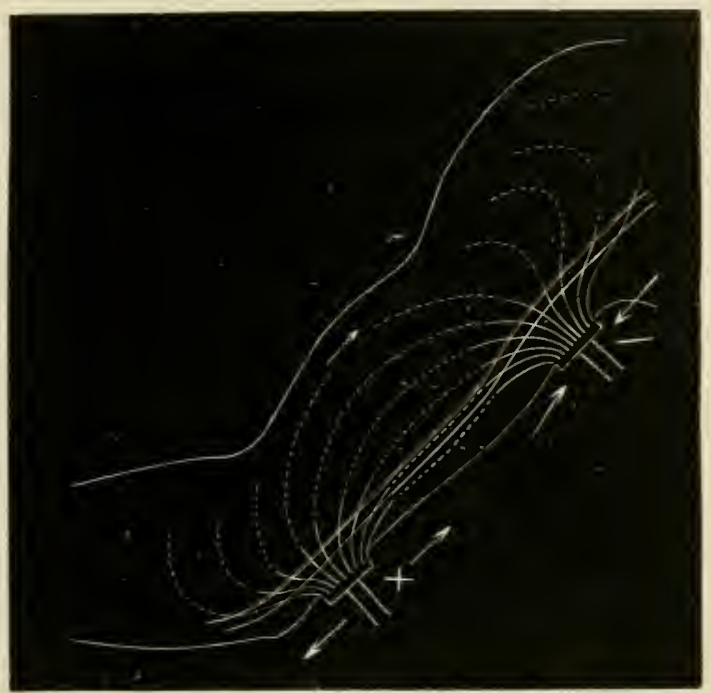

Fig. 164.-Sehrematic representation of the distribution of an electric current in a human arm on application of two electrodes over a nerve, after de Watteville.

ance of the induction current, and are to be regarded for this reason as a sort of opening contractions. But further discussion of their nature here would carry us too far afield.

The stimulating effects and the alterations of excitability produced by the clectric current follow the same laws in human nerves as in the exsected frog's nerves (Waller and de Watteville).

In experiments on living men, the electrodes of course cannot be applied to the nerves themselves, but ean only be placed on the skin; the nerre is stimulated then only by the threads of current which penetrate that far. It will be clear at once that the density of that portion of the eurrent reaching a particular nerve will be greater the nearer the nerve lies to the surface of the skin. Consequently in using the current for therapeutic purposes the electrodes are applied to the skin at those points where the nerve, which it is desired to stimulate, ean be reached most direetly.

The effective anode is of enurse the place where the eurrent enters the nerve itself, the effective eathode, the place where it leaves the nerve. If both poles were to be plaeed on the skin over the nerve, as in Fig. 16t. anodes and rathodes would be present at almost every possible point along the nerve, as indicated by the radiating lines. Evidently sueh an experiment would not be adapted to the study of electrical effects on human nerves. The monopolar method is therefore used, the eurrent being conveyed to and away from the body by electrodes 
of different size, a linge one $(12 \times 6 \mathrm{~cm}$. ) apllied to the breast, and a small one (0.5-2 em. diameter) applied orer the motor point to be tested. Suppose now the large eleetrode is the anode: the current enters then with relatively low density, spreads out thruugh the borly with still less density and finally colleets at the eathode with great density. Since now the effeets of a currexit depend upon its density, it follows that with eurrents of molerate strength these effeets will appear only at the smaller electrode. Some of the many threads of eurrent reaching the smaller electrode from all parts of the body, will necessarily pass

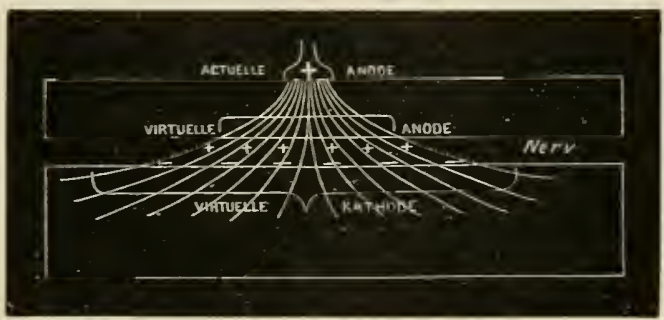

FIG. 165. - Schematic representation of the entrance into and exit from a nerve of a eurrent applied to the skin over the nerve, after de Watteville.

through the nerse under it. The effectire eathorle of the current lies where these threads pass out of the nerve, and if, as we have assumed, the smaller eleetrode is the rathode. other things being equal, the eurent will have its greatest possible density there. If the current is reversed so that it now enters the houly by the smaller electrode (which is still orer the nerve), the places where the threarls of eurrent leave the nerve constitute as before the effeetive eathode; the density of the current now however is less than in the first ease (Fig. 165).

The polar lau" of creitation applics also to muscle. both with the constant and induction current (r. Bezold. EngeImann. Biedemumn; cf. page 116 ).

We have a very instructive proof of this in the "polar failure" of exeitation discovered by Biedermam and Engelmann. If, for example, the end of a froc's sartorius muscle be nareotized and the eathole be applied to this injured place, on closing the current the muscle remains at rest. The normal muscle substance is not stimulated by the closure of a eurrent as it passes from the normal to the paralyzed or dead muscle substance, and the mere passage of a eurrent is not sufficient to discharge the contraction (Locke and Szrmanowski). Similar phenomena nay be shown on opening of the eurrent when the anode is plaeed at the injured plaee.

\section{E. EFFECT OF A RAPID SERIES OF STIMULI}

If a nerve or a muscle be affected br two stimuli in rapid sucession. sn that the action resulting from the first has not ret come to an end when the second hecomes effective. the relaxation which would otherwise follow the first contraction is interrupted and the effect of the seennd stimulus is added to the first: consequently the contraction of the muscle is greater than it commonly would he as the result of a single stimulus. It is only when the load of the muscle is very light that it contracts as strongly to a single stimulus as to rapidly repeated stimuli (r. Frey). 
In summated contractions the aseending limb of the second contraction curve is steeper than that of the first, hence the summit of the second appears carlier than would be experted if its course were the same as the first (v. Kries). The latent period of the superimposed eontraction is also said to be very much shorter than that following the first stimulus (Fick).

In order that successive stimuli may produce a summation they must not follow one another too rapidly. The smallest interval possible for any giren preparation depends upon the temperature and the strength of the stimuli: for the nerves of the frog at ordinary room temperature it may be estimater at about 0.001 to 0.005 second. We have a refractory period therefore in nerres and skeletal muscles just as we harc in heart muscle (cf. pagre 15.3).

If more than two stimuli affect the nerve or muscle at sufficiently short intervals the contraction of the muscle hecomes still greater, and its eurve is perfectly continuous. showing no separate summits (cf. Fig. 166). This form of contraction is called tetanus.

Complete tetanus appears only when the stimuli follow one another so rapidly that the interval between them is less than the time oceupied by the artive shortening of the muscle when that is maximal. The frequency depends there-

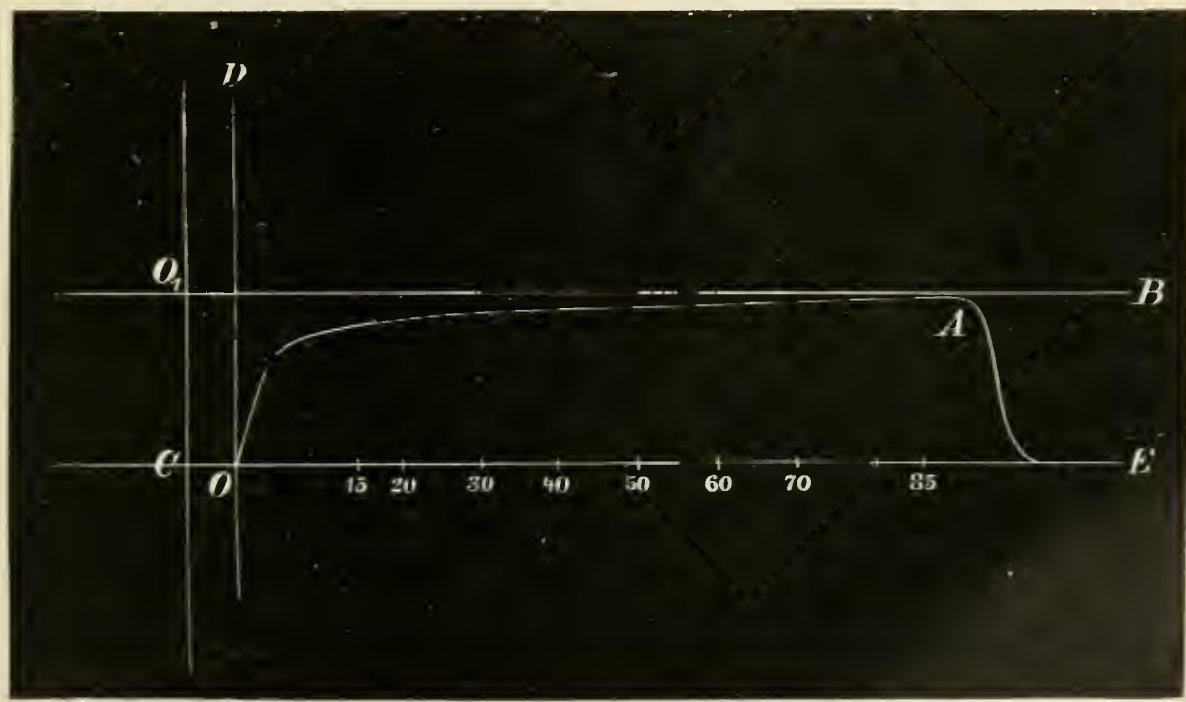

Fig. 166.-Tetanus eurve of the frog's gastrocnemius, after Bohr. Twenty-seven stimuli per second.

fore primarily upon the behavior of the muscle to single stimuli: the more rapilly a single contraction runs its course, the more frequently must the stimuli he given to produce enmplete tetanus. This is beautifully shown by the beharior of museles of warm-hlonderl animals composed mainly of red or white fihers. The red soleus musele of the rabbit falls into almost emmplete tetanus with ten stimuli per second. while the white gastrocnemins medius with the same frequeney of stimulation gives rory evirlent single contractions. I frequeney of six stimuli per second permits the white muscle to relax almost completels 
between contractions, whereas it keeps the red muscle almost continuously contracted (Ranvier, Kronecker and Stirling; cf. Fig. 167).

Everything which tends to make the single contractions occupy more time operates to reduce the frequency of stimulation necessary to evoke complete tetanus. Thus fatigued muscles are thrown into tetanus with a lower frequency than unfatigued, because their contractions are slower.

The more the frequency is reduced below that which is just sufficient to produce tetanus, the more distinctly do the contractions produced by the individual stimuli stand out from one another, until finally below a certain fre-

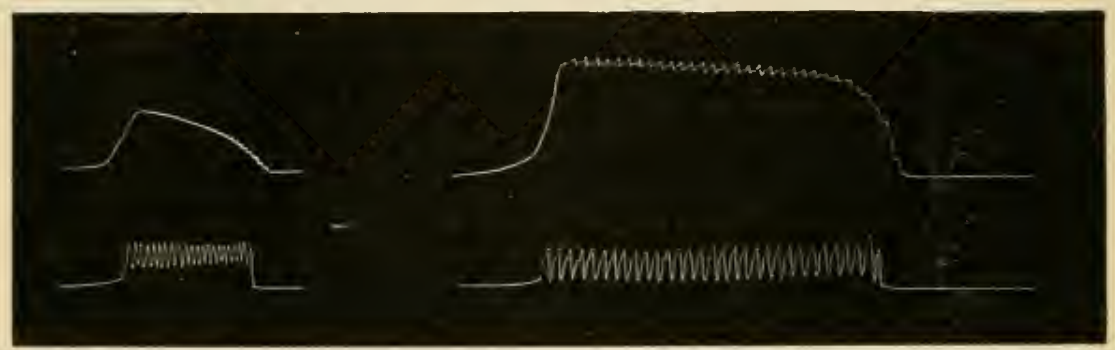

A

$B$

Fig. 167.-Tetanus curves of the white (lower tracings) and of the red (upper tracings) muscles of the rabbit, after Kronecker and Stirling. To be read from right to left. $A$, ten stimuli per second. $B$, six stimuli per second.

quency there is no fusion whatever. We have therefore all possible gradations between the isolated contractions and complete tetanus. This suggests that tetanus itself, notwithstanding the continuous curve by which it is represented graphically, is really a discontinuous process, and complete proof of this is furnished by the electrical variations accompanying tetanus (page 433).

How are we to conceive of the processes going on in the muscle in tetanus? One signinicant fact is that by artificially supporting the muscle, so that it does not lift its weight until it has contracted some distance, the single contractions can be made to reach the same height as tetanus with the same strength of current (v. Frey). We may say, therefore, that in tetanus the muscle contracts to its utmost, because to a certain extent it is supported on itself. In addition to this the irritability of both nerve and muscle is increased by a previous stimulation-i.e., if the excitation is not too strong or does not continue so long as to involve much fatigue. Hence not infrequently it happens that stimuli, which of themselves are ineffective, become effective merely by being repeated with sufficient frequency.

Tetanus may be looked upon therefore as a sort of hcaping up of small contractions due to the rapidity of the stimuli and to increased irritability.

\section{F. VOLUNTARY CONTRACTIONS}

If we compare voluntary contractions on the same drum with the rapir, twitchlike muscular contraction produced by a single artificial stimulus. we discover that the former are both slower and less abrupt. Comparing them with the contractions obtained by rapidly repcated shocks. we find more in common. Many other cireumstances strongly support this resemblance, the most important of them being, that the roluntary contraction as well as the contractions which appear reflexly with strychnine poisoning are accompanied, 
just as tetanus is, by action currents which signify a riscontinuous excitation (Lorén). But it is worthy of note that the rhythm of these action currents in voluntary contractions, and others produced under the influence of the central nervous system, is only about half as rapid as the frequency of stimulation necessary to produce a complete tetanus. And yet the voluntary contraction as ordinarily recorded is quite continuous. This must be due to the fact that the single impulses sent out to the muscles from the central organs to produce a voluntary contraction last longer than the ordinary instantaneous stimuli (Lovén), and that the separate twitches are therefore more readily fused. We know, indeed, that a "time stimulus" (page t?3) is longer drawn out than a momentary stimulus and that it is therefore better adapted.to produce summation with a low frequeney of stimulation.

The trembling of the muscles which accompanies a strained effort to overcome some great resistance or an attempt to hold a musele contracted voluntarily to its utmost, are generally regarded as expressions of the individual impulses discharged from the central nervous system. The regulation of the imnervating mechanisms would seem in these cases to be disturbed in some way so as to affect the fusion of the separate contractions. It has been shown that the number of such oscillations per second varies in man from seven or eight to twelve or thirteen (Lovén, v. Kries, Schäfer). The greatest muscular eftorts are made, it appears, with a frequency of ten to twelve impulses per second.

\section{\$ 4. SIGNS OF ACTIVITY IN MUSCLE AND NERVE}

\section{A. ELECTRICAL PHENOMENA}

1. Action Current.-The general law of the electrical variation known as the action current, which makes its appearance when nerve or muscle is active, has already been given on page 48 . In view of its great importance

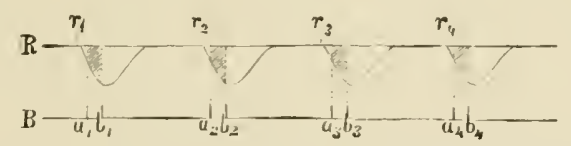

FIg. 168.-Schema illustrating a rheotome experiment.

for the general physiology of museles and nerves, howerer, we must discuss it here somewhat more in detail.

In order to study time relations of the action eurrent, one can use either the capillary electrometer whose excursions ean be recorded by the photographic methor, or the repeating rheotome of Bernstein.

Suppose we lave an electrieal variation of the form represented in Fig. 16s. The galvanometer is too slow to reproduee this form correctly. But if we arrange the experiment so that a definite portion of each variation of the eurrent-e. g., that included between $a_{1}$ and $b_{1}$ in Fig. 168-affects the gralvanometer, and this is repeated many times, from the excursion of the galvanometer we ean learn the extent of the electrieal variation during this portion. If now we ean determine in the same way the excursion of the galvanometer for the other 
portions, say $b_{1}$ to $c_{1}, c_{1}$ to $d_{1}$, $d_{1}$ to $c_{1}$, ete., of course it will be possible to obtain the form of the entine variation. An alplaratus which would enable us to make such determinations must jermit of comnection whth the galvanoneter at a definite monent after the begiming of the variation, and of breaking this conneetion at any desired moment during the variation. Since the clectrical variation in muscles and nerves is started by the excitation, the requinenents will be met if the galvanometer eircuit can be closed or broken at any giren interval after the instant of stimulation.

The rheotome of Bernstein (Fig. 169) consists of a wheel ( $r$ ) revolving about a rertical axis, and earring on its circumference three metal pegs, one of which $(c)$ gives the stimulus to the nerve by closing or opening the primary current to an induetion eoil; the other two pegs insulated from the first, but in electrical connection with each other, serve to close and open the galvanometer eircuit. At each revolution of the wheel the pegs $c_{1}$ and $r_{2}$ dip into the mereury troughs $\left(q_{1}\right.$ and $\left.q_{2}\right)$ respectively which are connected with the muscle on the one

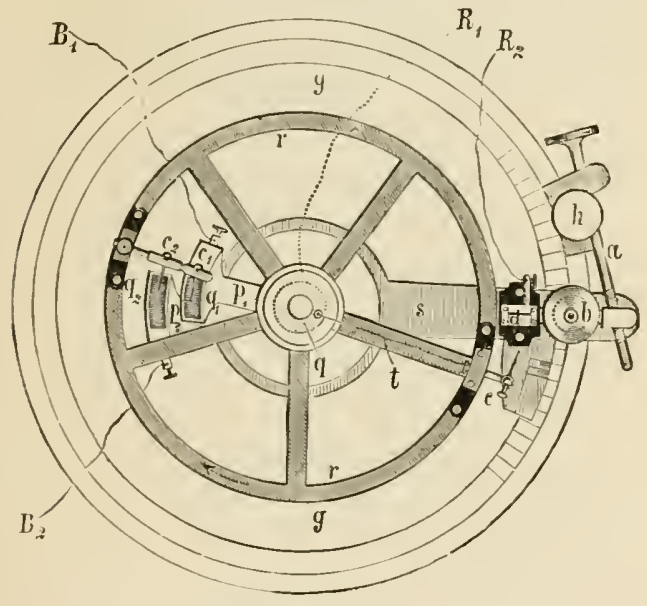

FIG. 169.-Rheotome of Bernstein. hand and the galvanometer on the other. The mereury troughs are morable with respect to each other, so that the duration of the galvanometer current can be varied within wide limits. If now the wheel is revolved at a certain speed, with each revolution the musele will receive a stimulus and the galvamometer circuit will be closed for a certain definite time after each stimulus. If we have the two contacts so arrangerl that the galvanometer is connecter with the unusele at the same instant that the stimulus is given, the exeursion of the galvanometer will represent the first part of the variation eroked by the stimulus. Then

ly shifting the contacts, the galvanometer can be connected at different intervals following the instant of stinulation until the entire variation is recorded.

If a musele (or the heart) or a nerve be connected at two uninjured places ( $a$ and b, Fig. 1\%0) with a galvanometer, and it be then stimulated at some outside point $(c)$, the galvanometer shows that the point $a$ situated nearer the point of stimulation beemes dectrically negative to $b$, and then the current is reversed and $b$ becomes negative to $a$ (ef. pages $t 8$ and 139 ). The action current therefore consists of two phases, each of which gives expression to the general law, that every active point of a muscle or nerve is electrically nogative to erery resting point (page fis). When the excitation spreads from the point $r$. the nearer of the two points naturally lecomes active first. While the more distant point $(b)$ is still resting: hence the first phase. When the excitation reaches the point $b$ and the point a first stimulated has gradually passed into a resting state, the second phase appears. 
The action current does not represent an artificial product, but is a process intimately connected with the process of excitation, for it is produced by all kinds of stimuli; it is propagated at the same rate of speed as the excitation and varies in strength to a certain extent with the strength of stimulation.

If the nerve or the muscle be led off to the galvanometer, not from two points on the longitudinal surface, but from the longitudinal surface and a cross section, the second phase of the action eurrent no longer appears, but the current is now directed from the longitudinal surface over to the cross section. It was in this form that the action current was first disenvered. Since it rums in the opposite direction from the current of rest (see page 45) it was designated by Du Pois-Reymond as the negative rariation of the eurrent of rest.

The action current is the only functional change which we have thus far been able to observe in living nerves. It is of erreat importance also for the reason that it permits us 10 determine the nature of any muscular contraction.

We have alpeady become acquainted with an example of this in studying the heart. The action eurrent there showed us that, notwithstanding its long duration, the contraction of the heart is in reality a simple muscular twitch (cf. page $17 !)$ ).

There are other kinds of contractions, like tetanus and voluntary contractions, which as we have seen are apparently continuous, but which the action enrrent proves to be discontinuous. If by the use of the rheotome, a nuscle be stimulated often enough to produce complete tetanus, the excursions of the galvanoneter will show that each separate stimulus produces a special action current of its own-i. e., every excitation causes a molecular change in the muscle, although the change may not be apparent in the mechanical behavior of the muscle.

The action current of muscle as well as of nerve is strong enongh to have a stimulating action of its own (Mattencei). If the nerve of one muscle. B. he laid across the belly of another muscle, $A$, and the seeond muscle be then stimu-

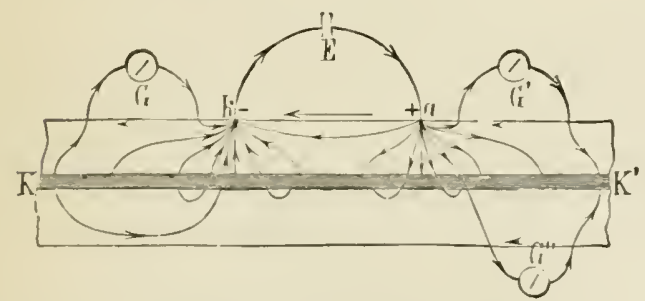

Fic. 171.- Illustrating the thenry of electrotonic currents, after Hermann. lated through its own nerve, with each contraction of $\mathrm{A}$. $\mathrm{B}$ also contracts, and this even in case $A$ is so tense that it no longer changes its form. The contractions of $B$ agree minutely in number, strength and sequence with those of $A$. If $A$ is tetanized. B also is tetanized. These phenomena are ealled secondary contructions. secondary tetanus, ete.

2. Elertrotonic Currents.-

II'hen an electric ("urrent is conducted through a errtain length of a meshllated nerve and another portion of the nerve outside of this length is connected with the cralranometer, an 
excursion of the needle is seen which indicates the presence of a current in the portion led off. This eurrent is in the same direction as the eurrent applied to the nerve (called the polarizing current), and is spoken of as an electrotonic current. The strength of this current depends upon many different circumstances; it is stronger, the less the distance from the portion of the nerve traversed by the polarizing current, and the stronger the latter is; moreover, the change (in the frog) is greater in the region of the anode than in the region of the cathole.

The electrotonic currents are branches of the polarizing current. According to Grimhagen, they arise because the inner parts of the nerve fibers, the axis cylinders, are better conductors than the medullary sheaths. Consequently the current (E in Fig. 171) spreads out over great lengths of the nerve, and when connection is made from these extrapolar parts with the galvanometer $\left(\mathrm{G}, \mathrm{G}^{\prime \prime}\right)$, the threads of current break through to the surface. It may be fairly doubted now whether, as Hermann imagined, a polarization between the inner and outer parts of the nerve plays any part in producing these electrotonic currents.

\section{B. THE MUSCLE TONE}

If a person sticks his finger in his ear and then contracts his arm vigorously, he hears a dull sound, the pitch of which has been determined by Wallasten and others to be about thirty-two to thirty-six vibrations a second. Helmholtz observed that the same sound is heard very clearly if the ears (best at night) be stopped with drops of sealing wax and the masseter muscles be powerfully contracted. So long as the muscles remain at a uniform tension, one hears a dull, roaring sound, whose fundamental tone is not changed materially by increasing the tension, whereas the accompanying roar becomes both stronger and higher.

Helmholtz demonstrated further that the vibrations of voluntary muscles which produce the muscular sound do not occur so regularly as those of a musical tone, nor so rapidly as thirty-two to thirty-six per second. He found on the average only about nineteen per second. The muscular sound is therefore an overtone of the true muscle vibrations. Since the pitch of this sound changes also with the condition of the ear drum, it follows that the sound experienced is a resonance tone of the tympanic membrane, produced by the irregular concussions of the muscles. From these facts it is not difficult to understand why the simple contraction of a muscle produced by a single stimulus, and the systole of the heart as well, is accompanied by a muscular sound (cf. page 168).

\section{THE CHEMICAL ALTERATIONS IN MUSCLE DUE TO ITS ACTIVITY}

Active muscle acquires an acid reaction. This is probably due in part to an increased percentage of monophosphates, and in part to the formation of lactic acid. According to Helmholtz, working muscle contains less substance soluble in water and more substance soluble in alcohol than resting muscle. Again it is stated that in work the total quantity of creatin and creatinin increases and that of the xanthin bases decreases. Finally, the percentage of glycogen in the muscle diminishes.

An acid reaction has been observed in the neighborhood of the electrodes when nerves are stimulated. Since however no such change can be demonstrated at points of the nerve which have not been touched by the stimulating current, this acid reaction must be regarded as a direct effect of the currenti. e., electrolysis. Waller concludes from certain phenomena with the action current that the nerve forms carbon dioxide during its activity. 


\section{MECHANICAL WORK}

The amount of mechanical work done by a muscular contraction depends primarily upon the strength of the stimulus. and upon the load.

1. Effect of the Strength of Stimulus.-If a muscle bearing a constant load be stimulated with a graded series of shocks beginning at a very low level and increasing slowly, it is found, both with direct electrical stimulation of the muscle and with mechanical or electrical stimulation of the nerve, that the height of the contractions increases more and more slowly with a uniform increase in the strength of the stimnli, and that it finally approaches its maximum after the manner of an asymptote (Fig. 172). The maximum shortening which can be obtained under the most farorable circumstances with a single contraction is about twenty per cent of the natural length of the muscle.

The muscular tension obtained with a maximal stimulus applied to the nerve is considerably smaller than that obtained by a maximal stimulus applied directly to the muscle itself (Dean). If this is true of the natural stimulation from the central nervous system also, it means that the muscles are always capable of more work than can ever, under normal circumstances, be obtained from them.

2. Effect of Load with Constant stimulus.-We shall consider only the case of a maximal stimulus.

One can vary the way in which the power of the muscle

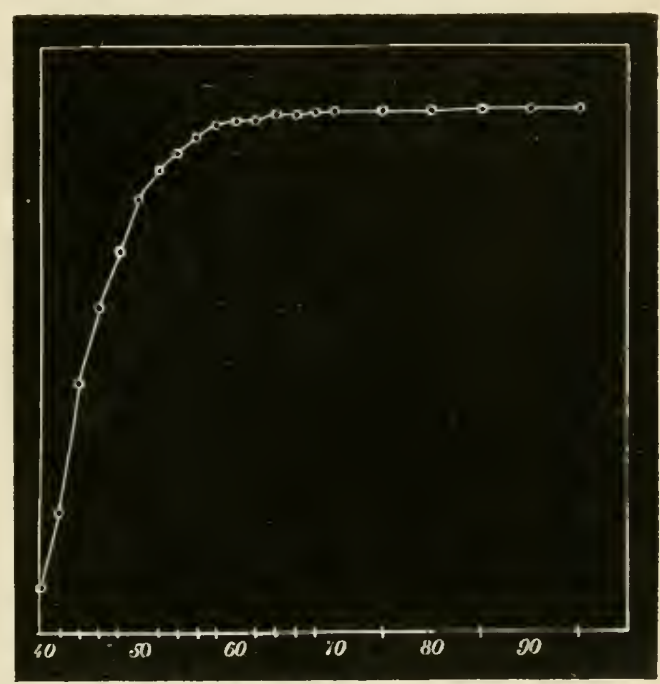

Fig. 172.-Frog's gastrocnemius. Stimulation of the nerie with break-induction shocks; load constant. The abscissie represent the strength of the stimuli, the ordinates the height of the contractions. is taken up by making the contraction: (1) isotonic-i.e., where the load is constant throughout the contraction; (2) auxotonic, where the load increases constantly throughout; and (3) by supporting the load so that it is not lifted until the muscle has contracted a certain distance (after-loading).

A perfect isotonic contraction is probably never obtained. Even when the mechanical conditions of the experiment fulfill the requirements for isotony as completely as possible, the contraction is retarded at its beginning by the incrtia of the masses to be moved, consequently the tension of the muscle is greater at the start than later.

We designate as auxotonic contractions. first those in which the muscle works against a stiff spring, where the tension naturally increases as long as the muscle continues to contract, and sccondly, those contractions in which the tension of the musele is purposely increased by retardation of the movement at its beginning. IIere belong the so-called simple projectile motion (Helmholtz), 
in which the muscle lifts a weight fastened directly to its free end, and the projectile motion with dead weights (Fick), where the muscle pulls on a leres with balanced weights.

In Figs. 17: and $17 t$ are given examples of some of the different forms of motion, namely: Fig. $173 a$, an isotonie contraction. Fig. $173 \quad b$, a simple pro-

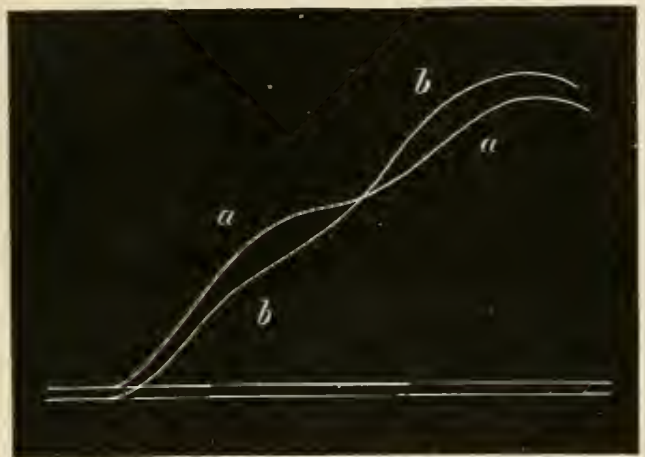

FIG. 173.-Frog's gastrocnemirs. $a$, isotonic contraction; $b$, simple projectile contraction. Both were obtained with the same loads, $80 \mathrm{~g}$, after Santesson. jectile motion, Fig. 1it, projectile motions with dead balanced weights.

In eurves approximately isotonie, Fig. $173 a$, as well as in pure anxotonic curres, which naturally reproduce the changes in length of the musele most exactly, we find in the ascending limb a break, which is not an artifact but which. on gromnds that caunot be discussed here, is probably due to the more sluggish contraction of the red muscle fibers (cf. page 416). In the projectile curre this irregularity does not appear, at least not so clearly, because the morement of the lever does not record the

finer details of the contraction. The contraction produced by a single stimulus is. thereforc, to a certain extent compound, owing to the fact that the different kiuds of fibers composing the musele become active at different times. In an exact analysis of muscular tontractions, it is necessary to give this circumstance its proper weight.

Fig. 175 represents the single contraction of a musele poisoned with reratrin, reeorled on a slow-moving drum. Veratrin affects the red musele fibers

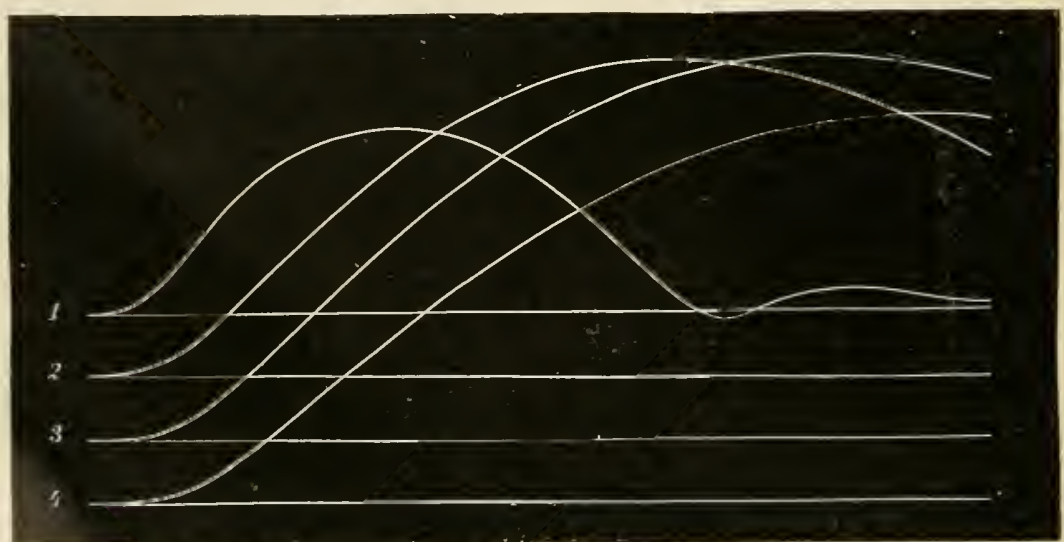

Fir. 17t.-Frog's gastrocnemius. 1, loaded with 4 g., i. e., with the bare lever; 2, 40 g. dead weight; $3,100 \mathrm{~g}$. dead weight; $4,200 \mathrm{~g}$. dead weight.

so that they contract much more slowly than is normal. The first rapid enre is referable to the white fibers, the sceond long-drawn-cint curve to the red fibers. 
After thesc preliminary remarks we can proceed with the discussion of the effect of load on the work of a muscle. We can say in general that the height of the contraction is less the greater the load. But this rule cannot stand without qualification. For under the isotonic arrangement we find the height less with a rery light load than it is with one somewhat hearier (v. Frey), and under the purely auxotonic arrangement the height increases with the load up to a fairly high primary tension. Ioreover, even if the height of the contraction docs decreasc as the load increases. it does so much more slowly than the load increases; so that up to a certain limit the work done (product of the load by the height of contraction) is greater, the greater the load (E. F. Weber).

Again, an increase in the tension of a muscle during its contraction has a decidedly favorable effect on its performance. Tnder some circumstances the contractions against a stiff spring are just as high or even higher than isotonic contractions obtained with a primary tension of the same amount (Santesson): and projectile contractions are sometimes higher than isotonic contractions with the same primary tension (cf. Fig. 173). Finally, cases have been recorded where auxotonic contractions which login with the same tension are higher with a strong spring than with a weak one. We can say, therefore, that within certain limits the work done by a muscle is increased both by a higher primary tension and by an increase in the tension during the contraction.

In close connection with this comes the adrlitional fact that under the isometric arrangement the increase in tension takes place much more rapidly than doe: the shortening under the so-called isotonic arrangement; or, in other words, its length remaining the same, the muscle reaches its maximum tension much carlier than it reaches its maximum shortening when the tension remains the same (Fick, Fig. 176).

A muscle appears thereforc to have the pomer of regulating the amount of work done under a given stimulus, accorling to the requirements of the case. We must forego a complete theoretical discusion of these facts here; but we would direct attention to the significance of the red fibers in this connection. 'They' are, as it appears, the most important sonree of the adelitional work done as the result of an increased tension. Thus we find that the sceondary lift due to these filcrs, in contractions against a tense spring in27

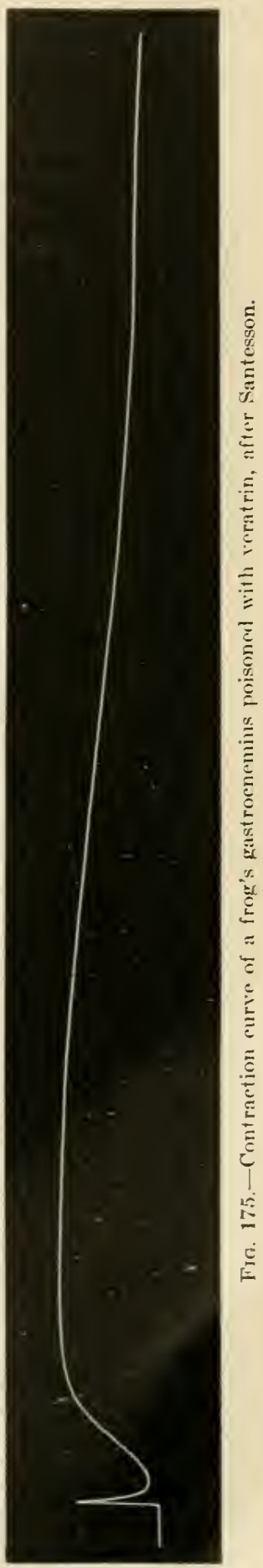


creases as the tension rises, whereas the primary lift caused by the white muscle fibers, decreases as a rule with a rising tension (cf. page 436).

3. The Alsolute Power of a Muscle.-The method of after-loading has been used for the purpose, among other things, of determining the so-called absolute power of the muscle. A muscle is loaded only with a lever, and the lever is supported mechanically so that the weights hung on it, which constitute the

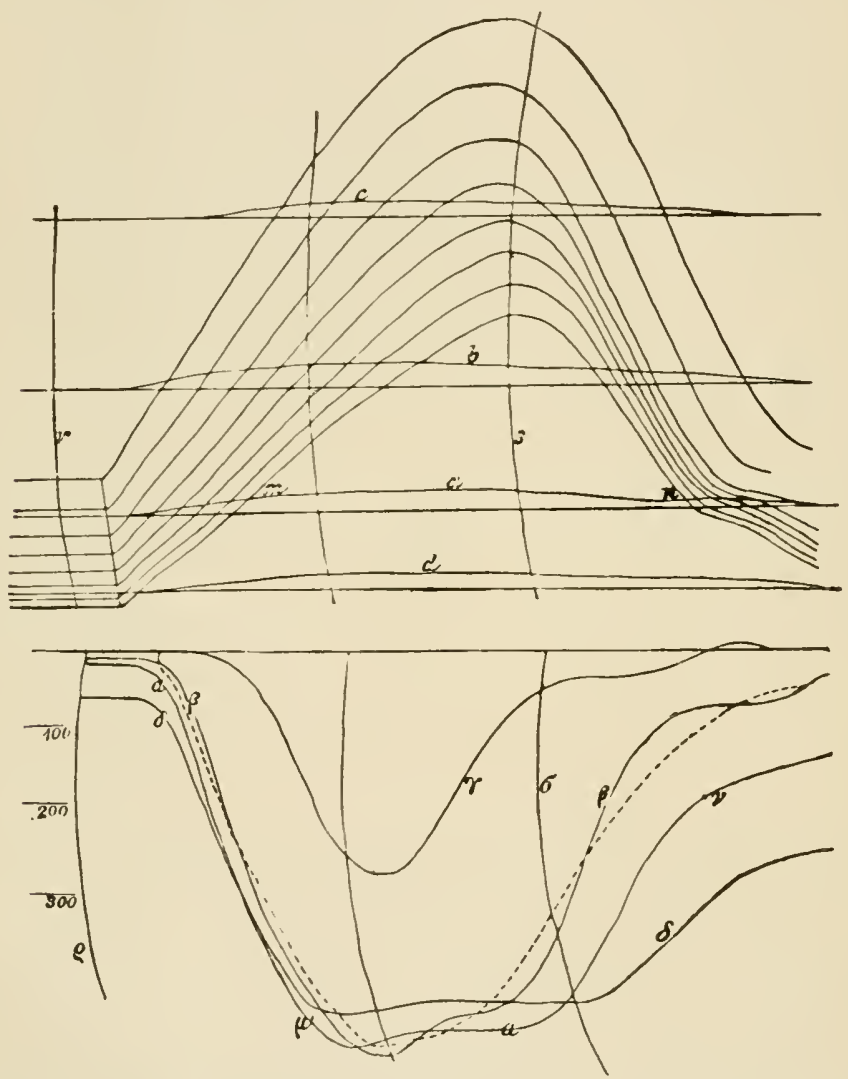

FIG. 176.-Isotonic (upper) and isometric (lower) contraction curves under the same primary tension, after Fick. To be read from left to right. The curves $a, b, c, d$, represent the shortening of the musele corresponding to the isometric contractions $\alpha, \beta, \gamma, \delta$.

after-load, do not affect the muscle so long as it is resting. It is loaded by the weights only when contraction begins, and lifts them only when its tension overeomes the after-load. By adding weights one reaches finally a mass which the muscle no longer has the power to lift. This weight is taken as the absolute power of the muscle (E. F. Weber).

It is evident that, other things being equal, the absolute power of a muscle must be proportional to its cross section, or in other words, among muscles composed of the same kind of fibers the thickest is the strongest. In tetanus the absolute power is greater than in simple contractions, and for the voluntary 
contractions of human muscles it amounts, according to various authors, to $10 \mathrm{~kg}$. per square centimeter of cross section.

If an experiment be so arranged that the muscle lifts its load after it has contracted to different heights, and the absolute power for these successire heights be determined, we find that it grows steadily less (Schwann's experiment).

4. The Work of Tetanized Muscles.-In tetanus it is evident that the work done after the tetanus has reached its full height is from a mechanical point of view nothing at all. Since, however, the contracted state always calls for an expenditure of energy, tetanus is accompanied by a relatirely great consumption of substance, which in its turn leads to rapid fatigue.

The work of tetanus as related to its shortening is in general similar to that of a single contraction, only it is more extensive, so that under farnoble cireumstances the shortening may amount to as much as sixty-fire to eightyfive per cent of the muscles length. Horeover the ratio of shortening in tetanus to shortening in simple contraction is very different for different kinds of muscles; thus it is stated that the maximum shortening in tetanus of the white nuscles of the frog is two to three times the maximum shortening in a simple contraction: of the red museles eight to nine times.

The height of tetanus with a constant load depends on the strength of stimulus, but not upon the frequeney of stimulation.

\section{E. HEAT FORMATION IN MUSCLE}

By employing the thermo-electrical metlod, Helmholtz (18ti) demonstrated the formation of heat in the tetanus of the exsected frog:s muscle. Later the production of heat in a simple contraction was demonstrated by Heidenhain. And Blix has shown that heat is formed even in resting musele. Even with the most delicate methods no heat production can be demonstrated in neries.

Since the performance of mechanical work and the production of heat are the two chief functions of muscle, and since, as we have seen above, the mechanical work done under a constant stimulus increases up to a certain limit with the load, it might be supposed that the heat production going on at the same time would be in inverse relation to the load, so that the dissimilatory process evoked in a muscle by a given stimulus would be independent of the load. and the latter therefore would influence only the apportionment of the total output of energy by the muscle to the two functions. But this is not the ease. Since the investigation of Heidenhain, we know that the total output of energy in an exsected frog's muscle under a constant stimulus, increases up to a certain limit with the load.

This property of the muscle appears to be of very great importance. For if the total performance of the muscle were independent of the load and were dependent only on the strength of stimulus, the development of energy in the muscle might often be out of all proportion to the work to be done. The relationship discovered by Heidenhain is to be looked upon as a regulatory mechanism which, independently of the nervous impulses. controls the metabolism in the muscle according to its momentary needs (cf. also page 4t1). 
Fiek and his pupils have made absolnte determinations of the amount of heat developed in muscular activity. and the amount of work done at the same time. Some of their results are brought together in the following table. In these experiments the load was allowed to fall again after each contraction, so that the observed quantity of heat expresses the total output of energy. Each experiment consisted of three maximal contractions following one another in rapid succession.

\begin{tabular}{|c|c|c|c|c|}
\hline $\begin{array}{l}\text { LoAl. } \\
\text { gr. }\end{array}$ & $\begin{array}{l}\text { lleat production in } \\
\text { micro-calories. }\end{array}$ & $\begin{array}{l}\text { Work, } \\
\text { g. mm. }\end{array}$ & $\begin{array}{c}\text { Thermal equivalent, } \\
\text { of work. }\end{array}$ & $\begin{array}{l}\text { Ratio of wrork } \\
\text { to heat. }\end{array}$ \\
\hline 0. & 14.6 & & & \\
\hline 30. & 18.3 & 465 & 1.09 & $16 . \tau$ \\
\hline 40. & 19.7 & 802 & 1.88 & 10.5 \\
\hline 80. & 23.9 & 1.420 & 3.34 & $\tau .1$ \\
\hline 120 & 24.2 & 1.914 & 4.50 & 5.4 \\
\hline 160 . & 25.8 & 2,402 & 5.64 & 4.6 \\
\hline 200. & 25.6 & 2.905 & $6.8: 3$ & 3.7 \\
\hline 160. & 26.2 & $2.40^{\circ}$ & 5.64 & 4.6 \\
\hline 120. & $2: 3.3$ & 1.914 & 4.50 & 5.2 \\
\hline 80. & 21.9 & 1.430 & 3.34 & 6.6 \\
\hline 40. & 19.5 & 819 & 1.92 & 10.2 \\
\hline 20. & 18.0 & 465 & 1.09 & 16.6 \\
\hline $0 \ldots$ & $1: 3.4$ & $\ldots$ & $\ldots$ & $\ldots$ \\
\hline
\end{tabular}

We see that under a maximal stimulus and with increasing load the ratio of work: heat changes in faror of the former. With the least load the total production of energy is $16 . \%$ times the amount of work done, whereas with the heaviest load it is only 3.r times as much. In other experiments a still greater part of the total production of energy appeared as meehanical work. But as a rule in the frog's muscle cut out of the body by far the greatest part of the energy developed in contraction is used for the production of heat.

\section{§5. THE CENTRAL INNERVATION OF A SKELETAL MUSCLE}

Each one of the muscles of the extremities receives motor-nerve fibers from several sucessive nerve roots. This is most elearly seen in the ease of the stemo-cleido-mastoid and the trapezius of man which are innervated by both the spinal accessory and the cervical nerves. This fact alone appears to indieate that under normal cireumstanees some of the fibers of a muscle are not thrown into action, but that the muscle has the power of contracting partially. The following experiment by Gad confirms this conclusion.

The lumbar plexus of the frog conveys nerve fibers to the gastrocnemius by two roots. If with a light load the muscle be given a tetanic stimulus directly or indirectly by one or by both of these roots the contractions are of equal size. But if the tension dereloped in the muscle in tetanus be studied by means of the apparatus figured on page 414 , it is found to be less when the stimulus is applied to only one root than when applied to both or to the muscle directly, and that in the latter two cases the tension is equal to the sum of the tensions developed by separate stimulation of the two roots. The result goes to show that on stimulation of different nerve roots, not the whole muscle but only eertain of its fibers are excited, or in other words that each nerve root produces a 
partial contraction. There can be no doubt that such partial contractions occur also normally under the influence of the nervous system, although probably with still nicer gradations. In this way the activity of the muscle is adapted to the work to be performed. If no great degree of tension is called for, only a few muscle fibers contract, the others remain quict and do not become fatigued. Since on the other hand the extent of the contraction does not depend upon the cross section, but upon the length of the muscle, we mar get just as much shortening with a partial contraction as when the whole muscle is active.

\section{\$6. FATIGUE AND RECOVERY OF MUSCLES AND NERVES}

\section{A. GENERAL PHENOMENA}

If a frog's muscle be stimulated repeatedly with single shocks given erery one to two seconds, at first its contractions inerease in size, even if the stimulus remain of the same strength ("treppe" of Bowditch and Puckmaster), and then they gradually decrease until romplete exhaustion is reached. From the first of the series the contractions become more prolonged, since both the ascending and the descending limbs of the curve, but especially the latter, oceupy more time. As fatigue progresses and the longer stimulation is kept up. there gradually develops a new condition of the muscle: at the end of the contraction it does not return to its resting position but renains more and more shortened. ${ }^{1}$ The muscle finally becomes a sluggish, stubborn mass yielding to the traction which strives to restore it to its original form, with extreme slowness (Funke). In the series represented in Fig. 177 a muscle kept perfused with blood was stimulated every 1.5 seconds. Only the first ten of every fifty contractions are here reproduced, the six series repre-

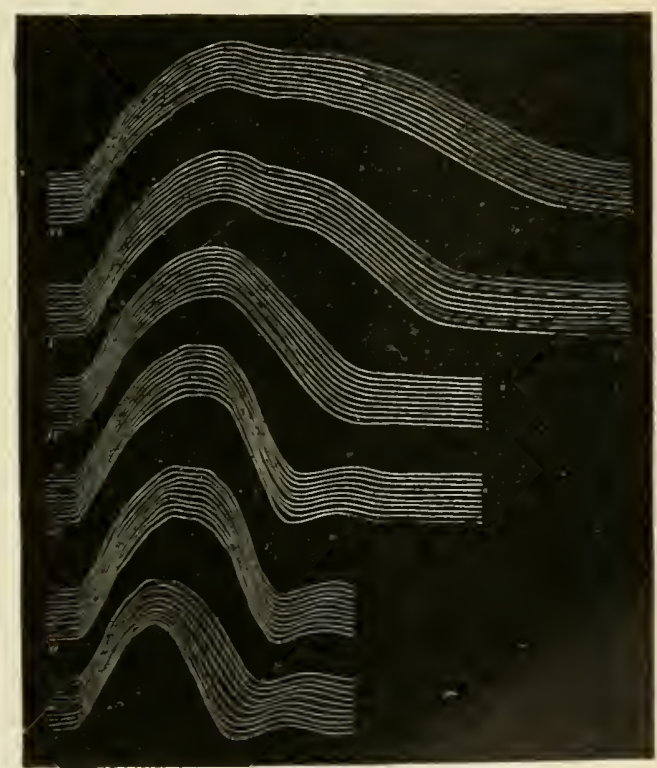

FIG. 177.-Changes in the eharacter of the contraction produced by fatigue, after Rollet.

senting all told some three hundred separate movements. When the interval between stimuli is made still shorter, say 0.5 second, as fatigue continues the desending limb of the curve does not reach the base line, before it is met by the following stimulus, and the curve becomes much like an incomplete tetanus. With a longer interval, say six seconds, the contraction is not prolonged, or only slightly so, and the reduction in the height of the curve is the only expression of fatigue.

The muscle of warm-blooded animals, kept perfused with blood, show, according to Rollet, only this latter form of fatigue, with no material increase in the duration of the contraction even when the interval between stimuli is very 
short. Consequently in these muscles the above-mentioned incomplete tetani are entirely wanting.

[According to F. S. Lee this difference in the mode of fatigue between the excised nuuscles of cold-blooded and of warm-blooded animals is due to a real physiological difference and not, as had been supposed by Sehenck and Lohmann, to a mere difference of temperature. Lee finds that the museles of the former exhibit the same characteristic slowing of the eontraction process (cf. Fig. 178) both at low and at high temperatures (though at the high temperature to somewhat less extent than at the low); whereas the muscles of the latter do not exhibit this phenomenon at either high or low temperatures. "The poikilothermal condition (cf. page 46 ) is more primitive than the homoiothermal, and it would seem that the constant influence of a uniform temperature acting for ages

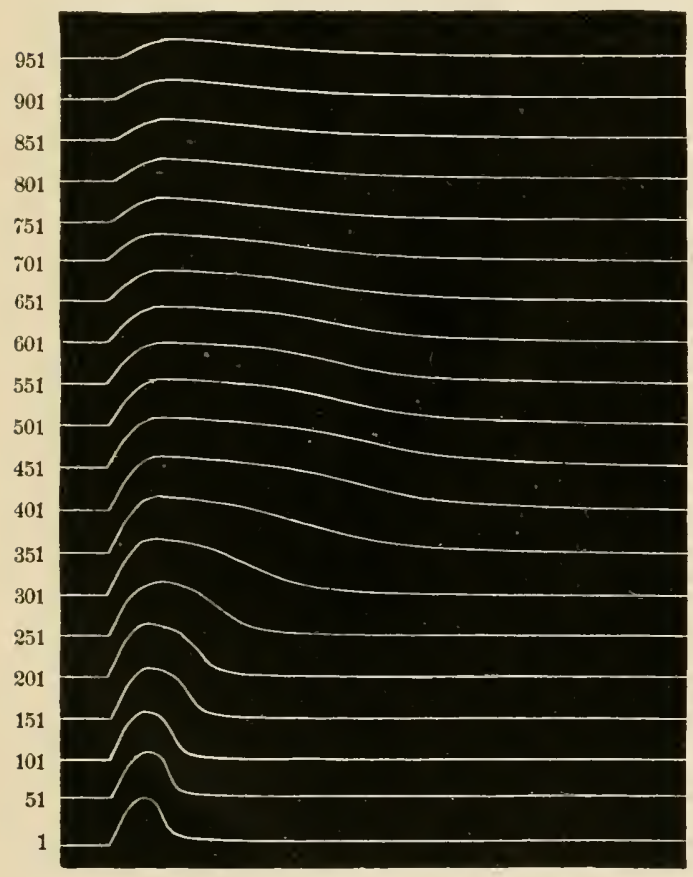

FIG. 178.-Isotonic contractions of a frog's gastrocnemius, after F. S. Lee, showing changes due to fatigue. Only every fiftieth contraction is recorded. on the skeletal museles of warm-blooded animals has impressed on them eertain pronouneed peculiarities." Possibly the part which these muscles themselves play in the production of heat is in some way associated with this physiological difference. -ED.]

With regard to the fatigue of nerves we must distinguish very clearly between the local fatigue which takes place in artificial stimulation at the point where the stimulus is applied, and which in part at least is due to the injurious effects of the stimulating agent, and the fatigue which is produced possibly by the transmission of stimuli. Since only the latter determines the normal behavior of nerve, we shall diseuss it alone.

In order to observe the fatigue of nerve, it is necessary to so arrange the experiment that its muscle is not stimulater. Bernstein fulfilled these requirements by stimulating the sciatie nerve of the frog a long distance from the muscle, at the same time conducting through the nerve between this point of stimulus and the muscle a strong constant current. The resistance at the anode of the constant current prevented the stimulus applied farther up from reaching the muscle. In this way Bernstein found that the nerve was much less capable of fatigue than the muscle. By the same method Wredensky was able to stimulate a motor nerve of the frog for six hours without exhausting it.

This same resistance of nerves to fatigue has been demonstrated also by Langendorff, Bowditch and others, on warm-blooded animals. If eurare, which throws out of action the end plates of the motor nerves, be administered to an 
animal, the poison will be gradually thrown off from the body, and the end plates will again recover their function. But several hours intervene, and a stimulus applied during the interval is of course without effect on the musele. But when the poison wears off, the eflect of stimulation returns with all its original force, which means that stimulation eontinued for hours has not fatigued the nerve. Brodie and Halliburton observed likewise that nonmedullated nerves, such as the splanchnic, were not fatigued by artificial stimulation lasting six hours.

Besides this any number of natural phenomena show that nerves have a much greater endurance. We know, indeed, that several efferent nerves, especially the vagus branches to the heart, are all the time under a tonic exeitation of greater or less intensity, also that the same is true of the afferent nerves, examples of which we have in the constant pains of certain nervous maladies.

From these facts the conelusion has been drawn that nerves in general are not fatigued, and it cannot be denied that this conception is, to a certain extent, well founded. Nevertheless, one must not imagine that no metabolie processes are taking place in an active nerve or that it mediates the transmission of stimuli, as for example a wire does an electric current; such a supposition has little probability in its favor on purely antecedent grounds, for a nerve is a living tissue. Moreover, there are a number of direct observations at hand which show the presence of ehemical processes in nerve with perfect definiteness.

For example, a nerve deprived entirely of oxygen becomes completely inexcitable within three to five hours, but recovers its excitability again within three to ten minutes when oxygen is supplied. This phenomenon as well as the production of carbon dioxide in active nerves (ef. page 434) substantiates the view that a nerve, so far as processes taking place within it are concerned, presents no essential difference from the other organs of the body. On the other hand its extraordinary resistance to fatigue presupposes a very low state of metabolism and a very great power of recuperation. This ability to reeover is probably different also in different nerves; for in the olfactory nerves of the pike unmistakable signs of fatigue make their appearance after only a short period of excitation (Garten).

Contractions can still be induced by direet stimulation long after the muscle fails to respond to a tetanizing stimulus applied to its nerve. Since the nerve itself does not fatigue we must suppose that the nerve endings fatigue much earlier than the musele substance itself (Waller).

\section{B. FATIGUE OF HUMAN MUSCLES AND NERVES}

The phenomena of fatigue in man have recently been studied by several authors by means of the ergograph, an apparatus first constructed by Mosso.

This ergograph is especially constructed for the flexion of the middle finger, and consists of two parts, one to which the hand is fastened and another which records the contractions of the muscle. The whole apparatus is shown in Fig. 179. The forearm is fixed in position by means of the elamps and the hand by means of the two tubes into which the index and ring fingers are thrust. A string fastened to the middle phalanx of the middle finger, earries the load and moves the writing lever. The latter records the eontraction of the muscle, enlarged about twice, on a slowly rotating drum. The work of the muscle is of course the product of the actual height of contraction by the load.

If now the load be not too light and the interval between contractions not too great, the height eontinually declines until finally the subject is no longer 
able to lift the load; but if the load be diminished, he can continue the work immediately. The fatigue curve either declines rapidly at first and more

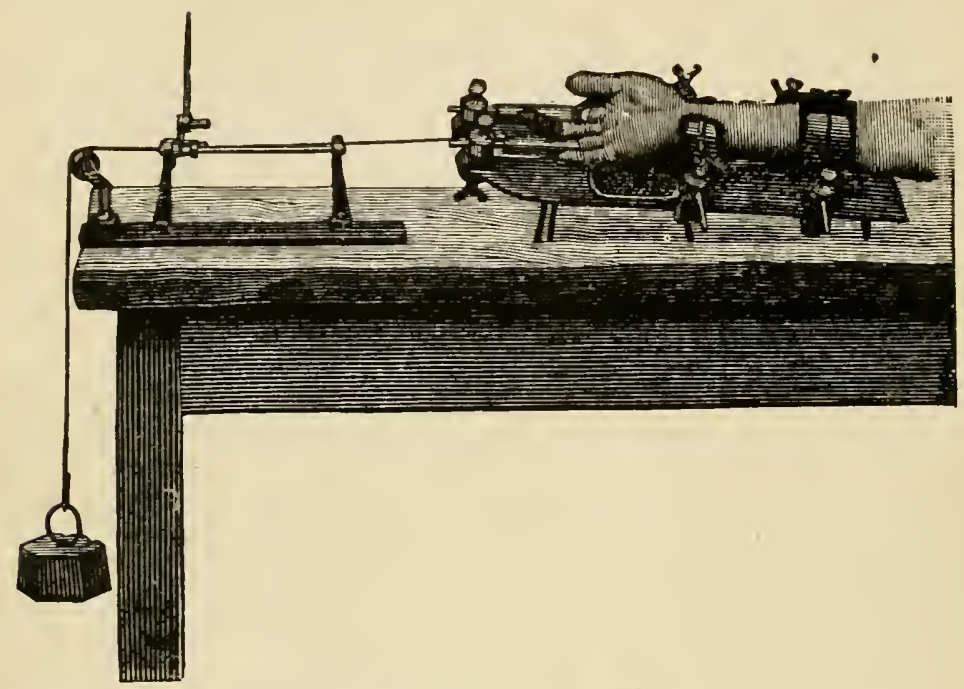

Fig. 179.-Ergograph, after Mosso.

slowly at the end, as in Fig. 180, A, or the fall at the heginning is slight and is rapid toward the end (Fig. 180, B). Judging by llosso's results every individual has his own peculiar form of fatigue eurve.

Of the factors which influence the progress of fatigue we shall investigate first the effect of frequency of contraction with a constant load. Figs. 181, A to

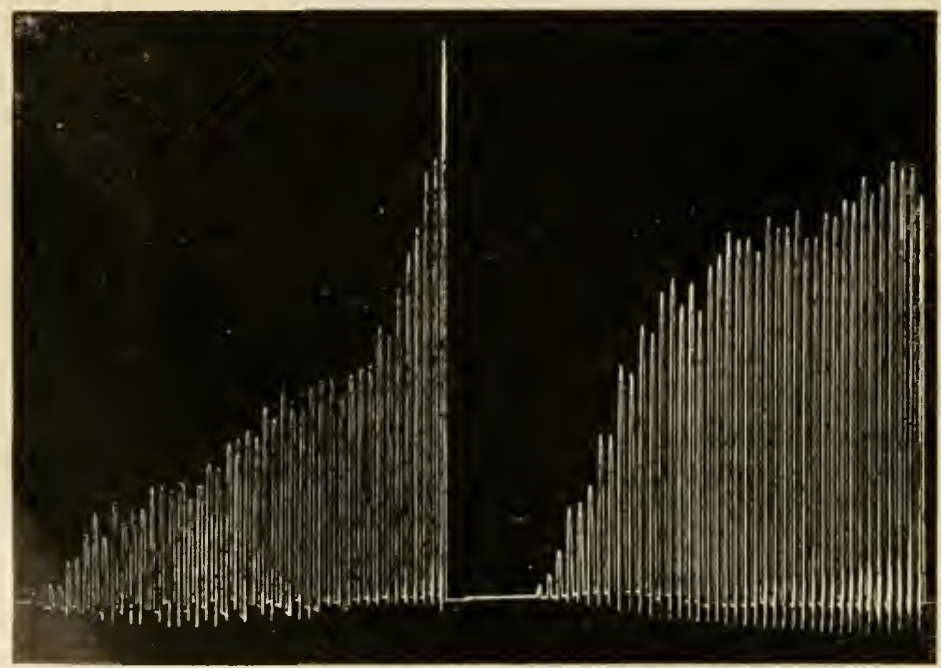

A

$B$

FIG. 180.-Fatigue tracings obtaned with the ergograph of Mosso. To be read from right to left. 
D show that exhaustion comes on more rapidly the smaller the interval between contractions. In Fig. 151, A we find only fourteen contractions before complete exhaustion, mechanical work $=0.912 \mathrm{~kg}$. m. In Fig. 181, B the number of contractions is eighteen, and the mechanical work done $1.080 \mathrm{~kg} . \mathrm{m}$. In Fig. 181, C the number of contractions is thirty-one and the mechanical work $1.842 \mathrm{~kg} . \mathrm{m}$. With a rhythm of one contraction every ten seconds no fatigue at all appears (Fig. 181, D). An interval of ten seconds, therefore, is sufficient to permit a skeletal muscle to recover completely.

When a muscle is worked at a rapid rhythm to the point of complete exhaustion, it requires a rather long time to recover completely-in the experiments of Maggiora from one and one-half to two hours. It was also shown in these experiments that the last contractions of a series ending in complete exhaustion, are the most fatiguing. If only the first part, say the first fifteen eontractions,

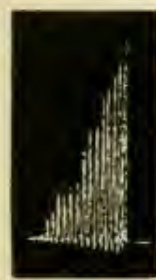

4

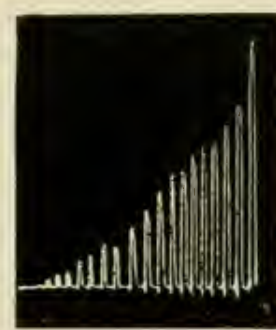

$B$

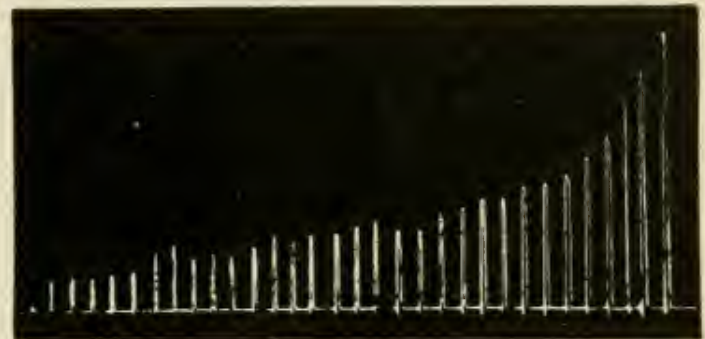

$C$

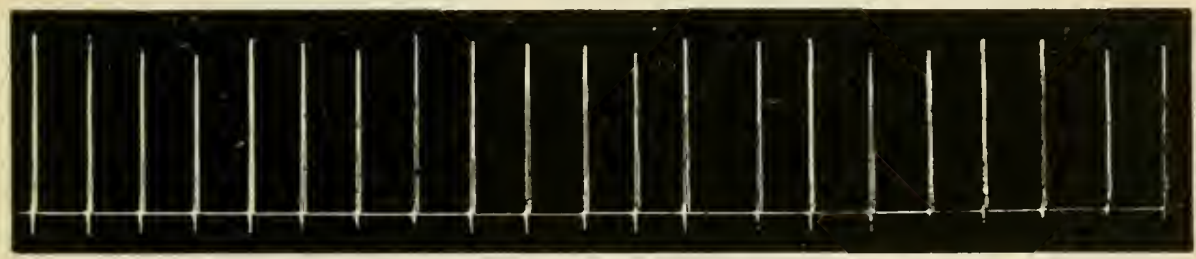

$D$

Fig. 181.- The onset of fatigue under stimuli of the same strength, given at different intervals, after Maggiora. $A$, once a second; $B$, onee every two seconds; $C$, once in four seconds; $D$, once in ten seconds. To be read from right to left.

of a fatigue series be carried out and rest be then permitted, the muscle will recover in a much shorter time proportionally than if it were completely fatigued. Consequently the total aniount of work which can be done in a day is considerably greater if the muscles be not pushed at any time to the limit of their powers. For example, a muscle making fifteen contractions every thirty minutes for fourteen hours did mechanical work of $26.9 \mathrm{~kg}$. m.; the same muscle when made to perform the whole series of fatigue curves every two hours accomplished a mechanical work of only $14.7 \mathrm{~kg} . \mathrm{m}$.; a difference of $12.2 \mathrm{~kg} . \mathrm{m}$.

Ancmia, fasting, want of sleep, among other things, reduce the working power, and favor the onset of fatigue. The capability of work is increased, on the nther hand, by rest, by taking food, and by massage-the latter even in case the muscle be previously not fatigued. The rffect of massage after work therefore consists not only in the removal of products arising from the expenditure of energy, but also, and to a considerable extent, in the more active circulation of the blood and lymph and possibly in some alteration of metabolism 
thereby produced. Experiments on exsected frog's muscles indicate that there is a direct influence on the contractile substance (Ruge).

Fatigue of one group of muscles exereises an unmistakable influence on other muscles-e.g., fatigue of the legs hastens fatigue of the arms; but muscular training reduces such effects.

It has been shown also that purely mental work hastens muscular fatigue to a very great extent. It might be supposed that this part of fatigue is purely central; but the matter is not so simple. The same result is obtained where an artificial stimulus is applied to the median nerve or directly to the flexor muscles of a person fatigued by mental work.

Finally, by other experiments which cannot be described here, Mosso has shown that while the mechanical work performed by a muscle decreases as fatigue comes on, the nervous effort and the intensity of the processes which call forth the contractions progressively increase. By a method especially adapted to the purpose, it may even be shown that the nervous mechanism is being greatly strained before there is any sign of fatigue in the external work done. 'This, as Treres remarks, would explain the fact that athletes not infrequently are attacked by severe neurasthenic pains.

An increase in the output of $\mathrm{CO}_{2}$ and in the consumption of $\mathrm{O}_{2}$ is another characteristic of fatigued muscle; that is, the utilization of energy becomes more and more unfavorable with the progress of fatigue.

What has been said here concerning fatigue and recovery applies espccially to the stecletal muscles. Other muscles fatigue much more slowly and require a much shorter time of recovery in order to remain permanently in functional condition. The best example of this is the heart, which throughout life works uninterruptedly with rest periods of only about 0.4 second. That the smonth muscles also are capable of long-continued work is shown by the tonus which they maintain in the arterial walls.

In view of the facts presented here it becomes a matter of interest to inquire under what eircumstances the greatest amount of muscular work ean be performed. This question cannot be answered fully at present. but we have some facts bearing on the subject which are of considerable interest. When one does the same amount of external work in two sets of experiments which differ only in the circumstance that the load and the distance through which it is lifted vary in reverse order (e.g., $20 \mathrm{~kg}$. $\times 0.3 \mathrm{~m}$. and $30 \mathrm{~kg} . \times 0.2 \mathrm{~m}$.) it is found that the fatigue comes on much more rapidly with the heavier load (Stupin). The conelusion is that the size of the load and not the absolute amount of muscular work done determines how long the movement can be continued. But if the load is too small the muscle evidently cannot accomplish much work. We may say, therefore, in general that the greatest quantity of work can be done when the load is of medium size.

This medium load may be found (Treves) by choosing a weight with which a person while perfectly fresh can do the greatest absolute amount of work and observing the record until the contractions exhibit evidence of fatigue. If now the weight be diminished so that the contractions of the same extent ean continue, and so on, a weight will finally be found with which the person can continue the work at the same rhythm indefinitely. 
The following table, compiled by Blix, contains some data on the maximal muscular capacity of man at different kinds of work:

\begin{tabular}{|c|c|c|c|}
\hline KIND OF WoRK. & Time. & Kg. m. per second. & Observer. \\
\hline 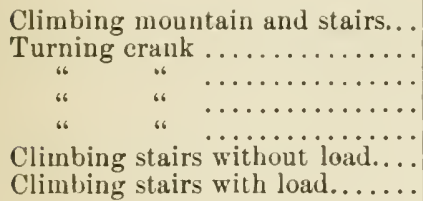 & $\begin{array}{l}8 \text { hours } \\
1 \frac{1}{2} \text { hours } \\
15 \text { minutes } \\
5 \text { minutes } \\
1 \frac{1}{2} \text { hours } \\
4 \text { seconds } \\
4.5 \text { seconds }\end{array}$ & $\begin{array}{r}10.5 \\
12.5 \\
17.0 \\
19.5 \\
27.7 \\
101.2 \\
95.4\end{array}$ & $\begin{array}{l}\text { Weissbach } \\
\text { Sjöstrom } \\
\text { "“ } \\
\text { "“ } \\
\text { Blix }\end{array}$ \\
\hline
\end{tabular}

It is evident that the capaeity for work ealeulated per seeond is greater, the shorter the total time oeeupied. The highest record of enduranee yet made was observed in a six-day bicycle contest in New York. Aceording to Atwater's calculation the rictor performed during his first day of twenty-three hours and ten minutes an average of $25 \mathrm{~kg}$. $\mathrm{m}$. per second, and in the whole time, one hundred and eight hours and forty-four minutes, an average of $20.2 \mathrm{~kg}$. m. per seeond.

\section{\& 7. RIGOR MORTIS}

A muscle ent out of the body or excluded from the circulation passes sooner or later (ten minutes to several hours) into a rigid condition known as the death stiffening or rigor mortis. It is now shorter, thicker and firmer, turbid, opaque and less extensible; its reaction is acid, probably owing to the transformation of a portion of the diphosphates into monophosphates brought about by the lactic acid formed.

Rigor of musele is produeed also by warming to $48^{\circ}-50^{\circ} \mathrm{C}$., by the effeets of distilled water, by aeids and by various other substanees. It appears more readily after heavy muscular work than otherwise, but on the other hand appears later if the muscle has been paralyzed by section of its nerve. Rigor mortis is the cause of the rigidity of the body after death. Under certain cireumstanees, which have not yet been successfully imitated, the stiffening comes on immediately after death, so that the body becomes fixed in the position it had at the instant of death.

Rigor is regarded by most authors as coagulation of the muscle proteids. But the processes taking place in rigor are only partially explained in this way, for we do not even know definitely how the proteids obtainable from muscle plasma oceur in the living muscle. Besides. the phenomena of enagnlation in a muscle extract, and the rigidity brought about artificially by different reagents, present several points of difference from the natural death stiffening.

\section{§ 8. SMOOTH MUSCLES}

The most satisfaetory smooth muscles for study are those whose fibers run parallel, like the retractor pen is of the dog and the cireular museles in the stomach of the frog. The extensibility of sueh museles is relatively great and the elastie after-effeet is very considerable. A small weight acting for a long time 
will produce the same anount of extension as a large weight acting for a short time. When a muscle has been extended greatly, its original length is recovered by a single contraction and can be maintained for some time if several contractions follow one another. The activity of smooth muscles, therefore, is intimately related to their elastic properties ( $P$. Schultz).

Smooth muscles cut out of the body immediately fall into a tonic state of contraction, and exhibit in addition spontaneous rhythmical contractions. These seem to be of purely muscular origin, for they appear in the rectractor penis which has no ganglia, and have been observed as much as twenty-four hours after the removal of the muscle from the body (Sertoli). They continue for an equal length of time in the exsected frog's stomach (Woodsworth). In resting preparations they can be induced by a single mechanical stimulus, and also by application of a constant current (Winkler).

A simple contraction of a smooth muscle runs a very different course from that of a skeletal muscle. The latent period is very long: in the musculature of the frog's stomach one to ten seconds, in the retractor penis 0.8 second, in the urinary bladder of the cat 0.25 second, and in the smooth muscles of the nictitating membrane, after stimulation of the nerve, $0.3-0.5$ second. With artificial stimulation of the rasomotor nerve we get about the same value-0.3-0.5 second-for the latent period of the vascular muscles. The contraction reaches its summit very slowly-in the frog's stomach fifteen to twenty seconds, and then falls still more slowly. sixty to eighty seconds. With the same muscle the amount of shortening in a single contraction is forty-five per cent of its original length, in tetanus fifty-nine per cent.

Summation phenomena may be obtained if the stimuli follow one another with sufficient rapidity; but they must not be identified with corresponding processes in skeletal muscles. Here instead of a simultaneous contraction of all of the muscular elements becoming stronger and stronger, we have to do rather with repeated contractions of the different cells in varying sequence (Zilwa, Schultz).

Finally, inhibition of tonic contractions can be demonstrated on smooth muscles. The tomus of the retractor penis can be intercepted by means of the eonstant current (Sertoli), and corresponding phenomena have been obtained in the frog's stomach. Furthermore, we know that the smooth musculature of the blood vessels and of the intestinal wall are under the influence of inlibitory nerves.

\section{SECOND SECTION}

\section{RECIPROCAL RELATIONS BETWEEN THE MUSCLES AND OTHER ORGANS OF THE BODY}

In the performance of their functions the muscles influence, and in many ways are influenced by. the other organs of the body. A muscle degenerates if its connection with the central nervous system be interrupted, and within a relatively short time it beeomes transformed into a mass of connective tissue. The same thing happens if the motor cells in the anterior horn of the spinal cord be destroyed by a lesion. The cause of degeneration under these circunstances is not that the muscle is inactive. Inactivity, as it appears, for example, as the result of brain disease, involves a reduction of the muscle substance, an atrophy, but the muscle does not degenerate; it retains its 
characteristic properties. On the other hand, a muscle increases in mass by work, and there is, generally speaking, no other means of strengthening a muscle. We see therefore that a muscle receives impulses from the central nervous system which are of the greatest possible importance for the maintenance of its substance and of its natural properties (see Chapter XXII).

A resting muscle has a relatively small supply of blood, but during work the quantity increases considerably, owing to the widening of the blood stream produced by the action of the vasodilator nerves (ef. page 240). Besides, we find as an accompaniment of muscular work an acceleration of the heart beat (cf. page 19\%) and, as a rule, an increase of arterial blood pressure. The latter is caused primarily by a contraction of blood ressels in other organs, especially those of the splanehnic region, which more than compensates for the dilation in the museles. The increase in amount of blood expelled from the heart in a unit of time likewise contributes to the same end.

It is impossible, on the basis of observations thus far reeorded, to make a closer analysis of the mechanisms concerned.

Vasodilatation in the muscles accompanying work is for the purpose of supplying them with an increased amount of oxygen and combustible materials; for a working musele uses large quantities of oxygen and produces large quantitics of carbon dioxide. In order to supply the necessary quantity of oxygen and to remove the great excess of carbon dioxide, the respiration must of course be augmented, and this should be mentioned as one of the accompaniments of muscular work (ef. page 332).

Muscular work evidently calls for an increased supply of food in order to meet the demands on the body. and increased appetite as the result of exercise is an experience with which everyone is familiar.

Whatever the effeet of work on the digestive process may be, it appears from the experiments of Rosenberg on dogs and of Wait on men that the absorption of food is equally good at rest and at moderately vigorous work.

With all voluntary muscular movements work is being done also in the central nervous system. When we learn a particular muscular movement, of whatever kind, the brain is always active. The newhorn ehild can move all of his muscles, but lacks the power to coördinate them into purposeful acts. This can only be acquired by the gradual formation of central connections betwcen the different nerve paths. We know, for example, that many muscles are necessary to keep the body in an upright position, but the coöperation of these different muscles is perfected only by long-continued practice. So it is with all of the other muscular movements which we make.

Unless we make a special study of the subject we are not aware of the position or arrangement of our muscles. We eannot therefore merely will that one musele or the other shall become active but can only resolve upon carrying out a certain morement. For example, if we bend the arm. the movement takes place chiefly by the contraction of the biceps muscle; but the aet of volition. which we are conscious of, is not a direct impulse to this particular muscle. but a command that the arm be moved. In short we carry out nur bodily movements with reference to the result, without troubling ourselves about how the result is attained. 
In practicing any particular movement therefore we are striving to bring about in our central nervous system such a combination of physiological factors as will accomplish the desired effect. The more complieated a movement is, the more difficult it is of course to discover this combination. But after the connection has once been established, the movement can be carried out with the greatest ease in almost a purcly mechanical manner.

Here comes in another peculiarity. When we practice a particular movement for the first time, we use a number of muscles which have no importance whatever for the movement intended, but rather interfere with it, since they fatigue the body to no purpose. The further the practice is carried, however, the more we learn to suppress these useless movements; and at the same time the respiration and circulation become more and more exactly adapted to the actual needs. It has been observed that the increase in combustion from a given additional amount of work becomes steadily less (down to a certain limit), as practice continues.

Referexces.-W. Biedermann, "Electro-Physiology," translated by Welby, New York and London, 1898.-R. Du Bois-Reymond, "Spezielle Muskelphysiologie und Bewegungslehre," Berlin, 1903.-A. Fick, "Mechanische Arbeit und Wärmeentwickeling bei der Muskeltätigkeit," Leipzig, 1882.-A. Mosso, "Fatigue," English edition by Margaret and W. B. Drummond, New York and London, 1904. 


\section{CHAPTER XVI \\ ON SENSATIONS IN GENERAL}

\section{FIRST SECTION}

\section{QUALITATIVE RELATIONS BETWEEN STIMULUS AND SENSATION}

We obtain our knowledge of the outside world entirely through our senses. The sense of touch, taken in its widest acceptation, teaches us to recognize the nature of those objects about us which come into actual contact with our bodies, and gives us information concerning the temperature of these and more distant objects.

$\mathrm{By}$ the sense of taste we ean distinguish certain properties of such substances as can be placed in the mouth.

The sense of smell enables us to judge something of the nature of the atmosphere. For certain animals this sense is of rery great importance, in that it furnishes the possessor with knowledge of prey or of enemies even at a considerable distance.

By the sense of hearing we are made aware of those vibrations of solid, fluid or gaseous bodies, which strike the ear. Through this sense we obtain knowledge not only of what goes on immediately about us, but also of what takes place at a distance.

The sense of sight reaches out to a still greater distance. By its help we can penetrate to the farthest point from which light rays can reach the eye.

But our sensations ${ }^{1}$ do not all relate to the outside world. From all the organs of the body information of their condition and of the processes taking place within them is all the time being brought by appropriate nerves to the central nervous system. Some of these messages never rise into conscionsness, but have a controlling influence on the functions of the body through the lower nerve centers. Others rise to the plane of consciousness and eventuate

${ }^{1}$ By sensation we mean the simplest possible state of eonsciousness, one which eannot be analyzed into simpler eomponents. But a sensation corresponding to this definition probably never exists, for psychologieal analysis has demonstrated that even the simplest eonscious processes are really composed of several simple sensations. For example. the simple sensation of sweetness is always associated with the feeling that we have something in the mouth; the sensation of a color likewise is complicated by its projection to a certain place in the outside world, ete. These processes in eonseiousness we shall designate as ideas. 
in sensations which are more or less present to the mind. Sensations by which we have knowledge of the position in space of our bodies and their members, also of the extent of their morements and the intensity of muscular eontractions-in short, all those sensations which are comprehended as belonging to the sense of motion come under this class. The sensations from other internal organs like the heart, stomach, intestines, bladder, ete., also belong here. The latter are not sharply defined unless intensified by some special cause; then they sometimes become very painfully conspicuous. As a rule. however, they are wholly indefinite and contribute in conscionsness only toward the general state of feeling, which not only varies greatly according to the nature of these vague sensations, but may very profoundly influence our whole being.

One of the most significant facts in connection with the physiology of sensation is that our conscions sensations do not arise in the organs to which the afferent nerves are distributed and to which the stimuli are applied. The sensation of sight, for example. is not in the eye. the sensation of sound is not in the ear, etc. The peripheral sense organs and the peripheral endings of afferent nerves in general are for the sole purpose of transferring the stimuli which strike them to the appropriate nerves. The nerves transmit the excitations thus aroused to the central organs of the nervous system and the conscious sensation arises only by the activity oceasioned in the brain. Different parts of the brain are set in action directly, aceording as one afferent nerve or another is exeited (cf. Chapter XXIII).

How can a material change in the brain give rise to a conscions sensation? Philosophers of all times have tried to answer this question. Since we are discussing it here only from the standpoint of natural science. we cannot enter into the philosophical considerations. It is likely, indeed, that the question can never be answered from the standpoint of natural science alone, for, as Du Bois-Reymond especially has pointed out, the question is at bottom a metaphysical one.

If our knowledge of nature were so far advanced that all the movements in the world could be resolved into the movements of atoms, and our explanation of nature could thus be reduced to the mechanies of atoms, we would of course be in a position to describe the material changes taking place in the brain in definite psychical processes very exactly. Satisfactory as this knowledge would be, it would nevertheless be unable to give us any conclusive information concerning the relation of such movements to such ultimate facts as: "I feel comfortable," "I feel pain," and the proposition immediately deducible therefrom: "I think, therefore I am." That is to say, it is impossible to conceive scientifically how consciousness and thought can arise out of the interplay of atoms. Indeed we could imagine a world similar to our own, in which everything would take place exactly as in our world, but where there were no consciousness and no thought; and yet the mechanics of atoms would be just as valid for such a world as for our own. ${ }^{2}$

In what sense do our sensations produced by external stimuli correspond to reality? Philosophy and natural science attack this problem from opposite

${ }^{2}$ Cf. Du Bois-Reymond, "Limits of Our Knowledge of Nature," translated by J. Fitzgerald in Popular Science Monthly, May, 1874. 
sides and ret the two have the same task in common. ${ }^{1}$ The former, which considers the psychical side, seeks to eliminate from the cognitive and perceptive processes everything which proceeds from the effects of the objective world, in order to oltain in its purity that which is proper to the mind itself. Natural science on the contrary seeks to remove the relative and the formal elements of thought, definition, notation, forms, hypothesis, etc., in order to secure what belongs to the world of actuality, the laws of which it seeks to know. In order to give a theoretical explanation of sensations from the scientifie standpoint we must bear in mind the following propositions.

1. There are two different degrees of distinction among sensations. The one most essential is the distinction between those belonging to the different senses, as between the sensations of blue, sweet. warm, and lond. This difference is designated as the difference in modality of sensation, and is so complete that it precludes any transition from one to the other or any relation of greater or less similarity between them. For example, one cannot say whether sweet is more like blue or red. The second difference, which Helmholtz limits to a difference in quality between sensations belonging to the same sense, is less exclusive. Within the same sense transition and comparison are possible. From blue we can pass through violet and carmine red to scarlet red and can say, e. g., that yellow is more like orange than like blue.

We distinguish the following modalities: pressure and touch; heat and eold; taste; snell; hearing; and sight. (With regard to pain cf. Chapter XVII, §4.)

2. Experiment has shown that the profound difference between the senses does not depend in any wise upon the kind of external stimuli by which the sensations are aroused, but is determined solely by the kind of sensory nerve affected.

For illustration, physies considers light as extremely rapid vibrations of a hypothetical, imponderable medium, the ether, which is distributed throughout all space. When these vibrations of the ether strike the retina, the latter is exeited and in its turn produces through the optic nerve an exeitation in the brain, which gives rise in consciousness to a sensation of light. But this sensation of light has not the least resemblance to the ribrations which constitute the objective phenomenon of light. This itself should be fairly convineing evidence that the sensation cannot agree in kind with its external cause. Conclusive proof is found in considerations such as the following: If the eveball be pressed upon, we receive even in piteh darkness a sensation which is characterized by a brilliant play of colors. A blow upon the eye produces a flash of light. Here we have a perfectly typical sensation, and yet no light at all has reached the ese. The sensation is unquestionably due to an excitation of the optic nerve produced by the mechanieal pressure on the cyeball. The same thing is experienced when an electric current is condueted through the exe; we get a sensation of light, even though no objective light mas be present.

3. Since therefore sensations of exactly the same nature are aroused by three wholly different kinds of stimuli-light. mechanical pressure, and elec-

${ }^{1}$ The following discussion is essentially a repetition of the views of Helmholtz as set forth in "Die Tatsachen in der Wahruehmung," Berlin, 1879. 
tricity-it is evident that the character of the sensation cannot agree in any way with the external cause by which it is produced.

This conclusion is confirmed by experiments demonstrating that one and the same external cause can produce entirely different sensations, by acting upon different sense organs. Thus, pressure on the skin gives a sensation of pressure or of contact; pressure on the eyeball a sensation of light. When illuminating rays strike the eye, we get a sensation of light; when the same rass, sufficiently strong, strike the skin, they produce a sensation of warmth. The sensation which is aroused by an electric current applied to the eye has an entirely different character from that which one gets when the current is applied to the skin.

4. Just as sensations have their origin in the brain, so also do they receive their specific character from the cerebral background. A sensation of light, however produced. is, in the last analysis, conditioned by a material change in the brain. It follows that such sensations may arise, when neither the eye nor the optic nerve is stimulated, if only the seat of sensation in the brain is excited in some way, as by a disturbance in the blood supply, etc.

Herein lies the cause of risual hallucinations. For our subjective experience it is a matter of indifference how this particular place in the brain is roused to activity, whether mediately by the optic nerve or immediately by some process in the brain itself. The sensation of light in the latter case must be just as real for the person experiencing it as a sensation produced in the normal manner by the action of light on the retina.

What we have said concerning the sensations of sight, will of course apply to those from other senses.

5. Although all our sensations inclusive of the organie sensations have their origin in the brain, they are not consciously referred to the brain, but are projected outward either to other parts of the body or to the surrounding space. Thus we refer the sensations of touch to the skin; the sensations of taste to the tongue; those of smell to the space around us, to the nose, or to the mouth; the sensations of sound commonly to the surrounding space, in exceptional cases to the ear; sensation of sight always to the outer world.

The information concerning the general condition of the body brought to the central nerrous system, is likewise projected for the most part to different organs. This occurs most definitely in the case of pains and motor sensations; but other organic sensations also are referred to peripheral organs-e. g., the sensation of thirst to the throat, the sensation of hunger to the stomach. etc.

Sensations which give us the general feeling of bodily tone, or of good spirits are not projected to any definite organ. Neither are they referred to the brain; they represent rather a general peculiar condition permeating the whole body, which is present to conseiousness as depression, vigor, indisposition, comfort, etc.

From all this it follows that in so far as the nature of our sensation gives II. any information of the peculiar external agency by which it is excited. it constitutes a sign rather than a picture of that agency. A picture demands some kind of likeness to the thing pictured. but a sign need bear no resemhlance to the thing signified. The only necessary relation between the two 
is that a given object, present under the same circumstances, shall always produce the same sign, and that unlike signs shall always correspond to unlike agencies.

To the popular understanding which assumes the complete truth of the pictures represented to us by our senses, this remnant of similarity may appear very meager. But in reality it is not so; for services of the greatest possible moment to us, such as the portrayal of uniformity in the processes of nature, can be performed for us by mere signs. Every natural law declares that conditions which are the same in a certain respect are always followed by results which are the same in a certain other respect. Sinee likeness in our world of sense is signified to us by like signs, the natural sequence of cause and effect will have its counterpart of a perfectly uniform sequence in the realm of sense. If therefore even the qualities of our sensations are nothing but signs which are entirely dependent in kind upon our nervous organization, they are not to be discarded as mere worthless eounterfeits. They are signs of something, whether of something merely existing, or something occurring, and what is more important, they are able to portray to us the law of oceurrence.

Physiology, therefore, acknowledges that the nature of sensation is, in the last analysis, subjective. In essence it is transcendental. But since experience proves that excitation of different afferent nerves produces different sensations, since we know further that sensation has its correlative physical process not in the excitation of the peripheral sense organ or that of the afferent nerves, but in the activity of the brain, and finally since investigation has shown that different afferent nerves terminate in different ficlds of the cerebral cortex, which in their turn are connected with other parts of the brain, it follows that the specific character of a sensation is determined by the part of the brain roused to action. It is in this sense that we shall understand the doctrine of specific sensations, as used in this book.

\section{SECOND SECTION}

\section{THE QUANTITATIVE RELATIONS BETWEEN STIMULUS AND SENSATION}

In order that an external stimulus may produce a sensation, it must exceed a certain lower limit of strength, which is called, after Herbart, the threshold value of the stimulus. ${ }^{1}$ If the stimulus be increased above this limit, the sensation increases also; but while the strength of the external stimulus may be increased indefinitely the intensity of the sensation never exceeds a certain upper limit. This maximum sensation follows a relatirely weak stimulus and a further rise not only does not produce a quantitative increase in the sensation but on the contrary and in ascending degree produces fatigue and exhaustion of the peripheral sense organ.

${ }^{1}$ The threshold value of the stimulus for the different modalities of sensation varies greatly according to circumstances. In absolute terms it may be given as follows: for the sensation of pressure rolvo th of an erg; for sensations of sound 10.000 .000 th of an erg; for sensations of sight (green) roo.0 0.000 th of an erg. 
Between the minimum and the maximum, as thus defined, variations in the strength of the stimulus will produce variations in the intensity of the sensation.

\section{\$ 1. WEBER'S LAW}

In estimating differences in the intensity of sensations we meet with a peculiar difficulty. We ean say that a certain sensation is stronger or weaker than another of the same kind, but we cannot say how much stronger or weaker it is; for every sensation constitutes a whole in itself and cannot be represented as the sum of several individual sensations. If. for example, a white surface is illuminated at one time by 1 candle power and at another by $n$ eandle powers, we can say perhaps that the sensation in the second case is stronger than in the first; but we eannot tell how mueh stronger it is.

The relation between the strength of the stimulus and the intensity of the sensation is not to be determined by merely setting arbitrary stimuli over against the sensations evoked by them. We can better approach the problem by inquiring how much a given stimulus must be changed to produce a perceptible change in the intensity of the sensation. E. H. Weber who made the first observations along this line (1831) laid down the following law known by his name: The increase in the stimulus necessary to produce a perceptible change in a given sensation must always bear the same relation to the size of the initial stimulus.

Thus, if to a weight of 1 unit a person must add a weight of $\frac{1}{20}$ th in order to make the second load perceptibly heavier in his own subjective appreciation of weight than the first. then, aceording to Weber's law, with an initial load of 10 the superadded weight must be $\frac{10}{20}$ ths to enable him to detect the difference.

By placing weights on both hands at the same time, the hands being supported on the table, Weber found that the "threshold difference" was one-third of the initial stimulus, but when the same hand was successively weighted it was only one-fourteenth to one-thirtieth of the initial stimulus. In estimating weights by the muscular sense-i.e., by lifting them-the threshold difference gnes down to one-fifteenth to one-trentieth when both hands are used simultaneously, and to one-fortieth when the weights are lifted successively with the same hand.

According to experiments by Merkel with fairly pure pressure stimuli, the threshold difference for $50,100,200,500$ and $1.000 \mathrm{~g}$. was $\frac{1}{17.9}$, $\frac{1}{15.6}$, $\frac{1}{18.5}$, $\frac{1}{20}$, and $\frac{1}{1 \frac{1}{3} \cdot 5}$ respectively. For weights above and below these values it is not so constant.

Another illustration of the law is the following: When one looks at a drawing with shadings under different degrees of illumination. the fine gradations of brightness come out with about the same clearness. For example. if he look at the drawing first with the naked eve, then through a gray glass which diminishes the intensity of the light rays from different parts of the drawing to the same extent proportionally, the different parts of it are still seen in their proper relations as regards light and shade. This would not be true if the same proportional decrease in the intensity of the stimuli coming from dif- 
ferent parts of the drawing produced proportionally different variations in the resulting sensations. It is owing to this same peculiarity of our organ of vision that we do not see the stars in daylight. The amount of light which the stars contribute to the illumination of the heavens is too slight in proportion to the total illumination for us to detect them.

Merkel has shown that the same law holds for the sense of hearing, and Camerer and Kepler for the sense of taste.

Weber's law is true within fairly wide limits for all the senses, but for very high or very low degrees of intensity certain variations come in. However, since the stimuli of medium intensity are the ones that occur most commonly in our everyday life. we may say that in general our estimates of differences in intensity follow this law.

In attempting a theoretical explanation of Weber's law it must not be forgotten that the conseions sensation aroused by an external stimulus oceurs only when the exeitation begun at the sense organ reaches the cerebral eortex. It is possible that in the purety physiolngieal events taking place in the peripheral sense organ, in the nerves and in the eentral nervous system a certain inerease in the stimulus produces the same absolute inerease in the exeitation aroused. If so, the relationship expressed in Weber's law would be due to something which is peeuliar to the process of arousing a eonseious sensation from a physiologieal exeitation. But it is also eoneeivable that the peripheral sense organ, nerres, ete., themselves reaet in aceordanee with Weber's law, and that the law is therefore a purely physiologieal one. The latter alternative is probably eorreet, for approximately the same relationship of exeitation to intensity of stimulus has been observed in many purely phrsiological processes. ${ }^{1}$

Referexces.-W. James, "Prineiples of Psyehology," New York, 1905.O. Kulpe, "Outlines of Psychology," translated by E. B. Titchner, New York and London, 1901.

${ }^{1}$ Fechner sought to deduce from this law of Weber a more general one. known as the psychophysical law. By giving the former an algebraic expression and using the differential calculus he arrives at the formula $\mathrm{E}=\mathrm{C} \log$. nat. $r$. (where $\mathrm{E}$ is the sensation, $\mathrm{C}$ a constant, and $r$ the stimulus), which means that the sensation is proportional to the natural logarithm of the stimulus. So many objections have been urged against this formulation that its further consideration here seems unwarranted by its importance for the physiologieal side of the questions involved.-En. 


\title{
CHAPTER XVII
}

\author{
THE SENSORY FUNCTIONS OF THE SKIN
}

ASIDE from serving as the outer covering of the body and in addition to what it does in the service of heat regulation, the skin has very important sensory functions. Notwithstanding that much has been explained by work done within the last decade, the intimate mechanism of these functions still appears to be very enigmatical. We shall divide then into three different groups, namely: (1) sensations of temperature, (?) sensations of pressure and touch, (3) sensations of pain.

\section{\$1. SENSATIONS OF TEMPERATURE}

Temperature sensations are of two kinds, cold and heat sensations, and both are probably related to the regulation of heat in our bodies. The nerves which mediate these sensations produce reflex effects, which manifest themselves as rariations in the intensity of combustion, in the distribution of blood, and in the activity of the sweat glands. The conscious sensations of temperature inform us how the thickness of our clothing and the temperature of our rooms need to be changed one way or the other, although it must be allowed that this information not infrequently leads us astray.

Until a few years ago it was generally supposed that the diametrically opposite sensations of heat and cold were mediated alike by all parts of the skin and that only one kind of nerve fibers was concerned in both sensations. Blix and Goldscheider independently of each other (1883, 1884) demonstrated. however, that not all points on the skin are capable of arousing temperature sensations of both kinds, but that the nerves which mediate sensations of heat have their end organs at different points from those which mediate sensations of cold.

This proposition is proved by the following experiments. A metallic tube drawn out to a fine point is filled with water of the desired temperature. When cold water is used and the tip of the tube is applied to the skin, care being taken not to exert pressure, one observes that the point can only be felt cold at certain spots, while at others it produces no sensation of temperature at all. If the experiment be repeated, using this time warm water instead of cold, we find that sensations of heat can be received only from certain points.

Marking off cold spots and heat spots on the skin with different colors, we find that the two do not coincide, although it must be said that a perfectly exact determination of their relative positions is rery difficult or quite impossible, owing to the conduction of heat by the skin (cf. Fig. 182). 
The presence of different temperature points has been established not only by use of the appropriate temperature stimuli but also by meehanical, electrical and chemical stimulation.

The sensation which is produced by stimulation of a single temperature point is not "pointlike"; instead, one experiences a sort of irradiation of the feeling, so that the sensation is more extensive than the temperature point -i.e., it appears to be disklike and at the same time to have depth. It is on this account that the temperature sensations aroused br contact with warm and cold objects appear to be perfectly continuous, giving no indication of the pointlike arrangement of the end organs. Then we are inclined also to fill up uneonsciously all the gaps in our special sensations (ef. the blind spot in the eye, Chapter XXI).

The number of eold spots in the skin of an adult is found to be $6-23$ per square centimeter of surface; the number of warm spots $0-3$. The entire surface of the body would contain, therefore, about 250,000 cold spots. and about 30.000 warm spots. In a child the temperature points appear to stand closer together, and this may be taken to mean that the child is born with his complete equipment of such points.

In order to obtain a more accurate idea of the topography of the temperature senses, Goldscheider has stimulated different portions of the skin with the ends of cold and hot rods $3-4 \mathrm{~cm}$. in diameter. One cannot obtain the number of temperature points by this method, but can test the relative sensitivity of different regions very well. Thus if there be no temperature points in a certain portion. application of the rods will produce no sensation of temperature at all; if points are present, they may vary both in number and excitability, so that the degree of sensitivity will vary. A surface with only a few intense points would give a stronger sensation than another with many weak points. etc. Fig. 183 is giren as an example of the topographical distribution of the cold and heat senses.

Goldscheider summarizes his numerous experiments on this subject as follow: (1) The cold sense is ereryhere more perfectly developed both extensively and intensively than the heat sense. (?) This relationship holis as well for the parts of the skin habitually clothed as for the parts habitually maked. Goldscheider finds the canse of this regional diflerence in the varying numler of nerve fibers supplied to the different places. Of course there shoulil be added also the varying thicknes of the epidermis covering the end organ-

The experiments of different authors agree fairly well with regard to the aeuteness of the temperature senses in the different regims. Thuse mont sensitive to temperature stimuli are the mipples. and the breast in greneral, the alae nasip. the anterior parts of the arm: then follow the outer angle of the eye, the upper. lip, the abdomen. the rolar side of the forearm, the inner parts of the thigh, the forclig, ete. Ieast sensitive of all is the saralp.

The lanel is hut slightly sensitive to temperature and in general it ean be said that thowe regions of the skin which are used e-pecially for touch are less sensitive to templature than other regions. 
The temperature sense is about equally developed at symmetrical points on the two sides of the body, but there is no special congruence exhibited betwcen such points.

The mucous membranes possess as a rule but a feebly developed temperature sense, or, as is true of the curnea, none at all. Especially is the heat sense poorly developed in sueh places.

A given cold stimulus will eridently produce a greater cooling in a unit of time and will therefore constitute a stronger stimulus for the cold nerves, on

a. Cold sense.

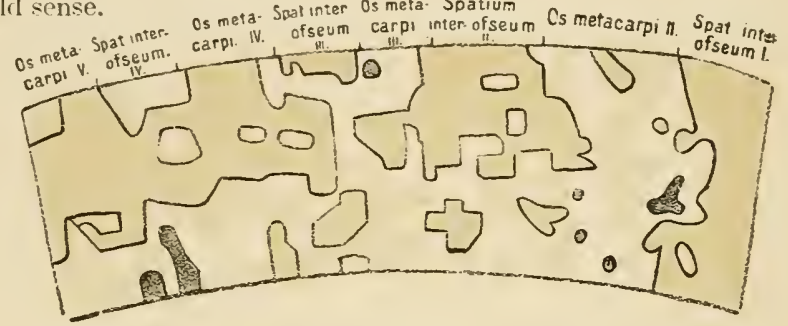

b. Warm sense.
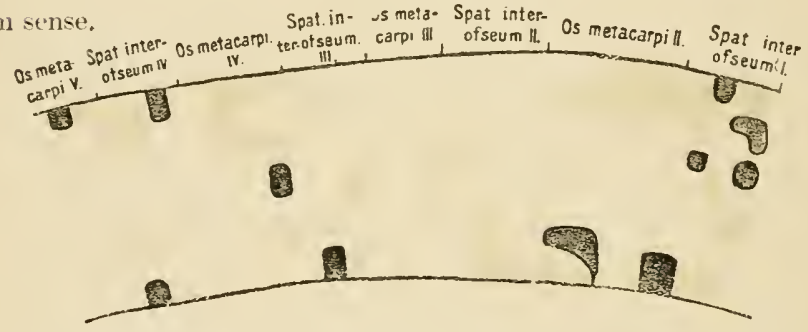

Fig. 183.-Topographical distribution of the cold and heat senses over the middle region of the back of the hand, after Goldscheider. The relative sensitivity is indicated by depth of shade.

parts of the body which are ordinarily clothed than on unclothed parts. The relation of the heat sense to the cold sense is for this reason somewhat different on clothed and unclothed parts.

So long as the temperature of the surrounding atmosphere changes but little, we do not as a rule experience any sensation of temperature, although some parts of the skin. according as they are clothed or not. may be very much warmer or colder than others. When a person goes from one room in which he feels neither cold nor warm into another which is colder (or warmer), he immediately feels cold (or warm). But if the difference bet reen the two rooms is not very great, all sensations of temperature disappear within a short time. If now he returns to the first room, his experience of temperature will be just the reverse of the former change, until again the sensation gradually wears off.

The temperature of the surromnding atmosphere therefore may vary within certain limits without producing in us any corresponding sensation. One night suppose that this ability of the skin to adapt itself to slight changes of temperature would be due to variations in the distribution of blood, so 
that the end organs would have a uniform temperature in spite of the variations outside. But this is not the case, for Thunberg has shown that the adaptation is to be observed even after a large quantity of blood has been drawn from the vessels.

E. H. Weber, to whom we owe the first eareful studies on the sensory functions of the skin, was of the opinion that the heat spots are stimulated specifically by an increase in the temperature of the skin and the cold spots by a fall. Hering, on the other hand, eoneeives that the determining factor is not the temperature of the skin but of the thermal apparatus itself. We cannot here enter into a diseussion of the merits of these two hypotheses. We may merely mention one phenomenon which can scareely be explained by either of them.

It is a eommon experienee that one sometimes feels a sensation of chill on getting into a hot bath. This is because the eold spots of the skin respond to the heat stimulus with their own peculiar sensation. Excitation of these spots by heat occurs only with stimuli of $45^{\circ} \mathrm{C}$. and upward (Lehman, v. Frey). The reverse process of stimulating the heat spots by cold gives no reaction.

The end organs of the temperature nerves share with other nervous end organs a peculiar property, in virtue of which the strength of the excitation aroused depends upon the rapidity of the stimulation, in this case upon the rapidity of the increase or decrease of temperature. The strength of the sensation depends also upon the size of the skin area stimulated: if the whole hand is dipped into water at $37^{\circ} \mathrm{C}$. the water feels warmer than water at $40^{\circ}$ into which only one finger is dipped.

If a piece of metal at $2-3^{\circ} \mathrm{C}$. be placed in eontact with the skin of the brow for, say, thirty seeonds and then removed, the sensation of cold on that part of the skin is experienced for some twenty seconds afterwards (E. H. Weber) -i.e., the temperature sensation persists after the stimulus is removed.

A change in the temperature of the skin reduces the excitability of both kinds of temperature nerve endings. If one hand be held in moderately cold water and the baek of the other hand be dipped in the same water, it seems colder to the latter hand. If the skin be overheated then dipped in cold water the water seems warmer than otherwise.

If hot and cold stimuli be applied simultaneously to the same skin area the sensation of cold appears first. Likewise on stimulation of the cold spots the sensation is sharper and reaches its maximum sooner than the sensation aroused by stimulation of the heat spots. This difference is not observed on stimulation of the temperature spots by electricity. From these facts v. Frey eoneludes that the heat endings lie in the deeper layers of the skin, the cold endings in the more superficial layers.

\section{\$2. PRESSURE AND TOUCH}

by the pressure sense we not only distinguish pressure and contact, but learn also whether the surface of an object is smooth or rough. whether an object is sharp or dull, hard or soft, solid or liquid, etc. Here belong also itching and tickling sensations and the like.

It is perfectly certain that these different sensations are not all mediated by the true nerves of pressure, but that other afferent nerves play an important part. If for example. we perceive an object to be hard, this sensation of hardness is caused not only by the effect produced on the nerves of pressure, but there is experienced also a sensation of resistance which is evoked by the 
so-ealled motor sense (ef. (hap)ter XVIII). Since, however, these different kinds of pressure sensations have not been sufficiently differentiated either physiologieally or psychologieally, we shall limit the following discussion to pressure sensations in their simplest form.

Blix was the first to demonstrate by meehanical stimulation of the skin with fine points, that the pressure sense like the temperature sense is not continuously represented over the entire skin, but that the end organs of the nerves mediating the sensation of pressure are separate from one another and are not identical with the end organs of the temperature nerves (see Fig. 182).

Stimulating the pressure points as lightly as possible with a bristle produees a delicate but vivid and often somewhat tickling sensation, such as is experienced when one of the fine hairs on the skin is moved. Aceording to Kiesow this shows that the tickling sensation is a sensation of pressure of a peeuliar shade oecurring under special conditions (and in certain cases connected with sensations of contraction). With a little stronger pressure the sensation takes on a perfectly characteristic quality, as if it were produced by a small, hard grain being pushed into the skin, hence the name "granular" used by Goldseheider.

The pressure spots can be sought out also by means of induction shocks. By monopolar stimulation of the spots a prickling sensation is experieneed with a strength of eurrent which gives no sensation at all if applied in the intervals between the spots. v. Frey, who has sturlied exhaustively the eleetrie stimulation of the pressure points, observes that induetion shocks produced by as many as 130 interruptions of the primary current per second are felt as independent shocks, also that the constant current causes a discontinuous excitation. On eertain regions of the skin (fingers, tip of tongue, red edges of lips), Sergi has found that meehanical shoeks can still be appreeiated as distinet if they occur at intervals of $0.001-0.002$ seeond.

The pressure points are arranged with special reference to the hairs. Each hair has a pressure point near its point of exit and directly above the deepest part of the follicle ( $\mathrm{v}$. Frey). It cannot be said however that the number of pressure points coineides exactly with the number of hairs. In the first place the hairs often stand in twos and threes and then are so elose together, that it is not always possible to demonstrate the presence of pressure points belonging to them. Besides, one finds here and there within the regions clothed by hairs some pressure points standing quite apart and wholly unrelated to any hair.

The number of pressure points varies in different parts of the skin-e.g., on the flexor surface of the wrist 28 per sq. em., on the anterior surface of the foreleg 5 per sq. em. (Kiesow). Aceording to v. Frey's estimate, the entire surface of the adult body, with the exception of the head, would probably contain about 500,000 pressure points.

Excitation of the pressure points appears to be accomplished by deformation of the skin. When a perfectly uniform pressure is applied to the skin no sensation is produced. the best illustration of which is the fact that we do not feel the pressure of the atmosphere. The following experiment also, 
first made by Meissner. illustrates the same point. If the hand be dipped into water or mercury at the temperature of the skin, no sensation is produced in any part of the shin submerged so long as the hand is hept perfectly still and contact with the ressel is avoided. But a sense of pressure is felt at the boundary line between air and liquid.

A weight allowed to rest upon the skin for a long time, is felt eontinuously, but with less and less distinetness as time goes on. Should the weight be rery small, it may be felt only at the moment of its application. Remoral of the weight is not of course aprreciated unless it is heary enough to be felt all the time it is present. Often the sensation uutlasts the stimulus, probably owing to the persistence of the leformation in the skin.

Kiesow gives the following data with regard to the sensitiveness of the different parts of the skin. The relative strength of the tetanizing induetion eurrent necessary for the threshold stimulus is: on the tip of the tongue, 1; lips, 1.1 ; anterior half of the tongue, 5 ; tips of the fingers, $14-17$ : tip of the thumb, 19-21: ertge of the kneepan, 21: styloid process of the uhna. 3t-37.

Stimulating the skin of the frog with pressure. Steinach was able to observe an action eurrent in the eorresponding nerves, the strength of which was found to depend upon that of the stimulus.

\section{THE LOCAL SIGN}

A person pricked on the skin with the point of a neelle can tell with the eyes closed exactly where the needle is applied. This ability to refer a entaneous stimulus to the correct place is often described for brevity as the sense of location, but is better described as the pouer of localization. E. II. Weber, who was the first to investigate this sense with any completeness, applied the two points of a draughtsman's compass to the skin and determined the least distance from each other at which they could be distinguished by the subject as two distinct points when applied to different parts of the skin. The less this distanco was found to be the greater was the ability of the shin to localize the stimulus accurately.

The following are some of Weber's results, given in millimeters: tip of the tongue, 1 ; tips of the fingers, 2; lips, 4.5 ; dorsal side of the third joint of the fingers, $\boldsymbol{T}$; side of the tongue, 9 ; onter surfaee of the eyelids, 11 ; dorsal side of the first finger joint, 16 ; brow, 23 ; baek of the hand, 31 ; sternum, 45 ; middle of the back, 68 .

We see that the distance is greatest on the trunk and deereases more and more as we pass toward the ends of the extremities. It is least on the tips of the fingers (negleeting the tip of the tongue)-i.e., just where the skin is used for the most delieate touch and where the discernment of slight intervals between oljoets is most necessary.

Our ability to distinguish slight intervals of space with the skin is, however, not quite so limited as it might appear. In the first place as we know from many experieness. it can be improped by practice: in the second place slight intervals are much more sharply distinguished, if the two places on the skin are stimulated not simultaneously, but suressively (Judd. v. Frey) : and in the third place, this ability is mol greater when two isolated pressure 
points are stimulated than when the needles are applied, as in Weber's experiments, quite at random. Under suitable conditions of the experiment the smallest distance at which any two stimuli applied to the skin can be recognized as distinet, corresponds closely with the distance. as determined by suceessive stimulation, of neighboring tactile points from each other (v. Frey and Metzner).

The differences already observed between different points of the skin, obtains also for the stimulation of isolated pressure points, as the following summary will show. The smallest perceptible distance for the nail joints, volar side is $0.1 \mathrm{~mm}$.; for the balls of the fingers, $0.1-0.2 \mathrm{~mm}$; palm of the hand, $0.1-0.5$; ball of the thumb, $0.2-0.4$; nose and chin, 0.3 ; hack of the hand, $0.3-0.8$; cheek, arm, brow, 0.4-1.0; foreleg, abdomen, 1.0-2.0; thigh, 3.0 ; back, 4.0-6.0 mm.

It has been found also that the smallest perceptible distances are shorter when the points applied simultaneously are placed in the transverse direction from each other than when the line joining them lies in the longitudinal direction of the part, and that they decrease with the distance of the points tested from the axis of rotation of the members; thus, on the arm above, $53.8 \mathrm{~mm}$; belou, 44.6 ; on the forearm above, 41.2 ; below, 22.5 ; on the hand above, 20.4 ; below, 7.8 ; on the third finger above, 7.5 ; below, 2.5 (Vierordt).

The power of localization is reduced by fatigue, anæmia, low temperature, etc., and is intensified by hyperemia of the skin. Children have a more precise power of localization than adults.

It is really very remarkable that we have the power to distinguish two points as two when they are applied to the skin simultaneously. For the mere excitation from the one must be just like that aroused from the other. But the fact that we have the power to feel them as two must mean that the two sensations of pressure differ in some definite property. Since now we can distinguish simultaneously stimulated points better the farther they are apart, it follows further that this difference between the sensations produced from different points is greater, the farther they are apart.

This difference between the resulting sensations which enables us to locate the place of stimulation is known, since Lotze, as the local sign. Since every sensation arises in the last analysis through cerebral processes. we may conceive of the local sign as a difference in some property of the different sections of the brain, excited by stimulation of the different pressure nerves. In a crudely schematic way we may imagine that every pressure nerve is connected in some way with a special nerve cell and that excitation of this nerve cell produces a specific shade of sensation which differs from all other sensations of pressure.

The temperature nerres of the skin likewise possess this power of localization, but it is not so highly developed for temperature as it is for pressure. The cold spots appear to have a more precise power of localization than the heat spots.

The porrer of lncalization of the retina, especially of the fovea centralis, will be taken up in Chapter XXI. 


\section{§ 4. PAIN}

If too strong a stimulus be applied to the skin or if it be continued too long or be repeated too often, a peeuliarly disagreeable sensation, which we call pain. is aroused. With a sufficiently strong stimulus the sensation is diffused in our pereeption more or less beyond the part of the skin direetly excited. And from pain of very great intensity convulsions, loss of consciousness, or even mental derangement may result.

Sensations of pain, whose important funetion it is to direct our attention to all kinds of influences, which, if negleeted, might bring us into great danger, are mediated not by the skin alone, but by all other parts of the body as well. Pathologieal processes in the internal organs of the body or in its members are often aceompanied by pain. Cramps of the muscles give rise to severe pains, and the feeling of great fatigue in the museles after severe work lies on the borderland of painful sensations. Pressure on the eye causes pain. a bitterly eold wind eauses pain. Then there are toothache, earache, headache, labor pains, and many others of which we have no need to be reminded.

It is very difficult to draw a sharp line between actual pain and a mere feeling of displeasure. High tones, e.g., are extremely unpleasant; so also are vibrations and rapid variations in the intensity of light; bad-smelling and bad-tasting substances produce nausea. Several of these and other analogous sensations produce in eertain individuals effeets quite similar to those of pronouneed pains.

Only the painful sensations aroused by the skin have been subjected to exaet analysis.

The eutaneous pains are not always of the same character, but exhibit differenees which are due mainly to different combinations of the various sensations mediated by the skin. but also to the extent and duration of the stimulus. Thus a burning pain is accompanied by a sensation of heat; in a stinging pain the disturbance is confined to a small area of the skin; we eall a pain cutting if it is distributed over some extent of the body with a certain speed: a throbbing pain is aroused when the pain eomes and goes with the pulse, as, e.g.. in the ease of inflammatory pains, where the pulsations eause an inerease in the pressure of the tissue.

Pain, more than any other sensation, has immediate reference to oneself. and likewise the intensity of pain more than that of any other sensation is influenced by the mind. When a person cuts himself accidentally with a knife, the cut produces no pain worth mentioning even though the wound be a deep one. But let him know beforehand that a slight operation, be it nothing more than a priek of the finger for a blood count, is to be performed on him. and it may cause him real agony. From this it follows that the imagination of pain inereases its intensity very greatly.

By directing the attention very intently to a certain part of the body, a person may evoke ereeping sensations, sensations of tension, pressure, ete., due to the dilatation of the arteries with the eardiac systole, to pressure of the clothes. ete., which otherwise he would not be conscious of at all, and by continued atten- 
tion to them they gradually become more and more unpleasant and, finally, actually painful.

In diseases accompanied by pain, the pain is often more severe at night than during the day. This is probably due to the fact that in the daytime our attention is distracted by many things outside ourselves, and is not dirceted so exclusicely to the body.

By purposely fixing one's attention on a definite object or idea it is possible to suppress not only the expression of pain, but to a large extent the pain itself. The following story of Immanuel Kant is much to the point. Kant suffered from time to time with attacks of gout which, as many know, may be very painful. "Out of patience at feeling mrself deprised of sleep." he writes, "I soon seized upon the stoical expedient of fixing my thought intently on some chance object, whatever it might be (e.g.. on the many ideas associated with the name of Cicero), and of consequently diverting my attention from all sensations. In this way the sensation speedily became blunted, so that the natmal tendency to sleep overcame them. And this I could repeat with equally good results each time in the little interruptions in my night's rest occasioned by recurring attacks. But in the morning the shiny redness of the toes of my left foot was sufficiently convincing to myself that these sensations had not been purely fanciful."

Although all men have not the same will power as Kant had, we may nevertheless lea:n from his example that it is possible actually to suppress pain to a certain extent, just as it is possible for us to accustom ourselres to bear a necessary pain without sounding it abroad with loud wailings.

The expression of pain, therefore, is not to be accepted as a measure of its intensity. A strong-willed person may feel very severe pain without wineing, while another may cry out at a pin prick. On the other hand, we must not forget the experience oft confirmed in animals as well as in men that sensitiveness to pain is very different in different individuals. And since nobody can tell with certainty how strong is the pain which another feels, we ought not to withhold our srmpathy from others when they give expression to pain.

It is very difficult to decide just wherein lies the real physiological cause of pain. Since we know that the pain aroused by any adequate stimulus has an altogether different character in different parts of the body-as. e. g.. those aroused by a high temperature differ from those aroused by a low temperature, as the pain of muscle cramps is of a different kind from that of high pressure insile the eye, and the pains occurring in inflammatory processes differ according to the organ inflamed-the assumption is undoubtedly suggested that pain is produced by an excessive excitation of the ordinary afferent nerres from different parts of the body.

The fact that in certain diseases of the nervous system the sensations of pain are lost while the ordinary tactile sensations do not suffer any considerable diminution, does not militate against this hypothesis. One might readily imagine that the maximum excitation necessary for the production of pain were not reached, although the threshold stimulus remained approximately the same; and this supposition could be brought into line with Schiff's observation that section of the gray matter of the spinal cord abolishes sensations of pain without affecting the tactile sensations.

Proceeding from this observation it has repeatedly been conjectured that painful impressions are conducted through the gray matter, and that the 
sensations of pain are aroused by a sort of summation taking place in the alls of the gray matter, and there is any number of obserrations at hand which show that tactile stimuli, of themselves wholly painless, produce serere pain if repeated frequently enough. Likewise the irradiation of pain, as well as the occurrence in pathological processes of many accessory sensations of a painful character, appear to speak for the participation of the gray matter.

While these and other obscrations can be explained on the gromnd that the sensory cutaneous nerves already discussed mediate the sensations of pain. they do not, howerer, constitute positive proof of that proposition. Let us see what we may learn from investigation of the different sense points of the skin.

There prevails among authors who have busied themselves with this question a most gratifring agreement on one point, namely, that neither stimulation of the temperature points by their appropriate stimuli nor mechanically (hy a needle thrust) produces any pain (Goldscheider et al.). Likewise when a heat spot is tested with very warm water, it gives a burning hot sensation but no pain. The heat pain might be regarded therefore as a separate sensation of pain merely colored by the excitation of the heat nerves, unless we suppose that the analgesia of the heat spots is due to the fact that the surface stimulated is too small; for it is a well-known fact that the size of the surface stimulated is a very important factor in the proknction of pain.

Blix demonstrated that on many parts of the body a needle can be thrust deep into the skin without producing any pain. The nerves which mediate pain therefore do not occur everywhere in the skin. Neither Blix nor Goldscheider however felt impelled to assume the existence of special nerves of pain with their own end organs, but conceived that sensations of pain have their origin in excitation of pressure nerves. r. Frey, on the other hani, entered the lists for special pain nerves and adduced the following weighty reasons, among others, for their existence.

(1) By observing certain preeautions, mechanical stimulation of the skin with a bristle produces a pure sensation of pain without any preliminary or aecompanying sensation of pressure. (It will be readily understood that the pain spots eannot be stimulated singly by meehanieal means when they lie in the immediate neighborhood of pressure points.)

(2) If a bristle be placed over a pressure point, the sensation appears immediately, but at once fades away again and usually becomes unnoticeable after a short time. Over the pain point the effect appears later. gradually increases in strength and decreases again after reaching a maximum. If the selsation is still present after the stimulus has ceased, it disappears slowly. Intimately connected with this behavior is the faet that rapidly repeated electrieal or mechanical stimuli (from five per second upward) applied to the pain point fuse as a rule into a continuous sensation, whereas through the pressure point we can distinguish very well 130 shoeks per serond (page 462 ).

(8) When the head of a pin is pressed for a moment intn the skin, there follows very often after the sensation of pressure and separated from it by a short interval, a second sensation which is painful. Only pain points in the neighborhood of pressure points exhibit this phenomenon. On isolated pressure points the painful after-effeet is wanting, and on isolated pain points the sen- 
sation of pressure accompanying the stimulus fails, while the painful after-effect appears very vividly.

With regard to the topographical distribution of the pain spots we learn from v. Frey and others that on the back of the hand over the metacarpus of the ring finger 16 pain points, as against 2 pressure points, can be demonstrated within $12.5 \mathrm{sq}$. mm.-i. e., 1.3 pain points to the square millimeter.

From reasoning which we need not enter into here v. Frey has reached the following conclusions with regard to the anatomical structures which may possibly serve as the end organs of the different cutaneous nerves:

(1) Among the well-known sensory nerve endings on parts devoid of hair there is only one form which occurs in sufficient number to fulfill the requirements of an end organ of the pressure points, namely, the tactile corpuscles of Meissner. According to this discoverer there are-e.g., over the metacarpus of the little finger in $1 \mathrm{sq} . \mathrm{mm}$. one to two of these corpuscles-which agrees well with the number of pressure points in the same place.

(2) These corpuscles however are quite exclusively confined to the parts devoid of hair. Anatomical investigations have brought to light the presence of a wreath of nerve fibers encircling the hair follicles down close under the opening of the sebaceous glands, their terminal processes penetrating the walls of the follicle as far as the glassy layer. This wreath of nerve fibers which occurs with the greatest regularity in every hair follicle may be the end organ of the pressure points associated with the hairs.

(3) The sensation of pain is probably aroused by stimulation of some mechanism lying nearer the surface. Since only free intraepithelial nerve endings are found external to the tactile corpuscles, we may look upon these as the organs of the (superficial) sensations of pain in the skin.

(4) Finally, v. Frey and Thunberg, the latter by careful analysis of the different phenomena attending stimulation with heat, have made it probable that the end organs of the heat nerves lie deeper than those of the cold nerves, also that the latter lie deeper than the end organs of the pain nerves.

References.-M. G. Blix, Zeitschrift für Biologie, Bd. xx, xxi, 1884, 1885.M. v. Frey, Abhandl. d. mathem.-phys. Cl. der königl. sächs. Ges. d. Wiss., Bd. xxiii, No. 3, 1896.-A. Goldscheider, Archiv für Anat. und Physiol., physiol. Abt., 1885, suppl. Bd.-A. Goldscheider, "Ueber den Schmerz," Berlin, 1884. 


\section{CHAPTER XVIII}

\section{ORGANIC SENSATIONS}

WE include as organic sensations all those sensations aroused independently of external stimuli by internal processes going on in the various peripheral organs. Sensations excited from the sense organs normally by external agencies or abnormally by pathological processes evidently do not belong in this category.

Among the sensations thus defined we may mention first those which constitute the source of our general bodily feelings (page 452). But analysis of this class of sensations has not progressed far enough as yet to entitle them to further consideration here. We should mention also certain occasional sensations of pain arising within the internal organs concerning the exact cause of which nothing positive is yet known.

The only organic sensations thus far studied critically are those by which we form ideas of the position of our bodies and their parts (head, trunk and extremities) in space, and those by which we are made aware of the extent. intensity and direction of our movements. These sensations play a considerable part in the regulation of our movements and besides are very important in the psychological elaboration of our sense impressions (even of those which arise through external agencies), although they appear as a rule to be indistinct and indefinite in comparison with the last naned.

The two groups of organic sensations just mentioned are not, however, everywhere sharply distinct from one another. The impulses by which we are made aware of our bodily morements, their direction and intensity, merge into the less distinct afferent impulses by which we form ideas concerning the orientation of our bodies. The anatomical substratum of our motor sensations and of our sense of position is furnished in part by the sensory nerve endings of the muscles, tendons, joints, skin and in part by those of certain portions of the inner ear (semicircular canals and otolith sacs).

\section{§1. MOTOR SENSATIONS}

Even with the eyes closed we have a very definite idea of the position of our limbs. If, for example, one arm be passively placed in a certain position. the person ean with his eyes closed place the other arm in exactly the same position. Likewise a person has a perfectly precise idea with respect both to direction and speed of the changes in the position of his limbs. Finally, one can estimate weights very accurately by lifting them.

These and other similar sensations are described by different authors by different names, such as motor sensations, muscular sense, sense of force, etc. 
This difference in terminology alone is evidence that views differ greatly as to the real cause of these sensations. According to some authors, like Ch. Bell and E. H. Weber, they are produced by exeitation of the sensory nerves to the museles; others, like Lotze and Sehiff, eoneeive that they are evoked by the different foldings of the skin incidental to different positions; aceording to Bermhardt the sensory nerves of the skin, of the faseias and of the periostenm as well as the nerve trunks rumning through the museles oeeasion museular sensations: Lewinsky seeks their cause in the exeitation of the nerves of the joints and bones; and many authors like Leyden, Meynert, Nothnagel and others assume that several different kinds of afferent nerves have a share in their production.

As for lifting an object with the hand, in a great majority of cases we send an impulse to the muscles which is exactly suited to the purpose, being neither too weak nor too strong. That is, if the object is a familiar one, we can adjust the voluntary impulse rery exactly to the work to be performed. From this the conclusion has been drawn that the fecting of offort is the all-important thing in the perception of active movements (J. Müller. Wundt).

As a matter of faet it is easy to show that we do assoeiate immediately with a voluntary impulse an idea of the morement as if it were already performed. Persons who have suffered amputation of a leg assert very positively that when they will to bend the lost part they experience a distinet feeling that muscles are being eontraeted.

But the central feeling of effort, however important it may be, is not the only determining factor. The mere development of our ability to adapt the necessary motor impulses to the lifting of different objects, involves the constant participation of afferent impulses which keep us informed of the results of the impulses sent out. It can be shown also without difficulty that the result of a voluntary impulse is usually controlled by afferent impulses. Thus, if we misjudge the reight of an object-e.g.. overestimate it-we give too strong an impulse, as a consequence of which the object is lifted considerably higher than we intended it should be and we are immediately aware of the fact even without the use of our eyes. Similarly we are aware of the fact, if the impulse is too weak. Naturally if these afferent impulses participate in loringing about active movenents, they must be the more necessary for making us aware of passive movements.

Let us see what are the afferent nerres mediating motor sensations. Anatomical proof of the presence of afferent muscular nerves has been furnished by Reichert, Kölliker, Odenius and others. We know too from the perfectly definite sensations of fatigue as well as from the pains of muscle cramps that these nerves are unquestionably able to mediate ennscious sensations. They also give rise to reflexes, among which those produeing vasodilatation and those involving the skeletal museles as answering organs are the most important (Tengwall). It seems probable therefore that these nerves do play a prominent part in the motor sensations.

In the ease of the eve muscles the afferent nerves are of great importance. We shall see later (Chapter XXI) that we have a very delieate appreciation of the slightest eontraction of the eve muscles. This could only be true, if afferent nerres from the museles or their tendons were present. 
Likewise the thyroarytenoid muscle, whose finely graduated contractions determine the pitch of the vocal tones, appears to possess a very delicate muscular feeling produced by the afferent nerves; there is, however, no feeling of movement connected with this.

According to the view which Goldscheider in particular has worked ont, the most important nerves for the perception of passive movements are the afferent nerves of the joints. The sensations of pressure and tension in the soft parts of the limbs not only do not produce the sensation of movement, they even interfere with it. Again, sinec the threshold value of the sensation -i.e., the smallest passive morement which one can perceive-is not influenced in any way by the degree of contraction of the muscles when the passive movement begins, coöperation of the muscular sensibility as a factor appears to be excluded. Finally the distance described by the moving force bears no relation to the amount of sensation which one experiences; the determining factor is the amount of rotation at the joint.

Lewinski made some experiments on ataxie patients (cf. page 472) by moving their limbs very slowly and very slightly at the ankle, knee and hip joints, part of the time pressing the parts together at the joint, part of the time not. When the parts were thus pressed the patients always perceived the movement very exactly, when not they could form no idea of the motion.

The perception of active movements likewise results from the rotation of the joints. To this are to be added, however, as contributing factors the sensations connected with the tension of the tendons and their epiphyses, possibly also the sensations aroused through the sensory nerves of the muscles. These sensations concern not merely the tendons, etc., of the actire muscles, but also their antagonists. In a passive movement the tendons simply follow the pull; some are stretched, others are only under the tonic resistance of their own museles.

In active movements, especially if the joint to be moved is loaded, we also experience sensations of weight and of resistance. The nerves of the joints and of the tendons are again of the first importance, the pressure on the surface of the joints and the tension of the tendons varying according to the resistance or the weight.

Jacobi has called attention to still another circumstance to which he ascribes great importance in the determination of the size of a weight, namely, the comparison of the amount of nerve force employed with the latent period of the movement-i. e., the time which clapses between the act of volition and the inception of the movement. The latent period, in his opinion, depends upon the amount of nerve force employed, and with the same amount of nerve force is proportional to the size of the weight.

The sensory nerves of the skin appear commonly to be of but slight importance in any kind of motor sensations. The sensation of weight remains unchanged after the skin is rendered insensitive to touch. And ret cutaneous sensations appear to contribute something to the quantitative refinement of a sensation of resistance as well as to the Iocalization of the sensation and so to the formation of a clearer total impression (Goldscheider and Blecher). 
In the case of the face muscles and the levator patpebre superioris distinet sensations which inform us of the displacenents suffered by the soft parts accompany the contractions (Goldscheider).

The sensations which make us aware of the position of the extremities lave their origin in the skin, tendons, and probably the joints. By combination with optical memory pictures they give us our idea of position. Sensibility of the muscles appears to have little to do with the perception of position in the case of the extremities, but in the case of the eye muscles it plays a very important part.

\section{§2. PHYSIOLOGICAL SIGNIFICANCE OF THE MOTOR SENSATIONS}

Taken in their broadest sense, the motor sensations are of very great importance for the regulation of all bodily movements. Whenever any part of the body suffers loss of the motor sensations or a decline in their intensity and fineness, that part of the hody exhibits disturbances in the coordination of its movements. In this way are brought about those pathological symptoms which are described as ataxia and which are defined in brief as a disturbance in the harmonious and purposeful coöperation of the muscles.

One of the most frequent forms of ataxia arising from lesion of afferent pathways is locomotor ataxia occurring in tabes dorsalis. It is claracterized by the peculiar way in which the legs are swung and the feet planted in walking. Instead of the slightly flexed position of the normal leg as it is swung forward, the knee is extended, sometimes exeessively, and the leg is thrust forward, the heel being planted on the ground with a sudden stamp. At the same time the legs are kept far apart, the trunk sways back and forth, and the body is in momentary danger of losing its equilibrium.

Coördination of the muscles being necessary to hold the body erect no less than to carry out movements of the limbs, ataxia is at times noticcable in standing. Thus ataxic persons are inclined to place the legs far apart in order to increase the area of support. If the feet are placed elose together the body sways, or may fall, especially if the eyes be at the same time closed so as to shut out control by visual impressions (Leyden and Goldscheider).

There are many clinical observations to support this dependence of exact movements upon different impulses, and they are confirmed in the most beautiful way by experiments on animals.

Thus, after section of the afferent roots which supply one hind leg, a dog is unable to run on the ataxic leg when the sound leg is tied up (Hering, Jr.). When the afferent roots to both hind legs are cut, a dog is utterly unable to walk, and can only pull himself along on the abdonen by means of the fore legs, the hind parts dragging. Gradually, however, the dog ean learn to walk again, and at the end of three to four weeks but few signs of the original disturbance are left (Bickel). There is therefore a means of compensating the loss of these afferent impulses.

J. R. Ewald observed that in cases of this kind the animal eould call into play certain aids not previously used for regulation of his movements, and in fact Bickel observed that a $\mathrm{dog}$ which has recovered the use of his legs after an operation, exhibits again the original symptoms when he is taken into a dark 
room; from which it appears that the optical apparatus constitutes the compensating medium. H. Munk found on monkeys that after section of all the nerves to one anterior extremity, the insensitive arm could be extended for food on the same day of the operation, but the hand could not be moved. During the following days the number and extent of isolated morements steadily increased (more rapidly so with practice), and in a few dass the animal could again grasp bits of food and convey them to its mouth. After some months the arm was used for almost all isolated acts, but continued to be more impulsive and cumbrous in its movements than the normal arm, which as time went on came to be used first on most occasions. The associated morements of the arm in walking, jumping, climbing, etc., however, were entirely, or almost entirely obliterated; at all events they were no longer used to ans adrantage.

We may sum up by saying that the messages conveyed by the afferent fibers to the central organs are of great importance not only for the coördination of movements but for the morements themselves, and that this depends primarily on the fact that it is through these messages that the individual learns to what extent the intended movement was carried out or failed to be carried out. The nerves of the organ itself are the ones most directly concerned, but they can be replaced to a greater or less extent by other nerres-as, e. g., the optic. When this compensation also fails the motor disturbance is greater than ever and it is conceivable at least that if all afferent impulses were completely inhibited, purposeful motor functions would no longer be possible.

\section{§3. THE SEMICIRCULAR CANALS AND OTOLITH SACS OF THE INNER EAR}

Physiological experiment and elinical experience both seem to have shown definitely that the afferent nerves of the semicircular canals and otolith sacs in the internal ear convey impulses to the nerve centers, which have much to do with the perception of position or changes in the position of the head as well as with other processes of orientation, etc.

We shall inrestigate these phenomena without for the present raising the question of how far the impulses gire rise to conscious sensations.

\section{A. ANATOMICAL}

It is not our intention to describe the internal ear fully in this place: we shall only mention briefly the structural relations which are important for our present purpose. The internal ear can be divided into two portions, the cochlea and the semicircular canals, togcther with the sacculus and utriculus. 'These two divisions have as a matter of fact entirely different functions.

The cochlea unquestionably represents the end organ of those nerve fibers the excitation of which arouses anditory sensations, particularly those of nusical tones. This is especially well borne out by the facts of comparative anatomy. In fishes the cochlea is represented only hy a rery small knoblike appendage to the saccule called the lagena. In frogs and toads the cochlea reaches a somewhat higher development and in the reptiles a regular progression of stages ean be followed from the turtles and snakes to the lizards 
and erocodiles. In the last named for the first, and in birds the cochlea becomes eurved and slightly spiral, while in the mammals it reaches its highest development by growing out into a long tube which deseribes upon itself one and one-half to four spiral turns.

The semieireular canals are arranged in the three dimensions of space. Inasmuch as the physiologieal investigations of these struetures relate mainly to the pigeon, we shall deseribe them for this animal at once, following the work of J. R. Ewald. We find on each side of the head an external, an anterior and a posterior canal (Figs. 184 and 185). The two external canals lie almost exactly in the same plane, which when the head is in its normal position with the beak slightly lowered, is approximately the horizontal plane (Fig. 184). The planes of the posterior eanal of one side and the anterior canal of the other are almost exactly parallel, but the projection of each is about $7 \mathrm{~mm}$. distant from the other (Fig. 186) and each forms an angle of about $45^{\circ}$ with the median vertical plane of the head. This relationship being

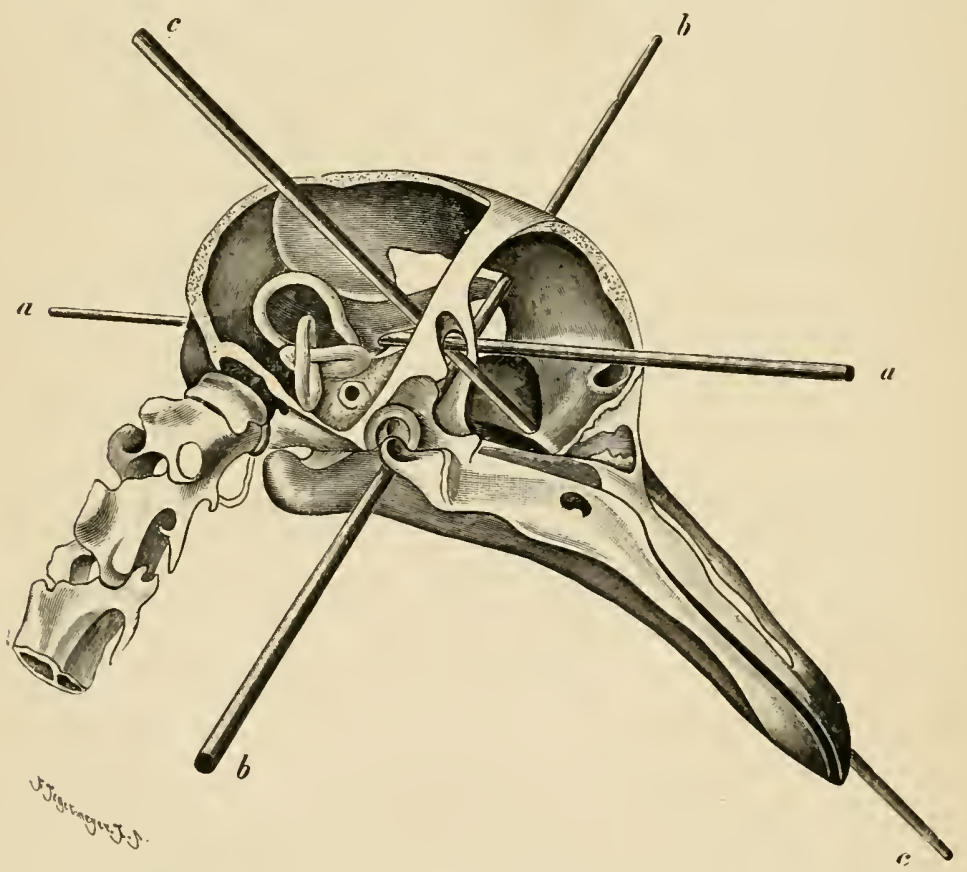

FIG. 184. - The semicircular canals of the pigeon laid bare in situ, after J. R. Ewald. The rods $a, b$ and $c$ are placed in the axes of the eyes, the skull and the beak.

true for both pairs (the left anterior with the right posterior, and the right anterior with the left posterior), it follows that the six canals together mark out three planes which lie in the three dimensions of space.

This deseription applies strictly only to the middle portion of each canal, for its ends deviate somewhat from the course taken by the middle.

Each canal bears at one end an enlargement, the ampulla, which contains in its crista acustica the nerve endings of the canal. The ampullæ of the two 
canals which lie in the same plane are so arranged that particles moving in the same direction in the two move toward the ampulla of one and away from the ampulla of the other.

In the sacculus and utriculus likewise are nerve endings contained in the maculce acustica.

These nerve endings consist of cells with hairlike processes, which in turn are connected with the terminal filaments of the eighth cranial nerve. In the

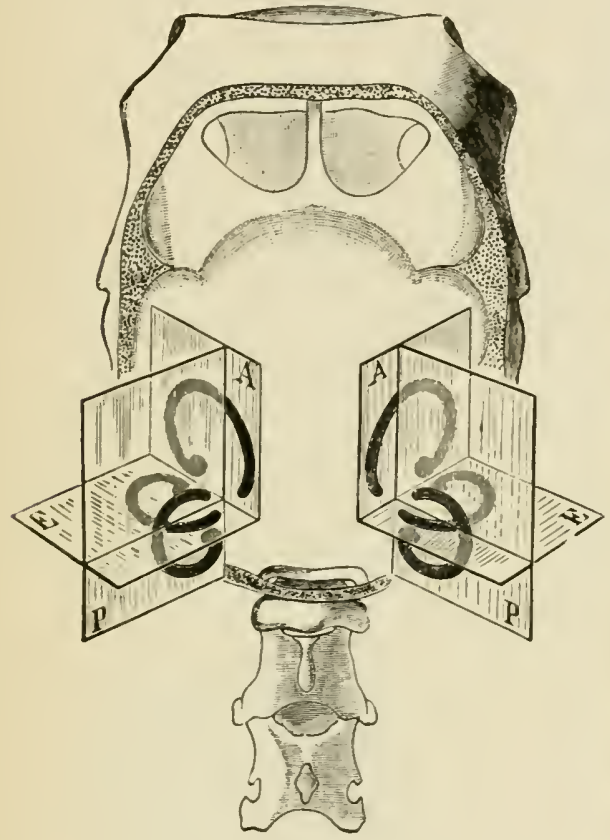

FIG. 185. ampullee the hairs are bound together by a substance which is probably slimy and gelatinous in life. This substance, however, does not reach down to the epithelial surface, but is separated from it by a small space filled with endolymph, through which the hairs

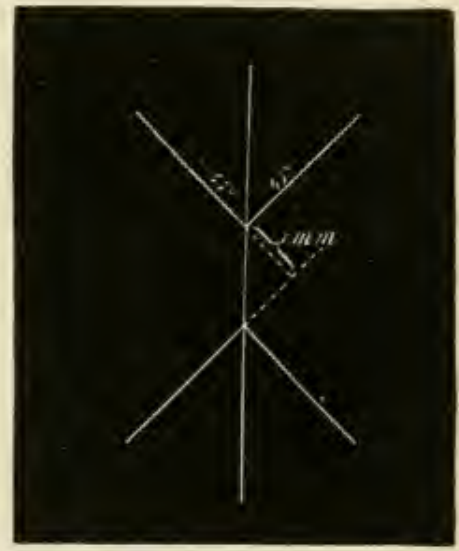

FIG. 186.

FIG. 185.-Schema showing the relations of the planes of the semicircular canals of the pigeon to each other, after J. R. Ewald. The open skull is seen from behind. The anterior canal lies in the plane $A$, the posterior in the plane $P$, and the external in the plane $E$.

FIg. 186.-Schema showing the distance of the planes of the anterior and posterior canals (prolonged) from each other.

project before entering the slimy material. A small solid body, the so-called otolith, rests upon the hairs in each of the maculie acustice. All vertebrates from the bony fishes up, with the exception of the mammals, have three otolith organs on each side (one in each of the three parts: utriculus, sacculus and lagena); the mammals have but two, since in them the lagena is absent, having been developed into the auditory cochlea.

These three (or two) otolith organs bear to each other the same spatial relations as the semicircular canals, the macula utriculi lying in the plane of the external canal, the macula sacculi in the plane of the anterior, and the axis of the lagena (where such can be made out) in the plane of the posterior canal.

It was long supposed that the semicircular canals and the ear sacs were called into play in the perception of noises-i.e., of sounds not produced by regular periodie vibrations-while the musieal tones exeited the nerrous end 
organs of the cochlea. Conclusive proofs for this apportionment of the acoustic stimuli to two kinds of terminal auditory apparatus, however, were not fortheoming. Instead, it has been shown by numerous experiments that the semicireular canals and the saes play a very important part in the mediation of our sensations of position, orientation, and the like.

\section{B. EXPERIMENTAL SUPPRESSION OF THE SEMICIRCULAR CANALS}

In 1828 Flourens published a paper on the phenomena which follow destruction of the semicircular canals of the pigeon. After transection of a canal he observed peculiar pendulumlitie movements of the head in the plane of the canal transected. Thus, if the horizontal canal were the one operated on, the head was rotated incessantly to and fro in the horizontal plane. These morements ceased after a time: but if the corresponding canal of the other side were sectioned, the morements began again with still greater intensity. They came on smldenly, if the animal was disturbed in any way. The pigeons could no longer fly and could only take food with dithiculty. The more extensive the destruction of the canals, the more intense were the disturbances produced, and the animals continued to exhibit such disturbances for years.

Goltz performed a great service for this line of investigation when he observed that the result of the operation can be described primarily as a disturbance in the ability of the animal to keep its body in equilibrium. He

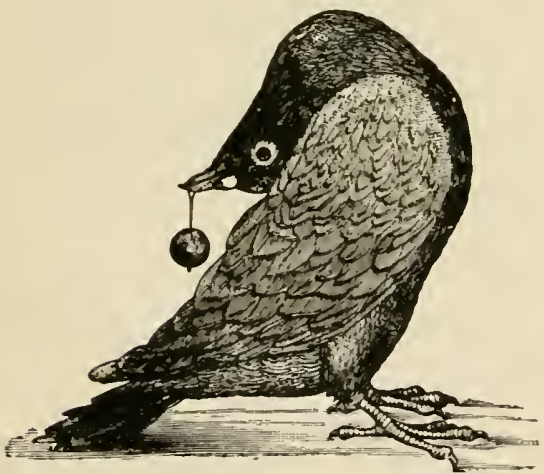

FIG. 187 .

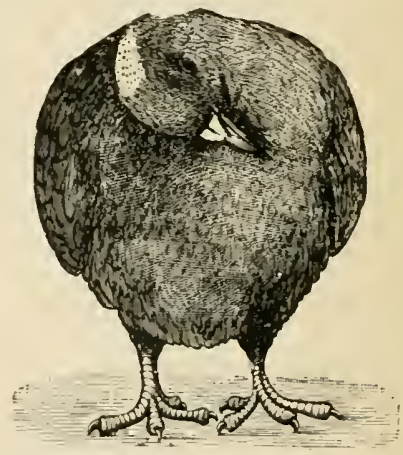

FIG. 188

Fig. 187.-Pigeon with both membranous labyrinths removed, after J. R. Ewald.

Fig. 188.-Pigeon five days after removal of the right membranous labyrinth, after J. R. Ewald. The head is inclined toward the operated side.

also laid stress on the ilea that since this disturbance persists for several years after the operation, it must be regarded not as a symptom of irritation. but as a synptom of some deficiency eaused by elimination of the semicircular canals. This, moreover, is confirmed by painting the canals with cocaine, exactly the same phenomena being produced as by section (Ch. Knenig. Gaglio). Goltz conchuled that the semicircular canals constitute a peripheral sense organ, which supplements the visual and motor senses in 
the perception of the position of the head and thus indirectly in perceiving the position of the whole body.

After removal of the entire membranous labyrinth from both sides the pigeon on casual examination exhibits no particularly prominent symptoms for some months after the operation. But on closer investigation one finds that all the muscles are abnormally atonic, that the animals have a certain disinclination to nove, that they cannot fly, and finally that their ability to recognize the position of their bodies is diminished.

The muscular weakness oceasioned by the operation is demonstrated by the following experiment. A small lead ball weighing $20 \mathrm{~g}$. is suspended on a thread and the thread is fastened by means of modeler's wax to the beak of a pigeon whose labyrinths have been

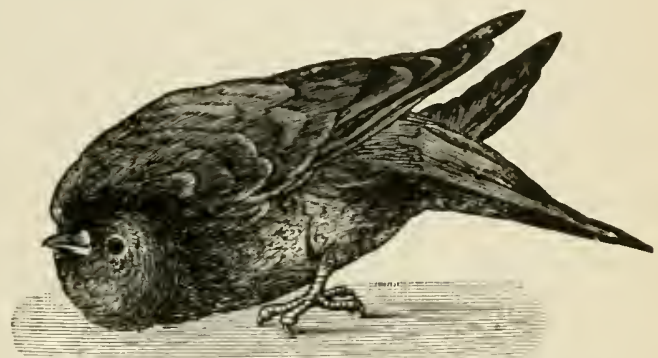

Fig. 189.- Pigeon twenty days after removal of the right membranous labyrinth, after J. R. Fwald. The head has been turned once around to the right.

removed. If the ball hangs in front, it draws the head far clownward, but the relatively strong museles of the baek of the neek are able to lift it and to dangle it about. The head follows the pendulumlike movements of the ball apparently without eoneem but in reality quite powerlessly until at last in the course of its swinging the weight is thrown around over the back. Immediately this happens the head is held by the ball in the position shown in Fig. 187. The muscles which otherwise would lift the head from this position are too weak to do so now that the labyrinths are wanting.

The following experiment shows how the sensations of position are affected. A pigeon deprived of its labyrinth is blindfolded by drawing a leather eap over its head. Because of the museular weakness the head falls down over the back and the museular sensation fails to apprise the nerve centers of the faet. Since the visual impulses do not now compensate for this defieieney, the animal no longer has any correet notion of the attitude of its head, and will allow it to remain in this muatural position.

After removal of the labyrinth on one side only the disturbances are less severe, so that the animals can still fly and ean take fond without difticulty. But they are not by any means normal, for the peculiar rotations of the head first described by Flourens, and which cease after bilateral extirpation, at times nuke their appearance.

I) uring the first days following the operation the pigeon begins to ineline its head toward the operated side. The turning inereases more and more as time goes on, and finally may amount to complete rotation (Figs. 185 and 189). The explanation is, that by remoring one labyrinth, say the right, the muscles which normally prevent the head from falling to the right are greatly weakened.

There is a decline in the functional pouer of other muscles after extirpation of one labyrinth. Aecording to Ewald each labyrinth is connected by way of the central nervous system with all the roluntary museles of the body, 
but more directly with those of the opposite side and in particular with those which more the head and vertebral column. Accordingly the muscles of either side would be roused to activity in any given casc chiefly by the opposite labyrinth. In agreement with this is the fact that if one labyrinth be left intact and the other be suppressed, rigor appears sooner after the death of the animal on the side opposite the normal labyrinth.

In other species of animals extirpation of one labyrinth produces somewhat different results. In the rabbit rolling of the entire body around its longitudinal axis sets in soon after the operation. This is caused by extension of the legs on the opposite side, and by the consequent rotation of the animal toward the operated side until it comes to lie on its back. The animal tries to regain its. feet, but as soon as it succeeds, begins once more to roll over. The legs of the operated side are entirely passive all the while. After bilateral extirpation in the dog, the animal exhibits a certain unsteadiness in his gait. When he jumps down from a table, he falls sprawling on the floor. Some difficulty in chewing and in swallowing may also be observed. All of which symptoms point to a reduction of muscular strength and of the ability to properly control the muscles.

The disturbances arising from bilateral extirpation of the labyrinths gradually disappear again. This occurs in all likelihood mainly because the animal gradually becomes accustomed to regulating his movements without the help of the afferent impulses from the semicircular canals.

The cerebrum appears to play the most important part in this regulation. With pigeons from which the cerebrum was removed, unilateral extirpation evoked the usual complex of symptoms, but some of them, especially the rotation of the head, were no longer compensated. After the symptoms accompanying bilateral extirpation in the dog had been improved as much as possible, J. R. Ewald removed the surface of the cortex from the motor zone of both sides. The dog exhibited disturbances of coördination of the profoundest kind. $\mathrm{He}$ could no longer jump or run or walk or even stand; in fact he could not lie on his belly. He lay rather on one side or the other, and despite his most vigorous efforts was unable to raise himself with his legs. The head, however, was used to more purpose. Gradually these disorders improved, but they immediately returned and in exactly the same fashion, as directly after the operation, when the animal was taken into a room which was suddenly darkened. The dog showed therefore that after exclusion of the impulses mediated through the labyrinths and through the so-called motor zone of the cortex, he had been thrown back upon his eyes for the regulation of his movements. Since now no such disturbances result from destruction of the cortex alone, even when the visual sensations also are excluded, it follows that after extirpation of the labyrinth the cerebral cortex takes upon itself the business of replacing the missing afferent impulses as far as possible. Then when the cerebral cortex also is destroyed, a compensation can once more be effected through the eyes, but this fails on exclusion of the visual sensations.

The disturbances which appear on suppression of the labyrinth are therefore, (1) a reduction of muscular strength, and (2) derangements in the coördination of movements, which to all appearances are due to the loss of afferent impulscs. 


\section{ARTIFICIAL STIMULATION OF THE SEMICIRCULAR CANALS}

Breuer (1874) made the first experiments of this kind and they were extended later by Ewald. In the following discussion we shall follow in the main Ewald's results.

The anatomical structure of the semicircular eanals, as Breuer and Mach have pointed out, make it highly probable that the specific stimulus for the nervous end organs in the ampullæ consists of currents in the endolymph.

When a ring-shaped tube containing a fluid is rotated in the plane of its curvature the fluid remains for a time at rest on account of its inertia-i.e., a current is set up in the opposite direction relative to the walls of the tube, until the fluid has had time to acquire the speed of the tube. Such a current must result as often as a change in the speed or direction of rotation takes place. The same phenomena evidently must occur in the semicircular canals with every rotation of the hearl. But the effect in the different canals will depend upon their position with reference to the axis of rotation. Rotation about the vertical axis acts almost exclusively on the two external canals. If the head is turned to the right there arises in the external eanal of the right side a current directed toward the end of the canal containing the ampulla, in that of the left side a current away from the ampulla. And thus there is in the different pairs of semicircular canals a current of a certain strength in a certain direction corresponding to every turn of the head. The sensory hairs of the maculæ are moved by these currents and in this way the corresponding nerve endings are excited.

These conclusions are capable of experimental proof by producing movements of the endolymph in a given direction. For this purpose Ewald opened a bony semicireular eanal at two points. Into the opening farther from the ampulla he introduced a plug so that the movement of fluid in that direction was prevented. He adjusted to the other opening a small apparatus by means of which he could exert pressure on the naked membranous canal. Since the fluid could not move away from the ampulla, when pressure was applied a current of endolymph was naturally producel toward the ampulla. With every stimulus of pressure the animal (pigeon) invariably moved its head and eves in the direction of the current and exactly in the plane of the canal stimulated. When the pressure was not released the animal brought its head back after a time to the starting point. If now the pressure was released and thus a current in the opposite direction was produced, the head and eyes were again turned, but this time in the opposite direction-i. e.. always in the direction of the current of endolymph and in the plane of the canal stimulated.

Proof that the currents of endolymph give the normal stimulus to the semicireular canals is furnished also by rotation experiments. To prevent complications with the sense of sight the animal must be blindfolded. If a pigeon be placed in a rotation apparatus in such a way that it is rotated to the right about a vertical axis. it turns its head in the horizontal direction to the left, that is, in the same direction as the current produced by the inertia of the endolymph. When the head has heen turned a certain distance to the left, it moves a certain distance to the right toward the median position, then is again rotated to the left. and so on. In this way the head swings incessantly to 
and fro and the eyes also take part in the movements. Now it is a probability supported by many facts that the first phase of the morement represents a reaction of the animal to the rotation; the second phase is proluced. because after the head has been carried far enough from the median position the afferent impulses from the joints, muscles. etc., are strong enough to arouse the opposite sets of muscles.

When the two external canals are plugged up so as to prevent movements of the fluid, the reaction to rotation in the horizontal plane is almost entirely wanting. On the other hand, one can destroy any number of the anterior and posterior semicircular canals without changing the reaction.

The characteristic eye movements occur also when mammals are rotated; they are wanting after section of the eighth cranial nerve or of the semicircular canals.

From these facts we may conclude that the scmicircular canals are influenced by morements of the head. and in all probability the immediate stimulus is caused by currents set up in the endolymph; this means that the sensory hairs of the corresponding crista acustica are put on the stretch and the appropriate end organs are consequently excited. These in their turn produce reflex responses by which the position of the head and of the eves is regulater.

The movements of the eves and of the head which have been seen to take place when the animal is rotated may appear after extirpation of the labyrinths when the eyes of the animal are open. At the beginning of rotation the animal experiences a displacement of the retinal picture, and seeks to resist that displacement by striving to hold the object steadily in view.

The subsequent motion of the head in the direction of the rotation is pure reflex, probably discharged by the excitation of the retina due to the displacement of the image or by impulses coming from the neck and ere muscles.

The effects of extirpation of the semicircular canals which have been summarized under $\mathrm{B}$ can be brought into line with these results without serious difficulty. Suppose a normal animal moves his head, say, to the right. The movement produces in both external semicircular canals currents in the endolymph in the opposite direction, and these in turn reflexly induce a rotation of the head in the direction of the current-i.e., in the direction reverse to the original rotation of the head. If the two external canals are now thrown out of function, either by being plugged or by being sectioned, the currents are not set up and consequently the muscular morements caused by them do not take place. But the head may swing to one side. If so, it will continue until the motor sensations from the joints, etc., discharge compensating morements. This mode of discharge, however, is not so finely graded, for the animal has lost the power of telling when the head has been returned to normal position: consequently it is difficult for the animal to regain its equilibrium after that has once been disturbed. When sereral canals are suppressed at the same time the swinging motions of the head become still more extensive.

The laxness of the muscles which has been observed affects most the muscles of greatest precision-e.g., the extrinsic muscles of the exes-and is probably due to the absence of impulses normally roused by the labyrinth (Jensen). 


\section{THE OTOLITH SACS}

It will be readily understood that a movement in a straight line will not produce any current in the semicircular canals, for the reason that the influence of inertia in the two halves of each canal will be found to be equal and in opposite directions. But, as Breuer has observed, it appcars that the otolith apparatus may be stimulated under these circumstances. The impression which the otolith will make at any time will depend on the position with reference to the direction of gravity, of the surface between the otolith and the subjacent epithelium, and will vary, therefore, with the position of the head with reference to the line of gravity. On account of the varying position of the different macula, the impressions from the different otoliths for any given position of the head will also be different. Hence, every position of the head would be accompanied by a definite combination of impressions discharged by the otoliths, and hence the otolith sacs would constitute an organ for the perception of the position of the head with reference to a plumb line.

Again, if we suppose, as Breuer has sought to show, that each otolith has a definite "groove," so to speak, in which it may exert the pressure liue to its inertia, we should have an arrangement by which translocation movements in any straight line could be pereeived.

Several observations on fishes have been cited in support of this function of the otolith saes, their purport being that when the sacs are injured or destroyed the orientation of the animal with reference to gravity is practically lost.

\section{E. OBSERVATIONS ON MEN}

The rotation experiments constitute a no less raluable means of studying the inflnenee of the semicireular eanals in man. When a man with normal ears is rotated about the rertical axis in an apparatus suitable for the purpose, the eyes are moved first slowly in the opposite direction, then quickly in the same direction as the rotation. This reaction appears to be perfectly constant in healthy individuals, but is often (fifty per cent of the cases ${ }^{1}$ ) wanting in the leaf and dumb (Kreidl).

Kreidl asserts furthermore that these same deaf-and-dumb persons who failed to gire the eye reaction. did not suffer from dizziness when the rotation ceased, as the normal persons do. and similarly. we find in James the statement that out of 519 deaf-and-dumb persons only 199 suffered from dizziness as the result of rotation.

The explanation which Breuer has advanced with referenee to the funetion of the otolith sacs in animals, namely, that they make the animal aware of its position with reference to the line of gravity, appears to apply also to man. Certain positions of the eves are unquestionably dependent upon the position of the head with reference to the line of gravity. Thus, for example, in the blind the bending of the head forward is acempanied br an eleration of the plane of vision with reference to the head, and bending the head backward by a corresponding lowering of the plane of vision (Breuer). In persons with unrmal eves these morements do not oceur. But we meet with

${ }^{1}$ Mygind has ascertained that in Copenhagen about fifty-six per cent of the deaf and dumb have the semicircular canals affeeted. 
a wheel-like rotation of the eye about its axis when the head is bent to one side or the other. This is not caused by the nerves which conver muscular sensations, for the same rotation appears when the whole body is inclined one way or the other withont bending the head or neek. When, for example, a person lying horizontally on his back turns his head to the right his eves turn to the left, while with the same rotation of the head in a standing position no rotation of the eres takes place. Such phenomena appear. therefore, to depend upon the changed position of the head with reference to the line of gravity. Since they are very different in character from those aroused from the semicircular canals, we should probably not go far astray in assuming that they are mediated by the otolith sacs, that is, that the latter furnish impressions which inform us of the direction of the line of gravity.

These impressions do not figure prominently except under eircumstances which exclude the ordinary visual, motor and tactual impressions, as for example in diving. It is said that many deaf-and-dumb persons lose all sense of direction when the body is submerged (James), also that such persons have great difficulty in standing on one leg, and when the eyes are elosed find it quite impossible. We may suppose that in these persons the otolith sacs have undergone pathologieal changes.

The dizziness produced by sending an electric current transversely through the head is also thought to be due to stimulation of the labyrinth. When the current is elosed the person feels as if the head and entire body were inclined toward the eathode; when it is opened one has the sensation of falling toward the anode.

From the observations and experiments here presented it appears quite probable that the labyrinth is a peripheral organ which reflexly regulates various finely graduated morements especially of the eves and of the head, and in general is of considerable importance for the tonus and functional capacity of the sheletal muscles. If the conclusion is eorreet that eonscious impressions as to the position of the head and orientation of the body are obtained from the labyrinth, it ought to be regarded also as an actual sense organ analogous to the organs of the motor sensations. That these impressions are usually indistinet says nothing against their oceurrence. for superficially considered, the sensations aroused through the nerves of the tendons, joints and muscles, in spite of their demonstrably great importance, appear to us much less vividly than the sensations which proceed from sense organs stimulated by external agencies.

Refrerexces.-St. von Stein, "Die Lehre von den Funktionen der einzelnen Teile des Ohrlabyrinthes," Jena, 1894.-J. R. Ewald, "Physiologisehe Untersuehungen über das Endorgan des Nervus octavus." Wiesbaden, 1892.-J. Breuer, Wiener Sitzungsber., November, 1903. 


\section{CHAPTER NIX}

\section{TASTE AND SMELL}

Br means of the sense of taste we learn something of the solid and fluid substances taken into the mouth, and by means of the sense of smell something of the nature of the atmosphere entering the nasal carities. The two senses very often work together, and many impressions which we ordinarily describe as sensations of taste, have, as a matter of fact, nothing whatever to do with the sense of taste, being mediated solely by the organs of smell.

\section{SENSATIONS OF TASTE}

Ordinarily only the upper suritce of the tongue is described as the peripheral organ of taste. But this appears to be incorrect, for according to different author: the under surface of the tip of the tongue. the soft and hard palate, the anterior pillars of the fances, the tomsils. urula. posterior wall of the pharyx, mosterior side of the epiglottis and of the larmix, as well as the mucous membrane of the check- mediate sensations of taste. Howerer. this is true only of children; in adults the mucous membrane of the check:- the urula, tonsils and middle of the tongue no longer react to sapid substances: in exceptional cases the anterior pillars of the fauces and the mnder surface of the tip of the tongue. loth sides of the frenum. continue to be percipient. Aceording to Hänig the central zone

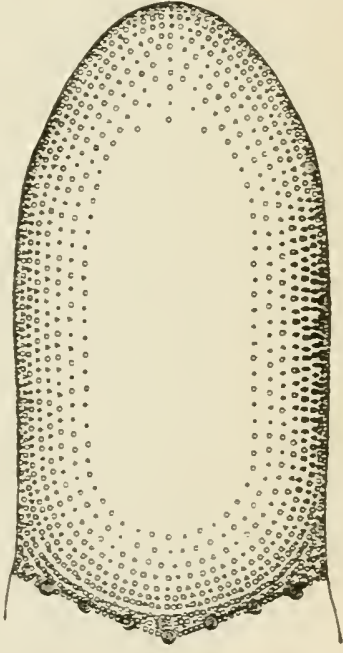

Fig. 190.-The taste zone on the upper surface of the tongue, after Hänig. of the tonsue which is not percipient is surrounded on all sicle by a " taste girdle" within which the sensitiveness decreases mole and more from the edge toward the middle line (cf. Fig. 190). where the sensitivity of the different portions is schematically represented hy the number of black spots).

The cul organs of the gustatory nerres are the taste buds or taste goblets discorered by Lovén and Schwalbe. They are oroid bodies, $0.0 \mathrm{~mm}$. Inng and $0.04 \mathrm{~mm}$. thick, which lie imbedded in the epithelium of the mucous membrane. They consist in part of outer, sustentacular or tegumental eells and in part of imner taste cells which represent the true neuroepithelium comnected in one way or another with the gustatnry nerve fibers. In order to stimulate these taste cells the sapid substance must come into actual contact with them, and this is made possible by the presence of a small taste pore at the top of the taste bud, into which the attenuated ends of the taste cells project. 
Because of the anatomical structure of the taste organ the entrance of the sapid substances in sufficient quantity to arouse gustatory sensations is rendered difficult, especially if the tongue is covered by a thick layer of mucus.

The taste buds are found ehiefly in the circumvallate papillse and in the sides of the foliate papillie, but occur also in the fungiform papille, and are scattered here and there orer the various parts of the mucous membrane of the mouth and throat endowed with the sense of taste.

The tougue possesses also nerres of touch, heat nerves, and cold nerves. What nerves supply gustatory fibers to the tongue can of course only be answered by observations on men in whom the afferent nerves from the tongue have been paralyzed in some way. It appears from such observations summarized by Cas-

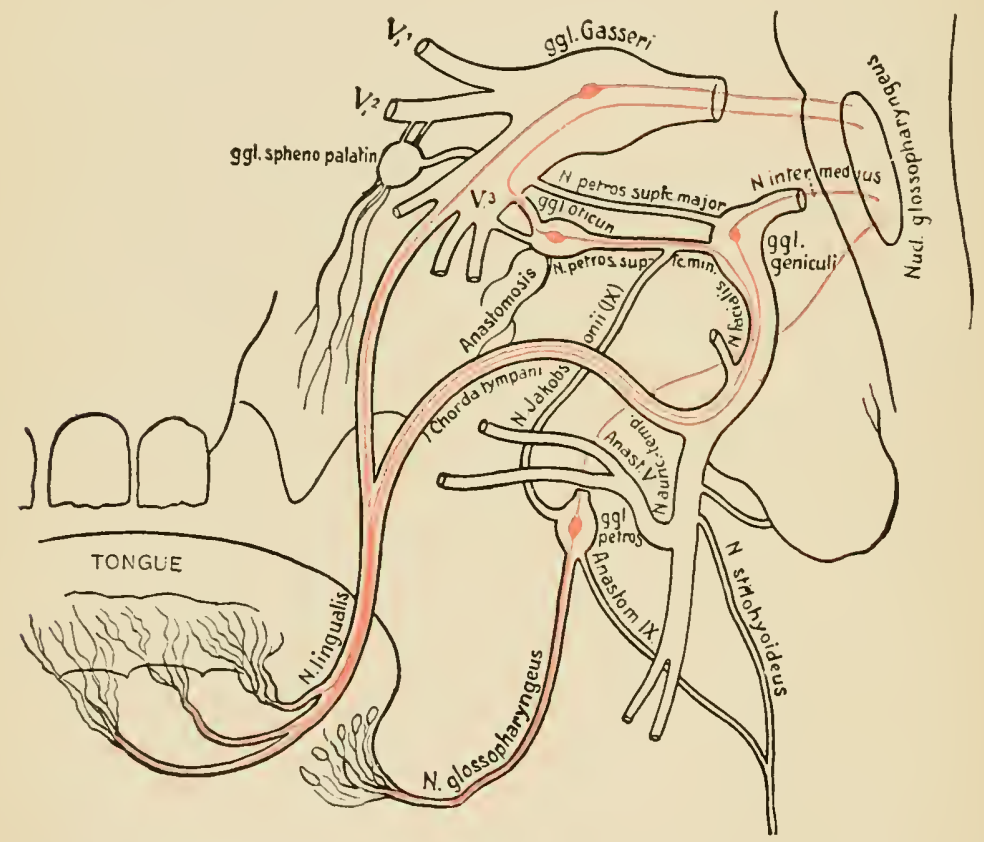

FIG. 191.-Course of the facial nerve and its communications with the trigeminal and glossopharyngeal nerves. The chief gustatory fibers are indicated in red, after Leube.

sirer that in by far the greater number of cases the gustatory fibers for the posterior part of the tongue traverse the glossopharyngeal, those for the anterior part the basal trigeminal nerve (Fig. 191). In certain cases it appears, however, that the glosiopharyngeal represents the gustatory nerve of the whole tongue, while in others it may happen that all the gustatory fibers traverse the trigeminal.

Only four qualitatively different kinds of sensation are mediated by the sense of taste: namely. sweet, acid, bitter and salt, to which alkaline and metallic are added by some authors.

These six qualities howerer cannot be regarded as pure taste qualities, for all of our gustator impressions are accompanied by tactile sensations (Kiesow). 
It is impossible to classify the gustatory impressions any further. For example, if we use solutions of $\mathrm{HCl}$. $\mathrm{HNO}_{3} \mathrm{H}_{2} \mathrm{SO}_{4}$, acetic, tartaric and oxalic acids of such strength as to produce sensations of the same intensity, they all taste alike. The same is true of bitter substances like strychnin, quinin, morphin and picric acid, and of sweet substances such as milk sugar, grape sugar, cane sugar. On the base of the tongue we can distinguish all the taste qualities, but on the tip there are considerable differences in this respect in different individuals. r. Vintschgau recognizes four groups of individuals: (1) those who distinguish with the tip of the tongue all the four qualities; (2) those who distinguish sweet, salt and acid readily, but bitter less easily; (3) those who distinguish none of the qualitics easily; (4) those who have no sense of taste at all on the tip of the tongue.

Moreover, the same substance placed on different parts of the tongue may have a different taste. Thus according to Howell and Castle brom-saccharin tastes bitter on the base of the tongue, but sweet on the tip. Shore found that a five-per-cent solution of $\mathrm{MgSO}_{4}$ has a faintly sweetish taste on the tip of the tongue followed by an acid taste, an acid and bitter taste on the edge and a pure bitter taste on the base.

By means of cocaine the sensibility of the tongue to gustatory stimuli can be considerably reduced. But the effect is different for the different taste qualities. A five-per-cent solution of cocaine acts most markedly on the sense of bitter, then on sweet and acid, while it is entirely without effect on salt (Shore, Kiesow). The faintly toxic substance eucain has approximately the same effect. Gymnemic acid obtained from Gymnema sylvestre placed on the tongue in a sufficiently concentrated form obliterates every trace of sensitiveness for sweet (Edgeworth); it acts secondarily on bitter and to a much less degree on salt and acid (Shore, Kiesow).

It is rery probable, from such observations as those just mentioned, that the different taste qualities are mediated by different nerves, just as in the case with the different qualities of the temperature sense. This inference has been directly confirmed by Ohrwall.

By means of a very fine brush he placed solutions of sugar, quinin and tartaric acid on different fungiform papillæ, and found that out of 125 such papillæ on the anterior part of the tongue 27 ( 21.6 per cent) did not react to either of these substances. Of the remaining 98,12 reacted only to tartaric acid, 3 only to sugar. 12 only to tartaric acid and sugar, $f$ only to quinin and tartaric acid, 4 only to sugar and quinin. No definite results were obtained with reference to the sensitivity of different papillæ for salt. Kiesow has reached similar conclusions.

Hoeber and Kiesow have discussed the significance of electrolytes as gustatory excitants, and have reached the conclusion that the specific sensations are aroused in part by ions. For example, the salty taste of $\mathrm{KCl} \mathrm{NaCl} . \mathrm{MgCl}_{2}$, $\mathrm{NaBr}, \mathrm{NaI}, \mathrm{Na}_{2} \mathrm{SO}$, is caused by the electronegative ions (Cl, Br. etc.); the threshold stimulus is given by a concentration of $0.020-0.025 \mathrm{~g}$. of the ion per liter; a swect taste produced by a very weak solution is caused by the $\mathrm{OH}$-ions, the threshold value of the stimulus being giren by $0.006-0.009 \mathrm{~g}$. ions per liter.

The acid taste produeed by the anode of a constant current is probably due to electrolytic dissociation of the saliva. 


\section{\$. SENSATIONS OF SMELL}

While the olfactory organ of man is particularly sensitive to certain odors, it in general is much less sensitive than that of many other mammals. The organ of smell is, in fact, much more important for the whole life of the lower animals. beeause it is mainly by this sense that they find and select their food. Among eivilized men this sense plays but a small part for such purposes, although it is stated that some so-ealled wild people are possessed of a rery highly developed sense of smell. Thus Humboldt relates that the Peruvian Indians ean follow the trail by seent with as much aceuracy as a hunting dog. Among civilized people the sense of smell serves to test the air inhaled or furnish information as to the nature of the food to be eaten. As a rule it is of no very great service eren in this respect for the olfactory sense very soon becomes blunted for a certain odor and then gives us no indication of the presence of harmful substances in the air. This is notalily true. for example, of those who live in close, poorly ventilated dwellings. The report made by the sense of smell as to the quality of the food is influenced largely by conventional eustoms, and these differ according to times and places. The olfactory sensations probably serve us most by arousing and promoting the desire for food.

It has long been known that only the uppermost part of the mueous membrane lining the nasal passages is provided with the olfactory epithelium. The investigations of $\mathrm{v}$. Brunn have shown that the region actually supplied with olfactory nerves extends over only a relatively small part of the superior turbinated bone and the opposite face of the nasal septum. The epithelium here covers an area somewhat smaller than a ten-cent piece each side of the olfactory cleft, situated, therefore, in the roof of the nasal earity as far removed as possible from the external nares.

Unless the act of inspiration is modified so as to earry the air directly to the upper part of the nose the air eurrent never goes higher than the anterior lower edge of the superior turbinated bone (Franke) and consequently does not pass over the olfactory region. Since, however, we experience olfactory sensations in ordinary respiration and since we have convineing evidence that the normal excitation of the olfactory organ takes place by means of material particles in the air (see below) we must suppose that the odoriferous particles reach the olfactory cleft $b y$ diffusion.

Since the nose is always in open communication with the throat, odoriferous substances can of course always pass thence into the nose and so reach the olfactory cleft. This is what happens when we eat. While a morsel of food is being masticated vapors pass into the nasopharynx and are then carried upward into the olfactory region by the expired air. In swallowing the nasal cavity is closed off from the throat but immediately afterwards communication is reestablished and the following expiration carries the vapor of substances moistening the wall of the pharynx into the nose. It is at this moment, but not so long as the fluid remains in the mouth, that one "tastes" the aroma or the bouquet of drinks.

It was thnught for a long time that the olfactory organ is stimulated by vibrations of the odorous substances, and that the organ of smell was, there- 
fore, analogous to the organ of hearing. The chief support of this view was that with certain strongly odorous sulstances no loss in weight could be detected with the balance, whereas, if it were true that the olfactory organ was excited hy material particles set free from them there should be such a loss. But Berthollet demonstrated that material particles are given off from odorous substances. He placed a piece of eamphor in a vacum of a barometer; the mereury of the barometer gridually fell, thus showing that small particles of camphor were given off, that they collected in the empty space and exerted presinre on the mercury.

Another proof which we owe to Tyndall is the following: Radiant heat passes through an absolutely empty space without being absorbed; if, however, a gas is placed in the path of the heat rass, a greater or less amount of heat, according to the nature of the gas. is held back by it. Now Tyndall showęd that an atmosphere which had been in eontaet with odorous substances and had taken up its rapor. absorbs radiant heat to a much greater extent than pure atmospherie air. Thus the vapor of patehouli absorbed thirty-two times as much as air, oil of rose thirtysix times, oil of anise three hundred and seventy-two times as much.

Odors are carried in a quiet atmosphere by diffusion. Of course air eurrents and the like also aid much in this distribution. The earrying power-i. e., the power of diffusion-varies with different odors.

Johannes Miiller and several other authors assumed that the particles of odoriferous substance were first dis-

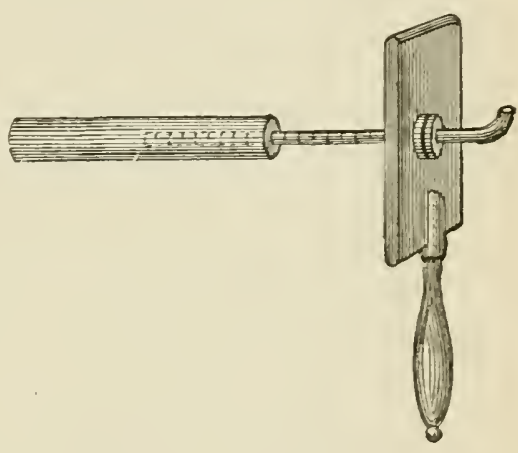

FIG. 192.-Olfactometer, after Zwaardemaker. solved in the mucus covering the olfactory region and then stimulated the olfactory epithelium. Since, however, very many odorous substanees are very slightly, if at all, soluble in water, Zwaardemaker has put forward the hypothesis that stimulation takes place hy direct contact of the gaseous molecules with the cilia of the olfactory cells. The fact that fishes-e.g., the dogfish-hare a well-developed sense of smell speaks pretty definitely in favor of Müller's riew.

Zwaardemaker has constructed a small apparatus, the olfactometer (Fig. 192). for the furpose of testing the aeuteness of the sense of smell. The essential parts of this apparatus are a paper eylinder and a tube through which one may inhale. The cevlinder, which can also be made of filter paper, is dipped in the secuted fluid, and when its pores are filled with this, it is withdrawn, dried out and hastily blown through. The smelling tube, which fits exactly into the tubulure of the eylinder, is then inserted and the other end placed in the nasal opening. The small woolen shield serves to keep the odor out of the other nasal opening.

When air is inhaled through the tube from the eylinder impregnated with the odorous substanee the number of ndoriferous partieles reaching the nose will vary inversely as the lepth to which the smelling tube is inserted into the cylinder. By graduating the tube, cne ean thus make very rapid and very exact 
relative determinations as to the acuteness of the olfactory sense in different individuals.

The following data by Passy give some idea of the quantitative capacity of this sense in man. All the sources of error involved tend to make the results rather too high than too low:

Mg. per liter of aiz.

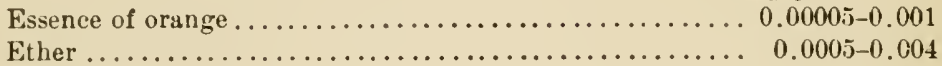

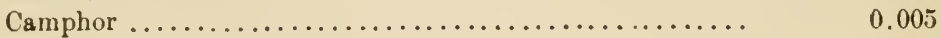

The smallest value thus far published for the threshold value of the sense of smell is that of Fischer and Penzoldt. They observed that $0.01 \mathrm{mg}$. of mereaptan uniformly distributed through an air-tight room of 230 cubic meters capacity still gave a faint but distinet odor. This would be only $0.00000004 \mathrm{mg}$. of mereaptan per l. of air.

Attempts have often been made to find a natural classification of the odors, and it cannot be denied that recent efforts in this direction as well as the observations of Hayeraft on the relation between the chemical eonstitution and the odor of various substances give promise that we shall some day have a real classification. For the present I shall only remark that many raporous or gaseous substances act to a greater or less extent upon the organs of taste connected with the trigeninal nerve so that the resulting sensation is in large part at least the result of a gustatory excitation. This is true of all the socalled pungent substances like chlorin, iodin. bromin, nitrie acid, acetic acid, ammonia, oil of mustard, ete. Aceording to Zwaardemaker structures are found in the olfactory region which resemble the taste buds and which mediate the sweet odor of chloroform. According to Nagel we have to do in this case with a stimulation of gustatory nerves on the posterior side of the urula.

Although we cannot yet erect a natural system of odors we can say definitely that different kinds of olfactory sensations, to a eertain degree at least, are mediated by different nerves. Certain individuals who possess a welldeveloped sense of smell for some substances are unable to pereeive the odor of others. For example, there are people who cannot smell ranilla and ret are sensitive enough to other odors. The same is true of the odor of violets. We must suppose that in these people certain nerve fibers or end organs are wanting.

The presence of different olfactory nerves is more definitely proved by the phenomena of fatigue of the olfactory organ. For example, Aronsohn has shown that when this organ beeomes fatigued for one odor it still remains entirely functional for others. Again, when the sense of smell is temporarily lost as the result of injury to the olfactory organ, it is not recovered for all odorous qualities within the same time-e.g., in one case, for creosote three days, skatol and mereaptan four days, musk serenteen days, roast beef two months, ete. (Rollet).

Referexces.-F. Kiesow, "Geschmackssinn," "Wundt's Philosophische Studien," vols. x, xii, 1894, 1896.-Hj. Öhrwall, "Geschmackssinn," Shandinavisches Arch. für Physiologie, vol. ii, 1897.-H. Zwaardemaker, "Die Physiologie des Geruches," Leipzie, 1895. 
CHAPTER XI

HEARING, VOICE AND SPEECH

\section{FIRST SECTION}

\section{AUDITORY SENSATIONS}

\section{§ 1. STIMULI APPROPRIATE FOR THE ORGAN OF HEARING}

TuE organ of bearing is stimulated by the vibrations of elastic hodies which we perceive as sound. Helmholtz, whose presentation of the subject ${ }^{1}$ we shall follow here in the main, divides auditory sensations into two groups: namely, noises and musical tones.

A musical tone is produced by regular periodic movements of the sounding body, which are communicated by it to the air or some other elastic metlium. By a regular periodic movement we mean a movement which is repeated at exactly the same interval of time. and always exactly in the same manner. The length of the interval from the beginning of one movement to the next repetition of it is ealled the wave length or the period.

As a rule. the vibrations are conveyed to the ear through the air. The particles of air must therefore execute regular periodic vibrations. moving to and fro within narrow limits so that the air is alternately condensed and rarefied (wave crest and wave trough). Sound is propagated in the form of concentric spherical waves. new particles of air in all directions from the sounding body being successively set in motion. timbre.

Three qualities of sound are to be distinguished: loulness, pitch and

\section{A. LOUDNESS}

The loudness of a sound depends upon the amplitude of the ribrations. The greater the excursions which, for example, a ribrating piano string describes, the louder is the sound at a given distance from its source. The greater the distance from the sonrce. the weaker is the sound. the loudness being inversely as the square of the distance.

\section{B. PITCH}

Pitch is determined by the vibration frequency, or in other words by the number of vibrations per second, and is independent of the form of the vibraMusik."

1 "Lehre von den Tonempfindungen als physiologische Grundlage für die Theorle der 
tion during the period. The more frequent the vibrations in a unit of timei. e., the shorter the period-the higher is the tone.

For an exposition of the fundamental facts of this subject it is very convenient to have a speeial apparatus, like the siren (Fig. 193), which permits an easy determination of the number of atmospheric vibrations producing different tones.

$A$ is a thin disk of pasteboard or metal which is provided with holes in several concentrie rows and at equal distanees from each other in the same row. It ean be set in rapid rotation by means of the string $f$ which runs over the pulley $b$. By means of the tube $c$ a blast of air of proper strength is direeted toward one of the rows of holes. Each hole therefore as it passes the mouth of the tube lets out a single puff of air and thus when the disk is rotated rapidly enough a tone is produced whose piteh depends upon the number of holes

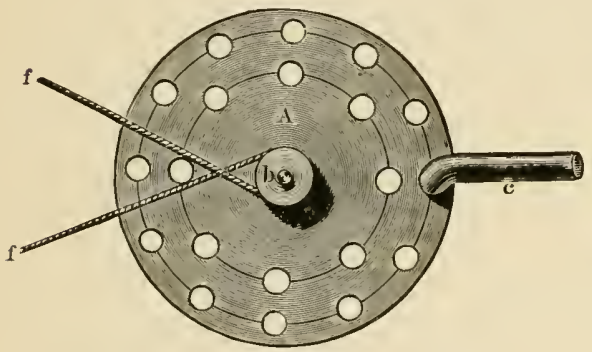

Fig. 193.-Seebeck's siren. blown through in a second of time. This number can be found by counting the rotations.

Now experiment has shown that pitch is entirely independent of the size of the holes or the strength of the blast and thus it is proved that pitel depends only on the number of vibrations.

The nearer the row of holes to the center of the disk-i.e., the smaller the number blown through in a single rotation - the lower will be the tone, the rate of rotation remaining the same. If one row with 8 and another with 16 be employed the tone produced by the latter is the octave of that produced by the former-i. e., the tone which constitutes the higher octave of the other contains within a given time exactly twice as many vibrations as the other, and the ratio of the two is as $1: 2$.

In the same way the following ratios have been found to obtain between the number of vibrations of the different tones used in music: $1: 2=$ octave; $2: 3=$ a fifth $; 3: 4=$ a fourth; $4: 5=$ major third $; 5: 6=$ minor third; $5: 8=$ minor sixth $; 3: 5=$ major sixth. These are all consonant intervals -i.e., in the octave every second vibration of the upper note begins at the same time with one of the lower; in the fifth, every third; in the fourth, every fourth, etc.

There is an upper and a lower limit to the frequency of periodic vibrations capable of exciting the auditory organ.

The smallest number per second which ean be heard by the human ear is given by Preyer as 15-24, by Helmholtz as 28 , by Bezold using highly improved experimental methods as 11; but sounds only begin to acquire a definite musical pitch at about 40 vibrations per second. The highest number which can be heard as a distinet sound according to Edelmann is in the neighborhood of 50,000. The whole range of pereeptible sounds $(11-50,000)$ amounts therefore in the most favorable case to over 12 octaves. In music only about 7 octaves $(40-4,700$ vibrations) are used. 


\section{TIMBRE}

If the same tone be struck successively on different instruments, as the violin, piano, clarinet. flute, etc., even a musically untrained ear can readily distinguish the instruments. This property of a musical tone which differs with the instrument producing it is described as the timbre or quality. It is this property also by which we distinguish human voices.

Inasmuch as the eanse of timbre cannot lie in the frequency nor the amplitude of the ribrations, it must be referred to dissimilarities in their form. 'To a certain extent also it is due to the way in which the tone is struck.

How is this difference in form of the vibration to be explainer? When a piano string is set in vibration the pitch of the tone produced depends upon two things: the length of the part vibrating, and the tension of the string. The tension remaining the same, the longer the vibrating part the deeper the pitch. If the operator tonch the middle of a string lightly with his finger and then cause it to vibrate, each half will vibrate independently and so twice as many vibrations per second are made as by the whole string. The tone produced is therefore the octave of the tone given by the whole string. In the same way a string can be caused to vibrate in thirds and fourths, etc., and the number of vibrations of the corresponding tone will then be three, four, etc.. times as high as that of the whole string.

Now whenever the string vibrates as a whole, it divides itself spontaneously into two, three, four, five, ete., vibrating parts. Hence, it gives in addition to its fundamental tone other tones whose viliration frequeneies are two, three, ete, times as great as the fundamental, all of them fused into the peculiar sound of that particular string. The tones produced by the partial vibrations of the string are called the overtones or partial tones, and when the ribration frequency of the orertones is a multiple of that of the fundamental, they are called harmonious orertones. The harmonious overtones for $c$ are given in the following example:

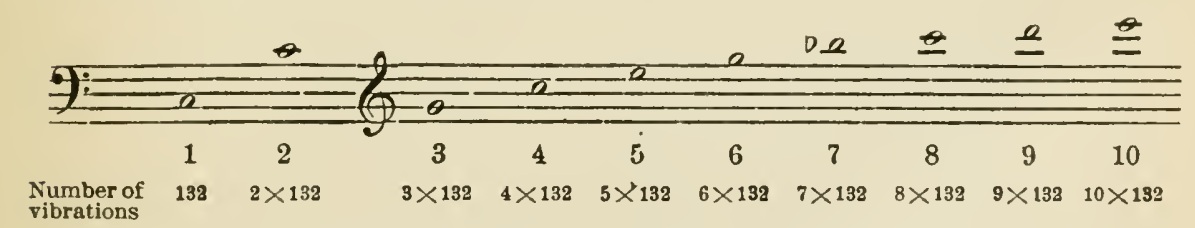

What has been said of the piano string is true for musical instruments in general, inclusive of the human voice. But there are sounds which are fairly free of overtones and so consist of a simple tone only-as, e. g.. the proper sound of a tuning fork. Such tones are unusually soft, and free from sharpness or roughness. Comparing the timbre of a simple trome with that of a compound tone, including its lower harmonious overtones, the latter is found to be fuller sounding, more metallic and brighter than the simple tone.

Since by far the greater number of tones are somponnd it is evident that any variation in the number or intensity of the overtones will produce some difference in the character of the tone; hence we may point to differences 
in the accompanying orertones as very probably the cause of difference in timbre.

There remains for us yet to consider how it is posible for the ear to perceive the differenees in the form of ribration calsed by the overtones.

The effect of overtones in altering the form of vibration may be represented diagrammatically as in Fig. 194. $a^{\prime} a^{\prime}$ is the base line of reference, the dotted lines $a, b$, and $c$ represent the ribrations of a fundamental tone ( $a$ ) and its first two orertones: the solid line $d$ is the resulting vilbration produced by interference of the three. It is evident that notwithstanding the change in form of the vibration the period of the fundamental tone remains unchanged.

But if these partial tones are not to he regarded as mere mathematical fictions, if they have a real existence, they should produce some mechanical effect which is recognizable. Such an effect we find in the phenomenon of sympathetic ribration (resonance), oceurring in all bodies which. once they are given the impetns. run through a series of different ribrations before they come to rest. The simplest example of this is witnessed when a certain note is sung into a piano. The same note is giren back by the piano, its intensity bearing a direct relation to the exactness with which the note of a particular string is struck by the roice. Srmpathetic vibrations between bodies producing compound tones can be aroused even in case the vibration frequency is not exactly reproduced, and this takes place more readily the smaller the mass of the simpathetic body (e.g., a catgut string responds more readily

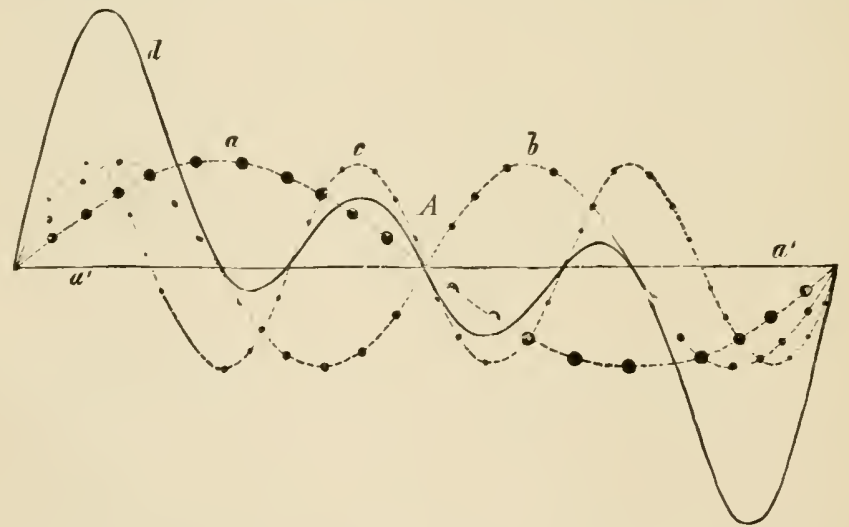

FiG. 194. - Schema illustrating the relation of overtones to their fundamental tone, after Hensen.

than a wire string of the same diameter). But it is much more difficult to induce sympathetic ribrations from a body which gives no overtones-e. g.. from a tuning-fork-becanse it will respond only to its own particular form of vibration.

It has been shown that a membrane adapted to a certain tone also exhibits the phenomenon of srmpathetic ribrations. if a lower tone, which contains the tone of the memirane among its orertones, is sounded. The tympanic membrane of the ear is not adapted to any nne tone-i. e., has no fundamental tone-hence does not select any single tone by resonance. 
The actual presence of overtones ean be demonstrated still more clearly by the use of the Helmholtz resonators. These may have different forms. The one shown in Fig. 195 has the form of a hollow sphere. one opening $(a)$ of which ends abruptly, while the other $(\zeta)$ is drawn out fumnellike and so shaped as to fit into the ear. The air of such a resonator in conjunction with that of the auditory passage and the eardrum forms an elastic system, which intensifies the fundamental tone of the sphere. Of course, one can have a whole series of resonators adapted to the different tones. If now a eertain resonator be placed to the ear and the attention is directed to a sound or series of sounds in which the particular tone of that resonator oceurs, this tone will be intensified to so great an extent that it can readily be heard above the others.

These and other observations which we cannot go into here make it perfeetly rertain that the different overtones actually exist in compound tones.

The following experiment shows directly that the car also can receive these overtones and is therefore sensitive to each and every simple vibration of this kind. If the tone $g$ of the first octare be struck on the piano and immediately afterwards the tone $r$ of which $g$ is the seconrl overtone and the attention be directed stuadily to $g$, one can hear it in the tone $c$, after the $g$ string has ceased vibrating. In the same way one can convince himself that $c$ of the second octave is one of the orertones of $c$. Often the overtones become clearer

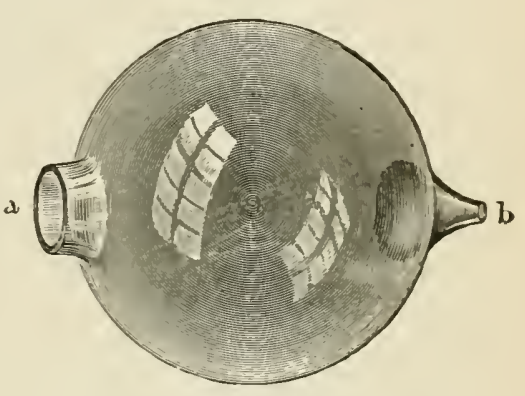

FIG. 195.-Resonator of Helmholtz. as the string ceases to vibrate, for it appears that they die out more slowly than the fundamental tone.

The ability of the ear to analyze sounds into their constituents is attested by our every-rlay experiences that we ean easily distinguish the individnal tones of an organ though only a person musically trained can name them.

The facts which make it possible for the ear to analyze sound may he summarized briefly as follows. Exery motement of the atmosphere which represents a compoumel of tones can be resolved into a number of simple pendulumlike vibrations, and for each such ribration there is a tone perceptible to the ear whose pitch is determined by the ribration frequency of the atmospheric morement (Ohm's law).

How does the ear accomplish this analysis? Since the endings of the auditory nerve are found in the internal ear. it is plain that analyis of sound must take place there. also that sounds must he transmitted thither without any considerable change. These phenomena will nceupy us in the pages immediately following.

\section{\$2. TRANSMISSION OF SOUND IN THE EAR}

The external and middle ear together constitute merely an apparatus for the transmission of sound. and careful investigation of auditory sensations has shown that this apparatus is able to transmit sound waves to the internal ear without any considerable modification. 


\section{A. THE EXTERNAL EAR}

Since, owing to the feeble development of the ear muscles, the human pinna camnot be turned in different directions, it is of but slight service in the collection of sound waves. It has been shown also that the reflection of sound waves by the pinna is of no importance (Harless, Mach).

The external auditory meatus ought probably to be described as a means of protection for the eardrum. The indirect course of the canal itself farors this view, since in order to see the drum the pinna must be drawn considerably upward and backward. Besides, this canal is provided with sensitive hairs which together with the disagreeable odor of the earwax secreted in the canal serve to prevent the entrance of insects. The passage also protects the middle and internal ear from variations of temperature.

Like every hollow space of the kind the external auditory meatus has its own resonance tone, situated between $c^{\mathrm{IV}}$ and $a^{1 \mathrm{~V}{ }^{1}}$ (Helmholtz, Hensen). If this tone be contained in a sound, naturally it will be intensified above other tones

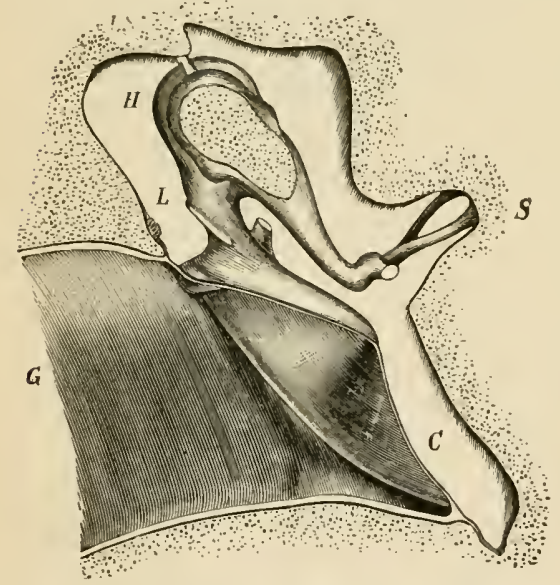

FIG. 196.-Transverse section through the left auditory canal and tympanic membrane of man, enlarged four times, after Hensen. The section is taken just behind the handle of the hammer in a plane parallel to the handle. $G$, external auditory meatus; $C$, tympanic eavity; $S$, the stapes; $H$, the hammer; a ledge projects at $L$, to which the ligaments are attached. Between the long process of the anvil and the handle of the hanmer the tendon of the tensor tympani may be seen; $L S$, ligamentum superior. by the sympathetic vibration of the air in the canal, but owing to its high position in the scale its resonance is of no great consequence from a practical standpoint.

A tuming fork allowed to die out until the vibrations are just imperceptible when it is held close to the ear, can be heard again if the handle be placed between the teeth. In this case the sound is conducted in part directly through the bones of the head to the internal ear and in part is transmitted from the bones to the eardrum and propagated thence as usual through the auditory ossicles.

\section{B. THE MIDDLE EAR}

1. Vibrations of the Eardrum.The tympanic membrane or eardrum is a fibrous membrane $0.1 \mathrm{~mm}$. in thickness, formed mainly of external radial and internal circular fibers. It is obliquely placed across the internal end of the external auditory meatus and is drawn inward at its middle by the long process of the mallens which is inserted into its tissue along one of its radii. In this way the membrane is given the form of a shallow, irregular funnel with an aperture of about $125^{\circ}$ (Fig. 196). 
The membrane is set in vibration by the oscillations of the atmosphere and is so arranged that it does not favor any particular tone.

Fick has worked out the following conception of the mechanics of the drum. The radii from the tip of the long process of the malleus to the periphery of the drum being of different lengths, the different sectors of the drum may be looked upon as to a certain extent independent of each other. If they were entirely independent strands, each would vibrate in response to its own particular tone. Being joined together into a membrane they do not thus seleet individual tones, although separate parts can be thrown into action without moving distant parts rery much. Consequently, because of the summation of successive vibrations, regular periodic movements are more farorably received by the drum than single vibrations. And yet vibrations of any form or frequency are faithfully transmitted to the handle of the malleus, for among the sectors and segments of the membrane there are always some which are suited to the component vibrations. Since, however, the malleus is a rigid body and can only vibrate as a whole, all the components will be represented in the form of its movements.

The peculiar form of the tympanic membrane is of special significance in another respect also;

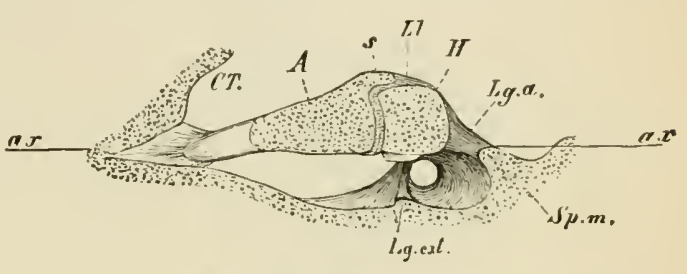

FIG. 197.-Nearly horizontal section through the tympanic eavity, $C T$, of the right ear, enlarged four times, after IIensen. The seetion is taken just above the noteh of Rivinus and vertical to the plane of Fig. 196. $H$, medial edge of the head of the hammer. A. anvil. The ligamentum anterius, Liy. $\tau_{\text {. }}$, is seen springing from the larger process, $S p . m$, of the wall of the tympanic cavity and passing to the hammer where it becomes continuous with the ligamentum laterale. $L l$ of the anvil-hammer joint. The ligamentum externum, Lig. crl. springs the notch of Rivinus and passes to the liammer.

the sound waves converging toward the middle point are damped-i. e., diminished-in amplitude, but are increased in intensity. This aids greatly in the transmission of vibrations to the perilymph (Helmholtz).

2. The Auditory Ossicles.-For the anatomical details of the auditory ossicles the reader is referred to text-books of anatomy. We give here briefly only the facts with reference to their mode of attachments, as made out by Hensen and Schwalbe, which are of most importance for an understanding of their physiological purpose (Figs. 196 and 19\%).

The malleus, or hammer, is attached to the wall of the tympanic eavity by three ligaments (Fig. 197). The first of these, the anterior, passes from the processus longus and around its base partly to the larger spine of the tympanum $(S p . m$. $)$, partly through the Glaserian fissure to the angular spine of the sphenoid boncl. The seeond or exterual ligament (Lig. ext.) is a short tense band which springs from the whole posterior half of the noteh of Rivinus as far as the smaller spine of the tympanum opposite the hammer, and from this relatively long line of insertion its fibers converge to the crista mallei. The third or superior ligament (Fig. 196, $L S$ ) limits the movability of the ossicles downward.

The tip of the short leg of the incus is fixed by means of a strong ligament (ligamentum incudis posterius) to the opposite wall of the trompanic eavity. 
When the tympanic membrane moves in and out in response to the atmospheric vibrations the handle of the hammer naturally moves with it; but the head of the hammer mores in the opposite direction. 'Too creat an excursion of the handle outward is prevented by the external ligament.

The incus articulates with the head of the mallens by means of a peenliar saddle-shaped joint, the physiological significance of which has been pointed ont by Helmholtz. 'This joint is provided with ratchet teeth, which, as will be evident from inspection of Fig. 198, engage each other in such a way that the incus is carried along with every movement of the manubrium inward, while they are disengaged when the manubrium noves ontward. In this way

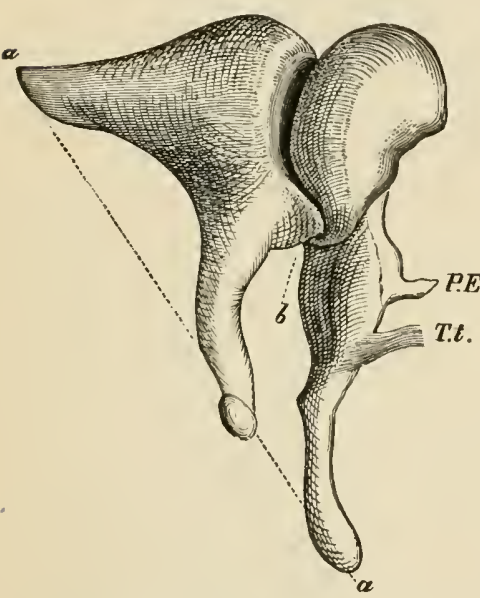

Fig. 198,-Hammer and anvil, after Helmholtz, $P E$, processus Folianus; $T \ell$, tensor tympani; $b$, ratchet tooth of the anvil. the danger of tearing the stapes from its fastening in the foramen oralis when the tympanie nembrane is for any reason pushed outward, is diminished. Helmholtz estimates that the hammer can be rotated five degrees outward without carrying the anvil with it.

If we imagine the hammer and anvil loeked together by their ratehet teeth so that the two move inward as one solid body, the system formed by the two ossicles can be regarded as a one-armed lever, the fulcrmm of which lies where the ajex of the short process of the anvil is supported against the wall of the tympanic cavity. The tip of the manubrium constitutes the point where the power is applied, the apex of the long process of the anvil the point where the load -i.e., the stapes-is aeted upon. These three points lie almost exactly in a straight line, the joint between the stapes and anvil lying only a little inside the line joining the other two. The lever a a (Fig. 198) is about $9.5 \mathrm{~mm}$. long, the short arm Jetween the two apices of the anvil being about $6.3 \mathrm{~mm}$.-i.e., just two-thirds of the long arm.

It follows that when the hammer and anvil are firmly engaged, the excursion of the ineus-stapes joint is only two-thirds that of the apex of the mannbrium, but the pressure which the stapes exerts on the oval window is one and one-half times as great as that which aets upon the apex of the manubrium (Helmholtz).

The top of the stapes is attached by a strong ligament to the long process of the ineus, and its base is fastened into the fenestra ovalis by means of a thin membrane. The stapes must accompany all the movements of the long process of the ineus, so that when the tympanic membrane moves inward, the base of the stapes is pressed into the labyrinth. At the same time there takes place a slight rotation of the stapes around the long axis of its base. A limit is set to the movement of the base inward by the resistance of the membrane holding it in the oval window. 
Politzer attached threads to the malleus and incus and recorded their movements on a revolving drum. In this way he was able to show by direct experiment what is supported also by theoretical considerations, namely, that sound is transmitted from the tympanic membrane to the labyrinth by molar movements of the auditory ossicles and not by molecular morements.

The round window is closed br a thin membrane bathed on the inside by the perilymph. The perilymph being incompressible, this membrane in all likelihood constitutes an arrangement by which the morement of the stapes inward can be compensated by an equal movement outward. The endolymph has a similar protective derice in the ductus endolymphatiens. which is connected on the one hand with the ntricle and saccule and by these with the scala media of the cochlea, and on the other passes through the petrous bone and terminates on its posterior surface in a little vesicle underneath the dura mater.

The round winclow might also serve for the purpose of eonveying ribrations to the perilymph, and this in faet has been observed when the oval window was rigilly closed.

By means of a capillary manometer introduced into the superior semicirculal canal. Bezold was able to determine the extent of the movements described hy the condueting apparatus of the human ear with the tympanic eavity open. The maximum movement of the mamubrum caused by variations of atmospleric presiure in the extemal auditory eanal was about $0.86 \mathrm{~mm}$. from one extreme to the other, one-third of this being the movement inward and two-thirds the morement ontward.

As Bezold remarks, this difference between the movement inward and outward is diflicult to harmonize with an exact transmission of sound waves, and probably would not occur under normal circumstances. As a matter of fact we hase in the internal musctes of the ear a derice which in life might correct this lack of coördination observed after deatl.

These are the tensor tympani and the strpedius muscles, the former innervated in the main by the trigeminal nerve. the latter by the facial. The tensor tympani draws the manubrimm inward and therehy presses the stapes farther into the labrinth. It serves thus to keep the chain of ossicles "keved up)." Section of it: tendon permits a molerate magnifieation of the movement of the whole chain and the increase is almost exclusively in the nutward movement (Bezold).

Experiments on dogs have shown that the tensor tympani contracts reflexly to acoustic stimuli (IIcnsen, IIammerschlag et al.) acting through subcortical centers not higher than the posterior corpora quadrigemina (Ostmann).

Hensen looks upon the tensor tympani as an apparatus for accommodating the ear in listening to faint sounds, and cites as evidence the fact that a weak sound becomes stronger for the moment when strong motor impulses are sent out, siy to the muscles of the face or limbs. The explanation would be that impulses are at the same time sent to the tensor tympani musele.

Ostmann would aseribe this function to the stapedius.

3. The Tympanic Crvity and Eustachinn Tubr.- In order that the midnle car mal fulfill its purpose of transmitting the vibrations of the atmosphere 
to the labyrinth to the best advantage, it is necessary that all extraneous ribrations be excluded as far as possible. Moreover, the tympanic cavity ought, if possible at all, to have no tone of its own, and finally no difference of atmospheric pressure, at least no permanent difference, ought to obtain between the tympanic eavity and the outside air.

'These requirements are sufticiently fulfilled, one ean readily see. by the structure of the tympanic cavity, this being at once rather small and very irregular in shape, so that resonance to special tones is prevented.

The pressure inside the tympanic cavity is regulated through the Eustachian tube communicating with the throat. Normally this tube is rather tightly elosed, but it is often opened-as, e. g., in swallowing. Since it is in this way that the pressure inside and outside the tympanic cavity is equalized, it is well for a person inclosed within a pneumatic eabinet, where the air pressure is considerably inereased, to swallow frequently. The tube is opened also in strong inspiration and in phonation, although to a less extent than in swallowing.

The Eustachian tube is lined with a ciliated epithelium which probably serves to drive the mueus, ete., toward the throat.

\section{§3. EXCITATION OF THE AUDITORY NERVE}

The vibrations of the stapes are transmitted to the perilymph, and these in turn set the endolymph in vibration.

\section{A. THE RESONATORS IN THE COCHLEA}

We have already remarked that the analysis of sound leads us to assume that the different perceptible sounds have their appropriate resonators in the ear. But it is possible also to imagine that the fibers of the auditory nerve themselves are thrown by the endolymph into vibrations which agree exactly with those of the conducting apparatus. Against this hypothesis, however, several ol,jections may be urged, chief of which is that we have nowhere else in physiology any analogous production in a nerve itself of 40,000 or 50,000 molecular vihrations per second. Besides, there are some observations which appear to speak directly in faror of the resonance theory. For example, Bezold has found by means of an instrument which enabled him to vary the number of ribrations per seend from that of the lowest sound to that of the highest. without any omissions, that for different individuals there are gaps of greater or less size in the series of perceptible tones. Some show defects both in the upper and the lower ends of the series. others only in the lower, and still others only in the upper end. Gaps of varying extent oceur alsn at different places along the course of the scale. All of them ean be explained by supposing that the corresponding resonators are wanting.

That the fihers of the auditory nerre are not set in vibration direetly by the ribrations of the endolymph is indicated by the following considerations with reference to fatigne of the ear:

If the ribrations of a tuning fork in a distant room be transmitted by means of two telephones to the two ears, the tone will appear to be loeated 
exactly in the mid line of the head. If it be transmitted to only one ear for a time, and then the two telephones be used again, the tone appears now to be on the side of the ear which was resting. If in this way the one ear be fatigued for a tone say of 360 vibrations per second, and immediately afterwards one of 365 vibrations be transmitted to both ears, the one fatigued for 360 vibrations will show no trace of fatigue for the new tone. It is diffieult to see how the nerve fibers could be exeited direetly by one of these tones and not by the other. The difficulty disappears by supposing that each has a resonator which is not affeeted by the other.

We ean think of the analysis of tones, therefore, as follows: In the internal ear there are a large number of resonators adapted for different tones, which are called into play if the appropriate ribrations are transmitted to the endolymph. Each of these resonators in some way affects a nerve fiber. The excitation thus aroused is transmitted to the brain and there, according to the nerve fiber which brings it, gives rise to a perception of one tone or another.

In order to test the plausibility of this hypothesis it is necessary to inquire whether the structures which might be regarded as resonators are present in sufficient number to account for the analytical powers of the ear.

Only exceptionally does one meet with a man who canunt tell definitely which of two successive tones is the higher. provided that the interval between them really is great enough. In musically educated indiriduals this ability is very great. According to Prever trained persons can recognize a difference of $0.3-0.5$ vibrations per second within the range from $a^{\mathrm{I}}$ to $c^{\mathrm{II}}$; above and below this range the ability is much less-e. g.. with $c^{\mathrm{v}}$ errors of as much as one hundred and more vibrations may ocenr.

According to Helmholtz's ealculations some 4.200 resonators-i. e., 600 per octare-would be sufficient to aceount for the best possible discernment of fractions of a half tone. Besides this, 300 resonators would be enough for the tones not used in music-i. e., 4.500 in all.

We have seen that the semicircular canals and the otolith sacs probably have no acoustic functions, or that at most they take part only in the perception of noises ( $\mathrm{cf}$. page $4 \mathrm{ij}$ ). The whole structure of the nerve endings in the cochlea, on the other hand, favors the view that the peripheral organ for the analyis of sound is to be sought here.

On the basilar membrane (Fig. 199, $m b$ ) we find the organ of Corti. This eontains a very large number of rodlike structures, the pillars of Corti (ic and äc), standing side by side throughout the whole length of the coehlea and bound together by means of a joint at the top into pairs.

These pillars are surrounded outside and inside by peeuliar epithelial cells. some of which, the outer ( $\ddot{h} h$ ) and inner (ih) hair cells, bear hairlike processes encling freely in the endolympli. These cells are in connection with the endings of the auditory nerve. The basilar membrane is of varying width at different parts of the cochlea and contains fibers which are stretched transversely to the cochlear canal. These are imberlded in a transparent matrix.

The required resonators must be found among these struetures and their number is quite sufficient for the purpose ; for, according to Retzius, the cochlea of man contains 5,600 inner pillar cells, 3.850 outer pillar cells, 3.500 inner 
hair cells, 12,000 outer hair cells (in four rows). and 24,000 fibers in the basilar membrane.

We can only conjecture which of these structures are the trne resonators. Originally. Helmholtz aseribed this funetion to the pillars of corti: later,

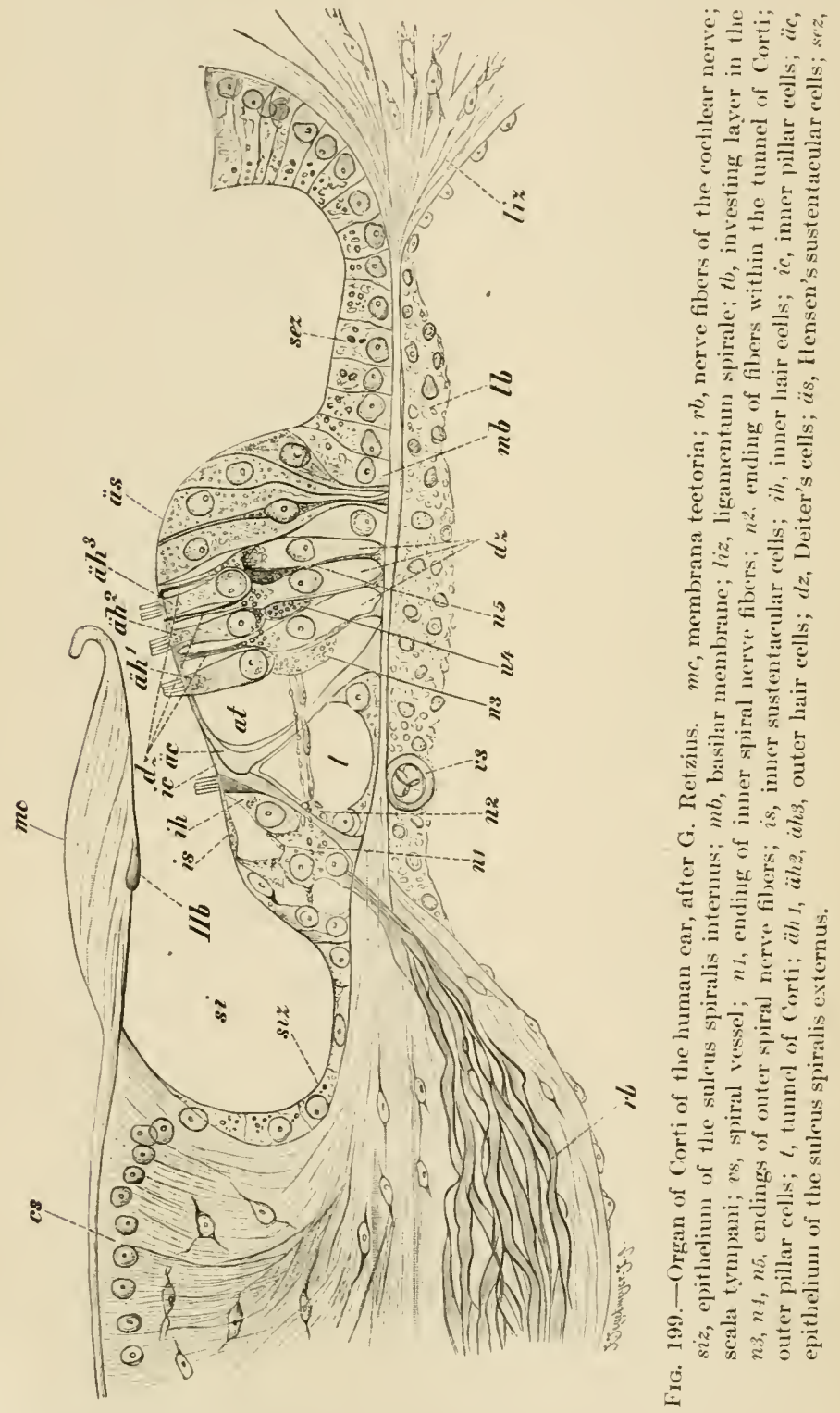

however, he gave up this view heeause it was found that birds and reptiles have no such pillars in their anditory orwan. After Hensen had established the fact that the basilar membrane varies in width in different parts of the cochlea, 
Helmholtz sought the resonators in the transverse strands of this structure. In a membrane of this kind where the longitudinal tension is small as compared with the transverse tension, the radial fibers act like a system of separate strings. The membrane commecting them serves only to give the pressure of the fluid a purchase on the strings and each one will therefore vibrate indepentuntly of the others.

Finally, the lair cells might serve as resonators. In short, although we cannot settle definitely on a choice hetween these various elements, it must be erident that there is no lack of struetures suitable for such a function.

\section{B. OBJECTIONS TO THE RESONANCE THEORY}

The resonance thenry of Helmholtz fits in remarkably well with the facts mentioned thus far. But there are some cireumstances under which the theory cannot be applied so readily, and these cireumstances must not be passed over in silence.

1. Beals.- When two tones of different vibration frequencies are sounded at the same time, if the difference between them is not too great, the ribrations of the two will interfere with each other, producing what are called beats. Thus if the difference in the number of vibrations be only one per second, and if the two tones be struck at the same instant, the air waves of the deeper tone will gradually fall behind those of the higher until at the end of a half seeond the summit of one wave will coincide with the valley of the other; after another half second the two summits will coincide, and so on. And in general if $n$ represent the number of vibrations of a tone per second, and $n+1$ that of another, then the loudness of the tone will be increased every second and be diminished every half second. The number of beats per second therefore will always be equal to the difference in the number of vibrations per second between the two tones.

Now if each tone has only one independent resonator in the cochlea, it is difficult to see how it wonld be possible for two tones to influence each other in this way. There is, however, very good reason for believing that each tone excites several neighboring resonators, and the difficulty offered by beats for the resonance theory is readily disposed of by this supposition. For two tones lying close together we suppose must influence several resonators in common; then since the objective strength of the tone varies incessantly beeause of the interference, the sympathetic vibrations of the resonators common to the two must likewise vary in strength, and hence the subjective sensation must present similar variations. Other phenomena connected with beats ean be explained from the same riewpoint.

2. Combination Tones. When two tones not too close together in the seale are sounded at the same time, one may hear, as was first pointed out by Sorge (17t0) and Tartini, a true tone, the vibration frequency of which is equal to the difference in the number of ribrations per second between the two. For example, striking a fund:mental and its fifth at the same time (ratio 2:3), one hears the lower dunderime of the fundamental. The first difference tone then forms a seeond difference tone with the first primary tone. Inder certain circumstances a tone may also be perceived which represents the sum of the ribution frequeneies of the two primary tones (IIelmholtz). These difference tones and summation tones are included under the term combination tones. 
Lagrange and Young regarded the difference tones as a kind of beats and explained them on the assumption of subjective interferenee. If this were shown to be true, it would eonstitute an absolute refutation of the resonance theory, for these particular tones would then have no objective existence and so could not, as the theory demands, exeite resonators in the car. The summation tones would constitute still greater difficulty for the theory.

Helmholtz, however, found an explanation for these tones by supposing that either the tympanic membrane or the incus-malleus joint, or both, are not uniformly elastic, and that the combination really takes place therefore in the conductors of the ear. Several authors do not find this explanation wholly satisfactory and, beeause of this and other difficulties which camnot be entered into here, have given up the resonance theory altogether and adopted other views. When all has been said, however, it is the opinion of the author that the resonance theory is better able to explain the essential features of the auditory sensations than any of its rivals. It is, of course, not improbable that this theory will need to be modified or extended in one way or another, as has been done by Wundt and by Hermann, for example, but the ground prineiple-the analysis of sound by resonators in the internal ear-will, it is the author's belief, endure.

\section{SECOND SECTION}

\section{PHYSIOLOGY OF VOICE AND SPEECH}

The physiology of roice and speech covers so wide a field that it will be necessary for us here to limit ourselves to the most important facts. Iet it be expressly understood that what follows is to be regarded only as a brief orienting survey.

The uppermost part of the trachea. the larynx. is fashioned in a peculiar way so as to serve for the production of the voice. The most essential parts of the larynx are the vocal cords. These are thin, elastic bands stretched across the lumen of the larynx, and like other struetures of the kind, they can be made to produce distinet tones by being set in vibration. In their case the vibration is caused by a blast of air from the lungs forced through the chink (glottis) between their free edges. The pitch and other qualities of the tones thus produced are altered by varying the tension and mode of vibration of the cords. This function it is the business of the laryngeal muscles to discharge.

\section{\& 1. ACTION OF THE LARYNGEAL MUSCLES}

The true vocal cords are attached at one end to the recurrent angle of the thyroid cartilage and at the other to the vocal processes of the arytenoid cartilages: consequently their tension and position can only be altered by changing the distance from the thyroid cartilage to the arytenoids and the distance from one arytennid cartilage to the other.

The arytenoids are fastened to the cricoid cartilage. so that every morement of the latter produces a change in the position of the former: hence, the distance hetween the thyroid and the arytenoids ean be altered by moving the cricoid.

The action of the separate muscles may be condensed somewhat as follows: 
Contraction of the cricothyroid increases the tension of the vocal cords by rotating the cricoid cartilage upon the thyroid around an axis running through the articulation which the small (lower) cornua of the thyroid make with the cricoid. Thus the broad posterior plate of the cricoid to which the arytenoids are attached is moved downward and hackward, and, the arytenoid being prevented by ligaments from slipping forward, as a consequence the rocal cords are put on a stretch.

The glottis is widened by moving the rocal processes of the arytenoid cartilages, to which the vocal cords are attached, farther asunder. This is accomplished chiefly by contractions of the posterior crico-arytenoid muscle springing from the cricoid cartilage and attached to the muscular processes of the arytenoid cartilages. The action of this muscle is represented schematically in Fig. 200. It contributes to the tension of the rocal cords by holding the arytenoid cartilage against the muscles which tend to draw it forward (Neuman). In this abducting action the posterior cricn-arytenoid is aided to some extent by the vertically directed portion of the lateral crico-arytenoid (Rühlmann).

But for the most part the lateral crico-arytenoid is an adductor of the rocal cord: (Fig. 201) and the thyro-arytenoid lying over this muscle has the same action.

The vocalis or internal thyro-arytenoid muscle, regarded by several authors as belonging to the thyro-arytenoid, runs from the angle of the thyroid car-

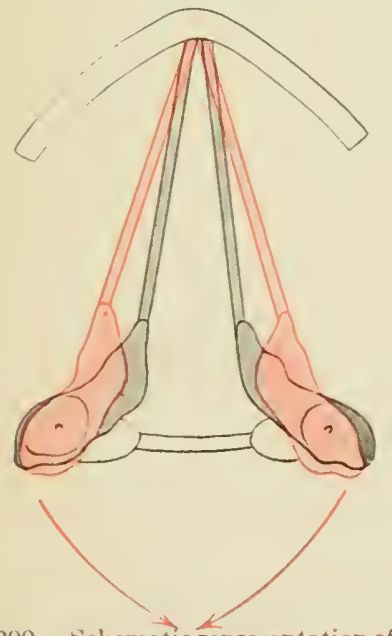

Tig. 200.-Schematic representation of the action of the posterior erico-arytenoid muscles, after Testut. The red color indieates the position of the vocal cords and of the arytenoid cartilages, when these muscles contract. tilage to the arrtenoid cartilage and is applied to the outer margin of the rocal cord of each side. It serres first to relax

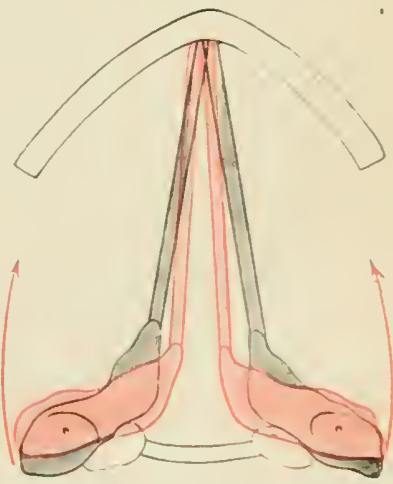

FIG. 201.-Sehematic representation of the action of the lateral crico-arytenoid muscle, after Testut. The red color inlieates the position of the vocal cords and of the arytenoid cartilages when these muscles contract.

the rocal cords by approximating the points of their attachment. But a much more important function is to impart the necesary internal ten-ion and firmness. as well as to give a farorable form and position to the whole mass of the rocal cord, for intonation (Gritzner). 
With the exception of the cricn-thyroid muscle which is innervated by the superior and median laryngeals. the latter arising from the pharyngeal branch of the ragus, the muscles of the larynx receive their nerve supply from the recurrent laryngeal.

\section{§ 2. VOICE PRODUCTION}

Production of sound in the larynx presupposes that the glottis is closed and that the rocal cords are placed in a state of tension. If then air is driren from the lungs under sufficient pressure, it forces its way through the glottis and as it does so sets the rocal cords in ribration.

Caginard-Latour and Grützner have estimated the air pressure necessary for this purpose. On patients with tracheal fistulæ they connecter a manometer with the trachea by means of a tracheal cannula and demonstrated for

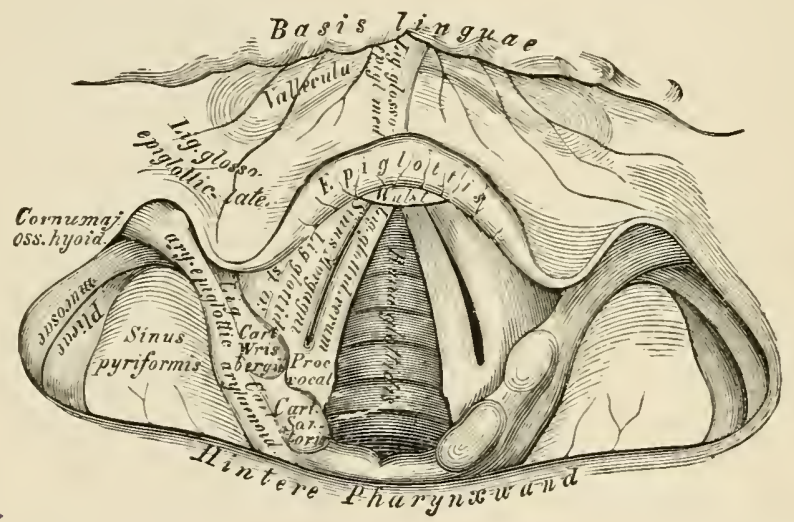

FIG. 202.-Laryngoscopic picture of the human throat, as seen during quiet inspiration. Enlarged twice (Heitzmann).

a tone of medium height and strength a pressure of 140 to $240 \mathrm{~mm}$. of water; for rery loud tones. as in shouting at the top of the roice, a pressure as high as $945 \mathrm{~mm}$. of water was olitained.

The porrer which produces this pressure comes from the muscles of expiration, chiefly the abdominal muscles. It is said that good singers use only the thoracic muscles of expiration.

The sound produced in the larrnx is modified as to its timbre but not as to pitch. hy the resonance chamhers-pharyx. mouth. nasal cavities, etc.and the task of the roice eulturist, besides that of inculcating correct labits of breathing. consists merely in training the pupil to so shape these carities as to impart the most agreeable quality.

\section{§3. REGISTERS OF VOICE}

Before the invention of the laryngoscope, our knowledge of the heharior of the rocal cords. etc. in the production of roice was based mainly on observations made with dissected preparations. But with the invention of 
this instrument by Garcia (1855) physiological and pathological study of the larynz entered upon an entirely new era.

The laryngoscope is a very simple instrument. A concave mirror held before the observer is provided with an apcrture through which the observer looks. It receives light from some artificial source, and reflects it upon a plain mirror held at the proper angle in the pharynx. The latter mirror serves both to illuminate the interior of the larrnx and to form an image of the same which can be seen by the observer.

Fig. 202 represents a laryngoscopic picture as seen in quiet breathing and Fig. 203 that seen in rocalizing.

Two different registers are distinguished: the chest roice and the falsetto or head roice. The former is fuller and richer-i.e., richer in lower overtones-than the falsetto. The chest tones are

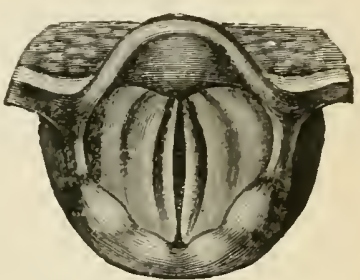

FIG, 203.-The appearance of the rocal cords while producing a chest tone, after Mandl. lower than the heal tones; although within a certain compass the same person ean prorluce identical tones with either the chest roice or the head roice.

In the production of chest tone: the rocal corts rilorate throughout their entire breatth. They are also pressed inward, thus narrowing the glottis

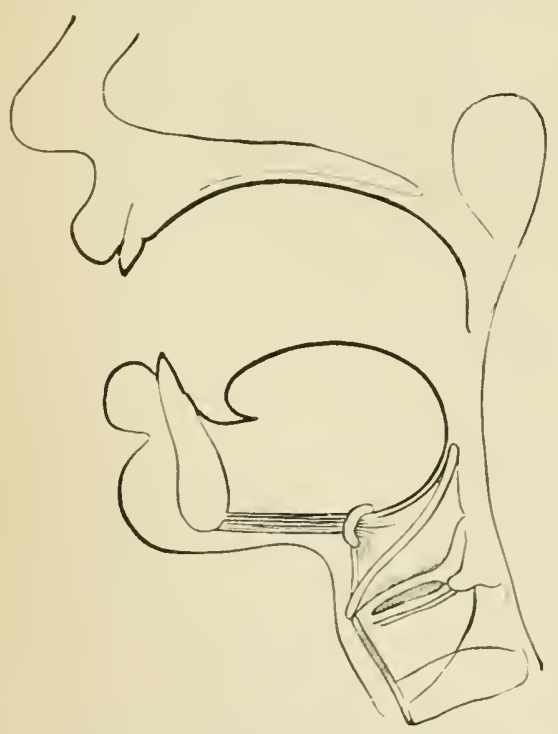

FIG. 204.-Position of the vocal organs in producing the sound of broad $\mathrm{A}$, after Grützner. so that the air can only escape very slowly. In the production of head tones only the edges of the rocal cords vibrate and the glottis is firmly closed posteriorly, but is rather widely open anteriorly. The air escapes therefore more readily than in the case of chest tones. For this reason chest tones can be held longer than head tones.

We have the following means in the larrnx itself of altering the pitrh of the voice (Griitzner): (1) By changing the longitudinal tension of the rocal cords: (?) by limiting the vibrating length of the vocal cords, which is done by applying the inner surfaces of the arytennid cartilages to each other progresively more and more from posterior to anterior: (3) by changing the form of the rocalis muscle, and thereby varying the width of the rocal cords; (4) by altering the air pressure in the trachea.

Higher tones within the same register therefore may be produced in two general ways: (a) By increasing the tension and at the same time lengthening the rocal cords; (b) by shortening the vibrating portion. Different individuals use one or the other of these methods more or less exclusively. 


\section{\$ 4. ELEMENTS OF SPEECH}

Language is made up of words. Words of sylables and syllables of elementary sounds called rowels and consonants. Towels are produced when the roice is modified hy merely changing the shape of the resonance carities -pharynx, mouth, and nasal passages: consonants when the air or roice is more or less obstructed by the morable parts of the organs of speechlips, tecth, tongue and palate.

In whispering the glottis is partially open and the air is allowed to pass through without setting the vocal cords in ribration. Since each of the resonance cavities has a sound of its own which it amits when the air contained in it is caused to ribrate, and since sounds may be produced by the lips, tongue, etc., alone, it is possible to speak without roice.

\section{A. VOWELS}

We cannot here discuss exhaustively the changes of the mouth carity necessary for the production of rowels. Grïtzner summarized the most inportant of them as follows: If the roice be sounded with the tongue well down

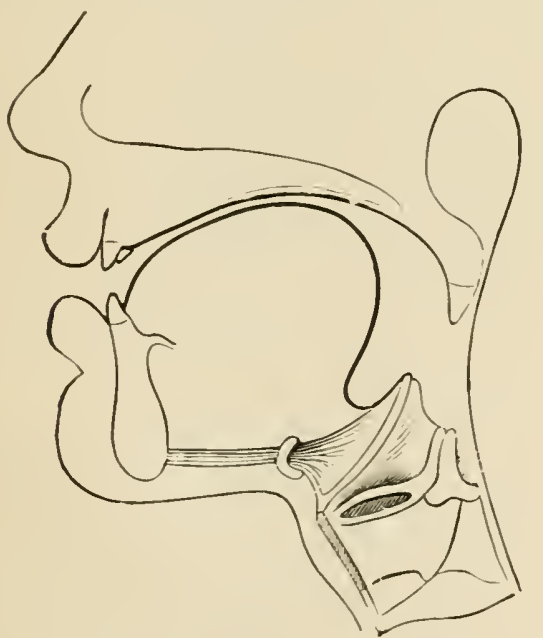

Fig. 205.-Position of the rocal organs in producing the sound of long $\mathrm{E}$, after Grützner. in the mouth, and the lips at first but slightly open, the sound of $T$ $(00)$ is produced. Then while the roice is sounding. if the month be opened more and more without changing the position of the tongue the sound of $O O$ gradually passes into that of $\mathrm{O}$ and finally into that of broad 1 , and rice versa. The rowels $[$. O. A, can be uttered therefore merely by changing the size of the mouth opening; in ordinary speech, however, the tongue and soft palate take part in the changes. If now the sound of loroad $A$ be uttered with the month moderately open (Fig. ?0t) and if without changing the size of the opening the tongue be gradually lifted more and more toward the hard palate we get successirely the snunds of long $\mathrm{A}$ and $\mathrm{E}$ (Fig. 205) (German $\mathrm{E}$ and I). In this series the space inclosed hetween the larrnx, posterior wall of the pharynx, soft palate and base of the tongue (larrngeal space. Purkinje) gradually becomes larger.

The other sounds of these same letters are produced by combination of the positions already mentioned for the two series. The larrnx and soft palate, howerer, undergo changes of position also.

Donders has shown that the buceal carity is attuned for the production of the different rowels not at the same pitch. but at different pitches. The 
tones which are favored by the shape of the carity may be found by blowing into the mouth while the organs are in the proper positions; then if these tones nceur as orertones in the sounds emitted by the rocal cords, they are sulected by the resonance of the cavity and are intensified. According to Helmholtz (1863), each rowel has one or two such tones (the pitch of which is constant) which are characteristic of it whenever it is either sung or spoken. Those rowels which are formed when the tongue is high in the mouth. thereby dividing it into two carities (riz.. long and short $A$ and E) have two tones, and those formed when the tongue is low (riz., 00,0 and broad $\lambda$ ) have but one.

\section{B. CONSONANTS}

The consonants are much more complicated in the mode of their production than the rowels, one important feature in their production consisting of changes in the resonance quality of the bucco-pharyngeal space. In most of the consonants the mouth and nasal earities are separated from me another by the soft palate, but in some not. But as more or less complete olsitruction of the air in some part of the passage is common to all, the distinguishing character of the sound depends on the place and manner of the olsstruction. Some consonants are uttered with voice, others without.

Referexces.-P. Grützner, "Physiologie der Stimme und Sprache," Leipzic. 1879 (Hermann's Handbuch der Physiologie, i, 2).-H. Helmholtz, "Die Lehre von den Tonempfindungen," fourth edition. Braunschweig, 1sit.-L. Hermann, several articles in the Archiv für die gesumte Physiologie, vols. xlvii, xlviii, liii, Iviii, lxi, lxxxiii, xci, 1590-1902.--H. Pipping, articles in the Zeitschrift für Biologie, vols, xxvii, xxxi, 1890, 1895. 


\section{CHAP'TER XXI}

VISION

If we wish to inrestigate an object by means of the tactile sense. we must be able to feel the different parts of it. In doing this different nerve fibers are stimulated; each nerve fiber produces a special sensation. which, owing to its "local sign," differs from those mediated by other nerve fibers: and the sum total of all these different sensations gives us our idea of the object.

It is the same with the eye. The retina constitutes a mosaic of nerve endings sensitive to the light; each of these nerve endings produces a sensation endowed with its own peculiar "local sign "; and just as with the skin, the total result of all these sensations constitutes our idea of the object as obtained by vision.

From this it is evident that a clear idea of an object perceptible to the eye can only be obtained, if each point of the object acts upon its own particular point of the retina.

Since light emanating from or reflected from an olject radiates in all directions, becoming more and more divergent the farther it proceeds. in order to form a sharp picture of the object on the retina the light must be collected by refraction of its rays, in such a manner that they will be focused on the retina. This is the purpose of the refracting media of the ere.

The physiology of the visual organ must begin therefore with a consideration of the eye as an optical instrument. After that we shall study the visual sensations, and the morements of the eve.

\section{FIRST SECTION}

\section{THE EYE AS AN OPTICAL INSTRUMENT}

\section{§ 1. THE OPTICAL CONSTANTS OF THE EYE}

The eve contains a number of refracting medin separated from one another by approximately spherical surfaces. These media named from anterior to posterior are: (1) The layer of tears; (2) the cornea: (3) the aqueous humor: (4) the crystalline lens composed of many lavers of different refracting power: (5) the ritreous body.

In order to follow the course of light rays in the eve we must determine (1) the refractive indices ${ }^{1}$ of the varions melia; $(:)$ ) the radii of the refract-

${ }^{1}$ The ratio between the velocity of light in a vacuum and its velocity in a given medium, as glass, is the refractive index of that medium. Since however, the velocity in air 
ing surfaces; (3) the distances of the different refracting surfaces from one anotker. These measurements are called the optical constants of the eye.

The following table after Helmholtz contains a summary of values found by different authors for the refractive indices of the various media in the human eye :

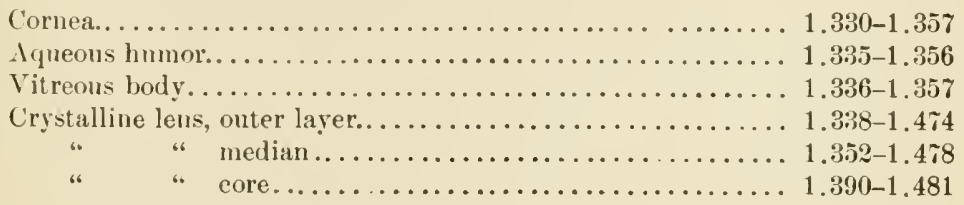

The lens, as appear's from the table, has a different refractive index in its different lavers, the value inereasing from without inward. As a consequence, the focal distances of the component lenses become smaller in the same order and the total refracting power greater than it would be, if the whole lens had the refractive index of its core (Young, Listing).

Hence it is a mistake to try to replace the erystalline lens by a homogenous lens of the same form and with an average refractive index. Such a lens must have a higher total refractive index than that of its densest part.

In calculating the course of the light rays in the eve, we shall follow Helmholtz in supposing the crystalline lens to be replaced by a homogenous lens with a refractive index of $1.43 \% 1$.

The problem to be solved is rendered

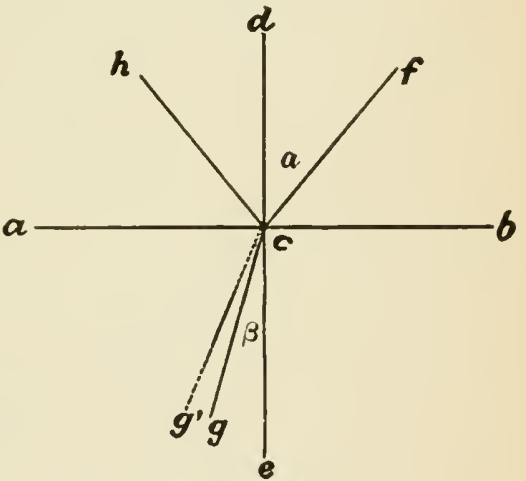

FIG. 206. much easier by this simplification and we can now treat the optical system of the eye as if it were composed of two relatively simple systems. The first consists of (1) air. (2) cornea, (3) aqueous humor: the second of (1) aqueous humor. (2) crystalline lens and (3) vitreous body.

The system of the cornea can be simplified still further for three reasons: it is rery thin, its surfaces are almost concentric and its refractive index is only a little greater than that of the aqueons humor. Since the refractive inclex of the layer of tears on the nutside differs but slightly from that of the aqueots humor inside. we may think of the cornea as a watch-glass-shaped

is but slightly less than in a vacuum, the refractive index of a medium is ordinarily given as the retardation which the light suffers in passing from air into that medium. The refractive index may be found by measuring the angle of incidence and the angle of refraction-e. g., the angles $\alpha$ and $\beta$ formed by the light ray $f g$ in Fig. 206. The refractive index of the medium below the line $a b$, supposing the medium above that line to be air, is given by the formula $n=\frac{\text { sine } \alpha}{\text { sine } \beta}$. 
lens immersed in aqueous humor. Such a lens does not change the course of the light rays to any appreciable extent. According to an estimate of Helmholtz the foeal distance of the cornea embedded in the aqueous humor would be $8 . \pi$ m., a distance which, in comparison with the dimensions of the eye, can be regarded as practically infinite.

The first refracting system is reduced therefore to a simple optical system composed of two media, the air and the aqueous humor, separated by a surface with the curvature of the cornea.

To be able to follow the course of the light rays in the eye we need therefore in addition to the refractive indices already mentioned, only the following data: (1) The radius of curvature of the cornea: (2) the distance of the anterior surface of the lens from the vertex of the cornea; (3) the radius

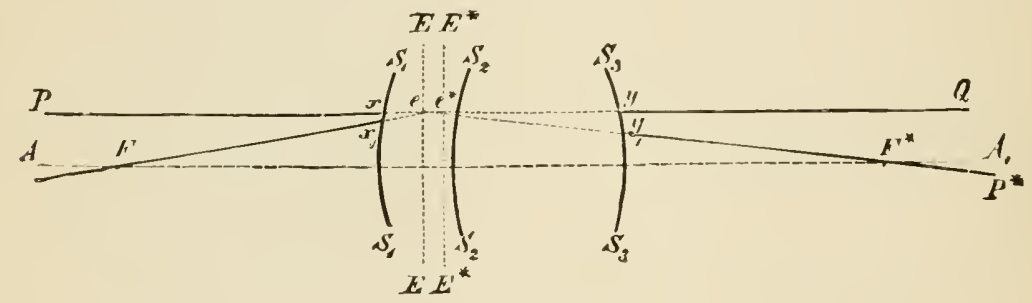

F1G. 207.

of curvature of the anterior surface of the lens; $(4)$ the thickness of the lens and $(5)$ the radius of curvature of the posterior surface of the lens.

some of the ralues found by different authors for these dimensions are given in the following table:

(1) Radius of curvature of the anterior surface of cornea . . . . . . . 6.852-8.154 $\mathrm{mm}$.

(2) Distance from vertex of cornea to anterior surfaee of the lens . . . . . 2.900-4.09 “.

(3) Distance from vertex of eornea to posterior surface of lens . . . . . . 6.844-7.69 "

(4) Radius of curvatmre of anterior surface of lens . . . . . . . . . . 7.860-12.58 "6

(5) Radius of curvature of posterior surface of lens . . . . . . . . . . . 5.13 -8.49 "

To enable us the better to follow light rays through an optical system like that represented by the liuman eye. let us suppose the refracting surfaces $S_{1}$, $S_{2}$ and $S_{3}$ in Fig. 207 to be related to each other as are the refracting surfaces of the eornea and lens. The points $F$ and $F^{*}$ will be the anterior and posterior foeal points of the entire system, the line $A A_{1}$ its axis. Imagine any incident ray parallel to the axis to be represented by $P x$. Since all rays parallel to the axis pass through the foeal point, whatever course this ray may take through the system, we know that after it is refracted it will pass through the focal point $F^{*}$. But the ineident and refracted rays must meet somewhere if prolonged. Let this point of meeting be $e^{*}$. Imagine the incident ray $P x$ projected toward $Q$ and call the portion $\mathrm{e}^{*} Q$ the incident ray. Since this is everywhere parallel to the axis it must have a corresponding ray which will pass through the anterior focus $F$. Prolonging the incident ray until it meets the refraeted ray again, we get the point $e$.

The rays $P x$ and $F x_{1}$, therefore, converge toward the point $e$, the rays $Q y$ and $F^{*} y_{1}$, toward $e^{*}-\mathrm{i}$. e., if we regard $e$ as a luminous point $e^{*}$ will be its image. 
If through these points two planes be drawn perpendicular to the axis of the system, then every point in the plane $e$ will have its image in the plane $e^{*}$, and the image will be on the same sicle of the axis and at the same distance

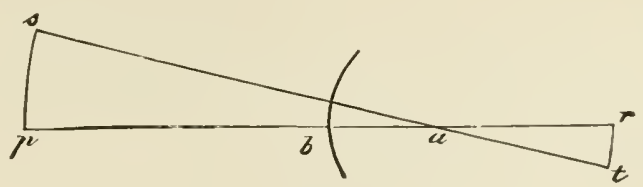

Fig. 208.

from it. In short an objeet in the plane $e$ has an ereet image of the same size in the plane $e^{*}$.

These two planes are ealled the principal planes of the system and the points at which they eut the optical axis are ealled the principal points.

All distanees in general are calculated from the prineipal points, those which concern the incident ray from the first, those which concern the refracted ray from the second.

Now what will be the relation between an objeet, whose rays are transmitted by a system of this kind, and its image? The answer is, just the same relation as between the objeet and image of a simple srstem.

If-e.g., in Fig. 208, which represents a simple optical srstem-an object, $s p$, be transmitted by a simple refracting surface, the size of the image, $t r$, will be to the size of the object as $a r$ is to $p a$ (from the similar geometrical figures asp and $a r t)$. The point $a$ of such a system is ealled the nodal point.

So also in Fig. 209 where $E E^{*}$ are the principal points and $F$ and $F^{*}$ the focal points, there will be two points $K$ and $K^{* *}$ so situated (at equal distanees from $E$ and $E^{*}$ ) that the size of the object $P A$ will be to the size of its image $P^{*} A_{1}$ as the distance $A K$ is to the distance $A_{1} K^{*}$. These two points are ealled the nodal points of the system. They may be defined as the two points so situated that a ray directed toward the first will be direeted toward the seeond after refraction, the rays before and after refraction being parallel.

It is erident that if we can locate accurately the nodal points of the ere and know the size and distance of any object, we can estimate the size of its image in the eye. Moser was the first (18t4) to make use of thenretical

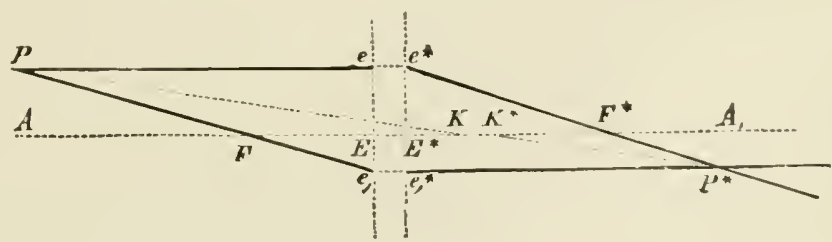

Fig. 209.

results obtained by Gause and Bessel and on the hasis of these to calculate the position of the two nolal points. Somewhat later Listing gave an estimate of the numerical values according to the best measurements completed at that time. Since his time the designation of schematic eye has heen applied to an eye whose optical constants correspond approximately to the mean value 
of the prevailing measurements. It must be observed, however, that, as will appear from the table on page 510, the indiridual variations are considerable.

In the following table are contained the optical constants from two schematic eyes, which have lieen calculated by Helmholtz on the basis of newer measurements.

The location is in all cases given as the distance in millimeters from the rertex of the cornea, and is reckoned as positive when it is posterior and negative when anterior.

\section{Directly Determined}

Refractive index of the aqueous humor and vitreous body.

Total refractive index of crystalline lens ..............

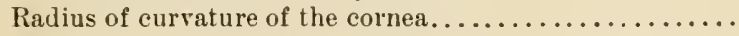

Radius of curvature of the anterior surface of the lens....

Radius of curvature of the posterior surface of the lens ...

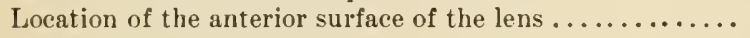

Location of the posterior surface of the lens.............

$\begin{array}{lc}\text { I. } & \text { II. } \\ 1.3376 & 1.3365 \\ 1.4545 & 1.4371 \\ 8.0 & 7.829 \\ 10.0 & 10.0 \\ 6.0 & 6.0 \\ 3.6 & 3.6 \\ 7.2 & 7.2\end{array}$

\section{Calculated}

\begin{tabular}{|c|c|c|}
\hline \multirow{2}{*}{ Cornea : anterior focal distance $\ldots \ldots \ldots \ldots \ldots \ldots \ldots$. } & & \\
\hline & 23.692 & 23.266 \\
\hline $\begin{array}{l}\text { Cornea : anterior focal distance } \ldots \ldots \ldots \ldots \ldots \ldots \ldots \ldots \ldots \\
\text { Cornea: posterior " } " \text { " } \ldots \ldots \ldots \ldots \ldots \ldots \ldots\end{array}$ & 31.692 & 31.095 \\
\hline 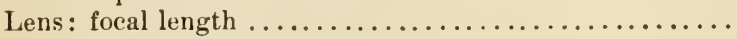 & $43 . \tau 0 \tau$ & 50.617 \\
\hline Posterior focal distance of the eye...$\ldots \ldots \ldots \ldots \ldots \ldots$ & 19.875 & 20.713 \\
\hline 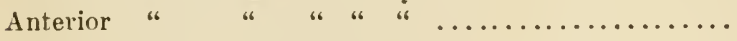 & 14.858 & 15.498 \\
\hline Location of the I principal point $\ldots \ldots \ldots \ldots \ldots \ldots \ldots$ & 1.9403 & 1.753 \\
\hline 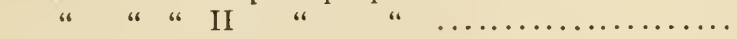 & 2.3563 & 2.106 \\
\hline I nodal point & 6.957 & 6.968 \\
\hline$\ldots \ldots \ldots \ldots \ldots \ldots \ldots$ & 7.373 & 7.321 \\
\hline anterior focal point $\ldots \ldots \ldots \ldots \ldots \ldots$ & -12.918 & -13.745 \\
\hline posterior focal point $\ldots \ldots \ldots \ldots \ldots \ldots \ldots$ & 22.231 & 22.819 \\
\hline
\end{tabular}

In Fig. 210 these values are brought together in a diagram of the human eye enlarged about three times. We see that the principal points $\left(h, h_{n}\right)$ lie in the middle of the aqueous chamber and the norlal points $\left(k, k_{n}\right)$ in the

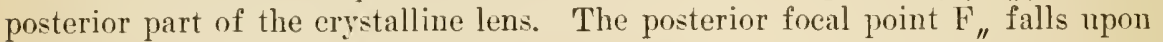
the retina.

By means of these so-called cardinal points, the path of any giren incident ray can be determined, as has been seen on page 511 , beyond its last refraction; likewise, the location of any point occurring in the neighborhood of the axis. Since, moreover, the two principal points and the two nodal points lie very elose together (by the above table, $0.416 \mathrm{~mm}$. and 0.353 $\mathrm{mm}$. apart respectively), for many purposes the two can be regarded as one point and the eye reduced to a single optical system. In this reduced eye the principal point lies (according to Listing's scheme) $2.345 \mathrm{~mm}$. posterior to the anterior surface of the cornea and the single nodal point 0.476 $\mathrm{mm}$. anterior to the posterior surface of the lens. If from this point a curve be drawn through the reduced principal point (radius of $5.125 \mathrm{~mm}$.) it will represent the anterior limiting surface of the reduced eye; in front of it is air, back of it aqueous humor or the vitreous body.

As appears also from the ahove table, the anterior focal distance of the cornea (II eye) is $23.3 \mathrm{~mm}$, that of the entire eye 15.5 and the focal length 
of the lens $50.6 \mathrm{~mm}$. The refracting power of the cornea is therefore 43.2 diopters ${ }^{1}(1,000 \div 23.3)$, that of the entire eye 64.5 diopters.

It follows that the strongest refraction of light takes place in the cornea.

Occasionally among old people the lens becomes turbid and opaque. In order to restore the sight in such cases the lens is removed. After the operation

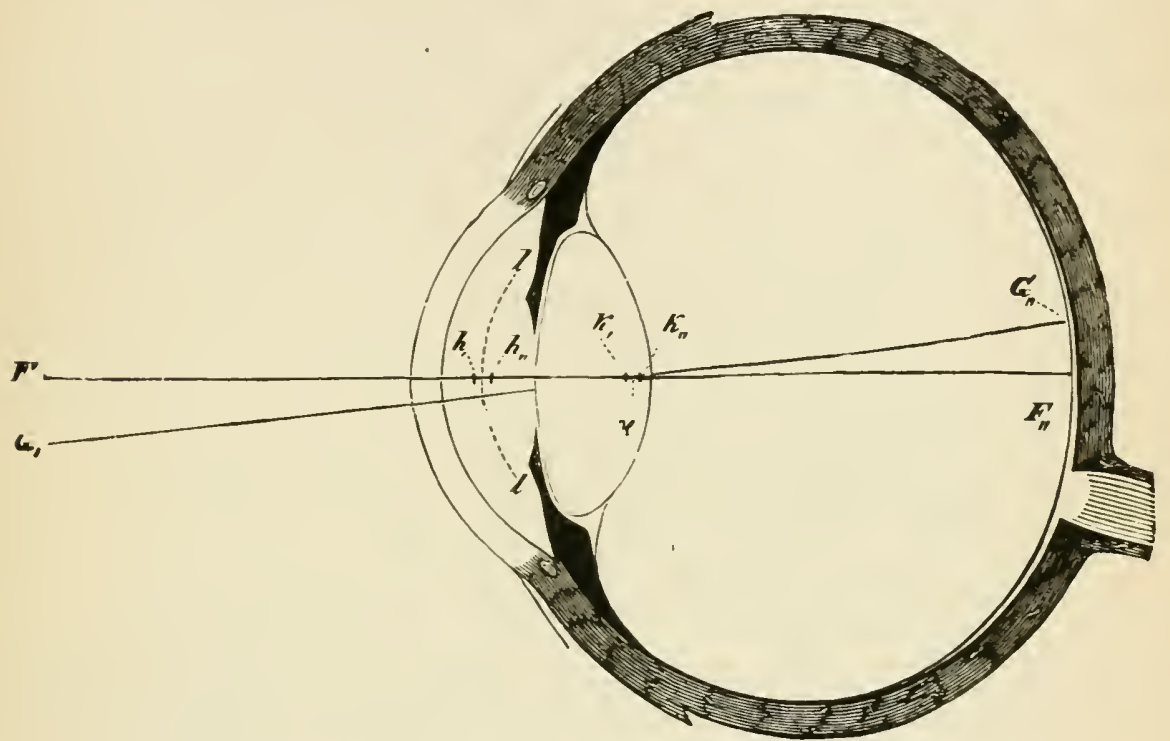

Fig. 210.-Position of the cardinal points in the schematic eye, after Helmholtz.

the refracting power of the eye, which can no longer be accommodated, is about $10 \mathrm{D}$, less than before-i. c., in the normal eye of old persons the lens raises the refracting power of the eye by about this amount.

\section{§ 2. IMAGES UPON THE RETINA}

The size and position of an image formed by a centered optical system depends not only upon the size and position of the object, but also upon the position of the cardinal points of the system. From Fig. 209 it is evident that so long as the distance $e P^{\prime}>F E$ the image will be inverted-i. e., so long as an object is beyond the outer or anterior focal point of the eye the image on the retina will be inverted. Again, so long as $e P^{\prime}>: F E$ the image will be smaller than its object or, applied to the eve. so long as the object is more than fwice the distance of the outer focal point from the cye, the image on the retina is smaller than the object. This tallies with our experience that we cannot foeus sharply on the retina rays from objects lying nearer the eye than twice its focal distance.

${ }^{1}$ One diopter (D) is the refracting power of a lens with a focal distance of 1 meter: the refracting power is the reciprocal of the focal distance. 


\section{A. DIRECT AND INDIRECT VISION}

When we wish to serutinize an object rery closely. we so direet the ere that the middle point of the object is pictured on the fovea centralis of the yellow spot in the retina. 'This point is therefore designated as the renter of exact rision. The diameter of the fovea according to Fritsch is $1-1.5 \mathrm{~mm}$, so that it corresponds to a visual angle (see page $51 \%$ ) of $t^{\circ}-6^{\circ}$.

The nervous elements of the retina. however, reach all the way to the ora serrata, and, being also sensitive to light. can produce conseious sensations from all parts. But these sensations, as compared with those aroused from the fovea, are more and more indistinct the farther the retinal cells affected lie from the fovea.

The reader can convince himself of this ly a very simple experiment. If one eve be closed and the other be directed intently at some object, he will find that of all the oljects in the room only that one directly regarded and those lying nearest it are seen distinctly, others appear less and less distinct the farther they are situated from the line of vision. Tision with those parts of the retina lying outside the foven centralis is called indircet vision.

Indirect vision is of very great service, for by it we obtain some idea of the space in which the object directly regarded is situated. Especially is it of service in walking, as anyone can prove to himself by trying to walk over an unfamiliar path with one eye closed and with indireet vision of the other excluded by looking through a tube or through the half-closed hand. He finds it difficult either to perceive or to avoid olstacles. In fact even close work, such as reading a printed page, is much more difficult under such circumstances, because only a small part of the print ean be seen at one time.

\section{B. THE LIGHT-PERCEIVING LAYER OF THE RETINA}

The retina consists of several different elements, part of which are nervous in nature and part serve as a supporting substance for the nervous structures. Ramon y (ajal has published not long since a detailed investigation of the strueture of the retina. II s chief results so far as the nervous elements are concerned. way be summarized briefly as follows (cf. Fig. 211):

The rod fibers $\left(\begin{array}{l}b \\ b\end{array}\right)$ whose bodies together with those of the cones, constitute the outer granular layer $(B)$ end inwarlly in little knots embraeed by the terminal fibers of the outer processes of the definitive bipolar cells $(c)$. These eells together with those belonging to the cones constitute the inner granular layer $(E)$; their outer tuft of dendrites is direeted vertically. Below the bipolar cell rests upon a ganglion eell $(n)$ and elasps it with fingerlike branches. These ganglion cells form the so-called ganglion-cell laver $(G)$.

The cone fiber $(a)$ ends in a broad base, from which short basilar dendrites are given off. With these the dendrites of the sprinal bipolar eells $(e)$ belonging to the cones eome into eontaet. The outer tuft of dendrites of these bipolar cells, in contrast with that of the bipolar cells belonging to the rods, is quite flat, and widely spread out. The inner proeess ends at various levels of the inner plexiform layer $(F)$ in a terminal arborization which comes into relation with the outwardly directed branchlets of definite ganglion cells. 
From the eells of the ganglion layer optic fibers are given uff, forming the innermost layer of the retina, the nerve-fiber layer $(H)$.

The lateral extent of the outer tuft of dendrites of the bipolar cells $(E)$, both of those which correspond to the rods and those which eorrespond to the cones, varies greatly. In general several rods or cones are connected with each of the bipolar cells. But each cone of the fovea centralis is in eontact with the dendrites of but one bipolar cell.

Compared with the end arborizations of the ganglion eells those of the bipolar cells are very small; consequently the smallest ganglion cells must be in touch with a relatively large number of bipolar cells.

In addition to these elements the retina contains still other eells of a nersous nature, lying either in the inner granular layer (outer and inner horizontal

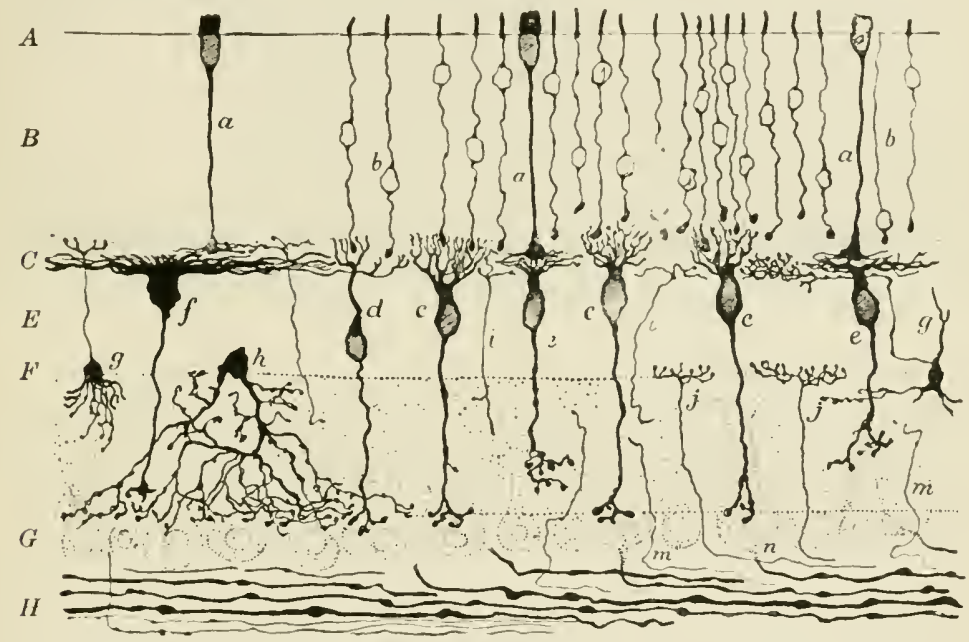

Fig. 211.-A section through the retina of a full-grown dog, after Cajal. A, layer of rods and cones; $B$, outer granular layer, containing the bodies of the visual cells; $C$, outer plexiform layer; $E$, inner granular layer, containing the bipolar cells; $F$, inner plexiform layer; $G$, ganglion cell layer; $I$, layer of the optie fibers. $\quad a$, cone fiber; $b$, body and fiber of a rod cell; $c$, bipolar cell with "brush" of fibrils belonging to the cones; $f$, giant bipolar cell with wide spreading brush of fibrils; $h$, diffuse amacrine celt, the varicose processes of which lie for the most part directly on the ganglion cells; $i$, ascending nerve fibers; $j$, eentrifugal fibers; $y$ and $g^{\prime}$, specialized cells which are seldom impregnated; $n$, ganglion cell receiving within it the terminal bruslı of a bipolar cell from the rods; $m$, nerve fiber which is lost in the inner plexiform laver.

cells) or in the inner plexiform layer (amacrine cells, $h$ ). The former, aecording to Cajal, are for the purpose of bringing definite groups of rods into relation with other definite groups more or less remote from them. Nothing positive can be sairl as to the signifieanee of the amacrine cells.

Finally, the retina contains also centrifugal nerve fibers $(j)$.

Which of these layers of the retina is the one primarily acted upon by the light?

Certainly not the nerve-fiber laver, for the optie nerre is just as insensitive to light as other nerve trunks. 'This is shown especially by the following experiment first performed hy Mariotte (about 1665). 
If the left eye he doserl and the right be fixed stealily on the white cross in Fig. :2: and the book be lueld at a distance of about 25 cm. from the eye, the white circle will disappear entirely from view, so that the black field appears uniform. There is. therefore, in the eye a spot which is not sensitive to light, and which is ealled for this reason the blind spot.

By measuring the apparent size of the blind spot. and its apparent distance from the fixation point of the eve, it can be shown to correspond exactly with the point of entranee of the optie nerve, where the mass of optic fibers. not corered by the hlack pigment, spreads outward toward the transparent media

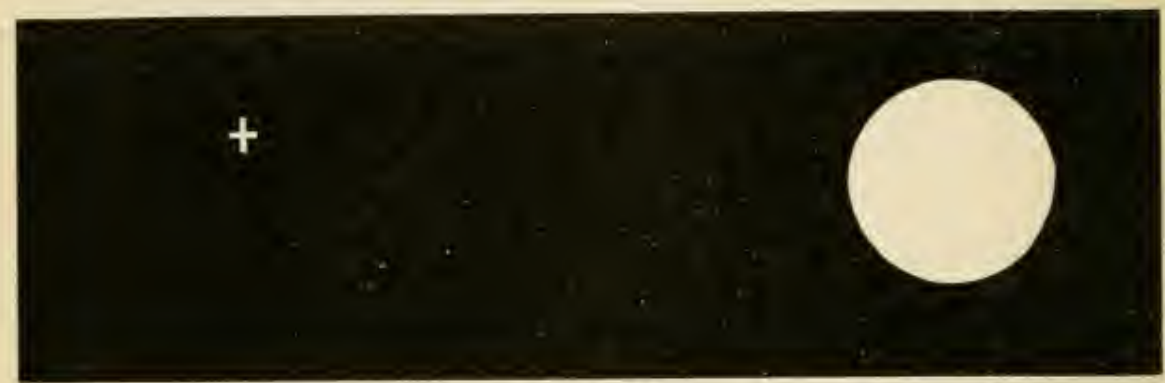

FIG. 212.

of the eye. The insensibility of the optic nerve fibers appears still more directly, if by means of a small mirror the light of a small flame be thrown into the eye so that it falls upon the point of entrance of the optic nerve. The subject experiences no sensation of light (Danders).

The blind spot is so large that at a distance of $1.7-2 \mathrm{~m}$. it can contain the image of a man's head. The reason why we do not ordinarily miss the object in our field of vision which falls upon the blind spot is, that we unconsciously fill the gap with something conformable to the rest of the ficld. Moreover the distance of the blind spot from the center of exact vision is such that objects in that quarter would be pretty indistinct if the spot were not blind.

'The light-perceiving layer of the retina, therefore, must lie behind the nerve-fiber layer, or still more aceurately behind the blond rescels of the retina, as was first shown by the famous experiment of Purkinje.

If a beam of light from a short-focus lens be concentrated on the conjunctiva of one eyc as far as posible from the cornea, and at the same time the gaze of this eve be directed toward a uniformly colored dark background, there appears at once in the field of rision a network of dark, branching ressels. This network is nothing else than the sharlow of the ressels of the retina.

Purkinje's figure, as this vascular tree is called, is rendered still more plainly risible if the illnminating lens be moved to and fro: it ran also be perceived, if while the gaze is directed to a dark backgroumd a burning candle be moved to and fro at one side and a little below the eye.

From the fact that we can perceive the sharlow of the retinal ressels in our own eyes, it follows that the vessels themselres are in front of the light- 
perceiving layer of the retina. Finally, loy exact physiological measurements, H. Mïller has shown that the distance between the ressels and the lightperceiving layer must be from $0.17-0.33 \mathrm{~mm}$., and microscopical measurements in tum have shown that the distance (0.2-0.3 mm.) takes us to the layer of rods and cones. Hence it follows with great probalibity that the latter structures, the rods and cones, are the light-perceiving parts of the retina.

Why do we not ordinarily see the Purkinje figures? Since the field of vision is always filled by objects which give more or less light to the eye, the pupil may be looked upon as a luminous disk throwing light upon the retina. Now the branches of the central vein of the retina are only about $0.085 \mathrm{~mm}$. in thickness; and with a pupillary diameter of $4 \mathrm{~mm}$., the umbra of these branches would be only $0.17 \mathrm{~mm}$. long and so would not quite reach the sensitive layer of the retina. The penumbra which does reach the rods and cones remains always in the same place and we have become so accustomed to its presence that we do not perceive it. In Purkinje's experiment, on the other hand, the shadow falls on an unusual place and the illuminated point has a smaller diameter than the pupil, both of which eircumstances tend to faror its pereeption in consciousness. If the source of light be not moved the figure disappears shortly, only to reappear when the source of light is again moverl, just as other objects are more readily pereeived when moving than when at rest.

Another cireumstance which strongly favors the light-pereciring function of the rods and cones is the fact that the other retinal layers gradually thin ont toward the yellow spot. so that in the very center of the fovea itself only cone cells are left. These are connected with the other layers of the retina by oblique, lateral branches (ef. Fig. ?11).

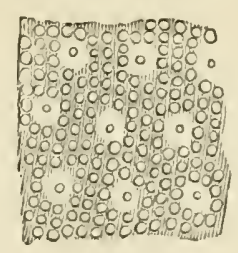

$\alpha$

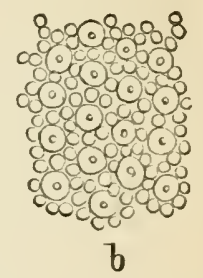

FIG. 213.-View of the rods and cones seen from the outer surface of the retina, after Max Schultze. $a$, arrangement of rods (small circles) and of cones (double circles) in most parts of the retina; $b$, arrangement in the region of the macula lutea.

Seen from the outside the layer of rods

and cones forms a mosaiclike surface (Fig. 213), an arrangement woll adapted to a light-perceiving function : for every object perceptible to the ere is tranformed by refraction into a mosaic picture of itself.

\section{VISUAL ANGLE AND THE LIMITS OF VISION}

When the eye receiges light from a luminons point, for whose distance it is not exactly accommodated. the light proceeding from the point is brought to a fochs in front of or back of the retina, and an illuminated cireular field (dispersion circle) is formed on the retina, the size of which depends upon the location of the focus. If the focus of the beam is close to the retina, either in front or lehind it. the dispersion eirele will be small: if farther from the retina, the circle will be larger.

All rays which nass through the pupil take a course in the vitreous body as if they proceeded from the picture of the pupil which the lens throws back 
into the vitreous boly. The actual size of the pupil therefore is, other things being equal, the factor determining the size of the dispersion circle.

We have alseady seen (page 511 ) that the position of the retinal picture of a luminous point can be determined in the schematic eye by drawing a straight line from the objective point to the first norlal point and another parallel to this from the second nodal point to the retina. In the reduced eye the two nodal points coincide and the retinal image falls where a line from the object through the nolal point meets the retina. Lines of this kind by which the location of the image on the retina can be determined are called lines of direction.

That particular line of direction which connects the middle point of an outer oljeet with the center of the forea in the retina is called the line of rision.

The lines of direction enable us to determine the size of the inage of an object formed on the retina. We have only to draw lines of direction from the extreme ends of the olject and solve the similar triangles thus formed (see page j11). By such a construction also we can calculate approximately the distance from each other of the images of two luminons points which are

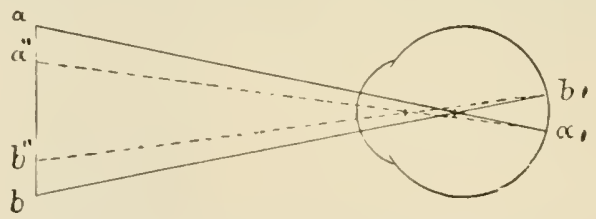

FIG. 214.-Diagram showing the visual angle, i. e., the angle subtended by two lines of direction $a^{\prime \prime} a^{\prime}$ and $b^{\prime \prime} b^{\prime}$ through the first nodal point.

just distinguishable, and can thus olstain a measure of the acuteness of rision. For several reasons, however, this linear measure is not used, but instead the angle which the two lines of direction sultend (Fig. 214) at the first or second nodal point. This angle is called the risual angle.

Acending to an old statement by Hooke, two stars whose apparent distance from one another is less than thirty celestial seconds always appear as one star. and searcely one person ont of a hundred can distinguish the two if their apparent distance is less than sixty seeonds. Later observers have obtained ralues varying all the way from fifty to ninety seconds.

In Listing's schematic exe a risual angle of sixty seconds corresponds to a distance on the retina of $0.0043 \mathrm{~mm}$. Microscopical measurements find the thickness of the cones in the yollow spot to be from 0.0054-0.0045 mm. (Kïlliker) to $0.0036-0.002-0.0015 \mathrm{~mm}$. Counts of the number of cones in the forea made by Salzer gave for the eyes of stillborn children 13,200-13,\$00 per square millimeter.

The limits of vision-i. e., the ability to distinguish two points-therefore depend upon the diameter of the cones in the eenter of rxact rision. To be able to perceive points as distinct and separate, they must fall upon cones which are separated by at least one resting cone. 


\section{§3. STATIC REFRACTION IN THE EYE}

The laws of refraction in an optical system teach $n$ s that for every different pasition of the olject the position of the image changes. For this rea-on in order to take a picture on a sensitive plate by means of a camera, the position of the plate must be adapted to the distance of the object.

But if the plate is immorable, as is true of the retina, a nearer object can be focused by using a stronger lens-i.e., by increasing the refracting power of its sytem. This is what happens in the eye. By arcommodation (see si), the refractive power of the erystalline lens can be inereased to different de-

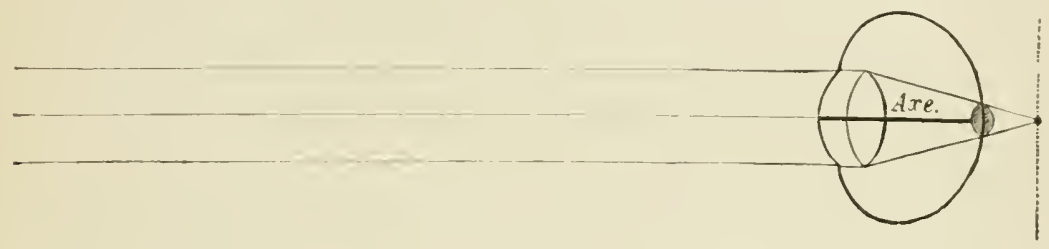

$A$

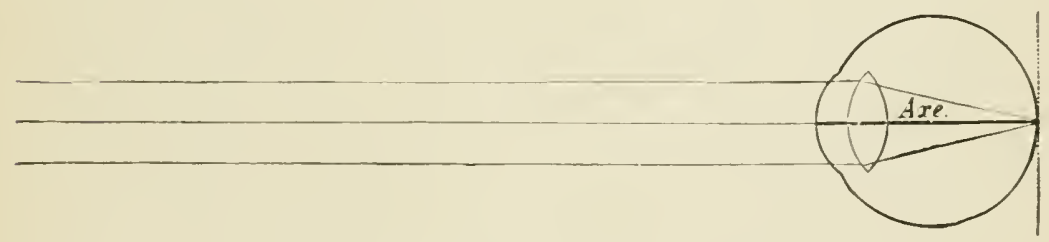

$B$

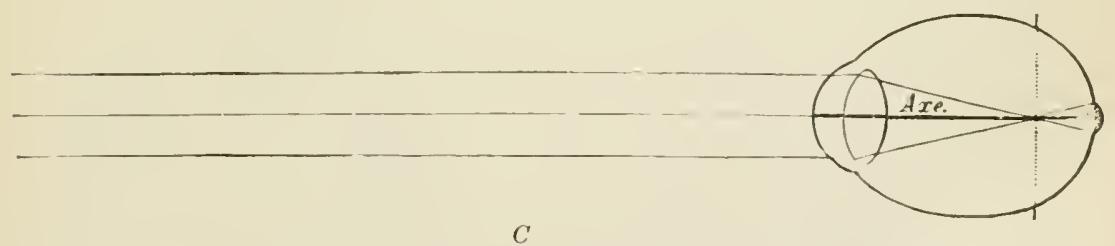

Fig. 215.-The static refraction of : $A$, a hypermetropie eye; $B$, an emmetropic eye; and $C$, a myopic eye.

grees, sn that objects at wiclely different distances ean be focused sharply on the retina.

An optical system is characterized by the distance of its posterior forml point: and we can distinguish three kinds of eyes according as the posterior focal point is on the retina, in front of or behind the rotina (Donders). Unaceommodated eyes with the posterior foeal point on the retina are to be regarded as normal and are called emmetropir (Fig. ?15. $B$ ).

Eyes of the seend kind where the focal point of parallel rays falls in front of the retina are called myopic or nearsiglited. becalus they are only able to focus on the retina such light rays as come from objects at a finite distance (Fig. : $15, C$ ). 
Eyes of the third kind, where the focal point falls behind the retina are called hypermetropic, or long-sighted (Fig. :215, 1). In order that incident rays may be brought to a focus on the retina of such an eye, they must already be convergent as they enter the eye. Since, however, converging rays never occur in nature. it is erident that a hypermetropic eye, not provided with artificial lenses. can focus parallel or divergent rays accurately only by accommodation : in short, the hypermetropic eye, if it is to see without glasses must always be accommodated.

Of the three kinds of eves the emmetropic is without doubt the best adapted to its purpose; for, as we have seen, rays from objects more than $5 \mathrm{~m}$. distant may be regarded as practically parallel for the eye so that the unacemmodated emmetropic eye ean form a distinct pieture of all such objects. The hypermetropie eye ean adjust itself for far distant and near abjeets by accommodation. But the myopic has no means at all of adjusting itself for distant objects and from this point of view at least must be regarded as the least serviceable of the three.

The far point of the eve is that point from which proceed light rays with the least divergence that can be focused by the eyc. In the emmetropic eve the far point lies of course at an infinite distance. The far point of the myopic eye lies at a finite distance in front of the eve. The far point of the hypermetropic eye lies behind the eye. It represents the point of convergence of those rays which, after refraction in the maccommodated ere, are brought to a focus on the retina.

We say therefore with reference to its structure that the refracting power of the myopic eve is too strong, that of the hypermetropic eve too weak.

By suitably chosen lenses both the myopic and the hrpermetropic eye can be made to focus parallel rays on the retina. If we place before a myopic eye a double concave lens of such a strength as to give the parallel rays the direction they would have if they came from the far point of the eye. it is evident that now the combination. lens + the eye. affects parallel rays, just the same as does an emmetropic eye.

If we place before a hypermetropic eye a double convex lens which converges parallel rays to its far point. then the combination, lens + the eye, must again be equal to the emmetropic eye.

The degree of myopia or hypermetropia is measured by the refracting power of the lens necessary to make the eye emmetropic. It is evident at once that the focal point of this lens coincides with the far point of the eye and the degree of myopia or hypermetropia is therefore expressed by the reciprocal ralue of the distance of the far point from the eve. This correction lens determines also the static refraction of the eye-i.e., the amount of refraction taking place without accommodation.

\section{§4. OPTICAL DEFECTS OF THE EYE}

In our discussion thus far we have silently assumed that the eye is a perfectly constructed optical instrument-that its refracting media are perfectly transparent, their surfaces exactly spherical and the centers of curvature 
of the various media all in the same straight line. Strictly speaking, however. this is not the ease, for the eve presents a number of optical defects. some of which in the majority of cases are quite negligible, while others occasionally affect its functional power to a very great extent. The shall have space here to discuss only the most important of these defects.

\section{A. TRANSPARENCY OF THE MEDIA OF THE EYE}

When we remember how complieated is the structure of the cornea and of the lens, it will not appear strange that these media are found not to be perfectly transparent. If a strong beam of light be thrown into the eye by means of a convex lens. the illuminated part of the cornea and of the lens immediately becomes visible-i. e.. these structures send out from all points an irregularly diffuse light. This diffuse light likewise passes to the retina. excites it and produces a mist of light within which the images regularly formed on the retina appear enshrouded. With ordinary illumination we do not perceive this mist and it does not interfere with vision, but one may be made aware of its existence in the following manner: If in the erening a person direct his gaze away from the artificial light and toward a dark corner. the differences of light and shadow from this quarter are much more readily perceptible than
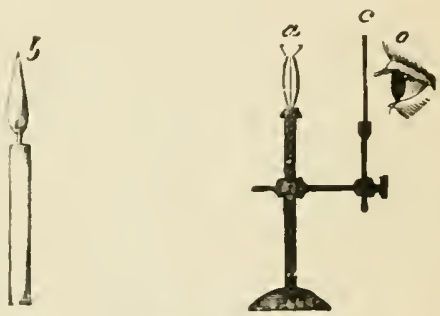

Fig. 216.-Method of demonstrating entoptic phenomena in one's own eye, after Helmholtz. equal differences coming into the eye from the direction of the source of light. The reason is that the mist of light thrown into the eye in the latter case by the highly illuminated pupil interferes with the contrast effects necessary to perception of such differences. Aecordingly, when one wishes to distinguish slight differences of light and shade, he instinetively turns his back to the source of light.

There also exist in the eve certain flecks which under eertain circumstances may interfere considerably with perfect vision, especially if they lie in the posterior part of the ritreous body. The perception of these flecks in the transmitting media is described as "entoptic" phenomena. We have already had an example of such phenomena in Purkinje"s figure (page .516).

Under ordinary circumstances these small dark flecks are not noticed: the reason is that an almost uniform amount of light enters the eve through every portion of the pupil, and thus the entire pupil constitutes the illuminating surface alike for all parts of the posterior portion of the eye. The flecks being smaller than the pupil, the shadows cast by them are naturally very short and do not ordinarily reach the retina.

The following method (Helmholtz) may be used for demonstrating these entopic phenomena. $\Lambda$ convex lens of large aperture and short foeal distance (a, Fig. 216) is placed before the eve; at some distance in front of the lens is placed a candle, $b$, a small image of which is formed by the lens at its focal point. Then a small screen, $c$, with a minute opening, is so placed that the redueed image of the flame falls in the opening. If the image lies in the 
anterior focal point of the ere, the rays from it which enter the eye will be parallel after refiaction and a shadow of any object (b, in Fig. 217) in the vitreous boly which is formed on the retina $(\beta)$ will be of the same size as the object itself.

\section{B. FORM OF THE REFRACTING SURFACES}

To be able to judge the ere as an optieal instrument we must have more detailed information of the actual form of the refracting surfaces. Our knowledge along this line is limited for the most part to the cornea, which, however. as we have already seen, is the most important

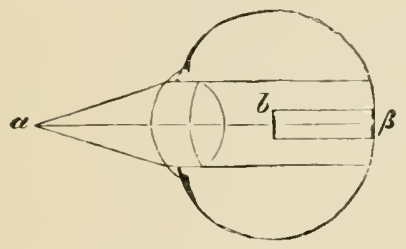

Fig. 217.-After Helmholtz. of the refracting media (cf. page 513).

The most exact study of this subjeet we owe to Gullstrand who used the following method. A lisk with concentrie eircles (Placido's keratoscope) is so placel as to be reflected by the cornea: the reflected image is photographed by the instantaneous method; and the distances of the cireles from one another are measured on the photograph. Knowing the corresponding differences on the object and the distance of the latter from the cornea, the radius of curvature of the different sectors of the cornea can be calculated.

We find as a result of this method that the optical zone of the corneai. e. that part immediately in front of the pupil-alwars approaches the spherical in form, but that it is often less sharply curved in one meridian than another. Instead of being the segment of a sphere with a circular cross section, it is then a dome with an oval eross section.

If the surface of the cornea were always perfectly spherical, it would share with all such surfaces the defect of spherical aberation (Fig. 218). It will be evident from the figure that spherical aberration can be corrected by flattening the refracting surface at the periphery enough to bring the several foci together. Gullstrand has found from his detailed study of the curvature of the cornea. that, as a matter of fact, the spherical aberration in the vertical plane is slightly oftset by a flattening directly above the line of vision. which is probably due to the pressure of the upper evelid. Elsewhere the flattening is not sufficient to affect the aberration. Hence we may say that that part of the cornea which is used for direct vision exhibits this defect.

\section{ASTIGMATISM}

When the optical zone of the cornea is not perfectly spherical but is curved more sharply in one merihian than another, the refraction of light will not be equal in the wo meridians. If this differenee is slight there will be no disturbance to rision; hut it not infrequently happens that the asrmmetry of structure is great enough to interfere with the ability to focus enrectly.

I heam of light which is not bronght to a single point after refraction. hut has different foeal distances for different meridians. is described as astigmalic. If the two mericlians in which the foeal distance is greatesi and least 
are perpendicular to each other, the astigmatism is tescribed as regular. THe shall discuss only this kind of astigmatism here.

An astigmatic heam may he formed in two ways: (1) When the optical system is asymmetrical and the incident rays vertical; and (?) when the optical system is symmetrical and the incident rays ohlique.

The first case is the simplest (for the second see page j25). Suppose we have a lens, which in the horizontal meridian has a refractive power of 10 diopters; in the vertical meridian a refractive power of 12 diopters. It is evident that the beam after refraction will no longer have a common focus, for the incident rays in the horizontal meridian are brought to a focus $\frac{1}{10} \mathrm{~m}$. behind the leis and those falling in a rertical meridian $\frac{1}{12} \mathrm{~m}$. behind the lens.

Further study of the problem las shown that if no account he taken of the spherical aberration. the light rays instead of being converged to foci at the focal points of the two meridians are converged into a focal line perpendicular to the principal ray at each of those points. The first focal line corresponds to the focal point of the meridian with the strongest refractive power and is perpendicular to that meridian-i. e., in the plane of the weakest meridian. The second focal line corresponds to the focal point of the weakest

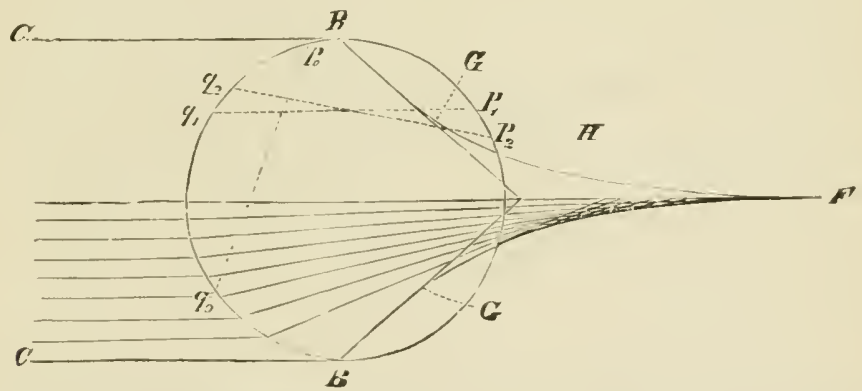

Fig. 21S.-Illustrating splerieal aberration. The rays parallel to the axis of the system are converged to foci nearer and nearer the comvex surfice the farther they are removed from the axis.

meridian and is perpendieular to that meridian-i. e., in the same plane as the strongest meridian.

In front of the first focal line the heam of rays forms in a cross section an ellipse with the longer axis in the direction of the first focal line, berond the second focal line the heam forms an ellipse with the longere axis in the direction of the secoud focal line. I transition from the one elongation to the other takes place between the two focal lines, the upright cllipse hecoming first a cirele and then a procumbent allipse (Fig. :-19).

lu an astigmatic "re. therefore. a homocentric ${ }^{1}$ humble of rays cannot be brought to a single foens. When the are is arljustod for the most refractire merirlian. the images on the retina are all drawn out in the direction of the

'That is, rays pro eeding from a common point or rays which pass through a common point when prolonged. 
first foeal line: when it is adjusted for the least refractive meridian the retinal images are drawn out in the direction of the second focal line-in both cases, therefore, distorted. To prevent this the eye is adjusted so that some point between the two focal lines falls on the retina. The distortion of objects is thereby rendered less, but the distinctness of the image is more or less reduced.

Astigmatism may be demonstrated subjectively by the use of a chart (like that in Fig. 220) composed of several radii, all of the same width and depth of

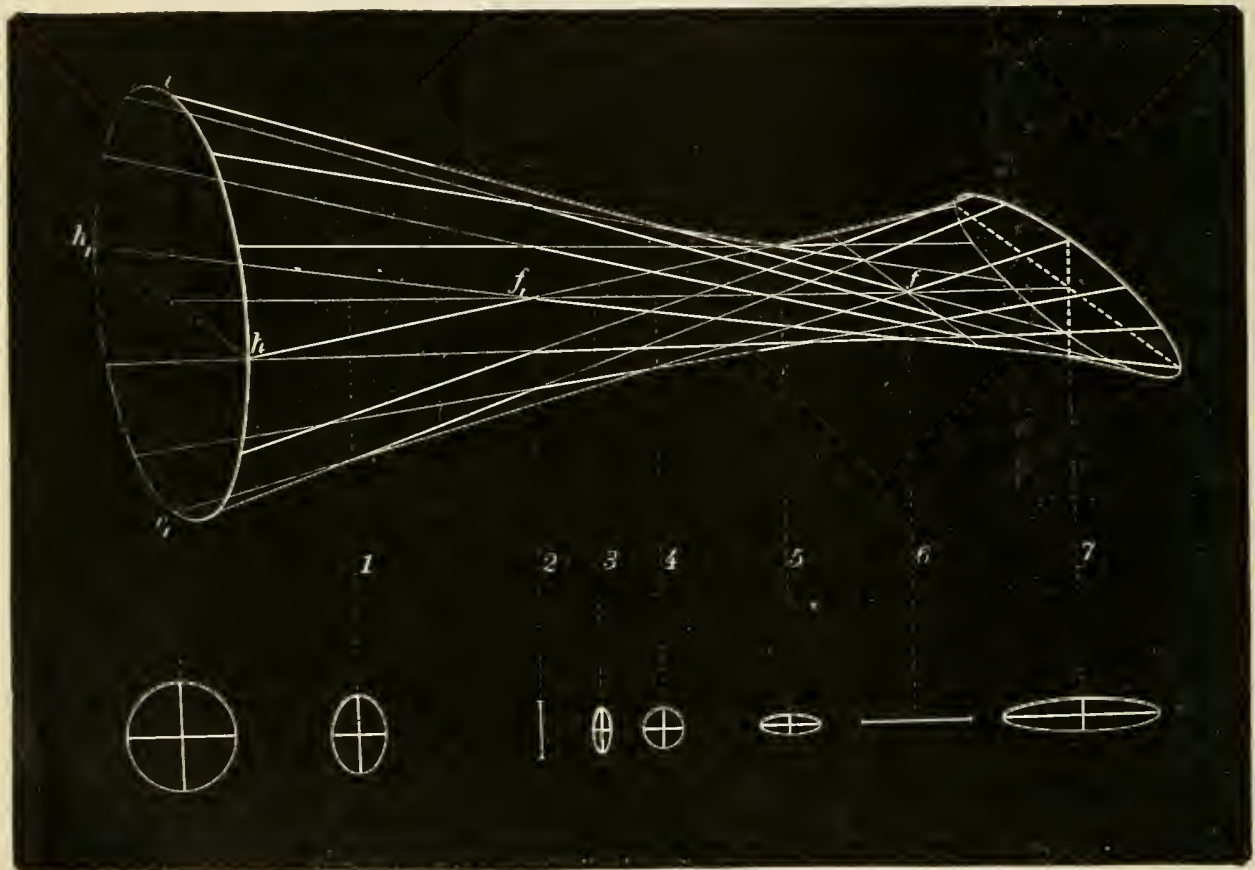

FIG. 219.-Refraction of the light rays in regular astigmatism, showing the form of a beam at different cross sections, after Fuchs, $v v$, vertical meridian of the cornea; $h, h$ the horizontal meridian. The focus for the horizontal meridian is at $f_{f}$; that for the vertical meridian at $f$; the image of a point is, therefore, not a point but a dispersion circle. The slape of the circle, however, is determined by the spot at which the retina is situated. At the position 2 , the image of a point would be a vertical line, at 4 a circle, at 6 a horizontal line, etc.

color. If this chart be held before the eye at such a distance that only one meridian can be seen distinctly, this meridian corresponds in direction to the most refractive meridian of the eye, and its image on the retina to the second focal line. If now the chart be brought as close to the eye as possible, again only one meridian is distinct. In regular astigmatism this meridian is at right angles to the first: it gives the dircetion of the least refractive meridian of the eye and its image corresponds to the first focal line.

A certain degrce of astigmatism occurs in all eves, although, as a rule, it is so slight as to have no practical importance. The astigmatism which causes a noticeable distortion of images is eaused mainly by the asymmetrical structure of the cornea. 
As a rule, however, the actual astigmatism of the cornea is greater than the total astigmatism as determined by the subjective method. This means that it is compensated to some extent by some structures in the ere itself-as, e. g., the lens.

Aceording to measurements made by Nordenson on pupils between the ages of seven and twenty, out of 452 eyes examined onl ${ }^{2}+2$ (nine per cent) had $n o$ astigmatism of the cornea which could be detected. Sixtr-nine pupils had an astigmatism of more than 1 diopter, and four an astigmatism of more than 1.5 D. However, a normal acuteness of vision is perfectly possible with an astigmatism of 1.5 diopters. In 85.1 per cent of the astigmatic eses examined the vertical meridian was the most refractive: in 1.5 per cent the horizontal, and in 13.4 per cent an oblique meridian. In the majority of cases therefore the vertieal meridian is the most sharply curved.

The difference in static refraction between the most refractive and the least refractive meridian of the eve, expressed in diopters, is known as the degree of astigmatism. After this has been determined (by methods which we cannot discuss here) it can be corrected by means of cylindrical lenses-i. e., glasses which represent segments of the eurved surface of a cylinder.

In using such glasses for the correction of astigmatism the glass is so placed that its own asymmetry is the reverse of that of the eve. Suppose an eye were myopic in the rertical meridian and emmetropic in the liorizontal. Then the eye could be made emmetropic by placing before it a suitable concave-eylindrical glass with a curvature in the vertical meridian. The myopia in this meridian woulı! be corrected by the curvature. Rays falling in the hori-

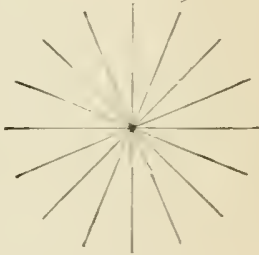

FiG. 220. zontal meridian would not be refracted at all, and would not neerl to be, for the eye we suppose is already emmetropic in that meridian. Correction for other sorts of astigmatism and for astigmatism combined with mropia and hypermetropia can readily be devised by the reader.

\section{THE ANGLE BETWEEN THE LINE OF VISION AND THE VISUAL AXIS}

The laws of refraction thns far discussed proceed on the assumption that the line of vision coincides with the optical axis of the eve. But this is not the case. The line of rision in front of the ere lies insille of and somewhat above the optical axis, the center of exact vision therefore lring nutside of and somewhat below the axis. In Fig. ?10 (page 513) $G, G_{11}$ marks the line of rision; $F, F$, the optical axis.

The angle between the line of rision and the optical axis is designated as the angle $a$. Its size in the horizontal meridian is $3.5^{\circ}-\% .0^{\circ}$, and in the rertical approximately $3.5^{\circ}$.

The rays of light entering the ere in the line of rision therefore strike it obliquely. Under these circumstances a homocentric beam remains no longer lomorentric. but hecomes astigmatic (sec page .5.3), the rays falling in the horizontal meridian heing most strongly refracted. This astigmatism however is more than compensated by the ordinary astigmatism of the opposite kint in the cornea.

As:mming the angle $a$ to be $5^{\circ}$, Gullstrand calculated the influener of the oblique incidence of the line of rision for the schematic eye and found that the 
distance between the two focal lines was only $0.03 \mathrm{~mm}$. and the degree of astigmatism only 0.1 diopter. These figures explain why, as has long been known. the sharpness of rision commonly suffers no reduction from this kind of astigmatism.

\section{E. CHROMATIC ABERRATION IN THE EYE}

The refractive index of solid and liquid media is different for rars of different wave length-e. g.. that of water for red (spectrum line C) is 1.331 ; 05 and for riolet (spectrum line G) $1.34128 j$. For a long time it was supposed to be impossible to prerent this dispersion of light into its colors in any optical system. Later. howerer. it was shown to be possible and instruments have long since heen constructed in which no color dispersion at all occurs.

Our everyday experience teaches us that the chromatic aberration in the eye cannot be very great, for in ordinary life it is almost entirely unnoticeable. But more exact investigation of the subject shows that the achromatism of the eye is by no means perfect.

Since, the refractive indices of the optical media in the eye for the most part do not differ much from that of water. Helmholtz calculated the dispersion for the reduced eye (see page 512), on the assumption that water was the

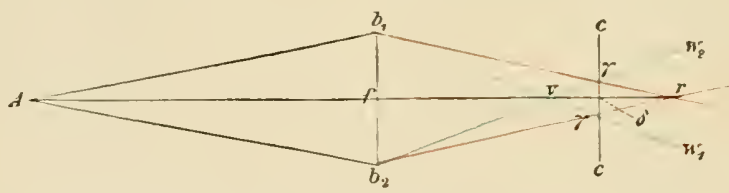

FIG. 221.-Diagram illustrating the chromatic aberration of an eve.

refractire substance throughout, and found that the posterior focal distance for red (line C) was $20.574 \mathrm{~mm}$. and for riolet (line G) $20.14 \mathrm{~mm}$. Actually the color dispersion in the human exe appears to be somewhat greater (the distance between the focal points of red and riolet $0.55-0.62 \mathrm{~mm}$. instead of $0.434 \mathrm{~mm}$.). According to Einthoren, the difference in focal distance between the $\mathrm{D}$ and $\mathrm{F}$ lines in the schematic eye is $0.272 \mathrm{~mm}$.

There is, howerer, a phrsiological reason as well as a structural one why the color dispersion is not plainly noticeable. When white light enters the eye and the eye adjusts itself for the most strongly effective rays of medium wave length, the latter come together on the retina almost exactly in one point, which is surrounded by a fringe of red and riolet rass. But the exciting effect of rays of very great or very small wave length is relatively slight, consequently the action of the fringe zone in comparison with that of the center is negligible. Besides, the center is more strongly illuminated than the fringe zone because lays of all ware lengths strike it.

The same thing is true of the dispersion circles caused by the spherical aberration when the eye is adjusted to the focal point of the central rays.

Only one experiment on color dispersion in the ese can be described here. If one holds before an ordinary petroleum flame a screen with a narrow opening in it and behind this a cobalt-blue glass which shuts out most of the orange. yellow and green rays, but lets through an abundance of ultra-red, indigo-blue and riolet rays, the opening may be seen as a luminous point sending out red 
and violet rays. Now this point appears differently to the observer according to the distance for which the eye is adjusted. If it is adjusted for the red rays, there appears a red spot with a violet halo; if it is adjusted for the violet rays, a violet point with a red halo. This will be evident from Fig. 218 if one imagines the retina in the first ease to be located at $r$ and in the second at $v$. This experiment is particularly beautiful if an electric incandescent lamp be used.

The colored circles of subjective origin (II. Merer's rings) which are perceptible around a source of light under certain abnormal eireumstances, as in conjunctivitis, or after the effect of osmium vapor, are to be explained by the diffraction of the light about dead epithelial cells, mueous eorpuseles, ete, on the surface of the cornea. A similar color phenomenon (Donder's rings) is produced by diffraction at the edges of the lens, but this oceurs normally only when the pupil is greatly dilated (Salomonsohn).

\section{F. SUMMARY}

Summarizing the optical defects of the eye, we may say that while it exhibits various defects which could not be pernitted in a good optical instrument, yet its capacity as an organ of vision is surprisingly little interfered with. The oblique incidence of the line of vision, the difference in the refraction between the different meridians of the cornea. the imperfect correction of spherical and chromatic aberration-none of these nor all of these together diminish the capacity of the ere to such an extent as to produce any perceptible disturbances in vision. But this is true only of the normal eye. It happens not infrequently that these defects exceed the normal limits and then the eye must be described as a rather poor optical instrument. Oftentimes in such cases. the optical properties of the eye can be rery considerably improved by practical treatment.

\section{\$ 5. THE IRIS}

In order that a proper image formed in a camera may not be interfered with by light reflected from the inner walls, the latter are always covered with a dull black color. The retinal pigment and the strongly pigmented choroid coat serve the same purpose in the eve.

The iris which is but the anterior prolongation of the choroid coat likewise has an important function. It has been shown that the laws of refraction in an optical srstem hold good in case only such rays enter as form a very small angle with the optical axis, and the peripheral rays are shut out. This exclusion of the peripheral rays, so important for the clearness of the images, is provided for by the iris. The pupil can be constricted or dilated by contraction of circular or radial fibers respectively in the iris. Such alterations in the size of the pupil serve the optical requirements of the ere in two ways: in near vision, if this is accompanied by convergence of the optical axes, the pupil constricts and thereby contributes to the sharpness of the image; again, when the asymmetry of the cornea is great, the resulting astigmatism is counteracted to a certain extent by constriction of the pupil. The pupil has in addition the important function of protecting the retina from too intense a light; it constricts in strong light and dilates in weak light. 
Constriction of the pupil is caused by contraction of a circular muscle, composed in most animals of smooth muscle fibers and known as the sphineter of the pupil: dilatution. by smooth radial tibers known collectively as the dilator of the pupil. The existence of an independent dilator was conclu-

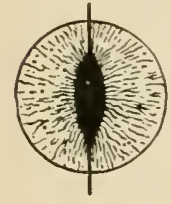

A

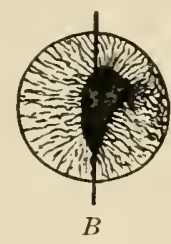

FIG. 222.-The iris of a cat. $A$, at rest ; $B$, on stimulating it at the upper right-hand side (Langley). sively proved several years ago by the physiological experiments of Langley and Anderson; it has recently been demonstrated anatomically as well.

The muscles of the iris receive their nerves hy both cerebral and sympathetic pathways. The constrictor fibers are found in the nculo motor. From this nerve they pass orer to the ciliary ganglion, connect there with nerve cells (Langendorff), and continue thence through the short ciliary nerves to the sphincter pupilla. Stimulation of a single one of the short ciliary nerves causes only partial contraction of the sphincter, so that the pupil takes an irregular form. It is stated that the oculo motor at the same time inhibits the dilator of the pupil.

The dilator fibers of the pupil come from the sympathetic. They pass out of the spinal cord by the anterior roots of the seventh to the eighth cervical and the first to the second thoracic spinal nerves, go to the first thoracic ganglion, then through the anterior arm of the annulus of Vieussens to the inferior cervical ganglion, and from this by way of the trunk of the cervical sympathetic to the superior cervical ganglion. From the superior cervical ganglion, the fibers pass to the Gasserian ganglion, follow the trigeminal and traverse the long ciliary nerves, without connecting with the ciliary ganglion, to the iris. Stimulation of the srmpathetic is said to cause inhibition of the sphincter as well as excitation of the dilator (Reid).

Both constrictor and dilator fibers of the pupil are in a state of tonic excitation: when the cerrical sympathetic is cut, the pupil constricts; when the oculo motor is cut, it dilates.

The following experiments by Langley and Anderson show that the dilatation of the pupil is not merely a matter of inhibition on the part of the sphincter pupillæ. When the sclerotic was stimulated locally with the induction current, a short local dilatation of the pupil (Fig. 222) was obtained. Were the dilatation due solely to inhibition of the sphincter, the movement would have been uniform all around the pupil. Again, when a sector of the iris is isolated except at its ciliary attachment by two radial cuts (Fig. 223), this sector shortens both on direct stimulation and on stimulation of the cerrical sympathetic.

Changes in the diameter of the pupil under normal circumstances are for the most part produced reflexly. The most

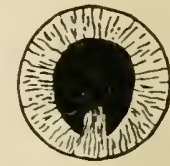

FIG. 223.-After Langley. important of these reflexes is mediated by the optic nerve. Constriction begins within 0.10 .5 second and reaches its maximum in about 0.1 second thereafter (Listing). It requires but an instantaneous flash of light to call out the reflex constriction ( $\mathrm{r}$. Tintschgau).

In all animals in which only part of the optic nerve fibers cross at the 
chiasm (man, monkey, predatory animals and some rodents) contraction of both pupils results-i. e., the reflex excitation passes orer from one optic nerve to both oculo motor nerves when light enters but one eye.

Stimulation of other afferent nerves, and powerful respiratory morements, as in dyspncea, etc. are as a rule accompanied by dilatation of the pupil, although reflex constriction has also been obserred with such stimulation. Likewise stimulation of the most widely different parts of the brain. cerebral cortex (motor zone and temporal convolutions), corpora striata, optic thalami, anterior and posterior corpora quadrigemina, produces dilatation. Dilatation of the pupil on stimulation of afferent nerres as well as on stimulation of these varions parts of the brain in many cases persists after bilateral section of both the cerrical sympathetic and the trigeminal nerres. It must be regarded therefore as, in part at least, the result of inhibition of the constrictor center.

The tomus of the constrictor nerves is mainly of reflex origin. for after section of the optic nerse section of the oculo motor no longer produces dilatation of the pupil (Knoll). But stimulation of the optic nerve cannot be the only cause of the sphincter tonus, for the pupil is strongly constricted in sleep.

The center for the constrictor nerves of the pupil is to be sought in the nucleus of the oculo motor nerve. According to Hensen and Völckers, in the dog it lies in the floor of the third ventricle close to the aqueduct of Sylrius and a little posterior to the center for accommodation (Fig. 230).

The center for the dilatation of the pupil was located by Budge in the cervical cord (centrum cilio spinale); other authors have been led by their investigations to conclude that the center is located in the brain and that fibers pass thence down the cord to the roots of exit. Since, howerer, after section of the cord high in the neck, the pupil is dilated on stimulation of the sciatic nerve, but is always constricted by section of the cervical cord alone, we may perhaps safely infer that there is a center in the cord, the normal tonic influence of which is to ktep the pupil dilated.

\section{\$. ACCOMMODATION}

\section{A. RANGE OF ACCOMMODATION}

A point of light starting from the far point of the eve and brought gradually nearer to it, can be kept constantly focused on the retina. But this is possible only up to a certain limit, there being for every exe a near point whence it receires the nost divergent rays which can be focused on the retina. In order that these most divergent rays may be focused on the retina the refraction of the eve must he increased in some way. The change in the eye by which this is accomplished is called accommodation. Knowing the far point and the near point of the eve. it is rery easy to calculate how much the refraction is increased by accommodation.

The focal distance of the lens which will gire to the rays proceeding from the near point the direction ther would hare if ther came from the far point furnishes the measure of the range of accommodation. 
We hare here to distinguish between range of accommodation and line of accommodation. The former, as just stated, is the measure of the increase in refracting power which can be brought about by accommodation. whereas the latter gives that depth of space within which the ere can form by the help of accommodation a clear picture on the retina. The range of accommodation is entirely independent of the static refraction of the eye: but the line of accommodation varies considerably in eves of different refractive conditions.

The range of accommodation decreases gradually with age, as the following table compiled by Donders will show:

\begin{tabular}{|c|c|c|c|}
\hline Age in Years. & $\begin{array}{l}\text { Range of accommodation. } \\
\text { Diopters. }\end{array}$ & Age in Years. & $\begin{array}{l}\text { Range of accommodation, } \\
\text { Diopters. }\end{array}$ \\
\hline 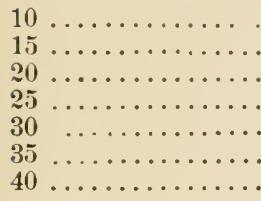 & $\begin{array}{r}14.0 \\
12.0 \\
10.0 \\
8.5 \\
7.0 \\
5.5 \\
4.5\end{array}$ & 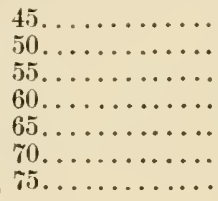 & $\begin{array}{l}3.5 \\
2.5 \\
1.75 \\
1.0 \\
0.75 \\
0.25 \\
0.0\end{array}$ \\
\hline
\end{tabular}

This gradual diminution in the optical power of the eve is called presbyopia. It must not be confused with hypermetropia, for hypermetropia is a

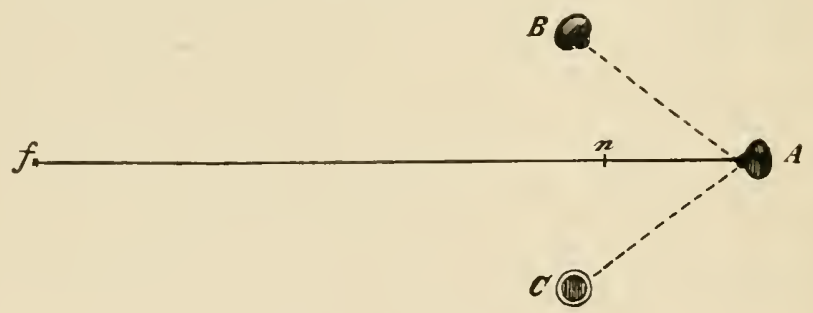

FIG. 224.-After Helmholtz.

particular kind of static refraction, while presbyopia is caused by a loss in the power of accommodation.

Presbyopia is treated with convex lenses, the strength being so chosen that rays proceeding from a point lying conveniently near the eve appear to come from the actual near point. Objects can then be held at any distance and be clearly focused on the retina.

\section{B. MECHANISM OF ACCOMMODATION}

The change in the optical apparatus which takes place in accommodation consists in an alteration of the form of the lens. This view was first expressed by Descartes (163r), but the first conclusive proof of it was furnished more than two hundred years later by Max Langenbeck, Cramer, and Helmholtz (1849-1854).

We have already seen (page 52: that the radius of currature of a spherical refracting surface can be calculated from the size of an image reflected from 
it. Now it has been shorn that in accommodation for near vision the image reflected from the cornea does not change, while that from the anterior surface of the lens, and to a less extent also that from the posterior surface. does. That is to say, the two surfaces of the lens become bulged out more in aceommodation, the anterior howerer to a much greater extent than the posterior.

In order to observe these ehanges of form. the eve to be examined is given two definite points to look at ( $f$ and $n$, Fig. $2: 2$ ), lying in the same straight line directly in front of it. Then two slits of light from a large bright lamp flame situated to one side of the line of vision and on the same level with the eye are thrown into the eye. In Fig. ?:t let $A$ be the observed eye and $C$ the flame, $B$ the eve of the observer. If now the observer move

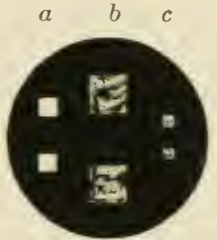

A

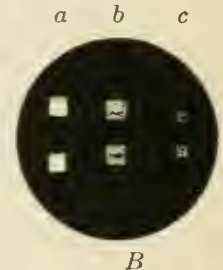

$B$

Fig. 225.- The reflected image from the cornea (to the left), that from the anterior surface of the lens (middle picture), and that from the posterior surface (to the right), after Helmholtz. $A$, as seen in an eye adjusted for distant vision; $B$, as seen in an eye accommodated for near vision. his eye back and forth in the neighborhood of $B$, so that the angle $B A f$ is approximately equal to $C A f$. he should see three pairs of images reflected from the observed ere, namely, $a$ (Fig. 2.25). the brightest coming from the cornea. and $b$ and $c$ from the anterior and posterior surfaces of the lens. When the eye is aljusted for distant rision the images hare the appearance of Fig. 2.5. $A$; for near rision (Fig. 2.5.5. $B$ ). the image $a$ does not change, but the image $b$ becomes rery much smaller. By very exact methods it can be shown also that $c$ becomes slightly smaller.

With these changes in the form of the lens the pressure in the anterior chamber of the eye does not increase, neither does the posterior surface of

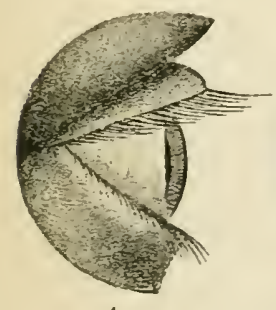

A

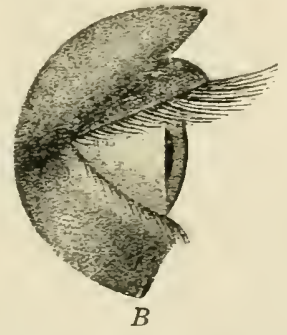

FIG. 226.-The protrusion of the iris in arcommodation, after Helmholtz. $A$, an eve adjusted for distant vision: $B$, an eye adjusted for near vision. the lens change its position, hence the lens as a whole is not displaced. But the anterior surface of the lens presses forward and pushes the iris before it. This can be seen by looking at the cornea of the ere of another person from the side and a little to the rear (Fig. 2?(i). With the obserred eye adju-ted for distant rision, the observer should place himself so that he can see just a little of the black pupil projecting in front of the sclerotic. Then when the ere is accommodated for near vision, the pupil becomes much more plainly visible. We have already called attention to the fact that the pupil itself becomes narroter in aceommodation.

Aceording to $\mathrm{O}$. Weiss, the radius of curvature of the anterior surface of the lens accommodated for a distance of $i+9 \mathrm{~mm}$., is $9 \mathrm{~mm}$.; for $33 i \mathrm{~mm}$.. $8 \mathrm{~mm}$.; and for $199 \mathrm{~mm} ., 7 \mathrm{~mm}$. 
The whole anatomical structure of the eye indicates that the ciliary muscle must in some way participate in bringing about the change in the curvature of the lens. But views ditler considerably as to the way in which this takes place.

In a meridional section of the eve, the citimry muscle (Fig. 2:? f flls up a triangular field in the ciliary body. It constitutes therefore in the whole circumference of the eyeball a circular three-sided, prismatic band. which, as

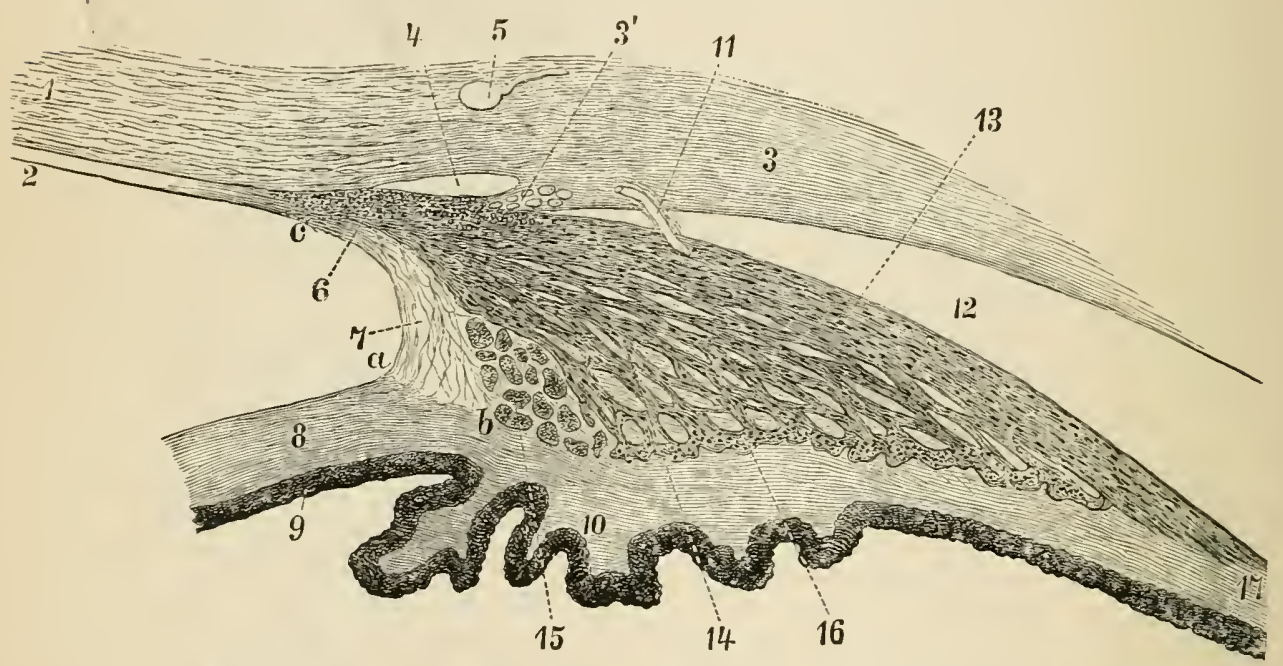

FIG. 227.-Meridional section through the ciliary body of a human eve, after Schwalbe. 1, cornea; 2 , membrane of Descemet; 3 , sclerotic coat; 4 , Scllemm's canal; 8 , stroma of the iris; 9 , pigment epithelium of the iris; 10 , inner connective-tissue layer of the ciliary body, continuous with the connective-tissue framework of the ciliary process; 13 , mericlional fibers of the ciliary muscles; 1 ' , rarlial fibers of the ciliary muscle; 1.5 , circular muscle of $\mathbf{1}$ üller; 16 , circular muscle fibers of the inner surface of the ciliary body: $1 \%$, choroid coat.

the figure shows, is often interlaced with strands of comnective tissue. Iwanoff distinguishes three kinds of muscular filsers according to their direction, namely, (1) meridional filsers running from the selerotic fold. (3', Fig. ?.? backward to the loundary of the trie choroid enat: (?) rarlial fibers extending from the lamellx beneath Schlemm's canal to the whole inner face of the triangle; and (3) the circular fibers. the strongest bundles of which rum along the short anterior face of the triangle and in its inner anterior angle (15, Fig. 2.7). Besides. all the radial bundles bend around on the inner face of t!le muscle. taking a cireular direction and forming in this way a more or less extensice circular layer.

According to Iwanoff the ring muscle appears to be developed to different degrees in eyes having different static refractive powers; thus in myopic eres it is almost entirely wanting. while in hrpermetropic eves it is strongly developed and amounts to about one-third of the whole ciliary muscle.

The lens rests in a concarity in the anterior face of the ritreous body and is attached by an anteriol prolongation of the hyaloid membrane known as 
the zonule of Zinn, to the ciliary body. The zonule of Zinn surrounds the periphery of the lens, fusing insensibly with its capsule. The greater part of the zonule, from the ora serrata to the tip of the ciliary process, is grown fast to the ciliary body. But, since the ciliary processes do not reach all the way to the lens, there is left a small zone between them and the periphery of the lens, within which the zonule is turned freely toward the posterior chamber. This free part of the zonule (Fig. 228) consists of several strands, which may be divided for conrenience into three groups: an anterior, passing to the anterior capsule of the lens and called the suspensory ligament; a middle group whose fibers are directed vertically to the capsule immediately back of the equator of the lens, and a posterior group lying close to the hyaloid nembrane and passing over into the posterior capsule of the lens. All these strands consist of parallel inelastic fibers.

Among the hypotheses which have been put forward to explain the form changes of the lens in accommodation, the following by Helmholtz is the one most generally accepted at this time:

The lens is an elastic body which, while the ciliary muscle is inactive, is somewhat compressed from before backward by the radial pull of the zonule attached to its equator. Now the zonule is firmly attached by its peripheral or posterior end with the choroid coat just at the posterior margin of the ciliary processes. ('onsequently by contraction of the meridional fibers of the eiliary muscle (Fig. $22 \%$ ) this posterior edge of the zonule (an be drawn forward, thereby releasing the radial tension which it exerts on the lens in the unacommoriated conditinn. The result is that the lens bulges out at its center rendering both anterior and posterior surfaces more ennwex. The only function of the circular fibers according to this riew would be to crowd the anterior part of the ciliary proceses toward the relaxing lens and the zonule, so as to prevent alike any rupture of the tissues and any traction

FIG. 22S.-Zonule of Zinn of an adult man, meridional section, after G. Retzius. $l$, edge of the lens at its equator; $y l$, vitreous body; $i$, iris; $a$, short, strong attachment fibers of the posterior group; $b$, fibers of the same group springing from the hyaloid membrane; $c$, the anterior group springing from the ciliary process; $d$, fibers springing from the ciliary process and connecting with other fibers; $e$, space between the capsule of the lens and the pericapsular membrane.

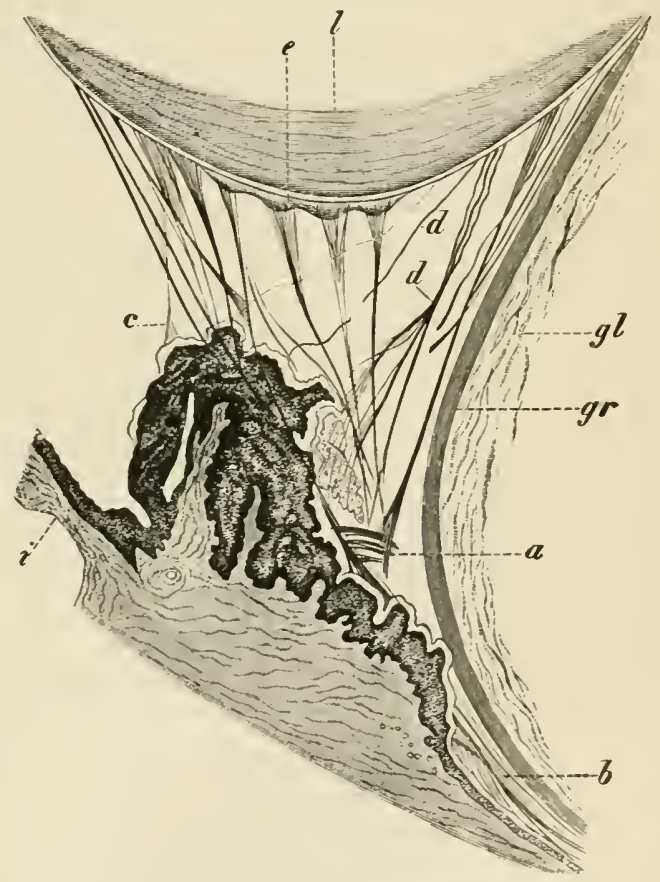


of the anterior part of the zonule which would antagonize the meridional fibers.

Schön seeks to explain the change in the form of the lens in quite another way. In his riew the circular fibers, and to a less extent the inner meridional fibers, of the ciliary muscle are the important parts. As a consequence of their contraction the ciliary processes are mored inward and somewhat backward in the direction of the arrow (Fig. 229); the lens, therefore, is pressed upon from all sides and as the schema in Fig. 229 shows, must bulge forward.

Space will not permit us to discuss these different hypotheses more fully. We would merely mention the fact that Hess has brought forward a very weighty argument in faror of the hypothesis of Helmholtz. When the meehanism of aecommodation is stimulated by dropping eserin in the eye, the ciliary processes push forward toward the cornea and, at the same time, inward toward

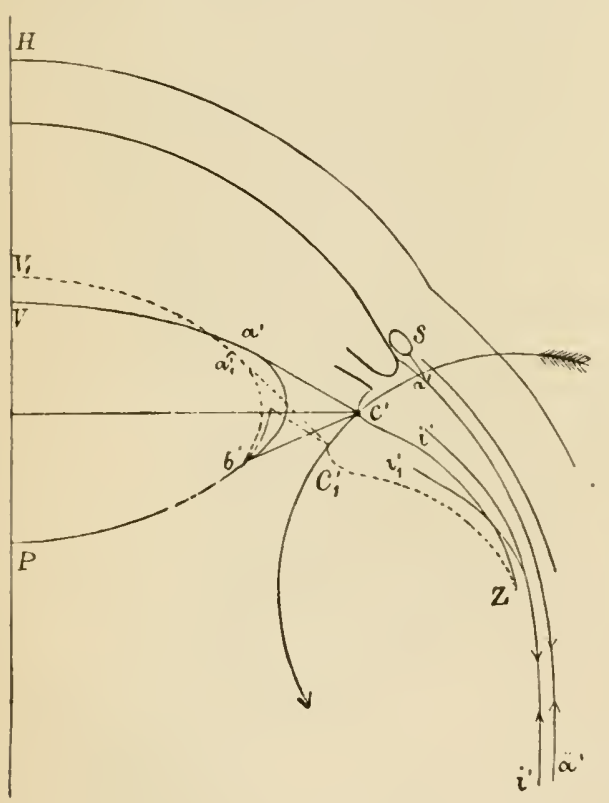

FIG. 229.- Schema of the mechanism of aceommodation, after Schön. The form of the lens when the eye is adjusted for near vision is shown by the dotted line. the edge of the lens, so that the ciliary processes are then found in front of the equator of the lens. Again, in accommodation for near vision the lens is loose while in the unaceommodated eye it is held firmly in place.

All authorities agree, that by museular action the eye ean only be adjusted for near vision and not for distant vision.

We have the following statements from Hensen and Völekers with regard to the innervation of the ciliary muscle. By stimulation of single eiliary nerves, the choroid is drawn forward, its displacement at the equator of the eve being as much as $0.5 \mathrm{~mm}$; the anterior surface of the lens bulges forward both in the uninjured eye and after removal of the eornea and iris; and the posterior surface of the lens pushes backward a little.

The fibers innervating the ciliary muscle arise from the oculo motor. From elinical evidence which has recently been gathered by Stuelp it appears that the nuclear center for the eiliary muscle lies close to that of the sphincter pupillæ, and that the accommodation center lies in the anterior medial nuclens of the oenlo motor, in front of the center for constriction of the pupil. [Fig. 230 represents the modern riew as to the location of this center (cf. pages 615, 616).-Ed.7

A contergence of the optical axes-i. e., a contraction of the internal recti muscles-takes place in accommodation eren when one eye is covered. But this association of convergence and accommodation is not an inseparable one, for a person can learn to converge the axes without accommodating, and vice versa. 


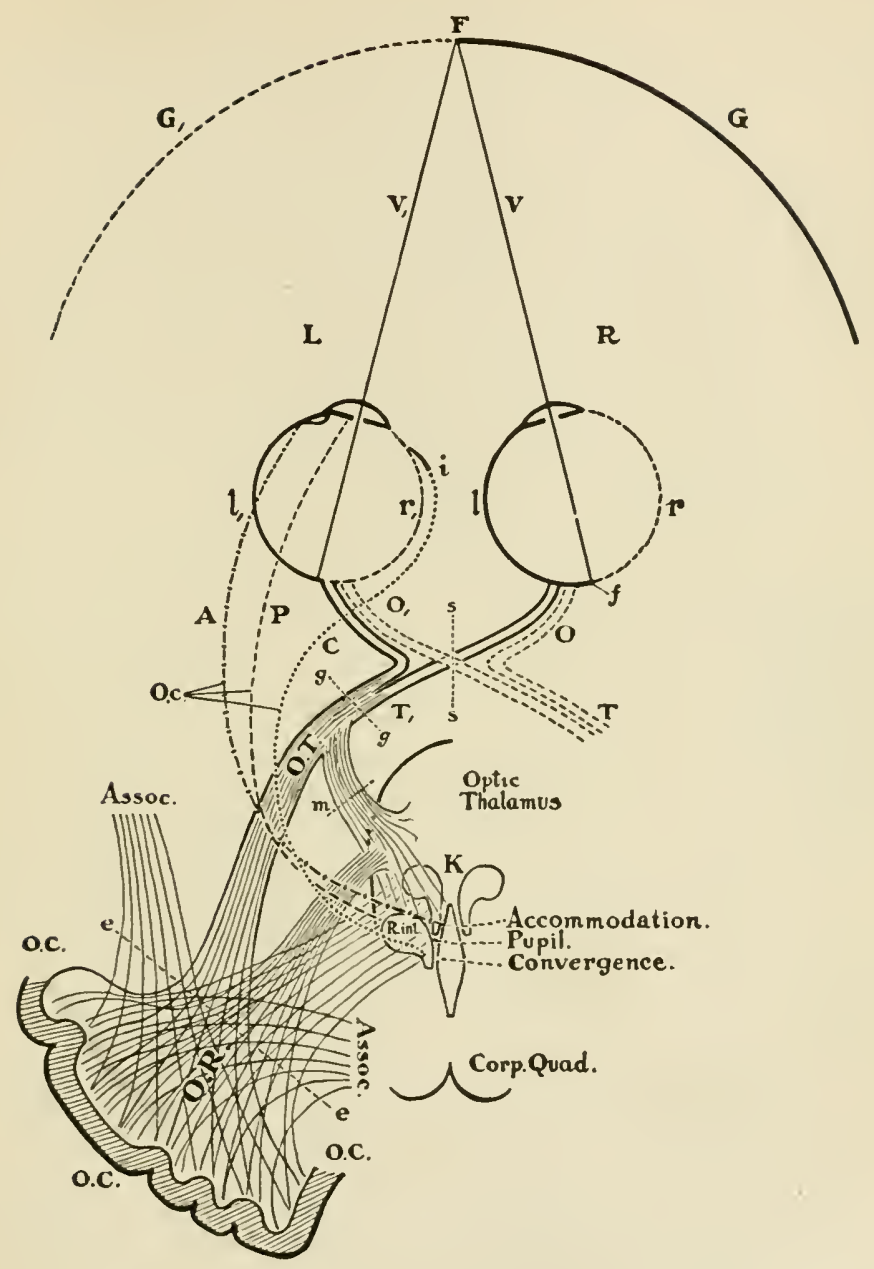

Fig. 230.- Schematic representation of the optic tracts, modificd from Fuchs.

The field of vision common to the $t$ wo eyes is composed of a right half, $G$, and a left half, $G$, . The former corresponds to the left halves $l$ and $l$, of the two retinæ, the latter to the right halves $r$ and $r$. The boundary between the two halves of the retina is formed by the vertical meridian. This passes through the fovea centralis, $f$, in which the line of vision $(V)$ drawn from the point of fixation, $F$, impinges upon the retina. The optic nerve fibers arising from the right halves, $r$ and $r_{f}$, of the two retine (indicated by the dotted line) all pass into the right optic tract, $T$, while the fibers belonging to the left halves, $l$ and $l$, of the two retina pass into the left optic tract, $T$, The fibers of each optic tract for the most part pass to the cortex of the occipital lobe, O.C. ; the smaller portion of them, $m$, goes to the oculo motor nucleus, $K$. This nucleus (cf. page 615) consists of a series of partial nuclei, the most anterior of which sends fibers, $P$, to the sphincter pupillir; the next one sends fibers, $A$, to the muscle of accommodation; and the third sends fibers, $C$, to the converging muscle (internal rectus, $i$ ). 


\section{SECOND SECTION}

\section{EXCITATION OF THE RETINA AND VISUAL SENSATIONS}

\section{\$1. LIGHT RAYS}

Modern physics assumes the existence throughout all space of a rarefied substance, the ether. which, although it has no weight, nerertheless obeys in general the laws which govern the movements of molecules. The density of the ether is so slight that it exercises no noticeable restraint on the movements of the heavenly bodies. with the possible exception of the comets.

Light is regarded as extremely rapid transcerse (i. e., vertical to the direction of propagation) vibrations of the ether, which are produced by the luminous point and are propagated through the ether with rery great relocity (Huygens. 16r8; Euler. Young. Fresnel).

When sunlight enters a dark room through a small slit and then passes through a glass prism, the small bundle of rays spreads out into a broad band, called the solar spectrum. which is not now white. as the light originally was. but is of different colors arranged always in the same order: red, orange, yellow, green. blue, indigo, and violet. Sunlight therefore consists of rays which are refracted by the spectrum to different degrees, the red rays being refracted least, the violet rays most.

The difference in refrangibility of these rays is conditioner upon the difference in the rate of their propagation through solid and liquid media. They are also distinguished by different ribration frequencies and consequently by different wave lengths. The wave length $(\lambda)$ of extreme red rays is 760 milliontlss of a millimeter $(\mu \mu)$, and of the extreme violet rays $397 \mu \mu$. But the solar spectrum is not limited to that which is visible to human eyes. It contains also rays of greater wave length than i60 $\mu \mu$ (ultra-red rays) and rays of less wave length than $39 r \mu \mu$ (ultra-violet rays). The former are characterized especially by their thermal effects; the latter by their chemical effects on certain silver salts.

The ultra-red rays are not visible becanse, although they are transmitted through the media of the eye, they do not stimulate the retina; while the ultra-violet rays are invisible for just the opposite reason-they are for the most part absorbed by the media of the ere. When. as in the operation for cataract, the lens is removed, the visible spectrum reaches down to $\lambda 313$.

Different sources of light contain the different rays in different quantitye. g.. the strontium light is red, the sodium light rellow. Accordingly, when the light from such a flame is refracted by a prism we get. not a continuous spectrum, but a spectrum which consists of more or less numerous distinct luminous lines which are characteristic for the different chemical elements.

The color of bodies which are not self-luminous depends upon the rays which are reflected in greatest number from them. or. if the ohjects are transparent. upon the rays which are transmitted by them. If. for example, a surface is red. it is due to the fact that of all the rays which fall on that surface. the red rays are thrown off in greatest number. Likewise a glass is 
red because it permits more of the red rays than of any other kind to pass through it. We must remember. however, that it is only the relative number of rays reflected or transmitted which gives the color to a nonluminous olject; for rays of other colors may as a rule be reflected or transmitted at the same time.

If all the light rays which fall upon a surface are reflected in the same relative numbers as they occur in colorless light the surface appears white, gray or black according as the total quantity of rays reflected is great or small. The same holds mutatis mutandis for transparent objects.

Whether a surface is colored or not its brightness depends upon the quantity of reflected rars: a bright red surface reflects much light of which a relatively large number of the rays are red: a dark red surface reflects the same rays in relatively largest number, but the total quantity of light reflected by it is relatively small.

Two inferences which may be drawn from the facts presented here should be kept steadily in view throughout the following discussion: that white light always consists of rays of different ware lengths and that the only really pure colors are the colors of a pure speetrum.

\section{\$ 2. THE PHENOMENA OF EXCITATION}

When light falls upon a freshly exposed retina, the latter undergoes a number of changes which are objectively demonstrable. Thus a pigment, present in all parts of the retina except the vellow spot and ealled because of its color the risual purple, fades (Fig. 2:31); the coloring matter of the pigment epithelium (frogs eye. Fig. 232) moves inward, being accompanied in this movement by a whifting of the cone cells in the same direction. and the action current of the retina (directed from the inner surface toward the rods and cones) undergoes a positive rariation. The significance of the first of these changes we shall discuss briefly on page $5+1$; of that of the second we know little more than what is contained in the statement that it furnishes us some external indication of an excitation proces: : the third goes perhaps a step farther and brings the mode of response of the risual apparatus into line with other forms of protoplasmie aetirity. But if we wish to know the course of the excitation process we must rely for the most part on our own subjective experiences.

To how great an extent these subjective phenomena are caused by procesacs going on in the retina itself, or by elianges in the many other parts of the nerrous system necessary for the production of a conscious visual sensation. nothing definite can be said (except with regard to certain details). [nless otherwise expressly stated the facts and discussion in what follows relate to the entire nerrous mechanism concerned in visual sensation.

When light falls upon the retina the resulting sensation does not reach its full strength immediately, and similarly vice iersa when light is suddenly 
turned off the sensation does not ranish instantly, but persists for a measurable time.

The latter statement is rery easily proved. When one looks for a moment at a bright lamp thame, then suddenly closes the eyes and cover them with the hand. or looks at an absolutely dark background. he still sees a bright image of the same form as that of the bright object itself. The image gradually disappears and as it does so changes its color. This phenomenon in which the bright parts of the object remain bright and the dark parts dark is called a positive after-image. Such an after-image has at first the proper color of the object, and very often it reproduces very exactly the separate parts of the object in their proper form and shade.

Proof that the rise of a visual sensation also requires a certain time is not much more difficult. Te need only consider for a moment the effect of

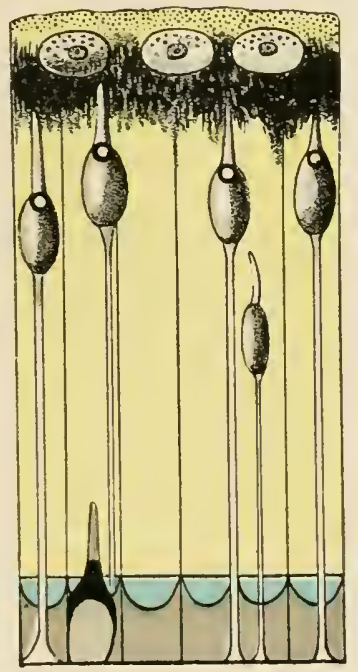

4

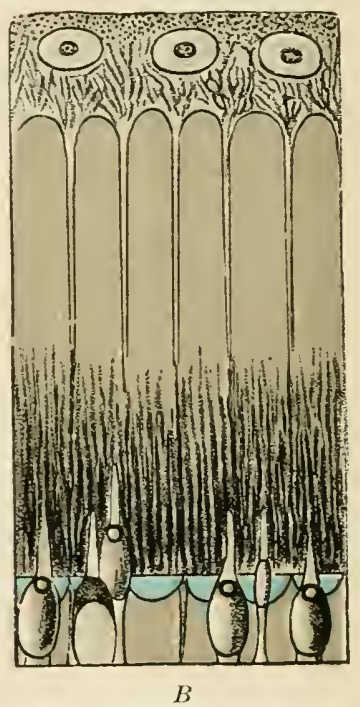

B

Fig. 232.-Section through the retina of a frog's eye, after Engelmann. A, after the eye was kept for from one to two day's in complete darkness; $B$, kept for 24 hours in the dark, then exposed for one-half hour to diffuse bright daylight (ef. page 537 ).

rotating a circular disk composed of black and white sectors (as in Fig. 233) to be convinced of this. So long as the rate of rotation is low, the black and white sectors remain perfectly distinct. But as the rate hecomes higher the edges of the sectors are obliterated, and this is true as well of the edges going hefore as of those coming after. whicherer the direction of rotation. If the excitation of the retina were instantaneous. the leading edges of the white sectors ought to continue sharply defined, while from what has just been said above, it is evident that the edges eoming after ought to be indistinet (cf. the dotted line in Fig. 234).

With a high rate of speed the rays enming from the white sectors no longer have sufficient time to produce the maximum excitation and on the other hand the light is never completely shut out by the black sectors: con- 
sequently the brightness of the black and white sectors oscillate around a mean value. From a certain rate of rotation onward the whole disk appears uniformly gray, its brightness being the same as would be obtained if all the light reflected by the white sectors were distributed uniformly over the whole disk.

$\mathrm{Or}^{\circ}$ in the form of a theorem, when a point on the retina is affected in regular periodic succession for a certain time $a$ by rays of a certain intensity, and is entirely unaffected for a certain time $b$, if the entire period $a+b$ is short enough, the sensation produced will be a perfectly continuous one and of a strength which (within certain limits at least) corresponds to that obtained by continuous stimulation with light rays of an intensity $\frac{a}{a+b}$ (Talbot's

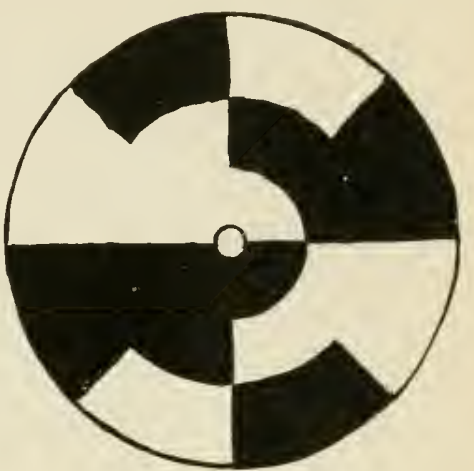

FIG. 233.-After Helmholtz. proposition). With light of medium intensity the period $a+b$ need not be less than 0.04 second.

The time required to reach the maximum excitation of the stimulus, whatever the interval, is but a fractional part of a second-e.g., as shown graphieally in Fig. 235, about 0.217 seeond. Beyond the maximal point, as is evident from the figure, the excitation gradually declines in intensity owing to the onset of fatigue.

The time required to produce the maximal excitation is different for the different pure colors, being least for the red and greatest for the green (Kunkel).

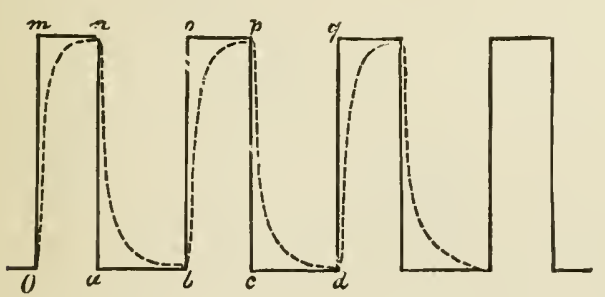

Fig. 234.-Schema to illustrate the course of excitation of the retina successively by black and white sectors (as in Fig. 233), after Fick. If $m-n, o-p$, ete., represent the white sectors, and $a-b, c-d$, etc., the black, then the progress of excitation is indicated by the broken line. Starting at $O$, the retina having just been exposed to darkness, the excitation rises suddenly at first then more slowly; at $n$ the excitation ceases suddenly, but requires some time to fall to the zero point, and so on. The more rapid the rotation, the more will the broken line tend to become a horizontal line.

tigue of some part of the risual organ, in all probability of the retina itself. The bright light falling contimmonsly on a certain point of the retina, fatigues retinal excitation to wear off is different for the different colors.

\section{A. FATIGUE AND RECOVERY OF THE VISUAL ORGAN}

When one looks fixedly for a time (with a light of moderate intensity, five to fifteen seconds), at a bright object. and then lirects the gaze at a uniforurly illuminated surface, he perceives on the latter an after-image, in which the bright parts of the object appear dark and the dark parts bright. That is, the image is just the reverse of what we have called a positive after-image and is deseribed as a negative after-image.

This phenomenon is due to faLikewise the time required for the 
that point. so that when light from the uniformly illuminated surface now strikes the retina, that particular point is incapable of being excited so strongly, as the remaining relatively unfatigued parts; hence, the corresponding point of the field of vision appears dark in comparison with the other parts.

In fact the sensitireness of the retina is all the time changing whether it is being acted upon by the light or is protected from the light-in the one case becoming progressively less and in the other progressively greater. These changes taken together are described by Aubert as the adaptation of the retina.

For example, when we pass from a light room into one very feebly lighted at first we are unable to see anvthing; gradually, however, the sensitiveness of the retina becomes greater, until the feeble light produces a plainly perceptible

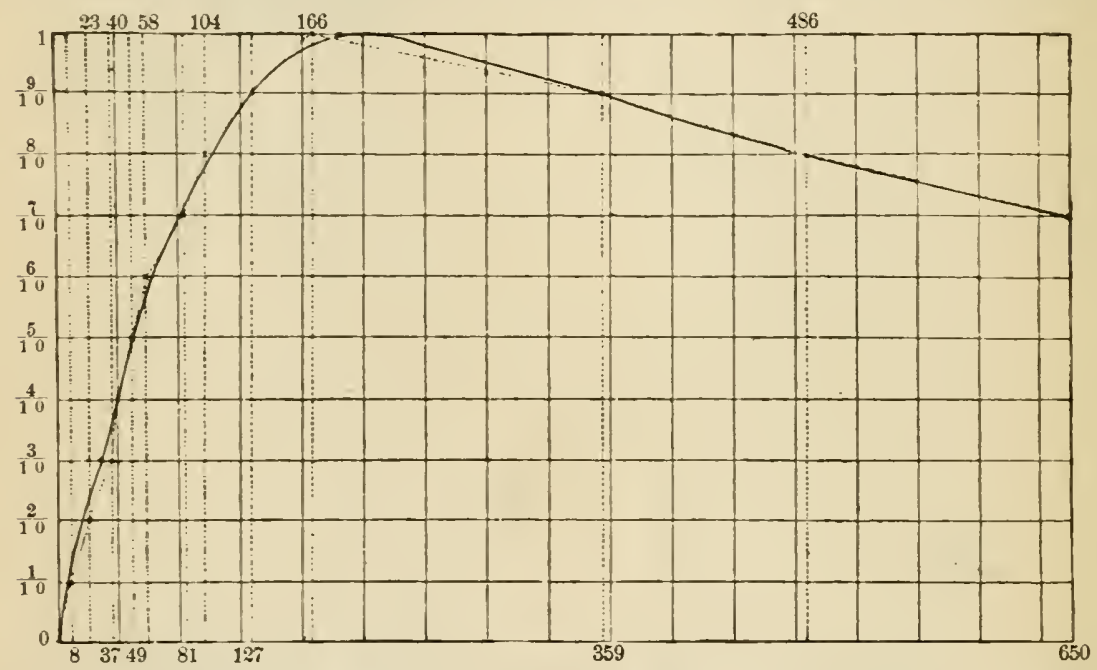

FIg. 235. - Excitation of the retina as a function of the time exposed, after Exner. The absciss:e represent the time in thousandths of a second, the ordinates the strength of the sensations.

impression; in fact after remaining longer in the dark room the light can be greatly reduced in intensity without passing below the threshold.

According to exact measurements on the adaptation of eyes to the dark the rate is about the same for different individuals, but the absolute increase in sensitivity varies all the way from 1,400 to 8,000 fold. With both eyes the increase in sensitivity is 1.6-1.7 times as great as with only one eye. These facts apply onls to the peripheral parts of the retina; for the fovea centralis the adaptation is very much less complete, the increase in sensitivity being only twenty to thirty times the sensitivity of the exe adapted for light.

When we pass back after complete adaptation to the dark into a brightly illuminated room, the strong light at first has a blinding effect upon the retina. which has meantime become extremely sensitive. But, after a short time, its sensitireness has so far decreased that there is no excessive stimulation. In other words, the eve adapted to the dark has now become adapted to a high degree of illumination. Another point of evidence that the condition of the retina is adapted to the strength of the light, is the fact that the size of the pupil remains the same for a rather wide range of intensity, changing only at the moment the intensity changes. 


\section{§3. SENSATIONS OF COLOR}

There are three different modifications of light which influence our sensations of color: brightness, which depends upon the energy of the ether vibrations; tone. which depends upon the ware length; and saturation. which depends upon the purity of a given wave length, or, in other words, upon the amount of white light present.

The human eye ean distinguish all of these properties. Indeed, its ability to distinguish differences of color is very highly developed. König has estimated that in the visible spectrum there are 165 different color tones, which can be distinguished, and that the total number of different degrees of intensity perceptible to the human eye is about 660 . When we remember that each tone can vary greatly in intensity and each tone and intensity in turn can have all possible degrees of saturation, we get some idea of the number of possible color sensations.

According to Herschel the mosaic workers in the Vatican can distinguish 30.000 different colors.

\section{A. RELATION OF THE PROPERTIES OF LIGHT TO DIFFERENT CONSTITUENTS OF THE RETINA}

Some color tones of the spectrum always appear brighter than others: with light of ordinary intensity the brightest of all is a certain tone of yellow $(535 \mu \mu)$. If the different colors be observed as the daylight fades it will be noticed that certain ones disappear sonner than others-e.g., the reds before the blues. In a very feeble light a weak spectrum can still be seen, but only as a band of light. Its colors have disappeared and that part of the spectrum which now appears brightest is nearer the more refractive end of the spectrum than it was in broad daylight. But if only a portion of the weak spectrum small enough to be imaged on the forea centralis be allowed to enter the eye, its colnr can he correctly perceived (König. Sherman).

T'hese and other facts have led to the assumption of a functional difference between the rods and cones. The latter, found everywhere in the retina and exclusively in the forea centralis, are thought to be sensitive to light of different wave lengths, but to require rather a high degree of illumination. The rods are sensitive to a much fecbler light but are not sensitive to color tones (v. Kries. Parinand et al.). Eves which are totally color blind, remaining sensitive only to light and darkness. are therefore supposed to be devoid of cones. Nocturnal animals like the owl, hat. monse, cat, ete., are known to have relatively fewer cones and more rods than diurnal animals (Max Schultze).

The risual purple (ef. page 5.3\%) is also thought to assist in vision by a feeble light. In the first place, it is not found in the cones: and. in the seennd. there is a close agreement between the brightnes: of the dlifferent wave lengths in a feeble light and their action upon solutions of the risual purple. Accordingly it is conjectured that the fading of the visual purple is of some service in the stimulation of the rods. 


\section{B. SUCCESSIVE COLOR INDUCTION}

Then one looks fixedly for some seconds at a red object on a white ground (Fig. 236), and then turns the ere toward the white ground, he sees on the latter a distinet after-image which reproduces the object exactly in all respects but one-instead of being red it is greenish blue. If the object were greenish blue the after-image would be red.

For erery color tone in the spectrum there is another, which in exactly the same way as in this example evokes and in turn is evoked by the first as an after-image. Pure green. however, forms an apparent exception to the

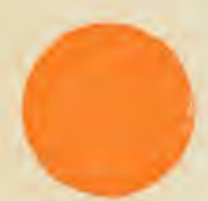

Fig. 236. rule. Its after-image is purple-but purple is a color which does not occur in the spectrum; its relations thereto will be mentioned presently. Other pairs of colors which are related to each other in this way are: orange and blue, golden yellow and blue. rellow and indigo, ete.

These phenomena show that oljective light ean be subjecticely destroyed, also that a certain intimate relation exists between the different colors. In order to inquire further into these facts which necessarily form the foundation stones for every theory of color, we must see what results from the mixture of colors.

\section{COLOR MIXTURE}

By a mixture of two or more colors we mean that color which is experienced when a given point on the retina is struck simultaneously by rays of different wave lengths. Every color mixture is therefore a summation effect of different light ravs.

The best and for many purposes the only possible mode of procedure is to mix pure spectral colors. This may be done ly complicated apparatus. which enables nne to isolate two spectral rays of different wave lengths and to throw them on the same spot of a screen where the mixture can be compared with a reforence color.

In this way the different rays are brought into the eye at the same time. But the experiment can be so arranged also that the rays to be tested will fall suceessively on the same spot of the retina. Then if the sequence is rapid enough a mixture of the two will take place just as in the experiment with white and black sectors (page 539).

Terr conrenient for this purpose are Maxwell's disks. They are circular. colored disks having a radial slit, so that two or more of them can be overlapped and rarying portions of each be exposed to view. If the complex disk thus composed of two or more colored sectors is rotated rapidly by merns of a clockwork, the resulting mixture will depend upon the saturation of the indiridual colors emplored and the relative sizes of the different sectors.

The results of color mixture which interest us most are those ohtained with the above-mentinned pairs of color-red and greenish blue. yellow and indigo, etc. Experiment has shown that each of these pairs when its components are mixed at a certain relatice intensity, produces the sensation of white or gray (which is but a feebly illuminated white). Since each of these colors 
complements the other, each one furnishing just what the other lacks of being white, they are called complementary colors.

The sensation of white therefore can be produced in very different ways, namely, first by the simultaneous action of all the rays contained in sunlight. when they necur in the same proportion as they are there mixed tngether, and secondly by the proper mixture of two complementary colors. Howerer it is impossible for the eye to tell whether a given white is composed of all the rays of the color spectrum or only of red and greenish blne, orange and blue. ete. White in other words presents only quantitative differences dependent upon different intensities of light. lut bearing no relation to the color tones of which it is composed. The eve therefore does not analyze: it lacks entirely the ability so highly dereloped in the ear, of rewolving a giren impression into its separate components.

When two colors which are not complementary are mixed together, instead of white we get a new color. If red and violet, the extreme color: of the spectrum, are mixed we get purple, the only color tone which does not oceur in the spectrum. Purple is the complementary color of green (see page jt: and is in every way different from the colors the mixture of which produces it.

When two simple colors, separated from each other in the spectrum by less distance than that which separates complementary eolors, are mixerl, we get a color lying between the two and approaching white more the greater the distanee between them, but becoming more nearly saturated the less the distance between the two components. When, on the other hand, two color's separated from each other by a greater distanee than that which separates complementary colors are mixed, one obtains purple, or some such color, which lies between one of the eomponents and the corresponding end of the spectrum. In this case the mixture is the more nearly saturated the greater the distance between the eomponents, and approaches white more the less the distance between them (Helmholtz).

\begin{tabular}{|c|c|c|c|c|c|c|c|}
\hline & Violet & Indigo & Dark blue & Blue green & Green & $\begin{array}{c}\text { Greenish } \\
\text { vellow }\end{array}$ & Yellow \\
\hline Rell & purpile & dark rose & light rose & white & $\begin{array}{l}\text { light } \\
\text { yellow }\end{array}$ & $\begin{array}{l}\text { gold } \\
\text { rellow }\end{array}$ & orange \\
\hline Orange & lark rose & light rose & white & $\begin{array}{l}\text { light } \\
\text { yellow }\end{array}$ & yellow & yellow & \\
\hline Yellow & light rose & white & light green & light green & $\begin{array}{l}\text { greenish } \\
\text { yellow }\end{array}$ & & \\
\hline $\begin{array}{l}\text { Greenish } \\
\text { yellow }\end{array}$ & white & light green & light greel & green & & & \\
\hline Green & light blue & sea blue & blue green & & & & \\
\hline $\begin{array}{l}\text { Blue } \\
\text { green }\end{array}$ & sea blue & sea blue & & & & & \\
\hline Dark blue & indigo & & & & & & \\
\hline
\end{tabular}


In the preceding table have been brought together after Helmholtz the results of mixing different spectral colors. At the top of the vertical columns and at the left are found the simple colors; where the vertical and horizontal columns intersect are found the colors resulting from the mixture of the two simple colors standing at the beginning of the intersecting columns.

\section{ON THE THEORY OF COLOR}

From the facts just given it appears that we ean produce the whole series of different color tones by appropriate mixture of a few simple colors. Any physiological theory of color has therefore to show what these simple colors are and to derire all color sensations from them.

There are at this time two principal opposing views as to the production of color, namely, the three-color theory, originally proposed by Thomas Young

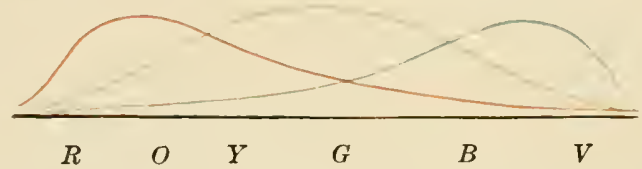

FIG. 237.-Excitation of the different components of the visual organ by light rays of different wave lengths, after Helmholtz.

and later dereloped by Helmholtz, and the theory of antagonistic colors, offered by Hering. Since an exhaustive critical discussion of these views would call for entirely too much room and inasmuch as it will probably be a long time yet before the question is finally settled, we shall limit the diseussion to a purely dogmatic statement of the essence of the two theories.

1. The Three-color Theory.- - Young regarded red, green and violet as fundamental or primary colors, because they cannot be obtained, at least not in complete saturation, by mixture of other colors. He supposed that in every part of the retina which is capable of all the color sensations, there are three separate nerre elements: stimulation of the first produces the sensation of red; stimulation of the second, that of green; stimulation of the third the sensation of violet. Since the action of light on the percipient parts of the retina is in all probability a chemical process in which certain compounds are broken down, there would be in the retina, according to this theory, three different visual substances corresponding to the three primary colors. In order not to commit ourselves as to the way in which the light aets directly, we shall designate these pereipient elements in general as components of the visual organ.

Light acts with varying intensity according to its ware lengths, on the three components. The red-perceiving component is exeited most powerfully by light of the greatest wave length: the green-perceiring component by light of medium wave length, and the violet-perceiving by light of the shortest wave length. However, it is possible, and for the explanation of certain phenomena it is necessary, to assume that each spectral color stimulates all the components. one of them feebly, the others powerfully. 
In Fig. 23i the three curves represent schematically, according to Helmholtz. the relative degree to which each component is stimulated by the different light ravs in the production of their appropriate color sensations, thus:

Simple red stimulates the red-perceiving component strongly, the other two feebly; sensations of red.

Simple yellow stimulates the red- and green-perceiving components moderately, the violet feebly; sensation yellow.

Simple green stimulates the green-perceiving substance strongly, the other two much more feebly; sensation green. Other effects can be readily combined from the figure.

Stimulation of all components with about the same intensity gives the sensation of white or of whitish colors.

According to the three-eolor thenry, black is only an extremely feeble white; between the two there is no qualitatire difference, but only a quantitative one.

Since according to this scheme the color srstem of a man with normal vision requires the assumption of three primary colors, the eves of this class of people are called trichromatic.

Starting with the Young-Helmholtz theory König and Dieterici have carried out a rery extensive series of measurements and have calculated the form

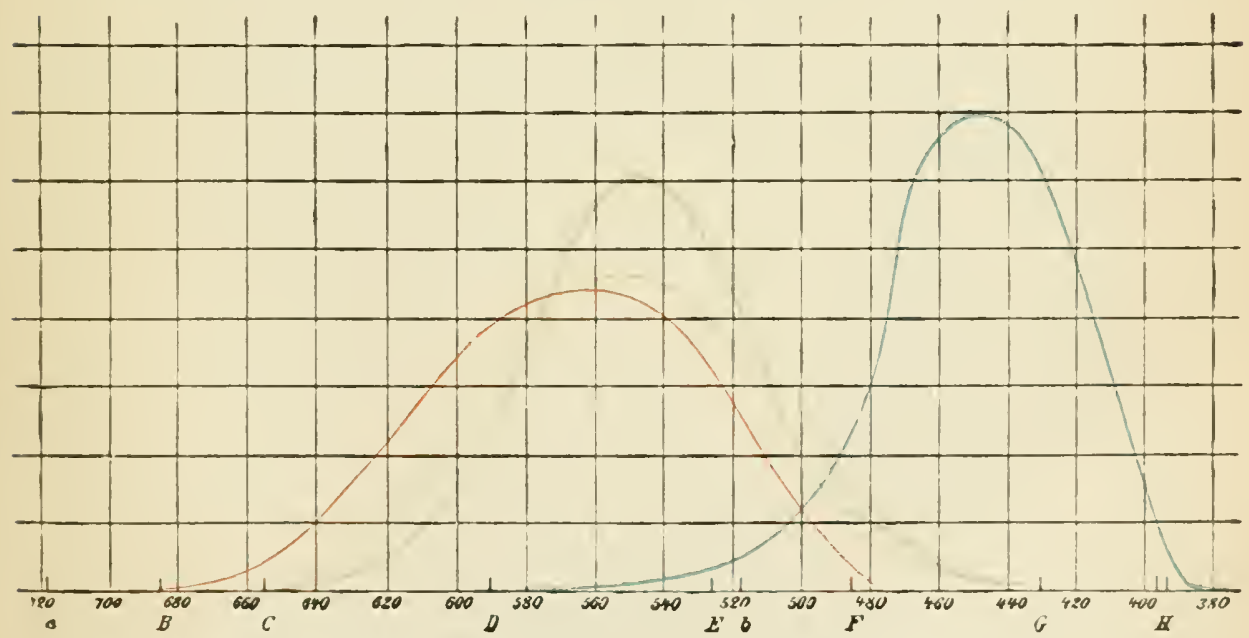

FIG. 238. -Excitation of the different components of the visual organ by light waves of different wave length, after König and Dieterici.

of their (own) curres of sensation for the three primary colors. They found that at the extreme red and the extreme riolet ends of the spectrum they could distinguish a difference of brightness. but no difference of color tone, hence these two portions of the spectrum. up to $6.5 \mu \mu$ and $430 \mu \mu$ respectirely, must stimulate nnly the red- and the violet-perceiving components. The results which represent graphically the mean value for the two authors are reproduced in Fig. 238.

But there are eves with other color systems, eyes for example for which 
a mixture of two definite rays, a long- and a short-waved one, can be found to match every homogeneous color. The color system of such eves is dichromatic. This almormality is as a rule inborm and is spoken of as color blindness. If the color system of the normal eye consists of three components, that of the dichromatic ere might he derired from it by the absence of some one constituent. According to the Young-Helmholtz theory there would thus be three possible kinds of color blindness: red blindness. green blindness and riolet blindness. From facts which will not be giren here it appears that the color systems of the red blind and the green blind do correspond fairly with what would be expected from the theory. Little is known with regard to the third form.

How the color blind actually experience colors can of comrse only be answered by persons in whom only one eve has been color blind from birth. Hippel and Holmgren have investigated two such cases. It must suffice here to remark that in one of them mixed white light appeared the same-i.e., colorles-to the color-blind as to the normal eve.

In indivect or averted vision the ability to distinguish colors decreases gradually from the center toward the periphery of the field of rision. The peripheral limits for the different colors. even for a perfectly normal eve, depend upon the intensity of the light. the saturation of the colnr and the size of the object. Thus Hess found that for a definite shade of red on a grar background, the limit was $20^{\circ}$ from the axis of rision. provided the size of the object was $\sim \mathrm{mm}$. in diameter: with a diameter of $30 \mathrm{~mm}$. the same red could be recognized $3 \%^{\circ}$ from the axis. According to Landolt. if the intensity of light could be made great enough and the object could be made extensive enough, we would be able to see all colors at the rery periphery of the retina.

At all erents the capacity for color is much less in the peripheral portions of the retina than in the central portions, and with colored objects of moderate size and moderate intensity of light one may say that a green (of $495 \mu \mu$ ) and a red with a moderate admixture of blue disappear entirely at a relatively short angular distance from the line of rision. Yellow and blue ean be recognized for some distance farther toward the periphery. in fact all rays of greater wave length than $495 \mu \mu$ are seen as yellow and all of less wave length as blue. Still farther toward the periphery the sensations of rellow and blue disappear and a zone which is tolerably color blind is reached (Hess).

2. The Theory of Antagonistic Colors.-Like the three-color theory, this also proceeds on the assumption that all our visual sensations are conditioned upon the coöperation of a few components (risual substances) in the organ of vision. According to the former theory these are present in the retina itself; but the theory of antagonistic color leares it undecided whether these substances occur in the retina. optic nerve or some portion of the brain concerned in vision.

The three-color theory, as we have seen, explains the sensation of white as the result of an equal excitation of the three components and regards white and black as only quantitatively different sensations. Aceording to Hering's theory, black and white are qualitatively different sensations. accompanied by opposite chemical processes in a special black-white-perceiving substance. The sensation of white arises while a process of katabolism is going on in this substance, that of black during a process of anabolism. The brightness or 
darkness of any purely colorless sensation, accordingly. is determined by the ratio in which the intensity of katabolism stands to that of anabolism.

Hering assumes four fundamental colors: red. yellou. green and blue. These colors are selected because they can occur without any tinge of another color occurring with them: or if they do exhibit any erident inclination toward another color, it is nerer toward more than one other at the same time. For example, yellow can merge into red or into green, but not into blue: blue only into red or green: red only into vellow or blue.

On the other hand, red and green are never clearly discernible in a color at the same time, nor vellow and blue. That is, the presence of an erident red sensation excludes that of an evident green; the presence of blue. that of ycllow, and rice rer:a; consequently, Hering calls these mutually exclusive color: antagonistic colors.

Just as the sensations of white and black are conditioned upon opposite processs taking place in the white or black sulstance, the antagonistic color: are produced by anabolism or katabolism. as the case may be, in two nther visual substances assumed by Hering, namely, the red-green- and the yellowblue-perceiving substances. Red and yellow arise ly katabolism, green and blue lis anabolism.

The main proposition of Hering"s theory therefore is this: the fundamental sensations of the visual substances are grouped in three pairs: black and white. yellow and blue. red and green. For cach of these three pairs there is a corresponding anabolic and hatabolic proces of special quality.

since the amount of anabolism or katabolism caused by a light stimulus in one of the three risual substances depends not only upon the intensity of the stimulus, but also upon the excitability of the risual substance, the same mixture of light may appear bright or dull colored, or colorless, according to the phrsiolngical condition of the risual nrgan.

When the risual organ has been protected from the light long enough so that a condition of balance between the anabolic and the katabolic processes is reached. and a colored light of moderate intensity is then admitted, the excitability for that particular color will decredse until it is less than that for the antagonistic color. Every mixed light which had previously appeared colorless will now he seen with a tint of the antagonistic color, or if before a mixture of fundamental colors was seen. it will now appear as a mixture of the two antagonistic colors. Hering's thenry can thus account for the successice induction of color or color contrast.

Agreealhy to his theory. Hering reduces all color blindness to red-green and rellow-blue blindnes.: Those who are blind to red and green lack the red-green visual substance: ererything which other see as red or green, they see devoid of color: in all mixed colors containing red or green, they see only the yellow or blue, ete.

\section{E. SIMULTANEOUS CONTRAST}

The idea of simultaneous contrast can be most simply presented hy means of one or two concrete examples. If small colored sectors be placed on a white disk. as in Fig. 239. and the mildlle point of each sector be interrupted by a black and white strip, then when the disk is rotated one ought really to 
see a gray ring, corresponding to the black and white strip. on a faintly colored whitish ground. But instead of looking gray, the ring takes the complementary color of the ground.

Standing in the moonlight and the gaslight at the same time, a person casts two shadows-one from the moonlight, the other from the gaslight. The ground, being illuminated by hoth the moon and the rellow-red light of the gas flame. takes the color of the latter. The shadow from the moonlight is also yellow red, for it is likewise illmminated by the gaslight. The other shadow which is illuminated by the moonlight ought to be gray, but is not. It has instead a bluish color-i. e.; the complementary color of the ground.

Simultaneous contrast therefore means that an object without color, in the neighborhood of a colored one, takes on a tint which is the complement

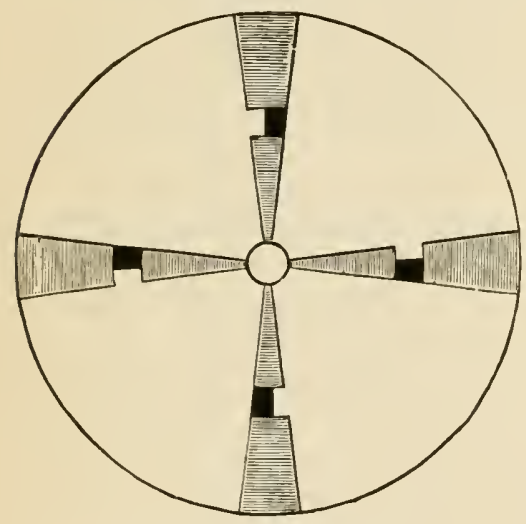

Fig. 239.-After Helmholtz. of the color in the object beside which it is placed. In the same way a bright object in the neighborhood of a dark one looks brighter than it really is.

We are all the time meeting with contrast phenomena which influence in many ways the impression we get of color compositions. If, for example, a black design be printed on a red material, the design does not appear black, but because of the contrast greenish blue. In order to make the design actually appear black, it is necessary to mix a little of the ground color with the black-i. e., in this case the design must be printed in a very dark red. The greenish blue produced by contrast then mixes with the red of the desigu, giving a faint white; hence the design no longer appears greenish blue, but black (Chevreul).

If on the other hand the design and ground work are complementary colors, they intensify each other. A yellow design on a blue material stands out much more prominently than it would on any other color; and the same is true of course of black and white. Phenomena of this kind are of no little importance in securing sharpness of vision.

It is evident that these contrast phenomena are entirely of subjective origin and cannot be cansed by any objective influence of the one color on another.

According to Helmholtz it is all a matter of judgment. Te are accustomed to subtract from all colored surfaces without distinction the light by which they are illuminated, so far as that is in the region of their own color. in order to find the body color itself. If gaslight and moonlight fall on the same spot, the illumination of the ground is a light yellow red. Now this yellow red we abstract not only from the color of the ground, but also from that of the shadow, on which no gaslight falls; hence it looks blue when it is really white.

Hering on the basis of a great variety of experiments makes different objections to this view, and in many cases at least has succeeded in showing 
that simultaneous contrast is not a delusion of the judgment, but rests upon the action of neighboring spots in the risual apparatus. The state of excitability of a retinal spot $A$, for example, is always dependent upon the physiological condition of all the rest of the retina, particularly of the parts adjacent to the spot $A$. Thus, if the spot $A$ is being constantly stimulated, its excitability may be raised or lowered merely by changing the strength of the light affecting other parts of the retina. Every increase in the intensity of the stimulus on other parts reduces the excitability of the given spot $\mathrm{A}$, so that the sensation mediated by it is less bright. Every decrease in the stimulus on the rest of the retina changes the condition of $A$ so that the corresponding sensation becomes brighter. The same laws apply, according to Hering, to color contrast. That is, if the spot $\mathrm{A}$ is exposed to white light and the rest of the retina to yellow-red light, the excitability of the spot $A$ for vellow red is rednced and the white field appears in the complementary color, etc. Hering believes that the effects of adjacent retinal spots on one another play an essential part also in the production of positive and negative after-images.

\section{THIRD SECTION}

\section{MOVEMENTS OF THE EYE AND VISUAL PERCEPTIONS}

\section{§1. ACTION OF THE EYE MUSCLES}

In discussing movements of the eye we assume what is only approximately true, namely, that they take place about a definite point called the center of rotation, also that when the head is ereet and the gaze is directed straight forward the two lines of vision are horizontal and parallel throughout (primary position).

Measurements which have been made to determine the point of origin and the point of insertion of the different muscles, with reference to the center of rotation and the line of vision, as the primary axis, have shown that the three pairs of muscles are not directly antagonistic. The axis of rotation of the superior rectus muscle does not coincide with that of the inferior rectus, nor does that of the external rectus coincide with that of the internal, nor that of the superior oblique with that of the inferior. For the sake of simplieity. however, we shall neglect these differences and assume that each pair of muscles rotates the eye about one and the same axis (Volkmann).

The positions of the assumed common axes for the two eyes are shown in Fig. 240. 'The line $D-D$ ' is the axis assumed to be common to the superior and inferior recti and $O-O^{\prime}$ that for the two oblique museles. The axis for the external recti would be vertical to the plane of the paper at $G$. The movement of either eye in the figure cansed by the isolated action of each of these muscles may be pictured to oneself by placing the book so that one's own line of vision coincides with the axis of any given muscle, and then imagining the eve in the pieture to rotate right or left about the observer's line of vision.

Fig. 2 41 represents, according to Hering, approximately the paths which 
the line of rision of the left ere would describe on a plane standing at right angles to the primary axis at the distance $d d$ from the center of rotation, if the eve were rotated about the several axes as given in Fig. 240. The position which the horizontal meridian of the eve wonld hare at the conclusion of the morement is shown by a short, heary line at the end of each path. The length of each path corresponds to a rotation of about $50^{\circ}$; the numbers mark the successive positions of the line of rision.

From this figure it is clear that eren if the relations of the axes were in fact as simple as we have supposed them to be. it would be possible to move

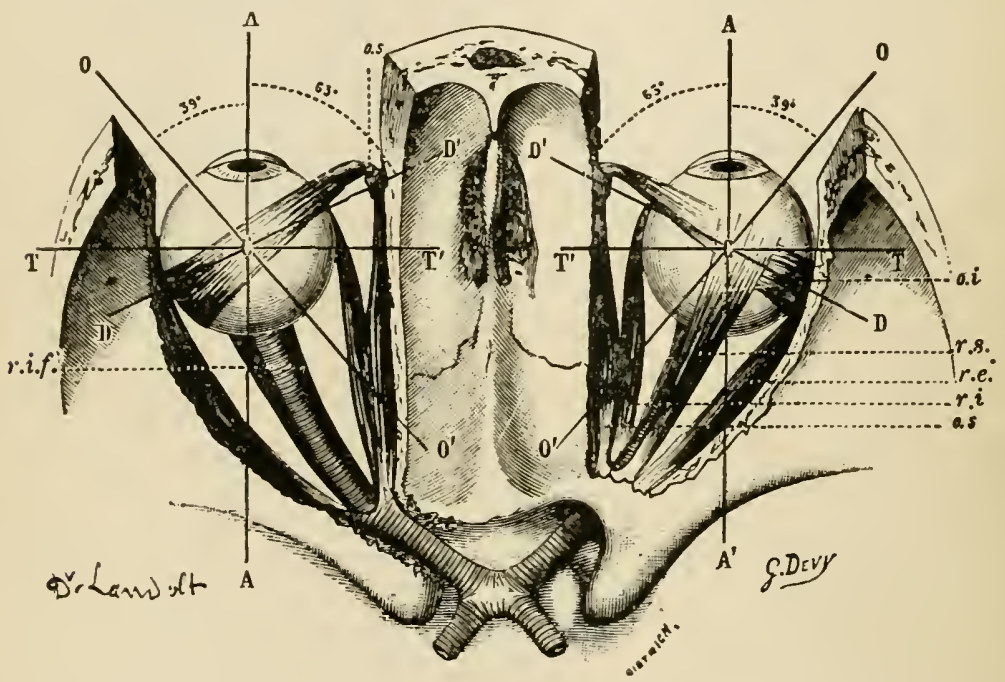

FIG. 240.-The extra-ocular musches and their axes of rotation, after Fox. The left eye is shown with the superior rectus removed. r.i.f., inferior rectus; r.s., superior rectus; r.e., external rectus; r.i., internal rectus; o.s., superior oblique; o.i., inferior oblique. The line $A A^{\prime}$ represents the line of vision; $T T^{\prime}$, the transverse axis of the eyeball; $D D^{\prime}$, the axis of rotation of the superior and inferior rectus muscles: this axis makes an angle of $63^{\circ}$ with the line of vision; $O O^{\prime}$, the axis of rotation of the inferior and superior oblique muscles: this axis makes an angle of $35^{\circ}$ with the line of vision. The axis for the internal and external rectus muscles is perpendicular to the plane of the paper at the center of rotation, $C$.

the line of vision, etc., along a vertical line only by the proper coöperation of at least two muscles. The morement directly upward involves the action of the superior rectus and the inferior oblique; the morement directly downward the action of the inferior rectus and the superior oblique. The former two assist each other in the rotation upward, but the one tends to roll the eye outward and the other inward, so that by a compensatory action the rolling can be prevented altogether. Exactly the same is true of the muscles which rotate the eve downward.

Knowing as we do that the different axes of the eye actually have a less simple arrangement than that here assumed. it is evident, as Volkmann has emphasized, that what are apparently the simplest morements of the eye involve the simultaneous action of several muscles. 


\section{A. LIMITS OF THE EYE MOVEMENTS}

Helmholtz, Aubert. Hering and others have determined how far the eye can be moved in the different directions by means of its muscles, and have thus mapped out the limits of the field of rision. With parallel lines of vision the monocular fields of the two eyes, projected upon a distant plane. have the positions represented in Fig. 242 . The point $m$ represents a very distant fixation point. The two monocular fields do not cover each other. The parts accessible only to the left eye are ruled and are designated by the letter 7 , those accessible to the right eye only are horizontally ruled and are designated by the letter $r$.

Howerer it would not be eorrect to suppose that the unruled part of the monocular field common to the two eyes is in fact the binocular field. On

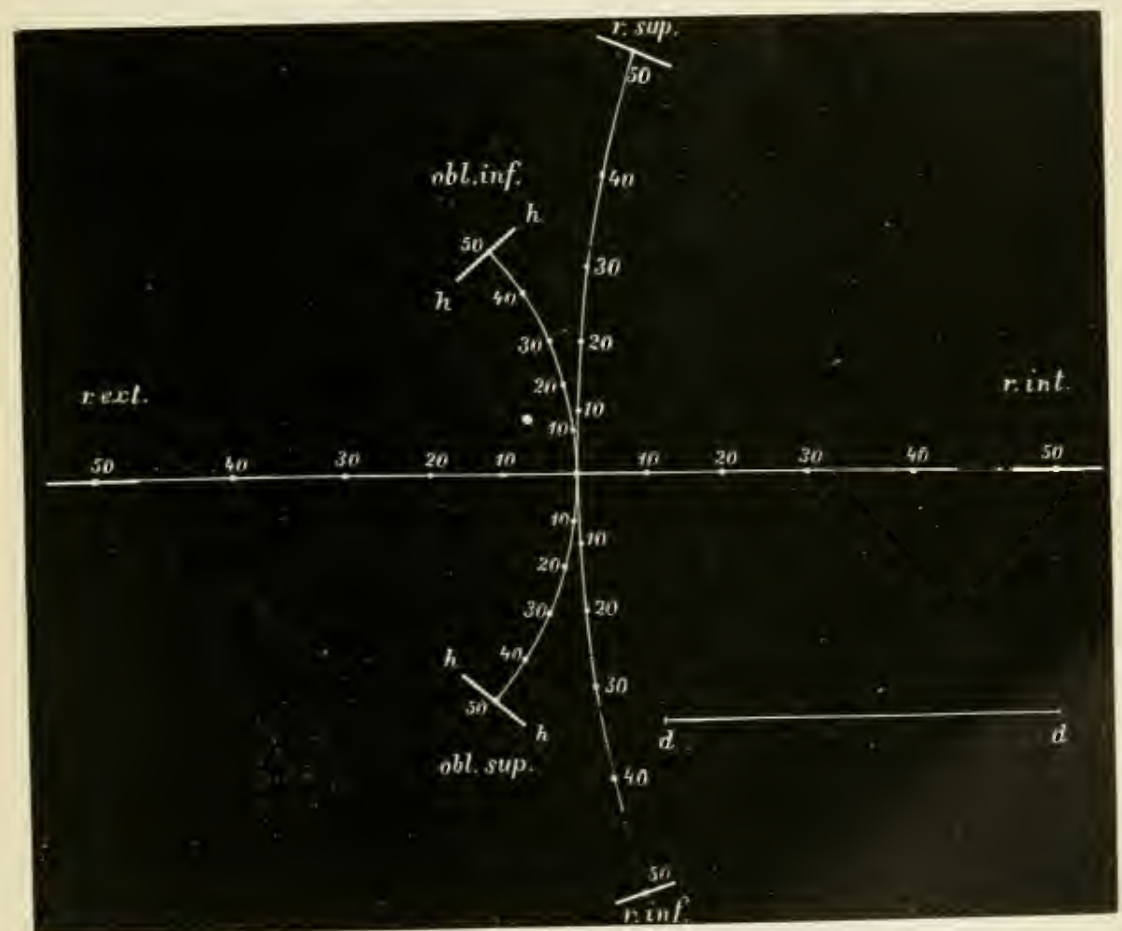

Fig. 241.- The paths described by the line of vision as the result of rotation by the separate eye muscles, after Hering.

the entrary the two lines of vision cannot he directed at the same time to every point in the outer space to which each line of rision can be directed alone. The space surromiled by the line $a$ a in Fig. "2 4 ? represents the binoeular field for distant rision. We see how small is the binocular field common to the two lines of vision: it is much smaller than the field common to both risual axes also for near vision. 
The two eves are rery closely associated in their morements. Tnder normal circumstances the line of rision of the one cannot be directed to a point higher than that to which the other is directed at the same time, and the two cannot be made to diverge.

Theoretically, by appropriately combined action of its six muscles, each eye can be turned in any direction and rotated on any axis; but the actual

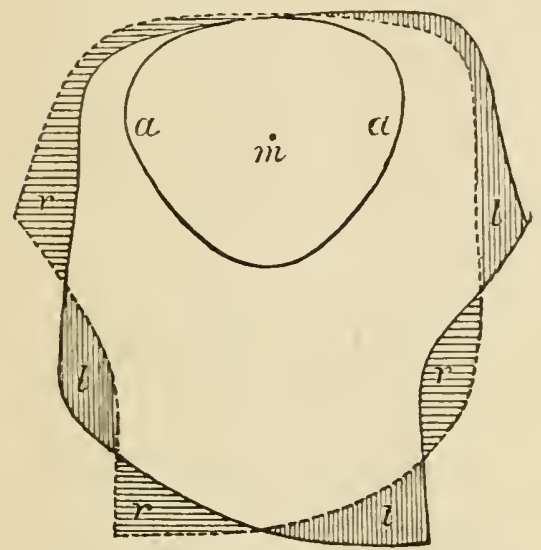

FIG. 242.-The field of vision projectert on a distant plane perpendicular to the line of vision, after Hering. movements are few in comparison with those theoretically possible. In general we may say that only morements with the lines of vision parallel or symmetrically converged-i. e., direeted toward a point in the mid line-are possible. Convergence of the lines of vision toward a point not in the mid line is always associated with great effort, and as a rule is obviated by moring the lead and thus aroiding. as we are always inclined to do, extreme movements of the eves.

This limitation of the eye morements is of very great importance for visual perceptions; for the connection between the retinal images and the position of the eyes is thereby rendered more constant than would be the case if all theoretically possible morements were carried out.

\section{§ 2. SIGNIFICANCE OF EYE MOVEMENTS FOR THE OUTWARD PROJECTION OF VISUAL PERCEPTIONS}

It is erident from the optical principles of the eye that the images thrown on the retina by refraction of light are always reversed, and yet we always see the objects to which the images correspond right side up. The explanation of this phenomenon has been much discussed, and yet is all rery simple.

The newborn child sees. but understands nothing of what it sees. Included in the knowledge which the child gains by experience with the sense of sight is the knowledge of the position of things. But this knowledge the child does not obtain by the sense of sight alone: the bodily movements plav a determining part as well. When the child looks at its nurse the image is upside down on the retina. But if it should wish to tonch the nurse's head with its hand. it must more its arm in the right direction. In this way a definite connection is established between the retinal image and the morements, and the child learns to project its visual impressions outward in the proper direction.

The reason then why we see all objects right side up is, that in developing our ability to recognize external objects and their position in space, we have 
always made use of morements of the arm and especially of the eyes themselves, which bave taught us the proper direction.

As an illustration of the way visual impressions are projected outrard we may take Scheiner's (1619) experiment, which at the same time is an interesting demonstration of accommodation. Two needles are placed one behind the other before a bright background, the one vertical and about $18 \mathrm{~cm}$. from the eve, and the other horizontal and about $60 \mathrm{~cm}$. from the eye. Then a card containing two small holes, whose distance from each other is less than the diameter of the pupil, is held before the eye, and the other eye is closed. If one accommodates now for one needle, while the card is being held so that the line joining the holes is in the same direction as the other needle, this second needle will appear double.

Suppose the ere be adjusted for the distant needle, $b$ (Fig. 243, A), then the image of the near needle $a$ falls at $a^{\prime}$. Since each of the two holes admits a beam of light from the near needle, and these two beams cannot fall in the same place on the retina, two faint images are formed at the places where they cross the retina. In the same way by accommodating for the near needle $a$ we get a double image of $b$ (Fig. 243, B), because the rass from that needle strike the retina at two places. If in the latter case one hole in the card is covered, the image on the same side will disappear; for the image which is formed by crossing (cf. Fig. 2:30) to the opposite side of the retina has been projected to this side of the field of vision-e.g., the upper image at $a^{\prime}$ in the direction of $b^{\prime} c$. If, however, the same hole $c$ be closed in the first case (Fig. 243, A), the image on the opposite side disappears; the lower image at $b^{\prime}$ is projected not in the direction $c$, but in the direction $d$.

Hovements of the eve determine the projection of our visual impressions in other connections also. When one looks through a wire gauze at the window

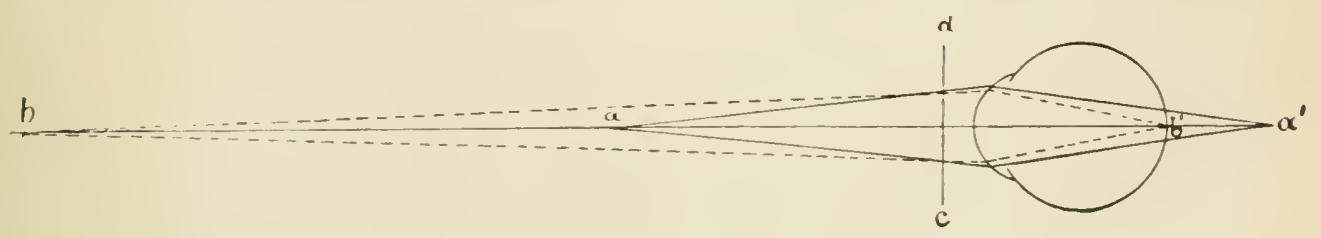

A

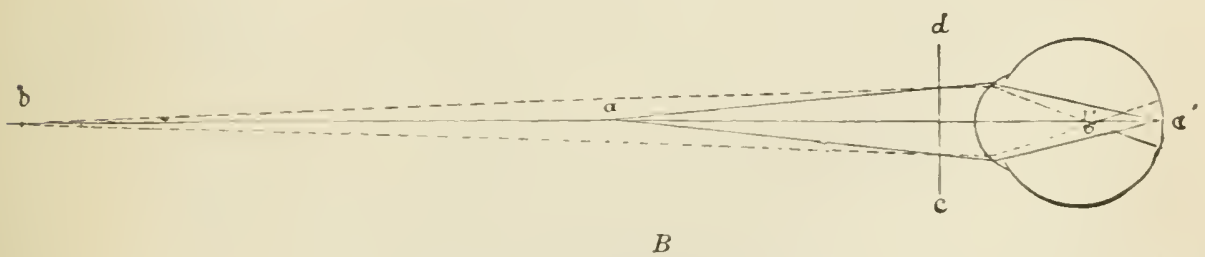

FIG. 243.-Seheiner's experiment.

the meshes appear large and far remored from the ere, but if the eres be focused on a pencil point held close to one's near point of vision in front of the gauze, the meshes appear small and near-i.e., appear in the plane of the fixed point or of the point where the lines of vision meet. Although the experiment gives the sane result in looking with one eve, the observer can plainly feel that the eyes are strongly converged in fixing the near object. 
If, after looking for a moment at the sun until the cye is fatigued, the eves be turned toward a uniformly lighted wall, one sees there an after-image of the sum, the size of which depends upon the distance of the wall-the farther away the wall the larger the after-image (H. Meyer).

The shall return again to the condi-

Fig. 244.-After Hering. tions for the perception of depth and the laws by which we judge the apparent distance of an object. From the facts just presented, which are exactly the same with and without accommodation, it follows that a retinal image of a given size is projected in different sizes according to the position of the visual lines, the object appearing smaller when they are converged, larger when they are parallel.

The size of the retinal image therefore is not always the determining factor in judging the size of objects. The apparent size of a well-known object-e. g., that of an adult man-does not vary noticeably when it is seen at different distances, although the size of the retinal image changes considerably. Such peculiarities are the result of a gradually acquired experience. A child relying on the size of its retinal images misjudges the size of objects much more than an adult.

In forming judgments of linear, vertical and horizontal distances, equally remored from us, the movements of our eyes

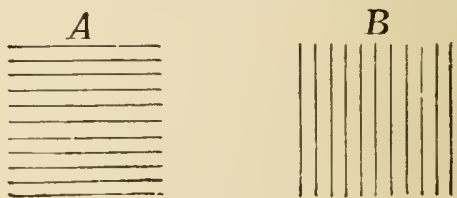

Fig. 245.-After Helmholtz. play a determining part (Wundt). If we compare a space divided by points or lines into intervals with an equal space not so diridect, the former appears greater than the latter (Hering. Fig. 2t-t). Two squares of the same size, one ruled horizontally, the other vertically, appear to be different in both breadth and height (Fig. 245). In both these examples the retinal images of the two objects compared are exactly equal in size, and the accommodation is the same. The hasis of the phenomenon appears to be that it requires less muscular effort to cast the eyes over an empty space than orer one interrupted at certain intervals. It is as if the eye had to make a fresh effort at each point in Fig. $24 t$, and at each line in Fig. $2+5$.

The vertical line in Fig. : 46 appears longer than the horizontal one because it requires greater muscular effort to move the line of vision up and down than to

Fig. 246. more it out and in. For in the morement of the risual line directly upward it is necessary that two muscles coöperate (cf. page 550). One of these, the superior rectus, tends to turn the eye upward and inward; the other, the inferior oblique, tends to turn it upward and outward. Hence part of the muscular force developed in each muscle is used in antagonizing the other. But in rotation of the eve directly outward and inward no such compensation is necessary: hence not so much muscular effort is required. The horizontal line therefore seems shorter. 


\section{§ 3. BINOCULAR VISION}

The study of vision with two eyes is of very great interest for physiological psychology, and has been treated by many excellent authorities. Here, however, we must limit ourselves to the most important points and shall only discuss the conditions of single rision and the perception of depth.

\section{A. CORRESPONDENCE OF THE TWO RETIN E}

It is a matter of everyday experience that a distant object regarded with both eyes in their ordinary position looks single, but that if one eye he pushed out of line the object then looks double. One condition of single vision with two cyes, therefore, must be that the images fall on parts of the two retinx which exactly correspond to each other. Those points of the retinæ upon which the same parts of the two images fall are called corresponding points.

On purely optical grounds it is erident that only two points can correspond, for with any giren position of the eve a luminous point can be pictured at
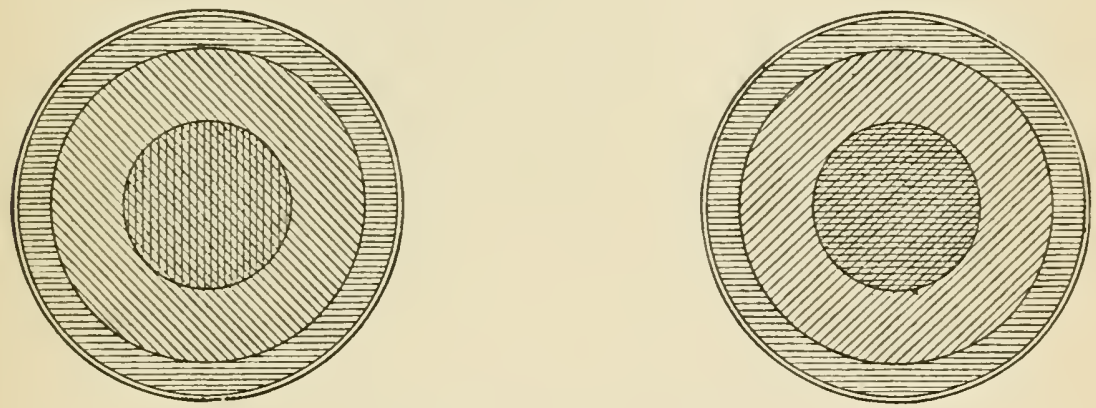

Fig. 247.-The rivalry of the retinæ.

but one definite spot in each eve. The centers of the two foræ centrales represent corresponding points. The exact position of others can be determined experimentally by means of an instrument known as the haploscope (Hering). It is evident on reflection that the nasal side of one retina must correspond to the temporal side of the other, since light from. say, the right side of the field of vision must strike the left side of both retinæ and vice versa.

\section{B. SINGLE VISION WITH TWO EYES}

It might be supposed in explanation of the remarkable fact of single rision with two eres. that the optic nerve fibers proceeding from corresponding points of the two retine end in the same ganglion cell of the brain. But this is not true, for the independence of each eye is much greater than it would he on this hypothesis. There is a form of squint-i.e.. pathological deviation in the positions of the eyes-which is due to an abnormal shortening of the cye muscles (muscular strabism). The line of vision of the squinting cre deviates by a certain angle from the proper position. Now it happens that the person so affected sees single with two eyes in which the images do not fall 
on symmetrical points. If so, these asymmetrical points would nerertheless be corresponding points. But suppose by a slight operation, the squinting eye be giren its proper position; at once louble rision results, which thongh for a time very disturbing, gradually disappears, either because the person learns to disregard one image, or it may be. by a new arrangement of the corresponding points of the two retinx (Wundt).

If we take two patterns ruled in different directions (as in Fig. $21 \%$ ) and look through eylindrical tubes at one with the left eve and at the other with the right, we should expect, if the corresponding points of the two eves were connected with the sanie ganglion cells, to get a double pattern ruled both ways. But instead, when the vertical lines of one pattern are seen clearly,

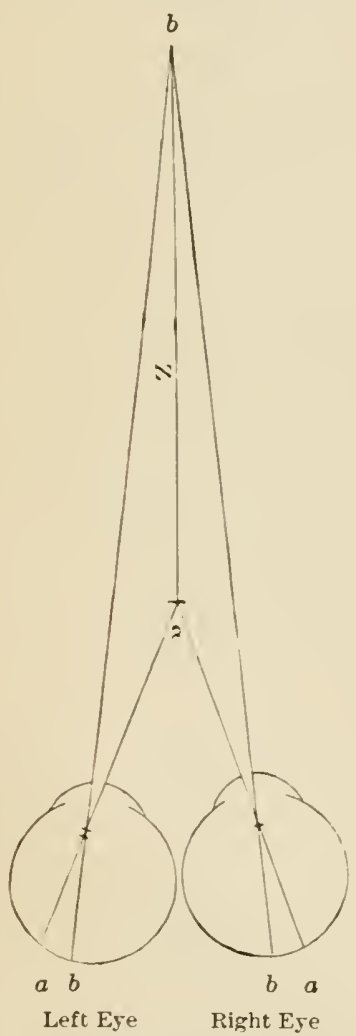

Fig. 248.- Schema illustrating the formation of images in the two eyes, of an oblique line in the median plane. the horizontal lines of the other are indistinct and vice versa. If the eves be moved in the rertical dircetion, the rertical lines stand out more and more prominently-if in the horizontal direction the horizontal lines.

Because the two fields of vision appear thus to contend for the supremacr, this phenomenon is known as the rivalry of the retince.

The question whether the correspondenee of the retine is inborn or acquired has been answered in very different ways. At all erents we may be sure that the nerve conneetions for the morements of the two eyes and for keeping them in their natural positions are established before birth. For this reason the portraval of an object on certain parts of the retina is especially farored. Sinee now the bilateral eonnection of the optic fibers with the cerebrum is, for the most part at least, inborn also, there must exist from the earliest moment of extrauterine life onward very favorable conditions for the eorrespondence of the retine. Hence it will be relatively easy for the ehild in the formation of his risual sensations to relate the two retinal images, together with the tactile impressions, to a single object and thus gradually to derelop a eorrespondence of the two retina.

\section{PERCEPTION OF DEPTH}

The principal significance of vision with two eyes is that it enables us to estimate distance in the sagittal direction more exactly and to obtain an idea of the solidity of objects.

It is true that one can estimate distances with one eye, but he can do so much more aceurately with two.

The factors which figure in the perception of depth with one eye are the following: (1) risual angle; (2) accommodation; (3) conrergence of the lines of rision. 
It is evident that the risual angle ean figure only when we are dealing with objects which vary but slightly in size, and which are well known to us. But under these eircumstances and especially at great distances where aceommodation and convergence can have no part the visual angle is of rery great importance.

A. we hare already seen (page 534), accommodation and convergence are very elosely conneeted, and convergence occurs in accommodating for near vision even when one eve is corered. Sinee accommodation is not necessary for vision with emmetropic eyes at distances in the sagittal direction of more than $5 \mathrm{~m}$., and only becomes of great importance at a much smaller dis-

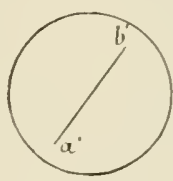

Left Eye

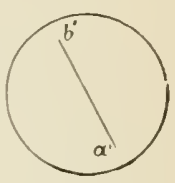

Right Eye

FIG. 249.-The position of the two images (Fig. 248) on the retinx.

tance. it is evident that these two factors can only figure for relatively slight distances.

If a thread be placed obliquely in the mid line of the body, so that its near end (Fig. 248, a) is higher than its farther end (b), one can tell even with an instantaneous flash of light from an eleetrie spark-when the eyes have not time to move-the correct position of the thread, and it never appears double (Aubert). And yet, as Fig. 249 shows, the images of the ends of the thread do not fall on eorresponding points of the retina, and from what we have already learned we should suppose that the thread would produce an impression of two lines lying in the same plane and crossing each other. By looking very sharply,
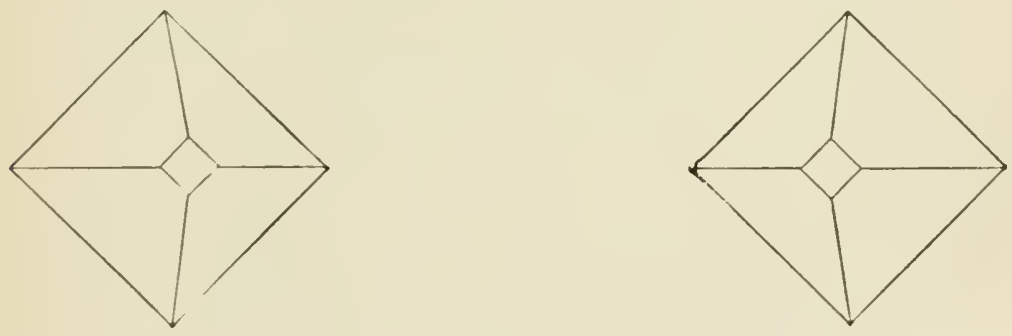

FIG, 250.

in fact, one ean get such an impression; this means that we have here an ability which is not inborn, but is aequired by practice and experience.

It follows from the experiment that the exeitation of two dissimilar points of the retina doe- not always produce a donble inage. but under some crevunstances gives the idea of a single objective point. This point, however. is not in the plane of the fixed point, but lies either in front of or lehind it.

The accuracy with which we ean perecive differences of depth by vision with disimilar points is exeedingly great. Acenrling to Heine, for persons endowed with extrandinary aenteness of vision a displacement of the retinal picture of only 6 seennds of an are $(0.0005 \mathrm{~mm}$.) is pereeptible. Thus at a distance of $5 \mathrm{~m}$. a displacement in the sagittal direction of $10 \mathrm{~mm}$. would be perceptible. and at a distance of $100 \mathrm{~m}$. a displacement of $20 \mathrm{~m}$. Indi- 
riduals with normal acuteness of vision could perceive a displacement of about twice this amount.

The abore-mentioned experiment represents stereoscopic rixion in its simplest form. When we look at a solid object, not too far remored. first with the right eye and then with the left, the picture we get of the object is not exactly the same for the two eyes. The right eye sees a little more of the right side of the object, the left a little more of the left side. In Fig. 250 are represented the images of a truncated pyramid as scen by the two eyes

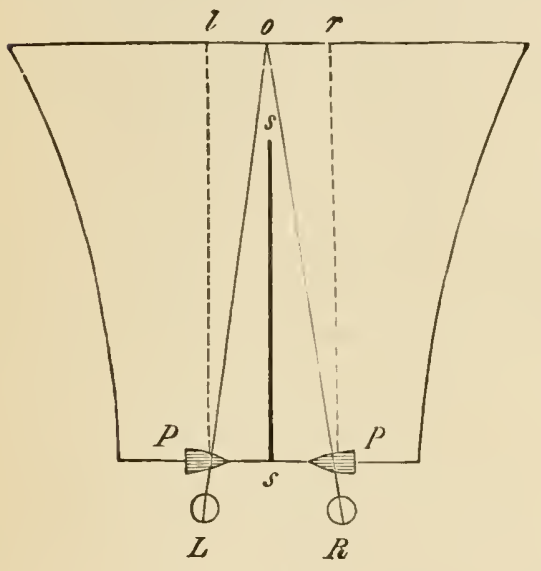

Fig. 251.-Brewster's stereoscope. separately. A glance at the two is sufficient to convince one that these two images could not possibly fall on corresponding points of the retinæ. But if these drawings be held before the eres so that the one may be seen with the right ere and the other with the left, the two fuse together in our minds into a picture of an actual pyramid.

Unless one is accustomed to accommodate the eyes without converging the lines of vision this experiment is difficult. The same result is obtained without accommolation if the two pictures be refracted separately into the two eyes by means of lenses. This is the principle of the common stereoscope of which Brewster's form (Fig. 251) may be taken as an example. It is apparent from the figure that two pictures situated at $l$ and $r$ will be refracted so as to be superimposed at $o$.

For stereoscopic vision to be of any importance the object must not be too far removed, for then the images belonging to the two eyes would not be noticeably different. The ordinary stereoscopic riews of landscapes are photographed with a double eamera so that the plates are farther apart than the distance between the two eyes. Consequently such photographs combined give us an impression of solidity such as natural rision does not afford.

Referexces.-Aubert, "Physiologische Optik" (Graefe-Saemisch's "Handbuch der Angenheilkunde," ii, 2, Leipzic, 1576).-Fick, Kühne and Hering, "Gesichtssinn" (Hermann's IIandbuch der Physiologie, iii, 1. Leipzic, 1879).-Helmholtz, "Handbuch der physiologischen Optik," second edition, Hamburg and Leipzic, 1886-1896. The last named cites a very complete literature of the subject of physiological optics.-Hering, "Zur Lchre fom Lichtsinn," Wien, 1878.- $v$. Kries, several articles on the "Physiologie der Gesichtsempfindungen," Leipzic, 1597-1902.- $v$. Kries. Nagel and Schenck. "Gesichtssimn" (Handbuch der Physiologie, iii, 1, Braunschweig, 1904).-Wundt, "Text-book of Physiological Psychology," translated by E. B. Titchner, New York, 1905. 


\section{CHAPTER XXI}

THE PHYSIOLOGY OF THE NERTE CELL AND OF THE SPINAL CORD

\section{\$ 1. GENERAL CONSIDERATIONS CONCERNING THE FINER STRUCTURE OF THE NERVOUS SYSTEM}

IT has for a long time been customary to divide nerve tissue into two elements: nere cells and nere fibers. The nerve cells were first seen by Ehrenberg (1833) in the spinal ganglia. Remak (1835) first pointed nut that the processes of nerre cells are continued in the sympathetic nerves of the vertehrates as an integral part of the nerve fibers. This was shown to be true also for the invertebrates by Helmholtz and Hanover (184?). Deiters (1863) demonstrated that all central nerve cells have two kinds of processes: first, axis-cylinder processes. which connect with the medullated nerve fibers and become directly continuous with this axis eylinder; and secondly, protoplasmic processes, which break up into rery fine branches whose ultimate fate Deiters was unable to ascertain.

$\mathrm{By}$ the introduction (18:3) of Golgi's method of impregnating the nerve elements with silver, a fresh impetus was given to research in the field of neurn-histology. With the application of this method. which has given us such a rich and eomprehensive riew of the structure of the nerrous system, are associated preëminently such names-apart from that of Golgi himself-as those of Cajal, Kölliker, Retzius and ron Lenhossek.

According to the riew represented by these investigators the nerrous sytem is to be regarded as made up of genetieally separate and distinet nerrnus units to which the general term neurons is now applied. The most essential and important part of the neuron is the nerve cell. Sereral processes are given off from this, one or two of which (from some cells more) are continued as the axis eylinders of nerve fibers and consequently are termed axiseylinder processes or axons. As for the remaining processes, the sn-called dendrites or protoplasmie processes of Deiters, they divide into numerous branches which become exceedingly attenuated, and in this way greatly inerease the superficies of the nerve cell.

The nerve process enntinues as an integral part of the nerve fiber to its final distribution. where it generally breaks up into a small terminal arborization. At different points alnng the course of the nerve fiber a variable number of side twigs or collaterals are usually given off. which. in turn. after a shorter or lnnger course. like the nerve fibers themselves, end in delicate ramifications.

Aceorling to the original conception of the neuron theory the individual nerve units do not form a continuous network, but are anatomically separate 
and distinct, although both in the central and in the sympathetic nerrous system the end tree of one neuron may twine about the cell body of the second so that the latter is brought into contact with the former neuron. Any anastomosis or actual structural continuity of dendrite with end arbor-

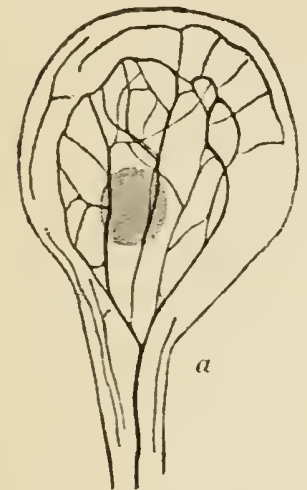

FIG. 252.-Ganglion cell of a leech (Hirudo), with fine peripheral network and coarse inner network. From the latter a stout efferent fibril is given off (Bethe).

ization is, therefore. emphatically denied. Everything takes place by mere contact.

In view of the work of Apáthy and Bethe, this position, however, is no longer tenable, for it appears to have been definitely shown that the different nerve units do unite by anastomosis.

According to Apáthy's researches-chiefly ou invertebrates-the nerve fibers consist of fine neurofibrils which constitute independent morphological elements. Within the nerve fiber they preserve their individuality throughout and have no comnection whatever with one another. In the peripheral end organs the individual fibrils split up and form an anastomosing network. Likewise in the ganglion cells the fibrils which enter become branched and form a network. But before entering the cells the delicate end twigs of the afferent fibers form a reticulum within the dense tangle known as the neuropile, which occupies the center of the ganglion. From this neuropile very delicate fibrils emerge, penetrate the ganglion cells and there form first a peripheral network (Fig. 252), from which are given off in turn radial fibrils that weare about the cell nucleus a seeond network of thicker fibrils and from this finally the stout efferent fibril emerges. The neurofibrils therefore represent the conducting portion of the nerrous srstem and through them all parts of the nervous system are brought into direct communication with one another (according to Bethe).

In certain invertebrates at least (green crab, crawfish), but a small portion of the neurofibrils pass through the nerve cells. Here, then, the fibrillar transition from fiber to fiber, and their intermixture must take place, for the most part, in the neuropile and its reticulum.

Bethe in particular showed that the neurofibrils are present as conducting elements in the nervous system of the vertebrates also. Without any interconnection the fibrils run a separate and unbroken course to the terminal arborizations of both the peripheral nerve fibers and their analogues the medullated fibers of the central nervous system. Ther oceur in the nerve cells also, and almost every cell process is connected with one adjacent to it by a bundle of fibrils of variable thickness. In like manner each dendritic process sends some fibrils into the axis-cylinder process of the cell.

Covering the surface of the nerve cells and of their dendritic process there is found a network with polygonal meshes (Fig. 253), concerning whose real nature different views have been advanced. It was first described by Golgi. According to Bethe, who, however. expresses himself rery cautinusly in this regard, this network is of a nervous character, connecting on the one hand with the neurofibrils of the nerve cells, and on the other with nerve 
fibers from without. Acepting this view, this periecllular network would be analogous to the extracellular fibrillary reticulum in the neuropile of the invertebrates. In riew of the fact that it is not confined alone to the surface of the cell, but spreads out in three dimensions through the entire gray matter of certain parts of the nervous sytem. this network may be looked upon as constituting a new kind of nerve matter. probally corresponding to the extracellular " gray " whose existence was postulated by Xissl. Nissl's inference was based on the ground that eren the great number of nerve cells. dendritic and axis-cylinder processes. neuroglia fibers and cells, and blood ressels taken collectively, especially in certain parts of the cereloral cortex but also in other places, fall far short of the bulk necessary to fill the entire space.

What the genetic relationship is that exists between the reticulum of the invertebrate ganglion or the Golgi network of the vertebrate nerve tissueif inleed it be a nervous structure-and the nerre cells is still quite unknown. Even if the pericellular network takes its origin from the nerve cells and is therefore to be regarded as a derivative of such a structure, the elassical definition of the neuron theory makes no provision or qualification for such an additional element. Moreover, Bethe and others have made observations which purport to show that the nerve fibers are not produced as outgrowths of the nerve cells but are laid down separately by other cells. If this be true, the neuron theory cannot be maintained in any form. But since much remains ret to be cleared up in regard to this question, and since different facts of " $\mathrm{x}$ perimental physiology which Bethe has adranced in support of his view (ef. page 575) really admit of another theoretical construction. the objection last urged against the neuron theory can searecly yet be aceepted as conclusive.

It present we may riew the strueture of the nerrons: sritem somewhat as follows: The nerve

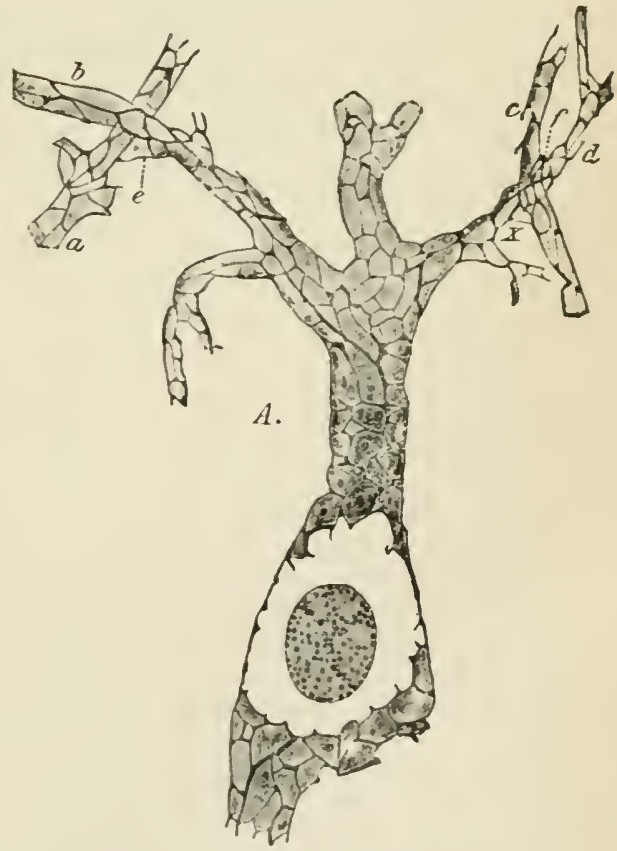

Fic. 253.-Golgi network ahout a cell of the nucleus dentatus of the dog, after Bethe. cells grive off several procesede nue or more of which leceme the axis exlinders of nerve fibers. These consist of fine fibrils which pursur a separate and unennmeder course in the nerve fiber. oftentimes penetrate the nerve well and there-in the invertebrates. lout not in the vertebrates-form a real notwork. Theor fibits andotomose fredy nutside the nerve cells, and alin within the colls in the invertebrates, and thus constitute a posible path for the transmision of stimuli from one cell to the other. 
It must be observed, however, in this connection, that our knowledge concerning the finest structure of the nervous system, especially in the vertebrates, is still too meager to admit of any one satisfactory or conclusive view.

\section{§ 2. THE STRUCTURE OF THE SPINAL CORD ${ }^{1}$}

A cross section of the spinal cord (Fig. 254) shows the central gray matter with its contained nerve cells, and surrounding it the white malter made up of nerve fibers. The anterior longitudinal or median fissure (a) and the pos-

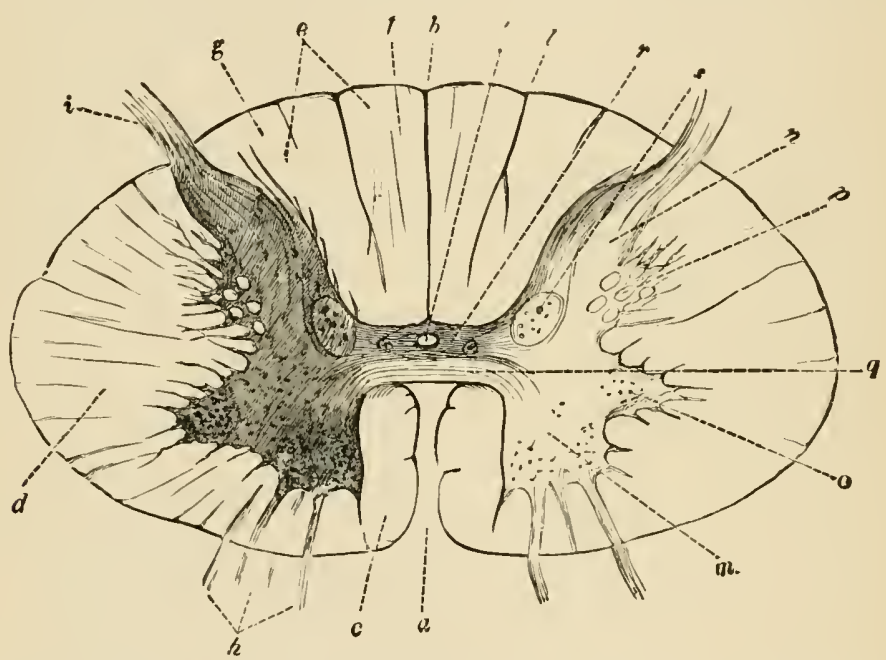

F1G. 254.- Semidiagrammatic section of the spinal eord, after Frb. $a$, anterior fissure; $b$, posterior septum; $c$, anterior column; $d$, lateral colunn; $e$, posterior column; funiculus gracilis; $g$, funieulus euneatus; $h$, anterior root; $i$, posterior root; $k$, central canal; $l$, suleus intermedius posterior; $m$, cclls of the auterior horn; $n$, cells of the posterior horn; $o$, lateral horn; $p$, processus reticularis ; $q$, anterior commissure; $r$, posterior commissure; $s$, Clark's column.

terior median septum $(b)$ divide the cord into two symmetrical halves, connected by two commissures $(q, r)$, the anterior white and the posterior gray commissures.

The gray matter, pierced in the middle by the central canal $(k)$, has in general the appearance of the capital letter II, but varies somewhat in form at different levels. The roots of the nerves enter each half of the cord in separate bundles, the posterior and the anterior spinal nerve roots. These divide the white matter into three main portions: (1) the anterior columi lying between the anterior longitudinal fissure and the anterior nerve root: (2) the lateral column lying between the anterior and posterior nerve roots; (3) the posterior column lying between the posterior nerve root and the posterior median septum.

${ }^{1}$ After Edinger's “Vorlesungen ïber den Bau der Nervösen Zentralorgane," seventh edition, Leipzic, F. W. C. Vogel, 1904. Since the more recent views, as set forth in the paragraphs above, on the structure of the nervous system are still immature, and fall short of a comprehensive exposition of the structure of the spinal cord, in the account here and in that which follows we shall make use of the anatomical facts thus far established without further reference to the relation and connection which may exist between the individual cells and fibers. 
The gray matter on each side of the eord is divided into an anterior and a posterior horn. In the lower eervical and in the upper thoracic regions of the cord, as woll as in the lumbar region, the lateral portion of the anterior horn becomes partly separated off as a lateral horn $(o)$.

Among the nerve cells of the gray matter we distinguish: (1) The cells arranged in groups in the anterior horn; (2) the cells of the so-ealled column of Clarke $(s)$ situated at the median side between the anterior and posterior horns, and extending from the end of the cervical enlargement to the beginning of the lumbar cord; (3) the cells of the substantia gelatinosa Rolandi capping the posterior horn; (4) the rest of the cells in the posterior horn.

The fibers of the anterior nerve roots are the axis-cylinder processes of the cells in the anterior horn of the same side, or, less frequently, of the opposite side, the latter fibers crossing via the anterior commissure before they gain the anterior root. The eclls of the posterior horn on the contrary do not connect directly with fibers of the posterior root, since the latter have their origin in the eclls of the spinal ganglia.

These cells of the spinal ganglia, for the most part, are unipolar-i. e., they have but one process which, however, after a short conrse, splits inte two branches. One of the two proceeds toward the periphery and joins the anterior nerve root in a mixed nerve trunk; the other enters the cord by the posterior nerve root. Practically all of the fibers which enter the eord divicle into an ascending and a descending branch, both of which give off collaterals, and sooner or later end like the collaterals about the cells of the gray matter of the cord. The peripheral nerve fibers, therefore, have their origin either in the cells of the anterior horn or in the cells of the spinal ganglia.

The nerve fibers from the anterior horn cells are all efferent in function, and the nerve fibers arising from the cells in the spinal ganglia are mainly afferent fibers.

With regard to the further connection of the two kinds of fibers we distinguish: (1) a secondary efferent path; (2) a secondary afferent path: and (3) the paths by which afferent pass over into efferent impulses.

Those tracts which anneet the nerve cells of the anterior horn with the highere centers we designate as secondary efferent paths. They are the paths by which impulses liberated in the (ells of the higher centers are envered to the motor cells of the anterior horn.

The fibers entering the cort from the spinal

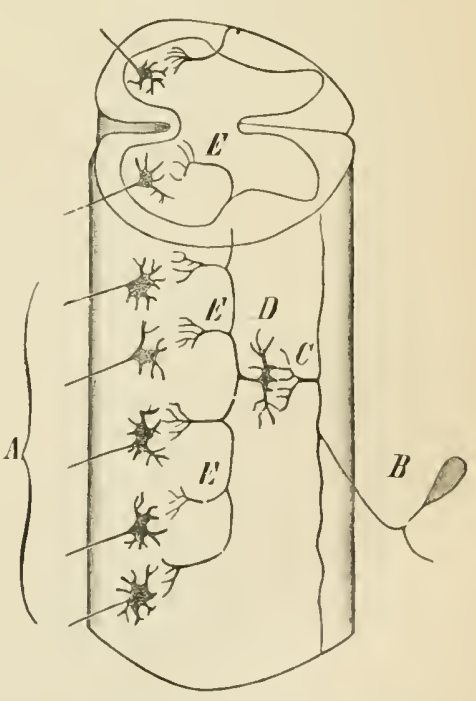

FIG. 255.-Schema, after Kölliker and lenhossik. A, motor cells with root fibers; $B$, spinal ganglion cell with its processes; $C$, a sensory collateral; $D$, column cell with 'T-shaped branching processes; $E$, collaterals of the same. ganglia are brought into relation with the eells of the posterior horn whose axis-cylinder processes constitute the secondary afferent paths. It is by these paths that impulses are transmitted to the higher centers.

The transition from afferent to offerent paths may oecur in several ways. The simplest instaner is when an afferent nerve fiber or one of its collaterals connects directly with the motor cell of an efferent nerve fiber or with some of its processes by means of fibrils. 
Again a nerve cell with its processes, etc., mas be intercalated as a new element between two primary paths, as shown in the schema (Fig. 255) based on the newron theors. The terminal fiber's of an afferent nerve fiber $(B)$ or its collaterals $(C)$ unite with a nerve cell (column cell) somewhere in the central nerous system $(D)$. This cell sends forth an axis-cylinder process which has several collaterals $(E)$ and these in turn serve to bring it into contact with an anterior horn cell $(A)$. Br this arrangement it is evident that an impulse coming ria a single afferent fiber is transmitted to a large number of efferent fibers. If now we imagine one or more such cells interposed between the cell $(D)$ and the motor cell $(A)$ the connection is made still more extensive.

Thus by means of collaterals and intercalated cells, and possibly through the agency of the pericellular network, every provision is made for an afferent impulse to be carried over at almost every point of its course, either directly or indirectly, to the motor cells of efferent fibers, and here we have the anatomical basis for facts, long since established by physiological observations, that a given afferent impulse may give rise to a great variety of efferent effects. Just what arrangement obtains by which different paths have been accommodated to certain special functions is a question which for the present can scarcely be answered. Only in a general way may we state that between certain parts of the nervous system a comnection-be it purely anatomical or only functional-is more easily established than between other parts. This, however, is but hedging the real question.

\section{\$3. KINDS OF NERVES}

\section{A. CLASSIFICATION ACCORDING TO FUNCTIONS}

Physiologically nerres may be divided into two large classes: afferent and efferent. The former bring messages from all parts of the body to the central nerrous system, the latter convey impulses from the central system to peripheral organs in all parts of the body.

The number of fibers in the posterior root is somewhat larger than the number in the anterior. In two frogs. weighing 23 and $63 \mathrm{~g}$. respectively. Birge found in the posterior roots 3,781 and 5,335 fibers, and in the anterior roots 3,528 and 4,283 respectively. According to counts made by Dale the posterior roots of the coccygeal nerves of the cat always contain more fibers than the anterior. Stilling previously had obtained the same result in man.

1. To the efferent fibers belong:

(a) The Votor Nerves-i. e., all nerves whose stimulation produces contraction of muscles, whether skeletal muscles, rascular muscles, muscles of the intestine, glandular ducts, bronchioles, etc.

(b) Secretory Terves, page 257 (salivary glands), page 263 (gastric mueosa), page 269 (pancreas), page 396 (sweat glands).

(c) Inhibitory Nerves-i. c., nerres which check or stop any dissimilatory process-e.g., the carlio inhibitory in the vagus (page 18s), the vasodilator nerves (page 234), the inhibitory nerves of the intestine (page 2os).

Little is known with regard to the inner processes which result from stimulation of imhibitory nerves in the different organs. We have some observations tending to show that when the ragus is stimulated changes are set up in the heart which antagonize the processes taking place during contraction, and from these observations the conchusion has been drawn that the vagus exercises a nutritive control over the heart. Other observations which have been reported at page 190 show, however, that under favorable circumstances an animal with 
both vagi cut can live for a long time without exhibiting any pathological alterations of the heart's structure. We shall return in the next section to this question of the trophic influence of the nervous srstem on other organs.

2. The afferent nerves include:

(a) All nerves which elicit conscious sensations, namely, nerves of the higher senses, tactile, temperature (and pain) nerres of the skin, and nerves of the internal organs in so far as they mediate conscious sensations.

(b) Nerves which do not elicit conscious sensations but which acquaint the central nervous system with the condition of the different organs-e.g., the depressor (page 193) and the pulmonary ragus (page 327 ).

No sharp line of demarcation can be drawn between $a$ and $b$, for it is rery probable that many nerves of the second group mediate sensations of pain when they are stimulated excessively.

\section{B. SPECIAL PROPERTIES OF DIFFERENT KINDS OF NERVE FIBERS}

Histological studies have shown that nerre fibers differ in structure, and it is to be assumed a priori that this difference is the expression of a certain physiological difference. Our information along this line, however, is still rery inadequate, and scarcely permits us to reach any definite conclusions. The following brief survey, mainly from the results reported by Engelmann, will serve to indicate the present tendency of investigations along this line.

(1) When a mixed nerre is compressed the conductirity of its sensory fibers is lost sooner than that of its motor fibers.

(2) The constant current acts on most efferent nerves only at the instant of closing and opening, but on most afferent nerres throughout the entire time the current is closed (cf. page +21). The same difference obtains between the two groups of functionally different nerves with respect to the tetanizing action of supranormal temperatures.

(3) The nerves of the extensor and flexor muscles in the same animal are unequally excited by induction currents. The same is true of those controlling the adductor and abductor muscles of the crab's claw: of the nerres of the extremities on the one hand and the vagi, sympathetic, sweat nerves on the other; the accelerator and inhibitory fibers of the heart.

(4) Many chemical agents have a powerful stimulating effect on motor nerves, but either no action at all or only a very feeble one on sensory nerves. The cardio-inhibitory fibers are thrown out of action by the local effect of a one-quarter-per-cent $\mathrm{KNO}_{3}$ solution applied to the cardiac branch of the vagus, but the accelerator fibers remain functional, etc.

Several of these differences may well be due to peculiarities in the end organs, but others probably are dependent upon actual differences in the physiological constitution of the nerve fibers. This question cannot be decided ensily and, as Engelmann points out, one will do well in any case to be cautious and not take it for granted that results obtained on one species of nerve will necessarily hold for all others.

\section{MAGENDIE'S DOCTRINE}

The famous anatomist Willis surmised that the anterior ronts of the spinal nerves make connection with the cerebrum. the organ of sensibility and motility, and the posterior roots with the hasal parts of the brain presiding orer the vegetative functions-circulation, nutrition, secretion, etc. In 1811 Bell attempted to establisll the truth of this view experimentally. but when Magen- 
die in 1822 published the results of his investigations. to be discussed immediately, Bell came orer to that author's position. The law which Magendie established is often known even ret as Bells doctrine.

Magendie's doctrine is that the anterior roots of the spinal nerve contain only efferent fibers, the posterior roots only afferent fibers.

Originally the demonstrations by Magendie, Bell, Johannes Müller and their followers only applied to the motor nerves in the strict sense. But after other efferent nerves had been discovered, proof was soon fortheoming that they also make their exit by the anterior roots. Proof for the vasoconstrictors was furnished by Pflüger and Claude Bernard, for the rasodilators by Dastre and Morat also Gaskell, and for the sweat nerves by Luchsinger.

Several very noteworthy exceptions to this general law have now to be admitted. Thus the posterior roots do not contain afferent fibers exclusively, but also a few efferent fibers. Stricker and his pupils find rasodilator nerves for the posterior extremity of the dog in the posterior roots of the fourth and fifth lumbar nerves, and for the anterior extremity in the posterior roots of the braehial plexus (ef. page 235). According to Steinach the posterior roots of the second to the sixth spinal nerves of the frog contain motor fibers for the œsophagus, stomach, and small intestine-those of the sixth and serenth, motor fibers for the rectum and those of the seventh to the ninth, the same for the bladder; but Dale was unable to confirm these findings. In exceptional cases Horton-Smith and Dale found fibers for individual skeletal muscles of the frog in the posterior roots.

Bayliss has used the method of degeneration (cf. page 56 5 ) for tracing out the vasodilators contained in the posterior roots and has found that they originate in the spinal ganglia. Hence they also constitute a definite exception to the rule.

Still another exception, which, however, is only apparent, has been observed. Magendie himself noticed that sometimes the anterior roots were sensitive. Later he found that this sensibility could only be demonstrated so long as the posterior roots were intact. It is now known that this sensibility is to be accounted for by the passing of fibers from the posterior root along the anterior root to sensory endings in the membranes of the cord. For this reason the sensibility of the anterior root is called recurrent sensibility.

It was long supposed that the sensory fibers of a mixed nerve originate only in the same pair of roots as the motor fibers. Clinical observation has shown, however, that the transition is much more widespread, since afferent nerres in the periphery of the body often pass from one nerve trunk to another. so that within certain limits scusory transmission may take place in both directions within the same nerve trunk.

\section{§ 4. FUNCTIONS OF THE NERVE CELL}

From the time nerve cells were first discovered it has been assumed almost universally that they constitute the seat of the central functions of the nerrous system. The most weighty support for this riew lay in the constant difference of behavior between the peripheral and central systems, the difference being referred almost as a matter of course to the one element which was found to he specific for the central system. In riew of more recent discoveries on the finer structure of the central system. it is not impossible that the extracellular net and the connections between neurofibrils play a still more im- 
portant rôle than the nerve cells in the discharge of central functions. Although our information is not ret definite enough to warrant taking such a position, it would be well if we had some designation for those constituents of the nerrous system discharging these central functions, which would not prejudice either view. For simplicity"s sake, we shall retain the old name. expressly remarking that the olservations brought together in this book and the conclusions deducible therefrom are on the whole but little affected by the newer ideas, as to the structure of the nerrous system. Those ideas will only become significant when it has been definitely proved that the functions hitherto ascribed to the nerve cell are exercised in greater or less part by extracellular structures.

\section{A. THE NUTRITIVE FUNCTIONS OF NERVE CELLS}

In 1852 Waller, Sr., found when he cut the pnsterior roots of the second cervical nerve between the spinal ganglia and the spinal cord and killed the animal (cat or $\operatorname{dog}$ ) some time later, that the peripheral end of the root still conneeted with the ganglion remained normal. while the central end and its continuation into the spinal cord degenerated. When he cut the nerve peripherally to the ganglion, the peripheral end degenerated. while the central end and its continuation into the spinal cord remained normal. Finally, it was shown that after cutting the anterior root the peripheral end of the efferent fibers degenerated while the central end remained normal.

Before Waller, Tïrck had found that a partially transverse section of the spinal cord produced degeneration above and below the section, and that this degeneration did not follow the same columns continuously.

Thus it was demonstrated that a nerve fiber maintains its normal condition only so long as its connection with the nerve cell is preserved. These facts hare been robled of much that was originally strange about them by the newer conceptions of the nerve fiber as a mere process of the nerve cell; for it is perfectly erident that a process must degenerate when its connection with the cell body is lost.

Wallerian degeneration has been of very great value in traeing out the nerve paths in the central nervous system (ef. later), in determining nerve roots, and in isolating physiologieally the different kinds of fibers belonging to a given nerve trunk. The latter is pussible beeause the different kinds of fibers do not degenerate at the same rate after section.

But we find it necessary to-day to amend the law of Waller somewhat. It turns out that both the stump of the nerve fiber left in eomection with the nerve cell and the eell itself undergo seeondary changes after section of a nerve. The motor cells and those of the spinal ganglia appear to behave somewhat differently in this respect. The former exhibit certain characteristic alterations of structure within twenty-four to forty-eight hours after the section, and within fifteen to twenty days nany of them have gone to piees. The remainder, even though the end of the nerve may not have healed at all, become from this time on the seat of regenerative changes and gramully reenver their normal properties. The same enurse of events is witnessed in the efferent sympathetie nerves. When the ecrvieal sympathetic is eut, certain eells in the anterior horn of the same side beeone atrophic: and after section of the fibers eoming from the 
first cervieal ganglion, the cells in the ganglion belonging to them for the most part perish.

The structural changes appearing in the spinal ganglion cells after section of a spinal nerve lead to complete loss of their integrity within about ninety days (r. Gehuehten). In other words, to continue in a normal state, the spinal ganglion cell must receive its impulses from the periphery.

On the other hand, section of the posterior root central to the ganglion in roung animals does not stop the development of the ganglion or of the peripheral nerve fibers connected with it (Anderson).

Section of afferent nerves produces changes even in certain nerve cells of the spinal cord, with which they are connected only secondarily. In young animals derelopment of the cells of Clark's eolumn is stopped by section of the sciatic nerve (Anderson). In fact, even the motor cells of the anterior horn as well as the anterior root fibers appear to be affected by section of the posterior roots, and especially if the homolateral half of the spinal cord also is cut through.

In view of these results we can readily understand how after amputation of a limb atrophy will gradually extend to those conducting pathways and gray masses of the nervous system which were formerly in functional connection with that particular limb. Such changes spread more rapidly in young than in older or adult individuals.

On the basis of these facts, Gudden has worked out an cxperimental method of tracing the conducting pathways belonging to a given organ. He merely extirpates the organ from a young animal, keeps the animal alive for a time, then works out the extent and localization of the resulting atrophy.

The most probable explanation of the atrophy resulting from such operations is, that individual nerve elements connected together exercise a nutritive influence on one another in virtue of the excitation processes which they mediate, and that failure of these excitation processes cuts off the nutritive influenec and the result is atrophy. Thus when a sufficient number of posterior root fibers are sectioned, the normal excitation conveyed to the cells of Clark's column by these fibers is prevented and those cells atrophy. The anterior horn cells robbed of their peripheral impulses by section of the posterior roots, and robbed of most of their central impulses by hemisection of the cord, on the same side, are thenceforth devoid of the proper nutritive influence, and they atrophy. When a limb is amputated the individual no longer has any oceasion for sending impulses to the motor cells of the lost nember, and not being used, nutritive control over them is withdrawn.

The nutritive influence of the nerve cells extends also to the peripheral tissues supplied by their fibers, for it has long been known, that the nutritive state of many an organ depends upon its connection with the central nervous system. We have already seen that a skeletal musele degenerates when its motor nerve is cut. The submaxillary gland decreases in size after section of its cerebral secretory nerves (page 256 ). and undergoes degeneration of the true glandular substance.

So far as we know yet muscle substance receives only a single kind of efferent nerve fibers. Consequently the very nerves which evoke the dissimilatory processes of the muscle serve at the same time in some way not ret understood to maintain the muscle in its normal condition (ef. page 449 ), and the same may be said of other organs.

Even afferent nerves have a nutritive influence of this kind on their periph- 
eral end organs. For example, the taste buds of the tongue degenerate after section of the glosso-pharyngeal nerve.

To sum up, we may say that the nerve cells constitute the nutritive or trophic centers of the nerve fibers proceeding from them, and likewise of the central or peripheral organs supplied by the nerve fibers.

In explaining certain phenomena of degeneration the belief has often been expressed that there are special nerves and centers whose sole function it is to maintain the normal state of nutrition in the organs and tissues, and such ne'ves have been designated as the trophic nerves. While we cannot regard the question of their existence as finally disposed of, the results of experiments thus far made tend to discredit the whole conception.

For example, frequent reference is made to inflammation of the cornea after section of the trigeminal nerve and to inflammation of the lungs after bilateral section of the vagus. But as regards the first, it is to be observed that the cornea is rendered insensitive by section of the trigeminal; consequently foreign particles which under normal circunstances would be removed voluntarily or reflexly by movements of the eyelids, are now permitted to scratch and otherwise injure the cornea, and in this manner an inflamnatory process can be started quite independently of any trophic influence. If the ear of the animal be sewn down over the eye so as to protect it from foreign particles no inflammation results from section of the trigeminal (Snellen).

The inflammation of the lungs (vagus pneumonia) can also be explained without invoking a trophic nervous influence. The osophagus is paralyzed as the result of the operation, and bits of food remaining adherent to its walls may very easily be sucked into the lungs and there set up the inflammation observed. Animals with an osophageal fistula in the neck (ef. page 246) undergo bilateral vagotomy without any inflammation of the lungs (Pawlow), the likelihood of food particles entering the lungs being very much reduced by the fistula.

Other experimental results which have been brought forward in support of trophic nerves are nothing more than pure vasomotor effects.

Bedsores, which frequently accompany diseases of the spinal eord (myelitis, lesions, compression, etc.), are probably to be explained rather as the result of a diminished vitality of the skin, which permits injury and infection, than as the specific result of a loss of trophic influence.

\section{B. PHYSIOLOGICAL STIMULI OF NERVE CELLS}

Under normal cireumstanees nerve cells may be roused to activity in any one of the following different ways:

(1) By external stimuli aeting upon the peripheral end organs of afferent nerves. ifferent nerves always connect with a nerve eell of some kind, henee any excitation of the former must be communicated to the latter. The cells of the spinal ganglia are roused to activity by stimulation of the spinal nerves and the nerve cells eonneeted with the nerves of speeial sense (e.g., the ganglion cells of the retina) are exeited by their appropriate stimuli.

(2) By the action of other nerve cells. This mode of excitation is very common, for whenever an impulse is sent throngh any length of the nervous system not covered loy a single fiber it must be transmitted to a fiber or fibers connected with another eell. For examples of this mole. we have only to think of the way in which the highest nerve centers are finally excited by a 
peripheral stimulus or low the efferent motor cells in the anterior horn of the cord are excited through the long cortico-spinal pathways by the cerebral cortex.

We must eall attention here to a very noteworthy difference in the behavior of nerve cells of different kinds. When the spinal eord is excited-e.g., by stimulation of the posterior spinal roots-an action eurrent makes its appearance in the cord, just as in the peripheral nerves; but on stimulation of the anterior roots no action current is obtained in the cord-i: e., the excitation cannot be communicated by the motor cells to other portions of the cord. And yet an excitation started in the cord by direct stimulation can be communicated to the afferent roots. At any rate in strychnine poisoning when a very strong excitation is roused in the cord an action current can be demonetrated in the posterior roots (Gotch and Horsley).

(3) The refler moress represents an important instance of transferred excitation within the central nervous system. This phenomenon was known to Descartes (16t9) and later received an essentially correct explanation throngh the writings of Proschaskas and of Marshall Hall.

A reflex may be defined as a physiologieal act in which an afferent nerve excites an efferent nerve through the coöperation of the central nervous system, but without any participation on the part of the will or of enccionsness.

We have already seen, in discussing the structure of the central nervous system, how this transfer of the afferent impulse to the efferent nerve may take place (ef. page 563 and Fig. 255 ).

(4) Nerve cells may be excited through the blood and lymph (automatic excitation). Products of decomposition and of internal secretion (cf. page 356 ) are always present in the bloot and lymph and are eajable of stimulating the nerve cells with which they are brought in contact.

(5) Nerve cells may be excited through the influcuce of the will. When we make a muscular movement by direct effort of the will, certain nerve cells are excited. The will therefore ean in some way act upon nerve cells, or, more correctly stated, in those cerebral processes which represent the physical correlate of our conscions rolitional states certain nerve cells are active. How this takes place we cannot say.

We might conceive that these movements which take place under the influence of the will in reality represent a particular kind of reflexes, and in fact one may by introspection convince himself that what he ealls a voluntary act is very often the direct result of an external stimulus even though it may be accompanied by a conscious sensation. But it is impossible, for the present at least, to explain the action of the will in its entircty from this point of view and to this question as to that conceming the origin of conscious sensations, physiology is compelled to waive an answer.

\section{MODE OF REACTION OF NERVE CELLS TO STIMULATION}

Whether a nerve cell is stimnlated directly or through the axis-cylinder process or other connection. it exhibits several characteristies in the mode of its behavine. (1) The first of these is its alvility to transform a single momentary stimulus into a long-contimed effert. 
Birge stimulated the spinal cord of the frog by plunging a very fine needle into it and immediately withdrawing the same. He recorded the muscular responses discharged by the stimulus and subsequently determined rery accurately the portion of the cord invaded by the needle. The result was that stimulation of the white substance was found to produce only a single contraction, but when the needle struck nerve cells in the anterior horn an actual tetanus always appeared-i.c., a stimulus occurring but once was transformed by the nerve cells into a stimulus lasting for a much longer time.

(2) Another peculiarity of nerve cells is that they respond especially well to frequent stimulation, even though the strength of the stimulus is relatively very weak. This means that nerve cells possess in a high degree the property of summation.

Thus Kronecker and Nikoläides found on stimulating the vasomotor center that single induction shocks of great strength produced but slight effect, and

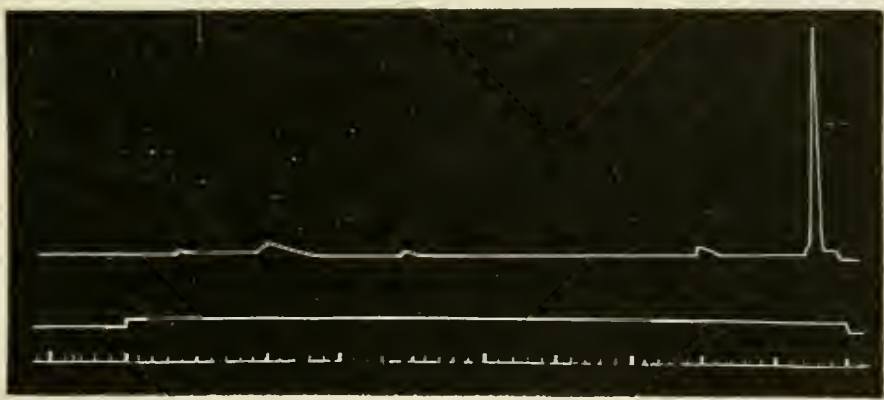

FIG. 256.- Reflex contractions of a frog's leg to electrical stimulation, after Stirling. To be read from left to right. The middle line shows the time of stimulation; the lower line is a time record in seconds.

that repeated shocks of moderate strength and high frequency (optimum twenty to thirty per second) were more efficacious than stronger shocks at a lower frequency.

Exactly the same thing is observed in reflex stimulation. It is extremely difficult to get any response from a normal spinal cord with single induction shocks (Setschenow). (Biedermann observed, however, that the responses are easily obtained, if the spinal cord first be cooled.) But if the afferent nerve be stimulated with rapidly repeated shocks, no difficulty is experienced, and with a given strength of current the muscular responses appear more promptly the more frequent the stimuli. This is not because a larger number of stimuli fall within the latent period with the higher frequency: for the absolute number of stimuli received before the end of the latent period may be even greater with a low than with a high frequencs. Onec an adequate frequency has been reached, the length of the latent perind is, within wide limits, independent of the strength of the stimulus (Stirling).

The power of the nerve cells to store up stimuli is demonstrated in the most striking way by the preliminary reflexes observed by Sanders-Ezn after chemical, and by Stirling (Fig. 256) after electrical stimulation. At first after a short latent period several small twitehes appear, then suddenly, after a long latent period, a very powerful contraction is made. The reflex mechanism is now exhausted; the preparation remains at rest notwithstanding the continu- 
ous stimulation for several seconds, then another powerful contraction appears, etc. The same thing' has been observed by Lombard with continuous thermal stimulation.

These and similar faets teach us that when the nerve eell has discharged an unusually strong impulse as the result of summation of its stimuli, it is to a certain extent exhausted and requires a certain time to be recharged. It is self-evident that the resistance of a cell to stimulation will depend upon the mode. strenstl. and frequency of the stimulation, and we know from everyday experience that nerve cells withstand the normal stimuli much better than they do our relatively crude artificial stimuli.

(3) Certain observations go to show that nerve cells, just like nerve fibers and muscles (cf. page 4:?), have a refractory period.

In stimulating the motor zone of the cerebral cortex Richet and A. Broca observed that a second stimulus was ineffective if it follows the first at a shorter interval than 0.1 second. The reflex closure of the eyelid to a second stimulus does not take place if the second stimulus follows the first at a shorter interval than 0.5-1 second (Zwaardemaker). According to Baglioni, the refractory period of the sensory elements in the spinal cord of a frog amounts to some 0.25-0.5 second. The inability of the normal spinal cord to mediate complete tetanic contractions reflexly is to be explained by this circumstance.

(4) Finally, artificial stimulation of nerve cells teaches us that they have the ability to transmute the stimuli which they receive into a perfectly characteristic rhythm.

Stimulating the spinal cord of a rabbit with forty-three induction shocks per second, Kronecker and Hall obtained muscular contractions showing a rhythm of twenty per second, whereas on stimulating the peripleral nerve fortythree times per second the contractions obtained had exactly the same rhythm as the stimuli. We are not to suppose, however, that the frequency of the impulses given off from the central nerrous system is always the same. It appears rather from the experiments of Stern on the muscular sound produced by stimulation of different portions of the nerrous system with induction shocks of different frequency, that the spinal cord is capable of discharging its impulses at varying rhythms up to 230 per second, although a number of observations tend to show (cf. page 431) that the frequency at which impulses are given off from the central nervous system is in general very much lower than this.

\section{DEPENDENCE OF THE NERVE CELL UPON THE BLOOD SUPPLY AND THE EFFECTS OF POISONOUS SUBSTANCES}

The nerve cells in the body are intensely active, hence they require an abundant supply of blood. In fact, it has been observed that the large ganglion cells of the vagus and the trigeminal nerves in the bony fish, Lophius piscatorius, have a small knot of eapillaries of their own penetrating into their substance and so supplying them with nourishment (Fritsch).

When the blood supply to the brain is considerably reduced by eompression of the carotids on both sides. uneonsciousness results, in many eases at least, because the nerve cells are functionally incapacitated. 
Stenson's experiment of clamping the abdominal aorta teaches us also that the nerve cells in the spinal cord very soon suffer from the lack of blood. 'The proterior extremities become paralyzed soon after the anta is closed off, not because of the absence of blood in those parts but because of its absence from the spinal cord.

Frederica has investigated these phenomena more elosely and has reached the following eonelusions for the dog: Some fifteen to twenty seconds after the elamp is applied a temporary exeitation of the motor cells begins, but within thirty to forty seeonds the motor paralysis is complete. Up to this time the sensibility of the posterior parts is entirely unaffeeted; but after one and one-

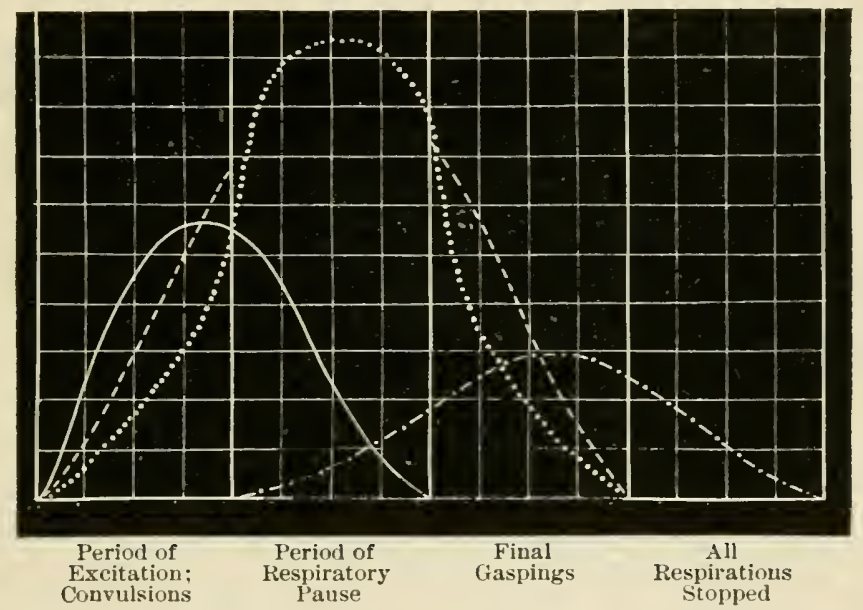

FIG. 257.-The relative resistance of several nerve centers in asphyxiation, schema, after Landergren. - the vasomotor center in the medulla; ......, the cardiac inhibitory center; ........, the respiratory center; ..........., the vasomotor center in the spinal cord.

half minutes a hypermsthesia sets in, followed by anxsthesia, which is complete at the end of three minutes. If now the elamp is removed, sensibility returns in five to ten minutes, but motility somewhat later. By eontinuing the occlusion long enough the paralysis and anasthesia become permanent.

From these facts we reach the very important conchusion that different nerve cells have very different powers of resistance to anamia.

Other observations go to show that the endurance of different nerve cells under acute asphyxiation is rery different. The schema in Fig. 25a represents, aceording to Landergren, the relative excitability and resistanes thronghout the ditferent phases of asphyxia of the following eenters: the bulbar vasomotor center. the cardiac-inhilitory center, the respiratory center, and the spinal rasomotor center (of. page :3s). The bullar rasomotor is first excited and has the least resistance. When the activity of this enter begins to decline the cardio-inhibitory center has reached the height of its irritability. The course which is run by the irritability of the respiratory center cannot be represented fully, owing to the rezpiratory pause which comes in, but it seems to agree in the main with that of the vagus center. The spinal 
vasomotor centers are excited at a rather late stage. but they continue active at a time when the other centers are on the wane.

Although this is not the place for a full discussion of the influence of different poisons upon the nervous system, attention ought to be directed to the fact that certain observations have been made which tend to show that these substances do not act alike on all nerve cells. 'Thus, according to Baglioni, carbolic acid in weak solution has a heightening effect upon the irritability of the motor mechanisms in the anterior horn, while the sensory mechanisms of the posterior horn are not pereeptibly affected. Strychnia on the other hand increases the excitability of the sensory mechanisms of the posterior horn and leares the motor mechanisms of the anterior unaffected. Immediately after its application nicotine stimulates the motor elements of the medulla and spinal cord, also the cells of the sympathetic ganglia, but has no effect upon the cells of the spinal ganglia (Langley).

\section{E. MORPHOLOGICAL CHANGES IN THE NERVE CELL. REPRODUCTION AND REGENERATION}

Within recent years the structure of the nerve cell has been made out in great detail, thanks to the great progress in histological technique, and certain differences have becn noted in the microscopical appearance of resting and of active or fatigued cells. A full account of this difference will be found in textbooks of histology.

Tarious attempts have been made also to demonstrate that nerve cells or their dendrites at least are capable of ameboid movements, and far-reaching physiological and psychological hypotheses have been erected on the basis of such assumptions. But these have with justice been very rigorously contested, and if the newer discoveries concerning the neurofibrils prove to be true in all respects (cf. page 560), ameboid movement will have lost its last vestige of support.

It is a question of great fundamental importance, whether nerve cells can be reproduced in post-embryonic life. Birge counted the motor cells in the spinal cord and the nerve fibers $i n$ the anterior spinal roots in frogs of different age and convinced himself that both either multiply from preëxisting nerve elements or develop from other elements throughout life, for he found an unmistakable relation between the weight of the animal and the number of eclls and fibers. For example, a frog weighing $1 \frac{1}{2} \mathrm{~g}$. had $5,98+$ motor nerve fibers, one of $9 \frac{1}{2} \mathrm{~g}$. 6,481 , one of $23 \mathrm{~g}$. 7,048 , up to a frog of $11 \mathrm{~g}$. with 11,468 fibers. On the average for each $1 \mathrm{~g}$. inerease in weight 52 motor fibers had been added.

How long after birth this new formation may take place we do not know. In certain inflanmatory processes in the brain mitotic figures have been seen in the vicinity of nerve cells, but these facts teach us nothing with regard to the normal multiplication of nerve cells in the adult body.

Most authors deny the regeneration of nerve tissues after extensive destruetion of them in the higher animals. But we have two observations recorded in the literature supporting such regenerations: One by Voit concerns regeneration in both hemispheres of the pigeon, the other by Vitzou regeneration of the occipital lobes in the monkey. These are extremely important observations and urgently demand confirmation.

It has been established by a great many observations that peripheral efferent fibers regenerute if the nerve cells to which they belong remain uninjured. 
Moreorer the central end of one efferent nerve can be united with the peripheral end of another. Two afferent nerves can likewise be crossed in the same fashion; but it has not yet been decided how far afferent nerves mediating different kinds of sensations can be joined together. It appears that no union of afferent with efferent nerves is possible.

Several authors reject the riew that an actual regeneration takes place in a nerve which has heen completely separated from the central nervous system, and Bethe has reported a number of interesting experiments which tend to discredit that view. Other authors have olserved in the peripheral stump of a cut nerve the appearance of spindle-shaped cells lying in the longitudinal direction of the nerve. Should it be shown berond a doubt that axis cylinders develop within these structures we could no longer regard axis cylinters as processes of the nerve cells, and the nutritive influenee over the nerve fibers ascribed to the nerve cell would sink to a matter of small importance. In short. our whole enneeption of the structure and functions of the nerrous system would of necessity be rery profoundly modified. Langley. howerer, on the hasis of some experiments of his own, believes that the nerre fibers which apparently arise de novo actually grow into the peripheral stump from nerves of the surrounding tissue and eventually trace back to nerve cells of the spinal enrd. It is to be obserred also that Bethe himself finds great rariation in the number of autochthonous ${ }^{1}$ fibers, since never in his experiments did all the fibers regenerate in this fashion. Besides, this form of regeneration appeared at its strongest only in young animals; in grown animals the fihers stopped, as Bethe puts it. "halfway," not heing powerful enough of themselves to complete the regeneration without the help of the spinal cord. For the present the matter cannot be regarded as settled in Bethe's faror.

Langley has eontributed some very important results on the regeneration of sympathetic nerves, but for several reasons it seems best to diseuss these in connection with the subject of physiology of special nerves (Chapter XXV).

\section{\$. REFLEX PROCESSES}

\section{A. SEGMENTATION IN THE CENTRAL NERVOUS SYSTEM}

We learn from the anatomy of the lower rertehrates (lamprer, salamander) that the nerve fibers from the spinal roots, in certain sections at least. run but a short distance up or down the spinal cord-i.e., that there is here an evident segmentation of the spinal cord.

Likewise in the higher vertebrates the spinal cord can he regarded as to a certain extent made up of serially homologous parts, connected together in a rery complex manner. Each such segment consists of a pair of nerre roots together with that portion of the spinal cord helonging to them and eonstitutes in itself the simplest kind of a central organ.

Becanse of the many short- and long-fibered pathways uniting the separate segments of the spinal cord with rach other and with the different portions of the brain. impulses arising in the different segments hare so many ways

${ }^{1}$ That is, originating in the place where they are found. 
of escape that the segmentation in the normal organism is not apparent. That it does exist, however, has been demonstrated by Sherrington's investigations on the posterior root refleses in the monker. It is unfortunate that space will not permit us to discuss these results in detail. The following concrete illustration of segmental reflexes in the higher vertebrates must suffice.

Goltz and Ewald isolated the spinal cord of the dog from the higher parts of the nervous system by a section in the lower cervical or upper thoracic region and then in a second operation removed the posterior end of the cord. There remained only the upper part of the thoracic cord controlling what they called the "middle animal." When the hand was rubbed over the right side of the thorax of such an animal, that portion of the rertebral column containing the remnant of the spinal cord was bent strongly to the right. If a very gentle stimulus was given distortion of the skin only was observed. Wetting the thorax with water caused the "middle animal" to tremble all over.

Sherrington has found that reflexes spread most readily to the motor fibers of the same pair of spinal nerves, and more readily to anterior ronts near the afferent path than to those far distant. They can also pass centrifugally as well as centripetally in the eord, for stimulation of the fore les will produce a reflex contraction in the hind leg. Motor fibers springing from the same segment of the spinal cord are not all roused to action with equal facilitye. g., in reflex excitation of the hind leg the flexors of the same side and the extensors of the opposite side are called into play much more easily than the extensors of the same and the flexors of the opposite side (cf. below, page $58 \%$ ).

\section{B. GENERAL FEATURES OF REFLEXES}

Although reflexes may be radiated very widely, as a rule, they have a rather limited distribution, certain efferent nerves being set in action by definite afferent nerves, whence the so-called regulative reflexes. Thus stimulation of the nerves of taste produces. a reflex secretion of saliva and of gastric juice; the afferent nerves of the lungs influence reflexly the respiratory muscles; the afferent nerves of the heart act reflexly upon the efferent nerves of the heart, and upon. the rasomotor nerves; the heat nerves and cold nerves produce reflex alterations in the secretion of sweat and in the supply of blood to the skin. etc.

From these eximples, which represent but a small number of such reflex processes, we may derluce the general rule: that the reflexes serve to regulate various functions of the body, and to adapt them to their appropriate cnds.

How extremely useful to the body this purely machinelike regulation is will be readily appreciated, if we but recall the importance of the examples just mentioned and try to picture to our minds what would happen in the event of their failure. How important it is, ton, that this regulation should go on independently of our own wills! It has only been by long and toilsome inrestigation that seientists have learned the little we know about the reflex processes in our bodies. If now our bodily functions conld only be carried out after mastering all the details, how should we ever learn them 
and how could they be regulated meantime? The regulative reflexes owe their existence to the native organization of the nerrous system. Among the many efferent nerves which may be excited by a single afferent nerve there are some to which the impulse is transferred more readily than to others. This naturally suggests that the anatomical connections in such cases are simpler. possibly shorter, than in others.

In his researches on the conditions influencing secretion in certain digestive glands Pawlow attention was drawn to one circumstance which is of the itmost importance for our comprehension of the reflex mechanisms. We refer to the psychical influence over certain glands, already mentioned at page 263. When the experiment animal had no desire for food stimulation of the mucous membrane of the mouth produced no secretion of gastric juice. The appetite therefore brings about a predisposition in certain portions of the nerrous systen which constitutes an indispensable condition for the reflex outpouring of gastric juice. In fact, appetite itself, or the mere sight of food. an eroke the secretion. We meet with similar phenomena in other portions of the body-e. g.. alterations of the heart beat under the influence of emotions. blushing, weeping, the involuntary evacuation of urine and freces induced by certain psychical states, romiting caused by disagrceable thoughts, and many more. Hence, while not under the direct control of the will the reflex processes are closely associated in manifold ways with states of the mind.

Many new reflexes are formed in the course of life, that is to say, movements which originally were executed under the control of the will become automatic by practice-e. g., standing. walking, piano playing. and the like.

When a person stumbles over a stone, the purposive movements by which he saves himself from a fall are pure redexes, as we know from the fact that very often the danger is apperceived only when it is all over. If in such cases the appropriate morements had to be made voluntarily, very often the bolly would suffer injury before the mishap could be prevented. Another purpose of reflex movements therefore is to protect the body from external injuries.

Reflexes play no small part also in personal culture. Good carriage of the body, for example, is nothing more than the result of practice of many muscular movements originally performed painstakingly, until they became purely reflex in character. The general eonduet of a cultivated man in his intercourse with his fellow-men is also largely a matter of reflex action. While much in this realm is purely conventional, even this can only be acquired, so as to be invariably performed, by practice.

\section{INHIBITION OF REFLEXES}

If it is highly important so to impress certain movements on the nerrous system that they will be performed more or less reflexly. it is none the less important to supprese certain others which may he unpleasant or otherwise undewirable. Many such acts are pure reflexes either inheriter or acquired by had training. Such, e.g.. are weeping and crying out under pain. A person can learn to suppress this reflex, just as a child can be taught not to ery when everything does not gn to its liking. Many facial expressions 
and gesticulations belong to the same class. (Recall, e. g., the old story of Demosthenes.)

The suppression of reflexes may be explained as follows: When the ccrebrum is removed from an animal it is observed that complex systemic reflexes can be more readily and more regularly induced than before. The cerebrum has therefore the power either consciously or unconsciously to restrain reflexes, which are discharged more easily by lower centers working alone. It may be supposed to have the same power over acts which have come to be easily performed because certain pathways are strongly developed either by inheritance or as the result of habit. Exercise of this control, however small it may be at first, will accomplish the suppression of such processes as secretion of tears and the like.

But it would be incorrect to suppose that reflexes are inhibited only through the cerebrum. It is not a diffieult matter to demonstrate such inhibitions on animals devoid of the cerebrum, notwithstanding that excitability of the refley are is greatly increased by the operation. On the strength of experiments involving chemical stimulation of the frog's skin. Setschenow taught that special inhibitory centers are to be found in the neighborhood of the optic thalami, the corpora quadrigemina and the anterior portion of the medulla oblongata, under the influence of which reflexes from the spinal cord are retarded. These centers ean be excited directly or by stimulation of afferent nerves, he said, and are always active throughout life. On the other hand, there are no inhibitory mechanisms for reflexes aroused by tactile stimuli.

Goltz demonstrated, however, that reflex acts induced by all sorts of tactile stimuli, as mere contact. stroking the skin, etc., can under certain circumstances be entirely suppressed, and he laid it down as a general rule that any center mediating a definite reflex suffers a distinct loss in excitability whenever it is acted upon at the same time by any other pathway not concerned in that particular reflex.

Goltz instanced the following examples of inhibitions of this sort. (1) The heart may be brought to a complete standstill by lightly tapping the abdominal viscera (Klopfversuch). But this otherwise invariable result is not obtained if at the same time a sensory nerve of one of the legs is stimulated powerfully. (2) If the skin between the fore legs of a male frog taken in the breeding season be stimulated lightly with the finger after the animal has been beheaded, the finger will be clasped firmly by the fore legs (clasping reflex). Ordinarily this reflex never fails, but if a drop of acetic acid be applied to the animal at the same time it very often fails. (3) If a strong solution of common salt be injected under the dorsal skin of a frog, all reflexes cease. The limbs hang perfectly limp and are not drawn up even when vigorously scraped with a knife. This condition lasts for some minutes and then the reflexes gradually return (Bethe).

Heidenhain and Bubuoff's observations on morphinized dogs furnish us further examples of inhibitory processes in the central nervous system. It is well known that muscular contractions may be induced by artificial stimulation of certain areas of the cerebral cortex (of which more in Chapter XXIV). Such contractions in morphinized dogs are long drawn out, disappearing but gradually when the stimulation ecases. But if, while the after-effect is still on, the skin be stroked lightly or some other sensory stimulus be applied, the contracted muscle immediately relaxes; moreover, the same result is obtained if the same area of the cortex be given another, this time a weak or transitory stimulus. 
The conclusion is, that when the cerebral cortex, or. more correctly, the nerve cells of the spinal cord are active, stimulation of the cortex, under certain circumstances, has an inhibitory effect on such activity.

The present status of our information on this subject may therefore be summarized as follows: reflex processes may under certain circumstances be retarded or entirely stopped by stimulation of different portions of the brainstem, of the cerebrum itself, or of afferent nerves in general.

So much is fact, but whether the facts are to be explained by postulating special inhibitory centers or in the manner conceired of by Goltz must remain an open question. It would appear, however, as Goltz observes, to require an absolutely orerwhelming number of inhibitory centers on the former hypothesis, to account for all the reflex inhibitions with which we are acquainterl.

But, as Biedermann remarks, it is also possible to explain the phenomena of inhibition in the central nerrous system on the basis of special afferent inhibitory nerves. If a center momentarily stimulated were to be acted upon by a nerve of this kind its activity would be interrupted or diminishedi. e., would be inhibited. Biedermann points to the automatic regulation of respiration (cf. page 328 ) and to certain locomotol reflexes (cf. page 5si) in the posterior extremities as examples of such inhibition. This inhibition of nerve cells in the central system would be entirely analogous to those inhibitions induced independently of the central system-e. g.. on the heart by stimulation of the cut ragus or on the intestine by stimulation of the cut splanchnic.

\section{AUGMENTATION OF REFLEXES}

But the effect of stimulating two intersecting pathways is not always an inhibition; it may be an augmentation of the response. A stimulus in itself subminimal applied to the motor cortex (rabbit) becomes effective if some appropriate reflex stimulus. likewise subminimal. be applied at the same time. This augmentation of the effect of one stimulus by the excitation of a different pathway is seen when, after remoral of the gray cortex. the corona radiata is stimulated directly. The two excitations need not be simultaneous, the reënforcement occurs just the same if the second stimulus be applied some tenths of a second after the end of the first.

Exner, who has made a special study of this phenomenon, calls it facilitation $^{1}$ (Bahnung) and ascribes to it very great significance in the functions of the central nerrous system.

Exner regards the case of two central nuclei (e.g.. the bilateral respiratory center) so closely connected that excitation of one always or usually ocenr: srnchronously with exeitation of the other, as a special form of facilitation. When the two are comected by commissural fibers, charging the one prorluces a change in the other which renders it more and more liable to discharge.

Just as self-culture often amounts to the suppression of unpleasant or undesirable reflexes, so its aim often is to establish reflexes of a pleasing or desirable character, and in this the reënforcement of one nervous pathway by another is of great service. 


\section{E. REFLEX RESPONSES TO DIFFERENT STIMULI}

The kind of stimulus employed has much to do with the appearance of reflexes. Not only the end organs of the nerves of special sense, but also the nerves of the internal organs (cf. pages $: 64$, $2: 0$ ) are adapted to receive stimuli of certain special kinds.

Since the researches of Marshall Hall, we have known that in general a reflex is more easily discharged by stimulation of the peripheral end organ than by stimulation of the corresponding afferent nerve trunk. The cause of this difference probably is, that peripheral end organs just because they are adapted to receive stimuli of a special kind react to a stimulus of a definite intensity more powerfully than does the nerve trunk. For this reason artificial stimulation of an afferent nerve trunk never gives a complete reproduction of the reflex functional capacity of the nervous system.

We are compelled for want of space to pass over the observations which have been made with regard to the different effects of mechanical, chemical, thermal and electrical stimulation of the same efferent nerves.

\section{§6. AUTOMATIC EXCITATION}

It is impossible at present to give an accurate estimate of the importance of automatic excitation, either in the central nervous system or in peripheral organs. The ease with which reflex effects can be ascertained has probably been the occasion of some negleet of this question.

That this form of excitation is extremely important, howerer, requires no demonstration. By special effort a person ean hold his breath. say, anywhere from thirty seconds to several minutes; but he eannot, eren with the utmost power of his will. voluntarily stop respiration altogether. This overpowering exeitation of the respiratory center is the work of aecumulated decomposition products in the blood or lymph. We have seen that the breath volume is inereased by muscular work. This again is due primarily to the stimulating effect of the decomposition products on the respiratory center, although the stimulation of afferent nerve fibers may play some part also.

The attendant effects of asphyxiation upon the cireulatory system and the skeletal muscles are a witness of how other centers in the brain and spinal cord may be thrown into a state of extreme activity by decomposition products present in excess.

Since we have good reasons for thinking that the respiratory center is stimulated normally by products of metabolism, albeit its activity is often regulated by reflexes, we may suppose that automatic excitation plays a considerable part in the tonic stimulation of other nerve centers, and that in general this is the inciting agency behind the coarser functions of many organs, whereas their finer adjustment to the momentary needs is accomplished through the various reflexes which play upon the corresponding centers. 


\section{\$. TONUS}

$\mathrm{By}$ tonus we mean in general a state of continuous excitation observable in many organs, the intensity of which may vary a great deal according to cireumstances. Recent contributions to the subject of internal secretion (cf. page 356 ) have resulted in showing that tonus is very often caused by a direct stimulating influence of substances formed in the body upon the peripheral organs or upon peripheral or central nerve cells.

A very interesting example of tonus, which is not dependent upon the central nerrous system, is furnished by the observation of Goltz and Ewald that a dog gradually recovers his vascular tonus after extirpation of a large part of the spinal cord (cf. page 583).

The importance of direet excitation of peripheral organs or nerve cells for the tonus of the different organs cannot be justly estimated at present, for the simple reason that our information on the subject is quite too limited. Nevertheless we know that many organs are kept in a state of tonic excitation through their efferent nerves, and this is evidence that the corresponding centers in the brain and spinal cord are themselves tonically stimulated. The cardiac ragus and the rasoconstrictor centers are notably of this class. Knowing that both these centers may be stimulated either directly as in asphyxiation, or reflexly by afferent nerres, we are driven to suppose that their tonus is of mixed origin. Whether the automatic or the reflex factor is the more important we cannot decide at present.

Cross-striated muscles, particularly the sphincters (sphincters ani and vesiex), are usually in a state of tonic contraction (cf. pages 299, 393).

It has been no simple matter to demonstrate tonus in cross-striated muscles. The observation made in amputations that on cutting through a muscle the cut ends draw asunder learing a gaping wound has no bearing on the question; for this merely means that the distance between the points of origin and insertion of a limb muscle is greater than the natural length of the muscle when it is not loaded-that is to say, a muscle completely at rest is stretched somewhat and when it is cut, must, of course. gape open.

The following observation, however, makes it clear that skeletal muscles are in a state of tonus. If a decapitated frog be rertically suspended with the hind legs downward and one, say the right, sciatic nerve be cut, the leg of the same side will hang down more limply than the other. This difference can only be due to the fact that the left leg is still under the influence of the central nerrous system (Brondgeest).

This form of tonus appears to be of reflex origin, for when the afferent spinal roots of the frog are cut the gastrocnemius of the same side relaxes somewhat (Cyon and Steinmann). Some muscles, howerer, do not elnngate when their efferent nerves are cut; which means that some muscles are not always tonically stimulated to the same extent as some others.

Nuscular tonus may be, to a eertain extent, of peripheral origin also. This conclusion is drawn from the experiments by Meade-Sinith eited on page 402, showing that heat is formed in a resting manmalian muscle even when physiological connection with the nervous system has been interrupted by ligating the nerve. 


\section{S. CENTRAL FUNCTIONS OF PERIPHERAL NERVE CELLS}

In diseussing the innerration of the heart, digestive organs, ureter, ete., we have had oceasion to mention the ganglion cells embedded in their museulatures. According to some authors, as we have seen, it is to these ganglion cells that the rhythmical contractions of these respective organs are due. Others aseribe to the muscles themselves an automatic property in virtue of which they are stimulated directly by the products of metabolism or by the normal variations in pressure.

We hare no data as ret, except perhaps in the case of the intestine (cf. page :88), which will enal,le 11 to reach a final decision as to the significance of these ganglinn cells. For this reason we shall limit the present discussion to nerve cells in the sympathetie ganglia, in the spinal ganglia, and the corresponding ganglia of the cranial nerres.

The first question to engage our attention is whether the nerre fibers which pass through the sympathetie ganglia actually form connections with the nerve cells contained in them.

Langley has shown that nicotine in not orer-large doses stops the propagation of impulses through the sympathetic ganglion cells, while it leaves the nerve fibers and the peripheral nerve endings quite untouehed; and he has made extensive use of this fact in answering the question before us. It is suffieient for the purpose merely to paint the ganglion with a solution of nicotine. Then if stimulation of the nerre central to the ganglion has the same effect as before applieation of the poison the nerre plainly does not enter into connection with the contained nerve cells. But if the effect of stimulation is nullified by the poison. we have eridence that the nerve cells are interealated in the condueting pathway.

In this way Langley has found that every efferent nerre fiber or collateral traversing the sympathetie pathways is connected with one peripheral ganglion cell, and one only. This relay station, as we may call it, on the way from the central system to the periphery may be situated either in a chain ganglion or farther along toward the periphery, eren as far as the vieinity of the peripheral organ itself. The rasoconstrictor fibers, the secretory sweat fibers and the pilomotor fibers of the fore paw (cat), all of which eonneet with the first thoraeic ganglion, may he mentioned as examples of fibers with the former mode of connection. But most of the fibers of the splanchnie nerve end in the ganglia of the solar plexus: and the nerres of the external genital organs likewise connect with nerve cells in the ricinity of the organs themselves (ef. Chapter $\mathrm{XXT}^{\mathrm{T}}$ ).

It is no easy matter to decide to what extent the nerve cells interpolated in the course of the simpathetic nerre fibers have anything more than a purely nutritire function. A priori the possibility is not to be denied that these nerve cells, like those in the spinal cord, can exereise some central functions, and certain observations which Goltz and Ewald have made on dogs from which the greater part of the spinal cord from the lower cervical or upper thoracic region backward had been removed, lend some support to this riew. 
Once the temporary effects of the operation had passed off, the animals exhibited the following phenomena. All the eross-striated muscles of the posterior parts degenerated and became transformed into connective tissue. The external sphineter of the anus alone withstood this degeneration, remaining completely functional as long as the animal lived. The digestive processes went on in regular fashion, just as in the normal dog. The urine was normal and was normally voided. A pregnant female gave birth to five whelps; one of the young, permitted to suckle, grew rapidls, the milk being perfectly normal. No secretion of sweat could be clearly made out. The blood vessels of the posterior parts recovered their tonus and remained capable of reacting to a local constrictor or dilator stimulus. But vaseular changes in distant parts of the skin could not be induced nor could alterations in the intestinal movements, nor movements of the sphincter ani nor of the bladder be induced by stimulation of the hind pars. Shedding of the hair took place in fairly normal fashion, but terminated earlier on the fore parts which were still in connection with the central system than on the hind parts. The bones took on a peeuliar rotten character. When the external temperature was not too low, the heat regulation was earried on with adequate precision.

It should be mentioned also that certain poisons, like anagyrin (from Anagyris fretidn. (iley), as well as certain substances obtainable from various organs of the body (extract of the kidneys and adrenals-cf. page 360), can produce a considerable vasoconstriction even when the entire nerrous system is destroyed.

These and other analogous phenomena show beyond a doubt that many functions of the body ean be earried on independently of the central nerwous system. It is probable, though not absolutely proved, that they take place with the help of nerve cells present in the peripheral ganglia. There remains. of course, a possibility that these organs act often quite automatically.

But there are some statements in the literature which show that reflexes can be mediated through the sympathetic ganglia. although ther teach us nothing as to the signifieance which these reflexes may have in the normal processes of the body.

Roschansky destroyed the spinal eord of the eat below the cervical region and then stimulater the eentral end of the splanchnie, whereupon the blood pressure rose several millimeters of $\mathrm{Hg}$. The rise in pressure did not appear when the sympathetic ehain was seetioned between the ninth and tenth ganglia; henee it was reflexly produced through sympathetie ganglia as a center.

Langley also has observed reflexes from svmpathetie ganglia and has given an explanation of their peculiar mechanism. After section of all the branches connecting the inferior mesenterie ganglion with the central nervous system (cf. page 392), contractions of the bladder and of the external anal sphincter. vasoeonstrietions in the lower parts of the rectal mueosa and in the mucosa of the uterus on the opposite side ean be obtained (best in the cat) by electrieal or meehanical stimulation of the eentral end of one hypogastric nerve. These effeets are dependent upon nerve cells in the ganglion itself. for they fail to appear after nieotine is applied to that ganglion. But they are not reflexes in the usual sense of the word, for by means of the degeneration method it has been shown that the nerve fibers earrying the excitation to the ganglion have their trophic center neither in the ganglion nor peripheral thereto, nor yet in the spinal ganglion. They are therefore efferent nerves. 
Langley would explain the discharge of these reflexes (axon reflexes) in the following manner. Nerve tibers, as we know, convey impulses in both directions: hence an impulse starting from $R$ (Fig. 25s) is transmitted along the efferent fiber toward the ganglion $(A)$. Here a collateral is given off, and it is

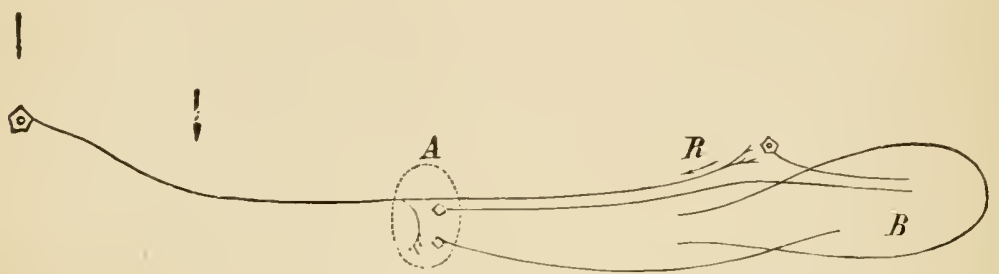

Fig. 258.- Schema of an axon reflex through peripheral ganglion cells, after Langley.

this which exeites the nerve fibers springing from the cells of the ganglion and proceeding to the bladder $(B)$.

- In a similar manuer Langley explains the fact that stimulation of the lumbar sympathetic causes an ereetion of hairs on regions of the skin innervated from the second, third, and fourth ganglia higher up (cf. Fig. 25y), and similar phenomena from stimulation of the sympathetic in the thorax.

We must be on our guard in this matter of reflexes through peripheral ganglia lest we be deceived by recurrent fibers. Suppose, for example, A (Fig. 260) to be a ganglion, 2 and 3 , two nerve fibers passing from it. We stimulate 2 and

$$
1
$$

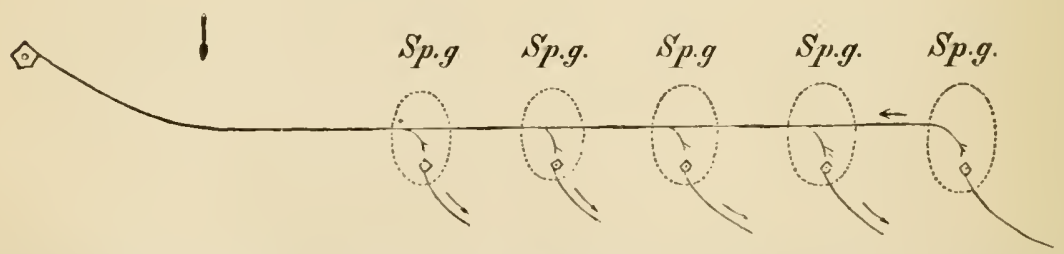

FIG. 259.- Schema of a reflex through peripheral ganglion cells, after Langley. $S p . y .$, sympathetic ganglia. The arrows indicate the direction in which the excitation aroused by stimulation of a lumbar sympathetic nerve is propagated.

get an effeet in the organ innervated by 3. Such an effeet may be a reflex; but it would be obtained also if some of the nerve fibers in 2 were to turn back and enter 3 , as indieated by the dotted line.

The chief purpose of the spinal ganglia consists in the purcly nutritive influence by which not only their afferent nerve fibers. but the posterior roots and their prolongations and collaterals in the spinal cord as well. are maintained in normal condition.

Sinee most of the eells of the spinal ganglion give off only one proeess which sooner or later splits into two fibers (the T-shaped fibers), one going each way, it might be supposed that the stimuli eoming from the periphery are eonveyed directly to the spinal cord without having anything to do with the anglion cell.

This question can be tested experimentally by determining whether a stimu- 
lus is delayed by passing through the ganglion-i.e., whether a reflex response eroked by stimulation of an afferent nerve will take place any carlier when the stimulus is applied central to the ganglion than when applied peripheral thereto. Wundt, in fact, found a delay in the reflexes from the spinal ganglion of a frog amounting to 0.003 second. Neither Exner nor Moore and Reynolds, however, were able to demonstrate such a delay. Gad and Joseph studied the jugular ganglion of the vagus, which is the homologue of the spinal ganglia, and used as an indieator the change in respiratory movements produced by stimulation. It was shown that as a mean result of a large number of readings the reaction appeared 0.036 second earlier when the stimulus was applied eentral to the ganglion than when applied peripheral to it. If these observations are confirmed we shall have proof that in this ganglion, at least, every impulse traversing a fiber afferent to the ganglion passes through a nerve cell.

But it appears to be unnecessary that the impulse should pass through the body of the ganglion cell. In the erab, Carcinus manas, Bethe observed that the tonus of the muscles moving the antenux persisted and reflex eontractions could be indueed in them after the mantle of solid ganglion cells inclusive of their nuelei had been pared off the cerebral ganglion which eontrols these muscles. In this ease the excitation had been propagated through the fibrillary reticulum (c. page 560)

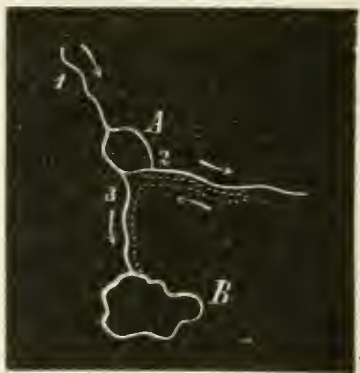

FIG. 260. still connected with the nerve fibers. Here we have

indulitable evidence of the importance of nerve fibrils as eonducting elements in the nervous system. It is true that the phenomenon eould only be observed for some two or three dar's after the operation: but this was to be expected, sinee we know that nonnucleated cell fragments camot live indefinitely.

Similar phenomena have been observed in the spinal ranglia of the vertebrates. Langendorff was able to show among other things that the posterior roots in the frog give an action eurrent when stimulated peripherally to the ganglion, as much as twenty-four hours after the heart had been extirpatedi. e., at a time when reflex movements had long since ceased. Shortly after this Steinach demonstrated for the same animal that ganglia which had lain for forty-eight hours in physiolngical salt solution were still permeable to the action current. The same thing took place if a canglion in the living animal were deprived of its blool supply for fourteen days. In both eases. to judge bs microscopical appearanees, all the ganglion cells had degenerated.

From all this it ought to be regarded as at least probable that an impulse can be propagated through an afferent spinal nerve without traversing the eell body of the corresponding ganglion eell.

\section{\$. CENTERS IN THE SPINAL CORD}

The spinal cord has a twofold function: it acts as an independent central organ, and serves as a great highway to connect the tributery afierent and efferent pathways with the brain. 


\section{A. CONTROL OF SKELETAL MUSCLES}

The independent influence of the spinal eord upon movements of the skeletal museles is primarily of a reflex nature. [nder suitable conditions all the muscles immervated from the cord can be thrown into action by stimulation of a single afferent nerve, even when the cord is isolated from the brain. These reflexes are in general well coördinated, and, as the examples given below will prove, are unquestionably purposive in character. Be it observed, however, that these phenomena are not to be regarded as the cxpression of a "conscious" activity on the part of the cord. We ourselves often perform much more complicated movements without being in any wisc conscious of them.

When a drop of sulphuric acid is placed on the leg of a decapitated frog, the animal tries to remove the irritant with the same leg. But if this leg be held fast, the other hind leg comes to the help of the first. When a toe is pinched lightly the leg is drawn up against the abdomen. But when the drop of acid is placed near the anus, both legs are drawn up and are then powerfully extended.

When the foot sole of a dog, whose spinal eord has been severed, is gently pressed against with a broad surface the leg makes a strong extensor movement. But if the same foot sole be touched with a sharp point, a flexor movement is made, as if the animal wished to withdraw the foot from a painful impulse (Sherrington).

Observations on the ability of the spinal cord, isolated from the brain and medulla, to regulate the muscular movements necessary for locomotion are of particular interest. An eel deprived of its head immediately after the operation swims about in a basin, behaving just like a normal fish. It does not nerely writhe about on the bottom, but swims up and down and about through the water in all direetions. But the beheaded eel is not able to maintain its normal position in the water and can no longer swim baekward.

Sehräder found that the entire medulla of the frog as far up as the tip of the calamus scriptorius can be removed without destroying the locomotor reaction to reflex stimuli. The morements were rather awkward but were nevertheless perfectly coördinated. Frog tadpoles and very young frogs exhibit movements of the hinder parts without any extemal stimulus (Babak).

It is a rery old observation that decapitated chickens ean still fly. And ducks with the spinal eord severed between the fourth and fifth cervical vertebra make perfectly regular and very energetic swimming movements with their feet, even when not stimulated externally; they make steering movements with the tail and flying movements with the wings, ete. But when set down on a table they can neither maintain their equilibrium nor walk (Tarehanoff).

So far as is known to the author nobody has ever yet observed movements of locomotion, either spontaneously or reflexly produced, in deeapitated mammals. We eonclude that in the lower vertebrates at least the spinal cord is of itself to a greater or less extent able to regulate the museular contractions of locomotor movements.

The investigations of Sherrington, Hering, Jr., and Biedermann have given us some very important information as to the mechanism concerned in these reflexes.

The first effeet of a brief. weak stimulation of the web of a frog's foot after the spinal cord has been isolated, is always a flexor movement on the same sirle or an extensor movement on the other side, in ease the flexur movement is pre- 
vented (ef. page 5T(i). Likewise, one finds in pigeons with the spinal cord cut that every stimulus applied to a toe causes a reflex impulse to be sent to the flexor muscles of the same leg and at the same time a reflex impulse to the extensor muscles of the other leg (Singer). Similar, though not identical, results have been obtained in the dog (Freusberg).

Inquestionably these reflexes are components in the mechanism of locomotion, and hence we may say that the locomotor movements observed in decapitated animals are conditioned primarily upen this coincidence of flexor and extensor reflexes from the cord. In dogs and monkeys having the spinal cord cut at the posterior end of the thorax. Heger has recently observed fairly well coörlinated morements of the hind parts. The animals were eren able to walk and run with the help of the hind legs, although, as was to be expected. not with the same preeision as normal animals.

The same mechanism is probably operative also in the uninjured nervous system. the motor impulse given out by the brain being apportioned automatically and in the proper order to the different motor cells down the cord.

We have still to mention the tendon reflexes. When a person crosses one leg over the other, allowing the foot to hang in an unrestrained position, then strikes the patellar tendon of this leg a sharp blow, the extensor eruris musele contracts suddenly giving the so-called "knee jerk." Similar contractions are obtained by stimulation of other tendons, and by mechanical stimulation of the joints and of the periosteum. They are wanting in tabes-i.e., they are wanting when certain afferent conducting pathwars are disabled.

In view of this latter circumstance, it is natural to suppose, as Erb first pointed out, that these contractions are pure reflexes. But rarious considerations, especially the short latent period of the knee jerk, made that explanation very difficult, and Westphal, the discoverer of such phenomena, now takes the view that the contractions are induced by the direet effect of the mechanical shock upon the muscles, but only in case the muscle has its normal tonus. This condition, as we know (ef. page 581), depends upon a normal state of the afferent nerves.

Evidence that the tendon reflexes are dependent upon the central nerrous system is found in the fact that their intensity varies directly with the general functional condition of the central system. Thus they are weakened by fatigue, hunger, and the like, but are augmented by rest, food, etc. (Lombard).

\section{B. INFLUENCE OF THE SPINAL CORD ON THE VEGETATIVE FUNCTIONS}

The above-mentioned observations on the behavior of the dog with a shortened spinal cord (page 583 ) call for some revision of our riews as to the influence of the cord on the regetative functions; for several of these functions which from previous observations had been regarded as totally dependent upon the spinal cord were there seen to be dependent upon peripheral nervous mechanisms. The urinary and sexual organs, for example, as well as the rectum, remained perfectly functional, even when the entire lower part of the spinal cord ras destroyed. But these parts are controlled to some extent also by centers in the central sytem, as can be shown conclnsively by stimulation of the appropriate nerves. These centers are located mainly in the lumbar region of the cord. 
Goltz has made the following observations on dogs with the spinal cord cut between the thoracic and lumbar regions. Erection of the penis was induced by mechanical stimulation either of the penis itself or of the hypogastrium, by pressure upon the bladder, and by excessive fullness of the bladder and of the rectum. The bladder was emptied in perfectly normal fashion as the result of mechanical stimulation of the amus. Rhythmical contractions of the anal sphineter. which could be inhibited by stimmlating the sciatic, were induced by inserting a finger into the rectum. Contractions of the uterus and ragina were obtained by stimulating the sciatic.

In the cat the center for micturition is located between the second and fifth lumbar norves; that for the anal sphineter between the sixth and serenth lumbar. In man the center for the bladder is said to lie at the extreme end of the spinal cord near the points where the third and fourth sacral nerres make their exit.

The spinal eord also contains centers for the secretion of sweat. When the spinal cord of a cat is severed below the merlulla and the animal is then asphyxiated. sweat appears in from two to three minutes. The same is true also after cutting at the level of the ninth thoracic rertebra.

The vasomotor and respiratory nerve centers oceurring in the spinal cord have already heen considered at pages 238 and $3: 5$ respectively.

Finally, mention should be made again of the cilio-spinal center (page $5: 9$ ) discovered by Budge. This center is of special interest because, although situated in the cord. it presides orer an organ in the head.

\section{\$10. CONDUCTING PATHWAYS IN THE SPINAL CORD}

\section{A. ELECTRICAL STIMULATION OF THE CORD}

Before we take up the subject proper, we must dispose of one question which has been rery actively discussed in its time, namely, whether or not the efferent fibers in the cord are capable of being stimulated directly by electricity. All authors agree that muscular contractions ean be produced abundantly enough by electrical stimulation of the cord; but it has been claimed by some that these contractions either were cansed by direct stimulation of the root fibers or that they were reflexes discharged by stimulation of the posterior columns and of the afferent fihers contained in them.

Biedermann. howerer, among others. has shown that the efferent pathways can actually be stimulated directly. He proceeded in the following manner. The spinal cord of a frog was first split by a frontal section into dorsal and ventral halves. Since the enrd had also heen cut transrersely farther up. there was found in it, as usnal. a decending demareation eurrent (ef. page 48) which inereased its excitability for a enrrent in the same directioni. e., for a eurrent whose eathole enincided with that of the demarcation current. Now it was shown that the rentral half of the eord was excitable at its upper end for descending induction currents. while a considerably stronger current was necessary to eroke a muscular contraction from a point farther down. That is, the current already traversing the eord on aceount of the injury was reënforced to a suffieient extent hy a weak induction shock applied where the current of injury was stronger, and by a strong induetion 
shock applied where the eurrent of injury was weak. 'This relationship would not hold if the stimulus were to traverse root fibers directly, and since it could not have come by way of the posterior columns or afferent fibers, the conclusion is that the stimulus was initiated in the efferent fiber's of the cord itself.

It might be ubjected that the effect in this experiment was due to exeitation of the gray matter. But this objection is met by the cireumstance that the gray matter left in the anterior half showed approximately the same degree of exeitability at whatever level it was stimulated.

Goteh and Horsley have found by stimulation of the long efferent paths of the spinal eord that the rate of propagation in the eord is $39.5 \mathrm{~m}$. per second.

\section{B. METHODS OF DETERMINING THE CONDUCT- ING PATHWAYS IN THE SPINAL CORD}

We have several fundamentally different methods of determining the location of the conduction pathwars, which supplement each other very nicely. They may be summarized under the following three heads:

A. Anatomical Methods.-To these belong: 1 . The method first employed by Stilling of making serial mierosenpical sections of the end and tracing nut the course of the separate fibers from one section to another. 2. A method first nsed extensively by Flechsig, which is based upon the fact that tracts having the same function acquire their medullary substance at about the same time in the embryonic or post-embryonic development. Fig. 261 representschematically the organization of the cord as made nut by this method.

B. P'athologiral-anatomical and C'linical Methorts. - Here belong: 3. Observations on patients suffering from diseases of the central nerrous system, and comparison of these olservations with the post-mortem findings. The observations fall into two divisions. namely:

(i) Where the patient lives long enough for Wallerian detreneration to develop in the tracts of the cord. Post-mortem examination then gives us the same sort of information als the method based upon development of the medullary substance. In Fig.

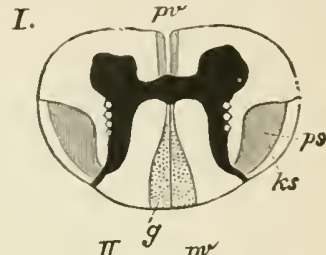

II.

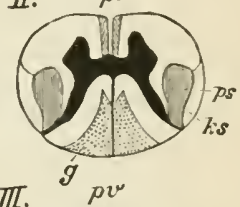

III.
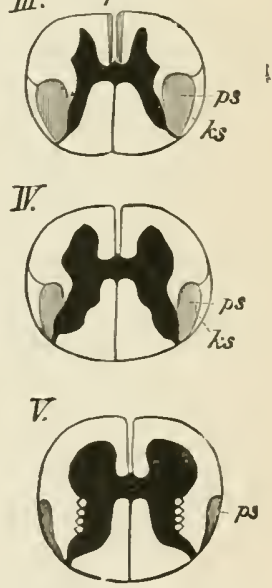

Fic. 261.-Cross-sections at different levels of the spinal cord, after Flechsig. $I$, at the point of exit of the sixth cervieal nerve; $I I$, at the point of exit of the thircl thoracic nerve; III, level of the sixth thoracie; $I V$, of the twelfth thoracic; $V$, of the fourth lumbar. $p s$, erossed pyramidal traet; $p v$, direct pyramdal tract; $k s$, lateral cerebellar tract; $g$, posterior column of Goll. 262 is represented the degeneration in the long motor tracts following upon lesion of the cerebral cortex.

(b) Even if the patient dose not live long enough for degeneration to be far advanced, comparison of the symptoms with the lesions found in the cord 
permit us to say on which side of the cord the pathway governing certain movements runs.

C. Purety Physiological Methods.-Among these are to be mentioned: 4. Partial eross section of the cord in live animals. The resulting functional
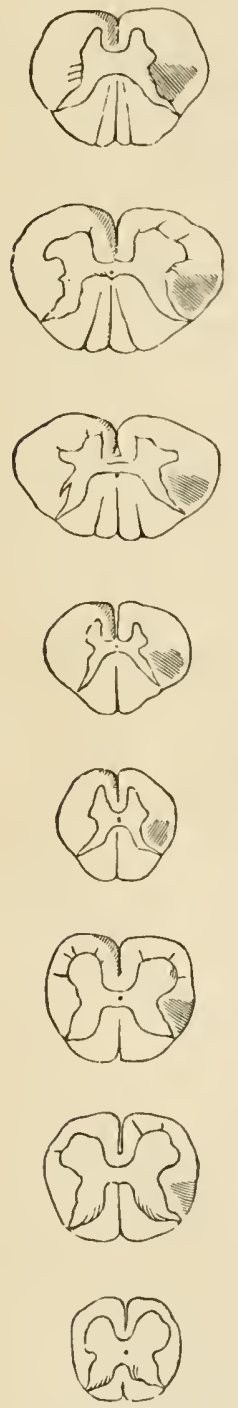

Fig. 262.

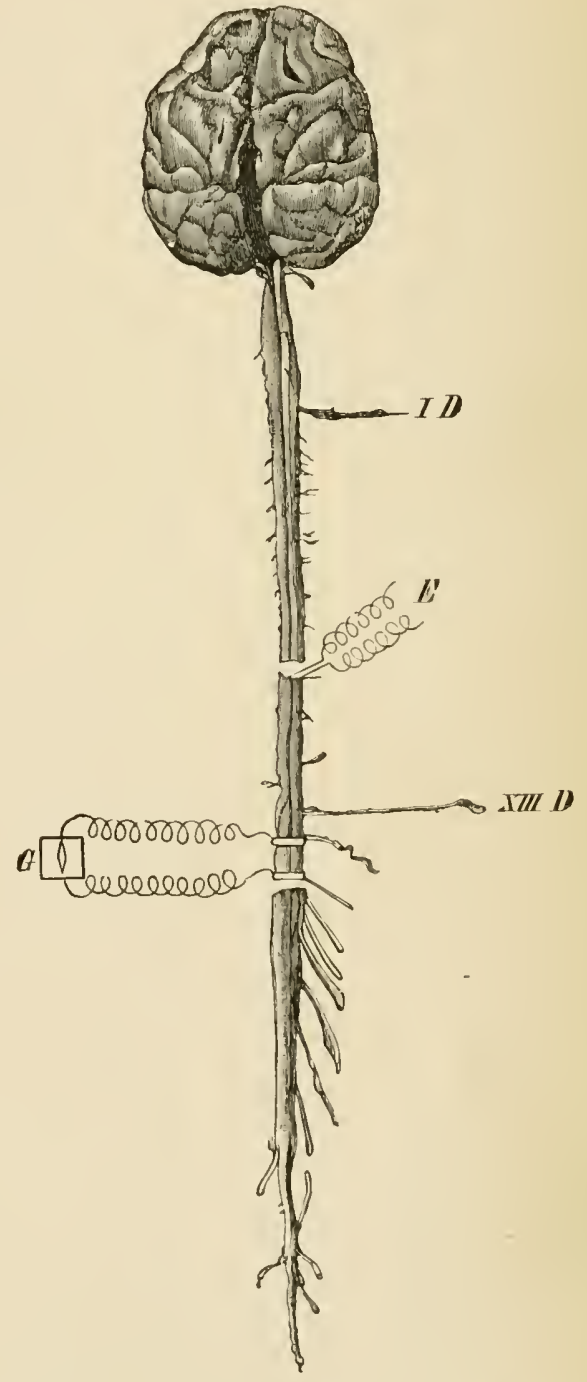

FIg. 263.

F1G. 262.--Secondary descending degeneration following a prinary lesion of the left cerebral hemisphere, after Erb.

Fig. 263.-Arrangement of the experiment for study of the conducting pathways in the spinal cord of the monkey by the electrical method, after Gotch and Horsley. The cord is cut in the middle of the thoracic region and in the upper lumbar region. The stimulus is applied at the upper section $(E)$ and connection with the galvanometer $(G)$ is made from the lower section. 
derangements give us information similar in kind to that obtained from clinical observations $(3, b)$. The resulting degenerations can also be used in the same way as corresponding observations on man $(3, a)$. Finally, after partial section of the cord, one can tell by stimulation of higher parts-e. g., the eerebral cortex, whether certain efferent pathways have been interrupted or not. 5. The Eleetrical Mlethod, which has been worked out especially by Goteh and Horsley. This is based upon the fact that action currents oceur in the central nervous srstem as well as in peripheral nerve trunks. Attention is paid to the strength of the action currents produced by stimulation of different parts after making various partial sections (ef. Fig. 263). 6. Gudden's Method (cf. page 568).

\section{ANATOMICAL DATA CONCERNING THE CONDUCTING PATHWAYS OF THE CORD}

We use the term afferent pathuays here and in what follows to designate all those tracts which convey impulses from lower to higher nerve centers. and the term efferent pathways to designate all those which convey impulses

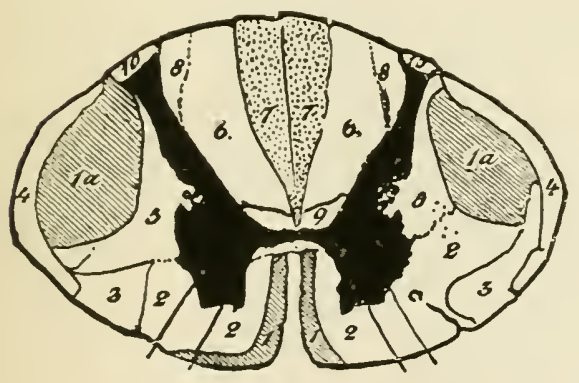

$A$

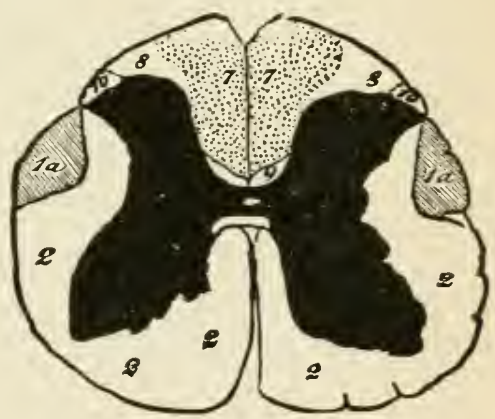

$B$

FIG. 264.-A, section through the cervical, and $B$, through the lumbar parts of the cord, after Edinger. The approximate limits of the various tracts are indicated. Ia, crossed pyramidal tracts; 1 , lirect pyramidal tracts; 2 , anterior ground bundle; 3 , ventrolateral cerebellar tract (or Gowers's tract); 4, dorsolateral cerebellar tract (or Flechsig's tract); 5, lateral boundary zone of the gray substance; 6 , Burdach's column; 7 , Goll's column; 8 , zone of entrance of posterior root fibers; 9, ventral portion of the posterior column; 10 , border zone.

from higher to lower nerve centers. To the former we shall add also all the paths which carry over an afferent impulse to an efferent pathway.

As we have already seen, stimulation of a single afferent nerve may excite reflexly a great many efferent nerves even when the spinal cord is isolated from the brain. The connection of the afferent nerres with the motor cells of efferent nerres must therefore be rery complex. This leads ns to assume that the afferent pathways in the spinal cord are very much more complicated than the efferent-an assumption which is sufficiently borne out by experiment.

The nerve fibers springing from the nerre cells of the spinal ganglia and entering the spinal eord hy the posterinr ronts for the most part divide immediately after their entrance into the cord. into an ascending and a (short) 
descending branch-all of which taken together make up the bulk of the posterior columns of the cord.

Some of the fibers of the posterior roots pass into the gray substance of the spinal cord, and either, like their collaterals, unite with cells in the an-

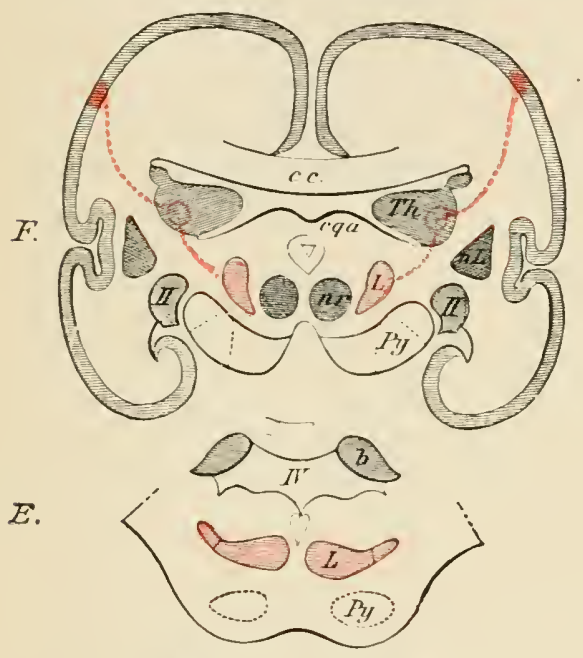
terior and posterior horns and in the substantia gelatinosa, or unite with the cells of Clark's column. The latter fibers, however, are regarded by some authors merely as collaterals. Other fibers of these roots ascend throughout the whole length of the spinal cord without passing to the opposite side. They shift their position somewhat in that they come to lie nearer the mid line the higher they go, so that the median part of the posterior columns in the higher segments of the cord contains the prolongations of the posterior lumbosacral and lower thoracic roots. While the higher thoracic root fibers lie outside these. At the cephalic end of the cord these different dirisions become separated externally by a strong connective-tissue septum; the median division is then known as Goll's column, the lateral as Burdach's colmmn. The fibers of Goll's column end in the gracilar nucleus, those of Burdach's column in the cuneate nucleus. There is anthority also for the statement that fibers from both columns pass directly to the cerebellum and end there.

The secondary afferent tracts arise from the nerve cells with which the fibers of the posterior ronts and their collaterals unite. The following are the better known among them: (1) Fibers from the gracilar and cuneate nuclei pass to the opposite side of the medulla and continue forward

FIG. 265.-Diagram of the course of the sensory conducting pathways after Strümpel. A, entrance of the posterior sensory root fibers in the lumbar cord; gi, spinal ganglion; $r p$, posterior root.

in the fillet. (2) Long fibers arising from cells of the posterior horn traverse the anterior and lateral columns of the same and of the opposite sides as the 
ventroluteral cercbellar tract or Gowers's bundle; in front of the pons they bend around and enter the cerebellum by way of the superior peduncle.

Fibers which originate in the cells of Clarke's. column pass forward to the cerebellum. Some of these are scattered among the fibers of other tracts, but part of them also form a compact bundle (Flechsig's bundle). which, from its position in the cord, is described as the dorsolateral cercbellar tract. All these fibers pass through the inferior peduncle and can be traced to the superior vermis of the cerebellum.

The anterior roots are for the most part connected with nerve cells of the anterior horn on the same side; a few anterior root fibers spring from cells of the opposite side.

secondary efferent pathuays descend from the cerebral cortex to these cells. forming the so-called pyramidal tracts (or the cortico-spinal tract). Their mode of comnection with the anterior horn cells, howerer, has not been definitely made out. In the medulla most of these fibers cross (pyramidal (rossing) and continue downward in what is known as the lateral or crossed pyramidal tract. which gives off collaterals to the motor cells of the same side. A varring number of pramidal fibers. however, do not take part in this crossing of the prramid, but descend in the anterior or direct pyramidal tract, also to a less extent in the lateral pramidal tract. During their downward course these direct tracts are all the while giving off fibers, most of them collaterals, to the opposite side of the spinal cord, so that the crossing of the cortico-spinal fibers becomes more and more complete the farther we proceed caudalward. The result is that the anterior pyramidal tracts can be followed only to about the middle of the thoracic cord, or, exceptionally, to the lumbar cord. But fibers of the direct pyramidal tract are also connected with anterior horn cells of the same side.

Tentral to the crossed pyramidal traet there runs another bundle of long fibers, namely, the rubro-spinal tract or Monakow's bundle, arising in the red muclens of the tegmentum and sending fibers to the opposite side of the cord. Other long-fihered efferent tracts are the tecto-spinal and the vestibulo-spinal. 'The former arises in the roof' of the mesencephalon and runs, as a crossed tract in the anterior column of the spinal cord, and as an uncrossed tract in the lateral columns. The latter springs from Deiter's nueleus in the medulla oblongata, where some of the vestibular nerve fibers have a terminal station, and is found in the anterior columns of the cord.

The tracts thus far described-Goll's and Burdach's columns, the dorsoanct ientrolateral cerebellar tracts, the pyramidal tracts and the efferent traets just mentioned-all represent connecting pathways between distant portions of the central nervous srstem. Flateau has drawn attention to the fact that they tend to occupy the border zone of the white columns in the cord; that while they may at certain levels be displaced from this zone, they always return to it at the first opportunity and thereafter keep their position until they turn into the gray matter.

The inner zones of the white columns are oceupied in the main by shortfibered tracts connecting different levels of the cord. Some of these tracts arise from widely distributed multipolar cells (column cells), which send axis cylinders into the antero-lateral column of the same or of the opposite side. 


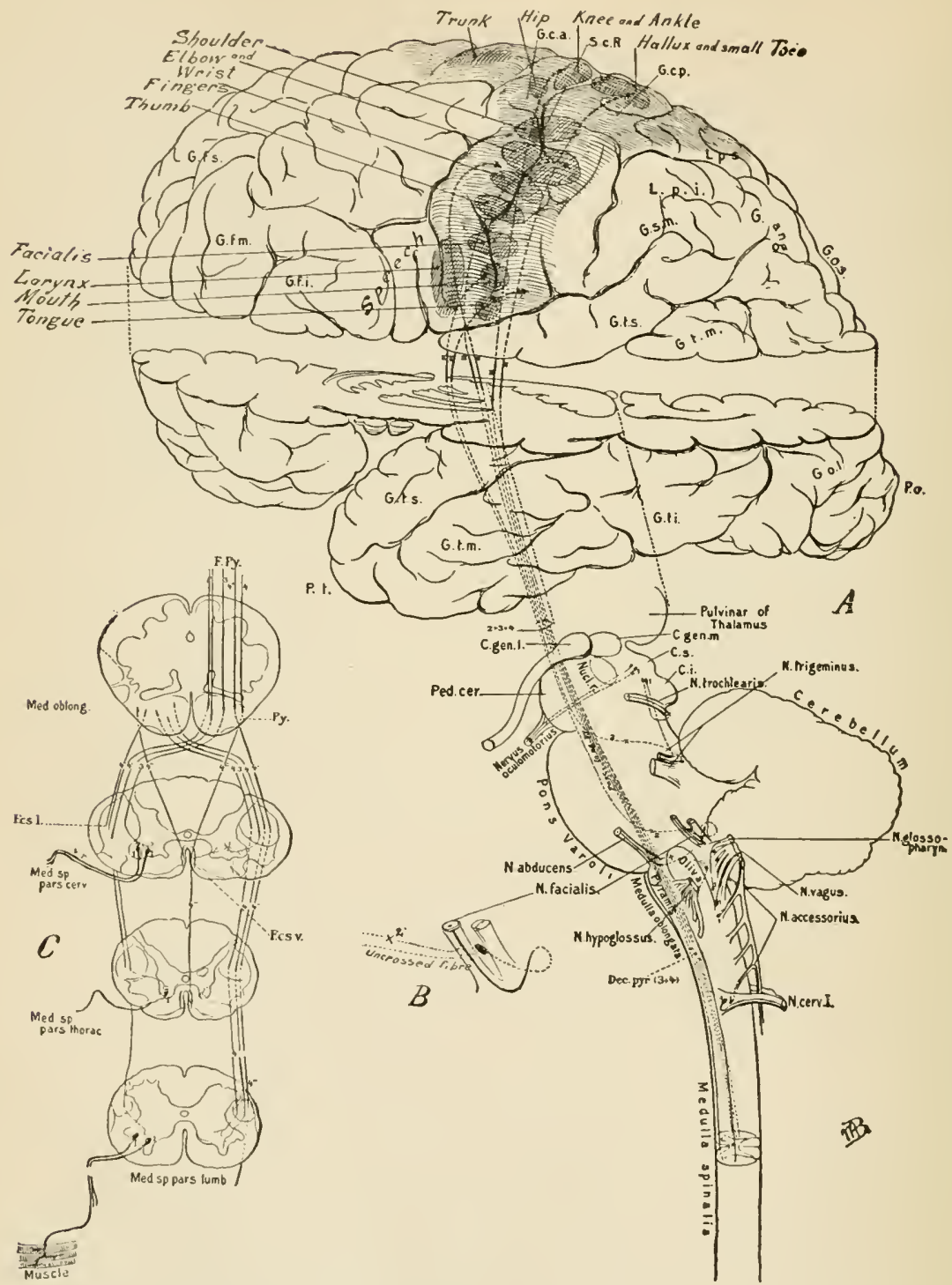

F1G. 266.-Diagram showing the upper $(A)$ and lower $(C)$ motor conducting pathways, after
Barker. The shaded portion of Barker. The shaded portion of the cortex represents the motor cortical zone, the crosshatched portions the motor areas for the various parts of the body. The diagram repreof the thalamus. II (in the space between the the dotted line running up from the pulvinar dicates fibers of upper motor pace between the upper and lower portions of the cerebrum) inthe cortex; 111 , fibers of upper lotways, the cell bodies of which are situated in the face area of of the cortex; $I V$, fibers of upper pat derived from pyramidal cells situated in the arm aren cortex; 1 , cell bodies of lower motor ways derived from pyramidal cells in the leg area of the to the cranial nerves; 3 , fibers of pyathways; 2 and $2^{\prime}$, fibers of pyramidal tract distributed muscles of the upper extremity which innervate the muscles of 4 , fbers from the pyramidal tract distributed to cord cells 
Here collaterals are given off which again betake themselves to the gray matter and there end in terminal arborizations about other cells. Other fibers of this class run in the posterior columns, being found chiefly in the most ventral section.

Still other cells, whose axis cylinders break up immediately without passing to any well-defined pathway, serve as connecting links between different clements at the same level. Such cells are found scattered throughout every cross section, but are particularly abundant in the ricinity of the posterior horn.

It will be apparent from what has gone before that the antero-lateral columns of the spinal cord are the most important. In these we have, besides the particularly prominent crossed and direct pyramidal tracts: the dorsoand ventrolateral cerebellar tracts, which are among the most important afferent conducting pathways to the brain; the mbro-spinal. the tecto-spinal. and the restibulo-spinal tracts: and finally. the most important commissural fibers binding together the different levels of the cord.

\section{EXPERIMENTAL AND CLINICAL OBSERVATIONS ON THE CONDUCTING PATHWAYS IN THE SPINAL CORD}

The question which first confronts us in experimental and clinical investigations of the pathways in the spinal cord is. whether or not these pathways cross in the cord itself. The second question to be answered is. in what columns do they run.

When we consider the diffienlties with which inve-tigation of this subject is beset-such. for example, as the difficulty in animal experiments of making just the cut intended. and the uncertainties attending the observation of disturbances to sensibility and motility resulting from the operation-we can understand why the statements of different authors differ greatly as to the results obtained. Obserrations on human patients are naturally well calculated to supplement the obserrations on animals: but here we meet with the difficulty that the lesinns occurring as the result of disease or accident are seldom or never limited sn exactly as to give us wholly merpuirocal results. The following summary must be regarded as largely provisional:

1. Efferent Pathways. - When a hemisection of the cord is made in a dog, immediately after the operation the muscles of the same side, whose nerves leave the eord below the section, are paralyzed, while the museles of the opposite side remain entirely functional. The hemiseetion seems therefore to have severed an important pathway of the homonymous side.

- But this paralysis is not final. It gradually disappears more or less completely, the degree of reenvery as well as the extent of the primary paralysis depending upon the loeation of the hemisection. Thus hemisection in the cervical cord produces a greater disturbance in the fore paw than in the hind paw. Reeovery is made in botl extremities, but it is more complete in the pisterior than in the anterior. The disturbanees to motility in the posterior extremity following hemisection of the thoracie eord last longer and the recovery is less perfeet than after hemiseetion of the eerrical enrd. The more distally the hemisection is loeated, the more profound and the more persistent are the motor disturbances which follow, and the less perfect is the subsequent recovery. 
From these obscrvations we may conclude that in the dog the motor pathways follow tracts on both sides of the cord, but that the traet on the same side as the muscles to which it convers impulses is the more important. If this tract is suppressed by hemisection, the one on the opposite side takes up the function. But the nearer the hemisection lies to the point of exit of any given nerve, the more completely have the fibers destined for that nerve alrearly crossed from the other side of the central system (see page 598); consequently the more profound is the disturbance.

When a hemisection is made in the thoracic cord of a dog, and the resulting disturbances have disappeared, a hemisection on the other sicle higher up or a sagittal section in the mid line of the eord will produce the same effects again; in either case the operation has broken the pathways coming from the heteronymous side.

But motility is not permanently lost even after a second hemisection like that just described. In fact after three alternating sections at different levels, some motor fibers to the muscles of the hind leg remain minterrupted (Osawa). The alternative motor efferent pathways therefore must be very numerous.

Observations on the motor effects of half-destruction of the spinal cord in man may be summarized. after Kocher, as follows: "Motor paralysis on the same sirle appears immediately in a rery intense form, but. as a rule. it abates in the course of a few days or weeks. and if the anterior horn nuclei are not too extensively destroyed, it is so far recorered from that only a slight paresis remains. The deep crossing just above the point of exit of the nerves to the extremities is of nore importance for the leg than for the arm.

To judge by the anatomical facts, the motor patbs destined for the muscles of a given extremity run in the crossed prramidal tracts and Monakow's bundle on the same side of the cord and in the direct pyramidal tract of the opposite side. In accordance with this we find it stated that a section involving all parts of the cord except the lateral columns produces only a slight reduction of motility, and that it is not finally abolished lyy section of the lateral columms alone; in fact, the motility gradually returns and becomes fairly complete again. The above-mentioned observations by Osawa show, however, that there are other efierent paths from the brain to the spinal cord than these.

We have the following statements concerning the course of the condueting pathways for the regetative functions. The vasoconstrictor nerves run in both the homonymous and heteronymous paths, the former appear to be the stronger. The tracts to the bladder and rectum are also found on both sides; those of either side being suffieient to innervate the musculature of the entire bladder and the entire rectum. The tract on either side, therefore, can be injured without any interference in the function of the bladder or rectum. Finally, the sympathetic fibers to the eye and to the eorresponding half of the face descend the whole length of the cerrical cord on the same side. Paralysis after destruction of this tract appears to be permanent, although it may decrease gradually in intensity (Kocher).

2. The Afferent Pathuays.-Of these the tracts for motor sensations are the best known. It has been known for a long time that in certain diseases of the spinal cord in man the sense of movement is lost to a greater or less extent without any other loss of sensibility (ataxia, ef. page $12 \cdot 2$ ). Patho- 
logical anatomy has shown that the seat of this disease is in the posterior colunnns, exchusive of their ventral sections. Hence we ean say that the tracts for motor sensations in part, at least, traverse the posterior columns. These tracts are on the homonymous side of the cord, substitution of the other side appearing very tarlily if at all.

In the dog, after section of the posterior columns, not only does the sensation of pain persist. but likewise the coarser sensations of touch and position as well as a crude power of localization. There is no apparent interference with walking nor with finer isolated movements (Borehert).

How the different sensory impressions receired by the shin are propagated through the spinal cord is a much more difficult question.

The original doctrine of Brown-Séquard that these sensations traverse only the heteronymous side of the cord has been both confirmed and denied by many anthors. We shall limit ourselves here to the view of Kocher, who has marle an exhaustive study hased on abmondant clinical material of his own.

- Aceorting to this author. a hemilesion of the spinal cord produces on the injured side hyperasthesia for touch and pain, and in many cases also for heat and cold. Even the deeper parts are included in this change. so that movements of the limbs become very painful. On the opposite side there is, as a rule, al reduction of sensibility. But it raries both as to intensity and quality according to the extent of the injury. Either every kind of sensation is lost altogether or. as is rery often the case. the sensation of touch remains intact while the others are lost. or, finally, the sensation of pain is merely blunted and the sensations of heat and cold are lost.

Homerer, these disturbances are not final on either side. The hyperæsthesia on the injured side declines and the loss of sensation on the opposite side gradually disappears, though for a long time it requires a stronger stimulus to produce the sensation which has been affected. The return of pain sensations may precede the revival of touch. the latter that of lieat. and beat that of cold. These rariations of the symptoms are referable to differences in the extent of the lesion.

After an exhaustive discussion of the elinical observations, Petrén has reached the following conclusions with regard to the tracts of the eord in which the different cutanenus sensations are propagated. The pressure sense is mediated by two different tracts: the one aseends in the posterior (o)lumns of the same side and is the direct continuation of the posterior roots: the other, after entering hy the posterior horm. crosses entirely to the opposite side and ascends probably als a part of Cowers's tract (cf. Fig. ?64) in the lateral column. The tracts for pain and temperature sensations follow this second tract for pressure, hence run in the cord only on the opposite side from the place in the skin where they originate.

Referexces.-L. F. Barker, "The Nerrous Srstem," New Jork, 1899.II. $v$. Bechtereu, "Die Leitungsbahnen im Gehirn und Rückenmark," second edition, Leipzic, 1898.-Bethe. "Allgemeine Anatomie und Physiologie des Nervens,ytems," Leipzic, 190:3.-L. Edinger. "Vorlesungen iiber den Bau der nervüsen Zentralorgane," seventh edition, Leipzic, 1904--Exner, "Entwurf zu 
einer physiologisehen Erklärungen der psychisehen Erscheinungen," i, Lcipzıg and Wien, 1s:9.---Van Gehuchten, "Le systeme nerveux de l'homme," third edition, Lierre, 1901.-Goltz, "Beiträge zur Lehre v. d. Funktionen der Nervenzentren des Frosehes," Berlin, 1569.-Goltz and J. R. Euald, Areh. f. d. ges. Physiologie. Bd. lxiii, 1s96.-Giotch and Horsley, Philosophical Transactions, vol. .lxxxii, B, 1s91.-Kocher, "Mittheilungen aus den Grenzgebieten der Medizin und Chirurrie," vol. i, 1596.-Langley, Journal of Physiology, vol. xvi, 1894.Leyden and Goldscheider, "Erkrankungen des Rückenmarkes und der Medulla oblongata," Wien, 1s95; 1597.-Ludwig's Arbeiten, 1566-1590.-E. Redlich, "Die Pathologie der tabisehen IJinterstrangserkrankungen," Jena, 1897.-Sherrington, "The Spinal Cord" in Sehäfer's "Text-book of Physiology," ii, Edinburgh, London, and New York, 1900.- Tulpian, "I.econs sur la Physiologie du système nerveux," Paris, 1866.-Th. Ziehen, "Nervensystem," i, 1 and 2, Jena, 1899-1903. 


\title{
CHAPTER XXIII
}

\author{
PHYSIOLOGY OF THE BRAIN-STEM
}

\section{\$. GENERAL SURVEY}

WE have seen in the previous chapter that the spinal ond exercises control over many different functions of the body. We have now to learn that an eren more complete control is exercised by the highest parts of the central nervous system, namely, the parts lodged in the cranim and which, taken collectively, we call the brain. For, as we shall see later. it is no difficult matter to demonstrate that even the cerebral cortex, the highet part of all, can exert its influence orer functions which are quite independent of the will. Experiment has shown that this influence varies with different divisions of the brain, and that from the standpoint of the different functions we must for this reason ascribe to the different parts a dignity of a very different order. For the purely regetative functions, especially those which have most to do with the mere maintenance of life, like the circulation. respiration, digestion, etc., the lower parts of the brain, particularly the medulla, are the most important: while the cerebrum is for very good reasons regarded as the material substratum of the conscious processes.

The extremely varied functions of the brain make it necessary that the nerrous pathways should be connected with each other in manifold ways, and accordingly we find the strueture of the brain extraordinarily complex. This circumstance is, for the physiological and clinical as well as for the anatomical mode of attack. the source of very great difficnlties. which sn far have been only rery imperfectly surmounted. Onr knowledge of the functions of the brain as a whole and of its different parts is therefore very inadequate, and the data which we have are unfortunately very contradietory as to many of the most important points.

\section{A. METHOD}

The methods which can be emploced in investigating the functions of the brain are in general similar to those with which we have already become familiar in the study of the spinal cord: anatomical study of its structure, artificial stimulation, section or remoral of different parts, clinical observations nn patients followed by post-mortem dissection, ete. But, as will be readily understood, the practical difficulties to be overeome here are very much greater than those met with in the study of the cord. Not only is the danger of clisturbance to the circulation, caused by section or removal of a part, as well as the shock produced by the operation, greater in dealing with the brain. so that effects are very often much exaggerated at first, but in many cases the function lost is assumed by 


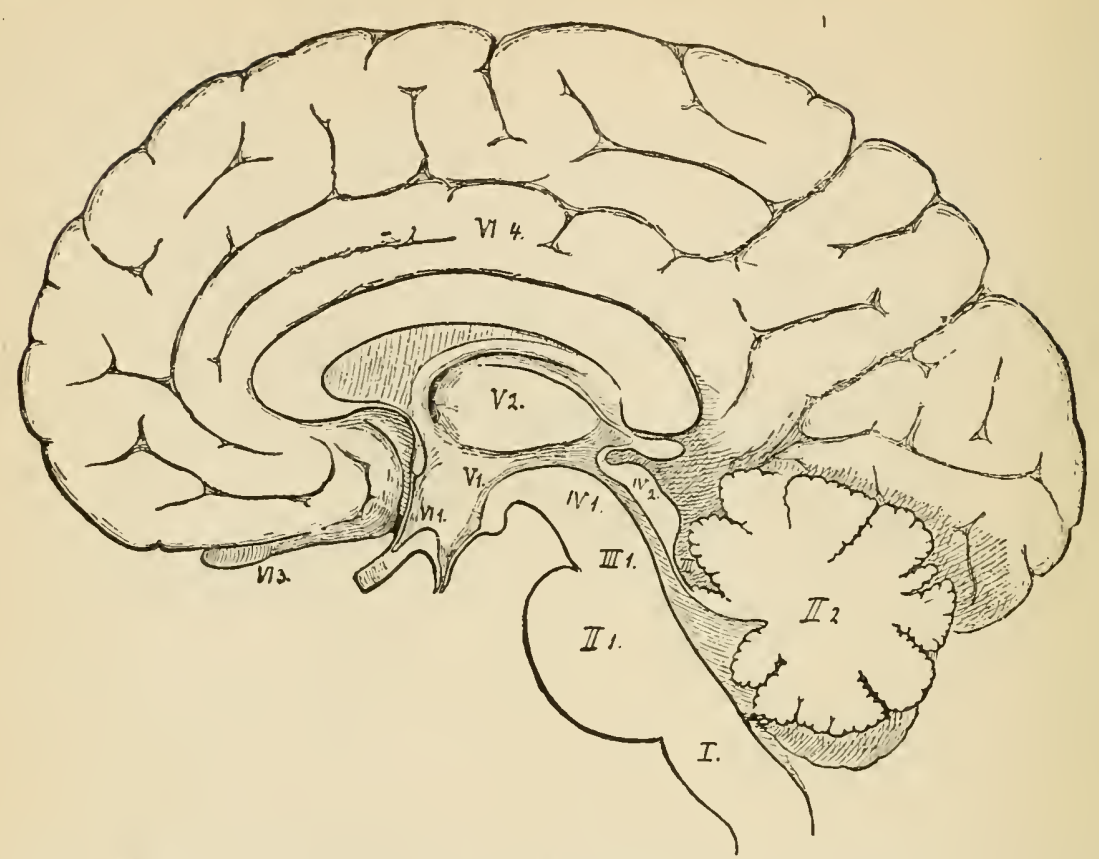

FIG. 267.-Median seetion through the brain of an adult, after His. The figures refer to the table below.

Encephalon (brain), I-VI (Fig. 267)

Rhombencephalon (hindbrain), I-III

Myelencephalon (afterbrain), I

Medulla oblongata (bulb), I

Metencephalon (secondary hindbrain), II

Pons, $\mathrm{II}_{1}$

Cerebellum, $\mathrm{II}_{2}$

Isthmus rhombencephali, III

Mesencephalon (midbrain), IV

Crura cerebri, $\mathrm{IV}_{1}$

Corpora quadrigemina, $\mathrm{IV}_{2}$

Prosencephalon (forebrain), $\mathrm{T}$ and VI

Diencephalon ('tweenbrain or interbrain), V

Pars mamillaris hypothalami (corpus mamillare, etc.), $\mathrm{V}_{1}$

Thalamencephalon, $\mathrm{V}_{2}$ to 4

Optic thalamus, $\mathrm{V}_{2}$

Metathalamus (corpora geniculata), $\mathrm{V}_{3}$

Epithalamus (pineal body, etc.), $\mathrm{T}_{4}$

Telencephalon (endbrain), VI

Pars optica hypothalami $\left\{\begin{array}{l}\text { tuber cinereum } \\ \text { infundibulum } \\ \text { pituitary body }\end{array}\right\} V I_{1}$

Hemisphærium, $\mathrm{VI}_{2}$ tn 4

Corpus striatum. $\mathrm{VT}_{2}$

Rhinenceplaton (olfactory lobe, ete.), $\mathrm{VI}_{3}$

Pallium (cortex cerebri), $\mathrm{VI}_{4}$ 
some other part, making the interpretation of results very difficult. Moreover this method has to contend with the difficulty of limiting the lesion produced exactly to the region intended.

In some parts of the brain, as for example the cerebral cortex, it is relatively easy to get clear results with ordinary electrical stimulation, but in others the results are too easily obscured by by-currents and in the deeper parts it is practically impossible to employ the method without a serious operation.

Comparative physiology has shown rery conclusively that the importance of different parts of the brain is very different in different vertebrates. Hence one caunot apply to man the results obtained upon animals without some qualification; hence also it is highly important that analogous results should be had upon man himself. The great variety of mental diseases furnish us the necessary material for this purpose, and in many respects the information obtained from them supplements the information we obtain from animal experimentation.

The weight of the evidence accruing from such material must, however, be estimated with caution and only by observance of certain definite principles. Thus a tumor may be located some place in the brain and all sorts of disturbances may appear in both the bodily and the mental functions of the patient. But one is not justified in concluding from this alone that all these disturbances result directly from destruction of the part where the tumor is located, for it may be that the tumor raises the intracranial pressure and has by this means disturbed functions far removed from the seat of the lesion. Again, a sudden hemorrhage in the brain occurs; the patient shows various severe symptoms and dies within a few hours. Now this is not equivalent to saying that the different disturbances observed were produced alone by paralysis of the part destroyed in the hemorrhage; they certainly were the result, in part, at least, of shock, and would doubtless have lisappcared to a certain extent had the patient lived longer. Only from cases where there is no rise of intracranial pressure and where the patient lives some time after the inception of the lesion can conclusions of any physiological importance be drawn.

These preliminary remarks with regard to the principles which must be borne in mind in the study of brain functions must suffice for the present. As we proceed with the subject we shall have opportunity of discussing these fundamental propositions more in detail.

\section{B. DIVISIONS OF THE BRAIN}

His has divided the brain on the basis of its embryological development as given in the table ' on opposite page.

The parts of the brain derived from the first primary brain vesicle (hindbrain) inclusive of the dieneephalon ('tweenbrain), were formerly deseribed collectively as the "brain-stem" in contradistinction to the endbrain (telencephalon). In presenting the subject of the brain functions it seems adrisable for several reasons to continue as formerly the use of this division and to apply the name cerebrum only to the parts developed from the endbrain.

1 This classification has been very slightly modified in accordance with more modern usage in English.-ED. 


\section{§. THE MEDULLA OBLONGATA, OR AFTERBRAIN}

The medulla oblongata extends from the upper end of the spinal cord to the lower edge of the pons. its npper borter lieing just a little dorsal to the lateral recess of the fomth rentricle. Its length on the rentral side is from 20 to $2 t \mathrm{~mm}$. and on the dorsal from 24 to $26 \mathrm{~mm}$.

The physiologicnl signifirance of the medulla consists chiefly in this, that within its borders the afferent and efferent pathways of the cord are brought

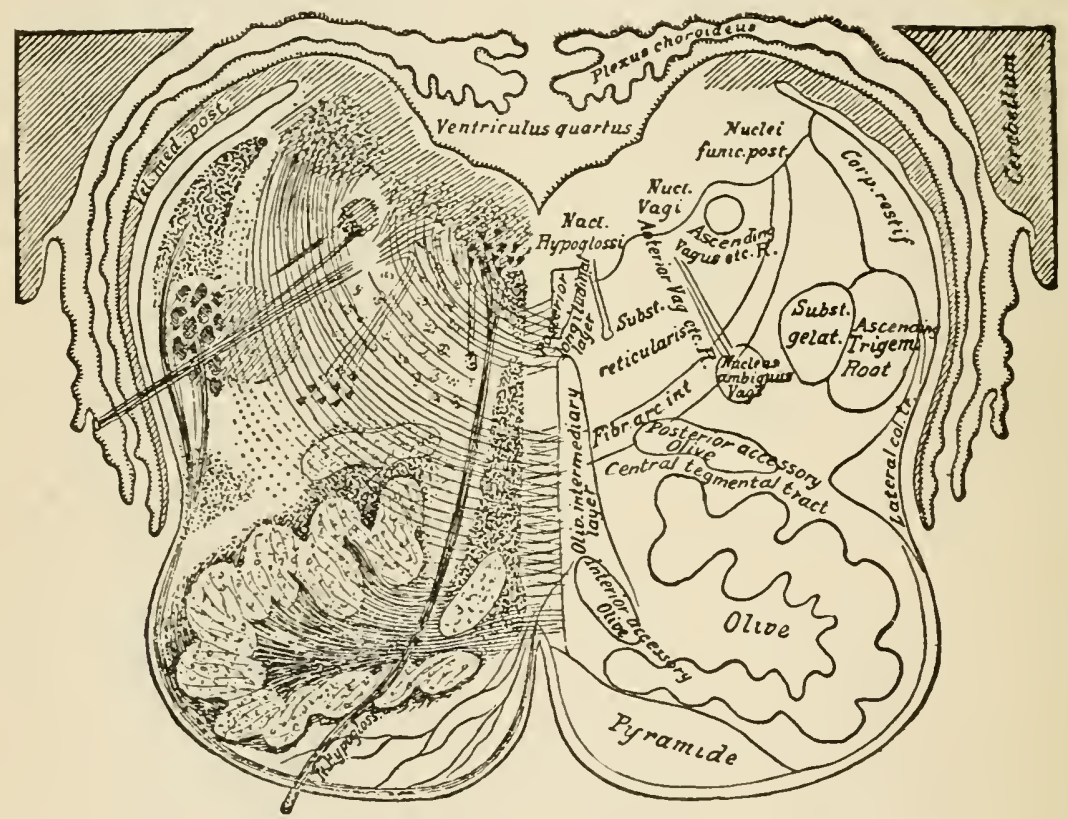

Fig. 268. - Transverse section of the medulla oblongata, aiter Edinger.

into much more intimate relationships with each other and with the cranial nerves and pathways than is the case in the cord itself. By this means the efferent nerves from the cord can act together for a common purpose in a much more orderly manner than would be possible on the basis of their connections in the spinal cord alone, a thing of profound importance for the unity of the bodily functions.

The centers which exemplify this influence of the medulla in the highest degree are the vasomotor and respiratory centers, the physiological purpose and mole of action of which have been discussed at pages $23 \%$ and 325 . Tomiting may also be mentioner as an instance of coördination of many different muscles to a common end, the center for which is probably situated also in the medulla (cf. page 286 ).

It is rery probable that the centers for several other general funetions, which, like rasodilatation, require the harmonious aetion of many different spinal nerves, lie in the medulla; experimental proof of their presence, however, is wanting at this time. 
Puncture with a sharp instrument of a certain spot in the medulla produces diabetes (puncture diabetes of Cl. Beriard) in the animal suffering the operation. The mechanism concerned in this is quite unknown, but we may conclude from the observed fact at any rate that in some way the medulla plars an essential part in the regulation of carbohydrate metabolism (ct. page 375 ).

Although the medulla of the higher vertebrates camot alone effect the coördination of skeletal muscles necessary for locomotor movements, nevertheless extensive motor effects, both reflex and automatic, appear more readily with the medulla intact than when it is removed; and we may imagine at least that this influence of the medulla over the skeletal muscles is not without its significance for their function as heat producer's.

Edinger observes that the centers which preside over the above-named and other similar associations are probably to be songht among the multipolar cells distributed through the substantia reticularis of the medulla, and described by Bechterew as the nucleus reticularis tegmenti (Fig. 268).

The medulla assmes a still higher dignity physiologically when we realize that it contains the nuclei of origin of many efferent cranial nerves as well as the nuclei around which the central endings of many afferent cranial nervez split up. Named from below upward, these nerres are the hypoglossal. the spinal accessory. the ragus. the auditory, the facial and the trigeminal (Fig. 269), although the last three and their nuclei do not belong exclusively to the medulla.

The efferent fibers contained in these nerves supply the most widely different organs, but especially those which are most important for the regetative processes of the body; such, e. g.. as the tongue, the salivary glands, the phar-

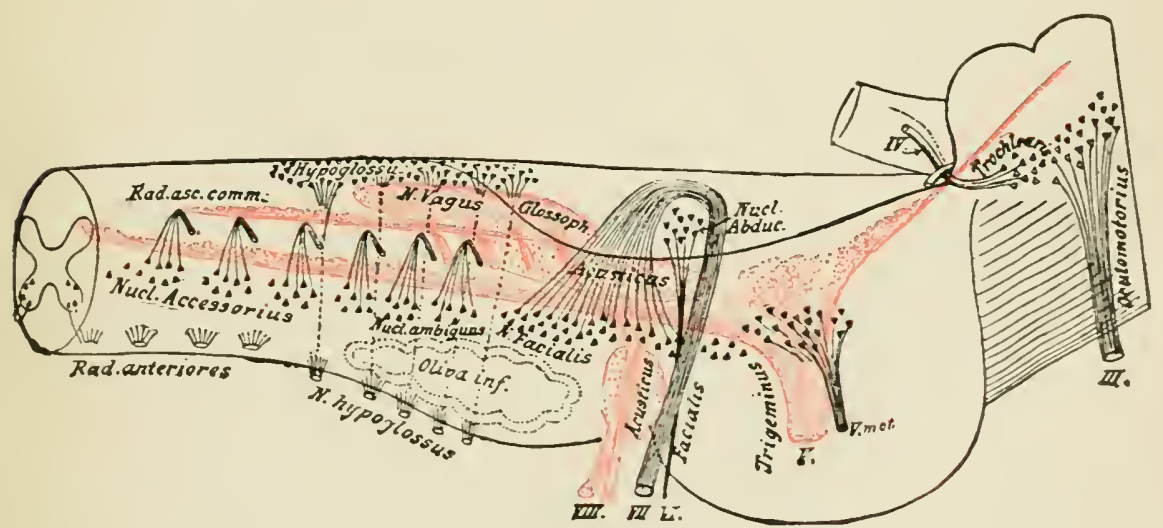

FIG. 269.-Position of the nuclei of the cranial nerves, after Edinger. The mellulla and pons are supposed to be transparent. The cells of origin of the efferent nerves are black, the endnuclei of the afferent nerves red.

ynx, csophagus. stomach and intestine; the larynx, air passages and lungs: the heart and blood vessels. The corresponding afferent fibers convey impulses to the medulla from the internal car: the skin of the face; the mucous membrane of the mouth inclusive of the tongue, the pharyx, asophagus. stomach and intestine; the larynx, air passages and lungs: the heart, etc.; 
and these impulses have a large part in the regulation of the important processes going on in these and other organs.

It follows that the medulla exercises a determining influence on the following functions: secretion of saliva, movements of the tongue, swallowing, morements of the stomach and intestine, romiting, secretion of the gastric and pancreatic juices; force and frequency of the heart beat, vascular tonus, and regulation of the blood flow; respiratory morements and morements of the larynx; also, to a certain extent, at least, the heat regulation of the body both through the blood ressels and the skeletal muscles. In short, digestion, circulation, respiration and heat regulation are all to a considerable extent dependent upon the medulla.

Some of these functions are, it is true, relatively simple; for example, the reflex secretion of saliva is on a plane with the simpler refiexes from the spinal cord. But others, and. in fact, most of them, are very eomplieated, as a critical study of the processes of swallowing. breathing, and distribution of blood to the different organs will readily convince one.

Moreover, experiment has shown that the different nerves act not only upon the efferent nerves belonging to the same organ, or organ system, but that their influence extends to other organ systems. Thus, e.g., by swallowing repeatedly the heart beats are at first quickened, but subsequently are lowered to a rate below the original; the vascular tomus decreases; the expiratory phases of respiration last longer; labor pains become weak or cease altogether; hiccoughing may be stopped by repeated swallowing. ete. (Kronecker and Meltzer).

When we remember that in addition to exereising this multifarious control over the funetions enumerated above, the medulla is the afferent pathway of impulses from the cord to the higher parts of the brain, and of efferent impulses from the latter to the former. it is apparent at once that it eonstitutes an organ absolutely indispensable to life. The immediate cause of death by destruction of the medulla is stoppage of the respiration, and by keeping up this function artificially. life can be prolonged somewhat. But this is not sufficient to maintain life indefinitely, for other disturbances, especially that of the heat regulation, are enough to bring on death within a relatively short time.

On the other hand, it can be shown that eren a mammal can surrive section of the brain at the upper edge of the medulla, provided its eontinuity with the spinal cord be not interrupted, without immediate danger to life and without resort to artificial respiration or anything of the kind. Since, however, such an animal cannot move about or take nourishment. it is of course impossible to keep it alive very long.

Frogs, which because of the much lower intensity of their metabolism require very little food and hence can go a long time without any food, live much longer when deprived of the brain ahove the medulla. In fact, Shräder suceeded in removing from frogs everything down to the medulla inclusive of the cerebellum and the most anterior part of the medulla itself, and in keeping them alive for four months. The most striking thing about the behavior of these animals was an apparently irresistible impulse to be constantly moring. 


\section{§3. THE CEREBELLUM}

The cerebellum is connected by means of its peduncles on the one hand with the spinal cord and on the other with the higher parts of the brain. Impulses to and from the cerebellum are conveyed over pathways contained in these peduncles.

Many nerve cells are found both in the gray cortex of the cerebellum and in the gray nuclei located in its interior. The rarious nuelei are connected by means of association fibers with the cerebellar cortex. and the different subdivisions of the latter are connected with each other in numerous ways by means of other association fibers.

In animals deprived of the cerebe!lum, and also in men suffering from extensive destruction of this organ. various characteristic symptoms are observed. But among them we do not find either motor or sensory paralysis of any kind. Hence we may conclurle. what is horne out also by anatomical connections. that the cerebellum is not in the direct line of connection between the higher parts of the brain and the medulla or the spinal cord, but that it constitutes a system in itself branching off to one side, which both acts upon and is acted upon by the other parts of the central nerrous system.

Remoral of the cerebellum does not of itself endanger life; it is therefore not an indispensable organ, although it does exert a profound influence orer certain functions of the body.

According to Steiner, artificial stimulation of the cerebellum in fish has no effect.-By mechanical stimulation with a fine needle Nothnagel observed in the rabbit that the head was turned to the opposite side and the rertebral column was curved so as to become concave toward the opposite side.-Electrieal stimulation between the left hemisphere and the vermis of a dog moving freely about the laboratory produced, in experiments by Lewandowsky, foreed flexion toward the same side, so that the vertebral column beeame bent convexly to the right; ultimately the animal fell orer to the right or went off in circular movements in the same direction.-On the other hand the tonic contraction of the skeletal muscles is inlibited by stimulation of the surface of the cerebellum (Sherrington). But from such observations as these we ean only conclude that the cerebellum is in some way related to the bodily movements. For more exact information as to what that relation is, we must direct our attention to the study of the symptoms attending lesions of the cerebellum.

In certain fishes where the cerebellum is highly deceloped. it can he removed without produeing any apparent disturhanee either to the hodily morements or to equilibrium: the animals merely wabble slightly sidewise while swimming. 'The cleaner cut the operation, the less marked are these wabblings. and within a day or so they practically disappear. Likewise after unilateral ablation of the cerebellum there is no disturlance in locomotion (Steiner).

In frogs, where the cerebellum is rery slightly developed, the posture of the body and the leaping morements after extirpation are not to be distinguished from those of the normal animal. When the animal is placed in water, it swims and behaves otherwise quite normally. But when it leaps 
upon the edge of the basin, one observes that rery often it leaps too far or not quite far enough. Again. when it loes succeed in reaching the bank it often settles down with a portion of the body projecting over the edge, whereas a normal frog is never content until it has a solid footing under the whole body. The symptoms attending ablation of the cerebellum are therefore not at all striking (Steiner).

Remoral of the cerebellum from the green lizard and the turtle produces no perceptible effect (Stciner, Bickel).

In operations similar to these on the higher vertebrates, it has been noted that no pain is produced unless the medulla or pons is injured.

Rolando, Magendie and Flourens long ago observed irregularities in the bodily movements following operations on the cerebellum, but they explained

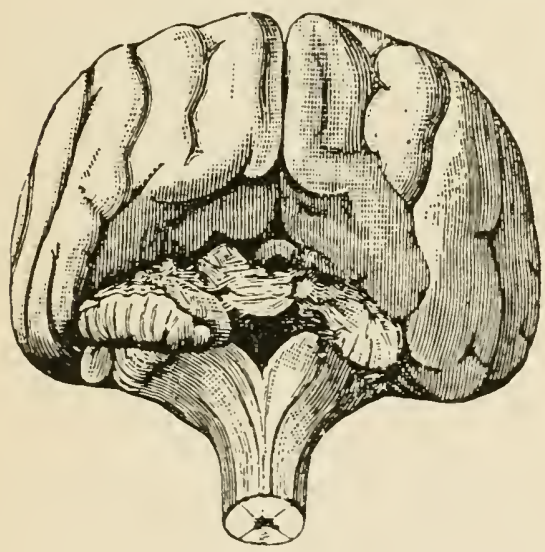

FIG. 270.-Almost complete extirpation of the cerebellum of a dog, after Luciani. them in very different ways. By many rescarches which have becn made on this subject since that time, these disturbances have been confirmed and their cause more closely analyzed.

VTe cannot discuss all of these inrestigations here, but must be content to consider some of the leading facts brought out by work done within recent years.

In order to make the phenomena following extirpation of the cerebellum more intelligible, we shall recite, after Luciani, the clinical history of a dog in which, as was ascertained subsequently by dissection, all but the lower outer portion of the cerebellum had been removed on the left side, while only a small, unimportant fragment had been left on the right (Fig. 2\%0). There were three successive operations. but the following description relates only to the phenomena which appeared after the last, performed on the 13 th of Altgust, 1883.

For some time after the operation the animal was unable to right himself, but lay on his back, the rertebral column bent strongly to the left and the fore limbs powerfully extended. This contracture increased and spread to the hind limbs when the animal tried to place his four feet straight on the floor. The animal ate and drank without help when the head was supported against the wall. Thrown into a tank of water he reared up suddenly with head out of the water and fell orer backward. But he soon recovered his equilibrium and swam in the normal fashion, his head out of the water. Coming to the edge of the tank and attempting to elimb out, he again fell over baekward but soon righted himself in the water. Now and then in turning round the head went under, but it was quickly lifted out and the equilibrium recovered.

About the second reek these symptoms began to abate somewhat. When the animal was placed in a standing posture with the four legs abducted so that he was well supported, and was left to himself, he stond for some seeonds swaying backward and forward, but the swayings rapidly beeame too extensive and he fell 
over backward to the left.-The contracture mentioned above gradually diminished, but the animal was still able to lift himself only by his fore legs. Muscular weakness, particularly in the hind limbs, was very marked.

Gradually, however, this weakness passed off and by the 24 th of September the animal began to stand on all fours and to take steps, supported against the wall. Some ten dars later he took his first steps unsupported, and from this on his ability to walk steadily improved. On the 31st of Oetober the following deseription was written coneerning his gait: "quick, almost twitehlike morements, the head lowered, the back slightly eonvex, very pronounced lateral movements of the spinal colunm, abnormal elevation and abduction of the fore leg, movements of the hind legs not in aeeord with those of the fore legs, often falling on a smooth floor, seldom on a rough one." Particularly noticeable was the extreme effort with which the dog walked, and which was expressed in the dyspnoea, lolling of the tongue and need of rest at short intervals. Thrown into a tank, he was now able to swim powerfully and well, getting his equilibrium rery promptly.

On the 11th of January, 185t, it was noted, among other things, that the animal eould not stand perfeetly still eren for a moment. The most he eould do was to stand for a few minutes with the legs wide apart, swaying back and forth until he deeided either to walk or to lie down. When the animal walked he presented a most perfect picture of ataxia. Coördination of his morements was frequently quite normal, but whenerer the regular rhythm was interrupted, as in turning or attempting to walk rapidly, or if one leg slipped eausing the body to fall down behind thereby impeding his progress, coördination between the fore and hind legs was lost for the time. It was noted also that the legs were lifted abnormally high in walking and that the spinal column undulated slightly up and down. Luring the animal on with food only aggravated his srmptoms without improving his speed. On the whole the gait was much slower and the loss of strength by exereise much greater than in a normal animal, leading to extreme fatigue in a very short time.

We see that the effects of removing the cerebellum wear off to a certain extent with time, and only those which remain after sereral months can be described as the final etlects. The latter Luciani summarizes as follows: asthenia, or loss of strength; atonia, or loss of tonus in resting muscles: and astasia, or loss of steadiness in all kinds of morements.

Several authors have reported that while lesion on one side of the cerebellum eaused motor disnrders. two symmetrical lesions on the opposite sides, whether large or small, either produced no effect at all or only slight ones. In Lucianis experience this was not the case. When the middle lobe or vermis was extirpated more or less completely, immediately after the operation tonic contraction of the fore leg or neck muscles came on whenever the animal attempted to do anything roluntarily. But these effects passed off in a few days, and whaterer permanent effects then remained stond out very clearly, although naturally less pronounced than after practically complete removal as above described. These disorders probably appeared in all muscles. but were more sharply defined in certain definite groups-e. g.. those of the hind limbs. In animals from which the rermis was remored to the same extent on both sides permanent effects were equally distributed to the two halves of the body. whereas when the removal was more extensive on one side than the other, the effects were more strongly marked on the one side. 
These effects gradually became compensated more or less completely, and in certain cases to such an extent that one could scarcely distinguish the animal from a normal one. We shall discuss this form of compensation presently.

Mere division of the cerebellum into a right and left half by a median longitudinal section is entirely without effect (Russell).

Complete remoral of, say, the right side of the cerebellum produces, immediately after the operation, rotation about the long axis of the animal from left to right (scen from the dog's back), squinting of the eyes to the left, nystagmus (to-and-fro movements of both eves from side to side). spiral twisting of the spinal column or at least of the neck region, curvature of the spine with concavity to the right, tonic extension of the fore leg and at times of the hind leg on the same side.

When these effects have passed off. we observe again, as the permanent effects. the complex of symptoms described as asthenia, atonia and astasia. The muscles of the operated side are the ones chiefly affected, and the disturbance is so great that for more than a month animals can neither stand up nor walk without support. Later compensation develops so that the equilibrium is preserved both in walking and in swimming. And yet for some months after the operation numerous effects due directly to the absence of the part removed are clearly perceptible.

In man many cases of rather extensive destruction of the cerebellum have been described in which no permanent effects were to be observed. This agrees very well with the obserration made on animals, that one part of the cerehellum can take over the work of another part removed.

When the defect is more extensive the most prominent symptoms are similar to those observed in animal experiments, namely, incoördination of locomotor movements; such as: msteadiness of gait, loss of equilihrium. swaying movements, etc. In light cases the patient may manage to stand, with the legs wide apart, quite steadily, lut in severe cases the body sways in spite of strong abduction. With the feet and legs close together, flexor and extensor movements of the metatarsi and of the toes are kept up, the whole body swaying to and fro until the patient may lose his balance entirely and fall over. When he walks he keeps his legs wide apart and his toes first flexed and then extended; sometimes he walks on his heels, sometimes tips forward on his tnes; he sometimes bends his knees, sometimes presses them far back or keeps them straight; the feet are only slightly lifted from the ground; the body totters and reels from one side to the other-in short, the patient walks like a drunken person and not infrequently falls to the ground. In some cases the patient cannot eren walk with support, whereas lying on his back he can move his legs perfectly and can tell exactly, without looking, where a leg iscan in fact place one leg in a position exactly like that in which the other has been placed for him; hence his motor sense is not impaired. In many cases the anterior extremities are entirely unaffected, so that the patient can make the most precise morements with his hands.

Another very frequent symptom in diseases of the cerebellun is vertigo, which however may be entirely wanting when the incoördination is very 
marked, or may be present when there is no derangement of the morements. These two symptoms are therefore entirely independent of each other. Vertigo is distinguished by its great intensity and is almost continuously permanent. Sometimes it is present while the patient is lying down, but as a rule only when he sits up. Sometimes it seems to the patient as if the oljects all about him were moving, but as a rule he imagines himself to be moring, that everything supporting him has fallen away and that his body assumes all sorts of impossible positions.

When we liave added that the patient often suffers pain in the head, which is commonly localized just above the neck on the same side, we have enumerated all the symptoms of a cerebellar lesion, so far as it is recognizable at all by exterual symptoms.

Individuals suffering from extensive or complete congenital defect of the cerebellum are observed to be considerably defective in intelligence also. But we cannot conclude from this that the cerebellum is of any direct significance as the seat of the psychical activities, for it is almost self-evident that the causes which operate to inhibit development of the cerebellum would have an inhibiting influence on other parts of the brain. Besides, we find in the literature cases of very extensive destruction of the cerebellum not accompanied by any noticeable effect on the intelligence.

From these experimental and clinical results Luciani concludes that the cerebellum both histolngieally and physiologically is a bilateral organ, but that its influence is rather direct than crossed; whereas the influence of the cerebrum, also a bilateral organ, is mainly crossed. While the influence of the cerebellum howerer is not limited to the muscles active in locomotion. but extends to the entire voluntary musculature, its chief influence is over the muscles of the posterior extremities and the extensor muscles of the spinal columm.

In general all regions of the cerebellum would, in Luciani's view, appear to have the same function, so that the permanent effects of removal of the different parts would differ not in kind, but merely in extent, duration and intensity, and also as to predominance on the one side of the body or the other. The cerebellum therefore would not be a collection of several functionally different parts, each having a direct relation to a special group of muscles; but on the contrary a functionally homogenous organ, the different parts of which have the same general purpose as the whole and are mutually replaceable so long as their natural connections are not disturbed.

This conception cannot at present be so definitely maintained, for we have some olservations which show pretty positively the presence of a functional localization in individual lobes of the cerebellum. Thus Thomas observes that destruction of the rermis disturbs more especially the movements of the posterior extremities: and, according to $v$. Rinnleck, destruction of the mildde half of the vermis affects the neck muscles, while sharply cireumscribed destruction of that part of the hemisphere just lateral to this middle region affects the movements of the anterior extremity $(\operatorname{dog})$.

Impulses are eonveyed to the cerebellum by many different pathways (Fig. 2i1). We shall consider first of all those which connect with the restibular nerve and those traversing the lateral cerebellar tract of the cord (cf. Fig. 264 
and page 593). because the anatomical relationships mark them as of special importance, and becanse we have such eridence also from physiological experiments.

As Stefani especially has pointed out, the symptoms following ablation of the cerebellum present in many respects a striking agreement with those

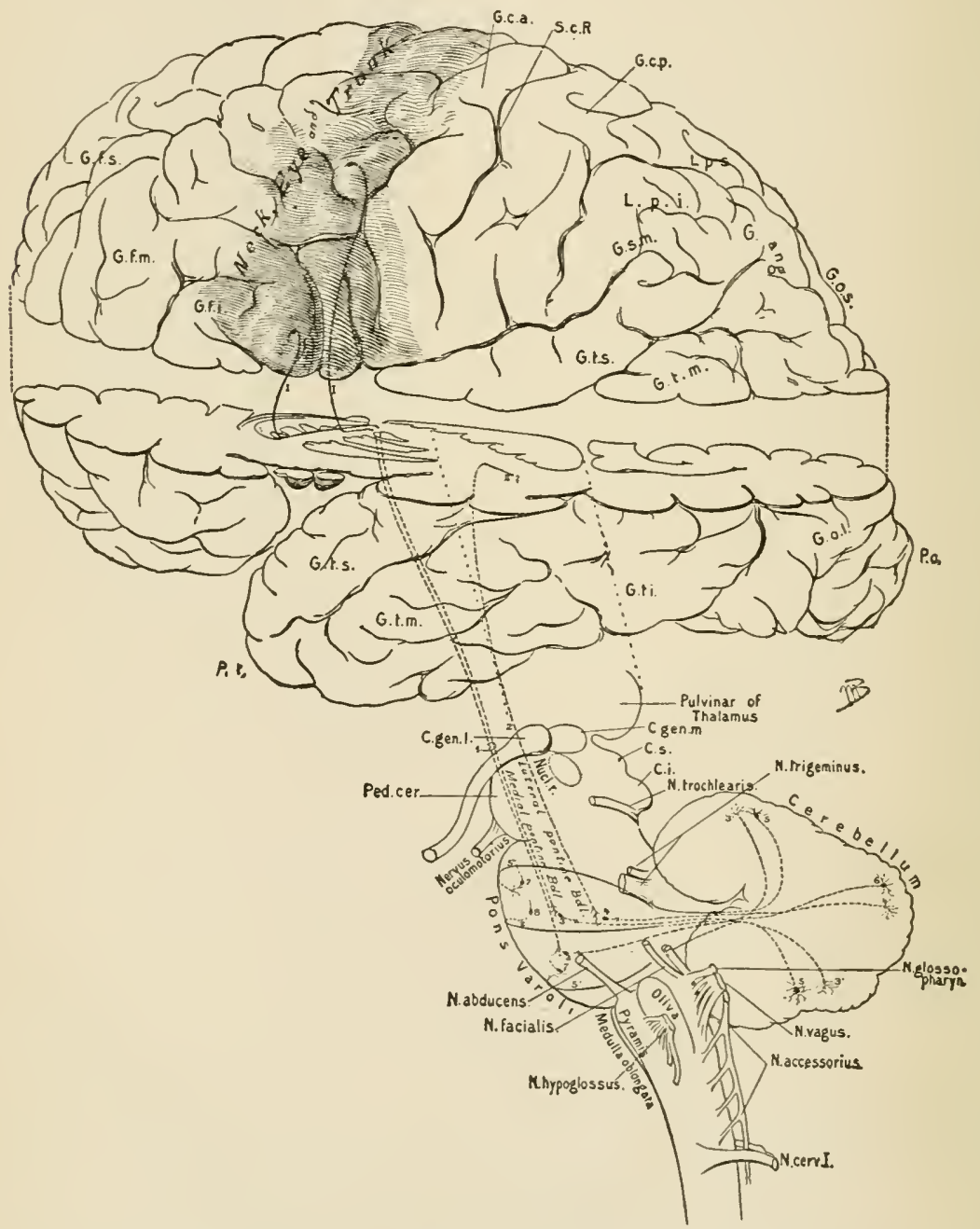

FIG. 271.-Diagram showing paths connecting the cerebellum and pons with the cerebrum, after Barker. I, fibers of frontal cerebro-cortico-pontal path clerived from pyramidal cells in the cortex of the frontal lobe. 1, Frontal cerebro-cortico-pontal path forming a medial bundle of white fibers on the ventral sicle of the superior peduncle; 2 , bundle of fibers connecting the temporal or temporal and occipital lobes with the cerebellum; 3 , cell body in the pons giving off a fiber to terminate in the opposite cerebellar hemisphere; 4 , cell borly connected with the temporal cerebro-cortico-pontal path giving off a fiber to the opposite hemisphere of the cerebellum; 5 and 6 , Purkinje cells in the cerebellar cortex giving off fibers to the nuclei pontis; 7 and 8 , cell bodies in the nuclei pontis sending fibers toward the cerebrum. 
which follow extirpation of the membranous labyrinth of the internal ear (cf. page $t_{i}(i)$, and the inference seems not too far drawn that the business of the cerebellum consists in part in the physiological elaboration of impulses contributed to it by the restibular nerre.

In so saying we do not wish to assert that the labrrinth acts exclusirely on the cerebellum, or that the cerebellum receises impulses only from the labyrinth, for other observations make such a riew quite untenable.

Recently Marburg has cut the lateral cerebellar tract in the cord of a dog at the level of the second cervical segment. After a bilateral operation. swaying morements appeared both in walking and in standing. the legs mere placed and held in abnormal positions, the pelvis was abnormally inclined and the spine abnormally curved. Toluntary morements, tonus of the muscles, sensibility of the skin and the general strength of the animal appeared to be unaffected.

These disorders are doubtless due to the absence of certain afferent impulses eoming from the locomotor organs, and the idea of Lussana, recently taken up and developed by Lewandowsty, that the symptoms following injuries to the cerebellum are really to be interpreted as a derangement of the muscular sense, might not be so far amiss as Luciani supposes.

No claim is made that the cercbellum constitutes the only center of the muscular sense, nor is there anything to prove that the conscious processes depend upon it, for plenty of other facts show with perfect clearness that the sensations of motion and position are present after the cerebellum has been remored, also that they are profoundly influenced by destruction of certain parts of the cerebral cortex when the cerebellum is uninjured.

The impulses brought to the cerebellum by the abore-named pathways and by other fibers are elaborated in that organ by some process which, so far as we know. is independent of conscionsness. At any rate the fibers learing the cerehellum are the medium of some influence winch increases the potential energy (sthenic activity) of the neuromuseular mechanisms, and the degree of their tonus (tomic activity) during functional pauses. It also quickens the rhythm of the impulses while the mechanisms are active and causes these impulises to be so fused and regrulated that they erentuate in harmonious morements of the proper extent, intensity, etc. (static activity).

Against this formulation of the cerebellar functions, which Luciani makes in summing up the effects of extirpation, different objections hare been urger by certain authors, who wish to regard the cerebellum as the seat of the muscular sense, the organ for the maintenance of equilibrium, or for the coïrdination of certain muscular morements. Since these views are not out of harmony with the facts, it seems to the author that they are not inconsistent with Lueianis position, but that they diffor from his view rather in the mole of expression than on fumdamental grounds.

Thomas, who has attempted to analyze the regulating influenee of the eerebellum still more closely, gives, among others, the following example of its action. When the fore foot is lifterl voluntarily from the rrouml. the impulse from the motor cortex of the eerebrum extends not only to the neessary museles, but by a special pathway it excites also the cerebellum on send out impulses which increase the tonus of the adductor and trunk muscles of the same side. But 
this increase of tonus would be of no use if the point of insertion of these muscles were not fixed, hence there nust be also an increase in the tonus of the trunk museles on the opposite side. The cerebellum exereises this regulating influenee by means of the various pathways proceeding from it to the motor nuelei in the spinal cord and to the motor cortex in the cerebrum (cf. Fig. 271).

It is likely that the compensution which gradually appears after extensive injury to the cerebellum is the work of the cerebrum. particularly of the motor regions (cf. Chapter XXIT). The following observations by Lueiani speak for such an explanation:

Three operations were performed on the same dog: in the first the right half of the cerebellum was removed; in the sceond the motor regions of the cortex were destroyed in both cerebral hemisplieres; and in the third the remainder of the cerebellum was taken away. The animal remained alive for eleven months after the operation and was then killed. During these cleven months he could neither hold himself up nor walk without support. In none of the animals obserted by Luciani in which the eerebellum alone was destroyed, did anything like this necur. The difference was due, as Luciani observes, not to the mere extirpation of the cerebral eortex, for this operation of itself produces only transitory symptoms. It appears rather that destruction of the motor cortex remored just those conditions which made it possible for the animal without a cerebellum to find the necessary compensatory movements. It is especially worthy of remark that swimming movements, which do not require to be coürdinated so finely as walking movements, could be performed by this animal perfeetly well.

The motor disturbances which appear immediately after the operation on the cerebellum. the peduncles, or the pons are partieularly serere and should be given special mention. The animal sometimes gets into certain attitudes called foreed positions, which it seems mable to get out of. returning inevitably to the same posture every time it is compelled to take another; or it performs what are called forced movements. rolling over and over around the long axis of the londy, or rumning around in a eirele like a eireus animal, or describing cranklike movements around its anterior end as a pirot-in all of thesc being quite unable 10 prevent the movement, or. to put it differently, apparently striving all the while for a state of equilibrium which it is unable to find.

The motor disturbanees appearing after unilateral cxlirpation of the cerebellum at their periofl of greatest intensity are: agitation, restlessness, oftimes whining or groaning, curvature of the spine with enneavity toward the operated side, accompanied by tonie extension of the anterior extremity of the same side and spasmodic movements of the three other extremities: spiral rotation of the head and neck toward the sound side accompanied by strabismus and nystagmus of one side, and often by deviation of the eye on the operated side inward and downward, of the other eye outward and upward; a tendeney to roll over about the long axis of the body in the direction of the twisting and of the strabismus-i. e.. as seen from the back of the animal, from the sound toward the injured side.

Thether these phenomena are caused by the excessive irritation on the cut side, or by the predominance of the sound side over the injured one. 
cannot be decided at present. Lueiani, who formerly regarded the morements as the effect of orerstimulation on the peripheral stump of the peduncle left by the wound, no longer expresses himself so positively.

\section{\$ 4. THE MESENCEPHALON OR MIDBRAIN}

The upper part of the midbrain is composed of the corpora quadrigemina and the pineal body, which is now regarded as a remmant of an ancestral eye; the lower part consists of the crura cerebri. Both parts stand in intimate relation to the visual organ, the former constituting a relay station in the optic nerve, the latter containing nuclei for the most important intrinsic and extrinsic museles of the eve. In addition the midbrain, like all other dirisions of the brain except the cerebellum, is a conducting pathway.

\section{A. THE CORPORA QUADRIGEMINA}

When the optic lobes, which, in the lower vertebrates, correspond to the corpora quadrigemina of the higher, are removed from fishes (Steiner), or from the frog (Bechterew), the one prominent symptom is blindness. According to Flourens the same thing is true in birds; but from more recent investigations it appears that after unilateral destruction the power of vision in the opposite eye is only reduced, not totally destroyed (Stefani).

In dogs Bechterew found after destruction of one anterior body that the homolateral halves of the two retine became blind, although the defeet in the opposite eye was the more extensive. By more complete removal of both anterior bodies almost total blindness was produced. The reaction of the pupil to light, however, was very little affected, which is the case also after the same operation in birls.

Destruction of one posterior body produced disturbances to vision in the median part of the opposite retina.

In view of these observations, that in the mammals as well as in the lower vertebrates the corpora quadrigemina are included in the optie tract, it is the more remarkable that in men suffering from disease of the anterior bodies no considerable derangement of vision has with certainty been established. Suppression of one entire anterior quadrigeminal body occasions only a moderate reduction of the visual power and leares the color sense quite intact. Likewise in the monkey. destruetion of the anterior bodies produces no demonstrable eflect on vision (Bernheimer).

Since now we know from anatomical disenreries that in both men and monkeys the anterior body receives fibers from the optie nerve of the same and of the opposite sides, and gives otf filers which can be followed to the visual area of the cortex, we conclute. supposing the olservations just mentioned to be correct, that the bundle of fibers running between the visual area and the anterior quadrigeminal body is of no direct importance for the act of rision. There is evidenes that this tract is enneerned rather with certain motor impulses discharged from the visual area. such for example as the influence of risual impressions upon the movements of the eye and of the body. 
Besides, it is rery probable that the optic-nerve fibers entering the anterior corpora yuadrigemina play a considerable part in the reflex excitation of the nuclei of the eye muscles located along the floor of the aqueduct of Sylvius. The fact that in the monkey, at least. these fibers end in large numbers under and about the aqueduct, and the results of electrical stimulation both favor this riew. By stimulating the anterior body of the dog. Adamuk obtained the following movements of the eyes: stimulating on the right side of one body, morement of both eyes to the left; stimulating in the midline, parallel morement of both eyes directly upward; stimulating the posterior side, simultaneous morements downward and inward. Novements of the iris were also observed. After a sagittal section in the median plane, only the eve on the same side was moved. Ferrier has made observations similar to these on the monkey.

Some clinical observations indicate that the posterior corpora quadrigemina are concerned in the propagation of auditory impressions, the hearing in the opposite ear being affected in cases where this part is diseased. Bechterew and Flechsig assert, in agreement with this view, that the ganglion of the posterior body receives fihers by way of the lateral fillet, from the cochlear nerve, and v. Nonakow has shown that the internal geniculate body is abundantly connected with the posterior quadrigeminal body and sends fibers to the cortex of the temporal lobe. The statements that stimulation of the posterior body in dogs and monkeys erokes a cry from the animal, and that production of roice is stopped by section of that body, lend some weight also.

\section{B. THE CRURA CEREBRI}

The crura cerel,ri. or more correctly the gray matter which forms the wall of the aqueduct of Sylvius. is of special interest mainly because the nuclei of the oculo motor and trochlear nerves are found there.

Fig. 272 represents in a frontal section the nuclei of the oculo motor as made out by Bernheimer. It is evident that this uucleus consists of several parts. namely, a lateral chief nucleus, a median nucleus with small eells (Ke $V I$ ) and an unpaired median nucleus with large cells $(G r M k)$. It is evident from the figure also that the nerve roots connected with the nucleus are in part crossed.

By successive and complete remoral of the extrinsie and intrinsic eye muscles innervated by the oculo motor, and by a study of the resulting changes in the nucleus, Bernheimer has reached the following conclusions with regard to the function of its different parts (Fig. 273): The extrinsic muscles are imnervated by the lateral chief nucleus, but its cells are not grouped into sharply divided individual nuclei. The small-celled median nuclei (Ke $M$, Fig. 272) supply the intrinsic museles of the homolateral eve, and the large-celled median nueleus ( $G r . M k$, Fig. 272) belongs to the intrinsic muscles of both eyes.

v. Monakow has made some clinical olservations as to the relations of these parts in man. but at present the only conclusions that can be drawn are that the intrinsic muscles (ciliary muscle and the muscles of the iris) are represented in the extreme anterior end of the nucleus, and the extrinsic muscles in the remaining divisions. 
Before this Hensen and Tölckers had observed. in substantial agreement with the findings of $r$. Monakow. that stimulation at the posterior end of the floor of the third rentricle gave movements of accommodation, and at a

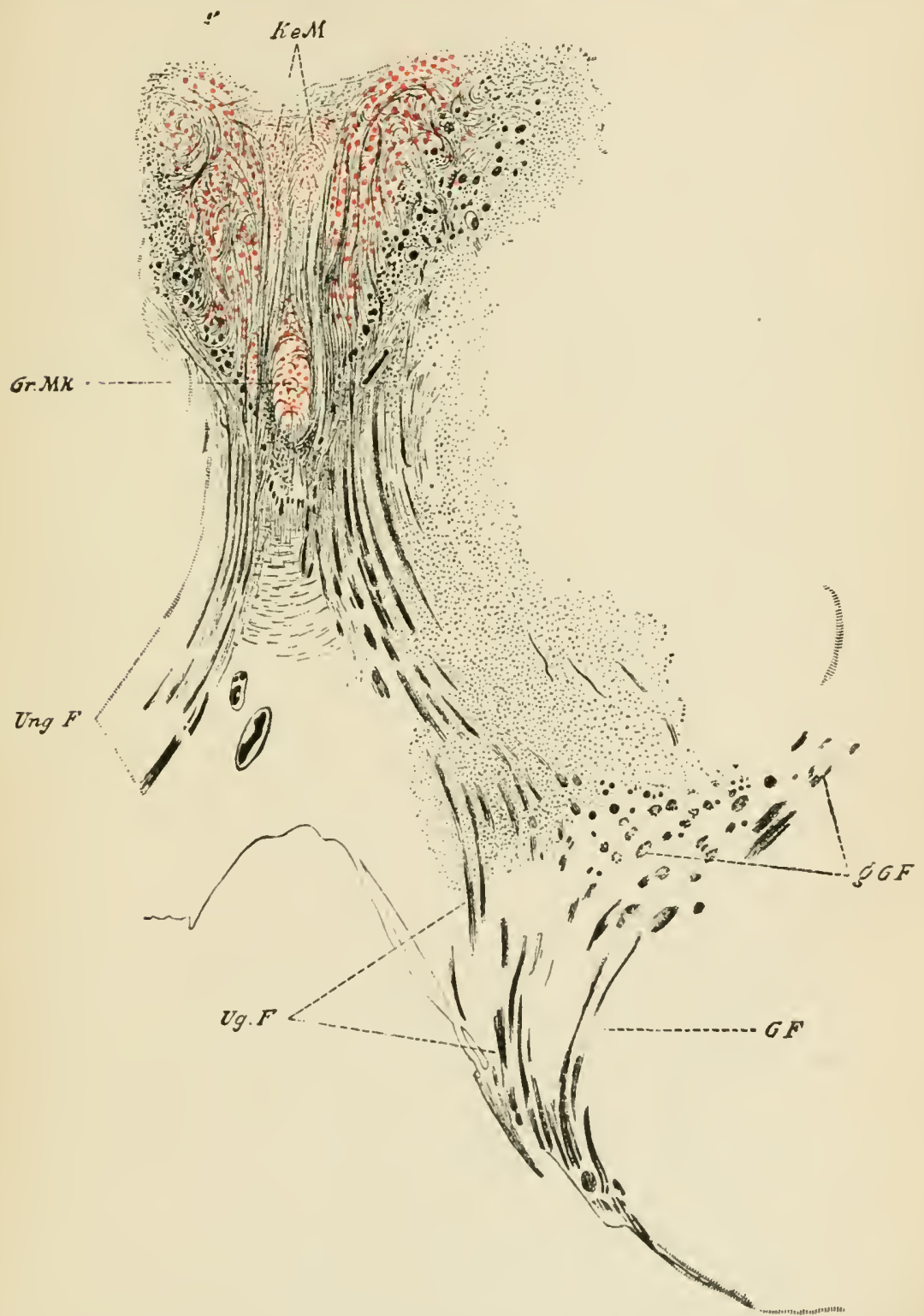

F1G. 272.-Frontal section through the anterior quadrigeminal hody of a $3: 2-34$ weeks' human fotus, after Bernheimer. The section passes through the lateral chief nuclets, the smatlcelled medial nuleus (KeM), the large-eelled median nucleus ( course of the medial and lateral fibers $\left(L^{\top} n y F\right.$, and $\left.L^{\top} g . F\right)$ of the third nerve, and the last bit of the extra-muelear course of the crossed lateral fibers $(G F)$. QGF, transierse sections of erossed fibers arising from behind and above. 
point somewhat farther back gare contraction of the pupil (cf. Fig. 230). Stimulation at the anterior border of the aqueduct of Sylvius gave contraction of the internal rectus. and stimulation somewhat farther back gave in serial order contraction of the superior rectus. levator palpebre superioris inferior rectus, and finally of the inferior oblique. When the stimulns was applied to the lateral surface or the deeper parts of the corpora quadrigemina, or to the cut surface of the transrerse section in the optic thalamus. the pupil became dilated.

Bernheimer emplored a similar method on monkevs. The two halres of the oculo motor nucleus were separated br a median sagittal section and weak

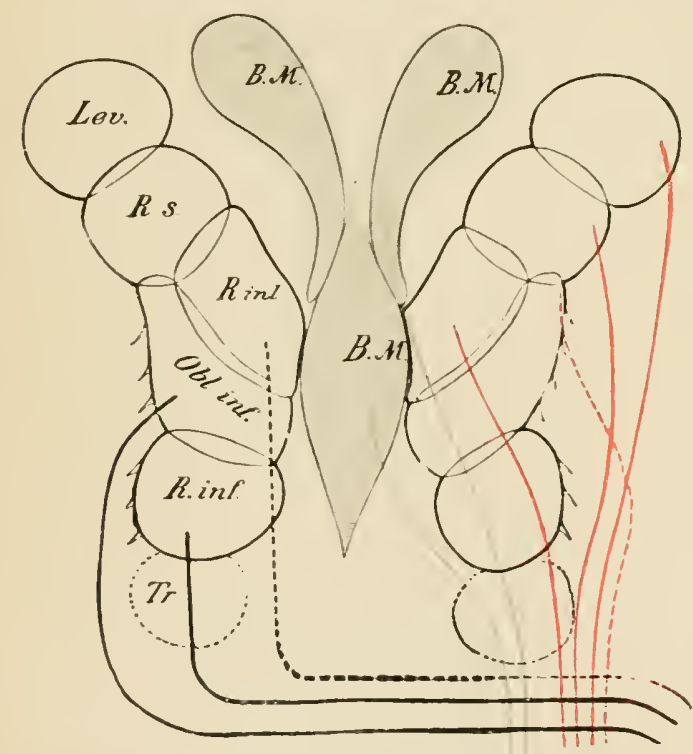

Fig. 273.-Scliematic representation of the nucleus of oculo motor nerves, after Bernheimer. The red lines indicate the direct, and the black the crossed root fibers. B..M., intrinsic muscles of the eye; Lev., levator palpebræ sup.; R.s., superior rectus; $R$.int., internal rectus; Obl.inf., inferior obliquus; $R . i n f$, inferior rectus; $T r$., superior oblique. movements cease when the paired nuclear region is split in two by a median sagittal section.

Complete division of the brain at the anterior end of the midbrain produce a remarkable state of inertnes in the muscles. which is described by Sherrington moler the name of acerebral rigidity. It is recognized by the fact that certain muscles become stiff: the elbows and knees. for example. are rigidly extended. the tail is inflexible. etc. This condition appears to be due to the influence of the afferent nerves from the regions affected. for the stiffness in the arm muscles, for example, entirely disappears after section of the posterior roots for the arm. 
Reflex stimulation of an animal in this condition produces certain coördinated movements which are ummistakably related to the morements of loenmotion. For example. the left anterior and the right posterior extremities beene Hexed, while the right anterior and the left posterior are extended at the same time, and rice rersa. Not infrequently these reflexes alternate, begimning regularly with flexion of the extremity directly stimulated. At the same time the head and neck are twisted toward the stimulated side; the month is opened, the lips and the tongue are retracted, the eyelids opened, the pupil is dilated; the animal utters cries or groans, etc. These reactions, which when the cerebrum is intact usually accompany painful sensations, sometimes appear singly, sometimes in certain combinations.

Rigidity of the triceps muscle can be intermitted by stimulation of the white matter between the anterior and the lateral columns or by stimulation of certain peripheral nerves of the posterior extremity. The effect is felt ehiefly on the homolateral side, but to a less extent on the heterolateral side also.

\section{5. THE DIENCEPHALON OR 'TWEENBRAIN}

The many connections of the twreenbrain with the gray matter of the cerebrum on the one hand and with the afferent nerve tracts on the other speak in most eloquent terms for the great physiological importance of this division of the brain. In fact, all the tracts in which we should expect to find prolongations of the posterior root fibers (the main part of the fillet layer, the superior peduncle of the cerebellum, the longitudinal bundle of the formatio reticularis), and the fibers of the optic tract-all enter the tweenbrain. from which in turn they are continued to the cerebral cortex. The latter also sends out fibers to the "tweenbrain, from which further efferent tracts are given off (Fleehsig).

It is possible that the external geniculate body is the point of origin of the efferent optic fibers, and that the reflexes discharged by optic stimuli are here earried over to them.

The experimental and elinical observations on the tweenbrain are not of such a kind as to give us eren a crude notion of its actual physiological purpose in the normal brain. We ean only say that it appears from clinieal observations and from the anatomical facts that the different nuclei in this portion of the brain have different functions. and that as a result we have here a fairly sharp localization of different paths and their ennections. Hence when the optic thalamus contains a sharply circumseribed lesion. certain aflerent impulses are wanting. and for this reason. as r. Nonakow observes, many eomplicated movements are deficient ; many nthers are abnormzlly performed, certain components heing overstimulated, certain others inhilited.

On the other hand the conditions appear to be very farorahle for substitution of functions in the optic thalamus, so that when lesions are not too extensive the eflects are only temporary or may be entirely wanting. This is probably to he explained in part by a bilateral influence of the thalami in which the commissura mollis connecting them together assumes a certain significance. 


\section{\$ 6. FUNCTIONS OF THE BRAIN-STEM AS A WHOLE}

While it is not possible as yet to name the exact functions of the separate centers in the corpora quadrigemina, the optic thalami and certain other parts of the brain-stem, we have some observations on decerebrated animals which should afford us some light as to the functions of the hindbrain, "tweenbrain and midbrain taken together. What the central nervous system is capable of without the cerebrum, considered in connection with the functions remaining after remoral of all the parts anterior to the medulla, should give us a general idea of the total powers of the brain-stem.

The lowest vertebrate, Amphioxus, has no true encephalon: its brain consists only of a slight enlargement at the anterior end of the spinal cord. Anteriorly and laterally this enlargement embraces a ventricle which is continuous posteriorly with the central canal of the spinal cord. This "brain" contains internally a ganglionic mass and externally a mass of nerve fibers. The former consists mainly of multipolar cells, whose fibers pass orer into the fibers of the outer layer running longitudinally of the animal.

Steiner divided this "fish" into two pieces, a head and a tail piece. After some minutes both parts responded to mechanical stimulation by making perfectly regular locomotor movements, at the same time preserving equilibrium and swimming with the anterior end of the piece forward. They fell over on their broad

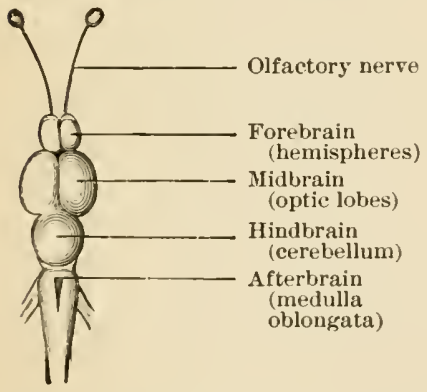

Fig. 274.-The brain of Squalius cephalus, a bony fish, after Steiner. side however as soon as the movement ceased. The animals could even be cut into three or four pieces, and under the circumstanees named each part could still make locomotor movements. Steiner's conclusion is that the body of Amphioxus consists of perfectly equivalent metameres and has in general no motor center.

Danilewsky obtained results of very different purport. After division of the animal into an anterior and a posterior half, he noticed in the piece containing the brain oceasional "voluntary" movements apparently independent of any external stimulus; while the posterior half remained perfectly motionless. $\mathrm{By}$ artificial

stimulation movements eould be obtained in the anterior half more easily than in the posterior. They continued for from fifteen to thirty seconds after stimulation and consisted of a series of bending and stretching movements.

When the head was cut off, the above-mentioned voluntary movements eeased. The animal then lay for one to two days without spontaneously changing its position in any wise, when care was taken to remove all external stimuli. The reflex movements to artificial stimuli were perfectly normal, but were not abundant, and the irritability of the headless animal was considerably less than that of the isolated anterior half.

Danilewsky concludes from these and other observations that the so-called brain of the Amphioxus contains the centers for voluntary motions: destruction or separation of these from the rest of the eerebral nervous system results in loss of motility, providing no external stimulus of sufficient strength acts upon the animal. 
In the true fishes the cerebrum is but slightly developed, and in the lampreys and bony fishes the cortex consists of only a simple layer of epithelial cells.

After extirpation of the cerebrum from a bony fish (Squalius cephalus, Fig. 274) the animal moves exactly like a normal animal, and, according to Steiner, it is quite impossible to discover anything anomalous in its movements. When an earthworm is thrown to the fish, it makes a rush for the booty, seizes it while it is still falling and devours it. A cord of about the same dimensions thrown into the water may or may not be seized, but is never caten. A decercbrated fish may be even fastidious about its food; spurning fish worms but taking crumbs of bread from the surface of the water. When one red wafer and four white ones are thrown to it, the fish regularly chooses first the red and then the white ones. It does not move to take the food from the observer's hand, but will take it from a long string. Finally, the decerebrated fish will exchange caresses with its uninjured companions. From these observations we may conclude that suppression of the cerebrum in this genus is of no particular consequence-that to judge from the beharior of the animal after the operation, the parts remaining are sufficient for the discharge of all the eentral functions.

We have no experiments which

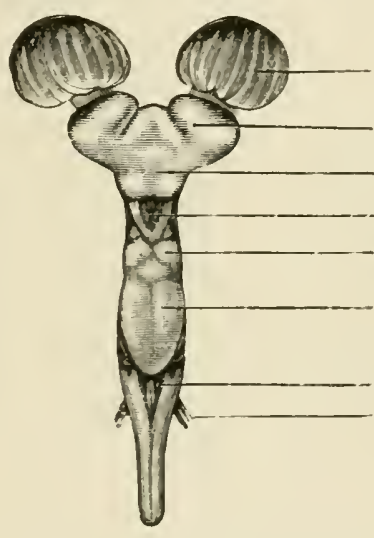

Nasal capsules

Olfactory bulb

Forebrain

(bemispheres)

Tweenbrain

Midarain (optic lobes)

Hindbrain (cerebellum)

Afterbrain

(medulla oblongata)

Vagus nerve

FIG. 275.-The brain of Scyllium canicula, a dogshark, after steiner. give us any clew as to the importance of the 'tweenbrain in the bony fish. But Steiner has reported some in which he removed both the midbrain and the 'twcenbrain along with the cerebrum. Following this operation the animal would lie entirely motionless on its side or on its back, with the fins hanging perfectly limp. Hence we can say that the higher functions of the central nervous sistem are dependent upon the 'tweenbrain and the midbrain, but just what share each one takes we do not yet know.

The selanchians also (dog shark, Scyllium canicula, Fig. 275) withstand removal of the cerebrum without suppression of their movements. After a few rounds about the tank the animal lies quietly on the bottom of the tank for many hours or even days at a time. Steiner having scarcely ever seen one in motion when it was not excited by some external stimulus. Besides, the animal does not spontaneously take food, but its inability to do so is not the result of loss of the cerebrum iself. but is rather due to the functional loss of its olfactory lobes. ${ }^{2}$ which of course is a necessary consequence of the operation. Careful investigation of the normal dogfish confirms this indication that it seeks food entirely by the sense of smell.

Simultaneous removal of both the 'tweenbrain and the cerebrum likewise produces only insignificant effects. Since this operation involves destruction of the optic nerves, such animals are of course blind: and yet thes can swim in a perfectly normal manner. One observes, however, that after some time, which appears to be shorter after removal of the forcbrain alone, the animal elings to

'The olfactory lobe consists of the olfactory bulb and the olfactory tract.-ED. 
some corner or wall and, at least so far as observed, never leaves its retreat except when disturbed.

After removal of the forebrain, 'tweenbrain and hindbrain the dogfish never spontaneously makes any movements. Roused artificially, its movements are effective and perfectly regular, and. so long as it doss not leave the normal plane with reference to the direction of gravity, it keeps its balance properly. But let. it once get out of the normal position in the water, and its equilibrium is easily

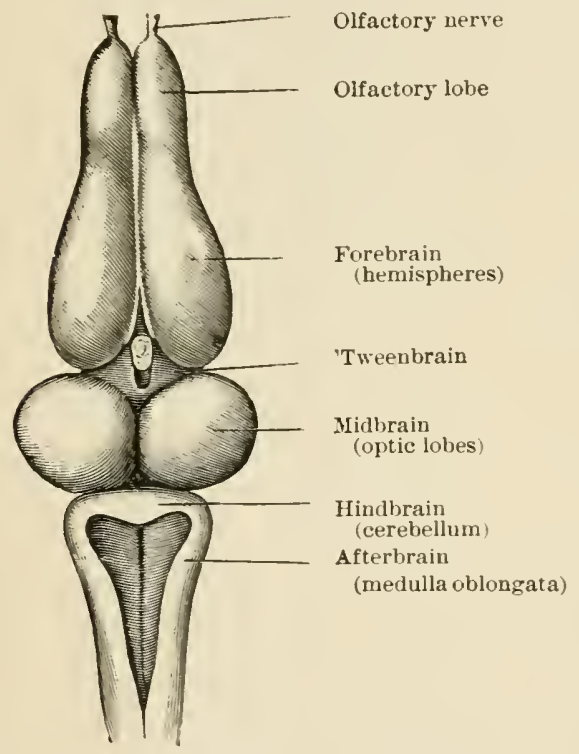

FIG. 276.-The brain of a frog, after Steiner. lost. It may even come to rest lying on its back. When the animal is suddenly and foreibly placed on its back it makes very evident efforts to regain its normal position, but does not always suefeed.

Hence in the dogfish also the so-called spontaneous morements and the finer coürdination of morements appear to be bound up with the 'tweenbrain and the midbrain. The lower parts of the brain, however, are alone sufficient to earry out fairly well coördinated movements started by artificial means.

Schrader also removed the cerebrum from frogs (Fig. 276) without injuring the 'tweenbrain. There was no noticeable effect: the frogs moved about "spontaneously" from one place to another, they swam like perfectly normal animals; at the approach of cold weather they burrowed into the mud or under stones; or, passing the winter in the open, they adapted themselves to external conditions and with the same results as did their normal companions. At the end of the hibernating season, or in summer some months after the wound was perfectly healed, the animals operated upon, just like the normal ones, caught all the flies in the cage, and so on.

But when the 'tweenbrain was injured along with the cerebrum, the same condition appeared as had formerly been described by Goltz as the consequence of removing the cerebrum alone. There were no motor effects strictly speaking, but the animals had lost all their spontaneity. When a frog in this condition was not roused by some external stimulus, it would sit perfectly still, until it dried up to a mummy; it never tried to catch flies, no difference how many were in the eage-it starred to death in the midst of plenty, unless it was artificially fed. Its movements were just like those of a normal frog except that thes were perfectly machinelike-a given stimulus always giving the same response. Since the optic nerves were left uninjured by the operation, the animal was influenced by visual impressions, aroiding obstacles by going round them or jumping over them. When it was lowered into and under the water very gradually. by means of a mechanism driven by a screw, the stimulus of the change of medium was not sufficient to cause the frog to move. It simply remained suspended in the water at a depth determined only by the amount of air in the lungs. 
We may conclude that in fishes and frogs the central nervous system up to and including the "tweenbrain is sufficient to regulate all the animal's functions (with the exception. of course, of those directed by the sense of smell) just as in the normal animal. Noticeable changes are produced in the behavior of the dogfish after removal of the tweenbrain and the midbrain, in the frog only after injury to the tweenbrain.

After taking out the cerebrum of a lizard (Fig. 27\%). Steiner observed no other result than loss of spontaneous ingestion of food and of roluntary movements. When stimulated the animal moved in a perfectly normal manner. avoided obstacles, climbed up the wall of the cage, exhibited no disturbance of the muscular sense, ete. On the other hand it would no longer try to eseape when threat'ned. Likewise, when the cerebrum and the tweenbrain both are removed, the lizard ean still make perfectly normal movements including leaps of large size. It appears, however, to become quieseent sooner and its movements in climbing seem less aceurately regulated than in the animal with the 'tweenbrain intact.

The turtle without a cerebrum differs only a little from the nomal animal. It makes spoutaneous movements, reacts like a normal animal to light rays and is able to estimate visual impressions properly for its own advantage. It is uncertain, however, whether such an animal takes food spontaneously. One such animal, it was observed, left tadpoles placed in its eage untonched for as long as three days. Since, however, an animal whose olfactory nerves only were ent did the same thing, it is possible that here as with the dogfish the determining factor is the sense of smell.

In extirpating the "tweenbrain from the turtle, it is necessary to destroy the optic nerves: hence the result of the operation is blindness. Nevertheless the animal is able to orient itself in space excellentlr, and, although it seldom does so, to move spontaneously. Some slight abnormalities also are exhibited in its gait and in the manner of its carriage.

Finally, when the midbrain in addition to the cerebrum and tweenbrain are re-

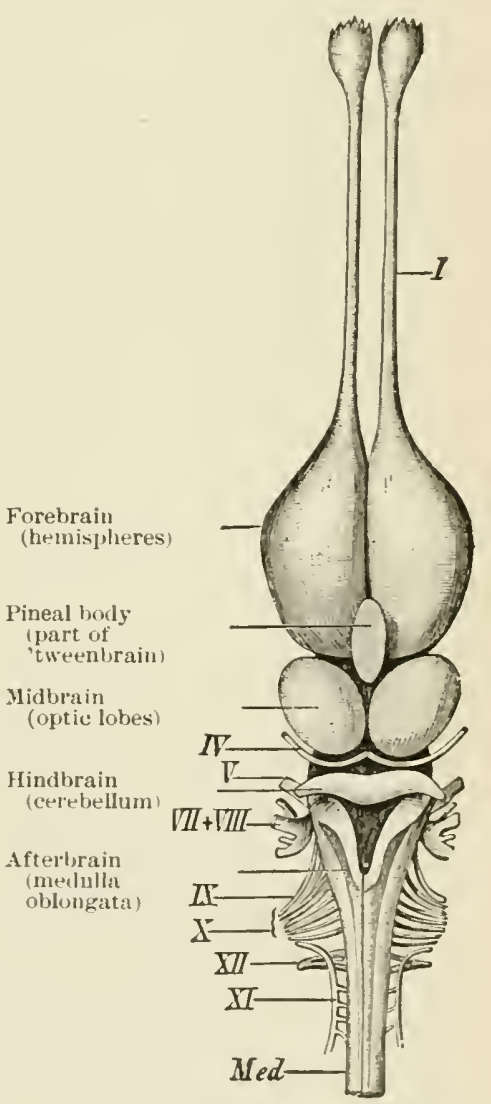

Fig. 27T.-The brain of a lizard (Hatteria punctata), after Wiedersheim. The eranial nerves are indicated by Roman mumerals. moverl. a remarkable phenomenon, first observed by Fano, ensues-namely, an montrollable impulse to move about (ef. the similar behavior of the frog, page 604). The animal creeps incessantly in an aimless way goes back and forth from lant to water and from water to land apparently without erer finding a comfortable place. There are, however, ummistakable abnormalities in its move- 
ments: in walking the limbs are lifted too high, extended too far and sometimes are set down too far to one side or the other; the result is that the earapace wabbles from side to side and strikes the floor first with one corner, then with the other.

The chief difference between the lizard and the turtle and the lower vertebrates after removal of the cerebrum, it would scem, is that they do not spontaneously take food, while the lizard also does not more at all spontane-

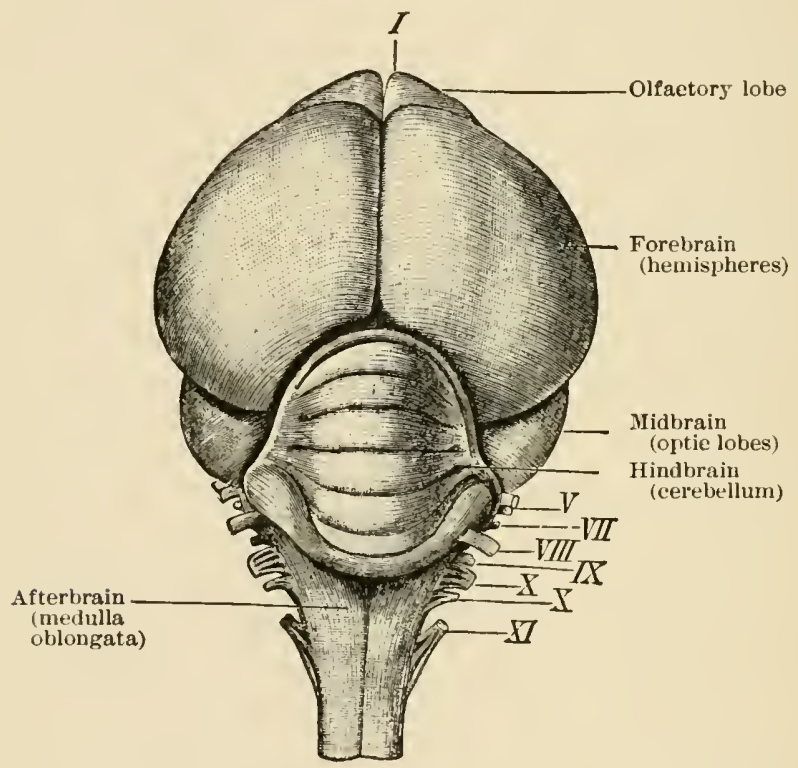

FIG. 278.-Brain of a pigeon, after Wiedersheim. The eranial nerves are numbered.

ously. It is likely therefore that the cerebrum is not of the same importance in animals of this grade as it is in the higher vertebrates such as birds and mammals. But even in the latter it can he demonstrated that the lower parts of the central nervous system ean maintain a high degree of activity.

Of the numerous observations on birds which have been made since the time of Rolando, we shall eite only those of Schrader on pigeons. 'These animals in Schrader's hands survived the operation of removing the eerebrum (Fig. 278) for four to five weeks and died then as the result of progressive general weakness which began about the fourth week.

During the first three or four days they remained in a sleepy condition, standing with feathers ruffed, head drawn in, eyes closed (and often on one leg), just where they were placed. Now and then they would shake themselves, smooth out their feathers with the beak, streteh themselves as if drowsy and, if desiring to defecate, would take a few steps. When thrown up into the air, they made flying movements but eame obliquely downward, striking the wall or other obstacles and rather falling to the floor than reaching it by "lighting"; then they once more sank into a stupor. In short, the animals appeared bereft of all initiative, and one would be inclined to declare them blind and deaf and to doubt 
whether even the sense of touch were intact. But if they eame through the first few days, they presented quite a different pieture.

They now began to wander about and to keep up a tireless march about the cage. The eadence was a moderately quiek step, but frequently as the movement went on it increased in frequency until it beeame a run, which then tapered off to the usual cadence again, or was sometimes suddenly interupted and the animal settled down to sleep. It appears that these restless movements were not the result of any abnormal state of excitation, for the same animals which wandered about tirelessly all day spent the night quietly in one spot.

These movements from the first are controlled by sight, for the animal always avoifls ohstactes about the same as a normal pigeon. They are also regulaterl by the sonse of touch and any temporary disturbance of the equilibrium is regularly compensated by the proper motions.

Only one reaction to auditory impressions was observed, namely that the pigenn drew back at the crack of a match. Tarious and sundry tones and noises were trierl but without any aprarent effect.

liut the movements of a decerebrated pigeon are readily interrupted by wher means: one las only to touch the animal lightly or to lift it and set it down again, ant it immerliately draws in the head, ruffles up its feathers and falls asleep.

By specially devised experiments it is possible to show that the pigeon is able to coürdinate its movements to a definite ent. When, for example. one

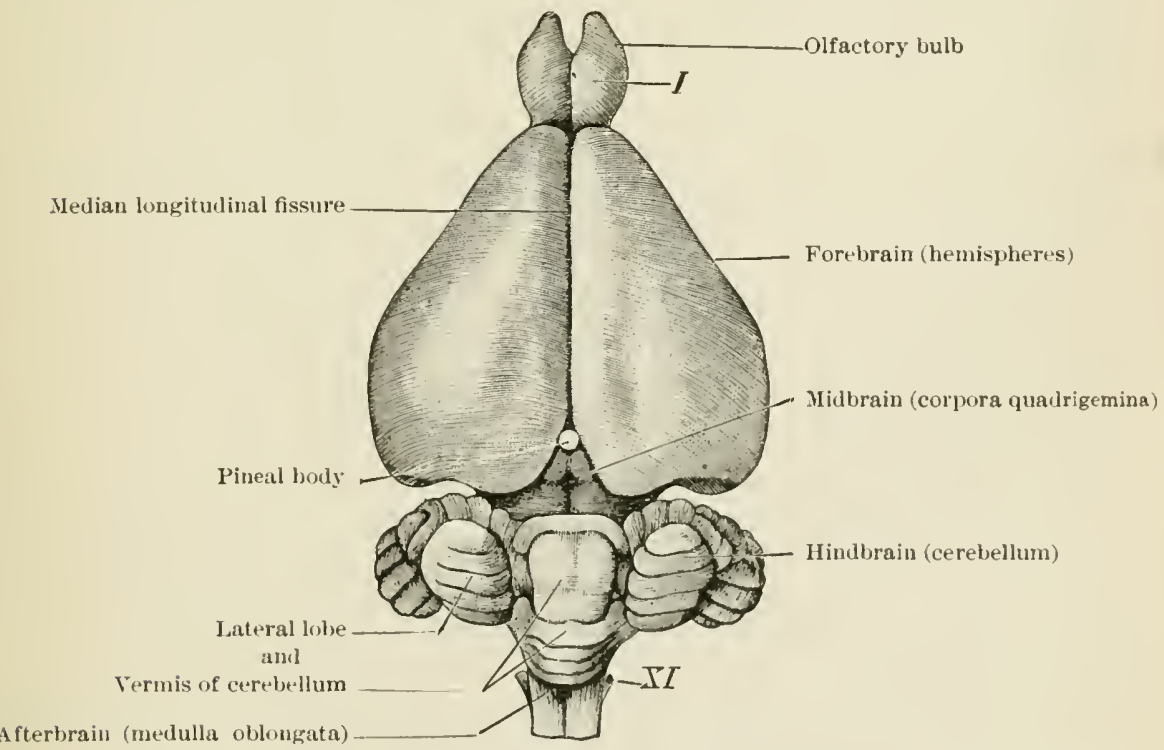

lig. 279.-Brain of rabbit, after Wielersheim.

was plaeed four or five feet from the flowr on a small flat surfaee and a perech was placerl one or tro yalds distant from it. the pigeon flew to the pereh and grasped it firmly with its feet. Moreover, when the pigenn was given a choiee between flying to the perch and flyiug to a table some yards farther away, it very deeidedly preferred the latter.

But it never flew up spontaneously from the floor. And it could not be aseertained positively that the decerebrated pigeon ate of its own aceord. 
Briefly stated, every action of the pigeon without a cerebrum gives the observer a peculiar but perfectly unmistakable impression of an automaton. Its actions are very diverse and very complicated, but under given eircumstances can be very definitely predicted with a high degree of certainty. The decerebrated bird moves therefore in a world of objects, the position in space, size, configuration of which determine the eharaeter of its morements, but which are otherwise entirely without meaning to the bird. One thing like another is a mere space-filling mass: it avoids or pushes aside another pigeon as it would a stone. 1 cat or a dog means no more than an inanimate object.

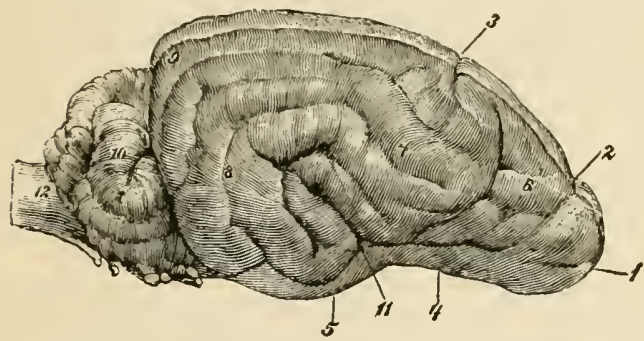

Fig. 280.-Lateral view of the dog's brain, showing the different lobes of the cerebrum, after Ellenberger and Baum. 1, Olfactory lobe; 2, boundary between the olfactory and frontal lobes; 3 , boundary between the frontal and parietal lobes (cruciate fissure); 4, olfactory tract; 5 , piriform lobe; 6 , frontal lobe; 7 , parietal lobe; 8 , temporal lobe; 9, occipital lobe; 10, cerebellum; 11, boundary between the parietal and temporal lobes (fissure of Sylvius); 12, medulla oblongata.

A decerebrated male coos like a normal male and exhibits evidence of sexual desire-but his affections are entirely objectless. It appears to be a matter of indifference to him whether a female is present or not. In the same way a female shows no interest in her young. If fullfledged, they follow the mother, screaming incessantly for food; but they might as well address their entreaties to a stone.

The functions left, however, are very important ones. To what extent they depend upon the 'tweenbrain cannot, for want of eritical attention to this point, be definitely stated. But from Schrader's observation that animals in which the optic thalami were injured extensively in removing the cerebrum stumbled over very slight obstacles and did not correct the positions of their limbs immediately when they were clisplaced, it seems probable that the "tweenlorain plays an important rôle in all these functions.

Among mammals we have observations on the complete removal of the cerebrum from rabbits and dogs (Figs. 2r9 and 280).

Aceording to Christiani, rabbits with the cerebrum removed sat immediately after the operation just as normal animals are eareful to sit, and when attempts were made to eateh them by the hind leg they ran. Spontaneous movements were also occasionally made. But when they were not disturbed in any way and were proteeted from powerful stimuli, they easily fell asleep. They woke from this sleep without being roused externally. They walked about for a long time but finally came to rest and went to sleep again. There was nothing abnormal in any of these movements: the animals avoided obstacles without tourhing them; they made stops in the midst of their wanderings; they climbed and sprang upon objects; etc.

The rabbit therefore can also regulate its movements quite normally without a cerebrum and can use its visual sense for this purpose. We have no 
more exact observations on their behavior, as the animals in these experiments were not observed for more than twelve hours after the operation.

It appears from Christiani's observations that this regulation is the work of the tweenbrain, for in rabbits deprived of this part, or in which it was extensively injured, the coördination necessary for locomotion and for maintaining the equilibrium in sitting and standing was entirely lost.

Wuch more significant than these observations are those of Goltz on a decerebrated dog which survived the operation for a long time. In this dog, whose history we shall now relate, not only was practically all the cerebrum destroyed, but the 'tweenbrain and to a large extent the corpora quadrigemina on the left side as well. The functions carried out by this $\log$ were therefore probably less extensive than would be possible if the cerebrum only were extirpated. Since this experiment is of the utmost importance for a proper eonception of the functions of the eentral nervous system, we shall report it somewhat extemsively.

The left hemisphere of this dog was removed in two operations on the 27th of June and the 2:3d of November, 1589, the entire right hemisplere was removed in one operation on the 17 th of June, 1590. The dog lived until Deember 31, 1591, when he was killed by bleeding, and was therefore under abservation for a year and a half after the last operation. Fig. $2 \$ 1$ is a pieture of the brain as it appearcel at autopsy.

On the third day after the last operation (June 20, 1890) the animal walked about the room without falling. From this time on his strength increased so rapidly that on the $22 \mathrm{~d}$ of July he easily elimbed up an inclined plane of twenty degrees. The ability to perform crude museular morements was therefore perfect.

After some months considerable disturbance in nutrition made its appearance, the hind parts becoming more and more emaciated. By feeding the animal heavily this progressive emaciation was finally overcome, but the eertainty of the dog's movements, which was su plain a feature for a few weeks after the operation, did not return. In spite of this until a few days before his death he was able to raise himself on his hiurl legs and to place his paws on the grating of his cage.

According to Goltz himself the cause of this emaciation lay partly in the fact that the animal

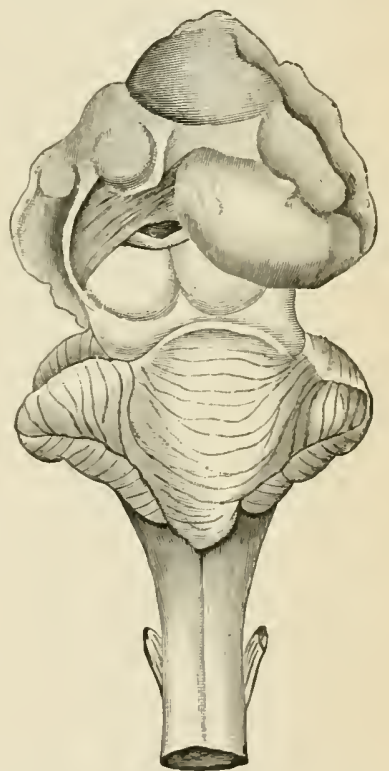

FIG. 281.-The remainder of the brain of Goltz's dog, after removal of the cerebral hemispheres. The medulla, pois, cerebellum and the roots of all the cranial nerves eonnected with the medulla and pons were perfectly normal. The eorpora quatrigemina were somewhat degenerated. All tlut was left of the erebral cortex was a sniall portion of the temporal lobe on cach side. continually mored about in his wage and that he never rested nor slept st) long as a normal animal. It is probable also that it was due to imperfect heat regulation, since the heat loss was greater than normal. At any rate it is stated that the skin was noticeably warm. Otherwise, judging by nothing nore than the fact that the animal livel so long, the heat recrulation must have been fairly good. When the dog stept, he enrled up as normal dogs do; in a wam room lie panted and stretched out his tongue; and in a cold room he shivered. 
Digestion went on normally: the tongue and the teeth were normally preserved; there was no foul odor from the mouth; the fieces were of normal color and comsistency. No observations were made as to the utilization of foulstuffs. The urine contained no proteid nor sugar. The animal (a male) gave no eridence of sexual heat.

The cruder movements, such as locomotion, were fairly normal and the gait on a rough fluor was tolerably good. On a smooth Hoor the animal slipped very easily, but recovered his feet without help. He never walked on the backs of his feet; and immediately straightened then when his toes were foreibly turnerl under.

Placed on a table with one foot over a trapdoor, the dog allowed the foot to follow the trap for a distance as it fell, but did not lose his equilibrium.

It happened onee that the $\operatorname{dog}$ had one hind paw injured. Tntil the paw was completely healed he hopped about on three legs, keeping the injured member voluntarily lifted from the floor.

Hence the bodily movements were regulated in many different ways. And ret his movements were not very precise, for when he was pinched he enuld not purposely reach the place. If for example he was pinehed on the left hind foot, he would snap to the left, but seldom caught the offender's hand.

The sense of touch was noticeably dull. When by means of a fine tube air was blown between the hairs on the back of his foot, he did not move; he was likewise insensitive to blasts on his nose. But certain parts of the skin, as for example, the interior of the ear, proved to be extremely sensitive. He responded promptly to stronger cutaneous stimuli and could be awakened from his sleep in this way. If while he was walking about he was pinched anywhere, he gave evidence of his displeasure br rarious expressions of the roice, or even snappel.

In order to test the sense of taste, Goltz made the following experiment. He placed some horse meat in each of two dishes. To the one he added milk, the other he covered with an extremely bitter solution of quinine. He fed the dog several pieces of the meat wet with milk, one after the other, by simply holding them close to his nose. They were seized, chewed and swallowerl. Suddenly he offered him a piece from the quinine dish. It also was seized and chewed once; then the dog made a wry face and spat it out.

The sense of smell was of course lost. It was only by stimulation of the branches of the trigeminal nerve that pungent odors had any effect on the animal.

Auditory sensations were very much blunted, although it was possible to rouse the animal from sleep by a purely auditory stimulus.

The sense of sight was practically lost. The pupils of both eyes contracter when light was thrown into them, and the eyes were elosed when a dazzlingly bright light from a bull's-eye lantern was thrown in the dog's face. In rare cases he turned his head to one side. That was all. Tle was unable with the aid of vision to avoid obstacles placed in his way: and the blank, idliotic expression of his eyes never changed in the least when threatening gestures were made or a strange dog was held so that the images must have been formed on the retina.

The animal's intelligence was very much reduced. He was so stupid that on the last day of his life he raised a howl when he was lifted out of the eage to be fed, just as he had done for months. IIe nerer gave any expression of joy and only showed displeasure when he was pinched or handled roughly. Once when he had gone without food for a longer time than usual, he made sounds indicating his impatience. Ile also ate more voraciously than usual. But when he had eaten his fill, he stopped and lay down to rest or to sleep.

He never learned to lick himself dry when he became wet, so that he shiv- 
ered much from cold at times. He likewise never tried to hold a bone with his fore paws.

In view of this it is the more remarkable that the animal again acquired the ability to eat and to drink. For a long time it was necessary to push the food far back in the animal's throat, for when it was merely laid on the front end of his tongue it was neither chewed nor swallowed. On the twenty-third day after the last operation it became unnecessary to push the food so deep into the mouth. It was seized by the tongue and carried back when placed pretty well forward in the mouth. Gradually the dog got better control of his jaws, and finally had made such progress that he could drink a large bowl of milk when his snout was held close in it, and could eat meat when the dish was placed so that his snout toucherl the fuod. The reason for touching the food will be apparent when we remember that the sense of smell was entirely lost and the sense of sight reduced to almost nothing.

The following experiment shows that the animal could do a rather more difficult task. A small blind alley was made by means of two boards placed endwise against the wall. When the $\operatorname{dog}$ was let into this alley, which was so narrow that loceould not turn round in it, he walked to the end and reached up on the wall, "trying" in vain to get out. Finally he began to walk backwarl, and after about twenty minutes managed to back all the way out, although the longth of the alley was only about twice the length of the animal.

It follows from these observations that a dog without his cerchrum is able to carry out all of the functions necessary to life, if only his food be placed immediately in front of his nose; that he is still able to perform locomotor movements satisfactorily; that these movements are influenced and regulated by the muscular and tactile senses: also that the sense of hearing and the scnse of sight, although in a very slight degree, can influence his movements. Finally. his behavior during hunger and after taking food teach us that the bodily desires are still "felt." The cerebrum we must conclude is not necessary for any of these functions, nor for passing from the sleeping to the waking endition and vice versa.

Flechsig was able to determine on a human monster, in which only the lower parts of the brain up to and including the posterior corpora quadrigemina were developed, that these findings for the dog apply at least in part to man. The child lived for a day and a half and during this time gave various signs of diseontent. It whimpered oceasionally and its whimperings became more vigorous and various movements of its limbs beeame more active when its skin was pinched.

The obscrvations here brought together on the effects of remoring the cerebrum from diflerent vertelsates nay be summarized briefly as follows: these effects are very stight or even unnoticeable in the lowest vertebrates. but the higher we ascend the scale of animal life, the more pronounced and ertensive they become. But cren in the highest of the lower animals studied $(\log )$, the functions of the central nervous system which remain are sutficient to maintain all the rital processes necessary for life. with the single cxecption of serking food. 'The effects are chiefly upon the highest powers of the nerrous system. especially upon those which we comprehend as belonging to consciousness. For these powers the cerebrum in the highest rertebrates at 
least plays the determining part, and cannot be replaced by the lower nerve centers. With regard to the state of consciousness in decerebrated animals, it is evident that no proposition can be laid down which is entirely free from objection, and there is no oceasion here to discuss the hypotheses bearing on the subject which have been put forward.

Refanbares.-Goltz, Archiv. f. d. ges. Physiol., Bd. li, 1892.-L. Luciani, "Das Kleinhirn," Leipzie, 1893.-v. Monakow, " Gehirnpathologie," Wien, 1897. -Nothnagel. "Topische Diagnostik der Gehirnkrankheiten," Berlin, 1879.schrader, Archiv. f. d. ges. Physiol., Bd. xli, xliv, 1887, 1889.-Steiner, "Die Funktionen des Zentralnervensystem und ihre Phylogenese," 1-1, Braunsehweig, 185.-1909.-A. Thomas, "Le cervelet," Paris, 1597. 


\section{CIIAPTER XII}

\section{PHYSIOLOGY OF THE CEREBRTM}

IT has long been assumed that the brain represents the, material substratum of the psychical activities. Deseartes regarded the pineal gland as the seat of the mind: Willis located pereeption in the corpora striata, inagination in the eorpus callosum, and menory in the convolutions; and Cabanis expounded his doctrine that the brain secretes thought in the same way as the liver seeretes bile.

(iall was the first to get a deeper insight into the significance of the brain as the substratum of the psychical life of man, and he undertook to prove this doctrine ly aetual observation. As Flourens, the most positive oplonent of Gall, put it, this doctrine existed in science before Gall, but after him it ruled there. Investigating each sense by itself, Gall excluded all of them, one after the other, from any direct participation in the powers of intelligence. So far from being developed in proportion to the intelligenee, most of the senses he saw are developed exactly in inverse proportion thereto. Taste and smell are sharper in the mammals than in man, sight and hearing are more keenly developed in the birds than in mammals; but the brain is everywhere developed in direet proportion to intelligence. Intelligenee remains after loss of sight and of hearing and woukl probably survive all the senses.

The brain therefore is the only organ of the mind. It consists however of many different parts, and the question naturally arises whether all of these parts are of the same importance for the psychieal activities. Gall and his pupils had the idea that only the cercbral hemispheres represent the substratum of the mind, and from what we have learned in the preceding chapter, and as we shall prove more fully in this one, we ean now make this aftimation with much greater definiteness. The lower parts of the brain probably have no direct significance for the psychical functions. As has been observed in the preeding chapter, their purpose secms to be rather to regulate quite independently of the consciousncss and of the will a number of the purely regetative functions and to connect the cerebral hemispheres with the remainder of the nervous system.

Gall however was not satisfied merely to have demonst mated the importance of the brain for the psychical life, but proeceded to work out a detailed psychology which he endeavored to bring into line with his ideas concerning the functions of the brain.

Gall's psychology subdivicted the intelligence into a number of different faculties entirely independent of one another, each of which had its own power of pereeption, memory, judgment, imagrination, etc.

The most positive objections ean be raised against this eonception of the mental personality of man as an aggregate of arbitrarily chosen aud independent faculties. This was early realized by Flourens who, in direet opposition to Gall, laid great emphasis on the mity of the ego. Morcover, the faeulties which Gall postulated were not coördinated with each other, hut were of all possible and impossible kinds. Some were partly metaphysical, some related to the emotions and some stood in direet eonnection with the sensations. 
It is praetically eertain that Gall's psycholngy would never have attraeted any further notice if he had not attempted also to locate the organs for the different faculties in different parts of the brain.

II is point of departure was an observation which he had made as a student. He thought he had discovered that those of his fellows who had a good memory for worls had prominent eyes. Hence the organ for this faculty must be situated above and behind the ere sockets. Ife conceived that the organs of the different faeulties lay only on the surface of the brain, also that wherever a certain organ was especially well developed the skull at that point was bulged out.

Hence if one were to observe the most charaeteristic peculiarities in the traits and the eharacter of many different individuals and were to study their skulls, one could determine the exact loeation of the separate nrgans. Then nothing would be simpler than to determine a person's character and the quality of his endowments by examining his skull. What a broad and extremely interesting perspective this simple and (in the fullest meaning of the worl) palpable doctrine openerl up! And how extraordinarily useful phrenology, as the new science was ealled by its disciples, would be in edueation and in the ehoice of a life work!

Gall was unquestionably a good observer, and in many points the fundamental principles of his method were not far wrong. But this did not prevent him from losing all eritieal sense and diseretion when it eame to determining empirically the location of his "organs." Gall's own writings and those of his followers furmish the most flagrant examples of this; nevertheless his doetrines were for a long time espoused in certain quarters with the greatest confidence.

In seience phrenology soon had its day, and since Flourens published his researehes on the functions of the brain (1522), it has belonged among the curiosities of the seientific lumber room.

Flourens' works deelared that only the cerebral hemispheres were of any direct importance for intelligence. He laid down the following propositions, which are given here in his own words: (1) One ean eut away from the front, the back, the top and from the sides, a fairly large part of the eerebral hemispheres without destroying the intelligence. Hence a rather limited portion of the brain is sufficient for the exereise of its mental functions. (2) The more one remores of the brain substance the more is the intelligence weakened, and its powers proportionally restrieted. When a certain limit is passed the intelligence vanishes altogether. For the complete development of the mental powers therefore all the different parts of the cerebrum work together. (3) When one particular function is lost, all are lost; when one faculty vanishes, all vanish. There are no different organs for the different faculties or sensations. The ability to perceive, judge, or will one thing has its seat in the same point as the ability to pereeive, judge, or will another. This ability, which in its essence is one and indivisible, has its seat in a single organ.

For more than a decade the conception expressed in the propositions above, partly owing to the reaction against phrenology, partly owing to the weight of Flourens' investigations on the physiology of the nervous system, was regarded as the last word of science with regard to the relation of the mind to the brain. This is not, howerer, the modern conception.

There was indeed a modicum of truth in phrenology. Not that its positing the different intellectual qualities in definite regions of the brain was correct, nor that its postulate that the form of the skull, its curvatures and prominenees, gives expression to the functional capabilities of the underlying parts, has been fonmil to aceord with faet. In this respect phrenolngy has been relegated far to the rear, we hope for once and all. But further research has demonstrated 
that the cerebral hemispheres have not one and the same function in all of their parts; it has shown that in the production and elaboration of the different kinds of sensations as well as in the influence of the cerebrum on the functions of the body, entirely different areas of the hemispheres are actire.

We may go farther and say that we hare certain grounds for believing that different sections of the cerebrum participate in the different mental processes; vet the modern doctrine of cerebral localization is at bottom something quite different from the old phrenology. Phrenology assumed that there were a number of different organs in the brain, each specifically set aside for some complex function, although that function was sometimes purely metaphysical. The new doctrine has been content to establish first of all the importance of the different parts of the brain for the functions of the bodr and for the sensations produced by stimulation of the afferent nerves. It has, it is true, ventured a step farther and has sought to bring the activity of the mind under physiologieal investigation. But these investigations aim to discover how the psychical functions can be earried out by the coöperation of the various parts of the brain-exactly the reverse process, therefore, of the phrenology of Gall. Finally, the spirit of modern research is poles asunder from the spirit of phrenology: it will not forcibly warp the facts into line with preconceived ideas and arbitrary hypotheses; but it secks to be entirely free from bias, and in this spirit to determine by obserration and experiment the facts which may be able to help us on toward a deeper theoretical comprehension of the cerebral functions.

As early as 1-25. Bouillaud tried to show that lesions of the cerebral hemispheres involved loss of the coürdinated movements neeessary for speech only when the most anterior divisions of the brain, the frontal lobes, were affeeted. Somewhat later (1836) Marc Dax stated that articulate speech was controlled by a place in the left half of the brain. But his ideas received no encouragement-in fact they were described as pseudo-seientifie. In 1861, howerer, Broca made definite observations on some diseased cases and was able to establish the fact that (in right-handed persons) destruction of the third frontal conrolution of the left hemisphere abolishes the power of speech.

These statements were soon corroborated by observations on similar cases by other authors, and thus, contrary to Flourens' doetrine, a functional differentiation of the cortex into different regions was demonstrated. But there was considerable hesitation about giving up the doctrine of the unity of the brain, and it was not until inrestigations had been carried much further that it was finally overthrown.

On purely anatomical grounds Meynert concluded that the anterior part of the cerebral hemispheres was more closely related to motion and the posterior part to sensation. Then eame $(15 \% 0)$ the work of Fritsch and Hitzig by which it was established for all time that different parts of the hemispheres actually have different functions.

Among the many articles of faith which had long been held with regard to the brain, was the belief that the eerebral cortex was nonexeitable electrieallyi. e., that no visible effect could be produced by application of the electric current to the cortex. Fritseh and Hitzig slowed that this idea was wholly erroneous and demonstrated that by electrical stimulation of the corkex nuseular morements could be obtained; but that they could only be obtained when the current was applied to certain definite portinis. The resulting morements appeared in various aroups of museles-those of the face, the fore or the hind leg, etc.-according to the exact point, within the general area, which was stimulated. From other portions of the cortex the eurrent produced no visible effect.

These diseoveries exeited the greatest interest and led to many new researches 
of rarious kinds which both served to establish the doctrine of different physiological functions for different cortical regions. and at the same time to greatly broaden and deepen our knowledge of the cerebral functions.

Sinee very little is known with regard to the physiological purposes of the basal ganglion (e.g.. the nucleus candatus, nucleus lentiformis, the gray masses of the claustrum, ete.) belonging properly to the eerebrum, we shall pass over them here and in this ehapter shall consider first the motor and sensory areas of the cortex, and then take up the psycho-phrsical functions of the eerebrum.

\section{FIRST SECTION}

\section{THE MOTOR AND SENSORY AREAS OF THE CORTEX}

\section{\$ 1. THE MOTOR AREAS}

\section{A. GENERAL SURVEY}

The results of Fritsch and Hitzig to which we haxe referred on the preceding page were as follows: To movements were obtained by stimulation

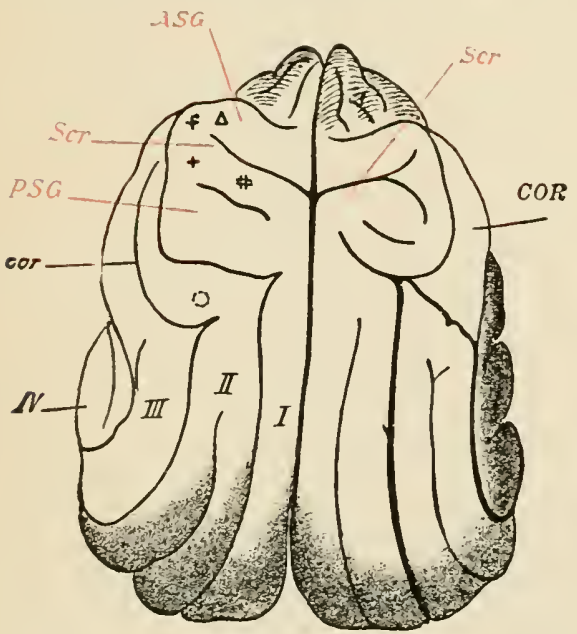

Fig. 282.-Dorsal surface of the dog's brain, with the excitation points indicated according to Fritsch and Hitzig. $\Delta$, neck muscles; + , extensors and adductors of the foreleg; +, flexion and rotation of the foreleg; $=$, hindleg; $\therefore$, face; Scr, sulcus eruciatus; $A S G$, anterior sigmoid gyrus; $P S S_{r}$, posterior sigmoid gyrus; COR, coronary gyrus; cor, coronary fissure; $I$. $I I, I I I, I V$, first to fourth external convolutions.

The answer is unanimous, that the cortex represents the immediate point of attack. The following are among the most important experimental proofs of this proposition: of the posterior part of the cerebral cortex with weak electric currents. But when the current was applied to the anterior part, movements appeared on the opposite side of the body. With a weak stimulus the effect was confined to certain sharply defined groups of museles. With a stronger stimulus the movements appeared also in other groups on the same side (cf. Fig. 28:).

With rapidly repeated induction shocks applied to the different points. the appropriate muscles could be thrown into tetanus. Continued for sereral seconds, this form of stimulus produced a persistent tetanus which might spread to all parts of the body (cortical epilepsy, (.f. below page (it1).

The first question suggested by these observations is. what part of the eerebrum is the part primarily stimulated by the eurrent-the cortex, the underlying white matter, or the deeper parts of the brain? 
In the first place it may be observed, that if the current took effect on the lower parts of the cerebrum, muscular movements should be obtained by application of the current to widely different regions of the cortex. Since this is not the case, it is merely a question between the cortex and the subjacent white matter. The following facts speak against the latter possibility :

(1) Inder certain circumstanees it is possible to stimulate the cortex meehanically, but the white matter camnot be so stimulated (Luciani and Tamburini). (2) It requires a stronger current to stimulate the corona radiata electrically than to stimulate the cortex. (3) On the other hand a muscular contraction caused by contimuous stimulation of the cortex ceases decidedly sooner than after stimulation of the corona (Levy). (4) After poisoning with chloral (Franck and Pitres), the cortex becomes inexcitable, but movements can still be obtained from the corona. Likewise the cortex is rendered inexcitable to a depth of 2-3 $\mathrm{mm}$. by painting it with cocain (Carvalho).

Again when a certain muscular contraction is aroused first from the cortex and then from the corona and the first two responses are recorded, it is found that the latent period of the first is considerably longer than that of the second -e. g., cortex, 0.065 second; corona, 0.045 second (Franck). The difference of 0.02

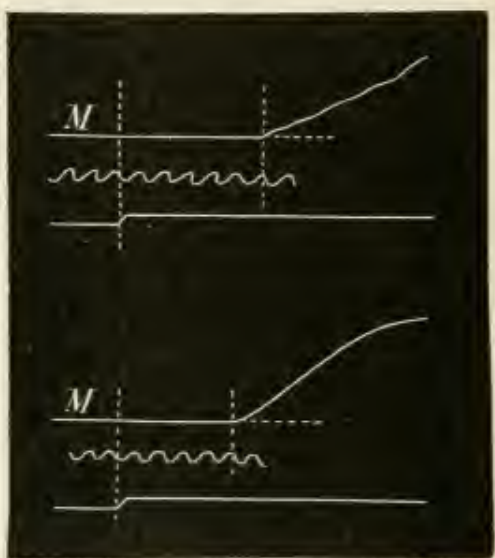

FIG. 283.-1 - latent period of muscular contraction induced by stimulation of the cortex (upper tracing), and by stimulation of the underlying white substance (lower tracing), after Franck. The time record in each case is in $1-100$ ths of a second. The instant of stimulation is indicated by the rertical line to the left, the beginning of the contraction by the vertical line to the right.

second is doubtless due to a delay in the excitation proeess occasinned by the nerve cells (Fig. 283). The facts also that the contraction curve following cortical stimulation rises more slowly and is not so regular as that following stimulation of the corona, and that cortical stimulation is accompanied by a clonic contraction, while stimulation of the corona is not, are probably to be explained by the presince of nerve cells.

Inence it is eonceivable that the electrical stimulus acts directly on the large pyramidal cells of the cortex (c.f. Fig. 254, right side Nos. 4, 5, 6) although this would not mean that there might not be other points of attack, as, c. g., the end arborizations of the afferent nerves as well.

These things being so, we may say that certain definito regions of the cortex stand in a more definite relation to the movements of the body than do other parts of the brain. 'These regions are described as the motor cortical areas of the cerebrum.

\section{B. STIMULATION OF THE MOTOR CORTICAL AREAS IN DIFFERENT MAMMALS}

It would lead us ton far afield to deseribe lore in dotail all the results obtained ly electrical stimulation of the cortex in the different mammals.

${ }^{1}$ By clonic contraction is meant one whose strength is continually changing (cf. Fig. 291) 

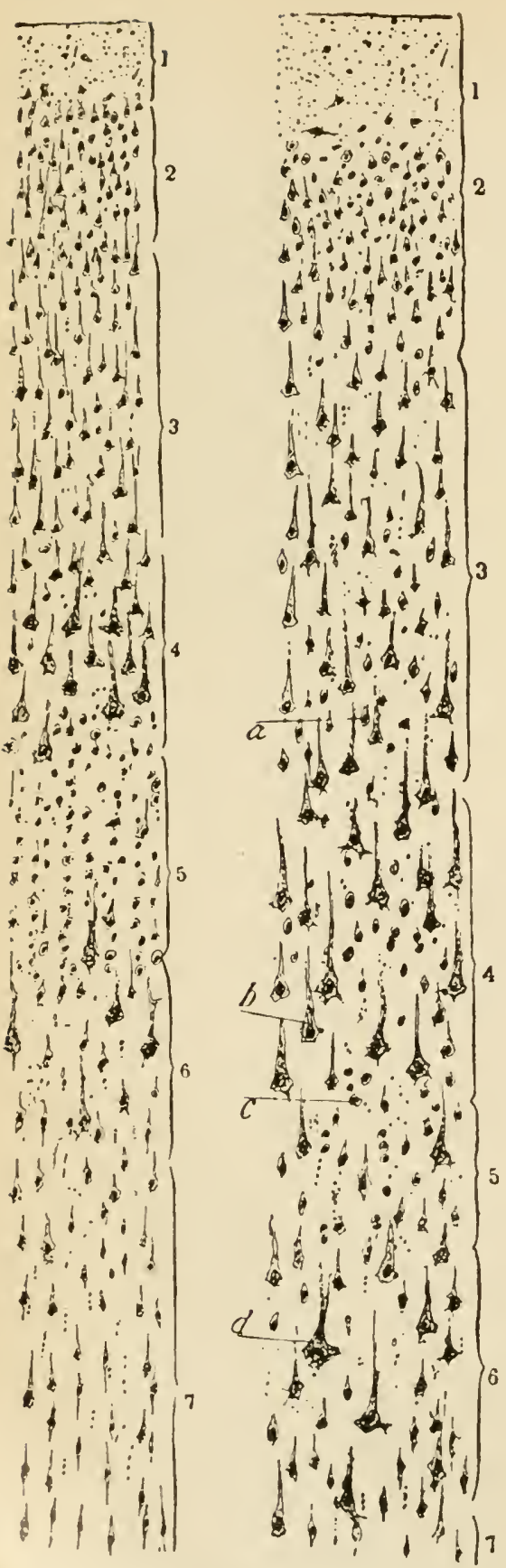

But there is one result which stands out very prominently: the higher the rank of the animal in the scale, the greater is the variety of isolated movements which can be olstained by sharply localized stimulation-i. e., the greater is the number of excitable points and lience the higher is the degree of localization. This fact together with the close similarity of structure between the simian brain and the human brain makes the results on monkeys of the utmost importance from the standpoint of human physiology: consequently we shall describe the experiments on these animals, which we owe to Beevor, Horsley, Schäfer and Sherrington, somewhat fully.

The arrangement of the fissures and convolutions in the monker's brain corresponds exactly to that of the human brain, or, more correctly speaking. it can be regarded as a simplificd schema of the human brain. Reference to Figs. 285 , and 286 will make this fact apparent without further description.

The motor cortical zone of the monkey's brain extends over parts of both the median and convex surfaces of the hemisphere. On the convex surface it consists of the two central convolutions and of the immediately adjacent parts of the frontal convolutions. On the medial side the greater part of the gyrus marginalis belongs to this zone.

Within this great motor zone can be distinguished areas for the larger divisions of the body musculature:

Fig. 284.-Structure of the cortex of the convolutions bordering on the fissure of Rolando, after Cajal. The figure to the right represents the structure of the anterior central convolution, that to the left the structure of the posterior central. 1, Plexiform layer; 2, small pyramidal cells; 3, medium-sized pyramidal cells; 4, large superficial prramiclal cells; 5, small star-shaped cells; 6, large, deep pyramidal cells; 7 , layer of spindle-shajed and triangular cells. 


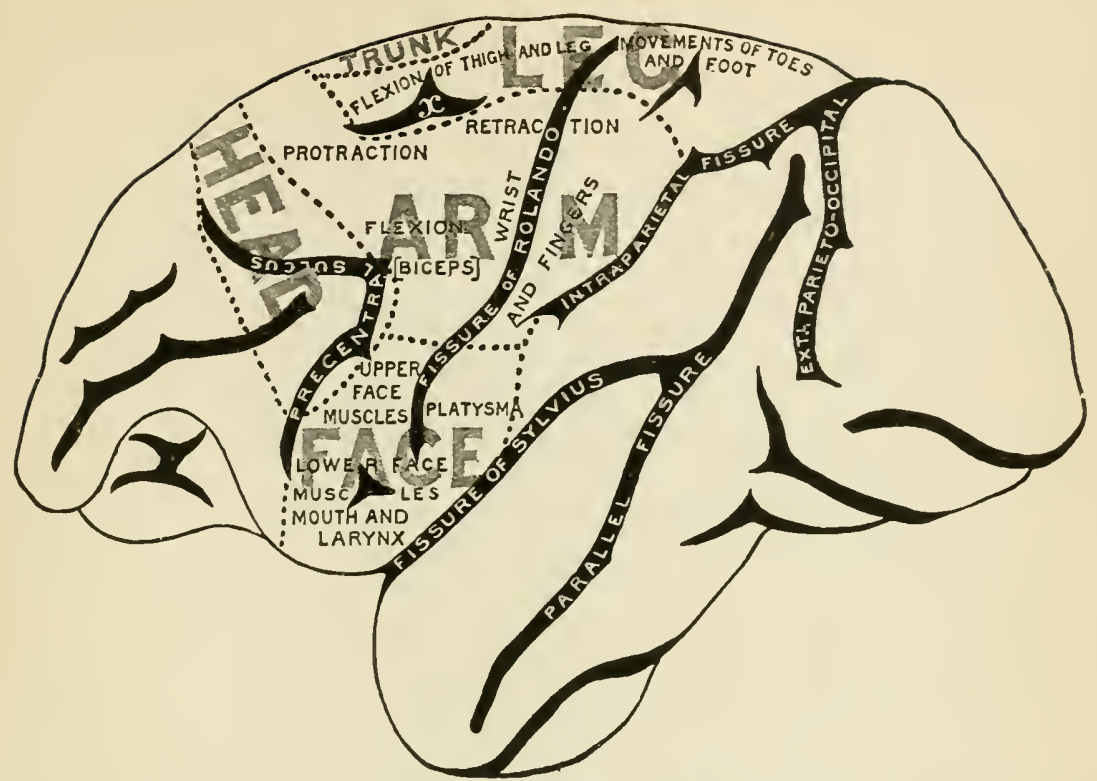

Fig. 2S5.-Motor cerebral localization in the monkey (Macacus sinicus), after Horsley and Schifer. Uuter surface of left hemisphere.

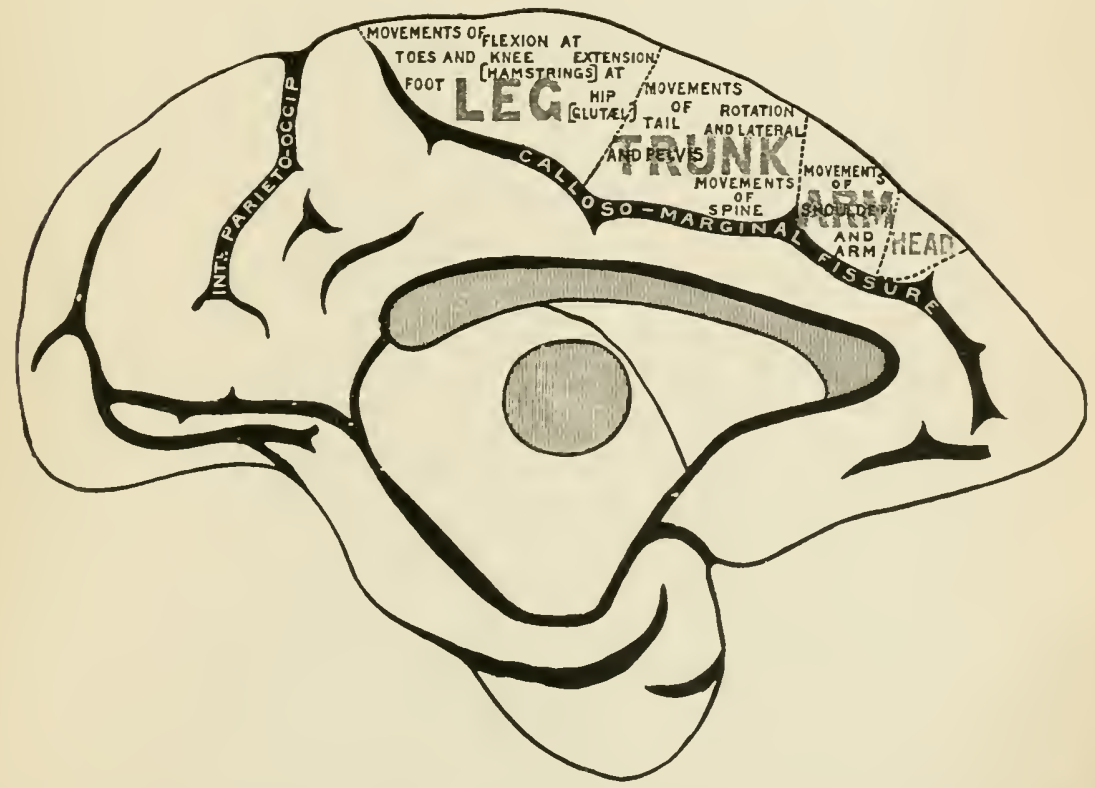

FIG. 286.-Motor cerebral localization in the monkey (Macacus sinicus), after Horsley and schifer. Inner surface of the left hemisphere. 
thus the lower part of the two central convolutions is related to the musculature of the face, the middle part to that of the anterior extremity, and the upper part to the muscles of the posterior extremity. On the very edge of the licmisphere is an area for the movements of the trunk. That portion of the motor zone lying immediately in front of the anterior central convolution is adapted for movements of the head and cyes.

In the grrus marginalis on the medial surface of the hemisphere we find in serial order from anterior to posterior areas for the head. the anterior extremity, the trumk ${ }^{2}$ and the posterior extremity.

On closer investigntion of the subject we find that within each of the cortical areas for the greater divisions of the musculature, a specialization like that shown diagrammatically in Fig. $288^{3}$ can be demonstrater.

The movements olstained by cortieal stimulation are in many respects similar to voluntary morements. As a rule ther represent the combined action of several groups of muscles: they are seldom performed by a single group and never by a simgle muscle.

In stimulating the cerebral cortex of the monkey Sherrington observed that simnltaneously with the contraction of certain eye muscles. the tonus of the antagonistic muscles decreased (cf. page 640). This is by no means an isolated phenomenon, for according to further observations by Hering, Jr.. and Sherrington, it appears to be a general rule that on stimulation of a definite point in the cortex, contraction of the appropriate muscle is accompanied by relaxation of its antagonist. For example, on stimulation of the point in the cortex for extension of the ellow, one gets contraction of the triceps gromp and at the same time relaxation of the biceps. or on stimmlation of the point for extension of the fingers, one gets contraction of the extensores and relaxation of the flexores digitorum, ete. 'These authors declare that in the monkey they never observed simultaneons contraction of true antagonists, such as the extensor and flexor of the elbow. The simultaneous contractions of antagonistic muscles described loy other anthors might have been due among other things to diffusion of the stimulus from one cortical field to another lying near it.

When a stimulus applied to a given field in the cortex produces movements in other muscles than those corresponding strictly to that ficld, it is observed that the movement always spreads first to other muscles of the same membere. g., contractions of the shonlder muscle are accompanied by movements in all the muscles of the anterior extremity even down to the fingers. If the initial contraction be in the muscles of the thmmb, the movements spread farther and farther up the arm to the wrist, ellow and shonlder.

The contributions of Becror and Horsley on the motor zone of the orang-

I According to Bechterew, contractions of the brow, closure of the lids, and movements of the ear are also obtained from this part of the cortex.

${ }^{2}$ According to H. Munk, the cortical area for the musculature of the trumk lies in the frontal lolee.

${ }^{3}$ For the sake of simplicity, the different fields in this figure have been represented as if they were sharply distinct from one another, whereas in reality there are no sharp boundaries demonstrable, either between the smaller areas or the larger areas. One field always passes gradually into the other. 
outang, and those of Sherrington and Grembaum on the orang-outang. gorilla. and the chimpanzec, are of rery great interest partly because these anthropoid apes stand closest in the scale to man himself. and partly for the special reason that a further progresive derelopment of this zone from the monkeys to the highest apes is therem unmistakably demonstrated. The faet of this development teaches us in the clearest possible manner how careful we must be in applying the results obtained from other anjmals to man himself.

The general dirision of the motor zone as it has been made ont in the monkeys is the sane in its larger features for the apes. There are however
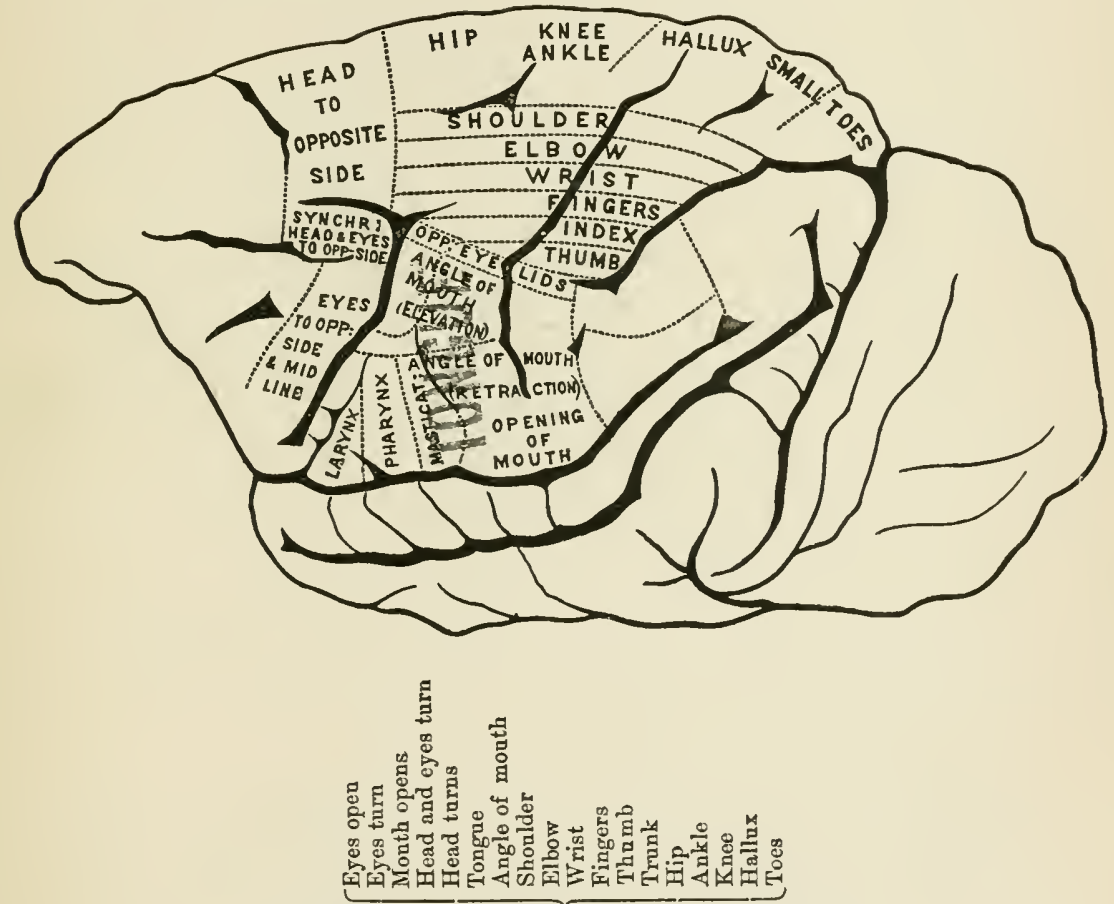

Arrangement of excitable fibers in the internal capsule.

Fig. 2S7.- Motor cortieal areas in the monk'y (.1/acucus sinicus), after Beevor and IIorsley.

several very noteworthy difforenese betwern the two gromps. In the monkeys (ct. Fing. Soj) we find on the romvex suldaces. both on the central and the l'ontal comvolutions. single excitalule pergions from which several kinds of movements (an he discharged. In the apes (of. Fig. ess) the region on the fromtal comolutions contains but one field from which only morements of the eres can be induced. The posterior central comsolution is entirely or in very lasere part incereitable, the motor entical areas heing for the most part wathererl together in the anterior contral convolution. Again. whereas in the monkeys there are no sharp drmarcations lotween the cortical areas for different groups of muscles, in the orang-ontang the costical areas for the main divisions of the holy are separated by regions which are increitable. 
While the isolation of smaller areas within any larger area, as of the arm or the leg. is not so marked as this localization of group areas, it is nevertheless much shaper than it is in the monkeys; for when contraction is induced by stimulation of a definite point, it is as a rule confined to one definite group of muscles and does not spread as in the monkeys to all or most of the muscles of the same member.

For purposes of diagnosis the exposed cerebral cortex of man (Figs. 289 and $9(90)$ has in rare cases been stimulated electrically, and results have been obtained which in general agree with olservations based on cortical lesions. as well as with the above-described results on the manlike apes. The motor

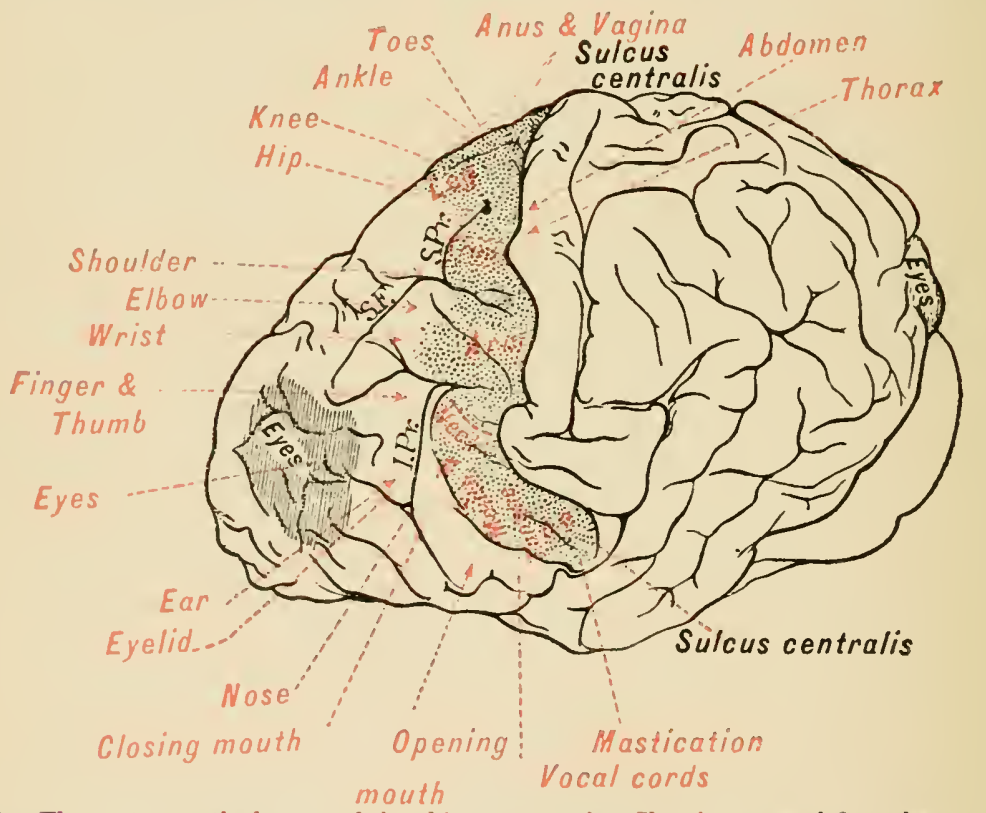

FIG. 288.- The motor cortical areas of the chimpanzee, after Sherrington and Greenbaum. The extent of the motor zone is indicated in black. 'The red arrows indicate the region in which the special areas are to be found.

eortical zone of man probably consists therefore of the anterior central convolution, the posterior part of the frontal comwlutions and the paracentral lobule. Within this zone the areas for lateral movements of the head and eyes are located in the posterior part of the second frontal convolution; the face musculatue is represented in the lower part of the anterior central conrolution. the muscles of the upper extremity in the midnle part, and those of the lower extremity in the upper part. The paracentral lobule in ench hemisphere (Fig. 290 ) seems to be associated with both opposite extremities. Above the cortical area for the upper extremity is found the area for the musculature of the trunk.

It is probably not too much to suppose that the smaller areas within each of these larger areas have the same general arrangement as have those of the apes. 
Moreover. it is found in these stimulation experiments on man that, just as in the manlike apes. the localization is very sharp. that the movements indeed are confined to single groups of muscles, and that between the excitable points are regions which are inexeitable.

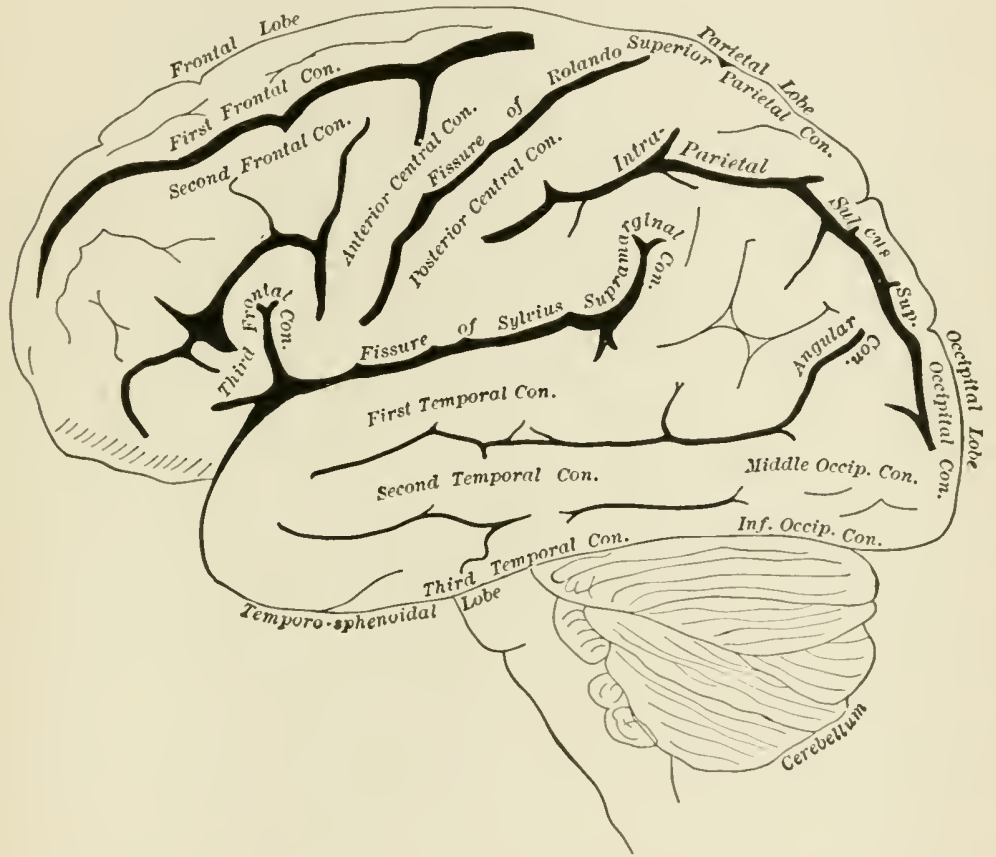

Fig. 289.-Diagram of the external surface of the left cerebral henisphere of man, after Ecker.

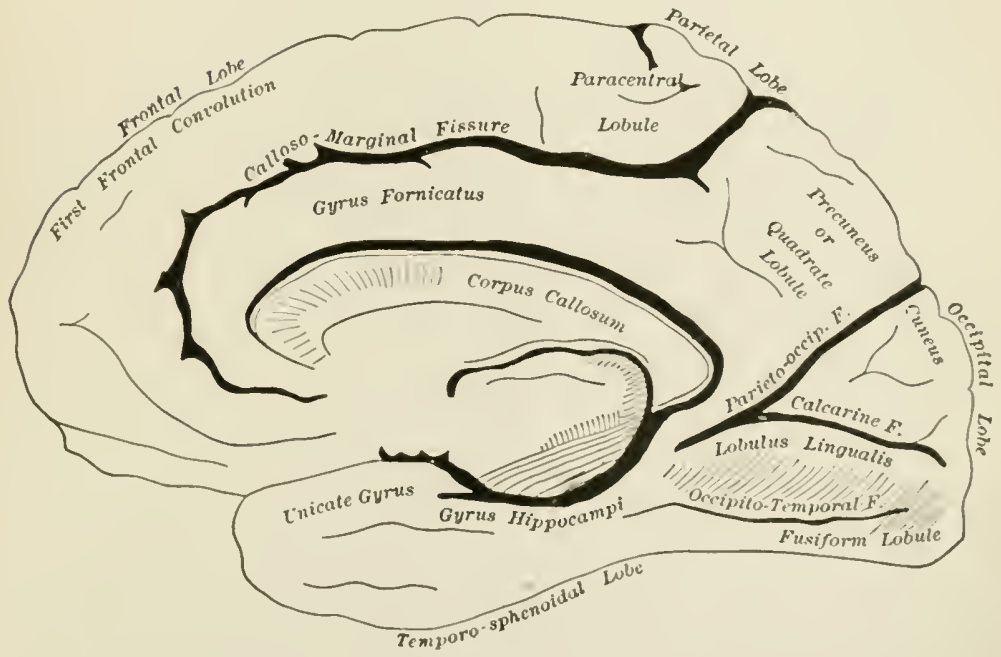

Fig. 290.-Diagram of the internal surface of the right cercbral hemisphere of man, after Ecker. 


\section{DIRECT AND CROSSED EFFECTS OF STIMULATION OF THE MOTOR CORTICAL AREAS}

As already noted at page 63.9 , the morements induced by stimulation of the cerebral cortex occur mainly in the opposite half of the horly. But movements can lie olstained also in the muscles of the same side. Of these bilateral movements some can be obtained eren with a rery weak stimulus. With the great majority of muscle groups, however. the movements on the same side can only be induced with relatively strong stimuli.

The eye movements are to be elassed as bilateral movements sinee stimulation of one lemisphere eanses both eres to be rotated toward the opposite side. But the bilaterality in this case is only an apparent one; for the internal rectus of one eve contracts at the same time as the external rectus of the other. Inhibition of the antagonistic muscle is also an important factor. IThen all the nerves exeept the abdueens to the ere muscles of one side, sav the left. are cut in the monkey, the left eye naturally is deflected to the left. because the tomus has been destroyed in all but the external rectus muscle. But if movement of the eres to the right is then induced by appropriate stimulation of the cerebral cortex, the left eye will turn back to the right as far as the median line even though the internal reetus has been paralyzed. That is, the stimulation has caused the tonus of the left external rectus to be intermitted. Since this experiment snceeds also when the corona radiata, the internal capsule, etc.. are stimulated, the inhibition in question must be started from some eenter below the cortex (Sherrington, ef. page 636).

The aetion incluced in the face muscles is really bilateral, although those of the opposite side contract the more powerfully. This is true of the buccinator as well as of the muscles of the tongue and vocal cords.

With regard to other museular contractions induced from the same side of the brain, it is to be remarked: (1) that their latent period is longer than that of muscles on the opposite side (Franck and Pitres); (2) that they require a stronger stimulus; and (3) that the museles of the same side of the body never make coördinated movements as do those of the opposite side, but show instead a tonic contraction more or less like an extended tetanus.

We see therefore that ennsiderable differences exist between the movements of the same and of the opposite side, and, as Gotch and Horsley especially have emphasized, it is probably to be assumed that the muscles of the same side are not sn immediately dependent upon the cortical areas as are those of the opposite side.

It is conceivable that the excitation is conveyed to the museles of the same side by first erossing in the brain to the corresponding motor areas of the opposite hemisphere. But if this be the ease, it is not the only course the excitation ean take, for contraetions on the same side have been obtained by a number of authors even after the removal of these opposite areas, or of the entire opposite hemisphere.

The erossing therefore must take place in the lower centers. T.ewaschew obtained morements in the left hind leg br stimulating the left hemisphere after hemisection of the spinal enrd on the left side. In this ease the excitation had erossed to the right side of the eord and had erossed back again below the level of the section (twelfth thoraeic segment) to the left half. But 
this does not teach us anything definite as to the part of the central nerrous system in which the stimulus branehes off from ine main path to reach muscles of the same side. It is probable that this place is to be sought among the gray masses of the brain-stem. As Goteh and Horsley suggest, the cerebellum might have a large share in this distribution of impulses from the cerebrum.

\section{THE COMMISSURES BETWEEN THE CORTICAL AREAS OF THE TWO HEMISPHERES}

One would suppose a priori that the corpus callosum, the great commissure binching together the two hemispheres, must he of very great physiological importance; and, in fact, the most far-reaching hypotheses have been erected on this supposition. But the results of actual experiments designed to throw light on the purpose of this part are very meager. Several authors (Longet, Magendie, Flourens, Franck, Ferrier. Koranyi and others) have found that separation of the two hemispheres by a complete sagittal section through the corpus callosum produces no effect on the hehavior of the animal (rabbit, dogr) provided the hemispheres be left entirely uninjured. Lesions of the corpus callosum also produce no permanent effect (Wernicke). The necessary coöperation between the two hemispheres in the functions of the brain is therefore not brought about hy the corpus callosum.

The fibers running in the corpus callosum from one motor zone to the other when stimulated from the upper surface of that body (except rostrum and the splenimm) produce bilateral muscular movements. Applying the stimulus just behind the anterior genu gives movement of the head and eyes; applying it farther posteriorly we get in serial order: movements of the two arms at the shoulder joints, and of the upper half of the trunk; movements of the forearm. hands and fingers; movements of the posterior half of the trunk and of the tail: movements of the posterior extremities. No movements of the face muscles have been obtained. It was only very rarely that the movements were so isolated and so sharply localized as with stimulation of the cortex.

After extirpation of the motor zone on one side, the morements are unilateral; they are induced therefore with the help of the motor zone. IThen the rorpus callosum is stimulated after sagittal section and after extirpation of one hemisphere, unilateral movements are oltained on the side from which the hemisphere has been removed. The excitation aroused by stimulating the fibers of the corpus callosum passes therefore to both motor regions and thence is propagated in the usual way to the nuelei of the motor nerves ( Mott and śchäfer).

For the efferts of seetioning the corpus callosum in cases of lesion of the cerebral cortex, see page (ifio.

\section{E. CORTICAL EPILEPSY}

It was observed hy Fritsch and Hitzig in their early work on this subjeet that by continuous stimulation of the cerebral cortex of mammals, cramplike contrictions can be prodiced which to not remain confined to the set of muscles associated with the area stimulated, but may extend to all the 
muscles of the body. Further inrestigations along this line have given us the following results:

The spasm begins always in the group of muscles whose cortical area is stimulated, and from there spreads in a perfeetly regular manner to the other

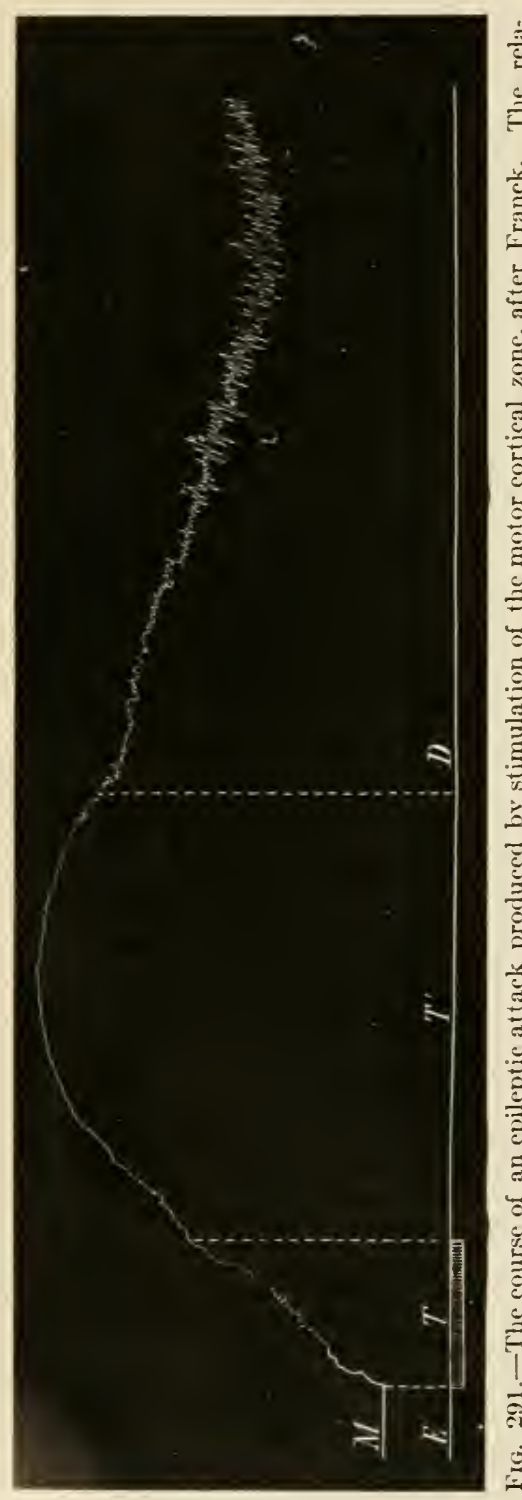
museles. If. for example in the dog, the left cortieal area for morements of the eyelids is stimulated, the attack begins in the eyelids of the opposite side, and from there passes to the face muscles. As a result the head is turned to the right, whereupon the spasm extends to the right anterior, and then to the right posterior extremity. Then for the first the muscles of the left side are affected and the spasm spreads in reverse order from below upward, sweeping orer the muscles of the posterior, then of the anterior extremity, and so on until. last of all, the museles of the eyelids on the left are reached.

Fig. 291 may be eited as showing the characteristies of the cramplike contractions. As will be seen, it is at first tonic, later becoming clonic in character. A sleepy condition or a condition of great agitation may ensme as an after-effect.

The attacks appear on prolonged stimulation, sometimes while the stimulation is in progress and sometimes after it has ceased. They may appear also "spontaneously" when superfieial lesions are made within the motor zone and the animal is kept alive; after the wound is healed the epileptic attacks come on without stimulation.

Likewise in man cortical epilepsy occurs as the result of irritative lesions of the motor zone, and on the whole is of about the same character as that following artificial stimulation in animals. This is distinguished from the usual form of epilepsy, by the retention of consciousness at least at the beginning of the attack, and sometimes throughout its whole course. The patient feels the attack approaching. and can protect himself from injuries while it is on. 
Since the excitation in cortical epilepsy spreads to different muscle groups just the same after extirpation of the motor zone on the opposite side from the one stimulated, and since a single group of muscles is not absolved from the effect by extirpation of its own particular field in the cortex when the stimulus is applied to another, it is probable that the actual irradiation takes place through the mediation of subcortical centers. This is borne out also by the fact that once an attack is well advanced extirpation of the motor zone does not stop it.

\section{F. SUPPRESSION OF THE MOTOR CORTICAL FIELDS}

As the observations given in the preceding chapter have shown, the entire cerchrum can be removed not only from the lower vertebrates but from the rabbit and $\log$ as well, without destroying the ability of the animal to earry out coördinated movements of locomotion. This proves at once that in these animals the motor regions of the cerebral cortex are not indispensable for movements of this kind. However. in the decerebrated dog there were noticeable disturbances in motion, which might not have been caused by removal of the motor region alone but also by the absence of other parts of the cerebrum. In order to establish the physiological importance of the motor areas, it is necessary therefore to study the behavior of animals from which these fields only have been extirpated.

When the motor fields of one hemisphere have been completely or mainly removed from a dog. for a time immediately following the operation there is a more or less profound disturbance in the movements of the opposite sille; but this effect is only temporary. The animal gradually recovers its ability to move the opposite muscles. and after some time the motor defects become quite minimal. A dog from which Goltz removed the left hemisphere became "silly": he was not so lively as before: did not play with other dogs. etc. But none of his muscles were entirely paralyzed. When he was called he came wagging his tail and let himself be stroked. When one started to go the dog followed. He fonght off other dogs that displeased him. He held a piece of bread just as skillfully as a normal dog, but did not hold a bone so well with the opposite font (the right) as with the other. He could stand up on his hind legs, although the right leg was somewhat weak. He ran here and there of his own aceord, but turned oftener to the left than to the right. He could turn to the right, though less skillfully and less quickly.

It is therefore unquestionably true that a dog which has lost the motor zone of one side can still move those muscles which respond to stimulation of that cortical zone. It has been supposed that such an animal could not perform intentional movements with these museles. But this view is controverted by the following observations on a dog whose entire cerebral cortex on the left side had been removed.

A bowl was placed hefore the animal containing bits of meat seattered in some coarse gravel. In seratching for the meat he nsed his left fore paw. But when this one was held fast he immediately made the same novement with the right fore paw (Goltz).

In a well-trained dog fanle trimmed off on hoth sides all the cortex which eould be visibly exeited with a weak constant "urlent. After the nsual phenomena of paralysis had passed off, Gaule trained the dog again and was able to 
teach him a whole series of complieated movements which gave evidence of his intelligence. However, he showed also a considerable number of disturbances of the motor mechanisms, among which may be mentioned especially his inability to perform isolated movements with only one extremity. Besides, his movements were excessive and were done with a waste of energy ; and there was no proper gradation of them-e. g., in order to extend his paw, he was eompelled first to sit upright and then to give both paws at the same time in a rather sudden and explosive manner.

From these and other experiments of the kind it appears that the morements of the dog. including those which must be regarded as intentional and conscious. can be carried out without the coöperation of the motor areas; but that on the other hand. the finer regulation of these movements is for the most part destroyed by extirpation of the corresponding areas. It would follow that in the dog the motor cortical areas are really necessary only for the nicer regulation of movements.

Horsley and Schäfer observed the following phenomena after extirpation of the cortical areas from the monkey (Macacus). If the whole excitable region on the convex side of the hemisphere were extirpated and only the median cortical region left, there was exhibited an almost complete paralysis of the opposite arm, paralysis of the facial muscles. weakness in the muscles of the posterior extremities. and a greater or less difficulty in moving the head towarl the opposite side. The muscles of the trunk were unaffected, and the weakness in the posterior extremity was not so great that the animal could not use it in walking and climbing.

When only a part of the excitable region on the convex surface of the hemisphere was destroyed-e. g.. the field for the wrist and fingers-a permanent weakness appeared in these muscles while the other muscles were movable in a perfectly normal fashion. In the same way destruction of the cortical fick of the arm produced paralysis of the arm withont any disturhance in the morements of the face, head, trunk or posterior extremity. When the destruction of the field was complete. paralysis of the corresponding muscles appeared to be permanent. But when a part of the field was left behind the ability to move the parts returned to a certain extent.

The ennsequences of destroying the notor region on the medial side are worthy of note. Following bilateral destruction of this region there was complete paralysis of the muscles of the trunk, a certain weakness in those of the arms and a very extensive paralysis in the muscles of the posterior extremities. The weakness in the arms involved mainly certain shoulder muscles, especially those which draw the shoulder blade upward and backward: it was less marked in the muscles of the arm and forearm, and scarcely or not at all noticeahle in the finger muscles. Paralysis of the posterior extremities extended to almost all the muscles, only a few flexors of the hip joint being exempt.

By practice the monkey, like the dog. can acquire the use of muscles correxponding to the extirpated cortical fields: can learn, in other words, to execute intentional morements with them.

Hering, Jr., found that the eortieal fields, electrical stimulation of which gave movements of the forearm, including grasping movements, could be entirely 
removed without destroying the animal's ability to close the fist on the opposite side or to use the hand in grasping objects.- Sherrington has made similar observations on the anthropoirl apes.

Goltz had the opportunity of observing for more than ten years a monkey in which the greater part of the frontal and parjetal lohes on the loft side had been destroyed. Thus the motor region of the left hemisphere was entirely or almost entirely thrown out of function. Nevertheless, by practice the monkey succeeded in recovering his ability to use the right arm and right hand for definite purposes. He learned to grasp fruits with the right hand and to offer it in greeting, ete. Te could move all of the muscles directly under control of the will, but the movements of the right limbs remained incomplete, cumbrous and awkward.

After these observations it scarcely ought to be longer assumed that the motor region in the monker is of much greater importance than it is in the dog. It is indeed rery probable that there is a difference in degree between the two. but certainly not a difference in kind.

Horsley and Schäfer: observations point to the interesting fact that in the monker the motor eortical areas on the upper medial surface of the hemispheres are concerned mainly with what we may call the conrser morements, those by which the body is kept in its natural position and moves itself from place to place. The enrtical areas on the convex surfaces of the hemisphere are of deridedly sreater importance for the more refined morements, e.g., these which ale executed by the muscles of the head. face and arms.

In order to establish the location and influenee of the motor cortienl areas in the human brain. we have recourse either to excitation cxperiments or to clinical and pathological observations. The former evidently can nerer be rery numerous. and our knowledge of the functions of the hunan motor cortex rests mainly on clinical observations of the effects of lesions in the cerebrum.

It not infrequently happens that in post-mortem examinations very extensive lesions of the cerehral cortex are found, which were not acompanied in life by any observable disorder. Compilations of such cases, which we owe to Chareot and l'itres, Exner. Sothmagel and others show that these cortical ficlds which have no direct significance for the bodily morements embrace all parts of the cortex with the exception of the anterior central convolution inclusive of the opereulum, the paracentral lobule. and the posterior part of the frontal convolutions. But if the lesions are found within the portions just named. a more or less extensive disturbance in the movements of the opposite half of the holy is sure to have been observed. Honce we ran say that the motor eortical field in man has on the whole the same extent as the cortical zone in the anthropoid apes, and that this eners the anterior central envolution inclusive of the paracentral Inbule, and the foot of the frontal combolutions.

For working out the cerebal localization in detail the cory small cortical lesions arr of eourse the important ones. The more restrieted the lesion, the more linited will be the disturbance of function, and of course the more definitcly an the location of a particular fold be decided upon. Finch lesions have vivlded results which agree escentially with the enresponding observations on the brain of the anthropoid apes. and with the excitation experiments on the liuman brain itself. 
The disturbance in function which makes its appearance after a lesion in the motor region is as a rule greater at first than later, owing no donbt to some interference with the circulation and to shock. Ifter this remote effect of the lesion has passed away, as it does within a few days, the primary loss of function comes more prominently to the front. Movements of parts comnected with the cortical area destroyed can no longer be executed as before, and in adults they are either finally lost or are always thereafter executed with abnormal weakness. It is to be observed, however, that even such movements can continue to be performed in association with others. When, for example, the cortical field for the extension of the right thumb is entirely destroyed, the ability to make sure. strong and precise extensor and abructor morements with that thumb is lost: but in connection with the fingers it can still be nsed very skillfully in various kinds of complicated movements (v. Nonakow).

The influence of the cerebral cortex in man on the movements of his body appears very clearly from the following observation. A patient was born with hemiplegia on the left side. When he was taken to the hospital at the age of twenty-nine, his left limbs were very much stunted. He could walk with the help of crutehes, but could not lift his left leg from the floor. On opening the skull it was found that the whole right hemisphere of the cerebrum had disappeared and was replaced by fluid (L'Allemand).

In considering the recovery of the muscular functions, we must bear in mind that the extremities are represented not only on the convex surface of the cerebrum, but also on the medial side: also that according to observations on monkers, it is only the coarser movements that are dependent on the latter region. When therefore the lesion oceurs only on the outer convex portion of the cortex, it is still possible for the medial portion to direct the coarser morements of the extremities.

IVith lesions acquired very early in life. a very considerable degree of rustitution is possible. In one case of defect of the two right central convolutions ohserved by $v$. Monakow, the patient at ten was able to nse his left arm (atrophied though it was) in the proper way, in all possible sorts of manipulations-e. g., in playing ball; some considerable clumsiness was apparent however in the use of the left hand and fingers.

Ifter a cortical lesion contractures-i.e., abnormal, persistent contractions-gradually make their appearance in the muscles of the paralyzed limbs. Different hypotheses have been put forward concerning the cause of these, but their discussion here would lead us too far afield. It must suffice to observe only that, according to H. Munk, contractures in the monker can be prevented, if, as soon as the limbs affected begin to offer some resistance to passive movements, they be stretched as far as possible for a few minutes erery day. The contractures are brought on by the loss of motility. Hence they do not occur in the case of animals which move about ipontaneonsly after the operation, for the paralyzed extremity can be used in connection with the other extremities in walking even though isolated movements cannot be executed. 


\section{G. THE COURSE OF THE CONDUCTING PATHWAYS FROM THE MOTOR CORTICAL FIELDS TO THE NUCLEI OF THE MOTOR NERVES}

The nerve paths which originate in the great pyramidal cells of the eerebral cortex proceed through the corona radiata to the internal eapsule, through this to the crus cerebri and then continue distalward to the nuelei of origin of the motor nerves, with which they are connected. The pyramidal pathways are connected with motor nerves of the opposite side. The fibers belonging to the cranial motor nerres pass to the opposite side in different parts of the brain-stem, while the pramidal fibers which reach the spinal cord cross for the most part in the medulla (crossed pyramidal traets), but in part also in the spinal cord itself (direct pyramidal tracts). All these paths degenerate after destruction of the cerebral cortex (see Fig. 260, page 50(0).

Clinieal evidence has shown that these paths pass through the corona radiata, forming, as we might expect, a pretty compact bundle. Lesions in the corona

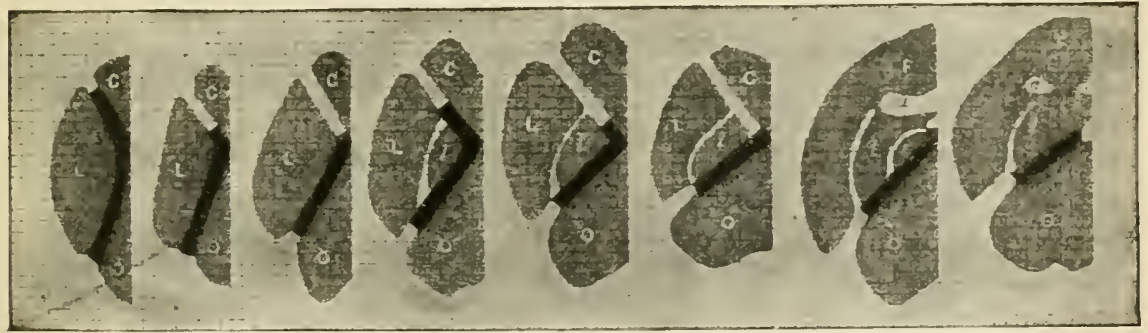

Fic. 292. - The motor tract (dark) at various levels of the internal capsule, after Beevor and Horsley. $L$, lenticular nucleus; $T$, optic thalamus; $C$, caudate nucleus; $a$, anterior commissure; $F$, point of junction of the lenticular and caudate nuclei.

produce isolated paralyses of the face, arm or leg museulature, showing that the paths proceeding from the motur cortical areas are distinct from one another also in their further course.

In the internal eapsule the prramidal paths are drawn closer together, the deeper they go. According to Beevor and Horsley, at a high level they fill the entire cross section of the capsule with the exception of its most anterior and most posterior sections. Further down they are restricted more and more to the posterior limb of the capsule, as may be seen from Fig. 292.

The separate traets can be fairly well stimulated in the internal capsule. Some responses are bilateral just as in the case of not overstrong stimulation of the cortex; but most are unilateral. The bilateral responses are: eversion of the lips, movements of mastication, swallowing, adduction of the rocal cords-all of them equally strong on both sides; opening and elosing of the exelids, protrusion of the lips, retraction of the angle of the mouth-all stronger on the opposite sicle: the rest are strictly unilateral.

Beginning at the most anterior part of the eapsule which can be stimulated. and moving the electrodes gradually backward, the following responses in the order named are obtained in the monkers (Beevor and Horsley): opening of the eyelids, turning the exes to the opposite side, opening of the angle of the mouth, rotation of the head and eyes to the opposite side, rotation of the head alone to the opposite side, movements of the tongue, of the angle of the moutl, 
shoulder, elbow, wrist and fingers. thumb, trunk, hip, font, knee, great toe and smaller toes (cf. Fig. 25i). The points corresponling to the morements within any given eross section, howerer, are not sharply delimited, but overlap each other.

But the pyramidal tracts are not the only motor pathways from the cerebral cortex. According to Rothman, ablation of the pyramidal paths alone in the dog eanses no essential change in the electrical stimulation of the motor region: the motor impulses are then conveved by Monaliow's bundle (see page 596\%). In monkers however the latter plays lut an unimportant rôle in this respect. for after section of the prramidal paths, only movements of the hand, fingers and toes could be obtained by electrical stimulation of the cortex.

Even after complete suppression of all those pathways in the monkey, and notwithstanding the failure of subsequent stimulation of the motor region. the motor functions of the limbs were not permanently abolished. Impulses which reach the cord in other way. can always produce slight isolated movements of the fingers: indexd, after complete severance of all the paths of the lateral and anterior columns of the cord on one side, a restitution takes place which. while very incomplete, makes possible not only associated but isolated morements as wall. 'There are therefore several pathways by which the cerebral cortex may influence the movements of the body.

\section{H. DEVELOPMENT OF THE MOTOR AREAS OF THE CORTEX}

The investigations of Flechig on the formation of the medullary substance in the nerve paths of the central nervous ssitem, have brought to light the fact that the pyramidal paths in man receive their medullary substance only at the very end of intranterine life. In the dog these same paths are not provided with their medullary substance until after birth.

In accordance with this fact the excitability of the motor region in newborn dogs is but slight, so much so that it has been stated by some authors to be altogether wanting until the tenth day. This appears certainly to be incorrect, for Paneth has found, for example, that responsive morements can be obtained by stimulation of the ceroural cortex in dogs only one to two days after birth.

According to Bary, the first movements obtainable exhibit various noteworthy differences from those of somewhat older animals. They are not eonfined to separate groups of muscles as are the latter, but involve the whole anterior or posterior extremity of the opposite side; the duration of the contraction and the latent period are also much longer. Moreover, in very young animals the exeitability of the eortex is easily destroyed by all sorts of injuries, nareosis, cooling, exposure, etc.

From about the tenth day onward special areas for the separate groups of muscles develop on the cortex, and pari passu with this development, the duration of the eontraction and the length of the latent period beeome shorter, and the resistance of the cortex to fatigue also greater.

On the other hand it should be observed that in the guinea pig. in which the pyramidal paths receive their medullary substance in utero, the cortex is excitable before birth.

Of great interest also is the observation made by IIerzen and others that 
newborn puppies from which the motor region was extirpated suffered no sort of motor disturbance, even immediately after the operation. This observation teaches us that at a time when the prramidal paths are not eomplete anatomically, the motor region is incapable of any apparent physiological function, which is borne out also by the fact that puppies begin to support themselves on their feet only after the pyramidal paths have reeeived their medullary substance.

\section{\$ 2. INFLUENCE OF THE CEREBRAL CORTEX ON THE VEGETATIVE PROCESSES OF THE BODY}

In discussing the innervation of the different regetative organs we have from time to time called attention to the infiuence of the cerebral cortex on their functions. In order to obtain a satisfactory conception of the cortical functions, it will be necessary to summarize briefly these and other similar phenomena in this comnection.

Artificial stimulation of the cerebrum, as we have seen, produces an epileptic attack all too easily; and the excitation in such an attack is spread through the subcortical centers to all the cross-striated muscles. At the same time the respiratory, cardiac and rasomotor centers, the centers controlling the digestive apparatus and those of the iris, are also excited. But while this is of great interest, it gives us no definite information with regard to the probable normal influence of the cerebral cortex itself on these organs and their functions.

In similar experiments on curarized animnls, the epileptic attack is masked because of the paralysis of the skeletal muscles, nerertheless the accompanying phenomena in the regetative organs make their appearance as usual. But these experiments on curarized animals must not be trusted too far (Franck). It appears that the influence which is exercised by the cerebral cortex on the regetative processes proceeds in general from the motor region and its immediate neighborhood. Indeed. Franck asserts that the effects which he has observed on respiration, the heart, blood ressels and salivary secretion in the dog after stimulation of the cerebral cortex can be obtained from almost the entire motor region, but from no other points on the cortex. Respiration is accelerated or slowed according to the strength of the excitation, just as in stimulation of the peripheral sensory nerres, and the depth of respiration is likewise affeeted. The glottis beenmes narrow with the tendeney to expiration and becomes wider with the tendency to inspiration, etc.- With weak stimulation the pulse rate as a rule is accelerated, with strong stimulation it is retarded. The blond ressels constrict. We know also that salivary secretion and contractions of the urinary bladder are influenced from the nuotor region (see page 239 ).

Other authors, however, have reached different conelusions. Aecording to Horsley and Semon, the muscles of the rocal cords and of the larynx in the monkey have their cortical area in the lowermost part of the central convolutions and within this region the following definite movements can be localized: (1) bilateral adduetion of the roeal cords; (2) the same movement. plus movements of the pharyn: (3) elevation of the laryux, aceompanied by movements of the face, the jaws and the tongue: (4) depressinn of the larmx.

Spencer has obtained the following effects on the respiratory morements by stimulation of the cerehral eortex in several different species of animals (monkey, dog, cat, rabbit): slowing and stoppage of respiration by stimulation of the border of the temporal-sphenoidal lobe lateral to the base of the olfactory tract; acceleration of respiration by stimulation of the convex upper surface in 
the region of the motor areas; clonic inspiratory spasm (snufting) by stimulation of the border of the olfactory bulb and tract. also on the uncinate gyrus.

Bechterew and Mislawsky make mention of a vasoconstriction from stimulating certain parts of the motor region, and a vasodilatation from other parts.'

From these observations it may be gathered that the cerebral cortex, especially the motor zone and it: immediate neighlorhond, exercises an unmistakible influence on the vegetative processes of the body.

Doubtless this influence is greater over some organs than over others. Invements like those of the larynx and to a certain extent also those of the thorax. which can be very exactly and very delicately graduated, especially after long practice, must naturally he rery intimately dependent upon the cerebral cortex, eren though the coarser morements of the same anatomical parts, such as are necessary for the mere rentilation of the lungs, are independent of the cerebrum. Quite different effects have been obtained from the cerebral cortex on the heart. blood ressels. etc. These effects, as has been repeatedly observed. are most correctly resarded as reflexes similar to those which are discharged loy all kinds of afferent nerres. Most of them are accessory to the muscular morements controlled by the cortex, and some at least, like the acceleration of the heart and rasoconstriction, accompany every voluntary movement. The chief significance of this cortical influence on the circulatory organs is that they can be thereby adapted to the different requirements placed upon them. The effects of psychical states on the regetative functions of the borly, which have been discussed at page 5\% , are in all probability mediated by the cerebral cortex.

Finally, there are certain observations which indicate that different portions of the cerebrum have a different influence on the general state of nutrition of the body. Thus, if a large part of the most anterior portion of the dog's cerebrum be extirpated on both sides, the animal always exhibits a tendency to become lean and to remain so; he suffers very extensively also from a persistent inflammatory skin disease which is associated with great redness and itching. On the other hand, a dog deprived of its nceipital tobe on both sides regularly becomes fat. It sometimes happens in this case that the dog acquires an eczema also, but it is much more easily held in check and mucli nore easily cured (Goltz).

\section{THE SENSORY CORTICAL AREAS}

'The first methol which we naturally think of in attempting to determine the significance of the cerebral cortex for sensation, jis the investigation of effects upon the different sensations in man and animals which result from lesion, destruction or extirpation of different portions of the cortex. In experiments on animals, however, we meet at once with an obstacle in the fact that we can only judge of the probable loss of sensation by the movements and general behavior of the animal. Our conclusions are therefore tery uncertain, especially in cases where the intelligence of the animal is greatly reduced. Since it is just such cases which ought to be most decisire for the purpose in hand.

${ }^{1}$ For the effects of the cerebral cortex on the digestive organs, see pages 261, 261, 284. 
we are often forced to be content merely with finding that the animal's morements are influenced by some sensory stimulns, without being able definitely to say how far the action may be regarded as the expression of a conscious sensation. or whether it is not rather purely reflex. Our safest and most important conclusions, therefore. we get from observations on man.

We can obtain valuable information also by excitation experiments (of which more further along), by the action current, and especially by anatomical study of the afferent conducting pathways. In this section we shall limit ourselves to the study of regions where the sensory paths end. These regions are known as the sensory areas-tactile area, olfactory area, auditory area, risual area, etc.

\section{A. AREA OF GENERAL SENSATION AND TOUCH}

Since, as we have seen, even the complete removal of a whole hemisphere from a doe does not greatly inconvenience the animal, the locomotor movements being surprisingly little affected, it follows that the regulation of the coarser movements which gres on under the influence of the afferent nerves can be accomplished independently of the cortex. On the other hand, observations by Goltz. H. Munk, and others show that in the dog extirpation of the motor region and of the cortical areas lying immediately adjacent thereto canses all sorts of derangements of the tactile and the motor senses. It follows that the afferent pathways from all parts of the body serving the taetile and motor senses enter these regions. Similar sensory disturbances have been observed in the monkey also after extirpation of the motor region.

When the entire cortical area for the hinder extremity is removed, and as a consequence the muscles of the opposite leg ean no longer execute finely graded movements, for some days after the operation there is eomplete insensibility in this extremity, and a certain bluntuess of sensibility becomes permanent.

With still more extensive destruction, the finer movements of the hand and foot are permanently arrested, and for some time after the operation the sensitiveness of the paws is very much reduced, so that the animal reacts only to very painful stimuli. In fact the sensitiveness of the hand and font becomes permanently so slight that a severe pineh produces no reaction at all (Mott). On the other hand. Schaifer has found that a monkey which does not react at all to a painful pinch immediately notices a very light tactile stimulus applied to the paralyzed extremity.

The monkey (page (6t5) from which (iolty had removed the entire motor reginn of the left henisphere, took no notice of the gentle tactile stimuli applied to the right extremity. Stronger pressure stimuli, howerer, were always folt. The motor sensations were also somewhat diminished.

Althongh the observations made on man difler from one another in many points, on one point there is positive agreement, mamely, that the motor region and its immediate neighborhond is the enrtical area for the sense of touch. It is noteworthy that the motor and sensory disorders are not as a rule eoterminous. In some cases the paralysis involves most of the muscles of the opposite side, whereas the disturbanee in sensation going with it is of but slight extent: in other ease with a shapply circmiscribed motor paralysis, there goes a reduction of sensibility covering a rery considerable area. 
From the summaries of clinical cases of this character it appears with perfect definiteness. howerer. that so far as these particular disorders are concerned. lesions of the occipital, temporal, and the greater part of the frontal lobes are of no consequence: that therefore the cortical field, lesion of which is accompanied by loss of general sensation and touch embraces the central and parietal convolutions. the paracentral lobule and possibly the posterior part of the frontal convolutions.

More detailed study of cases appertaining to this subject appears to show further that the anterior central convolution, the importance of which as a place of origin for the long-fibered efferent tracts was discussed at page 633, can be thrown out of function without entailing any loss of general sensation, that therefore the sensory cortical area consists for the most part of the posterior central and the parietal convolutions. The disturbances to the different modalities of sensation resulting from lesions within these parts of the cortex appear to be rather different in degree. The pain sensations suffer least: the pressure and temperature sensations are said to be somewhat reduced. lunt are not by any means always abolished. The power of localization is very profoundly affected and the patients make very great mistakes when tested for this sense. The motor sensations are likewise much disturbed; patients can neither recognize the exact position of their limbs nor tell when they are moved passirely. Whether there is any dependence of the modality affected upon the exact place of the lesion within the general region, we cannot say definitely at present.

Further proof of the functional relations here indicated is found in the anatomical discoveries concerning the conrergence of the condecting pathways of the tactile and other general sensory nerves into the cercbral cortex. As Flechsig has pointed out, these for the most part enter the posterior central convolution and only a small fractional part of them reaches the anterior central. Besides, the paracentral lobule, the first frontal conrolution and the gyrus fornicatus also receire such fibers. But, on the other hand, the origin of the prramidal pathwars is found chiefly in the paracentral lobule, in the whole anterior central convolution and in the posterior part of the first frontal convolution. It is significant also in view of this arrangement that the anterior central convolution, as well as the posterior part of the first and second frontal conrolutions. has a different structure from that of the other cortical regions and that of the posterior central convolutions. The chief difference consists in the enormous thickness in the former of the layers of the middlesized and the superficial giant pyramidal cells (Cajal. sce Fig. 2St). From these relations we can understand how it is that motor paralysis of cortical origin is not necessarily accompanied by loss of sensibility.

It is also possible to convince oneself by stimulation that the region under consideration is in fact a terminus of sensory nerves. If the central convolutions of an unæsthetized man be stimulated electrically. while he feels no pain there is at first an itchy, prickling sensation in that part of the body whose muscles contract to the stimulus-an observation which agrees with the statements of patients suffering from cortical epilepsy regarding the premonitory symptoms of epileptic attacks.

In short, from the clinical evidence obtained on men and from experiments 
on animals it appears that the cortical area of the general sensory and tactile nerves is rery closely related to the motor cortical field in a spatial sense as well as in a functional sense, but that in man it lies, at least for the most part, outside the motor cortical field (Fig. 293).

\section{B. THE CORTICAL AREAS OF TASTE AND SMELL}

The parts of the brain directly connected with the olfactory organ are very differently developed in different genera of animals. In man, as we hare already seen (page 486), this sense is but slightly dereloped.

Our knowledge of the cortical areas of the olfactory nerves is based almost exclusively on anatomical eridence. Judging by this, the olfactory area in man embraces the whole posterior edge of the base of the frontal lobe and the basal part of the grrus fornicatus on the one hand and the uncus and a part of the neighboring inner apex of the temporal lobe on the other. These two areas are connected at the base of the insula (Fig. 294).

Speaking of the cortical area for the gustatory nerve. Bechterer states that in the dog bilateral destruction of a region corresponding to the anterior lower portion of the third and fourth external convolutions (Fig. 282) obliterates the sense of taste entirely; with unilateral destruction there is total loss of taste on the opposite side and a slight weakening on the same side as the lesion. Following only slight injuries. an improvement is noticeable within a few days, while after more extensire lesions the defect continues for months. Stimulating these portions of the cortex. Bechterew noted contraction of the lips on the opposite side, morements of the tongue, morements of mastication and swallowing.

\section{THE AUDITORY AREA}

H. Munk finds that removal of the temporal lobes on both sides produces complete deafness, but no other disturbance. Extirpation of one temporal lohe makes the animal deaf in the opposite ear. Stimulation of the temporal convolutions produces movements of the external ear which are probably connected in some way with auditory impressions.

Similar results hare been observed by other authors, but we find it stated by still others that bilateral extirpation of these parts produces only temporary deafness or no erident sign of it at all. Brown and Schäfer completely removerl both temporal lobes from a monkey. Immediately after the operation the animal's intelligence was very much affected, but this condition graduelly passed away so that the animal once more became rers intelligent. The authors themselves and several other physiologists and physicians tried numerous experiments with the animal and came to the conclusion that all its senses including hearing were perfectly acute. Moreorer, there was no chance for the claim that the reactions of this animal to auditory stimuli were really due to excitation of the cutaneous nerres. From these observations it appears therefore that the auditory pathwars do not end in the temporal lobes alone, although they may be most concentrated there.

The course of the fibers of the cochlear nerve inside the cerebrum leares no doubt that the temporal lobes in inan stand in rery intimate relation with 


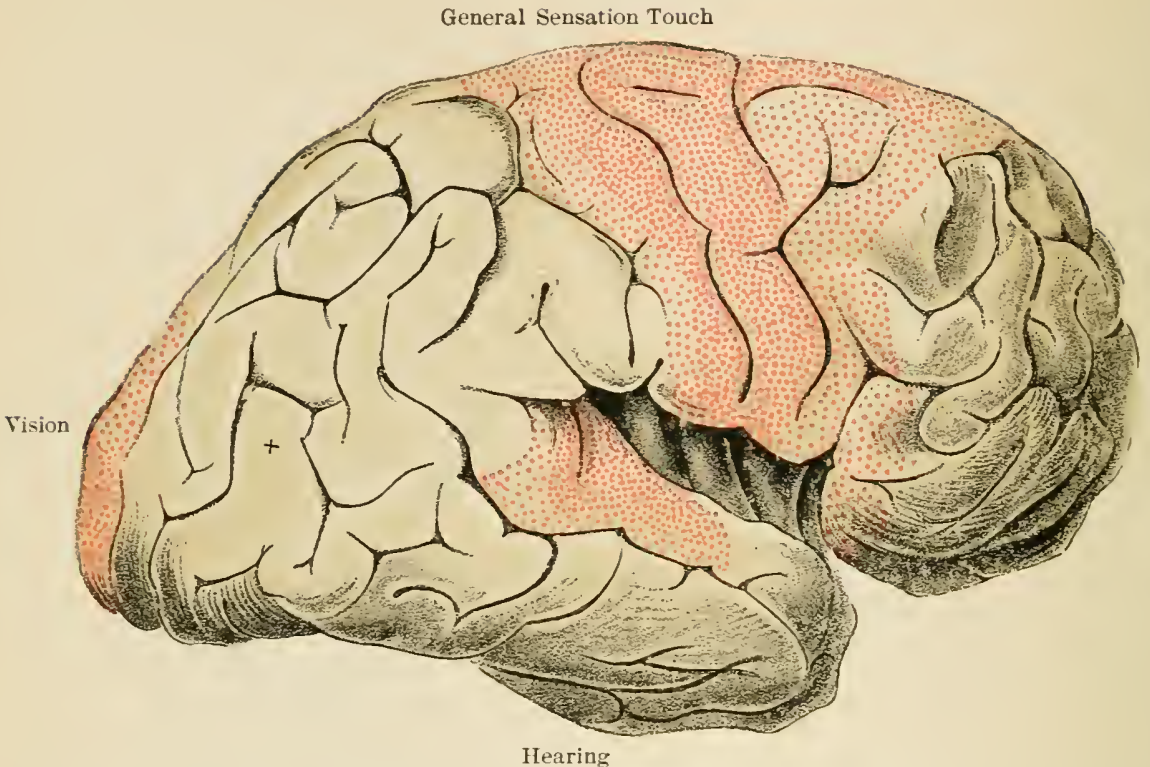

Fig. 293.- Right cerebral hemisphere seen from the outside, after Flechsig. In this and the following figure the sensory areas are inclicated with red dots. The region where the dots are. thickest is the region where most of the sensory pathways end.

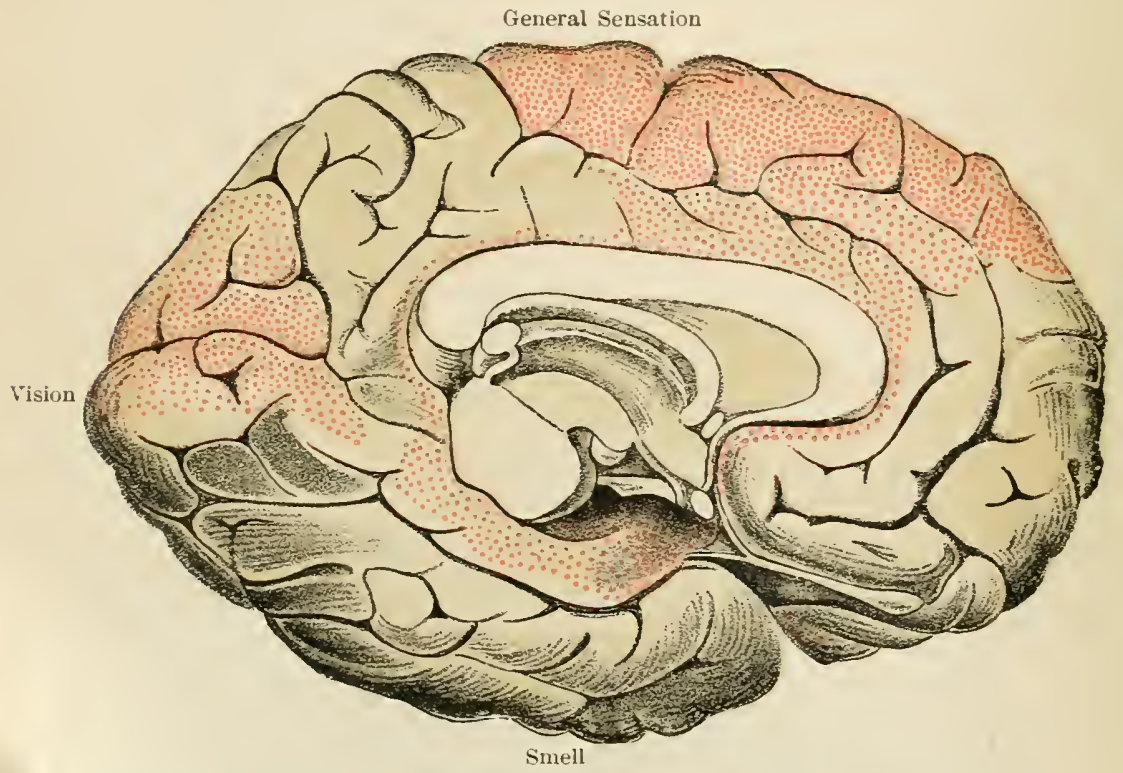

Fig. 294.-The inner surface of the left cerebral hemisphere, after Flechsig. 
the auditory nerves. The fibers of this nerve leaving the ganglion cells of the cochlear nucleus are carried by the lateral fillet to the posterior quadrigeminal body (Flechsig and Bechterew). This is abundantly connected with the internal corpus geniculatum, which in turn is connected exclusively with the cortex of the temporal lobe (v. Monakow). According to Flechsig. the two transverse convolutions of this lobe represent the substations of the auditory nerve.

These convolutions lie deep in the fissure of Sylvius, where they push in between the posterior border of the island of Reil and the outer free surface of the first temporal convolution. The fact that in all cases of total deafness as the result of bilateral destruction of the human cortex thus far known. this region of the two transverse convolutions was affected. speaks strongly for its importance as an auditory cortical area. Cases of deafness or of dull hearing on one side following injury to this region, or to its coronal radiation or to its fibers in the internal capsule, furnish evidence to the same effect.

\section{THE VISUAL AREA}

Experimental as well as clinical and anatomical evidence indicates that the cortical area for the optic nerve is to be sought chiefly in the occipital lobe. Statements differ a great deal as to the exact houndaries of this area, owing in part at least to the fact that in some animals the localization is sharper than in others.

In the $d o g$. according to H. Munk, the two retinæ are projected upon the occipital lobes in the following manner. The extreme lateral part of each retina is represented by the extreme lateral surface of the occipital lobe on the same side. But by far the greater part of each retina is represented by the remaining greater part of the occipital lobe on the opposite side. the inner edge of the retina corresponding to the median edge of the occipital lobe, the upper edge of the retina to the anterior edge of the lobe. and the lower edge to the posterior edge.

As opposed to this (ioltz, among others, has observed after bilateral extirpation of the occipital lobe, that while a great reduction of the visual power and a rery considerable loss of intelligence may result, the animal still cannot be called totally blind. For, although he may not respond to a threat with the hand or with a light, he still is able to avoid olstacles fairly well without being guided in any way by the sense of tonch. These observations show that the animal in this very low mental condition either receives visual sensations through the remaining parts of the cortex. or that the movements can be regulated by retinal impulses with the help of the subcortical centers.

Several authors, however, have observed that in the $\log$ a temporary reduction of the visual power on the eorresponding halves of the two eves (homolateral hemiamblyopia) may result from the removal of other cortical regions (e.g.. the motor zone). One would be inclined to eonelude from this that while most of the fibers from the optic tracts reach the oceipital lobe, some of them have termini in other parts of the cortex. But the following observations by Hitzig, which have recently been confirmed in their entirety by Exner and Imamura, prove that the relationship is still more complex. If a part of the oceipital cortex 
be removed from a dog, and then after the hemiamblyopia has disappeared the motor zone also be removed, no additional effects on vision are produced. But the remarkable thing is that the same is true if the operations be performed in

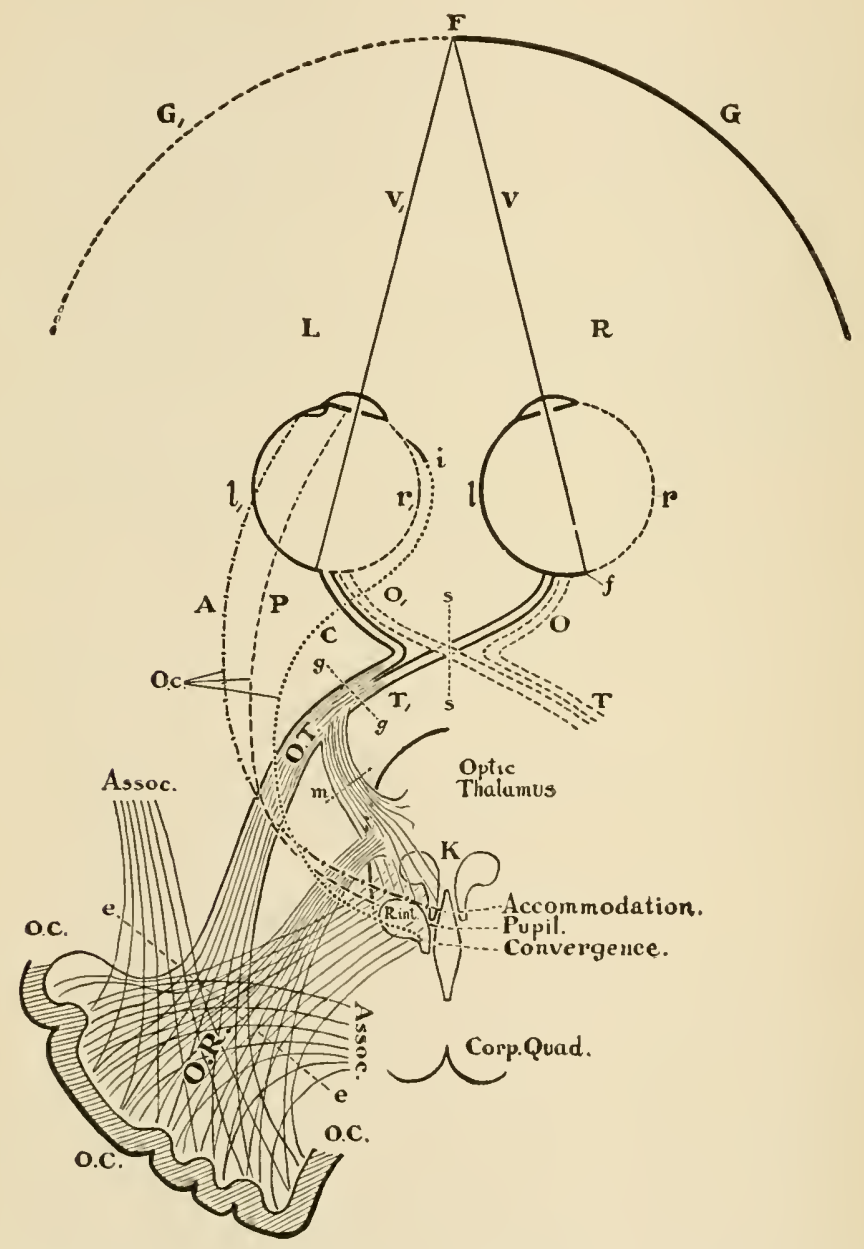

Fra. 295.- Schematic representation of the optic tracts, modified from Fuchs.

Division of the optic tract at $g g$, or $c e$, or removal of the left occipital lobe produces right hemianopia. In the first ease there would be no reaction of the pupil to light on illuminating the left half of either retina. Division of the chiasm at ss produces temporal hemianopia. Division of the fibers at $m$ abolishes the reaction of the pupil to light. The fibers connecting the optical cortex (O.C.) with the midbrain (cf. page 657) and with other portions of the cortex (Assoc.) (page 660) are shown. O.R., optical raliation; O.e., oculo motor nerve.

reverse order. After the hemiamblyopia resulting from removal of the motor zone has passed off, an extirpation within the oceipital lobe is entirely without. effect. We shall discuss the significanec of these facts further along (page 660). 
In the monkey the observations of H. Munk, Brown and Schäfer and others agree in showing that extirpation of one whole oecipital lobe results in loss of rision on the corresponding halves of the two retina (homolateral hemianopia, Fig. 295), and bilateral extirpation in total blindness. According to H. Munk, there should be a projection of the retina upon the occipital lobes of the monkey like that described above for the dog. But Brown and Schäfer have not obtained any positive results in this direction by partial removal of the occipital lobes.

The clinical evidence is perfectly clear that in man the cortical area for the optic nerve is situated in the occipital lobes. A sufficiently extensive lesion of the occipital cortex is followed just as in the monkey by homolateral hemianopia on both sides. As a rule, this is not complete, for the line of separation leares the central part of the visual field intact. In certain individual cases of bilateral hemianopia accompanying lesions of both oceipital lobes, the portion corresponding to the vellow spot may remain entirely free.

Opinions differ considerably as to the exact location of the risual area in the occipital lobe. According to Nothnagel, it is coterminous with the cuneus and the first occipital convolution; according to Vialet. with the whole median surface of the occipital lobe. Still others extend it further, to the first and third occipital convolutions. or even to the angular gyrus, which latter. according to Ferrier, is the region for distinct vision. As opposed to these, and on the strength of some rery convincing cases. Henschen in particular advocates the riew that only the cortex along the calcarine fissure is to be regarded as the area of rision.

Flechsig. on the basis of his embryological studies, takes rery much the same vicw. Most of the optic fibers end in the wall of the calcarine fissure, and those regions of the visual area situated outside of this limited tract have but a limited share in the true visual process.

The visual conducting paths, according to most investigators, take the following course to the occipital cortex. The optic fibers springing from the ganglion cell layer of the retina pass to the chiasm; those corresponding to the outer lateral parts of the retina remain unerossed; the remainder cross. With their end arborizations some come into relation with the ganglion cells of the anterior quadrigeminal boly: many more, and among them the fibers from the macula, with the cells of the external corpus; and a smaller number with cells in the pulvinar. New pathways spring from these rarious cells and make their way to the occipital lobes.

In the opinion of $\mathrm{v}$. Monakow. the reason the macula region so often remains intact in cerebral lesions is that it is probably represented throughout liv a rather extensive cortical zone: the macula fibers then would be connected witl practically all parts of the corpus geniculatum ext.: conseruently, if the lesion left any fibers to the cortex intact. impulses from the macula could still be transmitted.

According to Flechsig, efferent fibers pass out from the necipital lobes, and convey impulses from the cortex to the optic thalamus and the anterior corpus quadrigenum by way of which impulses can be conveyed from the optie lobes to various museles and other peripheral organs. 
Artificial stimulation of the cortex back of the angular grrus in the monkey (H. Munk. Schäfer) gives conjugate movements of the eves toward the opposite side, the plane of rision being at the same time directed upwarl, downward or horizontally, according as different points of this region are stimulated. The latent period of these movements is longer than that of corresponding eye movements which appear on stimulation of the frontal lnhe, they are also obtained after removal of the frontal lole; hence are probally evolied through the alove-mentioned sulieortical centers. The same movements occur when the occipital cortex and the eye region of the opposite frontal lobe are stimulated simultaneously.

Movements of the iris also can be aroused by stimulation of the cercbral cortex. Dilatation of the pupil is most easily obtained in the monkey by stimulation of the motor region for the cye muscles and of the occipital lobe. This dilatation appears when the eervieal sympathetics are cut, and probably must be regarded as at least partly due to an inhibition of the sphineter muscle. Constriction of the pupil seems to be obtained only as an exceptional result of cortical stimulation.

\section{E. RECAPITULATION}

" From the facts which have just been brought forward with regard to the cortical areas of the nerres of special sense, it appears probable that ther, like the motor areas. become more sharply concentrated the higher we ascend in the scale of mammals; also that their importance for special sensations becomes greater and greater. Moreover, it is evident that, as a general rule. efferent paths from all the sensory cortieal areas are so arranged as to convey impulses to just those muscles which are of the most serviee to the particular senses. Thus, the cortical field for the sensory nerres of the skin, of the muscles and the joints lies in the immediate vicinity of the great motor eortical area or practically enincides with it; we get movements of the ears from the temporal Inbes where lie the auditory areas, and movements of the eves from the occipital region. We shall discuss the deeper physiological and psychological significance of these enrtical areas in the following section.

\section{SECOND SECTION}

\section{THE PSYCHO-PHYSICAL FUNCTIONS OF THE CEREBRUM}

While an exhanstive discussion of the psychical activities of man is plainly out of the question in this book. a brief summary of the most important facts of morlern phrsiological psychnlogy secms called for here, because. quite independently of any particular psychological system, or of any spiritualistic or materialistic point of riew, these facts may of themselves afford us raluable insight into the complex mechanism of ecrebral activity. We designate these functions psycho-physical in order to expressly indicate that we shall discuss them not from the standpoint of metaphysics, but solely from the standpoint of physinlngy, and without wishing to take any position with reference to spiritualism or materialism. 


\section{\$ 1. THE SIGNIFICANCE OF THE MOTOR AND SENSORY CORTICAL AREAS}

We have seen that the motor cortical areas constitute the place of origin of the long-fibered motor pathways and that the sensory pathways terminate in different cortical areas. What then is the physiological and peychological significance of these areas:

Thenretically, the simplest psychical events probably take place in the cortical areas of the higher senses, for in such events the lonlily movements play but a relatively subordinate part, or at least do not oceupy so prominent il place in consciousness as do the sensory components of our experiences. We shall therefore begin with the sensory areas.

The conception most widely held at present is, that the excitation of these. rorlical fields itself produces the appropriate simple. special sensations; that the simple visual sensations, for example, arise in the visual area of the occipital lobe; the simple anditory sensations in the auditory area of the temporal lobe, ete.

But this cannot be looked upon as actually proved. If, for example. we follow in our imagination the conducting pathway of optical impressions frome the periphery to the cerebral cortex it is evident at once that any complete interruption of that pathway, no matter where it might ocenr, wonld eause total hindness: also that any partial intermption. wherever it might oceur, would necessarily produce partial blindness. From this point of riew it is a matter of indifference whether the interruption take place by a peripheral lexion or by a lesion in the corresponding part of the optical cortex. If only we can assume that the activity of any part of the cerelorum, be it never so small, will necasion a conscious process, then one can say that the simplest visual impression is produced by excitation of the optical area in the cortex. But this is only an unproved postulate.

Moreorer, our simplest conscious states are always very eomplicated. With the simplest optical impresion-that, for example, of a luminous point-we olserve not only the strength of the light and the colnr, but its position ine the field of rision, its apparent distance from the eve, its apparent size. All this is given at the first glance, and it is at least very ditficult to suppose that all this can come into consciousness by the aetivity of the optical cortex aline.

It would appear to be justifiable therefore to assume that pathways pass out from the optical eortex and connect this field with others, and that eren the simplest visual sensations require the coöperation of several different (urtical regions. The excitation furnished the optical cortical area is of (ourse an important. perhaps the most important, component of the whole proces. And with Flechig we would especially emphasize the point that what gives the sensation its active character. what makes it essentially clear and distinct. is bronght about by this rery enmponent.

The manifold ways in which the different sensory areas are connected together and the great importance of such ennnection for the oljective raluation of our sense impressions are beantifully illustrated by the following whervation on suecessfnlly operated patients hom hlind. Such mersons learn to recognize an external object presented to them by feeling it with the fingers 
-i. e., the risual impression gets its proper interpretation through the idea already gained by touch. But if the patient has seen in this way an object a single time, he is able to reeognize it immediately with the eye the next time. The connections of the optieal center with the other parts of the cerebral cortex were therefore already present, and it was only necessary for the patient to compare the visual impression with the tactile impression a single time in order to fix the memory picture of the object permanently. It can scarcely hec maintained therefore that the optical memory pictures are. as has so often been assumed, so to speak imprinted on the optical cortex, for in eases like these just deseribed there would not be time enough to form such an imprint.

The exhaustive analysis which Exner has made of the visual disorders observed by Hitzig following lesions of the motor cortex in the dog (ef. page 655) shows that different cortical fields participate in the pereeption of things visually. When the cortex within the motor region is destroyed, many fibers which comnect the oecipital lobe with this region are severed. Hence the perception aroused by appropriate stimulation of the optic nerve will be wanting in thrse components which relate to motility. Consequently the elaboration of the visual impression after the operation becomes deficient and hemiamblyopia sets in, notwithstanding that the optical cortex is intact. Reeovery from the visual disorder is possible because the hemisphere of the opposite side takes up the functions of the injured side, connections being gradually established which lead ultimately to complete restitution of function. Extirpation within the occipital lobe of the injured henisphere now is without effect because this hemisphere has no further part to play in the elaboration of visual impressions.

This interpretation reeeives substantial support from the faet that section of the corpus callosum-which in an injured animal is without demonstrable effert (see page 6+1) -in a dog which has already hst the motor zone and has recovered from the resulting hemiamblyopia, immediately produces this disorder again and leaves no possibility of reeovery. Likewise the hemiamblyopia continues permanently if one removes a piece of the cortex and at the same time sections the corpus callosum.

What has here been said of the visual area is of enurse true for the enrtical areas of the other higher senses, and for those of general cutaneous sensation, touch, etc.: the excitation immediately aroused is ennveyed by means of new pathwars to other parts of the brain. and loy the eöpperation of several different cortical fields the conscious proeess associated with those particular senses is aroused.

From all that we know of the central organs of the nerrous system. it appears very probalble that the motor cortical fields do not of themselves originate the impulses which they send to the muscles of the body, but that they must first be acted upon by other cortical regions. We naturally think first of the closely associated sensory cortical region as a source of such cxcitation, and it cannot be denied on purely a miori ground that in very many simple movements aronsed by the cortex, the efferent impulse is discharged hy an afferent impulse very much after the manner of a reflex. Here belongs the touch reflex, for example, described by H. Mnk, which consists of a feeble flexion of the toes and the font, when the hairs on the back of the foot are lightly stroked the wrong way, and which is permanently lost after 
extirpation of the cortical region corresponding to the extremities. This mechanism, however, does not suffice for complicated movements, and still less for learning new morements. In such cases several other portions of the cortex must be ealled into play and it is these which finally stimulate the discharging cells of the motor pathways.

This conclusion is supported by the circumstance that in localized artificial stimulation within the motor cortex (provided no epileptic attack is induced) the movements obtained are always relatively simple, being confined to a few groups of muscles. They almost always lack the orderly coördination of several different groups which characterize the voluntary movements, and even appear in certain reflexes from the spinal cord (see page $58 \%$ ).

The following observation may be cited as still further support for this conception. If the cortical area of a definite part of the body be sought out by electrical stimulation, and it be then isolated from the rest of the cortex by a circular cut, the effect is just the same as if it were extirpated in toto, although the blood supply may not have been disturbed by the process of eutting (Marique, Exner, and Paneth).

The following experiment by J. R. Ewald likewise speaks against the idea that the voluntary motor impulses originate in the motor cortical areas. A small hole is made in the skull of a $\mathrm{dog}$ and after opening the dura mater, electrodes are fastened in in such a way that the cortex can be stimulated as the animal moves freely about. Different movements can then be induced according as one or the other of the cortical fields is stimulated; but the animal takes no notice of them, even when just in the act of making a voluntary movement. It is clear that such a stimulus does not interfere with the normal stimulus, which, it would seem, therefore, must originate elsewhere.

\section{\$. 2. LANGUAGE FACULTIES}

The ability to use language, as even a cursory surrey of the way in which we acquire the power of speech will show, requires the coöperation of a number of different parts of the cerebral cortex. Lesions in different parts of the cortex and of the corona radiata produce various disorders in the language powers, the study of which will give us further insight into the mechanism conecrned in psychophysical processes. What foilows is based mainly on the ideas of $r$. Monakow.

A child is born with the ability to move all his muscles; he sces and hears. But he lacks for the most part the power to coördinate his morements to any purpose: he does not understand what he sees, he does not comprehend what he hears; he has "no language but a crry." But his power to see and to hear begins to be exercised. He gradually learns to recognize people and the commonest objects about him, he hears the names by which these people and things are called and learns little by little to recognize them. Finally, he begins to imitate these sounds and after many fruitless attempts succeds at last in compassing the first intelligible and orderly articulate sound. This is usually the name of his mother.

And so it goes on. The child gains wider knowledge from the appearance of different objects, learns their names and practices them-i.e., learns to make the necessary movements of his orgaus of speech. 
Soon the ability to form ideas is developed, by which we mean that the child learns to include the single concrete objects of the same kind under a common designation. And as his mental powers derelop still further, he comes to incorporate into his circle of ideas notions concerning the relations of objects to one another, notions of their properties, their position in time and space, etc. Finally, the abstract ideas also begin to be more than mere words for the child, and a view of the world, as yet of course very vague and indefinite, becomes his own.

In all this course of derelopment of the mental powers, speech plays a determining part and this part becomes more significant the more the child comes to rels upon abstract ideas. He requires no great store of words to represent objects themselves and their simplest relations to each other, for direct contemplation will serve him here. But when it comes to more complicated

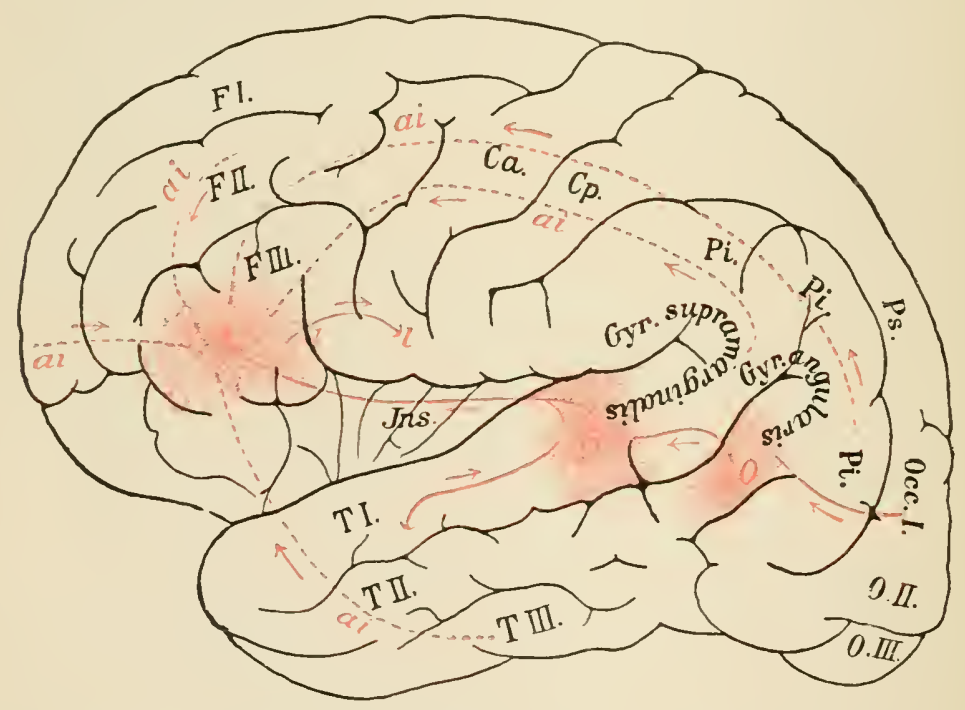

FIG. 296. - Diagram of the speech tract together with the various centers of the cerebral cortex concerned in speech. $L$, area of the image of speech movements; $A$, area of word-sound memory; $O$, area of memory for the optic images of writing; Occ.I., O.II.,O.III., first to third occipital convolutions; $F I ., F I I$., first and second frontal convolutions; $F I I I$, third frontal convolution (Broca's area); $T I ., T I I ., T I I I$., first to third temporal convolutions; $C p$., posterior central convolution: $P$ i., inferior parictal gyrus; Ins., island of Reil; $a i$, association tracts between $L$ and the central portions of the association areas; $L i$, motor speech tract.

relations of concrete objects, and especially to abstract ideas, a satisfactory conception can only be gained through the medium of language.

The names of concrete objects have therefore much less significance for our mental operations than the words by which we designate abstract ideas, and we may conclude from this that the latter require a more complex order of activity on the part of the brain than the former. Accordingly we find in certain disorders of speech resulting from injuries in the brain-e. g., in lighter forms of the so-called amnestic aphasia-that the patients forget proper names and the names of things, while abstract substantives, verbs, adjectives, conjunctions, etc., are retained. 
The language faculties make a distinet advance when the ehild learns to read and write. The symbols of spoken words used in written languagewords and the letters of which they are eomposed-are inculeated in the same way as spoken words, and at the same time the ability is aequired to reproduce these symbols in writing. The movements used in writing, just like other morements, are controlled by various afferent impulses.

Our powers of language are made up therefore of the following components: (1) Memory pictures of the written and spoken words: (2) the ability to make the coordinated morements necessary in speech and writing: (3) constant control of this ability through various afferent pathways.

Lesions in certain regions of the cortex or in the eorona radiata produce disturbanees of greater or less extent in these delieate mechanisms, which are comprehended under the name of aphasia, and differ in kind and extent according to the place of lesion.

One of the simplest forms of aphasia is that of alexia, or word blindness, which is characterized by the inability to recognize written or printed letters or to eompose words of them. This disorder (in right-handed people) follows injury to the white matter of the left angular gyrus and of the second occipital convolution. the corresponding cortex remaining uninjured. Simple alexia would thus be produced by interruption of the association fibers connecting the visual cortical area with other cortical regions which are active in the use of language. When the cortex alone of the angular grrus is affected. alexia does not ensue, and this may be taken as a proof that that portion of the cortex is not. as has been supposed by many authors. the "center " for reading.

Alexia may occur without affecting the ability to speak, and this is readily understood when we remember that aside from writing reading is the latest aepuirement in the development of the language powers, and might well exercise but a slight influence on the speech meehanism pure and simple.

It is possible for the patient to be able to write eren when he cannot read. and this is explained by supposing that the association pathwars which are active in writing have escaped the lesion. Such a patient may even sueceed in deciphering script or printing by exeeuting the appropriate movements for making the letters which he sees, but would not otherwise eomprehend. In this ans he reads by using the memory pietures of these movements and by bringing them through association fibers into eonnection with the cortical areas which mediate the necessary movements of the organ of speech.

Other disorders of the language powers are produeed by lesions within the red area in Fig. :96; and the white matter lying immediately under it. In right-handed people it is always the left hemisphere which is affected. These disorders differ both in kind and extent, and can be divided into two groups -motor and selsory aphasia-according as the expressive or the pereptive phase of language is the more affected. Between the two are various intermediate modifications.

Motor aphasia. which through the work of Broea has heen of so mueh importance for the development of our views concerning the functions of the corchrum (see page (i31), apprars in its purest and simplest form when only the special motor functions of specch are arrested. In this ease the person 
affected can write and can understand written or spoken words normally, but eannot speak or read aloud either voluntarily or after another person. The part affected is only the subeortical portion beneath the posterior third of the third frontal convolution. The lesion interrupts only the eonducting pathways serving the organs of speech, on their way to the internal eapsule.

But if the cortex of the posterior part of the third frontal convolution (Broca's convolution) is injured, other disorders appear even though the lesion be a very slight one. The patient now loses, besides the power of speaking. the power of writing spontaneously, although he may acquire it again. The ability to write by dictation is alwars partially destroyed soon after the lesion makes its appearance.

More profound still are the disorders when the third left frontal convolution is somewhat more extensively injured. Writing spontaneously and by dietation beeomes very difficult, although the defect is not due to any motor effects on the right arm. It is diftieult for the patient to understand written or printed words eren though he may recognize them perfectly; he quiekly tires of reading. and camnot compose words when the proper letters are shown him one after the other, cannot recognize words when the letters are placed rertieally instead of horizontally, ete. On the other hand, the ability to monderstand spoliten words and to copy works in writing is generally unimpaired.

When the superior temporal eonvolution is injured somewhat extensively, the other typical form of aphasia appears. This is called, from its most prominent symptom, word deafness or, after Wernicke who first lescribed it, sensory aphasia.

This form of aphasia may also be very simple in character: the patient ean speak, read and write: his comprebension of language is undisturbed, but he cannot understand spoken words, whereas he can not only hear hut also correctly interpret every other kind of noise and sound. He, lacks the ability to interpret the sounds of letters; and this is probably due to the interruption of eertain association pathways. the elements serving other language faculties remaining unimpaired.

As a rule, however, word deafness is closely associated with much more serious disorders. This is what we should expect, if we remember how great is the influence of spoken works on the total language powers, and how numerous are the connections of the auditory association pathways with other parts of the brain. Any enrtical lesion in the temporal lobe must therefore necessarily involve many different bundles of association fibers; consequently word deafness is accompanied by many different effects on the general language powers.

Clinical observations have given us the following faets with respeet to this form of aphasia. With lesions in the posterior part of the first temporal consolution, voluntary speech appears on superficial examination not to be particularly affeeted. hut in reality it is always paraphasic-i. e. the person shows an inclination to confuse words and to talk gibherish: and sinee the auditory control is largely impaired he makes all sorts of errors in enunciation without being aware of them. Repeating words after another person is for the most part impossible. because the sounds of words are not retained long enough in the memory to be understood. Reading aloud is ont of the 
question. because, while the letters are seen, they are not alwars recognized as signs of certain definite sounds. The ability to write spontaneously or after dictation is very profoundly affected and the ability to copy is often somewhat reduced. We find likewise when the destruction is somewhat more extensise that it is always difficult and sometimes impossible for the patient to umlerstand writing.

The disorders which are produced by lesions of the first temporal convolution may vary also according to the mental and literary culture of the individual. Ifighly edueated persons suffer less in their ability to understand written or spoken words or in their ability to write than do the unedueated.

liecovery of language pourers lost by these various lesions is to a greater or less extent possible. 'This is explained in part by the assmmption of the lost functions by the right hemisphere. and in part possibly by the establishment of new associations by means of collateral and other connections which have been left unharmed.

When the language powers are destroged to any great extent, the mental powers must naturally suffer. IIere again the extent and duration of the disorder will depend upon the position and extent of the lesion as well as upon the relative importance of the different components in the person's particular language mechanism. If, as is usually the ease, the individual is intlueneed most by the sound images of words, word deafness would naturally produce a greater reduction in his intelligence than if he relied mainly upon memory pictures of printed or written worls.

Closely related but not identical with the language faenlties are the musical faculties. Music constitutes a language of its own, the finer munees of which are intelligible only to a relatively few farored individuals. ('linical observations made with in recent vears have shown that hrain disedses may canse disorlers in these powers exactly similar to those affecting the ordinary language faculties. 'Thus we find losis of the ability to sing (vocal motor aphasia). note blindness, loss of the ability to write musical notes (musical agraphia). tone deafness, cte., all of which are comprehended muler the general term amusia. There is also a certain degree of independence hoth in the relation of these to one another and in their relations to aphasia. For example, a person may be able to sing and not to speak. or to speak and not to sing. It is probable that at least certain of the special clinical forms of amusia are anatomically independent, and that they are cansed by lesions in the ricinity of those which profluce the different forms of aphasia. The localization for that special form of amusia known as tone deafness, which is characterized by los: of the ability to recognize musical sound: as such. is probally in the first or first and sccond convolutions of the left temporal lobe in front of the region the destruction of which causes word deafness (Edgren).

\section{\$ 3. THE ASSOCIATION CENTERS OF FLECHSIG}

The discussion in the preceding paragraphs has taught us that the higher functions of the lorain which are in the immerliate service of the mental faculties are earried out under the coöperation of several cortical regions. Brain 
anatomy has long since demonstrated varjons systems of fiber's by which the two hemispheres and different rexions of the same hemisphere are joined together. And quite recently our knowledge of the subject has been enriched $\therefore$ materially by the investigations of Flechsig that future researches in this field will have a much safer point of departure than hitherto.

\section{A. ANATOMICAL}

From what we have learned in preceding sections we know that only about one third of the entire surface of the cerebrum is in direct connection with tracts which mediate sensory impressions and arouse mental mechanisms. We know, moreover, both from the anatomical strueture of the brain and from the fairly rertain localization of cortical motor and sensory areas, that the remaining parts of the cerchral cortex have nothing whatever to do with afferent or efferent tracts. 'They serve to connect and associate the impulses delivered by the sensory nerves, to originate the resulting motor impulses, and

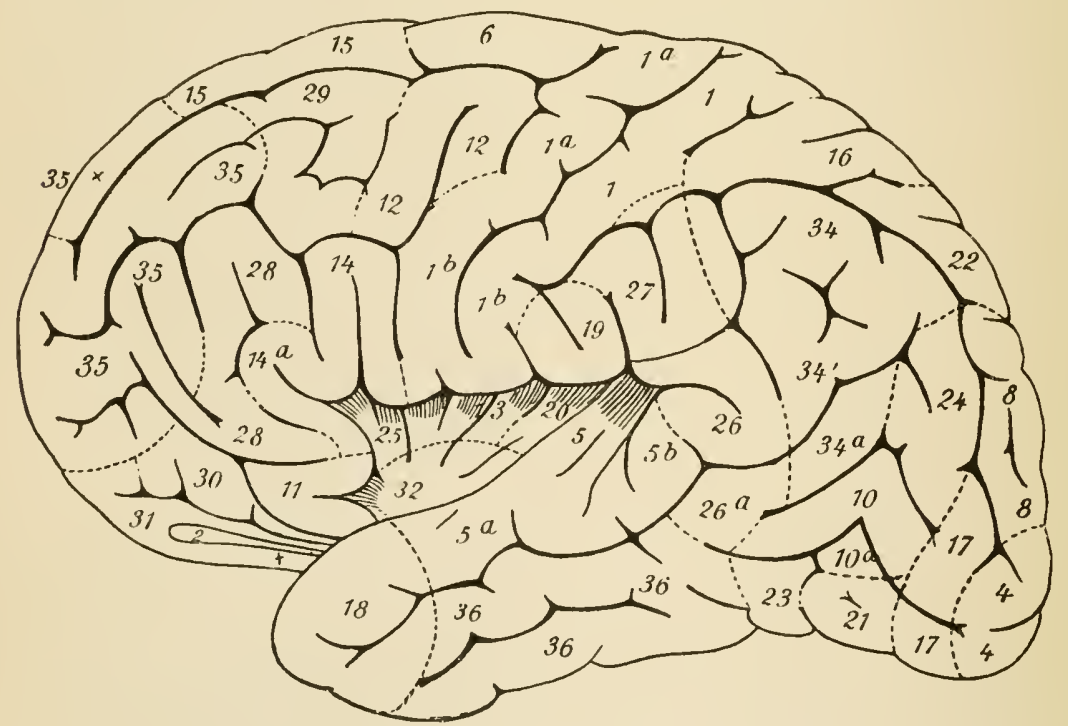

Fic. 297. - The myelogenetic areas of the human brain, outer surface, after Flechsig.

to elaborate pereptions into higher mental processes; in short. these parts are to be regarded as the organs of our purety psychical actirities. We shall speak of them in the following pages as the association centers.

The find sufficient grounds for this view both in the elinieal observations which have been made and in the results of anatomical investigation. The microseopical structure of these parts of the cortex alone indicates that they are of clifferent character from the other cortical areas. While the cortical arcas of the nerves of special sense possess in each ease something which clearly recalls the distribution of nerves, in the particular peripheral organ to which each corresponds, the association centers have more in common. Although 
they are scattered widely over the surface of the cerebrum, the microscopical structure is much the same type in all of them.

The same thing is taught by the mode of development of the myelin substance in the white matter of the brain. It is well known, through the work of Flechsig, that the fibers running to certain areas of the cortex receive their medullary sheaths much earlier than those running to other areas. In fact, at a time when the myelin substance in some convolutions is almost entirely complete, in others it is just beginning, and in still others has reached a medium stage of devolopment. At certain stages, therefore, we can distinguish medul-

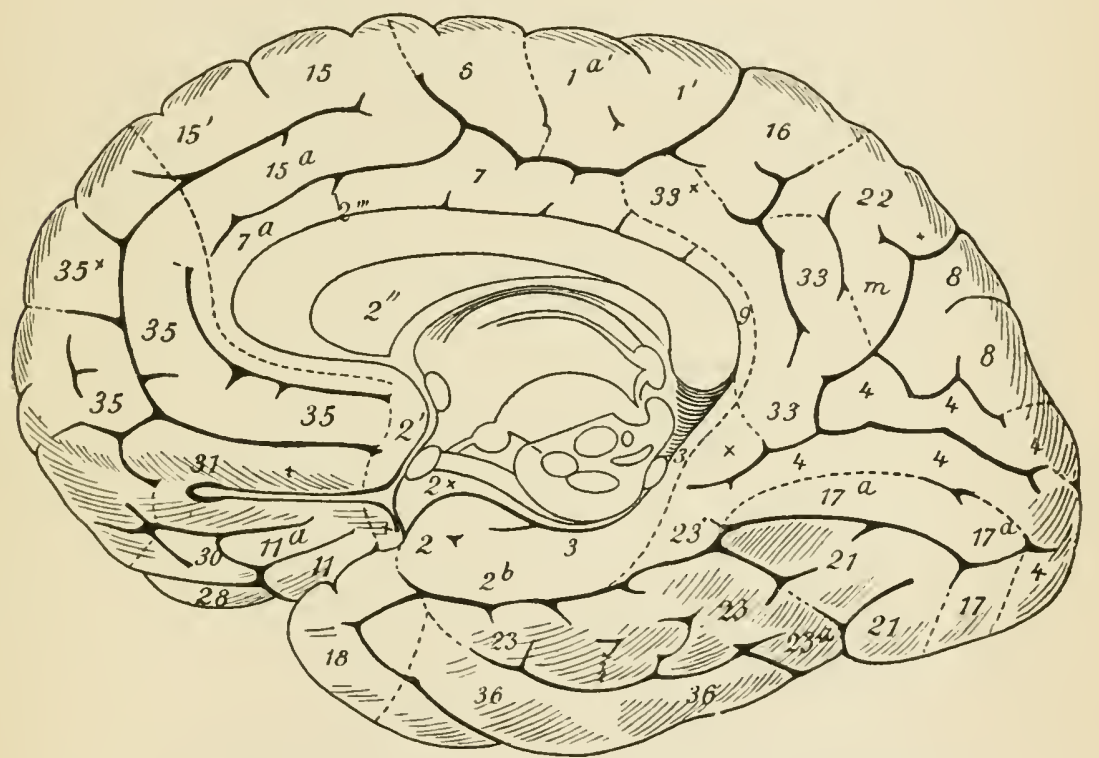

Fic. 298.-Myelogenetic areas of the human brain, inner surface, after Flechsig.

lated, nommedullated and half-medullated convolutions which present uniform structures throughout, and in all individuals of anproximately the same age have practically the same relative position. Flechsig distinguishes thirty-six such "myelogenetic" areas. They are numbered according to the order in which they receive their myelin substance, and are divided ehronologically into three groups.

'Those areas which are mostly myelinated at birth at term are called by Flechsig primordial regions: here belong Nos. 1 to 10, Figs. 297 and 295 . Anatomically they are distinguished manly by their great richness in paths to and from the subeortical centers (projection fibers). By comparison of Fig's. 297 and 298 with Figs. 298 and 294 , it may be seen that these areas rubrace the points of entrance into the cortex of all sensory pathways as well as the points of rxit of all the motor pathways. It is not known at present whether eertain of these primordial regions (for example, No. 10, Fig. 29\%) are connected with periplieral end organs or not.

The second group of cortical areas includes the intermediar! regions (Nos. 11 to 30$)$ in which the myelination bexins before the end of the first month after birth. To the third group, the terminal regions, betong these areas which are myelinated after the first month (31 to 36$)$. Tn these as well as the most 
intermediary regions there are fewer projection fibers than in the primordial regions. Individual fibers indeed are to be demonstrated, but they are rery searee as compared with those in other tracts.

The terminal regions, on the other hand, are richest in association fibers, that is, in fibers rumning from one region of the eortex to the other; in fact they may be said to constitute the nodal points of the long assoeiation systems. But there are no long systems to be found which ean he said to unite any two primordial regions regarded as sensory eenters. A visual and an auditory impression, for example, could not meet in a primordial center: this conld only happen in one of the intermediary or terminal regions.

The last named therefore constitute association centers. Three regions in each hemisphere are embraced by them, namely, a frontal or anterior. an insular or middle, and a parieto-occipito-temporal or posterior region. There is mo reason to believe that these three are of equal importance for the psychical functions: in fact their positions with reference to the different sensory areas would seem to indicate that they have special functions. The postrior association eenter is interealated between the risual, the auditory and the tactile areas: the anterior between the tactile and the olfactoryprobahly also the gnstatory-areas: the midnle between the auditory. the olfactory and the tactile areas.

The anterior center is formed by the anterior half of the first and the greater part of the seeond convolutions. On the basal side of the frontal lobe the grrus rectus partieularly belongs to this center. The midlle eenter eovers the insula. The posterior center embraces the precuneus. the parietal conmolutions, parts of the lingual gyrus. the fusiform grrus. the second and third temporal and the anterior portions of all three oceipital conrolutions (see Figs. 293 and 294).

\section{B. THE ANTERIOR ASSOCIATION CENTER}

We have already learned from obserrations on animals that extirpation of the frontal lobes produces noteworthy alterations in the intelligence and charaeter of the animal. After removal of the most anterior portion of the brain, dogs become exceedingly irritable. Harmless, good-natured animals become fieree and malieious, so that after the operation they will not even allow themselves to be touehed. The animal's movements are exeeedingly cumbrous and awkward. He eannot hold a bone firmly. his whole carriage of himself is unsteady, he stumbles easily and on a slippery floor at once loses his footing (foltz).

In line with this. Bianchi has observed that the intelligence with which a monkey performs complicated acts is often greatly affected by the removal of both frontal lobes.

Similar changes in character have not infrequently been ohserved in men with lesions of the frontal conrolutions. Persons. who before were well disposed and orderly, beeame foolish, impatient and headstrong. and at the same time changeable and fickle. Teither sensory nor motor disorders of any kind can he demonstrated on them (ITelt).

THechsig has given the following description of the offects of lesions in the frontal association centers observer on men. The patient sometimes loses 
all sense of his actual relations to the world, imagining hinisilf possessed of great wealth, or the recipient of high honors; sometimes loe confuses perceptions of external objects with the inner consciousness of his own person, or vice rerst, his conscionsness of himself with impressions of the outer world, so that he either forgets that he exists or takes no notice of his surroundings. There need be no confusion of ideas in the strict sense of the term. He may speak rationally and in a perfectly orderly way about rarious subjects within his mental grasp, but he is unable to distinguish hetween the true and the false, the imaginary and the real, the possible and the inpossible; and along with this defect of the logical sense there goes a loss of the ethical and esthetic julgunents. so that he does things which are ntterly irreencilalule with his former clabracter. The patient thus loses his composure, and this to a greater degres the more he is actuated by stroner feeling or is unter the influence of passion. When once he becomes angered, a fit of rage eomes orer him like an avalanche. $A$ stage is finally reached where all self-entrol is lost and he is ruled in everything merely liy the lngic of madness. Whatever is uppermost in his mint he does without regard to his surroundings or to good taste. At last imbeeility sets in and the personality is lost entirely.

\section{THE POSTERIOR ASSOCIATION CENTER}

Gioltz observed the following effects of removing the oceipital lobes from dogs. The tactile sense was undisturbed, the animal was not merely able to move all the museles of his body voluntarily, but enuld perform all kinds of movements with almost as much facility as a normal animal. He had no trouble in eating and could hold a bone between the paws. ete.

If the animal were vicious before the uperation, removal of the oecipital lobes made him docile. Nothing then served to "x"itr him; he was always calm and deliberate. But his pereeptive faculties steffered considerable diminution and his intelligence sank to a low level.

In man lesions within the posterior association center have heen observed to problue alexia (cf. prage fi6i3), and a more or less distinctive lose of the power to interpret ristal impressions of other kinds. 111 sucts disorders. whatever their extent, are induded under the term " mind blindnes." eriven by H. Munk.

Typieal mind hlinduess in man is characterized low v. Mnnakow in the following manner: The peron affected has impressions and sensations of light but can no longer recognize the objects of his surroundings. This is not beeanse bis memory pietures of the objects are gone, but beause the associations necessary for understanding them are no longer possible, that is, the memory pietures eamnot he ealled up by the retinal stimulus, although they may be aronsed by anotler sense, or quite spontaneonsly. Among other things: a person ean tell one color from another but eamot find the right names for the colors. IIe cannot tell just the quality of the collor of the sky, or of leaves, or of blood, ete.

While the memory for many different forms of visual impressions may be inst as good as ever, it appears as a rule to be ennsiderably impaired for recent impressions. Such patients are mable to deseribe the forms of objects presented to them just a moment before, while they have a perfeetly elear pieture of objects with which they are faniliar, such as a knife or a watch, and can 
describe them. They can also acquire new optical images, but it is much more difficult than formerly. Sometimes the memory for old and familiar objects as well as for less familiar ones is affeeted and the person cannot describe wellknown buildings and streets of his own town so as to direet another person how to go from one point to another. In severe forms of mind blindness all objects and persons alike appear strange, and may not be recognized even in their general relations.

What the patient is unable to recognize by optical impressions alone, he can, however, properly orient by means of other impressions-for example, auditory inpressions. Thus a patient who fails to recognize his own friends by sight may reeognize them by their voices, ete.

Mind blinduess enmes on if the lesion extends to the white matter of the necipital lobe. and in all probability is eansed by the interruption of the association pathways and by injury to the association areas. It is not referable to any definite locality, but can be produced by alscesses in different parts of the lobe. In the great majority of cases thus far observed, the abseesses are sitnated in both hemispheres. Mind blindness has not ret been observed as the result of disease on the right side alone.

The phenomena of mind blindness undoubtedly show that the necipital lobes play a determining part in the proper evaluation of optical impressions. Observations on more extensive lesions of the posterior association eenter, in Flechsig's sense, teach us also that mental disorders of a more serious nature may result from the loss of its function.

The first symptom of a diseased condition involving a large part of this eenter is ineoherence of ideas, that is, a primary intellectual defieieney and something ruite independent of the effeets which follow purely and simply as the result of a loss of ordinary associative connection of external impressions. Many of these patients exhibit no lack of elearness as to their own person. evinee no lack of eomposure in their ennduet, no deep perversion of their feelings or desires; but they do not correctly interpret external objects, and consequently misuse them. They mistake one person for another, and lose their bearings both spatially and temporally. 'The mental images of what goes on outside are lost. consequently a elear understanding of the external world and that knowledge of it which is eapable of being put into words: in short. all empirieal interpretations of external impressions are reduced to naught. The patient has thus hecome imporerished for ideas, eventually nothing either true or false enters his head-he has become an idiot.

\section{FINAL SURVEY}

It is likely that in the more enmplieated mental proenses all the association and sensory centers enöperate, since they are united with each other by numerous nerve fibers. and that from this coöperation results the harmony of the cerebral functions.

Flechsig has worked ont some riews with regard to the mechanics of the higher brain functions. which I shall abstract briefly here, because amnng morlern researches on the brain which have a plyysiological bearing those of Flechsig undoubtedly take first rank. 
Since the memory always sulfers to a great extent from destruction of the association centers, the nervous elements with which the ability to recall sense impressions is connected must unquestionably be sought mainly in those centers. The ganglion cells play the chief rôle in this becanse, so far as our experience ret goes. they alone of all the nervous elements are able to store up impulses and to become charged with energy. Without knowing anything about it, we may suppose that the number of nerve elements which are active in the simplest event of consciousness must he rery great.

What we do know with certainty is, that tokens of memory (memory pietures) which are imprinted, so to speak, in the brain elements are more or less firmly related to each other; and the basis of this organic unity of memory lies in the systematic arrangement of the numberless disparate constituents of its physical gromndwork.

The question as to what are the physical forees which bring the memory pietures hack to consciousness is one of particular interest. We commonly attribute the greatest importance to our sense impressions. impressions of the outer world, and, as a matter of fact. throughout our waking hours, these are all the time rousing memory tokens.

But a second important factor comes in here. External impressions act to rouse the imagination or a reflective train of thought most potently if they at the same time rouse certain feelings or emotional impulses. Anything that pleases not only stimulates but also quickens the imagination.. But hunger, thirst, sexual passion and many other bodily sensations have a direct summoning influence on all agreeable ideas connected with them. We have then in the bodily feelings and general bodily spirits, which are the real primary forees of the imagination, a second regulating factor upon which rests a very substantial and by no means the most sordid part of art and poetry.

Primarily the senses appear to be only subordinate helps to the impulses coming from within. lut ther provide us a store of material for the expresion of our feelings. The artistic perfection of the pictures which we ereate with our minds will depend in large part upon the care with which this preparatory work is done, upon the sharpness of our grasp of the aetual: and the imagination will work to a given end the more effectively, the more this sensory material is allowed to appeal to our feelings, and so to take on tokens by which it can be recalled to mind.

But even in the most magnificent creations of the imagrination we have to do to a certain extent with simple mechanical processes. Here again eonducting pathwars, nerve fibers, which connect the mechanisms enneerned in the production of bodily feelings with the central workshops of organized memory, namely the association centers, have a part to play. Ind since the nerves which serve to bring the sensory impulses to consciousness push through to the cortex and enter the sensory centers. we have converging toward the same cortical regions nerve paths which make us aware of the treasures and charms of the outer world, and those which bring to conscionsness the everyday needs of the body in the form of desires. Both without distinction act from these their highest points of attack upon the motor mechanisuls on the one hand and upon the intellectual centers on the other. 
The pathways between the centers which ronse our desires and the intellectual regions of the cortex are not called upon merely to elothe the content of sense experiences in ideas, to idealize them in short, nor merely to facilitate their satisfaction by recognition of means to that end. But there is set up along some associative pathway an interplay, a working of ideas which leads to the maturation of self-consciousness as a contest between sense and reason. Along with inciting impulses there arise some with which feelings of restraint are connected-and thus the discharge of memory pietures through the bodily desires comes to have a distinctly moral significance. The motives are necessarily robhed of all their ideal character-the struggle between the sensuous and the moral feelings is sure to lapse, the moment the force of the intellectual centers is paralyzed and the rational content of the emotions disappears. Control of the emotions requires a powerful cerebrum, which probably means in the first instance soundness of the frontal association centers.

A purely meclanical factor is concerned in this control of the lower impulses of the cerebrum. In so far as the bodily impulses do not arise by the automatic excitations of the central nerve cells. they belong by nature to the category of reflex processes. and like all reflexes are continually held in check by the cerebrum. When the cerebrum becomes weak this mechanical restraint is relaxed and the bodily incentive gains greater control over the rational centers.

Throngh the investigation of the material conditions of the mind's activity, medicine is thus brought into immediate relations with the moral sciences, and it is indeed conceivahle that once she has properly grasped the problem, she will unhesitatingly press forward to the front rank of those forees which have made the moral elevation of mankind their ehief concern. Investigation to-day is not led, as was the philosophy of the Enlightenment in the Eighteenth Century, by an instinctive hatred for the dogma of the immateriality of the soul. for that dogma in no way prevents our undertaking the moral elevation of the race from the bodily side. What we must insist upon is merely thisthat the moral powers of the mind like its other powers depend to a great extent upon the body.

A general elearing up of problems pertaining to the hygiene of the brain is therefore eminently necessary. Much remains to he done along this line, if we are to sneceed in strengthening and establishing the natural grounds of the moral feelings eren for future generations. Certain it is that our efforts will be succes:ful in a measure directly proportional to the opportunities afforded the mentally and morally unfortunate of profiting by the deeper insight and better desires of those whose lives are ruled by high ideals.

But it is not alone the practical goals of life of which we get a glimpse in these considerations of the mechanics of the mind. As that which we already realize to be one of the nohlest sides of our being. and which is bestowed on mankind in virtue of the intellectual centers of the brain. becomes embodied in the desire to comprehend the natural order of things in the realm of spirit also. the real advances of our knowledge in this realm of natural science lead us with the compelling force of a natural law at last to an ideal riew of the worth. The more the true magnitude of the real power resident in the realm of mind itself is revealed to us, the more clearly do we 
feel that back of the world of phenomena powers are at work for which human knowledge can scarcely find an adequate metaphor.

\section{§ 4. THE TIME CONSUMED BY PSYCHOPHYSICAL PROCESSES}

'There remains for us to summarize briefly what bas been discovered with reference to the time oceupied by psychophysical processes.

The point of departure in all investigations of this subject is the time required for a person to react with a definite voluntary movenent to some external stimulus (simple reaction time). It will be apparent at once that some measurable time is required for such reactions. if we but reflect that the propagation alone of a stimulus along the afferent and efferent nerves concerned consumes a certain amount of time (cf. page $41 \%$ ). But in the process which we are considering now. something takes place in the sensorium and something in the motor region, and between these something. probably. elsewhere in the cortex, all of which constitute the psychophysical factors. "The special interest attaching to these determinations is that they will give us some information as to how much time is required for these purely central processes.

Experiments in this field are usually earried out by having the subject of the experiment open the current of an electric signal the moment he receives a given stimulus. If, for example, the reaction time is being taken for an auditory stimulus, it is necessary to have in the same electrical connection: (1) the signal, (2) a key for the subject. (3) a key by which the current is closed by the director of the experiment and which at the same instant eanses a sound to be marle by (4) an eleetric bell or other deviee. The sound which is made when the current is elosed constitutes the stimulus to which the subject reacts by opening the eurrent. If the electric signal be arranged so as to record on a moving surface the instants of opening and elosing, the time which intervenes will be the reaction time. This time can be determined direetly if a clockwork whose hands mark thousandths of a second be set in motion by the closing and stopped by the opening of the current. Such an instrument is known as a chronoscope.

The simple reaction time varies all the way from 0.11 to 0.55 second according to the nervous organization of the subject, and the kind of sensory stimulus employed. Likewise if a series of experiments be carried ont on the same person and with the same kind of stimulus, only varying in strength, a considerable variation in the reaction time is noted, which cannot he the to any variation in the rate of propagation in the nerves exereised. consequently must he accounted for hy differences in the time consumed in the psychophysical processes. Such rariations moreover can be perecived subjectively, so that one ean tell within 0.05-0.06 of a second whether a given reaction time was longer or shorter than a previous one. Remembering that the propagation of the sensory stimulus lefore it rouses the conscions sensation. as well as the motor impulse after it has once been discharged. is an entirely uneonscions process. we see that the time subjectively estimated covers the span between perception of the sensory impulse and release of the voluntary impulse. 
The following table will give us some idea of the reaction time for the different senses:

\begin{tabular}{|c|c|c|c|}
\hline АІтноR. & Sight. & Hearing. & $\begin{array}{l}\text { Electric stimulation } \\
\text { of the skin. }\end{array}$ \\
\hline 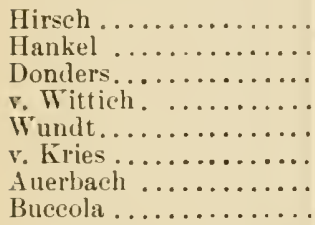 & $\begin{array}{l}0.200 \\
0.206 \\
11.188 \\
0.186 \\
0.222 \\
0.193 \\
0.191 \\
0.168\end{array}$ & $\begin{array}{l}0.149 \\
0.151 \\
0.180 \\
0.182 \\
0.167 \\
0.120 \\
0.122 \\
0.115\end{array}$ & $\begin{array}{l}0.182 \\
0.155 \\
0.154 \\
0.130 \\
0.201 \\
0.117 \\
0.146 \\
0.141\end{array}$ \\
\hline
\end{tabular}

For the sense of taste $r$. Tintschgau has found the following reaction times for common salt. sugar and quinin: tip of the tongue, $0.59 \%, 0.75 \%$ and 0.993 seond respectively: for the base of the tongue, $0.5+3,0.552$ and 0.502 second repectively. The reaction time for different odors (oil of peppermint, oil of rose and hergamot oil) raries in Moldenhaner"s findings between 0.199 and 0.374 second.

It is not surprising that the reaction times found by the different authors for a given sense differ considerably, for the nervons organization of the sul,ject has always to be taken into account.

In most eases it requires some time for odoriferons and sapient substances to come in contact with the appropriate nerve endings: hence the longer time consumed by a reaction to these stimnli than to others.

The differences observed between the reaction times for sight. hearing and touch are, as Wundt remarks. probably dependent upon the different intensities of these stimuli. For one and the same sense the reaction time is always shorter the stronger the stimulus. We cannot ordinarily compare the intensity of a certain auditory stimulus with that of a certain visual stimulus, for there is no standard of measurement common to the two. The thresloold stimuli for the different senses. howcrer, being in all cases just sufficient to produce an effect. must be relatively of the same strength. Wundt found in fact that the reaction times for the visual. auditory and taetile stimuli in the neighborhood of their threshold values were almost exactly equal, namely $0.331,0.33 \%$, and 0.322 second respectively. We infer from this and the facts summarized in the table that auditory stimnli in general are more powerful than optical or cutaneous stinuli.

The reaction time is inereased as the body or mind beeomes fatigued, also as the result of all sorts of exciting influences, but is reduced by practice, in some cases rery eonsiderably. All this goes to prove that the length of the reaction time depends essentially on the duration of the psychophrsical proeess. or in other words, that we dare not look upon the psyehophysical process as a perfectly constant factor.

If warning be given of the signal just before it is made, the reaction time is considerably shorter than otherwise. The subjeet has his whole attention fixed on the coming event. and. by sufficient practice. he can make the central comnection so tense as to give the response almost as promptly as if it were a 
pure reflex. The muscular process particularly is facilitated in this way and the reaction is then described as muscular reaction. A reaction in which the attention is strained more especially to receive the impresion is called a sensory reaction. If the attention be not first aroused, it requires more time also to perceive a stimulus. 'Thus Wundt found in one experiment with the auditory stimulus that when warning was given the sound was heard in 0.076 second, when not given, in 0.253 second.

The study of the changes produced in the reaction time by nerve poisons, such as alcohol, collece and tea, is an important means of learning the physiologieal effects of these substances.

If instead of a single stimulus, a series of stimuli following each other at a definite interval be given. the reacting person repeats the rhythm to a certain extent independently. and the reaction time sinks to nil. In absolute determination of the time cannot be made under these cireumstances: the reation may take place either at the instant of stimulation, or a little after or eren a little before. Aecording to Martius the errors amount to \pm 0.01 of a second.

We very often meet with phenomena of this kind in our everyday life. The plaving of an orchestra under the direction of a leader, dancing and marching to music. are all cases in point: likewise the enmmeration of heart beats. But if the rhythu of stimuli be not perfectly miform and the intervals not exactly equal, it is impossible to react to them srnchronously. and the ortinary reaction time comes into play again. By varying the method of exprinentation, we can penetrate still farther into this yuestion of the time consumed hy the psichophyieal process. The methods mployed for this purpose ean best be explained hy a few conerete examples.

Suppose the stimulus be applied either to the right or left font: in the first ase the subject is to respond with the right hand. in the seeond with the left. He has then not only to pereeve a stimulus, but to distinguish a definite property and to chonse between two movements. On the average the time repuired for this reaction is. accorting to de Jeager, 0.066 second longer than the simple reaction time.

In the ease just given the choice was a relatively easy one, because a stimulus on one foot naturally suggests a reaction with the hand of the same side. But if the experiment be so arranged that when a red disk appears the subject is to react with the right hand, and when a blue, with the loft, the time is on the average 0.154 seeond longer than the simple reaction time. The pirchophysical processes in this case are of exactly the same kind as the former: the greater interval of time is due to the fact that there is no natural connection between the sense impression and the movement, eonsequently the choice is more difticult. The time is shorter if a reaction be required for only one of two stimuli. For example, a red or a blue disk may appear: the subject is to react to the latter, hut not to the former. The time is then on the average $0.03 t$ second longer than the simple leaction time and thus 0.12 second shorter than in the ease last mentioned. The principle of this method of simple choiere is exactly the same as the other: the individual must recognize a definite quality in the stimulus and chonse betweren acting and not acting. But the reason why the choice can be made more quickly is that the attention is concentrated on the par- 
ticular impression which ealls for the reaction. The time found is practically the time required to pereeive a given quality in an impression, and is ealled the discrimination time.

\section{APPENDIX}

\section{NOURISHMENT OF THE BRAIN}

1. Blood Supply.-As already remarked at page 572, the normal activity of the brain is very much dependent on the blood supply. If the blood supply is greatly diminished, uneonseiousness is the result; this usually happens, for example, when the carotids are compressed. Convulsions may also be produced in the same way. Thus if the right innominate artery and the left subclavian central to the vertebral be ligated in a rabbit, the animal almost immediately falls into eonvulsions.

Variations in the blood supply to the brain have been diseussed at page 240.

In eases of accidental defect in the skull, the brain pulsates in grown persons just as do the fontanels in roung ehildren. Mosso has found on suth persons that the blood supply to the brain inereases with mental work, and to a marked degree also when the person is under strong emotional exeitement, and that the ressets to the extremities beeome at the same time constricted.

If now it is true, as supposed by the majority of authors, that rasomotor nerves are wanting in the ressels of the brain, such ehanges in the blond supply can only be explained by supposing that in mental work or under the stress of emotions the vasomotor center is stimulated and constrietion produeed in various extracranial vascular regions.

- Likewise in undisturbed sleep, when no conscious processes are going on in the brain, the blood supply to the brain may be inereased by all sorts of sensory stimuli, without waking the individual.

2. Fatigue and Sleep.--Not only mental work but the waking condition of itself fatigues the brain, or more correetly the eerebrum, and it must from time to time be given an opportunity to reeuperate. This recuperation of the brain takes place in sleep. If a person is denied sleep for a long time, very profound physical and mental disorders result.

Experiments have been made to determine the soundness of sleep by finding the threshold value of an auditory stimulus necessary to wake the person at different intervals after he fell asleep. Aceording to Mönninghoft and Piesbergen, the depth of sleep inereases very gradually up to the second quarter of the second hour. Within the second and third quarters of the same hour it increases very rapidly and very greatly and then decreases just as rapidly up to the first quarter of the third hour. From this point onward there is a gradual decrease of depth which continues to the seeond half of the fifth hour. Here a second slight rise begins, but the level is comparatively miform from about the fifth hour onward (ef. Fig. 299).

Metabolism is less active in sleep than in the waking condition and the falling off is greater the sounder the sleep. If the carbon dioxide output be taken as a measure of the metabolism, that of sleep is related to that of the waking condition (not working nor yet completely resting) as 100:145. This reduction of metabolism in sleep is dependent in the main upon the cessation of roluntary movements, for it may reach just as low a level in the waking eondition if the muscles be completely relaxed and every voluntary motion be suppressed (Johansson). 
According to some experimental determinations the carbon dioxide elimination reaches its minimum in the second hour of slcep, and this probably constitutes to a certain extent the expression of the deepest sleep in a sleeping period of perhaps six to eight hours.

The following peculiaritics have also been observed in sleep. The eyes with pupils contracted are turned inward and somewhat upward. The respiratory movements are less frequent than in the waking condition, and even in the man are mainly of the costal type. The respirations are also sometimes periodically suspended. The heart action is retarded; the vascular tone decreases in the cutancous vessels and probably also in the visceral ressels, and as a consequence the blood pressure falls. This in its turn is said by many authors to cut down the supply of blood to the brain, to produce in short a condition of ecrebral anamia.

Howell has observed the volumetric variations of the hand and the lower part of the forearm in sleep by means of the plethysmngraph, and has found

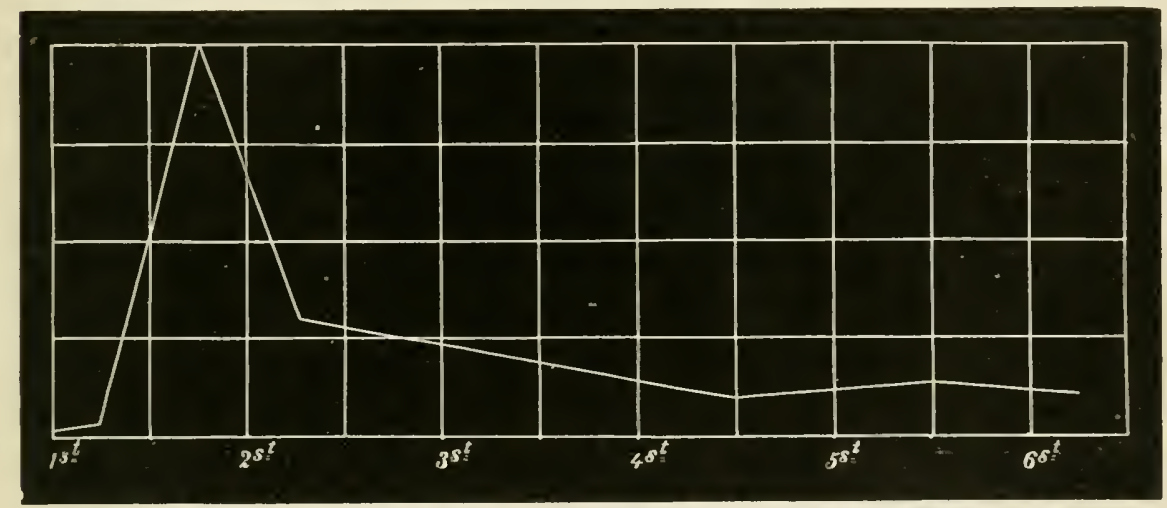

Fig. 299.-Curve representing the depth of sleep, after Piesbergen. The abscissa ropresent hours.

that the amount of blood in the part increases gradually from the beginning of sleep and reaches its maximum within one to one and three-quarter homs. It remains at this level until about three-quarters of an hour befure awakening and then falls rather rapidly to the end of slecp.

The inception of sleep is favored by entting off the scusory stimuli, especially if the attention be not kept aroused by any active mental proceses. Strümpell has reported a case in which the patient became blind in one cye and teaf in one car merely by stopping all cutaneous sensations. $A$ s soun as the gool ere was closed and the functional ear was stopped he foll asleep.

Sleep does not depend entirely upon processes going on in the cerehral enrtex. for as mentioned at page (i2:) a change from the sluping to the waking condition and viee rersa can loe observed on deremelonted animals.

[lerhaps the most satisfactory theory which has ret been given to explain the rause of slepp, is that of Howell. The dilatation of the eutaneous vesicels during sleep observed by this author, taken in conjunction with many other observations that there is during sleep) a reduction of the general blowl pressure. and that there is at the same time a diminished blool flow to the brain. suggested the idea that the depression of the psechioal activities bolow the threshold of consciousness is due primarily to anmuia of the brain (cf. page 240). To 
account for this anamia Howell supposes that that portion of the rasomotor center which maintains the tonus of the entaneous ressels periodically becomes fatigued, just as the cells of the cortex which mediate the psychical processes may be supposed also to become fatigued. If under these circumstances the usual external stimuli which serve to keep the vasomotor center active be withdrawn; as for example, the eyes be closed, noises be excluded and the voluntary museles be relaxed, the vasomotor center relaxes its control of the eutaneous ressels, the resulting dilatation withdraws blood from the cortical cells and the consequence of this is a further and a comparatively sudden decline of cerebral activity below the threshold of consciousness. When the vasomotor center has been recuperated it reasserts its activity, blood is again supplied to the cortical cells and consciousness returns.-Ed.]

3. The Temperature of the Brain.-By means of a very delicate thermometer Mosso made a careful study of the temperature of the brain in animals and in men with defects in the cranium, and found among other things that on account of its slight covering it has a lower temperature than the rectum. But a rise in temperature is caused by the local effects of atropine, cocaine and alcohol, by electrical stimulation, by anmmia and asphyxia-in all these eases due to alterations in the circulation. Chloroform, painful sensations, ete., produce no change in the temperature of the brain worth mentioning. In like manner the conscious activities of the brain produce so shight an effect on the temperature that they cannot be recognized, or else they occur along with other processes, as the result of which the brain is cooled, even though the psrchical functions continue.

On the other hand some unconscious processes brought on by external ageneies increase the temperature of the brain.

4. The Intracranial Pressure.-The cerebro-spinal fluid filling the subarachnoid space exerts a pressure on the walls of the cerebro-spinal canal, which when measured by a manometer of suitable construction inserted into an opening in the skull, is found to be about equal to the renous pressure $(5-10 \mathrm{~mm}$. of $\Pi \mathrm{g}$.), if the animal is in a horizontal position. When the hind parts of the body are raised above the head the pressure becomes greater, when they are lowered it falls and may even become negative (Sivén).

According to Bayliss and Hill, there is no meehanism for maintaining a eonstant intracranial pressure; the functions of the brain appear, within wide limits, to be independent of intracranial pressure, so long as the circulation is not impaired. If the foramen magnum be constricterl so as to obstruct the cireulation, the centers of the merhlla may be affeeted and, among other things, the respiration be retarded and finally stopped, the heart action retarded, and the blood pressure increaserl.

The outlet for the cerebro-spinal fluid is by was of the veins. Within fifteen to thirty minutes after injection of methylene blue, in a salt solution into the cranial eavity, the color appears in the urine (Hill).

References.-Beevor, Horsley, Schäfer and others, several articles in the Philosophical Transactions for 1857, 1858, 1890.-Charcot and Pitres, "Les centres moteurs eorticaux chez lhomme." Paris, 1595._S. Exner, "Entwurf zu. einer phrsiologischen Erklärung der psychischen Erseheimungen," Wien, 18?4.-Flechsig, "Gehirn und Seele," second edition, Leipzie, 18s6.-Flechsig, "Die Lokalization der geistigen Vorgänge," Leipzic, 1s96.-Franck, "Les fonctions motrices du cerveau," Paris, 1ssi.-Goltz, "Ther die Verrichtungen res Grosshirns," Bonn, 18st.-Goltz, several articles in Archir f. 1. ges. Physiologie. Bds. 34, 42, 51, 76.-Hitzig, "Trutersuchungen über das Gehirn," Ber- 
lin, 197t.-IItzig, "Physsiologische und klinische Untersuchungen über das Gehim," Berlin, 1904.-Howell, "A Contribution to the Physiology of Sleep," in the Journal of Experimental Medicine, wol. ii, 1897.- - . Monakow, "Gehirnpathologie," Wien, 1897.-II. Munk, "C̈ber die Functionen der Grosshirnrinde," second elition, Berlin, 1590.-Nothnagel, "Topische Diagnostik der Gehirnkrankheiten," Berlin, 1579._Willrand and Saenger. "Anatomie und Physsiologie der optischen Bolmen und Zentren," Wiesbaden, 1904.-Wrund, "Grundzüge der physiologischen Psychologie," iii, Leipzie, 1903. 


\section{CHAPTER IXV}

\section{PHYSIOLOGY OF SPECIAL NERVES}

TuE innervation of the different organs and organ systems has been diseussed in connection with their functions, hence in this chapter we need only present the physiolngy of special nerves in the broadest outlines. For details and controverterl points, reference must be made to the previous chapters of this book. and for the purely anatomical data to the text-books of anatomy.

\section{\$1. THE CRANIAL NERVES}

I. The olfactory, or the nerve of smell (ef. page 486).

1I. The optir. or the nerve of rision (ef. page 5os), contains not only afferent but efferent fibers.

111. The oculomotor, or the common nerve of the eye museles, innervates the levator palpehre superioris. the superior. inferior and internal recti. the infering oblique, the ciliary muscle or the musele of accommodation (c.f. page 5:3:) and the sphincter of the pupil (ef. page 5:8).

IV. The trorlifearis, or patheticus, innervates only the superior oblique muscle of the eye.

V. The trigeminal, or trifacial, contains both afferent and efferent fibers.

The efferent filers innervate the jaw muscles (masseter, temporal, pterygojd:). also the mylohyoid, the tensor palati and the tensor tympani (ef. page $49 ;$ ) and the anterior belly of the inferior digastric. Besides it is stated that the trigeminal contains secretory fibers for the lachrvmal glands and the sweat glands of the face, rasodilator fibers for the skin of the face and the ere, ete.

The afferent filers of the trigeminal constitute first, the sensory nerves of ahmost all the skin of the face, of the eye, the nose, the mucous membrane of the mouth, the tongue and the teeth. Secondly, the trigeminal carries a number of nerves of taste (c. page 484 ).

VI. The abducens imnervates the external rectus and is sait also to contain fibers for the sphincter of the pupil.

TI1. The facial, or nerve of expression, contains secretory fibers for the submaxillary, mblingual (cf. jage $25 \check{5}$ ) and lachrymal glands. vasodilator fibers for the submaxillary glands and anterior part of the tongue, and motor nerves for the stapedius muscle. Its chief significance, however, is that it innerrates the muscles of the face by contraction of which the skin of the face is folded in various ways, produeing the different expressions. 
VIII. The auditory, or nerve of hearing, by its cochlear ront mediates anditory sensations (ef. Fig. 199) and by the restibular root (cf. page 4.3) the various functions of the semicircular canals and otolith sacs.

Various experimental observations indicate that the restibular root probably has no significance whatever for the auditory sensations. Sinee the eighth eranial nerve therefore is at least not exclusively auditory in function, J. R. Ewald has proposed that it be simply called the eighth nerve (N. octavus).

IX. The glossopharyngeal conveys, besides some motor fibers to the tongue and pharrnx, secretory fibers to the parntid glands (cf. page 2.ji) and rasodilator fibers to the anterior pillars of the fauces and tonsils. Among its afferent fibers are the taste filsers, also sensory fibers for the mucous membrane of the tympanic cavity and Enstachian tube.

$\mathrm{X}$. The ragus, or pneumogastric, and

XI. The spinal accessory.

In view of the fact that these two nerves are intimately related anatomically and that diverse views are held as to the share each takes in controlling the organs innervated by then, it is most profitable to onsider them, as Grossman has proposed. as one nerve composed of three hundles named, in order of their exit from the medulla, the upper, middle and lower. The upper buntle can readily be separated in the monkey and in man from the glossopharyngeal. The lower bundle is the outer branch of the spinal accessory which innervates the trapezius and the sterno-eleido-mastoid museles. There remains then the trunk composed of the ragus and the inner or true accessory branch in which are to be distinguished an anterior and a middle portion.

According to the experimental results of Kreidl on the monkey, motor nerves pass in this anterior portion (the ragns of anatomists) to the palatoglossal and palatopharyngeal museles as well as to the ennstrictors of the pharyx and weophagus. Moreover. it is here that the motor fibers of the superior laryngeal are found, also the afferent pulmonary fibers which assist in the automatic regulation of respiration, and in the rablot, dog and cat at least, the depressor fibers (Fuchs. (Codman: (f. page 193).

In the middle bundle (accessory of the anatomists) are the inhibitory fihers of the heart (ef. page 18s), the motor fibers for the levator palati and the motor fibers contained in the inferior laryngeal nerve.

In the trunk of the ragus are the following fibers, the origin of which is not fully kuown: (1) efferent fibers. $a$. To the cireulatory organs: accelerator fibers to the heart (page 191): vasoconstrictor fibers for the heart, the stomach, intestine, kidneys, spleen, aud possibly the lungs (page 240) : vasodilator fibers for the coronary vessels and the lungs (page 235). b. Digestive organs: motor nerves for the stomach (page 2s4), the small intestine and the upper part of the large intestine (page 2s9): inhibitory fibers for the eardiac sphineter of the stomach and the longitudinal muscles of the small intestine (pages 2st, 2s9): secretory nerves for the gastric mueosa and the panereas (pages 26i3, 2699). c. Respiratory orgaus: motor and possibly inhibitory fibers for the bronchial muscles (page 324).

(2) Afferent fibers. Respiratory organs: afferent fibers from the larynx (page 330$)$.

XII. The hypoglossal innerrates the musculature of the tongue. 


\section{SPINAL NERVES}

The anterior and posterior roots of the same side belonging to each segment of the spinal cord unite peripherally to the spinal ganglion to form a mixed nerve trunk. Each of these nerve trunks then divides into a dorsal and a ventral branch. The dorsal branches are relatively small and supply only the skin and muscles of the back: the ventral branches, which are much larger, are allotted to the anterior and lateral parts of the neck, thorax, abdomen and extremities.

The dorsal branches all run separately to their destination; but with the exception of the twelve thoracic nerves, the ventral branches anastomose freely with one another, forming plexuses corresponding to the main divisions of the body.

A number of experimental and clinical researches have heen made on the distribution of the fibers arising from the different roots. We shall here pay regard chiefly to the exposition given by Kocher on the relations obtaining in man.

\section{A. SENSORY NERVES}

Each spinal nerve ront, eren if its fibers unite with others to form a plexus, supplies a continuous region of the skin. These regions overlap, however, so that a single region on the lateral aspect of the body is provided with a twofold or even a threefold supply (Sherrington).

Fig. 300 represents schematically, aecording to Kocher, areas of distribution of the different spinal roots. This is construeted on the basis of clinical observations of patients with total lesions of the spinal cord. 'The boundary lines in the figure mark the upper limits of sensibility for lesions at the different levels. In reality the regions supplied by the different nerves, in man as in animals. overlap considerably both ahove and helow. The areas blocked out in the figure represent therefore the central parts of the fields actually supplied by the separate roots.

\section{B. MOTOR NERVES}

In the following table are summarized, after Kocher, the distributions of the different motor rools:

ROOT. MUSCLES.

I C. Small neck muscles; sternohyoid; sternothyroid; omohyoid.

II C. Sterno-cleido-mastoid; trapezius.

III C. Platisma myoides.

IV C. Scaleni; diaphragm.

V C. Rhomboidei; supra- and infraspinatus; coraeobrachialis; biceps; brachialis anticus; deltoid; supinator longus and brevis.

VI C. Subscapularis; pectoralis major and minor; pronator teres and quadratus; latissimus dorsi; teres major; triceps; serratus magnus.

VII C. Extensors and flexors of the wrist.

TIII C. Extensors and Hexor longus of the fingers. 


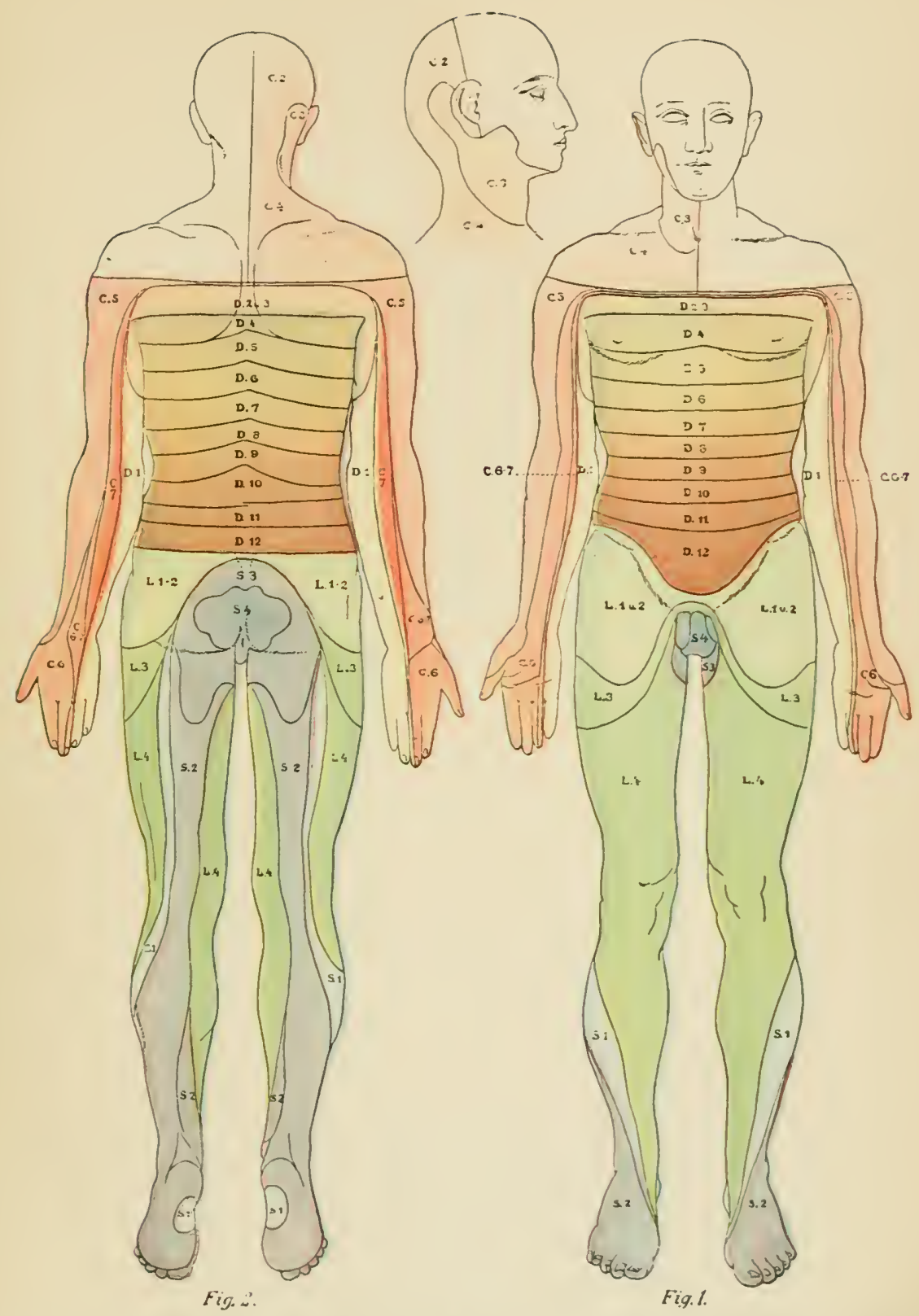

Fig. 300.-Distribution of the superficial areas served by the different sensory roots, after hocher.

Red: area of eervical roots- $C_{2}$ to $C_{i}$.

Yellow: area of ilorsal roots $-D_{1}$ to $D_{12}$.

Green: area of lumbar roots $-L_{1}$ to $L_{\downarrow}$.

Blue: area of sacral roots- $S_{1}$ to $S_{\downarrow}$. 

I T. All the small muscles of the hand and fingers.

I-XII T. Museles of the back.

I-XI T. Intereostal museles.

VII-III T. Abdominal muscles.

I L. Lowermost parts of the abdominal museles; quadratus lumborum.

II L. Cremaster.

III L. Psoas; sartorius; iliacus minor; pectineus; adductors of the thigh.

IV L. Quadriceps femoris; gracilis; ubturator extermus (!).

$\checkmark$ L. (Bluteus medius and minimus; tensor fascix femoris; semitendinosus; semimembranosus; biceps.

I S. Pyriformis; obturator internus; gemelli; quadratus femoris; gluteus maximus; long extensors of the foot and toes; peruneus longus and brevis.

II S. Long tlexors of the foot and toes; large calf muscles; small foot muscles.

III S. Ejaculator muscles; muscles of the perineum.

IV S. Sphincter and detrusor muscles of the bladder; sphineter ani.

$Y$ s. Levator ani.

The same must be said of this summary that was said of the sensory nerves, namely, that a given muscle is supplied by more than one spinal root. Accordingly the data given here indieate the central regions of distribution, or. the other way about, the chief nerve supply for the separate muscles. Starr finds, for example, that the scaleni muscles are innervated by the second and third cervical roots, the diaphragm by the third and fourth, the deltoid by the fourth and fifth, the biceps by the fifth and sixth cervical, the sartorius by the first and sceond lumbar, the quadriceps femoris by the second and third, the adductors of the thigh by the third and fourth, etc.

It was formerly asserted by Preyer and Irause that the skin corering any given musele is supplied with sensory fibers by the same spinal nerve as that which supplies the underlying muscle with motor fibers. Sherrington finds. however, that this is not the case; for certain displacements occur causing the skin region to be situated farther distally than the eorresponding muscle. The flexor sides of the thigh and fore leg and the extensor side of the arm appear to be the only exceptions to this rule. The different sensory fibers of the muscles themselves appear to belong to the same segment as the motor fibers.

\section{\$ 3. THE SYMPATHETIC NERVES}

\section{A. RELATIONS OF THE SYMPATHETIC NERVES TO THE CENTRAL NERVOUS SYSTEM}

The nerve fibers traversing the sympathetic nerves are both afferent and eficrent in function; and they mediate a great variety of functions not under direct influence of the will. To these belong the vasoconstrictor and rasodilator nerves, accelerator nerves of the heart, motor and inhibitory nerves of the stomach, intestine. bladder. etc. Ther constitute therefore the greater part of the visceral nerves. It is justifiable to enmmerate along with the components just named the visceral fibers contained in certain cranial nerves and those arising from the sacral roots. l)oing this. we can then say, that 
the sympathetic or autonomic (Langley) nervous system presides orer all of the funetions not under the direet control of the will.

All these nerres agree in having their origin in the central nerrous system. In the strict sense the sympathetic nerres constitute processes of the lateral horn cells on the same side of the cord.

The efferent fibers

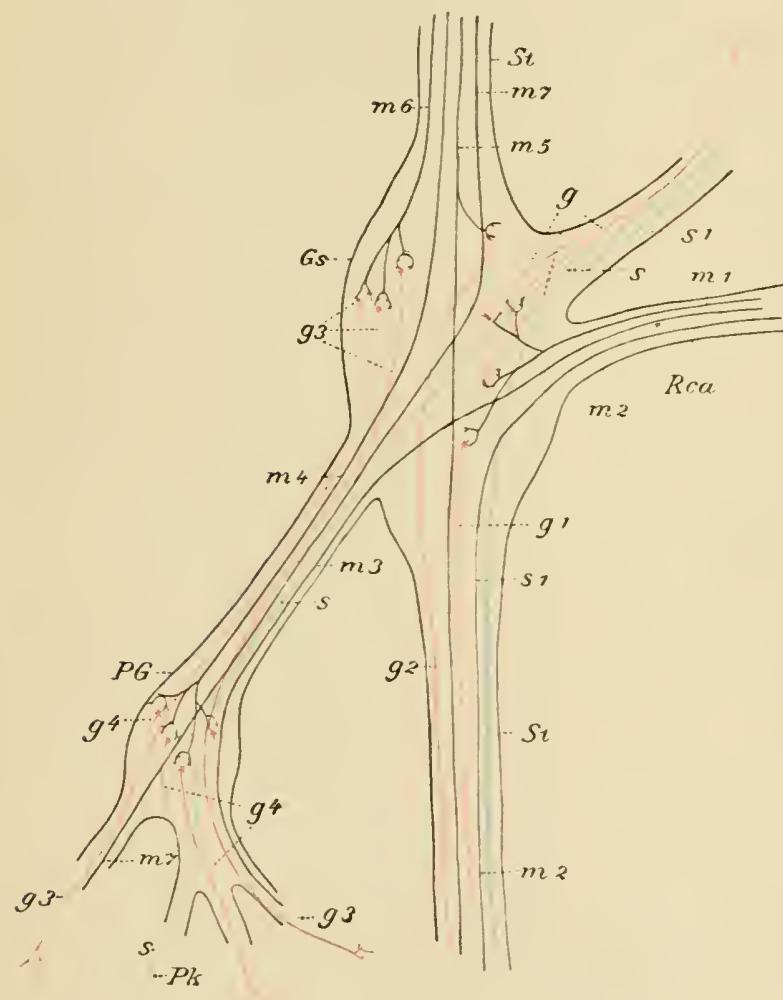

FIs. 301.-Schematic representation of the connections of the sympathetic fibers, after Kölliker. $P G$, peripheral ganglion: Gs, chain ganglion; $P k$, Pacinian corpuscle; Rea, white ramus communicans; Regr, gray ramus communicans; $S t$, sympathetic trunk. The preganglionic fibers are black, the postganglionic red, the afferent fibers blue. belonging to the autonomic nerves are slender in eomparison with other efferent nerve fibers, and, mnlike the motor nerres to the skeletal museles, connect somewhere along their course with ganglion cells from which new fibers issue to complete the pathway.

The afferent fibers found in the simpathetie nerves are for the most part offshnot= from the ganglion cells in the spinal ganglia ; there are among them some which spring from peripheral ganglion cells, and this constitute true sympathetie fibers.

The most important visceral fibers of the cranial nerres have already been studied. We have then to eonsider only the visceral fibers coming from the spinal cord.

The preganglionic fibers, to use Langley's term, make their exit exclusirely in the white rami communicantes of the spinal cord (Gaskell), and all of them end with their terminal arborizations about ganglion cells situated at a greater or less distance from the eord. There are no connections between the separate ganglion cells either within the same or different ganglia.

The length of these fibers varies greatly (cf. Fig. 301, $m_{1}-n_{7}$ ). Some 
of them $\left(m_{1}\right)$ end about the cells of the nearest ganglion. others $\left(m_{4}, m_{6}\right)$ pass through sereral ganglia before reaching their endings, and ly means of (ollaterals may therefore act upon a number of cells. Still others find their destination only when they reach ganglion cells situated far away in the peripherv.

Postiganglionic fibers $\left(g, g_{1}, g_{2}, g_{3}, g_{4}\right)$ arise in the simpathetic ganglia and. withont any connection with other ganglion cells. terminate. sometimes near. sometimes far away, in the free endings on smonth muscle cells. gland cells, ete. Langley believes that the comre of each fiber or collateral is interrupted by one anglion cell only. (see page js: for Langley"s use of nientine in this connection.)

Part of the postganglionic fibers traverse the gray rami communicantes to the spinal nerres and reach their destination by these paths; part of them belong to branches which run an independent course to the periphery.

The plexuses of Auerbach and Meissner, found in the wall of the alimentary eanal from the lowermost part of the aesophagus onwarl. which are commonly included in the spmpathetic system, present some variations from the general beharior of the simpathetic nerves. For this reason they are set apart by Langley in a class by themselves. Nothing definite can be said at present as to their physiological status.

\section{B. COURSE OF THE SYMPATHETIC FIBERS}

According to Gaskell. the sympathetic trunk itself receives preganglionic fibers only from the first thoracic to the second to fourth or fifth lumbar roots. The cervical roots conver no visceral nerves: but visceral nerves are found in the first or second and third sacral. These latter do not unite with the sympathetic but contain fibers which are autonomic in function.

'The preganglionic fibers belonging to the sympathetic unite either with cells in the ganglia of the srmpathetic chain (lateral ganglia), or witlo cells in ganglia situated farther toward the periphery (collateral ganglia).

The following accomnt of the course of pre- and postganglionic fibers and their connections, relating to the cat, is taken from Langley.

The cervieal sympathetic receives fibers from the first to the serenth thoracie roots; in their exit from the spinal cord they are to a certain extent arranged aceording to their function. The most powerful effect on the dilator of the pupil is obtaned from the first and secourl, wn the nictitating membrane. on the eyelids, ete., from the first to the third, on the submaxillary grands from the second and third, on the ressels of the ear and the conjunctiva from the second to the fourth, on the pilomotor nerves of the head and nerk from the fourth to the sixth. These details are mentioned beeanse they are important for a proper conception of the regeneration phenomena to be deseribed presently.

All these fibers teminate in the superior cervical ganglion, the cells of which send out postganglionic fibers to the plexuses about the blond ressels, to certain erunial nerves, and to the three upper cervical nerves. These joining the last named aceompany their scnsory branches to the skin and innervate the erector muscles of the hair, enstituting therefore the pilomotor nerves.

The stellate ganglion receives fibers from the (third) furth to the eighth (ninth) thoracic roots. Among its postganglionic fibers pilomotor fibers pass 
to the third to the eighth cervical nerves and the first to the third (fourth) thoracic nerves: they make their exit through the fifth to the eighth thoracic roots. Vasomotor and sweat nerves for the fore paw are contained in the fourth to the ninth thoracic roots. They unite with cells in the stcllate ganglion, from which postganglionic fibers are given off to the brachial nerves, the latter like the pilomotor fibers rumning in the posterior branches of those nerves. This ganglion also sends accelerator nerves to the heart and possibly vasomotor nerves to the lungs; but it is not ret conclusively proved that these nerves actually proceed from cells in the stellate ganglion.

Those spinal nerve roots which send out fibers to the chain ganglia lying distally to the stellate ganglion, each supply three, four or more ganglia. The postganghionic fibers (pilomotor and vasomotor) unite with the corresponding spinal nerves and aceompany their dorso-cutaneous branches to the skin.

The vasomotor and sweat nerves to the hind paw pass out probably in the twelfth thoracic to the second lumbar nerve roots; they unite with the sixth lumbar to the second sacral ganglia to be continued in the cutaneous branches of the spinal nerves.

The inhibitory and vasomotor nerves contained in the splanehnic are connected for the most part with cells in the solar plexus and have no relay station in the chain ganglia. They proceed from all roots between the fifth thoracic and second lumbar nerves.

The organs of the pelvis receive nerves both from the lumbar sympathetic and the sacral (cf. page 393). The former arise from all roots between the twelfth thoracic and fifth lumbar, and traverse the sympathetic cord either to the inferior mesenteric ganglion or to the sacral ganglia. Those entering the inferior mesenteric ganglion unite for the most part with its cells, but to a less extent also with ganglion rells situated in the peripheral organs. Most of the sympathetic nerves to the external genital organs are connected with cells in the sacral ganglia.

The autonomic fibers passing out through the first to the third sacral roots and uniting to form the nervi erigentes comnect with the cells of ganglia strewn along their course and lying for the most part in the immediate vieinity of the organs for which they are destined.

Ganglia of THE SYMPATHETIC SYSTEM

\begin{tabular}{|c|c|c|c|c|c|}
\hline SPINAL & КоOт. & CERVICAL. & THORaCIC. & LUMBAR. & Sacral. \\
\hline $\begin{array}{l}\text { Thoracie } \\
\text { Isumbar }\end{array}$ & $\begin{cases}I & \ldots \\
I I & \ldots \\
I I I & \ldots \\
I V & \ldots \\
V & \ldots \\
V I I & \ldots \\
V I I & \ldots \\
V I I I & \ldots \\
I X & \ldots \\
X & \ldots \\
X I & \ldots \\
X I I & \ldots \\
I & \ldots \\
I I & \ldots\end{cases}$ & 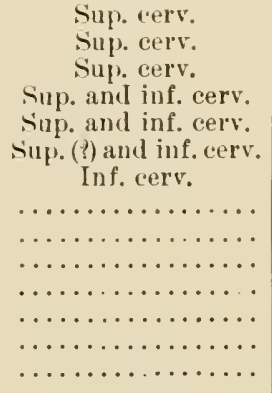 & 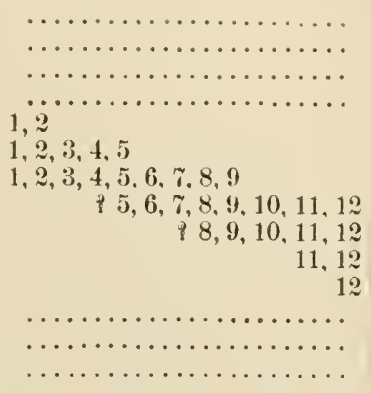 & 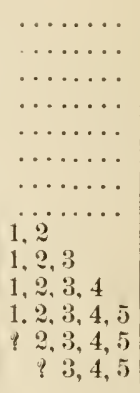 & $\begin{array}{l}\cdots \cdots \\
\cdots \cdots \\
\cdots \cdots \\
\cdots \cdots \\
\cdots \cdots \\
\cdots \cdots \\
\cdots \cdots \\
\cdots \cdots \\
\cdots \cdots \\
\cdots \cdots \\
\cdots \cdots \\
1,2,3 \\
1,2,3,4,5\end{array}$ \\
\hline
\end{tabular}

On the basis of his experiments upon animals and on the hasis of comparative anatomy, langley has constructed the above table illustrating 
the relations of the spinal roots to the ganglia of the sympathetic system in man. It will be observed that the main outflow of simpathetic fibers takes place between the first thoracic and second lumbar roots.

\section{REGENERATION IN THE SYMPATHETIC NERVOUS SYSTEM}

Regeneration in the sympathetie șstem is of particular interest because it is the only place in the entire nervous system where ganglion cells are found interpolated in the direct course of definite nerve fibers. As we have already scen (page 6si) the fibers running in the cervical sympathetic which are interrupted by the superior eervical ganglion are distributed to the different spinal roots aceording to their destination. If now the eervical sympathetic is eut, after a time regeneration takes place just as in all the nerves. But what is specially remarkable in this ease is this: that stimulation of the separate spinal roots after regeneration produces in the main the same effects as before they had been sectioned. Again, if the superior cervical ganglion be painted with nicotine after regeneration, we get the same negative results as if the painting were done previous to sectioning. It follow's that the regenerated nerwe fibers have reëstablished their old connections, or have made new connections in the same ganglion with cells of exactly the same kind. It would seem that the growing nerve fibers must be guided by some chemotropic influence to the very cells with which they were formerly connected (Langley).

By the same methol Langley has found that postganglionie fibers likewise regenerate and reëstablish their old connections and that they also form new olles.

When the superior cervieal ganglion is cut out, the cervical sympathetic does not recover its functions possibly because the preganglionie fibers are not capable of establishing functional connection with the peripheral tissues directly. We may suppose that the mutritive influence of the ganglion cell does not extend far enough to permit the fibers to grow farther than the interpolated ganglion. It is likewise impossible to bring about a union of the true efferent cranial or spinal nerve fibers with the postganglionie fibers, although union of these nerves with preganglionic fibers has often been demonstrated.

\section{AFFERENT NERVES IN THE SYMPATHETIC}

The sympathetic contains afferent fibers. whose trophie eenters are for the most part in the spinal ganglia. The number of such fibers is much smaller than that of the etlerent fibers. 'Thus Langley has found by the method of regeneration that only one-tenth of all the fibers in the hypogastric are atlerent in function: in the nervus erigens the number is one-third.

Stimulation of any one of the white rami communicantes produces reflex movements and variations in the blood pressure. Hence they must eontain afforent fibers. It appears that such fibers run almost exclusively to the thoracic and abdominal viseera, and that they probably have the same distribution as the corresponding efferent nerves. It is probable that they aceount for such conscious sensations as "referred pains." so called because they are referred to regions of the skin innervated from the same ront as the diseased organ. Impulses from the latter are therefore convered in some way, either by mediation 
of the spinal ganglia or by mediation of the nerve eells of the spinal cord, to the sensory neurous of the skin.

For reflexes from the sympathetic ganglia, ef. page $58 \%$.

References.-Gastell, Journal of Physiology, vol. vii, 1886.-Kocher, "Mittheilungen aus den Grenzgebieten der Medizin und Chirurgie," vol. i, 1886. -Langley, several articles in the Joumal of Physiology, vols. xii, xv, xvii, xviii, xix, xx, xxiii, xxv, xxvii-xxxi; 1891-1904.-Langley, "Ergebnisse der Physiologie," ii, 2, Wiesbaden, 1903. 


\title{
('HAPTER NXTI
}

\author{
REPRODLCTION AND GROWTH
}

\section{FIRST SECTION}

\section{REPRODUCTION}

THE physiology of reproduction in general covers so wile a ficld and is relater to so many branches of biology that eren a superficial presentation of its most salient features would require more space than we have at our disposal. We shall therefore limit the discussion to those features of reproluction in man and the higher animals which are very important from the standpoint of human physiology, but which are not usually treated as belonging to the special provinee of embryology. The following brief survey of this field will indieate the scope we have in mind.

Reproduction in most of the higher animals is inaugurated by the conjugation of two different sexual elements, the male and the female. The female element. the orum, is formed in the ovary: it was first demonstrated for the mammals by $\mathrm{v}$. Bacr in 18:2. The male element, the spermatozoon, is formed in the testes and represents the "seminal bodies" discorered by Lenwenhoeck in $165 \%$.

In mammals the spermatozoa are introduced into the female borly by the aet of copulation. If fertilization of the orum then takes place. there develops within the female body a new indiridual, which, when it has reachel a certain stage in its development, is expelled from the body of the mother. This latter process is called birth or parturition.

At birth the new indiridual is not dereloped far enough to seek independently and to ntilize the ordinary food of the species. but must for a time derive its nourishment from the motloer. 'The mill gtands of the mother at this time are roused to a high degree of activity. and furnish a secretion, the mill, which contains in proper proportions the fondstuff's necessary for the maintenance of the newhorn child.

The physiology of reproduction. as we shall limit the subject here. will accordingly inclule: the functions of the male and female sexual organs, the processes of coputution and conception, birth, and the secretion of mith.

\section{\$ 1. THE MALE SEXUAL ORGANS}

These are: the testes, which produce the spermatozoa; the accessory glands (vesicular glands, prostate body, and the glands of Cowper), which produce 
secretions to be mixed with the spermatozoa in the seminal fluid: and the male organ. the penis, by which the seminal flud is introduced into the female organs.

\section{A. THE TESTES}

Sexual maturity. or mubrty. appears in the man at about the age of fifteen. The testes begin to increase in rolume and to secrete seminal fluid. At the same time the foreskin becomes lonsened from the glans penis, and the rest of the body exhibits many changes: the bones and the muscles become stronger (cf. below, page 709 ) ; the larynx increases in size, in consequence of which the voice becomes fuller and deeper, ete.

When the testes are remored br castration before sexual maturity, these changes do not take place-which proves clearly that they are occasioned by the testes.

The general character of the indiridual also is ehanged by castration. as may be seen best perhaps by comparison of the disposition of an ox with that of a bull. It follows that all the characteristics by which a man is distinguished from a woman depend essentially upon the testes and their actirity (cf. also page $35 \hat{\imath}$ ).

The spermatozoa are minute bodies consisting of a thick head and a slender tail, which. in virtue of the whiplike morements of the tail. are capable of independent motion. The speed of their locomotion, considered with reference to their size, is rather high, namely. 0.05 to $0.15 \mathrm{~mm}$. per second.

The spermatozoa are formed by a peculiar transformation of certain cells in the testes, known as spermatids. Aceording to Lode, in $1 \mathrm{cu}$. $\mathrm{mm}$. of human seminal fluid there are about 60.000 spermatozoa. The quantity of seminal fluid discharged at a single ejaculation may be estimated at about 3 ce.; whence the total number of spermatozoa in a single ejaculation would be in the neighborhood of $180,000,000$ - a perfectly enormons number in riew of the fact that but a single spermatozoon is necessary for fertilization of the orum.

Foges reports the interesting observation that the testis of a cock transplanted into the abdominal carity will continue to produce spermatozoa, from which we mar conclude that spermatogenesis is in part at least independent of the nerrous system.

\section{B. THE ACCESSORY SEXUAL GLANDS}

In a castrated animal the accessory glands atrophy, showing that they must play some essential part in the sexual functions. If castration be performed before sexual maturity, they do not develop at all.

Nothing is known at present as to the special functions of the separate rlands; but from the fact. established by comparative anatomical studies. that there is considerable variation in their relative sizes in different species. we may surmise that they all have an essentially common purpose.

The so-called seminal vesicles are not properly a receptacle for the seminal fluid, although they do always contain a greater or less number of spermato- 
zoa: they produce a secretion of their own, which has led Owen to describe them as the resicular glands. When they are extirpated either alone or in conjunction with the prostate body. sexual desire remains unimpaired, and copulation takes place in the same way as in the normal animal and with the usual frepnency.

The fecundity of the animal, however, is rery much reduced by the extirpation of the resicular glands (in white rats) and if the prostate body be remored along with them, the procreative power is entirely lost. The accessory sexual glands therefore are absolutely necessury for the full fruition of the male sexual functions (Steinach).

Probably their most important purpose is to provide for the dilution of the testicular secretion-a condition which is indispensable for the motility of the spermatozoa. In the testis itself and in the epididymis where the thid is thick the spermatozoa are not motile: but when semen from the testes is mixed with physiological salt solution, active movements appear wherever an actual mixing takes place (Iranoff). The ova of rabbits, guinea pigs and dogs can be successfully fertilized by injecting into the vagina a mixture of sperm from the epididymis and phrsiological salt solution (Walker).

On the other hand it was found in Steinach's experiments that the spermatozoa remain motile in the prostate secretion from seven to ten times longer than they do in the physiological salt solution. This shows that the secretion contains other substances which have a farorable action upon the spermatozoa. Since acids are very harmful to the spermatozoa, it is possible that the secretion has the additional function of neutralizing any acid that may chance to be present in the vaginal mucus.

In the guinea pig and other rodents, the secretion of the resicular gland eoagulates in the vagina so as to form a phug which prevents the escape of the seminal fluid. This coagulation is caused by the action of an enzyme occurring in the secretion of the prostate (Camus and Gley).

The vasa deferentia in the cat receive their motor nerves from the (second) third to fourth (fifth) lumbar roots: these nerves have about the same peripheral course as the lumbar nerves to the bladder (Langley and Anderson: af. page 3933).

The vesicular glants of the guinea pig receive motor as well as secretory fiber's by the hypogastrie nerves; they leave the spinal cord in the second to the fourth lumbar nerves (Akutsu).

Mislaws and Bormann state that the secretory fibers of the prostate run in the hypogantric nerves and that its muscles are supplied also with fibers from the nervi erigentes.

\section{ERECTION AND EJACULATION}

Just previons to the act of enpulation the penis beenmes rigid and erect. thus fitter to be introduced into the ragina. Frietion of the glans against the walls of the vagina sets $u p$ a reflex ly which the seminal fluid containing all the secretions of the acessory glands is discharged into the female organ (ejaculation). The rigidity of the male organ then passes oft and the act of copulation is ended.

Erection is due to an in-rush of blond into the three carernous bodies of the penis. cansed by dilatation of its arteries under the influence of raso-

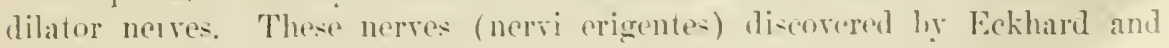


studied later by Lovén and others, leave the spinal cord in the anterior roots of the first to third sacral nerves, mite with the hypogastric plexus and rum thence to the penis. They have their center in the lowermost part of the cord. so that erection can still be reflexly induced after section of the spinal cord hetween the dorsal and the lumbar regions (cf. page 58s). In fact, at the moment of making such a section (in the guinea pig) erection and ejaculation oceur (Spina).

Aecording to L. R. Miiller erection and ejaculation ean be indneed (in the dog) by rubbing the penis after extirpation of the lumbar and upper part of the saeral cord. It is likely therefore that the reflex can be mediated by periph: eral ganglion cells.

Erection may be brought about also through the influence of higher nerve centers. Eckhard was able to induce the phenomenon in animals by the electrical stimulation of the cervical cord, of the pons, and of the crura cerebri. The fact that in man erection often occurs merely as the result of erotic ideas, is eridence that the nervi erigentes may be excited in the same way also by the cerebrum.

Stimulation of the nervi erigentes increases the volume of blood flowing throngh the purlenda interna rein beyond the month of the penis vein to about eightfold the volume flowing during the relaxed condition of the penis. Since, however, erection oecurs as the result of the same stimulation the inflow of blood must be still greater. In ercetion as it oceurs naturally the veins of the penis are eompressed by eontraetion of the musculature about the urethra, thereby rendering the outflow of blood from the penis more difficult, which in turn serves to heighten the degree of ereetion. Compression of these veins alone however does not eause ercetion.

Erection obviously must be elosely related to the functions of the testes; and yet observations on both men and animals go to show that erection is possible after eastration and that sexual passion may not be entircly destroyer.

When ejaculation occurs, the seminal fluid is thrown by foreible contractions of the vasa deferentia into the urethra in the direetion of the pars membranarea urethre. Entrance to the urinary bladder is prevented ehiefly by the sphincter of the bladder and by contraction of the musculature of the prostate.

The ejaeulatory duets open at the summit of the seminal eminence, while the months of the numerous ducts from the prostate are so arranged that they empty their secretion in exactly the opposite direetion. When the semen pours out of the ejaculatory ducts, numerous streams of the secretion from the prostate are at the same time poured into the urethra and there results a very uniform mixture of the two fluids (Walker).

The seminal fluid is expelled from the urethra by contraction of the bulbocarernosus and the isehio-eavernosus museles: aecorling to Walker the sphineter urethre membranacese should play an essential part in this also.

Ejaculation may take plaec without erection-in the guinea pig, for example, when the spinal cord is erushed by means of an exploring instrument. In the same animal Remy found on the inferior vena cava at the level of the renal veins a small ganglion eleetrical stimulation of which produced a sulden cjaeulation. Sexual desire was not destroyed by seetion of the nerves issuing from this ganglion, but erection and ejaeulation were no longer possible. 


\section{§ 2. THE FEMALE SEXUAL ORGANS}

\section{A. THE OVARIES AND OVIDUCTS}

The primorlial ora, which are lestined ultimately to beenme the mature ova capable of fertilization, are formed at a very early stage of intrauterine life. In the further course of development they become surrounded by a layer of germinal epithelial cells, the whole group being then known as the primary follicle.

From this primary follicle what is known as a Graafian follicle is developed in the following manner: The epithelium which surrounds the orum lregins to proliferate and becomes many-layered. Then in the space hetween these layers a fluid gradually collects, partly by transudation from the surrounding blood resels and partly hy disintegration of epithelial cells. In the luman ovary this liquor folliculuris is found only in that part of the follicle presenting toward the surface of the ovary. On the medial sirle of the follicle the epithelium forms a mass of cells surrounding the orum and projecting into the follicular cavity as the discus proligerus. The follicle is also surroumbed by a ennective tissue envelope known as the theca folliculi.

At the same time the ormm, its nucleus (germinal resicle) and muclenlus (germinal spot) grow in size and the orum hecomes surrounderl by a memhrane, the zona pellucida, secreted by the follicular epithelium. The memhrane, however, is separated from the ormu by a small space.

In the further development of the nrum, the protoplasm from the center outward becomes transformed into yolk spherules, until finally there remains of the true protoplasm only a thin layer situated peripherally, and containing the nuclens.

Derelopment of the primary follicle into the Grafan follicle takes place before sexual maturity. in fact before the birth of the young female. But the ova are not ret capahle of being fertilized and will not be before the heginning of sexual noaturity-i. c., abont the fourteenth rear. By this time the ova are about twice as large as when the Graafinn follicle was former, measuring now about $0.2 \mathrm{~mm}$. in diameter, and have extruded from themselves half the chromatin (staining substance) of their nuclei.

When the follicle has reached a certain size. an internal proliferation in the immer layer of the theca folliculi takes place which finally leads to its rupture aurl to the consequent liberation of the ormm. The processes concrenert in this, acroreling to Nagel's description, shape themselves on this wise:

The rusels of the theea become strongly dereloped, and the cells about them multiply cuormousy. It the same time the protoplasm of the cells beeomes filled with a material (lutein) which gives the whole inner wall of the

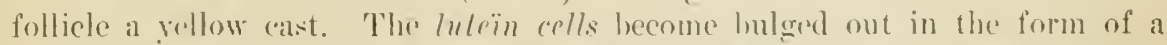
papilla on the inner layer of the theca and this bulging continues. crowing the follienlar eontents more and more towarl the thinnest part of the follicular wall turned toward the surface of the ovary, until finally the follicle bursts. Hand in hand with this proliferation of the lutrön redls there groes a fatfy degeneration of the follicular epithelium, by which the orum with its epi- 
thelium is released from the discus proligerus. The contents of the follicle are replaced in part at least by a blood clot: we then have instead of the Graafian follicle a corpus luteum.

Thus the orum comes into the abdominal cavity and is ready to enter the Fallopian tube to be passed on into the uterns. The abdominal opening of the tube spreads out in the form of a funnel surrounded by fringelike processes known as fimbrice, one of which, the fimbria orarica, comes quite close up to the orary. Along this fimbria. extending from the orary to the tube. runs a groove, which, like the fimbrix themselves and the mueous membrane lining the tubes, is clothed by a ciliated epithelium. These cilia beat in the direction of the tube, ereating a current in the surrounding capillary spaces between the viscera, which probably plays a predominant part in guiding the orum. The production of this current is materially aided by the peenliar position of the tube, its relation to the ovary being such as to form about the latter a sort of poeket, closed off from the abdominal eavity.

Once in the Fallopian tube the ovum is earried along to the uterus by the morements of the eilia. In this journey, which requires about three days, the remains of the follienlar epithelium alherent to the orum when it is set free, become stripped off, leaving the orum naked.

It is probable that many of the ova set free from the ovary never reach the Fallopian tubes, but are lost in the abdominal eavity.

Opinions differ very much as to the time of ovulation (liberation of the orum from the ovary), and a definite decision between them eamnot be given at this time. Some authors suppose that it takes place only in eonneetion with menstruation (before or after), others that it ean oceur at any time in eonnection with eopulation.

\section{B. THE UTERUS}

The uterus is a hollow organ which serves the purpose of harboring the ovum during its development into the mature fatus and of supplying the necessary nourishment for this derelopment. The wall of the uterus consists externally of numerous smooth muscle fibers interlaced together, and internally of a mucons membrane lined with a ciliated epithelium. invaginations of which toward the muscle layer constitute the mucous glands. The cilia of the epithelium heat from above downward-i.e., from the fundus toward the mouth of the uterus.

The uterus differs radically from all other organs of the body in that its tissues undergo profound alterations under perfeetly normal circumstances. Some of these alterations are related to menstruation. some of them to pregnancy.

$\mathrm{By}$ menstruation is meant a periodic discharge of blood from the uterus of the sexually mature female. which oecurs about every twenty-eight days and continues on the arerage about four days. It begins at about the fourteenth year of age and constitutes the external sign of sexual maturity. The quantity of blood discharged at each period has been estimated at from $100-200 \mathrm{cc}$, but the amount is subject to great variations. At the age of forty-five to fifty vears menstruation gradually ceases. and with it the ability to bear young is permanently lost. This age is designated as the climacteric. 
It had long been supposed that menstruation was due to some nerrous influence of the ovary over the uterus. But it has been observed that in monkers menstruation can take place even when the ovaries have been removed from their normal position in the body and transplanted elsewhere, all nerrous connections with the ovary being severed. Hence it is not improbable that the internal secretion of the ovary is the essential medium of influence (cf. page 355 ).

Just as in man, the appearance of puberty in woman is marked by other changes in the body: the mammary glands increase in size, the figure loses its childish delieacy and, by the deposition of subcutaneous fat, becomes more rolmst. Castration of the female (extirpation of the ovarics) likewise produces more or less sharply pronounced changes (ef. page 358).

The monthly changes in the uterus proceed as follows: five to ten dars before the period of discharge the blood ressels of the mucous membrane become dilated, the membrane itself as a result swells up and a proliferation of its more superficial lavers takes place. Then follows a hemorrlage in the subepithelial tissue which is probably not due to rupture of blood reseds. but to the esape from them of red blood enrpuscles. The nutritive condition of the mueous nembrane thus beeomes impaired, and as a consequence its outermost lavers (the decidua menstrualis) slough off (according to some authors the loss of the mucous membrane is not due to lack of mutrition, but to pressure of the escaping blood in the subjacent tissues) ; the period of discharge continues for about four days. when a process of restitution sets in. These changes proceed by a regeneration of tissue fuom the remaining epithelium and its invaginations, and last from five to ten days. Hence the tissue changes accompanying menstruation cover all told from fourteen to twenty-foul days out of each month.

The phrsiological significance of menstruation probably consists in a preparation of the uterine wall for the reception of the fertilized orum.

Like the rest of the mucous membrane of the uterus, that of the cervix bears on its surface a ciliated epithelium, invaginations of which form the cervical glands. These glands secrete a clear, viscid mucus which eollects in the cervical eanal soon after conception and remains there as a plug serving to keep the passage closed throughout pregnaney.

After the climaeteric has been passed. and ova are no longer being formed, the mucous membrane of the uterus shrivels up, the connective tissue underlying it increases in quantity, the cervical glands atrophy, and the epithelium luse's its cilia.

\section{PREGNANCY AND BIRTH}

Spermatozoa are independently motile. and in virtue of this property of motility ean traverse great distances, relatively speaking. Their entranee into the uterns and Fallopian tubes is due no doubt to some chemotactic influence over them exercised by the secretions of those organs, and their ascent toward the ovaries within the tuhes is traceable to their rheotactic properties (cof. page si). Coming into contact with the orum, the spermatozon enter's it, possibly umber the spell of a thigmotartir intluener (ef. page sti). luside the orum the spermatozonn produces changes comprehended under the term fertilization, which make it possible for the ovum to develop into a new individual. 
When the ormm has been fertilized, it becomes attached to the mucous membrane of the uterus already prepared for it, and later becomes surrounded by the proliferating epithelinin of the mucous membrane.

The material necessary for the nourishment of the orum is received from the mother through the placenta. As the orum grows the uterus increases in size, so that while before impregnation its capacity is 3-5 cc., at the close of pregnaney it is 5.000-5.000 ec. This colossal derelopment produces remarkably little change in the organism as a whole, and the only permanent alterations remaining after pregnancy are certain folds in the subcutaneous connective tissue of the abdomen caused by the extreme tension to which it has been subjeeted, and certain anatomical differences in the wall of the uterus.

The period of gestation covers ten menstrual periods-i.e., about two hundred and eighty days-at the end of which time birth takes place.

The feetus is discharged from the uterus by powerful contractions of its muscular walls, aided by simultaneons contractions of the diaphragm and abdominal museles. The first effect of the uterine contractions is to draw the cerrix on all sides tightly against the foetus and to dilate the passage way until the ehild can be foreed through. This stage of labor is ealled the opening period; that following. which terminates in the complete discharge of the offspring. is called the expulsion period. In eases of first lirtlss the former period lasts about twelve hours. in subsequent births six hours; the length of the expulsion period is estimated at two hours. These howerer are only arerage figures, and the duration of birth may vary considerably either way.

Owing to their painful character the contractions of the uterus in childlirth are commonly called labor pains. They are not continuous, but like

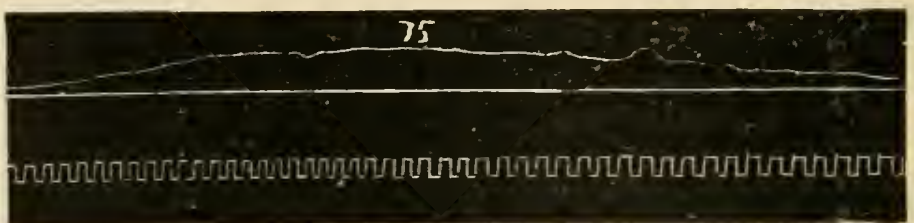

Fig. 302.- Normal curve of a contraction of the uterus, after Westermark. To be read from left to right.

the contractions themselves are intermittent and beeome progressively longer and more severe until near the eulmination of labor.

The frequency of labor pains is variable. At the beginning of the first stage of labor, the interval between them is greatest, but it hecomes steadily less until it reaches its mininum (less than one hundred seconds) at the end of this stage or some time during the second. When the pains are unusually long and screre. the pauses are also longer.

So long as there is no change in the volume of the contents of the uterus. the intranterine pressure during the pauses, as estimated by Schatz, Polallion. Westermark, and others. remains remarkably cren in any particular case of labor: lont in different cases of labor it varies from 20 to $50 \mathrm{~mm}$. Hg. When the amnion is ruptured a decrease in the volume of the uterine contents takes 
place, and this occasions a fall of the intrauterine pressure at the next pause. After this fall. however. the pressure during the following pauses tends to return to its original level, although that level is seldom reached. partly becanse the amniotic fluid escapes dming each contraction of the wall, and partly becanse the child is pressed deeper and deeper into the pelvis, thus decreasing the volume of the uterine contents.

During a single pain the intranterine pressure increases slowly at first, then rather rapidly, and finally slowly again until it reaches its highest point.

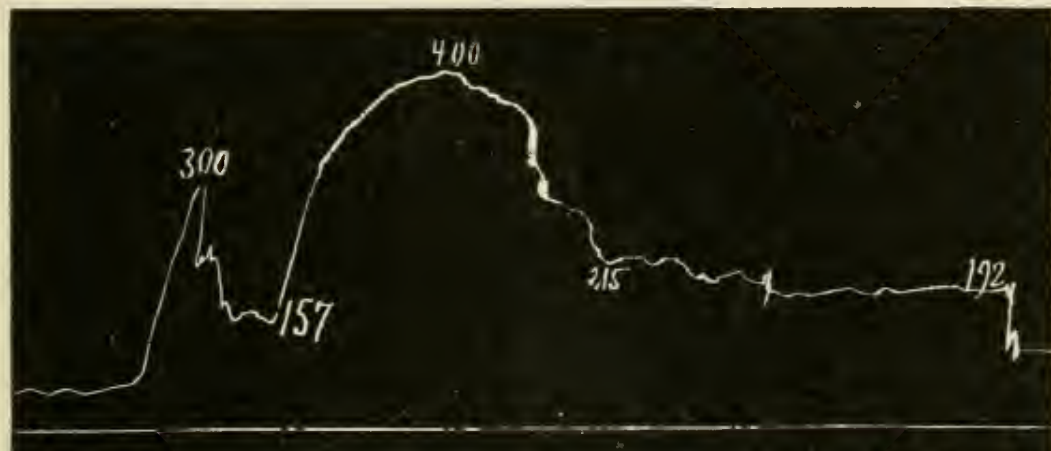

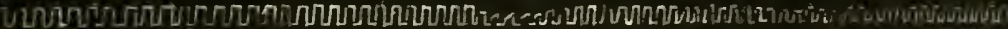

FIG. 303.-Pressure curve of the last contraction of the uterus in parturition, after Westermark. The high curve, reaching a pressure of $400 \mathrm{~mm}$. $\mathrm{Hg}$., represents the effect of the abdominal muscles. To be read from left to right.

For about eight seconls it remains at this maximum, after which it falls at first slowly, then for fire to twenty-five seconds more rapidly and at the last very slowly ( Fig. 30\%).

'The highest pressure due to the contractions of the uterus alone. attained during the individual pains, inereases during the progress of birth and reaches its maximmm at the end. ()ut of 58 s determinations made by Westermark the lowest was $20 \mathrm{~mm}$. Hg., the highest 220 , and the average $109 \mathrm{~mm}$. The value naturally is consilerably increased when the abdominal pressure also is brought to bear on the wall of the uterus. Especially is this the ease during the last pains of the expulsive perion, where values of $400 \mathrm{~mm}$. Hg. have been obserred ( Fig. 3013).

A short time after the birth of the ehild the placenta becomes loosened and with the amnion is expelled from the uterus as the afterbirth. The severe hemorrhage which oecurs at first is stopped by the powerful contractions of the uterus. Then the organ gradually returns to its original size, the mueous membrane becomes regenerated, the muscle fibers deerease in longth and breadth. Connected with these regeneration changes, which are eomplete after abont two months, there is for a couple of weeks a discharge of a slimy, and at first bloody. material. The first menstruation howerer does not as a rule appear until about the tenth month, when lactation has ceased (ef. §3). 


\section{INNERVATION OF THE SEXUAL ORGANS}

Experimental data on the innervation of the nterus differ widely. While some authors state that the circular muscle fibers are innervated by the nervi erigentes and the longitudinal fibers by the hypogastric, Langley and Anderson have reached the conclusion that (in the rabbit and cat) only the lumbar nerves convey motor fibers and that these supply both the longitudinal and circular musenlatures. The effect of unilateral stimulation is felt chiefly on the same side.

Nagel describes the innervation of the uterus in the woman as follows: one trunk arises from the lypogastric plexus, while others arise from the sacral nerves. The former reeeives fibers from the third sacral and sends a branch to the ureter. It then betakes itself to the cervical ganglion (plexus utero-vaginalis) which lies in the neighborhood of the lateral vaginal fold.

Besides this ganglion, which receives branches from the fourth sacral and is also commected with the hemorrhoidalis nerve, there are found in the vicinity of the ureter two other ganglia (the vesical plexus): the three ganglia are connected with one another and send branches to the uterus, the vagina, ete. Most of the uterine nerves come from these ganglia; a smaller part of them pass directly from the hypogastrie plexus.

The nerves of the ovaries arise from the plexus renalis and from the lower portion of the plexus aorticus abdominalis.

The plexus surrounding the vagina arises from the cervical and resicular ganglia, but also receires twigs from the third and fourth sacral nerves.

Morements of the uterus can be produced by stimulation of the different parts of the central nervous system (lumbar cord, medulla oblongata, anterior part of the optic thalami, cerebral cortex, probably the motor zone). But the uterus contracts spontaneously at a certain rhythm even when it is cut out of the body, and birth has been known to take place in a perfectly normal manner with all the uterine nerves cut (Rein) and after entire extirpation of the lower end of the spinal cord (Goltz and Ewald, cf. page 583). The central nervous system therefore plays a relatively unimportant part in controlling the movements of the uterus.

According to Keilmann and Kinupffer, parturition takes place at once if the cervix be everted as far as the ganglion of the cervix. But Rein states that (in the $\operatorname{dog}$ ) parturition takes place also after extirpation of the ganglion.

\section{\$ 3. SECRETION OF MILK}

The newborn child is not far enough developed to seek and to take food without help. Its digestive organs are not yet capable of modifying the ordinary mixed diet of man, consequently nourishment for the child must be prepared for some months in the body of the mother. This is accomplished through the activity of the mammary glands which form and secrete the milk.

\section{A. MILK}

Milk constitutes the natural food of the child and hence contains in proper relative proportions all the foodstuffs necessary for the maintenance and devel- 
opment of the young body. We therefore find in milk proteid, fat, carbohydrate and mineral substances.

Among the proteids of mill we find: in small quantities lact-globulin, which is probably identical with serum globulin; lact-albumin, which is distinguished by certain properties from serum albumin; and, most important of all, casein. Cow's milk contains on the average about 3 per cent of casein and $0 . \tilde{s}$ per cent of other proteids.

Cascin of cow's milk is a nucleo-albumin (cf. page 75) which is characterized chiefly by the fact that it coagulates under the influenec of rennin (cf. page 250$)$. In the dried state casein is a fine white powder. It is insoluble in water and very difficultly soluble in solutions of the common neutral salts, but in water to which a very slight trace of alkali has been added it is very readily soluble. It is soluble also in the presence of calcium earbonate from which the casein, acting as an acid, displaces the carbon dioxide. Its solutions do not coagulate on boiling and are not precipitated by magnesium sulphate, metallic salts, or mineral acids in excess.

The cascin of woman's milk is distinguished from that of cow's milk chiefly in the form of the clot. While the clot of en's milk is composed of dense, compact masses, in the coagulation of woman's milk a rery loose and finely flocculent precipitate is formed. This difference, as will be readily understood, is a matter of great importance for digestion in the stomach of the infant. Besides, the casein of woman's milk does not always coagulate under the influence of rennin, and in its digestion, according to Kobrak, pseudonuclein is formed in very much smaller quantities than in digestion of cow's milk casein.

Varions other circumstances point to the conclusion that the casein of woman's milk is a compound of a nucleo-albumin similar to the casein of cow's milk with a basic proteid body, probably a histon or a protamin. In fact it is possible to prepare from the casein of woman's milk a body which in its coagulation forms a compact cake not unlike that of cow's milk casein (Kobrak).

Finally, there has been found in woman's milk a proteid substance, very rich in sulphur and relatively poor in carbon, called opalisin (Wroblewsky), which occurs in cow's milk only in very slight quantities.

The fat of milk is present in the form of small droplets. For a long time it was believed with Ascherson that these droplets were surrounded by a proteid membrane (haptogen membrane). Later researches seemed to hare shown that this is not true, but that the fusion of milk droplets is prevented only by the surface tension of the constituents of different specific grarity present in milk, or by a laver of casein or proteid solution held about the droplets by molecular attraction. But more recently the former view has been taken up again. and it is now stated rery definitely by Toltz that the milk droplets possess envelopes of solid substance. which are probably true membranes. 'T'hese envelopes entain both nitrogenous and nomnitrogenous compounds, as well as inorganic substances of which calcium is the chief. Their chemical composition varies greatly.

In woman's milk the fat droplets are larger and their number smaller than in cow's milk.

Butter, which is the fat of milk, consists mairly of palmitin and olein. Besides we find: stearic acid, mristinic acid, small quantities of butyric acid, caproic acid, cte., in the form of triglyecrides. The melting point of the fat 
of woman's milk is $34^{\circ} \mathrm{C}$., the congealing point, $20^{\circ} \mathrm{C}$., and its specific gravity 0.966.

'The most important carbohydrate of milh is milh sugar (cf. page 81).

Bunge has made the very remarkable observation that in dogs and rabbits the mineral constituents are present in the same relative proportion as in the ash of newborn animals. while the percentage composition of the ash of the blood and blood sertum are quite different (ef. the following table).

\begin{tabular}{|c|c|c|c|c|c|c|}
\hline $\begin{array}{l}\text { ONE. HCXDRED PARTS } \\
\text { ASH CONTAIN }\end{array}$ & $\begin{array}{l}\text { Suckling } \\
\text { dog. }\end{array}$ & $\begin{array}{l}\text { Dog's } \\
\text { milk. }\end{array}$ & $\begin{array}{l}\text { Dog's } \\
\text { blood. }\end{array}$ & $\begin{array}{c}\text { Dog`s } \\
\text { serum. }\end{array}$ & $\begin{array}{l}\text { Young } \\
\text { rabbit. }\end{array}$ & $\begin{array}{l}\text { Rabbit's } \\
\text { milk. }\end{array}$ \\
\hline 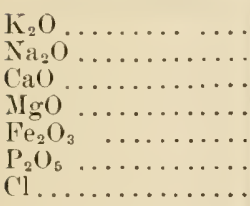 & $\begin{array}{c}8.5 \\
8.2 \\
35.8 \\
1.6 \\
0.34 \\
39.8 \\
7.3\end{array}$ & $\begin{array}{c}10.7 \\
6.1 \\
34.4 \\
1.5 \\
0.14 \\
37.5 \\
12.4\end{array}$ & $\begin{array}{r}3.1 \\
45.6 \\
0.9 \\
0.4 \\
9.4 \\
13.2 \\
35.6\end{array}$ & $\begin{array}{c}2.4 \\
52.1 \\
2.1 \\
0.5 \\
0.12 \\
5.9 \\
4.6\end{array}$ & $\begin{array}{r}10.8 \\
6.0 \\
35.0 \\
2.2 \\
0.29 \\
41.9 \\
4.9\end{array}$ & $\begin{array}{c}10.1 \\
7.9 \\
35.7 \\
2.2 \\
0.08 \\
39.9 \\
5.4\end{array}$ \\
\hline
\end{tabular}

This agreement is wanting, however, when we compare the composition of hmman milk with that of the ash of the human infant, as the following summaries of observations by de Lange, Hugonenq and söldner will show.

\begin{tabular}{|c|c|c|c|c|c|}
\hline \multirow{2}{*}{$\begin{array}{c}\text { ONE HUNDREd Parts } \\
\text { ASH CoNTAIN }\end{array}$} & \multicolumn{4}{|c|}{ INFANT. } & \multirow{2}{*}{$\begin{array}{l}\text { Mother's milk, } \\
\text { average } \\
\text { composition. }\end{array}$} \\
\hline & $\begin{array}{l}\text { Söldner, } \\
\text { I. }\end{array}$ & $\begin{array}{l}\text { Söldner, } \\
\text { II. }\end{array}$ & Hugonenq. & De Lange. & \\
\hline 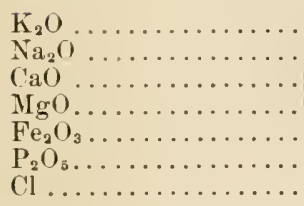 & $\begin{array}{r}8.9 \\
10.0 \\
33.5 \\
1.3 \\
1.0 \\
37.7 \\
8.8\end{array}$ & $\begin{array}{r}6.8 \\
8.3 \\
38.7 \\
0.6 \\
0.7 \\
40.2 \\
6.6\end{array}$ & $\begin{array}{r}6.2 \\
8.1 \\
40.5 \\
1.5 \\
0.4 \\
35.3 \\
4.3\end{array}$ & $\begin{array}{r}6.5 \\
8.8 \\
38.9 \\
1.4 \\
1.7 \\
37.6 \\
6.3\end{array}$ & $\begin{array}{r}30.1 \\
14.8 \\
15.6 \\
2.8 \\
0.5 \\
16.3 \\
20.1\end{array}$ \\
\hline
\end{tabular}

Bunge refers this striking difference to the circumstance that the composition of milk ash agrees more elosely with that of the ash of the young, the more rapidly the animal grows in weight after birth, pointing ont that it is only by means of such an agreement that it would be possible for the rapidly growing animal to get every necessary mineral constituent in the proper proportion for its growth. In the slowly growing human infant this agreement is not necessary. But it is important that those constituents of the ash that serve to kcep the composition of the urine normal should be supplied: hence the woman's milk is found to eontain relatively more alkaline chlorides than the dog or rabbit milk.

In support of this riew, Bunge compares the percentage composition of milk in tissue-forming substances, proteid and ash (ealcium and phosphoric acirl) in rapidly and slowly growing animals. It will be obsered from the following table that these pereentages are much higher in the former than in the latter. 
TIME IN WHICH THE NEWBORN OFFSPRING LOEBLES ITS WEIGHT.

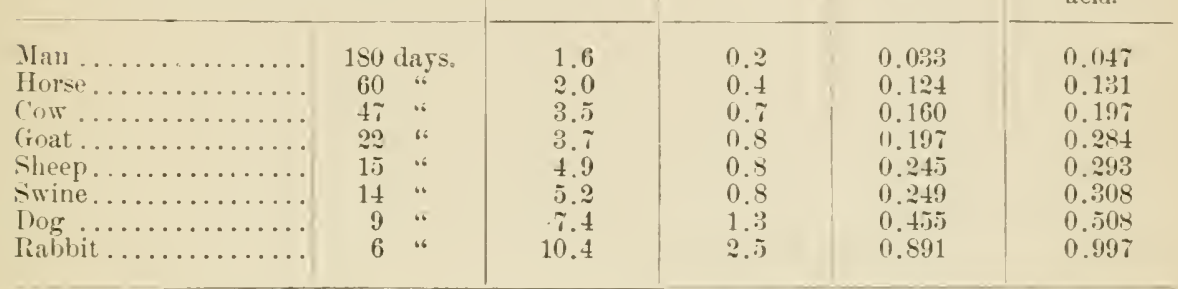

The arerage composition of cow's milk. taken from a very larere number of analyses, is: 87.2 per cent water. 12.8 per cent solids, 3.0 per cent easein, 0.5 per cent albumin, $3 . \tilde{\imath}$ per cent fat, 4.9 per cent sugar and $0 . \hat{\imath}$ per cont mineral constituents.

IIoman's milk contains: $8 \%-89$ per cent water. $10.8-12 . t$ per cent solids, $1-2$ per cent proteid, $3-t$ per cent fat. $5-8$ per cent sugar and $0.2-0 . t$ per cent mineral matter.

In general womans milk is poorer in proteid and mineral constituents and richer in sugar and lecithin than cow's milk. The absolute quantity of milk secreted during the lactation period increases up to the twentr-eighth week, and then falls oti. The proteid content. lowever. shows an almost constant decrease, as the following figures from soldner will show. Part of the data are from different individuals.

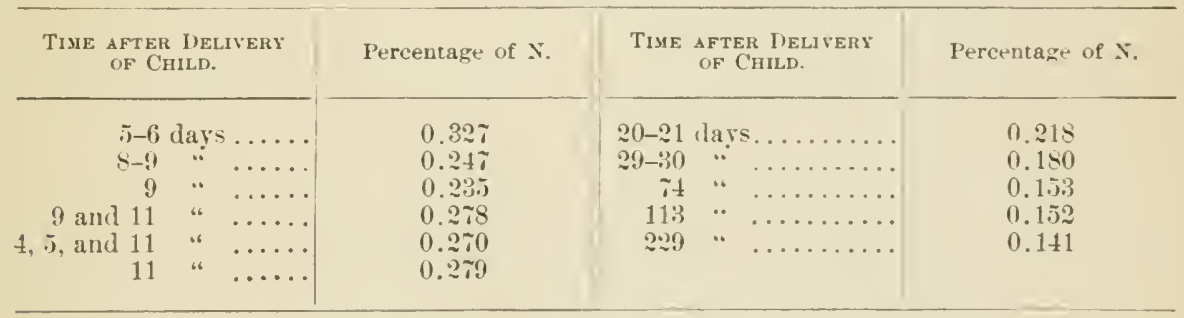

The fat content likewise decreases somewhat in the course of the lactation period: but the perentuge of sugar increases, at first pretty rapidly. then more and more slowly.

According to Bunge the mineral constituents of woman's milk luare the

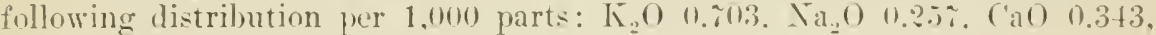
$\operatorname{IgO} 0.065 . \mathrm{Fe}_{2} \mathrm{O}_{3}\left(1.0060 . \mathrm{P}_{2} \mathrm{O}=0.469\right.$. ('l 11.445.

The quantity of milk secreted daily ly both hreasts of a mursing mother may he estimated at about 1.300 g.. but this quantity is subject to great variations.

\section{B. SECRETION OF MILK}

The milk is secreted he the mammary glands. Each crlard consists of 15-20 lobes grouped about as many duets which open in the nipple. They 
are fully formed in the boy as well as in the girl at birth, and up to the end of the second to eighth ireek after birth they secrete a milky fluid called "witch's milk." In males the mammary glands as a rule become only slightly developed and nerer produce any secretion. In the female they begin at puberty to grow and increase considerably in size at that time. But a really important increase takes place only in connection with pregnancy. During the last few weeks of gestation, a fluid which differs considerably in composition from the milk and is known as the colostrum, is given off, and after birth has ocenrred the glands enter upon a period of vigorons activity which, with the child at the hreast, continues for months. When the child is not nursed by the mother, the mammary glands atrophy and sirivel up to a small mass of connectire tissne.

The nerves of the mammary glands end about the gland cells as a net of cirrous arborizations. In the human species they arise from the fourth to sixth intercostal nerves.

In animals the mammary glands are situated more distally and accordingly are supplied by more distal nerves. Ir the guinea pig, which has only a single pair of mammary glands, the nerves come from the spermatics. The five pairs of glands in the dog receive their nerves from this and several other nerve trunks.

The influence of the nervous system on the secretion of milk is a subject which has not yet been sufficiently investigated. From the observations of Goltz and Ewald on animals with the lower end of the spinal cord exsected (page 583), we learn that the mammary glants can secrete milk independently of the central nerrous system. But the milk secreted by glands whose nerves have been sectioned exhibits morphological changes which go to show that the secretion is influenced in certain ways by the nervous system ( $K$. Basch). Besides in the above experiments of Goltz and Ewald the influence of the peripheral simpathetic ganglia was not exchuded.

Concerning the mechanism of milh secretion, the most divergent riews hare been expressed, and for the present we eannot decide whether the gland cells heeome disintegrated and contribute their own substance to the secretion, or whether they prepare the constituents of the milk from other materials. It seems, however, that there can be no very extensive destruction of cells, and the real question therefore narrows down to whether or not nuclei and protoplasm become to some extent transformed into secretion. Most recent writers on the subject think that this is the case; but that only the free end of the gland cell is lost, and that after the secretory products have in this way been discharged, a regeneration of the protoplasm from the basal, nucleated end of the cell takes place, and the same process of transformation, disintegration, etc., is repeated. For more detailed information we must refer to the literature bearing on the subject. Here we may only add that during lactation a varying number of lencocytes rander out of the interstitial connective tissue into the alreoli of the glands. It is possible that in the erent of arrested lactation, they convey the fat away from the nammary gland.

Neither casein nor milk sugar is found in the hlood: hence it is evident that they must be formed in the mammary gland itself. 
K. Basch conceires that casein is formed by combination of a pseudonuclein, which is set free from the nuelei of the gland cell, with proteid. He bases this view on the fact, among other things, that by the action of a xanthin-free and sugar-free nucleic acid, prepared from the mammary gland, on the serum of ox blood, he was able to get a substance which had all the physieal and chemical properties of cow's milk casein.

The pereentage of fat in the milk ean be raised by feeding fat. This increase is explained in different ways by different authors; but it is fairly probable that some of the fat of the food at least is carried over into the seeretion. The fact that when iodized swine fat has been fed, it can be demonstrated in the milk in fairly large quantities (Winternitz) would faror this riew. When iodine alone or potassium iodide is fed only the merest traces of iodine are found in the milk (Caspari).

On the other hand we hare obserrations by Henriques and Hansen which indicate that the fat of the food in its passage through the cells of the milk glands suffers changes in its composition.

Even when an animal in lactation receives a diet which is poor in fat, the milk contains a considerable quantity of fat. In this case the milk fat must have been formed either from the earbohydrates fed or from the large deposits of fat in the body. This is demonstrated especially by the appearanee of iodized fat in the milk at a time when there was no iodized fat in the foocl, but when iodized fat had previonsly been stored in the body (Caspari).

$A$ cow on a restricted diet naturally sceretes less milk than on a full diet; but the fat in her milk still has a lower melting point than the body's fat. This means that when the fat deposited in the body is called into requisition, relatirely more olein is mobilized than palmatin and stearin (Henriques and IIansen).

It has ofttimes been confirmed that both the quantity of milk and the percentage of fat secreted inerenses on a diet which is rich in proteid, and this can only mean that proteid either direetly or indirectly is a souree of fat.

Aceording to Thierfelder the sugar of milk arises from some mother substance not ret definitely identified, by the action of an enzrme associated with the grant reells.

The following mar be mentioned here among the many different externai agencies which influciee the quantity and quality of the milk: (1) Frequent milking farors the activity of the glands. When the milking is done at stated intervals, the last milk stripped from the glands is richest in fat. This is probably due to the adherence of many fat particles to the walls between the fold of the nueous membrane as the earlier milk flowed through, the stripping proees: being necessary to distodge them. (2) Tor vigorous exereise diminishes the quantity of the milk, probably beeause the blood stream is diverted from the glands to the muscles. On the other hand, moderate exercise inereases the sceretion of milk in women, probahly owing to its farorable effects on respiration, circulation, digestion, ete. (II. Munk).

\section{SECOND SECTION}

\section{GROWTH OF THE HUMAN BODY}

sereral different periods may he recngnized in the life of an indiridual human being. They are not marked ofl' by sharply defined boundaries, so that one can say for example that on a certain day the indiridual is a youth 
and the next day a man or woman: but are recognized by the eharacteristics which plainly prevail. once they are fully establisherl. These periots are:

(1) Periud of the Teuborn. from birth to the loss of the umbilical cord, which usually takes place in four or five dars.

(2) Period of Infancy. up to the appearance of the first teeth. from the serenth to the ninth month.

(3) Later Childhood. up to the appearance of the permanent teeth about the serenth year.

(4) Age of Boyhood and Girlhood. up to the beginning of puberty. thirteenth to fourteenth vears.

(5) Age of Iouth or Adolescence. up to the time of bodily maturity, nineteenth to twenty-first year.

(6) Age of Maturity, up to the prime of life (climacterie in the moman), forty-fifth to fiftieth year.

(i) Old Age.

The first fire periods are the ones of particular interest here beeause they corer almost the entire period of growth. The sixth period is the age within which man reaches his full phrsical and mental revelopment. During the seventh period rarious disorders. caused more or less by chronic ailments of one kind or another. gradually eneroach upon the normal functions, and the phrsical and mental powers are on the wane.

In turning now to the subject of the size relations of the bodr. let it be understood that the data presented are arerage results and that many individual variations from them are to be observed. In any exhaustive discussion of the subject it would be necessary to consider these variations and their meaning. but it will be impossible to do so here. The following is a concrete example of the method employed in arriving at arerage results.

Quetelet and Altherr carried out a series of observations on the weight of the newborn child, and found the mean ralue. irrespective of sex, to be $3,100 \mathrm{~g}$. The extremes however were rery considerable, for among the children weighed there were some under $1.5 \mathrm{~kg}$., and some over $4.5 \mathrm{~kg}$. In order to get a general riew of the rariations and thus to be able to grasp the significance of the mean ralue more correctly, the entire series of observations may be divided into groups according to weight: $1.0-1.5,1.5-2.0$, etc., and the proportion of indiridual cases belonging to each calculated in percentages of the entire number. We get in this way the following table, the results of which might be made still more clear by a graphic representation like that in Fig. 302 .

\begin{tabular}{|c|c|c|}
\hline $\begin{array}{l}\text { BodY WEIGHT OF THE NETBORY } \\
\text { CHILD, IN KILOGRAIS. }\end{array}$ & Number of cases. & Percentage of cases. \\
\hline 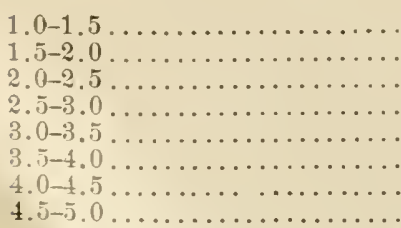 & $\begin{array}{r}2 \\
8 \\
54 \\
180 \\
251 \\
88 \\
15 \\
1\end{array}$ & $\begin{array}{r}0.33 \\
1.34 \\
9.01 \\
30.05 \\
41.90 \\
14.69 \\
2.51 \\
0.17\end{array}$ \\
\hline
\end{tabular}


The weight of the child at term is, on the arerage. $3.000-3.500 \mathrm{~g}$. (extremes, 2. $400-5.500)$. Boys are usually from 80 to $150 \mathrm{~g}$. hearier than girls.

The length of the newborn child is. on the arerage, $50-51 \mathrm{~cm}$. Bors appear as a rule to be $1 \mathrm{~cm}$. longer than girls.

The weight of the newborn child increases with the number of pregnaneies and with the age of the mother up to her fortieth vear, as the following compilations by Ingerslew will show:

\begin{tabular}{|c|c|c|c|}
\hline $\begin{array}{l}\text { NTMBER OF THE } \\
\text { PREGANCY. }\end{array}$ & $\begin{array}{l}\text { Weight of the child } \\
\text { at birth. in grams. }\end{array}$ & AGE OF THE MOTHER. & $\begin{array}{l}\text { Weight of the child } \\
\text { at birth, in grams. }\end{array}$ \\
\hline 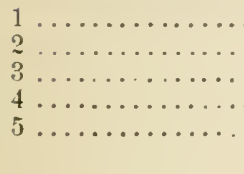 & $\begin{array}{l}3.254 \\
3,391 \\
3.400 \\
3.424 \\
3,500\end{array}$ & 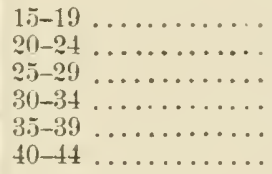 & $\begin{array}{l}3.241 \\
3.299 \\
3.342 \\
3.375 \\
3.428 \\
3.326\end{array}$ \\
\hline
\end{tabular}

The general phrsical condition and derelopment of the mother also hare much to do with the weight of the child. The greater the length of the mother's body, and the better its nutritive condition. the hearier and longer, generally speaking, will be the weight and length of the child at birth.

During the first two days after birth the child"s body loses 100-200 g. in weight. lut about the third day it begins to grow. and on the fifth to serenth day reaches its first weight again.

From this time on the growth in weight is rery rapid, and by the twentyfourth week it has doubled. At the end of the first year it is two and threequarter times what it was at birth. The average monthly increase as given by Albrecht for the first twelve months is as follows: $900 \mathrm{~g} . .8 \% 0.8 ; 0 . ; 20.600$. $540,420,330,330,220.240$, and $210 \mathrm{~g}$; within the entire twelve month: therefore, a tntal of $6.300 \mathrm{~g}$. is gained. Hence at the end of the year the weight is about $9.500 \mathrm{~g}$.

The length of the infant's body at the end of fire months is about $68 \mathrm{~cm}$. and at the end of the first year about $i \tau \mathrm{cm}$. Growth therefore is more rapid at first than at any subsequent time.

The food of the child may be set down as the most important factor in determining the rate of growth during the first year. So far as we are able to judge from published observations on the subject, the child thrives better and its weight increases more rapidly when it is fed exclusively at the breast throughout the infaney period. This doubtless signifies that no artificial means of nourishment has ever been found which makes so little exactions on the delicate digestive apparatus as the mother's milk.

In three years the child:s body has already reached half the length it will be when fully grown. During this period a boy will on the arerage have attained to a weiglit of $18-21 \mathrm{~kg}$. and a girl, $1 \%-21 \mathrm{~kg}$. 
The growth of the body in length during the later years of ehildhood will be erident from the following table:

\begin{tabular}{|c|c|c|}
\hline YEAR OF AGE. & Boys: length in $\mathrm{cm}$. & Giris: length in $\mathrm{cm}$. \\
\hline 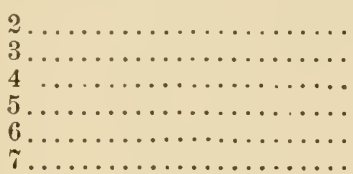 & $\begin{array}{r}74.2 \\
85.3 \\
91.9 \\
96.6 \\
103.2 \\
106.5\end{array}$ & $\begin{array}{r}77.2 \\
83.5 \\
90.0 \\
96.1 \\
100.6 \\
104.9\end{array}$ \\
\hline
\end{tabular}

Obviously it is much more difficult to get an extensive series of observations on the growth of the child during the first five or six years of life than it is later. Within the years of seven and nineteen the material is much more accessible and the total number of observations on the rate of growth in length and body weight, made on children of school age by Bowditch in Boston, Key in Sweden, Kotelmann in Hamburg, Pagliani in Turin, Roberts in England and Porter in St. Louis, foots up a total of more than 125,000 individuals.

But we should not be warranted in drawing an average from all of this material taken together. There are certain racial characteristics which would need to be taken into account in so doing, and our purpose here will be better served if the material chosen he as homogeneous as possible. The observations of Key in Sweden probably fulfill this requirement as well as any. ${ }^{1}$ It may be remarked however that the conelusions drawn from this material have been fully confirmed in the gross by observations in other countries. Certain age differenees only are to be noted.

Fig. 304 represents, according to Key, the mean height and mean weight of male and female pupils in the higher schools of Swelen between the years of seren and twenty-one.

Up to and including the eleventh year boys are both taller and heavier than girls. From the twelfth year to the sixteenth this relationship changes: girls are then both taller and heavier on the average than boys. With the serenteenth year the relationship once more changes and the curve of development for boys rises above that for girls and the difference becomes greater and greater thereafter until complete maturity.

The yearly increase in height and weight in boys for the seventh year is $5 \mathrm{~cm}$. and $2.3 \mathrm{~kg}$., and for the eighth year, $5 \mathrm{~cm}$. and $3.4 \mathrm{~kg}$. For the ninth to the thirteenth year the growth in heiglit by years is $4,2,3,4,4 \mathrm{~cm}$., and the growth in weight by years is $1.7,1.0,1.9,2.3,3.1 \mathrm{~kg}$. The growth in boys is at its feeblest during the twelfth and thirteenth years. With the fourteenth year the period of puberty is reached and the growth hoth in height and weight becomes much more rapid, the inerease in the former for the fourteenth, fifteenth, sixteenth and seventeenth rears being $5, \%, 6$, $5 \mathrm{~cm}$., and the increase in the latter being $4.7,4.5,5.5,5.3 \mathrm{~kg}$. respectively. The most rapid growth in height takes place earlier (fifteenth and sixteenth

${ }^{1}$ Certainly much better than would observations made in any of the larger cities of the United States.-ED. 
years) than the greatest growth in weight (sixteenth and serenteenth rears). Since increase in weight is of greater significance than increase in height, the sixtecnth and seventeenth years may be regarded as the years of most rapid physical development (cf. page $14 t$ ).

After the serenteenth year the vearly rate of growth in heiglit and weight is less, but the increase continues until about the twenty-first year, when the

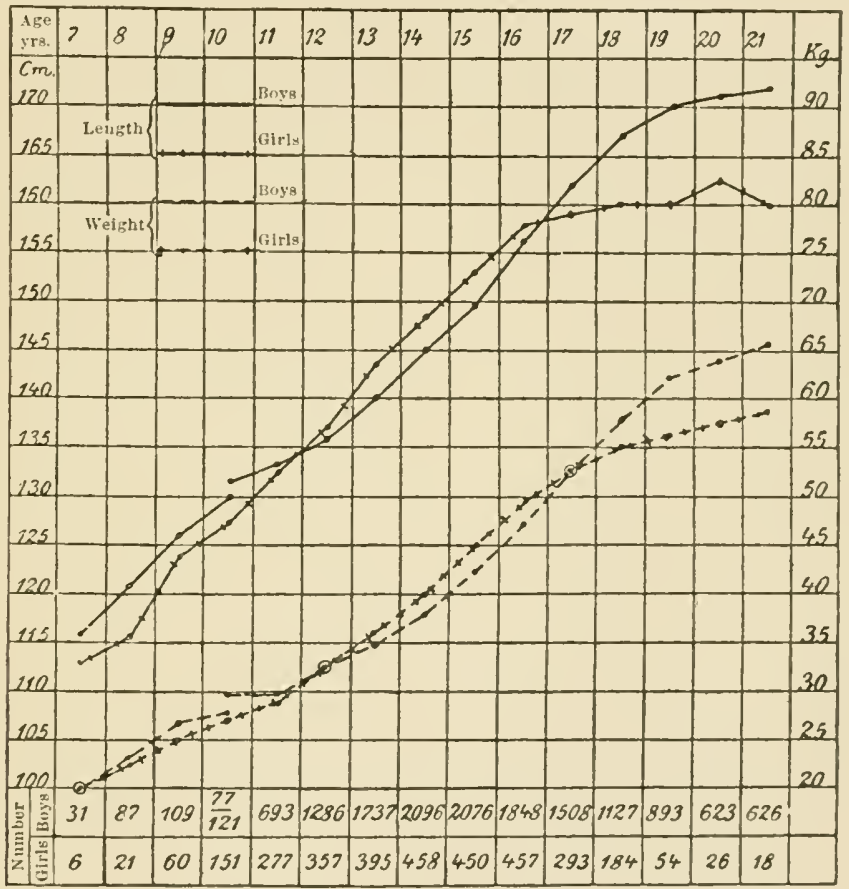

FIG. 304.-Curves representing the height and weight of boy's and girls of different age, after Key:

youth reaches his full physical stature. The height at this time is on the average $12: 2 \mathrm{~cm}$. and the body weight $65.2 \mathrm{~kg}$. The man entinues to grow, though very slowly, for several vears more.

The physical development of girls runs quite a different comrse. The periol of feoble growth, which is so sharply marked for boys just provinus to puberty, comes carlier for grirls. namely, so far as concerns height. in the ninth year. The rearly increase in height of girls from the ninth to the serenteenth rear is $\approx, 4,5,5,6,5,4,2,1 \mathrm{~cm}$. 'The increase in weight for the

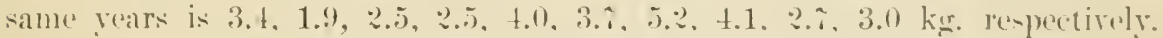
We see that there is a period in the development of girls also, from the ninth to the eleventh years inclusive. when the rate of growth in weight is relatively slow. The true puberty periol, which is characterized hy a rapid growth in weight. begins in the twelfth your and lasts until the fifteenth roar (inclusire).

IIth girls the wrowth in height continues until only about the seronteenth year. while the increase in weight can be demonstrated up to the twentieth year. 
From these and many other observations it follows that the physical derelopment of girls is run through in less time than that of boys and that it terminates more abruptly.

Hand in hand with the more rapid development in height and weight during the puberty period, there goves also a eorrespondingly stronger development of the ehest, as contraster with the develonment during the years just preceding puberty. The mean increase in the chest measurement at the position of decpest inspiration, in boys from ten to serenteen years of age, is given by Lotelmamn (for Hamburg) as follows: 1.6s cm., 1.97, 1.52, 0.99, 3.75, 3.47, 4.02, 2.4t $\mathrm{cm}$. respectively.

According to Key's observations, the resistance of the body to harmful influences during the rears just previous to pulerty is relatively weak. But in the course of the puberty period, when the youthful life asserts itself in all its vigor,

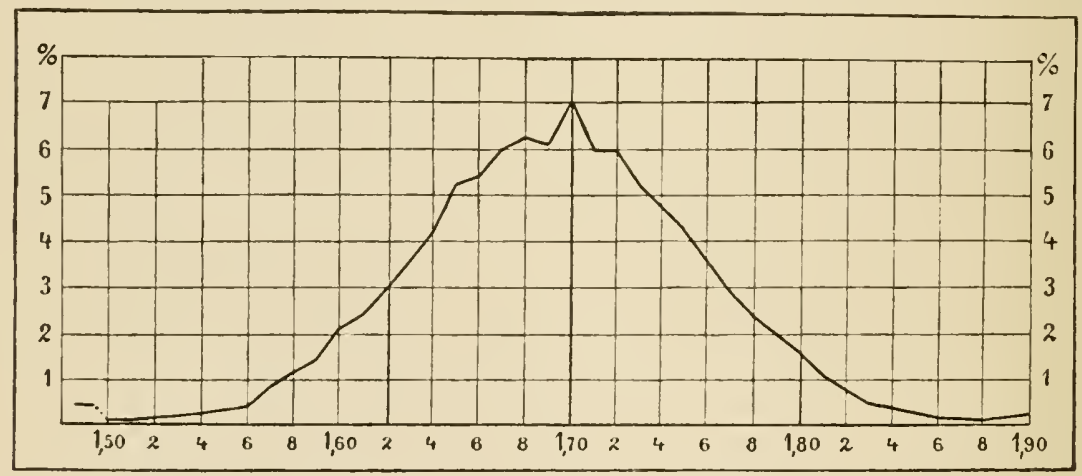

FIG. 305. - Variations in the height of military recruits in Sweden, after Hultkranz. The ordinates represent the percentage of the whole mumber $(232,367)$ of individuals who were of the height (in meters) represented by the abscissie.

the resistance of the body increases, the percentage of siekness in the schools declines and reaches its minimum in the last year of this period (seventeen).

The economie eireumstances in which the children live exereises a very considerable influence on their physical development. The children of the poorer classes fall behind their companions of the same age from the homes of the well-to-do, both in height and weight. The period of feeble development just before puberty is longer for the poorer ehildren. But once puberty begins, the period of rapid growth seems to proceed all the more rapidly in spite of its delay, and to terminate in the same year as for children of the well-to-rlo. The whole period is therefore shorter for poor children, but is characterized by an even more aetive development during its last years (Key).

Malling-IIansen has shown by a very extensive series of observations in Denmark that there is a seasonal variation in the rate of growth in children. From the end of November or the beginning of December to the end of IIarch or the middle of April children grow very feebly-so much so that the increase in height is less than usual, however slow that may be. After this period of feeble growth follows a period during which growth in height is very aetive, but the increase in weight is reduced to a minimum. Indeed, children even lose in meight during this perior of most active growth in height, almost as much as they have gained in the preceding period. This period lasts from March or April 
to July or August. Then follows a third period which continues until Norember or December. The inerease in height is now very fueble, wut the increase in weight rises rapidly and becomes considerable.

The weight of the adult body caries greatly. but may be estimated at $6.5-50 \mathrm{~kg}$. for men and $56-60 \mathrm{~kg}$. for women. At a mature age the weight in both sexes as a rule becomes greater by the deposit of fat.

The height of men of different nationalities is somewhat variable, as the following table compiled from arerage measurements of military recruits at the age of twenty to twenty-one years in the different countries will show:

\begin{tabular}{|c|c|c|}
\hline Laplander.......... & 150.0 & $\mathrm{~cm}$. \\
\hline II ungarian... & $16: 3$ & “ \\
\hline Bavarian .... & 163.8 & “ \\
\hline líussian ... & $16+.2$ & “ \\
\hline French......................... & 164.9 & “* \\
\hline 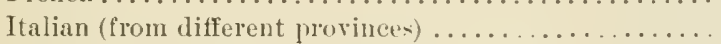 & $156.0-160.5$ & “ \\
\hline Finlauder (from different provinces) ............. & $165.9-169.9$ & ، \\
\hline English and Irish $\ldots \ldots \ldots \ldots \ldots \ldots \ldots \ldots \ldots$ & 169.0 & “ \\
\hline 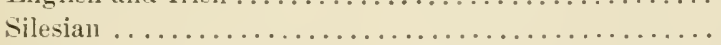 & 169.2 & “ \\
\hline 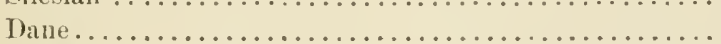 & 169.2 & “ \\
\hline Norwegian $\ldots \ldots \ldots \ldots \ldots \ldots \ldots \ldots \ldots \ldots \ldots \ldots$. & 169.8 & “ \\
\hline 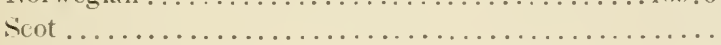 & 170.8 & “ \\
\hline 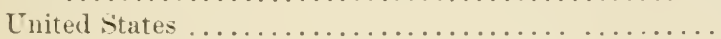 & 173.3 & ، \\
\hline
\end{tabular}

Tariations within the same nationality are considerable. as may be seen from Fig. 30.5. This represents, accorling to Hultkrunz, the height of Swedes as determined by measurements of 232.369 military recruits made between 18s: and 18!t.

We liave no measurements similar to these for women but from observations which have been made, we may say that, on the average, a grown woman is about $12 \mathrm{em}$. shorter than a grown man.

Refenaxces.-Beyer, Proceedings of the United States Varal Institute, xxi, 1895.-Daffner, "Das Wachstum des Menseden," Leipzic, 1s!T.-Exmer, "Phrisiologie der Mïmnlichen Geschleehtsfunktionen," in the "IIandbueh der Irologie," Wien, 1:103.-Key. Terhandlungen des. I. internationalen medizinischen Kongresses, vol. i, Bertin, 1s.0.-W. Nagel, "Die Wriblichen Creschlechtsorgane," in $r$. Bardeleben's Handbuch der Anatomie des Menschen, vii, 2., 1, Jenia, 1n:ti. - 11. T. Porter, Transuctions, Acredem! of science. St. Louis, 14!:3-1,94.-

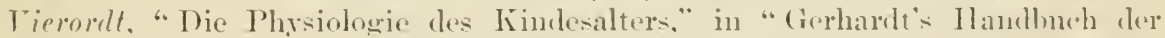
kinderkrankheiten," i, "Tïbingen, 1s-1.-E. B. II ilson. "The C'ell in Inerelopment and Inheritance," second editions. Nuw York, 1900. 



\section{N D E X}

Ahdominal pressure, 299, 699 .

Abdominal type of respiration, 317,315 , Fig. 126, A.

Abdominal viscera, vasomotor nerves of, 233, 235.

Abducens nerve, 6SO.

Aberration, chromatic, 526, Fig. 221. spherical, 223, 522, Fig. $21 \mathrm{~s}$.

Absorption, 31, 35, 301.

from serous cavities, 353 .

influence of stimulants on, 302.

of carbohydrates, 303 .

of fats, 304 .

of gases, by liquids, 334 .

by naked cells, 31 .

of iron, 307, Fig. 119; 30 S.

of mineral substanees, 308 .

of proteid, 305 .

of water, 302.

relative power of, in different divisions of the alimentary canal, 302.

Accelerator nerves of heart, 191, 68s.

Accessory sexual glands, 691, 692 .

Accommodation in vision, 529 .

center for, 535, Fig. 230.

mechanism of, 530 seq.

protrusion of iris, 531, Fig. 226.

refleeted images, 531, Fig. 225.

structure of ciliary muscle, 532, Fig. 227.

theory of Helmholtz, 533 .

theory of Schön, 534, lFig. 229.

zonule of Zinn, 533, Fig. 228.

range of, 529,530 .

Accrebral rigiclity, 616 .

Acetic acicl, 3s4.

Aceto-acetic aeid, 376.

Acetone bodies, 376,384 .

Achroöllextrin, 246 .

Acids as cxeitants of pancreatic secretion, 269, 270.

Acid albumin, 292.

Aeid albuminate, 74,249 .

Acid equivalent of fats, 79 .

Acid of gastric juice, 2.47 .

Acid sulphur, 373.

Acid taste, 484.

Actinia, 5 f.
Action eurrents, defined, 48.

in glands, $4 S$.

in heart, 13, Fig. 13; 179, Fig. 63; 180, Fig. 64.

in muscle and nerve, $4 \mathrm{~S}, 410,431$.

in plants, 49, 50 .

Acrivation of oxygen, 19 , note.

of zymogen, 38 .

Aetive movements, perception of, 471 .

Aclamkiewicz's reaction for proteid, 73 .

Adaptation of eve to different lights, $5 \mathbf{4 0}$.

Adelomorphous secreting cells, 266.

Adenin, 76,372 .

Adolescence, period of, 706 .

Adrenal bodies, internal secretion of, 364 seq.

Arlrenalin, 366.

Afferent and efferent nerves, 564,555 .

Afferent and efferent pathways in cord, 591, 592, $593,595,596$.

Afterbirth, 699.

Afterbrain or myelencephalon, 600, 602.

After extension of musele, 412.

After-image, negative, 539 .

positive, 535.

After-loading of muscle, 435.

After shortening of muscle, 412.

Age, changes due to, 66 .

influence of, on metabolism, 120.

influence of, on rate of heart beat, 197.

Agglutination, 149, 156.

Agraphia, musical, 66.5.

Air, alveolar, exchange of, with blood, $3 \$ 0$. atmospheric, composition of, 334,342 . ehanges produced in, by respiration, 342 . complemental, rexiclual, ete., 320.

exchange of, in lungs, 31 ?.

expired, 342.

explanation of evil effrets of, 34.5.

poisonous gases in, 344 .

Air pressure, influence of, on number of corpuscles, 149 .

Air pump, 334.

Air space, noxious, in lungs, 320 .

Air-transmission, method of recording by゙, 11 .

Alanin, 70,373 .

Albuminates, 7 t.

Albumins, propertics of, 73 . 
Albuminous glands, 261.

Albumoid, $7 \mathrm{~S}$.

Albumoses, 74, 249.

food value of, $10 \mathrm{~s}$.

influence of, on coagulation, 159.

poisonous effects of, 25 ).

primary and secondary, formed in digestion, 249.

Alcohol, food value of, 110 .

formed in body, 376 .

Alcoholic fermentation, 28, 40, so.

Alcoholism, 30.

Aldehyde, glycerin, 373 .

Alexia, or word blindness, 663, 669.

Algæ at high temperature, 29.

Alimentary canal, digestion in different divisions of, 290.

movements of, 278 .

Alimentary glycosuria, $127,363,374$.

Alkali albuminates, $7 t$.

tlkaline taste, 484 .

"All or none" law, 183 .

Allantoïn, 373, 3S2.

Alloxuric hases, 76 ; see also Purin hases.

Alveoli, exchange of gases in, $34 \%$.

partial pressure of gases in, 341 .

Amacrine cells, 515, Fig. 211.

Amblystoma, 59, 60.

Amino acids, part played by, in synthesis of proteid, 23.

as products of digestion, 249, 25.5.

as a source of urea, 370.

Amino-acetic acid, 70 .

Amino-butyric acid, 70, 72 .

Amino-caproic acid, 70 .

Amino-ethyl-sulphonic acid, 253.

Amino-propionic acid, 70.

Amino-pyro-tartaric acid, 70.

Amino-suceinic acirl, 70,110 .

Amino-valerianic acid, $70,72,249$.

Ammonia, formation of, in body, 370 .

in expired air, 345.

in urine, 372,382 .

Ammonium carbamate, 370 .

Ammonium carbonate, 37 ().

Ammonium isocyanate, 381 .

Ammonium lactate, 371 .

Amnestic aphasia, 662 .

Amaba, ingestion of food by, 36 .

movements of, 42.

under low temperature, 29.

protoplasmic currents in, 43, Fig. 26.

successive phases in life of, 36, Fig. 21 .

A maba polypodia, 35, Fig. 20.

Amphibolous biliary fistula, 243.

Amplioxus, functions of "brain of," 615 .

Ampulla of semicircular canal, $47 t$.

Amusia, 665.

Amylolytic enzyme, 243.
Amylolytic enzyme, in the bile, 254.

in the pancreatic juice, 251.

in the saliva, 246.

An:emia, effect of, on fatigue, 445 .

of brain in sleep, $67 \%$.

on power of localization, 464 .

Anaerobic bacteria, 28.

Antesthesia, 360,597 .

Anagyrin, producing vasoconstriction, 583.

Analysis of sound, 493.

Anatomy, comparative, 2.

Anelectrotonus, 425, Fig. 162.

Angle $a, 525$.

Angle of incidence, 509, Fig. 206. of refraction, 509, Fig. 206.

visual, $51 \mathrm{~s}$.

Angular convolution, 639, Fig. $2 \$ 9$.

Animal diet, 14.5 .

Animal gum, 82 .

Animal heat, relation of muicular activity to, 116; see also Heat production.

Anisotonic solutions, 32.

Anode, reduction of excitability by, 425. stimulating effect of, 59,424 .

Answering organ, defined, 411.

Antagonistic muscles, inhibition of, by stimulation of cortex, 636,640 .

Antennularia antenina, 64, Fig. 37.

Anterior columns of spinal cord, 562, Fig. 254 .

Anterior horn of spinal cord, 563.

Anterior roots of spinal cord, 563, 566, 593.

Antero-lateral columns of spinal cord, 595.

Anthrax bacillus, ingestion of, 37, Fig. 22 .

Anthrax spores, survival of, at low temperature, 29.

Antibodies, 156.

Antienzymes in blood, 155.

in organs, 269.

Antilytic effect in bloor, $15 \pi$.

Antiperistalsis, 289, Fig. 117.

Antiprecipitating effect in blood, 15\%.

Antiseptic methods, 5 .

Antitoxin in blood, 156.

Antrum pylori, 283.

Anus, innervation of splincters of, 299 .

Anvil of ear, 495, Fig. $197 ; 496$, Fig. 195.

Aorta, 162.

blood pressure curve in, 170, Fig. $57 ; 171$, Fig. 5.s.

cubic enlargement of, 201.

Aper beat, 172 serl.

curve of, in horse, 173, Fig. 60).

schema illustrating Lulwig's theory of, 172,

Fig. 59.

time relations of, in man, 175, Fig. 62.

Aphasia, fifi3.

alexia (word blindness), 6.33, 6,69 .

amnestic, 662.

motor, 663 . 
Aplasia, sensory, 664 vocal motor, 66.5.

1 plysia, 35.

Apncea, 332

true and falke, 333.

Apparatus figured

Circulatinn:

capillary pressure, 221, Fig. 91.

(ardiograph, 174, Jig. 61.

li:(modromograpl, 20!), Fig. S1.

leeart sound, 16S, Fig. 5.j.

manometer, clantic or membrane, 9, Fig. 5.

mamometer, mercury, s, Fig. 3.

plethy-mograph, 211, Fig. \$3.

sphÿgnogr:1ph, 215, Fig. $\$$.

spliyermomanometer of Erlanger, 203, Fig. 76.

stromuhr, 20!, Fig. So.

Gemeral methods:

electric signal, 10, Fig. 7.

kymograplı, 6, Fig. 1;9, Fig. f.

recording tambour of Marey, 11, Fig. 9.

Iu-cle and nerve physiology:

eapillary electrometer, 13, Fig. 12.

elasticity apparatus, 412, Fig. 151.

ergograph, 44t, Fig. 179.

induetion coil, 420, Fig. 15s.

muscle lever, 6, lig. 1.

nonpolarizable electrodes, 119, Fig. 157.

rheocuril, +18, Fig. 156.

rheotome, 432, Fig. 169.

tension recurler, 414 , Fig. 153.

W*:1gner hammer, 421, Jig. 159.

Ietabulism:

face mask, s.i, Fig. 3!).

respiration calorimeter of Itwater and

Beneslict, sehema, 86, Fig. 4').

of sondin and Tigorstedt, ss, lïg. 12. of Vit and Pettenkoffer, ST, löig. 41 .

Respiration:

air-pump of Ludwig, 334, Fig. 131).

illustrating experiment with rabbit's lungs, 311 , Fig. 120.

longe ratheter, Lurwig's enotruction, 341 , Fig. 133.

registering volume of expired air, 313,

Fig. 122.

spirometer, 320, 1Fig. 12x.

Special senser:

black and white dicics, 539, Fig. 233.

cntoptir plunomena, 521, Fig. 216.

olfactumeter of Zwaarlenaker, 457, Fig. 192.

resonator of Helmholtz, 4!3, Fig. 195.

siren of secbeck, 49t), Jig. 193.

stereoscope of Brewster, 5.5s, Fig. 2.j1.

Appetite, importance of, in indigestion, 263. $264,290$.

Aquerluet of sylvins, 611.

42
Aqueous humor, 505, 509.

refractive index of, 512 .

Arabinose, S1.

Arcellee, motility, 4.5 .

Arenicula cristata, effects of salts on larves of, 2.5.

Arginin, 70, 25.5.

Irgon in blucxl, 33.j.

Aromatic oxyacids, 375.

Arterial bloud, gases in, 33!).

tensiun of carbon dioxide and oxygen in, $3+1$.

Arterial pulse, 212; sce also Pulse.

Arteries, 161.

bloorl pressure in, 204.

coronary, 180 ).

eubic enlargement of, 201, Fig. 75.

(la-ticity of, 2(0), 2t)1.

flow of blookl in, 200 ).

innervation of, 231, 234.

movernents of blood in, 218.

resistance in, 20.5.

resistance of, to rupture, 201, 202.

veloeity of blood flow in, 209.

Arterin, 150 .

Ascaris, anaerobic mole of life of, 27.

A.h constituents, see . Ifineral substances and Inorganic substances.

absorption of, 307 .

in bloorl, 154.

in foorl, 83 .

in milk, 702 .

in urine, 394 .

Asparagin, fuecl ralue of, 110 .

Aspartic acisl, 7()$, 72,249,370$.

Asphyxiation, $333,396,5 \times 0$ ).

resistance of different nerve eells to, $5 \pi 3$, lig. 25\%.

A-piration of thorax, 310, 311; see also Suction in thoracic cavity.

effect of, on reins, 223 .

Asimilation, 22, 26.

A-similative processes inclueel by stimulation, 62.

Asinuciation centers of lechnig, 615.5-e1.

anterior, ficis.

enöperation of, with sensory" areas, 670.

mechanies of, 67()$-6)-3$.

miilule, $66 \mathrm{~s}$.

posterior, 669.

seat of organized memory in, 1971.

Association fibers, fiti3, fifit, ligs.

Association pathways, tif 4,670 .

Astasia, bot.

Lsterina, if).

Asthenia, 607.

Istigmatism, 522, 524, Tig. 219.

correction of, 525 .

Ataxia, 472 . 
Ataxia, cerebellar, 611 .

Atmospheric air, 334; see also Air.

Atonia, 607.

Atrio-ventricular valves, 165, 166, Fig. 54.

Atrophy, 148.

Atropine, formation of urine and, 38.9. secretion of saliva and, 25.

Auditory area of cortex, 654, Fig. 293.

Auditory meatus, external, 494, Fig. 196.

Auditory nerve, 681 .

excitation of, 498 seq.

Auditory ossicles, 495.

Auditory sensations, 489 .

Anerbach's plexus, 284, Fig. 114; 28S, 687.

Augmentation of reflexes, 579 .

Aurclia, osmotic relations in, 34 .

Auricle, 161 ; see also Heart. in cardiogram, 173, Fig. 60. maximum pressure in, 169. negative pressure in, 177 .

time relations in, 173, Fig. 60 .

Autochthonous fibers, 575 .

Autointoxication, 295.

Autolytic processes, 38 .

Automatic excitation, 52, 356, 570, 580 .

Automatism of the heart, $185,156$.

Autonomic nervous system, 686 .

Auxotonie eontraetion, $435,436$.

Avidity of two acids for a base, 338 .

Axis cylinder processes, 559 .

Axis of rotation of the eye, $549 ; 550$, Fig. 240.

Axis, visual or optical, 513, Fig. 210; 525.

Axon reflex, 584, Fig. 258.

Axons, 559.

Azobacteria, 24.

Bacillum volutans, 55.

Bacillus typhosus, 156.

Bacteria, anaerobic, 28.

decomposition of proteids by, 250 .

in the blood, 155,156 .

in the intestine, 295, 297.

in the respiratory passages, 323 .

in the stomach, 247, note; 291.

production of light by, 45 .

Bacterium photomrtricum, 57, Fig. 33.

Bacterium phosphorescens, 29.

Basal ganglia of the brain, 632 .

Basilar nembrane, organ of Corti, 499; 500 , Fig. 199.

Bathmotropic effect of vagus, 189.

Beats in musical sound, 501.

Becquerel rays, 58.

Bell's doctrine, 566 .

Benzoic acid, 378.

Benzoyl-glycocoll, $378,383$.

Blateral movenents from stimulation of eortex, 640.
Bile, 253.

absorption of, from intestine, 273.

antiseptic properties of, 298.

eirculation of, 273.

composition of, 254 .

digestion after exclusion of, 296.

discharge of, into intestine, 275, Fig. 110.

enzymes in, 254.

excretory products in, 254.

influence of, on amylolytic digestion, 251. influence of, on tryptic digestion, 294.

reabsorption of, from lymphaties, 275.

secretion of, $2 \% 2$.

dependence of, on blood supply, 273.

speeifie excitants of, 275 .

solubility of fatty acids in, 254, 296.

Bile acids, 253, 384.

Bile pigments, 253.

in urine, 384 .

Bile salts, 253, 254 .

Biliary ducts, 27.5 .

Biliary fistula, 243, 298.

Biliprasin, 253.

Bilirubin, 253.

Biliverdin, 253.

Biliverdinic acid, 254.

Binocular field of vixion, 551; 552, Fig. 242.

Birds, extirpation of eerebrum in, 622 . extirpation of liver in, 371.

Birtl, 697.

Bitter taste, 484.

Biuret reaction, 73 .

Bladder, gall, 275 .

urinary, 391.

Blind spot, 516 .

Blood, 147.

amount of, in body, 148.

amount of, supplied to different organs, 240. antitoxins in, 156 .

bacteriocidal action of, 156 .

coagulation of, $147,154,157$.

constituents of, 147 .

constitution of, variable aecording to organ, $15 \%$.

corpuscles of, red, 148, 150 .

white, 153.

cytolytie action, 156.

distribution of, in body, 239.

effect of condition of, on respiratory center, 331.

enzymes in, 155.

gases in, 335 .

general survey of movements of, 161 .

menstrual, 696 .

precipitins in, 156 .

quantitative composition of, 154 .

quantity of, supplied to different organs, 240.

reaction of, 147 .

in urine, 384. 
Blood, viscosity of, 2:22.

Bloul rorju-cles, red, 145, 150 .

clemical composition of, 150), 152.

destruction of, $1.50,36 \mathrm{~s}$.

dry substance in, 14 ?.

formation of, 150 .

gaves in, 336, 33s.

h:rmoglobin coutent in, 152.

movenunts of, in capillaries, 221.

nuclei of, 17 .

number of, 149 .

percentage of, in whole blood, 149.

permeability of, 33 .

specifie gravity of, 149.

stroma of, 150.

Bloor corpuscles, white, 153 ; sce also Lencocytes.

Bluod rrystals, 150, Fig. 46: 153. Fig. 49.

Bloorl flow in arteries, 200, 218.

in eapillaries, 219.

in veins, 223.

inuseular work and, 149.

through coronary vessels, 1 so.

through heart, 165.

velocity of, in arteries, 209.

in diastole and systrle. 210.

variations of, in man, 212.

in eapillaries, 221.

in verins, 224.

Bloud gases, 333.

distribution of, between enrpuseles and plasina, 340.

metlusds of determining, 335, 341 .

quantity of, 339.

trension of, 341 .

Bloodletting, 208.

Blood pignents, 150,152 ; sree also Hamoglobin.

in urinc, $3 \$ 4$.

l3lood plasma, 154.

I3loorl platelets, 153 .

Blood pressure, 202.

comparative, in arteries of different sizes, $20 \mathrm{~s}$.

curves of, S, Fig. 4; 20.5, Fig. 7.: 206, Fig. TA; 20), Fig. 79 .

in loft ventriele and aorta, 171, lig. si. intracardial, 169, lig. jff.

eompared with aper beat, 173, Fig. 60. effeet of aclrenalin on, 366).

effect of, on lieart, 171.

effet of vagus stimulation on, 205, Fig. 77 ; 206, Fig. 7S: 207, Fig. 7!).

factors determining, 204, 2(1.5, 201).

fall in, 206, Fing. $\mathrm{x}$.

heart frevulueney and, 205.

height of, 204.

in arteries, 204, $20 \mathrm{~S}$.

111 capillaries. 219, 221, lig. 91.
Blood pressure in museular work, 449.

in pulmonary vessels, 228,229 .

in reins, 223 .

maximum systolic, 2() 4 .

minimum diastolic, 204.

reflex fall in, 237, lig. 9S.

reflex rise in, 236 , Fig. 97 .

regulation of, $194,219$.

regulation of respiratory variations in, 230.

respiratory variations in, 229.

Blood serum, 154, 15.5.

agglutination of 13acillus typlzosu= by, 156 .

Blood supply to brain, firf.

to different organs, 240.

to heart, 180.

Blood volume, influence of, on blood pressure, 206.

Bodily movements, see. Iuscular work. influence of, on blood pressure, 149.

on metabolism, 10S, 110,123 .

on pulse rate, 197 .

on respiration, 318 .

on storage of proteid, 63.

Body, human, chemieal constituents of, 68 . distribution of blood in, 239.

growth of, 70.5 .

influence of attitude of, on blond flow, 226, 227.

height of adult, 711 .

weight of, 96,711 .

temperature of, 395 ; see also Temperature of body.

Bones, destruetion of, in starvation, 98. conduction of sound through, 494.

Iony fish, extirpation of cercbrum in, 619.

Boyhoorl, age of, 71$)(j$.

Boys, growth of, T(I), 7(19, Fig. 304.

nutritive requircment: for, 144.

Bowman's eapsule, 35.5, Fig. 141; 3.56.

Brain, as organ of the mind, 629, 670.

bloorl supply to, 676.

divisions of, 600 , Fig. 267 .

fatigue and reevery in, 6if 6 , 6i.

influence of anterior parts of, on re-piration, 329 .

Brain of . Imphinxus, 61s.

of bony fish (Aquulius ceplualus), fiss, Fig. 274.

of togr, 624, Fig. 280; 62.5, Fig. 2\$1 - 6.32, Fig. 2\$2.

of dog shark (Scyllium canicula), fis, löig. 275.

of lizard (IIatteria punctata), 621, lig. 27\%. of pigeon, 622, lig. 27..

of rabbit, 623, Fig. 279.

principles of interpreting resiults in study of, 601.

temperature of, 678 . 
Brain-stem, functions of, as a whole, 618 seq. methods of study of, 599. physiology of, 599.

13 reath rolume, 319.

Brightnes:, highest in spectrum, 541.

Broca's area, 631, 662, Fig. 296.

Broea s convolution, 664 .

Bronchial muscles, 324.

Bronchisi sound, 322.

I3rumner, glands of, 255 .

Burdach's column, 591, Fig. 264; 592.

Butter, 701.

Butyric acid, 701.

( $:$ I ratio in fieces, 90 .

in proteicl, 92.

in urine, $9($ ).

Cadaverin, 249.

Cieeum, 289, 298.

Calearine fissure, 639, Fig. 290; 657.

Calcimm, absorption and excretion of, 133.

effect of, on heart, 25.

in coagulation, $15 \mathrm{~s}$.

on museular moveurents of larvæ, 25.

on skeletal muscles, 25.

on smooth muscles, 25.

hunger, 98 .

importance of, in plant, 24.

in milk of cow, 3.51 ; see also Milk, composition of.

rennin and, 250 .

salts of, certain ones farorable for higher animals, poisonous for uniceltular, 26.

Calcium chloride, 25.

Caleium oxalate formed in cells, 41.

Catorie, definition of, 26 , note.

Calorimetry, direet and indirect, 94.

Cane sugar, 81, 126, 127, 251, 255.

Capillaries, blood flow in, 219.

blood pressure in, 221.

contractility of, 220. Fig. 89.

lymph formation from, 350 seq.

nerves for, 221.

stimulated ancl not stimulated, 220, Fig. 90.

structure of, 220.

velocity of blood flow in, 221.

Capillary electrumeter, 13, Fig. 12.

Caproic acicl, 7() 1 .

Capsule, internal, 647, Fig. 292.

Carbamie aciıl, 155,371$).$

Carbanide, 381 ; see alsir C'ren.

Carbohydrate group in nucleic acid, 77 .

Carbohydrate groups in proteid molecule, 71 .

Carbohydrates, absorption of, 303.

chemical nature of, so.

decomposition of, 374 .

determination of, in food, $\mathrm{S} 4$.

digestion of, in stomach, 291.

formation of mlyeogen from, 374,375 .
Carbohydrates formed from proteid, 127, 373 .

in blood, $15.5,374$.

in intestines, 297 .

influence of, on motabolism, 10.5.

influence of panereas on metabolism of, 364.

metabolism, total, aceorting to supply of, 106.

metabolized before fats, 10.5 .

metabolized in muscular work, 113.

quantity of, in diet, 142.

relation of, to proteici retention, 121 .

specifie need of body for, $12 \mathrm{~s}$.

storage of, in boty, 124, 364 .

utilization of, 139 .

Carbolic acil, effect of, on nervous system, 574 .

Carbon, channets of exeretion of, $89,90,342$, 39 .

in expirert air, 89.

in frecer, 90.

in urine, 89 .

Carbon dioxide, absorption of, by hamoglobin, 339, Fig. 132.

coefficient of absorption of, $33 \mathrm{~S}$.

determination of, in metabolism, S.5 seq.

diurnal variations of, 344 , Fig. $135 ; 345$, Fig. 136.

effect of, on respiratory center, 332 .

elimination of, by young, 11s, 143.

daily, per hour, 346.

through skin, 397.

formation of, in nerve, 434 .

in atmospheric air, 342 .

in blookl, 337 .

combination of, 337 .

distribution of, between orpuscles and plasma, 340).

influence of, on absorption of oxygen, 337.

pereentages of, in arterial and renous, 33 .).

tension of, in blood and lungs, 341.

increased output of, in fatigue, 146.

in expired air, $89,342,343$.

in lymph, $34 \mathrm{~S}$.

production of, by animals and plants, 27.

reduction of, by chlorophyll, 23.

tension of, in tissues, 342 .

Carcinus (green crab), osmotic pressure in, 34.

neurofibrils in, 560 .

reflex movements of, 58.5 .

Cardia of stomach, $2 \$ 2$.

inuervation of, 284, Fig. 114.

opening of, in deglutition, 282.

Cardiac inhibitory eenter, resistance of, to asphyxiation, 573, Fig. 257.

Cardiac nerve centers, 195.

Cardiac nerves, $18 \mathrm{~s}$.

of log, 191, Fig. 67 . 
Carcliral points of eye, 512; 513, Fig. 210.

(areliograri, 173, Fig. 60; 175, Fig. 62.

Cardiograph, 174.

Carliographie sound, 16s, Fig. 55.

Carniferrin, 307, Fig. 119.

Carnin, 413.

('arnosin, 413.

Carsin, coagulation of, in stomach, 250 ).

ligestion of, 255, 291.

formation of, 70.5 .

of woman's and of cow's milk, 701 .

percentage composition of, $\$ 2$.

trypsin and, 252.

Castration, 357 , 35s, 367, note, 692 .

Catelectrotonus, 124, Fig. 161.

Catheter, lung, of Ludwig, 341, Fig. 133

Cathode, increase of excitability by, 425 resistance to impulse caused by, 426 . stimulating effect of, $59,424$.

Cell, animal, like young plant cell, 21. as elementary organism, 1, 15. ascimilation of, inclueed, 62 . automatic excitation of, 52 . chenical stimulation of, 52 . conductivity in, 62 .

consumption of oxygen by, 27 .

contents, kinds of, 21. Fig. 16;22. morphology of, 20, 21.

clependence of, upon temperature, 28 .

digestion in, $3 s$.

effect of external influenees on, 50 ).

effects of ultra violet rays (m, 57.

of X-rays on, 58.

of Beequerel rays un, is.

electrical stimulation of. 59.

elimination of decomposition procluets by, 4 ().

form and size of, 16 .

formation of heat in, 46 .

generation of electrieity by, 46 .

ingestion of food by, 30 ).

mechanieal stimulation of, 56 .

membrane, 16.

motility of, 42.

osmosis in, 31 .

osmotic pressure in, 31 .

oxidative processes of, 39 .

processes, protoplasinic of, 42 ; see also Pseudopodia.

production of light by, 45.

sap of, 21, Fig. 1f.

secretion in, 41.

stinulation of, by neans of lieat, 58

by means of light, 56 .

vital phenomena of, 22.

Cellulose, digestion of, 297 .

food value of 110 .

propertics of, $\$ 2$.

Cellulose membrane of foods, 139.
Centers, see the various organs and uerves.

Central convolutions, 634, 637, 639, Fig. 289.

importance of, for regetative functions, 649 , 6.50 .

motor cortical areas in, $036,638$.

sen-ory cortical areas in, 652.

Central nervous srstem, see variou parts of nervous sistem.

Cereals as food, 139.

Cerebellar peduncles, 593, 612.

Cerebellar tracts in the cord, 593, 595.

section of, 611 .

Cerebellum, 6(0), 605 .

afferent tracts to, in corl, 593, 611.

artificial stimulation of, 60.5 .

bilateral morements from, 640 .

compensation for effects of removal of, 612 . connections of, 605, 610, Fig. 271.

distributor of cerebral impulses, 641 .

effects of complete extirpation of, in various lower animals, 605 seq.

in $\log , 606$, Fig. $270 ; 607$

(unilateral), 612.

example of regulating influence of, 611 .

field of chief influence of, 609.

forcel movements from, 612 .

lesions of, in ma11, $60 \%$.

relation of, to labriuth of ear, 611 .

relaxation of antagonistic museles from, $636,6+10$.

Cerebral cortex, electrical stimulation of, 601 , $631,632,633$.

histological strueture of, 634, Fig. 2\$4.

influence of, on regetative functions, 599,649 .

mechanical stimulation of, 633 .

motor areas in, 632 .

proufs that stimulation of, is possible, 633. sensory areas in, 650).

Cerebral functions, moral significance of, 672 .

Cerebral hemispheres, coöperation of, fit1.

Cerebral localization, in brain of apes, 637 , 6.3., Fig. 2ss.

in brain of man, 639.

in brail of nonkey, 63.5, Figs. 25.5, 2S6; 636. 637, rig. 2st.

phrenology compared with, 631.

Cerebrosides, 79.

Cerebro-spinal fluicl, 6 -s.

Cerebrum, commissures of, $6+1$.

compensating of loss of semiciscular canals by*, 4 -s.

definition of, $6(31$.

effects of renoval of, from birds, 622, 623 .

from bony fish, 619.

from dog (Goltz's), 625.

from log shark, 619, 620.

from frog. 620 .

from lizard, 621 .

from rabbit, 624 . 
Cerebrum, effects of removal of, from turtle, 621.

myelogenctic areas of Flechsig of, $66 \overline{\text {. }}$

physiology of, 629 .

psycho-physical functions of, 658 .

summary of effects of remoral of, 627 .

vegetative functions of, 649 .

wanting in human monster, 627 .

Cervical sympathetic, see Sympathetic nerves.

as pupilo-dilator nerve, 528 .

as secretory nerve, 258.

as vasodilator nerve, 235 .

Chemotaxis, 53, 54, Fig. 31 ; 697.

Chemotropic influcnce, 689.

Chest tones, 505.

Cheyne-Stokes respiration, 333.

Chief cells of gastric glands, 266.

Child, growth of, 707 .

heat regulation in, 409 .

weight of, at birth, 706,707 .

Childhood, period of, 7116.

Children, metabolism in, 11S, 119.

nutrition of, 143, 144 .

Cinlorophyll, 21, 22.

function of, 23.

movements of, in Lemna, 42, Fig. 25.

Cholagogic substances, 273.

Cholera spirilla, survival of, at low temperatures, 29.

Cholesterin, 80, 254. percentage composition of, 82 .

Choleic acid, 253.

Cholic acid, 253.

Cholin, 2.54.

Chondroitin-sulpluuric acid, 77.

Chondro-mucoid, 82.

Chondro-proteids, 77 .

Chorda tympani as secretory nerve, 257.

as vasodilator nerve, 235 .

Chorde tendinx, 166.

Choroid coat, 527.

Chromatic aberration, 526, Fig. 221.

Chromatin, 695.

Chromophyll, 24.

Chronoscope, 673.

Chronotropic effect of vagus excitation, 189.

Cilia, $43,44$.

mechanism of action of, 44 .

Ciliary movements, effects of salts on, 25.

Ciliary muscle, 532, Fig. 227.

Ciliated epithelium of air passages, 323. of oviduct, 696 .

Circulating proteid, 134.

Circulation, see Elond.

course of, 161,162 , Fig. 50 .

effect of suction of thorax on, 176 .

greater or ststemir, 162.

influence of adrenal bodies on, 365 .

influence of pituitary body on, 367 .
Circulation, lesser or pulmonary, 227.

mechanics of, 200, Fig. Tt.

significance of, for heat regulation, 407 .

Circulation of organic elements in nature, 67.

Circulation of protoplasn in plant cells, 42.

Circulatory system, function of, 30 .

Chyle, 304, 305.

Chyle ressels, innervation of, 349 .

Cluyme, 255, 291.

Chymosin, 250.

Clarke's column, 562, Fig. 254; 563.

Cleavage, hydrolytic, 70, 297.

Climaeteric, $358,696,697$.

Closing contraction, 420, 423.

Clostridium Pasteurianum, 23.

Clotling, natural and artificial, use of, 405,406 .

Clotting, see Coagulation of blood.

Coagulation of blood, 154, 157.

importance of, 159 .

why not in blood vessels? i59.

Coagulation of milk, 250.

of proteid, 75 .

of protoplasm, 29.

Cocaine, effect of, on sensc of taste, 485 . on membranous labyrintlı, 476.

Cochlea, 473.

Cochlear nerve, course of, 653, 655 .

Cock, easiration of, 357,367 , note.

Cold-blooded animals, $46,4+2$. reaction of, to external temperature, 114.

Cold, influence of, on metabolism of warmblooded animals, 114, 115, 401 .

of simple organisms, 29.

sensations of, 458 .

Cold nerves, $40 \mathrm{~S}$.

end-organs of, 468 .

Cold sense, 459; 460, Fig. 183.

Cold spots or points on skin, 45s, 459, Fig. 182; 461.

Collagen, 78 .

perentage composition of, $\$ 2$.

Collateral fibers in spinal cord, 563; Fig. 255; 592 .

Collateral ganglia, 657 .

Color, theories of, $544,5+6$.

induction, successive, 542, Fig. 236.

mixture, $5+2$.

reactions of proteid, 72 .

sensations, 541.

system, dichromatic, $5 \mathbf{4 6}$.

trichromatic, 545 .

tone, 541,543 .

Color blindness, 546,547 .

Colors, complementary, 543.

Colostrum, 704.

Column cells in spinal cord, 563, Fig. 255.

Columns of the spinal cord, 562, Fig. 254; 589,

Fig. 261; 591, Fig. 264; 592, Fig. 265; 593 . 
Combination tones, 501.

Combustion, 26, 27.

as source of animal heat, 402 .

heat of, 92 .

of fooclstuffs, 92 .

of fieces, 93.

of urine, 93.

Commissures between cerebral hemispheres, 641 ; see also C'orpus callosum.

Compensation in ataxia, 473 .

after extirpation of labyrintls, 478.

after lesions in cerebellum, 612.

Compensatory pause, 183, Fig. 65.

Complemental air, 320.

Complementary colors, 543.

Coneomitant respiratory movements, 321 .

Conclucting pathways, from motor cortical areas, 647 .

in spinal cord, afferent, 592, Fig. 265; 593, $595,596$.

efferent, 594, Fig. 266; 595.

methorls of determining, 589 .

to auditory area, 614 .

to visual area, 656, Fig. $295 ; 657$.

Conduction, isolation of, in nerves, 41

of excitation, 411 .

radiation of heat and, 403.

Concluctivity, a general property of protoplasm, 62.

in both clirections in nerves, 410 .

not same as oxcitability, 411.

resistance to, in nerves, $425,426$.

C'onjugaterl proteirls, 75 .

Conjugation of male and female elements, 691.

Conseiousness, simplest state of, 451 , note.

Comservation of energy, 2, 93.

Consonant intervals, 490.

Consonants, $50 \%$.

Coustant current, 60.

alterations of excitability produced by, 424 . stimulating affects of, 423 .

Constituents, cliemieal, of the body, 68 .

inorganic, of animals, 25.

of plants, 24.

Contractile cells cmbracing capillaries, 220, Fig. \$9.

C'ontractile vacuoles, $2: 2$.

Contraction, auxotonic, 43.j.

elonic, 633, 642 .

isometric, 414: 43s, Fig. 176.

isotonice, 415, 43.j; 436, Fig. 173; 438, Fig.

$176 ; 442$, Fig. $17 \mathrm{~s}$.

musieal tore of, 434 .

opening and closing. 420, 423.

of peurloposlia, 43.

Pflüger's law of, 423 .

secondary, 433.

simple, of cross-striated muscle, 415, Fig. 154.
Contraction, simple, of smooth muscle, 448 . simple projectile, 436 , Fig. 173.

summated, of cross-striated muscle, 415, 42 ?.

of smooth muscle, 448 .

tetanic, 429, Fig. 166: 430, Fig. 167.

veratrin, 437 , Fig. 175 .

voluntary, 430 .

tonic, of vaseular wall, 238.

of smooth muscle, 44 S.

Contractions, fibrillary, of heart, 181.

Contracture after destruction of motor cortex, 646.

after destruction of cerebellum, 606.

Contrast, simultaneous, in vision, 547 .

explanation of, $548,5+9$.

Convergence of the eyes, $534,556$.

accommodation and, 534,557 .

assymmetrical, 5.5̃2.

center of, 53.5, Fig. $230 ; 616$.

Convolutions of cerebrum, see under individual names.

Cooking, importance of, 110, 242.

Coördination of morements, 473 .

determination of, reflexly, $\overline{5} \mathbf{5}$.

in acerebral rigidity, 617 .

loss of, by destruction of internal ear, 478 .

by lesions of cerebellum, 607, 60s:

by loss of motor sensations, 472 .

Copper ferrocyanide as semipermeable membrane, 31 .

Copulation, 691, 693.

Corne: , form of, 522.

radius of curvature of, 510,512 .

refractive index of, 509.

refractive power of, 513.

Corona radiata, 647 .

Coronary arteries, 180 .

Coronary veins, 181.

Corpora geniculata, $600,614,617,655,657$

Corpora quadrigemina, 600, 613.

frontal section of, 615, Fig. 272 .

relation of, to auditory impressions, 614 . to eye movements, 613 .

Corpora striata, 600 .

as heat center, 408 .

Corpus callosum, 641 .

section of, 641,660 .

stimulation of, 641 .

Corpus geniculatum external, 617, 6.57.

Corpus genieulatum internal, 614, 655.

Corpus luteum, 696.

Corpuscles, red, 145; : a al $\leqslant$ Blood corpuscles. white, 1533; see alsor Lrucorytrs.

Correspondence of the retinat, 5.5.5.

Corti, organ of, 499, 500, Fig. 199. pillars of, 499, 50(), Fig. 199.

Cortical areas, sce Motor and Sensory cortical arcas. 
Cortical areas for vegetative functions, 649 , 650.

Cortical epilepsy; 632, 641, 642, Fig. 291; 652. progress of, 642 .

spread of, through subcortical centers, 643.

Cortical lesions, see Lesions.

Cortico-spinal tract in the cord, 593.

Cosmic influences on the body, 61 .

Coughing, 321 .

Cowper's glands, 691 .

Crab, green, osmotic relations of blood of, 34 .

neurofibrils in, 560 .

reflex movements of, 585 .

Cramp fish, 49.

Cramplike contractions in cortical epilepsy, 641,642 .

Cranial nerves, 680.

crossing of motor fibers of, 647 .

Crawfish, osmotic relations of blood of, 34 . nerve fibrils in, 560 .

Creatin, 155, 264, $413,434$.

Creatinin, 264, 3S2, 383, 434.

Cretinous child, 360, Fig. 13s.

Crico-arrtenoid muscle, lateral, action of, 503, Fig. 201.

posterior, action of, 503, Fig. 200.

Cricoid cartilage, 502 .

Crista acustica, 474 .

Crossing of nerve fibers in the brain, $64 \overline{7}$, 592.

in the optic chiasm, 657 .

in the spinal cord, $592,593,596,597$.

Crystalline lens, distance of, from cornea, 510. radius of curvature of, 510,512 .

refractive index of, 509 .

relation of, to accommodation, 531, Fig. $225 ; 532 \mathrm{seq}$.

Crura cerebri, 600, 613, 614.

Ctenolabrus, egg of, in absence of oxygen, 26.

Cubic enlargement of aorta of rabbit, 201, Fig. 75 .

of rena cara of cat, 223, Fig. 92.

Cucumaria, 56.

Curare as lymph producer, 351.

Curare in artificial respiration, 5.

Current clock, 209, Fig. S1.

Currents, electrical; see also under individual names.

action, $4 \mathrm{~S}$.

constant, 59 .

demarcation, 47,48 .

frog, 47 .

in plants, 49 .

induction, fatal strength of, 61 .

skin, 49.

('urves, central nervous system:

asphyiation, resistance of various centers to, 573, Fig. 25\%.

cortical epilepsy, course of, 642, Fig. 291.
Curves, central nervous system:

latent period of muscular contractions inducel from cortex underlying white matter, 633, Jig. 253.

preliminary reflex movements of frog's leg, 571, Fig. 256.

Circulation:

action current of heart, 13, Fig. 13; 179, Fig. 63; 1S0, Fig. 64.

apex beat. 173, Fig. 60; 175, Fig. 62.

blook pressure:

depressor, 194, Fig. 70.

in aorta, 170, Fig. 57; 171, Fig. 5s.

in auricle, 169, Fig. 56; 173, Fig. 60).

in ventricles, 169, Fig. 56;170, Fig. 57;

171, Fig. 58; 173, Fig. 60.

reflex fall, 237, Fig. 98.

reflex rise, 236, Fig. 97 .

respiratory variations, 229, Fig. 95; 230, Fig. 96.

vagus stimulation, 205, Fig. $7 ; 206$,

Fig. 7 ; $20 \overline{7}$, Fig. 79 .

cubic enlargement of aorta, 201, Fig. 75. of reins, 223, Fig. 92.

influence of temperature on, 1S4, Fig. 66.

isolated cat's heart, direct stimulation, 183, Fig. 65.

plethysnographic curve, 212, Fig. 84.

pulse curve, 12, Fig. 11: 216, Fig. \&8.

pulse rate, 192, Fig. 68 ; 197, Fig. 71 .

ragus and accelerator compared, 192, Fig. 68 .

velocity curve, 210, Fig. S2.

Digestion:

digestire action of gastric juice, 265, Fig. 104.

discharge of bile into intestine, 275 , Fig. 110.

enzymes of pancreatic juice, 271, Fig. 10 . secretion of gastric juice, 265, Fig. 103.

secretion of pancreatic juice, 270, Figs. $106,10 \%$.

Growth:

in length and weight, in boys and girls, 709, Fig. 304.

variations in length of adult body, 710 ,

Fig 30.5 .

Metabolism:

excretion of nitrogen in 2 -hr. periods, 102 ,

Fig. 44.

excretion of urea in a fasting dog, 101, Fig. 43.

Muscle and nerve:

alterations of excitability, 424, Fig. 161; 125, Fig. 162.

elasticity, 412, Fig. 150; 413, Fig. 152.

entrance of current through skin to nerve, 428, Fig. 165.

ergogram, 444, Fig. 180;445, Fig. 181. 
Curves, Muscle and nerve:

fatigue, 441, Fig. $177 ; 442$, Fig. $17 \mathrm{~S}$.

isonetric eontractions, 43S, Fig. 176.

isotonic entractions, 436, Fig. 173; 43S,

l.ig. $176 ; 442$, Fig. 178.

projectile motion, 436, Fig. 173; 436, Fig. $17 t$.

rate of conductivity, 417. Fig. 155.

simple muscle curve, 7, Fig. 2; 415, Fig. 154 .

stimulation by make and break induction slocks, 426, Fig. 163.

strength of stimuli and height of contraction, 435, Fig. 172.

tetanus, 429, Fig. 166; 430, Fig. 167 .

veratrinized muscle, 437, Fig. 175.

Reproluction:

curves of intra-uterine pressure in labor.

69S, Fig. 302; 699, Fig. 303.

Respiration:

absorption of $\mathrm{CO}_{2}$ by hremoglobin, 339, Fig. 132.

absorption of $\mathrm{O}_{2}$ by blood, 337, Fig. 131. elimination of $\mathrm{CO}_{2}, 343$, Fig. 134; 344 , Fig. 135; 34.5, Fig. 136.

number of respiratory movements, 319 , Fig. 127.

pneumorgraphic curve of man, 313, Fig. 121.

respirations influenecl by vagus, 325 , Fig. 129.

respiratory curve of rabbit, 314 , Fig. 123; 32S, Fig. 129.

Special semses:

excitation of different components of visual organ by light rays of different wave lengths, 544, Fig. 237; 545, Fig. 23.S.

excitation of retina as function of time exposed, 540, Fig. 235.

Temperature of body:

daily variations in, 399 , Fig. 147 .

post mortal fall of, 401, Fig. 149.

Cutaneous nerves, reflex action of, on respiration, 331.

Cutaneous sensations, 458 ; see also under śensations.

traets for, in the cord, 597 .

('vsteîn, 373.

(ystin, 7), 249.

Cytolytic action of blood, 156.

Cytosin, 77.

l)alton's law, for absorption of gases, 334 .

leath, 66 .

leeidua menstrualis, 697 .

1)ecomposition of carbohydrates, 374 .

of fat, 376 .

of protcids, 369 .
Decomposition products, elimination of, by elementary organism, 40 .

in blood, 15.5 .

influence of, on organs, 356 .

stimulating action of, 52 .

Defecation, 2ฯ, 299.

Degeneration, of peripheral tissues, 568. secomlary, in nerre cells, $567.56 \mathrm{~S}$.

in spinal corıl, 590, Fig. 262.

Wallerian, 56.7.

Deglutition, 279.

muscles of, 281.

reflex nature of, 280.

sounds of, 282.

Delomorphous secreting cells, 267.

l)emarcation current, $4 \overline{7}$, lig. $29 ; 48$.

in spinal cor l, 5s\$.

1)endrites of nerve ecll, 5.59.

Density of current, 420 .

Depressor nerve of heart, 193.

Depth, pereeption of, in vision, 556.

Deuteroalbumoses, 249.

Development, see firruth. of myelin substance in brain, 667 .

Dextrins, formation of, in ligestion, 246. properties of, 82 .

Dextrose, as product of digestion, 246, 251. as source of glycogen, 127 .

from alanin, 373 .

from lactic aciul, 374, note.

from leucin, 374 .

in urine, $3 \mathrm{~s} 3$; see also Diabetes.

properties of, 80 .

l)iabetes mellitus, 127,375 .

Diabetes, panereatic, 127, 128, 362, 375. pliloriılzin, 127, 374, 375.

puncture. 375.

Diamino acicls, 70 .

Diamino-eaproic aciı, 70.

Diamino-ralcrianic aciı, $70,72,370$.

Diaphragm, movements of, in respiration, 316.

paralysis of, 324.

Diaphragmatie type of respiration, 31 S.

Diastatic enzyme, definition of, 243.

in bile, 254 .

in intestinal juice, 25.5.

in panereatic juice, 251.

in saliva, 246.

in sweat, 395.

preserverl in stomach, 291.

Diastole, rlefinition of, 162.

suction of heart in, $177,225$.

time relations of, 175 , Fig. $62 ; 176$.

Dihasic monamino acids, 70 .

Dichromatic color system, 546 .

Dichrotic clevation, 175.

on cardiogram, 173, Fig. 60; 175, Fig. 62.

on sphygmogram, 216, Fig. SS. 
Diencephalon, $600,601,617$; sec also 'Tueenbrain.

1) set, see Vutrition and Vutritive requirements. animal and regetable, 145 .

construction of, 14.5 .

digestibility of, in stonach, 293.

importance of variation in, 134 .

mixed, utilization of, 139.

natural, of man, 146.

Difference tones, 501 .

Difflugix, motility of, $\mathbf{4 5}$.

Diffusion, absorption and, 353 ; see also Osmosis. of orlors, 486,457 .

relation of, to exeretion. 41 .

Digestibility of food in stomach, 293.

Digestion, artificial, 244, 218.

definition of, $3 \mathrm{~S}$.

Bacterial, in intestine, 297.

in different divisions of alimentary canal, 290 seq.

in intestine, $294 \mathrm{seq}$.

in large intestine, 298.

in mouth, 290.

in stomach, 291.

in unicellular organisns, $3 \mathrm{~s}$.

intraeellular and extracellular, 38 .

netabolism and work of, 108 .

Digestive enzymes, 243; sep also Enzymes.

Digestive fluids, 242 seq.; see also under individual names.

methods of study of, 243.

secretion of, 256 seq.

Digestive glands, 256 seq.; see also individual glands.

conclitions for secretion in, 256 .

electric phenomena of, $48,49,25 \%$.

extracts of, 243.

fistulse of, 243.

heat production in, 257.

morphological changes in, 260, Fig. 100;261,

Fig. 101; 262, Fig. 102; 272, Fig. 109; 277 , Fig. 111.

specific excitants of, $264,271,275$.

Digestive products, effects of injection of, into blood, 250 ).

Digestive system, function of, 30 .

Dihexosamin, 249.

Dilator center of pupil, 529 .

T)ilator nerves of pupil, 528 .

Ilopter, definition of, 513 , note.

I)ioxy-pheny-acetic acid, 384.

l)ioxy-pyrimiclin, 76 .

Direct vision, 514 .

Direction, lines of, in vision, 518.

Directive influences on movements of organisus:, 59, note.

Disaccharides, properties of, 81 .

percentage conıposition of, $\$ 2$.

Discrimination time, 676 .
Discus proligerus, 69.5.

Dispersion circle, 51\%.

Dissimilation equivalent to oxidation, 27.

Dissinilation, necessity of, to growth, 26.

Dissimilation source of kinetic energy, 26.

Dissociation, electrolytic, 32.

Distances, estimation of, with eye, 554 .

Distribution of blood in body, 239.

Diuresis, 390.

Diuretic substances, 273, 399, 390 .

Dizziness in the deaf and dumb, $4 \$ 1$.

Dog, extirpation of cerebrum in. 625 .

extirpation of spinal cord in, $581,582,5 \$ 7$.

Dorsolateral cerebellar tract, 593 .

Double refraction of eontractile protoplasm, 20 .

Double vision, 5.5.5.

Dromotropic effect of vagus, 159.

Dry rigor, 20.

Dry substance, determination of, in food, 84 . utilization of, in body, 139.

Dulcite, 80 .

Duodenum, influence of, on evacuation of stomach, 285.

secretion of pancreatic juice and, 2\%0.

Dyspnoea, 332.

Ear, analysis of sound in, 493, 498 .

anditory ossicles of, 49.5 .

beats, how explained, 501.

cochlea of, 495 .

combination tones in, 5 (1)1.

Eustachian tube of, 497,498 .

exeitation of auditory nerve in, $49 \mathrm{~s}$.

external. 494.

movements of, on stinulation of brain, 658.

vasodilator nerves of, 23.5 .

intrinsic museles of, 49 .

midrlle, 494, 495, Figs. 196, 197.

organ of Corti in, 499, 500, Fig. 199.

otolith sacs of, 473,481 .

resonance theory of hearing in, 498.

objections to, 501 .

resonators in, 498 .

semicircular canals of, 473 .

transmission of sound in, 493.

tympanic cavity of, $495,497$.

tympanic nombrane, 494, 495, 496.

Earthworm, phototaxis of, 57 .

Echinoderms, galvanotaxis of, 60 .

Echinoderms (Asterina), geotaxis of, 56 .

Eck fistula, 227, 2ד 4,371 .

Edestin, 70, 71.

Egg, white of, 245 .

Egg albumin, 74, 264.

Eggs, dependence of, on oxygen, 26.

osmotic phenomena in, 34 .

thigmotactic influence of, 697 .

Ejaculation, 693. 
Elastic manometer, 9, Fig. 5.

Elastic tubes, flow of liquid in, 199.

waves in, 212.

Elasticity, coefficient of, in arteries, 201.

of arterial wall, $200,201$.

of lungs, $310 ; 311$, Fig. $120 ; 317$.

of resting muscle, 412 , Fig. $150 ; 413$, Fig. 152.

Elasticity apparatus, 412 , Fig. 151.

Elastin, 78 .

percentage composition of, 82 .

Electric fishes, 45 , 50 .

Electric phenomenu in central nervous sysiem, $570,588$.

in rutaneous glands, 48 .

in digestive glankli, $2.5 \%$.

in muscles and nerves, 47,431 .

in plants, 49,50 .

in resting muscle, 47 .

in retina, $53 \%$.

in skin, 49.

in starch formation, 49,50 .

Electric signal, 10, Fig. 7 .

Electrical stimulation in general, 59, 418 .

Electrical stimulation of the cord, 5ss.

Electrical stimulation of the cerebral cortex, $601,631,632$, (3.3.3.

Electrical stimulation of human nerves, 427 .

Electricity, sce Electric currents.

artion of strong currents of, 61 .

animal, 46.

generation of, 46 .

Electrocles, nonpolarizable, 418,419 , Fig. 157 .

Electrolysis in nerves, 43.4 .

Electrolytes, relation of, to osmotic pressure, 32.

lilectrometer, capiliary, 13, Fig. 12.

Electrotonic currents, 43:3, Fig. 171.

Electrotonus, see dnclectrotonus and Catflestrutomms.

Elements, chemical, behavior of, in metabolism, 131 sey.

necesiary for animal boly, 25, 26.

Hlenents of speech, ing.

limmetropic eye, is

Emotions, rationalizeri, moral power of, 672. summoning influence of, on memory, 671.

Ginulsion in intestine, 29.5, 296.

Finceplanlon, (i(1); see alut Brain.

Find products, of proteid (lierstion, 24!).

lind products, nitrogen exullilsrium on, 124.

linlbrain, $6(0), 601$; see also Corcbrum.

Endulymph, in corhlen, 497, 49s.

movements of, in semicircular canals, 479 , 480.

Energy, conservation of, 2.

in a nimal boly, 93, 94.

kinetic, 26.

liberated, greater than cnergy of stimulus, 51 .
Energy, potential, measure of, in substance, 26. of foodstuffs, 92.

stored in processes of assimilation, 26.

transformation of, into external work, 113.

utilization of, in diet, 139.

production of, in cells, 26.

requirements of, of an adult man, 140 .

of an adult woman, 143 .

of children, 14 .

source of, in muscular work, 112, 113.

total output of, in muscle, 439 .

Entoptic phenomena, 521.

Enterokinase, 252, 25.5.

Enucleated cells, 18.

Enzymes, 35, 3.56 .

amylolytic, 243, 251.

in bile, 254 .

in blood, 15.5 .

in liver cells, 375 .

in pancreatic juice, 251.

lipolytic, $243,253$.

measure of artivity of, 245.

precursors of, 244 .

preotolytic, 243,252 .

properties of, 38 .

revervible processes of, 39.

Epidirlymus, 693.

Epiglottis in swallowing, 281, rig. 112; 282.

Epiglottis laryngoseopic picture of, 504, Fig. 202.

Epilepsy, cortical, 632, 641, 642, Fig. 291 ;652.

Epilepsy in myxoedema, 360.

Epithalamus, 600.

Equilibrium, loss of, after removal of cerebellum, 606.

nitrogenol1s, 91, 100, 103, 120, 121, 122.

of substance in borly; 137 .

Equimolecular solutions, 32, 33.

Erection, 5SS, 693.

center of, 694.

Frepsin, 255, 3(1).5.

Ergograph, 443. 444, Fig. 179.

Frgographic record, 444, Fig. 1S0; 445, Fig. 1 1S1.

Erlanger's apparatus, for determination of blood presicure in man, 203, Fig. 76.

Erucic acid, 130.

lirythrodextrin, 246.

Ethereal sulphates, $373,379$.

Eudendrium, 64.

Euglobulin, 154.

Eustachian tube, 498.

Evacuation of large intestine, 299. of stonach, 2s.5.

Excitability, alterations of, 52, 425.

by extraction of water, 53.

influence of heat on, 58 .

Excitants. specific, in secretion, 264, 271, 275. 
Excitation, see Stimulation.

accompanied by leat and electricity, 51 . automatic, 52, 356, 570, 580.

of muscle and nerve, 414 .

pelar law of, 424,426 .

propagation of, through the heart, 187.

rate of transmiscion of, see Transmission of stimulus.

Excrements, see Faces.

Excreta, apportionment of chemical elements to, 89.

determination of, in metabolism experiments, S4; see also various excretory organs.

Excretion, definition of, 40.

by kidney, 384 .

by lungs, 346 .

ly skin, 394.

in unieellular organisms, 40.

of carbon dioxide, 89 .

of iron, 308,309 .

of nitrogen, 89,90 .

througl intestine, 13:3, 298, 309.

Excretory organs, function of, 31 .

Expansion of thorax, 310, 312.

Expansion movements of pieudopodia, 43.

Expiration, see Respiration and Respiratory morements.

definition of, 310.

description of, 317 .

effects of, on arterial blood pressure, 230.

muscles of, 317 .

pressure changes in air passages in, 321, 322.

in thorax in, 310, 312.

Expired air, eomposition of, 342 .

poisonous constituents in, 344.

Expulsion period in parturition, 698.

Extension, eurve of, in resting musele, 112 , Fig. $150 ; 413$, Fig. 152 .

External auditory meatus, 494, Fig. 196.

Extractives, effect of, on gastric glands, 264 . food value of, 109 .

Extremities, vasoconstrictor nerves of, 232. vasodilator nerves of, 235.

Eye, accommodation in, 529 ser. after-images of, negative, 539 . positive, 538 .

binocular field of vision of, 551, 552, Fig. 242. blind spot of, 516, Fig. 212.

cardinal points of, 512, 513, Fig. 210.

changes produced in retina of, by action of light, 537, Fig. 231; 538, Fig. 232.

choroid coat of, 527 .

convergence of visual axes of, $534,556,557$, Fig. 230.

center for, 535.

dichromatic, 546.

dispersion circles in, $\mathbf{5 1 7}$.

emmetropic, 519, Fig. 215.
Eye, excitation of retina of, 536 .

far-point of, 520 .

fatigue and recovery of, 539.

focal distances of, 512 .

fovea centralis of, $514,517,541$.

hypermetropia of, 519, Fig. 215; 520 .

inages, formation of, on the retina of, 513 , $5.56, \mathrm{Fig} .248$.

iris of, 527 .

light-pereeiving layer of retina of, 514 .

muscular strabism of, 55.5 .

myopia of, 519, Fig. 215.

near-point of, 529 .

optical constants of, 508 .

optical defects of, 520 .

angle between line of vision and risual axis, 525.

astigmatism, 522, 524, Fig. 219.

chromatic aberration, 526, Fig. 221.

entoptic phenomena, 521, Fig. 216; 522,

Fig. 217.

form of refracting surfaces in, 522 .

spherical aberration, 522, 523.

ora serrata of, 514 .

perception of depth by, 556 .

primary position of, 549 .

pupil of, constriction of, 528 .

center for, 529 .

dilatation of, 528 .

center for, 529 .

reduced, 512.

refraeting media of, $50 \mathrm{~S}$.

refraction in, 510, Fig. 207.

rotation center of, 549 .

schematic, 511, 513, Fig. 210.

sensations of color in, 541 .

complement:ary colors, 543.

successive color induction, 5.42.

theories of color vision, 544,546 .

simultaneous contrast in vision in, 547 .

explanation of, 548,549 .

static refraction of, 519 , Fig. 215.

stereoscopic vision of, 5.58 .

trichromatic, 545 .

ultra-red rays, effect of, on, 536 .

ultra-violet rays, effect of, on, 53 ?

visible rays of spectrum in, 536 .

visual angle and limits of vision in, 517 .

Eye as an optical instrument, 508.

Fye movements, 549 .

induction of, by stimulation of cerebral cortex, 640,658 .

limits of, 551, Fig. 241.

relation of corpora quadrigemina to, 613 .

significance of, for projection of visual impressions, 552.

synergic, 616.

Eye muscles, 549 .

action of, 549, 550, Fig. 240. 
Eye muscles, axes of rotation in, 550, Fig. 240 . cruters for, 614, 615, Fig. 273.

iunervation of, 6S().

Eyes, single vision with two, 555.

lace mask for respiration experiments, \&5, Jig. $39 ; 10.5$.

Face muscles, contraction of, by stimulation of cortex, 640 .

lacial nerve, 680 .

as nerve of expresion, 680.

as nerve of taste, 484, Fig. 191.

as seeretory nerve of salivary gland, 257.

Fires, clemareation of, 8.5 .

formation of, 298.

heat of combustion of, 93.

in fasting, 96.

metabulic significance of, 90.

$\mathrm{N}: \mathrm{C}$ in, 90.

Fallopian tubes, 696.

Falketto voice, 505.

Far-point, 520.

Fasting, 95.

cause of death by, 9S.

firees formed in, 96.

in animals of different size, 117.

influence of, on different organs, $97,9 \mathrm{~s}$.

on futigue, 445.

metalulism in, $9.5,96$.

of elementary urganisms, 28.

plysiolugreal comelition in, 95.

Jat, absurption of, 304.

colls, 21.

elemiral nature of, 79 .

clavage theory of aligestion of, 296 .

determination of, in fool, s4.

digestion of, by panereatic juice, 253.

in inte'stinc', 29.5.

in stonuach, 250).

(Iroplets in various cells, 22.

dynause value of, 9:3.

(mulsion theory of digestion of, 295.

final decompusition of, 376 .

formı of, in milk, $7(1)]$.

formation of, in mammary glands, 705 .

from fatty acils, 130 .

in blowel, 15\%.

in numein:s, 74 .

in musele, 113.

influener of, on gastrie digestion, 285, 293.

(u) nuetabolisin, 10-I.

metalublisul of, in fasting, 97, 104.

in museulat work, 113.

pereentage eonupusition of, 82.

physiological heat value of, 93.

proteid sparer, as a, 121.

relation of, to glycogen, 128.

to pancreatic secretion, 270.

to proteid retention, 121 .
Fat, resynthesis of, 304.

sources of, in budy, 129, 130.

storage of, in bocly, 129.

subeutaneous, as protection against heat losis, 41$) .5$.

transportation of, in budy, 376 .

utilization of, 138.

Fatigue, 65.

effect of, on power of localization, 464 .

influence of niental work on, $\mathbf{4 6}$.

loeal, 442 .

of brain, 676 .

of ear, 499 .

of muscles, 441 .

human, 443.

of nerves, 4.2.

human, $4+13$.

of olfactory organ, 488 .

of visual uruan, 539 .

rate of stimulation and, 446 .

reeorel of, with ergograpll, 44t, Fig. 1S0; 445 , Fin. 181.

Fatty acids, fool value of, 1139.

produetion of, by digestiun, 29.5.

solubility of, in bile, 254, 296.

Fatty elegeneration, 129.

Fatty infiltratiou, 129.

Fat-splitting enzymes, 250, 253; see also steapsin.

Feathers as protection agrinst heat loss, 405.

Fechner's psycho-physical law, 457, note.

Feeling, fietitious, 263.

Feeling, greneral state of, 452 .

Feeling of effort in motor sensation, 470 .

Feelings, summoning jower of, on memory, 671.

Fellic acid, 253.

Female sexuml organs, 605; see also Sexual orymis.

lenestra ovalis, 496 .

Fenestra rotunda, 497 .

Ferment action, 4).

Fermentation, aleoliolic, 28, 41), 80).

Verments, wrganizerl, 40; sed alsu Enzymes.

Fertilization, 691, 697.

librillary eontractions of heart, 181

löbrin, 147 .

formation of, 157,158 .

Fibrin ferment, 1 is.

Fibrinogen, 154, 1.57.

eleavage uf, 158.

Fibrino-globulin, 159.

Fillet, 592

lateral, 6i14, tij.5.

Filtration, tleory of, in urine formation, 387. in lymph formation, 349 .

Fimbria ovariea, tis)(

Fish, effect of low temperature on, 29. electric, $4 \mathrm{~s}, 50$. 
Fish, extirpation of cerebrum in, 619 . geotaxis of, 56 .

Fissure, calcarine, 639, Fig. 290; 659. cruciate, 624, Fig. 280.

of Rolanda, 639, Fig. 289. of Sylvius, 624, Fig. 2S0; 639, Fig. 289.

Fistula, biliary, 243, 295.

Eek's, 227, 274, 371.

fundus, 264 .

gastric, 243,246 .

intestiual, 243, 295.

cesophageal, 263.

panereatic, $243,251$.

pyloric, 267.

Flagella, definition of, 43,44 .

vibrations of, independent of $\mathrm{NaCl}, 25$.

Flagellata, 44.

Flavors, 133.

Flechsig's tract or bundle in the cord, 591, Fig. $264 ; 593$.

Flow of blond in arteries, 200 seq., 218.

in capillaries, 219.

in veins, 223 .

Flow of liquid in elastic tubes, 199.

in rigid tubes, 198, Fig. $72 ; 199$, Fig. 93.

Fluids, absorption of, gases by, 334 .

Fluttering of heart, 187.

Focal distances of the eye, 512 .

Focal lines, 523, 524, Fig. 219.

Focal points in eye, 512, 513, Fig. 210.

in optical system, 510, Fig. 207; 511, Fig. 20 s.

Folin's theory of proteid metabolism, 137.

Follicle, graafian, 695 .

primary, 695.

Food, construction of diet from different articles of, 145 .

definition of, 137 .

influence of, on metabolism, 98 .

Food requirements, see Nutrition.

of grown man, 140.

of grown woman, 143.

of infants, 144 .

of youtlis, 143 .

Foodstuffs, sce Mrtabolism, Nutrition diet, and indiviclual foodstuff:

decomposition of, 369 .

definition of, 83 .

inorganic, 83, 131.

effect of cleprivation of, 131.

organie, 83 .

plastic, 111.

potential energy of, 92.

replace one another, 93.

respiratory, 111.

Foraminifera, 41.

Forced movements and positions, 612.

Forebrain, 600.

Forea centralis, $514,517,541$.
Freezing point, lowering of, 32 .

Frittillaria imperialis, 21, Fig. 16.

Frog, extirpation of cerebrum in, 620.

behavior of, in absence of $\mathrm{O}_{2}, 27$.

galvanotaxis of, 60 .

geotaxis of, 56 .

osmotic relations in, 34 .

Frog current, 47.

Frontal association centers, 668, 669.

Frontal convolutions, 631, 637, 63S, 639, Figs. 289,$290 ; 664$.

Frontal lobes, extirpation of, 668 .

Frontana leucas, 41, Fig. 24.

Fructose, so; see also Levulose.

Fruit sugar, 80; see also Levulose.

Fruits as exclusive food of man, 146.

Fundamental colors, 544, 547.

Fundamental tone, 491, 492, Fig. 194.

Fundic glanels, 266.

Fundulus, egg of, 25, 34 .

Funclus fistula, 264.

Galactose, 80, 81, 251.

Gall blackler, 275.

Galvani's diseovery, 46.

Galranotaxis, 60.

Galvanotropism, 64, 65.

Ganglia, basal, of brain, 632 .

collateral, 6s7.

lateral, 687.

peripheral, 583; 584, Figs. 258, 259.

spinal, ehief purpose of, 584 .

sympathetic, reflexes through, 5s3.

table of connections of, 688 .

Ganglion, inferior mesenteric, 392, Fig. 145; $393,6.58$.

stellate, 687, 6ss.

superior cervical, 689.

superior mesenteric, 392, Fig. 145; 393.

Ganglion cells, degeneration of, 585 .

in heart, $186,190$.

in intestinal wall, 2ss; see atso duerbach's plexus and Meissner's plexus.

in stonach wall, 284, Fig. 114.

in ureter wall, 391.

peripheral, funetions of, 583.

reflexes through, 5S4, Fig. 259.

Gas pump, 334, Fig. 130.

Gases, absorption of, in liquids, 334 .

exeliange of, between alveolar air and blood, 3.41 .

between blood and lymph, 342 .

in bloorl, 333, 339.

in intestine, 295.

pressure of, in alveoli, 341 .

tension of, in tissues, 342 .

Gastric glands, 266.

morphological changes in, 268.

nerves of, 263. 
Gastric juice, 246.

acid of, 247 .

antiseptic properties of, 292.

hourly course of digestive action of, 265 , Figs. 103, 104 .

pepsin in, 248, 268.

rennin in, 250, 267.

Gastric mucus, 266.

Gastric steapsin, 250.

Gelatin, is.

composition of, 75,82 .

digestion of, $247,252$.

foorl value of, 109 .

produets of digestion of, 75,78 .

Gelatin peptones, 78 .

Gelatin-forming substances, 247.

digestion of, $247,252,291,294$.

food value of, 109 .

Generation, organs of, see Sexual organs. vasomotor nerves of, 233, 235.

spontaneous, 16.

Geotuxis, 56.

Geotropism, 64.

Germinal spot, 695 .

Germinal vesiele, 695 .

Gestation, period of, 698 .

Giant eells of alg:r, 16 . of bone-marrow; 16.

Girlhord, age of, 706 .

Girls, fool requirements of, 14 . growth of, 708,709 .

Glands, albuminous, 245, 261.

gastric, 266.

lachrymal, 245 .

mixecl, 245.

mueous, $245,261$.

of large intestine, 27 $\overline{\boldsymbol{T}}$, Fig. 111.

of small intestine, 276 .

parotid, 245,257 .

of cat, 261, Fig. 101.

of rabbit, 260, lïg. 100 .

preputial, of mouse, 394 , ligg. 146 .

salivary, $25 \pi \mathrm{kec}]$.

sebaceous, 394.

sublingual, 245, 257, 2.5.

submaxillary, $245,257,258$.

Globin, 75,152 .

Globulins, it.

alkaline combination of, in hioxd, 338

of blosed, 154 .

Glomerulus of kidney, 385 .

Glossopharyngeal nerve, 4*t. 1:11.

as nerve of taste, 4S4, Fig. 191.

as secretory" nerve of salivary glands, 257 .

respiration and, 331.

Glottis, 502.

Gluencamin, 71, 72.

Gluense, so; see also Dextrose.

Glutamic acisl. 70, 72, 249.
Glutin-forming substanees, 250 ; see also Gclatinforming substances.

Glycerie acid, $3 \pi$.

Glycerides, 79.

Glyeerin, food value of, 110.

from cleavage of fat, 29.5.

in blood, 15.5 .

Glycerin aldehyrle, 373.

Glyeerin-phosploric acid, 78 .

Glyeocholic acis, 253.

Glycocoll, 71 ), $72,253,370,378$.

Glyeogen, 81, 124, 37t seq.

affected by extirpation of pancreas, 364 .

amount of, stored in body, 125 .

consumption of, in muscular work, 126.

formation of, from carbohyclrates, 126.

from fats, 128 .

from proteids, 127 .

in liver, 125, 126, Fig. 45.

in muscle, 413 .

in nature, wecurrence of, 81 .

percentage of, in various organs of boly, 125 .

transformation of, into sugar, 37.5.

Glveogenie function of the liver, 375 .

Glyeol, 3\% 7 .

Glyeolie aeirl, $37 \%$.

Glycesuria alimentary, 12 $7,363,374$.

Glycuronic acid, 376, 379, 383 .

Glyoxylic, 377 .

Golgi's methorl, 559 .

Goll's column in the eord, 591, Fig. 264; 592.

Gower's tract or bundle in the cord, 591, Fig. $264 ; 593$.

Graafian follicle, 695 .

Grape sugar, 80; see also Dextrose.

Graphic methorl, 6.

Gray, extracellular, of Nissl, 561.

Gray matter of spinal eord, 562, 589.

Gray rami communieantes, 687.

Green blindness, 546 .

Gromia oriformis, 35, Fig. 19.

Growth energy, inherent in eells, 63.

Growth of human body, 705 seq.

by years, 70), 709 .

of males and females, 709, Fig. 304.

faetors cletermining rate of, 707 .

influence of eechomic cireumstances on, 710 . of puberty on, $708,709,710$.

of season on, 710 .

periods of, 706 .

Guanidin rest, 70. 72 .

Guanin, 76, 252, 413.

Guanylic acisl, 77 .

Gudilen's methorl of tracing nerve paths, 56,8 , 591.

fiums, properties of, 82 .

Gymnenic acid. 48.5.

Gyrus anguları, 662, Fig. 296; 663.

Gyru= fornicatus, 639, Fig. 290; 653. 
Gyrus marginalis, 634 .

Grrus sigmoicles, 266, 632, Fig. 282.

Gyrus supramarginalis, 662, l. ig. 296

Hallucinations, visual, 454 .

Haploscope, 5.5.5.

Haptogen membrane of milk, 701.

Hamatin, 152.

Hamatinie acid, 254.

Hermatrgens, 308.

Hamatridin, 254.

11:xrnatoporphyrin, 152, 393.

Hremin erytal:, 153, Jig. 49.

Hiemoclxromogen, 75, 152.

Hamodromograph, 209, Fig. \$1.

Hænoglobin, 150, 151.

absorption of $\mathrm{CO}_{2}$ by, 339, Fig. 132.

absorption of $\mathrm{O}_{2} \mathrm{by}, 336$.

abiorption spectra of, 151, Figs. 47, 48.

carbon-dioxide, 152.

carbon-monoxide, 152.

nitric-oxide, 152.

percentage of, in red blood corpuscles 150 .

- relation of, to bile pigments, 254 .

union of, with $\mathrm{CO}_{2}, 339$.

Hamoglobins, 75.

Hamopyrrol, 152.

Hair as protection against loss of leat, 405.

Hair cells of organ of Corti, 499, 500), Fig. 199.

Hammer of middle ear, 495, Fig. 197; 496 Fig. 198.

Head, vasomotor nerves of, 232, 235.

Hearl tones, 505.

Hearing, see Ear.

cortical field for, 653, 654, Fig. 293.

range of, 490.

reaction time to, 673,674 .

sense of, 451,489 .

Heart, action current of, 13, Fig. 13; 179, Fig. $63 ; 180$, Fig. 64.

anxmia of, 181.

artificial nourishment of, 25, 182.

automatism of, 185 .

chambers of, 161 ; see also under individual names.

changes in form of, 163, 1 (it.

changes of pressure in, $16 \mathrm{~s}$.ey.

compensaiory pause of, 183, lig. 65.

contraction of, nature of, 179 .

coronary circulation in, 180.

cross section through, 163, Fig. 51.

diastole of, $162,176$.

electrical stimulation of, $182 \mathrm{seq}$.

fibrillary contractions of, 181.

filling of, in diastole, 176 .

fluttering of, 187.

influence of thoracic suction on, 176 .

intrusic ganglia of, 186 .

Krehl's cone of, 163, Fig. 52.
Heart, muvements of, 162.

nutrient melium for, 25 , note, 182.

mutrition of, 180 .

period of ejection of, 171

periorl of rising tension of, $170,175$.

power of, 177, 178 .

presisure in different chambers of, 169.

propagation of excitation wave in, 187.

muscular theory, 186.

nervous theory, 187.

pulse volume of, 204 .

reflexes, 193.

refractory period of, 183, Fig. 65.

separation of auricles from ventricles in, $18.5,159$.

sound i, $167,168,175$.

structure of wall of, $162,163$.

suction of, in diastole, $17 \%$.

systole of, 162.

tactile sensations in, 194.

tenacity of life in, 182.

tetanus of, 184 .

time relations of events in, 170,$171 ; 173$, Fig. 60: 175, Fig. 62; 176 .

valves of, 165 .

variations of electrical potential in, 179, lig. 63.

vasomotor nerves of, $233,235$.

work of, 178.

Heart beat, acceleration of, by inflation of lung:s, 195.

cause of, 18.5 .

force of, 188 .

influence of blond on, 184, 204.

of vagus on, 189.

frequency of, as affected by age, 197.

by foorl, 197, Fig. 71 .

by individual peculiarities, 198.

by muscular exercise, 197.

by sex, 197 .

by size of body, 197 .

by temperature, 184, Fig. $66 ; 19$

by vagus nerve, 188 .

Heart muscle, contraction of, nature of, 179 . propagation of excitation wave in, 187. properties of, 179.

Heart nerves, 188.

accelerator, 191, Fig. $67 ; 688$.

afferent, 193.

centers for, 195 .

depressor, 193, lig. 69; 681.

efferent, $18 s$.

inlibitory, 188; 191, Fig. 67.

reflexes tlırorigli, 193.

Heat, conduction and racliation of, 403 . formation of miversal in nature, 46. influenced of, on elementary organisms, 29. production of, in cold-blooded animals, 46 . in man, 402. 
Heat, production of, in plants, 46 .

Heat as stimulus, 58 .

Heat centers, 408 .

Ileat loss, from the bocly by different means, 403.

proteetion against, 404 .

regulation of, 407 .

Heat nerves, $40 \mathrm{~s}$.

enil organs of, 465 .

Heat production, $46,402$.

amount of, in human body, 94.

in glands, 402 .

in muscles, $402,439$.

in nervous swtem, 402 .

influenced by amount of foorl, 407 .

by muscular work, 116.

by surroumding temperature, 114 .

ratio of, to externa! work of musele, $t+1$ ).

Heat rogulation, 407.

eenters for, 408 .

disturbances to, by extirpation of thyroid, 361.

in the newborn, 409 .

Heat sense, 459; see also Temperature sensations.

topographical ilistribution of, 460, Fig. 1 S.3. tracts for, in tlie cord, 597.

Heat spots on the skin, $458 ; 459$, Fig. $182 ; 461$.

Heat units, 26 , note.

IIeliot ropions, 6.t.

Heller's test for proteill. 69, 394.

Hemiamblyopia, 6.5.) 660 .

Hemianopia, 657.

Hemilesion of the curd, 597 .

II emiplegia, 6itf.

If mintetion of the corl, 595, 596, 640.

H(misplueres of the lorain, 600 .

Henle's loop, 35.5, l“ig. I44; 356 .

Henry's law of absorption of gases, 334 .

Hepatı-pancreas of isopod, 244, rig. 99.

Herine's theory of eolor vision, 54t, 546.

Jerminn's theory of animal eurrent, 4 .

Heteroalbumose, 24?.

forrl value of, $10 \mathrm{~s}$.

Hexuses, oceurrenee of, so.

Ilimblitin, or rhomene(phalon, 600, foll. seenndary, or metencephalon, 600, 601.

IIippuric aeid, 15.5, 37s, 383.

Ilistidin, $72,255$.

Ilistolongieal mothods, 4.

IIistons, 77.

Ilomoentric lundle of light rays, 523, note.

Ilomoiothermous animals, $46,398,404,442$.

IIvaloplasm, 19.

IYrelrobilirubin, 254.

IIvlruchloric acicl, action of, on ptyalin, 246. antiveptic properties of, 292.

influence of, on tryptic digestion, 294.

of gastric juice, 247 .
Ifydrochloric acid, where formed, 268.

Ilyoglosisal nusicles, action of, in deglutition, $2 \mathrm{~s} 0,281$.

Ifydrolytie eleavage, 70,243 .

Ifydrometric pendulum, 210.

Hyperemia, influence of, on transudation, 349.

Hypersesthexia, 597.

Hypermetropia, .519; I*ig. 215; 520.

Hypertunic solutions, 32.

Hypogastric nerves, 392, Fig. 145; 693, 700.

Hypogastrie plexus, 392, Fig. 145, 393, 694, 700 .

Ilypoglo-sil nerve, $6, \$ 1$.

Hypoplyyis cerebri, 367; see also Pituitary borly.

II ypotonie solutions, 32.

Hypoxanthin, 7f, 2.52, 372, 373, 413 .

Ideas, definition of, 451, note.

formation of, 662 .

Jelioey, 670.

Images in eye, 513 seq., 5.5\%, Fig. 24 s.

in optical system, 511, Ï̈igs. 20.5, 209.

Imbeeility, 669 .

Imbibition, eapillary and molecular, 353.

Immunity, 156 .

Inanition, state of, 15.5; see also Fasting.

Incidence, angle of, 509, Fig. 206.

Ineoördination of movements, 60) ; see also Coördination of morements, loss of.

Ineubation, liberation of oxygen in, 27.

Incus of michlice ear, 49.5, Fig. 197.

artieulation of, with malleu=, 496, Fig. 198.

Indiean, 379.

Indigosulplute of sodium, elimination of, by kinheys, 3ss.

Indol, 37s, 379.

Indol nucleus in proteid, 71 .

Indoxyl, 379.

Indoxyl-sulplurie acid, 379.

Intuetion eoil, 419, 4:20, lig. 15s.

currents, 426.

shocks, $422,423$.

stimulation of museles and uerves by, $41 \mathrm{~s}$, +22, Fig. 1(ii).

unipolar effects of, 126 , Fig. 163.

Infundibulum, 6o().

Infusoria, ehemotaxis of, $5 \overline{5}$.

geotaxis of, 56 .

ingestion of foonl in, by ciliary action, 37.

osmotic relations in, 34 .

Ingesta, determination of, in metabulism, 83 .

Ingestion of foud hy elomentary organism, 30, 36, Fig. $21 ; 37$.

Ingestion of foreign houlies hy leucocytes, 37.

Inhibition, definition of, iso.

of auricle, 189 .

of eentral veins, 159 .

of muscles, antagonistic, 640 . 
Inluibition of reflexes, 577 . of ventriele, 189 .

Inhibitory senters, 579 .

Inhibitory nerves, 564 .

of gastric glands, 263.

of intestinal glands, 276 .

of intestinal movenients, 2ss, 289, 290.

of heart, 1ss ser.

centers for, 195.

colurse of, 191, Fig. $67 ; 6 \$ 1$.

of pancreas, 269.

of stomach musculature, 284 .

Inoculation, protective, 29.

Inorganic foodstuffs, 83 .

Inorganic substances, see Mineral substances. absorption of, 139,307 .

of blood, 154 .

of diet, 139.

of food, $\$ 3$.

of milk, 702 .

of urine, 384.

Inotropic effect of vagus on heart, 159.

Inosinic acid, 413 .

Inosit, 413.

Iodin, amount of, in blood of dog, 351 . as constituent of thyroid gland, 26, 362 .

Iodothyrin, 362.

Ions, dissociation of, 32 .

permeability of cells to, 34,35 .

relation of, to sense of taste, 455 .

stimulating effects of, 53 .

Insensible perspiration, 397 .

Inspiration, influence of, on arterial blood pressure, 229.

pressure changes in air passages in, 321 .

in thoracie eavity in, 312.

Inspiratory muscles, $315,316$.

Invula, see $I$ sland of Reil.

Iutercellular bridges, 62, Fig. 36.

Intercostal muscles, $315,324$.

Interference of sound waves, 501 .

Intermediary myelogenetic regions of the cortex, 667 .

Internal capsule, motor fibers in, 637, Fig. 287; 6.17, Fig. 292.

Internal secretion, definition of, 356 .

of adrenal borlies, 364 .

of kidneys, 367 .

of ovaries, $35 \mathrm{~s}$.

of pancreas, 362.

of pituitary borly, 367 .

of spleen, 368 .

of testes, 357 .

of thyroid, 358 .

Interrupter, automatic, of induction coil, 421 , Fig. $159 ; 422$, Fig. 160 .

Intersystole, 170, Fig. 57; 174.

Intoxication, 30.

Intracardial ganglion cells, 186.
Intracardial pressure, 169, Fig. 56.

Intracranial pressure, $67 \mathrm{~s}$.

Intrathoracie pressure, 310 .

clata for, in man, 312.

demonstration of, 311, Fig. 120.

methods for determining, 311

Intrauterine pressure, 698, 699.

Intravascular clotting, 159 ; see also Coagulation.

Inversion of disaccharicles, $\$ 1$.

Intestinal epithelium and absorption of fat, 30-4, Fig. 118.

Intestinal fistule, 243, 29.5.

Intestinal gases, 29.5.

Intestinal glands, 276 .

Intestinal juice, 255 .

Intestinal movements, 286, 288.

Intestinal putrefaction, 297, 298.

Intestine, large, absorption in, 302 digestion in, $277,298$.

extirpation of, 298.

innervation of, 289, 290.

movements of, $2 \$ 9$.

small, absorption in, 302 seq.

digestion in, 294.

extirpation of, 298.

innervation of, $2 S s$.

movements of, 286.

Iris, 527 .

innervation of, 52s.

movements of, incluced from cortex, 6.5s.

protrusion of, in aecommodation, 531, Fig. 226.

Iron, absorption of, 307 .

elimination of, $30 \mathrm{~s}$.

in clalorophy $11,24$.

in hamoglobin, 152.

in red bloou corpuscles, 26.

Irritability, definition of, 50 .

of nerves, 410.

Island of Reil, 655, 662, Fig. 296; 66s.

Isobutyl-amino-acetic aeid, 70 .

Isodymamic quantities of foodstuffs, 93.

Isolaetose, 39 .

Isolated concluction in nerves, 411.

Isomaltose, 246, 3\$3.

Isometric eontraetions, -414 .

Isotonic eontractions, 415.

Isotonic solutions, 32.

Istlımus, rhombencephali, 600 .

Jaw, lower movements of, in mastieation, $27 \mathrm{~s}$.

in suching, 279 .

Jecorin, 79.

Jennings' theory of animal behavior, 55.

Keratin, 7 .

percentage composition of, 82 . 
Hidney extract, effect of injecting, intravenously, $36 \mathrm{~s}$.

Jidney, bloot supply to, 3Sis, Fig. 143.

effert of removal of, 367,390 .

internal secretion (?) of, 367 .

tubules of, 3S.5, Fig. 1t4.

vasomotor nerves of, $233,235$.

volume of blorel flow through, 240.

"kl)pfversucls," 57s.

line-jerk, js.

Kivmograph, 6, Fig. $1 ; 7$.

rutlesi papor, 9, Fig. 6.

long paper, 10.

Lahor, 6!s.

I.abur pains, 698, Fig. 302; 699, Fig. 303.

Labururs' rations, 141.

I,atsrinth, membranous, extirpation of, in pigern, 476, Figs. 1S7, 1Ss, 1S9; see also siemicireular canals, Cochlea, vtulith sacs.

Lact-albumin, 701 .

Lactase, 251.

Lactation periol, 703 .

I act-globulin, 7 71 .

Lactic acisl, $15 \bar{j}, 297,373,374,376,434,447$.

Laetroe, SI.

Lagena, 473, 47.5.

Laked blowel, 1.50 .

Lumplmyis, 4.5 .

Janguage faculties, 6,61.

affecterl by lexions in cortex, 663, 664 .

huw : acruired, 661, 662.

recovery of, after lesion: in cortex, 66.5.

Lanolin, so, 2of.

Jaryongeal museles, su2.

Laryngeal nerves, inferior, motor for larynx, 324,651 .

superior, 6Sl.

influence of, on respiratory movements, 331 .

motor for laryux, 324, 504.

Larynguserope, 504.

Laryngesenpic picture, 504 , Fig. 202; 50.5 , Fig. 2113.

Larynx, in's.

control of, by cerchral cortex, 649, 6,50.

Latent periot of entractions induces from cortex, fi33, Fig. 2s3.

of motor nerve endings, 418 .

of miscle, $415,416,424$.

Jateral columus of the corrl, ifi2, Fig. 254.

Lateral horn of the cort, if;2, Fig. 254.

Lateral presiure, 2012, 22:3; ste also Blool pressurs.

I.angling, 321.

Lecethin, chemical nature of, $i s$.

elcetive solvent puwer of, 34.

percentage composition of, 82 .

I.ecethin-alloumins, 7 9.
Jeech extract, 159,351 .

Leguminosa, ront tubercles of, 23, Fig. 18; 24.

Lemna triccula, 42, Fig. 25.

Leptoplana, 6-1, note.

Lesions of cerebellum, 608.

of corona racliata, 647,663 .

of frontal as-ociation center, 668 .

of millbrain, 613 .

of motor cortex, $645,646,660,661$.

of posterior association center, 669.

of sensory cortex, 650, 65\%, 65.3.

of speech tract, $603,664,665$.

of spinal cord, 595.

of temporal convolutions, 665.

of 'tweenbritin, 6i17.

Leucin, 70, 72, 249, 255, 370, 374, 394.

Leucocytre, chemotaxis of, 54.

formation of, 353 .

ingestion of foreign bolies by, 37, Fig. 22. movenents of, described, 42,43 , rig. 27 . participation of, in absorption of proteid (?), 306 .

permeability of, to various solutions, 33.

phagrocytic function of, 37 .

Leucomaines, 29.5.

Levator ani, 299.

Levatores costarum, 315.

Lever, recording, 6, Fig. 1 ; 7 .

Levuluse, behaviur of, in liabetes, 363 .

properties of, si).

source of glyeogen, 127.

Lieberkiihn, glands of, $276,277$.

Liebig's classification of foodstufis, 111.

Light, action of, on iri., 527,525 .

on retina, 537 .

muclifications of, $5+1$.

pluysical cause of, 536 .

plysiological caune of, 453.

production of, by living cells, 4.5.

stimulation ly neans of, 56 .

Light rays of solar spectrum, 536.

Light rays, relation of, to organ of vision, 541 .

Lingual nerve as secretory nerve, 25.

a* viliomotor nerve, 234 .

I.jpolytic enzymes, 2.43.

in pancreatic juice, 253.

in stomacl, 2.51).

Liquor follienlaris, 695.

Listing': schematic eye, ill, 313, Fig. 210; 5is.

Liver, blext supply to, 273, 27 1 .

exchuson of, from circulation, 227, 274, 371. extirpation of, in hirel<, 371.

glyeogen formation in, 375.

regeneration of, 6.5.

regulation of circulation by, 207, 227 .

secretion in, 272.

sugar formation in, 37.5 .

urea formation in, 371 . 
Living substanee, 15 ; see also Protoplasm.

bchavior of, in metabolism, 135, 137 .

constitution of, 20.

form of, 15.

impetus to formation of, 63,64 , note.

Load, effect of, on performance of muscle, 43.5, 446,449 .

Lobule, paracentral, 635, 639, Fig. 290; 652 .

Localization, in retina, $51 \mathrm{~s}$.

in skin, 463.

of temperature sense, $\mathbf{4 6 4}$.

power of, affected by different conditions, 464.

Local sign, 463.

Locomotor movements, control of, by spinal cord, $5 \mathrm{~s} 6$.

in decapitated animals, 587.

Lophius piscatorius, 572 .

Loudness of sound, 489 .

Ludwig's air pump, 334, Fig. 130.

Lumbar nerves, innervation of urinary bladder by, 392, Fig. 145 .

I.ung eatheter, 341, Fig. 133.

Lungs, see Respiration and Respiratory movements.

circulation in, 227.

elasticity of, 310 .

exelange of air in, 319 .

means of protection for, 323, 330 .

noxious air space in, 320 .

vasomotor nerves of, $233,235$.

vital capacity of, 320 .

Luteïn, 695.

Lutein cells, 695.

Lymph, chemical properties of, 347 .

composition of, 3 ts.

definition of, 317 .

formation of, $3+9$.

filtration theory, 349,350 .

secretion theory, 350 .

gases in, 348 .

medium for tissue cells, 30 .

morements of, 348 .

quantity of, formed in 24 hrs., 348.

Lymph glands, 352 .

Lymph hearts of amphibia, 349 .

Lymph vessels, contractions of, 349 . valves of, 349 .

Lymphoeytes, 153.

Lymplogogic: substances, 352.

Lympl-producing substances, $350,351$.

Lysin, 70, 72, 249.

Macula acusticx, 475.

Magendie's doctrine, 565.

Magnesium, absorption and excretion of, 133 . in bones, 26.

Magnesium salts, effect of, on ciliary movements, 25.
Magnesium salts, importance of, in plants, 24.

Malapterurus, 50 .

IIale scxual organs, 691 .

Malic acid, 54 .

Malleus of midclle ear, 494, Fig. $196 ; 495$.

articulation of, with incus, 496, Fig. 198.

Malonic acid, 377 .

Malpighian corpuscle, 386 .

Malt sugar, 81 ; see also . Maltose.

Maltase, 246, 251.

Maltose, 81 .

action of reversible enzyme on, 39.

Mammary glands, 703.

fat in, 705 .

innervation of, 704 .

morphological changes in, 704 .

Mannite, so.

Mannose, so.

Manometer, clastic, 9, Fig. 5.

in determination of blood pressure, 202.

mercury, 8, Fig. 3.

Marginal gyrus, $63 t$.

Mariotte's experiment, 515, 516, Fig. 212.

Marrow, red, of bones, 150.

Marsh gas, 295.

Mastication, 278.

Maturity, period of, 706 .

sexual, 692, 696.

Maxwell's disks, 542.

Meals, S3.

Ieat as article of food, 145; see also Protein.

Mechanieal stimulation, 56 .

of cortex, 633 .

of nerves, 418 .

Medulla oblongata, or bulb, 600, 61)2.

cardiac centers in, 195.

functions controlled by; 604 .

importance of, 604 .

nuclei of cranial nerves in, 603, Fig. 269.

respiratory center in, 325.

transwerse section of, 602, Fig. 268.

various centers in, 602, 603, Fig. 269.

vasomotor centers in, 238.

vomiting center in, 286.

Meissner's plexus, 2ss, 687.

Membrane, animal, osmotic properties of, 32, 352.

basilar, of organ of Corti, 499, 500, Fig. 199. of cells in general, 16.

of plant cells, 21, Fig. 16.

semipermeable, 31.

Memory, seat of, 671 .

Memory pictures, $660,663,665,669,671$.

Menstruation, cause of, 697 .

cosmic phenomena and, 62 .

deseription of, 696 .

physiological significance of, 697 .

Mental work, influence of, on fatigue, $4 \pm 6,676$.

Mesencephalon, 600, 613. 
Mesncarpus scalaris, 54, Fig. 31.

Meoporphrin, 152.

Mc $=0 x a] i c$ acid, 377.

Metabolic products, St. influence of, on organs, 356 . removal of, by massage, 445.

Metabolism after extirpation of pancreas, 363 . of thyroid, 360 . after feerling thyroid extract, 361 .

Vetabolism, definition of, 83 . effect of castration on, $35 \pi, 35 \mathrm{~s}$. experiment in, example of, 91, 92. in different organs, 402. in fasting, 9.5 .

influener of age on, 119, 120. of fool on, ys. of muscular work on, 110. of size of boly on, 117. of temperature on, 114.

intermediary, 373, 376, 377.

in the young, 118, 119.

methork of, 83 ser.

of albumoses, 108.

rí alcuhol, 110.

of a-paragin, 110 .

of carbolyydrates, 105.

of cellulose, 110.

of fat, 104.

of fatty acicls, 109.

of gelatin, 109.

of gelatin-forming substances, 109.

of peptones, $10 \mathrm{~s}$.

of proteid, 102.

theories of, 134 seq.

Mretacusein, 252.

Metallic taste, 484.

Mctathalanus, 600 .

Metencephalon, 600 .

Methamoglobin, 151.

Methyl-glyou-cyanamid, 3\$2.

Methy-iudol-amino-acetic acisl, 71.

Methyl mercaptan, 295.

Micturation, 390. conter for, 393, 588.

Midbrain, 600$), 613$.

importance of, in fishes, 619.

in turtles, 621 .

Mirllle ear, 494.

llilk, 7()() .

es:agulation of, 250 .

compusition of, 701, 703.

effect of, on propertics of gastric juice, 26 i).

secretion of, 703.

influence of nerves on, 704 .

meclianism of, 70.4 .

yuantity of, T(l).

Milk sugar, 81 ; see also Lactose.

origin of, 7 ().i.
Millon's reaction, 72 .

Mind blindness, 669,670 .

Mind, mechanies of, 670,673 .

Mineral substances, see Inorganic substances. absorption of, $139,30 \%$.

in young animals and milk, 702 .

required by animals, 25, 26.

by plants, 24.

Minimal air, 320).

Uinimal requirements of food, 95. of proteid, 124.

Minimal stimulus, 51 .

Mitral valve, 165.

Moclalities of sensation, 4.53.

Moderate worker, nutritive requirements of, 1.12 .

Molisch's reaction, 73 .

Monamino acids, 70 .

IIonokow's bundle in the cord, 593, 596.

Monosaccharicles, so.

percentage eomposition of, 82 .

Moral significance of cerebral proces-es, 672 .

Morphinism, 30.

Morphological changes during activity of gastric glanils, 26s.

of hepato-pancreas of isopod, 244, Fig. 99.

of intestinal glanis, 27\%, Fig. 111.

of mammary glanils, 704 .

of nerve cells, 574 .

of pancreas, 272, Fig. 109.

of retina, 537, 53s, Fig. 232.

of salivary glands, 260, Fig. 100; 261, Fig. 101.

Motility, forms of, 42.

Motor aphasia, 663.

Motor cortical areas, 633; see also Cerebral localization.

action on, by other areas, $660,661$.

connection of, with motor nerves, 594, Fig. $266 ; 647$.

development of, 648.

extirpation of, in monkey, 644 .

finer inovements dependent on, 641.

in human brain, 645.

psycho-physical signifieance of, 6.59.

stimulation of, 601, 631, 632, 633.

direet and crosised effects of, 640 .

suppression of, in dogs, 643.

recovery of functions after, 646 .

Motor nerves, 5 fit.

Motor response in Paramucium, 54, lig. 32.

Motor sensations, 469 .

areas of, in cortex, 652 .

conlucting tracts of, from cortex to cord, 647 . in the corrl, 596 .

physiologieal significance of, 472 .

Motor sense, $\$ 62$.

Motor spinal nerves, distribution of, 682, 6,55.

Notor zone of cortex, 634 . 
Mouth, digestion in, 290.

rections of floor of, 2\$1, Fig. 112.

Mouth eavity, closure of, in sucking, 279.

IIorements, actire, perception of, 471.

asiociated, 473.

coorrlination of, 473 .

passive, perception of, 469 .

voluntary, 449 .

how acquired, 450 .

regulation of, 472 .

Morements of abdominal organs in respiration, 316 , Fig. 12.5.

of alimentary eatual, $27 \mathrm{~S}$.

of diaphragm, 316, Fig. 125.

of elementary organisms, 42.

of eyes, 549 ; see Eye morements.

of intestine, 286.

of larrnx, in deglutition, 281.

in respiration, 312.

in rocalization, 503 .

of cesophagus, 279.

of ribs, 314 .

of stomach, 283 .

of voeal cords, in respiration, 312, 504, Fig. 202.

in vocalization, 503, Figs. 200, 201; 505.

Muscle, cross-striated, functions of, 410 .

absolute power of, $43 \mathrm{~S}$.

action currents in, $48,431$.

afferent nerves of, reflexes through, 470.

blood supp!y to, 241), 449.

central inmervation of, 440 .

chemical changes in, due to activity, 434.

chenistry of, 413 .

curves of, $7,414,415,417$; see also under

Curres.

degeneration of, $44 \mathrm{~s}$.

effect of veratrin on, 437, Fig. 175.

elasticity of, 412, Fig. 150; 413, Fig. 152.

electrical phenomena of, 47,431 .

fatigue of, 441 seq.

general properties of, 410 .

glycogen in, $81,125,374,413$.

heat formation in, $402,404,439$.

latent period of, 415 , Fig. $154 ; 416$.

mechanical work of, 435, Fig. 172 .

musical tone produced by contraction of, 434.

permeability of, to solutions, 34 .

polar law of excitation of, 428 .

Pflüger's law of contraction of, 423 .

relation of, to other organs, $44 \mathrm{~s}$.

red and white, comparison of, 416 .

rigor of, 447 .

signs of activity in, 431.

simple contraction of, 415 ; see also Contraction.

stimulation of, 414 .

summation in, $415,429$.
Muscle, cross-striated, tetanus of, 429, Fig. 166; 430 , Fig. 167 ; 433 ; see also Trtanus.

tonus of, demonstration of, $5 \mathbf{s} \mathbf{1}$.

variations in tension of, 414 , Fig. 153.

voluntary contractions of, 430 .

work done by single contraction of, 435.

work done in tetanus of, 439 .

smooth, general physiology of, $\mathbf{4 7 7}$.

Muscles, sce under individual names.

skeletal, afferent nerves of, 470 .

motor nerves of, 682 .

tonus of affecterl by removal of semicircular canals, 477 .

Muscular sense, 469 ; see also Motor seneations. cortical area of, 652 .

Muscular work, $\mathrm{CO}_{2}$ production in, 112.

central nervous system and, $44 \mathrm{~s}$.

destruction of nonnitrogenous substances in, 112.

of proteid in, 111.

effect of, on circulation, 449 .

on digestion in stomach, 293.

on formation of living substance, 63 .

on heart beat, 197 .

on respiration, 31 S.

in tetanus, 439.

maximum capacity for, in man, 447 .

metabolism in, 110.

ratio of, to heat production in muscles, 441).

regulation of, by muscles themselves, 437 , 439.

Musical agraphia, 66.5.

Musical aphasia, 66.5.

Musical faculties, 665.

Musical tone, 489.

Mucin, 245.

composition of, 82 .

in bile, 2.53 .

in saliva, 245.

Mucins, 74 .

Mueoids, 74 .

Mucous glands, 245 .

morphological changes in, 262, Fig. 102.

Myelencephalon, 600, 602 .

Myelogenetic areas, of cerebrum, 666, Fig. $297 ; 667$, Fig. 298.

Mylohyoid muscles, importance of, in deglutition, 280.

Myoehrome, 114 .

Myogen, 113.

Ifyogram, 8 .

Myopia, 519, Fig. 215, 520.

Myosin, 413.

Myosinogen, 413.

Myristinic acid, 701.

Myxcedema, 3.5.

Myxoedenatous woman, 359, Fig. 137.

Myxomycetes, 27. 
$\mathrm{N}: \mathrm{C}$ ratio in freces, 90.

in proteid, 92.

in urine, 90 .

Nareotices, pluysiological effect of, 6.5 .

Nasal breathing eompared with mouth breathintr, 323.

Nasal cavity, closed in swallowing, 281. closed in vomiting, 286 .

Sative proteicls, 73.

Sature, limits of knowledge of, 452 .

Vegative pressure in thorax, 310.

Vorgative variation, 433.

Nerve abluesns, etc., ses under individual names.

Nerve cells, central functions of, 566, 582 . dependence of, on blood supply, 572 . mode of reaction of, 5it).

morphological changes 11,574 .

nutritive functions of, 567 .

physiological stimuli of, 569 .

physiology of, $559 \mathrm{scc}$.

regeneration and reproluction of, 574 .

rlythm of discharge of, 572 .

Nerve centers, fatigue of, $676,67 \mathrm{~s}$. in spinal eord, is.5; see also sipinal cord.

in medulla oblong:2ta, 603; Fig. 269; see also under individual names.

Nerve endings, of pain nerves, $467,46 \mathrm{~S}$.

of pressure nerves, $461,46 \mathrm{~s}$.

of temperature scnse, 461,469 .

Nerve fibers, autochthonous, 575.

autonomic, 6is6.

degeneration in, 567 .

origin of, from nerve cells, 559 .

plyowiological differences between afferent andl cfferent, joij.

pre-ganglionic and post-ganglionic, $656,687$. regeneration of, 564 .

Nerve fibrils as conducting elements, j60, 5S.5.

Nerve inpulse, rate of transmission of, in motor nerves of lower animals, $417, \mathrm{Fig}$. 1isi.).

in motor nerves of man, 418.

in spinal cord, jS9.

Nerve prucesses, 5.59.

Nerves, aceelerator, 191, 6ss.

action currents in, 4S, 431 .

afferent, 56.t, ij6.j.

alterations of excitability in, 425.

ancleetrotouls in, 425; Fig. 162.

("arbon dioxide" formend in, 134.

earrliac, 188 sere.

catelectrotonus in, $424, \mathrm{Fig}$. 161 .

classification of, accorcling to function, 564.

depresiars, of heart, 1!)3, 6s1.

efferent, 564, 565.

electrical exeitation of, 418 .

general law of, 420 ).

electrolymis in, 434.
Nerves, fatigue of, 442,413 .

general propertics of, 410,411 .

heat proluction in, $\$ 102$.

inhibitory, 188.

intereostal, 324.

isolated conduction in, 411.

mechanical stimulation of, 41 s.

motor, of blatiler, 393.

of stomach, 284, Fig. 114: sce also Stomach.

of throat, 2S2, Fig. 113.

polar law of excitation of, 424.

Pflüger's law of contraction of, 59, 123.

promoting, 192.

pulmonary, 6S1.

rate of transmission in, 417,418 .

signs of activity in, 431.

special, physiology of, 680 .

specific responsc of, 411 .

spinal, 682.

stimulation of, by induction currents, 426 , Jig. 163.

in arm of man, 427, Fig. 164.

sympathetic, 685 .

trophic, 569 .

vasoconstrictor, $231,582,6 \$ 1,65.5$.

vasodilator, 233, 234, 449, 691, 6.8.5.

Nervi erigentes, 393, 6S5, 693, 694, 700.

Nervous system, 31 .

central, 559.

effect of different poisons on, 574

elemental structure of, summary, 561 .

influence of thyroid on, 360.

of testes, $35 \%$.

segmentation of, 575 .

simpathetic or antonomic, 6sf.

Network, intracellular, of nerve cells, 560 , Fig. 252.

pericellular, of Golgr, .561, lig. 253.

Jeuro-fibrils, $560(0,58$.$) .$

Neuron theory, 5.59 .

Neurons, $5 \overline{5} 9$.

Neuropile, 560, 561.

Newborn, periud of, 706 . weight of, 706,707 .

Nicotin, use of, in tracing ganglionic connections, 5\$2.

in tracing varus fibers, 190, 191.

Nitric-oxide liamoglobin, 152.

Vitrogen. absorption of, hy the bluod, 33.j.

by plant<, 23, 24 .

channels of exeretion of, S!, (30).

deternination of, in foul and excreta, $\$ 3, \mathrm{~S} 4$.

fixed by 13acteria, 24.

in hlowel, 33\%.

in digestive protluets of proteid, 295.

in expired air, \$?.

in f:eces, 90 .

in parotid gland, 259.

in swcat, 89 . 
Nitrogen in urine, 89.

Nitrogen excetion, \$9, no.

cliurnal variations of, 102 , Fig. 44.

in starvation, $100,101$.

proportional to $\mathrm{N}$ absorbed, 101.

Jitrogenous equilibrium, 91, 120, 121, 122. minimum proteid for, 103.

on various quantities of protcid, 100.

Nitrogenous substances in the body, 68 .

Codal points of optical system, 511, Fig. 209. of schematic eye, 513, Fig. 210.

Nonnitrogenous foodstuffs, see Carbohydrates and $F$ ats.

destruction of, in muscular work, 112.

Nonnitrogenous substances in the body, 79 .

Nonnucleated cells, 17 .

Nubecula in urise, 380 .

Nuclei of cranial nerves, 603, Fig. 269.

Nucleic acid, digestion of, 25.5. percentage composition of, 82 .

入uclein bases, 76 ; see also Purin bases.

Nucleins, $76,351,372$.

digestion of, 252, 255 .

percentage composition of, 82 .

Nucleo-albumins, 75 .

Nucleo-histon, percentage composition of, \$2.

Nucleo-proteids, 77.

Nucleus, agency $c f$, in activation of oxygen, 19, note.

form and size of, 16.

importance of, 17,18 .

number in cells, 16.

of cell, 16 .

of oruun, 695 .

reciprocal relations of, with protoplasm, 17.

red, of tegmentum, 593.

Nucleus reticularis tegmenti, 603.

Nutrition, see Food and Nutritive requirements. definition of, $\$ 3$, note, 137 .

of the brain, 676 .

of the heart, 180 .

of the young, 143.

physiology of, 137.

Nintritive influence of cerebral cortex, 650 . of nerve cells, $567,568,582,584$.

of spinal ganglia, 584 .

Nutritive requirements of adult males, 140 . of persons of different ages, 144.

Occipital convolutions, 639, Fig. 289; 657.

()etave, 490.

Oculo-motor nerve, $6 \$ 8$.

accommodation and, 534 .

nuclei of, 535, Fig. 230; 615, Fig. 272;616, Fig. 273.

pupil and, 52s.

Odors, classification of, $48 \mathrm{~s}$.

theories of transmission of, 486,487 .

Esophageal fistula, 263.
Esophagus, innervation of, $2 \$ 1$.

movements of, in swallowing, 280.

Ohm's law for analy'sis of sound, 493.

Oil and coagulation of blood, 159 .

Old age, netabolism in, 120 .

periorl of, 706 .

Oleic acid, 296.

Olein, 79, 701 .

Olfactometer, 487, Fig. 192.

Olfactory areas in the cortex, 653 .

Olfactory cells, 487 .

Olfactory epithelium, 486.

Olfactory lobe, $600,619$.

Olfactory nerves, action of, on respiration, 330 . specific, of smell, $4 \mathrm{SS}$.

Opalina ranarum, 61, Fig. 35.

Opening contraction, 420, 423.

Opening period of parturition, 698 .

Operative interference, $\mathbf{5}$.

Optic cortex, activity of, 660 .

connections of, 660, 662, Fig. $296 ; 663$.

efferent fibers from, 657 .

Optic lobes, Figs. 274, 275, 276, 277, 27s.

equivalent to corpora quadrigemina, 613;

which also see.

Optic nerve, 330; 535, Fig. 230; 656, Fig. 295; 657,680 .

efferent fibers in, 515, Fig. 211.

reflex effect of, on rexpiration, 330 .

Optic thalamus, 600 .

effect of lesions in, 617.

substitution of functions in, 617 .

Optic tracts, schematic representation of, 535 . Fig. 230; 656, Fig. 29.5.

Optical axis, 513, Fig. 210; 525.

Optical constants of the eye, 508 .

Optical defects of the eye, 520.

Optical system, nodal points of, defined, 511 . Fig. 200.

of the eye, 509,510 .

Optical zone of the cornea, 522 .

Optogram, 537.

Orgau of Corti, 499, 500, Fig. 199.

Organ system, definition of, 30 .

Organic foodstuffs, $\$ 3$.

Organic sensations, 469.

Organs, coöperation of, 30 .

influence of, on one another, 1, 355.

surviving, 6 .

Orientation, importance of otolith sacs for, 473,481 .

Oscillaria, 29.

Osmosis, 31.

Osmotic phenomena, significance of, for absorption, 35, 301, 353.

for different organs and tissues, $34,355$.

for elementary organisms, 33, 34 .

for excretion, 41 .

for lymph formation, 349 . 
Osmotic plienomena, significance of, for production of urine, $38 \%$.

O-motic pressure, definition of, 31 .

() motic tension in animal cells, 35 . in plant cells, 33.

()-sein, 7s.

(1)-icles of middle ear, 495 .

()tolith, 481 .

()tolith sacs, functions of, 4 S1.

(Naries, 695.). interual secretion of, 35 \$.

Overtones, definition of, 491, 492, Fig. 194. in human voice, 505 .

() viduct, 69.5 .

()ovitellin, in.

Wrulation, 696 .

Oxalic acid, $41,376,377,383$.

Oxiclation, 27; see also Combustion.

Oxidative processes in cells, 39.

()xyacich, aromatic. 37s.

()xyben\%uric acisl, 378 .

(X)hutyric acid, 376, 354.

()yethyl-t rimethyl-ammonium lıyclroxide, is.

1) xygen, absence of, effect on ('ggs of, 26 . brhavior of frogs in, 27. suitability of, for certain Bacteria, 28. absorption of, by blond, 336, 337, Fig. 131. total in man, 346 .

activation of, 19 , note.

amount of, absorbed under different circumstances, 346 .

consumed by elenientary organisms, 27. coefficient of alsosprtion of, 336 . combination of, in blood, 336.

determination of, in bloud, 334, Fig. 130; 335 .

in metabolisin experiments, $86, \mathrm{SS}$.

distribution of, in blond, 34 ().

importance of, for divelopment, 26, 27.

increased consumption of, in fatigue, 446 . partial pressure of, in alvenar air, 336. percentage of, in arterial and venous blood, 339.

in expirert air, 343 .

in inspired air, 342 .

stored in loose compoumds, 27.

tension of, in howd, 341 .

in lympls, 34 .

()xylurmalubin, 150, 151 .

absorption spectrum of, 1:1, Fig. 47.

Oxymonamino acikl; 70 .

Uxypheny-amino-propionic acid, 71.

Oxyproteic acil, $373,3 \$ 2$.

Oxyprinidin, 76 .

()xypyroliclin-carboxylic acid, 72.

Pain, 465.

after liemilesion of the cord, 597 .

area for, in cortex, 6.52 .
Pain, end organs of, 468.

nervis, (?) 467 .

physiological cause of, 466 .

tract for, in the cord, 597 .

Pain points in the skin, $46 \overline{7}$.

Pains, labor, 69s, Fig. 302.

Palrmoncles, 60, Fig. 34.

Pallium of the brain, 600 .

Palmitic acirl, 79 .

Palmitin, 79, 701 .

Pancreatic diabetes, 127, 125, 362. 37.).

Pancreatic fistula, 243, 251.

Pancreatic juice, 2.51.

action of, on carbohydrates, $251,297$.

oll fats, 253, 29.5.

on proteids, 252, 294.

enzymes in, 251, 271, Fig. 108.

influence of bile on, 2.51, 294.

of food on, 270, Fig. 107; 271, Fig. 108.

properties of, 251.

secretion of, 269.

daily conrse of, 270, Figs. 106, 107.

nervous control of, 26!).

Pancreas, effects of extirpation of $127,362,375$.

internal secretion of, 362 .

morphological changes in, 272, Fig. 109.

specifie excitants of, 270,271 .

Papillary mu-cles, action of, 166.

Paracasein, 250.

Paracentral lobule, 63S, 639, Fig. 290; 652.

Paracresol, 379.

Paracresol-sulphuric acid, 379.

Paralactic acid, 15.5.

Paralysis, definition of, $50,6.5$.

following partial destruction of the cord, 596. following removal of motor cortex, 644 .

Paramarcium, chemotaxis of, 5.5.

directive influences on, 55,59 , note.

electrical stimulation of, 59.

geotaxis of, 56 .

motor response of, 55, Fig. 32.

starvation of, $2 S$.

thermotaxis of, 59 .

thigmotaxis of, 56 .

Paramyosinogen, 413.

Paranuclein, 75 .

Para-pheny-amituo-propionic acid, 71.

Parenchyma cells: of root cortex, 21, Fig. 16.

Parictal cells, 26\%.

secretion capillaries of, 267, Fig. 10.5.

Parictal convolutions, see Central coniolutions.

Parietal lobes, 624, Fig. 2\$0; 6it.5.

Parotid glands, innervation of, 25i, $25 \mathrm{~S}$. morphological rhanges in, 200, Fig. 100; 261, Fig. 101.

Paroxy-benzuric acisl, 3-s.

Paroxy-phuny-areetic acil, 37s.

Paroxy-pheny-propionie acid, 37s.

Pars manillarıs lipothalami, 600. 
Pars optica hypothalami, 600.

Partial pressire of gases, 334.

Parturition, 691, 697.

Passive movements, perception of, 469.

Pathogenic bacteria, ingestion of, by leucocytes, 37.

Pathology, relation of, to physiologr, 4 .

Pectorales as muscles of respiration, 316.

Pcduncles of the cerebellum, 593, 612.

Pclomyxa, 57.

Pendulum hydrometric, 210.

Penchulum morements of the intestine, 287.

Penis, 692, 693.

Penta-methyl-endiamin, 249.

Pentoses, 81.

Pepsin, formation of, 267.

properties of, $24 \mathrm{~S}$.

Pepsin-hydrochloric aciel, action of, 291.

Pepsinogen, 248.

Peptoids, 249.

Peptones, 75, 249, 255, 351.

food value of, $10 \mathrm{~S}$.

intestinal juice and, 255.

Peptozymes, 250.

Pericardium, rôle of, in action of heart, $17 \%$.

Perilymph, 495.

Period of ejection of the heart, 171 .

of relaxation of muscular contraction, 416 .

of rising tension of the heart, 171.

of shortening of muscular contraction, 416 . refractory, of heart, 183.

of nerves, 429.

of nerve cells, 572 .

Peripheral gauglia, 5\$3, 584, Figs. 258, 259.

Periphery of retina, adaptation of, to light and dark, $\mathbf{5 4 0 .}$

color vision with, 546 .

vision with, 514 .

Periplencta, 56.

Peristalsis, 28s.

Permeability of blood corpuscles, 33, 34 .

of cross-striated muscles, 34 .

of living and dead membranes, 34 .

Perspiration, see Swcat.

insensible, 394, 397.

Pflüger's law, 423.

Phagocytosis, 37,54 .

Pharynx, action of, in swallowing, 280.

Phenol, 295, 378, 379.

Phenolplithalein, $147,379$.

Phenol-sulphuric acid, 379.

Phenyl-acetic acid, 378 .

Phenylalanin, 71, 72, 249.

Phenyl-propionic acid, 378.

Phlebin, 150.

Phloridzin, 127, 374, note, 375.

Pholas, 45.

Phospho-carnic acid, 413.

Phosphorescence, 45.
Phosphorus, absorption of, 132.

excretion of, 132.

in ioclothyrin, 362.

in proteids, 75, 76, 82 .

Phosphorus poisoning, 129.

Photography, registration by, 13.

Phototaxis, 57.

Phrenic nerve, 324, 331.

Phrenology, 630.

Phylloporphyrin, 152.

Physical methods of investigation, 4.

Physiological salt solution, 53.

Physiology, general and special, 15.

province of, 2.

Pigment granules, 22.

Pigments in the bile, 253.

in the blood, 150.

in the eye, 527,537 .

in muscle, 414 .

in urine, 383.

Pilocarpine and formation of urine, 389.

Pilomotor fibers, 6S7, $6 \mathrm{SS}$.

connection of, with ganglion cells, 5\$2.

Pineal body, 600, 613.

Pitch of sound, 4 S9.

of human voice, how caused, 505.

Pituitary body, internal secretion of, 367 .

Placenta, 69S.

Plasma, chemical constitution of, $15 \pm$.

Plasmolysis, 33 .

Plastic foodstuffs, 111.

Platelets of the blood, 153.

Plethysmograph, 211, Fig. 83.

Plethysmographic curve, 212, Fig. 84.

in slecp, 67\%, Fig. 299.

Plexus, cardiac, 191, Fig. 67.

hypogastric, 392, Fig. 145; 393, 694.

myentericus, $2 \mathrm{SS}$.

of Auerbach, 284, Fig. 114; 288, 687.

of Meissner, $288,687$.

vesical, 392 , Fig. 145.

Pneumograplic curve, 313, Fig. 121.

Poikitothermous animals, 46, 442.

Poisons, pliysiological significance of certain, 574.

Poisonous constituents in expired air, 344.

Poisseuille's formula, 222.

Polar law of excitation, 424.

"Polar failure" of excitation, 428.

Polarizing current, 425, 434.

Polysaccharides, chemical constitution of, 82 . properties of, 81 .

Polystomella, 17, Fig. 14.

Pons, 600, 612.

Portal circulation, 137, 162.

Portal vein, 162; see also Eck fistula.

Position of the body, influence of, un flow of hlood, 226, Figs. 93, 94; 227.

perception of, 469,481 . 
Posterior columns of the cord, 562, Fig. 254.

P'osterior horn of the cord. 563.

lasterior roots of the spinal nerves, 563, 564, jfi6.

Postganglionic fibers, $687,6 \times 5,689$.

Potassium salts, effect of, on heart, 25. on smooth muscle, 2.5.

importance of, in plants, 24.

toxicity of urine due to, 351 .

l'otential, electrical differences of, $47,41 \mathrm{~s}$.

l'otential mergy of foolstuffs, 92 ; sec also Energy.

Precipitins in the blool, 156.

Preganglicnic fibers, 6\$6, 659 .

Pregnamey, 697.

l're-lyopia, 530.

Prenure, abrlominal, 299, 699.

in the montl cavity, 279, 2 so.

in the respiratory passiges, 321.

intraceardial, 169, Fig. 56;170, Fig. 57; 171,

Fig. $58 ; 173$, Fig. 60 .

intracranial, 678 .

intrathoracic, 228, 310 .

intrauterine, 698, Fig. 302; 699, Fig. 303.

of the bloosl, see Bloud pressure.

osmotic, 31 ; see also Osmotic phenomena.

Pressure puints or spots in the skin, 459, lig. $152 ; 462$.

Pressure sellsations, $459,461$.

application of W'eber's law to, 456 .

local sign of, 463.

Pressuro senke, 461.

are: for, in cortex, 652.

end urgans of, $+6 \mathrm{~S}$.

nerves of, 461 .

tract for, in the cord, 597.

Primary folliele, 69.5.

Primorlial myelogenetic regions of the cortex, 6iti.

Primordial ova, 69.5 .

J'rimordia! sleath, 3.3.

Products of metabolism, see Decomposition products.

Projection of sensations in general to the external world, 454.

of risual sensations to the cxternal world, 552.

Projection fibers of the brain, 6fi.

Promoting nerves of the heart, 192.

l'rosinemplialon, 600 .

Prostate, 6!)1.

P'osthetic group in compound proteids, 75 .

Protagoll, 79.

Protamins, 70, 77.

Protection, against loss of heat, $\mathbf{1 0 4}$.

insured by blood, $15 \%$.

means of, for lungs, $323,324$.

Proteil, absorption of, 30.5 .

anomet of. in laily ration, $1+2$.
Proteicl, chemistry of, see Proteids. circulating, 134 .

decomposition of, in body, 369 .

determination of, in foor, $\$ 3,84$.

importance of, in metabolism, 98 .

in urine, 384.

metabolism of, 99 .

in fasting, 97 .

in muscular activity, 112.

influence of body mass on, 117.

influcnce of, on total metabolism, 102.

proportional (1) proteicl ingested, 99.

with carbohylrates, 10.5.

with fats, 114.

playisiologieal heat value of, 93.

putrefaction of, in intestine, $37 \mathrm{~s}$.

relation of, to living substance, 20.

requirements, different views on, 142.

retention, 120 ).

in growing body, 123.

source of fat in the body, 129, 130.

source of glycogen, 127.

synthesis of, in animals, 25 .

in plants, 23.

tiscue, 134.

utilization of, 135.

Proteicls, action of digestive fluids on, 245, 252, 25.).

as con-tituents of dead protoplasm, 20.

atomic groups in, 70 .

carbohyclrate groups in, 71 .

cluemical constitution of, 69, 70, 82 .

colur reactions for, 72 .

compound, 75 .

conjugated, 75 .

crystallizerl, 68, 69, Fig. 38.

formation of, in plauts, 23.

morlified, 65 .

native, 69.

of blood, 154 .

of milk, 701,703 .

origin of, 23.

percentage composition of, 82 .

physiology of, see uncler Proteid.

phosiphorus-containing, 75,76 .

precipitants of, 69.

properties of, 6.S.

s:ilterl out, 69.

simple, 75 .

solubility of, 6s, 69 .

Proteolytic enzyme, 243.

in intestine, 25.5 .

in pancreas, 2.52.

in stomach, 248.

Proteoses, 250.

Protoalhumose, foul value of, ios.

Protoplasm, appearance of, 29.

clumieal constitution of, 20.

chemical nature of, $6 \mathrm{~S}$. 
Protoplasm, chemical and physical properties of, 19.

decomposition products of, $68,70, .249$.

differentiations of, 16 .

fornation of, in animals, 25.

in plants, 23.

inclosures in, 21, 22.

morphology of, 20.

notility of, 42.

osmotic properties of, 31 seq.

power of, to store oxygen, 27.

relation of, to nucleus, 17 .

state of aggregation of, 19.

Protoplasmic processes, 42.

of nerve cells, 559 .

Pseudoglobulin, 154.

Pseudohremoglobin, 152.

Pseudonuclein, 75.

Pseudoporlia, 36, 42.

of Amoba, 35, Fig. 20; 36, Fig. 21; $42,43$.

of Gromia oviformis, 35, Fig. 19.

of Polystomella venusta, 17, Fig. 14.

of Thalassicola nucleota, 18, Fig. 15.

Psychical activities, organs of, 666.

substratum of, 629 .

Psychical disturbances after extirpation of thyroid, 361.

Psychical influence over reflcxes, 577, 579.

Psychology of Gall, 629, 630.

Psycho-physical erents, time required by, 673 .

Psycho-physical functions of the cerebrum, 658.

Pterygoid muscles in mastication, 278.

Ptyalin, 245, 246.

Puberty, in the male, 692. in the female, 697 .

influence of, on growth, 708, 709, 710

Pulmonary arteries, 161.

pressure in, 228.

Pulmonary circulation, 227 seq.

Pulse, arterial, 212.

venous, 234.

Pulse curve, 12, Fig. 11; 216, Fig. S8.

Pulse rate, see Heart beat.

as affected by food, etc., 197.

at different ages, 197, Fig. 71.

Pulse volume, 204.

dependence of, on flow from great veins, 184

Pupil, constriction of, 528.

by cortical stimulation, 658 .

center for, 529 .

dilatation of, 528 .

by cortical stimulation, 658 .

center for, 529 .

Purin bases, 76, 255, 372, 382.

Purkinje's figure, 516 .

Putrefaction in the intestine, 297, 298, 378.

Putrefactive prolucts, 29.5, 378.

Putrescin, $2+3$
Pyloric fistula, 267.

Pyloric glands, 266.

Pylorus, innervation of, 284, Fig. 114.

movements of, 283.

Pyramidal cells of the cortex, 634, Fig. 294.

Pyramidal tracts in the cord, 593, 595, 596, 647,648 .

Pyrimiclin, 76.

Pyrroliclin nucleus, 71.

Pyrrolidin-carboxylic acid, 71, 72, 249.

Qualitative relations between stimulus and sensation, 451.

Quantitative relations between stimulus and sensation, 45.5 .

Quotient, respiratory, 105, 343.

Radiation of heat, 403.

Radium, 58.

Rami communicantes, 687,689

Ration, Voit's, 142.

Ration for woman, 143 .

Reaction time, 673 .

as effected by fatigue, etc., 674 .

discrimination, 676 .

muscular, 675 .

simple, 673 .

to different sensory stimuli, 674 .

Receptaculum cliyli, 349 .

Recovery after fatigue, 66 . of muscle, 445,446 .

of nerve, 443 .

of visual organ, 539 .

Recovery of muscular functions after destruc- tion of cortex, 646 .

Rectum, innervation of, 289. reflex induced from, 299.

Recurrent fibers, 584.

Recurrent sensibility, 566.

Red blindness, 546 .

Red blood corpuscles, see under Blood.

Red-green blindness, 547 .

Reduced eye, 512.

Reducing substance in urine, 383.

Referred pains, 689.

Reflection of pulse waves, 214, 218.

Reflex, causing cjaculation, 693.

contractions, 571, Fig. 256.

definition of, 411,570 .

fall of blood pressure, 237, Fig. 98.

origin of tonus, 581 .

processes, 575 .

responses to different stimuli, 580 .

rise of blood pressure, 236, Fig. 97.

stimulation of nerve cells, 570,571 .

touch, 660.

Reflexes, axon, 5\$4, Fig. 258.

augmentation of, 579 .

facilitation of, 579 . 
Reflexes, flexor and extensor, 587.

from heart, 194.

general features of, 576 .

inhibition of, 577 .

locomotor, 617 .

purposive, 577, 586.

psychical influence over, 577.

reënforcement of, 579 .

regulative, 576 .

respiratory, $3: 27$.

segmental, 576 .

suppression of, 578,579 .

tendert, 587.

through sympathetie ganglia, 5\$3.

to different stimuli, 58).

to beart, 193.

to pancreas, 270 .

to salivary glanels, 260.

to stomach. 263.

vasomotor, 235.

Refraction, angle of, 509.

in eye, 510 .

of light, 5os.

static, in ere, $\$ 19$.

Refractory period of heart, 183.

of nerve cells, 572.

of nerves, 42!).

of skeletal muscle, 429 .

Regeneration, (j.t.

determining factor in, 64 , note.

in sympathetic system, 6\$9.

of kislney tisisue, 65.

of liver tisisue', 6i.j.

of nerve tissue, 5it.

Registers of voice, 504.

Rogistration, see (irnphic method.

by air-transmision, 11.

by photograply. 13.

liegulation of bluod pressure, 194, 219.

of heart activity, 186, 19.4.

of respiration by vagi, 327 .

of temperature in horly, 406 .

Regurgitation of bloml, $166,16 \%$.

Remnin, 250.

Reproduction, physiology of, figl. pust-embryonie, of nerve cells, 574 .

leverve air, 320 ).

Resiclual air, 320).

Resistaner in arteries, 205.

to conduetion in nerves, $411,425,426$.

(1) electric current, $41 \mathrm{~s}, \mathrm{Fig} .156$.

(1) fatigue of nerves, 442 .

Resonanee, 492.

Resonanee theory of hearing musical sounds, 498.

Resonance tone of external aulitory meatus, 494.

objections to, 501 .

Resonator of Ilelmholtz, 493, Fig. 195.
Resonators of cochlea, $49 \mathrm{~S}$.

Respiration, action of various efferent nerves on, 330 .

artificial, 5, 231, 325.

effeet of suction in thorax on work of, 312 .

exchange of air in lungs in, 319.

heat loss and, 403.

influence of higher brain centers on, 329 .

innervation of, $3: 3$.

movements of, 310 .

muscular work and, $31 \mathrm{~s}$.

periodie variations in, 333 .

regulation of, by vagi, 327 .

residual air, reserve air, etc., of, 320 .

types of, 31s, Fig. 126; 333.

Respiration apparatus, of Atwater and Benedict, Sf.

of Pettenkoffer, 86 .

of Pettenkoffer and Voit, S7, Fig. 41 ; SS.

of Sondén and Tigerstedt, SS, Fig. 42 ; 89.

Respiration calorimeter, 86, Fig. 40.

Respiratory centur, 325.

normal stimulation of, 331 .

resistance of, to asphyxiation, 573, Fig. 257.

Respiratory centers, spinal, 325, 326.

Respiratory curve of rubbit, 314 , Fig. 123; 32s, Fig. 129.

Respiratory exchange of gases, 340 .

amount of, 34.5 .

Respiratory fooks, 111.

Respiratory movements, 310 .

concomitant, 321.

effeet of, on blood pressure, 227 .

on heart. 176.

force of, 322 .

innervation of, 323.

number of, 31s, 319, Fig. 127.

registration of, 312 .

special forms of, 321 .

Respiratory nerves, 324 .

le-piratory pasiages, $310,323$.

ciliated epithelium in, 323.

pressure variations in, 321.

Respiratory proflucts, $89,342$.

Rexpiratory quotiont, $10.5,343$.

we of, in metabolism experiments, 10.5.

values of, under different circumstances, 343.

Respiratory reflexes, 327.

Respiratory soumds, 3:22.

Respiratory system, 31 .

Respiratory variations of blood pressure, 2:29, Fig. 95; 230, Fig. 96.

Restitution after lesions of cortex, 646 .

Retention of proteid, 120.

in growing body, 123.

Reticulin, TS.

percentage eomposition of, $\$ 2$.

Reticulum of the neuropile, $560,561,585$. 
Retina, action eurrent in, 537. adaptation of, 540 . centrifugal fibers to, 515, Fig. 211. excitation of, 536 seq. fatiguc and recotery of, 539 .

histological structure of, 515, Fig. 211. images upon, 513 .

light-perceiving layer of, $\mathbf{5 1 4}$.

morphological changes produced in, by light, 537, 538, Fig. 232.

relation of properties of light to different coustituents of, 541 .

Retinx, correspondence of, 555 . projection of, on cortex, 655 . rivalry of, 555, Fig. $247 ; 556$.

Retinal images, 511, 513 .

relation of, to tactile impressions, 556 . size of, 554 .

Retinal pigment, $\mathbf{5} \mathbf{1 1}$.

Retinal vessels, shadows of, 516 .

Rlieocord, 418, Fig. 156.

Rheotactic influence on spermatozoa, 697 .

Rheotaxis, 56.

Rheotome experiment, 431, Fig. 168.

Rheotome of Bernstein, 432, Fig. 169.

Rheotropism, 64.

Rhinencephalon, 600.

Rhizopoda, 37 .

Rhombencephalon, 600.

Rhythmical contractions of cross-striated muscle, 53.

Rhythmicul segmentation, 2S7, 2SS, Fig. 116.

Rib-lifting muscles, 315 .

Ribs, movements of, 314 .

Rigor mortis, 447.

Ringer's solution, 25 note; 182 .

Rise of temperature, effect of, on lower organisms, 29.

in human body, 401 .

Ritter's tetanus, 421 .

Rivalry of retinie, 555 , Fig. $247 ; 556$.

Rods and cones, 515, Fig. 211.

functions of, $5+1$.

Röntgen rays, $5 \mathrm{~s}$.

Root tubercles, 23, Fig. 1S; 24.

Rotation, an effect of removing cerebellum, 608 .

in protoplasm, 42.

Rotation axes of eye, 549, 550, Fig. 240.

Rotation center of the eye, 549 .

Round window, 497.

Rubro-spinal tract in the cord, 593, 595.

Saccharinic acid, 374.

Saccharose, 81 .

Sacculus of internal ear, 473 .

Sacral nerves, 392, Fig. 145; 393.

Salicylic acid, 378.

Salleyluric acid, $37 \mathrm{~S}$.
Saliva, $245,246$.

Salivary glands, 257.

electrical phenomena of, $48,257$.

morphological changes in, 261.

nerves of, 257,258 .

centers for, 261.

specific excitants of, 260 .

Salt, common, physiological importance, 25. physiological solution of, 53 .

Salt hunger, 131.

Salt plasma, 157 .

Salt taste, $\mathbf{4} \mathbf{4}$.

Salting out, 69.

Salts, required by animals, 25, 26; see also Inorganic substances and Constitucnts, inoryanic.

by heart, 25,182 .

by plants, 24.

Sap of plant cells, 21, Fig. $16 ; 33$.

Saponification equivalent of fats, 79 .

Sarcolactic acid, 376.

Sarcolemma, 16.

Saturation of color, 541 .

Scaleni muscles, 315.

Scheiner's experiment, 553, Fig. 243.

Schematic eye, 511, 513, Fig. 210.

Schwann's experiment, 439.

Scyllium canicula, brain of, 619, Fig. 275 .

Season, influence of, on growth, 710 .

Sebaceous glands, 394.

Sebum, 394.

Secondary contractions, 433.

Secondary sexual characters, 357.

Secondary tetanus, 433 .

Secretin, 271.

Secretion, as a process, definition of, 41 .

conditions for, in stomach, 265.

filtration theory of, 259 .

in intestinal glands, 276 .

in pancreas, 269.

in salquary glands, 257.

in sebaceous glands, 394 .

internal, 356; see also Internal scerction.

of bile, 272 .

of digestive fluids, 256 .

of sweat, 396 .

paralytic, 259.

psychical, 263.

Secretion as a product, see under individual names.

Secretion capillaries, 267, Fig. 105.

Secretion droplets, 244, Fig. 99.

Secretion vacuoles, 261, Fig. 101.

Secretory nerves, 564,681 ; sce also under different glands.

Segmental reflexes, 576 .

Segmentation of central nervous system, 575 .

Selachians, extirpation of cerebrum in, 619 . 
Self-consciousness, origin of, 672 .

Self-digestion of the stomach, 269.

Self-regulation of respiratory movements, 328.

Semicireular eanals, 473.

artifieial stimulation of, 479 .

experimental suppression of, 476, Figs. 187, 18s; 477 , Fig. 189.

Semilunar valves, 167.

closure of, 171 .

muscular supports of, 167 .

opening of, 171.

Seminal fluirl, 692, 693, 694.

Seminal vesicles, 692.

Semipermeable membrane, 33 .

Semipermeable walls, 31 .

Senescenee, 66.

Sennations, auditory, 489.

correspondence of, to reality, 4.52 .

definition of, 451 .

degrees of distinetion of, 4.33 .

gustatury, $4 \$ 3$.

morlalities of, 453 .

motor, 469.

physiological significance of, 472 .

of colur, 541 .

of pain, $45 \mathrm{~s}, 465$.

of position, 472,473 .

of pressure and touch, $458,461$.

of resistance, $461,4 \pi 1$.

of temperature, 4.58 .

of weiglit, 456,471 .

olfactory, 486 .

organic, $454,469$.

place of origin of, 454,659 .

rualitative relations of, to stimuli, 451 .

quantitative relations of, to stimuli, 455.

specific, doetrine of, 455 .

tactile, 461, 466, 652 .

theoretical explanation of, 453.

threslubl stimuli of, 45.5 .

tickling, 462 .

tran-cendental, in esience, 45.5 .

visual, 536 .

Weber's law conceruing, 456.

Sense of cold, 459 .

of force, 469.

of liearing, $49 \mathrm{~S}$.

of heat, 459 .

of mution, 452 .

of pain, 46.5 .

of position, 469.

of presisire, 461 .

of siglit, 508 .

of smell, 54, 456 .

of taste, 483.

Senses, classification of, 451,452 ; see also Sensations.

Sensory aphasia, 664.

Sensury areas of cortex, 650.
Sensory areas of cortex, connected together, 659.

general sensation and touch in, 6ijt, Figs. 293 and 294.

hearing in, 6.54, Fig. 293.

psyeho-physical significance of, 659 .

recapitulation concerning, 6.59 .

taste and smell in, 653, 654, Fig. 294.

vision in, 6.54, Fig. 293.

Sensory impressions, conduction of, in cord, 597.

Sensory spinal nerves, 682 .

clistribution of, 683, Fig. 300 .

Serin, 70, 72.

Serous cavities, absorption from, 353.

Serrati muscles, 316 .

Serum, 154.

agglutinating aetion of, $156,157$.

bacteriociclal action of, $155,156$.

$\mathrm{CO}_{2}$ in, 340 .

cytolytic action of, 156 .

mineral substances in, 154 .

organic substances in, $154,155$.

oxygen in, 340 .

Serum albumin, 154 .

Serum globulin, 154.

Sex, influence of, on heart beat, 197.

on metabolism, 144.

Sexual glands, accessory, 691, 692 .

Sexual maturity, in man, 692.

in woman, 696.

Sexual organs, female, 695.

male, 691 .

shock, effect of, in experiments on respiration 326.

in lesions of motor areas, 646 .

Shrimp, galvanotaxis of, 60, Fig. 34 .

sighing, 321.

Sight, sense of, 451 ; 50 ; see also V'ision and Eye.

cortical area for, 6.5.5.

reaction time to, 674 .

Sigmoid flexure of colon, 299.

Sigmoiel gyrus, 266, 632, Fig. 282.

Signal, electric, 10, Fig. 7.

Simultaneous contrast, 547.

Sinuses of Valsalva, 167.

siren, seebeck's, 490, Fig. 193.

size, judgment of, by vision, 554, Figs. 24t, $245,246$.

Skatol, 295, 37s, 379 .

Skatoxyl, 379.

skatoxy]-sulphuric acid, 379.

skeletal muscles, see Muscles.

skin, electrical phenomena of, 48 .

excretory functions of, 394 .

gland:, stimulation of, by alkalies, 59 .

heat loss by, 395, 403.

insensible perspiration of, 397. 
Skin, sensory functions of, 458 .

temperature of, 399.

Sleep, 676.

curve of depth of, 67\%, Fig. 299

effect of loss of, on fatigue, $\mathbf{1 4 5}$.

Howell's theory of, 6i:7.

metabolism in, 676 .

Small intestine, see Intestine, small.

Smell, see Olfactory sensations, Odors, etc.

as a chemical sense, 54 .

cortical area for, 653, 654, Fig. 294.

definition of, 451,483 .

quantitative capacity of, 485 .

sneezing, 321 .

Soaps as fat producers, 130 .

coaps in intestine, 295 .

injected into blood, 305.

Sobbing, 321.

sudium chloride, excretion of, in starvation, 13 i.

importance of, for heart, 25, 182 .

osmotic pressure of, 32.

Sindium glycocholate, 254 .

Sodium taurocholate, 254, 351 .

Solar spectrum, see Spcctrum.

Sorbite, so.

sound, cardiographic, 16S, Fig. 55.

qualities of, 489, 491; sce also under Ear.

transmission of, in ear, 493.

Siounds, respiratory, 322

Siounds in swallowing, 282.

Sounds of heart, $16 \bar{T}, 168$.

special nerves, physiology of, 680 .

specific action of enzymes, 3S, 39.

Specific affinities in absorption, 35.

Specific drnamic action of foolstuffs, 107.

specific excitants of digestive glands, 264, 271, 275 .

specific gravity, changes of, in elementary organisms, 45 .

of blood, 147 .

of sweat, 395 .

of urine, $3 \mathrm{SO}$.

Specific response, law of, in nerves, 411.

ipecific stimuli for end organs, 580 .

ipectrum, visible rays of, $\mathbf{5 3 6}$.

sineech, center of, 631 .

elements of, 506 .

powers of, 661,662 .

tract in cortex, 662, Fig. 296.

ipermatozoa, 691, 692.

clemotactic influence on, 54,697 .

thigmotactic influence on, 56,697 .

spermatozoids of fern, chemotaxis, 54.

Spherical aberration, 523, Fig. 218; 522.

Splincter ani, 299.

innervation of, 299.

tonus of, $583,58 S$.
Sphincter o. urmary bladder, 391.

innervation of, 393.

Sphincter pupillar, innervation of, 528 .

Ephygmogram, see Pulse curve.

Sphygmograph, 215, Fig. S7.

spring of, 214 , Fig. S6.

Sphygmomanometer, 202, 203, Fig. 76 .

Spinal accessory nerve, $6 \$ 1$.

Spinal cord, centers in, 58.5 . columns of, 562, Fig. 254; 589, Fig. 261 ; 591, Fig. 264; 592, Fig. 265; 593.

conducting pathways in, 588 .

afferent, 592, Fig. 265; 593, 595, 596 .

efferent, 593, 594. Fig. 266; 595.

motor, 594, Fig. 266.

sensory, 592, Fig. 265.

control of skeletal muscles by, $5 \$ 6$.

electrical stimulation of, 5\&\&, 590, Fig. 263.

extirpation of, $5 \$ 1,5 \$ 2,587$.

hemisection of, $595,596,640$.

influence of, on vegetative organs, 587.

rate of propagation in, 589 .

section of, 58s, 595, 597.

structure of, 562, Fig. 254; 563, Fig. 255.

spinal ganglia, 563, Fig. 255.

chief purpose of, 584 .

delay of impulse in, 585 .

Spinal nerves, 682.

Spinal nerve roots, 562,564 .

efferent fibers in posterior, 566 .

various functions of, 565 .

Spirogyra, 18.

Spirometer, 320, Fig. 128.

Splanchnic nerve, 6SS; see also Sympathetic nerves.

as secretory nerve of pancreas, 269.

as vasomotor nerve, $233,235$.

connection of, with ganglion cells, $5 \$ 2$.

intestinal movements and, 2 ss.

movements of stomach and, 284.

respiration and 331 .

Spleen, function of, 368 .

trypsin and, 252.

Spongioplasin, 19.

Spontaneous generation, 16.

Squalius cephalus, brain of, 61s, Fig. 274.

Squint, 5.5.

Stapedius muscle, 494 , Fig. $196 ; 497$.

Stapes, 494, Fig. 196; 496.

Staphylococcus pyogenes albus, 54 .

Starch, see Carbohydrates.

absorbed, 139.

action of salixa on, 246.

digestion of, in intestine, 251, 297.

in mouth, 291.

in stomach, 291.

formation of, 23.

kinds of, $\$ 1$.

Starch cellulose, $\$ 1$. 
Starch granules in food, 242.

Starch granulose, 81 .

Starciı paste, $\mathbf{S 1 .}$

Stasis of blood in heart, 207 .

Static aetivity of cerebellum, 611.

Static refraction in the eye, 519 .

Steapsin, gastric, 250 .

in pancreatic juice, 253.

Stearic acid, 79,701 .

Stearin, 79.

Stentor, 43.

Stereoscope, Brewster's, 558, Fig. 251.

Stereoseopic vision, 5.58 .

Sterkobilin, 295, 383.

Sterno-cleirlo-mastoid muscle, 316.

Sthenic activity of cerebellum, 611.

Stimulation, assimilation and, 62.

by lieat, 58,59 .

by light, 56,57 .

eluemical, 52.

electrical, $59,60,418$.

general laws of, 420 .

mechanical, 56 .

of muscle and nerve, 414.

Stimuli, in general, 50 .

of muscles and nerves, 410 .

of nerve cells, 569 .

rapidly" repeated, 428.

stummation of, 572 .

Stimulus, effect of, on performance of muscle, 43.5.

effective, from minimum onward, 51.

qualitative relations of, to sensations, 451 . quantitative relations of, to sensations, 455 . threshold value of, 455 .

Stomach, absorption in, 303.

antiseptic function of, 292.

digestion in, 291.

evacuation of, 28.5 .

innervation of inusculature of, 284, Fig. 114. movements of, 283.

prineiples as to digestibility in, 293.

protective function of, 294 .

why not digest itself? 269.

Stomach fistula, see Gastric fistula.

Stomach glands, see Gastric glands.

Storage of carboliyilrates, 124.

of fat, 129.

of phosphiorus, 132.

of proteid, 120; see Retention of proteid.

Strabism, muscular in the eve, 5.55 .

Streamings of protoplasm, 42 .

Stretching movements, influence of, on bloodflow, 225 .

Stroma of red corpukcles, 150.

Stromuhr, 209, Fig. So.

Strychinia, effect of, on nervous system, 5\%0, 574.

Sublingual glands, 257 ; see also Salivary glands.
Sublingual saliva, 245 .

Submaxillary glands, 257; see also Salivary glands.

Submaxillary saliva, 245.

Substance, living, constitution of, 20 ; see also Protoplasm.

definition of, 15.

relative stability of, 135,137 .

Substitution of fondstuffs, 93.

of functions in the optic thalamus, 617 .

of tracts in the cord, 597 .

Succinic acid, 297.

Sucking, 279.

Suction in heart, 177, 225.

in mouth, 279; see also Sucking.

in thoracie cavity, $176,225,310$.

diastole of lieart and, 176 .

effeet of, on blood pressure, 229, 230.

effect of, on flow of lymph, 349 .

in veins, 225.

Sugar in blood, 155, 374 .

in muscles, 413.

in urine, $127,128,362,363,374,375,344$; see also Diabetes.

origin of, 23.

product of decomposition, 373,374 .

production of, in liver, 374.

storing of, as fat or glycogen, 374 .

Sulphates, 373.

ethereal, $373,383$.

Sulphocyanic acid, 373.

Sulphocyanide of potassium in saliva, 245.

Sulphur, acid, 373 .

elimination of, 373 .

in bile, 254.

in proteid, 69.

in urine, 383,384 .

neutral, 373.

Sulphureted hydrogen, 295.

Summation as property of protoplasm, 51 .

Summation in central nervous system, $5 \mathbf{7} 2$.

in museles and nerves, 429 .

Surviving organs, 6 .

Swallowing, 279.

innervation of, 281.

sounds of, 282.

Swallowing reflex, 280 .

Sweat, collection of, in metabolism experiments, $\$ 5$.

composition and properties of, 395 .

excretory process of, 396.

nitrogen in, 89.

part played by, in leat regulation, 403.

quantity of, excreted, $396,408$.

Sweat centers, 396, 588 .

Sweat fibers, connections of, 582, 685 .

Sweat glands, 395.

innervation of, 396 .

Sweet taste, $45 L$ 
Symbiosis, 22

Simpathetic fibers, 686 .

afferent, 689 .

connection of, with peripheral ganglion cells, 5S2, 686, Fig. 301.

course of, 687 .

postganglionic, 687 .

preganglionic, 686 .

regeneration of, 689 .

Sympatletic ganglia, 582 .

connections of, 6S6, Fig. 301.

reflexes through, 583 .

Simpathetic nerves, 685.

accelerator, of heart, 191, $6 \mathrm{SS}$.

as vasomotor nerves, 231, 234, 6\$5, 685 .

of intestine, 2ss.

of pancreas, 269.

of receptaculum chyli, 349 .

of salivary glands, 258 .

of sebaceous glands, 394 .

of stomach, 2S4, Fig. 114.

of thoracic duct, 349 .

of urinary bladder, 393.

Sympathetic vibration, 492; see also Resonance.

Syntheses in animals, 24 ; see also Assimilation. in plants, 23 .

of nonliving substances, 65 .

organic, 24.

Sintonin, 74.

System of organs defined, 30 .

Systole, auricular, duration of, 176 .

definition of, 162.

ventricular, duration of, 176 .

Tabes dorsalis, 472 .

Tactile corpuscles, 468 .

Tactile sense, area of, in eortex, 651, 652.

Tail, vasomotor nerves for, 233.

Talbot's proporition, 539 .

Tambour, receiving, 12, Fig. 10 . recording, 11, Fig. 9.

Tartaric acid, 377.

Tartronic acicl, 377.

Taste, cortical area for, 653.

definition of, 451 .

effect of cor'aine, eucaine, etc., on, 485.

qualities of, 484,485 .

sense of, 4 \$ 3 .

Taste buds, 4S3.

Taste nerves, $4 \mathrm{~S} 4$.

reaction time to, 674 .

Taste zone on tongue, 483, Fig. 190.

Taurin, 253, 373.

Taurocholic acid, 253.

Tears, laver of, on cornea, sos.

Tecto-spinal tract in the cord, 503 .

Telencephalon or endbrain, 600,601 ; see also Cierebrum.
Temperature, action of, on heart, 1S4, Fig. 66. effect of, on elimination of $\mathrm{C}_{2} \mathrm{O}_{2}$ and water vapor, $397,403$.

influence of, on elementary organisms, 28. on metabolism, 114.

of birds, 398 .

of cold-blooded animals, 46 .

of human borly, 398, 399 .

after death, 401, Fig. 149.

cause of variations in, 399 .

importance of clothes in preserving, 405.

importance of thyroid for, 361 .

in fasting, 95.

mode of recording, 395.

normal compared with $\mathrm{CO}_{2}$ exeretion, 4 (), Fig. 1tS.

normal diurnal variations of, 399, Fig. 147.

normal for man, 398 .

regulation of, 406 .

supranormal, 401 .

of manmals, 398 .

constancy of, 401.

Temperature nerves, 461 .

Temperature sensations, 458 .

Temperature sense, area for, in cortex, 6.52 .

tract for, in cord, 597 .

Temperature spots or points on the skin, 4.59 , Fig. 182.

topographical distribution of, 460 , Fig. 183.

Temporal convolutions, 639, Fig. 2S9; 653, 6.55.

Tendon reflexes, 587 .

Tension of gas in liquicl, methorl of, 33.5.

Tension of gas in bloorl, method of, 341 .

Tension of musele, $414,437$.

Tension, osmotic, see Osmotic pressure.

Tensor tympani muscle, 497 .

Terminal myelogenetic regions of cortex, $66 \%$.

Testes, 692.

extirpation of, $35 \overline{7}, 692$.

internal secretion of, $35 \%$.

Testicular extract, $35 \%$.

Tetanus, 429, Fig. $166 ; 430$, Fig. $167 ; 433$.

explanation of, 430 .

number of stimuli necessary for, 429.

of red and white museles, 430, Fig. 167.

Ritter's, 421.

secondary, 433.

work of muscles in, 439.

Wundt's, 421 .

Tetra-oxyamino-caproic acid, 374.

Thalamencephalon, 600 .

Thalassicola nucleata, 18, Fig. 15. mode of movement of, 45 .

Theea folliculi, 69.5.

Thermotaxis, 59.

Thigmotaxis, 56 . of spermatozoa, 56,697 .

Thigmotropism, 64 . 
Thioalbumose, 249

Thio-monamino acid, 70 .

Thio-nonamino-propionic acid, 70.

Thoracic cavity, 314.

inportance of suction of, for filling heart, 177. suetion of, 176 .

Thoracic duet, muscles and nerves of, 349.

Thoraeic type of respiration, 317, 318, Fig. 126.

"Threshold clifference," 456.

Threshold value of stimulus, 455 .

Thirombin, 158.

Thrombogen, 158.

Thymin, 76.

Thyroirl cartilage, 502.

Thiyroid extract, 359. effects of treatment with, 359, Fig. 137; 360, Fig. 138.

Thyrroid gland, $35 \mathrm{~S}$.

blood supply of, 240 .

chemistry of, 362.

extirpation of, in dogs, 358 .

in man, 359 .

in monkey, 360.

histology of, 361.

innervation of, 361 .

internal secretion of, $3.5 \mathrm{~s}$ seq.

morphological changes in, 361.

transplantation of, 359 .

Timbre of sound, cause of, 491 .

Time, determination of, in psycho-physical processes, 673 .

Time recorders, 10.

Tine stimuli, 423.

Tissue proteid, 134.

Tine rleafness, 665.

Tine, fundamental, 491. musical, 489.

produced by muscle, 434.

Tones, combination of, 501 .

Tonguc, action of, in swallowing, 279.

taste nerves of, 4.S. I.ig. 191.

vasomotor nerves of, 235.

Tonie activity of rerebellum, 611 .

Tonic excitation, state of, 581 .

Toms, cause of, .5\$1.

definition of, 581 .

demonstration of, in cross-striated muscles, ¿s1.

inhibition of, by stimulation of cortex, 636 , (64).

of blool vessels, 232 .

Torperlo, 49, ․ig. 30 .

Total netabolism, aftr.r ingestion of carbohydrates, 106.

after ingestion of fat, 104.

after ingestion of proteid, 102.

ii) fasting, 96 .

in growing chiltren, 118.

influence of work of digestion on, 107 .
Touch, definition of, 451 .

end organs of, 468 .

sensations of, 461 .

Touch reflex, 660 .

Toxins, 40.

in blood, 156.

Trachea, 502 .

Tracts in spinal cord, 563 seq.

Transfusiom, 207.

Transmission of stimulus, rate of, in muscle, 417.

in nerves, 417 .

in spinal corcl, $5 \$ 9$.

Tran<udation, 207.

Treppe, 4.11.

Trichromatic color system, $\overline{5} 45,546$.

Tricuspirl valve, 16.5 .

Trigeminal or trifacial nerve, 680 .

as nerve of smell, $4 \mathrm{~s}$.

as nerve of taste, 484 .

influence of, on respiration, 330 .

Triglycericles, 79,701 .

Trioxypurin, 382.

Trochlear nerve, 680 . nucleus of, 614.

Trophic centers in spinal ganglia, 568 .

Trophic effect, definition of, 50 .

Trophic influenee of nerve cells, 569.

Trophic influence through motor nerves, 63.

Trophic nerves, 569.

Trophoblasts, 22 .

Trypsin, 252.

spleen and, 368.

Tryptophan, 71, 72, 109, 249.

Tuber cinereum, 600 .

Tuning fork as time recorder, 10.

Turgor, 33.

Turtle, extirpation of cercbrum in, 621 .

"Tweenbrain, or diencephalon, 600, 601, 617.

importanee of, in birds, 624 .

in bony fish, 619 .

in dogfish, 620.

in $\mathrm{frog}, 620$.

in lizard, 621.

in rabbit, 625 .

in turtle, 621 .

Tympanic cavity, 495, Fig. $197 ; 497$.

Tympanies membrane, 49-4, Fig. $196 ; 495,196$.

Tyrosin, 71, 72, 249, 255, 37s, 354.

Ultra-red rays, 536.

Ultra-violet rays, 536.

stimulating effect of, 57 .

Unicellular organisms, 2, 15.

Uracil, 76.

Uramia, 368.

Lramic poisoning, 367 .

Urates, 3s2.

Urea, amount of, in urine, $3 \$ 1$. 
Urea, amount of, in various organs, 3S2. as product of metaholism, $\mathrm{S} 9$. cristal=, 382, Fig. 139 . elimination of, in fasting, 101, Fig. 43. in blood, 155,359 .

in sweat, 39.5 .

sources of, 370,373 .

where formed, 370 seq.

Ureters, 391 .

muscular contractions of, 391 .

Lrethra, 392.

Lric acid, amount of, in urine, 382.

composition of, 382.

crystals, 352, Fig. 140; 3\$3, Fig. 141.

fate of, in mammals, 373 .

in blood, 15.5 .

microscopic detection of, in kidney, $3 \$ \$$.

production of, in birds, $3 \pi 1$.

properties of, 382 .

seat of destruction of, 373 .

sources of, 372 .

Urinary bladder, 391.

centers for control of, 393.

innervation of, 392, Fig. $145 ; 393$.

Urinary tubules, 385, Fig. 144.

Urine, amount of, excreted, 380.

combustion heat value of, 93 .

composition of, 381 .

excretion of, 384 .

filtration theory, 387 .

secretion theory, 388 .

general properties of, 379 .

ratio of $\mathrm{N}: \mathrm{C}$ in, 90.

retention of, 393 .

Trine indican, 379.

Trine mucoid, 380.

Trobilin, 295, 383.

Crochrome, 383 .

Urotoxy, $3 \$ 1$.

Uterus, 696.

contractions of, 698, Fig. 302; 699, Fig. 303.

growth of, in pregnancy, 698 .

innervation of, 700 .

menstrual changes in, 696.

movements of, incluced in various ways, 700 . pressure curve in, in parturition, 699, Fig. 303.

Utilization of foodstuffs, 138.

of energy, 139.

of mixed diet, 139 .

Utriculus of internal ear, 473 .

Vacuoles, contractile, 22.

in plant cells, 21 .

Vagina, innervation of, 700 .

Vagus nerve, 681 .

components of, 681 .

influence of, on blood pressure, 204 seq.

on heart, $188,190$.

on intestinal movements, 289.
Vagus nerve, influence of, on movements of stomach, 2^t, Fig. $11 t$.

on respiration, 327.

explanation of, 329 .

on secretion of pancreas, 269.

of stomach, 263.

Vagus pneumonia, 569 .

Valves, atrio-ventricular, 165.

closure of, 166, Fig. 54.

semilunar, $166,167,171$.

venous, 225.

Vampyrella spirogyro, 37, Fig. 23.

Vasa deierentia, 693, 694.

Vascular tonus, 232.

adrenal bodies and, 366 .

Vasoconstrictor nerves, 231, 596, 6\$1, 685. connection of, with ganglion cells, 582 .

Vasodilator nerves, 231, GS1, 685.

Vasomotor centers, 237.

influence of, on distribution of blood, 239.

resistance of, to asplyxiation, 573, Fig. 257.

Vasomotor nerves, 231, 234, 688 .

Vasomotor reflexes, 235.

Vegetable diet, 145.

Vegetable starches, $\$ 1$.

Vegetarianism, 145.

Vegetative functions, conducting pathways for, 596 .

influence of cortex on, 649 .

spinal cord on, 587.

Veins, blood flow in, 223.

influence of position of body on, 225, 226, Figs. 93, 94; 227.

blood pressure in, 223.

cubic distention of, 223, Fig. 92.

innervation of, 233.

valves of, 225 .

Veins of Thebesius, 180, 181.

Velocity of blood in arteries, 210, Fig. 82.

in capillaries, 221.

in veins, 224 .

Velocity of current in tubes, 198, 199.

Velocity of nerve impulse, 417, Fig. 155.

Velocity of pulse wave, 215.

Venæ cavæ, 161, 162.

Venomotor nerves, 233.

Venous blood, percentage of gases in, 339 . tension of gases in, $3 \pm 1$.

Venous ostia, 185.

Venous sinus, automaticity of, 183.

Venous valves, 225.

Ventilation of the lungs, 319.

Ventricles, 161.

maximum pressure in, 170 .

negative pressure in, 177.

structure of, 163.

work of, $17 \mathrm{~s}$.

Ventricular cavities, casts of, in rigor, 164, Fig. 53. 
Ventrolateral cerebellar tract, 593.

Veratrin, effect of, on muscular contraction, 437 , Fig. 175.

Vermis of cerebellum, 607 .

function of, 609 .

Vertigo, an effect of cerebellar lesions, 608 .

Vesical plexus, 392, Fig. 145; 393.

Vesicular glands, 691.

Vesicular noise, 322.

Vestibular nerve, $\mathbf{4 8 0 , 6 8 1 .}$

Vestibulo-spinal tract in cord, $593,595$.

Vibration frequency of tone, 489.

Vibration limits for organ of hearing, $\mathbf{4 9 0}$.

Ticia Faba, root tubercles of, 23, Fig. 18.

Vision, 50s; see also Eye.

binocular, 5.51, 552, Fig. 242; 555.

direct and indirect, 514.

limits of, 517,518 .

line of, 518 .

stereoscopic, 5.58.

Visual angle, 518, Fig. 214; 556, 557.

importance of, for perception of depth, 556 .

Visual area for exact vision, 657.

Visual area of cortex, 65.5, 663.

Iisual axis, 525; see also Optical axis.

Visual conducting pathways, 6.57 .

Visual purple, $537,541$.

Visual sensations, as effected by eye movements, 552.

elaboration of, 660 .

projection of, to external world, 552 .

Yisual substances, 546 .

Vital capacity of the lungs, 320.

Vitalism, theory of, 2.

Vitcllin, 75.

Vitellinie aeid, 76.

Vitreous body, 508, 509.

entoptic phenomena in, 521 .

refractive index of, 509 .

Voeal eorils, 502.

movements of, in respiration, $312 ; 504$, Fig. 202.

in vocalization, 503, Figs. 200, 201; 505.

Voice, 502 .

change of, 692 .

pitel of, rletermination of, 505 .

produetion of, 504 .

registers of, 504 .

Voit's theory of proteid metabolism, 134.

Volta's discovery, 47.

Volume, breath, 319. pulse, 204.

Voluntary muscular contractions, 430 .

Vomiting, 286.

Vorticella, 44, Fig. 28.

contraction in, independent of $\mathrm{NaCl}, 25$. motility of, 43.

Vowels, how produced, 505, Fig. 204; 506, Fig. 205.
Wagner's hammer, 421, Fig. 159.

Wallerian degeneration, 567.

Warm-blooded animals, 46, 398, 405, 406 , 441.

reaction of, to external temperature, 114.

Water, absorption of, 302 .

a constituent of living substance, 20 .

determination of, in metabolism experiments, 85 seq.

elimination of, through expired air, 89,312 , 404 .

through kidneys, 89,379 .

through skin, $89,397,404$.

requirement in fasting, 9.5 .

Wave lengths of visible light rays, 536 .

Weber's theory of the pulse, 213, Fig. 85 .

Weber's law, 456.

Weight, estimation of, 469,470 .

growth in, of human body, 707 seq.

sensation of, 471 .

White matter of spinal cord, 562.

White rami communicantes, $686,689$.

Will, influence of, as stimulus, 570. power of, over pain, $\mathbf{4 6 6 .}$

Window, oval, of ear, 496. round, of ear, 497 .

Witch's milk, 704 .

Word blindness, 663, 669.

Word deafness, 664.

Work, assimilation and, 63; see also Muscular work.

external, and total energy, 113.

of heart, 178 .

Worker, moderate, nutritive requirements for, 142.

Woman's milk, 701 .

Women, nutritive requirements for, 143 .

Wundt's tetanus, 421 .

I rays, 58.

Xanthin, 76, 252, 413.

Xanthin bases, 76,434 .

Iantlıo-proteic reaction, 72 .

Yellow as brightest light, 541 .

Yellow-blue blindness, 547.

Yellow spot, 517.

Yolk splierules of orum, 695.

Young, metabolism in the, 118.

nutrition of the, 143.

Young-Helmholtz' theory of color vision, 544 .

Youth, age of, 706.

Zona pellucida, 16, 695.

Zonule of Zinn, 533, Fig. 228.

Zymase, 40.

Zymogens, 38, 244.

activation of, 38,252 . 



\title{
NORMAL

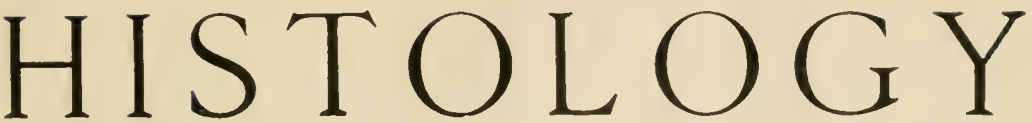

BY

\section{JEREMIAH S. FERGUSON, M.Sc., M.D.}

Instructor in Histology, Cornell University Medical College, New York City

\author{
With 462 Illustrations, many in colors \\ Cloth, \$4.00 Half Leather, $\$ 4.50$
}

\section{SOLD ONLY BY SUBSCRIPTION}

"This is an eminently practical and useful book, and one in which the subject is treated exhaustively. The author has that all tou rare faculty of making things plain which comes from full knowledge and an aptitude for teachings. Since histology is at the basis of our comprehension of physiology, pathology: bacteriology, and clinical medicine unusual space has been devoted to all those organs which serve as a field for the specialist in medicine. This is especially true of the chapters on the central nervous system, which are comprehensive and exhaustive. What is true of this department is more or less true of all, and specialists, practitioners, and students will find a sufficiently adequate treatment of the histology of erery tissue of the body." - Fournal of Medicine and Science.

"The subject-matter in this excellent book is thoroughly modern, and is presented in clear and readable fashion, while the unusual profusion and quality of the illustrations contribute a great deal to the attractiveness of the volume. An interesting feature is the free use of drawings made from plastic reconstructions of organs, which should be of great assistance to the student in understanding such structures as the adrenals, various glands, the blood, and lymphatic systems of different regions, etc. . . The minute anatomy of the eye and of the ear is discussed at much greater length than is customary, and the section devoted to the nervous system is also worthy of note, both on account of its completeness and of the character of its illustrations. The bibliography is conveniently grouped by topics at the end of the volume and presents a wellselected list of the more important contributions to histological literature."

- Vew York lledical Record.

"Both as to text and illustrations this work is the most comprehensive and best-arrangred text-book on the subject which has as yet appeared in this country."-Albany Medical Annals.

"This recent claimant to favor should easily dispel existing impressions as to the superiority of foreign works, for Dr. Ferguson has written a work of which nothing but praise can be spoken."-.Medical Monthly, Memphis, Tenn.

D. APPLETON A D D C MPANY, PUBLISHERS 436 Fifti Avenue, New York. 


\title{
CHEMICAL AND MICROSCOPICAL DIAGNOSIS
}

\author{
By FRANCIS CARTER WOOD, M.D.
}

Adjunct Professor of Clinical Pathology, College of Physicians and Surgeons, Columbia University, New York; Pathologist to St. Luke's Hospital, New York

With One Hundred and Eighty-eight Illustrations in the Text and Nine Colored Plates

8vo. Cloth, $\$ 5.00$ net

"No practitioner of medicine, whatever may be his special work, can afford to be without some book of this sort, and the present volume may frankly be recommended as satisfactory."

- New York Medical Journal.

"We regard this as one of the most important medical books that have appeared of late, and venture the opinion that it will not be long before it will be found in the hands of every laboratory worker, whether teacher or pupil."-Buffalo Medical Journal.

"The work at present before us may be unhesitatingly pronounced one of the best."-Medical Review of Reviews.

"It is unnecessary to emphasize, in the present state of medical knowledge, the importance of microscopical and chemical examinations of the blood and the secretions and excretions of the body in the diagnosis of disease. Indeed, this has been so universally appreciated within recent years that a distinct and increasing demand has been created for works of reference on these and allied subjects. Several such books already occupy honored positions in this literature, and Dr. Wood's book, the subject of this review, is the latest addition to the library of clinical pathology. Dr. Wood's book is undoubtedly the most complete book of its kind that has appeared in the English language."

- California State Journal of Medicine.

D. APPLETON A N COMPANY, NEW YORK 




$$
=
$$




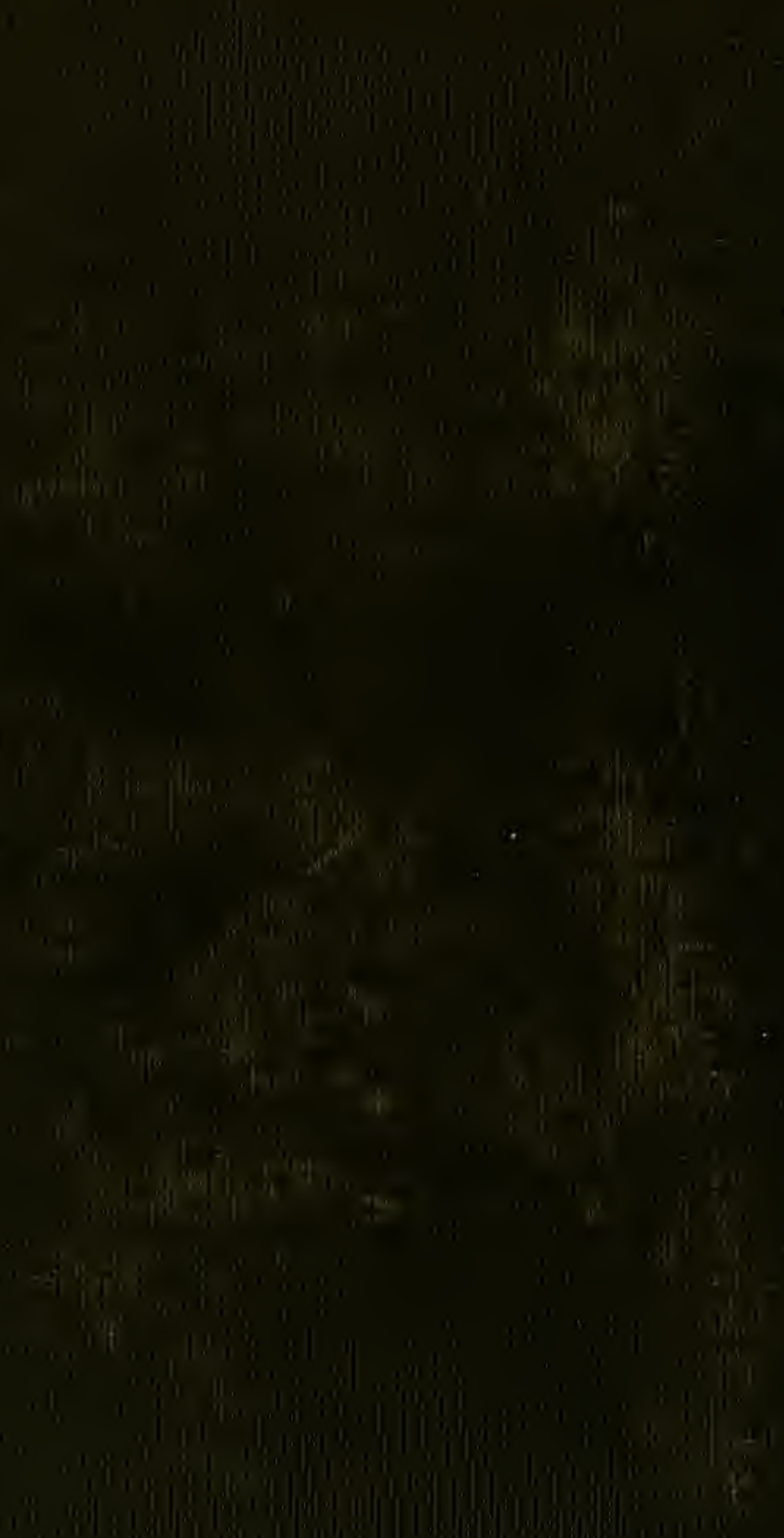

